ABHANDLUNGEN ZUM

URHEBER- UND KOMMUNIKATIONSRECHT

Manuel Kleinemenke

Fair Use im deutschen und

europäischen Urheberrecht?

Eine rechtsvergleichende Untersuchung zur Flexibilisierung des urheberrechtlichen Schrankenkataloges nach dem Vorbild der US-amerikanischen Fair Use-Doktrin 


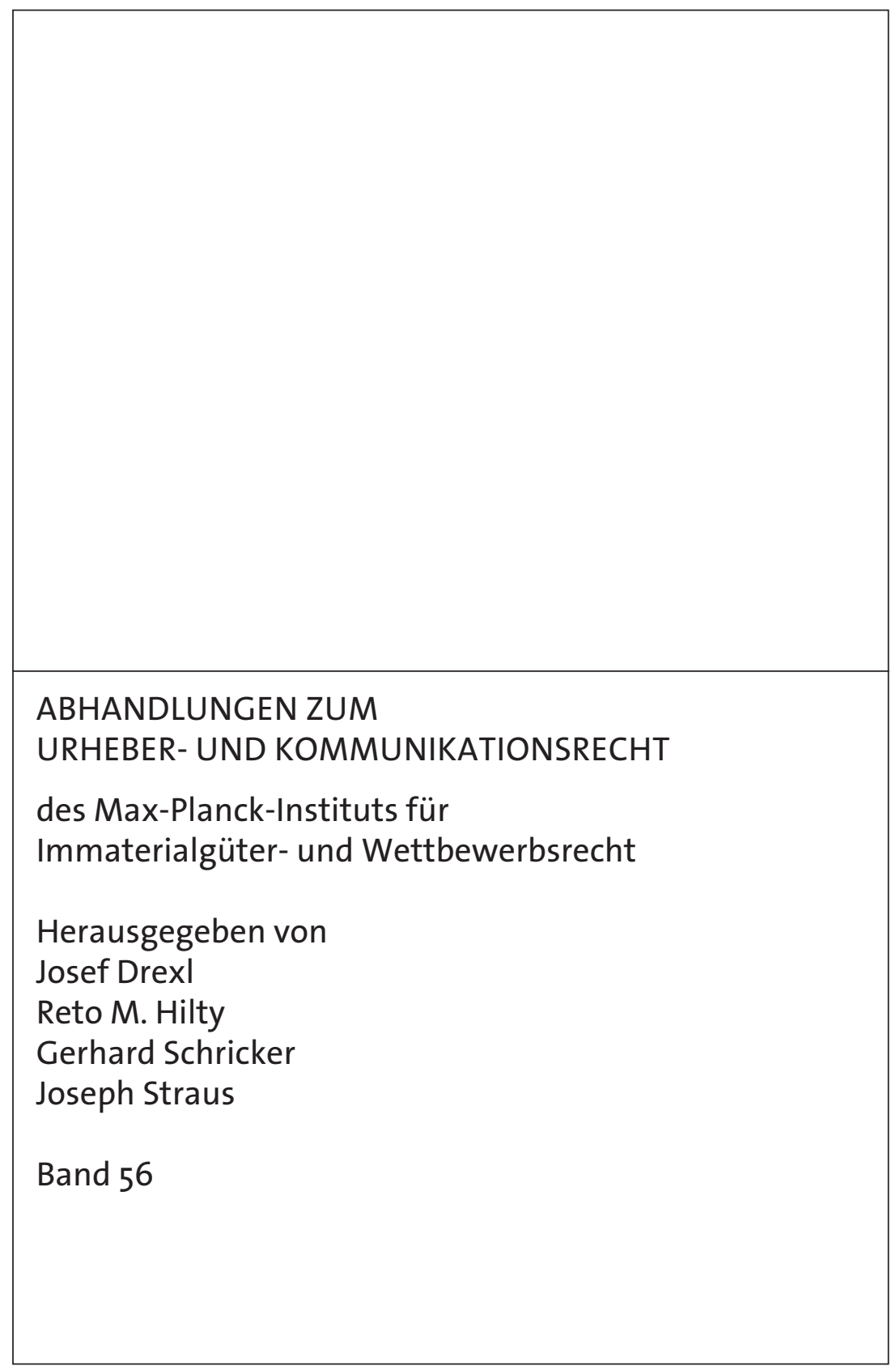


Manuel Kleinemenke

\section{Fair Use im deutschen und} europäischen Urheberrecht?

Eine rechtsvergleichende Untersuchung zur Flexibilisierung des urheberrechtlichen Schrankenkataloges nach dem Vorbild der US-amerikanischen Fair Use-Doktrin 
Die Deutsche Nationalbibliothek verzeichnet diese Publikation in der Deutschen Nationalbibliografie; detaillierte bibliografische Daten sind im Internet über http://dnb.d-nb.de abrufbar.

Zugl.: Bonn, Univ., Diss., 2013

ISBN 978-3-8487-0643-3 (Nomos Verlag Baden-Baden)

ISBN 978-3-7272-7736-8 (Stämpfli Verlag AG Bern)

Die Schriftenreihe ist bis Band 51 beim Verlag C.H. Beck, München erschienen.

1. Auflage 2013

(c) Nomos Verlagsgesellschaft, Baden-Baden 2013. Printed in Germany. Alle Rechte, auch die des Nachdrucks von Auszügen, der fotomechanischen Wiedergabe und der Übersetzung, vorbehalten. Gedruckt auf alterungsbeständigem Papier. 


\section{Vorwort}

Die vorliegende Arbeit entstand während meiner Zeit als wissenschaftlicher Mitarbeiter am Lehrstuhl für Bürgerliches Recht, Recht des Geistigen Eigentums und Wettbewerbsrecht der Rheinischen Friedrich-WilhelmsUniversität Bonn. Sie wurde von der dortigen Rechts- und Staatswissenschaftlichen Fakultät im Wintersemester 2012/2013 als Dissertation angenommen. Für die Veröffentlichung konnten Rechtsprechung und Literatur im Wesentlichen bis Mai 2013 berücksichtigt werden.

Mein ganz herzlicher Dank gilt in erster Linie meinem Doktorvater Prof. Dr. Matthias Leistner, LL.M. (Cambridge), für die hervorragende Betreuung durch zahlreiche hilfreiche Diskussionen und Anregungen zu dieser Arbeit sowie für die wissenschaftlichen Herausforderungen und Freiheiten während meiner Zeit als Mitarbeiter an seinem Lehrstuhl. Prof. Dr. Michael Loschelder danke ich herzlich für die zügige Erstellung des Zweitgutachtens.

Danken möchte ich auch den Herausgebern der „Abhandlungen zum Urheber- und Kommunikationsrecht", Prof. Dr. Josef Drexl, LL.M. (Berkeley), Prof. Dr. Reto M. Hilty, Prof. Dr. Dr. h.c. mult. Gerhard Schicker und Prof. Dr. Dres. h.c. Joseph Straus für die Aufnahme der Arbeit in diese Schriftenreihe sowie der Deutschen Vereinigung für gewerblichen Rechtsschutz und Urheberrecht (GRUR), die die Veröffentlichung dieser Arbeit mit einem großzügigen Druckkostenzuschuss unterstützt hat.

Großen Dank schulde ich außerdem der Faculty des Chicago-Kent College of Law, insbesondere Prof. Sarah Harding, Prof. Edward Lee und Jason Du Mont, die mich in meiner Zeit als Visiting Scholar des dortigen Program in Intellectual Property Law sehr freundlich aufnahmen, mir eine umfangreiche Materialsammlung für den rechtsvergleichenden Teil dieser Arbeit ermöglichten und für zahlreiche Fragen und Diskussionen zum USamerikanischen Urheberrecht zur Verfügung standen.

Danken möchte ich auch meinen lieben ehemaligen Kolleginnen und Kollegen am Lehrstuhl, Benedikt Flöter, Dr. Sebastian Hühner, Martin Königs, Alexander Koof, Dr. Katrin Osinski, Dr. Felix Stang und Dr. Michael Zenker, für eine schöne Zeit, gute Zusammenarbeit, viele interessante juristische und noch mehr mindestens ebenso interessante unjuristische Gespräche. 
Alle Rechtschreib- und Interpunktionsfehler, die diese Arbeit nicht enthält, sind meiner Schwester, Janina Kleinemenke, zu verdanken, die sich mit größter Sorgfalt durch hunderte fachfremde Seiten gekämpft hat. Hundertfachen Dank schulde ich daher ihr. Dennoch in der Arbeit enthaltene Fehler sind hingegen allein mein Verdienst.

Mein größter Dank gilt schließlich meinen Eltern, Beate und Alfons Kleinemenke, die mich während meiner gesamten Ausbildungszeit liebevoll und uneingeschränkt unterstützt haben. Ohne sie wäre diese Arbeit nicht möglich gewesen. Gleiches gilt für meine liebe Doro, die mir viel Unterstützung, Kraft und den gelegentlich erforderlichen Antrieb gegeben hat. Ihr und meiner Familie ist diese Arbeit gewidmet. 
Inhaltsverzeichnis

$\begin{array}{lr}\text { Abkürzungen } & 19\end{array}$

Einleitung 25

A. Gegenstand und Zielsetzung der Arbeit 26

B. Gang der Untersuchung 28

$\begin{array}{lll}\text { Teil } 1 \text { Grundlagen } & 31\end{array}$

1. Kapitel Urheberrechtsgewährung im deutschen und USamerikanischen Recht 31

A. Deutsches Urheberrechtsgesetz: Urheberrecht als umfassend gewährtes Recht

I. Die Entstehung des Urheberrechts und, ,geistigen Eigentums" in Deutschland 32

II. Urheberrechtsschutz und -gewährung heute 44

B. Das Copyright im US-amerikanischen Rechtssystem 47

2. Kapitel Einschränkung des Urheberrechts im deutschen und USamerikanischen Recht

A. Regelungstechniken: Enumerationsprinzip versus Schrankengeneralklausel 58

B. Das Schrankensystem des deutschen Urheberrechts 59

I. Inhaltliche Schranken des Urheberrechts im Urheberrechtsgesetz $\quad 60$

1. Unterschiedliche Intensität der Eingriffe 61

a) Freistellung 61

b) Gesetzliche Lizenz 62

c) Zwangslizenz 64

d) Verwertungsgesellschaftspflichtigkeit 65

2. Die Auslegung und Analogiefähigkeit urheberrechtlicher Schrankenbestimmungen 66

a) Rechtsnatur der urheberrechtlichen Schranken $\quad 67$ 
b) Grundsatz der engen Auslegung? 73

c) Analogiefähigkeit von Schrankenbestimmungen? 83

d) Ergebnis zur Auslegung und analogen Anwendung der Schranken

3. Schrankenbestimmungen außerhalb des Schrankenkataloges der $\S \S 44 \mathrm{a} f f$. UrhG

a) Die freie Benutzung gemäß $\S 24 \mathrm{UrhG} \quad 88$

b) $\S 12$ Abs. 2 UrhG als Schrankenbestimmung 92

II. Urheberrechtliche Schranken außerhalb des

Urheberrechtsgesetzes

C. Das Schrankensystem des US-amerikanischen Copyright Law 98

I. Die Fair Use-Doktrin

1. Entwicklung der Fair Use-Doktrin als richterrechtliche Generalklausel

2. Aufnahme der Fair Use-Doktrin in den Copyright Act of 1976

a) Die Regelung des 17 U.S.C. § 107

aa) Die Präambel

bb) Die vier Fair Use-Faktoren

(1) Erster Faktor: "The Purpose and Character of the Use"

(2) Zweiter Faktor: "The Nature of the Copyrighted Work"

(3) Dritter Faktor: "The Amount and Substantiality of the Portion Used"

(4) Vierter Faktor: "The Effect of the Use upon the Potential Market for or Value of the Copyrighted Work"

b) Leitentscheidungen des U.S. Supreme Court zur Fair Use-Doktrin

aa) Sony Corporation of America v. Universal City Studios, Inc.

bb) Harper \& Row, Publishers, Inc. v. Nation Enterprises

cc) Luther R. Campbell v. Acuff-Rose Music, Inc.

c) Status quo der Anwendung und Auslegung der Fair Use-Doktrin 
3. Rechtsfolge des Fair Use-Einwandes: „Alles oder Nichts"

II. Sonstige Schrankenregelungen im U.S.C.: Die „Limitations on exclusive rights“ der 17 U.S.C. $\S \S 108-122$

Teil 2 Enumerativer Schrankenkatalog versus Generalklausel im digitalen Kontext: Die Anwendung der Schrankenbestimmungen des deutschen und USamerikanischen Urheberrechts auf neue Formen der Werknutzung - Dargestellt am Beispiel der Nutzung urheberrechtlich geschützter Werke im Rahmen der Google Buchsuche und in Form von Thumbnails durch Bildersuchmaschinen

3. Kapitel Die Geschäftsmodelle „Google Books“ und Darstellung von Thumbnails durch Suchmaschinen

A. Die Google Buchsuche

I. Das Partner-Programm

II. Das Bibliotheksprogramm

B. Darstellung von Thumbnails durch Suchmaschinen

4. Kapitel Länderbericht Deutschland: Urheberrechtliche Probleme der Google Buchsuche und der Bildersuche im Internet nach deutschem Urheberrecht

A. (Möglicherweise) Betroffene Verwertungsrechte des Urhebers

I. Die Verwendung von Thumbnails im Rahmen der Bildersuche

1. Verneinung einer relevanten Nutzungshandlung

2. $\S \S 23 \mathrm{~S} .1,16 \mathrm{UrhG}-$ Bearbeitung/Umgestaltung und Vervielfältigungsrecht

a) Herstellung und Speicherung von Thumbnails der Originalwerke

b) Verhältnis von $\S 23$ UrhG zu $\S 16$ UrhG 150

3. §19a UrhG - Recht der öffentlichen

Zugänglichmachung 
II. Google Buchsuche

1. §16 UrhG - Vervielfältigungsrecht

2. § $19 \mathrm{a} U \mathrm{UhG}-$ Recht der öffentlichen Zugänglichmachung

B. Vorgeschlagene Lösungsansätze und deren Bewertung

I. Rechtfertigung der Verwendung von Thumbnails im Rahmen der Bildersuche

1. Rechtfertigung auf Ebene der urheberrechtlichen Schranken

a) (Analoge) Anwendung des $\S 44 \mathrm{a}$ UrhG

b) (Analoge) Anwendung des $\S 49$ UrhG

c) (Analoge) Anwendung des $\S 51$ UrhG

d) Anwendung des $\S 53 \mathrm{UrhG}$

e) (Analoge) Anwendung des $\S 58 \mathrm{UrhG}$

f) Analoge Anwendung des $\S 59$ UrhG

g) Anwendung der $\S \S 17$ Abs. 2, 59 UrhG

h) Umkehrschluss zu § 12 Abs. 2 UrhG

2. (Konkludente) Nutzungsrechtseinräumung und Einwilligung

a) Einräumung von Nutzungsrechten und (schlichte) Einwilligung

b) Rechtfertigung der Thumbnail-Nutzung durch Nutzungsrechtseinräumung oder Einwilligung

c) Untersagung künftiger Nutzungen

d) Zwischenergebnis

3. Haftungsprivilegierung des Suchmaschinenbetreibers unter Anwendung des Art. 14 Abs. 1 E-CommerceRichtlinie

4. Zusammenfassung zur Rechtfertigung der ThumbnailNutzung

II. Rechtfertigung der Google Buchsuche nach deutschem Urheberrecht

1. Anwendung des $\S 44 \mathrm{a} U \mathrm{UrhG}$

2. Anwendung des $\S 51 \mathrm{UrhG}$

3. Anwendung des $\S 52 \mathrm{a} U \mathrm{UrhG}$

4. Anwendung des $\S 53 \mathrm{UrhG}$

5. Anwendung des $\S 53 \mathrm{a}$ UrhG

6. Einwilligung 
7. Zusammenfassung zur Rechtfertigung der Google Buchsuche

III. Zwischenergebnis 228

C. Verletzung von (Urheber-)Persönlichkeitsrechten? 229

I. Anerkennung der Urheberschaft $-\S 13$ UrhG 230

1. Thumbnails 231

2. Google Buchsuche 235

II. Entstellung des Werkes $-\S 14$ UrhG 238

1. Thumbnails 239

a) Beeinträchtigung durch Verringerung der Auflösung/Qualität des Originalbildes? 239

b) Beeinträchtigung durch Herausreißen aus dem Kontext bei isolierter Anzeige des Bildes in Originalgröße?

c) Beeinträchtigung durch Herausreißen aus ursprünglichem Kontext und Darstellung in neuem Zusammenhang

d) Beeinträchtigung durch Herabstufung des Werkes auf rein funktionale Nutzung und der Verminderung des Werkgenusses?

e) Einwilligung in die urheberpersönlichkeitsrechtsverletzende Nutzung?

2. Google Buchsuche

a) Beeinträchtigung durch Fehler bei der Texterkennung (OCR)

b) Beeinträchtigung durch schlechte Scanqualität oder lückenhafte Scans

c) Beeinträchtigung durch Darstellung in Form von Snippets

d) Beeinträchtigung durch fehlerhafte Metadaten 249

III. Allgemeines Persönlichkeitsrecht 250

IV. Zwischenergebnis 252

D. Exkurs: Anwendbares Recht und internationale Zuständigkeit 253

I. Anwendbares Recht 254

1. Google Buchsuche 262

2. Thumbnails 263

II. Internationale Zuständigkeit 264

1. Google Buchsuche 270 
5. Kapitel:Länderbericht USA: Urheberrechtliche Probleme der

Google Buchsuche und der Bildersuche im Internet nach US-amerikanischem Copyright

A. Betroffene Verwertungsrechte der Urheberrechtsinhaber

I. Reproduction right

1. Thumbnails

2. Google Book Search

II. Distribution right

1. Thumbnails

2. Google Book Search

III. Right to publicly display

1. Thumbnails

2. Google Book Search

B. Google Book Search und Darstellung von Thumbnails als Fair Use?

I. Thumbnails

1. Kelly v. Arriba Soft Corp.

2. Perfect 10 v. Google, Inc.

a) Erste Instanz: District Court for the Central District of California

b) Zweite Instanz: Court of Appeals for the Ninth Circuit

3. Rezeption der Entscheidungen in der USamerikanischen Literatur

4. Ergebnis: Thumbnail-Nutzung als Fair Use

II. Google Book Search

1. Fair Use-Analyse

a) Die Präambel

b) Erster Faktor: "The Purpose and Character of the Use"

c) Zweiter Faktor: "The Nature of the Copyrighted Work"

d) Dritter Faktor: "The Amount and Substantiality of the Portion Used" 
e) Vierter Faktor: "The Effect of the Use upon the Potential Market for or Value of the Copyrighted Work"

aa) Beeinträchtigung des bestehenden Buchmarktes

bb) Beeinträchtigung des Marktes für die Lizenzierung zur digitalen Werknutzung in kommerziellen (Fach-)Datenbanken mit Volltextsuchangeboten insbesondere für wissenschaftliche Werke

cc) Beeinträchtigung des (potentiellen) Marktes für die Lizenzierung digitaler Werkexemplare zur Verwendung im Rahmen der Volltextsuche in Suchmaschinen

dd) Beeinträchtigung des Marktes für den Verkauf digitaler Werkexemplare an Bibliotheken und Archive

ee) Ergebnis zum vierten Fair Use-Faktor 323

f) Berücksichtigung weiterer Umstände? 324

g) Abwägung der Faktoren und Ergebnis 328

2. Exkurs: Das Google Book Settlement und seine Folgen 333

a) Inhalt des Google Book Settlement

aa) Die erste Fassung des Google Book Settlement

(1) Wesentliche Regelungen des GBS

(2) Kritik am GBS

bb) Das Amended Settlement Agreement (ASA)

(1) Wesentliche Änderungen gegenüber dem ursprünglichen GBS

(2) Kritik am ASA

b) Unterschiede zu einer (möglichen) Fair Use-

Entscheidung

C. Zusammenfassung für das US-amerikanische Copyright 


\section{Inhaltsverzeichnis}

Ergebnis zu Teil 2 der Untersuchung - Vor- und Nachteile eines enumerativen Schrankenkataloges und einer Generalklausel im digitalen Kontext

Teil 3 Flexibilisierung der Urheberrechtsschranken de lege ferenda

6. Kapitel Vorgaben für die gesetzgeberische Ausgestaltung der Urheberrechtsschranken durch inter- und supranationales Recht sowie durch das deutsche (Verfassungs-)Recht

A. Konventionsrecht als Grenze der gesetzgeberischen Gestaltungsfreiheit

I. Allgemeine Erklärung der Menschenrechte (AEMR) 384

II. Europäische Menschenrechtskonvention (EMRK) 388

III. Charta der Grundrechte der Europäischen Union 392

1. Anwendbarkeit und Bedeutung der Charta der Grundrechte

2. Inhaltliche Relevanz der Charta für das Urheberrecht 394

IV. Revidierte Berner Übereinkunft (RBÜ) 398

1. Schutzsystem und Anwendungsbereich der RBÜ 400

2. Inhaltliche Relevanz der RBÜ für die Untersuchung 402

V. Welturheberrechtsabkommen (WUA) 408

VI. Rom-Abkommen (RA) 409

VII. TRIPS-Übereinkommen 411

1. Schutzsystem und Anwendungsbereich des TRIPSÜbereinkommens

2. Inhaltliche Relevanz des TRIPS-Übereinkommens für die Untersuchung

VIII. WIPO-,Internet Treaties“ WCT und WPPT

1. Schutzsystem und Anwendungsbereich von WCT und WPPT

2. Inhaltliche Relevanz von WCT und WPPT für die Untersuchung

B. Schrankenvorgaben durch das europäische Gemeinschaftsrecht

I. Gemeinschaftskompetenz zur Harmonisierung des Urheberrechts

II. Computerprogramm-Richtlinie, Vermiet- und

Verleihrechts-Richtlinie und Datenbank-Richtlinie

III. InfoSoc-Richtlinie 2001/29/EG 
C. Der Dreistufentest

I. Funktion und Wirkung des konventionsrechtlichen

Dreistufentests

II. Funktion und Wirkung des gemeinschaftsrechtlichen

Dreistufentests

III. Auslegung der drei Stufen 444

1. Zur Methode der Auslegung des Dreistufentests 445

2. Die drei Stufen des Dreistufentests 448

a) Bestimmte Sonderfälle 449

aa) Bedeutung der ersten Stufe 449

bb) Anforderungen an die Bestimmtheit 452

cc) Vorliegen eines Sonderfalls 456

b) Beeinträchtigung der normalen Auswertung $\quad 460$

aa) Historische Auslegung 462

bb) Normative Auslegung 465

c) Ungebührliche Verletzung berechtigter Interessen 473

aa) Auswirkung der Wortlautabweichung „Urheber“- „Rechtsinhaber“" 474

bb) Berechtigte Interessen 476

cc) Ungebührliche Verletzung 478

3. Zusammenfassende Stellungnahme 482

IV. Exkurs: Vereinbarkeit der Fair Use-Doktrin mit dem

Dreistufentest 484

1. Hinreichende Bestimmtheit der Fair Use-Schranke 485

2. Vorliegen eines "Sonderfalles“ 488

3. Historische Betrachtung der Vereinbarkeit 489

4. Ergebnis: Vereinbarkeit der Fair Use-Doktrin mit dem Dreistufentest

D. Der verfassungsrechtliche Rahmen gesetzgeberischer

Gestaltungsfreiheit

I. Verfassungsrechtlicher Schutz der Interessen der Urheber

1. Art. $14 \mathrm{GG}$ - Eigentumsschutz

a) Institutsgarantie

b) Sozialpflichtigkeit, Art. 14 Abs. 2 GG 497

c) Grundsatz der Verhältnismäßigkeit 498

2. Art. 5 Abs. 3 S. 1 GG - Kunst- und

Wissenschaftsfreiheit 
3. Art. 1 und Art. 2 Abs. 1 GG -

Persönlichkeitsgrundrecht

II. Verfassungsrechtlicher Schutz der Interessen der

Werkmittler

1. Art. $14 \mathrm{GG}$ - Eigentumsschutz 506

2. Art. $12 \mathrm{GG}$ - Berufsfreiheit 508

III. Verfassungsrechtliche Anerkennung der Interessen der Kulturverbraucher, einzelner Nutzergruppen oder der Allgemeinheit an der Werknutzung

1. Art. 5 Abs. $1 \mathrm{~S} .1 \mathrm{GG}$ - Informationsfreiheit

a) Schutzbereich des Art. 5 Abs. 1 S. 1 2. Hs. GG 511

b) Einschränkung der Informationsfreiheit 514

2. Art. 5 Abs. 3 S. 1 GG - Kunst- und

Wissenschaftsfreiheit

IV. Zusammenfassung zu den verfassungsrechtlichen Vorgaben

7. Kapitel Mögliche legislative Maßnahmen zur Flexibilisierung der Schranken des Urheberrechts und ihre Vereinbarkeit mit den rechtlichen Vorgaben

A. Einführung einer Schrankengeneralklausel im europäischen Recht

I. Alleinige Schrankengeneralklausel im europäischen Recht

1. Änderung des Richtlinienrechts

2. Schrankengeneralklausel als Teil einer europäischen Urheberrechtsverordnung

3. Opportunität und Umsetzbarkeit der Rechtsetzungsvarianten

II. Schrankengeneralklausel als Auffangtatbestand

1. Der Entwurf einer generalklauselartigen Öffnungsklausel in Anlehnung an den Dreistufentest im „European Copyright Code“

a) Ausgestaltung der Schranken im European

Copyright Code-Entwurf

b) Kritische Bewertung der vorgeschlagenen

Auffanggeneralklausel

c) Fazit zum ECC-Entwurf 
2. Auffangtatbestand nach dem Vorbild des Dreistufentests und des Fair Use

a) Formulierungsvorschlag 549

b) Erläuterung des Formulierungsvorschlags $\quad 550$

c) Opportunität der vorgeschlagenen Schrankenbestimmung

III. Zusammenfassung und Bewertung

B. Einführung einer Schrankengeneralklausel im deutschen Urheberrecht

I. Vollständige Ersetzung des Schrankenkataloges des deutschen Urheberrechtsgesetzes durch eine

Generalklausel

1. Formulierungsvorschlag und Erläuterung 560

2. Opportunität des Vorschlags 563

3. Vereinbarkeit mit den rechtlichen Vorgaben $\quad 564$

II. Integration einer Generalklausel in den bestehenden

Schrankenkatalog

1. Formulierungsvorschlag und Erläuterung 568

2. Opportunität des Vorschlags 573

3. Vereinbarkeit mit den rechtlichen Vorgaben $\quad 576$

III. Zusammenfassung und Bewertung 578

C. Ergänzung einzelner Urheberrechtsschranken um flexiblere Elemente

I. Die Einführung von Regelbeispielen

II. Die Einführung generalklauselartiger, weiter Formulierungen innerhalb einzelner Tatbestände

D. Fazit und Perspektive zur Flexibilisierung der urheberrechtlichen Schrankenbestimmungen in Deutschland und Europa

8. Kapitel Zusammenfassung der wesentlichen Ergebnisse in Thesen 


\section{Abkürzungen}

1st Cir., 2d Cir., usw.

a.A.

a.a.O.

AB1.

Abs.

AcP

a.E.

AEUV

a.F.

AfP

AGB

allg.

Alt.

AMI

Amtl. Begr.

Anm.

Art.

ASA

AT

Aufl.

BeckRS

Begr.

Beil.

BGB

BGB1.

BGH

BGHZ

bspw.

BT-Drs.

BVerfG
U.S. Court of Appeals for the $1^{\text {st }}$ ( $2^{\text {nd }}$, usw.) Circuit

andere(r) Ansicht

am angegebenen Ort

Amtsblatt

Absatz

Archiv für civilistische Praxis

am Ende

Vertrag über die Arbeitsweise der Europäischen Union alte Fassung

Zeitschrift für Medien- und Kommunikationsrecht, vormals: Archiv für Presserecht

Allgemeine Geschäftsbedingungen

allgemein(e/s)

Alternative

Tijdschrift Voor Auteurs-, Media \& Informatierecht

Amtliche Begründung

Anmerkung

Artikel, Article

Amended Settlement Agreement

Allgemeiner Teil

Auflage

Beck-Rechtsprechungsdienst

Begründung

Beilage

Bürgerliches Gesetzbuch

Bundesgesetzblatt

Bundesgerichtshof

Entscheidungen des Bundesgerichtshofs in Zivilsachen

beispielsweise

Bundestags-Drucksache

Bundesverfassungsgericht 
BVerfGE

BVerwGE

bzgl.

bzw.

C.C.D. Mass.

C.D. Cal.

CDPA

Cl.

CMLR

CR

CRi

DdA

ders.

d.h.

dies.

ebd.

ECC

EG

EGMR

EGV

Einl.

EIPR

EMRK

Eng. Rep.

Erw.-Grd.

et al.

etc.

EU

EuGH

EuGRZ

EUV

EuZW

f., ff.

F. $(2 d / 3 d)$

F.Cas.
Entscheidungen des Bundesverfassungsgerichts

Entscheidungen des Bundesverwaltungsgerichts

bezüglich

beziehungsweise

U.S. Circuit Court for the Central District of Massachusetts

U.S. District Court for the Central District of California Copyright, Designs and Patents Act

Clause

Common Market Law Review

Computer und Recht

Computer Law Review International

Le droit d'auteur

derselbe

das heißt

dieselbe(n)

ebenda

European Copyright Code

Europäische Gemeinschaft(en)

Europäischer Gerichtshof für Menschenrechte

Vertrag zur Gründung der Europäischen Gemeinschaft

Einleitung

European Intellectual Property Review

Europäische Menschenrechtskonvention

English Reports

Erwägungsgrund/-gründe

et alii/a/ae

et cetera

Europäische Union

Gerichtshof der Europäischen Union

Europäische Grundrechte-Zeitschrift

Vertrag über die Europäische Union

Europäische Zeitschrift für Wirtschaftsrecht

folgende

Federal Reporter (2nd Series/3rd Series)

Federal Cases 
F.Supp. (2d)

FG

Fn.

FS

GATT

GB

GBS

GG

ggfs.

GPR

GRC

grds.

GRUR

GRUR Int.

GRUR-RR

GRUR-Prax.

h.L.

h.M.

H.R. Rep.

Hrsg.

Hs.

ICLQ

i.d.R.

i.E.

i.e.

i.H.v.

IIC

insbes.

IPQ

IPRax

i.R.d.

IRDI
Federal Supplement (2nd Series)

Festgabe

Fußnote

Festschrift

General Agreement on Tariffs and Trade

Grüner Bote

Google Book Settlement

Grundgesetz

gegebenenfalls

Zeitschrift für Gemeinschaftsprivatrecht

Charta der Grundrechte der Europäischen Union

grundsätzlich

Gewerblicher Rechtsschutz und Urheberrecht

Gewerblicher Rechtsschutz und Urheberrecht - Internationaler Teil

Gewerblicher Rechtsschutz und Urheberrecht - Rechtsprechungs-Report

Gewerblicher Rechtsschutz und Urheberrecht - Praxis im Immaterialgüter- und Wettbewerbsrecht

herrschende Lehre

herrschende Meinung

House of Representatives Reports

Herausgeber

Halbsatz

International \& Comparative Law Quarterly

in der Regel

im Ergebnis

id est

in Höhe von

International Review of Intellectual Property and Competition Law

insbesondere

Intellectual Property Quarterly

Praxis des internationalen Privat- und Verfahrensrechts

im Rahmen der/des

Intellectuele Rechten - Droits Intellectuels 
i.S.d.

i.V.m.

JIPITEC

jurisPR-ITR

jurisPR-WettbR

$\mathrm{JuS}$

$\mathrm{JZ}$

Kap.

KG

$\mathrm{KOM}$

$\mathrm{K} \& \mathrm{R}$

KUG

KUR

LG

Lit.

lit.

LMK

LUG

MarkenG

MarkenR

M.D. Tenn.

MMR

MR-Int.

MünchKomm

m.w.N.

n.F.

NJW

NJW-RR

No. im Sinne der/des

in Verbindung mit

Journal of Intellectual Property, Information Technology and E-Commerce Law

juris PraxisReport IT-Recht

juris PraxisReport Wettbewerbsrecht

Juristische Schulung

Juristenzeitung

Kapitel

Kammergericht

Dokumente der Kommission der Europäischen Gemeinschaften

Kommunikation und Recht

Gesetz betreffend das Urheberrecht an Werken der bildenden Künste und der Photographie

Kunst und Recht

Landgericht

Literatur

littera

Kommentierte BGH-Rechtsprechung Lindenmaier-Möhring

Gesetz betreffend das Urheberrecht an Werken der Literatur und der Tonkunst

Markengesetz

Markenrecht - Zeitschrift für deutsches, europäisches und internationales Kennzeichenrecht

U.S. District Court for the Middle District of Tennessee Multimedia und Recht - Zeitschrift für Informations-, Telekommunikations- und Medienrecht

Medien und Recht International

Münchener Kommentar

mit weiteren Nachweisen

neue(r) Fassung

Neue Juristische Wochenschrift

Neue Juristische Wochenschrift - Rechtsprechungs-Report

Number 
$\mathrm{Nr}$.

o.ä.

OLG

p.m.a.

Pub. L.

RA

RBÜ

RegE

RGB1.

RGSt

RGZ

RIDA

RL

$\mathrm{Rn}$.

R.S.C.

Rspr.

S.

S.D. Cal.

S.D.N.Y.

Sec.

Slg.

sog.

st. Rspr.

Stat.

StGB

TMG

TRIPS

u.a.

UFITA

UrhG

UrhR

URL

Urt.
Nummer(n)

oder ähnliche(s)

Oberlandesgericht

post mortem auctoris

Public Law

Rom-Abkommen

Revidierte Berner Übereinkunft

Regierungsentwurf

Reichsgesetzblatt

Entscheidungen des Reichsgerichts in Strafsachen

Entscheidungen des Reichsgerichts in Zivilsachen

Revue internationale du droit d'auteur

Richtlinie

Randnummer(n)

Revised Statutes of Canada

Rechtsprechung

Satz, Seite(n)

U.S. District Court for the Southern District of California

U.S. District Court for the Southern District of New York

Section

Sammlung der Rechtsprechung des Gerichtshofes und des Gerichts erster Instanz

sogenannt(e/er)

ständige Rechtsprechung

United States Statutes at Large

Strafgesetzbuch

Telemediengesetz

Agreement on Trade-Related Aspects of Intellectual Property Rights

und andere, unter anderem

Archiv für Urheber- und Medienrecht

Urheberrechtsgesetz

Urheberrecht

Uniform Resource Locator

Urteil 
U.S.

U.S.C.

usw.

UWG

v.

Var.

Verf.

vgl.

VO

Vorb.

WCT

WIPO

WPPT

WRP

WTO

WUA

z.B.

ZEuP

ZfRV

ZGE

ZPO

ZRP

z.T.

ZUM

ZUM-RD
United States (of America), United States Reports

United States Code

und so weiter

Gesetz gegen den unlauteren Wettbewerb

versus, von $/ \mathrm{m}$

Variante

Verfasser

vergleiche

Verordnung

Vorbemerkung(en)

WIPO Copyright Treaty

World Intellectual Property Organization

WIPO Performances and Phonograms Treaty

Wettbewerb in Recht und Praxis

World Trade Organization

Welturheberrechtsabkommen

zum Beispiel

Zeitschrift für Europäisches Privatrecht

Zeitschrift für Rechtsvergleichung, Internationales Privatrecht und Europarecht

Zeitschrift für Geistiges Eigentum

Zivilprozessordnung

Zeitschrift für Rechtspolitik

zum Teil

Zeitschrift für Urheber- und Medienrecht

Zeitschrift für Urheber- und Medienrecht - Rechtsprechungsdienst 


\section{Einleitung}

"I am not an advocate for frequent changes in laws and constitutions. But laws and institutions must go hand in hand with the progress of the human mind. As that becomes more developed, more enlightened, as new discoveries are made, new truths discovered and manners and opinions change, with the change of circumstances, institutions must advance also to keep pace with the times. We might as well require a man to wear still the coat which fitted him when a boy as civilized society to remain ever under the regimen of their barbarous ancestors.”

- Thomas Jefferson

Auszug aus einem Brief vom 12. Juli 1816 an Samuel Kercheval, Inschrift am Jefferson Memorial in Washington, D.C.

Mehr als 195 Jahre sind vergangen, seit Thomas Jefferson, dritter Präsident der Vereinigten Staaten von Amerika, diese Worte in einem Brief an den Historiker Samuel Kercheval schrieb - an Aktualität haben sie bis heute nichts eingebüßt. Sie veranschaulichen eindrucksvoll, dass die Anpassung an sich wandelnde technische und wirtschaftliche Bedingungen seit jeher eine der wesentlichsten Aufgaben und Herausforderungen für das Recht ist.

Dies gilt in der heutigen Zeit in ganz besonderem Maße für das Urheberrecht. Es wird aufgrund der ständig neuen und wachsenden Möglichkeiten im Bereich der Informations- und Kommunikationstechnik und deren Umsetzung, der Digitalisierung von Information, der Weiterentwicklung von Computernetzwerken, insbesondere des Internets, und damit einhergehender neuer Geschäftsmodelle vor immer neue Herausforderungen von (auch) erheblicher wirtschaftlicher Bedeutung gestellt. Die Digitalisierung ermöglicht es, die unterschiedlichsten Medien und urheberrechtlich geschützten Werke, unabhängig davon, zu welcher der bislang unterscheidbaren Werkarten sie gehören und in welcher Form sie bisher gespeichert oder verkörpert waren, in Sekundenbruchteilen und zumeist ohne signifikante Kosten und Qualitätsverluste weltweit zu verbreiten. Diese neuen Technologien führen so zu neuen Anwendungsbereichen der urheberrechtlich geschützten Werke und $\mathrm{zu}$ entsprechend neuen Nutzungsarten und Geschäftsmodellen. Zudem erlaubt ständig verbesserte Software, das urheberrechtlich geschützte Werk (fast) beliebig zu verändern, zu manipulieren und zu bearbeiten. 


\section{Einleitung}

Manchen dieser Herausforderungen lässt sich dabei rechtlich nur in der Weise begegnen, dass die einschlägigen Gesetze nachträglich an die veränderte Nutzungsrealität angepasst werden. Alternativ können solche durch neue technische Entwicklungen auftauchende Gesetzeslücken dauerhaft oder auch nur vorübergehend, bis der Gesetzgeber tätig geworden ist - durch die Rechtsprechung im Wege der Rechtsfortbildung geschlossen werden. Ein zeitgemäßer Ausgleich zwischen den Interessen der Urheber, Nutzer und Werkmittler verlangt gerade in Zeiten rapider Entwicklung die Möglichkeit sinnvoller Anpassung des Urheberrechts an die sich wandelnde Nutzungsrealität. Dies fällt jedoch schwer, wenn das geltende Recht so konzipiert ist, dass es durch die gewählte Art der Gestaltung schnell „veraltet" und somit in der Praxis (ungewünschte) Konflikte erzeugt. Ein ständiges Tätigwerden des Gesetzgebers zur Vermeidung ungerechter und unerwünschter Konflikte im Einzelfall ist - verstärkt durch die zunehmende Europäisierung der Gesetzgebungsverfahren - bereits aus rein praktischen Gründen nicht möglich. Gerade deshalb erscheint es dringend notwendig, der Rechtsprechung hinreichende Gestaltungsfreiheit einzuräumen, um mehr Einzelfallgerechtigkeit und somit auch eine größere Akzeptanz für das Urheberrecht zu gewährleisten.

\section{A. Gegenstand und Zielsetzung der Arbeit}

Bei dem Versuch, das Urheberrecht zukunftsfähig zu machen, ist immer wieder bemängelt worden, dass insbesondere enumerative Kataloge urheberrechtlicher Schrankenbestimmungen, wie die des deutschen Urheberrechtsgesetzes und anderer droit d'auteur-Systeme, aufgrund fehlender Flexibilität die Gefahr bergen, gewisse höherrangige Interessen, die sich durch eine Veränderung der Rahmenbedingungen ergeben, nicht genügend zu berücksichtigen. Bei neuen Geschäftsmodellen, die sowohl gesellschaftlich wünschenswert erscheinen als auch positive Effekte für Urheber und sonstige Rechteinhaber haben mögen und sich dennoch nach geltendem Recht nicht rechtfertigen lassen, wird dies augenscheinlich. So wurde gerade im Zusammenhang mit den neuen Möglichkeiten der Google Buchsuche oder der Darstellung von sog. Thumbnails durch Suchmaschinen oftmals der Vorwurf laut, das deutsche und (kontinental-)europäische Urheberrecht hinke den technischen Entwicklungen stets hinterher und werde weder den Interessen der Allgemeinheit, noch denen der Urheber gerecht. Vielfach werden die neuen Technologien bereits angewendet, unab- 
hängig davon, ob dies rechtlich zulässig ist oder nicht. Um die Anpassungsfähigkeit des Urheberrechts an veränderte wirtschaftliche, technische und soziale Gegebenheiten zu gewährleisten, wird es daher vielfach für notwendig gehalten, von einem starren Regelungswerk Abstand zu nehmen und Flexibilisierungsmechanismen einzuführen. Dem wird zum Teil entgegengehalten, die Vorteile eines starren Schrankensystems würden dessen Nachteile deutlich überwiegen.

Im Rahmen dieser Arbeit soll deshalb darüber nachgedacht werden, inwieweit im Bereich der Schrankenregelungen sinnvoll eine größere Flexibilität im Urheberrecht erzeugt werden kann. Als Elemente zur Flexibilisierung der Schrankenregelungen sollen dabei in erster Linie die Implementierung einer Schrankengeneralklausel und offener Rechtsbegriffe in das Urheberrechtsgesetz untersucht werden.

Prominentester und wirtschaftlich bedeutendster Vertreter eines Systems von umfassend gewährtem Urheberrecht, dem eine als offene Generalklausel ausgestaltete Urheberrechtsschranke gegenübergestellt ist, sind die Vereinigten Staaten von Amerika. Eine Untersuchung der Fair UseDoktrin des US-amerikanischen Copyright - die in über einhundertjähriger Rechtsprechung entwickelt und 1976 in den Copyright Act der USA (17 U.S.C. § 107) aufgenommen wurde - bietet die Möglichkeit, Vor- und Nachteile einer derartigen Schrankengeneralklausel gegenüber einem starren, abschließenden Schrankenkatalog aufzuzeigen. Einen Schwerpunkt der Untersuchung soll dabei die Anwendung der Fair Use-Doktrin bei der Konfrontation mit neuen digitalen Nutzungsformen urheberrechtlich geschützter Werke durch US-amerikanische Gerichte in den letzten Jahren und deren Bewertung durch die (amerikanische) Fachliteratur darstellen.

Eine rechtliche Begutachtung konkreter aktueller technischer Neuerungen und aus diesen entstehender neuer Geschäftsmodelle ermöglicht eine vertiefte und zugleich besonders plastische Auseinandersetzung mit den Vor- und Nachteilen eines enumerativen Kataloges von Einzelausnahmen und einer Schrankengeneralklausel in Bezug auf neue digitale Nutzungsformen urheberrechtlich geschützter Werke. Zur Illustration sollen deshalb maßgeblich die Geschäftsmodelle der Google Buchsuche und der Verwendung sogenannter Thumbnails bei der Bildersuche dienen, die erhebliche urheberrechtliche Probleme sowohl nach deutschem als auch nach US-amerikanischem Urheberrecht aufwerfen und daher in jüngster Zeit die Gerichte auf beiden Seiten des Atlantiks beschäftigt und zu einer regen wissenschaftlichen Diskussion geführt haben. 


\section{Einleitung}

Abschließend soll die Möglichkeit und Opportunität der Einführung einer Generalklausel nach dem Vorbild der US-amerikanischen Fair UseDoktrin oder der Übernahme einiger aus dem US-amerikanischen Copyright gewonnener Erkenntnisse in das deutsche und europäische Urheberrecht erörtert werden. Eine derartige Betrachtung de lege ferenda erfordert eine detaillierte Auseinandersetzung mit den durch inter- und supranationales Recht sowie durch das deutsche (Verfassungs-)Recht bestimmten rechtlichen Rahmenbedingungen für die gesetzgeberische Ausgestaltung der Urheberrechtsschranken. Jedoch soll die Untersuchung keinesfalls bei einer reinen Analyse der rechtlichen Rahmenbedingungen stehen bleiben, sondern vielmehr konkrete Formulierungsvorschläge für einzelne Rechtsetzungsvarianten liefern.

\section{B. Gang der Untersuchung}

Um eine klare Darstellung der bereits beschriebenen Ziele zu erreichen, ist diese Arbeit in drei Teile untergliedert. Teil 1 der Untersuchung widmet sich ausgewählten Grundlagen des Urheberrechtsschutzes und dem System der urheberrechtlichen Schranken in Deutschland und in den USA. Nach einem Überblick über die Unterschiede bei der Urheberrechtsgewährung werden die unterschiedlichen Regelungstechniken eines enumerativen Kataloges von Einzelausnahmen und einer Schrankengeneralklausel gegenübergestellt. Anschließend soll das Schrankensystem des deutschen Urheberrechtsgesetzes näher dargestellt werden, bevor schließlich die Fair Use-Doktrin des US-amerikanischen Copyright näher erörtert wird.

In Teil 2 der Arbeit erfolgt eine Auseinandersetzung mit den Vor- und Nachteilen der jeweiligen Regelungstechnik in Bezug auf neue digitale Nutzungsformen urheberrechtlich geschützter Werke. Zur Illustration sollen dabei im Wesentlichen die Geschäftsmodelle der Google Buchsuche und der Verwendung sogenannter Thumbnails bei der Bildersuche dienen, da sie als neue Nutzungsformen erhebliche urheberrechtliche Probleme sowohl nach deutschem als auch nach US-amerikanischem Urheberrecht aufgeworfen haben. Eine detaillierte Untersuchung der Ansätze zur Lösung dieser Probleme in der Rechtsprechung und rechtswissenschaftlichen Literatur beider Rechtsordnungen ermöglicht wichtige Erkenntisse für die Frage der Flexibilisierung des deutschen Urheberrechts de lege ferenda.

Einem (auch) rechtspolitischen Ansatz folgend, widmet sich Teil 3 der Untersuchung diesen Möglichkeiten einer Flexibilisierung des deutschen 
Urheberrechts de lege ferenda. Dabei werden einzelne Rechtsetzungsvarianten erörtert und anschließend auf ihre Opportunität und Vereinbarkeit mit den Vorgaben des inter- und supranationalen Rechts sowie des deutschen Verfassungsrechts überprüft. 


\section{Teil 1 Grundlagen}

\section{Kapitel Urheberrechtsgewährung im deutschen und US- amerikanischen Recht}

Das Immaterialgüterrecht an Geisteswerken wird im kontinentaleuropäischen Rechtsraum als Urheberrecht (,droit d'auteur"), im angloamerikanischen Recht als Copyright bezeichnet. Hinter dieser unterschiedlichen Terminologie verbergen sich - jedenfalls traditionell - grundlegende inhaltliche Divergenzen, deren Verständnis für diese Untersuchung von entscheidender Bedeutung ist. Während im Mittelpunkt des kontinentaleuropäischen Urheberrechts traditionell die Person des Werkschöpfers steht, deren Leistung durch die Gewährung eines Ausschließlichkeitsrechtes anerkannt werden soll (dazu sogleich A.), stellt das angloamerikanische $\mathrm{Co}$ pyright ökonomische Aspekte in den Vordergrund; es geht in erster Linie um den Schutz der „, copy“ - der produzierten Ware (sodann B.).

\section{A. Deutsches Urheberrechtsgesetz: Urheberrecht als umfassend gewährtes Recht}

Das Urheberrecht, wie wir es heute kennen, ist ein relativ junges Rechtsinstitut. Obwohl es schon seit der Antike Bestrebungen zum Schutz literarischer und künstlerischer Werke gab, fand der Schutz des Werkschöpfers erst im 18. Jahrhundert eine rechtswissenschaftliche Fundierung und schließlich eine positivrechtliche Anerkennung. Für das Verständnis der grundlegenden Unterschiede von deutschem und US-amerikanischem Urheberrecht und der sich daraus ergebenden Konsequenzen für den Umgang mit urheberrechtlich geschützten Werken lohnt sich ein kurzer Blick auf die historischen Grundlagen und Entwicklungslinien des Urheber- 
rechtsschutzes in Deutschland und Europa. ${ }^{1}$ Der folgende rechtshistorische Teil soll und kann jedoch aufgrund der notwendigen Kürze nicht die zahlreichen bereits existierenden Darstellungen der geschichtlichen Entwicklung des Urheberrechts um eine weitere - notwendigerweise unvollständige - Beschreibung ergänzen. Vielmehr sollen lediglich knapp die wesentlichen Entwicklungen und Entwicklungslinien insbesondere zum Gedanken des ,geistigen Eigentums“ nachgezeichnet werden (sogleich I.), um die kulturell-historisch verwurzelten Unterschiede und Gemeinsamkeiten beider Rechtskreise zu verdeutlichen und so eine fundierte Auseinandersetzung zu ermöglichen, bevor das heutige System des Schutzes geistiger Leistungen durch das Urheberrecht in Deutschland kurz dargestellt wird (sodann II.)

\section{Die Entstehung des Urheberrechts und ,geistigen Eigentums “ in Deutschland}

In der römischen Antike war ein Urheberrecht als umfassendes Recht an einem Geisteswerk trotz eines hochentwickelten Schriftwesens und eines gut ausgebildeten Handels mit den Handschriften ${ }^{2}$ nicht bekannt. Es fand grundsätzlich keine Differenzierung zwischen dem Eigentum an einem Werkstück und der in diesem verkörperten geistigen Leistung statt. ${ }^{3}$ Es wurde nur ein Recht am Werkexemplar gewährt, das jedoch immerhin in gewissem Maße durch Verkauf wirtschaftlich verwertet werden konnte. ${ }^{4}$ Wer den höheren Künsten, den sog. ,,artes liberales“, nachging, hatte dies im Übrigen nach der stoischen Ethik unentgeltlich zu tun; sein Lohn war ein immaterieller in Form von persönlichem Ansehen und Prestige. ${ }^{5}$ Ein Schutz gegen Vervielfältigung und Verbreitung eines Werkes bestand

1 Vgl. ausführlich zur Entwicklung des Urheberrechts von der Antike bis zur Neuzeit Bappert, Wege zum Urheberrecht; Gieseke, Vom Privileg zum Urheberrecht.

2 Siehe zum Buch- und Verlagswesen im alten Rom Seifert, NJW 1992, 1270 (1271 f.).

3 Vgl. Bappert, Wege zum Urheberrecht, S. 16.

4 Vgl. Bappert, Wege zum Urheberrecht, S. 17; Gieseke, Vom Privileg zum Urheberrecht, S. 2.

5 Vgl. Gieseke, Vom Privileg zum Urheberrecht, S. 2; Rehbinder, Urheberrecht, Rn. 12. Die bildenden Künste verstand man hingegen im alten Rom als niederes Handwerk, das in der Regel von Sklaven geleistet und werkvertraglich entgolten wurde; vgl. Schack, Urheberrecht, Rn. 103. 
nicht. Vielmehr sollte es grundsätzlich jedermann frei stehen, von jedem veröffentlichten Schriftwerk Abschriften in beliebiger Zahl zu fertigen oder fertigen zu lassen. Diese Auffassung hatte ihren Ursprung darin, dass die Werkentstehung philosophisch nicht als eigenpersönliche Schöpfung angesehen wurde, sondern vielmehr als das Auffinden vorbestehender Wahrheiten. Der Urheber war nach dieser Vorstellung nicht als Schöpfer des „Neuen“ tätig, sondern als Vermittler geistig-ästhetischer Wirklichkeiten im göttlichen Reich des Schönen, Wahren und Guten oder gar als Medium zwischen den Göttern und der werkempfangenden Allgemeinheit. ${ }^{6}$ Eines Ausschließlichkeitsrechts als Möglichkeit zur finanziellen Absicherung der Urheber bedurfte es jedoch auch deshalb nicht, weil die Künstler in der Regel durch eigenen Reichtum oder aber durch die Zahlung eines ehrbezeugenden Honorars durch einen Mäzen materiell abgesichert waren. ${ }^{7}$

Auch im christlichen Mittelalter entwickelte sich kein mit dem uns heute bekannten System vergleichbarer Urheberrechtsschutz. Es herrschte die schon in der Antike bestehende und im Mittelalter christlich umgedeutete Vorstellung vom Werkschöpfer als einem bloßen Mittler zwischen Gott und den Menschen vor, der geradezu dazu verpflichtet war, der Allgemeinheit das Werk bestimmungsgemäß zuzuführen. ${ }^{8}$ Das (Kunst-)Werk vertrug keine persönliche Identifizierung mit seinem Schöpfer, so dass auch eine „Schöpferpersönlichkeit" nicht anerkannt wurde; in der Regel blieb der Künstler gar anonym. ${ }^{9}$ Ein Schutz gegen Vervielfältigungen und Verbreitung und selbst gegen die Entstellung ${ }^{10}$ von Werken wurde daher nicht als notwendig erachtet. Vielmehr sollte die Anfertigung von Ab-

$6 \mathrm{Zu}$ dieser sog. Nachahmungs- und Inspirationstheorie siehe Bappert, Wege zum Urheberrecht, S. $21 \mathrm{ff}$. Ausführlich zum Urheberrechtsverständnis der römischen Antike, Eggert, UFITA 138 (1999), 183 (185 ff.).

7 Vgl. Schack, Urheberrecht, Rn. 103; Rehbinder, Urheberrecht, Rn. 12.

8 Vgl. Bappert, Wege zum Urheberrecht, S. 63 ff.; Hubmann, Recht des schöpferischen Geistes, S. 68.

9 Man spricht daher in Bezug auf diese Epoche auch oftmals von den „unbekannten Meistern"; vgl. Pohlmann, Frühgeschichte, S. 35.

10 Die Sorge der Urheber um die Integrität ihrer Werke führte zur Entwicklung der sog. Bücherflüche, deren bekanntester wohl die Reimvorrede zum Sachsenspiegel (um 1230) ist, in der Eike von Repgow all denjenigen Aussatz und Hölle wünscht, die versuchen sollten, den Inhalt seiner Rechtsaufzeichnung zu verfälschen und den geänderten Text als den ihrigen auszugeben; vgl. Gieseke, Geschichtliche Entwicklung, S. 19; Ulmer, S. 51. Zur Frage der Urheberschaft von Repgows, siehe Müller, UFITA 10 (1937), $383 \mathrm{ff}$. 
schriften, die zumeist in Klöstern oder an den ersten Universitäten erstellt wurden, frei sein. Zudem wurde die für die Vervielfältigung eines Werkes notwendige Mühe und das Aufbringen der damit verbundenen Kosten grundsätzlich als größere Leistung angesehen als die ursprüngliche geistige Schöpfung. Der sittliche und geistliche Rang des geistigen Schaffens schloss zudem den Gedanken an eine materielle Entlohnung für diese Tätigkeit aus. Ähnlich wie in der Antike waren daher auch im Mittelalter die meisten Künstler auf eine finanzielle Absicherung durch die Zugehörigkeit zu einem Orden oder einer Zunft, durch die Herkunft aus ,gutem Hause“ oder die Gunst eines Mäzens angewiesen. ${ }^{11}$

Mit Beginn der Renaissance und dem Aufkommen des Humanismus in den Geisteswissenschaften gingen auch entscheidende Änderungen im Hinblick auf das künstlerische Schaffen einher. Zum einen führten die geistigen Strömungen dieser Zeit zu einer Überwindung der mittelalterlichen Anonymität geistigen Schaffens und zu einem Erwachen eines Persönlichkeitsgefühls der Künstler hin zu einem „Urheber-Bewusstsein“.12 Zum anderen ermöglichten die ebenfalls in diese Zeit fallende revolutionäre Erfindung des Buchdrucks (um 1450) ${ }^{13}$ sowie die Entwicklung des Kupferstichs und Holzschnittes plötzlich die Vervielfältigung und Verbreitung geistiger Werke in größerer, nur schwer kontrollierbarer Auflage. Während der Nachdruck der Werke zunächst als etwas Selbstverständliches oder Unvermeidliches und jedenfalls nichts Unrechtmäßiges angesehen wurde, ${ }^{14}$ formierte sich nach und nach erste Kritik am unbegrenzten Nachdruck. Ein Bedürfnis nach rechtlichem Schutz gegen die unkontrollierte Vervielfältigung und Entstellung der Werke und nach einer materiel-

11 Vgl. Bappert, Wege zum Urheberrecht, S. 88 ff.; Gieseke, Vom Privileg zum Urheberrecht, S. 173.

12 Vgl. Hubmann, Persönlichkeitsrecht, S. 31 ff.; Pohlmann, Frühgeschichte, S. 19 f.

13 Tatsächlich wurden Drucktechniken für Bücher bereits seit mindestens dem 10. Jahrhundert in Korea und China angewendet, dies allerdings zunächst nicht mit beweglichen Lettern, sondern mit Holztafeln, in die das Druckbild wie bei einem Stempel geschnitzt wurde; vgl. Feather, History, S. 7. Wahrscheinlich ab dem 13. Jahrhundert, spätestens jedoch im 14. Jahrhundert, wurden in Asien Drucktechniken mit einzelnen beweglichen Lettern aus Holz, Ton oder Metall angewandt; vgl. Youm, 17 UCLA Pac. Basin L.J. 276, 278 f. (1999/2000). Ausführlich zur Erfindung und Durchsetzung der Drucktechnik in Europa Höffner, Geschichte und Wesen des UrhR I, S. $20 \mathrm{ff}$.

14 Vgl. zum „Grundsatz der Vervielfältigungsfreiheit“ Gieseke, Geschichtliche Entwicklung, S. 20; ders., Vom Privileg zum Urheberrecht, S. 14, 33. 
len Absicherung der Urheber ${ }^{15}$ und insbesondere der Drucker und Verleger für die eigene Arbeit und Investition wurde offenbar. ${ }^{16}$ Diesem Schutzbedürfnis wurde in Form befristet gewährter Monopolrechte, der sogenannten Privilegien, nachgekommen, die von Städten, Landesherren oder dem Kaiser verliehen wurden. ${ }^{17}$ Die Privilegien räumten regelmäßig dem Privilegierten das ausschließliche Recht ein, während eines gewissen Zeitraums das in der Urkunde aufgeführte Druckwerk zu vervielfältigen und zu verbreiten. Gleichzeitig wurde es allen Nicht-Privilegierten verboten, das Druckwerk nachzudrucken und verbotenermaßen gedruckte Exemplare einzuführen oder zu veräußern. ${ }^{18}$ Einen entscheidenden Beweggrund der Privilegienerteilung stellten Überlegungen des Gemeinwohls dar. Ein Privileg wurde daher grundsätzlich nur für solche Druckwerke erteilt, die einen Nutzen für das Gemeinwesen brachten. ${ }^{19}$ Ein solcher Gemeinnutzen wurde in der Regel dann angenommen, wenn ein Text gedruckt und veröffentlicht und somit jedermann zugänglich gemacht werden sollte, wenn er ,neu“ - also noch nicht anderweitig gedruckt und veröffentlicht - war und wenn er eine ,gewisse Bedeutung“ hatte. ${ }^{20}$ Die Gewährung der Privilegien knüpfte dabei an die Druck- und nicht die Geisteswerke an, da ihr Ziel nicht in erster Linie der Schutz der Autoren, sondern ein Gewerbeschutz zugunsten der Drucker und Verleger in ihren Investitionen war, um so eine Förderung des Gemeinwohls zu erreichen. ${ }^{21}$

15 Zunächst war es weiterhin verpönt, eine Entlohnung für die Urhebertätigkeit anzunehmen, da sich diese mit dem zunächst fortwirkenden mittelalterlichen Weltbild und der daraus folgenden Mittlerfunktion des Autors zwischen Gott und den Menschen nicht vereinbaren ließ. Der wirtschaftlichen Notwendigkeit, die Autoren in den sich wandelnden gesellschaftlichen Bedingungen zu entlohnen, wurde deshalb oftmals durch Zahlungen in Form von „Ehrengeschenken“ der Verleger Rechnung getragen; vgl. Bappert, Wege zum Urheberrecht, S. $146 \mathrm{f}$.

16 Vgl. Ulmer, S. 51.

17 Vgl. Gieseke, Vom Privileg zum Urheberrecht, S. 39 f.; Rehbinder, Urheberrecht, Rn. 14 ff.; Ulmer, S. 51 ff.

$18 \mathrm{Vgl}$. Bappert, Wege zum Urheberrecht, S. 185. Zu den verschiedenen Formen von Privilegien siehe etwa Gieseke, Vom Privileg zum Urheberrecht, S. 39 ff.; Rehbinder, Urheberrecht, Rn. $15 \mathrm{ff}$.

19 Vgl. Bappert, Wege zum Urheberrecht, S. 186; Gieseke, Vom Privileg zum Urheberrecht, S. 63.

20 Vgl. Gieseke, Vom Privileg zum Urheberrecht, S. 65.

21 Vgl. Bappert, Wege zum Urheberrecht, S. $183 \mathrm{ff}$;; Dölemeyer/Klippel, in: FS GRUR, S. 185 (189, 193 f.). Zum Gewerbeschutz durch Nachdruckverbote siehe Hilty, in: Notwendigkeit des Urheberrechtsschutzes, S. 20 ff.; Wadle, in: Histo- 
Mit der Steigerung des Persönlichkeitsbewusstseins und der Betonung der Individualität im Zuge der Renaissance versuchten jedoch zunehmend auch die Urheber selbst, einen Schutz ihrer schöpferischen Leistung zu erlangen. So entwickelten sich ab der Mitte des 15. Jahrhunderts und zunehmend im 16. Jahrhundert auch Autorenprivilegien, ${ }^{22}$ die als Belohnung für die geistige Schöpfung gedacht waren und die ideellen Interessen des Urhebers schützen sollten. ${ }^{23}$ Trotz ihrer Belohnungsfunktion für den Urheber in Form erster Tendenzen eines Schutzes urheberpersönlichkeitsrechtlicher Interessen können diese Privilegien noch nicht als Beginn des Urheberrechts im heutigen Sinne verstanden werden. Der Schutz des Privilegs knüpfte weiterhin an das Druckwerk an und nicht an die geistig-schöpferische Leistung, so dass der Schutz des Geisteswerkes allenfalls mittelbar erfolgte. ${ }^{24}$ Es handelte sich somit bei den Privilegien in erster Linie um ein Mittel zur Lösung ,gewerblicher" und nicht urheberrechtlicher Probleme. ${ }^{25}$ Dennoch spielten die Druckprivilegien in den folgenden Jahrhunderten eine wesentliche Rolle, da sie als rechtliche Schutzmaßnahmen durch-

rische Studien, S. $33 \mathrm{ff}$. Vielfach wird neben der Gewährung eines Schutzes des Gewerbes als entscheidender Beweggrund für die Privilegienerteilung auch die Möglichkeit zu obrigkeitlicher Kontrolle und Zensur gesehen; vgl. Gieseke, Geschichtliche Entwicklung, S. 42 ff., ders., Vom Privileg zum Urheberrecht, S. 70 f.; ders., in: Historische Studien, S. $22 \mathrm{ff}$.

22 Das erste bekannte Autorenprivileg wurde im Jahre 1486 in Venedig an Marcus Antonius Sabellicus für seine Geschichte der Stadt Venedig erteilt; vgl. Kohler, Urheberrecht, S.36. Erste derartige Privilegien der kaiserlichen Hofkanzlei in Deutschland finden sich zu Beginn des 16. Jahrhunderts, etwa das 1511 an Albrecht Dürer für sein „Marienleben“ erteilte Privileg; siehe Rehbinder, Urheberrecht, Rn. 17. Eine chronologische Übersicht kaiserlicher Autorenprivilegien aus dem 16. Jahrhundert findet sich bei Pohlmann, UFITA 33 (1961), 169 (196 ff.); vgl. auch ders., GRUR 1962, 9 (24 f.).

23 Die Autorenprivilegien enthielten zum Schutz ideeller Interessen etwa die Verpflichtung zur Autorennennung, Entstellungsverbote oder Verbote der Veröffentlichung ohne Zustimmung des Autors; vgl. Gieseke, Vom Privileg zum Urheberrecht, S. 59 f.; Rehbinder, Urheberrecht, Rn. 17; Schack, Urheberrecht, Rn. 107.

24 Vgl. Gieseke, Geschichtliche Entwicklung, S. 36; Rehbinder, Urheberrecht, Rn. 17. Zur der wesentlich von Pohlmann angestoßenen Diskussion (siehe Pohlmann, UFITA 33 (1961), 169 und ders., GRUR 1962,9) über den vermeintlich urheberrechtlichen Charakter der Privilegien, auf die hier nicht näher eingegangen werden soll, vgl. etwa Bappert, Wege zum Urheberrecht, S. 183 ff.; Dölemeyer/ Klippel, in: FS GRUR, S. 185 (190 ff.); Gieseke, Vom Privileg zum Urheberrecht, S. 67 ff.; Höffner, Geschichte und Wesen des UrhR I, S. 240 ff.; Jänich, Geistiges Eigentum, S. 23 ff., jeweils mit zahlreichen weiteren Nachweisen.

25 Vgl. Jänich, Geistiges Eigentum, S. 20. 
aus dazu geeignet waren, die Stellung der Autoren bei geschickter Nutzung der mit den Privilegien verbundenen Möglichkeiten und gutem Willen der Obrigkeit wesentlich zu stärken. ${ }^{26}$

Bereits ab der Mitte des 16. Jahrhunderts ließ jedoch die Bedeutung der Privilegien nach. Bei den durch erhebliche Gewinne immer mächtiger werdenden Druckern und Verlegern entstand die Auffassung, dass ihnen aufgrund ihrer Leistung und der zum Teil erheblichen Investitionen für den (Nach-)Druck von Werken und aufgrund der inzwischen üblichen Zahlung von Honoraren an die Autoren auch ohne ausdrücklich erteilte Privilegien „Verlagseigentum“ an den von ihnen gedruckten und verlegten Werken zustehen sollte; also ein originär erworbenes gewerbliches Schutzrecht. ${ }^{27}$ Erstmals belegt ist ein derartiges „Verlagseigentum“ im England des 16. Jahrhunderts, wo die Stationers' Company, eine 1556 gegründete englische Buchhändlergilde, den Inhaber eines ausschließlichen Verlagsrechts als „owner of copy“ bezeichnete. ${ }^{28}$ Auch in einigen deutschen Gebieten wurde die Lehre vom Verlagseigentum zum geltenden Recht, etwa in Form der Frankfurter Buchdruckerordnungen von 1588, 1598 und $1660,{ }^{29}$ ohne jedoch die Privilegien vollständig abzulösen, da diese oftmals weiterhin Voraussetzung für die Verfolgung von unrechtmäBigen Nachdrucken waren. ${ }^{30}$

Mit dem Vordringen naturrechtlichen und aufklärerischen Gedankenguts im ausgehenden 17. Jahrhundert fand in mehreren Ländern, insbesondere aber in Deutschland, England und Frankreich auch ein Paradigmenwechsel in Bezug auf das geistige Schaffen statt. Der rechtmäßige Manuskripterwerb setzte sich als allgemein anerkannte Voraussetzung für das rechtmäßige Drucken und Verlegen eines Werkes durch, ${ }^{31}$ wodurch sich auch das Augenmerk der Rechtsgelehrten langsam von den Druckern und Verlegern zu den Urhebern der Werke verschob. ${ }^{32}$ Hatte man den unberechtigten (Nach-)Druck eines Werkes vorher nur als moralisch verwerflich angesehen, empfand man dies nunmehr als Verletzung des dem Ei-

26 Vgl. Gieseke, Vom Privileg zum Urheberrecht, S. 72.

27 Vgl. Bappert, Wege zum Urheberrecht, S. 217 f.; Gieseke, Geschichtliche Entwicklung, S. $51 \mathrm{f}$.

28 Vgl. Gieseke, Geschichtliche Entwicklung, S. 64; Rehbinder, Urheberrecht, Rn. 20.

29 Siehe dazu ausführlich Gieseke, Vom Privileg zum Urheberrecht, S. 99.

30 Vgl. Rehbinder, Urheberrecht, Rn. 20.

31 Vgl. Gieseke, Geschichtliche Entwicklung, S. $69 \mathrm{ff}$.

32 Vgl. Hansen, Warum Urheberrecht, S. 18; Rigamonti, Geistiges Eigentum, S. 18. 
gentum an einer Sache vergleichbaren natürlichen Rechts des Urhebers an seinem Werk. ${ }^{33}$ Das Privilegiendenken und die vom Gewerbeschutzgedanken getragene Theorie vom Verlagseigentum wurden allmählich zugunsten der Vorstellung von einem unabhängig vom Verwertungsvorgang bestehenden, eigenen und ursprünglichen Nutzungsrecht des Urhebers an seinem Werk - seinem ,geistigen Eigentum " - in den Hintergrund gedrängt. ${ }^{34}$ Zur Begründung dieser besonderen rechtlichen Verbindung des Urhebers zu seinem Werk wurde wesentlich an die ursprünglich für das Sacheigentum entwickelte Arbeitstheorie von John Locke angeknüpft, ${ }^{35}$ nach der das Eigentum an Gegenständen seine Rechtfertigung in der auf sie verwendeten Arbeit findet und dem Menschen somit ein natürliches Recht an den von ihm geschaffenen Gütern als den Früchten seiner Arbeit zusteht. ${ }^{36}$ Demnach erlangt der Urheber allein durch den Schöpfungsakt und unabhängig von einer gesetzlichen Anerkennung geistiges Eigentum an seinem Werk, welches durch eine ausschließliche, generell unbeschränkte, vollständige Beherrschung einer unkörperlichen Sache gekennzeichnet und damit dem Sacheigentum im Wesentlichen gleichgestellt ist. ${ }^{37}$ Auch wenn nach dieser zu Beginn des 18. Jahrhunderts entstandenen Lehre vom geistigen Eigentum nun der Urheber aufgrund seiner natürlichen Verbindung zu seinem Werk als Subjekt des Rechtsschutzes in den Mittelpunkt der Rechtstheorie gerückt war, darf diese Entwicklung nicht darüber hinwegtäuschen, dass weiterhin die Sicherung der ökonomischen Interessen der Verleger durch ausschließliche Nutzungsrechte im Vordergrund der Rechtspraxis stand, die nun lediglich eine dem Zeitgeist ent-

33 Vgl. Ulmer, S. 54.

34 Vgl. Bappert, Wege zum Urheberrecht, S. 254; Schack, Urheberrecht, Rn. 112.

35 Vgl. Bappert, Wege zum Urheberrecht, S. 254; Klippel, in: Historische Studien, S. 131 f.; Luf, in: Woher kommt das Urheberrecht, S. 9 (10 ff.).

36 Vgl. Locke, Two Treaties of Government, Book II, Chapter V, § 27: "The labour of his body, and the work of his hands [...] are properly his. Whatsoever then he removes out of the state that nature hath provided, and left it in, he hath mixed his labour with, and joined to it something that is his own, and thereby makes it his property. It being by him removed from the common state nature hath placed it in, it hath by this labour something annexed to it, that excludes the common right of other men: for this labour being the unquestionable property of the labourer, no man but he can have a right to what that is once joined to, at least where there is enough, and as good, left in common for others.".

37 Vgl. Gieseke, Vom Privileg zum Urheberrecht, S. 131 f.; Höffner, Geschichte und Wesen des UrhR I, S. 75 ff. 
sprechende, naturrechtliche Fundierung gefunden hatte. ${ }^{38}$ An die Stelle eines Verlegerschutzes durch die Theorie vom Verlagseigentum trat nun ein Schutz gegen den unerlaubten Nachdruck aus einem vom Urheber abgeleiteten Recht. ${ }^{39}$

Auch die ersten Urheberrechtsgesetze, deren zentrale Ziele der Schutz der Verleger vor unerlaubtem Nachdruck und die Abschaffung der zwischenzeitlich durch die Anmaßung eines ewigen Verlagseigentums entstandenen Monopole der Verleger waren, spiegeln diese Entwicklung wider. ${ }^{40}$ In England etwa wurde durch das Statute of Anne $e^{41}$ aus dem Jahre $1710,{ }^{42}$ das als erstes modernes Urheberrechtsgesetz ${ }^{43}$ gilt, das feudale Privilegienwesen beendet und das in der Person des Autors entstehende werkbezogene Urheberrecht begründet, welches sich freilich regelmäßig die Verleger abtreten ließen. Es erfolgte somit letztlich nur ein mittelbarer Schutz des Urhebers über den Verleger.

In der Rechtspraxis blieb die Lehre vom geistigen Eigentum auch nach ihrer vollen Entfaltung gegen Ende des 18. Jahrhunderts zunächst ohne großen Einfluss, da sich die von ihr propagierte Vorstellung von einem natürlichen Recht des Urhebers an seinem Werk noch nicht allgemein durchgesetzt hatte. ${ }^{44}$ So lässt sich ein erhebliches Auseinanderklaffen der von Idealismus und Liberalismus geprägten Überhöhung des individuellen Schöpfers durch die Rechtstheorie und einer durch Privilegien und straf-

38 Vgl. Bappert, Wege zum Urheberrecht, S. 257; Gieseke, Vom Privileg zum Urheberrecht, S. 133.

39 Vgl. Bappert, Wege zum Urheberrecht, S. 256.

40 Vgl. Schack, Urheberrecht, Rn. 114.

418 Anne c. 19. Siehe dazu auch unten S. 22.

42 Vielfach wird das nach Königin Anne benannte Statute of Anne in Anlehnung an den damals in England geltenden Kalender auch auf das Jahr 1709 datiert, vgl. Feather, The Making of the Copyright Act of 1710, S. 39; Höffner, Geschichte und Wesen des UrhR I, S. $88 \mathrm{f}$.

43 Zum Teil wird bezweifelt, dass es sich bei der Statute of Anne tatsächlich um das erste echte Urheberrechtsgesetz handelt, vgl. Patterson, Copyright in Historical Perspective, S. 143. Unbestritten ist jedoch die herausragende Bedeutung dieser Kodifikation für die Entwicklung des Urheberrechts, insbesondere des angloamerikanischen Copyright; siehe dazu unten S. 22 f.

44 Vgl. Gieseke, Vom Privileg zum Urheberrecht, S. 158 ff. 
rechtliche Nachdruckverbote ${ }^{45}$ gekennzeichneten Rechtspraxis bis weit in das 19. Jahrhundert belegen. ${ }^{46}$ Erst ihre zögerliche gesetzliche Verankerung verhalf der Theorie vom geistigen Eigentum und dem Urheberschutz nach und nach zum Durchbruch. Den fortschrittlichen französischen Revolutionsgesetzen von 1791 und 1793, die den Schutz der ,propriété littéraire, musicale et artistique" normierten und dem Autor ein ausschließliches Verfügungsrecht über alle seine Werke einräumten, kommt dabei eine zentrale Rolle zu; insbesondere beeinflussten sie entscheidend die Urheberrechtsentwicklung in den einzelnen deutschen Staaten. ${ }^{47}$ Erst 1835 wurde durch einen Beschluss der Bundesversammlung des Deutschen Bundes festgelegt, dass die Mitgliedstaaten vom Privilegienwesen Abstand zu nehmen und einen generellen Schutz des ,schriftstellerischen Eigentums“ zu gewährleisten hatten. ${ }^{48}$ Nur zwei Jahre später wurde das „Königlich Preußische Gesetz vom 11. Juni 1837 zum Schutze des Eigenthums an Werken der Wissenschaft und Kunst gegen Nachdruck und Nachbildung“" als erstes deutsches Gesetz erlassen, das nicht nur diese Lösung vom Privilegienwesen vollzog, sondern darüber hinausging, indem es erstmals umfassend das Urheberrecht regelte, auch unveröffentlichte Werke unter Schutz stellte und Urheberrechtsschutz bis 30 Jahre post mortem auctoris gewährte. ${ }^{49}$ Die erste einheitliche Regelung des deutschen Urheberrechts erfolgte durch das „Gesetz betr. das Urheberrecht an Schriftwerken, Abbildungen, musikalischen Kompositionen und dramatischen Werken des Norddeutschen Bundes“ vom 11. Juni 1870, das schließlich als Reichsgesetz übernommen wurde, nachdem die Reichsver-

45 So etwa die Bestimmungen im Allgemeinen Preußischen Landrecht von 1794 (ALR) zum Verlagsrecht und die dortigen Strafvorschriften wegen des Nachdrucks, die noch ganz aus der Perspektive der Verleger und ihres ewigen Verlagseigentums verfasst waren; vgl. Gieseke, Vom Privileg zum Urheberrecht, S. $188 \mathrm{ff}$. (mit Auszügen aus dem ALR); Schricker/Loewenheim/Vogel, Einl. Rn. 103.

46 Vgl. dazu Gieseke, Vom Privileg zum Urheberrecht, S. 181 f.; Hansen, Warum Urheberrecht, S. 22 m.w.N.

47 Vgl. Wandtke, UFITA 2008, 389 (407).

48 Vgl. Rehbinder, in: Woher kommt das Urheberrecht, S. $99 \mathrm{ff}$.

49 Vgl. Schricker/Loewenheim/Vogel, Einl. Rn. 105. Ausführlich zum preußischen Urheberrechtsgesetz von 1837 und dessen Vorgeschichte Wadle, in: Woher kommt das Urheberrecht, S. 55 ff. Dem preußischen Gesetz folgten weitere, allerdings weniger ausführliche Gesetze zum Schutz des Urheberrechts in anderen deutschen Staaten. 
fassung vom 16. April 1871 den „Schutz des geistigen Eigentums“ der Gesetzgebungskompetenz des Reiches zugewiesen hatte. ${ }^{50}$

Die Lehre vom geistigen Eigentum hatte jedoch nicht nur in der Rechtspraxis mit Widerstand zu kämpfen; die zögerliche Durchsetzung in der Praxis war vielmehr Ausfluss der erheblichen Kritik in der Rechtstheorie, der die Lehre ausgesetzt war. Trotz ihrer lange Zeit geringen Bedeutung in der Rechtspraxis und des rechtsdogmatischen Widerstandes, lässt sich jedoch festhalten, dass die Erkenntnisse der Lehre vom geistigen Eigentum den Beginn moderner urheberrechtlicher Vorstellungen kennzeichnen und für die theoretische Legitimation des Urheberrechts eine zentrale Rolle spielen. ${ }^{51}$ Die mit ihr einhergehende Abkehr von den Mängeln des Privilegienwesens, die Erweiterung des Eigentumsbegriffs über das Sacheigentum hinaus auch auf nichtkörperliche Gegenstände und die zentrale Annahme einer persönlichen Verbindung des Urhebers zu dem von ihm geschaffenen Werk und eines daraus resultierenden eigenen, ursprünglichen, ausschließlichen Rechts an diesem Werk bilden die Grundlage der weiteren Entwicklung der kontinentaleuropäischen Urheberrechtstheorie. Aus der vielfältigen Kritik an der Lehre vom geistigen Eigentum entwickelte sich schließlich die heute ganz überwiegend vertretene Theorie vom Immaterialgüterrecht.

Zum einen wurde die Theorie vom geistigen Eigentum von Kreisen verworfen, die einem urheberrechtlichen Schutz als solchem ablehnend gegenüberstanden, da sie den freien Nachdruck und die dadurch ermöglichte weite Verbreitung der Werke zu angemessenen Preisen als wesentlich für die Aufklärung und Bildung der Menschheit und die Entwicklung der Wissenschaft ansahen. ${ }^{52}$ Zum anderen stieß die Lehre vom geistigen Eigentum neben derartigen grundsätzlichen Bedenken auch bei Befürwortern eines Urheber(rechts)schutzes auf erheblichen Widerstand rechtsdogmatischer Natur. Von Teilen der rechtswissenschaftlichen Literatur wurde das Bestehen eines originären subjektiven Rechts des Urhebers abgelehnt und der aufkommende gesetzliche Schutz des Urhebers als bloßer Reflex gesetzlicher Nachdruckverbote verstanden. ${ }^{53}$ Die Pandektenwissenschaft,

50 Vgl. Vogel, GRUR 1994, 587 (588 f.).

51 Vgl. Gieseke, Geschichtliche Entwicklung, S. 73; Klippel, in: Historische Studien, S. 121.

52 Vgl. Gieseke, Vom Privileg zum Urheberrecht, S. $158 \mathrm{ff}$. Ausführlich zu dieser sog. Nachdruckbewegung Wittmann, UFITA 106 (1987), $109 \mathrm{ff}$.

53 Vgl. Schricker/Loewenheim/Vogel, Einl. Rn. 107; Vogel, GRUR 1987, 873 (876). 
die die deutsche Zivilrechtswissenschaft des 19. Jahrhunderts maßgeblich prägte, lehnte den Begriff des ,geistigen Eigentums“ hingegen als unwissenschaftlich und unjuristisch ab, da er mit dem römischrechtlichen, auf Sachen beschränkten Eigentumsbegriff unvereinbar sei. ${ }^{54}$ Unter dem Eindruck dieser dogmatischen Kritik an der Theorie vom geistigen Eigentum und ergänzt durch idealistische Kritik, diese berücksichtige die ideellen Interessen der Urheber nicht hinreichend, entwickelte sich im Anschluss an die Schriften von Immanuel Kant über die Unrechtmäßigkeit des Büchernachdrucks ${ }^{55}$ die Lehre vom Urheberrecht als Persönlichkeitsrecht, die namentlich von Johann Caspar Bluntschli, ${ }^{56}$ Otto von Gierke, ${ }^{57}$ Felix Dahn und Carl Gareis ${ }^{58}$ ausgebildet wurde. Nach deren persönlichkeitsrechtlichem Begründungsansatz wurde die individuelle geistige Schöpfung ganz der Persönlichkeit des Urhebers zugewiesen und das Urheberrecht somit dogmatisch als Persönlichkeitsrecht betrachtet. Die Proponenten dieser Theorie vertraten die Ansicht, das Urheberrecht diene in erster Linie dem Schutz der persönlichen Interessen des Urhebers; die vermögensrechtliche Komponente des Urheberrechts sei hingegen eine bloße Ausstrahlung der persönlichkeitsrechtlichen Ausschließungsbefugnis. ${ }^{59}$

Auch die Theorie vom Persönlichkeitsrecht war jedoch nicht unumstritten. Sie sah sich insbesondere der Kritik ausgesetzt, die persönlichkeitsrechtlichen Aspekte des Urheberrechts überzubetonen und so an der (Rechts-)Wirklichkeit vorbei zu gehen, in der tatsächlich vermögensrechtliche Interessen im Vordergrund stehen. ${ }^{60}$ In Anknüpfung an die Überlegungen von Johann Gottlieb Fichte, Georg Wilhelm Friedrich Hegel und Arthur Schopenhauer ${ }^{61}$ führte schließlich Josef Kohler die Theorie vom

54 Vgl. Lange, Kritik der Grundbegriffe vom geistigen Eigentum (1858), Nachdruck in: UFITA 117 (1991), 169 (insbes. 176 ff.).

55 Vgl. Kant, Von der Unrechtmäßigkeit des Büchernachdrucks (1785), Nachdruck in: UFITA 106 (1987), 137 ff. Siehe dazu den Kommentar von Hubmann, UFITA 106 (1987), 145 ff. sowie ausführlich Jacob, Ausschließlichkeitsrechte, S. 38 ff.

$56 \mathrm{Zu}$ Bluntschlis Beitrag zur Theorie des Urheberrechts, siehe Dölemeyer/Klippel, in: FS GRUR, S. 185 (210 f.); Rehbinder, UFITA 123 (1993), 29 ff.

57 Siehe v.Gierke, Deutsches Privatrecht I, S. 748 ff.

$58 \mathrm{Zu}$ letzteren beiden, siehe Rehbinder, UFITA 129 (1995), $69 \mathrm{ff}$.

59 Vgl. Schricker/Loewenheim/Vogel, Einl. Rn. 108; Dölemeyer/Klippel, in: FS GRUR, S. 185 (211); Rehbinder, Urheberrecht, Rn. 29.

60 Vgl. Hansen, Warum Urheberrecht, S. 24.

$61 \mathrm{Zu}$ deren grundlegenden Überlegungen, siehe Rehbinder, Urheberrecht, Rn. 30 m.w.N. 
geistigen Eigentum und die Lehre vom Persönlichkeitsrecht zusammen und entwickelte seine dualistische Theorie vom Immaterialgüterrecht. ${ }^{62}$ Danach wird der Urheber in seinen vermögenswerten Interessen durch ein (veräußerliches) ausschließliches Recht am Werk und in seinen ideellen Interessen durch ein zwar mit diesem verklammertes, jedoch selbständiges (unveräußerliches) Individualrecht ohne spezifisch urheberrechtlichen Gehalt geschützt. ${ }^{63}$

Die Lehre vom Immaterialgüterrecht bildet bis heute die Grundlage der deutschen und kontinentaleuropäischen Urheberrechtsdogmatik. Allerdings wird sie in Deutschland nicht mehr in ihrer dualistischen Ausprägung vertreten. Unter dem Eindruck der gerade überwundenen Zeit des Nationalsozialismus, in der es in der Urheberrechtstheorie zu einer Überbetonung und Pervertierung der Gemeinwohlbindung getreu der nationalsozialistischen Parole „Gemeinnutz vor Eigennutz"64 gekommen war, ${ }^{65}$ erlebte die naturrechtliche und arbeitstheoretische Urheberrechtsbegründung im Geiste der Lehre vom geistigen Eigentum und der Theorie vom Immaterialgüterrecht nach dem zweiten Weltkrieg eine Renaissance. ${ }^{66}$ Nach dem Vorbild Österreichs ${ }^{67}$ setzte sich dabei in der deutschen Urheberrechtswissenschaft - insbesondere aufgrund der Arbeiten von Ulmer ${ }^{68}$ und Hubmann ${ }^{69}$ - die auf Überlegungen von Allfeld ${ }^{70}$ und de Boor ${ }^{71}$ basie-

62 Ausführlich zur Entwicklung des Urheberrechts im Lichte von Kohlers Immaterialgüterrechtslehre Wandtke, GRUR 1995, $385 \mathrm{ff}$.

63 Vgl. Kohler, Urheberrecht, S. 128 ff.; Vogel, GRUR 1987, 873 (876 f.).

64 Vgl. Punkt 24 des NSDAP-Parteiprogramms vom 24.2.1920, abgedruckt bei Hofer, Der Nationalsozialismus, S. $30 \mathrm{f}$.

65 Auch das Reichsgericht nahm auf diesen Programmsatz ausdrücklich Bezug, s. RGZ 153, 1 (22). Vgl. auch Meißner, UFITA 7 (1934), 189 ff.; Bull, UFITA 7 (1934), 378 ff.; ders., UFITA 8 (1935), 400 ff. Grundlegend zur Überbetonung des Gemeinwohls im nationalsozialistischen Recht Stolleis, Gemeinwohlformeln im nationalsozialistischen Recht, S. 76 ff. Ausführlich zum Urheberrecht im Nationalsozialismus Hefti, in: Woher kommt das Urheberrecht, S. $165 \mathrm{ff}$.

66 Hansen, Warum Urheberrecht, S. 34 f. und Pahud, S. 21 verwenden diesbezüglich das treffende Bild eine zurückschwingenden Pendels. Vgl. auch Schack, in: Geistiges Eigentum - Schutzrecht oder Ausbeutungstitel?, S. 123 (128).

67 Vgl. dazu Rehbinder, Urheberrecht, Rn. 31.

68 Siehe Ulmer, S. $109 \mathrm{ff}$.

69 Siehe etwa Hubmann, Urheber- und Verlagsrecht, § 8.

70 Siehe Allfeld, Urheberrecht, Einl. S. $20 \mathrm{ff}$.

71 Siehe de Boor, Vom Wesen des Urheberrechts, S. 27 ff.; ders., UFITA 16 (1943/44), 345 (351 f.). 
rende sogenannte monistische Theorie durch. ${ }^{72}$ Nach dieser wird entgegen der dualistischen Auffassung angenommen, das Urheberrecht bestehe nicht aus zwei getrennten Teilen, sondern es handele sich um ein aus persönlichkeits- und vermögensrechtlichen Bestandteilen zusammengesetztes einheitliches Recht mit doppelter Funktion. ${ }^{73}$ Die monistische Theorie fand schließlich 1965 Eingang in das heutige individualistisch-monistisch konzipierte deutsche Urheberrechtsgesetz. Danach ist der Urheber in seiner Beziehung zum Werk Ausgangspunkt des Schutzes. Seine ideellen und materiellen Schutzinteressen als Individuum haben grundsätzlich Vorrang gegenüber den Schutzbedürfnissen der Nutzer beziehungsweise der Allgemeinheit. Zudem sind aufgrund der nach monistischer Überzeugung unauflösbar miteinander verbundenen ideellen und materiellen Interessen nicht nur die persönlichkeitsrechtlichen, sondern auch die vermögensrechtlichen Befugnisse nach deutschem Recht unübertragbar. Der Urheber kann lediglich Nutzungsrechte an seinem Werk einräumen (vgl. §31 UrhG).

\section{Urheberrechtsschutz und -gewährung heute}

Das deutsche Urheberrechtsgesetz gewährt dem Urheber eines Werkes ein absolutes subjektives Recht zum Schutz seiner materiellen und ideellen Interessen in Bezug auf sein Werk. Abweichend vom früheren Recht $(\S 1$ LUG, §1 KUG), nach dem den Urhebern schlechthin Schutz gewährt wurde, stellt § 1 UrhG klar, dass die Urheber für ihre Werke Schutz genießen. Durch die Anknüpfung an das Ergebnis der Tätigkeit des Urhebers verdeutlicht das Gesetz seinen personenbezogenen Zweck - nicht das Werk, auf das sich der Schutz bezieht, sondern die Person des Urhebers steht im Vordergrund. ${ }^{74}$ Für die nähere Definition der zu schützenden

72 Vgl. statt vieler Schack, Urheberrecht, Rn. 343.

73 Vgl. nur Ulmer, S. $114 \mathrm{ff}$,, dessen berühmtes Baum-Beispiel das monistische Verständnis äußerst anschaulich darstellt: „Die beiden Interessengruppen [Persönlichkeits- und Vermögensinteressen, Einf. des Bearbeiters] erscheinen, wie bei einem Baum, als die Wurzeln des Urheberrechts, und dieses selbst als der einheitliche Stamm. Die urheberrechtlichen Befugnisse aber sind den Ästen und Zweigen vergleichbar, die aus dem Stamm erwachsen. Sie ziehen die Kraft bald aus beiden, bald ganz oder vorwiegend aus einer der Wurzeln.", ebd., S. 116.

74 Siehe Begr. RegE, BT-Drs. IV/270, S. 37. Vgl. auch Schricker/Loewenheim/ Loewenheim, § 2 Rn. 2. 
Werke und für Art, Inhalt und Umfang des Schutzes verweist die Norm in die nachfolgenden Bestimmungen. Der Anwendungsbereich des Urheberrechtsgesetzes wird von einer Kombination aus beispielhaften Aufzählungen und unbestimmten Rechtsbegriffen umschrieben. Das Werk ist dabei der zentrale Begriff. Auch wenn dieser Begriff in $\S 2$ Abs. 2 UrhG als „persönliche geistige Schöpfung“ definiert ist, handelt es sich um einen unbestimmten Rechtsbegriff, der der Ausfüllung und Konkretisierung im Einzelfall bedarf. ${ }^{75}$ Nur ein Geisteswerk, das als Werk in diesem Sinne zu bewerten ist, genießt urheberrechtlichen Schutz nach dem Urheberrechtsgesetz. Auch wenn $\S 2$ Abs. 1 UrhG einige Werkkategorien aufzählt, die grundsätzlich einem Urheberrechtsschutz zugänglich sind, ergibt sich aus der Verwendung des Wortes „insbesondere“, dass es sich hierbei lediglich um eine beispielhafte und nicht abschließende Aufzählung handelt. ${ }^{76}$ Durch die gewählte gesetzliche Definition und die nur beispielhafte Aufzählung der Werkarten ist der Werkbegriff des Urheberrechtsgesetzes bewusst flexibel ausgestaltet, so dass auch neue, zum Zeitpunkt des Erlasses noch nicht bekannte Ausdrucksformen eines persönlichen geistigen Schöpfungsprozesses als urheberrechtsschutzfähige Werke vom Gesetz erfasst werden können. ${ }^{77}$

Den Inhalt des Urheberrechts regeln nahezu umfassend die $\S \S 11$ bis 27 UrhG, die dieses in drei unterschiedliche Aspekte aufteilen: Die Regelung

75 Vgl. Fromm/Nordemann/A.Nordemann, § 2 Rn. 12; Schricker/Loewenheim/ Loewenheim, § 2 Rn. 8 f. Zur europäischen Harmonisierung des urheberrechtlichen Werkbegriffs durch den EuGH auf dem Niveau einer „eigenen geistigen Schöpfung des Urhebers" siehe grundlegend EuGH, Urt. v. 16.7.2009, C-5/08, Slg. 2009, I-6569 = GRUR 2009, 1041, Rn. 33 ff. - Infopaq International A/S./. Danske Dagblades Forening; bestätigt durch EuGH, Urt. v. 22.12.2010, C-393/09, Rn. 44 ff. = GRUR 2011, $220-$ BSA./. Kulturministerium; EuGH, Urt. v. 4.10.2011, C-403/08 und C-429/08, Rn. 153 ff. = GRUR 2012, 156 - Football Association Premier League Ltd. u.a../. QC Leisure u.a. und Murphy./. Media Protection Services Ltd.; EuGH, Urt. v. 1.12.2011, C-145/10, Rn. 85 ff. = GRUR 2012, 166 - Painer./. Standard VerlagsGmbH u.a.; zuletzt EuGH, Urt. v. 2.5.2012, C-406/10, Rn. 65 ff. - SAS Institute Inc../. World Programming Ltd. Siehe zu dieser Anerkennung eines allgemeinen europäischen Werkbegriffs im Wege der Rechtsfortbildung durch den EuGH etwa Leistner, GRUR 2010, 987 f.; ders., GRUR 2011, 761 (763 f.); Metzger, GRUR 2012, 118 (121 f.); Schulze, GRUR 2009, $1019 \mathrm{ff}$.

76 Vgl. BGHZ 155, 257 (262 f.) - Sendeformat; Fromm/Nordemann/A.Nordemann, $\S 2$ Rn. 11; Schricker/Loewenheim/Loewenheim, § 2 Rn. 75.

77 Vgl. Begr. RegE, BT-Drs. IV/270, S. 37; Poeppel, Neuordnung, S. 31 f. 
urheberpersönlichkeitsrechtlicher Aspekte ( $\S 12$ bis 14 UrhG), die verwertungsrechtlichen Befugnisse ( $\S 15$ bis $24 \mathrm{UrhG}$ ) und sonstige Rechte des Urhebers ( $\S 25$ bis 27 UrhG). Die für den Urheber wirtschaftlich oftmals besonders bedeutenden - und daher auch im Hinblick auf die urheberrechtlichen Schranken besonders wichtigen - Befugnisse zur Verwertung des Werkes in körperlicher und unkörperlicher Form regelt das Urheberrechtsgesetz umfassend. § 15 UrhG begründet ein allgemeines Verwertungsrecht, das dem Urheber nicht nur die gegenwärtigen, in den $\S \S 16 \mathrm{ff}$. UrhG aufgezählten Verwertungsarten, sondern auch die künftig erst entstehenden Nutzungsarten vorbehält. ${ }^{78}$ So wird der Erkenntnis Rechnung getragen, dass jede gesetzliche Aufzählung von der Entwicklung der Technik überholt wird und daraus resultierenden Schwierigkeiten der Rechtsprechung, neue Nutzungsformen unter eine bestehende Verwertungsart zu subsumieren, durch eine flexible Regelung vermieden werden können. ${ }^{79}$ Eine Ausnahme zur umfassenden Regelung der ausschließlichen Befugnisse stellen die Regelungen mit persönlichkeitsrechtlichem Bezug dar. Der Gesetzgeber hat bewusst auf die Aufnahme eines allgemeinen Urheberpersönlichkeitsrechts verzichtet ${ }^{80}$ und stattdessen einzelne Aspekte des Urheberpersönlichkeitsrechts in den $\S \S 12$ bis 14 UrhG und in einigen weiteren Regelungen ${ }^{81}$ bestimmt. Auch auf die durch persönlichkeitsrechtliche Befugnisse der Urheber gesetzten Grenzen der Nutzung urheberrechtlicher Werke wird im Rahmen dieser Arbeit zurückzukommen sein. ${ }^{82}$

78 Vgl. den Wortlaut des $\S 15$ Abs. 1 UrhG (,insbesondere“). Vgl. auch Fromm/ Nordemann/Dustmann, $\S 15$ Rn. 4.

79 Vgl. Begr. RegE, BT-Drs. IV/270, S. 29; Rehbinder, Urheberrecht, Rn. 295.

80 Vgl. Begr. RegE, BT-Drs. IV/270, S. 29, 43 f.

81 So etwa in $\S 25$ UrhG (,sonstiges“ Recht auf Zugang zum Werkstück), in $\S 29$ Abs. 1 UrhG (Unübertragbarkeit des Urheberrechts), in §34 UrhG (Erfordernis der Zustimmung des Urhebers zur Übertragung von Nutzungsrechten), in §39 UrhG (Verbot von Änderungen des Werkes) und in § 42 UrhG (Rückrufsrecht wegen gewandelter Überzeugung); ausführlich und mit weiteren Beispielen Rehbinder, Urheberrecht, Rn. 390.

82 Zur Beeinträchtigung urheberpersönlichkeitsrechtlicher Interessen durch die Nutzung von Thumbnails bei der Bildersuche und durch die Google Buchsuche, siehe unten 4. Kapitel, C. Zur Berücksichtigung der Urheberpersönlichkeitsrechte bei der Neugestaltung der urheberrechtlichen Schranken, siehe unten 7. Kapitel, B.II. 


\section{B. Das Copyright im US-amerikanischen Rechtssystem}

Während das Urheberrechtssystem in Kontinentaleuropa naturrechtlich geprägt ist und das Urheberrecht als Immaterialgüter- und Persönlichkeitsrecht des Werkschöpfers versteht, steht im US-amerikanischen Copyright nach der ökonomisch-utilitaristisch motivierten sog. incentive theory ${ }^{83}$ traditionell nicht die Anerkennung der naturrechtlich begründeten ideellen und vermögensrechtlichen Interessen des Autors, sondern die Förderung des Allgemeinwohls im Vordergrund. Bereits durch die Wahl der Bezeichnung des Rechtsgebietes als „Copyright" wird deutlich, dass - anders als im kontinentaleuropäischen „Urheberrecht“/,droit d'auteur" - nicht der Autor in den Mittelpunkt gerückt wird, sondern das Werk. ${ }^{84}$

Nach klassischen incentive-Vorstellungen wird das Urheberrecht als Exklusivitätsrecht nur gewährt, um notwendige Anreize zur Schaffung neuer Geisteswerke zu setzen. Diese Vorstellung basiert zum einen auf der Annahme, dass es sich bei Schrift-, Musik-, Bild- und Filmwerken um Kulturgüter handelt, deren Schaffung und Verbreitung eine gesellschaftlich wichtige und wertvolle Aufgabe ist. ${ }^{85} \mathrm{Zum}$ anderen basiert die incentive-Theorie auf der Annahme, dass die Produktion und Verbreitung dieser Werke ohne den Anreiz eines urheberrechtlichen Schutzes nicht auf einem gesamtwohlfahrtlich optimalen Niveau stattfände. ${ }^{86}$ Eines besonderen Anreizes für die Schaffung neuer Geisteswerke bedarf es demnach insbesondere, weil es sich bei den Ergebnissen kreativen Schaffens grundsätzlich um Öffentliche Güter handelt, die durch Nicht-Rivalität und Nicht-Exklusivität $t^{87}$ gekennzeichnet sind. ${ }^{88}$ Nicht rivalisierend sind sie insofern, als die Nutzung eines Geisteswerkes durch eine Person eine parallele Nutzung durch eine weitere Person nicht ausschließt und dessen Nutzwert für wei-

83 Ausführlich zur incentive theory und zum Folgenden Förster, Fair Use, S. $119 \mathrm{ff}$. m.w.N.

84 Vgl. Schack, Urheberrecht, Rn. 25 ff.

85 Vgl. Bently/Sherman, Intellectual Property, S. 35.

86 Vgl. Merges/Menell/Lemley, Intellectual Property, S. $11 \mathrm{f}$.

87 Grundlegend zu diesen Merkmalen der Öffentlichen Güter Gordon, 82 Colum. L. Rev. 1600, $1610 \mathrm{ff} . \quad$ (1982); Landes/Posner, Economic Structure, S. 13 ff.; Schäfer/Ott, Ökonomische Analyse, S. 108.

88 Vgl. Bently/Sherman, Intellectual Property, S. 35; Schechter/Thomas, Intellectual Property, S. 8. 
tere Nutzer auch nicht absenkt. ${ }^{89}$ Auch bei einer verletzenden Nutzung, etwa einer nicht berechtigten Vervielfältigung, muss - anders als in der Welt der Sachgüter - niemandem etwas „weggenommen“" werden..$^{90} \mathrm{Zu}$ dem sind Geisteswerke nicht exklusiv, soweit es nicht oder nur mit unverhältnismäßig hohen Kosten möglich ist, solche Personen von der Nutzung auszuschließen, die für diese nicht zahlen. ${ }^{91}$ Diese übliche Einordnung der Geisteswerke als nicht-exklusive Güter beansprucht jedenfalls im analogen Kontext für die meisten „klassischen“ Werkarten, bei denen effektive (technische) Schutzmaßnahmen zum Ausschluss „unerwünschter“ Nutzer kaum anwendbar sind, weiterhin Geltung. $\mathrm{Zu}$ relativieren ist das Merkmal der Nicht-Exklusivität freilich in gewissem Umfang in Bezug auf diejenigen Formen der Werkverbreitung und verwertung, insbesondere im digitalen Kontext, bei denen inzwischen Digital Rights Management-Systeme und technische Schutzmaßnahme eine weitgehende Steuerung und Begrenzung der Nutzung ermöglichen..$^{92}$ In vielen Bereichen, in denen der Einsatz technischer Maßnahmen zum Schutz und zur Kontrolle urheber-

89 Schäfer/Ott, Ökonomische Analyse, S. 108 liefern hierfür das Beispiel eines Leuchtturmes, dessen Nutzen für alle vorbeifahrenden Schiffer gleichhoch ist. Leistner/Hansen, GRUR 2008, 479 (484) weisen jedoch darauf hin, dass es hinsichtlich bestimmter qualifizierter Nutzungsformen urheberrechtlich geschützter Werke an der Nicht-Rivalität der Nutzung fehlen kann - etwa mit Blick auf berühmte Romanfiguren kann z.B. eine massenhaft verbreitete Bearbeitung des Originalwerkes dessen wirtschaftlichen Wert durchaus aushöhlen. Hansen, Warum Urheberrecht, S. 130, Fn. 531 weist zudem zurecht darauf hin, dass die Nicht-Rivalität im Einzelfall zweifelhaft sein mag, wenn das immaterielle Geisteswerk beispielsweise nur in einem einzigen Originalwerkstück verkörpert ist, so dass eine Differenzierung zwischen dem immateriellen Werk und dessen konkreter Verkörperung faktisch nicht möglich ist. Gerade im Bereich der digitalen Nutzung ist dies jedoch in der Regel anders. Immer neue Vervielfältigungsmöglichkeiten führen hier zu einer allgegenwärtigen, vom Trägermedium losgelösten Nutzungsoption und daher zu einer deutlich erhöhten Vulnerabilität. Lehmann, in: FS Loewenheim, S. 167 (168) stellt hierzu ironisch fest, der ,geistige Diebstahl“ sei nie zuvor so „transaktionskostengünstig“ gewesen wie heutzutage in den globalen Netzen.

90 Vgl. Lehmann, in: FS Loewenheim, S. 167 (168).

91 Vgl. Gordon, 82 Colum. L. Rev. 1600, 1610 ff. (1982); Schäfer/Ott, Ökonomische Analyse, S. 108.

92 Ausführlich zu den Möglichkeiten und Implikationen technischer Schutzmaßnahmen und des Digital Rights Management im Hinblick auf urheberrechtlich geschützte Werke und zum diesbezüglichen Nutzerschutz siehe etwa Bechtold, Vom Urheber- zum Informationsrecht, S. 19 ff., 147 ff., 387ff.; Hansen, Warum Urheberrecht, S. $413 \mathrm{ff}$. 
rechtlicher Werke möglich ist und verbreitet Anwendung findet - wie etwa in der Musikindustrie -, lässt sich jedoch gerade in jüngerer Zeit, insbesondere aufgrund weiterhin weit verbreiteter Ressentiments bei den Nutzern, ein Überdenken und teilweise eine Abkehr von derartigen Verwertungsstrategien erkennen. ${ }^{93}$ Auch im digitalen Kontext zeichnen sich Geisteswerke daher oftmals weiterhin - oder nun wieder - durch ihre Nicht-Exklusivität aus.

Im Falle der Nicht-Exklusivität entsteht leicht ein Trittbrettfahrer-Problem: Viele Marktteilnehmer warten die Schaffung neuer Werke durch Dritte $a b$ - in der Hoffnung, diese später als sog. free rider kostenlos oder zumindest kostengünstig mitbenutzen zu können -, anstatt Investitionen für eigene Schöpfungen zu tätigen. Es droht somit bei diesen Public Goods (in einem unregulierten Markt) ein Marktversagen. Diesem Marktversagen durch die Gewährung zeitlich beschränkter Monopole vorzubeugen beziehungsweise es zu korrigieren, ist nach der incentive-Theorie das (Haupt-)Anliegen des Urheberrechts. ${ }^{94}$ Durch die Schaffung eines privatrechtlichen Monopols wird dem Urheber die Möglichkeit eröffnet, Dritte von der Nutzung seines Werkes auszuschließen und so einen Preis für die Werknutzung zu verlangen, der ihm zumindest die Amortisation der Kosten oder sogar eine Gewinnerzielung ermöglicht. ${ }^{95}$ Die mit derartigen Monopolen grundsätzlich einhergehenden Nachteile für die Allgemeinheit etwa in Form erhöhter Preise aufgrund der Kosten für Lizenzvergabe, Rechteverwaltung und -verfolgung und der Gefahr anderer Wettbewerbsbeschränkungen, etwa durch die Möglichkeit, Genehmigungen für weitere Verwertungen durch Dritte zu verweigern - müssen in gewissem Umfang hingenommen werden.

Individuelle Ausschließlichkeitsrechte werden somit im US-amerikanischen Copyright nicht aus der Sicht des Schöpfers, sondern im Sinne einer folgenorientierten Fokussierung auf das Gemeinwohl nach ihren Auswirkungen für die Allgemeinheit beurteilt. Sind die durch das urheberrechtliche Monopol verursachten Nachteile in dieser Situation geringer als die gesamtwirtschaftlichen Vorteile, so sind sie als „,notwendiges Übel“ zur Korrektur eines Marktversagens in Kauf zu nehmen. ${ }^{96}$ Ein urheberrechtli-

93 Vgl. Hansen, Warum Urheberrecht, S. 413 f. m.w.N.

94 Vgl. Gordon, 82 Colum. L. Rev. 1600, 1610 (1982).

95 Vgl. Schechter/Thomas, Intellectual Property, S. 8.

96 Vgl. Ohly, in: Geistiges Eigentum und Innovation, S. 279; ders., in: Geistiges Eigentum - Schutzrecht oder Ausbeutungstitel?, S. 141 (144). 
ches Ausschließlichkeitsrecht wird folglich nur insoweit gewährt, als es einen notwendigen Anreiz ${ }^{97}$ dafür erzeugt, der Allgemeinheit weiterhin Vorteile durch kreatives Schaffen zu gewähren. ${ }^{98}$ Das heißt der Urheberrechtsschutz ist grundsätzlich nur auf dem (niedrigsten) Niveau gerechtfertigt, das gerade noch ausreicht, um Urheber und Verwerter zur Schaffung und Verbreitung von Werken zu veranlassen. ${ }^{99}$

Auch wenn die incentive-Theorie in der hier skizzierten „Reinform“ eines bloßen Abstellens auf die Anreizwirkung für den Urheber zur Schaffung neuer Werke - heute wohl auch in der US-amerikanischen Wissenschaft kaum noch vertreten wird und empirisch und verhaltenspsycholo-

$97 \mathrm{Ob}$ es sich dabei tatsächlich um einen ,notwendigen” Anreiz handelt, muss man auf Grundlage aktueller empirischer und verhaltensökonomischer Untersuchungen allerdings bezweifeln. Da viele Kreative nicht oder zumindest nicht ausschließlich aus einer extrinsischen, monetären Motivation schaffen, spricht vielmehr vieles dafür, dass die Anreizwirkung des Urheberrechtes zumindest für den Urheber deutlich geringer ist, als zumeist pauschal angenommen wird. Zum einen bestehen begründete Zweifel an der überschätzten monetären Anreizwirkung urheberrechtlichen Schutzes, zum anderen belegt die verhaltenswissenschaftliche Forschung, dass Menschen ihr Verhalten auf solcherart Anreize bestenfalls beschränkt rational ausrichten und zudem unter bestimmten Voraussetzungen bereit sind, auf eine eigennützige Nutzenmaximierung zu verzichten. So gibt es viele Schaffensbereiche, in denen nicht monetäre, sondern ideelle Anreize wie etwa die Hoffnung auf Anerkennung in der scientific community oder das Bedürfnis nach künstlerischer Selbstverwirklichung entscheidend sind; vgl. Ricketson, IIC 1992, 753 (757, 759). Auch der Erfolg der Open Source- und Open Access-Bewegung zeigen, dass nicht primär wirtschaftliche Anreize zur Schaffung urheberrechtlicher Werke führen (wobei diesbezüglich empirische Erfahrungen zeigen, dass diese Schaffens- und Verbreitungsformen zunächst weiterhin auf das Urheberrecht als rechtlichen Rahmen für die Ausgestaltung einzelner Modalitäten angewiesen sind, vgl. Leistner/ Hansen, GRUR 2008, 479 (485). Zu diesen und weiteren Kritikpunkten an der „reinen“ incentive-Theorie, siehe ausführlich Hansen, Warum Urheberrecht, S. $134 \mathrm{ff}$. Mit Blick auf Werkmittler wie Verlage und Medienunternehmen, aus deren Sicht der Copyright-Schutz ein reiner Investitionsschutz ist, erscheint die Anreizthese hingegen weiterhin plausibel; vgl. Ohly, in: Geistiges Eigentum und Innovation, S. 279 ( 288 f.).

98 So ausdrücklich der US Supreme Court in Harper \& Row, Publishers, Inc. v. Nation Enterprises, 471 U.S. 539, 545 f. (1985) unter Bezugnahme auf Sony Corporation of America v. Universal City Studios, Inc., 464 U.S. 417, 429 (1984). Vgl. auch Davies, Copyright and Public Interest, 5-041; Gordon, 82 Colum. L. Rev. 1600, 1602 ff., 1610 ff. (1982).

99 Vgl. Nimmer/Nimmer, On Copyright, § 1.03 [A]. Zur Erfordernis der Befristung des Urheberrechts als Ausfluss der incentive-Theorie, vgl. Stang, Das urheberrechtliche Werk, S. 59. 
gisch eher widerlegt als bestätigt ist, ${ }^{100}$ ist nicht von der Hand zu weisen, dass das US-amerikanische Copyright-System als Ganzes nach wie vor vom Leitbild des Anreizgedankens geprägt ist ${ }^{101}$ und daher stets im Lichte dieses rechtshistorischen und -philosophischen Hintergrundes zu betrachten ist. So wird in der ganz überwiegenden US-amerikanischen Literatur $^{102}$ und der Rechtsprechung des U.S. Supreme Court ${ }^{103}$ weiterhin an der incentive-Terminologie zur Begründung des Urheberrechts festgehalten. Allerdings haben sich die hinter dieser Argumentation stehenden Begründungsansätze inzwischen zumeist im Sinne eines neoklassischen Property Rights-Ansatzes ${ }^{104}$ - weg vom reinen Anreizdenken bezogen auf den Urheber - hin zu Überlegungen zur effizienten Ressourcenallokation und zur Anreizwirkung für die Verwerter allein durch die Schaffung von Funktionsbedingungen für Märkte verlagert, in deren Rahmen der Wettbewerb die Schaffung und Verbreitung von urheberrechtlichen Werken im Sinne

100 Vgl. Leistner, ZGE 2009, 403 (405); Leistner/Hansen, GRUR 2008, 479 (484). Vgl. auch Bechtold, GRUR Int. 2008, 484 (485).

101 Vgl. Förster, Fair Use, S. $136 \mathrm{f}$.

102 Vgl. statt vieler Balganesh, 122 Harv. L. Rev. 1569 (2009) mit ausführlichen weiteren Nachweisen.

103 Vgl. Sony v. Universal, 464 U.S. 417 (1984): "The purpose of copyright is to create incentives for creative effort."; Harper \& Row v. Nation Enterprises, 471 U.S. 539 (1985): "By establishing a marketable right to the use of one's expression, copyright supplies the economic incentive to create and disseminate ideas."; Campbell v. Acuff-Rose, 510 U.S. 569 (1994): "And underprotection of copyright disserves the goals of copyright just as much as overprotection, by reducing the financial incentive to create.". Einen interessanten Sonderfall stellt insofern die Entscheidung Eldred v. Ashcroft, 537 U.S. 186 (2003) dar, in der der US Supreme Court über die Verfassungsmäßigkeit der Verlängerung der urheberrechtlichen Schutzfrist durch den Sonny Bono Copyright Term Extension Act 1998 (CTEA) zu entscheiden hatte. Aufgrund der Retrospektivität der Schutzfristverlängerung konnte ein Anreiz für das Werkschaffen bezüglich bereits bestehender Werke offensichtlich nicht angenommen werden. Der Supreme Court musste sich in diesem Zusammenhang intensiv mit der Frage der Anreizfunktion des Urheberrechts und deren Verankerung in der Intellectual Property Clause der Constitution auseinandersetzen, stellte jedoch schließlich in einer ausweichenden Entscheidung lediglich fest, es sei Aufgabe des Kongresses und nicht der Gerichte, über die bestmögliche Umsetzung der Vorgaben der Verfassung in Form der Intellectual Property Clause zu entscheiden und erklärte den CTEA daher im Ergebnis für verfassungsgemäß.

104 Ausführlich zum marktbasierten, neoklassischen Property Rights-Ansatz als Rechtfertigung des Urheberrechts, siehe Hansen, Warum Urheberrecht, S. 170 ff. m.w.N. 
der Allokationseffizienz steuern soll. ${ }^{105}$ Dieser Ansatz betont also die $\mathrm{Al}$ lokationsfunktion des Urheberrechts stärker als dessen Anreizfunktion und vertraut dabei fest auf die Kräfte des Marktes zur Herbeiführung von Allokationseffizienz. ${ }^{106}$ Zur Ermöglichung eines Marktes für urheberrechtliche Werke und zur Herbeiführung privater Verhandlungen ist nach diesem Ansatz die Gewährung eines Property Rights, also eines universalistischen, frei übertragbaren, eigentumsähnlichen Ausschließlichkeitsrechts, ${ }^{107}$ erforderlich, da nach diesem Ansatz das Urheberrecht seine Allokationsfunktion am besten erfüllen kann, wenn der Urheber sein Werk als nutzenmaximierender Entscheidungsträger durch private Verhandlungen mit Interessierten einer Verwertung zuführt und so selbst den vollen Nutzen seines Werkes ausschöpfen kann. ${ }^{108}$

Diese für das angloamerikanische Urheberrecht charakteristische Ausrichtung am Leitgedanken der Förderung des Fortschritts von Wissenschaft und Kunst ist im Wesentlichen historisch begründet. Wie eine Vielzahl weiterer US-amerikanischer Rechtsgebiete findet auch das Urheberrechtssystem seine Wurzeln und sein Vorbild im englischen Recht. Am Leitbild des Allgemeinwohls orientierte sich bereits das englische Statute of Anne ${ }^{109}$ aus dem Jahre 1710. Dieses erste Urheberrechtsgesetz ${ }^{110}$ bezeichnete sich als ,Act for the Encouragement of Learning, by Vesting the Copies of Printed Books in the Authors or Purchasers of such Copies, during the Times therein mentioned." In der Präambel wird als Zweck des Gesetzes zudem angeführt, es solle dem „Encouragement of Learned Men to compose and write useful Books" dienen. ${ }^{111}$

105 Vgl. Landes/Posner, Economic Structure, S. 21 ff.; Leistner, ZGE 2009, 403 (407 f.); Leistner/Hansen, GRUR 2008, 479 (484).

106 Vgl. Hansen, Warum Urheberrecht, S. 171 m.w.N.

$107 \mathrm{Zu}$ dieser Definition des englischen Begriffs Property Right und den weiteren vielfältigen Bemühungen um eine treffende Übersetzung, siehe Hansen, Warum Urheberrecht, S. 172. Im Folgenden soll der inzwischen eingebürgerte englische Begriff Property Right verwendet werden, um Missverständnisse zu vermeiden.

108 Vgl. Hansen, Warum Urheberrecht, S. $174 \mathrm{f}$.

1098 Anne c. 19.

110 Siehe dazu bereits oben Fn. 42.

111 Ausführlich zum Statute of Anne und seiner historischen Bedeutung Cornish, in: Historische Studien, S. 57 ff.; ders., in: Bently/Suthersanen/Torremans, Global Copyright, S. 14 ff.; Deazley, in: Bently/Suthersanen/Torremans, Global Copyright, S. 26 ff.; Dietz, GRUR Int. 2006, 1; Höffner, Geschichte und Wesen des UrhR I, S. 88 ff.; Leval, 103 Harv. L. Rev. 1105 (1108 f.); Reuß, Naturrecht 
Das US-amerikanische Urheberrecht in seiner heutigen Form findet schließlich seine Grundlage in der sog. Intellectual Property Clause ${ }^{112} \mathrm{der}$ U.S. Constitution von 1787. Art. I, Sec. 8, Cl. 8 der U.S. Constitution enthält die Ermächtigung des Kongresses „To promote the Progress of Science and useful Arts, by securing for limited Times to Authors and Inventors the exclusive Right to their respective Writings and Discoveries". Auf Basis dieser Ermächtigungsgrundlage verabschiedete der Kongress im Jahr 1790 das erste, als ,Act for the encouragement of learning by securing the copies of maps, charts and books, to the authors and proprietors of such copies, during the times herein mentionend" bezeichnete Bundesurheberrechtsgesetz der USA, ${ }^{113}$ in dem sowohl der Schutzgegenstand als auch die Verwertungsrechte abschließend formuliert waren.

Der 1790 Copyright Act wurde mehrfach revidiert, ${ }^{114}$ wobei regelmäßig der Schutzgegenstand und -umfang zugunsten des Urhebers ausgedehnt wurde; es blieb jedoch bis zur ersten grundlegenden Revision durch den 1909 Copyright Act ${ }^{115}$ in Kraft. Die zweite große Revision des Urheberrechts erfolgte schließlich mit dem auch heute noch geltenden und in 17 U.S.C. aufgenommenen 1976 Copyright Act, ${ }^{116}$ der das US-amerikanische Urheberrechtssystem grundlegend änderte. In 17 U.S.C. § 102 wurde erst-

oder positivistisches Konzept, S. 64 ff.; Rose, in: Bently/Suthersanen/Torremans, Global Copyright, S. 70 ff.; Suarez, in: Bently/Suthersanen/Torremans, Global Copyright, S. $54 \mathrm{ff}$.

112 Vielfach wird auch der Begriff Copyright Clause verwendet, vgl. etwa Götting/ Fikentscher, in: Assmann/Bungert, US-HGW, Kap. 7 D I; Patterson, Copyright in Historical Perspective, S. 193 f.; Seltzer, Exemptions and Fair Use, S. 8 ff. So auch mehrfach der US Supreme Court, zuletzt in Eldred v. Ashcroft, 537 U.S. 186 (2003). Die Bezeichnung Intellectual Property Clause erscheint dennoch vorzugswürdig, da Art. I, Sec. 8, Cl. 8 sich neben dem Urheberrecht auch auf das Patentrecht bezieht und soll daher im Folgenden verwendet werden.

113 Copyright Act of May 31, 1790 (1 Stat. 124), abgedruckt bei Nimmer/Nimmer, On Copyright, Appendix $7 \S \mathrm{D}$. Die starke Anlehnung an die Statue of Anne im Titel des 1790 Copyright Act verdeutlicht erneut, dass sich dieser in der englischen Tradition sieht. Ausführlich zur Entwicklung des 1790 Copyright Act Reu $\beta$, Naturrecht oder positivistisches Konzept, S. $449 \mathrm{ff}$.

114 Revisionen erfolgten in den Jahren 1831, 1846, 1856, 1870 und 1874.

115 Act of March 4, 1909 (35 Stat. 1075).

116 Der 1976 Copyright Act trat zum 1. Januar 1978 in Kraft und findet auf Werke Anwendung, die ab dem 1. Januar 1978 Schutz erlangten, sowie auf Verträge über Urheberrechte und Lizenzen, die seit dem 1. Januar 1978 geschlossen wurden. Werke, die vor dem 1. Januar 1978 veröffentlicht wurden, unterfallen hingegen weiterhin dem 1909 Copyright Act. 
malig das Subjekt des urheberrechtlichen Schutzes in einer Generalklausel als „original work of authorship“ ausdrücklich definiert. Der Copyright Act of 1909 kannte die Unterscheidung zwischen Werk (work of authorship) und Werkstück (copy) hingegen noch nicht. Zudem wurde als Voraussetzung für die Entstehung des Urheberrechtsschutzes das Erfordernis der Veröffentlichung (publication) durch das einer Verkörperung des Werkes (fixation) ersetzt.

In jüngerer Zeit hat die internationale Rechtsentwicklung im Urheberrecht zu einer gewissen Angleichung der kontinentaleuropäischen und USamerikanischen Urheberrechtssysteme geführt. Auslöser war dabei zumeist die Umsetzung völkerrechtlicher Vorgaben, insbesondere der Revidierten Berner Übereinkunft (RBÜ). ${ }^{117}$ So erforderte der Beitritt der USA zur RBÜ im Jahre 1989 die Einführung eines (begrenzten) Urheberpersönlichkeitsrechts (moral rights), ${ }^{118}$ welche durch den Visual Artists Rights Act 1990 (VARA $)^{119}$ umgesetzt wurde. Auch hinsichtlich der Formalitäten der Registrierung (copyright notice) wurden durch den Berne Convention Implementation Act $1988^{120}$ grundlegende Veränderungen vorgenommen; die Entstehung des Urheberrechtsschutzes erfordert nun nicht mehr zwingend die Einhaltung von Registrierungsformalitäten. ${ }^{121}$

117 Zur Annäherung von kontinentaleuropäischem und US-amerikanischem Urheberrecht, siehe Davies, IIC 1995, 964 (974 ff.); Dreier, in: Expanding the Boundaries, S. 295 (298 ff.).

118 Allgemein zu den moral rights im US-amerikanischen Copyright, vgl. Ginsburg, GRUR Int. 1991, 593; Goldstein, Copyright, § 5.12 ff.; Schechter/Thomas, Intellectual Property, S. 138 ff.; Peifer, ZUM 1993, 325 ff. Ausführlich zu moral rights in den Common Law-Ländern Dworkin, 19 Colum.-VLA J.L. \& Arts 229 (1995).

119 Pub. L. No. 101-650, 104 Stat. 2853.

120 Pub. L. No. 100-568, 102 Stat. 2853.

121 Die Entstehung des Urheberrechts und auch dessen klageweise Durchsetzung erfordern nun grundsätzlich nicht mehr die Registrierung des Werkes. Allerdings ist nach 17 U.S.C. $§ 412$ die Geltendmachung von pauschaliertem Schadensersatz (statutory damages) und Anwaltsgebühren in einem Verletzungsverfahren weiterhin von der vorherigen Registrierung des Werkes abhängig. Dies gilt auch für ausländische Werke; jüngst bestätigt durch den District Court for the Southern District of New York im Urteil Elsevier B.V. v. UnitedHealth Group, Inc., 2010 WL 150167 (S.D.N.Y. January 14, 2010). Ausführlich zum Berne Convention Implementation Act of 1988 und den damit einhergehenden Rechtsänderungen, siehe Baumgarten/Meyer, GRUR Int. 1989, 620; Freys, ZUM 1989, 125; Nordemann/Scheuermann, GRUR Int. 1990, 945. Kritisch zum Erfolg des Umsetzungsvorhabens Goldstein, IIC 2008, 216. 
Während aufgrund dieses stetigen Abbaus charakteristischer Elemente des traditionell ökonomisch-utilitaristisch begründeten Copyright und der Einführung kontinentaleuropäischer Elemente zum Teil von einer Legitimationskrise der US-amerikanischen Urheberrechtstheorie gesprochen wird, ${ }^{122}$ ist jedenfalls zu beachten, dass weiterhin einige grundlegende Unterschiede zwischen den Rechtssystemen bestehen: ${ }^{123}$ Das US-amerikanische Urheberrecht gestattet - entgegen dem im deutschen Urheberrecht vorherrschenden Schöpferprinzip ${ }^{124}$ - die Trennung zwischen dem tatsächlichen Schöpfer und dem Inhaber des Urheberrechts durch die sog. work made for hire-Doktrin (17 U.S.C. § 101) ${ }^{125}$ und die Übertragbarkeit des Urheberrechts. ${ }^{126}$ Zudem wird im US-amerikanischen Copyright dem Gesichtspunkt der wirtschaftlichen Investition für die Begründung des Urheberschutzes erhebliche Bedeutung beigemessen. Der urheberrechtliche Schutz von Leistungen mit geringer Schöpfungshöhe hängt daher nicht selten von ihrem kommerziellen Wert ab. ${ }^{127}$ Schließlich ist festzuhalten, dass das US-amerikanische Urheberrecht traditionell kein Urheberpersönlichkeitsrecht kennt. Soweit zur Umsetzung internationaler vertraglicher Verpflichtungen in begrenztem Umfang moral rights in den 1976 Copyright Act aufgenommen wurden, erscheinen diese weiterhin als „Fremdkörper" mit geringer praktischer Relevanz. ${ }^{128}$

122 Vgl. Förster, Fair Use, S. 124 ff. m.w.N.

123 Zusammenfassend zu den Grundlagen des US-amerikanischen Copyright und zu Unterschieden zur kontinentaleuropäischen Rechtstradition siehe Götting/Fikentscher, in: Assmann/Bungert, US-HGW, Kap. 7 D I.

124 Vgl. Wandtke/Bullinger/Thum, § 7 Rn. 1 f. und ausführlich oben 1. Kapitel, A.

125 Die work made for hire-Doktrin weist das Urheberrecht an in einem Arbeitsoder Auftragsverhältnis geschaffenen Werken unmittelbar dem Arbeit- bzw. Auftraggeber zu. Daraus spricht der Grundgedanke, dass von Beginn an Rechtsinhaberschaft und wirtschaftliches Risiko bei der Verwertung einander parallel zugeordnet werden sollen. Grundlegend zur work made for hire-Doktrin: Community for Creative Non-Violence v. Reid, 490 U.S. 730 (1989). Siehe auch Bodewig, in: FS Schricker I, S. 833 (844 ff.); Hoebbel, Schutz von Sammelwerken, S. 242 ff. Zur Kollision der US-amerikanischen work made for hire-Doktrin und deutschem Urheber(vertrags)recht, siehe W.Nordemann/J.B.Nordemann, in: FS Schricker II, S. $473 \mathrm{ff}$.

126 Dazu grundlegend Eggersberger, Übertragbarkeit des Urheberrechts, S. $257 \mathrm{ff}$.

127 Vgl. Bleistein v. Donaldson Lithographing Co., 188 U.S. 239 (1903).

128 Vgl. Götting/Fikentscher, in: Assmann/Bungert, US-HGW, Kap. 7 D IV 2; Merges/Menell/Lemley, Intellectual Property, S. 519; Miller/Davies, Intellectual Property, S. 428 f. Ausführlich zum Urheberpersönlichkeitsschutz im US-amerikanischen Urheberrecht Dieselhorst, Urheberpersönlichkeitsrecht, S. 26 ff. 
Neben den bundesrechtlichen Regelungen besteht im US-amerikanischen Recht eine Reihe von Regelungen der Einzelstaaten zum Urheberrechtsschutz. ${ }^{129}$ Dieses Landesrecht ist nach der sog. preemption doctrine jedoch grundsätzlich gegenüber dem Bundesrecht subsidiär. ${ }^{130}$ Es erlangt daher in der Regel nur dort Bedeutung, wo kein bundesrechtlicher Urheberrechtsschutz besteht. Nach 17 U.S.C. $\S 301$ (a), in dem die preemption doctrine als sog. statutory preemption aufgenommen wurde, ${ }^{131}$ richtet sich der Urheberrechtsschutz für verkörperte (veröffentlichte oder unveröffentlichte) Werke ausschließlich nach Bundesrecht, wenn erstens das Werk vom Autor selbst oder mit seiner Zustimmung in körperlicher Form festgehalten ist und dem Schutz des Copyright Act unterfällt und zweitens nach dem sog. test of equivalence eine Gleichwertigkeit zwischen dem Recht des Einzelstaates und einem der im Copyright Act genannten ausschließlichen Nutzungsrechte besteht. Durch die Erstreckung des urheberrechtlichen Schutzes auch auf unveröffentlichte Werke hat das Landesrecht somit zumeist nur noch Bedeutung für den Schutz unverkörperter Werke (z.B. Vorträge, Live-Berichterstattungen, Choreographien).

129 Ausführlich Götting/Fikentscher, in: Assmann/Bungert, US-HGW, Kap. 7 D I 2 lit. b-c.

130 Die preemption doctrine ist Ausdruck der Regelung des Art. VI, cl. 2 der US Constitution, der sog. Supremacy Clause, die den grundsätzlichen Vorrang von Bundes- vor Landesrecht festschreibt.

131 Vor der Kodifikation in Form der statutory preemption war die Rechtsprechung des Supreme Court zu Fragen einzelstaatlichen Urheberrechtsschutzes für vom Bundesrecht nicht erfasste Werke höchst uneinheitlich; vgl. Sears, Roebuck \& Co. v. Stiffel Co., 376 U.S. 225 (1964); Compco Corp. v. Day-Brite Lighting, Inc., 376 U.S. 234 (1964); Goldstein v. California, 412 U.S. 546 (1973) = GRUR Int. 1974, 229, mit Anm. E. Ulmer. 


\section{Kapitel Einschränkung des Urheberrechts im deutschen und US-amerikanischen Recht}

Das Urheberrecht und mit ihm die Verwertungsrechte sind zwar absolute, jedoch keine unbeschränkten Rechte. Das Urheberrecht ist in Deutschland als „geistiges Eigentum“ des Urhebers durch Art. 14 GG geschützt; ${ }^{132}$ ebenso wie das Sacheigentum unterliegt es jedoch im Interesse der Allgemeinheit auch einer Sozialbindung. ${ }^{133}$ So betonte bereits das Reichsgericht, der Gedanke der „sozial gebundenen Befugnis“ müsse auch für das Recht an Geisteswerken gelten. ${ }^{134}$ Gewisse Einschränkungen seines ausschließlichen Herrschaftsrechts muss der Urheber folglich im Interesse der Allgemeinheit hinnehmen, da diese ein in Grenzen legitimes Interesse an der erlaubnisfreien Nutzung von urheberrechtlich geschützten Werken hat. ${ }^{135}$ Die Ausschließlichkeitsrechte des Urhebers finden daher ihre Grenzen in den Schranken des Urheberrechts. Diese bestimmen den Inhalt des Urheberrechts und verdeutlichen, an welcher Stelle der Gesetzgeber die Interessen der Nutzer oder der Allgemeinheit für (in der Regel) schwerwiegender gehalten hat als die des Urhebers und daher durch die Schranken Inhalt und immanente Grenzen des Urheberrechts festgelegt hat. ${ }^{136}$ Bei der Ausgestaltung dieser Grenzen des urheberrechtlichen Ausschließlichkeitsrechts haben sich im Wesentlichen zwei unterschiedliche Typen von Schrankenregelungen entwickelt.

132 BVerfGE 31, 229 (239) - Kirchen- und Schulgebrauch; BVerfGE 49, 382 (392) - Kirchenmusik.

133 Vgl. Schricker/Loewenheim/Melichar, Vor $\S \S 44 a$ ff. Rn. 1; Loewenheim/Götting, § 30 Rn. 1 m.w.N.

134 RGZ 140, 264 (270).

135 Vgl. Schack, Urheberrecht, Rn. 512.

136 Str.; siehe zur hier vertretenen Auffassung und der Gegenansicht näher unten 2. Kapitel, B.I.2.a). 


\section{A. Regelungstechniken: Enumerationsprinzip versus Schrankengeneralklausel}

Traditionell in den kontinentaleuropäischen Rechtsordnungen findet sich eine Beschränkung der dem Urheber umfassend gewährten Rechte durch enumerative Kataloge von Einzelausnahmen. Diesem Konzept ist auch der Gesetzgeber des deutschen Urheberrechtsgesetzes gefolgt, indem er im Sechsten Abschnitt des Ersten Teils des Urheberrechtsgesetzes fest umrissene Einzeltatbestände geschaffen hat. Neben den $\S \S 44 \mathrm{a} f f$. UrhG enthalten die $\S \S 69 \mathrm{~d}$ und 69e UrhG einige besondere Schranken für Computerprogramme und der $\S 87 \mathrm{c}$ UrhG für Datenbankwerke. Nur in den dort ausdrücklich genannten Fällen sind (in der Regel) ${ }^{137}$ Einschränkungen der absoluten Rechte des Urhebers zulässig.

Dem Modell des abschließenden Schrankenkataloges steht die - insbesondere im angloamerikanischen Rechtskreis verbreitete - Beschränkung des umfassend gewährten Urheberrechts durch eine generalklauselartige Schrankenregelung gegenüber. Während sich im britischen Copyright, Designs and Patents Act von 1988 (CDPA) das (restriktive) Konzept des „Fair Dealing“ findet ( $\S 29,30$ CDPA), ${ }^{138}$ beinhaltet der US-amerikanische Copyright Act von 1976 die Schrankengeneralklausel des „Fair Use“ (17 U.S.C. § 107). Trotz terminologischer Ähnlichkeit von Fair Use und Fair Dealing, bestehen jedoch zwischen diesen beiden Regelungskonzepten erhebliche Unterschiede. Das britische Modell des Fair Dealing ist durch eine zweistufige Prüfung gekennzeichnet, wobei die fragliche Nutzung zunächst an den in $\S \S 29$ und $30 \mathrm{CDPA}$ ausdrücklich privilegierten Handlungen zu messen ist. Fällt die Nutzung unter den Katalog der $\S \S 29$, 30 CDPA, wird auf einer zweiten Stufe gefragt, ob es sich um Fair Dealing handelt. Somit enthält lediglich diese zweite Stufe des britischen Modells flexible Elemente. ${ }^{139}$ Deutlich mehr Flexibilität bei der Abwägung

137 Zum Problem der Auslegung und analogen Anwendung der Schrankentatbestände siehe unten 2. Kapitel, B.I.2.b) und c).

138 Auch in den Urheberrechtsgesetzen vieler anderer Staaten mit einer common lawTradition findet sich das Konzept des Fair Dealing, das jedoch ähnlich dem britischen Recht deutlich restriktiver ausgestaltet ist als die US-amerikanische Fair Use-Doktrin; vgl. etwa im australischen Copyright Act von 1968, sec. 40-42, im kanadischen Copyright Act, R.S.C. 1985, C-42 § 29 und im neuseeländischen Copyright Act von 1994, No. 143, sec. 42, 43.

139 Ausführlich zum Konzept des Fair Dealing und zur Vorgehensweise bei der Prü- 
von Urheber- und Nutzerinteressen bietet die US-amerikanische Fair UseDoktrin. Nach dieser offenen Generalklausel muss der Urheberrechtsinhaber stets dann Einschränkungen seiner umfassenden Rechte hinnehmen, wenn eine „faire“ Benutzung vorliegt. ${ }^{140}$

Da nur die US-amerikanische Fair Use-Doktrin eine „echte“ Generalklausel - und damit einen direkten Gegensatz zum kontinentaleuropäischen Modell des enumerativen Schrankenkataloges - darstellt, bietet sie deutlich größere Flexibilität als das britische Modell. ${ }^{141}$ Deshalb soll in dieser Arbeit lediglich das Konzept des Fair Use einer genaueren Begutachtung unterzogen werden.

\section{B. Das Schrankensystem des deutschen Urheberrechts}

Wie bereits dargestellt, muss der Urheber im Interesse der Allgemeinheit gewisse Einschränkungen seiner Ausschließlichkeitsrechte hinnehmen. Erst eine Gesamtschau des Inhaltes des Urheberrechts und seiner Schranken lässt daher das Ausmaß der dem Urheber vorbehaltenen Nutzung seines Werkes erkennen. ${ }^{142}$ Die wohl einschneidendste und zugleich auch eindeutigste Schranke des Urheberrechts im System des Urheberrechtsgesetzes ist dessen zeitliche Begrenzung, da mit dem Ablauf der gesetzlichen Schutzdauer grundsätzlich der Schutz des Urheberrechts endet. Die Einschränkungen zugunsten der Allgemeinheit durch die gesetzliche Festlegung einer zeitlich beschränkten Schutzfrist sind jedoch an anderer Stelle ausführlich beschrieben worden ${ }^{143}$ und sollen daher im Rahmen dieser

fung, vgl. Bently/Sherman, Intellectual Property, S. 192 ff.; Cornish/Llewelyn, Intellectual Property, S. 473 ff., jeweils m.w.N.

140 Ausführlich zur Fair Use-Doktrin siehe unten 2. Kapitel, C.I.

141 Zur fehlenden Flexibilität der britischen Fair Dealing Defence in Bezug auf die Rechtfertigung der für diese Arbeit besonders interessierenden neuen Geschäftsmodelle, die zu neuen Nutzungsformen urheberrechtlich geschützter Werke führen, vgl. Stokes, Digital Copyright, S. 143 f.; ders., EIPR 2000, 22(12), 599, 602 (Verwendung von Thumbnails im Rahmen der Bildersuche kein Fair Dealing) und Ganley, 10 No. 5 J. Internet L. 1, 14 ff. (2006) (keine Rechtfertigung der Verwendung fremder Werke im Rahmen der Google Buchsuche als Fair Dealing).

142 Vgl. Schack, in: FS Schricker II, S. 511.

143 Siehe ausführlich zur Behandlung des urheberrechtlichen Werkes nach Ablauf der Schutzfrist statt vieler Beier, Die urheberrechtliche Schutzfrist; Seidel, Die zeitliche Begrenzung des Urheberrechts; Stang, Das urheberrechtliche Werk. 


\section{Kapitel Einschränkung des Urheberrechts}

Untersuchung nicht näher betrachtet werden. Einer genaueren Betrachtung bedürfen hingegen die inhaltlichen Schranken, die dem Urheberrecht während seiner Geltungsdauer gesetzt sind (sogleich I.). Das Urheberrechtsgesetz enthält eine Vielzahl inhaltlicher Schrankenregelungen, die im Wesentlichen in Form enumerativer Kataloge von Einzelausnahmen gestaltet sind. Zudem wird das Urheberrecht durch Schranken außerhalb des Urheberrechtsgesetzes eingeschränkt (unten II.).

\section{Inhaltliche Schranken des Urheberrechts im Urheberrechtsgesetz}

Während seiner Geltung ist das Urheberrecht einer Reihe von inhaltlichen Schranken unterworfen. Im Kontrast zu den weit gefassten und flexiblen Regelungen über die Entstehung und den Inhalt des Urheberrechts hat der deutsche Gesetzgeber die inhaltlichen Schranken des Urheberrechts als einen detailreichen, enumerativen Katalog ausgestaltet, der den „Interessen der Gemeinschaft“ beziehungsweise „berechtigten Interessen der Allgemeinheit" dienen soll. ${ }^{144}$ Zur Erreichung eines angemessenen Interessenausgleichs heben die Schrankenregelungen des Urheberrechtsgesetzes das Ausschließlichkeitsrecht des Urhebers durch unterschiedlich intensive Eingriffe punktuell auf (siehe sogleich 1.). Die Schrankenregelungen des Sechsten Abschnittes des Urheberrechtsgesetzes ( $\S$ 44a ff. UrhG) und die in weiteren Vorschriften des Urheberrechtsgesetzes enthaltenen Schranken $^{145}$ beziehen sich dabei nahezu ausschließlich auf die Verwertungsbefugnisse des Urhebers. Das Urheberpersönlichkeitsrecht bleibt hingegen grundsätzlich unangetastet. ${ }^{146}$ Aus dem dogmatischen Verständnis der Schrankenregelungen als Ausnahmevorschriften zu dem in § 15 UrhG manifestierten umfassenden Urheberrecht oder aber als Rechtstechniken zur Bestimmung des Inhaltes und der Grenzen der Rechte der Nutzer ${ }^{147}$ ergeben sich Folgen für die seit langem umstrittene Frage nach ihrer Auslegung, die wiederum erhebliche Auswirkungen auf die Anpassungsfähig-

144 Vgl. Begr. RegE, BT-Drs. IV/270, S. 30. Eine Kategorisierung dieser „Interessen der Allgemeinheit" findet sich bei Schricker/Loewenheim/Melichar, §§ 44a ff. Rn. 4.

145 Weitere Schrankenregelungen finden sich in $\S \S 69 \mathrm{~d}$ und e UrhG für Computerprogramme und in $\S 87 \mathrm{c}$ UrhG für Datenbanken.

146 Vgl. Schricker/Loewenheim/Melichar, Vor $\S \S 44 a$ ff. Rn. 14.

147 Siehe unten 2. Kapitel, B.I.2.a). 
keit des deutschen Urheberrechts gerade in Bezug auf neue Nutzungsarten haben (sodann unten 2.). Schließlich enthält das Urheberrechtsgesetz weitere Regelungen, die die Ausschließlichkeitsrechte der Urheber beschränken und wesentliche Charakteristika einer Schrankenbestimmung aufweisen, die jedoch nicht als „klassische“ Schrankenbestimmungen im Rahmen des Schrankenkataloges der $\S \S 44 \mathrm{a} f f$. UrhG geregelt sind (dazu unten 3.).

\section{Unterschiedliche Intensität der Eingriffe}

Die Schrankenregelungen des Urheberrechtsgesetzes folgen hinsichtlich der Intensität des Eingriffs einem abgestuften System. Die Eingriffe lassen sich nach ihrer Intensität in verschiedene Gruppen einteilen, ${ }^{148}$ wobei bei einem schwerer wiegenden Interesse, mit dem die Ausnahme vom Urheberrechtschutz gerechtfertigt wird, auch der gestattete Eingriff umso gröBer ist. 149

\section{a) Freistellung}

Den weitestgehenden Eingriff stellen diejenigen Tatbestände dar, die eine ersatzlose Aufhebung der betroffenen Befugnisse des Urhebers vorsehen. In diesen Fällen wird - zumeist unter engen Voraussetzungen - die zustimmungs- und vergütungsfreie Nutzung des Werkes gestattet. Eine solche Freistellung kommt nur in Betracht, wenn das Ausschließlichkeitsrecht des Urhebers unangemessen und unpraktisch wäre und darüber hinaus das Interesse des Urhebers, möglichst an jeder Verwertung seines

148 Dabei wird insbesondere aufgrund einer unterschiedlichen dogmatischen Einordnung der Zwangslizenz z.T. eine sehr unterschiedliche Kategorisierung vorgenommen. Während z.B. Hilty, GRUR 2005, 819 (821) und Seydel, Zitierfreiheit, S. 10 f., von einer Aufteilung in drei Kategorien ausgehen, nehmen beispielsweise Schricker/Loewenheim/Melichar, Vor $\S \S 44 a$ ff. Rn. 6, Dreier/Schulze, Vor $\S \S 44 \mathrm{aff}$. Rn. 11 ff., HK-UrhR/Dreyer, Vor $\S \S 44 \mathrm{aff}$. Rn. 32 ff. und Poeppel, Neuordnung, S. 35 f. eine Vierteilung vor. Loewenheim/Götting, § 30 Rn. 15 ff. unterteilt die Eingriffe gar in fünf Kategorien, da er die Regelung zu amtlichen Werken in $\S 5$ UrhG als ,gravierendsten Eingriff“ ansieht.

149 Vgl. Loewenheim/Götting, § 30 Rn. 14. 
Werkes zu partizipieren, ${ }^{150}$ ausnahmsweise hinter schützenswerte Belange der Allgemeinheit zurücktreten muss. ${ }^{151}$ Derartige Einschränkungen enthalten beispielsweise $\S 44 \mathrm{a}$ UrhG für die vorübergehende Vervielfältigung, die Regelung zur Berichterstattung über Tagesereignisse in $\S 50$ UrhG und das Zitatrecht des § 51 UrhG.

\section{b) Gesetzliche Lizenz}

Eine weniger scharfe Form der Begrenzung des Urheberrechts stellt die beispielsweise in $\S 46$ UrhG (Sammlungen für den Kirchen-, Schul- oder Unterrichtsgebrauch) und $\S 47$ UrhG (Schulfunksendungen) vorgesehene sog. gesetzliche Lizenz ${ }^{152}$ dar. Hier ist die Nutzung des Werkes zwar ebenfalls nicht von der Zustimmung des Berechtigten abhängig, jedoch ist kraft Gesetzes eine „angemessene“ Vergütung zu bezahlen. Das Gesetz knüpft also an die bloße Vornahme einer Nutzungshandlung des Werkes als Rechtsfolge einen Vergütungsanspruch. ${ }^{153}$ Derartige Schrankenregelungen kommen regelmäßig dort zur Anwendung, wo aufgrund der unüberschaubaren Zahl der betroffenen Rechteinhaber und/oder Nutzer beziehungsweise der Massenhaftigkeit urheberrechtsrelevanter Vorgänge eine Kontrolle gar nicht oder jedenfalls nicht mit vertretbarem Aufwand möglich ist und Einzelverhandlungen daher zu umständlich wären. ${ }^{154}$ In diesen Fällen stellt die gesetzliche Lizenz einen Ausgleich zwischen solchen Allgemeinwohlinteressen her, die zwar eine Aufhebung der Untersagungsbefugnis des Berechtigten legitimieren können, jedoch nicht die ersatzlose Aufhebung seiner Ausschließlichkeitsbefugnisse und somit eine völlige Versagung der wirtschaftlichen Beteiligung. ${ }^{155}$

Eine gesetzliche Lizenz sieht das Urheberrechtsgesetz auch für die wichtige - und kontrovers diskutierte - Schranke der Vervielfältigung zum privaten und sonstigen eigenen Gebrauch gemäß $\S 53$ UrhG vor. ${ }^{156}$

150 Zum sog. Beteiligungsgrundsatz siehe sogleich unten 2. Kapitel, B.I.2.c), d).

151 Dreier/Schulze, Vor $\S \S 44$ a ff. Rn. 15.

152 Der Begriff „,gesetzliche Lizenz" hat sich eingebürgert, ist jedoch wenig glücklich, da der Nutzer eine echte (übertragbare) Lizenz nicht erwirbt, vgl. Berger, in Berger/Wündisch, Urhebervertragsrecht, § 1 Rn. 42.

153 Vgl. Schricker/Loewenheim/Melichar, Vor $\S \S 44 a$ ff. Rn. 23.

154 Siehe Dreier/Schulze, Vor $\S \S 44$ a ff. Rn. 14.

155 Vgl. Begr. RegE, BT-Drs. IV/270, S. 30.

156 Vgl. Dreier/Schulze, §53 Rn. 1, §54 Rn. 1 m.w.N. 
Auch hier lässt der Gesetzgeber die Werknutzung in gewissen Grenzen zustimmungsfrei zu, verknüpft die zustimmungsfreie Nutzung allerdings mit der Pflicht zur Zahlung einer ,angemessenen Vergütung“ gemäß § 54 Abs. 1 UrhG beziehungsweise eines ,gerechten Ausgleichs“ ${ }^{157}$ Es besteht jedoch die Besonderheit, dass der Vergütungsanspruch gemäß $\S \S 54 \mathrm{ff}$. UrhG nicht gegenüber den einzelnen Nutzern besteht, die die Vervielfältigungen zum privaten oder zum sonstigen eigenen Gebrauch vornehmen. Die Vergütung wird vielmehr von den Herstellern beziehungsweise Händlern und Importeuren solcher Geräte und Speichermedien geschuldet, die allein oder in Verbindung mit anderen Geräten, Speichermedien oder Zubehör zur Vervielfältigung geschützter Werke benutzt werden $(\S \S 54-54 \mathrm{~b}$ UrhG), sowie in bestimmten Fällen auch von denjenigen, die Vervielfältigungsgeräte betreiben ( $§ 54 \mathrm{c}$ UrhG). ${ }^{158}$ Im Rahmen des „Zweiten Korbes“ der Urheberrechtsreform wurde dabei das zuvor bestehende System einer Pauschalvergütung nach Maßgabe der Bestimmung eines Geräts zur Vervielfältigung durch eine Vergütungspflicht ersetzt, die gemäß § 54a UrhG an das urheberrechtsrelevante Maß der tatsächlichen Nutzung des Gerätetyps oder des Speichermediums zu Vervielfältigungszwecken anknüpft. ${ }^{159}$ Anders als im Falle der Schranken der $\S$ 46, 47 UrhG wird die Höhe der Vergütung jedoch nicht durch die individuellen Rechteinhaber ausgehandelt, sondern zwischen den Verwertungsgesellschaften und den im Sinne von $\S 12$ WahrnG gesamtvertragsfähigen Industrieverbänden wie etwa

157 Siehe näher zur Auslegung des Merkmals des „gerechten Ausgleichs“ im Sinne des Art. 5 Abs. 2 lit. b der Richtlinie 2001/29/EG durch den EuGH in der Padawan-Entscheidung (EuGH, Urt. v. 21.10.2010, C-467/08, ABl.EU 2010, C 346/05 = GRUR 2011, 50 - Padawan./. Sociedad General de Autores y Editores de España [SGAE]) und nachfolgenden Judikaten unten S. $328 \mathrm{ff}$.

158 Zur Zulässigkeit dieser Verlagerung der Vergütungspflicht auf die Hersteller und Importeure zur Gewährleistung einer effektiven Erhebung des gerechten Ausgleichs siehe EuGH, Urt. v. 16.6.2011, C-462/09, Rn. 34, 37, ABl. EU 2011, C 232/07 = GRUR 2011, 909 (911) - Stichting de Thuiskopie./. Opus Supplies Deutschland $\mathrm{GmbH}$; dazu näher unten S. 329 f.

159 Vgl. Wandtke/Bullinger/Lüft, § 54a Rn. 2 m.w.N. Nach der Rspr. des EuGH muss der Ausgangspunkt der Bestimmung der urheberrechtlichen Abgaben dabei der den Rechteinhaber durch die Privatkopierfreiheiten entstehende „Schaden“ sein, vgl. EuGH, Urt. v. 21.10.2010, C-467/08, Rn. 42, 50 - Padawan./. SGAE; bestätigt durch EuGH, Urt. v. 16.6.2011, C-462/09, Rn. 24 - Stichting de Thuiskopie./. Opus Supplies Deutschland GmbH; siehe dazu auch unten S. 287 und 328. 
BITKOM und ZItCo. ${ }^{160}$ Nur die Verwertungsgesellschaften sind nach $\S 54 \mathrm{~h}$ UrhG zur Geltendmachung des Vergütungsanspruchs für die Vervielfältigung zum privaten und sonstigen eigenen Gebrauch berechtigt. Unmittelbar und originär Berechtigte des Anspruchs auf gerechten Ausgleich aufgrund der Privatkopieausnahme bleiben jedoch - wie der EuGH zuletzt ausdrücklich betont hat ${ }^{161}$ - die Urheber beziehungsweise Rechteinhaber. Durch die konkrete Ausgestaltung der anschließenden Verteilung der Einnahmen muss daher sichergestellt werden, dass der von den Verwertungsgesellschaften erhobene gerechte Ausgleich den Rechteinhabern tatsächlich zufließt.

\section{c) Zwangslizenz}

Des Weiteren kann das Ausschließlichkeitsrecht durch die Gewährung einer Zwangslizenz begrenzt werden. Die Zwangslizenz ist dogmatisch zwar keine Schranke des Urheberrechts, die in seinen Inhalt eingreift, sondern lediglich eine Regelung seiner Ausübung, ${ }^{162}$ soll der Vollständigkeit halber dennoch hier genannt werden. Entgegen der gesetzlichen Lizenz ist bei der Zwangslizenz die Nutzung nicht erlaubnisfrei; die Nutzungshandlung darf erst nach Abschluss eines entsprechenden Lizenzvertrages erfolgen. Die Zwangslizenz verpflichtet jedoch den Urheberrechtsinhaber zum Abschluss eines Nutzungsvertrages, unterwirft ihn also einem gerichtlich

160 Die Geeignetheit dieser sog. Verhandlungslösung gemäß $\S 54$ ff. UrhG i.V.m. $\S \S 12 \mathrm{ff}$. WahrnG, von der sich der Gesetzgeber eine „,weitgehende Selbstregulierung“ durch ein ,partnerschaftliche[s] Zusammenwirken der Beteiligten“ erhofft hatte (siehe Begr. RegE, BT-Drs. 16/1828, S. 16, 34), ist - zu Recht - vielfach bezweifelt worden; vgl. etwa kritisch Dreier/Schulze, §54a Rn. 1, § 13a UrhWG Rn. 1 ff.; Melichar, ZUM 2005, 119 f.; Verweyen, GRUR 2012, 875 (876f.); Wandtke/Bullinger/Gerlach, §13a WahrnG Rn. 1 ff. Tatsächlich ist auch mehr als vier Jahre nach der Gesetzesänderung und trotz zahlreicher Verhandlungen und Klagen in mehreren Bereichen - etwa hinsichtlich der praktisch äußerst bedeutsamen Abgabepflicht für PCs - keine Einigung oder verbindliche Entscheidung zwischen den Verhandlungsparteien erreicht worden.

161 Siehe EuGH, Urt. v. 9.2.2012, C-277/10, Rn. 88 ff., 95, ABl. EU 2012, C 80/04 = GRUR 2012, 489 (493) - Luksan./. van der Let; dazu Obergfell, GRUR 2012, 494 (496).

162 Vgl. Amtl. Begr. zu § 42a UrhG, in: UFITA 2004, 216 f.; Schricker/Loewenheim/ Melichar, Vor §§ 44a ff. Rn. 6, 29; Rehbinder, Urheberrecht, Rn. 434. 
durchsetzbaren Kontrahierungszwang. ${ }^{163}$ Sie nimmt ihm also „nur“ die Abschlussfreiheit, nicht jedoch das Verbotsrecht. ${ }^{164}$ Im Urheberrecht wurde eine Zwangslizenz erstmalig mit der Novelle vom 22.5.1910 in $\S \S 22$ bis 22 c LUG ,zum Zwecke der mechanischen Wiedergabe“ eingeführt. ${ }^{165}$ Regelungen zu Zwangslizenzen enthält das Urheberrechtsgesetz heute in $\S 42 \mathrm{a}$ UrhG zugunsten von Tonträgerherstellern, zugunsten von Verlegern privater Normwerke in $\S 5$ Abs. 3 S. 2 UrhG und in $\S 87$ Abs. 5 UrhG für die Sendeunternehmen betreffend Kabelweitersendungen.

\section{d) Verwertungsgesellschaftspflichtigkeit}

Schließlich besteht die Möglichkeit, das Verwertungsrecht des Urhebers einzuschränken, indem man die Ausübung eines ausschließlichen Nutzungsrechtes verwertungsgesellschaftspflichtig ausgestaltet, d.h. es der individuellen Wahrnehmung durch den Urheber entzieht. Die Verwertungsgesellschaftspflichtigkeit stellt ebenso wie die Zwangslizenz keine Schrankenregelung, sondern lediglich eine Ausübungsbestimmung im Sinne des Art. $11^{\text {bis }}$ Abs. 2 RBÜ dar. ${ }^{166}$ Die individuelle Ausübung urheberrechtlicher Befugnisse wird in diesem Fall zwingend durch deren Wahrnehmung durch eine Verwertungsgesellschaft ersetzt. ${ }^{167}$ Das deutsche Urheberrechtsgesetz hat von dieser Möglichkeit in $\S 20 \mathrm{~b}$ Abs. 1 UrhG beim Kabelweitersendungsrecht und seiner Vergütung Gebrauch gemacht. Ziel der zwingenden kollektiven Wahrnehmung ist es, das Ausschließlichkeitsrecht als solches zwar aufrecht zu erhalten, sog. Außenseiter jedoch von einer individuellen Geltendmachung des Verbotsrechts auszuschließen. ${ }^{168} \mathrm{Zu}-$ dem kann die Wahrnehmung durch eine Verwertungsgesellschaft auch für Vergütungsansprüche aus einer gesetzlichen Lizenz vorgesehen werden. ${ }^{169}$

163 Vgl. HK-UrhR/Dreyer, Vor §§ 44a ff. Rn. 34; Rehbinder, Urheberrecht, Rn. 603.

164 Schack, Urheberrecht, Rn. 481.

165 Vgl. RGBl. 1910, 793.

166 Vgl. Amtl. Begr. zu § 42a UrhG, abgedruckt in: UFITA 2004, 217; Loewenheim/ Goetting, § 30 Rn. 19.

167 Vgl. Rehbinder, Urheberrecht, Rn. 434.

168 Vgl. Dreier/Schulze, Vor $\S \S 44$ a ff. Rn. 13.

169 So sind etwa die Vergütungsansprüche in $\S 52 \mathrm{a}$ und $\S 53$ i.V.m. $\S \S 54,54 \mathrm{a}$ UrhG verwertungsgesellschaftspflichtig ausgestaltet; siehe dazu bereits oben S. $30 \mathrm{f}$. 
2. Die Auslegung und Analogiefähigkeit urheberrechtlicher Schrankenbestimmungen

Die Schrankenregelungen der $\S \S 44 a$ ff. UrhG spiegeln nach wie vor im Wesentlichen den Interessenausgleich wider, den der Gesetzgeber bei Verabschiedung des Urheberrechtsgesetzes im Jahre 1965 und den nachfolgenden Novellierungen auf der Grundlage der zum jeweiligen Zeitpunkt bekannten Technologien für angemessen hielt. ${ }^{170}$ Die Antwort auf die Frage, ob und inwieweit die bestehenden Schrankenbestimmungen im Wege einer erweiternden Auslegung oder der Analogie an die Bedingungen der sich - insbesondere durch digitale und vernetzte Vervielfältigungs- und Kommunikationstechnologien - stetig wandelnden technologischen Rahmenbedingungen angewandt werden können, ist daher von zentraler Bedeutung für ein anpassungsfähiges und somit zukunftstaugliches Urheberrecht. Während in Teilen der Rechtsprechung und auch des Schrifttums geradezu gebetsmühlenartig wiederholt wird, bei den Schrankenbestimmungen des Urheberrechtsgesetzes handele es sich um Ausnahmebestimmungen, die grundsätzlich eng auszulegen und einer analogen Anwendung nicht zugänglich seien, ist diese Auffassung bei genauerer Betrachtung durchaus fragwürdig und hat daher zu Recht in letzter Zeit zunehmend Kritik erfahren. Obwohl (insbesondere im Rahmen von Kritik an diesen traditionellen Annahmen) schon einiges zu diesem Thema geschrieben wurde, soll es dennoch hier aufgegriffen werden, da die Frage der Auslegungs- und Analogiefähigkeit der Schrankenbestimmungen gerade für die Erfassung neuer Nutzungsformen von erheblicher oder gar entscheidender Bedeutung ist. Zudem erscheint die gelegentlich vorzufindende Aussage, das Postulat der engen Auslegung und Analogiefeindlichkeit von urheberrechtlichen Schrankenbestimmungen dürfe als überkommen gelten, ${ }^{171}$ bei einem Blick in die aktuelle (Kommentar-)Literatur und angesichts neuerer Rechtsprechung - insbesondere der (in der Folge in Bezug auf die Aussagen zur Schrankenauslegung wieder etwas relativierten) Infopaq-Entscheidung des EuGH ${ }^{172}$ - sowie auch im Hinblick auf die Entwicklung in ande-

170 Vgl. Dreier/Schulze, Vor $\S \S 44$ a ff. Rn. 7.

171 Hilty, GRUR 2005, 819 (823) spricht davon, dass das „Ammenmärchen der engen Auslegung [...] mittlerweile als entlarvt angesehen werden“ dürfte.

172 EuGH, Urt. v. 16.7.2009, C-5/08, Slg. 2009, I-6569 = GRUR 2009, 1041 - Infopaq International A/S./. Danske Dagblades Forening. Zur Infopaq-Entscheidung sowie zu deren späterer Relativierung in der Football Association Premier Lea- 
ren kontinentaleuropäischen Ländern ${ }^{173}$ als zu optimistisch. Auch die Diskussion um die (zutreffende) Interpretation des in der InfoSoc-Richtlinie enthaltenen Dreistufentests ${ }^{174}$ verleiht der Frage nach der Auslegung von Schrankenbestimmungen neue Brisanz.

\section{a) Rechtsnatur der urheberrechtlichen Schranken}

Der Frage nach der Rechtsnatur der Beschränkungen des Urheberrechts ist erstaunlicherweise lange Zeit in der Literatur verhältnismäßig wenig Aufmerksamkeit gewidmet worden. ${ }^{175}$ In jüngerer Zeit ist diese Frage jedoch stärker in den Fokus der urheberrechtlichen Diskussion gerückt, da ihre Beantwortung nicht allein von theoretischem Interesse ist, sondern - ganz im Gegenteil - auch erhebliche praktische Konsequenzen hat, insbesondere im Hinblick auf die Frage nach der Auslegung der Schrankenbestimmungen, ${ }^{176}$ aber auch hinsichtlich des Verhältnisses der Schranken zu technischen Schutzmaßnahmen ${ }^{177}$ und vertraglichen Bestimmungen. ${ }^{178}$

gue Ltd. und Murphy-Entscheidung (EuGH, Urt. v. 4.10.2011, C-403/08 und C-429/08 = GRUR 2012, 156 - Football Association Premier League Ltd. u.a../. QC Leisure u.a. und Murphy./. Media Protection Services Ltd.) siehe näher unten S. $45 \mathrm{f}$.

173 Zur sehr restriktiven Handhabung der Schranken des Urheberrechts in Frankreich durch die Rechtsprechung und ganz überwiegende Literatur vgl. Galloux, in: Hilty/Geiger, Europäische Harmonisierung, S. 321 ff. Zu Tendenzen zugunsten eines weniger starren Ansatzes in der französischen Literatur und zu einer möglichen vorsichtigen Öffnung hin zu einer flexibleren Handhabung durch den Cour de Cassation vgl. Geiger, IIC 2005, 842; ders., in: Hilty/Geiger, Europäische Harmonisierung, S. 335 (336).

174 Siehe dazu unten 6. Kapitel, C.

175 Eine ausführliche Auseinandersetzung mit dieser Frage findet sich soweit ersichtlich erstmals bei Geiger, in: Hilty/Peukert, Interessenausgleich, S. $143 \mathrm{ff}$.

176 Auf diese Frage wird unten 2. Kapitel, B.I.2. noch ausführlich einzugehen sein.

177 Zur Behandlung der Kollision technischer Schutzmaßnahmen mit den Schranken des Urheberrechts siehe etwa die Monographien von Bechtold, Vom Urheberzum Informationsrecht, S. 249 ff., 387 ff.; Koch, Auswirkungen der digitalen Informationstechnologie, S. 140 ff., 227 ff.; Stieper, Schranken, S. 433 ff.; Trayer, Technische Schutzmaßnahmen, S. 66 ff., 142 ff.

178 Zur Frage der vertraglichen Abdingbarkeit urheberrechtlicher Schranken siehe die fundierte Behandlung des Themas bei Stieper, Schranken, S. $171 \mathrm{ff}$. Siehe auch Zech, in: Wissen - Märkte - Geistiges Eigentum, S. 187 ff. Zur Abdingbarkeit von Schranken durch AGB siehe auch LG Berlin, GRUR-RR 2009, 329, mit Anm. Gräbig, MMR 2010, 47. 
Zumeist wird - oftmals floskelartig und ohne nähere Begründung - davon ausgegangen, es handele sich bei den Schrankenregelungen um Ausnahmen zum Regelfall der umfassenden Rechtsgewährung an den Urheber beziehungsweise Rechteinhaber. ${ }^{179}$ Diese traditionelle Ansicht basiert auf dem Gedanken, der Urheber sei tunlichst angemessen an der wirtschaftlichen Nutzung seiner Werke zu beteiligen, da das Urheberrecht dem möglichst umfassenden Schutz des Urhebers diene, so dass jede Beschränkung dieses Schutzes eine begründungsbedürftige Ausnahme darstelle. ${ }^{180}$

Zunehmend wird hingegen eine Abstandnahme von diesem Regel-Ausnahme-Verhältnis propagiert. ${ }^{181}$ Nach neuerer Auffassung stellt die Gewährung eines Ausschließlichkeitsrechts in Form des Urheberrechts die begründungsbedürftige Ausnahme gegenüber der Regel der Informationsfreiheit beziehungsweise des freien Wettbewerbs dar. Zur Begründung dieser Auffassung wird angeführt, das Urheberrecht basiere auf der Annahme, dass sich verschiedene verfassungsrechtlich fundierte Belange und Rechte gleichwertig gegenüberstehen und zu einem gerechten Ausgleich gebracht werden sollen. Eine Hierarchie zugunsten des Urhebers könne es daher nicht geben, im Gegenteil, die Freiheit müsse sogar das Prinzip sein, weil das Gesetz dem Urheber nur unter gewissen Voraussetzungen Verwertungsrechte gewähre. Die Schranken geben danach dem Nutzer also nur die Freiheit zurück, die ihm grundsätzlich ohnehin zusteht und erst durch das urheberrechtliche Monopolrecht genommen wird. ${ }^{182}$ Sie stellen nach dieser Sichtweise also nicht Ausnahmen vom urheberrechtlichen

179 Vgl. statt vieler Fromm/Nordemann/W.Nordemann, Vor $\S \S 44 a$ ff. Rn. 3; Schricker/Loewenheim/Melichar, Vor $\S \S 44 \mathrm{a}$ ff. Rn. 18.

180 Vgl. BGHZ 134, 250 (262 f.) - CB-InfobankI.

181 So insbes. Findeisen, Auslegung, S. 82 ff.; Geiger, GRUR Int. 2004, 815 (819); ders., in: FS Hilty, S. 77 (81 ff.); ders., in: Hilty/Peukert, Interessenausgleich, S. 143 (150 f.); Hilty, in: Klippel/Ohly, Geistiges Eigentum und Gemeinfreiheit, S. 107 (111); Hoeren, GRUR 1997, 866 (869 f.); ders., MMR 2000, 3; ders., in: Hilty/Geiger, Europäische Harmonisierung, S. 265 (267 ff.); Möhring/Nicolini/ Hoeren, §69d Rn. 2; Kröger, Informationsfreiheit und Urheberrecht, S. 224; ders., MMR 2002, 18 (20 f.); Löffler, NJW 1980, 201 (204); Pahud, S. 109 ff.; Rogge, Elektronische Pressespiegel, S. 219; Sattler, Status quo, S. 71 f.; Stieper, Schranken, S. $67 \mathrm{ff}$.

182 Vgl. Möhring/Nicolini/Hoeren, § 69d Rn. 2; ders., in: FS Sandrock, S. 357 (370); Rogge, Elektronische Pressespiegel, S. 219. 
Schutz dar, sondern lediglich Bestimmungen, die Inhalt und immanente Grenzen des Urheberrechts festlegen. ${ }^{183}$

Dieser zweitgenannten Ansicht ist - mit gewissen Einschränkungen zuzustimmen. Mit der Gewährung von Monopolrechten in Form der urheberrechtlichen Befugnisse hat der Gesetzgeber zum Ausdruck gebracht, dass die schöpferische Leistung und auch die mit dieser im Zusammenhang stehenden persönlichkeitsrechtlichen Aspekte einen besonderen Stellenwert genießen und deshalb hoheitlichen Schutz von verfassungsrechtlichem Rang verdienen. Dem Schutz des Urhebers stehen jedoch die Interessen der Nutzer und der Allgemeinheit - insbesondere in Form der ebenfalls verfassungsrechtlich garantierten Kunst- und Informationsfreiheit gegenüber. Der Informations- und Kommunikationsfreiheit kommt im Rahmen einer freiheitlichen Rechtsordnung besondere Bedeutung als ein die Demokratie konstituierendes Grundprinzip zu. Eine die Informationsfreiheit sichernde Bestimmung kann daher - unabhängig von der konkreten gesetzestechnischen Einbettung und Formulierung - schon ihrem Wesen nach nicht grundsätzlich Ausnahmecharakter haben. ${ }^{184}$ Ein genereller Vorrang des Urheberrechts kann daher nicht angenommen werden. Vielmehr stehen der durch die Verfassung gewährleistete Schutz des geistigen Eigentums des Urhebers und seines Persönlichkeitsrechts zu den ebenfalls verfassungsrechtlich basierten Interessen der Nutzer und der Allgemeinheit in einem Verhältnis der Gleichrangigkeit. ${ }^{185}$ Alle diese Belange verdienen Berücksichtigung und sind daher in jedem Einzelfall gegeneinander abzuwägen und im Wege ,praktischer Konkordanz“ zu einem gerechten Ausgleich zu bringen. ${ }^{186}$ Die urheberrechtlichen Schranken stellen somit nicht Ausnahmen von einem grundsätzlich umfassenden Urheberschutz, sondern das Ergebnis einer gesetzgeberischen Abwägung der beteiligten Interessen dar und bringen zum Ausdruck, an welcher Stelle der Gesetzgeber die Interessen der Nutzer oder der Allgemeinheit für in der Regel schwerwiegender hält als die des Urhebers und daher durch die Schranken Inhalt und immanente Grenzen des Urheberrechts festgelegt

183 Vgl. v.Becker, GRUR 2004, 104 (108); Geiger, in: Hilty/Peukert, Interessenausgleich, S. 143 (151).

184 Dies betont zutreffend erstmals Löffler, NJW 1980, 201 (204).

185 Ebenso Löffler, NJW 1980, 201 (204); Pahud, S. 110; Stieper, Schranken, S. $68 \mathrm{ff}$.

186 So auch Kröger, Informationsfreiheit und Urheberrecht, S. 222; ders., MMR 2002, 18 (19 f.); Pahud, S. 110. 
hat. Ein festgelegtes Rangverhältnis zwischen den Ausschließlichkeitsrechten der Urheber und den Schrankenregelung besteht daher nicht.

$\mathrm{Zu}$ weitgehend oder zumindest missverständlich ist hingegen die teilweise geäußerte Auffassung, die Schranken seien generell als subjektive Rechte des Nutzers anzusehen, die diesem also einen Anspruch auf Nutzung einräumen. ${ }^{187} \mathrm{Ob}$ dies tatsächlich der Fall ist, hängt nämlich entscheidend vom jeweiligen Verständnis des (unscharfen) Begriffs des ,subjektiven Rechts" ab. Versteht man unter einem subjektiven Recht nur ein absolutes Herrschaftsrecht, das einem einzelnen Berechtigten einen körperlichen oder unkörperlichen Gegenstand zur ausschließlichen Beherrschung zuweist, mit der Folge, dass dieser die Befugnis hat, den Gegenstand auf die genannten Arten zu nutzen und zugleich alle anderen Personen von einer solchen Nutzung auszuschließen, ${ }^{188}$ so trifft dies auf die Schrankenregelungen des Urheberrechts zweifelsohne nicht zu. Die Schranken weisen dem Nutzer zwar die Befugnis zu, eine bestimmte Nutzungshandlung vorzunehmen. Die betreffende Nutzung wird ihm jedoch nicht zur alleinigen Ausübung zugewiesen, so dass der Nutzer anderen Personen eine entsprechende Nutzung nicht untersagen kann. Vielmehr erlauben die Schranken die beschriebene Nutzung allen Personen, die die gesetzlichen Voraussetzungen erfüllen. Es handelt sich somit bei der eingeräumten Rechtsposition primär um eine rechtliche Freiheit, da dem Nutzer weder geboten noch verboten wird, die fragliche Nutzungshandlung vorzunehmen. ${ }^{189}$ Allein aufgrund dieser Feststellung ein subjektives Recht abzulehnen, griffe jedoch zu kurz. Es erscheint nämlich zutreffend, den Begriff des subjektiven Rechts nicht auf die soeben dargestellte ausschließliche Herrschaftsstruktur zu beschränken. ${ }^{190}$ Vielmehr kann auch demjenigen ein subjektives Recht zugeordnet sein, dem aufgrund einer Rechtsnorm die Freiheit eingeräumt wird, von einem oder allen anderen zu verlangen, nicht an der Vornahme einer bestimmten (Nutzungs-)Hand-

187 So aber (zumindest für alle grundrechtlich basierten Schranken) Geiger, in: Hilty/ Peukert, Interessenausgleich, S. 143 (149); ders., GRUR Int. 2004, 815 (818); Pichlmaier, CR 2003, 910 (913); Rehse, Ungeschriebene Schranken, S. 47 f.

188 So etwa Larenz/Wolf, Allgemeiner Teil des Bürgerlichen Rechts, § 14 Rn. 17; dem folgend Hohagen, in: FS Schricker II, S. 353 (355); Zech, in: Wissen Märkte - Geistiges Eigentum, S. 187 (190).

189 Vgl. Stieper, Schranken, S. 159 f.

190 Vgl. Bork, BGB AT, Rn. 283 ff.; Larenz, in: FG Sontis, S. 139 (141 ff.); Schack, BGB AT, Rn. 45 ff. 
lung gehindert zu werden. ${ }^{191}$ Dieses Verständnis, nach dem auch rechtliche Freiheiten als subjektive Rechte qualifiziert werden können, sagt jedoch noch nichts darüber aus, ob die urheberrechtlichen Schranken auch tatsächlich subjektive Rechte im Sinne eines „Rechts auf Nutzung“ gewähren. Stieper unterscheidet daher - im Anschluss an Alexy ${ }^{192}$ - weiter danach, inwieweit zu der von einer Schrankenregelung angeordneten rechtlichen Freiheit eine subjektive oder objektive Bewehrung hinzutritt. ${ }^{193}$ Eine unbewehrte Freiheit erschöpft sich allein in der Abwesenheit eines rechtlichen Verbots, während die bewehrte Freiheit es dem Berechtigten ermöglicht, den ihm zugewiesenen Freiheitsbereich gegenüber jedem Dritten zu verteidigen. ${ }^{194}$ Nur wenn einer urheberrechtlichen Schrankenregelung eine Bewehrung der eingeräumten Nutzungsfreiheit entnommen werden kann, gewährt diese dem Nutzer also tatsächlich ein subjektives Recht im Sinne eines Rechts auf Nutzung. Eine solche subjektive oder objektive Bewehrung der rechtlichen Freiheit kann etwa durch einen Anspruch auf die Beseitigung eines Hindernisses für die Ausübung der von der Schranke gewährten Nutzungsfreiheit gekennzeichnet sein, insbesondere in Form einer Bewehrung gegenüber vertraglichen Verboten oder gegenüber technischen Schutzmaßnahmen. ${ }^{195}$ Eine solche Regelung enthält das geltende Urheberrecht in $\S 95$ b Abs. 2 S. 1 UrhG. Die Norm gewährt dem Begünstigten einen - wenn auch in der Praxis kaum durchsetzbaren ${ }^{196}$ - Anspruch gegen den Verwender technischer Schutzmaßnahmen auf Zurverfügungstellung der Mittel, die zur Verwirklichung der durch bestimmte Schranken eingeräumten Befugnisse benötigt werden. ${ }^{197}$ Der in $\S 95$ b Abs. 2 S. 1 UrhG kodifizierte Beseitigungsanspruch zeigt, dass dem

191 Vgl. Stieper, Schranken, S. 163 f. mit dem treffenden Beispiel der Freiheitsgrundrechte, die dem Grundrechtsträger ein subjektiv-öffentliches Recht gewähren, da sie ihm erlauben, ungehindert von dieser Freiheit Gebrauch zu machen, etwa frei die Meinung zu äußern. Zugleich beinhalten die Freiheitsgrundrechte jedoch nicht das Recht, anderen eine gleichartige Handlung - also ebenfalls etwa eine freie Meinungsäußerung - zu verbieten.

192 Alexy, Theorie der Grundrechte, S. $202 \mathrm{ff}$.

193 Stieper, Schranken, S. 165.

194 Vgl. Alexy, Theorie der Grundrechte, S. 203 f.

195 Dazu ausführlich Stieper, Schranken, S. $171 \mathrm{ff}, 433 \mathrm{ff}$.

196 Vgl. zur Kritik an §95b UrhG aufgrund der Unverhältnismäßigkeit des für die Rechtsdurchsetzung erforderlichen Aufwands siehe etwa Bechtold, Vom Urheber- zum Informationsrecht, S. $427 \mathrm{f}$. (,zahnloser Tiger“); Schricker/Loewenheim/Götting, § 95b Rn. 4.

197 Im Ergebnis ebenso Rehse, Ungeschriebene Schranken, S. 47 f. 
Schrankenbegünstigten in gewissem Maße ein Anspruch auf Nutzung und somit ein subjektives Recht gewährt werden soll. Es ist jedoch zu beachten, dass sich diese Regelung ausdrücklich nur auf die in $\S 95 \mathrm{~b}$ Abs. $1 \mathrm{~S} .1$ UrhG abschließend aufgezählten Schrankentatbestände bezieht. Für die in $\S 95 \mathrm{~b}$ Abs. 1 S. 1 UrhG nicht benannten Schrankenregelungen - darunter so wesentliche Schranken wie die Zitierfreiheit des $\S 51 \mathrm{UrhG}$ und die $d i$ gitale Privatkopie gemäß $\S 53$ Abs. 1 UrhG - kann also nicht ohne weiteres angenommen werden, dass diese dem Nutzer ebenfalls ein subjektives Recht gewähren. ${ }^{198} \mathrm{Zu}$ weitgehend wäre es auch, pauschal für alle grundrechtsbasierten Schranken anzunehmen, dass diese subjektive Rechte der Nutzer darstellen. ${ }^{199}$ Zwar gewähren die Freiheitsgrundrechte subjektivöffentliche Rechte. ${ }^{200}$ Diesen kommt jedoch zuvorderst die Bedeutung zu, die Rechte der Bürger im Verhältnis zum Staat zu sichern. ${ }^{201}$ Im Verhältnis Privater zueinander kommt den subjektiv-öffentlichen Rechten hingegen keine unmittelbare Wirkung zu, sondern lediglich eine Ausstrahlungswirkung in Form der mittelbaren Drittwirkung der Grundrechte. ${ }^{202}$ Diese ist bei der Auslegung und Anwendung der Schranken zu beachten, ${ }^{203}$ eine objektive Bewehrung der durch die Schranken eingeräumten Nutzungsfreiheiten folgt aus den Grundrechten der Nutzer allerdings nicht. ${ }^{204}$ Dies heißt jedoch auch nicht, dass für alle Schranken, die nicht in $\S 95 \mathrm{~b}$ Abs. 1 S. 1 UrhG aufgezählt sind, die Einstufung als subjektives Recht ausscheiden muss. Sieht das positive Recht - etwa in Form von Verboten der vertraglichen Abbedingung oder aufgrund des Kartellrechts - eine entsprechende Bewehrung der von der Schranke eingeräumten rechtlichen Freiheit vor, so gewährt diese dem Nutzer ein subjektives Recht.

Zur Rechtsnatur der urheberrechtlichen Schranken lässt sich somit Folgendes festhalten: Die Schranken stellen nicht Ausnahmen von einem grundsätzlich umfassenden Urheberschutz dar. Sie sind vielmehr das Ergebnis einer gesetzgeberischen Abwägung der beteiligten Interessen und

198 So auch Stieper, Schranken, S. 167; a.A. wohl Geiger, in: Hilty/Peukert, Interessenausgleich, S. 143 (149); ders., GRUR Int. 2004, 815 (818); Rehse, Ungeschriebene Schranken, S. 48.

199 So aber Geiger, in: Hilty/Peukert, Interessenausgleich, S. 143 (149); ders., GRUR Int. 2004, 815 (818).

200 Vgl. näher unten 6. Kapitel, D.I.

201 Vgl. nur Maunz/Dürig/Remmert, GG, Art. 19 Abs. 2 Rn. 42 ff. m.w.N.

202 Vgl. nur Dreier/Dreier, GG, Vorb. Rn. 96 ff. m.w.N.

203 Siehe dazu unten 2. Kapitel, B.I.2.b).

204 Ebenso Stieper, Schranken, S. 167 f. 
bringen zum Ausdruck, an welcher Stelle der Gesetzgeber die Interessen der Nutzer oder der Allgemeinheit für in der Regel schwerwiegender gehalten hat als die des Urhebers. Sie bestimmen somit Inhalt und immanente Grenzen des Urheberrechts. Ein festgelegtes Rangverhältnis zwischen den Ausschließlichkeitsrechten der Urheber und den Schrankenregelungen besteht somit nicht. Ob die urheberrechtlichen Schranken dem Begünstigten ein subjektives Recht, also einen Anspruch auf die konkrete Nutzungshandlung, gewähren, kann nicht pauschal beantwortet werden. Vielmehr muss im Einzelfall ermittelt werden, ob die durch die Schrankenregelung gewährte rechtliche Freiheit durch positives Recht objektiv oder subjektiv bewehrt ist, indem es dem Schrankenbegünstigten ermöglicht, die Ausübung der Nutzungsfreiheit gegenüber etwaigen Hindernissen, insbesondere solchen durch technische Schutzmaßnahmen oder vertragliche Nutzungsbeschränkungen, durchzusetzen. Ist dies der Fall, so kommt der Schranke die Qualität eines subjektiven Rechts zu.

b) Grundsatz der engen Auslegung?

Lange Zeit sind Rechtsprechung und Literatur einhellig davon ausgegangen, urheberrechtliche Schrankenbestimmungen seien als Ausnahmebestimmungen zum urheberrechtlichen Ausschließlichkeitsrecht grundsätzlich eng auszulegen. ${ }^{205} \mathrm{Nach}$ diesem traditionellen „Dogma der restriktiven Auslegung" 206 soll der Anwendungsbereich der urheberrechtlichen Schrankenregelungen innerhalb ihres möglichen Wortsinns anhand der tatsächlichen und rechtlichen Lage zu ermitteln sein, die der Gesetzgeber bei

205 Aus der Rspr. siehe etwa RGZ 130, 196 (202) - Codex aureus; RGZ 153, 1 (23) - Rundfunksendung von Schallplatten; BGHZ 11, 135 (143) - Lautsprecherübertragung; BGHZ 17, 266 (282) - Grundig-Reporter; BGHZ 50, 147 (152f.) Kandinsky I; BGHZ 58, 262 (265) - Landesversicherungsanstalt; BGHZ 87, 126 (129) - Zoll- und Finanzschulen; BGHZ 99, 162 (164) - Filmzitat; BGHZ 114, 368 (371) - Liedersammlung; BGHZ 116, 305 (308) - Altenwohnheim II; BGHZ 123, 149 (155 f.) - Verteileranlagen; BGHZ 126, 313 (317) - Museumskatalog; BGHZ 134, 250 (264) - CB-Infobank I. Aus der älteren Literatur siehe z.B. Fromm/Nordemann/Nordemann, 9. Aufl., Vor $\S 45$ Rn. 3; v.Gamm, UrhG, $\S 45$ Rn. 4; Schricker/Melichar, 2. Aufl., Vor $\S \S 45$ ff. Rn. 15 f. m.w.N.

206 Raue, in: FS Nordemann, S. 327. 
Erlass der jeweiligen Bestimmung vorgefunden hat. ${ }^{207}$ Unter verschiedenen auf diese Weise ermittelten Bedeutungen einer Schrankenregelung muss wiederum diejenige als „eng“ bezeichnet werden, die im Verhältnis $\mathrm{zu}$ anderen möglichen Bedeutungen einen engeren Anwendungsbereich hat, ${ }^{208}$ also bezogen auf das Urheberrecht die Auslegung, die dem Urheber sein Ausschließlichkeitsrecht am weitesten belässt. Bei einer strikten Anwendung dieser Methodik können neue technische Möglichkeiten und daraus resultierende neue Nutzungsformen, die bei Einführung einer Schrankenregelung für den Gesetzgeber noch nicht absehbar waren, innerhalb des Anwendungsbereichs dieser Schrankenregelung also keine Berücksichtigung finden, da das Ausschließlichkeitsrecht des Urhebers andernfalls über den ursprünglichen Willen des Gesetzgebers hinaus beeinträchtigt würde. ${ }^{209}$

Auch wenn inzwischen die allgemeine Rechtslehre vom „alten Rezept $^{\text {‘210 }}$ der engen Auslegung von Ausnahmevorschriften abgerückt ${ }^{211}$ und diese Auffassung auch im urheberrechtlichen Kontext mehr und mehr in die Kritik geraten ist, ${ }^{212}$ wird von einem nicht unerheblichen Teil der

207 Vgl. BGHZ 17, 266 (282 ff.) - Grundig-Reporter. Vgl. auch Schricker/Melichar, 2. Aufl., Vor $\S \S 45$ ff. Rn. 15; Schulze, ZUM 2000, 432 (441, 449); ders., in: FS Erdmann, S. 173 (180). Allgemein zur Rechtsmethodik einer engen und weiten Schrankenauslegung, siehe Engisch, Einführung in das juristische Denken, S. $100 \mathrm{ff}$.

208 Siehe Larenz, Methodenlehre, S. 354.

209 Vgl. RGZ 153, 1 (23) - Rundfunksendung von Schallplatten; BGHZ 17, 266 (286 f.) - Grundig-Reporter; BGHZ 134, 250 (262 ff.) - CB-Infobank I.

210 Bydlinski, Methodenlehre, S. 440.

211 Vgl. Bydlinski, Methodenlehre, S. 440; Larenz, Methodenlehre, S. 355 f.; Larenz/ Canaris, Methodenlehre, S. 243; Würdinger, AcP 206 (2006), 946 (956 ff.).

212 Vgl. etwa v.Becker, GRUR 2004, 104 (107f.); Dreier/Schulze, Vor $\S \S 44 \mathrm{aff}$. Rn. 7; Geiger, Droit d'auteur, Rn. 225 f.; ders., GRUR Int. 2004, 815 (819); ders., in: Hilty/Peukert, Interessenausgleich, S. 143 (152); Hansen, Warum Urheberrecht, S. 398 ff.; Hilty, in: FS Schricker II, S. 325 (327 f.); ders., GRUR 2005, 819 (823 f.); Hoeren, in: Hilty/Geiger, Europäische Harmonisierung, S. 265 (267 ff.); Koch, Auswirkungen der digitalen Informationstechnologie, S. 47; Kreutzer, Modell des deutschen Urheberrechts, S. 289 ff.; Kröger, Informations freiheit und Urheberrecht, S. 222 ff.; ders., MMR 2002, 18 (19 ff.); Leistner, GPR 2007, 190 (192); Limper/Musiol/Grosskopf, Urheber- und Medienrecht, Kap. 3 Rn. 708 ff.; Löffler, NJW 1980, 201 (204); Loewenheim/Götting, § 30 Rn. 12 f;; Macciacchini, Urheberrecht und Meinungsfreiheit, S. 46 ff.; ders., UFITA 2000, 683 (686); Nielen, Interessenausgleich, S. 271 ff.; Niggemann, Informationsfrei- 
Rechtsprechung und Literatur weiterhin daran festgehalten, ${ }^{213}$ so dass dieses Postulat und die damit verbundenen Folgerungen die Anpassung der Schrankenregelungen an den technologischen Fortschritt weiterhin erheblich beeinflussen. Die Annahme, das Dogma der engen Auslegung von urheberrechtlichen Schrankenbestimmungen dürfe als überkommen gelten, ${ }^{214}$ erscheint daher als zu optimistisch. ${ }^{215}$ Der „Grundsatz der engen Auslegung" soll deshalb im Folgenden einer kritischen Prüfung unterzogen werden, um zu zeigen, dass es tatsächlich an der Zeit ist, endgültig Abstand von diesem Grundsatz zu nehmen.

Versteht man - wie zuvor befürwortet ${ }^{216}$ - die Schranken des Urheberrechtsgesetzes nicht als Ausnahmen zum Ausschließlichkeitsrecht des Urhebers, sondern vielmehr als Inhaltsbestimmungen des Urheberrechts, die verdeutlichen, an welcher Stelle der Gesetzgeber die Interessen der Nutzer oder der Allgemeinheit für (in der Regel) schwerwiegender gehalten hat als die des Urhebers und daher durch die Schranken Inhalt und immanente

heit und Urheberrecht, S. 59; Nolte, Informationsmehrwertdienste, S. 163 f.; $P a$ hud, S. 109 ff.; ders., UFITA 2000, 99 (134 ff.); Poeppel, Neuordnung, S. 41 ff.; Raue, in: FS Nordemann, S. 327 (339); Rehse, Ungeschriebene Schranken, S. 59 ff.; Rigamonti, Geistiges Eigentum, S. 136; ders., GRUR Int. 2004, 278 (284f.); Sattler, Status quo, S. 74 ff.; Schaefer, Bildersuchmaschinen, S. 93 f.; Schricker/Loewenheim/Schricker/Spindler, § 51 Rn. 8 f.; Schricker/Loewenheim/ Wild, § 97 Rn. 38 f.; Senftleben, in: Hilty/Peukert, Interessenausgleich, S. 159 (177); Stieper, Schranken, S. 65 ff.

213 Weiterhin für eine grundsätzlich enge Auslegung der Schranken etwa OLG Dresden, ZUM 2007, 203 (205); OLG Jena, GRUR-RR 2008, 223 (225) Thumbnails; OLG Köln, GRUR-RR 2009, 4 (5) - Auktionsportal für Kunstwerke; OLG Frankfurt a.M., GRUR-RR 2010, 1 (4) - Elektronische Leseplätze; LG Hamburg, ZUM 2009, 315 (321); aus der neueren Lit. etwa Fromm/Nordemann/ W.Nordemann, Vor $\S \S 44$ a ff. Rn. 3; HK-UrhR/Dreyer, Vor $\S \S 44 a$ ff. Rn. 18; Möhring/Nicolini/Nicolini, $§ 45 \quad$ Rn. 2; Schricker/Loewenheim/Melichar, Vor $\S$ 44a ff. Rn. 18 ff.; Wandtke/Bullinger/Lüft, Vor $\S \S 44 a$ ff. Rn. 1; Förster, Fair Use, S. 183 f.; v.Gierke, in: FS Erdmann, S. 103 (107f.); Obergfell, GRUR 2011, 208 (210); Schack, Urheberrecht, Rn. 95; Schulze, ZUM 2000, 432 (441, 449); ders., in: FS Erdmann, S. 173 (180); Seydel, Zitierfreiheit, S. 11; Wandtke/ Schunke, Urheberrecht, Kapitel 5 Rn. 16; Wenzel/Burkhardt, Urheberrecht, S. 130.

214 Vgl. Hilty, GRUR 2005, 819 (823).

$215 \mathrm{Zu}$ optimistisch erscheint aufgrund des Festhaltens gewichtiger Stimmen in der Lehre am Grundsatz der engen Auslegung der Schranken (siehe Nachweise in Fn. 188) auch die Behauptung von v.Ungern-Sternberg, GRUR 2010, 273 (278, Fn. 99), die Abkehr von diesem entspreche inzwischen der ,ganz h.L.“.

216 Siehe oben 2. Kapitel, B.I.2.a). 
Grenzen des Urheberrechts festgelegt hat, so kann ein schematischer „Grundsatz der engen Auslegung“ der Schranken nicht überzeugen. ${ }^{217}$ Es wäre jedoch auch falsch, aus einer Abkehr vom Regel-Ausnahme-Verhältnis zu folgern, dass in Zweifelsfällen grundsätzlich die Freiheit der Information beziehungsweise der freie Zugang zu Informationen dem Urheberrecht vorzugehen habe und somit die urheberrechtlichen Befugnisse im Sinne eines ,in dubio pro libertate“ ihrerseits generell eng und die Schranken hingegen stets weit auszulegen seien. ${ }^{218}$ Im Gegenteil, es kann nach hiesigem Verständnis eine derartige vorherige Festlegung auf eine bestimmte „Richtung“ der Auslegung nicht geben. Es muss sowohl eine Beschränkung einer allzu umfassenden Nutzungsmöglichkeit als auch eine sinn- und maßvolle Erweiterung einer Schrankenregelung möglich sein, da sich zwei durch das Gesetz gewährte und verfassungsrechtlich basierte Rechte gleichrangig gegenüber stehen. Maßgeblich für die Auslegung der Schranken muss daher ihr jeweiliger Regelungsgrund und Zweck sein. Es muss also in jedem Einzelfall durch verfassungskonforme Auslegung und unter Beachtung des Verhältnismäßigkeitsprinzips ein gerechter Ausgleich zwischen den widerstreitenden Interessen im Wege ,praktischer Konkordanz" hergestellt werden. Dies hat anhand des allgemein üblichen Auslegungskanons der zivilrechtlichen Methodenlehre zu erfolgen.

Selbst wenn man jedoch annimmt, bei den Schrankenregelungen handele es sich um Ausnahmen vom Regelfall der Rechtsgewährung, kann die Annahme eines Grundsatzes der engen Auslegung nicht überzeugen, da sich aus der formalen Einordnung einer Norm als Ausnahmevorschrift noch keine automatischen Rückschlüsse auf deren Auslegung ziehen lassen. Ein allgemeiner methodischer Grundsatz, wonach Ausnahmevorschriften eng auszulegen sind, existiert dementsprechend in der juristischen Methodenlehre auch nicht. ${ }^{219}$ Problematisch ist nämlich schon die

217 So auch v.Becker, GRUR 2004, 104 (108); Kröger, MMR 2002, 18 (20 f.); Poeppel, Neuordnung, S.45; Rehse, Ungeschriebene Schranken, S.61; Stieper, Schranken, S. 69.

218 So aber insbes. Möhring/Nicolini/Hoeren, §69d Rn. 2; ders., MMR 2000, 3 (4 f.); ders., in: FS Sandrock, S. 357 (370); zustimmend Rogge, Elektronische Pressespiegel, S. 219.

219 Vgl. Bydlinski, Methodenlehre, S. 440; Larenz, Methodenlehre, S. 355, jeweils m.w.N. Auch der BGH weist in seiner jüngeren Rechtsprechung darauf hin, der Grundsatz der engen Schrankenauslegung habe seinen Grund weniger darin, dass 
Feststellung, wann eine Vorschrift eine „Ausnahmevorschrift“ im Sinne eines solchen Grundsatzes darstellen soll, denn dies ergibt sich nicht schon aus der Formulierung des betreffenden Rechtssatzes im Gesetz. ${ }^{220}$ Die Qualifizierung einer Norm als Ausnahme zur Regel bedeutet nicht automatisch, dass das in dieser Norm zum Ausdruck kommende Interesse gegenüber dem der Regelnorm zugrunde liegenden Interesse zweitrangig ist und daher hinter diesem zurücktreten muss. Andernfalls hätte der Gesetzgeber diese Interessen nicht durch eine Ausnahmevorschrift unter besonderen rechtlichen Schutz gestellt. ${ }^{221}$ In manchen Fällen mag das einer Ausnahmevorschrift zugrunde liegende Interesse aus Sicht des Gesetzgebers daher sogar höherwertig erscheinen als das durch das Ausschließlichkeitsrecht geschützte Interesse des Urhebers. ${ }^{222}$ Somit lässt sich aus Sicht der juristischen Methodenlehre die Regel, Ausnahmevorschriften seien generell eng auszulegen, in dieser Grundsätzlichkeit nicht aufrecht erhalten. $^{223}$

Allenfalls dann, wenn es sich bei einer Ausnahmevorschrift auch um eine „Ausnahme der Sache nach“ handelt, hat der „Grundsatz der engen Auslegung" eine gewisse Berechtigung, denn dann muss vermieden werden, dass durch eine allzu weite Auslegung dieser Bestimmung oder durch eine allzu weitreichende Analogie die Regelungsabsicht des Gesetzgebers letztlich in ihr Gegenteil verkehrt wird.224 Eine „Ausnahme der Sache nach“ liegt nach Larenz dort vor, ,wo das Gesetz eine Regel, der es in möglichst weitem Umfang Geltung zu verschaffen sucht, für bestimmte, meist eng umgrenzte Fälle durchbrochen hat, weil ihre Durchführung auch in diesen Fällen dem Gesetzgeber wenig praktikabel oder als unangebracht

Ausnahmevorschriften generell eng auszulegen wären, sondern beruhe vielmehr auf dem Gedanken, dass der Urheber an der wirtschaftlichen Auswertung seines Werkes tunlichst angemessen zu beteiligen sei und daher die ihm hinsichtlich der Werkverwertung zustehenden Ausschließlichkeitsrechte nicht übermäßig beschränkt werden dürften; siehe etwa BGHZ 150, 6 (8) - Verhüllter Reichstag; BGHZ 151, 300 (311) - Elektronischer Pressespiegel.

220 Vgl. Engisch, Einführung in das juristische Denken, S. 133; Larenz, Methodenlehre, S. 355.

221 Vgl. Kröger, MMR 2002, 18 (20); Macciacchini, Urheberrecht und Meinungsfreiheit, S. 47.

222 Vgl. Macciacchini, Urheberrecht und Meinungsfreiheit, S. 47; Pahud, UFITA 2000, 99 (136 f.).

223 Vgl. Bydlinski, Methodenlehre, S. 440; Larenz, Methodenlehre, S. 355.

224 Vgl. Larenz, Methodenlehre, S. 355 f.; Larenz/Canaris, Methodenlehre, S. 176. 
erschien und er deshalb hier glaubte, darauf verzichten zu können.“225 Selbst wenn eine solche „Ausnahme der Sache nach“ vorliegt, folgt daraus jedoch nicht, dass diese so eng wie möglich auszulegen ist oder einer Analogie grundsätzlich unzugänglich ist. ${ }^{226}$ Vielmehr ist auch hier der Sinn und Zweck der jeweiligen Norm zu ermitteln. ${ }^{227}$ Liegt der fraglichen Ausnahme ein Regelungsgrund zugrunde, der auch für vom Wortlaut nicht erfasste Fälle Geltung beansprucht, so ist auch eine solche Norm gegebenenfalls durch eine ausdehnende Auslegung oder durch vorsichtige Analogie zu erweitern. ${ }^{228}$

Ein Blick auf die neuere Rechtsprechung des Bundesgerichtshofs und des Bundesverfassungsgerichts zeigt, dass auch diese inzwischen in gewissem Umfang Abstand vom Grundsatz der engen Auslegung der urheberrechtlichen Schranken genommen hat. Auch wenn der BGH weiterhin formell an dem Gebot festhält, indem er es regelmäßig seinen Überlegungen zur Auslegung der Schranken voranstellt, ${ }^{229}$ finden sich diesbezüglich tatsächlich erhebliche Einschränkungen. In mehreren Urteilen hat der BGH inzwischen Schrankenregelungen mit Blick auf die dahinterstehende Interessenlage und die Intention des Gesetzgebers erweiternd ausgelegt oder gar analog angewandt.

Etwa in seiner Entscheidung zum „verhüllten Reichstag“ argumentierte das Gericht, ein gesteigertes öffentliches Interesse an der Wiedergabe eines geschützten Werkes sei bei der Auslegung der Schrankenbestimmungen zu berücksichtigen und könne im Einzelfall dazu führen, dass die enge, am Wortlaut orientierte Auslegung einer großzügigeren, der verfassungsrechtlich geschützten Position des Verwerters Rechnung tragenden

225 Larenz, Methodenlehre, S. 355 f.

226 Vgl. Larenz, Methodenlehre, S. 356.

227 Vgl. BVerfGE 37, 363 (405) - Zustimmungsgesetz: „Für jede Vorschrift, auch für eine Ausnahmevorschrift, gilt, daß sie korrekt und das heißt hier ihrem eindeutigen Inhalt und Sinn entsprechend auszulegen ist. Der Charakter einer Ausnahmevorschrift verbietet nur, sie über ihren eindeutigen Inhalt und Sinn hinaus ausdehnend auszulegen; mehr gibt die Formel „Ausnahmevorschriften sind eng auszulegen" nicht her.".

228 Vgl. Bydlinski, Methodenlehre, S. 440; Larenz, Methodenlehre, S. 356; Loewenheim/Götting, § 30 Rn. 13; Stieper, Schranken, S. 66.

229 Siehe etwa BGHZ 150, 6 (8) - Verhüllter Reichstag; BGHZ 151, 300 (311) Elektronischer Pressespiegel; BGH, GRUR 2002, 1050 (1050 f.) - Zeitungsbericht als Tagesereignis; GRUR 2005, 670 (671) - WirtschaftsWoche; BGHZ 185, 291 (301) - Vorschaubilder. 
Interpretation weichen müsse. ${ }^{230}$ In seiner Entscheidung zum Kopienversanddienst durch Bibliotheken lehnte der BGH nach einer ausführlichen Untersuchung des Regelungszwecks des $\S 53$ UrhG eine einschränkende Auslegung der Schrankenregelung ab, da der Gesetzgeber den Kopienversand durch öffentliche Bibliotheken privilegiert habe, um den freien $\mathrm{Zu}-$ gang der Allgemeinheit zu Informationen zu gewährleisten. ${ }^{231}$ In der Entscheidung Elektronischer Pressespiegel wandte der BGH die Schrankenregelung des $\S 49$ UrhG im Rahmen einer ,ausnahmsweise extensiven Auslegung" unter besonderer Berücksichtigung der Auswirkungen der Anwendung der Schrankenregelung auf die Interessen der Urheber auf elektronische Pressespiegel an. Das Gericht erkannte an, dass ein im Rahmen der Schrankenregelungen des Urheberrechtsgesetzes verwendeter Begriff in Folge technischer Fortentwicklungen veralten könne. Trete an die Stelle der ausdrücklich privilegierten Nutzung eine neue Form, so sei daher im Einzelfall zu prüfen, ob der mit der Schrankenregelung verfolgte Zweck auch bei der neuen Nutzungsform eintritt und ob dem verfassungsrechtlichen Gebot der angemessenen Beteiligung des Urhebers an der Verwertung seines Werkes zu genüge Rechnung getragen werde. ${ }^{232}$ In seiner Gies-Adler-Entscheidung ${ }^{233}$ hat der $\mathrm{BGH}$ diese Linie fortgeführt. Der BGH stellte fest, neben den Interessen der Urheber müssten auch Drittinteressen schon bei der Auslegung der Schrankenbestimmungen berücksichtigt werden, was im Einzelfall dazu führen könne, dass eine enge, am Gesetzeswortlaut orientierte Schrankenauslegung einer großzügigeren, dem Informations- und Nutzungsinteresse der Allgemeinheit Rechnung tragenden Interpretation der Schranken weichen müsse. ${ }^{234}$

Noch weitergehend hat das Bundesverfassungsgericht im speziellen Fall der Verwendung von Zitaten in Kunstwerken entschieden. In seinem Beschluss aus dem Jahre 2000 zur Zulässigkeit der Übernahme umfangreicher Brecht-Zitate in einem Theaterstück von Heiner Müller vertrat das Bundesverfassungsgericht die Auffassung, der grundgesetzliche Schutz der Kunstfreiheit durch Art. 5 Abs. 3 S. 1 GG gebiete eine kunstspezifi-

230 Siehe BGHZ 150, 6 (8 f.) - Verhüllter Reichstag.

231 Vgl. BGHZ 141, 13 (37) - Kopienversanddienst.

232 Vgl. BGHZ 151, 300 (311) - Elektronischer Pressespiegel; siehe dazu die Anmerkung von Hoeren, GRUR 2002, 1022 (insbes. 1025 f.). Bestätigt durch BGH, GRUR 2005, 670 (671) - WirtschaftsWoche.

233 BGHZ 154, 260 - Gies-Adler.

234 Siehe BGHZ 154, 260 (265) - Gies-Adler. 
sche Betrachtung der urheberrechtlichen Schrankenbestimmungen, im konkreten Fall der Regelung des Zitatrechts in $§ 51$ Nr. 2 UrhG a.F. ${ }^{235}$ Unter gleichzeitiger Berücksichtigung der durch Art. 14 GG geschützten Belange des Urhebers kam das BVerfG zu der Überzeugung, ein Zitat sei über die (in ständiger Rechtsprechung etablierte) Belegfunktion hinaus auch als Mittel künstlerischen Ausdrucks und künstlerischer Gestaltung anzuerkennen, und erweiterte so den Anwendungsbereich dieser Schranke. ${ }^{236}$

Diese „auslegungsfreundliche“ Linie hat das Bundesverfassungsgericht zuletzt fortgeführt. In seiner Entscheidung zur Vergütungspflicht für Drucker und Plotter ${ }^{237}$ hat das Bundesverfassungsgericht betont, die Gerichte seien nicht nur befugt, sondern auch verpflichtet, Gesetze durch Auslegung an die aktuellen Gegebenheiten anzupassen, wenn ehemals eindeutige und vollständige gesetzliche Regelungen auf Grund eines durch die technische Entwicklung bedingten „Alterungsprozesses“ lückenhaft, ergänzungsbedürftig und zugleich ergänzungsfähig würden. ${ }^{238}$

Diese zustimmungswürdige Entwicklung der deutschen Rechtsprechung hin zu einer flexibleren Handhabung der Schrankenregelungen könnte jedoch - zumindest auf den ersten Blick - durch Äußerungen des EuGH in seiner Infopaq-Entscheidung 239 bedroht sein. In dieser vertrat das Gericht - wenig reflektiert und ohne der andersartigen urheberrechtlichen und methodologischen Entwicklung in den Mitgliedstaaten ausreichend Rechnung zu tragen ${ }^{240}$ - die Position, die Ausnahmen vom Urheberrechtsschutz seien als Bestimmungen, die von einem in der InfoSocRichtlinie aufgestellten allgemeinen Grundsatz abweichen, eng auszule-

235 Siehe BVerfG, GRUR 2001, 149 (151) - Germania 3; dem folgend KG, GRURRR 2002, 313 (315) - Das Leben, dieser Augenblick.

236 Siehe BVerfG, GRUR 2001, 149 (151 f.) - Germania 3; zustimmend Metzger, ZUM 2000, 924 (930 f.); Raue, in: FS Nordemann, S. 327 (331 ff.). Ebenso jüngst OLG Brandenburg, Urt. v. 9.11.2010 - 6 U 14/10 (Rechtmäßigkeit der Übernahme vollständiger Zeitungsartikel und Lichtbilder in ein literarisches Werk aufgrund des Vorranges der Kunstfreiheit des Autors vor den Urheberrechten der Zeitungsautoren und -fotografen).

237 BVerfG, GRUR 2010, 999 - Drucker und Plotter.

238 Siehe BVerfG, GRUR 2010, 999 (1002) - Drucker und Plotter.

239 EuGH, Urt. v. 16.7.2009, C-5/08, Slg. 2009, I-6569 = GRUR 2009, 1041 - Infopaq International A/S./. Danske Dagblades Forening.

240 Kritisch auch Leistner, GRUR 2010, 987 (988); Metzger, in: Europäische Perspektiven des Geistigen Eigentums, S. 101 (116 ff.). 
gen. ${ }^{241}$ Es besteht freilich aufgrund eines Urteils aus jüngerer Zeit gewisse Hoffnung, dass auch der EuGH diese (zu) enge Interpretation der urheberrechtlichen Schranken langfristig nicht aufrecht erhalten wird. In der Entscheidung Football Association Premier League Ltd. und Murphy ${ }^{242}$ wiederholte der EuGH zwar unter Bezugnahme auf sein Infopaq-Urteil zunächst die pauschale Aussage, Schrankenregelungen seien eng auszulegen. ${ }^{243}$ Diesen Grundsatz schränkt die Kammer jedoch anschließend mit dem Hinweis ein, gleichwohl müsse es die Auslegung der Schranken erlauben, deren praktische Wirksamkeit gerade auch in Anbetracht neuer Technologien zu wahren und dadurch einen angemessenen Rechts- und Interessenausgleich zwischen den Beteiligten zu gewährleisten. ${ }^{244}$ Die Murphy-Entscheidung gibt somit Hoffnung, dass auch der EuGH nicht krampfhaft am Dogma der engen Schrankenauslegung festhalten will, sondern bereit ist, diesen Grundsatz - ähnlich der deutschen Rechtsprechung - aufzuweichen und die Schranken flexibler anzuwenden, wo dies zur Erreichung eines gerechten Interessenausgleichs erforderlich erscheint. ${ }^{245}$

Eine solche Aufweichung des in der Infopaq-Entscheidung durch den EuGH noch einschränkungslos aufgestellten Grundsatzes der engen Schrankenauslegung ist begrüßenswert und dringend erforderlich, um im Rahmen des starren Schrankenkataloges wenigstens ein gewisses Maß an Flexibilität zu ermöglichen. Eine Abstandnahme von einer engen Schrankenauslegung durch den EuGH erscheint schließlich auch im Lichte der Artikel 11 der Charta der Grundrechte der EU und Artikel 10 der Europä-

241 EuGH, GRUR 2009, 1041 (1045) - Infopaq/DDF.

242 EuGH, Urt. v. 4.10.2011, C-403/08 und C-429/08 = GRUR 2012, 156 - Football Association Premier League Ltd. u.a../. QC Leisure u.a. und Murphy./. Media Protection Services Ltd.

243 EuGH, a.a.O., Rn. 162 - Football Association Premier League Ltd. u.a... QC Leisure u.a. und Murphy./. Media Protection Services Ltd.

244 EuGH, a.a.O., Rn. 163 f. - Football Association Premier League Ltd. u.a../. QC Leisure u.a. und Murphy./. Media Protection Services Ltd.

245 Vgl. Berger, ZUM 2012, 353 (358); Hugenholtz/Senftleben, Fair Use in Europe, S. 25; Leistner, JZ 2011, 1140 (1145); Metzger, GRUR 2012, 118 (123); Stieper, MMR 2011, 825 (827), die die sich andeutende Flexibilisierung der Schrankenauslegung ebenfalls begrüßen. 
ischen Menschenrechtskonvention jedenfalls dann geboten, wenn die dort garantierte Meinungs- und Informationsfreiheit betroffen ist. ${ }^{246}$

Angesichts dieser neueren Tendenz zu einer Abstandnahme vom strikten „Grundsatz der engen Auslegung der Schranken“ (auch) durch den EuGH, erscheint es wahrscheinlich, dass die deutschen Gerichte bei ihrer begrüßenswerten flexibleren Handhabung der Schrankenregelungen bleiben. Insofern mag in der derzeitigen Vorgehensweise des BGH, nach der regelmäßig betont wird, die Schranken seien grundsätzlich eng auszulegen und sodann dieser Grundsatz im Sinne einer Einzelfallbetrachtung und -abwägung der im konkreten Fall betroffenen Interessen auf Seiten der Urheber, der Allgemeinheit und Dritter aufgeweicht wird, gegenüber einer völligen Aufgabe des „Grundsatzes der engen Schrankenauslegung“ sogar ein gewisser Vorteil liegen. Durch dieses formale Festhalten an der engen Schrankenauslegung läuft die deutsche Rechtsprechung nämlich nicht in gleichem Maße Gefahr, im Widerspruch zur diesbezüglich weiterhin eher restriktiven Rechtsprechung des EuGH zu handeln. Vielmehr bestehen sogar gute Gründe, dieses Vorgehen als im Einklang mit der Rechtsprechung des EuGH anzusehen, da dieser in ständiger Rechtsprechung betont, dass bei der Auslegung einer Gemeinschaftsvorschrift neben ihrem Wortlaut auch der Regelungszusammenhang, in dem diese steht, sowie die mit der Regelung verfolgten Ziele zu berücksichtigen sind. ${ }^{247}$ Eine (deutsche) Rechtsprechung, die die urheberrechtlichen Schranken "grundsätzlich“ eng auslegt, dann aber in aller Regel dem Regelungszusammenhang und den mit der Schrankenbestimmung verfolgten Zielen besondere Beachtung schenkt und diese gegebenenfalls durch erweiternde Auslegung oder vorsichtige Analogie besonders berücksichtigt, handelt daher im Einklang mit den Vorgaben des EuGH.

246 Vgl. Hugenholtz/Senftleben, Fair Use in Europe, S. 25 f. Siehe zur Beachtung der europäischen Grundrechte-Charta und Menschenrechtskonvention bei der Flexibilisierung der urheberrechtlichen Schranken näher unten 6. Kapitel, A.II. und III.

247 St. Rspr., siehe EuGH, Urt. v. 17.11.1983, C-292/82, Slg. 1983, 3781, Rn. 12 Merck./. Hauptzollamt Hamburg; Urt. v. 19.9.2000, C-156/98, Slg. 2000, I-6857, Rn. 50 = EuZW 2000, 723 (725) - Deutschland./. Kommission; Urt. v. 7.12.2006, C-306/05, Slg. 2006, I-11519, Rn. 34 = GRUR 2007, 225 (226 f.) - SGAE./. Rafael; Urt. v. 16.7.2009, C-5/08, GRUR 2009, 1041 (1044) - Infopaq./. DDF. 
c) Analogiefähigkeit von Schrankenbestimmungen?

Ebenso wenig wie die grundsätzliche Annahme eines Gebots der engen Auslegung der urheberrechtlichen Schranken vermag die grundsätzliche Absage an die analoge Anwendung der Schrankenregelungen ${ }^{248}$ zu überzeugen. Ein allgemeiner methodischer Grundsatz, dass Ausnahmevorschriften einer analogen Anwendung nicht zugänglich seien, existiert ebenfalls nicht. ${ }^{249}$ Nähme man ein striktes Analogieverbot an, so würde man letztlich den Richter dazu zwingen, rechtsähnliche Fälle verschieden zu behandeln und somit gegebenenfalls gegen das Gleichbehandlungsgebot zu verstoßen. ${ }^{250}$ Hat sich der Gesetzgeber - wie im Falle der Schranken des Urheberrechts - grundsätzlich für eine kasuistische Aufzählung einzelner Tatbestände und somit gegen die Einführung einer Generalklausel entschieden, so ist es methodisch unzulässig, im Wege der Rechtsanalogie aus den einzelnen Tatbeständen einen allgemeinen Rechtsgedanken zu ermitteln. ${ }^{251}$ Die analoge Anwendung eines einzelnen (Ausnahme-)Tatbestandes auf einen gesetzlich nicht geregelten Fall, die sogenannte Gesetzesanalogie, bleibt jedoch möglich. ${ }^{252}$ Wie andere Normen müssen daher auch die urheberrechtlichen Schrankenregelungen grundsätzlich insoweit der Analogie fähig sein, als eine planwidrige Regelungslücke besteht und das ihnen zugrunde liegende Prinzip aufgrund gleicher Interessenlage seinem Sinn nach Anwendung auf den nicht ausdrücklich geregelten Fall fin-

248 Grundsätzlich keinen Raum für eine analoge Anwendung der urheberrechtlichen Schrankenbestimmungen sehen weiterhin etwa: Fromm/Nordemann/W.Nordemann, Vor §§44aff. Rn. 3; Möhring/Nicolini/Nicolini, § 45 Rn. 2; Schricker/ Loewenheim/Melichar, Vor $\S \S 44 \mathrm{aff}$. Rn. 21. Ähnlich HK-UrhR/Dreyer, Vor $\S \S 44$ a ff. Rn. 20 (,,allenfalls in seltenen Ausnahmefällen“).

249 Vgl. ausführlich Würdinger, AcP 206 (2006), 946 (956 ff.). Canaris, Feststellung von Lücken im Gesetz, S. 181 formuliert sogar: „Kaum eine verfehlte Regel hat soviel Unheil gestiftet wie die Behauptung, Ausnahmevorschriften seien ihrem Wesen nach einer Analogie unzugänglich“ und stellt weiterhin fest, „daß es Vorschriften, die ihrer Natur nach jeder Analogie unzugänglich sind, nicht gibt.", ebd., S. 183.

250 Vgl. Canaris, Feststellung von Lücken im Gesetz, S. 183; Würdinger, AcP 206 (2006), 946 (973); ders., JuS 2008, 949 (950).

251 Vgl. Stieper, Schranken, S. 67.

252 Vgl. Canaris, Feststellung von Lücken im Gesetz, S. 184 ff. mit zahlreichen Beispielen. Zu den Begriffen der Rechts- und Gesetzesanalogie und ihrer Abgrenzung siehe Larenz, Methodenlehre, S. $383 \mathrm{f}$. 
den kann. ${ }^{253}$ Insbesondere ist es nicht ausgeschlossen, einen bestimmten, im Gesetz geregelten Sondertatbestand einem zweiten rechtsähnlichen Sondertatbestand gleichzustellen, um die widerstreitenden Grundrechte zu einem interessengerechten und angemessenen Ausgleich zu bringen. ${ }^{254} \mathrm{Zu}$ Recht ist daher die grundsätzliche Möglichkeit einer analogen Anwendung der urheberrechtlichen Schrankenbestimmungen inzwischen in der höchstrichterlichen Rechtsprechung ${ }^{255}$ und auch in weiten Teilen der Literatur ${ }^{256}$ anerkannt.

Dennoch ist bei der analogen Anwendung der urheberrechtlichen Schrankenbestimmungen generell eine gewisse Zurückhaltung geboten. Gerade die für den Bereich der analogen Werknutzung eingeführten

253 Vgl. Schockenhoff, in: FS Bechtold, S. 419 (427): „Richtigerweise muss jede scheinbare ,Ausnahmevorschrift' im Rahmen der objektiv-teleologischen Auslegung gemäß ihrer ratio legis interpretiert werden. Infolgedessen sind Ausnahmevorschriften analogiefähig, sofern die Analogievoraussetzungen im Übrigen [...] gegeben sind." Vgl. auch Schack, in: FS Schricker II, S. 511 (514); Würdinger, AcP 206 (2006), 946 (973). Ausführlich zu den Voraussetzungen eines Analogieschlusses etwa Bydlinski, Methodenlehre, S. 475 ff.; Larenz, Methodenlehre, S. $381 \mathrm{ff}$.

254 Vgl. OLG Hamburg, ZUM-RD 1998, 2 (4 f.) - Parfumflakon; Canaris, Feststellung von Lücken im Gesetz, S. 181; Würdinger, JuS 2008, 949 (959).

255 Siehe etwa BGHZ 87, 126 (129ff.) - Zoll- und Finanzschulen (analoge Anwendung des $\S 52$ Abs. 1 Nr. 1 UrhG a.F. auf Werkwiedergabe durch eine Einrichtung der öffentlichen Hand; i.E. abgelehnt); BGHZ 99, 162 (164 ff.) - Filmzitat (analoge Anwendung des $\S 51$ Nr. 2 UrhG a.F. auf Filmwerke); BGHZ 123, 149 (155 f.) - Verteileranlagen (analoge Anwendung des $\S 52$ UrhG a.F.; i.E. abgelehnt); BGHZ 174, 359 (366 ff.) - Drucker und Plotter (analoge Anwendung des $\S 54 \mathrm{a}$ Abs. 1 UrhG a.F.; i.E. mangels vergleichbarer Interessenlage abgelehnt); GRUR 2009, 53 (55) - PC (analoge Anwendung des § 54a Abs. 1 UrhG a.F.; i.E. im Anschluss an Drucker und Plotter-Entscheidung mangels vergleichbarer Interessenlage abgelehnt) GRUR 2009, 403 (405) - Metall auf Metall (analoge Anwendung des $\S 24$ UrhG, bei dem es sich nach Ansicht des BGH „der Sache nach" um eine Schranke handelt). Vgl. auch BGH, GRUR 2007, 500 (501 f.) Sächsischer Ausschreibungsdienst (analoge Anwendung der Schranke für amtliche Datenbankwerke ( 55 UrhG) auf Datenbanken, die dem Sui-generis-Schutz der $\S \S 87$ a ff. UrhG unterfallen).

256 Siehe etwa v.Becker, GRUR 2004, 104 (107f.); Dreier/Schulze, Vor §§ 44a ff. Rn. 7; Geiger, in: Hilty/Peukert, Interessenausgleich, S. 143 (152); Hoeren, in: Hilty/Geiger, Europäische Harmonisierung, S. 265 (267 ff.); Kröger, Informationsfreiheit und Urheberrecht, S. 222 ff.; ders., MMR 2002, 18 (20 f.); Leistner, GPR 2007, 190 (192); Poeppel, Neuordnung, S. 45 f.; Raue, in: FS Nordemann, S. 327 (339); Rehbinder, ZUM 1991, 220 (225); ders., Urheberrecht, Rn. 435; Schricker/Loewenheim/Loewenheim, § 44a Rn. 3; Stieper, Schranken, S. 72 f. 
Schranken sollten nicht unbesehen auf den digitalen Bereich übertragen werden. Vielmehr bedarf es für eine analoge Anwendung bei der Feststellung des Vorliegens einer planwidrigen Regelungslücke und der Vergleichbarkeit der Interessenlage eines besonders gründlichen Blickes auf die Auswirkungen einer solchen Ausdehnung sowie auf die hinter der konkreten Schrankenregelung stehenden Überlegungen und Beweggründe des Gesetzgebers. Hat dieser einen Reformbedarf und daher eine Erweiterung einer Schrankenregelung trotz der Kenntnis existierender oder möglicher zukünftiger Spannungen ausdrücklich verneint, so darf ein solches „Versäumnis“ nicht im Wege einer Analogie korrigiert werden. Gerade in den (wenigen) gesetzlichen Fällen, in denen der Gesetzgeber bereits versucht hat, eine gewisse Flexibilisierung einer Schranke durch deren Umgestaltung in eine generalklauselartige Bestimmung zu erreichen - so insbesondere bei der Änderung des Zitatrechts durch den sogenannten ,Zweiten Korb" der Urheberrechtsreform ${ }^{257}$-, ist besondere Zurückhaltung bei der analogen Anwendung geboten. ${ }^{258}$ Lässt sich eine fragliche Nutzung nicht im Wege der Auslegung unter die Generalklausel subsumieren, deren Ziel ja bereits die Flexibilisierung und Erweiterung des Anwendungsbereichs der Schrankenregelung ist, so droht im Falle einer analogen Anwendung eine Überschreitung der Wertentscheidung des Gesetzgebers und der darin zum Ausdruck kommenden, grundsätzlich abschließenden 259 Abwägung der widerstreitenden Interessen und Grundrechte. Es bedarf daher in einem solchen Fall einer besonders gründlichen Prüfung, ob die analoge Anwendung der Bestimmung auf einen vergleichbaren Sachverhalt nach ihrem Sinn und Zweck aufgrund vergleichbarer Interessenlage geboten und mit dem Grundrechtsschutz aller Beteiligten zu vereinbaren ist. Gerade bei der Frage nach der analogen Anwendbarkeit solcher Schrankenbestimmungen, die vom Gesetzgeber für gänzlich andere Nutzungssachverhalte konzipiert wurden, auf vollkommen neuartige Sachverhalte, die bislang geregelten oder zumindest bekannten Fällen nicht ähnlich sind, wird diese Gebotenheit oftmals zu verneinen sein. ${ }^{260}$ Besondere

257 Siehe dazu unten 4. Kapitel, B.I.1.c). und 7. Kapitel, C.I.

258 Ähnlich Schricker/Loewenheim/Schricker/Spindler, § 51 Rn. 8.

259 Vgl. BGHZ 150, 6 (8) - Verhüllter Reichstag; Bornkamm, in: FS Piper, S. 641 (648 f.); Schack, in: FS Schricker II, S. 511 (518).

260 Zutreffend LG Hamburg, ZUM 2009, 315 (323). Zu Beispielsfällen, in denen solche neuartigen Nutzungsformen sich nicht - auch nicht im Wege vorsichtiger 
Zurückhaltung ist vor dem Hintergrund des Beteiligungsgrundsatzes zudem bei der entsprechenden Anwendung solcher Schrankenregelungen geboten, die nicht nur eine zustimmungsfreie sondern auch eine vergütungsfreie Nutzung des Werkes erlauben, insbesondere, wenn die Nutzung kommerziellen Zwecken dient. ${ }^{261}$ Kein Raum ist jedenfalls schon aus verfassungsrechtlichen Gründen für eine völlig ,freischwebende“ richterliche Güter- und Interessenabwägung im Lichte verfassungsrechtlicher Vorgaben $^{262}$ oder für die Einführung völlig neuer Schrankenregelungen im Wege richterlicher Rechtsfortbildung, ${ }^{263}$ etwa einer allgemeinen Schranke zugunsten der „Bedürfnisse der Internetgemeinde“.264

\section{d) Ergebnis zur Auslegung und analogen Anwendung der Schranken}

Bei den Schranken des Urheberrechtsgesetzes handelt es sich nicht um Ausnahmen zum Ausschließlichkeitsrecht des Urhebers, sondern vielmehr um Inhaltsbestimmungen des Urheberrechts, die verdeutlichen, an welcher Stelle der Gesetzgeber die Interessen der Nutzer oder der Allgemeinheit für (in der Regel) schwerwiegender gehalten hat als die des Urhebers und daher durch die Schranken Inhalt und immanente Grenzen des Urheberrechts festgelegt hat. Die Schranken sind daher weder grundsätzlich eng auszulegen, noch unterliegen sie einem Analogieverbot. Sie sind jedoch auch nicht generell weit auszulegen oder regelmäßig „krampfhaft“ im Wege der Analogie zu erweitern. ${ }^{265}$ Somit können weder die Annahme, es sei generell nach der Maßgabe ,in dubio pro auctore“ auszulegen, noch die

Analogie - im Rahmen des geltenden Rechts erfassen lassen, siehe ausführlich unten 4. Kapitel, B.

261 Vgl. zur Auslegung der „Straßenbildfreiheit“" gemäß § 59 UrhG v.Gierke, in: FS Erdmann, S. 103 (107).

262 Siehe dazu auch unten 2. Kapitel, B.II.

263 Für eine solche Schaffung neuer Schranken im Wege richterlicher Rechtsfortbildung (unter Beachtung der Vorgaben des Dreistufentests) wohl Bornkamm, in: FS Erdmann, S. 29 (48) sowie ausführlich Rehse, Ungeschriebene Schranken, passim. Dazu zu Recht kritisch Leistner, Konsolidierung und Entwicklungsperspektive, S. 35.

264 Vgl. LG Hamburg, GRUR-RR 2004, 313 (317); LG Hamburg, ZUM 2009, 315 (323); zustimmend Dreier/Schulze, Vor $\S \S 44$ a ff. Rn. 7.

$265 \mathrm{Zu}$ derartigen „krampfhaften“ Versuchen, etwa Überlegungen, die Verwendung von Thumbnails im Rahmen der Bildersuche durch eine übermäßige Ausdehnung des Zitatrechts zu rechtfertigen, siehe unten 4. Kapitel, B.I.1.c). 
entgegengesetzte Auffassung einer grundsätzlichen Auslegung ,in dubio pro libertate" in dieser Allgemeinheit überzeugen. ${ }^{266}$ Anstelle einer solchen „Schwarz-Weiß-Malerei“" sind vielmehr die Ratio der jeweiligen Urheberrechtsschranke und ihre Reichweite im Einzelfall im Wege der Abwägung der entgegenstehenden Interessen und Grundrechte durch Auslegung zu ermitteln, um über ihre Anwendbarkeit zu entscheiden. Nicht jede Schrankenregelung basiert schließlich auf so wesentlichen verfassungsrechtlichen Interessen der Nutzer oder der Allgemeinheit wie beispielsweise die Schranke der Zitierfreiheit oder auch der Presseberichterstattung. Je nach „Stärke“ der verfassungsrechtlichen Fundierung einer Schrankenregelung kann sich demnach das Erfordernis einer eher restriktiven Auslegung zur Eindämmung einer zu weitgehenden Nutzungsmöglichkeit oder aber einer extensiven Auslegung oder analogen Anwendung im konkreten Fall ergeben. Freilich dürfen dabei die Grenzen der zulässigen Auslegung anhand der etablierten Auslegungsmethoden nicht überschritten werden. Lässt sich eine vormals unbekannte - etwa durch technologische Neuerungen entstandene - Nutzungsform dennoch nicht unter eine der bestehenden Schranken subsumieren - auch nicht mit Hilfe vorsichtiger Analogie -, so ist dieses Ergebnis zu akzeptieren. In diesem Fall ist der Gesetzgeber gefragt, einen erforderlichen angemessenen Interessenausgleich durch Gesetzesänderung, etwa durch die Schaffung einer neuen Schrankenregelung oder die Flexibilisierung des bestehenden Schrankensystems, zu ermöglichen.

Eine solche Auslegung, die anhand der Umstände des Einzelfalls neben den Interessen der Urheber auch den Zweck der jeweiligen Schrankenregelung und die durch die Schrankenregelung geschützten Interessen der anderen Beteiligten berücksichtigt, steht auch im Einklang mit dem Beteiligungsgrundsatz des Urheberrechts, nach dem der Urheber tunlichst angemessen an dem wirtschaftlichen Nutzen zu beteiligen ist, der aus seinem Werk gezogen wird. ${ }^{267}$ Die wirtschaftliche Teilhabe des Urhebers an der Werknutzung ist zwar eines der konstituierenden Merkmale des Urheberrechts als Eigentum im Sinne des Art. 14 GG. ${ }^{268}$ Umgekehrt bestehen aber

266 Leistner hat daher treffend formuliert, Schranken seien „nicht eng und nicht weit, sondern richtig auszulegen“" (zitiert nach Geiger/Engelhardt/Hansen/Markowski, GRUR Int. 2006, 475 (483) [Hervorhebung durch den Verfasser]).

267 Vgl. BGHZ 11, 135 (143) - Lautsprecherübertragung; BGHZ 13, 115 (118) Platzzuschüsse; BGHZ 17, 266 (282) - Grundig-Reporter.

268 Siehe dazu unten 6. Kapitel, D.I.1. 


\section{Kapitel Einschränkung des Urheberrechts}

auch an der Nutzung und Verbreitung eines geschützten Werkes Interessen der Werkmittler und der Allgemeinheit von verfassungsrechtlichem Rang, ${ }^{269}$ die mit den Interessen der Urheber in Einklang zu bringen sind. Ergibt die (gegebenenfalls erweiternde) Auslegung einer Schrankenbestimmung und die Abwägung der beteiligten Interessen, dass eine Nutzung nicht von der Schranke erfasst ist, so muss dem Ausschließlichkeitsrecht des Urhebers volle Geltung zukommen. Lässt sich eine Nutzung jedoch anhand der vorbeschriebenen Kriterien im Wege der Auslegung oder vorsichtigen Analogie einer bestehenden Schranke zuordnen, so ist die Reduzierung der Beteiligung des Urhebers auf einen gesetzlichen Vergütungsanspruch oder gegebenenfalls auch eine freie Nutzungsmöglichkeit als angemessen im Sinne des Beteiligungsgrundsatzes anzusehen, da dieses den vom Gesetzgeber vorgenommenen Wertungen entspricht.

3. Schrankenbestimmungen außerhalb des Schrankenkataloges der $\S \S 44 \mathrm{aff}$. UrhG

Neben den zuvor überblicksartig dargestellten „klassischen“, überwiegend im Rahmen des Schrankenkataloges der $\S \S 44 \mathrm{aff}$. UrhG verankerten Schrankenregelungen enthält das Urheberrechtsgesetz einige weitere Bestimmungen außerhalb des Schrankenkataloges, die die urheberrechtlichen Ausschließlichkeitsrechte (zumindest) schrankenähnlich begrenzen. Von Interesse für die vorliegende Untersuchung sind insoweit insbesondere die Regelungen der $\S \S 24$ und 12 Abs. 2 UrhG. Beiden Bestimmungen ist gemein, dass sie wesentliche Charakteristika einer Schrankenbestimmung aufweisen, vom Gesetzgeber jedoch - wie bereits ihre Stellung im Gesetz verdeutlicht - nicht als „klassische“ Schranken konzipiert beziehungsweise angesehen wurden. Ihr Schrankencharakter ist entsprechend umstritten.

a) Die freie Benutzung gemäß $§ 24 \mathrm{UrhG}$

In der Literatur ist umstritten, ob das Recht der freien Benutzung gemäß $\S 24$ UrhG lediglich als Bestimmung und Begrenzung des urheberrechtlichen Schutzbereichs oder als eine Schrankenbestimmung anzusehen ist.

269 Siehe dazu unten 6. Kapitel, D.II und III. 
Gewichtige Stimmen in der Literatur ${ }^{270}$ verstehen die Regelung als reine Schutzumfangsbestimmung oder negative Inhaltsabgrenzung zu $§ 23$ UrhG. Diese Ansicht wird zum einen mit dem Hinweis auf die Gesetzessystematik begründet. Die Regelung des $\S 24$ UrhG finde sich im Urheberrechtsgesetz im 4. Abschnitt, im Rahmen der Regelungen zu den Verwertungsrechten - und somit gerade nicht bei den Bestimmungen, die der Gesetzgeber im 6. Abschnitt als "Schranken des Urheberrechts“ in den $\S \S 44 \mathrm{aff}$. UrhG geregelt hat. ${ }^{271}$ Zum anderen spricht nach dieser Auffassung auch die Funktion des $\S 24$ UrhG gegen dessen Einordnung als Schrankenbestimmung. ${ }^{272}$ Bei den im Rahmen der $\S \S 44 a$ ff. UrhG zugelassenen Möglichkeiten der Vervielfältigung urheberrechtlicher Werke stehe die uneingeschränkte und weitgehend gleichbleibende Übernahme und Benutzung des älteren Werkes zu den jeweils konkret - und grundsätzlich enumerativ - benannten Zwecken im Vordergrund. Im Falle des $\S 24$ Abs. 1 UrhG diene hingegen das bereits vorhandene Werk lediglich als Anregung. Im Vordergrund stehe die eigene schöpferische Tätigkeit des Nutzenden, die Schaffung eines neuen, eigenen und selbständigen Werkes. Letztlich würden somit im Falle der Anwendung des § $24 \mathrm{UrhG}$ die Rechte des Urhebers gar nicht betroffen, da sich eine Verwendung des Werkes - wenn § 24 UrhG einschlägig sei - gerade außerhalb des Schutzumfangs des urheberrechtlichen Werkes bewege. §24 UrhG fehle somit ein wesentliches Merkmal einer Schrankenregelung: Während Schranken im Falle ihrer Einschlägigkeit die Rechte des Urhebers in einem Bereich verkürzten, in dem sie dem Urheber andernfalls zustünden, sei dies bei der Anwendung des $\S 24$ UrhG gerade nicht der Fall. ${ }^{273}$

270 Siehe etwa Chakraborty, Freie Benutzung, S. 25 f.; Czernik, Die Collage, S. 306; Franzen/v.Olenhusen, UFITA 2007, 435 (439); Fromm/Nordemann/A.Nordemann, §§ 23, 24 Rn. 2; v.Gamm, UrhG, § 24 Rn. 4; Lindhorst, GRUR 2009, 406 (407); Rehse, Ungeschriebene Schranken, S. 49; Schricker, JZ 2004, 311 (312); Wantke/Bullinger/Bullinger, § 24 Rn. 1; Wandtke/Schunke, Urheberrecht, Kapitel 5 Rn. 10; Wegmann, Der Rechtsgedanke der freien Benutzung, S. $154 \mathrm{ff}$.

271 Vgl. Wandtke/Schunke, Urheberrecht, Kapitel 5 Rn. 10; Wegmann, Der Rechtsgedanke der freien Benutzung, S. 154 f. m.w.N.

272 Vgl. Chakraborty, Freie Benutzung, S. 25 f.; Czernik, Die Collage, S. 306; Lindhorst, GRUR 2009, 406 (407); Wegmann, Der Rechtsgedanke der freien Benutzung, S. $157 \mathrm{ff}$.

273 Vgl. Chakraborty, Freie Benutzung, S. 26; Wegmann, Der Rechtsgedanke der freien Benutzung, S. 158. 


\section{Kapitel Einschränkung des Urheberrechts}

Die Gegenansicht ${ }^{274}$ erblickt in $\S 24$ UrhG eine Schranke des Urheberrechts, die lediglich nicht im Rahmen des Schrankenkataloges, sondern an anderer Stelle - bei den Verwertungsrechten des Urhebers - geregelt ist. Dieser Auffassung hat sich in jüngerer Zeit der Bundesgerichtshof in seiner viel beachteten Entscheidung Metall auf Metall275 angeschlossen, in der er feststellte, bei der Bestimmung des $§ 24$ Abs. 1 UrhG „handel[e] es sich der Sache nach um eine, wenn auch an anderer Stelle des Urheberrechtsgesetzes geregelte Schranke des Urheberrechts“. 276

Trotz der Stellung des $\S 24$ UrhG außerhalb des Kataloges „klassischer“ Schrankenbestimmungen und trotz der gewissen funktionalen Unterschiede zwischen der freien Benutzung und den herkömmlichen Schranken ist der letztgenannten Ansicht zuzustimmen. Es spricht Vieles dafür, § 24 UrhG als eine Schranke des Urheberrechts anzusehen, die im Interesse der wissenschaftlichen und künstlerischen Auseinandersetzung und unter Abwägung der sich gegenüber stehenden Belange im Einzelfall die Übernahme fremden individuellen Gedankengutes erlaubt, ${ }^{277}$ denn die Regelung weist wesentliche Charakteristika einer Schrankenbestimmung auf.

Die Schranken des Urheberrechts sollen nach dem Willen des Gesetzgebers den „Interessen der Gemeinschaft“ beziehungsweise „berechtigten Interessen der Allgemeinheit" dienen. ${ }^{278}$ Auch $\S 24$ UrhG dient kulturellen Interessen der Allgemeinheit, zu der auch (andere beziehungsweise zukünftige) Urheber zählen, die als aktive „Kulturverwender“ ein Interesse an möglichst ungehindertem und idealerweise kostengünstigem Zugang zu bestehenden urheberrechtlich geschützten Werken haben. ${ }^{279}$ Diesem Zweck dient die Regelung des $\S 24$ UrhG. Sie soll die Freiheit der geistigen und künstlerischen Auseinandersetzung mit bestehenden Werken ge-

274 Siehe etwa Dreier/Schulze, § 24 Rn. 10; Garloff, GRUR 2001, 476 (477); Haberstumpf, Handbuch, Rn. 316, 324; ders., ZUM 2003, 83; Leinemann, Sozialbindung, S. 99; Stieper, Schranken, S. 7; ders., ZUM 2009, 223 (224); Weßling, Digitales Sound-Sampling, S. 116.

275 BGH, GRUR 2009, 403 - Metall auf Metall mit Anm. Lindhorst.

276 Siehe BGH, a.a.O., S. 405 - Metall auf Metall.

277 So auch Haberstumpf, ZUM 2003, 83.

278 Vgl. Begr. RegE, BT-Drs. IV/270, S. 30. Eine Kategorisierung dieser „Interessen der Allgemeinheit" findet sich bei Schricker/Loewenheim/Melichar, §§44a ff. Rn. 4.

279 Siehe dazu näher unten 6. Kapitel, D.III. 
währleisten, die für die Entwicklung und die Entfaltungsmöglichkeit von Künstlern von grundlegender Bedeutung ist. 280

Zur Erreichung eines angemessenen Ausgleichs zwischen Allgemeinund Urheberinteressen heben die Schrankenregelungen des Urheberrechtsgesetzes das Ausschließlichkeitsrecht des Urhebers durch unterschiedlich intensive Eingriffe punktuell auf. Wenn die Voraussetzungen einer Schrankenbestimmung erfüllt sind, kann der Urheber die Nutzung durch Dritte folglich nicht verbieten. So liegt es auch im Fall des § 24 UrhG. Die freie Benutzung gestattet, schutzfähige Elemente des fremden Werkes zu benutzen, um diese als Anregung für eigenes Werkschaffen zu verwenden. $^{281} \S 24$ UrhG setzt voraus, dass ein selbständiges Werk entsteht, welches in freier Benutzung des Werkes eines anderen geschaffen wird. Die Neuschöpfung muss also ihrerseits selbständig schutzfähig sein, und zwar unabhängig von den anregenden Elementen des benutzten Werkes. ${ }^{282}$ Nach ständiger Rechtsprechung ist dies der Fall, wenn angesichts der Eigenart des neuen Werkes die entlehnten eigenpersönlichen Züge des geschützten älteren Werkes so verblassen, dass die Benutzung des älteren Werkes durch das neuere Werk nur noch als Anregung zu einem neuen, selbständigen Werkschaffen erscheint. ${ }^{283}$ Anhand eines Vergleichs der einander gegenüberstehenden Werke ist zu ermitteln, ob und gegebenenfalls in welchem Umfang eigenschöpferische Züge des älteren Werkes übernommen worden sind. ${ }^{284}$ Werden diese - strengen - Anforderungen der Rechtsprechung eingehalten, so kann der Urheber diese Form der Nutzung seines Werkes nicht untersagen. Sein Verbotsrecht wird insoweit ebenso wie im Falle der Anwendbarkeit einer „klassischen“ Schranke begrenzt.

280 Vgl. Wandtke/Bullinger/Bullinger, § 24 Rn. 1 m.w.N.

281 Siehe Dreier/Schulze, § 24 Rn. 6 f. m.w.N.

282 Vgl. BGH, GRUR 1961, 631 (632) - Fernsprechbuch; Dreier/Schulze, § 24 Rn. 5.

283 Vgl. BGH, GRUR 1994, 191 (193) - Asterix-Persiflagen; BGHZ 154, 260 (267) - Gies-Adler; BGHZ 181, 98 (106 f.) - Tripp-Trapp-Stuhl; zuletzt BGH, GRUR 2011, 134 (137) - Perlentaucher, jeweils m.w.N.

284 Siehe dazu näher unten 4. Kapitel, A.I.2. 
b) $\S 12$ Abs. 2 UrhG als Schrankenbestimmung

Nach $\S 12$ Abs. 2 UrhG ist die öffentliche Beschreibung des Inhalts eines Werkes dem Urheber solange vorbehalten, bis das Werk selbst, dessen wesentlicher Inhalt oder eine Beschreibung des Werkes mit seiner Zustimmung veröffentlicht worden ist. Eine Ansicht in Literatur und Rechtsprechung ${ }^{285}$ folgert im Wege eines Umkehrschlusses aus dieser Regelung, dass nach der Veröffentlichung des Werkes grundsätzlich jedermann berechtigt sein soll, den Inhalt des Werkes öffentlich mitzuteilen oder zu beschreiben, selbst wenn die Inhaltsmitteilung eine Form annimmt, die grundsätzlich dem Urheber vorbehalten ist. Nach dieser Ansicht stellt § 12 Abs. 2 UrhG daher eine besondere Schrankenbestimmung dar. ${ }^{286}$ Dabei sollen nach zum Teil vertretener Ansicht sogar solche Inhaltsmitteilung zulässig sein, die in das Bearbeitungsrecht des Urhebers gemäß $§ 23$ UrhG eingreifen, etwa weil sie fast ausschließlich aus übernommenen Versatzstücken des Originals bestehen. ${ }^{287}$ Die Grenze des Zulässigen ist jedoch auch nach dieser Ansicht jedenfalls dann überschritten, wenn die öffentliche Inhaltsmitteilung oder -beschreibung einen so weitgehenden Werkgenuss ermöglicht, dass sie geeignet ist, die Lektüre des Originalwerkes zu ersetzen. ${ }^{288}$

Nach anderer Ansicht ${ }^{289}$ enthält die Regelung des $\S 12$ Abs. 2 UrhG hingegen (nur) einen über die Rechte aus $\S 12$ Abs. 1 UrhG hinausgehen-

285 Vgl. LG Frankfurt a.M., ZUM 2007, 65 (67); Erdmann, in: FS Tilmann, S. 21 (30 f.); Haberstumpf, Handbuch, Rn. 205; ders., ZUM 2011, 158 (160 f.); Hackemann, GRUR 1982, 262 (267); Loewenheim/Dietz, 1. Aufl., § 16 Rn. 11; Müsse, Urheberpersönlichkeitsrecht, S. 147 f.; Rehbinder, Urheberrecht, Rn. 511; Schricker/Dietz, 3. Aufl., § 12 Rn. 29; Ulmer, S. 213; im Ergebnis zustimmend HKUrhR/Dreyer, $\S 12$ Rn. 25.

286 Siehe zu den Möglichkeiten, die Thumbnail-Nutzung durch einen Rückgriff auf den Umkehrschluss zu $§ 12$ Abs. 2 UrhG zu rechtfertigen, unten 4. Kapitel, B.I. 1.h).

287 Vgl. LG Frankfurt a.M., ZUM 2007, 65 (67); a.A. OLG Frankfurt, GRUR 2008, 249 (251).

288 Vgl. LG Frankfurt a.M., ZUM 2007, 65 (67); Fromm/Nordemann/Dustmann, $\S 12$ Rn. 21; Schricker/Dietz, 3. Aufl., § 12 Rn. 29.

289 Vgl. BGH, GRUR 2011, 134 (139) - Perlentaucher; OLG Frankfurt, GRUR 2008, 249 (251); LG Hamburg, GRUR-RR 2004, 65 (69); Dreier/Schulze, § 12 
den, zusätzlichen Schutz des Urhebers vor der Erstveröffentlichung seiner Werke, aber keine Einschränkung seiner Rechte nach der Werkveröffentlichung. Was nach der Erstveröffentlichung zulässig ist, soll sich demnach allein nach den sonstigen Vorschriften des Urheberrechtsgesetzes, hinsichtlich der Möglichkeit von Inhaltsangaben also im Wesentlichen nach den $\S \S 23,24$ UrhG, richten, die nicht durch einen Umkehrschluss zu § 12 Abs. 2 UrhG umgangen werden sollen. Hätte der Gesetzgeber einen über $\S 24$ UrhG hinausgehenden Entlehnungstatbestand schaffen wollen, so wäre dies im Gesetz expressis verbis zum Ausdruck gebracht worden. ${ }^{290}$ Gegen einen Umkehrschluss zu Lasten des Urhebers werden zudem Bedenken aufgrund der positiven Formulierung der Norm und aufgrund deren sytematischer Stellung bei den Urheberpersönlichkeitsrechten geltend gemacht. 291

Sieht man von den - schwerwiegenden - systematischen Bedenken ab, die dem dargestellten Umkehrschluss zu $§ 12$ Abs. 2 UrhG entgegenstehen, so kann man diese Regelung tatsächlich als Schranke des Urheberrechts deuten. $\S 12$ Abs. 2 UrhG betrifft die Mitteilung des vollständigen oder des wesentlichen gedanklichen Inhalts eines urheberrechtlich geschützten Werkes in eigenen Worten. Die Zusammenfassung des gedanklichen Inhalts eines Schriftwerkes in eigenen Worten stellt grundsätzlich eine freie Benutzung gemäß $§ 24$ UrhG dar. Die Zulässigkeit der freien Benutzung setzt jedoch keine vorherige Veröffentlichung des benutzten Werkes voraus. ${ }^{292}$ Wäre die Zulässigkeit einer Inhaltsangabe jedoch nur nach den $\S \S 23,24$ UrhG zu beurteilen, so bliebe für die Regelung des $\S 12$ Abs. 2 UrhG zumindest für Sprachwerke praktisch kein Anwendungsbereich. ${ }^{293}$ Es sind allerdings zahlreiche Fälle denkbar, in denen auch jenseits des so (begrenzt) verstandenen Anwendungsbereichs des $\S 12$ Abs. 2 UrhG ein berechtigtes Interesse der Allgemeinheit an der Unterrichtung über den Inhalt eines Werkes besteht, die die unmittelbare Kenntnisnahme des Werkes durch Lesen, Hören oder Betrachten nicht er-

Rn. 24; Fromm/Nordemann/Hertin, 9. Aufl., § 12 Rn. 14; Loewenheim/Dietz/ Peukert; § 16 Rn. 29; Obergfell, GRUR 2011, 208 (210); Ott, ZUM 2009, 345 (350); Pohl, Abstracts, S. 186 ff.; Schricker/Loewenheim/Dietz/Peukert, § 12 Rn. 29; Wandtke/Bullinger/Bullinger, § 12 Rn. 22.

290 Siehe LG Hamburg, GRUR-RR 2004, 65 (69); Fromm/Nordemann/Hertin, 9. Aufl., § 12 Rn. 14.

291 Siehe Wandtke/Bullinger/Bullinger, § 12 Rn. 22.

292 Vgl. HK-UrhR/Dreyer, § 24 Rn. 9.

293 Vgl. Haberstumpf, ZUM 2011, 158 (160). 
setzt. So ist etwa bei knappen Inhaltsangaben zu wissenschaftlichen Texten in Fachdatenbanken die Einhaltung des von der Rechtsprechung im Rahmen des $\S 24$ UrhG streng angewendeten Maßstabs des notwendigen Abstands zum individuellen gedanklichen Inhalt des zusammengefassten Werkes ${ }^{294}$ oftmals zweifelhaft oder auch offensichtlich nicht erfüllt. ${ }^{295}$ Dennoch offenbaren diese Fälle, dass ein erhebliches Interesse der Allgemeinheit besteht, durch solche Kurzwiedergaben auf relevante Literatur hingewiesen zu werden. Die Lektüre des Originalwerkes ersetzen die Hinweise im Falle wissenschaftlicher Beiträge offensichtlich nicht. Gerade deshalb entsprechen diese Mitteilungen in aller Regel aber auch dem Interesse des (wissenschaftlichen) Urhebers, der - nach der von ihm kontrollierten Veröffentlichung seines Werkes - von anderen Mitgliedern der "Scientific Community" wahrgenommen werden möchte. Ebenso ist jenseits der Sprachwerke eine (sinnvolle) Inhaltsangabe oftmals nur durch Darstellung des gesamten Werkes - gegebenenfalls in verkleinerter Form wie bei den Thumbnails - möglich. Auch hier ersetzt die Inhaltsmitteilung jedoch vielfach nicht den Genuss des Originalwerkes. ${ }^{296}$

In den dargestellten Fällen verleiht die Anwendung des dargestellten Umkehrschlusses der Regelung des $\S 12$ Abs. 2 UrhG somit ein typisches Charakteristikum einer Schrankenregelung: sie dient der Verwirklichung und dem Ausgleich (berechtigter) Interessen der Allgemeinheit und begrenzt zu diesem Zweck das Verbotsrecht des Urhebers.

\section{Urheberrechtliche Schranken außerhalb des Urheberrechtsgesetzes}

Die urheberrechtlichen Ausschließlichkeitsbefugnisse finden grundsätzlich ihre Grenzen nicht nur in den im Urheberrechtsgesetz geregelten Schrankenbestimmungen, sondern auch in den allgemeinen zivilrechtlichen Rechtfertigungsgründen. So ist eine Anwendung des Schikaneverbots (§ $226 \mathrm{BGB})$, der Notwehr (§ $227 \mathrm{BGB})$ oder auch des rechtfertigen-

294 Vgl. dazu bereits oben 2. Kapitel, B.I.3.a).

295 Deutlich wird dies etwa bei den knappen Inhaltswiedergaben zu Fachbeiträgen in der juristischen Datenbank juris oder den Hinweisen zu Aufsätzen in anderen Publikationen bei beck-online, die oftmals nur aus einer wörtlichen Wiedergabe der Einleitung, des Fazits oder aus einzelnen Versatzstücken des Originalbeitrags bestehen; ebenso Haberstumpf, ZUM 2011, 158 (160 f.).

296 Siehe dazu näher 4. Kapitel, B.I.1.h). 
den aggressiven Notstandes ( $\$ 904$ S. 1 BGB analog) $)^{297}$ zur Rechtfertigung von nicht mehr durch die $\S \S 44 \mathrm{aff}$. UrhG gedeckten Nutzungen urheberrechtlich geschützter Werke nicht grundsätzlich ausgeschlossen. Obwohl eine Anwendung dieser Rechtfertigungsgründe systemkonform ist, sind tatsächlich jedoch kaum Fälle vorstellbar, in denen ihre engen Voraussetzungen im Zusammenhang mit Eingriffen in das Urheberrecht erfüllt sein könnten. ${ }^{298}$

Gerade vor dem Hintergrund der in urheberrechtlichen Sachverhalten wohl kaum jemals erfüllten Voraussetzungen des rechtfertigenden Notstandes ${ }^{299}$ ist überlegt worden, Eingriffe in das Urheberrecht durch das Institut des übergesetzlichen Notstands zu rechtfertigen. ${ }^{300}$ Das Institut wurde im Strafrecht aus dem allen Rechtfertigungsgründen zugrunde liegenden Prinzip entwickelt, dass der Täter bei einer unvermeidlichen Kollision widerstreitender Interessen nicht rechtswidrig handelt, wenn er das höherwertige Interesse dem geringwertigeren vorzieht und somit im Ergebnis etwas sozial Nützliches tut. ${ }^{301}$ Dieser in umfangreicher Rechtsprechung fortentwickelte Rechtsgedanke wurde schließlich 1975 als heutiger $\S 34$ in das StGB aufgenommen. Für das Urheberrecht wurde dieser Gedanke erstmals in einer Entscheidung des LG Berlin aus dem Jahre 1960 fruchtbar gemacht. ${ }^{302}$ Danach soll eine Urheberrechtsverletzung ausnahmsweise dann gerechtfertigt sein, wenn die Benutzung des urheberrechtlich geschützten Werkes zum Schutz höherrangiger Interessen beziehungsweise eines höherwertigen Rechtsguts erforderlich ist. Im Kern geht es somit um eine Abwägung des urheberrechtlichen Schutzes mit grundgesetzlichen Positionen, insbesondere mit der Meinungs-, Informations-, Presse- und

$297 \S 904$ S. 1 BGB bezieht sich unmittelbar nur auf Eingriffe in das Sacheigentum. Die Regelung findet jedoch nach h.M. analoge Anwendung bei Eingriffen in alle subjektiven Privatrechte; vgl. Staudinger/Seiler, § 904 Rn. 46 m.w.N; für das Patent- und Urheberrecht Bornkamm, in: FS Piper, S. 641 (647).

298 Vgl. Schack, in: FS Schricker II; S. 511 (516); Schricker/Loewenheim/Melichar, Vor $\S \S 44 a$ ff. Rn. 16.

$299 \S 904$ S. 1 BGB setzt voraus, dass der Eingriff in ein fremdes Recht - in diesem Fall also in das Urheberrecht - ,zur Abwendung einer gegenwärtigen Gefahr notwendig und der drohende Schaden gegenüber dem aus der Einwirkung dem Eigentümer entstehenden Schaden unverhältnismäßig groß“ ist.

300 So soweit ersichtlich erstmals Schricker/Wild, 1. Aufl., §97 Rn. 20.

301 Vgl. RGSt 61, 242 sowie statt vieler Schönke/Schröder/Perron, StGB, § 34 Rn. 2 m.w.N.

302 Siehe LG Berlin, GRUR 1962, 207 (210) - Maifeiern. 
Kunstfreiheit des Art. 5 GG. ${ }^{303}$ Die Rechtfertigung von Urheberrechtseingriffen mit Hilfe des Instituts des übergesetzlichen Notstands oder der $\mathrm{Me}$ thode einer unmittelbaren Güter- und Interessenabwägung unter Rückgriff auf Grundrechte hat in Rechtsprechung ${ }^{304}$ und Literatur ${ }^{305}$ teilweise $\mathrm{Zu}$ stimmung gefunden, ist jedoch ganz überwiegend abgelehnt worden. ${ }^{306}$

Dieser Ablehnung ist aus mehreren Gründen zuzustimmen, da eine solche „übergesetzliche“ Schrankenregelung weder systemkonform noch erforderlich ist. Schon die Herkunft des Instituts des übergesetzlichen Notstands aus dem Strafrecht lässt Zweifel an der Eignung für die Anwendung im Urheberrecht aufkommen. Im Strafrecht wurde das Institut des übergesetzlichen Notstands entwickelt, weil die Notstandsregelungen des BGB aufgrund ihres Bezugs auf Sachen unpassend waren. Im Urheberrecht stellt sich diese Situation jedoch anders dar. Die allgemeinen Rechtfertigungsgründe des BGB, insbesondere des $\S 904$ S. 1 BGB finden nach ganz h.M. ohne weiteres (zumindest analoge) Anwendung auf alle sonstigen subjektiven Privatrechte und somit auch auf das Urheberrecht. Ein Rückgriff auf das - seit der Kodifizierung im $§ 34$ StGB nicht mehr exis-

303 Vgl. Fromm/Nordemann/J.B.Nordemann, § 97 Rn. 23.

304 In Erwägung gezogen etwa von LG Berlin, NJW 1995, 881 (882) (Abwägung „unterschiedlicher Rechte von Verfassungsrang“"); KG, NJW 1995, 3392 (3394) - Botho Strauß; LG Hamburg, AfP 1999, 379 (380) - Berufungsschrift; OLG Hamburg, NJW 1999, 3343 (3344) - Berufungsschrift (nicht beanstandet von BVerfG, ZUM 2000, 316 (316f.)); offen gelassen von KG, ZUM 2008, 329 (331).

305 Siehe Schricker/Wild, 1. Aufl., § 97 Rn. 20 (die seit der 3. Aufl. allerdings nicht mehr vom übergesetzlichen Notstand spricht, sondern den Begriff ,,verfassungskonformer Interessenausgleich“" verwendet); Wandtke/Bullinger/v.Wolff, 2. Aufl., $\S 97$ Rn. 32 (etwas anders nun die 3. Aufl., in der ein Ausschluss der Rechtswidrigkeit als Ergebnis einer Güterabwägung befürwortet, allerdings ein Rückgriff auf das Institut des übergesetzlichen Notstands für ,nicht erforderlich“ gehalten wird); wohl auch Fromm/Nordemann/Nordemann, 9. Aufl., §97 Rn. 19 (a.A. jetzt Fromm/Nordemann/J.B.Nordemann, 10. Aufl., §97 Rn. 23).

306 Siehe BGHZ 154, 260 (266) - Gies-Adler; BGHZ 185, 291 (301) - Vorschaubilder; Bornkamm, in: FS Piper, S. 641 (647 f.); Findeisen, Auslegung, S. 124 f.; Förster, Fair Use, S. 81 f.; Fromm/Nordemann/J.B.Nordemann, §97 Rn. 23; Hoeren/Herring, MMR 2011, 500 (502 f.); Poeppel, Neuordnung, S. 49f;; Schack, in: FS Schricker II, S. 511 (517); Schricker/Loewenheim/v.UngernSternberg, § 15 Rn. 29; Schricker/Loewenheim/Melichar, Vor $\S$ 44a ff. Rn. 16 f; Schricker/Loewenheim/Schricker/Spindler, § 51 Rn. 8; Seifert, in: FS Erdmann, S. 195 (209); Seydel, Zitierfreiheit, S. 13 f.; wohl auch HK-UrhR/Meckel, § 97 Rn. 36. 
tierende - strafrechtliche Institut des übergesetzlichen Notstands zur „Überwindung“ der strengeren Voraussetzungen der sachnäheren zivilrechtlichen Rechtfertigungsgründe erscheint als Systembruch und ist daher abzulehnen. ${ }^{307}$ Auch wenn in einigen Konstellationen eine Ausweitung des urheberrechtlichen Schrankenkataloges aus verfassungsrechtlichen Gründen notwendig oder gerecht erscheinen mag, sind Bestrebungen, Eingriffe in das Urheberrecht durch eine unmittelbare Güter- und Interessenabwägung unter direktem Rückgriff auf das Grundgesetz zu rechtfertigen, abzulehnen. Eine derartige ,zweistufige Prüfung“308 - zunächst „normale“ Auslegung der Schrankenbestimmungen, sodann eine nachgelagerte ,freischwebende Güterabwägung “309 - überschreitet die Kompetenz der Zivilgerichte, da sie die gesetzgeberische Entscheidung zugunsten einer „grundsätzlich abschließenden Güterabwägung“310 bei der Kodifizierung der urheberrechtlichen Schranken in jedem Einzelfall in Frage stellt. ${ }^{311}$ Es droht sonst eine Umgehung und Aushöhlung der Entscheidung des Gesetzgebers, dass der Urheber grundsätzlich die öffentliche Nutzung seiner Werke durch Ausschließlichkeitsrechte steuern können soll. ${ }^{312}$ Die ganz überwiegende Zahl der Fälle, in denen die gesetzlichen Schranken aus verfassungsrechtlichen Gründen tatsächlich als zu eng erscheinen, lässt sich zudem unter Rückgriff auf die etablierten Methoden verfassungskonformer Auslegung und gegebenenfalls analoger Anwendung der Schranken $^{313}$ lösen. ${ }^{314}$ Durch verfassungskonforme Auslegung können die Gerichte das vom Gesetzgeber Gewollte im Sinne eines engeren oder weiteren Verständnisses präzisieren, es aber nicht inhaltlich verändern, so dass eine Rückbindung an die gesetzgeberische Interessenabwägung gesichert

307 Vgl. BGHZ 154, 260 (266f.) - Gies-Adler; Bornkamm, in: FS Piper, S. 641 (647 f.); Rehse, Ungeschriebene Schranken, S. 75; Schack, in: FS Schricker II, S. 511 (517).

308 Bornkamm, in: FS Piper, S. 641 (650).

309 Schack, in: FS Schricker II, S. 511 (517).

310 BGHZ 150, 6 (8) - Verhüllter Reichstag.

311 Vgl. BGHZ 154, 260 (266 f.) - Gies-Adler; Fromm/Nordemann/J.B.Nordemann, $\S 97$ Rn. 23.

312 Vgl. Schack, in: FS Schricker II, S. 511 (516).

313 Zur Auslegung der urheberrechtlichen Schranken, siehe oben 2. Kapitel, B.I.2.

314 Vgl. BGHZ 154, 260 (265 ff.) - Gies-Adler; Bornkamm, in: FS Piper, S. 641 (649f.); Poeppel, Neuordnung, S. 49 f.; Schack, in: FS Schricker II, S. 511 (517 f.). 


\section{Kapitel Einschränkung des Urheberrechts}

ist. ${ }^{315}$ Ist eine verfassungskonforme Auslegung im Einzelfall wegen eines entgegenstehenden eindeutigen Wortlauts nicht möglich oder führt diese im Einzelfall zu untragbaren - oder vom Gericht für untragbar gehaltenen

- Ergebnissen, so bleibt den Gerichten die Möglichkeit einer Vorlage an das Bundesverfassungsgericht nach Art. 100 Abs. 1 GG. ${ }^{316}$ Eine solche Vorlage durch die Anwendung einer gesetzlich nicht vorgesehenen und mit gesetzlichen Wertungen unvereinbaren Güter- und Interessenabwägung zu umgehen, widerspräche dem Willen des Gesetzgebers, der ausschließlich das Bundesverfassungsgericht ermächtigt hat, die Verfassungswidrigkeit einer Regelung festzustellen. ${ }^{317}$ Hält auch das Bundesverfassungsgericht eine bestimmte Regelung für unvereinbar mit grundgesetzlichen Wertungen, so ist es Aufgabe des Gesetzgebers, für eine verfassungskonforme Ausgestaltung der gesetzlichen Regelung zu sorgen - etwa durch die flexible Ausgestaltung der Schrankenregelungen, die eine angemessene Berücksichtigung der Wertentscheidungen des Grundgesetzes im Einzelfall ermöglicht.

\section{Das Schrankensystem des US-amerikanischen Copyright Law}

Auch im US-amerikanischen Copyright Law werden die Ausschließlichkeitsrechte dem Rechteinhaber nicht schrankenlos gewährt. Ebenso wie das deutsche und kontinentaleuropäische Urheberrecht kennt das Copyright einen gesetzlichen Katalog von Schrankenbestimmungen, unterscheidet sich aber insoweit erheblich vom deutschen Urheberrecht als zusätzlich eine generalklauselartige Schranke existiert. Dieser Generalklausel, der richterrechtlich entwickelten und inzwischen in 17 U.S.C. $\$ 107$ geregelten Fair Use-Doktrin (dazu sogleich I.), kommt dabei - im Gegensatz zu den zumeist sehr detaillierten Schrankenbestimmungen der 17 U.S.C. $\S \S 108-122$ (zu diesen sonstigen „Limitations on exclusive rights“ unten II.) - eine überragende Bedeutung bei der Rechtfertigung von Eingriffen in die Verwertungsrechte des Urhebers zu.

315 Vgl. Findeisen, Auslegung, S. 124 f.; Förster, Fair Use, S. 82; Schack, in: FS Schricker II, S. 511 (517 f.).

316 Vgl. Fromm/Nordemann/J.B.Nordemann, § 97 Rn. 23.

317 Vgl. BGHZ 154, 260 (266f.) - Gies-Adler; Bornkamm, in: FS Piper, S. 641 (650). 


\section{Die Fair Use-Doktrin}

Wie das gesamte US-amerikanische Urheberrecht findet auch die Fair Use-Doktrin ihr Vorbild und ihre Wurzeln im angelsächsischen Recht. In einigen englischen Gerichtsentscheidungen aus dem 18. und frühen 19. Jahrhundert findet sich bereits die Ablehnung von Urheberrechtsverletzungen mit der Begründung, die vorgenommene Nutzung sei im konkreten Fall als „fair“ anzusehen. ${ }^{318}$ In diesen frühen Entscheidungen wurde die Nutzung stets dann als „fair“ beurteilt, wenn lediglich einzelne Teile eines Originalwerkes übernommen wurden und nur als Ausgangspunkt für ein neues, eigenständiges Werk dienten und somit dem wissenschaftlichen Fortschritt und letztendlich der Allgemeinheit zugute kamen. ${ }^{319}$

\section{Entwicklung der Fair Use-Doktrin als richterrechtliche Generalklausel}

Einige dieser Überlegungen übernahm als erstes US-amerikanisches Gericht der Circuit Court of Massachusetts in seiner Entscheidung Gray v. Russell aus dem Jahre 1939, 320 ohne jedoch von einer „fairen“ Nutzung zu sprechen. ${ }^{321}$ Eine ausführliche Auseinandersetzung mit der englischen Rechtsprechung zum ,fair abridgement" fand jedoch erstmals durch Justice Story als Richter desselben Gerichts zwei Jahre später in der Entschei-

318 Vgl. etwa Gyles v. Wilcox, 26 Eng. Rep. 489, 490 (Ch. 1740) [,fair abridgement"]; Campbell v. Scott, 59 Eng. Rep. 784, 787 (Ch. 1802) [,fair criticism"]; Wilkins v. Aikin, 34 Eng. Rep. 163, 164 (Ch. 1810) [,fair quotation“]. Ausführlich zum englischen Case Law von 1740-1839 als Ursprung der Fair Use-Doktrin siehe Patry, Fair Use (1985), S. 6 ff.

319 Vgl. Patry, Fair Use (2009), § 1:19.

32010 F. Cas. 1035 (C.C.D. Mass. 1839).

321 Justice Story setzte sich jedoch bereits in dieser Entscheidung mit der Frage auseinander, ob ein „,bona fide abridgement" vorliege. Ein solches komme nicht in Betracht, wenn das neue Werk das Originalwerk verdränge oder beeinträchtige (,[...] whether it will, in the present form, prejudice or supersede the original work [...]“"). Dabei sei nicht in erster Linie der Umfang der Werkübernahme entscheidend, sondern der (qualitative) Wert des ausgewählten Materials („In many cases, the question may naturally turn upon the point, not so much of the quantity, as of the value of the selected materials. [...] The quintessence of a work may be piratically extracted, so as to leave a mere caput mortuum, by a selection of all the most important passages in a comparatively moderate space. “); 10 F.Cas. 1035, 1038-1039 (C.C.D. Mass. 1839). 
dung Folsom v. Marsh ${ }^{322}$ statt, die daher zumeist als Grundstein der Entwicklung der Fair Use-Doktrin im US-amerikanischen Copyright gesehen und zitiert wird. ${ }^{323}$ Im Rahmen einer Entscheidung zur Frage, ob die Übernahme urheberrechtlich geschützter Briefe George Washingtons aus der umfassenden Washington-Biographie des Klägers in die vom Beklagten verfasste Kurzbiographie die Urheberrechte des Klägers verletze, beschäftigte Justice Story sich ausführlich mit der in den englischen Urteilen behandelten Frage, wann ,fair abridgement", ,fair criticism" oder eine ,fair quotation" angenommen werden könne. ${ }^{324}$ Besondere Bedeutung in der weiteren Entwicklung der Fair Use-Doktrin im US-amerikanischen Copyright erlangte dabei die Passage dieses Urteils, in der Justice Story Kriterien aufstellte, anhand derer das Vorliegen einer fairen Benutzung festzustellen sei:

"In short, we must often, in deciding questions of this sort, look to the nature and objects of the selections made, the quantity and value of the materials used, and the degree in which the use may prejudice the sale, or diminish the profits, or supersede the objects, of the original work." 325

In den folgenden Jahrzehnten - bis zur Kodifizierung der Fair Use-Doktrin durch den Copyright Act of 1976 - ergingen zahlreiche Entscheidungen, die sich unter Bezugnahme auf Folsom v. Marsh und die dort aufgestellten (Prüfungs-)Kriterien - angepasst auf die Umstände des Einzelfalls - mit der Frage der Einschränkung der Ausschließlichkeitsrechte des Urheberrechtsinhabers aufgrund des Vorliegens eines Fair Use auseinandersetzten. ${ }^{326}$

3229 F.Cas. 342 (C.C.D. Mass. 1841).

323 Die heutige Bezeichnung „Fair Use“ verwendet das Urteil Folsom v. Marsh allerdings nicht. Diese Formulierung findet sich erstmals in der Entscheidung Lawrence v. Dana, 15 F.Cas. 26, 58 (C.C.D. Mass. 1869) aus dem Jahre 1869; vgl. Förster, Fair Use, S. 18; Patry, Fair Use (1985), S. 34 f.

324 Im Ergebnis wurde in Folsom v. Marsh eine Urheberrechtsverletzung festgestellt und keine Rechtfertigung als „fair" angenommen.

325 Folsom v. Marsh, 9 F.Cas. 342, 348 (C.C.D. Mass. 1841) [Hervorhebung durch den Verfasser].

326 Eine detaillierte Übersicht über diese Urteile findet sich bei Patry, Fair Use (1985), S. 25 ff. sowie Yankwich, 22 U. Chi. L. Rev. 203 (1954). 


\section{Aufnahme der Fair Use-Doktrin in den Copyright Act of 1976}

Im Rahmen eines langwierigen und umfangreichen Gesetzgebungsverfahrens, ${ }^{327}$ dessen Ergebnis die Verabschiedung des am 1. Januar 1978 in Kraft getretenen Copyright Act of 1976 war, beschloss der Kongress, die bisher ausschließlich als Richterrecht existierende Fair Use-Doktrin in das geschriebene Recht zu integrieren. Dabei entschied sich der Gesetzgeber, lediglich die durch die Rechtsprechung in etlichen Entscheidungen anhand der seit Folsom v. Marsh etablierten Kriterien entwickelten Prüfungsmaßstäbe in das Gesetz aufzunehmen. Der Kongress wollte ausdrücklich nicht die richterrechtlich entwickelten Maßstäbe verändern, verengen oder auch nur endgültig festschreiben, sondern vielmehr eine kontinuierliche Weiterentwicklung durch die Rechtsprechung und Anpassung an zukünftige technologische Entwicklungen gewährleisten und entschied sich daher für die gesetzliche Anerkennung des bisherigen Richterrechts durch die Schaffung einer generalklauselartigen Regelung. ${ }^{328}$ Es handelt sich daher bei der Regelung des 17 U.S.C. $§ 107$ mit ihrem offenen Wortlaut ${ }^{329}$ nicht - wie vielfach irreführend oder zumindest unglücklich formuliert ${ }^{330}$ - um eine „Kodifikation“ der Fair Use-Doktrin durch den Copyright Act of 1976, sondern richtigerweise vielmehr um eine gesetzgeberische Bestätigung des existierenden Richterrechts mit einem durch die offene Fassung in die Zukunft gerichteten Regelungsauftrag der Gerichte. ${ }^{331}$

327 Vgl. dazu Förster, Fair Use, S. 18 m.w.N.

328 Vgl. H.R. Rep. No. 94-1476, S. 66 (1976) ["Congress does not intend to restate the present judicial doctrine of fair use, not to change, narrow, or enlarge it in any way."]. Kritisch Seltzer, Exemptions and Fair Use, S. 19.

329 Vgl. die Wortwahl ,shall include“ vor der Nennung der Fair Use-Kriterien in 17 U.S.C. $\S 107$.

330 So etwa Harper \& Row v. Nation Enterprises, 471 U.S. 539, 547 (1985).

331 Vgl. Förster, Fair Use, S. 18 f.; Gordon, 82 Colum. L. Rev. 1600, 1603 (1982); Merges/Menell/Lemley, Intellectual Property, S. 523; Patry, On Copyright, $\S 10: 8$; ders., Fair Use (2009), § 2:1; Patry/Perlmutter, 11 Cardozo Arts \& Ent. L.J. 667, 674 (1993); Patry/Posner, 92 Cal. L. Rev. 1639, 1644 (2004); Rieder, Copyrightverletzungen, S. 197. 
a) Die Regelung des 17 U.S.C. $§ 107$

Die durch den Copyright Act of 1976 etablierte Regelung der Fair UseDoktrin in 17 U.S.C. $§ 107$ wurde bis heute zwei Mal ergänzt ${ }^{332}$ und hat in der derzeitigen Fassung folgenden Wortlaut:

17 U.S.C. § 107. Limitations on exclusive rights: Fair Use

Notwithstanding the provisions of sections 106 and 106A, the fair use of a copyrighted work, including such use by reproduction in copies or phonorecords or by any other means specified by that section, for purposes such as criticism, comment, news reporting, teaching (including multiple copies for classroom use), scholarship, or research, is not an infringement of copyright. In determining whether the use made of a work in any particular case is a fair use the factors to be considered shall include-

(1) the purpose and character of the use, including whether such use is of a commercial nature or is for nonprofit educational purposes;

(2) the nature of the copyrighted work;

(3) the amount and substantiality of the portion used in relation to the copyrighted work as a whole; and

(4) the effect of the use upon the potential market for or value of the copyrighted work.

The fact that a work is unpublished shall not itself bar a finding of fair use if such finding is made upon consideration of all the above factors.

Obwohl die Gerichte sich vielfach mit der Frage des Fair Use beschäftigt haben, ist es nicht gelungen, das Konzept des Fair Use umfassend zu definieren, was ihm den zweifelhaften und viel zitierten Ruf als ,the most

332 Durch den Visual Artists Rights Act of 1990 wurde im ersten Satz der Regelung „§ 106A“ eingefügt. Durch den Act of October 24, 1992, 102 Pub. L. No. 102-492, 106 Stat. 3145 (1992) wurde schließlich der letzte Halbsatz zu unveröffentlichten Werken eingefügt; zur diesbezüglichen Diskussion siehe Förster, Fair Use, S. 59 ff.; Hoebbel, Schutz von Sammelwerken, S. 342 ff. 
troublesome [issue] in the whole law of copyright" eingebracht hat. ${ }^{333}$ Auch die bewusst vage Formulierung der gesetzlichen Regelung ${ }^{334}$ beseitigt diese Schwierigkeit nicht, so dass bisher weder Rechtsprechung, noch Literatur die Fair Use-Doktrin anders als durch die in 17 U.S.C. § 107 genannten Faktoren umfassend definieren konnten. ${ }^{335}$ Es findet sich in der US-amerikanischen Rechtsprechung und Literatur jedoch eine Vielzahl von Versuchen, die Doktrin zumindest treffend zu umschreiben. Der Kongress und U.S. Supreme Court haben Fair Use dabei zumeist sehr weit als „equitable rule of reason" bezeichnet, mit deren Hilfe die Richter einen fairen Ausgleich in jedem Einzelfall erreichen und so das Recht schrittweise weiterentwickeln sollen. ${ }^{336}$ In der Literatur findet sich beispielsweise die vielzitierte Formulierung, Fair Use sei ,a privilege in others than the owner of a copyright to use the copyrighted material in a reasonable manner without his consent, notwithstanding the monopoly granted to the owner by the copyright ". ${ }^{337}$ Einigkeit besteht jedoch, dass auf Grundlage der Tatsachen eines jeden Falles eine Einzelfallbetrachtung stattfinden muss, die sich grundsätzlich - jedoch nicht zwingend - an den in 17 U.S.C. $§ 107$ genannten Faktoren orientiert.

\section{aa) Die Präambel}

Im ersten Satz der Regelung, der sogenannten Preamble, werden ausdrücklich sechs Nutzungszwecke aufgezählt. Es handelt sich dabei nach inzwischen herrschender Auffassung nicht etwa um eine abschließende Liste von Nutzungen, sondern lediglich um unverbindliche Beispielsfälle,

333 So erstmals Dellar v. Samuel Goldwyn, Inc., 104 F.2d 661, 662 (2d Cir. 1939); zitiert unter anderem in Time Inc. v. Bernard Geis Associates, 293 F.Supp. 130 (D.C.N.Y. 1968); Sony Corp. of America v. Universal City Studios, Inc., 464 U.S. 417, 475 (1984); aus der Literatur vgl. Dannay, 55 J. Copyright Soc'y U.S.A. 449, 451 (2008); Gamble, 9 Tul. J. Tech. \& Intell. Prop. 365, 371 (2007); Goldstein, 31 Colum. J.L. \& Arts 433 (2008); Gordon, 82 Colum. L. Rev. 1600, 1602 f. (1982); Liu, 31 Colum. J.L. \& Arts 571 (2008).

334 Siehe dazu kritisch Seltzer, Exemptions and Fair Use, S. $19 \mathrm{ff}$.

335 Vgl. H.R. Rep. No. 94-1476, S. 65 (1976); Patry/Posner, 92 Cal. L. Rev. 1639, 1645 (2004).

336 Vgl. H.R. Rep. No. 94-1476, S. 65 (1976); Sony Corp. of America v. Universal City Studios, Inc., 464 U.S. 417, 448 (1984).

337 Ball, Copyright, S. 260. 
in denen eine faire Benutzung typischerweise aufgrund eines besonderen sozialen, politischen oder kulturellen Nutzens in Betracht kommt. ${ }^{338}$ Aufgrund des nur beispielhaften Charakters der Aufzählung kommt somit eine Anerkennung als Fair Use auch für Nutzungszwecke in Betracht, die nicht ausdrücklich in der Präambel genannt sind. So wurde etwa vom U.S. Supreme Court in der Entscheidung Sony v. Universal ${ }^{339}$ auch die private Vervielfältigung als Fair Use anerkannt; eine Nutzungsform, die in der Aufzählung der Präambel nicht genannt ist. Gleichzeitig bedeutet die Tatsache, dass eine Nutzung einem der explizit aufgelisteten Zwecke dient, auch nicht, dass es sich automatisch um eine faire Benutzung handelt. ${ }^{340}$ Etwa in der Entscheidung Harper \& Row v. Nation Enterprises ${ }^{341}$ versagte der U.S. Supreme Court die Berufung auf den Fair Use-Einwand und stellte eine Urheberrechtsverletzung fest, obwohl es sich zweifelsohne um einen Fall des in der Präambel erwähnten „,news reporting“ handelte.

Auch wenn die Aufzählung der Präambel nur beispielhaft ist und selbst für die dort genannten Fälle eine Ablehnung eines Fair Use möglich ist, wäre es dennoch falsch, der Präambel jegliche Bedeutung bei der Fair Use-Prüfung abzusprechen. Insbesondere im Rahmen des ersten Fair UseFaktors („Purpose and Character of the Use“) kommt den in der Präambel genannten Nutzungszwecken durchaus eine Bedeutung zu: Dient die fragliche Nutzung einem der genannten Zwecke, so kann dies im Rahmen des ersten Faktors als Argument zugunsten des Nutzers gelten, da die aufgelisteten Zwecke in der Regel wünschenswert sind. Selbstverständlich sind jedoch auch die weiteren Faktoren noch zu beachten, so dass insgesamt eine faire Benutzung weiterhin abgelehnt werden kann. ${ }^{342}$

338 Vgl. statt vieler Campbell v. Acuff-Rose, 510 U.S. 569, 577 (1994) mit dem auf die Definition von ,such as" in 17 U.S.C. $§ 101$ abgeleiteten Hinweis, die in der Präambel genannten Nutzungshandlungen seien ,illustrative and not limitative“; Goldstein, Copyright, §10.2.1; Patry, On Copyright, § 10:12; ders., Fair Use (2009), § 2:7; Schechter/Thomas, Intellectual Property, S. 217, jeweils m.w.N. Kritisch zur Aufnahme der Nutzungszwecke teaching, scholarship und research in die Präambel Seltzer, Exemptions and Fair Use, S. 19, 21 ff.

339464 U.S. 417 (1984). Siehe dazu unten 2. Kapitel, C.I.2.b)aa).

340 Vgl. Nimmer/Nimmer, On Copyright, § 13.05 [A](1)(a); Patry, Fair Use (2009), $\S 2: 7$.

341471 U.S. 539 (1985). Siehe dazu unten 2. Kapitel, C.I.2.b)bb).

342 Vgl. Nimmer/Nimmer, On Copyright, § 13.05 [A](1)(a); Patry, Fair Use (2009), $\S 2: 7$. 
bb) Die vier Fair Use-Faktoren

Entscheidende Bedeutung bei der Fair Use-Prüfung kommt den vier in 17 U.S.C. § 107 genannten Fair Use-Faktoren zu. Obwohl grundsätzlich die im Gesetz aufgelisteten vier Faktoren nicht abschließend sind, ${ }^{343}$ so dass auch weitere Faktoren bei der Fair Use-Prüfung berücksichtigt werden können, ${ }^{344}$ konzentriert sich die gerichtliche Prüfung in der Regel allein auf die vier explizit genannten Faktoren, die im Folgenden lediglich kurz skizziert werden sollen. ${ }^{345}$ Dabei wird von den Gerichten zumeist im Rahmen einer einzelfallbezogenen Prüfung zunächst jeder der vier Faktoren einzeln untersucht, bevor abschließend eine Gesamtabwägung und -beurteilung erfolgt. ${ }^{346}$ Eine Hierarchie unter den vier Faktoren gibt es dabei grundsätzlich nicht, so dass keinem der Faktoren durchgehend eine letztentscheidende Rolle zukommt. ${ }^{347}$ Allerdings hat der Supreme Court in der Entscheidung Harper \& Row v. Nation Enterprises festgestellt, der vierte Faktor sei „undoubtedly the single most important element of fair $u s e^{\text {" }}, 348$ was vielfach - gerade von den Instanzgerichten - wiederholt wurde. ${ }^{349}$

343 Vgl. den Wortlaut ,[...] the factors to be considered shall include [...]" [Hervorhebung durch den Verfasser].

344 Siehe etwa Time Inc. v. Bernard Geis Associates, 293 F.Supp. 130 (D.C.N.Y. 1968) (Besonderes „Public Interest“ als zusätzlicher Faktor); Leval, 103 Harv. L. Rev. 1105, 1129 f. (1990) (Berücksichtigung der „Privacy“ als zusätzlicher Faktor) sowie Campbell v. Acuff-Rose, 510 U.S. 569, 585 (1994) und zuletzt Field v. Google, 412 F.Supp.2d 1106, 1122 f. (D. Nev. 2006) zur Berücksichtigung des Handelns in „Good/Bad Faith“ als zusätzlichen Faktor; siehe dazu auch unten 5. Kapitel, B.II.1.f).

345 Zum Inhalt der einzelnen Faktoren siehe ausführlich unten 5. Kapitel, B. bei der Darstellung der Vereinbarkeit von Googles Buchsuche und der Anzeige von Thumbnails im Rahmen der Bildersuche mit US-amerikanischem Recht. Ausführlich zu den einzelnen Fair Use-Faktoren Patry, Fair Use (2009), Chapter 3-6. Zusammenfassend Förster, Fair Use, S. 43 ff.

346 Vgl. Campbell v. Acuff-Rose, 510 U.S. 569, 578 (1994): "Nor may the four statutory factors be treated in isolation, one from another. All are to be explored, and the results weighed together, in light of the purposes of copyright.".

347 Vgl. Patry/Posner, 92 Cal. L. Rev. 1639, 1645 (2004) m.w.N.

348 Harper \& Row v. Nation Enterprises, 471 U.S. 539, 566 (1985). Siehe dazu unten 2. Kapitel, C.I.2.b)bb).

349 Vgl. statt aller Campbell v. Acuff-Rose, 510 U.S. 569, 574 (1994); Dr. Seuss Enterprises, L.P. v. Penguin Books USA, Inc., 924 F.Supp. 1559, 1568 (S.D. Cal. 
(1) Erster Faktor: "The Purpose and Character of the Use"

Der erste in 17 U.S.C. $\S 107$ genannte Faktor der Fair Use-Analyse betrifft den Zweck und Charakter der Nutzung einschließlich der Frage, ob ihr Gebrauch kommerzieller Natur ist oder gemeinnützigen Erziehungsbeziehungsweise Unterrichtszwecken dient. Während ursprünglich im Rahmen der Prüfung des ersten Fair Use-Faktors zumeist entscheidend darauf abgestellt wurde, ob es sich um eine Nutzung zu kommerziellen oder zu gemeinnützigen Zwecken handelte, bildet inzwischen regelmäßig die Frage, ob es sich bei der untersuchten Handlung um einen sogenannten transformative use handelt, einen weiteren deutlichen Schwerpunkt der Prüfung.

(2) Zweiter Faktor: "The Nature of the Copyrighted Work"

Nach 17 U.S.C. $§ 107$ (2) ist im Rahmen des zweiten gesetzlichen Faktors bei der Fair Use-Prüfung die Natur des urheberrechtlich geschützten Werkes zu beachten. Dabei wird zum einen nach dem Grad der Kreativität eines Werkes differenziert und geprüft, ob das benutzte Werk eher kreativer oder eher faktischer Natur ist. Zum anderen kommt der Frage entscheidende Bedeutung zu, ob das Werk zum Zeitpunkt der Nutzung bereits veröffentlicht oder noch unveröffentlicht war. Zum Teil wird zusätzlich berücksichtigt, ob es sich um ein bereits vergriffenes Werk handelt.

(3) Dritter Faktor: "The Amount and Substantiality of the Portion Used"

Als dritter Faktor der Fair Use-Analyse ist nach 17 U.S.C. § 107 (3) der Umfang und die Bedeutung des verwendeten Werkteils im Verhältnis zum urheberrechtlich geschützten Werk als Ganzem zu berücksichtigen. Der Wortlaut der Norm verdeutlicht, dass also sowohl die Quantität (,Amount“) als auch die Qualität (,Substantiality“) der Nutzung bei der Bewertung zu beachten sind.

1996); Castle Rock Entertainment v. Carol Pub. Group, Inc., 955 F.Supp. 260, 270 (S.D.N.Y. 1997); Field v. Google, 412 F.Supp.2d 1106, 1118 (D. Nev. 2006) und zuletzt Bouchat v. Baltimore Ravens Ltd. Partnership, 587 F.Supp.2d 686, 696 (D. Md. 2008). 
(4) Vierter Faktor: "The Effect of the Use upon the Potential Market for or Value of the Copyrighted Work"

Der vierte Fair Use-Faktor schließlich betrifft den Effekt der Benutzung eines Werkes auf den Markt für dieses Werk. Zu beachten sind dabei neben den vom Urheberrechtsinhaber tatsächlich bedienten Märkten auch bisher noch nicht bediente, potentielle Märkte. Diesem Faktor wird - wie gezeigt - oftmals entscheidende Bedeutung beigemessen, so dass die Rechtsprechung das Vorliegen einer fairen Benutzung bei einer tatsächlichen und wahrscheinlichen Marktschädigung in der Regel ablehnt.

\section{b) Leitentscheidungen des U.S. Supreme Court zur Fair Use-Doktrin}

Aufgrund der starken Einzelfallbezogenheit der Fair Use-Analyse und des vagen Wortlautes des 17 U.S.C. $§ 107$ lassen sich die vier zuvor kurz skizzierten Fair Use-Faktoren ohne einen Blick auf das Case Law nicht verstehen beziehungsweise nur schwerlich „mit Leben füllen“. Seit der gesetzlichen Fixierung der Fair Use-Doktrin im Jahre 1976 hat der U.S. Supreme Court diese insbesondere in drei großen Entscheidungen interpretiert und weiterentwickelt und so aufgrund der Präjudizienwirkung seiner Entscheidungen die spätere Anwendung der Doktrin durch die Instanzgerichte ganz wesentlich geprägt. Diese grundlegenden Entscheidungen, auf die sich auch alle neueren Urteile zur Frage des Fair Use im Zusammenhang mit neuartigen Nutzungsformen urheberrechtlich geschützter Werke - etwa zur Verwendung von Thumbnails im Rahmen der Bildersuche ${ }^{350}$ beziehen, sollen daher im Folgenden in ihren wesentlichen Zügen kurz nachgezeichnet werden.

aa) Sony Corporation of America v. Universal City Studios, Inc.

In dem Verfahren Sony v. Universal ${ }^{351}$ musste sich der U.S. Supreme Court mit der Frage der Zulässigkeit des sogenannten ,time-shifting“, der Aufzeichnung und einmaligen zeitversetzten Wiedergabe urheberrechtlich

350 Siehe dazu unten 5. Kapitel, B.I.

351 Sony Corporation of America v. Universal City Studios, Inc., 464 U.S. 417 (1984). 
geschützter Fernsehsendungen mit Hilfe des Betamax-Heimvideorecorders $^{352}$ auseinandersetzen. Universal als Inhaber der Urheberrechte an vielen Fernsehsendungen hatte Sony als Hersteller und Verkäufer des Betamax-Videorecorders wegen (mittelbarer) Urheberrechtsverletzungen durch die Nutzung des Videorecorders verklagt. Der District Court for the Central District of California hatte in erster Instanz eine Urheberrechtsverletzung verneint und die Klage abgewiesen, da das Gericht die nicht-kommerzielle Nutzung des Heimvideorecorders als Fair Use einstufte. ${ }^{353}$ Der Court of Appeals for the Ninth Circuit hob diese Entscheidung auf. ${ }^{354}$ Entgegen der Vorinstanz vertrat das Gericht die Auffassung, die private, nicht-kommerzielle Aufzeichnung urheberrechtlich geschützter Fernsehformate mit Hilfe des Betamax-Heimvideorecorders sei nicht als Fair Use anzusehen und stelle daher eine Urheberrechtsverletzung dar, für die Sony als Hersteller wegen mittelbarer Urheberrechtsverletzung haftbar sei. Der U.S. Supreme Court schließlich widersprach dem Court of Appeals und lehnte - in einer knappen 5:4-Entscheidung - eine Haftung von Sony ab, da das Gericht die Nutzung des Heimvideorecorders ebenso wie das erstinstanzliche Gericht als Fair Use einstufte.

Der Supreme Court setzte sich zunächst mit den Voraussetzungen des „contributory infringement", also der mittelbaren Urheberrechtsverletzung, auseinander. Nur eine solche kam in Bezug auf Sony in Betracht, da die (vermeintlichen) Urheberrechtsverletzungen von den Eigentümern der Videorecorder selbst begangen wurden. Eine Haftung für „contributory infringement" setzt einen gewissen Tatbeitrag und ein Wissenselement voraus, wobei grundsätzlich jede Form der Teilnahme ausreicht ${ }^{355}$ und auch

352 Das Betamax-Heimvideosystem wurde von Sony in den 1970er Jahren entwickelt und erschien im Jahre 1975 in den USA und Japan, im Jahre 1978 schließlich in der Bundesrepublik Deutschland auf dem Markt, wo es sich jedoch letztlich nicht gegen das Video Home System (VHS) von JVC durchsetzen konnte.

353 Siehe Universal City Studios, Inc. v. Sony Corp. of America, 480 F.Supp. 429 (C.D. Cal. 1979).

354 Siehe Universal City Studios, Inc. v. Sony Corp. of America, 659 F.2d 963 (9th Cir. 1981).

355 Vgl. Gershwin Pub. Corp. v. Columbia Artists Management, Inc., 443 F.2d 1159, 1162 (2d Cir. 1971): ,[O]ne who, with knowledge of the infringing activity, induces, causes or materially contributes to the infringing conduct of another, may be held liable as a 'contributory' infringer." [Hervorhebungen durch den Verfasser]. 
ein „Wissenmüssen“ (,constructive knowledge“) genügen kann. ${ }^{356357}$ Der Supreme Court stellte daher fest, eine mittelbare Haftung von Sony müsse ausscheiden, wenn die Nutzer der Betamax-Videorecorder diese tatsächlich ganz überwiegend zu nicht urheberrechtsverletzenden Zwecken einsetzten oder aber wenn - in Anlehnung an die patentrechtliche staple article of commerce-Doktrin ${ }^{358}$ - das Produkt zumindest in substantiellem Umfang zu nicht urheberrechtsverletzenden Zwecken eingesetzt werden könne (,capable of substantial noninfringing uses“). ${ }^{359}$ Entscheidend für die Frage der mittelbaren Haftung waren somit die urheberrechtliche Bewertung des ,time-shifting“ durch die Nutzer und die Ermittlung des Potentials des Videorecorders für legale Nutzungen.

Diesbezüglich stellte der Supreme Court zunächst fest, viele Urheberrechtsinhaber seien bereit, die Aufzeichnung zum einmaligen späteren Abruf - das time-shifting - zuzulassen, da sie dies als Möglichkeit sähen, die Zuschauerzahlen für ihre Programme zu erhöhen. Die von den privaten Nutzern mit Hilfe des Heimvideorecorders erstellten Aufzeichnungen dieser Programme stellten daher bereits aufgrund des Einverständnisses der Urheberrechtsinhaber keine Urheberrechtsverletzung dar. ${ }^{360}$ Zudem bestehe an einem Teil der aufgezeichneten Programme schon kein Urheberrechtsschutz, so dass auch diesbezüglich eine Urheberrechtsverletzung durch das time-shifting ausscheiden müsse. Der Supreme Court kam daher zu dem Ergebnis, die Betamax-Heimvideorecorder hätten durchaus das Potential für eine erhebliche nicht-kommerzielle und nicht-verletzende Nutzung in Form der Aufzeichnung dieser Programme. Diese Nutzungen

356 Vgl. A\&M Records, Inc. v. Napster, Inc., 239 F.3d 1004, 1020 (9th Cir. 2001): „Contributory liability requires that the infringer 'know or have reason to know' of direct infringement".

357 Ausführlich zu den Voraussetzungen des „contributory infringement“ Nimmer/ Nimmer, On Copyright, § 12.04 [A][3]; Patry, On Copyright, § 21:42-61, jeweils m.w.N. Aus der deutschen Literatur siehe Spindler/Leistner, GRUR Int. 2005, 773 (775 ff.).

358 Diese ist für das Patentrecht inzwischen in 35 U.S.C. § 271(c) gesetzlich geregelt. $\mathrm{Zu}$ Entwicklung und Inhalt der staple article of commerce-Doktrin siehe Chisum, On Patents, § 17.03, § 19.04; Oddi, 44 U. Pitt. L. Rev. 73, 75 ff. (1982), jeweils m.w.N.

359 Sony v. Universal, 464 U.S. 417, 441 f. (1984). Zur Übertragung der staple article of commerce-Doktrin auf das Urheberrecht in Sony v. Universal siehe DeSimone, 53 UMKC L. Rev. 126, 132 ff. (1984); McCambridge, 18 J. Marshall L. Rev. 703 (1985) jeweils mit zahlreichen weiteren Nachweisen.

360 Siehe Sony v. Universal, 464 U.S. 417, 443 ff. (1984). 
würden durch einen Unterlassungsanspruch gegen den Hersteller oder Verkäufer des Aufzeichnungsgerätes zu Unrecht unterbunden. ${ }^{361}$ Eine Haftung für ,contributory infringement" müsse also hier schon mangels einer rechtswidrigen Haupttat scheitern.

Auch hinsichtlich solcher urheberrechtlich geschützter Programme, bei denen keine Einwilligung zur Aufzeichnung vorlag, verneinte der Supreme Court jedoch im Ergebnis eine Urheberrechtsverletzung, da er dieses „unauthorized time-shifting“ als Fair Use einstufte. Bevor sich das Gericht in seiner Prüfung den einzelnen Fair Use-Faktoren widmete, hob es hervor, bei der Fair Use-Doktrin handele es sich um eine „equitable rule of reason", die vom Gesetzgeber durch die Aufnahme in den Copyright Act in Gesetzesform gegossen worden sei. Da die im Gesetz genannten Faktoren jedoch nicht abschließend seien, sei auch der schon zuvor anerkannte weite Beurteilungsspielraum der Gerichte bei der Fair Use-Prüfung nicht eingeschränkt worden. ${ }^{362}$ In der anschließenden Prüfung anhand der in 17 U.S.C. $§ 107$ genannten Faktoren kam das Gericht zu folgendem Ergebnis: Da die Betamax-Nutzer in der Regel die Aufzeichnungen zu privaten und nicht-kommerziellen Zwecken erstellten, wertete das Gericht den ersten Fair Use-Faktor (,Purpose and character of the use“) als starkes Indiz zugunsten einer Zulässigkeit der Nutzungshandlung. ${ }^{363}$ Dem zweiten Faktor (,Nature of the copyrighted work") schenkte das Gericht in seiner Begründung überraschenderweise gar keine Beachtung, obwohl es sich bei den durch die Nutzer aufgenommenen Fernsehformaten in den meisten Fällen um kreative, originelle Werke gehandelt haben dürfte, was grundsätzlich eher gegen die Annahme eines Fair Use sprechen würde. ${ }^{364}$ Auch den dritten Faktor (,Amount and substantiality of the portion used") wertete das Gericht schließlich mit knapper Begründung zugunsten der Nutzer. Es sei im konkreten Fall unerheblich, dass die urheberrechtlich geschützten Werke in der Regel vollständig vervielfältigt würden, da das time-shifting es dem Nutzer lediglich ermögliche, eine Fernsehsendung zu einem späteren Zeitpunkt zu sehen, die er nach dem Willen des Urheberrechtsinhabers zu einem anderen Zeitpunkt ebenfalls

361 Siehe Sony v. Universal, 464 U.S. 417, 446 f. (1984).

362 Siehe Sony v. Universal, 464 U.S. 417, 448 f. (1984).

363 Siehe Sony v. Universal, 464 U.S. 417, 448 f. (1984).

364 Vgl. dazu die kritischen Äußerungen der von Justice Blackmun abgefassten und von den Richtern Marshall, Powell und Rehnquist unterstützten dissenting opinion, Sony v. Universal, 464 U.S. 417, 496 f. (1984) (Blackmun, J., dissenting). 
kostenfrei hätte sehen können. ${ }^{365}$ Auch der vierte Fair Use-Faktor (,Effect of the use upon the potential market") sprach nach Ansicht des Gerichts schließlich für die Annahme eines Fair Use, da die insoweit beweispflichtige Klägerin nicht dargelegt habe, dass das private time-shifting zu nachweisbaren wirtschaftlichen Einbußen bei den Urheberrechtsinhabern geführt habe oder solche bei dessen weiterer Verbreitung in Zukunft mit einer gewissen Wahrscheinlichkeit zu erwarten seien. ${ }^{366}$

Da nach Auffassung des Supreme Court folglich weder das autorisierte noch das nicht-autorisierte time-shifting eine Urheberrechtsverletzung darstellte und der Betamax-Videorecorder somit eine Vielzahl nicht-urheberrechtsverletzender Nutzungen ermöglichte, kam das Gericht zu dem Ergebnis, dass eine urheberrechtliche Sekundärhaftung (,contributory infringement") von Sony als Hersteller und Verkäufer dieses Gerätes ausscheide. ${ }^{367}$

bb) Harper \& Row, Publishers, Inc. v. Nation Enterprises

Im folgenden Jahr beschäftigte sich der U.S. Supreme Court in der Entscheidung Harper \& Row, Publishers, Inc. v. Nation Enterprises ${ }^{368}$ erneut und besonders umfassend mit dem Fair Use-Einwand. Die Entscheidung zog großes Medieninteresse auf sich, da sie die Memoiren von Gerald $R$. Ford, dem 38. Präsidenten der USA, zum Gegenstand hatte. ${ }^{369}$ Ford hatte sich im Februar 1977, unmittelbar nach seinem Ausscheiden als Präsident, mit dem Verlag Harper \& Row über die Veröffentlichung seiner (bis da-

365 Siehe Sony v. Universal, 464 U.S. 417, 449 f. (1984). Diese Feststellung kritisiert die Minderheitsmeinung ebenfalls scharf, da durch die vollständige Vervielfältigung der Originalwerke ein Substitut für dieses hergestellt werde und nicht etwa eine produktive Nutzung (,productive use“) erfolge, durch die, wie es das Ziel der Fair Use-Doktrin sei, die eigene kreative Tätigkeit der Nutzer ermöglicht oder gefördert würde; siehe Sony v. Universal, 464 U.S. 417, 497 (1984) (Blackmun, J., dissenting).

366 Siehe Sony v. Universal, 464 U.S. 417, 452 ff. (1984).

367 Siehe Sony v. Universal, 464 U.S. 417, 456 (1984).

368471 U.S. 539 (1985).

369 Ausführlich (und größtenteils kritisch) zur Entscheidung des Supreme Court $D a$ niels, 19 J. Marshall L. Rev. 501 (1986); Feingold, 72 Cornell L. Rev. 218 (1986); Hamel, 19 Colum. J.L. \& Soc. Probs. 253 (1985); Perry, 65 Neb. L. Rev. 631 (1986); Shipley, 1986 B.Y.U. L. Rev. 983; Williams, 24 Hous. L. Rev. 363 (1987); aus der deutschen Literatur Freys, ZUM 1985, 500. 
hin noch nicht geschriebenen) Memoiren geeinigt und dem Verlag umfassende Rechte an diesem Werk eingeräumt. Im Rahmen des Verlagsvertrags war Harper \& Row nicht nur zur Veröffentlichung der fertigen Memoiren berechtigt, sondern auch dazu, Dritten Lizenzen für sogenannte ,prepublication excerpts“ zu erteilen. Gegen Zahlung von 25.000 US-Dollar (zu zahlen hälftig vor und nach der Veröffentlichung) gestattete Harper \& Row dem Time Magazine exklusiv die Vorabveröffentlichung eines 7.500 Wörter umfassenden Textauszugs aus den nun unter dem Titel „A Time to Heal“" zur Veröffentlichung vorgesehenen Memoiren. Kurz vor der geplanten Veröffentlichung dieses Vorabauszugs im Time Magazine erhielt jedoch ein Herausgeber der politischen Zeitschrift The Nation, eines Konkurrenten des Time Magazine, aus ungeklärter Quelle das Manuskript der Ford-Memoiren. Wenig später wurde in The Nation ein 2.250 Wörter umfassender Artikel über die bald erscheinenden Memoiren veröffentlicht, der zu nicht unerheblichen Teilen (mindestens 300-400 Wörter) aus wörtlichen Zitaten aus der Präsidenten-Biographie bestand und gerade Teile der mit besonderer Spannung erwarteten Schilderungen Fords im Zusammenhang mit der Watergate-Affäre und der Begnadigung Richard Nixons enthielt. Nach dieser Veröffentlichung in The Nation, die dem Time-Artikel zuvorgekommen war, stoppte das Time Magazine die vorgesehene Vorabveröffentlichung, trat vom Vertrag mit Harper \& Row zurück und weigerte sich, die noch ausstehenden Lizenzgebühren in Höhe von 12.500 US-Dollar zu zahlen. Harper \& Row verklagte daraufhin die Herausgeber von The Nation auf Schadensersatz wegen einer Verletzung des „right of first publication" und bekam diesen in erster Instanz vom District Court for the Southern District of New York in Höhe der ,actual damages" (12.500 US-Dollar) zugesprochen. ${ }^{370}$ In zweiter Instanz wurde dieses Urteil jedoch vom Court of Appeals for the Second Circuit aufgehoben, da das Gericht die Auffassung vertrat, der Abdruck der Auszüge aus der Ford-Biographie in The Nation sei als Fair Use anzusehen. ${ }^{371}$ Dem trat schließlich der Supreme Court in einer 6:3-Entscheidung entgegen.

370 Harper \& Row, Publishers, Inc. v. Nation Enterprises, 557 F.Supp. 1067 (S.D.N.Y. 1983).

371 Harper \& Row, Publishers, Inc. v. Nation Enterprises, 723 F.2d 195 (2d Cir. 1983). Ausführlich und kritisch zur Entscheidung des Court of Appeals Morrill, 79 Nw. U. L. Rev. 587 (1984); Re, 58 St. John's L. Rev. 597 (1984). 
Ebenso wie in Sony v. Universal zeichnete der Supreme Court zunächst kurz die Geschichte der Fair Use-Doktrin nach und stellte klar, dass diese zwar durch den Copyright Act von 1976 kodifiziert worden sei, sich an deren Auslegung und Anwendung durch die Gerichte dadurch jedoch nichts geändert habe. ${ }^{372}$ Weiterhin sei daher zur Feststellung von Fair Use eine Einzelfallanalyse vorzunehmen, die anhand der vier im Gesetz genannten, nicht abschließenden Faktoren erfolgen könne. Diesen vier Faktoren wendet sich die von Justice O'Connor verfasste Begründung der Majorität sodann detailliert zu.

Hinsichtlich des ersten Faktors (,Purpose and character of the use“) stellte das Gericht fest, das Berufungsgericht habe die strittige Nutzung durch The Nation zutreffend als ,news reporting“ eingestuft. Dieses sei im Rahmen der beispielhaften Aufzählung der Präambel zwar ausdrücklich als generell einer Privilegierung zugänglicher Nutzungszweck genannt, was jedoch nicht per se die Zulässigkeit der Nutzung zur Folge haben müsse. ${ }^{373}$ Das Gericht wertete den ersten Faktor letztlich sogar zuungunsten von The Nation, da es sich um eine kommerzielle Nutzung handele und die Herausgeber sich durch die Veröffentlichung unmittelbar vor dem Erscheinen eines entsprechenden Artikels bei einem Konkurrenten gezielt zu dessen Lasten einen wirtschaftlichen Vorteil verschaffen wollten, ohne zudem für den Abdruck die erforderliche Lizenz vom Urheberrechtsinhaber zu erwerben. Auch die Tatsache, dass The Nation wissentlich ein auf nicht-autorisiertem Wege erhaltenes Manuskript zur Grundlage der eigenen Veröffentlichung gemacht hatte, sprach nach Ansicht des Gerichts gegen die Annahme eines Fair Use. ${ }^{374}$

Auch den zweiten Faktor (,Nature of the copyrighted work") wertete der Supreme Court im Ergebnis zuungunsten von The Nation. Zwar stellte das Gericht fest, dass ein Teil der aus dem Manuskript übernommenen Zitate als faktische Darstellungen zu qualifizieren seien, denen grundsätzlich ein geringerer Schutz gegen Übernahme zukomme als fiktiven Darstellungen. The Nation habe jedoch nicht nur diese Fakten, sondern auch solche beschreibende Darstellungen aus den Memoiren wiedergegeben, die Ausdruck der persönlichen Ansichten des Verfassers seien. ${ }^{375}$ Noch wesentli-

372 Siehe Harper \& Row, Publishers, Inc. v. Nation Enterprises, 471 U.S. 539, 549 ff., 560 (1985).

373 Siehe Harper \& Row v. Nation Enterprises, 471 U.S. 539, 561 (1985).

374 Siehe Harper \& Row v. Nation Enterprises, 471 U.S. 539, 562 f. (1985).

375 Siehe Harper \& Row v. Nation Enterprises, 471 U.S. 539, 563 f. (1985). 
cher gegen die Annahme eines Fair Use sprach jedoch nach Auffassung des Gerichts, dass es sich bei den Präsidenten-Memoiren um ein zum fraglichen Zeitpunkt noch unveröffentlichtes Werk handelte. Bei unveröffentlichten Werken sei der Anwendungsbereich der Fair Use-Doktrin bereits grundsätzlich enger. Im konkreten Fall habe zudem ein ganz besonderes Interesse an der Geheimhaltung des Werkes bis zu dessen Veröffentlichung bestanden, was sich in den speziellen vertraglichen Regelungen zur Verschwiegenheit widerspiegele. Insbesondere sei Teil des Vertrags mit dem Time Magazine zur Vorabveröffentlichung eine Verpflichtung zur Übersendung des geplanten Exzerpts an Harper \& Row vor dessen Veröffentlichung zum Zwecke einer Inhalts- und Qualitätskontrolle gewesen. Eine Nutzung, die sowohl diese Inhaltskontrolle umgehe als auch das Geheimhaltungsinteresse des Urheberrechtsinhabers eindeutig verletze, könne nur schwerlich als „fair“" eingestuft werden.376

Auch den Umfang und die Wesentlichkeit der verwendeten Werkteile im Verhältnis zum Gesamtwerk (dritter Faktor: „Amount and substantiality of the portion used") wertete der Supreme Court im Ergebnis als Indiz gegen die Annahme eines Fair Use. Absolut betrachtet handele es sich bei den zitierten Werkteilen zwar lediglich um einen unwesentlichen Teil des etwa 200.000 Wörter umfassenden Gesamtwerkes. Eine qualitative Betrachtung der zitierten Stellen ergebe jedoch, dass es sich in Wirklichkeit gerade um die für den Leser interessantesten und bewegendsten Teile des gesamten Manuskripts handele. Die in einem Umfang von 300-400 Wörtern wörtlich zitierten Passagen beträfen somit - wie schon der District Court in erster Instanz zutreffend festgestellt habe - ,essentially the heart of the book".377

Hinsichtlich des als vierten Faktor zu untersuchenden ,effect of the use upon the potential market for or the value of the copyrighted work" stellte das Gericht zunächst fest, es handele sich zweifelsohne um das wichtigste Element der Fair Use-Analyse (,undoubtedly the single most important element of fair use"). ${ }^{378}$ Im konkreten Fall hielt der Supreme Court das Ergebnis für besonders eindeutig, da nicht lediglich die Möglichkeit einer potentiellen Beeinträchtigung bestehe, sondern sogar tatsächlich ein konkreter Schaden in Höhe von 12.500 US-Dollar für entgangene Lizenzein-

376 Siehe Harper \& Row v. Nation Enterprises, 471 U.S. 539, 564 (1985).

377 Siehe Harper \& Row v. Nation Enterprises, 471 U.S. 539, 564 ff. (1985).

378 Harper \& Row v. Nation Enterprises, 471 U.S. 539, 566 (1985). 
nahmen eingetreten sei. ${ }^{379}$ Neben diesem tatsächlichen Schaden im konkreten Fall stellten die Richter jedoch auch auf die Konsequenzen ab, die die Anerkennung des Verhaltens der Beklagten als Fair Use für die zukünftige Lizenzierung sogenannter, ,first serial rights" hätte. Das Gericht stellte fest, eine Fair Use-Doktrin, die den ungenehmigten Abdruck unveröffentlichter Werke für zulässig erkläre, stelle eine erhebliche Gefahr für den Markt der Lizenzierung von Vorabveröffentlichungen insgesamt dar, und wertete daher auch den vierten Faktor entschieden zuungunsten der Beklagten. ${ }^{380}$

Im Ergebnis sprachen nach Auffassung der Majorität somit alle vier im Gesetz genannten Fair Use-Faktoren gegen die Zulässigkeit der strittigen Übernahme der Textteile aus dem unveröffentlichten Manuskript durch The Nation. ${ }^{381}$

cc) Luther R. Campbell v. Acuff-Rose Music, Inc.

Im Jahr 1994 erließ der U.S. Supreme Court seine dritte große Fair UseEntscheidung, Campbell v. Acuff-Rose. ${ }^{382}$ Gegenstand des Verfahrens war eine Klage des Musikverlags Acuff-Rose Music wegen eines Songs der Rapgruppe „2 Live Crew“. Diese hatte für ihren Song „Pretty Woman“unter Hinweis auf die Originalurheber - das einprägsame Bass-Riff und die erste Textzeile der bekannten Rockballade „Oh, Pretty Woman“ von Roy Orbison und William Dees aus dem Jahr 1964 verwendet, jedoch den restlichen Originaltext durch einen eigenen, parodistischen und wortspie-

379 Siehe Harper \& Row v. Nation Enterprises, 471 U.S. 539, 567 (1985).

380 Siehe Harper \& Row v. Nation Enterprises, 471 U.S. 539, 569 (1985).

381 Die von Justice Brennan abgefasste und von den Richtern White und Marshall unterstützte ausführlich begründete dissenting opinion sah das Vorgehen von The Nation hingegen als vom Fair Use-Einwand gedeckt an, da es einen wichtigen Beitrag zur Deckung des Informationsbedürfnisses der Öffentlichkeit in einer politisch wichtigen Debatte leiste und so der Förderung wesentlicher Werte der amerikanischen Verfassung diene; vgl. Harper \& Row v. Nation Enterprises, 471 U.S. 539, 579 ff. (1985) (Brennan, J., dissenting). Zum Inhalt der Minderheitsmeinung siehe auch Freys, ZUM 1985, $500 \quad$ (503).

382 Luther R. Campbell v. Acuff-Rose Music, Inc., 510 U.S. 569 (1994). Ausführlich zu dieser Entscheidung siehe etwa Babiskin, 8 Harv. J.L. \& Tech. 193 (1994); Jacobson, 31 Hous. L. Rev. 955 (1994); Lee, 29 U.S.F. L. Rev. 279 (1994); Leval, 13 Cardozo Arts \& Ent. L.J. 19 (1994); Timkovich, 5 Tul. J. Tech. \& Intell. Prop. 61 (2003); aus der deutschen Literatur Hasse, Parodie vs. Parody, S. 205 ff. 
lerischen Text ersetzt. ${ }^{383}$ Vor der Veröffentlichung des Liedes hatte die „2 Live Crew" versucht, gegen Zahlung einer Lizenzgebühr eine Genehmigung für diese Übernahme zu erhalten, die Acuff-Rose als Inhaber der Urheberrechte am Originalwerk jedoch verweigerte. Fast ein Jahr nach der Veröffentlichung der Parodie und nachdem diese bereits etwa eine Viertelmillion Mal verkauft worden war, verklagte Acuff-Rose Music die „2 Live Crew" schließlich wegen Urheberrechtsverletzung. Der District Court for the Middle District of Tennessee hatte die Klage zunächst abgewiesen, da er die Parodie als Fair Use einstufte. ${ }^{384}$ Der Court of Appeals for the Sixth Circuit hingegen sah die Nutzung des urheberrechtlich geschützten Originalwerkes aufgrund des Umfangs der Übernahme und deren kommerzieller Natur als nicht mehr vom Fair Use-Einwand gedeckt an. ${ }^{385}$ Diese Entscheidung hob schließlich der Supreme Court einstimmig auf, da das Gericht nach einer detaillierten Analyse der vier Fair Use-Faktoren zu dem Ergebnis kam, die parodistische Nutzung des Originalwerkes sei trotz ihres kommerziellen Charakters als Fair Use einzustufen.

Bei der Prüfung des ersten Faktors (,Purpose and character of the use $e^{\text {") }}$ ) stellte das Gericht fest, die zentrale hier zu beantwortende Frage sei, ob die fragliche Nutzung lediglich das Originalwerk ersetze oder aber diesem Werk durch die Nutzung etwas Neues hinzugefügt werde, etwa durch die Nutzung in einem neuen Zusammenhang, so dass sich Charakter, Wirkung, Aussage oder Bedeutung des Werkes änderten. Unter Bezugnahme auf Leval ${ }^{386}$ führt der Supreme Court für diese Art der Nutzung den Begriff des "transformative use“ als zentrales Merkmal des ersten Fair UseFaktors in die Rechtsprechung ein. Eine solche transformative Nutzung sei zwar nicht zwingend notwendig, um eine fragliche Nutzung als Fair Use zu kategorisieren, je transformativer eine Nutzung sei, desto größer sei jedoch letztlich die Wahrscheinlichkeit, dass es sich um einen Fair Use handele. ${ }^{387}$ Ein solcher transformative use komme insbesondere - wie im vorliegenden Fall - bei der Nutzung für eine Parodie in Betracht, da diese üb-

383 Der Originaltext und der Text der Parodie sind als Appendix A und B zum Urteil des Supreme Court abgedruckt in 510 U.S. 569, 594-596.

384 Acuff-Rose Music, Inc. v. Luther R. Campbell, 754 F.Supp. 1150 (M.D. Tenn. 1991). Ausführlich und kritisch zu diesem Urteil O'Connor, 2 Fordham Ent. Media \& Intell. Prop. L.F. 239 (1992).

385 Acuff-Rose Music, Inc. v. Luther R. Campbell, 972 F.2d 1429 (6th Cir. 1992).

386 Leval, 103 Harv. L. Rev. 1105, 1111 (1990).

387 Luther R. Campbell v. Acuff-Rose Music, Inc., 510 U.S. 569, 578 f. (1994). 
licherweise durch eine kritische Auseinandersetzung mit dem ursprünglichen Werk gekennzeichnet sei. ${ }^{388}$ Das Gericht hob zudem hervor, für die Annahme eines Fair Use müsse es unerheblich sein, ob es sich dabei um eine positive Kritik handele oder ob die Auseinandersetzung dem „guten Geschmack“ entspreche und somit als „qualitativ hochwertig“ anzusehen sei. ${ }^{389}$ Der Supreme Court stellte zudem klar, dass der kommerzielle Charakter der Nutzung - entgegen der Annahme des Court of Appeals - nicht zwangsläufig gegen die Annahme eines Fair Use spreche. Vielmehr zeige der Wortlaut des Gesetzes (,including"), dass die Frage der Kommerzialität lediglich eines von mehreren Elementen des ersten Faktors sei, dem nicht eine solche Bedeutung beigemessen werden dürfe, dass beim Vorliegen einer kommerziellen Nutzung automatisch die Prüfung abgebrochen werde und die Annahme eines Fair Use ausscheiden müsse. Andernfalls könnte auch ein Großteil der in der Präambel beispielhaft genannten Nutzungszwecke nicht als Fair Use anerkannt werden, da die dort genannten Formen des kreativen Schaffens sehr häufig mit Gewinnerzielungsabsicht erfolgten. 390

Hinsichtlich des zweiten Faktors, der ,nature of the copyrighted work", stellte das Gericht zunächst fest, dass das Originalwerk - wie auch schon die beiden Vorinstanzen angenommen hatten - als sehr kreatives Werk einzustufen sei, das folglich zum „Kern“ des vom Urheberrecht bezweckten Schutzes gehöre und daher grundsätzlich einen starken Urheberrechtsschutz verdiene. Gerade im Fall der Parodien bestehe jedoch die Besonderheit, dass diese in der Regel auf bekannten und kreativen Werken beruhten, um ihren Effekt zu erreichen. Im konkreten Fall sei dem zweiten Faktor daher kein besonderes Gewicht beizumessen. ${ }^{391}$

Auch bezüglich des Umfangs und der Bedeutung des übernommenen Teils (dritter Faktor) stellte der Supreme Court eine Besonderheit für den Fall der Verwendung eines fremden Werkes zum Zwecke der Parodie fest: Für eine gelungene und überzeugende Parodie sei es in der Regel gerade erforderlich, besonders markante, wiedererkennbare Teile des parodierten Werkes zu übernehmen. Entscheidend sei somit, dass die Parodie vom Originalwerk nicht mehr als zu diesem Zweck nötig übernehme. Lasse die Parodie zudem neben der Übernahme dieser Werkteile noch substantielle

388 Siehe Campbell v. Acuff-Rose, 510 U.S. 569, 579 ff. (1994).

389 Siehe Campbell v. Acuff-Rose, 510 U.S. 569, 582 f. (1994).

390 Siehe Campbell v. Acuff-Rose, 510 U.S. 569, 583 ff. (1994).

391 Siehe Campbell v. Acuff-Rose, 510 U.S. 569, 586 (1994). 
eigene kreative Leistungen erkennen, könne der dritte Faktor nicht zuungunsten des Parodierenden gewertet werden. ${ }^{392}$

Bei der Untersuchung des vierten Faktors (,Effect of the use upon the potential market for or the value of the copyrighted work") hielt der Supreme Court zunächst fest, es seien zum einen die Auswirkung zu beachten, die die konkrete streitgegenständliche Nutzung auf den Markt für das verwendete Werk selbst hätten, zum anderen aber auch, welche Auswirkungen die weite Verbreitung der fraglichen Praxis auf den potentiellen Markt für das Originalwerk haben könnte. Neben dem Markt für das verwendete Werk selbst, sei zudem der potentielle Markt für Bearbeitungen zu berücksichtigen. ${ }^{393}$ Das Gericht betonte jedoch, dass ein relevanter Marktschaden bei der ungenehmigten Verwendung von Werkteilen zum Zweck der Parodie aufgrund des transformativen Charakters dieser Nutzung in der Regel nicht anzunehmen sei, da Parodie und Original unterschiedlichen Zwecken dienten und die Parodie das Originalwerk somit nicht zu substituieren drohe. Es möge zwar durchaus Parodien geben, die etwa aufgrund ihrer „beißenden“ Kritik den Marktwert des parodierten Werkes schmälerten - dies stelle jedoch keinen Schaden dar, vor dem das Urheberrecht den Urheberrechtsinhaber schützen solle. ${ }^{394}$

Im Ergebnis wertete der Supreme Court die Nutzung des Originalwerkes durch „2 Live Crew“ zum Zwecke der Parodie nach gründlicher Analyse der vier im Gesetz genannten Faktoren trotz der Kommerzialität der Nutzung als Fair Use, da es sich um einen „transformative use“ handele, zu dessen Zweck insbesondere auch die Übernahme prägender Werkteile aus kreativen Werken zulässig sei.

c) Status quo der Anwendung und Auslegung der Fair Use-Doktrin

Durch die Kodifizierung der Fair Use-Doktrin in 17 U.S.C. $§ 107$ im Jahre 1976 hat sich an der Auslegung und Anwendung der Doktrin durch die Gerichte grundsätzlich nichts geändert. Weiterhin ist daher zur Feststellung von Fair Use eine Einzelfallanalyse vorzunehmen. Diese erfolgt in der Regel anhand der vier im Gesetz genannten, nicht abschließenden Fak-

392 Siehe Campbell v. Acuff-Rose, 510 U.S. 569, 586 ff. (1994).

393 Siehe Campbell v. Acuff-Rose, 510 U.S. 569, 590 (1994).

394 Siehe Campbell v. Acuff-Rose, 510 U.S. 569, 591 f. (1994). 
toren, kann jedoch auch einzelne Faktoren außer Betracht lassen oder weitere Kriterien heranziehen.

Im Rahmen des ersten Faktors - „Purpose and character of the use“ erfolgt eine Betrachtung des Zwecks der fraglichen Nutzungshandlung. Eine wesentliche Rolle kann dabei die Frage der Kommerzialität der Nutzung spielen. Handelt es sich um eine kommerzielle Nutzung, so spricht dies zunächst generell gegen die Annahme eines Fair Use. Diese Bewertung kann sich aber insbesondere ändern, wenn ein ,transformative use“ (oder auch ,productive use“) ${ }^{395}$ vorliegt. Einer solchen Nutzung, bei der das Originalwerk nicht lediglich substituiert, sondern dem Werk durch die Nutzung etwas Neues hinzugefügt wird, etwa durch die Verwendung in einem neuen Zusammenhang, so dass sich Charakter, Wirkung, Aussage oder Bedeutung des Werkes ändern, kommt daher besondere Bedeutung zu. Je transformativer und somit kreativer die Nutzung des Originalwerkes erfolgt, desto wahrscheinlicher ist es, dass eine faire Benutzung vorliegt.

Als zweites Element nennt 17 U.S.C. $\$ 107$ die „Nature of the copyrighted work". Bei der Bewertung der Auswirkung der Art des geschützten Werkes auf die Fair Use-Prüfung wird zumeist zunächst auf den Grad der im Originalwerk zum Ausdruck kommenden Kreativität abgestellt. Zeichnet sich das verwendete Werk durch besondere Kreativität aus, so genießt es grundsätzlich einen weiterreichenden Schutz gegen Übernahmen, als ein eher faktisches Werk. Neben diesem qualitativen Merkmal kommt besondere Bedeutung der Frage zu, ob das verwendete Werk zum Zeitpunkt der Benutzung bereits veröffentlicht war oder nicht. Bei unveröffentlichten Werken ist die Hürde für die Annahme eines Fair Use

395 Die Terminologie ist insoweit uneinheitlich. Beide Ausdrücke werden z.T. synonym verwendet. Genau genommen ist der Begriff ,productive use“ jedoch insofern enger, als davon nur solche Formen der Werknutzung erfasst werden, bei denen das ursprüngliche Werk verwendet wird, um ein neues Werk zu erschaffen. Der Ausdruck ,transformative use“ ist hingegen weiter, da von der Rechtsprechung darunter - neben dem ,productive use“ - auch solche Formen der Werknutzung subsumiert worden sind, bei denen das Originalwerk vollständig weiterverwendet und ihm lediglich durch die Art der Nutzung ein völlig neuer Zweck gegeben wird (siehe dazu ausführlich die Fair Use-Analyse der Thumbnail-Nutzung, unten 5. Kapitel, B.I.). Zur Kritik an dieser terminologischen Ungenauigkeit und der daraus teilweise resultierenden Verwirrung siehe Heymann, $31 \mathrm{Co}-$ lum. J.L. \& Arts 445, 450 ff. (2008); Lee, 83 S. Cal. L. Rev. 797, 836 f. (2010); Tushnet, 31 Colum. J.L. \& Arts 497, 500 ff. (2008); Zimmerman, 46 J. Copyright Soc'y U.S.A. 251 ff. (1998). 
grundsätzlich besonders hoch. Nachdem im Anschluss an Harper \& Row v. Nation Enterprises mehrere Entscheidungen ergingen, die einen Fair Use unveröffentlichter Werke generell ausschlossen, ${ }^{396}$ wurde die Bedeutung des Veröffentlichungsstatus eines Werkes durch eine Gesetzesänderung im Jahre $1992^{397}$ als Reaktion auf die zahlreiche Kritik an dieser Entwicklung 398 etwas abgeschwächt. Der US-Kongress stellte durch die Änderung des 17 U.S.C. $§ 107$ klar, dass der Frage der Veröffentlichung des Originalwerkes eine Ausschlusswirkung im Sinne einer per se rule zugunsten der Urheberrechtsinhaber nicht zukommen dürfe und ergänzte die Regelung um den Satz:

"The fact that a work is unpublished shall not itself bar a finding of fair use if such finding is made upon consideration of all the above factors".

Im Rahmen der Prüfung des dritten Faktors der Fair Use-Prüfung sind Umfang und Bedeutung des übernommenen Werkteils (,Amount and substantiality of the portion used") ins Verhältnis zum gesamten Originalwerk $\mathrm{zu}$ setzen. Es ist somit sowohl eine quantitative als auch eine qualitative Betrachtung vorzunehmen. Werden nur minimale Teile des Originalwerkes übernommen, so liegt die Möglichkeit einer fairen Benutzung näher als bei einer Übernahme in einem quantitativ größeren Umfang. Der Umfang der Übernahme ist jedoch nicht mehr als ein Indiz für oder gegen die

396 Siehe etwa die beiden Entscheidungen des Court of Appeals for the Second Circuit Salinger v. Random House, Inc., 811 F.2d 90 (2d Cir. 1987) und New Era Publications International ApS v. Henry Holt \& Co., 873 F.2d 576 (2d Cir. 1989).

397 Act of October 24, 1992, 102 Pub. L. No. 102-492, 106 Stat. 3145 (1992).

398 Siehe etwa die kritischen Äußerungen zu den vorgenannten Urteilen von Leval, 36 J. Copyright Soc'y U.S.A. 167 (1989); ders., 103 Harv. L. Rev. 1105 (1990); Miner, 37 J. Copyright Soc'y U.S.A. 1 (1990); Newman, 37 J. Copyright Soc'y U.S.A. 12 (1990). Vor einer solchen Überbetonung des Veröffentlichungsstatus als mögliche Konsequenz der Entscheidung Harper \& Row v. Nation Enterprises warnte auch bereits Justice Brennan in seiner von den Richtern White und Marshall unterstützte dissenting opinion zu dieser Entscheidung, Harper \& Row v. Nation Enterprises, 471 U.S. 539, 595 (1985) (Brennan, J., dissenting): „At this point the Court introduces into analysis of this case a categorical presumption against prepublication fair use. [...] This categorical presumption is unwarranted on its own terms and unfaithful to congressional intent. [...] [T] he fair use inquiry could never be resolved on the basis of such a "two dimensional" categorical approach." [Hervorhebungen durch den Verfasser]. 
Annahme eines Fair Use. ${ }^{399}$ So kann auch die Übernahme ganz wesentlicher, prägender Teile des Originalwerkes ${ }^{400}$ oder sogar in Einzelfällen dessen vollständige Übernahme ${ }^{401}$ zulässig sein. Entscheidende Bedeutung als Korrektiv einer rein quantitativen Betrachtung kommt daher im Rahmen des dritten Faktors der qualitativen Beurteilung der Übernahme zu. So kann insbesondere auch schon im Fall der Übernahme kleinerer Werkteile eine Anerkennung als Fair Use scheitern, wenn es sich bei diesen Teilen tatsächlich gerade um die „Herzstücke“ des Originalwerkes handelt. ${ }^{402}$ Neben dieser im Gesetzestext angelegten qualitativen Betrachtung der verwendeten Werkteile in Bezug auf das Originalwerk als Ganzes wird von den Gerichten zudem teilweise als weiteres Indiz für oder gegen

399 Vgl. Ringgold v. Black Entertainment Television, Inc., 126 F.3d 70, 76 (2d Cir. 1997): "The third fair use factor concerns a quantitative continuum. Like all the fair use factors, it has no precise threshold below which the factor is accorded decisive significance. If the amount copied is very slight in relation to the work as a whole, the third factor might strongly favor the alleged infringer, but that will not always be the case.".

400 So insbesondere im Falle der Verwendung wesentlicher Werkteile des Originalwerkes im Rahmen einer Parodie; vgl. Campbell v. Acuff-Rose, 510 U.S. 569, 588 (1994); siehe dazu oben 2. Kapitel, C.I.2.b)cc).

401 Als Fair Use anerkannt wurde beispielsweise die vollständige Übernahme eines Werkes bei der privaten Aufzeichnung von Fernsehformaten zum Zwecke des „time-shifting“ (vgl. Sony v. Universal, 410 U.S. 417, 449 f. (1984); siehe dazu oben 2. Kapitel, C.I.2.b)aa)), die vorübergehende vollständige Vervielfältigung eines Computerprogramms zum Zwecke des Reverse Engineering (vgl. Sega Enterprises Ltd. v. Accolade, Inc., 977 F.2d 1510, 1526 f. (9th Cir. 1992)), die Vervielfältigung eines dreidimensionalen Originalwerkes in Form eines zweidimensionalen Bildes zum Abdruck in einem Katalog bzw. Sammlerleitfaden (vgl. Ty, Inc. v. Publications Intern. Ltd., 292 F.3d 512, 522 (7th Cir. 2002)) und die vollständige Übernahme des Originalwerkes bei der Verwendung zur verkleinerten Anzeige als sog. Thumbnail im Rahmen der Bildersuche (vgl. Kelly v. Arriba Soft Corp., 336 F.3d 811, 821 (9th Cir. 2003); Perfect 10, Inc. v. Amazon.com, Inc., et al., 508 F.3d 1146, 1167 f. (9th Cir. 2007); ausführlich zur Frage der Einstufung von Thumbnails als Fair Use siehe unten 5. Kapitel, B.I.). Zu weiteren Urteilen, in denen die vollständige Übernahme eines Werkes als Fair Use anerkannt wurde, siehe Patry, Fair Use (2009), § 5:3.

402 Siehe Harper \& Row v. Nation Enterprises, 471 U.S. 539, 564 f. (1985): „, [T] he Nation took what was essentially the heart of the book." [Hervorhebung durch den Verfasser] (siehe dazu bereits oben 2. Kapitel, C.I.2.b)bb)). Vgl. auch Sag, 11 Mich. Telecomm. \& Tech. L. Rev. 381, 391 (2005) [„,The third factor does not rely on mechanical quantification of the amount of the original work used; it asks courts to asses how much of the value of the original work is present in the later use."]. 
eine faire Benutzung evaluiert, welche Rolle die übernommenen Werkteile im übernehmenden Werk spielen. Kommt diesen hier eine „Schlüsselrolle" zu, so wird auch dies für die Übernahme eines substantiellen Teils und somit eher gegen die Einstufung der Nutzung als Fair Use sprechen. ${ }^{403}$

Als viertes Element der Fair Use-Prüfung ist schließlich der „effect of the use upon the potential market for or the value of the copyrighted work" zu berücksichtigen. Dieser Faktor wurde vom Supreme Court als „undoubtedly the single most important element of fair use“ bezeichnet. 404 $\mathrm{Ob}$ dem vierten Faktor jedoch tatsächlich eine solch entscheidende Bedeutung bei der Fair Use-Prüfung zukommt, ist mehrfach bezweifelt worden. ${ }^{405}$ Richtig ist jedenfalls, dass der Untersuchung der negativen Auswirkungen einer Benutzung des Originalwerkes auf dessen (Markt-)Wert innerhalb der Fair Use-Analyse eine entscheidende Bedeutung zukommen kann. Dies ist insbesondere der Fall, wenn tatsächlich eine negative Auswirkung der Werknutzung auf den Wert des Originalwerkes beziffert werden kann, wenn also tatsächlich ein Schaden schon eingetreten ist, ${ }^{406}$ oder wenn zu erkennen ist, dass im Falle der weiten Verbreitung der fraglichen Nutzungsform alle derartigen Nutzungen zusammen deutlich spürbare

403 Siehe Harper \& Row v. Nation Enterprises, 471 U.S. 539, 566 (1985): „The Nation article is structured around the quoted excerpts which serve as its dramatic focal points. In view of the expressive value of the excerpts and their key role in the infringing work, we cannot agree with the Second Circuit that the "magazine took a meager, indeed an infinitesimal amount of Ford's original language'." [Hervorhebungen durch den Verfasser]; vgl. auch Salinger v. Random House, Inc., 811 F.2d 90, 98 f. (2d Cir. 1987): "The copied passages, if not the 'heart of the book', are at least an important ingredient of the book as it now stands. To a large extent, they make the book worth reading.".

404 Harper \& Row v. Nation Enterprises, 471 U.S. 539, 566 (1985) unter Hinweis auf Nimmer/Nimmer, On Copyright, § 13.05 [A].

405 So hat etwa eine Untersuchung von David Nimmer ergeben, dass bei 60 neueren Fair Use-Entscheidungen in weniger als 50 Prozent das Ergebnis der Untersuchung des vierten Faktors mit dem Gesamtergebnis der Fair Use-Prüfung des Gerichts übereinstimmte, siehe Nimmer, 66 Law \& Contemp. Probs. 263, 280 (2003). Siehe auch Patry, Fair Use (2009), § 6:2-5; Förster, Fair Use, S. 65 ff., jeweils m.w.N.

406 So etwa im Fall Harper \& Row v. Nation Enterprises, 471 U.S. 539 (1985), in dem Harper \& Row aufgrund der Werknutzung durch The Nation tatsächlich Lizenzeinnahmen in Höhe von 12.500 US-Dollar entgangen waren; siehe dazu oben 2. Kapitel, C.I.2.b)bb). 
Folgen für die Auswertung einer bestimmten Werkart hätten. ${ }^{407}$ Nicht ausgeschlossen ist auch, dass im Einzelfall eine Werknutzung einen positiven Effekt auf den Marktwert des verwendeten Originalwerkes hat. Lässt sich ein solcher tatsächlich feststellen, kann dies im Rahmen der Fair UseAnalyse gegebenenfalls als Indiz zugunsten des Nutzenden gewertet werden. ${ }^{408}$ In vielen anderen Fällen wird die Stellung des vierten Fair UseFaktors jedoch weniger prominent sein. Da im Rahmen der Untersuchung die Auswirkungen auf bereits tatsächlich bediente Märkte, ebenso wie die Folgen für die Auswertung des Werkes auf bisher noch nicht bedienten, potentiellen Märkten berücksichtigt werden sollen, stellt der vierte Fair Use-Faktor vielfach das problematischste Element der Fair Use-Prüfung dar. Hier droht die Untersuchung aufgrund der vielen Unwägbarkeiten, insbesondere des nur selten tatsächlich vorliegenden oder zumindest kaum zu beziffernden Schadens auf aktuellen Märkten und der hypothetischen Betrachtung hinsichtlich potentieller Märkte, zu reiner Spekulation zu werden und mangels ausreichender Anhaltspunkte je nach Interessenlage zu einer zu weiten oder zu engen Einschätzung der Marktauswirkungen zu führen. ${ }^{409}$ Gerade der vierte Faktor hat daher für sich genommen nur wenig Aussagekraft; in Verbindung und im Zusammenspiel mit den Ergebnissen der Untersuchung der anderen drei Faktoren kommt ihm jedoch oftmals eine zentrale Bedeutung zu. ${ }^{410}$

Neben den in 17 U.S.C. $§ 107$ ausdrücklich genannten Faktoren haben die Gerichte gelegentlich auch weitere Faktoren im Rahmen der Fair UsePrüfung herangezogen. Dieses Vorgehen steht im Einklang mit der historischen Entwicklung der Fair Use-Doktrin als Abwägung aller im Einzelfall relevanten Interessen und Aspekte und entspricht auch dem ausdrücklichen Willen des Gesetzgebers, der im Copyright Act die Prüfungspunkte lediglich beispielhaft und nicht abschließend aufgezählt hat und durch die gesetzliche Verankerung der Doktrin an deren Zuschnitt und ihrer Anwen-

407 Vgl. Sony v. Universal, 410 U.S. 417, 451 (1984) (im konkreten Fall lehnte der Supreme Court einen solchen kumulativen Effekt allerdings ab); Harper \& Row v. Nation Enterprises, 471 U.S. 539, 568 f. (1985) (angenommen, dass die weite Ausbreitung der fraglichen Art der Nutzung erhebliche negative Folgen für die zukünftige Lizenzierung sogenannter ,first serial rights" hätte; siehe dazu oben 2. Kapitel, C.I.2.b)bb)); Patry, Fair Use (2009), § 6:10 m.w.N.

408 Vgl. Leval, 103 Harv. L. Rev. 1105, 1124 (Fn. 85) (1990); ders., 44 UCLA L. Rev. 1449, 1459 (1997); Patry, Fair Use (2009), § 6:11.

409 Vgl. kritisch Patry, Fair Use (2009), § 6:1 ff.

410 Vgl. Leval, 44 UCLA L. Rev. 1449, 1460 (1997). 
dung durch die Gerichte nichts ändern wollte. ${ }^{411}$ Solche zusätzlichen Wertungen kann ein Gericht daher nach freiem Ermessen heranziehen und ihnen bei der Entscheidung über die Frage des Vorliegens einer fairen Benutzung das im konkreten Fall als angemessen empfundene Gewicht beimessen. ${ }^{412}$ Eine Überlegung, die in der Vergangenheit besonders häufig zusätzlich von den Gerichten angestrengt wurde und sich auch in neueren Entscheidungen gelegentlich findet, ist die Frage nach dem ,good faith" des Nutzers, also eine moralische Beurteilung seines Handelns. ${ }^{413}$

Die vom Gericht ermittelten Resultate zu den einzelnen Fair Use-Faktoren und möglicherweise zusätzlich berücksichtigte Aspekte sind schließlich im Rahmen einer Gesamtbetrachtung anhand der Umstände des Einzelfalls abzuwägen und zu gewichten. Das Ergebnis der Fair Use-Analyse lässt sich folglich keinesfalls allein dadurch ermitteln, dass eine Mehrzahl von Faktoren für oder gegen die Annahme einer fairen Benutzung spricht. ${ }^{414}$ Wie gezeigt ist es zudem einzelfallabhängig, welchen Faktoren das Gericht zur Erreichung eines gerechten Ausgleichs der beteiligten Interessen, insbesondere unter Berücksichtigung der Ziele des Urheberrechts, besondere Bedeutung oder ein nur geringes Gewicht beimisst. Erst das Ergebnis dieser Gesamtabwägung ist die Antwort auf die Frage, ob die konkrete Nutzung als Fair Use zu qualifizieren ist.

411 Vgl. H.R. Rep. No. 836, 102d Cong., 2d Sess. 9 f. (1992). Siehe auch die gesetzliche Definition der in 17 U.S.C. $\$ 107$ verwendeten Begriffe ,including“ und „such as" in 17 U.S.C. § 101: „The terms, including' and , such as' are illustrative and not limitative.".

412 Vgl. Patry, Fair Use (2009), § 7:1 m.w.N.

413 Eine ausführliche Auseinandersetzung mit der Frage der Beachtung des „good faith" als zusätzlichem Fair Use-Faktor findet sich im Urteil Field v. Google Inc., 412 F.Supp.2d 1106, 1122 f. (D.Nev. 2006); siehe dazu auch unten 5. Kapitel, B.II.1.f). Vgl. auch Harper \& Row v. Nation Enterprises, 471 U.S. 539, 540 (1985) („Fair use presupposes good faith“); Campbell v. Acuff-Rose, 510 U.S. 569, 585 (Fn. 18) (1994); Marcus v. Rowley, 695 F.2d 1171, 1175 (9th Cir. 1983) (,[F]air use presupposes that the defendant has acted fairly and in good faith [...]"); zustimmend Fisher v. Dees, 794 F.2d 432, 436 (9th Cir. 2986); Bill Graham Archives, LLC. v. Dorling Kindersley Ltd., 386 F.Supp.2d 324, 333 (S.D.N.Y. 2005); kritisch zu "good faith"-Überlegungen im Rahmen der Fair Use-Analyse Leval, 103 Harv. L. Rev. 1105, 1126 f. (1990).

414 Vgl. Leval, 103 Harv. L. Rev. 1105, 1110 (1990) [,,The factors do not represent a score card that promises victory to the winner of the majority."]. 
3. Rechtsfolge des Fair Use-Einwandes: „Alles oder Nichts“

Nach dem Wortlaut des 17 U.S.C. $§ 107$ ist ,[...] fair use of a copyrighted work [...] not an infringement of copyright." Daraus ergibt sich eine sehr einschneidende Rechtsfolge: Jede Nutzung eines urheberrechtlich geschützten Werkes, die als von der Fair Use-Doktrin gedeckt und somit als „fair" anerkannt wird, ist zustimmungsfrei möglich und zudem nicht an die Zahlung einer monetären Entschädigung gebunden. Diese starre Rechtsfolge erscheint aus kontinentaleuropäischer Sicht überraschend und möglicherweise ungerecht, da die Möglichkeit eines ,fine-tuning“ im Rahmen des Ausgleichs der beteiligten Interessen durch die Zahlung einer Vergütung nicht besteht. Nach dem US-amerikanischen Verständnis des Copyright als Anreizmechanismus zur Förderung von Wissenschaft und Fortschritt wird das „Alles oder Nichts“ jedoch als logische und gerechte Folge eines Fair Use angesehen. ${ }^{415}$ Dem Urheber oder Verwerter soll schließlich nur insoweit ein Monopol in Form urheberrechtlicher Ausschließlichkeitsbefugnisse eingeräumt werden, als dieses als Anreiz und zur Marktsteuerung erforderlich ist. Sind die durch das Monopol verursachten Nachteile geringer als die gesamtwirtschaftlichen Vorteile, so sind sie als „notwendiges Übel“ zur Korrektur eines Marktversagens in Kauf zu nehmen. ${ }^{416}$ Hat eine bestimmte Nutzung jedoch die Fair Use-Prüfung „überstanden“ und ist sie somit als „fair“ zu klassifizieren, so geht man davon aus, dass diese Nutzung einen sozialen, kulturellen oder politischen Nutzen hat, der alle möglicherweise aus der Nutzung resultierenden Beeinträchtigungen des verwendeten Werkes überwiegt. Das urheberrechtliche Monopol muss somit zugunsten der im konkreten Fall überwiegenden gesamtwohlfahrtlichen Vorteile weichen.

Auch wenn die Berücksichtigung einer Vergütung als Aspekt der „Fairness" einer Nutzung der US-amerikanischen Fair Use-Doktrin derzeit fremd ist, ist jedoch in der US-amerikanischen Literatur gerade mit Blick auf die kontinentaleuropäische Handhabung des gerechten Ausgleichs der beteiligten Interessen mehrfach erwogen worden, die Rechtsfolgen des Fair Use durch die Einführung von Vergütungsregelungen abzumildern. Eine solche Relativierung des „Alles oder Nichts“ könnte zum einen durch die Gerichte selbst bei der Anwendung der Fair Use-Schranke erfolgen,

415 Vgl. Kur, 8 Rich. J. Global L. \& Bus. 287, 299 f. (2009).

$416 \mathrm{Zu}$ incentive-Überlegungen im US-amerikanischen Copyright Law, siehe bereits oben 1. Kapitel, B. 
etwa durch Berücksichtigung einer Zahlungsmöglichkeit und -willigkeit des Werknutzers oder durch unmittelbare richterliche Festlegung einer angemessenen Vergütung. ${ }^{417}$ Zum anderen ist eine Abmilderung durch eine gesetzgeberische Änderung der Fair Use-Bestimmung und ihre Ergänzung um eine ausdrückliche Vergütungsregelung denkbar. ${ }^{418}$

\section{Sonstige Schrankenregelungen im U.S.C.: Die „Limitations on exclusive rights " der 17 U.S.C. $\$ \S 108-122$}

Neben der Generalklausel des Fair Use enthält der Copyright Act of 1976 einen Katalog mit speziellen Schrankenbestimmungen, den sogenannten Statutory Exceptions (17 U.S.C. §§ 108-122). Dieser Schrankenkatalog ergänzt die Generalklausel des Fair Use und enthält sehr spezielle, zum Teil aufgrund des weiten Ausuferns schwer lesbare Sonderregelungen, die - so die häufige Kritik ${ }^{419}$ - vor allem die Durchsetzungskraft bestimmter Verwerterlobbys vermuten lassen; so etwa die Regelungen zur Reproduktion von Werken durch Bibliotheken und Archive, ${ }^{420}$ Ausnahmen für bestimmte Formen der öffentlichen Wiedergabe und Darstellung ${ }^{421}$ oder sekundären Übertragung. 422

Diese Regelungen seien an dieser Stelle nur der Vollständigkeit halber genannt, da sie für die vorliegende Untersuchung keinen wesentlichen Erkenntnisgewinn ermöglichen. Lediglich dort, wo die Statutory Exceptions

417 In diese Richtung gehen die Überlegungen von Gordon, 82 Colum. L. Rev. 1600, 1622 f. (1982); Timberg, 75 Nw. U. L. Rev. 193, 233 ff. (1980); Yu, 40 U.C. Davis L. Rev. 1039, 1095 ff. (2007).

418 So etwa Timberg, 75 Nw. U. L. Rev. 193, 241 ff. (1980); Wasoff, 34 Colum. J.L. $\&$ Arts 731, 745 f. (2011).

419 Vgl. etwa Brown/Denicola, Copyright, S. 448 ff.; Clarida, Copyright, S. 528; Cohen/Loren/Okediji/O'Rourke, Copyright, S. 372; Dinwoodie/Hennessey/Perlmutter/Austin, International IP Law, S.600; Merges/Menell/Lemley, Intellectual Property, S. 516 f.; Schack, in: FS Schricker II, S. 511 (512).

420 Vgl. die äußerst detaillierte Regelung des 17 U.S.C. § 108. Zur Frage der möglichen Rechtfertigung eines Eingriffs in das reproduction right im Rahmen der Google Buchsuche nach 17 U.S.C. § 108 siehe unten 5. Kapitel, A.I.2.

421 Siehe die kaum überschaubare Regelung des 17 U.S.C. $\$ 110$ (Exemption of certain performances and displays), bestehend aus elf jeweils weiter untergliederten Absätzen.

422 Siehe 17 U.S.C. $§ 111$ (Secondary transmissions) der aus unglaublichen 4.088 [sic!] Wörtern besteht. 
in Bezug auf bestimmte Aspekte dieser Arbeit relevant werden - etwa dort wo sich aus ihrer Unanwendbarkeit im Einzelfall gewisse, für die Fair Use-Analyse wertvolle e contrario-Schlüsse ziehen lassen -, soll näher auf einzelne Regelungen eingegangen werden. ${ }^{423}$

423 Siehe unten bei der Frage der urheberrechtlichen Zulässigkeit der Google Buchsuche und der Verwendung von Thumbnails im Rahmen der Bildersuche nach US-amerikanischem Recht 5. Kapitel, A. 
Teil 2 Enumerativer Schrankenkatalog versus Generalklausel im digitalen Kontext: Die Anwendung der Schrankenbestimmungen des deutschen und US-amerikanischen Urheberrechts auf neue Formen der Werknutzung - Dargestellt am Beispiel der Nutzung urheberrechtlich geschützter Werke im Rahmen der Google Buchsuche und in Form von Thumbnails durch Bildersuchmaschinen

Die bestehenden Schrankenbestimmungen des deutschen Urheberrechtsgesetzes beziehen sich stets auf eines oder mehrere einzelne der in $\S \S 15$ ff. UrhG genannten Verwertungsrechte und schränken diese in unterschiedlicher Weise - abhängig vom verfolgten Zweck - ein. Die Anwendung der Schranken auf normtextlich nicht erfasste Sachverhalte bereitet dabei besondere Schwierigkeiten. Gerade bei neuen digitalen Nutzungsformen urheberrechtlich geschützter Werke stößt die Anwendung der Schrankenbestimmungen deshalb immer wieder an ihre Grenzen. Dies hat verschiedene Gründe: Oftmals ist bereits die Bestimmung der betroffenen Verwertungsrechte problematisch, was die Subsumtion unter die dazugehörigen Schrankenregelungen erschwert. Darüber hinaus enthalten die historisch gewachsenen Schrankenbestimmungen eine Reihe technologiespezifischer Begriffe, die sich auf den digitalen Kontext nicht problemlos anwenden lassen. ${ }^{424}$ Selbst wenn jedoch der Gesetzeswortlaut technologieneutral erscheint oder im Wege der Auslegung auch digitale Formen der Werknutzung erfasst werden können, ist zu beachten, dass Art und Umfang der Beschränkung vor dem Hintergrund der wirtschaftlichen Verhältnisse des damaligen technologischen Umfeldes festgelegt worden sind. Bei neuen technischen Entwicklungen muss daher für jeden Einzelfall detailliert geprüft werden, ob die einschlägige Regelung dem veränderten, digitalen Kontext noch gerecht wird. ${ }^{425}$ Schließlich wird durch den im deutschen Recht zu Unrecht weiterhin vielfach propagierten und angewandten Grundsatz, Urheberrechtsschranken seien generell eng auszule-

424 Bspw. § 49 UrhG: „Zeitungsartikel“, „Rundfunkkommentare“ und „Informationsblätter".

425 Vgl. Dreier, in: Schricker, Informationsgesellschaft, S. 141. 
gen und nicht analogiefähig, ${ }^{426}$ neuen Nutzungsformen - selbst wenn diese erwünscht sind - eine urheberrechtliche Grenze gesetzt.

Besonders deutlich lässt sich dieses Dilemma erkennen, wenn man einige neue technische Entwicklungen der letzten Jahre, die bereits zu einem erheblichen Mehrwert für die Gesellschaft geführt haben oder diesen voraussichtlich in der Zukunft noch haben werden, auf ihre Vereinbarkeit mit dem deutschen Urheberrecht untersucht. Zur Veranschaulichung dieses Dilemmas sollen im Folgenden die in jüngerer Zeit sowohl in Deutschland als auch in den USA lebhaft diskutierten Geschäftsmodelle „Google Buchsuche“ und die Darstellung sogenannter Thumbnails durch Suchmaschinen genauer betrachtet werden. Beide Geschäftsmodelle werfen eine Vielzahl von urheberrechtlichen Fragen auf, die sich vor dem Hintergrund des geltenden deutschen Rechts nur schwer befriedigend beantworten beziehungsweise lösen lassen.

Einleitend sollen die beiden Geschäftsmodelle kurz vorgestellt werden (sogleich 3. Kapitel). Anschließend werden in einem „Länderbericht Deutschland" die urheberrechtlichen Probleme im Zusammenhang mit diesen neuen Nutzungsformen für das deutsche Urheberrecht dargestellt (4. Kapitel), wobei zunächst auf die möglicherweise betroffenen Verwertungsrechte einzugehen ist (A.), um anschließend mögliche Lösungswege zur Erfassung der urheberrechtlichen Nutzungen im Rahmen des geltenden Schrankenkataloges zu erörtern (B.).

Dem jedenfalls in Bezug auf neue digitale Nutzungsformen zu starren Schrankenkatalog des deutschen Urheberrechtsgesetzes wird schließlich die Handhabung neuer technischer Entwicklungen und insbesondere der beiden genannten Geschäftsmodelle durch das US-amerikanische Copyright gegenübergestellt (5. Kapitel). Um Vor- und Nachteile der unterschiedlichen Ausgestaltung der Schranken im deutschen und US-amerikanischen Urheberrecht herauszuarbeiten, erfolgt eine Darstellung der betroffenen Verwertungsrechte (A.), um auf dieser Grundlage eine detaillierte Fair Use-Analyse beider Geschäftsmodelle zu ermöglichen (B.). Dem dies- und jenseits des Atlantiks besonders intensiv diskutierten Rechtsstreit um die Google Buchsuche und insbesondere dem Google Book Settlement und seinen möglichen Folgen widmet sich die Untersuchung dabei ausführlich im Rahmen eines Exkurses (B.II.2.).

426 Zur Kritik an dieser Annahme siehe bereits ausführlich oben 2. Kapitel, B.I.2. 


\section{Kapitel Die Geschäftsmodelle „Google Books“ und Darstellung von Thumbnails durch Suchmaschinen}

\section{A. Die Google Buchsuche}

Ende 2004 kündigte Google an, im Rahmen des Projektes „Google Print“ einen bedeutenden Teil des weltweiten Bestandes an gedruckten Büchern der Volltextsuche zugänglich machen zu wollen. ${ }^{427}$ Im Herbst 2005 wurde das Projekt von „Google Print" in „Google Book Search“, beziehungsweise im deutschsprachigen Raum in „Google Buchsuche“, umbenannt. Dies wurde damit begründet, dass dieser Name dem eigentlichen Verwendungszweck näher komme, denn entgegen gelegentlichen anders lautenden Darstellungen in der Öffentlichkeit sei die Errichtung einer umfassenden Online-Bibliothek nicht geplant.428 Vielmehr versteht Google die Buchsuche als ein Such-Tool ähnlich der etablierten Web-Suche beziehungsweise als ein „Online-Buchmarketingprogramm“.429 Die Google Buchsuche soll Nutzern helfen, Bücher aufzufinden und entweder zu kaufen oder in Bibliotheken in ihrer Nähe finden zu können. ${ }^{430}$ Die Google Buchsuche speist sich aus zwei Quellen - dem sog. Partner-Programm

427 Im Oktober 2004 stellten die beiden Google-Gründer Sergey Brin und Larry Page das Projekt „Google Print“ auf der Frankfurter Buchmesse erstmals offiziell der Öffentlichkeit vor. Im Dezember 2004 wurde der Start des Bibliotheksprogramms mitgeteilt, siehe Pressemitteilung vom 14.12.2004, abrufbar unter: http:// www.google.com/press/pressrel/print_library.html [zuletzt abgerufen am 26.5.2013]. Beteiligt waren zunächst die Bibliotheken der Harvard University, University of Michigan, New York Public Library, Oxford und Stanford University.

428 Siehe „Die Geschichte der Google Buchsuche“, abrufbar unter: http:// books.google.de/intl/de/googlebooks/history.html [zuletzt abgerufen am 26.5.2013].

429 Vgl. „Über Google Buchsuche: Google Buchsuche verwenden“ abrufbar unter: http://support.google.com/books/bin/topic.py?hl=de\&topic=9259 [zuletzt abgerufen am 26.5.2013].

430 Google setzt dabei eine Technik ein, die automatisch den Standort des Nutzers ermittelt, so dass dieser an die nächstgelegenen Bibliotheken verwiesen werden kann; siehe „Google Buchsuche-Hilfe“, abrufbar unter: http://books.google.com/ intl/de/googlebooks/help.html [zuletzt abgerufen am 26.5.2013]. 
und dem sog. Bibliotheksprogramm - die sich auch im Hinblick auf die mit ihnen verbundenen urheberrechtlichen Probleme grundlegend unterscheiden.

\section{Das Partner-Programm}

Das Partner-Programm ${ }^{431}$ stellt ein Kooperationsprojekt zwischen Google und den Verlagen und/oder Autoren ${ }^{432}$ dar. Diese haben die Möglichkeit, Google ihre Bücher in einer digitalen Volltextversion oder zum Scannen zur Verfügung zu stellen. Nach dem Übermitteln der Buchtitel oder dem Hochladen als.pdf-Datei fügt Google diese seinem Suchindex hinzu. Dabei können die Rechteinhaber den Umfang, in welchem die Nutzer Einblick in ein Buch erhalten sollen, selbst bestimmen. Teilweise sind ganze Kapitel oder mehrere Seiten einsehbar, können jedoch nicht ausgedruckt werden. In der Regel erhält der Nutzer aber lediglich eine kurze Vorschau zum Buchtitel mit Links zu Bezugsquellen. Zusätzlich zu der Möglichkeit, über diese Links den Absatz ihrer Bücher zu steigern, werden die Verlage an den Einnahmen aus den Klicks auf Anzeigen auf der Suchseite beteiligt.

Soweit die Verlage von den Autoren umfassende Nutzungsrechte erworben haben, die auch die Digitalisierung und Online-Nutzung der Werke beinhalten, wirft das Partner-Programm keine urheberrechtlichen Probleme auf.

Bei Verlagsverträgen, die vor 1995 abgeschlossen wurden, können sich jedoch im deutschen Recht auch bezüglich des Partner-Programms urheberrechtliche Probleme ergeben, da diese in der Regel keine Nutzungsrechtseinräumung für die damals noch unbekannte Online-Nutzung von Werken im Internet ${ }^{433}$ beinhalten. Dieses Problem ist allerdings durch die

431 Vgl. auch Googles „Informationen für Autoren und Verlage“, abrufbar unter: http://books.google.com/intl/de/googlebooks/publishers.html [zuletzt abgerufen am 26.5.2013].

432 Laut Google haben Ende 2007 bereits über 10.000 Verleger und Autoren aus über 100 Ländern am Partner-Programm teilgenommen, vgl. „Die Geschichte der Google Buchsuche“, abrufbar unter: http://books.Google.com/intl/de/Googlebooks/history.html [zuletzt abgerufen am 26.5.2013].

433 Die Bekanntheit von Nutzungsarten, die die Bereitstellung von Werken auf Websites und in Datenbanken im Internet zum Gegenstand oder zur Voraussetzung haben, ist zumindest in Deutschland nach wohl herrschender Ansicht nicht vor 
Streichung des $\S 31$ Abs. 4 UrhG a.F. und die Einführung der Übergangsregelung des $\S 1371$ UrhG $^{434}$ deutlich entschärft worden. Während nach altem Recht eine Rechtseinräumung für unbekannte Nutzungsarten grundsätzlich unzulässig war, ${ }^{435}$ sieht $§ 1371$ Abs. 1 S. 1 UrhG nun eine gesetzliche Fiktion der Rechtseinräumung für unbekannte Nutzungsarten vor. Danach gelten für Verträge, durch die der Urheber zwischen dem 1. Januar 1966 und dem 1. Januar 2008 einem anderen alle wesentlichen Nutzungsrechte ausschließlich sowie räumlich und zeitlich unbegrenzt eingeräumt hat, die zum Zeitpunkt des Vertragsschlusses unbekannten Nutzungsrechte als dem Anderen ebenfalls eingeräumt, sofern der Urheber nicht dem Anderen gegenüber der Nutzung widerspricht. Der Widerspruch konnte für Nutzungsarten, die am 1. Januar 2008 bereits bekannt waren - also auch für die Online-Nutzung -, nur innerhalb eines Jahres, also spätestens bis zum 1. Januar 2009, erfolgen. Einer Mitteilung an den Urheber über die neue Werknutzung bedurfte es für den Beginn der Widerrufsfrist nicht, ${ }^{436}$ so dass nun bei Altverträgen, in denen alle wesentlichen Nutzungsrechte ausschließlich sowie räumlich und zeitlich unbegrenzt eingeräumt worden sind und für die ein Widerspruch nicht (rechtzeitig) erfolgt ist, aufgrund der Rechtseinräumungsfiktion des $\S 1371$ Abs. 1 S. 1 UrhG auch die Nutzungsrechte ${ }^{437}$ zur Digitalisierung und Online-Nutzung der Werke bei den Verlegern liegen.

Keine Anwendung findet $\S 1371$ Abs. 1 UrhG hingegen, wenn in einem Vertrag nicht alle wesentlichen Nutzungsrechte ausschließlich sowie räumlich und zeitlich unbegrenzt eingeräumt wurden. Eine Übertragungs-

1995 anzunehmen, vgl. Dreier/Schulze, § 31a Rn. 52 f.; Hoeren, CR 1995, 710 (714); Schack, Urheberrecht, Rn. 624; Wandtke/Bullinger/Wandtke/Grunert, $\S 31 \mathrm{a}$ Rn. 41; a.A. OLG Hamburg, ZUM 2005, 833 (836), das annimmt, die Veröffentlichung von urheberrechtlich geschützten Werken in Form von digitalisierten Zeitungen bzw. Zeitschriften im Internet sei spätestens 1993 nicht mehr als eine ,noch nicht bekannte Nutzungsart" anzusehen gewesen.

434 Eingefügt mit Wirkung zum 1.1.2008 durch das Zweite Gesetz zur Regelung des Urheberrechts in der Informationsgesellschaft vom 26.10.2007 (BGB1. 2007 I, S. 2513).

435 Vgl. zum alten Recht statt aller Dreier/Schulze, § 31 Rn. 64 ff.

436 Vgl. Mestmäcker/Schulze/Scholz, § 1371 Rn. 30.

437 Zur strittigen Frage, ob durch $\S 137$ Abs. 1 S. 1 UrhG einfache oder ausschließliche Nutzungsrechte in Bezug auf die unbekannte Nutzungsart fingiert werden, siehe Mestmäcker/Schulze/Scholz, § 1371 Rn. 21 ff., der überzeugend davon ausgeht, dass lediglich einfache Rechte zur Nutzung fingiert werden. So auch Spindler/Heckmann, ZUM 2006, 620 (626); a.A. Berger, GRUR 2005, 907 (911). 
fiktion soll demnach - zu Recht - nur für solche Verträge gelten, deren Vertragszweck es gerade ist, dem Verwerter die Möglichkeit einer umfassenden und dauerhaften Auswertung des Werkes zu geben. In diesen Fällen stellt der nachträgliche Erwerb der Rechte an vormals unbekannten Nutzungsarten sich als logische Ergänzung des Vertragswerkes dar. ${ }^{438} \mathrm{Ge}-$ rade im Bereich der - in Bezug auf die Rechteübertragung für die Google Buchsuche relevanten - Verlagsverträge dürfte eine solche umfassende Rechteeinräumung jedoch vielfach vorliegen, da es dem Regelfall entspricht, dass Verlage sich - gerade auch im Hinblick auf noch unbekannte Nutzungsformen - die umfassende Werkauswertung sichern. 439

Von der Übergangsregelung des $§ 1371$ UrhG nicht erfasst sind Verträge, die vor dem 1. Januar 1966, also vor Inkrafttreten des Urheberrechtsgesetzes in seiner Fassung von 1965, geschlossen wurden, da für diese Verträge auch das Verbot des $\S 31$ Abs. 4 UrhG a.F. nicht galt. 440441 Obwohl daher vor dem 1. Januar 1966 Nutzungsrechte grundsätzlich auch für unbekannte Nutzungsarten eingeräumt werden konnten, kann in der Regel nicht davon ausgegangen werden, dass dies auch der Fall ist. ${ }^{442}$ Bei diesen Altverträgen ist vielmehr zu berücksichtigen, dass nach früherem Recht die Anwendung der Zweckübertragungslehre ${ }^{443}$ regelmäßig der Rechtseinräumung an nicht bekannten Nutzungsarten entgegenstand, selbst wenn die Rechte seinerzeit uneingeschränkt übertragen wurden. ${ }^{444}$

Bei diesen Altverträgen, die vor dem 1.1.1966 geschlossen wurden, und bei Verträgen aus der Zeit vom 1.1.1966 bis zum 1.1.2008, bei denen der Urheber von seinem Widerspruchsrecht Gebrauch gemacht hat oder von vorneherein nicht sämtliche wesentlichen Nutzungsrechte ausschließlich sowie räumlich und zeitlich unbegrenzt eingeräumt hat, besteht daher die

438 Siehe Wandtke/Bullinger/Jani, § 1371 Rn. 7 f. m.w.N.

439 Auf die streitige Frage, wann alle ,wesentlichen” Nutzungsrechte übertragen wurden, wird es somit aufgrund der umfassenden Rechteeinräumung oftmals nicht ankommen; siehe dazu näher Dreier/Schulze, § 1371 Rn. 24 ff. m.w.N.

440 BGH, GRUR 1988, 296 (299) - GEMA-Vermutung IV.

441 Vgl. Mestmäcker/Schulze/Scholz, § 1371 Rn. 53.

442 Dreier/Schulze, § 31 Rn. 86.

443 Danach gilt der Grundsatz, dass der Urheber ,im Zweifel keine weitergehenden Rechte überträgt, als es der Zweck des Nutzungsvertrages erfordert", BGH, GRUR 1984, 119 (121) - Synchronisationssprecher.

444 Vgl. BGH, GRUR 1988, 296 (299) - GEMA-Vermutung IV; GRUR 1991, 133 (135) - Videozweitauswertung. 
Gefahr einer Verletzung des Urheberrechts im Rahmen des Partner-Programms der Google Buchsuche.

\section{Das Bibliotheksprogramm}

Deutlich mehr urheberrechtliche Probleme ${ }^{445}$ wirft die von den Urhebern und ihren Verlagen nicht konsentierte Digitalisierung durch Google für das Bibliotheksprogramm auf, das deshalb auch im Mittelpunkt der Diskussionen steht. Im Rahmen des Bibliotheksprogramms hat Google Verträge mit (derzeit) einundzwanzig akademischen Bibliothekspartnern ${ }^{446}$ geschlossen, um deren Bücher zu scannen und mit Hilfe von $\mathrm{OCR}^{447}$ als E-Texte zu indexieren, um sie so der Volltextsuche zugänglich zu machen. Auf eine Suchanfrage werden den Nutzern, wie in einem Kartenkatalog, bibliographische Informationen wie Titel, Autor, Veröffentlichungsdatum, Seitenanzahl und Thema zum jeweiligen Buch angezeigt. Ist ein Buch nicht (mehr) urheberrechtlich geschützt, wird es vollständig angezeigt und kann heruntergeladen werden. Jedoch werden auch urheberrechtlich geschützte Werke grundsätzlich nicht von der Digitalisierung ausgenommen. ${ }^{448}$ Allerdings bietet Google den Rechteinhabern, die nicht möchten, dass ihre Bücher Teil der Buchsuche werden, die Möglichkeit eines Opt Out. Übermittelt der Rechteinhaber Google eine Liste der Bücher, die

445 Dazu sogleich 4. und 5. Kapitel.

446 Bibliothekspartner sind derzeit (Stand: Mai 2013) die Bayerische Staatsbibliothek, die Columbia University in New York, das Committee on Institutional Cooperation (CIC) - ein Konsortium von zwölf US-amerikanischen Universitäten, die Cornell University Library, die Harvard University, die Universitätsbibliothek Gent, die Bibliothek der Keio-Universität in Tokio, die Bibliothèque Municipale de Lyon, die Katalanische Nationalbibliothek, die New York Public Library, die Oxford University, die Österreichische Nationalbibliothek, die Princeton University, die Stanford University, die University of California, die Universität Complutense Madrid, die Universitätsbibliothek Lausanne, die University of Michigan, die University of Texas in Austin, die University of Virginia und die University of Wisconsin in Madison.

447 OCR steht als Abkürzung für Optical Character Recognition und bezeichnet ein Verfahren zur automatischen Texterkennung einer gedruckten Vorlage.

448 Einige der Bibliothekspartner, z.B. die Universitätsbibliotheken in Harvard, Oxford und Stanford und die Bayerische Staatsbibliothek, gestatten die Digitalisierung urheberrechtlich geschützter Bücher hingegen nicht. Aus den Beständen dieser Bibliotheken werden lediglich urheberrechtsfreie Werke digitalisiert. 
nicht digitalisiert werden sollen, so scannt Google diese im Rahmen des Bibliotheksprogramms nicht oder entfernt sie wieder aus seiner Datenbank, wenn sie bereits digitalisiert wurden. ${ }^{449}$ Bei allen Büchern, die urheberrechtlichem Schutz unterliegen und bei denen nicht von der Opt OutMöglichkeit Gebrauch gemacht wurde, erhält der Nutzer auf seine Suchanfrage entweder nur die bibliographischen Angaben oder aber einige wenige Sätze, sogenannte Snippets, die den vom Nutzer eingegebenen Suchbegriff im Kontext anzeigen. Unabhängig davon, wie oft ein Suchbegriff in einem bestimmten Buch vorkommt, werden dem Nutzer dabei jedoch nie mehr als drei Snippets angezeigt. ${ }^{450}$ Zudem sind zum Schutz der so angezeigten Daten die Funktionen „drucken“, „speichern“, ,ausschneiden“ und „kopieren“ deaktiviert. ${ }^{451}$ In allen Fällen werden Links angezeigt, die die Nutzer direkt zu Online-Buchhandlungen und Bibliotheken weiterleiten, in denen sie das Buch kaufen oder ausleihen können. ${ }^{452}$ Weder Google noch die Bibliotheken sind an den Umsätzen aus diesen Bücherverkäufen beteiligt. ${ }^{453}$ Die teilnehmenden Bibliotheken erhalten kein Entgelt für die Zurverfügungstellung der Bücher, sondern lediglich eine digitale Ko-

449 Näher zu den Problemen der Opt Out-Lösung von Google siehe unten 5. Kapitel, B.II.

450 So die Angabe von Google zu den „Ansichten in der Google Buchsuche“, abrufbar unter: http://books.google.de/googlebooks/screenshots.html [zuletzt abgerufen am 26.5.2013].

451 Es kursieren allerdings im Internet Anleitungen, um diesen Schutz zu umgehen und Programme, die die Begrenzung der angezeigten Seiten aufheben und sogar ein Speichern ganzer Bücher als.pdf-Datei ermöglichen (sollen); siehe etwa den Bericht „Hacking Google Print“, abrufbar unter: http://www.kuro5hin.org/story/ 2005/3/7/95844/59875 [zuletzt abgerufen am 26.5.2013]. Es existieren zudem zahlreiche Anleitungen und Programme, die das Abspeichern ganzer Bücher ermöglichen, die für den „full view“-Modus freigeschaltet sind; siehe etwa „How to download Google Books?“", abrufbar unter: http://www.downloadgooglebooks.com/ [zuletzt abgerufen am 26.5.2013]. Auch hier können sich rechtliche Probleme ergeben, insbesondere wenn etwa mit Hilfe dieser Programme und durch den Einsatz sog. Proxy-Server der vollständige Download solcher Bücher ermöglicht wird, die lediglich in einzelnen Ländern, z.B. in den USA, zur Vollansicht freigeschaltet sind.

452 Siehe die Informationen zum „Google Buchsuche-Bibliotheksprogramm“, abrufbar unter: http://books.google.de/googlebooks/library.html [zuletzt abgerufen am 26.5.2013].

453 Siehe http://books.google.com/intl/de/googlebooks/help.html\#11 [zuletzt abgerufen am 26.5.2013]. 
pie aller gescannten Werke aus ihrem Bestand. ${ }^{454}$ Im Übrigen trägt jede der Vertragsparteien die ihr entstehenden Kosten, ${ }^{455}$ insbesondere trägt Google die Kosten des Scannens und Indexierens. Die Höhe der Kosten für die Digitalisierung von (geplanten) 15-30 Millionen Büchern ${ }^{456}$ wird von Google nicht bekannt gegeben. 457

Rechteinhaber haben somit derzeit die Wahl zwischen drei Varianten: Sie können sich am Partner-Programm beteiligen und so den Umfang der Darstellung ihrer Werke selbst bestimmen und unmittelbar finanziell profitieren. Sie können für ihre Werke von der Möglichkeit eines Opt Out Gebrauch machen und diese so ausdrücklich von der Aufnahme in die Buchsuche ausschließen oder aber untätig bleiben und Google ihre Werke digitalisieren lassen, so dass diese in die Google Buchsuche aufgenommen werden, jedoch lediglich in Snippet-Form einsehbar sind.

454 Zur besonderen Problematik der Weitergabe dieser Kopien an die Bibliotheken siehe unten 5. Kapitel, B.II.1.e)cc).

455 Vgl. „Google Buchsuche-Hilfe“, http://books.google.de/support/bin/answer.py? answer $=43751$ \&topic $=9082$. Einige der Bibliothekspartner haben zudem die mit Google geschlossenen Verträge veröffentlicht, z.B. die University of Texas in Austin (Vertrag abrufbar unter: http:/www.lib.utexas.edu/sites/ default/files/ google/utexas_google_agreement.pdf) und die University of Wisconsin (Vertrag abrufbar unter: http://www.library.wisc.edu/digitization/agreement.html [jeweils zuletzt abgerufen am 26.5.2013]).

456 Die Angaben in der Literatur schwanken stark, da aufgrund der Informationspolitik von Google hinsichtlich der angestrebten Gesamtzahl lediglich Schätzungen anhand der Bestände der beteiligten Bibliotheken möglich sind. Kubis, ZUM 2006, 370 (372) und Ott, GRUR Int. 2007, 562 (563) gehen von ca. 15 Millionen Büchern aus. Varian, Google Library Project, S. 2 nennt hingegen eine Zahl von 25-30 Millionen Büchern und gibt an, Google-Mitarbeiter hinsichtlich der Richtigkeit dieser Angaben konsultiert zu haben. Google selbst hat am 9. Oktober 2009 bekannt gegeben, bereits über 10 Millionen Bücher gescannt zu haben, vgl. die Meldung unter http://googleblog.blogspot.com/2009/10/tale-of-10000000books.html [zuletzt abgerufen am 26.5.2013]. Nach Angaben von v.Lohmann, GBS 2.0: Evaluating Access, waren es am 19. November 2009 bereits mehr als 12 Millionen Bücher. Bei einem Zuwachs von ca. 2 Millionen Büchern innerhalb von nur eineinhalb Monaten erscheint die Annahme von 25-30 Millionen Büchern als Gesamtziel durch Varian, a.a.O., realistisch.

457 Aufgrund der Unsicherheit über die Zahl der digitalisierten Bücher schwanken auch die Schätzungen der Kosten des Projektes zwangsläufig erheblich. Vgl. beispielsweise die Angaben bei Ganley, 10 No. 5 J. Internet L. 1, 8 (2006) (ca. 100 Mio. US-Dollar); Ott, GRUR Int. 2007, 562 (563) (ca. 150 Mio. US-Dollar); Mönninger, ZEIT Online 32/2005, S. 40 (200 Mio. US-Dollar); Singer/Conde, Bibliothek im Internet, S. 1 (mehr als 200 Mio. US-Dollar). 


\section{B. Darstellung von Thumbnails durch Suchmaschinen}

Während sich die Google Buchsuche - gerade in Deutschland - noch nicht endgültig bei den Suchmaschinennutzern durchgesetzt hat, ist die Bildersuche längst ein „Erfolgsmodell“. Schon lange konzentrieren sich Betreiber von Internetsuchmaschinen nicht mehr nur auf ihre Kernfunktion der Suche nach Webseiten, sondern erweitern ihre Angebote durch zahlreiche spezielle Suchfunktionen. Eine dieser technischen Neuerungen der letzten Jahre, die zu einer erheblichen Modifikation des Geschäftsmodells „Internetsuchmaschine" geführt hat und erhebliche urheberrechtliche Probleme in sich birgt, ist die Erweiterung von Suchmaschinenangeboten um Bildersuchfunktionen und die damit einhergehende Erstellung, Speicherung und Anzeige sogenannter Thumbnails. 458 Während bei der „klassischen“ Suche nach Internetseiten gewöhnlich innerhalb der Suchtrefferliste eine auszugsweise Darstellung einzelner Textfragmente der verlinkten Website ohne eigenständigen Werkcharakter ${ }^{459}$ genügt, um dem Nutzer einen Eindruck von deren Inhalt und ihrer Relevanz für seine Suchanfrage zu vermitteln, erscheint es bei der Bildersuche notwendig, aufgefundene Bilder komplett - wenn auch nicht notwendigerweise in voller Qualität und Größe - darzustellen, um dem Nutzer eine Möglichkeit zu geben, über deren Relevanz für seine Suchanfrage zu entscheiden. Die rechtlichen Probleme im Zusammenhang mit der Implementierung einer Bildersuche in Suchmaschinen sind dabei in jüngerer Zeit mehrfach im juristischen Schrifttum erörtert worden. Insbesondere die Dienste des Marktführers Google, ${ }^{460}$ der damit wirbt, die umfassendste Bildsuche im Internet zu ermöglichen, ${ }^{461}$

458 Die Bezeichnung Thumbnail resultiert aus der etwa daumennagelgroßen Darstellung der verkleinerten Bilder, die regelmäßig eine Länge von 200 Pixeln nicht überschreitet; vgl. Schrader/Rautenstrauch, UFITA 2007, 761.

459 Vgl. Nolte, ZUM 2003, 540 (542).

460 In Deutschland erzielt Google einen Marktanteil von ca. $81 \%$ bei Suchanfragen (Stand: 26.5.2013), vgl. die regelmäßig aktualisierte Statistik unter http:// www.webhits.de/deutsch/index.shtml?webstats.html; in den USA erzielt Google einen Marktanteil von mehr als $66 \%$ bei den Suchanfragen (Stand: 15.5.2013), vgl. http://www.comscore.com/Insights/Press_Releases/2013/5/comScore_Releas es_April_2013_US_Search_Engine_Rankings [jeweils zuletzt abgerufen am 26.5.2013].

461 Die Funktion „Image Search“ ist seit Juli 2001 unter http://images.google.com verfügbar und ermöglichte anfänglich den Zugriff auf 250 Millionen Bilder, vgl. http://www.google.com/googlefriends/jul2001.html. Nach Angaben von Google 
waren auch bereits Gegenstand mehrerer Gerichtsurteile in Deutschland und in den USA. ${ }^{462}$

Beim Suchmaschinenangebot von Google handelt es sich um eine sogenannte indexbasierte Suchmaschine, das heißt, sie liest automatisch alle erreichbaren und nicht für den Zugriff gesperrten Dokumente aus dem Internet ein und erstellt daraus eine Art elektronischen Katalog. Dieser sogenannte Index ist in weltweit verteilten Rechenzentren gespeichert. Bei einer Suchanfrage wird anstelle des gesamten Internets nur dieser zentrale Index durchsucht, aus diesem eine Trefferliste erzeugt und dem Nutzer angezeigt. ${ }^{463}$ Die Trefferliste besteht aus einer Vielzahl elektronischer Verknüpfungen (Links), die zu den als relevant eingestuften Websites Dritter führen.

Für das Angebot speziell zum Auffinden von Bildern im World Wide Web, die Google Bildersuche, analysiert Google mit Hilfe von sogenannten Crawlern fortlaufend die Dateinamen von Dateien in Grafikformaten, deren verbalen Kontext und ihre Beschreibung im Quelltext, die sogenannten Metadaten, und andere Faktoren auf Webseiten, die den Inhalt der dort eingestellten Bilder bestimmen. Nicht erfasst werden hingegen Bilddateien, die vom Webseitenbetreiber durch Aufnahme eines entsprechenden Befehls in der ,robots.txt"-Datei im Stammverzeichnis der Webseite für die Crawler von Google ,gesperrt" wurden. Dem Betreiber stehen dabei detaillierte Möglichkeiten zur Verfügung, den Umfang des Zugriffs der Crawler auf die Webseite durch die nähere Ausgestaltung der „robots.txt"-Datei zu bestimmen. ${ }^{464}$ So ist es etwa möglich, die Indexierung der gesamten Internetseite durch Googles Crawler auszuschließen ${ }^{465}$ oder

(siehe http://googleblog.blogspot.de/2010/07/ooh-ahh-google-images-presentsnicer.html [jeweils zuletzt abgerufen am 26.5.2013]) waren im Juli $2010 \mathrm{mehr}$ als 10 Milliarden Bilder in der Google Bildersuche verfügbar, was diese nach Googles Werbeaussage zur ,umfassendsten Bildsuche im Web" macht.

462 Auch von anderen Suchmaschinenbetreibern, etwa Bing und Yahoo!, wird eine Bildersuche angeboten. Diese gleicht jedoch in Aufbau und Funktion weitestgehend der Google Bildersuche. Aufgrund ihres überragenden Marktanteils (vgl. Fn. 475) soll diese im Folgenden als repräsentatives Beispiel dienen.

463 Vgl. Köhler/Arndt/Fetzer, Recht des Internet, Rn. 9.

464 Siehe dazu im Einzelnen etwa die Anweisungen von Google zum Blockieren und Entfernen von Website-Inhalten unter http://support.google.com/webmasters/bin/ answer.py?hl=de\&answer=156449 [zuletzt abgerufen am 26.5.2013].

465 Durch die Aufnahme des Befehls „User-agent: Googlebot-Disallow: “ wird (sämtlichen) Crawlern der Suchmaschine Google die Indexierung aller auf der Internetseite enthaltenen Informationen untersagt. Entsprechend können auch 
auch nur die Erfassung von auf der Webseite enthaltenen Bilddateien für die Bildersuche. ${ }^{466}$ Ebenfalls möglich ist es, nur einzelne Bilddateien, -formate oder -verzeichnisse der Webseite für die Crawler zu sperren und so von der Indexierung auszuschließen ${ }^{467}$ und/oder etwa die Erfassung einzelner Bilddateien oder Dateiformate ausdrücklich zu gestatten. 468 Jedenfalls dem technisch etwas versierten Website-Betreiber ist somit durch die entsprechende Gestaltung der „robots.txt"-Datei eine weitgehende und individuelle Festlegung der Indexierung seiner Internetseite durch Suchmaschinen sowohl in Bezug auf Art und Umfang der Erfassung durch einzelne Suchmaschinen als auch hinsichtlich der unterschiedlichen Suchmaschinen und -dienste möglich.

Die aufgefundenen - nicht für die Suchmaschinen-Crawler gesperrten Bilder werden von Google indexiert, verkleinert, komprimiert und gespeichert. Die so erstellten verkleinerten digitalen Abbildungen der Original-

(nur) die Robots anderer - in der „robots.txt“-Datei namentlich benannter Suchanbieter ausgeschlossen werden. In der unter http://www.robotstxt.org/ db.html abrufbaren sog. Web Robots Database [zuletzt abgerufen am 26.5.2013] sind die am häufigsten verwendeten Suchrobots aufgeführt. Schließlich ist auch der Ausschluss sämtlicher Suchmaschinen-Crawler durch die Aufnahme des Befehls „User-agent: * Disallow: " möglich. Die Internetseite wird somit in Bezug auf sämtliche enthaltenen Informationen für alle Suchmaschinen gesperrt.

466 Durch den Befehl „User-agent: Googlebot-Image - Disallow: “ würde Googles Crawlern die Indexierung aller auf der Internetseite enthaltenen Bilddateien untersagt. Auch hier ist durch deren namentliche Benennung oder die Verwendung von Platzhaltern eine Ausweitung des Verbotsumfangs auf Crawler weiterer oder sämtlicher Suchmaschinenanbieter möglich. Sonstige Inhalte der Internetseite würden hingegen weiterhin durch die Suchmaschinen-Robots erfasst.

467 Es ist bspw. eine Differenzierung nach bestimmten Verzeichnissen oder Dateitypen denkbar, z.B. durch Verwendung der Befehle „User-agent: Googlebot-Image - Disallow: /Privat" (keine Indexierung der Bilder, die sich in dem (Unter-)Verzeichnis „Privat“ befinden) oder „User-agent: Googlebot-Image - Disallow: / *.gif\$“ (keine Indexierung von Dateien mit der Dateiendung,..gif“). Auch der Ausschluss konkreter, einzelner Bilddateien ist möglich. So würde z.B. durch den Befehl „User-agent: Googlebot-Image - Disallow: /Privat/Bewerbungsfoto.jpg“ die Aufnahme des auf der Website angezeigten Bildes „Bewerbungsfoto.jpg“ in den Index der Bildersuche verhindert.

468 Ebenso wie hinsichtlich der Untersagung ist auch bei der ausdrücklichen Zulassung der Indexierung eine Differenzierung nach bestimmten Verzeichnissen oder Dateitypen möglich, etwa durch Verwendung der Befehle „User-agent: Googlebot-Image - Allow: /Bilder" (nur Indexierung der Bilder, die sich in dem Verzeichnis „Bilder“ befinden) oder „User-agent: Googlebot-Image - Allow: /*.jpg $\$ “$ (nur Indexierung von Dateien mit der Dateiendung ,.jpg“"). 
werke, die sogenannten Thumbnails, werden den Nutzern der Suchmaschine auf ihre Suchanfrage hin in einer Ergebnisliste angezeigt. Diese Vorschaubilder haben aufgrund der starken Komprimierung den Vorteil einer gegenüber den Originalbildern vielfach höheren Anzeigegeschwindigkeit. Die Suchmaschinenbetreiber speichern die verkleinerten Grafiken regelmäßig auf eigenen Servern, um sie so noch schneller abrufbar zu machen und nicht auf die Reaktionszeit anderer Server angewiesen zu sein. Durch diese Komprimierung und Zwischenspeicherung auf eigenen Servern kann eine Suchanfrage schnell und effektiv abgewickelt werden und so gleichzeitig das eigene Angebot im umkämpften Markt für Online-Werbeanzeigen attraktiver gestaltet werden. 


\section{Kapitel Länderbericht Deutschland: Urheberrechtliche Probleme der Google Buchsuche und der Bildersuche im Internet nach deutschem Urheberrecht}

Die Google Buchsuche und das Erstellen, Speichern und Anzeigen von Thumbnails durch Internetsuchmaschinen werfen oftmals identische oder jedenfalls ähnliche urheberrechtliche Probleme auf. Vielfach sind dieselben Rechte des Urhebers betroffen und auch bei der Erfassung der Nutzungshandlungen im Rahmen des Schrankenkataloges des Urheberrechtsgesetzes ergeben sich vergleichbare Schwierigkeiten. Daher sollen beide Geschäftsmodelle im Folgenden hinsichtlich der (möglicherweise) betroffenen Verwertungsrechte der Urheber (sogleich A.) und möglicher Privilegierungen durch gesetzliche Schrankenregelungen (dazu B.) in gemeinsamen Abschnitten dargestellt werden. Dort, wo eines dieser Geschäftsmodelle spezielle Probleme aufwirft, wird jedoch zu differenzieren sein. Neben den Verwertungsrechten der Urheber können durch die Werknutzung beider Geschäftsmodelle auch Urheberpersönlichkeitsrechte verletzt sein (sodann C.). Werden durch die dargestellten Geschäftsmodelle urheberrechtliche Ausschließlichkeitsrechte verletzt, so ist schließlich aufgrund der internationalen Dimension der internetbasierten Nutzungsformen zu prüfen, ob Urheber die Möglichkeit haben, sich gegen diese Verletzung in Deutschland zu wehren, und ob in diesem Fall deutsches Urheberrecht anwendbar ist. Diese Fragen sollen im Rahmen eines Exkurses geklärt werden (unten D.).

\section{A. (Möglicherweise) Betroffene Verwertungsrechte des Urhebers}

Durch die Digitalisierung von Büchern und deren Anzeige im Rahmen der Google Buchsuche und durch das Erstellen, Speichern und Anzeigen von Thumbnails durch Internetsuchmaschinen können ausschließliche Rechte der Urheber betroffen sein, namentlich das Vervielfältigungsrecht, das Recht der öffentlichen Zugänglichmachung und das Bearbeitungsrecht. 


\section{Die Verwendung von Thumbnails im Rahmen der Bildersuche}

1. Verneinung einer relevanten Nutzungshandlung

In der Literatur ist versucht worden, im Falle der Verwendung von Thumbnails im Rahmen der Bildersuche nicht erst auf der Ebene der Rechtswidrigkeit über Lösungsmöglichkeiten nachzudenken, sondern durch eine funktionale Auslegung der betroffenen Verwertungsrechte bereits das Vorliegen einer urheberrechtlich relevanten Nutzung zu verneinen. ${ }^{469}$ Dieser Ansatz stützt sich im Wesentlichen auf Überlegungen des Bundesgerichtshofs in der Kopienversanddienst-Entscheidung ${ }^{470}$ und in weiteren Judikaten zur Bestimmung des Werknutzers in anderen Konstellationen. ${ }^{471}$ In seiner Kopienversanddienst-Entscheidung hat der BGH klargestellt, dass Werknutzer im rechtlichen Sinne nicht derjenige ist, der die Nutzung technisch bewerkstelligt, sondern derjenige, der sich des technischen Vorgangs zum Zweck der Werknutzung bedient. ${ }^{472}$ Die Frage nach der urheberrechtlichen Verantwortung ist daher nicht rein technisch, sondern vielmehr aufgrund einer wertenden Betrachtung zu beurteilen. ${ }^{473}$

Eine Übertragung dieser funktionalen Auslegung auf die Bildersuche ergibt nach Ansicht von Wimmers/Schulz, dass der Suchmaschinenbetreiber nicht Werknutzer ist, da er durch das automatisierte Erstellen und Anzeigen von Thumbnails im Rahmen der Bildersuche eine rein technische

469 So erstmals Wimmers/Schulz, CR 2008, 170 (176f.); zustimmend Conrad, ZUM 2010, 585 (587); Härting, Internetrecht, 3. Aufl., Rn. 816 (anders nun 4. Aufl., Rn. 970); Heymann/Nolte, K\&R 2009, 759 (762f.); Niemann, CR 2009, 97; ders., CR 2009, 661 (663); Nolte, Informationsmehrwertdienste, S. 254 f.; Schricker/Loewenheim/Wild, § 97 Rn. 118; Wäßle, K\&R 2008, 729 (731).

470 BGHZ 141, 13 - Kopienversanddienst.

471 Vgl. BGHZ 79, 350 - Kabelfernsehen in Abschattungsgebieten; BGH, GRUR 1988, 206 - Kabelfernsehen II; BGHZ 123, 149 - Verteileranlagen; Z 134, 250 - CB-Infobank I; BGH, GRUR 1997, 464 - CB-Infobank II; GRUR 2000, 699 - Kabelweitersendung; BGHZ 152, 317 - Sender Felsberg.

472 Vgl. BGHZ 141, 13 (21) - Kopienversanddienst; Z 134, 250 (261) - CB-Infobank $I$.

473 Vgl. zur wertenden Betrachtung in Bezug auf das Senderecht Dreier/Schulze, $\S 20$ Rn. 12; Schricker/Loewenheim/v. Ungern-Sternberg, § 20 Rn. 16, 35, jeweils m.w.N. Ausführlich zum Erfordernis einer wertenden Betrachtung außerdem Wimmers/Schulz, CR 2008, 170 (171ff.) mit Hinweisen zur Rechtsprechung. 
Dienstleistung erbringt. ${ }^{474}$ Da Bildersuchmaschinen in einem rein automatisierten, softwaretechnischen Verfahren textbasierte Hinweise auf Bildinhalte von Websites indexieren, bestehe keinerlei Beziehung zum indexierten Inhalt. Bei wertender Betrachtung sei der Suchmaschinenbetreiber daher nicht Werknutzer, sondern lediglich „notwendiges Werkzeug“ desjenigen, der sich der technischen Leistung „Suchmaschine“ bedient, um seine Inhalte auffindbar zu machen, und desjenigen, der das Internet zur Suche nach (Bild-)Informationen nutze. Schließlich unterliege die Indexierung und der Verbleib der Bildinhalte im Suchindex allein der Kontrolle und Steuerung desjenigen, der diese Inhalte in das Internet einstelle, da die Tätigkeit der Suchmaschinen durch diesen auf der Basis standardisierter Befehle gezielt steuerbar sei. ${ }^{475}$

Im Ergebnis kann diese Argumentation nicht überzeugen. An einer Vergleichbarkeit mit den vorgenannten, vom Bundesgerichtshof zu beurteilenden Konstellationen fehlt es bei der Frage der Verantwortlichkeit von Bildersuchmaschinenbetreibern bei genauerer Betrachtung: Zwar bietet die Dienstleistung „Suchmaschine“ einem Webseitenbetreiber die Möglichkeit, dass die von ihm ins Internet eingestellten Inhalte für andere Internetnutzer auffindbar werden. ${ }^{476}$ Die Entscheidung, Bilder in der Trefferliste als Thumbnails anzuzeigen, und die Auswahl der in der Trefferliste angezeigten Bilder erfolgt jedoch - wenn auch automatisiert - anhand eines Abgleichs der indexierten Bilder mit dem vom Nutzer eingegebenen Suchbegriff allein durch den Suchmaschinenbetreiber. Weder der Betreiber der Website, auf der sich das als Thumbnail angezeigte Originalwerk befindet, noch der Nutzer der Suchmaschine hat somit die alleinige Kontrolle über die Werknutzung. Vielmehr entscheidet letztlich gerade der Suchmaschinenbetreiber durch die Ausgestaltung seines Angebotes über den möglichen und tatsächlichen Umfang der Nutzung. Der Webseitenbe-

474 Vgl. Wimmers/Schulz, CR 2008, 170 (176 f.); zustimmend Conrad, ZUM 2010, 585 (587); Härting, Internetrecht, 3. Aufl., Rn. 816 (anders nun 4. Aufl., Rn. 970); Heymann/Nolte, K\&R 2009, 759 (762 f.); Niemann, CR 2009, 97; ders., CR 2009, 661 (663); Nolte, Informationsmehrwertdienste, S. 254 f.; Schricker/Loewenheim/Wild, § 97 Rn. 118; Wäßle, K\&R 2008, 729 (731).

475 Wimmers/Schulz, CR 2008, 170 (177).

$476 \mathrm{Zu}$ beachten ist allerdings, dass vielfach die durch die Suchmaschine indexierten Bildinhalte ohne oder gegen den Willen des Rechteinhabers ins Internet gestellt worden sein werden. In diesen Fällen kann keinesfalls davon ausgegangen werden, dass der Rechteinhaber sich der Bildsuchmaschine als Dienstleistung bedient. $\mathrm{Zu}$ dieser Konstellation ausführlich unten 4. Kapitel, B.I.2. 
treiber kann die Indexierung von Bildinhalten zwar ganz oder teilweise durch die Aufnahme entsprechender Befehle in die ,robots.txt"-Datei seiner Internetseite verhindern. ${ }^{477}$ Nimmt er solche (Schutz-) Maßnahmen jedoch nicht vor, so werden die Inhalte der Webseite von den Crawlern erfasst, Bilddateien für die Bildersuche indexiert und als Thumbnails in der Ergebnisliste der Suchmaschine angezeigt. Die derartige Ausgestaltung der Crawler-Programme, die nur dann nicht „zugreifen“, wenn der Website-Betreiber die Erfassung von Inhalten seiner Internetseite durch ein technisches Opt Out ausdrücklich untersagt hat, zeigt, dass der maßgebliche „Nutzungsimpuls“ vom Suchmaschinenbetreiber ausgeht.

Diese Beurteilung ändert sich selbst dann nicht, wenn der Betreiber einer Internetseite von der Möglichkeit Gebrauch gemacht hat, durch die entsprechende Gestaltung der „robots.txt"-Datei Suchmaschinen-Crawlern ausdrücklich die Erfassung der Bilddateien zu gestatten. ${ }^{478}$ Auch in diesem Fall erfolgen die wesentlichen Nutzungsschritte durch den Suchmaschinenbetreiber. Dieser muss seine Suchmaschinenleistung so ausgestalten, dass die Bilddateien auch tatsächlich ,wunschgemäß“ erfasst und in die Bildersuchdatenbank aufgenommen werden. Insbesondere obliegt es aber allein dem Suchmaschinenbetreiber, anhand von Algorithmen die automatisierte - Auswahl der in der Trefferliste als Thumbnails angezeigten Bilder so zu gestalten, dass diese dem durch den Suchbegriff gekennzeichneten „Suchinteresse“ des Nutzers möglichst weitgehend entsprechen. Auf diesen entscheidenden Schritt haben weder der Betreiber der Website, auf der sich das als Thumbnail angezeigte Originalwerk befindet, noch der Nutzer der Suchmaschine Einfluss. Gerade dieser letzte Schritt und die erzielte Treffergenauigkeit stellen jedoch für den Nutzer - und somit auch für den Betreiber - den wesentlichen Wert einer Bildersuchmaschine dar. Nur so erreicht der Suchmaschinenbetreiber sein Hauptziel die Steigerung der Attraktivität der eigenen Dienstleistung durch die Verwendung von Thumbnails im Rahmen der Bildersuche.

$477 \mathrm{Zu}$ den technischen Möglichkeiten der Steuerung der Suchmaschinen-Crawler durch die Aufnahme von Befehlen in die ,robots.txt.“-Datei der Internetseite siehe oben 3. Kapitel, B.

478 In diesen Fällen liegt eine Werknutzung durch den Suchmaschinenbetreiber dennoch vor. Diese Nutzung kann jedoch rechtmäßig sein, wenn man das ausdrückliche Opt In des Webseitenbetreibers als Einwilligung in die Werknutzung ansieht; siehe dazu näher unten 4. Kapitel, B.I.2. 
Die Thumbnail-Nutzung dient folglich unmittelbar eigenen wirtschaftlichen Interessen des Suchmaschinenbetreibers. Es liegt daher durch das Umgestalten der Originalbilder und deren Bereithalten und Anzeigen in verkleinerter Form eine eigene urheberrechtlich relevante Nutzungshandlung des Suchmaschinenbetreibers vor. ${ }^{479}$

2. $\S \S 23 \mathrm{~S} .1,16 \mathrm{UrhG}-$ Bearbeitung/Umgestaltung und Vervielfältigungsrecht

a) Herstellung und Speicherung von Thumbnails der Originalwerke

Nach $\S 23$ S. 1 UrhG dürfen Bearbeitungen und andere Umgestaltungen eines Werkes nur mit Einwilligung des Urhebers veröffentlicht oder verwendet werden. Die Herstellung der umgestalteten Fassung ist hingegen, abgesehen von den Fällen des $\S 23 \mathrm{~S} .2 \mathrm{UrhG}$, frei. ${ }^{480}$ Sie ist im Verhältnis zum ebenfalls betroffenen Vervielfältigungsrecht gemäß $§ 16$ UrhG privilegiert und stellt daher noch keine einwilligungsbedürftige Verwertungshandlung dar. ${ }^{481}$ Stellt die Herstellung und Speicherung von Thumbnails der Originalwerke also eine Bearbeitung im Sinne des $\S 23 \mathrm{~S} .1$ UrhG dar, so bedarf deren Veröffentlichung der Zustimmung der Urheber, nicht jedoch die Erstellung selbst. Nimmt man hingegen gar an, dass die Erstellung von verkleinerten Vorschaubildern für die Trefferliste eine freie Benutzung der Originalbilder im Sinne des $\S 24$ Abs. 1 UrhG darstellt, so wäre eine Verwendung der Thumbnails vollständig zustimmungsfrei möglich.

Zur Festlegung, ob eine Bearbeitung nach §23 S. 1 UrhG vorliegt, muss daher eine Abgrenzung zur freien Benutzung im Sinne des $\S 24$

479 So auch BGHZ 185, 291 (297 f.) - Vorschaubilder; OLG Jena, GRUR-RR 2008, 223 (224) - Thumbnails; LG Hamburg, ZUM 2009, 315 (320 f.); Dreier/Schulze, $\S 16$ Rn. 14; Fromm/Nordemann/Dustmann, § 19a Rn. 22; Ensthaler/Weidert/ Weidert/Molle, Handbuch, Kap. 7 Rn. 236; Ernst, jurisPR-WettbR 11/2008 Anm. 4; Kleinemenke, CR 2009, 55; Leistner/Stang, CR 2008, 499 (501); Roggenkamp, K\&R 2007, 328; Schack, MMR 2008, 414 (414 f.); ders., GRUR 2007, 639 (643); Scherzer, jurisPR-ITR 5/2009 Anm. 2; Schricker/Loewenheim/v.Ungern-Sternberg, § 19a Rn. 47; Schricker/Loewenheim/Vogel, § 72 Rn. 26; Wandtke/Bullinger/Heerma, § 16 Rn. 21; Wandtke/Bullinger/Thum, § 72 Rn. 23.

480 Vgl. nur Schricker/Loewenheim/Loewenheim, § 23 Rn. 17 ff. m.w.N.

481 Vgl. Wandtke/Bullinger/Bullinger, § 23 Rn. 25. 
Abs. 1 UrhG erfolgen. Eine freie Benutzung setzt nach dem Gesetzeswortlaut voraus, dass ein selbständiges Werk entsteht, das in freier Benutzung des Werkes eines anderen geschaffen wird. Die Neuschöpfung muss also ihrerseits selbständig schutzfähig sein, und zwar unabhängig von den anregenden Elementen des benutzten Werkes. ${ }^{482}$ Nach ständiger Rechtsprechung ist dies der Fall, wenn angesichts der Eigenart des neuen Werkes die entlehnten eigenpersönlichen Züge des geschützten älteren Werkes verblassen, so dass die Benutzung des älteren Werkes durch das neuere Werk nur noch als Anregung zu einem neuen, selbständigen Werkschaffen erscheint. ${ }^{483}$ Anhand eines Vergleichs der einander gegenüberstehenden Werke ist zu ermitteln, ob und gegebenenfalls in welchem Umfang eigenschöpferische Züge des älteren Werkes übernommen worden sind. Der für eine freie Benutzung erforderliche Abstand zu den entlehnten eigenpersönlichen Zügen des benutzten Werkes kann dabei - selbst bei der Übernahme deutlicher Teile - auch darin liegen, dass das neue Werk zu den entlehnten eigenpersönlichen Zügen des älteren Werkes einen so großen inneren Abstand hält, dass es seinem Wesen nach als selbständig anzusehen ist. ${ }^{484}$ Maßgebend für die Entscheidung ist letztlich ein Vergleich des jeweiligen Gesamteindrucks der Gestaltungen, in dessen Rahmen sämtliche übernommenen schöpferischen Züge in einer Gesamtschau zu berücksichtigen sind; es kommt also entscheidend auf die Übereinstimmungen, nicht dagegen auf die Verschiedenheiten zwischen beiden Werken an. ${ }^{485}$ Für die Ermittlung des jeweiligen Gesamteindrucks und den Vergleich kommt es auf das ästhetische Urteil des für Kunst empfänglichen und mit Kunstfragen einigermaßen vertrauten Menschen an. ${ }^{486}$

Die Annahme des Vorliegens einer freien Benutzung durch das Erstellen von Thumbnails muss also bereits dann ausscheiden, wenn die

482 Vgl. BGH, GRUR 1961, 631 (632) - Fernsprechbuch; Dreier/Schulze, § 24 Rn. 5.

483 Vgl. BGH, GRUR 1994, 191 (193) - Asterix-Persiflagen; BGHZ 154, 260 (267) - Gies-Adler; BGHZ 181, 98 (106f.) - Tripp-Trapp-Stuhl; zuletzt BGH, GRUR 2011, 134 (137) - Perlentaucher, jeweils m.w.N.

484 Siehe BGH, GRUR 2011, 134 (137) - Perlentaucher.

485 Vgl. BGH, GRUR 2004, 855 (857) - Hundefigur; BGHZ 181, 98 (116f.) Tripp-Trapp-Stuhl; Schricker/Loewenheim/Loewenheim, § 24 Rn. 15.

486 St. Rspr., vgl. BGHZ 62, 331 (336f.) - Schulerweiterung; BGH, GRUR 1980, 853 (854) - Architektenwechsel; GRUR 1982, 107 (110) - Kirchen-Innenraumgestaltung; GRUR 2008, 984 (986) - St. Gottfried; BGHZ 181, 98 (109f.) Tripp-Trapp-Stuhl. 
Thumbnails keine selbständigen Werke im Sinne des Urheberrechtsgesetzes darstellen. Die verkleinerten Vorschaubilder dienen dazu, dem Nutzer einen möglichst schnellen und genauen Überblick über den mit Hilfe der Suchanfrage aufgefundenen Inhalt zu verschaffen. Die wesentlichen, prägenden Züge des Originalwerkes müssen zu diesem Zweck gerade erkennbar bleiben, da andernfalls die Vorschau für den Nutzer wenig ergiebig wäre. Die Thumbnails weisen daher aber gerade keinen ausreichenden künstlerischen Abstand zum benutzten Werk auf, so dass nicht von einem Verblassen der individuellen Züge des Originalwerkes gesprochen werden kann. ${ }^{487}$ Ein rein wirtschaftlicher Funktionswandel durch eine grundlegende Veränderung des Verwertungszusammenhanges ohne Schaffung eines selbständigen Werkes kann - zumindest nach deutschem Recht ${ }^{488}$ - die Annahme einer freien Benutzung nicht rechtfertigen. ${ }^{489}$ Zudem werden die Thumbnails durch ein maschinelles, vollständig automatisiertes Verfahren erstellt, ${ }^{490}$ so dass die nach $\S 2$ Abs. 2 UrhG für die urheberrechtliche Schutzfähigkeit erforderliche persönliche geistige Schöpfung nicht gegeben ist. ${ }^{491}$ Das Erstellen von Thumbnails ist aus diesen Gründen nicht als freie Benutzung im Sinne des $\S 24$ Abs. 1 UrhG zu werten. 492

Fraglich ist somit, ob das Erstellen von Thumbnails eine Bearbeitung oder sonstige Umgestaltung im Sinne des $\S 23$ S. 1 UrhG darstellt. Nimmt man mit einem Teil der Literatur an, Bearbeitungen seien nur solche Abwandlungen des Werkes, die die notwendige Schöpfungshöhe besitzen,

487 So auch LG Hamburg, GRUR-RR 2004, 313 (316); OLG Jena, GRUR-RR 2008, 223 (224) - Thumbnails; LG Hamburg, ZUM 2009, 315 (318); vgl. auch Fromm/ Nordemann/A.Nordemann, § 72 Rn.21; Ott, ZUM 2007, 119 (125); Schack, MMR 2008, 414 (415); Schrader/Rautenstrauch, UFITA 2007, 761 (763).

488 Zur Rechtslage nach US-amerikanischem Recht siehe ausführlich unten 5. Kapitel, B.I.

489 Vgl. Leistner/Stang, CR 2008, 499 (501).

490 Zum technischen Hintergrund siehe oben 3. Kapitel, B.

491 So auch LG Hamburg, GRUR-RR 2004, 313 (316); OLG Jena, GRUR-RR 2008, 223 (224); LG Hamburg, ZUM 2009, 315 (318); Leistner/Stang, CR 2008, 499 (501); Ott, ZUM 2007, 119 (125); Schrader/Rautenstrauch, UFITA 2007, 761 (763 f.).

492 Im Ergebnis ebenso Dreier/Schulze, § 24 Rn. 37; Harte-Bavendamm/Jürgens, in: FS Schricker II, S. 33 (47); Kleinemenke, CR 2009, 55; Leistner, IIC 2011, 417 (423); Leistner/Stang, CR 2008, 499 (501); Ott, ZUM 2007, 119 (125); ders., K\&R 2008, 306 (308); Roggenkamp, K\&R 2007, 328; ders., jurisPR-iTR 14/2008 Anm. 2; Schack, MMR 2008, 414 (415); Schrader/Rautenstrauch, UFITA 2007, 761 (763 f.); Schricker/Loewenheim/Loewenheim, § 24 Rn. 15. 
um selbst als Bearbeitung nach $\S 3$ UrhG urherberrechtschutzfähig zu sein, ${ }^{493}$ so stellen Thumbnails keine Bearbeitung im Sinne des $§ 23$ S. 1 UrhG dar. Dieser Auffassung folgend unterfielen die Thumbnails als Änderungen des Ausgangswerks ohne eigenen Werkcharakter jedoch als ,andere Umgestaltungen" dennoch der Regelung des $§ 23$ S. 1 UrhG. ${ }^{494}$ Die Gegenauffassung, die sich auf die amtliche Begründung zum Urheberrechtsgesetz stützt, sieht hingegen den Unterschied zwischen Bearbeitung und anderer Umgestaltung darin, dass die Bearbeitung eine dem Originalwerk dienende Funktion habe und dieses einem veränderten Zweck anpassen wolle, während dies bei der Umgestaltung nicht der Fall sei. ${ }^{495}$ Folgt man dieser Ansicht, so stellen die Thumbnails eine Bearbeitung dar, da sie als Vorschau auf das Originalbild eine diesem dienende Funktion haben. 496

Während die zweitgenannte Ansicht vorzugswürdig erscheint, spielt die strittige Frage der Abgrenzung von Bearbeitungen und sonstigen Umgestaltungen im Sinne dieser Norm hier letztlich keine entscheidende Rolle, da sowohl für die Verwendung einer Bearbeitung als auch die einer sonstigen Umgestaltung stets die Einwilligung des Urhebers erforderlich ist.

493 Vgl. Fromm/Nordemann/A.Nordemann, §§ 23/24 Rn. 10; Rehbinder, Urheberrecht, Rn. 216; Schack, Urheberrecht, Rn. 268; ders., Kunst und Recht, Rn. 332; Wandtke/Bullinger/Bullinger, $\S 23$ Rn. 3; Wandtke/Wandtke, Urheberrecht, Kapitel 3 Rn. $165 \mathrm{ff}$.

494 Vgl. OLG Jena, GRUR-RR 2008, 223 (224) - Thumbnails; Dreier/Schulze, § 23 Rn. 7; Fromm/Nordemann/A.Nordemann, §§ 23/24 Rn. 10; Ott, K\&R 2008, 306 (308); Roggenkamp, jurisPR-iTR 14/2008 Anm. 2; Schrader/Rautenstrauch, UFITA 2007, 761 (763 f.); Wandtke/Bullinger/Bullinger, § 23 Rn. 4; Wandtke/ Wandtke, Urheberrecht, Kapitel 3 Rn. 165. A.A. Dreier, in: FS Krämer, S. 225 (228); Hüsch, CR 2010, 452 (453 f.); Schack, MMR 2008, 414 (415) und Schricker/Loewenheim/Vogel, § 72 Rn. 26, die erst bei größeren Abweichungen vom Ausgangswerk eine ,andere Umgestaltung“ i.S.d. §23 S. 1 UrhG annehmen möchten und daher im Erstellen der Thumbnails lediglich eine Vervielfältigung i.S.d. § 16 UrhG sehen.

495 Vgl. BT-Drs. IV/270, S. 51; OLG Düsseldorf, GRUR 1990, 263 (266) - Automaten-Spielplan; KG, GRUR-RR 2004, 129 (131) - Modernisierung einer Liedaufnahme, Chakraborty, Freie Benutzung, S. 33 f.; Dreier/Schulze, § 23 Rn. 5 ff.; Leistner/Stang, CR 2008, 499 (501); Schricker/Loewenheim/Loewenheim, § 23 Rn. 4 m.w.N.

496 A.A. OLG Jena, GRUR-RR 2008, 223 (224) - Thumbnails, das annimmt, die Verkleinerung auf Thumbnail-Größe diene allein der technischen Ausgestaltung der Bildersuche und habe daher keine eigenständige, dem Werk dienende Funktion. 
Das Erstellen von Thumbnails unterfällt somit der Regelung des $§ 23$ S. 1 UrhG.

b) Verhältnis von $\S 23$ UrhG zu $\S 16$ UrhG

Die Speicherung der Thumbnails auf den Servern der Suchmaschinenbetreiber könnte neben der Bearbeitung beziehungsweise Umgestaltung eine Vervielfältigung der Originalwerke im Sinne des $\S 16$ Abs. 1 UrhG sein. Nach $\S 16$ Abs. 1 UrhG ist das Vervielfältigungsrecht das Recht, Vervielfältigungsstücke eines Werkes herzustellen, gleichgültig ob vorübergehend oder dauerhaft und unabhängig vom Verfahren und der Anzahl. Der Begriff der Vervielfältigung ist dabei umfassend zu verstehen. Vervielfältigung ist jede körperliche Festlegung des Werkes, die geeignet ist, das Werk den menschlichen Sinnen auf irgendeine Weise unmittelbar oder mittelbar wahrnehmbar zu machen. ${ }^{497}$

Eine Vervielfältigung liegt im Rahmen der Bildersuche zum einen bereits durch die vorübergehende Speicherung der auf den Webseiten durch die Crawler aufgefundenen Bilder in Originalgröße auf den Servern des Suchmaschinenbetreibers vor. Diese Speicherung ist als Vorstufe zur Erstellung und Speicherung der verkleinerten Thumbnails erforderlich. Dass die Bilder in Originalgröße anschließend wieder von den Servern des Suchmaschinenbetreibers gelöscht werden, ändert nichts daran, dass eine vorübergehende körperliche Festlegung im Sinne des §16 Abs. 1 UrhG vorliegt.

Unter das Vervielfältigungsrecht fallen jedoch nicht nur identische Festlegungen des Originalwerkes, sondern auch solche in veränderter Form, etwa in einen anderen Werkstoff, in eine andere Dimension oder in eine andere Größe. ${ }^{498}$ Eine Festlegung ist demnach stets dann als Vervielfältigung des Ausgangswerkes anzusehen, wenn sie ohne eigene schöpferische Ausdruckskraft geblieben ist und noch im Schutzbereich des Originals liegt, weil dessen Eigenart auch in der Nachbildung erhalten bleibt

497 Vgl. Amtl. Begr., BT-Drs. IV/270, S. 47; ebenso schon RGZ 107, 277 (279); BGHZ 17, 266 (269 f.) - Grundig-Reporter.

498 Vgl. BGH, GRUR 1963, 441 (443) - Mit Dir allein; GRUR 1988, 533 (535) Vorentwurf II; GRUR 1991, 529 (530) - Explosionszeichnungen; Dreier/Schulze, $\S 16$ Rn. 10; Fromm/Nordemann/Dustmann, § 16 Rn. 11; Schricker/Loewenheim/ Loewenheim, § 16 Rn. 8 m.w.N. 
und ein übereinstimmender Gesamteindruck besteht. ${ }^{499}$ So liegt der Fall bei der Erstellung und Speicherung verkleinerter und komprimierter Thumbnails als Vorschaubilder für die Originalwerke: Der Gesamteindruck der Originalbilder soll trotz erheblicher Verkleinerung und reduzierter Qualität gerade gewahrt werden, um dem Nutzer einen möglichst guten Überblick über die Relevanz der in der Trefferliste angezeigten Bilder für seine Suchanfrage zu ermöglichen. ${ }^{500}$ In Form der Bearbeitungen (oder anderen Umgestaltungen) im Sinne des $\S 23$ S. 1 UrhG erfolgt eine körperliche Festlegung des Originalwerkes; das Erstellen und Speichern der Thumbnails ist somit eine Vervielfältigung im Sinne des $\S 16$ Abs. 1 UrhG. ${ }^{501}$

Das Vervielfältigungsrecht ist ein Verbotsrecht. Dem Urheber des Originalwerkes stünde somit nach dem Wortlaut des Gesetzes die Möglichkeit zu, das Erstellen und Speichern von Thumbnails wegen eines Eingriffs in $\S 16$ UrhG zu untersagen. ${ }^{502}$ Nach $\S 23 \mathrm{~S} .1$ UrhG steht dem Urheber hingegen nur ein Verbietungsrecht hinsichtlich der Veröffentlichung und Verwertung der Thumbnails zu, das Erstellen der Bearbeitung selbst ist hingegen auch ohne seine Einwilligung - und sogar gegen seinen ausdrücklichen Willen - zulässig. ${ }^{503}$

Wie diese Konfliktsituation zwischen der Regelung des $\S 16$ UrhG und des $\S 23$ UrhG aufzulösen ist, ist umstritten. Nach einer Ansicht schließen

499 Vgl. BGH, GRUR 1965, 45 (47) - Stadtplan; GRUR 1988, 533 (535) - Vorentwurf II; BGHZ 185, 291 (296) - Vorschaubilder; Dreier/Schulze, § 16 Rn. 10.

500 Vgl. bereits oben 4. Kapitel, A.I.1. zum Vorliegen einer urheberrechtlich relevanten Nutzungshandlung.

501 So auch LG Hamburg, GRUR-RR 2004, 313 (316); Dreier/Schulze, § 16 Rn. 10; Fromm/Nordemann/Nordemann, 9. Aufl., § 16 Rn. 1; Rehbinder, Urheberrecht, Rn. 318; Schack, Urheberrecht, Rn. 417; Schricker/Loewenheim/Loewenheim, $\S 16$ Rn. 9; Wandtke/Bullinger/Heerma, § 16 Rn. 21; a.A. Fromm/Nordemann/ Dustmann, § 16 Rn. 11; HK-UrhR/Dreyer, § 16 Rn. 9. Ausdrücklich offen gelassen von OLG Jena, GRUR-RR 2008, 223 - Thumbnails mit dem Hinweis, dass etwaige Vervielfältigungshandlungen im konkreten Fall unstreitig in den USA stattgefunden hätten und sich daher der deutschen Gerichtsbarkeit entzögen. Kritisch zu dieser Annahme des OLG Jena, Schack, MMR 2008, 414.

502 Vgl. Dreier/Schulze, § 16 Rn. 18; Fromm/Nordemann/Dustmann, § 15 Rn. 1; Wandtke/Bullinger/Heerma, § 15 Rn. 5; Schrader/Rautenstrauch, UFITA 2007, 761 (766).

503 Vgl. Dreier/Schulze, § 23 Rn. 16 ff.; Fromm/Nordemann/A.Nordemann, § 23/24 Rn. 15; Schricker/Loewenheim/Loewenheim, § 23 Rn. 17 ff.; Wandtke/Bullinger/ Bullinger, §23 Rn. 1, 7 f. 
sich Bearbeitung beziehungsweise Umgestaltung und Vervielfältigung aus. Bearbeitungen und Umgestaltungen im Sinne des $\S 23$ UrhG sind daher auch nicht als Vervielfältigungsstücke des Originalwerkes zu sehen. ${ }^{504}$ Nach der Gegenauffassung kann es sich bei Bearbeitungen zugleich um Vervielfältigungen nach $\S 16$ UrhG handeln. Die Herstellung der Bearbeitung ist jedoch durch $\S 23$ UrhG als lex specialis privilegiert und stellt daher keine einwilligungsbedürftige Verwertungshandlung dar. ${ }^{505}$ Innerhalb dieser Ansicht wird teilweise anhand eines quantitativen Elements weiter differenziert. So sollen Bearbeitungen und Umgestaltungen unter das Vervielfältigungsrecht fallen, wenn sie nur eine geringfügige Abweichung vom Originalwerk darstellen. ${ }^{506}$

Um die Regelung des $\S 23 \mathrm{~S} .1$ UrhG nicht weitgehend leer laufen zu lassen, erscheint es vorzugswürdig, die Norm als Sonderregelung mit Vorrang vor der allgemeinen Regel des $\S 16$ UrhG anzusehen. ${ }^{507}$ Letztlich kann jedoch auch hier eine Entscheidung zugunsten einer der vorgenannten Ansichten dahinstehen, da nach beiden Auffassungen in der Herstellung und Speicherung der Thumbnails jedenfalls eine urheberrechtlich relevante Nutzungshandlung gesehen wird - in Form nur einer Vervielfältigung gemäß $\S 16$ UrhG, als Bearbeitung nach $\S 23 \mathrm{~S} .1 \mathrm{UrhG}$ oder als Vervielfältigung einer Bearbeitung nach $\S \S 16,23$ S. 1 UrhG.

\section{3. § 19a UrhG - Recht der öffentlichen Zugänglichmachung}

Neben dem Bearbeitungs- und Vervielfältigungsrecht könnte durch das Bereitstellen der Thumbnails im Rahmen der Bildersuche auch das Recht der öffentlichen Zugänglichmachung nach §19a UrhG betroffen sein. $\S 19$ a UrhG behält dem Urheber das ausschließliche Recht vor, sein Werk in Netzwerke - insbesondere das Internet - einzuspeisen und es so Mitgliedern der Öffentlichkeit drahtlos oder drahtgebunden von Orten und zu Zeiten ihrer Wahl zugänglich zu machen. Gegenstand des Rechts der öffentlichen Zugänglichmachung ist das Bereitstellen von Werken zum in-

504 Vgl. Möhring/Nicolini/Kroitzsch, § 16 Rn. 10.

505 Vgl. Dreier/Schulze, § 16 Rn. 5; Wandtke/Bullinger/Heerma, § 16 Rn. 6; Wandtke/Bullinger/Bullinger, $\$ 23$ Rn. 25.

506 Vgl. Dreier/Schulze, § 23 Rn. 16.

507 So insbesondere Wandtke/Bullinger/Heerma, $\S 16$ Rn. 6; Wandtke/Bullinger/Bullinger, §23 Rn. 25. 
teraktiven Abruf. Die maßgebliche Verwertungshandlung ist das Zugänglichmachen des Werkes für den interaktiven Abruf. Ein Zugänglichmachen im Sinne dieser Vorschrift liegt also vor, sobald Dritten der Zugriff auf das sich in der Zugriffssphäre des Vorhaltenden befindende geschützte Werk eröffnet wird; auf den tatsächlichen Abruf des Werkes kommt es folglich nicht an. ${ }^{508}$

Eine öffentliche Zugänglichmachung im Sinne dieser Norm käme beim Bereitstellen von Thumbnails grundsätzlich sowohl im Hinblick auf das Originalwerk als auch hinsichtlich der Bearbeitung - also des Thumbnails selbst - in Betracht. Ob in dieser Konstellation auch das Originalwerk öffentlich zugänglich gemacht wird, ist umstritten, ${ }^{509}$ kann letztlich jedoch dahinstehen, weil jedenfalls die Thumbnails selbst zugänglich gemacht werden und somit eine öffentliche Zugänglichmachung der Bearbeitungen im Sinne der $\S \S 19$ a, 23 S. 1 UrhG vorliegt, ${ }^{510}$ die in die ausschließlichen Rechte des Urhebers eingreift, da jede Art der Verwertung einer Bearbeitung erlaubnispflichtig ist. 511

Beim Abruf der Thumbnails durch die Suchmaschinennutzer werden zudem Kopien im Arbeitsspeicher des Computers beim jeweiligen Nutzer angefertigt. Auch das Zwischenspeichern im Arbeitsspeicher eines Computers ist eine Vervielfältigung, da es auf eine Dauerhaftigkeit der Festlegung ausdrücklich nicht ankommt. ${ }^{512}$ Bei diesen Kopien im Arbeitsspei-

508 Vgl. BGH, GRUR 2009, 845 (847) - Internet-Videorecorder; BGHZ 185, 291 (297) - Vorschaubilder; zuletzt BGH, GRUR 2011, 56 (58) - Session-ID; Dreier/ Schulze, § 19a Rn. 6; Wandtke/Bullinger/Bullinger, § 19a Rn. 10.

509 Ablehnend Schrader/Rautenstrauch, UFITA 2007, 761 (769); wohl auch Dreier/ Schulze, § 19a Rn. 6; a.A. LG Hamburg, ZUM 2009, 315 (318); Wandtke/Bullinger/Thum, § 72 Rn. 23.

510 So auch LG Hamburg, GRUR-RR 2004, 313 (316) (allerdings noch vor Inkrafttreten des § 19a UrhG); LG Hamburg, ZUM 2009, 315 (318 f.); Kleinemenke, CR 2009, 55; Leistner, IIC 2011, 417 (424); Leistner/Stang, CR 2008, 499 (502); Ott, ZUM 2007, 119 (125); Schricker/Loewenheim/v.Ungern-Sternberg, §19a Rn. 47; Wandtke/Bullinger/Heerma, § 16 Rn. 21. Das OLG Jena, GRUR-RR 2008, 223 (223 f.) - Thumbnails stellt ebenfalls auf die Verwertung einer Umgestaltung ab, sieht diese jedoch als einen Eingriff in ein unbenanntes Verwertungsrecht nach $\S 15$ Abs. 2 UrhG an.

511 Vgl. oben 4. Kapitel, A.I.2.

512 Dies war früher umstritten, dürfte jedoch heute als ganz h.M. gelten, vgl. OLG Hamburg, GRUR 2001, 831 (832) - Roche Lexikon Medizin; Dreier/Schulze, § 16 Rn. 13 f.; Dreier/Schulze, §69c Rn. 8; Schricker/Loewenheim/Loewenheim, $\S 69 \mathrm{c} \mathrm{Rn.} \mathrm{7;} \mathrm{Wandtke/Bullinger/Heerma,} \mathrm{§} 16$ Rn. 16, jeweils m.w.N. 
cher handelt es sich somit erneut um Vervielfältigungen der Bearbeitung im Sinne der $\S \S 16,23$ S. 1 UrhG. Diese können dem Suchmaschinenbetreiber ebenfalls über die Grundsätze der Störerhaftung zugerechnet werden. ${ }^{513}$

\section{Google Buchsuche}

Auch im Rahmen der Google Buchsuche sind ausschließliche Rechte des Urhebers betroffen, namentlich das Vervielfältigungsrecht ( $\$ 16$ UrhG) und das Recht der öffentlichen Zugänglichmachung (§ 19a UrhG).

\section{1. §16 UrhG - Vervielfältigungsrecht}

Das Vervielfältigungsrecht gemäß $§ 16$ UrhG ist umfassend und erstreckt sich auf Vervielfältigungen jeglicher Art. Eine Vervielfältigung ist dabei jede körperliche Festlegung eines Werkes, die geeignet ist, dieses den menschlichen Sinnen auf irgendeine Weise mittelbar oder unmittelbar wahrnehmbar zu machen. ${ }^{514}$ Eine solche körperliche Festlegung erfolgt bei der Google Buchsuche gleich mehrfach. Zunächst durch die optische Erfassung des Werkes im Rahmen des Scanvorganges und die anschließende Speicherung als Bilddatei und sodann durch die darauf folgende Umcodierung der Bilddatei in eine maschinenlesbare Textdatei. Selbst wenn es bei diesem zweiten Schritt zu Fehlern kommen sollte, so dass kein exaktes Vervielfältigungsstück des Originalwerkes mehr vorliegt, ${ }^{515}$ ändert sich diese Bewertung nicht, da nicht nur identische, sondern auch nahezu identische Vervielfältigungen und Teilvervielfältigungen, wenn in diesen die geistige Schöpfung des Urhebers zum Ausdruck kommt, von $\S 16$ UrhG erfasst werden. ${ }^{516}$ Das Vervielfältigungsrecht des Urhebers

513 So im Ergebnis ebenfalls LG Hamburg, GRUR-RR 2004, 313 (315); Leistner/ Stang, CR 2008, 499 (502).

514 Vgl. Amtl. Begr., BT-Drs. IV/270, S. 47; BGHZ 17, 266 (269 f.) - Grundig-Reporter.

$515 \mathrm{Zu}$ den urheberpersönlichkeitsrechtlichen Implikationen solcher Konvertierungsfehler siehe unten 4. Kapitel, C.II.2.

516 Vgl. zur nahezu identischen Vervielfältigung BGH, GRUR 1988, 533 (535) Vorentwurf II; GRUR 1991, 529 (53) - Explosionszeichnungen; Dreier/Schulze, 
nach § 16 UrhG ist durch Googles Vorgehen somit gleich zweifach betroffen. ${ }^{517}$

Zudem stellt auch der Abruf der Suchergebnisse durch die Nutzer der Google Buchsuche aufgrund der damit einhergehenden Anfertigung einer (zumindest vorübergehenden) Kopie im (Arbeits-)Speicher des jeweiligen Computers einen Eingriff in das Vervielfältigungsrecht des Urhebers dar. ${ }^{518}$ Hier erfolgt freilich eine mögliche Urheberrechtsverletzung nicht unmittelbar durch Google als Betreiberin der Buchsuche, sondern durch den Nutzer selbst, der die (rechtswidrige) Vorlage abruft und vervielfältigt. Eine Haftung von Google für diese Vervielfältigungshandlungen käme folglich nur dann in Betracht, wenn dem Suchmaschinenbetreiber die Nutzungshandlung zurechenbar ist und er deshalb als (mittelbarer) Störer haftet. Eine Verantwortlichkeit nach den Grundsätzen der Störerhaftung setzt voraus, dass der Störer - ohne Täter oder Teilnehmer zu sein - in irgendeiner Weise willentlich und adäquat kausal zur Verletzung eines geschützten Gutes beiträgt. ${ }^{519}$ Dabei kann als Beitrag auch die Unterstützung der Handlung eines eigenverantwortlich handelnden Dritten genügen, sofern der in Anspruch Genommene die rechtliche Möglichkeit zur Verhinderung dieser Handlung hatte. ${ }^{520}$ Nach der Rechtsprechung des Bundesgerichtshofs darf die Störerhaftung jedoch nicht über Gebühr auf Dritte erstreckt werden, die die rechtswidrige Handlung nicht selbst vorgenommen haben. Daher setzt die Haftung als Störer die Verletzung zumutbarer Verhaltenspflichten, insbesondere Prüfpflichten, voraus, deren Umfang sich danach bestimmt, ob und inwieweit dem als Störer in Anspruch Genom-

$\S 16$ Rn. 10; zur Teilvervielfältigung siehe EuGH, Urt. v. 16.7.2009, C-5/08, Slg. 2009, I-6569, Rn. 47 ff. = GRUR 2009, 1041 (1044) - Infopaq International A/S./. Danske Dagblades Forening; OLG Köln, ZUM 2011, 414 (416) - Suchdienst für Zeitungsartikel; Wandtke/Bullinger/Bullinger, § 2 Rn. 42.

517 So im Ergebnis auch Bohne/Elmers, WRP 2009, 586 (588); Bohne/Krüger, WRP 2009, 599 (606); Heckmann, AfP 2007, 314 (315); Lucke, Google Buchsuche, S. 70 f., 75 f.; Meyer, K\&R 2007, 177 (183); Ott, GRUR Int. 2007, 562 (564).

518 Ebenso Meyer, K\&R 2007, 177 (183); allgemein zur (weiterhin) umstrittenen Frage, ob bei der bloß vorübergehenden Festlegung im Arbeitsspeicher bereits eine Vervielfältigung vorliegt, siehe OLG Hamburg, GRUR 2001, 831 - Roche Lexikon Medizin; Dreier/Schulze, § 16 Rn. 13 m.w.N.

519 Siehe nur BGH, GRUR 2010, 633 (634 f.) - Sommer unseres Lebens m.w.N.

520 Siehe zuletzt BGH, GRUR 2012, 651 (652) - regierung-oberfranken.de. 
menen nach den Umständen eine Prüfung zuzumuten ist. ${ }^{521}$ Das Geschäftsmodell der Google Buchsuche zielt gerade darauf ab, Nutzern fremde Werke ganz oder teilweise zugänglich zu machen, was zwingend eine Vervielfältigung der angezeigten Werkausschnitte im Arbeitsspeicher der Nutzer erfordert. Jedenfalls bei einem weit verstandenen Störerbegriff ist deshalb nicht auszuschließen, dass ein Gericht bei der Beurteilung der Google Buchsuche auch diese Vervielfältigungen durch die Nutzer selbst Google nach den Grundsätzen der Störerhaftung zurechnen würde.

\section{2. § 19a UrhG - Recht der öffentlichen Zugänglichmachung}

Es könnte zudem durch die Ermöglichung der Volltextsuche und die Anzeige der Suchergebnisse ein Eingriff in das Recht der öffentlichen $\mathrm{Zu}$ gänglichmachung gemäß $§ 19 \mathrm{a}$ UrhG vorliegen. Rechtlich grundsätzlich unproblematisch ist die vollständige Darstellung solcher Werke, bezüglich deren öffentlicher Zugänglichmachung im Rahmen des Partner-Programms die Einwilligung des Rechteinhabers vorliegt. Problematisch sind hingegen die Fälle, in denen eine solche Einwilligung fehlt und dem Nutzer anstelle einer vollständigen Wiedergabe beim Abruf der Suchergebnisse lediglich ermöglicht wird, einzelne Textpassagen der ausgewählten Werke, sogenannte Snippets, einzusehen. Allerdings kommt eine Verletzung des § 19a UrhG nur dann in Betracht, wenn es sich bei der Anzeige der Textausschnitte um die öffentliche Zugänglichmachung eines Werkes im Sinne des $\S 2$ UrhG handelt, die Snippets selbst also urheberrechtlichen Schutz genießen. Die Textauszüge zeigen die Fundstelle des vom Nutzer gesuchten Ausdrucks in einem bestimmten Werk, indem der gesuchte Ausdruck im Zusammenhang der ihn umgebenden Wörter oder Sätze dargestellt wird. Die Snippets haben daher in der Regel eine Länge von meh-

521 Vgl. grundlegend zur Störerhaftung im Urheberrecht BGH, GRUR 2010, 633 Sommer unseres Lebens mit Anm. Stang/Hühner, GRUR 2010, 636 f.; zur Störerhaftung im Markenrecht BGH, GRUR 2004, 860 - Internet-Versteigerung I; GRUR 2007, 708 - Internet-Versteigerung II; GRUR 2011, 1038 - Stiftparfüm; grundlegend zur wettbewerblichen (täterschaftlichen) Haftung für mittelbare Schutzrechtsverletzungen wegen des Verstoßes gegen Prüfungs- und Verkehrspflichten BGH, GRUR 2007, 890 - Jugendgefährdende Medien bei eBay. Ausführlich zur Störerhaftung und mittelbaren Schutzrechtsverletzung im Urheber-, Kennzeichen- und Wettbewerbsrecht Leistner, GRUR-Beil. 2010, 1 ff.; Leistner/ Stang, WRP 2008, $533 \mathrm{ff}$. 
reren Halbsätzen oder maximal einigen wenigen vollständigen Sätzen. Eine Schutzfähigkeit als Sprachwerk im Sinne des $§ 2$ Abs. 1 Nr. 1 UrhG kommt grundsätzlich auch für sehr kurze (Wort-)Gebilde in Betracht, also potentiell auch für einzelne Teile eines Buches bis hin zu einzelnen Sätzen. ${ }^{522}$ Unzweifelhaft ist dies der Fall, wenn es sich bei dem aus wenigen Worten bestehenden betroffenen Werkteil um eine persönliche geistige Schöpfung im Sinne des $\S 2$ Abs. 2 UrhG handelt, in diesem also eine hinreichende schöpferische Eigenart zum Ausdruck kommt, so dass er die nach deutschem Recht grundsätzlich notwendige Schöpfungshöhe erreicht. ${ }^{523}$ Das Vorliegen einer persönlich geistigen Schöpfung ist zwar in Einzelfällen nicht auszuschließen, wird jedoch in der Regel aufgrund mangelnder Schöpfungshöhe nicht anzunehmen sein. ${ }^{524}$

Durch horizontale Harmonisierungsbestrebungen der EU zeichnet sich jedoch eine Tendenz ab, allgemein geringere Anforderungen an die Schutzfähigkeit zu stellen und somit auch Werken mit geringerer Individualität urheberrechtlichen Schutz zuzugestehen. ${ }^{525}$ Diese Tendenz hat der EuGH in seiner Entscheidung in Sachen ,Infopaq/DDF“ im Rahmen einer Frage zur Auslegung des Vervielfältigungsrechts der InfoSoc-Richtlinie dahingehend konkretisiert, dass grundsätzlich für alle Werkarten als Mindestschutzvoraussetzung der für den Schutz von Computerprogrammen, ${ }^{526}$ Datenbanken ${ }^{527}$ und Fotografien ${ }^{528}$ durch europäisches Recht vorgegebene

522 Vgl. BGHZ 9, 262 (267 f.) - Lied der Wildbahn; BGHZ 116, 136 (144 ff.) - Leitsätze; OLG Frankfurt, GRUR 2008, 249 (251) - Abstracts; Dreier/Schulze, § 3 Rn. 17; Schricker/Loewenheim/Loewenheim, § 2 Rn. 89 f.; Raue, GRUR 2011, $1088 \mathrm{f}$.

523 Vgl. BGHZ 116, 136 (144 f.) - Leitsätze.

524 Ähnlich Heckmann, AfP 2007, 314 (316); Ott, GRUR Int. 2007, 562 (564).

525 Vgl. Dreier/Schulze, § 2 Rn. 22; Leistner, Rechtsschutz von Datenbanken, S. 66 f.; Schulze, GRUR 2009, 1019.

526 Siehe Art. 1 Abs. 3 S. 1 Richtlinie 91/250/EWG des Rates vom 14. Mai 1991 über den Rechtsschutz von Computerprogrammen (jetzt: Art. 1 Abs. 3 S. 1 Richtlinie 2009/24/EG des Europäischen Parlaments und des Rates vom 23. April 2009 über den Rechtsschutz von Computerprogrammen (kodifizierte Fassung)). Siehe zur Computerprogramm-RL auch unten 6. Kapitel, B.II.

527 Siehe Art. 3 Abs. 1 S. 2 Richtlinie 96/9/EG des Europäischen Parlaments und des Rates vom 11. März 1996 über den rechtlichen Schutz von Datenbanken. Ausführlich zu dieser Regelung Gaster, Rechtsschutz von Datenbanken, Art. 3 Rn. 115 ff.; Leistner, Rechtsschutz von Datenbanken, S. 66 ff. Siehe zur Datenbank-RL auch unten 6. Kapitel, B.II.

528 Siehe Art. 6 S. 1 Richtlinie 93/98/EWG des Rates vom 29. Oktober 1993 zur Harmonisierung der Schutzdauer des Urheberrechts und bestimmter verwandter 
(niedrigere) Maßstab einer „eigenen geistigen Schöpfung“ des Urhebers verlangt werden soll. ${ }^{529}$ Auch (sehr) kurze Werkteile, etwa auch Snippets, können demnach urheberrechtlichen Schutz genießen, wenn sie bestimmte Elemente enthalten, die die eigene geistige Schöpfung ihres Urhebers - also ein Mindestmaß an Individualität - zum Ausdruck bringen. Diese grundlegenden Aussagen zum Werkbegriff hat der EuGH inzwischen - im Hinblick auf verschiedene Werkarten - näher konkretisiert und differenziert. ${ }^{530}$ In der Entscheidung Painer/Standard ${ }^{531}$ hat der Gerichtshof in Bezug auf Fotografien im Sinne des Art. 6 der Richtlinie 93/98/EWG ${ }^{532}$ festgestellt, um eine „eigene geistige Schöpfung“ handele es sich dann, wenn in dem Werk die Persönlichkeit des Urhebers zum Ausdruck komme. Dies sei dann der Fall, wenn er bei der Herstellung des Werkes seine schöpferischen Fähigkeiten zum Ausdruck bringen konnte, indem er frei kreative Entscheidungen getroffen hat. ${ }^{533}$ Das Merkmal der im Werk zum

Schutzrechte (jetzt: Art. 6 S. 1 Richtlinie 2006/116/EG des Europäischen Parlaments und des Rates vom 12. Dezember 2006 über die Schutzdauer des Urheberrechts und bestimmter verwandter Schutzrechte (kodifizierte Fassung)).

529 EuGH, Urt. v. 16.7.2009, C-5/08, Slg. 2009, I-6569 = GRUR 2009, 1041 (1044) - Infopaq International A/S./. Danske Dagblades Forening.

530 Siehe etwa zur Urheberrechtsschutzfähigkeit von Computerprogrammen und ihrer Einzelteile EuGH, Urt. v. 22.12.2010, C-393/09, Rn. 44 ff., Abl. EU 2011, C 63/08 = GRUR 2011, $220-$ BSA./. Kulturministerium; EuGH, Urt. v. 2.5.2012, C-406/10, Rn. 29 ff., 63 ff., Abl. EU 2012, C 174/05 = GRUR 2012, 814 - SAS Institute Inc... World Programming Ltd.; zur Schutzfähigkeit von Sportereignissen und der Sendefolge EuGH, Urt. v. 4.10.2011, C-403/08 und C-429/08, Rn. 96 ff., Abl.EU 2011, C 347/02 = GRUR 2012, 156 - Football Association Premier League Ltd. u.a... QC Leisure u.a. und Murphy./. Media Protection Services Ltd.; zur Schutzfähigkeit von Fotografien EuGH, Urt. v. 1.12.2011, C-145/10, Rn. 86 ff., Abl. EU 2012, C 32/07 = GRUR 2012, 166 - Painer./. Standard Verlags GmbH u.a; zum urheberrechtlichen Schutz von Datenbanken EuGH, Urt. v. 1.3.2012, C-604/10, Rn. 29 ff., Abl. EU 2012, C 118/05 = GRUR 2012, 386 - Football Dataco Ltd. u.a../. Yahoo! UK Ltd.

531 EuGH, Urt. v. 1.12.2011, C-145/10, Abl. EU 2012, C 32/07 = GRUR 2012, 166 Painer./. Standard Verlags GmbH u.a.

532 Entspricht Art. 6 der Richtlinie 2006/116/EG (sog. Schutzdauer-Richtlinie).

533 Siehe EuGH, C-145/10, Rn. 88 f. = GRUR 2012, 166 (168) - Painer./. Standard VerlagsGmbH u.a. Entsprechend hat der EuGH die Werkeigenschaft abgelehnt für Sportereignisse, die Spielregeln unterliegen, die für eine künstlerische Freiheit im Sinne des Urheberrechts keinen Raum lassen; siehe EuGH, Urt. v. 4.10.2011, C-403/08 und C-429/08, Rn. 98 = GRUR 2012, 156 (160) - Football Association Premier League Ltd. u.a../. QC Leisure u.a. und Murphy./. Media Protection Services Ltd. 
Ausdruck kommenden Persönlichkeit entnimmt der EuGH dem 17. Erwägungsgrund der Richtlinie 93/98/EWG. ${ }^{534}$ Ob dieses zusätzliche Merkmal der im Werk zum Ausdruck kommenden Persönlichkeit des Urhebers nur bei der Bestimmung der Schutzfähigkeit von Fotografien Geltung beansprucht oder ob es allgemein bei allen Werkarten eine Schutzvoraussetzung darstellen soll, beantwortet der Gerichtshof nicht. Für Letzteres spricht jedoch, dass der EuGH seine Begründung nicht als bereichsspezifische Abweichung, sondern als Fortentwicklung und Präzisierung der bisherigen Rechtsprechung zum Werkbegriff formuliert. ${ }^{535}$ Es erscheint daher wahrscheinlich, dass der EuGH in Zukunft unabhängig von der Werkart für die Schutzfähigkeit einer „eigenen geistigen Schöpfung“ die - gegenüber den Vorgaben der Infopaq-Entscheidung modifizierte, leicht erhöhte - Anforderung einer gewissen persönlichkeitsrechtlichen Prägung durch die Ausnutzung eines Gestaltungsspielraumes durch den Urheber stellen wird. ${ }^{536}$

Der Gerichtshof hat weiter festgestellt, keine der Richtlinien, die auf eine „eigene geistige Schöpfung“ abstellen, enthalte einen Anhaltspunkt dafür, dass sich der Umfang des Schutzes nach etwaigen Unterschieden bei den künstlerischen Gestaltungsmöglichkeiten bei der Herstellung verschiedener Kategorien von Werken richte. Weise ein Werk oder Werkteil die Qualität eines Werkes im Sinne einer „eigenen geistigen Schöpfung“ des Urhebers auf, so sei der Schutz nicht schwächer als derjenige, der anderen Werken zukommt. ${ }^{537}$

Dem in den einschlägigen Richtlinien nur punktuell harmonisierten Werkbegriff hat der EuGH somit inzwischen deutlichere Konturen gegeben. Wendet man das vom EuGH befürwortete Schutzniveau unter Berücksichtigung der traditionellen Position der deutschen Gerichte zum Werkcharakter auf die Google Buchsuche an, so zeigt sich, dass die Werkqualität einzelner Snippets nicht ausgeschlossen ist, keinesfalls jedoch je-

534 Entspricht Erwägungsgrund 16 der Richtlinie 2006/116/EG (sog. SchutzdauerRichtlinie).

535 Metzger, GRUR 2012, 118 (122).

536 So i.E. ebenfalls Berger, ZUM 2012, 353 (355), der allerdings zu Recht eine Ausnahme für die Fälle solcher Datenbanken erwartet, die typischerweise keine persönlichkeitsrechtliche Prägung aufweisen, da ein Spielraum für Auswahl und Anordnung der Informationen (weitgehend) fehlt; Metzger, GRUR 2012, 118 (122).

537 Siehe EuGH, C-145/10, Rn. 95, 99 = GRUR 2012, 166 (169) - Painer./. Standard Verlags GmbH u.a. 
dem Snippet zwangsläufig urheberrechtlicher Schutz zukommt. Kommt in einem Werkausschnitt aufgrund der konkreten Auswahl des dargestellten Textauszugs keinerlei Individualität zum Ausdruck, handelt es sich also beispielsweise um eine reine Faktendarstellung, eine „Allerwelts-Aussage" oder um eine aufgrund der zufälligen Auswahl und des fehlenden $\mathrm{Zu}$ sammenhanges sinnlose Aneinanderreihung von Wörtern, so muss die Annahme eines Werkcharakters auch trotz eines niedrigeren Schutzniveaus ausscheiden. In dem im Infopaq-Urteil konkret zu beurteilenden Fall hat der EuGH daher die Schutzfähigkeit eines aus elf aufeinander folgenden Wörtern bestehenden Auszugs aus einem Tageszeitungsartikel lediglich für nicht grundsätzlich ausgeschlossen gehalten, die konkrete Feststellung aber dem vorlegenden Gericht überlassen. ${ }^{538}$ Die Auslegung und Anwendung des Begriffs der „eigenen geistige Schöpfung“ obliegt folglich weiterhin den nationalen Gerichten. Es bleibt ihnen somit weiterhin überlassen, diesen (niedrigen) Schutzstandard konkret anzuwenden, ihn im Hinblick auf einzelne Werkarten zu spezifizieren und im Einzelfall festzustellen, ob ein „Werk“ vorliegt. ${ }^{539}$ Eine vollständige Harmonisierung des Werkbegriffs in den Mitgliedstaaten ist demnach (noch) nicht erfolgt. Da die Vorgaben des EuGH den nationalen Gerichten auch weiterhin erhebliche Spielräume lassen, dürfte das traditionelle Werkverständnis in den Mitgliedstaaten weiterhin eine erhebliche Rolle spielen und zu Unterschieden bei der Bestimmung der Werkqualität führen. ${ }^{540}$ Eine horizontale Harmonisierung auf dem Niveau der ,eigenen geistigen Schöpfung“ muss daher nicht notwendig zur Folge haben, dass auch die Schutzuntergrenze für alle Werkarten einheitlich niedrig ist. Es steht somit im Ergebnis weder fest, dass sämtliche Snippets generell urheberrechtsschutzfähig sind, noch ist grundsätzlich auszuschließen, dass einzelne der im Rahmen der Google Buchsuche angezeigten Snippets tatsächlich Werkcharakter haben und so-

538 EuGH, GRUR 2009, 1041 (1044) - Infopaq/DDF.

539 So auch Klett/Apetz, K\&R 2010, 441 (447); Leistner, in: FS Loschelder, S. 189 (198f.); ders., GRUR 2010, 987 (987f.); Schricker/Loewenheim/v.UngernSternberg, § 15 Rn. 40; Schulze, GRUR 2009, 1019 (1021 f.). Unzutreffend ist insoweit die Darstellung von Czychowski/Nordemann, NJW 2010, 735 (736), der EuGH habe ,dem Auszug aus einem Zeitungsartikel in Form von elf aufeinanderfolgenden Wörtern Werkqualität zugebilligt" [Hervorhebung durch den Verfasser]. Zur Werkeigenschaft kurzer Zitate und Sprichwörter, siehe auch Raue, GRUR 2011, $1088 \mathrm{ff}$.

540 So auch Berger, ZUM 2012, 353 (354). 
mit durch deren Anzeige in das Recht der öffentlichen Zugänglichmachung nach § 19a UrhG eingegriffen wird.

Eine öffentliche Zugänglichmachung gemäß § 19a UrhG wäre zudem dann anzunehmen, wenn sich durch die geschickte Kombination von Suchwörtern und Suchanfragen oder durch den Einsatz zusätzlicher Programme ${ }^{541}$ eine Folge aus mehreren Werkausschnitten zu längeren Textpassagen oder gar zu ganzen Werken zusammenfügen ließe, da an der Werkqualität solcher großen Werkausschnitte oder gesamter Werke in der Regel keine Zweifel bestehen. Hinsichtlich einer solchen Werknutzung drängt sich jedoch die Frage auf, wer als derjenige zu gelten hat, der das Werk öffentlich zugänglich macht und dieses im urheberrechtlichen Sinne nutzt - Google, der Ersteller oder der Nutzer des Programms. Eine Haftung von Google für diese Zugänglichmachung käme nur dann in Betracht, wenn Google die Nutzungshandlung zurechenbar ist. Dies erscheint jedenfalls bei einem weiten Verständnis des Störerbegriffs ${ }^{542}$ nicht ausgeschlossen, wenn sich die von Google eingesetzten Schutzmaßnahmen gegen einen derartigen Missbrauch als vollkommen ungeeignet zum Schutz vor Werkentnahmen erwiesen ${ }^{543}$ oder Google etwa trotz entsprechender Hinweise keine Maßnahmen zum effektiven Schutz der enthaltenen Werke ergriffe.

\section{B. Vorgeschlagene Lösungsansätze und deren Bewertung}

Betrachtet man die Schrankenregelungen in den $\S \S 44 a$ bis 63 a UrhG, so finden sich dort - zumindest auf den ersten Blick - nur wenige Vorschriften, die neue digitale Werknutzungen, wie die Buch- und Bildersuche, erfassen und somit privilegieren könnten. Ist tatsächlich keine Schrankenregelung einschlägig, ist daher auch über die Möglichkeit einer erweiternden Auslegung einzelner Schrankentatbestände oder über Analogien zu diesen nachzudenken. Schließlich ist zu überlegen, ob - wenn die vorgenannten

541 Zahlreiche Anleitungen für die Umgehung der Druck- und Speichermodalitäten der Google Buchsuche und mehrere entsprechende Programme, die den Download vollständiger Bücher aus der Google Buchsuche (tatsächlich oder angeblich) ermöglichen (und deren Legalität daher bezweifelt werden darf), sind inzwischen im Internet verfügbar, so etwa der Google Book Downloader; siehe auch bereits oben Fn. 451.

542 Siehe näher zur Störerhaftung oben S. $104 \mathrm{f}$.

543 Ebenso i.E. Ott, GRUR Int. 2007, 562 (564 f.). 
Optionen ausscheiden - auf anderem Wege das Ziel eines Ausschlusses der Rechtswidrigkeit einzelner Eingriffe in die Rechte des Urhebers erreicht werden kann.

\section{Rechtfertigung der Verwendung von Thumbnails im Rahmen der Bildersuche}

Da die Bildersuche, in deren Rahmen Vorschaubilder im Thumbnail-Format angezeigt werden, allgemein als sozial nützlicher Dienst gesehen wird, der eine effektive und nutzerfreundliche Suche nach Bildinformationen im ansonsten unüberschaubaren Internet ermöglicht, ist vielfach über Möglichkeiten nachgedacht worden, die mit diesem Geschäftsmodell einhergehenden Eingriffe in urheberrechtliche Ausschließlichkeitsrechte zu rechtfertigen. Dabei kommt zum einen eine unmittelbare Anwendung der urheberrechtlichen Schrankenbestimmungen in Betracht, zum anderen deren erweiternde Auslegung oder analoge Anwendung. Über die letztgenannten Möglichkeiten ist aufgrund der Schwierigkeiten, die Bildersuche auf Grundlage des derzeit geltenden Schrankenkataloges des Urheberrechtsgesetzes zu rechtfertigen, in der Rechtsprechung und insbesondere in der rechtswissenschaftlichen Literatur besonders intensiv diskutiert worden. Einige der unterbreiteten Vorschläge zur Rechtfertigung der Werknutzung auf der Ebene der Schranken erscheinen tatsächlich geeignet, zumindest einen Teil der urheberrechtlichen Probleme in diesem $\mathrm{Zu}$ sammenhang in den Griff zu bekommen (sogleich 1.). Einen vielversprechenden Lösungsweg stellt schließlich der Rückgriff auf die zivilrechtliche Einwilligungslehre dar (sodann 2.). Gewisse Konstellationen lassen sich jedoch - wie zu zeigen sein wird - auch auf diesem Wege nicht erfassen. Insbesondere für diese Fälle, die sich weder auf Grundlage der Schranken des Urheberrechtsgesetzes noch durch die Anwendung des Einwilligungsgedankens legitimieren lassen, ist zudem darüber nachgedacht worden, durch eine Anwendung der Haftungsprivilegierung des Art. 14 Abs. 1 der Richtlinie 2000/31/EG die Haftung des Suchmaschinenbetreibers auszuschließen (unten 3.). 
1. Rechtfertigung auf Ebene der urheberrechtlichen Schranken

a) (Analoge) Anwendung des $\S 44 a \mathrm{UrhG}$

Nach $\S 44 \mathrm{a}$ UrhG, der die zwingende Schrankenbestimmung des Art. 5 Abs. 1 der Infosoc-Richtlinie in das deutsche Recht umsetzt, sind Vervielfältigungshandlungen zulässig, die lediglich vorübergehend, flüchtig oder begleitend sind, einen integralen und wesentlichen Teil eines technischen Verfahrens darstellen und keine eigenständige wirtschaftliche Bedeutung haben. Derartige für den Benutzer nicht verwertbare Vervielfältigungen, die rein technisch bedingt sind, sollen der Verfügungsbefugnis des Rechtsinhabers entzogen sein, um ein effizientes Funktionieren der Übertragungssysteme zu ermöglichen. ${ }^{544}$

Das Bereithalten und Anzeigen von Thumbnails in Trefferlisten einer Suchmaschine stellt keine lediglich flüchtige oder begleitende Nutzungshandlung ohne eigenständige wirtschaftliche Bedeutung im Sinne von $\S 44 a$ UrhG dar, da die Thumbnails einerseits dauerhaft zum Abruf bereitgehalten werden; ${ }^{545}$ bedingt durch Aktualisierungsintervalle teilweise sogar länger als auf den Internetseiten, auf denen diese von den Crawlern gefunden wurden. ${ }^{546}$ Zudem hat die Nutzung der Thumbnails auch eine eigenständige wirtschaftliche Bedeutung, da sie dem Verwerter eine Vielzahl von Einnahmemöglichkeiten - insbesondere durch Werbung - eröffnet. ${ }^{547}$ Schließlich vermag $\S 44$ a UrhG die Verwendung von Thumbnails keinesfalls zu rechtfertigen, soweit es um die öffentliche Zugänglichmachung der Werke (§ 19a UrhG) geht, da § 44a UrhG ausschließlich Vervielfältigungshandlungen im Sinne von $\S 16$ UrhG privilegiert. ${ }^{548}$

544 Vgl. Dreier/Schulze, §44a Rn. 1; Schricker/Loewenheim/Loewenheim, §44a Rn. 1.

545 So auch OLG Jena, GRUR-RR 2008, 223 (224) - Thumbnails; Leistner, IIC 2011, 417 (424); Ott, ZUM 2007, 119 (125); Schack, MMR 2008, 414 (415); Scherzer, jurisPR-ITR 5/2009 Anm. 2; Schrader/Rautenstrauch, UFITA 2007, $761(770)$.

546 Vgl. LG Hamburg, ZUM 2009, 315 (322); Schrader/Rautenstrauch, UFITA 2007, 761 (770).

547 Ebenso BGHZ 185, 291 (299) - Vorschaubilder; OLG Jena, GRUR-RR 2008, 223 (224f.) - Thumbnails; LG Hamburg, ZUM 2009, 315 (322); Berberich, MMR 2005, 145 (147); Ernst, jurisPR-WettbR 11/2008 Anm. 4.

548 Vgl. BGHZ 185, 291 (299) - Vorschaubilder; LG Hamburg, ZUM 2009, 315 (321 f.); HK-UrhR/Dreyer, §44a Rn. 3; Schack, Urheberrecht, Rn. 419 f.; Schricker/Loewenheim/Loewenheim, § 44a Rn. 1; Spindler, GRUR 2010, 785 (787). 
Auch eine analoge Anwendung des $\S 44$ a UrhG auf die vorliegende Konstellation muss ausscheiden. Insofern fehlt es bereits an einer planwidrigen Regelungslücke. Die Einfügung des $\S 44 a$ UrhG in das UrhG ist Ausdruck des gesetzgeberischen Willens, eine Schranke für solche Nutzungshandlungen zu schaffen, die im digitalen Zeitalter auf jeden Fall erlaubt sein sollen, um neue Nutzungsformen nicht unnötig zu behindern. Danach sollen gerade nur technisch bedingte und notwendige flüchtige Zwischenspeicherungen ausnahmsweise erlaubt sein, wenn sie keine negativen wirtschaftlichen Auswirkungen auf den Urheber erwarten lassen, da sie keine eigenständige wirtschaftliche Bedeutung haben. Weitergehende Ausnahmen zur Ermöglichung sonstiger neuer, digitaler Nutzungsformen, die die Ausschließlichkeitsrechte der Urheber tangieren, sind nach dem Willen des Gesetzgebers somit gerade nicht vorgesehen. ${ }^{549}$

\section{b) (Analoge) Anwendung des $\S 49 \mathrm{UrhG}$}

$\S 49$ UrhG gestattet die Vervielfältigung und Verbreitung einzelner Rundfunkkommentare und einzelner Artikel sowie mit ihnen im Zusammenhang veröffentlichter Abbildungen aus Zeitungen und anderen lediglich Tagesinteressen dienenden Informationsblättern in anderen Zeitungen und Informationsblättern dieser Art sowie die öffentliche Wiedergabe solcher Kommentare, Artikel und Abbildungen, wenn sie politische, wirtschaftliche oder religiöse Tagesfragen betreffen und nicht mit einem Vorbehalt der Rechte versehen sind. Während bis zum 1.1.2008 vom Gesetzestext nur eine Übernahme von Rundfunkkommentaren und Artikeln, also Sprachwerken im Sinne des $\S 2$ Abs. 1 Nr. 1 UrhG, von der Privilegierung erfasst war, erfolgte durch den zweiten Korb der Urheberrechtsreform eine Erweiterung der Schrankenregelung dahingehend, dass auch Abbildungen übernommen werden dürfen, die „,im Zusammenhang“ mit solchen Artikeln veröffentlicht wurden. Eine unmittelbare Anwendung der Schrankenregelung scheidet trotz dieser Erweiterung aus, da die Bildersuchmaschinen die von ihnen indexierten und als Thumbnails dargestellten Bilder gerade nicht danach aussuchen, ob diese Teil einer Berichterstattung über tagesaktuelle Ereignisse sind oder nicht. Im Gegenteil, es werden grundsätz-

549 Vgl. BGHZ 185, 291 (299) - Vorschaubilder; Roggenkamp, K\&R 2007, 328 (329). 
lich alle Webseiten erfasst, unabhängig davon, ob sie tagesaktuelle Inhalte enthalten. Ziel der Bildersuche ist es nämlich nicht, über tagesaktuelle Ereignisse $\mathrm{zu}$ berichten; ihr Mitteilungsgegenstand ist vielmehr allein die Bildinformation und der Hinweis auf deren Fundstelle. ${ }^{550}$

Da eine Rechtfertigung der Bildersuche auf Grundlage einer unmittelbaren Anwendung des $\S 49$ UrhG offensichtlich ausscheidet, käme allenfalls eine analoge Anwendung der Regelung in Betracht. Eine solche ist in Anlehnung an Überlegungen des BGH in seiner „Elektronische Pressespiegel"-Entscheidung ${ }^{551}$ - namentlich von Niemann vorgeschlagen worden. ${ }^{552}$ Dieser hält den hinter der Regelung des $§ 49$ UrhG stehenden Gedanken eines ungehinderten Zugangs zu Informationen über aktuelle Tagesfragen $^{553}$ für auf die Tätigkeit von Bildersuchmaschinen übertragbar, da Suchmaschinen allgemein in der Online-Gesellschaft zu einem erheblichen Teil dieselbe Funktion erfüllten wie traditionelle Pressespiegel in Zeitungen und Zeitschriften: Die Ermöglichung eines schnellen Überblicks über die unterschiedliche Aufbereitung und Darstellung bestimmter Themen in verschiedenen Medien. Dies müsse ebenso für Bildersuchmaschinen gelten, da diese - auch wenn sie nur Bildinformationen auffindbar machen - ebenfalls zur Information der Konsumenten und zum Meinungsbildungsprozess beitragen. ${ }^{554}$ Für eine entsprechende Anwendung des $\S 49$ UrhG spreche zudem, dass durch eine solche keine negativen Auswirkungen auf die Interessen der Urheber zu befürchten seien. ${ }^{555}$

Diese Argumentation und die entsprechende Anwendung der Regelung des $\S 49$ UrhG auf die Bildersuche kann letztlich nicht überzeugen. Die analoge Anwendung einer Schrankenregelung auf einen nicht dem Wortlaut unterfallenden Sachverhalt ist zwar grundsätzlich möglich, ${ }^{556}$ setzt jedoch - wie jede Analogie - eine Vergleichbarkeit der Interessenlage und das Vorliegen einer planwidrigen Regelungslücke voraus. ${ }^{557}$ Beide Voraussetzungen sind im vorliegenden Fall jedoch bei genauerer Betrachtung nicht erfüllt, da die Schrankenregelung vom Gesetzgeber für gänzlich an-

550 So auch Schaefer, Bildersuchmaschinen, S. 97.

551 BGHZ 151, 300 - Elektronischer Pressespiegel.

552 Siehe Niemann, CR 2009, 97 (98 ff.).

553 Vgl. Dreier/Schulze, § 49 Rn. 1; Schricker/Loewenheim/Melichar, § 49 Rn. 1.

554 Vgl. Niemann, CR 2009, 97 (100 f.).

555 Vgl. Niemann, CR 2009, 97 (101 f.).

556 Siehe zur Analogiefähigkeit urheberrechtlicher Schrankenregelungen oben 2. Kapitel, B.I.2.c).

557 Siehe nur Bydlinski, Methodenlehre, S. $475 \mathrm{ff}$. 
dere Nutzungssachverhalte konzipiert wurde. Bildersuchdienste dienen zwar der Auffindung von (Bild-)Informationen. Sie sind jedoch nicht speziell darauf zugeschnitten, dem Allgemeininteresse an der Information über politische, wirtschaftliche oder religiöse (Tages-)Fragen Vorschub zu leisten. Vielmehr werden von den Bildersuchmaschinen alle aufgefundenen Bildinformationen unabhängig von deren Inhalt und Aktualität erfasst, indexiert und schließlich auf die Nutzeranfragen angezeigt. Die bei einer Suchanfrage in der Ergebnisliste angezeigten Thumbnails werden dabei gerade nicht nach ihrer Aktualität geordnet, es sei denn diese Suchoption ist vom Nutzer ausdrücklich ausgewählt. Die Sortierung in der Ergebnisliste bestimmt sich nach der "Treffergenauigkeit" - also der Übereinstimmung der einem Bild zugeordneten Stichworte mit der Suchanfrage - und nach der „Beliebtheit“ eines Bildes - insbesondere also nach der bisherigen Häufigkeit des Abrufs -, wodurch tagesaktuelle Bilder gerade weniger häufig unter den ersten Treffern zu finden sind. Aufgrund dieser erheblichen Unterschiede fehlt es bereits an der Vergleichbarkeit der Sachverhalte. ${ }^{558}$

Eine planwidrige Regelungslücke lässt sich aufgrund derselben Überlegungen ebenfalls nicht begründen. Hinzu kommt, dass dem Gesetzgeber die urheberrechtlichen Probleme der Suchdienste, insbesondere auch der Bildersuche, bei der letzten Änderung des $\S 49$ UrhG bereits bekannt waren, dieser jedoch offensichtlich keine Veranlassung sah, diese im Gesetz zu regeln, keinesfalls jedoch über eine Regelung im Rahmen der „Pressespiegelfreiheit" des $\S 49$ UrhG nachgedacht hat. Eine analoge Anwendung der Schrankenregelung des $\S 49$ UrhG auf die Verwendung von Thumbnails würde letztlich die Regelungsabsicht des Gesetzgebers in ihr Gegenteil verkehren ${ }^{559}$ und muss daher im Ergebnis ausscheiden.

c) (Analoge) Anwendung des $\S 51 \mathrm{UrhG}$

Es ist mehrfach überlegt worden, die im Rahmen der Bildersuche verwendeten Thumbnails als nach $\S 51$ UrhG zulässige Bildzitate anzusehen. Der im Rahmen des sogenannten „Zweiten Korbes“ der Urheberrechtsreform

558 So im Ergebnis auch Schaefer, Bildersuchmaschinen, S. 97; Ziem, Suchdienste im Internet, S. 260.

559 Vgl. zu dieser Grenze eines Analogieschlusses Larenz/Canaris, Methodenlehre, S. 176. 
neu gefasste $\S 51 \mathrm{UrhG}^{560}$ gestattet im Interesse der Allgemeinheit an freier geistiger Auseinandersetzung, an Dialog, Kritik und kultureller Entwicklung das zustimmungs- und vergütungsfreie Zitieren aus fremden geschützten Werken zu den in der Norm genannten Zwecken und im dort genannten Umfang. ${ }^{561}$

Nach der neu eingefügten Generalklausel in $\S 51 \mathrm{~S} .1$ UrhG darf ein veröffentlichtes Werk nun ganz generell zitatweise genutzt werden, sofern die Nutzung in ihrem Umfang durch den besonderen Zweck gerechtfertigt ist. Entscheidende Voraussetzung für die Anwendung des $\S 51$ UrhG ist somit der für den zulässigen Umfang des Zitats entscheidende Zitatzweck. ${ }^{562}$ Was der Zitatzweck ist, definiert $\S 51$ UrhG nicht. Lediglich die Regelung des sogenannten wissenschaftlichen Großzitats in S. 2 Nr. 1 der Norm nennt ausdrücklich die Voraussetzung, dass das zitierte Werk zur Erläuterung des Inhaltes des zitierenden Werkes dienen muss. Für die übrigen in S. 2 genannten Zitatarten und die nach der Generalklausel zulässigen, nicht explizit genannten Zitate kommen dagegen auch weitergehende Zitatzwecke in Betracht. ${ }^{563}$ Stets muss das Zitat jedoch zur Erleichterung der geistigen Auseinandersetzung Belegfunktion für referierende oder eigene Ausführungen haben, ${ }^{564}$ so dass zwischen dem eigenen und dem fremden Werk eine innere Verbindung hergestellt wird. ${ }^{565}$ Dient das Zitat

$560 \S 51 \mathrm{~S} .1$ UrhG ist seitdem als Generalklausel formuliert, die in S. 2 durch die bis zum 31.12.2007 geltende Regelung in Form von Regelbeispielen (,,insbesondere") ergänzt wird. Durch die Beibehaltung des Wortlautes wird verdeutlicht, dass die bisher zulässigen Nutzungen auch weiterhin zulässig bleiben, vgl. BT-Drs. 16/1828, S. 25.

561 Vgl. BGH, GRUR 1973, 216 (217) - Handbuch moderner Zitate; GRUR 1986, 59 (60) - Geistchristentum; Dreier/Schulze, § 51 Rn. 1; Fromm/Nordemann/ Dustmann, §51 Rn. 1; Schricker/Loewenheim/Schricker/Spindler, §51 Rn. 6 m.w.N.

562 Vgl. BGHZ 85, 1 (10f.) - Presseberichterstattung und Kunstwerkwiedergabe I; BGH, GRUR 1986, 59 (60) - Geistchristentum; Dreier/Schulze, §51 Rn. 3; Fromm/Nordemann/Dustmann, § 51 Rn. 16.

563 Vgl. Fromm/Nordemann/Dustmann, § 51 Rn. 16.

564 Vgl. BGHZ 50, 147 (154) - Kandinsky I; BGH, GRUR 1986, 59 (60) - Geistchristentum; GRUR 1987, 34 (35) - Liedtextwiedergabe I; BGHZ 175, 135 (147) - TV-Total; BGHZ 185, 291 (300) - Vorschaubilder; OLG Jena, GRUR-RR 2008, 223 (225) - Thumbnails; Schricker/Loewenheim/Schricker/Spindler, § 51 Rn. 16 m.w.N.

565 Vgl. BGHZ 28, 234 (240) - Verkehrskinderlied; BGH, GRUR 1987, 362 (364) Filmzitat [insoweit nicht abgedruckt in BGHZ 99, 162]; BGHZ 175, 135 (147) TV-Total; Fromm/Nordemann/Dustmann, § 51 Rn. 16 m.w.N. 
einem legitimen Zitatzweck, so ist es dennoch immer nur in dem Umfang zulässig, der für den konkreten Zitatzweck geboten ist. In welchem Umfang das Zitat erforderlich ist, ist dabei stets eine Frage des Einzelfalls und durch umfassende Abwägung aller Umstände, insbesondere etwa des Zitatzwecks sowie der Besonderheiten des zitierten und zitierenden Werkes, zu ermitteln. ${ }^{566}$ Der Umfang eines Zitats darf jedoch nicht soweit gehen, dass dadurch die Verwertung des zitierten Werkes durch dessen Urheber unzumutbar beeinträchtigt wird. ${ }^{567}$

Neben einem legitimen Zitatzweck und der Einhaltung des erforderlichen Umfangs war Voraussetzung für die Anwendung aller drei Varianten des $\S 51$ UrhG a.F. ${ }^{568}$ zudem, dass das Zitat in einem selbständigen Werk aufgenommen wurde, es sich bei dem zitierenden Werk also um ein urheberrechtlich schutzfähiges Werk im Sinne der $\S \S 1,2$ Abs. 1 und 2 UrhG handelte. ${ }^{569} \mathrm{Ob}$ auch nach der Neufassung des $\S 51$ UrhG die Urheberschutzfähigkeit des übernehmenden Werkes weiterhin generell vorauszusetzen ist, ist umstritten, da sich eine derartige Einschränkung ausdrücklich nur in $\S 51$ S. 2 Nr. 1-3 UrhG findet. Ein Großteil der Literatur und auch die höchstrichterliche Rechtsprechung geht davon aus, durch den geänderten Gesetzeswortlaut habe sich am Erfordernis des Vorliegens eines selbständigen zitierenden Werkes nichts geändert, da die Neuregelung lediglich der Schließung einzelner, aus der unflexiblen Grenzziehung des alten Rechts folgender Lücken dienen, nicht jedoch das Zitatrecht grundlegend erweitern sollte. ${ }^{570}$ Demgegenüber wird zum Teil angenommen, der

566 Dreier/Schulze, § 51 Rn. 5; Fromm/Nordemann/Dustmann, § 51 Rn. 18; Schricker/Loewenheim/Schricker/Spindler, § 51 Rn. 19; Wandtke/Bullinger/Lüft, § 51 Rn. 6.

567 Vgl. BGH, GRUR 1986, 59 (61) - Geistchristentum; BGH, GRUR 1987, 362 (364) - Filmzitat [insoweit nicht abgedruckt in BGHZ 99, 162]; Schack, Urheberrecht, Rn. 545; Wandtke/Bullinger/Lüft, § 51 Rn. 7, jeweils m.w.N.

$568 \S 51$ UrhG in der bis zum 31.12.2007 geltenden Fassung.

569 Vgl. zur Rechtslage vor dem „Zweiten Korb“ statt vieler Schricker/Schricker, 3. Aufl., § 51 Rn. 20 m.w.N.

570 Vgl. BGHZ 185, 291 (300) - Vorschaubilder; LG Hamburg, ZUM 2009, 315 (322); Barabash, Bildzitat im Internet, S. 73 f.; Bisges, GRUR 2009, 730 (731); Fromm/Nordemann/Dustmann, § 51 Rn. 19; HK-UrhR/Dreyer, § 51 Rn. 9; Hoeren/Sieber/Raue/Hegemann, 7.3 Rn. 92; Kubis, ZUM 2006, 370 (376); Limper/ Musiol/Grosskopf, Urheber- und Medienrecht, Kap. 3 Rn. 790; Schack, Urheberrecht, Rn. 545; ders., MMR 2008, 414 (415); Schricker/Loewenheim/Schricker/ Spindler, § 51 Rn. 20; Spindler, GRUR 2010, 785 (788); Wandtke/Bullinger/Lüft, 
selbständige Werkcharakter des aufnehmenden Werkes sei in der neu gefassten Generalklausel des $\S 51$ S. 1 UrhG ausdrücklich nicht erwähnt und daher nicht mehr zwingend erforderlich. ${ }^{571}$

Nimmt man mit der zuvor dargestellten - überzeugenden - ersten Ansicht an, dass $\S 51$ UrhG auch nach der Neufassung durch den ,zweiten Korb" weiterhin einen selbständigen Werkcharakter der Leistung, in der zitiert wird, voraussetzt, so scheitert die Anwendung des $\S 51$ UrhG auf die Thumbnails bereits an dieser Hürde: Die von der Suchmaschine maschinell generierte Trefferliste stellt kein urheberrechtsschutzfähiges Werk im Sinne der $\S \S 1,2$ Abs. 1 und 2 UrhG dar. ${ }^{572}$

Folgt man hingegen der Gegenansicht, die keinen Werkcharakter des zitierenden Werkes verlangt - wofür sich ebenfalls einige Argumente anführen lassen ${ }^{573}$-, so lässt sich die Verwendung der Thumbnails dennoch nicht nach $\S 51$ UrhG rechtfertigen: Es fehlt an einem legitimen Zitatzweck, da die Belegfunktion fehlt. Die erforderliche eigene geistige Auseinandersetzung findet bei der Darstellung eines Bildes in einer maschinell

$\S 51$ Rn. 8 unter Berufung auf die Gesetzesbegründung, in der angeführt wird, die Schranke der Zitierfreiheit werde durch die Neuregelung ,mit Blick auf weitere Werkarten vorsichtig [...], jedoch nicht grundlegend erweitert", BT-Drs. 16/1828, S. 25.

571 Vgl. OLG Jena, GRUR-RR 2008, 223 (225) - Thumbnails; Dreier/Schulze, § 51 Rn. 6, 24; Dreier, in: FS Krämer, S. 225 (232); Schricker/Loewenheim/Wild, § 97 Rn. 45 f. Diese Minderansicht kann neuerdings zur Stützung ihrer Argumentation auch die Auffassung des EuGH ins Feld führen. Der EuGH hat jüngst für die europäische Zitatregelung des Art. 5 Abs. 3 lit.d InfoSoc-RL entschieden, dass es für die Rechtmäßigkeit eines Zitats nicht darauf ankomme, ob innerhalb eines urheberrechtlich geschützten (Sprach-)Werkes zitiert werde; vgl. EuGH, Urt. v. 1.12.2011, C-145/10, Rn. 137 = GRUR 2012, 166 - Painer./. Standard Verlags GmbH u.a.

572 Ebenso OLG Jena, GRUR-RR 2008, 223 (225) - Thumbnails; LG Hamburg, ZUM 2009, 315 (322); Berberich, MMR 2005, 145 (147); Fahl, K\&R 2010, 437 (439); Gey, Öffentliche Zugänglichmachung, S. 170; Ott, ZUM 2007, 119 (125); Scherzer, jurisPR-ITR 5/2009 Anm. 2; Schricker/Loewenheim/Schricker/Spindler, § 51 Rn. 54.

573 Zum einen lässt sich der Generalklausel des § 51 S. 1 UrhG ein derartiges Erfordernis nicht entnehmen, zum anderen setzen auch die internationalrechtlichen Vorgaben des Art. 10 Abs. 1 RBÜ und des Art. 5 Abs. 3 lit. d RL 2001/29/EG eine Übernahme in ein selbständiges Werk nicht voraus; vgl. Dreier/Schulze, $\S 51$ Rn. 24; Schricker/Loewenheim/Wild, § 97 Rn. 45 f. 
erstellten Trefferliste nicht statt. ${ }^{574}$ Allenfalls erleichtert es die Suchmaschine durch die Darstellung der Bilder in Form von Thumbnails den Nutzern, die aufgefundenen Bilder später zum Gegenstand eigener geistiger Auseinandersetzungen zu machen. Eine solche „Vermittlerrolle“ zur Ermöglichung der geistigen Auseinandersetzung eines Dritten mit einem Werk ist jedoch von $\S 51$ UrhG nicht privilegiert. 575

Die von Dreier vertretene Auffassung, die Verwendung von Thumbnails im Rahmen der Bildersuche sei durch $\S 51$ UrhG gerechtfertigt, da sie von dem legitimen Zitatzweck gedeckt sei, dem Nutzer einen Nachweis auf den Inhalt jedes einzelnen, mit Hilfe der Bildersuche gefundenen Bildes zu geben, ${ }^{576}$ stellt hingegen eine deutliche Überdehnung der zulässigen Zitatzwecke dar und kann daher nicht überzeugen. Diese Annahme stünde zum einen im Widerspruch zur eindeutigen Absicht des deutschen Gesetzgebers, der mit der Flexibilisierung des Zitatrechts diese Schranke nicht grundsätzlich erweitern und somit auch nicht vom Erfordernis einer geistigen Auseinandersetzung und einer Belegfunktion Abstand nehmen wollte. ${ }^{577}$ Das Zitatrecht wurde geschaffen, um die geistige Auseinandersetzung zu fördern, nicht hingegen - wie etwa die ausdrücklich zu diesem Zwecke eingeführte Schrankenregelung des § 44a UrhG um technische Gegebenheiten zu vereinfachen. ${ }^{578}$ Es genügt daher nicht, wenn die Verwendung des fremden Werks nur zum Ziel hat, dem Endnutzer dieses leichter zugänglich zu machen oder sich selbst eigene Ausführungen zu ersparen. ${ }^{579}$ Diese Wertung darf bei der Auslegung der generalklauselartigen Schrankenregelung nicht ignoriert werden. Zudem wird diese Überlegung der Regelung des Art. 5 Abs. 3 lit.d InfoSoc-Richtlinie nicht gerecht, nach der das Recht der öffentlichen Zugänglichmachung für

574 Vgl. OLG Jena, GRUR-RR 2008, 223 (225) - Thumbnails; LG Hamburg, ZUM 2009, 315 (322); Ernst, jurisPR-WettbR 11/2008 Anm. 4; Fahl, Bilder- und Nachrichtensuche, S. 61; Kleinemenke, CR 2009, 55; Leistner, IIC 2011, 417 (424 f.); Rössel, MMR 2010, 480 (481); Spindler, GRUR 2010, 785 (788); Schricker/Loewenheim/Schricker/Spindler, § 51 Rn. 16, 54; Wiebe, GRUR 2011, 888 (893); wohl auch Scherzer, jurisPR-ITR 5/2009 Anm. 2.

575 Vgl. Schack, MMR 2008, 414 (415).

576 Siehe Dreier/Schulze, § 51 Rn. 24; ders., in: FS Krämer, S. 225 (234 f.); zustimmend Schricker/Loewenheim/Wild, § 97 Rn. 46, 118.

577 Vgl. Begr. RegE, BT-Drs. 16/1828, S. 25.

578 Vgl. Schricker/Loewenheim/Schricker/Spindler, § 51 Rn. 20.

579 Vgl. BGHZ 185, 291(300) - Vorschaubilder; zustimmend Härting, Internetrecht, Rn. $1027 \mathrm{f}$. 
Zitate nur beschränkt werden darf, wenn diese der Kritik, Rezension oder verwandten Zwecken dienen. Eine reine Erleichterung des Auffindens in Form eines Nachweises auf den Inhalt eines Bildes genügt diesen europarechtlichen Vorgaben somit nicht. ${ }^{580}$ Ein solch weites Verständnis des Zitatzweckes wie es von Dreier vertreten wird, um die Verwendung von Thumbnails durch Bildersuchmaschinen zu rechtfertigen, hätte zudem eine ganz erhebliche Beeinträchtigung der ausschließlichen Rechte des Urhebers an der öffentlichen Zugänglichmachung und Vervielfältigung seiner Werke zur Folge, nicht zuletzt da nicht nur die gewünschte zustimmungsfreie Nutzung der Originalwerke, sondern auch eine vergütungsfreie Nutzung ermöglicht würde.

Eine Rechtfertigung der Verwendung von Thumbnails nach § 51 UrhG ist somit auch nach der Erweiterung des Zitatrechts durch den ,zweiten Korb" der Urheberrechtsreform nicht möglich. Zum einen stellt die von der Suchmaschine maschinell generierte Trefferliste kein urheberrechtsschutzfähiges Werk im Sinne der $\S \S 1,2$ Abs. 1 und 2 UrhG dar. Ein solches ist jedoch auch nach geltendem Recht weiterhin Voraussetzung eines von $\S 51$ UrhG privilegierten Zitats. Zum anderen fehlt es an einem legitimen Zitatzweck, da die erforderliche eigene geistige Auseinandersetzung bei der Darstellung eines Bildes in einer maschinell erstellten Trefferliste nicht stattfindet.

\section{d) Anwendung des $\S 53$ UrhG}

Nach $\S 53$ Abs. 1 S. 1 UrhG sind einzelne Vervielfältigungen eines Werkes zum privaten Gebrauch in gewissen Grenzen zustimmungsfrei zulässig. Unter privatem Gebrauch im Sinne dieser Norm versteht man den Gebrauch durch eine natürliche Person in der Privatsphäre zur Befriedigung rein persönlicher Bedürfnisse der eigenen Person oder die mit ihr durch ein persönliches Band verbundenen Personen. ${ }^{581}$ Anders als der sonstige eigene Gebrauch im Sinne des $\S 53$ Abs. 2 UrhG darf der private Ge-

580 So auch Spindler, GRUR 2010, 785 (788).

581 St. Rspr., vgl. BGH, GRUR 1978, 474 (475) - Vervielfältigungsstücke (noch zum insoweit entsprechenden Begriff des ,persönlichen Gebrauchs“ in $\S 53$ UrhG a.F.); BGHZ 134, 250 (256 f.) - CB-Infobank I; OLG München, GRUR-RR 2003, 365 (366) - CD-Münzkopierautomaten; vgl. aus dem Schrifttum statt vieler Schricker/Loewenheim/Loewenheim, § 53 Rn. 14 m.w.N. 
brauch weder mittelbar noch unmittelbar Erwerbszwecken dienen. Zudem dürfen stets nur einzelne Vervielfältigungsstücke angefertigt werden, also einige wenige Exemplare, die zur Deckung des rein persönlichen Bedarfs erforderlich sind. ${ }^{582}$ Die Vervielfältigung darf dabei auf beliebigen Trägern, also sowohl mit analogen als auch mit digitalen Mitteln, stattfinden. ${ }^{583}$ Der zur Vervielfältigung Berechtigte muss die Vervielfältigungsstücke nicht zwingend eigenhändig herstellen, sondern kann sie nach §53 Abs. 1 S. 2 UrhG auch durch einen Anderen herstellen lassen, solange dies unentgeltlich ${ }^{584}$ geschieht oder es sich lediglich um analoge Vervielfältigungen handelt. „Anderer“ im Sinne dieser Norm kann dabei jeder Dritte sein. ${ }^{585}$ Nach dem Willen des Gesetzgebers soll so sichergestellt werden, dass die Privilegierung auch den Nutzern zugute kommt, die sich eigene Kopiergeräte nicht leisten können. ${ }^{586}$ Es stellt sich somit auch hier die Frage der Abgrenzung zwischen Werknutzer und bloßem Dienstleister. ${ }^{587}$ Wer Vervielfältigungen im Auftrag eines Dritten anfertigt, muss sich darauf beschränken, gleichsam ,an die Stelle des Vervielfältigungsgeräts“ " zu treten und somit bei normativer Betrachtung als ,notwendiges Werkzeug”

582 Wie viele Vervielfältigungsexemplare maximal zulässig sind, ist umstritten. Die Rechtsprechung hat zum alten Recht (§ 53 i.d.F. vom 9.9.1965) in Bezug auf die damals vergütungsfrei ausgestaltete Vervielfältigung zu Unterrichtszwecken eine Obergrenze von sieben Kopien angenommen; vgl. BGH, GRUR 1978, 474 (476) - Vervielfältigungsstücke. $\mathrm{Zu}$ den verschiedenen Auffassungen in der Literatur vgl. v.Diemar, Digitale Kopie zum privaten Gebrauch, S. 101 f.; Dreier/Schulze, $\S 53$ Rn. 9; Fromm/Nordemann/W. Nordemann, § 53 Rn. 13; HK-UrhR/Dreyer, $\S 53$ Rn. 29; Mestmäcker/Schulze/Kröber, § 53 Rn. 7; Rehbinder, Urheberrecht, Rn. 440; Schack, Urheberrecht, Rn. 558; Schricker/Loewenheim/Loewenheim, $\S 53$ Rn. 17; Wandtke/Bullinger/Lüft, § 53 Rn. 13.

583 Vgl. Amtl. Begr., BT-Drs. 15/38, S. 20; Schricker/Loewenheim/Loewenheim, $\S 53$ Rn. 18.

584 Die Herstellung eines Vervielfältigungsstückes durch einen Dritten ist auch dann noch als unentgeltlich i.S.d. $\S 53$ Abs. 1 S. 2 UrhG anzusehen, wenn ein Entgelt verlangt wird, das lediglich der Kostendeckung dient. Ist die Tätigkeit hingegen auf Gewinnerzielung ausgerichtet, so ist sie nicht mehr unentgeltlich im Sinne der Norm; vgl. Begr. RegE, BT-Drs. 15/38, S. 20 f.; bestätigt und präzisiert durch BGH, GRUR 2009, 845 (850) - Internet-Videorecorder.

585 Vgl. Schricker/Loewenheim/Loewenheim, § 53 Rn. 25.

586 Amtl. Begr., BT-Drs. IV/270, S. 72, 74.

587 Vgl. dazu bereits oben 4. Kapitel, A.I.1. 
des Anderen tätig zu werden. ${ }^{588}$ Nur dann ist die Werknutzung gemäß $§ 53$ Abs. 1 S. 2 UrhG dem Auftraggeber und nicht dem Hersteller selbst zuzurechnen.

Ein solches „notwendiges Werkzeug“ des Anderen stellt der Suchmaschinenbetreiber bei der Bildersuche jedoch gerade nicht dar. Die Grenze des erlaubnisfrei zulässigen „Herstellenlassens“ im Sinne des §53 UrhG ist dann überschritten, wenn nicht mehr der privilegierte Nutzer selbst die Auswahl der zu vervielfältigenden Werke trifft, sondern der Dritte die Vervielfältigungsstücke unabhängig von einer konkreten Anfrage auf der Grundlage eigener Recherchen erstellt. ${ }^{589}$ Dies ist bei Bildersuchmaschinen der Fall. Die Suchmaschine erfasst die von ihren Crawlern im Internet aufgefundenen Bilddateien unabhängig von einer konkreten Suchanfrage und bereitet diese in Form verkleinerter Vorschaubilder für einen späteren Abruf durch alle Nutzer auf. Nur aus diesen bereits vorab zum Abruf vorbereiteten Bilddateien wird die dem Nutzer auf seine Suchanfrage angezeigte Trefferliste erstellt. Der Nutzer ist daher nicht Auftraggeber im Sinne des $\S 53$ Abs. 1 S. 2 UrhG, sondern die Werknutzung ist dem Hersteller der Vervielfältigungsstücke selbst zuzurechnen. ${ }^{590}$ Zudem mag in den meisten Fällen durch die Nutzer zwar ein privater Gebrauch im Sinne dieser Norm vorliegen, es ist jedoch auch nicht auszuschließen, dass die Bildersuche mittelbar oder unmittelbar zu Erwerbszwecken genutzt wird - etwa indem Bilder für eine gewerbliche Nutzung auf einer Webseite gesucht werden.

Eine Anwendung der Schrankenregelung des § 53 UrhG auf die Bildersuche ist daher im Ergebnis abzulehnen.

e) (Analoge) Anwendung des $\S 58 \mathrm{UrhG}$

$\S 58$ Abs. 1 UrhG begrenzt das Vervielfältigungsrecht, das Verbreitungsrecht und das Recht der öffentlichen Zugänglichmachung, indem er dem Veranstalter einer Ausstellung oder dem Kunsthandel das Recht verleiht,

588 Vgl. BGH, GRUR 2009, 845 (846) - Internet-Videorecorder; OLG Köln, GRUR 2000, 414 (417) - GRUR/GRUR Int; v.Diemar, Digitale Kopie zum privaten Gebrauch, S. $104 \mathrm{f}$.

589 Vgl. BGHZ 141, 13 (21 f.) - Kopienversanddienst.

590 Zur eigenen Nutzungshandlung der Suchmaschinen siehe auch schon oben 4. Kapitel, A.I.1. 
mit einem gezeigten oder angebotenen Werk der bildenden Künste oder einem Lichtbildwerk genehmigungs- und vergütungsfrei in einem Verzeichnis, etwa einem Ausstellungs- oder Versteigerungskatalog, zu werben, soweit dies zur Förderung der Veranstaltung erforderlich ist. ${ }^{591}$ Die sogenannte Katalogbildfreiheit kommt dabei dem offensichtlichen Interesse aller Beteiligten nach, die Herausgabe illustrierter Ausstellungs- und Versteigerungskataloge zu erleichtern. ${ }^{592}$ Die Schranke dient somit nicht nur dem Interesse der Veranstalter an der Durchführung von Ausstellungen oder öffentlichen Verkaufsveranstaltungen, sondern auch den Interessen des Urhebers, die eigene Bekanntheit und den Werkabsatz durch die genannten Maßnahmen zu fördern. 593

Es ist darüber nachgedacht worden, diese Regelung auf die Verwendung von Thumbnails im Rahmen der Bildersuche anzuwenden. ${ }^{594}$ In dem Einstellen urheberrechtlich geschützter Bilder in das Internet könnte man tatsächlich eine „öffentliche Ausstellung“ derselben sehen. Der Erstellung eines durchsuchbaren Archivs aller im Internet „,ausgestellten“ Bilddateien käme insoweit eine einem klassischen Ausstellungskatalog vergleichbare Funktion zu, da auch die Bildersuche die ,ausgestellten“ Werke kategorisiert und so einen schnellen Überblick über diese ermöglicht. Trotz dieser Vergleichbarkeit traditioneller Ausstellungen und der "Ausstellung“ von Bildern im Internet kann die Anwendung des $\S 58$ Abs. 1 UrhG auf die Verwendung von Thumbnails im Rahmen der Bildersuche jedoch letztlich nicht überzeugen. § 58 Abs. 1 UrhG begrenzt nämlich den Kreis der Privilegierten auf die „Veranstalter“, das heißt auf diejenigen, die die Ausstellungen oder den öffentlichen Verkauf der Werke verantworten. ${ }^{595}$ Als Veranstalter kommt im Fall der „Ausstellung“ von Bildern im Internet in erster Linie der Einstellende selbst in Betracht, allenfalls noch der Webmaster oder Serviceprovider - jedoch keinesfalls der Suchmaschinenbetreiber. Kataloge, die von Dritten anlässlich einer (fremden) Ausstellung herausgegeben werden, unterfallen der Privilegierung des $\S 58$ Abs. 1

591 Vgl. Schricker/Loewenheim/Vogel, § 58 Rn. 1.

592 Vgl. BGH, GRUR 1993, 822 (823) - Katalogbild; Möhring/Nicolini/Gass, § 58 Rn. 1.

593 Vgl. Dreier/Schulze, § 58 Rn. 1. Ausführlich zu Inhalt und Grenzen der Katalogbildfreiheit Schulze, in: FS Dittrich, S. $311 \mathrm{ff}$.

594 So insbes. Schrader/Rautenstrauch, UFITA 2007, 761 (771 ff.); erwogen auch von OLG Jena, GRUR-RR 2008, 223 (225).

595 Vgl. Schricker/Loewenheim/Vogel, § 58 Rn. 15. 
UrhG jedoch nicht. Um einen solchen „Dritten“ handelt es sich aber im Fall der Thumbnail-Nutzung beim Suchmaschinenbetreiber. Dessen Interesse an der Optimierung seiner Bildersuchmaschine unterfällt daher nicht der Privilegierung durch $\S 58$ Abs. 1 UrhG. ${ }^{596}$

\section{f) Analoge Anwendung des $\S 59$ UrhG}

Zu den ältesten Schrankenbestimmungen des Urheberrechts gehört die sogenannte „Straßenbildfreiheit“" ${ }^{597}$ Heute ist in $\S 59$ UrhG geregelt, dass urheberrechtlich geschützte Werke, die sich bleibend an öffentlichen Wegen, Straßen und Plätzen befinden, mit Mitteln der Malerei oder Grafik, durch Lichtbild oder durch Film vervielfältigt, verbreitet und öffentlich wiedergegeben werden dürfen. Für die genannten Nutzungshandlungen bedarf es - selbst bei kommerzieller Nutzung ${ }^{598}$ - weder einer Erlaubnis des Urhebers des abgebildeten Werkes noch einer Vergütung an diesen. ${ }^{599}$ Dahinter steht nach der amtlichen Begründung zum Urheberrechtsgesetz der allgemeine Gedanke, dass derjenige, der sein Werk an einem öffentlichen Ort aufstellt, dieses der Allgemeinheit widmet. Aus dieser Widmung rechtfertigt sich eine Beschränkung des Urheberrechts in der Weise, dass jedermann das Werk abbilden und die Abbildungen verwerten darf.600

Eine unmittelbare Anwendung des $\S 59$ UrhG auf die Verwendung urheberrechtlich geschützter Werke im Rahmen der Bildersuche kommt offensichtlich nicht in Betracht, da sich die Regelung nur auf Werke bezieht, die sich unter freiem Himmel an den genannten Orten - öffentlichen Wegen, Straßen oder Plätzen - befinden und tatsächlich physisch für jeder-

596 So im Ergebnis ebenfalls OLG Jena, GRUR-RR 2008, 223 (225); LG Hamburg, ZUM 2009, 315 (322); Berberich, MMR 2005, 145 (147); Dreier/Schulze, § 58 Rn. 5; Nolte, Informationsmehrwertdienste, S. 248 f.; Ott, ZUM 2009, 345 (350 f.); Schrader/Rautenstrauch, UFITA 2007, 761 (772); Schricker/Loewenheim/Vogel, § 58 Rn. 15.

597 Zur Entstehungsgeschichte der Freiheit des Straßenbildes v.Gierke, in: FS Erdmann, S. 103 (104 f.).

598 Zur Empfehlung der Enquete-Kommission „Kultur in Deutschland“, eine Vergütungspflicht für die Abbildung von Werken (ausgenommen Bauwerken) im öffentlichen Raum einzuführen, siehe Deutscher Bundestag, Schlussbericht der Enquete-Kommission „Kultur in Deutschland“, BT-Drs. 16/7000, S. 265, 267.

599 Vgl. Dreier/Schulze, § 59 Rn. 1, 6.

600 Vgl. Amtl. Begr., BT-Drs. IV/270, S. 76. 
mann frei zugänglich sind. ${ }^{601}$ Es ist jedoch überlegt worden, diese Regelung analog auf die Thumbnail-Nutzung im Rahmen der Bildersuche anzuwenden, da sich das Internet als im Grundsatz jedermann frei zugängliches Datennetz längst zu einem dem Straßenverkehr vergleichbaren öffentlichen Raum entwickelt habe. ${ }^{602}$ Tatsächlich ließe sich eine vergleichbare Interessenlage begründen, wenn man annehmen wollte, derjenige, der sein Werk im Internet ungeschützt zum virtuellen Abruf anbietet, stelle dieses der Allgemeinheit in vergleichbarer Weise zur Verfügung wie derjenige, der sein Werk an einem physisch frei zugänglichen öffentlichen Ort jedermann zugänglich macht. Insofern ließe sich der hinter der Norm stehende allgemeine Rechtsgedanke der freien Verwendbarkeit frei zugänglicher, der Allgemeinheit gewidmeter Gegenstände auf frei verfügbare Internetinhalte übertragen.

Gegen die analoge Anwendung der Schrankenregelung des §59 UrhG zur Rechtfertigung der Thumbnail-Nutzung im Rahmen der Bildersuche bestehen dennoch Bedenken. Zum einen erscheint bereits zweifelhaft, ob dem Akt des freien Einstellens eines Bildes in das Internet tatsächlich ein mit dem Anbringen eines (Kunst-)Werkes im öffentlichen Raum vergleichbarer Widmungswille entnommen werden kann. Wesentlich schwerwiegendere Bedenken ergeben sich jedoch aus einer Rechtsfolgenbetrachtung. Die entsprechende Anwendung des $\S 59$ UrhG hätte nämlich weitreichende und grundsätzliche Konsequenzen für den Umgang mit urheberrechtlich geschützten Inhalten im Internet. Nähme man an, dass im freien Einstellen eines urheberrechtlich geschützten Werkes in das Internet eine widmende Freigabe dieses Werkes für die Allgemeinheit zu sehen sei, so ließe sich dies nicht auf die Konstellation der Bildersuche beschränken. Vielmehr wäre die logische Folge der Übertragung des hinter dem $§ 59$ UrhG stehenden allgemeinen Rechtsgedanken auf den Fall der Bildersuche auch die Übertragung auf sonstige Internetfälle, mit der Konsequenz, dass letztlich alle im Internet frei zugänglichen Inhalte uneingeschränkt und vergütungsfrei verwendbar wären. Eine solche Rechtsfolge ist aber in dieser Allgemeinheit keinesfalls zu rechtfertigen. ${ }^{603}$ Auch der BGH hat in

601 Vgl. v.Gierke, in: FS Erdmann, S. 103 (110); Schricker/Loewenheim/Vogel, § 59 Rn. 9 f.

602 Dies diskutieren erstmals (im Ergebnis jedoch ablehnend) Leistner/Stang, CR 2008, 499 (502).

603 So auch Leistner/Stang, CR 2008, 499 (502); zustimmend Nolte, Informationsmehrwertdienste, S. 249; Ott, ZUM 2009, 345 (351). 
Bezug auf $\S 59$ UrhG betont, dieser - einen ganz speziellen Tatbestand regelnden - gesetzlichen Bestimmung sei gerade kein derart weitreichender, allgemeine Geltung beanspruchender Rechtsgedanke zu entnehmen, nach dem an allgemein zugänglichen Gestaltungen durchweg ein den Belangen des Urhebers vorzugswürdiges Freihalteinteresse der Öffentlichkeit anzuerkennen sei. ${ }^{604}$ Es bestehen somit bereits de lege lata Bedenken hinsichtlich der unflexiblen Rechtsfolge des $\S 59$ UrhG, insbesondere bezüglich der vergütungsfreien Verwendungsmöglichkeit selbst bei gewerblicher Nutzung. ${ }^{605}$ Eine analoge Anwendung der Norm und somit eine Übertragung dieser starren Rechtsfolge auf weitere, vom Gesetzgeber nicht ausdrücklich geregelte Fälle kann daher allenfalls in einigen wenigen, eng umgrenzten Fällen in Betracht kommen. Hat die analoge Anwendung der gesetzlichen Regelung jedoch - wie hier - aufgrund der Unbegrenzbarkeit der Sachverhalte eine Ausweitung des Rechtsgedankens und der Rechtsfolge der Norm auf eine unüberschaubare Anzahl von Nutzungsvorgängen und -arten zur Folge, so muss eine Analogie ausscheiden.

Daher kann auch eine analoge Anwendung des $§ 59$ UrhG - trotz der auf den ersten Blick vergleichbaren Interessenlage - im Ergebnis aufgrund ihrer weitreichenden Konsequenzen nicht überzeugen.

\section{g) Anwendung der $\S \S 17$ Abs. 2, 59 UrhG}

In Anlehnung an Überlegungen des BGH in seiner „Parfumflakon“-Entscheidung ${ }^{606}$ ist zudem argumentiert worden, die Verwendung von Vorschaubildern im Rahmen der Bildersuche sei nach den $\S \S 17$ Abs. 2, 59 UrhG als öffentliches Zugänglichmachen zum Zwecke der Verkaufsförderung zulässig. Die nach den $\S \S 17$ Abs. 3, 59 UrhG zulässige Werbung zu Verkaufszwecken müsse sich auch auf die Einstellung der vertriebenen Waren in Suchmaschinen erstrecken. ${ }^{607}$ Dieser Argumentation ist das LG Hamburg zu Recht entgegen getreten. Die Privilegierung des öffentlichen

604 Vgl. BGHZ 144, 232 (237) - Parfumflakon; zustimmend v.Gierke, in: FS Erdmann, S. 103 (108).

605 Vgl. zur Kritik an dieser unflexiblen Rechtsfolge auch Dreier/Schulze, §59 Rn. 1; Schricker/Loewenheim/Vogel, § 59 Rn. 2.

606 BGHZ 144, 232 - Parfumflakon.

607 So das Vorbringen der Beklagten im Thumbnail-Urteil des LG Hamburg, ZUM 2009, 315 (318). 
Zugänglichmachens zu Werbezwecken im Rahmen des von $\S 17$ Abs. 2 UrhG privilegierten Weitervertriebs von urheberrechtlich geschützten Waren kommt nämlich allein demjenigen zugute, der die Waren selbst vertreibt. Nicht privilegiert ist hingegen derjenige, der - wie der Suchmaschinenbetreiber - lediglich Bilder aus Angeboten Dritter wiedergibt, um auf deren Existenz an einem bestimmten Ort im Netz ohne weiteren inhaltlichen Bezug hinzuweisen, und selbst mit dem Vertrieb der Waren in keiner Weise befasst ist. Ziel der besonderen Privilegierung zu Werbezwecken ist es, die Warenverkehrsfreiheiten nach Art. 28, 30 EGV zugunsten des Händlers abzusichern. Die Aufnahme von Thumbnails in die Ergebnislisten erfolgt hingegen ohne jeden erkennbaren Bezug zu einer körperlichen Verbreitungshandlung und kann daher selbst schon nicht als werbliche Maßnahme bewertet werden, so dass im Ergebnis eine Anwendung der $\S \S 17$ Abs. 2, 59 UrhG ausscheiden muss. ${ }^{608}$

h) Umkehrschluss zu $§ 12$ Abs. 2 UrhG

Schließlich ist in der Literatur erwogen worden, die Verwendung von Thumbnails bei der Bildersuche durch einen Umkehrschluss zur gesetzlichen Bestimmung des $\S 12$ Abs. 2 UrhG zu rechtfertigen. ${ }^{609}$ Nach $\S 12$ Abs. 2 UrhG ist die öffentliche Beschreibung des Inhalts eines Werkes dem Urheber solange vorbehalten, bis das Werk selbst, dessen wesentlicher Inhalt oder eine Beschreibung des Werkes mit seiner Zustimmung veröffentlicht worden ist. Hieraus lässt sich im Wege eines Umkehrschlusses folgern, dass nach der Veröffentlichung des Werkes grundsätzlich jedermann berechtigt sein soll, den Inhalt des Werkes öffentlich mitzuteilen oder zu beschreiben. ${ }^{610}$ Eine Ansicht in Literatur und Rechtsprechung erkennt deshalb in $\S 12$ Abs. 2 UrhG eine besondere Schrankenbestimmung,

608 Vgl. LG Hamburg, ZUM 2009, 315 (322).

609 So erstmals Leistner/Stang, CR 2008, 499 (502f.), die - trotz methodischer Zweifel - in der Anwendung des § 12 Abs. 2 UrhG auf die Bildersuche einen „zumindest nachdenkenswerten Weg“ zur Lösung der Problematik sehen; dem (mit unterschiedlichen Begründungen) folgend Heymann/Nolte, K\&R 2009, 759 (762); Kleinemenke, CR 2009, 55 (56) (mit Einschränkungen hinsichtlich der Konstellation der „Drittinhaberschaft“ des Urheberrechts, siehe dazu unten 4. Kapitel, B.I.2.); Nolte, Informationsmehrwertdienste, S. 251 ff.; Schricker/Loewenheim/Wild, § 97 Rn. 118 (ohne nähere Begründung).

610 Siehe dazu auch bereits oben 2. Kapitel, B.I.3.b). 
nach der jedermann berechtigt ist, den Inhalt eines veröffentlichten Werkes öffentlich mitzuteilen oder zu beschreiben, selbst wenn die Inhaltsmitteilung eine Form annimmt, die grundsätzlich dem Urheber vorbehalten ist. ${ }^{611}$ Dabei sollen nach zum Teil vertretener Ansicht auch solche Inhaltsmitteilung zulässig sein, die das Bearbeitungsrecht des Urhebers gemäß § 23 UrhG verletzen, etwa weil sie fast ausschließlich aus übernommenen Versatzstücken des Originals bestehen. ${ }^{612}$ Die Grenze des Zulässigen ist jedoch jedenfalls dann überschritten, wenn die öffentliche Inhaltsmitteilung oder -beschreibung einen so weitgehenden Werkgenuss ermöglicht, dass sie geeignet ist, die Lektüre des Originalwerkes zu ersetzen. ${ }^{613}$

Diese Argumentation wurde in der Rechtsprechung zuletzt im Zusammenhang mit der Problematik der sogenannten Abstracts - verkürzter Darstellungen eines Werkes zu Informations- oder Dokumentationszwecken $^{614}$ - aufgegriffen, ${ }^{615}$ zu denen die Darstellung eines Werkes als Thumbnail im Rahmen der Bildersuche durchaus Parallelen aufweist. Ebenso wie ein Abstract, dient ein Thumbnail als Mitteilung und Inhaltsbeschreibung des gezeigten Bildes im Sinne einer Information über dessen Existenz und den Ort seiner Auffindbarkeit. ${ }^{616}$ Anders als bei einem Abstract, bei dem sich die Übernahme wesentlicher schutzfähiger Teile des Originalwerkes etwa durch Umformulierungen kennzeichnender Textpas-

611 Vgl. LG Frankfurt a.M., ZUM 2007, 65 (67); Erdmann, in: FS Tilmann, S. 21 (30 f.); Haberstumpf, Handbuch, Rn. 205; ders., ZUM 2011, 158 (160 f.); Hackemann, GRUR 1982, 262 (267); Loewenheim/Dietz, 1. Aufl., § 16 Rn. 11; Müsse, Urheberpersönlichkeitsrecht, S. 147 f.; Rehbinder, Urheberrecht, Rn. 511; Schricker/Dietz, 3. Aufl., § 12 Rn. 29; Ulmer, S. 213; im Ergebnis zustimmend HKUrhR/Dreyer, $\S 12$ Rn. 25; a.A. BGH, GRUR 2011, 134 (139) - Perlentaucher; OLG Frankfurt, GRUR 2008, 249 (251); Dreier/Schulze, § 12 Rn. 24; Fromm/ Nordemann/Hertin, 9. Aufl., § 12 Rn. 14; Loewenheim/Dietz/Peukert; § 16 Rn. 29; Obergfell, GRUR 2011, 208 (210); Ott, ZUM 2009, 345 (350); Pohl, Abstracts, S. 186 ff.; Schricker/Loewenheim/Dietz/Peukert, § 12 Rn. 29; Wandtke/ Bullinger/Bullinger, $\S 12$ Rn. 22.

612 Vgl. LG Frankfurt a.M., ZUM 2007, 65 (67); a.A. OLG Frankfurt, GRUR 2008, 249 (251).

613 Vgl. LG Frankfurt a.M., ZUM 2007, 65 (67); Fromm/Nordemann/Dustmann, $\S 12$ Rn. 21; Schricker/Dietz, 3. Aufl., § 12 Rn. 29.

614 Ausführlich zur urheberrechtlichen Bewertung von Abstracts und anderen Inhaltsmitteilungen Pohl, Abstracts, S. $59 \mathrm{ff}$.

615 Vgl. LG Frankfurt a.M., ZUM 2007, 65; OLG Frankfurt, GRUR 2008, 249; zuletzt jedoch abgelehnt von BGH, GRUR 2011, 134 (139) - Perlentaucher; siehe dazu die kritische Anmerkung von Haberstumpf, ZUM 2011, $158 \mathrm{ff}$.

616 Vgl. Leistner/Stang, CR 2008, 499 (503). 
sagen vermeiden lässt, besteht diese Möglichkeit bei Bildern oder anderen graphischen Darstellungen jedoch in der Regel nicht. Um dem Nutzer einen (sinnvollen) Überblick über den Inhalt der aufgefundenen Werke zu vermitteln, bedarf es einer verkleinerten Darstellung des vollständigen Ausgangswerkes und somit auch notwendigerweise der Übernahme kennzeichnender Werkteile. ${ }^{617}$ Auch wenn die Thumbnails so den Inhalt des Originalwerkes erkennen lassen, eignen sie sich dennoch - abgesehen von der als rein hypothetisch anzusehenden Verwendung als Bild für Mobiltelefone ${ }^{618}$ - nicht als Substitut für das Originalwerk.

In Fällen, in denen der Urheber seine Bilder selbst im Internet veröffentlicht oder Dritten eine Online-Nutzung erlaubt hat, erscheint daher eine sach- und interessengerechte Lösung für das Spannungsverhältnis zwischen den Interessen der Allgemeinheit, den wirtschaftlichen Interessen von Suchmaschinenbetreibern und den Urheberinteressen im Wege eines Umkehrschlusses zu $§ 12$ Abs. 2 UrhG durchaus möglich zu sein. Dabei muss allerdings ein strenger Maßstab hinsichtlich der Eignung zur Substituierung des Originalwerkes gelten. ${ }^{619}$ Gerade dieses Abgrenzungskriterium ist nämlich aufgrund der notwendigen Unschärfe einigen Zweifeln ausgesetzt. ${ }^{620}$ Diese können jedoch im Fall der Verwendung von Vorschaubildern durch Bildersuchmaschinen meines Erachtens ausgeräumt werden, obwohl die stark verkleinerte Thumbnail-Ansicht das Originalwerk erkennen lässt und so einen Werkgenuss des Originalbildes (wenn

617 Vgl. Nolte, Informationsmehrwertdienste, S. 253.

618 Eine Nutzung der Thumbnails als Hintergrundbilder für Mobiltelefone wird zwar immer wieder von den Klägern vorgebracht - so etwa auch im Thumbnail-Verfahren vor dem LG Hamburg (ZUM 2009, 315 (316)) -, sie ist jedoch bei realistischer Betrachtung äußerst unwahrscheinlich. Moderne Handys sind in der Lage, deutlich höhere Auflösungen als die der Vorschaubilder anzuzeigen, so dass wenn überhaupt - wohl nicht die Thumbnails, sondern die mit Hilfe der Suchmaschine aufgefundenen Originalbilder für das Handy verwendet würden. Im Urteil Perfect 10 v. Google Inc. (508 F.3d 1146 (9th Cir. 2007)) hat auch der U.S. Court of Appeals for the Ninth Circuit darauf hingewiesen, dass eine solche Verwendung als rein hypothetisch anzusehen ist, obwohl in diesem Fall der Kläger seine Bilder sogar für die Verwendung als Handybilder an einen Dritten lizenziert hatte.

619 Ähnlich Nolte, Informationsmehrwertdienste, S. 253; auch Leistner/Stang, CR 2008, 499 (503), jedoch mit allgemeinen Bedenken zur Methodik des Umkehrschlusses zu $§ 12$ Abs. 2 UrhG.

620 Vgl. Wandtke/Bullinger/Bullinger, § 12 Rn. 22. 
auch stark vermindert) noch ermöglicht. ${ }^{621}$ Die Ermöglichung des Werkgenusses ist jedoch nicht das primäre Ziel der Anzeige der Vorschaubilder, sondern lediglich eine notwendige „Nebenerscheinung“. Vielmehr geht es bei der Thumbnail-Verwendung ausschließlich darum, dem Nutzer im Sinne einer bloßen Hinweis- und Zeigerfunktion den Fundort des Originalwerkes aufzuzeigen und so dessen „Konsum“ zu erleichtern oder gar erst zu ermöglichen. ${ }^{622} \mathrm{Da}$ eine sinnvolle „Inhaltsangabe“ aber - wie gezeigt - gerade nur durch die verkleinerte Wiedergabe des gesamten Originalwerkes möglich ist, kann in diesem Fall ausnahmsweise auch die vollständige Wiedergabe des Originalwerkes als Inhaltsangabe im Sinne eines Umkehrschlusses zu $\S 12$ Abs. 2 UrhG gerechtfertigt sein. Insofern unterscheidet sich die Inhaltsmitteilung durch Thumbnails deutlich von anderen Inhaltsangaben, bei denen die vollständige oder weitgehende Übernahme des Originalwerkes vermieden werden könnte, etwa im Falle eines Abstracts, dessen Autor lediglich aufgrund von Faulheit oder eigenem Unvermögen große und insbesondere wesentliche Teile des Originalwerkes kopiert. Das Vorschaubild gibt nur so viel vom Originalwerk wieder, wie für die Zweckbestimmung - die Inhaltsbeschreibung - erforderlich ist. Es soll und kann somit gerade den Genuss des Originalwerkes nicht vollständig ersetzen.

Sieht man über die methodischen Bedenken hinsichtlich des dargestellten Umkehrschlusses zu $\S 12$ Abs. 2 UrhG zu Lasten des Urhebers hinweg, ${ }^{623}$ so stellt dieser Ansatz einen praktikablen Lösungsweg für die Problematik der Verwendung urheberrechtlich geschützter Werke in Form von Vorschaubildern im Rahmen der Bildersuche dar. ${ }^{624}$

621 A.A. Heymann/Nolte, K\&R 2009, 759 (762) und Nolte, Informationsmehrwertdienste, S. 253, die annehmen, die Thumbnails ermöglichten keinen eigenständigen Werkgenuss.

622 Vgl. Heymann/Nolte, K\&R 2009, 759 (762); Leistner/Stang, CR 2008, 499 (503); Nolte, Informationsmehrwertdienste, S. $252 \mathrm{f}$.

623 Gegen einen Umkehrschluss zu Lasten des Urhebers werden insbesondere Bedenken aufgrund der positiven Formulierung der Norm und aufgrund der sytematischen Stellung der Regelung bei den Urheberpersönlichkeitsrechten angeführt, siehe Wandtke/Bullinger/Bullinger, $§ 12$ Rn. 22 sowie oben 2. Kapitel, B.I.3.b).

624 So im Ergebnis auch Heymann/Nolte, K\&R 2009, 759 (762); Nolte, Informationsmehrwertdienste, S. $252 \mathrm{f}$; einschränkend aufgrund methodischer Zweifel Leistner/Stang, CR 2008, 499 (503); Leistner, IIC 2011, 417 (425 f.); a.A. BGHZ 185, 291 (299) - Vorschaubilder sowie Spindler, GRUR 2010, 785 
Keine Anwendung kann ein solcher Umkehrschluss allerdings im Falle der „Drittinhaberschaft“ der erforderlichen Nutzungsbefugnisse finden, das heißt in Konstellationen, in denen der Urheber die fraglichen Werke nicht selbst im Internet veröffentlicht und auch Dritten die dafür erforderlichen Nutzungsrechte nicht eingeräumt hat. ${ }^{625}$ Eine Einschränkung der Urheberrechte nach $\S 12$ Abs. 2 UrhG kommt nämlich keinesfalls in Betracht, wenn das Werk ohne Zustimmung des Urhebers im Internet veröffentlicht wurde. ${ }^{626}$ Die dargestellte Anwendung eines Umkehrschlusses zu $\S 12$ Abs. 2 UrhG als Schrankenregelung beruht auf der Annahme, dass nach Erschöpfung des Mitteilungsvorbehaltes jedermann den Inhalt des Werkes öffentlich mitteilen oder beschreiben können soll, ohne den Urheber fragen zu müssen. ${ }^{627}$ Der Umkehrschluss ist somit entwickelt worden, um ein zu weitgehendes Monopol des Rechteinhabers in Bezug auf Vorund Nachstufen der Werknutzung - im Sinne einer alleinigen „Hinweishoheit" - zu verhindern. Auch wenn die Veröffentlichung im Sinne des § 12 Abs. 2 UrhG grundsätzlich nicht an eine bestimmte Form der Offenbarung beziehungsweise ein bestimmtes Medium - etwa die analoge oder digitale Veröffentlichung - gebunden ist, kann vor diesem Hintergrund eine Ausdehnung des Anwendungsbereichs des $\S 12$ Abs. 2 UrhG auf die Thumbnail-Nutzung nur dann gerechtfertigt werden, wenn die Veröffentlichung im Internet durch den Rechteinhaber selbst oder mit dessen Zustimmung erfolgte. Nur dann hat sich der Urheber seines alleinigen „Mitteilungsrechts" derart begeben, dass eine Beschränkung durch $\S 12$ Abs. 2 UrhG sinnvoll und angemessen erscheint.

Es ist zu beachten, dass die Darstellung in Thumbnail-Form das Originalwerk vollständig erkennen lässt und so einen Werkgenuss des Originalbildes (wenn auch stark vermindert) bereits ermöglicht. Insoweit unterscheidet sich die Thumbnail-Nutzung doch deutlich von den Bereichen, für die der Umkehrschluss zu $\S 12$ Abs. 2 UrhG von Rechtsprechung und

(786f.), der einen Umkehrschluss zu $§ 12$ Abs. 2 UrhG zwar für einen ,vielversprechenden Weg“ hält, diesen letztlich jedoch - entgegen der hier vertretenen Auffassung - daran scheitern lässt, dass die Thumbnails bereits einen Werkgenuss ermöglichen.

625 Vgl. Kleinemenke, CR 2009, 55 (56). Dies übersieht Nolte, Informationsmehrwertdienste, S. 251, der die Anwendung eines Umkehrschlusses zu $§ 12$ Abs. 2 UrhG gerade (auch) als Lösung für die Konstellation der „Drittinhaberschaft“ des Urheberrechts sieht.

626 Vgl. Schricker/Loewenheim/Dietz/Peukert, § 12 Rn. 29 m.w.N.

627 Vgl. LG Frankfurt a.M., ZUM 2007, 65 (67). 
Literatur entwickelt und herangezogen worden ist. Hier ist eine Substitution des Originalwerkes typischerweise ausgeschlossen, weil die Inhaltsangabe in einer anderen Form erfolgt und/oder tatsächlich nur einen „Vorgeschmack" auf das eigentliche Werk bietet. Die Thumbnail-Verwendung bietet dem Nutzer hingegen bereits einen verminderten Genuss des gesamten Werkes, der erforderlich ist, um die Hinweis- und Zeigerfunktion auf den Fundort des Originalwerkes sinnvoll zu erfüllen und dessen „Konsum“ zu erleichtern oder gar erst zu ermöglichen. Auch wenn der Thumbnail den Genuss des Originalwerkes nicht vollständig ersetzen kann und soll, stellt dies doch eine weitreichende Einschränkung der Rechte des Urhebers dar. Ist das Originalwerk mit Zustimmung des Rechteinhabers im Internet veröffentlicht worden, so erscheint diese weitgehende Einschränkung gerechtfertigt, da das Vorschaubild nur so viel vom Originalwerk wiedergibt, wie für die Inhaltsbeschreibung erforderlich ist und somit die einzige praktikable Hinweismöglichkeit darstellt. Hat der Rechteinhaber hingegen der Internet-Veröffentlichung seines Werkes nicht zugestimmt, so widerspricht auch ein Hinweis auf dessen Online-Fundstelle durch die verkleinerte Werkwiedergabe den Interessen des Urhebers. ${ }^{628}$ Eine so weitreichende Einschränkung seiner Rechte ist dem Rechteinhaber nicht zuzumuten und auch nicht von dem Umkehrschluss zu $§ 12$ Abs. 2 UrhG bezweckt. Der Umkehrschluss soll im Interesse der (potentiellen) Werknutzer die Alleinstellung des Rechteinhabers in Bezug auf Hinweise und Inhaltsangaben seines Werkes begrenzen. Die erweiternde Gesetzesanwendung soll hingegen nicht dazu dienen, durch entsprechende Hinweise Rechtsverletzungen durch unerlaubte Werknutzung - hier in Form einer unzulässigen öffentlichen Zugänglichmachung im Sinne von § 19a UrhG - zu vertiefen. Ein schutzwürdiges Interesse an entsprechenden Hinweisen auf rechtsverletzende Nutzungen besteht nicht.

\section{2. (Konkludente) Nutzungsrechtseinräumung und Einwilligung}

Aufgrund der aufgezeigten Schwierigkeiten bei der Erfassung der Problematik der Thumbnail-Nutzung im Rahmen der gesetzlichen Schrankenbestimmungen ist in der Literatur und Rechtsprechung zur Vermeidung des

628 Siehe zur insoweit gleichlaufenden Argumentation in Bezug auf die Einwilligung in die Werknutzung unten 4. Kapitel, B.I.2.b). 
unbefriedigenden Resultats einer Unzulässigkeit der allgemein als äußerst nützlich angesehenen Bildersuche anhand von Thumbnails erwogen worden, die Verwendung von Thumbnails bei der Bildersuche durch den Rückgriff auf allgemeine Grundsätze der Rechtsgeschäftslehre durch schuldrechtliche beziehungsweise vertragsähnliche Konstruktionen, insbesondere durch die Annahme einer Einwilligung, ${ }^{629}$ zu rechtfertigen. ${ }^{630}$ Dieser Ansatz beruht auf Überlegungen, dass ein Urheber beziehungsweise Rechteinhaber, der seine urheberrechtlich geschützten Werke frei zugänglich im Internet einstellt und zum Abruf durch Mitglieder der Öffentlichkeit bereithält, auch möchte, dass diese von Nutzern gefunden werden - wozu Suchmaschinen einen ganz wesentlichen Beitrag leisten. Das „Gewand" der gegenüber den starren Schranken deutlich flexibleren und wertungsoffeneren Einwilligungslösung bietet dabei die Möglichkeit, gerade auch solche Aspekte bei der Rechtfertigung zu berücksichtigen, die im Rahmen der veralteten, zum Teil nicht technologieneutralen Schrankenbestimmungen keine oder allenfalls sehr beschränkte Beachtung finden können. So sind von der Rechtsprechung über den Umweg der Einwilligung etwa wesentliche Interessen der Allgemeinheit an der Erhaltung und Förderung einer effektiv funktionierenden und sinnvollen Internetinfrastruktur - also im Wesentlichen reine Nützlichkeits- und Funktionalitätsüberlegungen - ebenso in die Erwägungen zur Rechtfertigung der ThumbnailNutzung einbezogen worden wie offene Transaktionskostenaspekte, etwa in Form der Frage nach der Möglichkeit einer Einzellizenzierung oder eines Einzelwiderrufs. ${ }^{631}$ Dieser offene Rückgriff auf zusätzliche, wünschenswerte Aspekte, die in den bestehenden Schranken keine hinreichende, interessengerechte Berücksichtigung(-smöglichkeit) finden, ist grundsätzlich zu begrüßen. Zugleich wirft eine derart weitreichende Anwendung des allgemeinen zivilrechtlichen Instituts der Einwilligung im Urheber-

629 Grundlegend zur Rechtsnatur der Einwilligung Ohly, Volenti non fit iniuria, S. $178 \mathrm{ff}$.

630 Vgl. aus der Rechtsprechung BGHZ 185, 291 (301 ff.) - Vorschaubilder; OLG Jena, GRUR-RR 2008, 223 (225 ff.) - Thumbnails; LG Erfurt, ZUM 2007, 566 (567); LG Hamburg, GRUR-RR 2004, 313 (316 f.); aus der Literatur etwa Berberich, MMR 2005, 145 (147 f.); Heymann/Nolte, K\&R 2009, 759 (761 f.); Hüttner, WRP 2010, 1008 (1011 ff.); Leistner/Stang, CR 2008, 499 (503 ff.); Nolte, Informationsmehrwertdienste, S. 249 ff.; Ott, ZUM 2007, 119 (126f.); Roggenkamp, jurisPR-ITR 14/2010 Anm. 2; Schaefer, Bildersuchmaschinen, S. 107 ff.; Spindler, GRUR 2010, 785 (789 ff.); v.Ungern-Sternberg, GRUR 2009, 369 (370 ff.).

631 Siehe dazu näher unten 4. Kapitel, B.I.2.b) und c). 
recht jedoch Fragen der Methodenehrlichkeit auf, die das Bedürfnis für die Einführung einer Schrankengeneralklausel verdeutlichen. ${ }^{632}$

\section{a) Einräumung von Nutzungsrechten und (schlichte) Einwilligung}

$\mathrm{Zu}$ differenzieren ist zunächst zwischen der (unentgeltlichen) Einräumung eines einfachen Nutzungsrechts und der (schlichten) Einwilligung 633 in die Nutzung. Beides kann nicht nur durch eine ausdrückliche Erklärung, sondern auch konkludent erfolgen, die Voraussetzungen und Rechtsfolgen und somit die Intensität der rechtlichen Bindung unterscheiden sich jedoch. ${ }^{634}$ Das einfache Nutzungsrecht wird von der herrschenden Meinung als gegenständliches Recht mit dinglicher Wirkung angesehen, ${ }^{635}$ das zwar ein positives Nutzungsrecht, jedoch grundsätzlich keine Abwehrbefugnis gegenüber dem Urheber oder Dritten begründet. Es genießt jedoch Sukzessionsschutz gemäß $\S 33$ UrhG. Wurde ein Nutzungsrecht mit gegenständlicher Wirkung eingeräumt, so lässt dieses bereits einen Eingriff in

632 Siehe näher zu der aufgeworfenen Frage der Methodenehrlichkeit unten S. 151 ff. und $279 \mathrm{ff}$.

633 Die Terminologie ist insofern uneinheitlich. Zumeist wird lediglich von einer „Einwilligung“ gesprochen, wobei dieser Begriff teilweise auch ebenso für die insbesondere konkludente - Nutzungsrechtseinräumung verwendet wird [Vgl. auch den Wortlaut des $\S 23$ UrhG, der allgemein die „Einwilligung des Urhebers“ verlangt, womit letztlich eine Nutzungsrechtseinräumung gemeint ist; vgl. Fromm/Nordemann/A.Nordemann, $\S 23 / 24$ Rn. 13]. In Abgrenzung zur Nutzungsrechtseinräumung wird daher zum Teil klarstellend von einer ,schlichten Einwilligung“ [v.Ungern-Sternberg, GRUR 2009, 369; dem folgend BGHZ 185, 291 (304) - Vorschaubilder] oder einer „Einwilligung im engeren Sinne“ [Ohly, Volenti non fit iniuria, S. 178] gesprochen.

634 Grundlegend zur „Qualität“ der unterschiedlichen Erlaubnisarten und zur damit einhergehenden Abstufung in der Intensität der rechtlichen Bindung Ohly, Volenti non fit iniuria, S. 141 ff., der hierfür den Begriff der „Stufenleiter der Gestattungen“ geprägt hat. Speziell zur Abstufung der Erlaubnisarten im Urheberrecht Schricker/Loewenheim/Schricker/Loewenheim, Vor § 28 Rn. 45 ff.

635 Vgl. BGHZ 180, 344 (353) - Reifen Progressiv; BGHZ 185, 291 (304 f.) - Vorschaubilder; LG München I, GRUR-RR 2004, 350 - GPL-Verstoß; Dreier/Schulze, § 31 Rn. 52; Fromm/Nordemann/J.B.Nordemann, § 31 Rn. 87; Rehbinder, Urheberrecht, Rn. 556; Schack, Urheberrecht, Rn. 604; Schricker/Loewenheim/ Schricker/Loewenheim, Vor § 28 Rn. 83; Ulmer, S. 368; a.A. (nur schuldrechtlicher Charakter) Fromm/Nordemann/Hertin, 9. Aufl., §§31/32 Rn. 2; Götting, in: FS Schricker I, S. 53 (68); Möhring/Nicolini/Spautz, § 31 Rn. 39; Pahlow, ZUM $2005,865 \mathrm{ff}$. 
die Ausschließlichkeitsbefugnisse des Urhebers oder Rechteinhabers entfallen. ${ }^{636}$ Die auf die Nutzungsrechtseinräumung gerichtete Willenserklärung muss daher auch den Anforderungen an eine dingliche Verfügung über Rechte genügen, das heißt es muss unter Berücksichtigung der gesamten Begleitumstände nach dem objektiven Inhalt der Erklärung unzweideutig der Wille des Urhebers zu Tage treten, einem Dritten ein bestimmtes Nutzungsrecht einräumen zu wollen. ${ }^{637}$ Anders als bei der (konkludenten) Nutzungsrechtseinräumung ist hingegen für die Einwilligung entsprechend der allgemeinen Figur der Einwilligung im Deliktsrecht ${ }^{638}$ auch für das Urheberrecht anerkannt, dass diese lediglich die Rechtswidrigkeit eines Eingriffs in die Ausschließlichkeitsrechte entfallen lässt. ${ }^{639}$ Der Eingreifende erwirbt also weder ein dingliches Recht noch einen schuldrechtlichen Anspruch oder sonstige durchsetzbare Rechte - weder gegenüber dem Urheber noch gegenüber Dritten. ${ }^{640}$ Daher sind - unabhängig von der Frage, ob man die Einwilligung als rechtsgeschäftsähnliche Handlung, ${ }^{641}$ auf die allerdings im Wesentlichen die für Willenserklärungen geltenden Regeln Anwendung finden, oder als Willenserklärung mit Besonderheiten ${ }^{642}$ betrachtet - die Voraussetzungen für die rechtfertigende Einwilligung in eine Nutzung nach richtiger Auffassung weniger streng als die Anforderungen an eine Nutzungsrechtseinräumung. Die Einwilligung muss zwar nach außen erklärt werden, es bedarf jedoch keiner

636 Vgl. nur Schricker/Loewenheim/Wild, § 97 Rn. 28 m.w.N.

637 Vgl. BGHZ 185, 291 (302 f.) - Vorschaubilder.

638 Siehe dazu BGHZ 105, 45; sowie ausführlich MünchKomm-BGB/Wagner, § 823 BGB Rn. 665 ff.

639 Vgl. BGHZ 174, 359 (366 f.) - Drucker und Plotter; BGHZ 185, 291 (304) Vorschaubilder; Dreier/Schulze, $\S 97$ Rn. 15; Fromm/Nordemann/J.B.Nordemann, § 97 Rn. 24 f.; Schricker/Loewenheim/Schricker/Loewenheim, Vor § 28 Rn. 57; Schricker/Loewenheim/Wild, § 97 Rn. 32; v.Ungern-Sternberg, GRUR 2008, 247 (248 f.); ders., GRUR 2009, 369 (371); Wandtke/Bullinger/Wandtke/ Grunert, § 31 Rn. 37; a.A. Ohly, Volenti non fit iniuria, S. 197 ff., der - allerdings ohne Bezug auf die Besonderheiten des Urheberrechts - der Einwilligung im Zivilrecht tatbestandsausschließende Wirkung beimisst.

640 Vgl. BGHZ 185, 291 (305) - Vorschaubilder; Ohly, Volenti non fit iniuria, S. 144, 176 f.; Spindler, GRUR 2010, 785 (789).

641 So die h.M., vgl. etwa Schricker/Loewenheim/Schricker/Loewenheim, Vor $\S 28$ Rn. 57; v.Ungern-Sternberg, GRUR 2009, 369 (370); Wandtke/Bullinger/Wandtke/Grunert, § 31 Rn. 37, jeweils m.w.N.

642 So mit ausführlicher Argumentation und zahlreichen Nachweisen Ohly, Volenti non fit iniuria, S. $201 \mathrm{ff}$. 
auf die Einräumung eines dinglichen Rechts gerichteten rechtsgeschäftlichen Willenserklärung, die einen auf den Eintritt einer solchen Rechtsfolge gerichteten Rechtsfolgewillen zum Ausdruck bringt. ${ }^{643}$ Es reicht vielmehr aus, wenn durch Auslegung vom objektiven Empfängerhorizont dem (schlüssigen) Verhalten des Urhebers beziehungsweise Rechteinhabers objektiv die Erklärung entnommen werden kann, dieser sei mit einer bestimmten Nutzung seines Werkes einverstanden. ${ }^{644}$ Die dem Verhalten aus Sicht des Erklärungsempfängers objektiv beizumessende Bedeutung hat somit Vorrang vor dem subjektiven (inneren) Willen des Erklärenden. ${ }^{645}$ Es kommt daher auch bei fehlendem Erklärungsbewusstsein eine Einwilligungserklärung in Betracht, wenn der Erklärende bei Anwendung der im Verkehr erforderlichen Sorgfalt hätte erkennen und vermeiden können, dass seine Äußerung nach Treu und Glauben und mit Rücksicht auf die Verkehrssitte als Willenserklärung aufgefasst werden durfte, und wenn der Empfänger sie auch tatsächlich so verstanden hat. ${ }^{646}$ Wird einem bestimmten Verhalten im Rahmen des redlichen Rechtsverkehrs sozialtypisch ein bestimmter Erklärungsgehalt beigemessen, so muss daher eine Berufung auf einen entgegenstehenden inneren Willen ausscheiden. Die Einwilligung ist jedoch grundsätzlich frei widerruflich, ${ }^{647}$ das heißt der „Erklärende“ kann der Annahme einer konkludenten Einwilligung durch eine ausdrückliche gegenteilige Erklärung entgegen treten. Zum Teil wird angenommen, selbst eine solche ausdrückliche Erklärung solle ausnahmsweise unbeachtlich sein, wenn sie in einem deutlichen Widerspruch zum eigenen tatsächlichen (sozialtypischen) Verhalten steht. ${ }^{648}$

643 Vgl. BGHZ 145, 343 (346f.); BGHZ 185, 291 (305 f.) - Vorschaubilder; v.Ungern-Sternberg, GRUR 2009, 369 (370).

644 Vgl. BGHZ 185, 291 (306) - Vorschaubilder; Leistner/Stang, CR 2008, 499 (504 f.); Ott, Linking und Framing, S. 368; v.Ungern-Sternberg, GRUR 2009, 369 (370).

645 Vgl. Ohly, Volenti non fit iniuria, S. 341 f.; v.Ungern-Sternberg, GRUR 2009, 369 (370). Allgemein zur Willenserklärung BGH, NJW-RR 2005, 639 (640).

646 St. Rspr., siehe nur BGHZ 109, 171 (177); BGHZ 149, 129 (136), jeweils m.w.N.

647 Vgl. nur Ohly, Volenti non fit iniuria, S. 177 f. m.w.N.

648 Vgl. BGHZ 185, 291 (307f.) - Vorschaubilder; v.Ungern-Sternberg, GRUR 2009, 369 (370). Allgemein zur sog. protestatio facto contraria BGH, NJW 1965, 387 (388); NJW 2000, 3429 (3431); MünchKomm-BGB/Kramer, Vor $\S 116$ BGB Rn. 40; sowie ausführlich Teichmann, in: FS Michaelis, S. $294 \mathrm{ff}$. Siehe näher zu den Möglichkeiten des Widerrufs der Einwilligung unten 4. Kapitel, B.I.2.c). 
b) Rechtfertigung der Thumbnail-Nutzung durch Nutzungsrechtseinräumung oder Einwilligung

Die aufgezeigten Grundsätze der Einräumung von Nutzungsrechten und rechtfertigenden Einwilligung lassen sich auf die Verwendung urheberrechtlich geschützter Werke durch Bildersuchmaschinen wie folgt anwenden:

Eine ausdrückliche Einräumung eines einfachen Nutzungsrechts oder zumindest die ausdrückliche Einwilligung des Rechteinhabers in die Erstellung und Zugänglichmachung der Vorschaubilder ist grundsätzlich denkbar und technisch möglich. Sie kann insbesondere angenommen werden, wenn der Urheber oder Rechteinhaber die Crawler von Bildersuchmaschinen ausdrücklich zur Durchsuchung der Website, auf der er seine Werke veröffentlicht hat, und zur Indexierung der dort gefundenen Bilddateien auffordert. ${ }^{649}$ In aller Regel - und insbesondere in den Fällen, die tatsächlich zu einem Streit über die Berechtigung des Suchmaschinenbetreibers führen - wird eine solche ausdrückliche „Einladung“ an die Crawler und somit auch eine ausdrückliche Nutzungsrechtseinräumung beziehungsweise Einwilligung jedoch nicht vorliegen.

In Betracht kommt jedoch im Falle einer fehlenden ausdrücklichen Nutzungsrechtseinräumung oder Einwilligung die Annahme einer die Rechtswidrigkeit ausschließenden konkludenten (schlichten) Einwilligung in die Thumbnail-Nutzung. Stellt der Urheber oder ein Rechteinhaber ein urheberrechtlich geschütztes Werk frei zugänglich - das heißt ohne jegliche technische Sicherungsmaßnahmen - im Internet ein, so weiß er - oder nimmt zumindest bewusst in Kauf -, dass jedem beliebigen Mitglied der

649 Eine solche ausdrückliche Zustimmung zur Durchsuchung und Idexierung der Bilddateien ist insbesondere in Form der Aufnahme eines entsprechenden Befehls in der „robots.txt“"-Datei im Stammverzeichnis der Webseite denkbar. Etwa durch den Befehl „User-agent: Googlebot-Image - Allow: " würde den Crawlern der Suchmaschine Google ausdrücklich die Indexierung aller auf der Internetseite enthaltenen Bilder gestattet. Es ist jedoch auch eine Differenzierung nach bestimmten Verzeichnissen oder Dateitypen möglich, bspw. durch die Befehle: „User-agent: Googlebot-Image - Allow: /bilder" (nur Indexierung der Bilder, die sich in dem Verzeichnis „bilder" befinden) oder "User-agent: GooglebotImage - Allow: /*.jpg\$“ (nur Indexierung von Dateien mit der Dateiendung ,.jpg“"). Siehe ausführlich zu den technischen Möglichkeiten der Zulassung und Untersagung der Indexierung von Bilddateien durch die Crawler oben 3. Kapitel, B. 
Öffentlichkeit ein Abruf dieses Werkes möglich ist. Bei einer Betrachtung vom objektiven Empfängerhorizont kann dem Verhalten des Urhebers beziehungsweise Rechteinhabers somit objektiv die Erklärung entnommen werden, dieser wolle, dass seine Inhalte von anderen Nutzern aufgefunden werden, und sei daher mit allen solchen Nutzungen seiner Werke einverstanden, die nach der Verkehrssitte im Internet üblich sind. ${ }^{650}$ Dazu zählen auch solche Nutzungshandlungen, die für diese übliche Nutzung (technisch) notwendig oder mit ihr zumindest typischerweise verbunden sind. ${ }^{651} \mathrm{Zu}$ einem wesentlichen Funktionselement des Internets gehören Suchmaschinen. Ohne diese ist ein gezieltes Auffinden von Webseiten und insbesondere von auf diesen enthaltenen Informationen beinahe unmöglich. Dem Nutzer bliebe andernfalls nur die Möglichkeit, das Internet durch die Eingabe von Internetadressen ,auf gut Glück“ zu durchstöbern oder sich bestenfalls anhand von Verlinkungen von Internetseite zu Internetseite zu „hangeln“. Dies erscheint - bildlich gesprochen - aufgrund der unüberschaubaren Fülle von Informationen etwa so erfolgversprechend wie die Nutzung einer großen, nicht-fachspezifischen Bibliothek ohne Bibliothekskatalog. Wer als Urheberrechtsberechtigter ein Werk ungeschützt in das Internet einstellt, willigt daher konkludent jedenfalls in solche Nutzungen durch Suchmaschinen ein, die für diese zur Erstellung eines effektiven Suchsystems und somit zur Ermöglichung der üblichen Nutzung durch Dritte zwingend erforderlich sind. Für die ,,herkömmliche“ Internetsuche mit Trefferlisten in Textform sind dies namentlich alle mit der Erfassung, Indexierung und Speicherung für die spätere Abfrage verbundenen Nutzungen, da ohne diese der wirksame und effektive Betrieb einer Suchmaschine nicht vorstellbar ist und es somit auch für die Nutzer nicht möglich wäre, gezielt Informationen zu finden. Da dieses Angebot der Suchmaschinen die Verbreitung der indexierten Webseiten und somit deren Bekanntheit steigert und zugleich die eigene Werkverwertung durch die Webseitenbetreiber nicht beeinträchtigt, liegt es deutlich im Interesse der verlinkten Anbieter. Für die „herkömmlichen“ Suchmaschinen mit Trefferlisten in Textform ist daher inzwischen auch nicht mehr umstritten, dass im ungeschützten Einstellen von Online-Inhalten tatsächlich zumindest eine konkludente Einwilligung der Webseitenbetreiber in deren Nut-

650 Ausgenommen sind von einer solchen Einwilligung allerdings rechtswidrige Nutzungen, selbst wenn diese in bestimmten Bereichen im Internet üblich sein mögen.

651 So auch v.Ungern-Sternberg, GRUR 2009, 369 (371). 
zung im für die effektive Websuche erforderlichen Umfang zu sehen ist. ${ }^{652}$

Bezweifelt worden ist jedoch, ob es sich bei der von Bildersuchmaschinen angebotenen Verweisung auf Bilddateien in Form der Thumbnails um eine ebenso unerlässliche und wesensmäßig mit der Internetnutzung verbundene Nutzungshandlung handelt. 653 Jedenfalls ist eine beschreibende Verweisung auf Bilddateien in Textform nicht zwangsläufig völlig unbrauchbar und somit auch nicht von vornherein unvorstellbar. ${ }^{654}$ Allerdings würde ein effektives und vor allem schnelles Auffinden von Bildinformationen durch eine derartige Darstellung der Suchergebnis ganz erheblich erschwert. Ein schneller Überblick über die aufgefundenen Bilddateien und eine schnelle Auswahl relevanter Bilder wäre dem Nutzer gerade nicht mehr möglich. Zudem bestehen derzeit noch keine ausgereiften technischen Möglichkeiten, um eine solche Darstellung der Suchergebnisse automatisiert umzusetzen. ${ }^{655}$ Die Crawler der Suchmaschinen müssten dafür in der Lage sein, den Inhalt der aufgefundenen Bilddateien tatsächlich zu ,verstehen" und dann in sprachlicher Form beschreibend und möglichst detailliert wiederzugeben. Wie dargestellt, erfassen die Crawler jedoch derzeit lediglich die einer Bilddatei zugeordneten Informationen, etwa den Dateinamen und den verbalen Kontext, in dem sie stehen, und ordnen diese so bestimmten Suchbegriffen zu. Eine Umsetzung der Bildersu-

652 Vgl. schon Bettinger/Leistner/Leistner, Teil 1 B Rn. 73 ff.; Härting, Internetrecht, Rn. 977; Rath, Internet-Suchmaschinen, S. 141; v.Ungern-Sternberg, GRUR 2009, 369 (372).

653 Vgl. Omsels, jurisPR-WettbR 7/2010 Anm. 1; Roggenkamp, K\&R 2007, 328 (329); ders., jurisPR-ITR 14/2008 Anm. 2; ders., jurisPR-ITR 14/2010 Anm. 2; Schack, MMR 2008, 414 (416); zustimmend Fahl, K\&R 2010, 437 (439); ders., Bilder- und Nachrichtensuche, S. 125.

654 So der Vorschlag des LG Hamburg in der mündlichen Verhandlung des Thumbnail-Verfahrens; vgl. Hoeren, MMR 2009, 62. Vgl. auch das anschauliche Beispiel einer solchen Darstellung in sprachlicher Form bei Ott, ZUM 2009, 345. Diese Form der Darstellung wurde auch im US-amerikanischen Verfahren Perfect 10 v. Google, Inc. (416 F.Supp.2d 828 (C.D. Cal. 2006)) von der Klägerin als Alternative zur Thumbnail-Vorschau vorgeschlagen, vom Gericht jedoch im Ergebnis abgelehnt; ebd., S. 850.

655 An der Weiterentwicklung derartiger Techniken zur Bilderkennung, dem sogenannten Content-based image retrieval (CBIR), wird jedoch intensiv gearbeitet. Zur Entwicklung und den Problemen siehe etwa Datta/Joshi/Li/Wang, 40 ACM Computing Surveys 5:1 (2008); Lew/Sebe/Djeraba/Jain, 2 ACM Transactions on Multimedia Computing, Communications, and Applications 1 (2006). 
che in Textform ist daher weder nutzerfreundlich, noch (derzeit) technisch möglich.

Für die Annahme einer konkludenten Einwilligung in die Werknutzung durch Bildersuchmaschinen spricht jedoch, neben den vorgenannten Bedenken, ganz wesentlich eine andere Überlegung: Eine Betrachtung vom objektiven Empfängerhorizont ergibt, dass derjenige, der Bildwerke ungesichert in das Internet einstellt, ja gerade will, dass diese von anderen Internetnutzern aufgefunden und genutzt werden. Erst die Aufnahme in eine Suchmaschine ermöglicht jedoch in der Regel eine weitreichende Auffindbarkeit und eröffnet dem Webseitenbetreiber die Aussicht auf (zusätzlichen) traffic. Eine Suchmaschine, die dies möglichst einfach und effektiv ausgestaltet - was durch die Darstellung in Form stark verkleinerter Vorschaubilder, die den Werkgenuss des Originals nicht ersetzen, sondern lediglich auf dessen Fundort hinweisen, zweifellos der Fall ist -, dient daher objektiv gerade den Interessen des Einstellenden. Zudem muss die Nutzung durch Bildersuchmaschinen inzwischen allgemein als bekannt gelten, da sie von allen (großen) Suchmaschinenbetreibern angeboten wird und zu deren besonders häufig genutzten Dienstleistungen gehört. ${ }^{656}$ Bildersuchmaschinen gehören somit zweifelsohne längst zur festen Infrastruktur im Internet.

Bei objektiver Betrachtung aus der Sicht der Suchmaschinenbetreiber (als Erklärungsempfänger) und mit Rücksicht auf die Verkehrssitten im Internet willigt der Urheber oder Rechteinhaber durch das ungeschützte Einstellen von Bildern in das Internet daher gerade auch in eine Werknutzung in dem für den effektiven Betrieb der Bildersuchmaschine erforderlichen Umfang ein. ${ }^{657}$ Dies gilt umso mehr, wenn man bedenkt, dass es dem

656 Vgl. Ott, ZUM 2009, 345 (347).

657 Dies kann inzwischen als h.M. gelten, da sich dieser Argumentation weite Teile der Literatur und auch der Rechtsprechung angeschlossen haben; vgl. BGHZ 185, 291 (306 ff.) - Vorschaubilder; LG Erfurt, ZUM 2007, 566 (567); OLG Köln, ZUM 2010, 706 (707) [Konkludente Einwilligung in Zugriff durch Personensuchmaschine]; LG Hamburg, Urt. v. 16.6.2010, Az. 325 O 448/09, Rn. 22; Berberich, MMR 2005, 145 (147 f.); ders., CR 2007, 391 (393 f.); Bernreuther, WRP 2008, 1057 (1065); Bullinger/Garbers-v.Boehm, GRUR-Prax. 2010, 257; Engels, GRUR-Prax. 2010, 156; Ernst, jurisPR-WettbR 9/2008 Anm. 5; Gey, Öffentliche Zugänglichmachung, S. 170 f.; Heymann/Nolte, K\&R 2009, 759 (761 f.); Kleinemenke, CR 2009, 55; Leistner/Stang, CR 2008, 499 (505); Nolte, Informationsmehrwertdienste, S. 250 f.; Ott, ZUM 2007, 119 (126 f.); ders., ZUM 2009, 345 (346 f.); Schaefer, Bildersuchmaschinen, S. 134 f.; Schricker/Loewen- 
Einstellenden ohne großen Aufwand möglich ist, die Werknutzung durch die Suchmaschinen technisch zu verhindern. Selbst wenn eine derartige Einwilligung im Einzelfall nicht der Absicht des „Erklärenden“ entspricht, muss er sie dennoch gegen sich gelten lassen, da er bei Anwendung der im Verkehr erforderlichen Sorgfalt hätte erkennen und - durch technische Vorkehrungen - vermeiden können, dass sein Verhalten nach Treu und Glauben und mit Rücksicht auf die Verkehrssitte als entsprechende Erklärung aufgefasst werden durfte. ${ }^{658}$

Nicht von der Einwilligung gedeckt sind hingegen solche Nutzungen, die über den notwendigen Umfang hinausgehen und deshalb dem (objektiv ermittelten) Interesse des Urhebers zuwider laufen. ${ }^{659}$ Insbesondere ist einschränkend zu fordern, dass bei der Thumbnail-Anzeige und der weiteren Verweisung deutlich erkennbar sein muss, dass es sich um fremde Inhalte handelt und wer der ursprüngliche Anbieter dieser Inhalte ist. ${ }^{660}$ Diesem Erfordernis wird allerdings bei der Ausgestaltung aller derzeit üblichen Bildersuchmaschinen genügt. Eine Einwilligung in die Werknutzung kann zudem nicht angenommen werden, wenn der Urheber oder Rechteinhaber der Nutzung von Anfang an gegenüber einem oder allen Suchma-

heim/v.Ungern-Sternberg, § 19a Rn. 47; Schricker/Loewenheim/Schricker/Spindler, § 51 Rn. 54; Schricker/Loewenheim/Vogel, § 72 Rn. 26; Schricker/Loewenheim/Wild, § 97 Rn. 117 f.; v.Ungern-Sternberg, GRUR 2009, 369 (372); Wandtke/Bullinger/Heerma, § 16 Rn. 21; a.A. OLG Jena, GRUR-RR 2008, 223 (225) Thumbnails [allerdings Lösung über $\S 242$ BGB unter Heranziehung derselben Überlegungen, die die h.M. im Rahmen der konkludenten Einwilligung fruchtbar macht]; Eichelberger, GB 2010, 212 (213); Fahl, K\&R 2010, 437 (439 f.); ders., Bilder- und Nachrichtensuche, S. 88 ff.; Roggenkamp, K\&R 2007, 325 (329); ders., jurisPR-ITR 14/2008 Anm. 2; ders., jurisPR-ITR 14/2010 Anm. 2; Schack, GRUR 2007, 639 (643); ders., MMR 2008, 414 (416); Schrader/Rautenstrauch, UFITA 2007, 761 (776 ff.).

658 Vgl. BGHZ 174, 359 (367 f.) - Drucker und Plotter; BGH, GRUR 2009, 53 (55) - PC; BGHZ 185, 291 (306 f.) - Vorschaubilder; Leistner/Stang, CR 2008, 499 (504 f.); Schricker/Loewenheim/v.Ungern-Sternberg, §19a Rn. 47; v.UngernSternberg, GRUR 2009, 369 (372).

659 Vgl. den Fall des LG Hamburg, GRUR-RR 2004, 313 (317), in dem das Gericht - zu Recht - die zwingende Notwendigkeit der Verwendung von Thumbnails als „Schmuck“ für die Nachrichtensuche und somit auch das Vorliegen einer konkludenten Einwilligung verneinte.

660 Vgl. Bettinger/Leistner/Leistner, Teil 1 B Rn. 76; zustimmend Schricker/ Loewenheim/Vogel, § 87b Rn. 41. 
schinenbetreibern ausdrücklich widersprochen hat ${ }^{661}$ oder seine Ablehnung einer Thumbnail-Nutzung durch die Verwendung technischer Sperren, etwa eines entsprechenden Eintrags in der „robots.txt“-Datei ${ }^{662}$ oder eines Passwortschutzes, zum Ausdruck gebracht hat.

Grundsätzlich ausscheiden muss die Annahme einer rechtfertigenden Einwilligung in die Thumbnail-Nutzung durch Bildersuchmaschinen zudem immer dann, wenn der Urheber seine Werke nicht selbst auf einer Webseite zum Abruf durch die Öffentlichkeit bereitgestellt und auch Dritten die erforderliche Zustimmung nicht erteilt hat. In solchen Konstellationen einer „Drittinhaberschaft“ der erforderlichen Nutzungsbefugnisse, ${ }^{663}$ Fällen in denen das Werk also ausschließlich unberechtigt im Internet verfügbar ist, kommt eine Einwilligungslösung nicht in Betracht, da es schon an einer anknüpfungsfähigen Handlung des Rechteinhabers fehlt. ${ }^{664}$

661 Entgegen der Ansicht des BGH, der entsprechend seiner Argumentation in den Vorschaubilder-Entscheidungen (wohl) auch in diesem Fall eine konkludente Einwilligung des Rechteinhabers durch das ungeschützte Einstellen seiner Werke annehmen würde, kann eine Einwilligung im Falle eines tatsächlichen (anfänglichen) Widerspruchs des Rechteinhabers gegenüber dem Suchmaschinenbetreiber nicht angenommen werden - auch dann nicht, wenn die Inhalte anschließend ungeschützt eingestellt werden. Die tatsächliche Willenserklärung des Rechteinhabers muss insoweit Vorrang vor einem Verhalten haben, dem vom objektiven Empfängerhorizont ggfs. eine Einwilligung entnommen werden könnte. Vgl. zur entsprechenden und auf diese Konstellation übertragbaren Argumentation zum Widerruf einer (konkludenten) Einwilligung ausführlich unten 4. Kapitel, B.I. 2.c).

$662 \mathrm{Zu}$ den technischen Möglichkeiten eines „Ausschlusses“ der SuchmaschinenCrawler siehe näher oben 3. Kapitel, B.

663 Eine solche Konstellation lag erstmals in einem deutschen Urteil dem Verfahren vor dem LG Hamburg, ZUM 2009, 315 zugrunde. Das US-amerikanische Urteil Perfect 10, Inc. v. Amazon.com, Inc., et al., 508 F.3d 1146 (9th Cir. 2007), betraf ebenfalls eine solche Konstellation.

664 Vgl. BGHZ 185, 291 (309) -Vorschaubilder; Berberich, CR 2007, 391 (394); Ernst, jurisPR-WettbR 11/2008 Anm. 4; Fahl, K\&R 2010, 437 (439); Kleinemenke, CR 2009, 55; Leistner/Stang, CR 2008, 499 (506 f.) [die allerdings davon aus gehen, derartige Fälle dürften nicht „flächendeckend gerichtsnotorisch“ werden dass eher das Gegenteil der Fall sein dürfte, da gerade diese Fälle sich nicht durch die Einwilligungslösung erfassen lassen und deshalb drohen, das Geschäftsmodell von Bildersuchmaschinen in Frage zu stellen, unterstreicht das Urteil des LG Hamburg (ZUM 2009, 315)]; Ott, ZUM 2007, 119 (127); Schricker/ Loewenheim/v.Ungern-Sternberg, § 19a Rn. 47. 
Etwas Anderes ergibt sich auch nicht aus der Vorschaubilder II-Entscheidung ${ }^{665}$ des Bundesgerichtshofes. In dieser hatte der BGH über einen Fall der „Drittinhaberschaft“ der Urheberrechte zu entscheiden. Unstreitig hatte der Urheber die in der Bildersuche auffindbaren Bilder nämlich weder selbst auf der Webseite eingestellt, auf der sie von der Suchmaschine indexiert worden waren, noch einem Dritten die Erlaubnis zur dortigen Zugänglichmachung erteilt. Dennoch unterschied sich der dem Urteil zugrunde liegende Sachverhalt von den vorgenannten Fällen, in denen eine Einwilligungslösung keinesfalls in Betracht kommt, da das Werk ausschließlich unberechtigt im Internet verfügbar ist, der Urheber also gar keine Zustimmung zur Online-Veröffentlichung erteilt hat. Einen Anknüpfungspunkt für die Annahme einer Einwilligung sah der Bundesgerichtshof im zu entscheidenden Fall nämlich dennoch: Der klagende Urheber hatte einem Dritten überhaupt das Recht eingeräumt, das fragliche Lichtbild im Internet öffentlich zugänglich zu machen. ${ }^{666}$ Auch wenn das von der Suchmaschine als Thumbnai angezeigte Bild letztlich nicht auf die Internetseite verwies, auf der das Originalwerk mit Zustimmung des Urhebers veröffentlicht wurde, fehlte es somit nach Auffassung des Gerichts nicht vollständig an einer anknüpfungsfähigen Handlung des Rechteinhabers. Mit dem Einstellen von Abbildungen des Originalwerkes ins Internet habe der - vom Urheber ermächtigte - Dritte durch schlüssiges Verhalten gegenüber den Betreibern von Suchmaschinen seine schlichte Einwilligung zur Anzeige von Vorschaubildern der Abbildungen in Ergebnislisten von Bildersuchmaschinen erklärt. ${ }^{667} \mathrm{Da}$ es für die Auslegung der Einwilligung auf den objektiven Erklärungsinhalt aus der Sicht des Erklärungs-

665 BGH, GRUR 2012, 602 - Vorschaubilder II.

666 Vgl. BGH, GRUR 2012, 602 (605, Rn. 26) - Vorschaubilder II. Das OLG Hamburg hatte in der Vorinstanz Fragen der Einwilligung noch umgangen, indem es den Fall unter Rückgriff auf die Darlegungs- und Beweislast löste. Da eine berechtigte Einstellung im Internet in Betracht komme, müsse der Berechtigte nachweisen, dass die konkrete Nutzung unberechtigt sei. Der bloße Hinweis, er habe dem Betreiber der fraglichen Webseiten keine Lizenz erteilt, genüge insoweit nicht; siehe OLG Hamburg, Urt. v. 23.6.2010, 5 U 220/08, BeckRS 2012, 521 Dem trat der BGH zu Recht mit der Begründung entgegen, aus der Tatsache, dass der Kläger anderen die Nutzung gestattet habe, folge nicht, dass sich der Kläger zu den erteilten Lizenzen erklären müsse. Es reiche, wenn er darlege, dass er dem Betreiber der Webseite keine Lizenz erteilt habe; siehe BGH, a.a.O., S. 604, Rn. $22 \mathrm{f}$.

667 Siehe BGH, GRUR 2012, 602 (605, Rn. 27) - Vorschaubilder II. 
empfängers ankomme, sei die Einwilligung auch nicht auf die Anzeige von Abbildungen des Originalwerks beschränkt, die mit Zustimmung des Urhebers ins Internet eingestellt wurden, sondern erfasse auch Abbildungen des Werkes, die anschließend - ohne Zustimmung des Rechteinhabers - auf weiteren Internetseiten aufzufinden seien. Habe der Berechtigte oder mit seiner Zustimmung ein Dritter die Einwilligung zum Aufsuchen und Anzeigen von Abbildungen eines vom Berechtigten geschaffenen Werkes durch Bildersuchmaschinen erteilt, verhalte sich der Berechtigte daher widersprüchlich, wenn er von dem Betreiber einer Suchmaschine verlange, nur Vorschaubilder solcher Abbildungen des Werkes anzuzeigen, die vom Berechtigten oder mit seiner Zustimmung von Dritten ins Internet eingestellt wurden. Ein solches Verhalten sei daher auch unter dem Gesichtspunkt einer protestatio facto contraria unbeachtlich. ${ }^{668}$ Wurde ein Bild also einmal irgendwo im Internet mit Einwilligung des Rechteinhabers und ohne technische Schutzmaßnahmen eingestellt, so verletzt nach Ansicht des BGH der Suchmaschinenbetreiber durch dessen Anzeige im Thumbnail-Format - unabhängig vom konkreten Fundort des Werkes, auf den das Vorschaubild verweist - keine Urheberrechte.

Aus rein praktischer Sicht ist dem vom Bundesgerichtshof gefundenen Ergebnis zuzustimmen; der vom Senat gewählte Weg vermag jedoch dogmatisch nicht zu überzeugen. ${ }^{669}$ Möchte man das Geschäftsmodell der Bildersuche vor dem deutschen Urheberrecht mit seinem insoweit veralteten und zu starren Schrankenkatalog 670 „retten“, so bleibt de lege lata nur ein „Kunstgriff“ wie ihn hier der BGH durch die weitere Ausdehnung der Einwilligungslösung vorgenommen hat. Dass das „Schicksal“ eines einmal im Internet öffentlich zugänglich gemachten Bildes weitgehend unkontrollierbar ist, sollte inzwischen tatsächlich allgemein bekannt sein. Ebenso ist richtig, dass Suchmaschinenbetreiber - wenn überhaupt - allenfalls mit ganz erheblichen Kosten und gegebenenfalls durch Änderungen ihres Geschäftsmodells überprüfen können, ob die von Ihnen angezeigten

668 Siehe BGH, GRUR 2012, 602 (605, Rn. 28) - Vorschaubilder II.

669 Ebenso i.E. Conrad, ZUM 2012, 480 (481); Fahl, MMR-Aktuell 2012, 331727; Klass, ZUM 2013, 1 (5 ff.); Ohly, GRUR 2012, 983 (992); Spindler, MMR 2012, 386 (387). Thum, GRUR-Prax 2012, 215 sieht hingegen in dem Urteil eine auch „dogmatisch konsequent[e]“ Fortentwicklung der Einwilligungslösung.

670 Siehe zum Versagen der urheberrechtlichen Schranken bei der Rechtfertigung der Thumbnail-Nutzung und insbesondere in Fällen der Drittinhaberschaft der Rechte ausführlich oben 4. Kapitel, B.I.1.a) bis h). 
Thumbnails auf eine legale Quelle - also ein vom Rechteinhaber oder mit dessen Zustimmung veröffentlichtes Werk - verweisen. Technisch kaum sinnvoll möglich erscheint derzeit eine automatische Überprüfung, welches von mehreren aufgefundenen, identischen Bildern das „Original“, also das mit Zustimmung des Rechteinhabers veröffentlichte Werk, ist. Eine allenfalls denkbare Einzelfallüberprüfung der Berechtigung durch den Suchmaschinenbetreiber würde prohibitiv hohe Kosten verursachen. ${ }^{671}$ Vor dem Hintergrund dieser offenen Praktikabilitäts- und Tranksaktionskostenprobleme dehnt der BGH - zur Erhaltung der Bildersuche konsequent - die Wirkungen der Einwilligung in die Online-Nutzung eines Werkes erheblich aus. ${ }^{672}$ Für den Fall, dass der Urheber der Zugänglichmachung seines Werkes im Internet überhaupt einmal zugestimmt hat, wird die Einwilligung beziehungsweise deren Wirkung auch auf alle weiteren Fälle erstreckt, in denen das Bild (auch) auf einer anderen Internetseite aufgefunden wird als derjenigen, auf die sich die ursprüngliche $\mathrm{Zu}$ stimmung des Urhebers bezog.

So zustimmungswürdig auch die Bemühungen des BGH sein mögen, neue Formen der Werknutzung, hier das Geschäftsmodell der Bildersuche, zu erhalten - aus dogmatischer Sicht kann das Vorschaubilder II-Urteil nicht überzeugen. Die Grenzen einer maßgeblich von Praktikabilitätserwägungen gesteuerten Überdehnung der Einwilligungslösung zeigen sich deutlich, wenn man sie auf den zuvor dargestellten - vom BGH (noch) nicht zu entscheidenden - Fall überträgt, in dem ein Bild „,völlig“ unberechtigt im Internet verfügbar ist, der Rechteinhaber einer Online-Veröffentlichung also überhaupt nicht zugestimmt hat. Tatsächlich kann ein Suchmaschinenbetreiber - wie auch der BGH hervorhebt - nicht feststellen, „ob ein aufgefundenes Bild von einem Berechtigten oder einem Nichtberechtigten ins Internet eingestellt worden ist" ${ }^{\text {"673 }}$ Aus Sicht des Suchmaschinenbetreibers, der das Internet mit seinen Crawlern automatisch durchsucht, macht es jedoch keinen Unterschied, ob es sich bei ei-

671 Vgl. Ohly, GRUR 2012, 983 (988).

672 Spindler, MMR 2012, 386 (387) weist jedoch zu Recht darauf hin, dass durch eine derartige Ausdehnung der Einwilligungslösung zugunsten der Suchmaschinenbetreiber jegliche Anreize genommen werden, Technologien zu entwickeln, die den automatisierten Abgleich von Lizenzen und Rechteeinräumungen ermöglichen.

673 BGH, GRUR 2012, 602 (605, Rn. 28) - Vorschaubilder II. 
nem aufgefundenen Bild um eine ,ursprünglich illegale“674 oder erst „nachträglich illegale“ 675 Vervielfältigung des Werkes handelt, dieses also von einem Nichtberechtigten erstmalig in das Internet eingestellt wurde oder ein weiteres Exemplar eines ursprünglich mit Zustimmung des Rechteinhabers im Internet veröffentlichten Werkes ist. Im erstgenannten Fall kommt eine Einwilligungslösung jedoch schon deshalb nicht in Betracht, weil es vollständig an einer anknüpfungsfähigen Handlung des Rechteinhabers fehlt. Eine Einwilligung bedarf zwar keiner auf die Einräumung eines dinglichen Rechts gerichteten rechtsgeschäftlichen Willenserklärung, die einen auf den Eintritt einer solchen Rechtsfolge gerichteten Rechtsfolgewillen zum Ausdruck bringt. ${ }^{676}$ Es muss sich dem (schlüssigen) Verhalten des Urhebers beziehungsweise Rechteinhabers jedoch zumindest durch Auslegung vom objektiven Empfängerhorizont objektiv die Erklärung entnehmen lassen, dieser sei mit einer bestimmten Nutzung seines Werkes einverstanden. ${ }^{677}$ Hat der Rechteinhaber allerdings einem Einstellen in das Internet niemals zugestimmt oder dieses sogar ausdrücklich untersagt, so fehlt ein (schlüssiges) Verhalten, dem sich eine Einwilligungserklärung entnehmen ließe. Allein ein „Nicht-Verhindern“, dass ein Werk im Internet erscheint, kann insofern zur Annahme einer Einwilligung durch den Urheber in spätere Online-Nutzungen nicht ausreichen. Andernfalls müsste man auch den Urheber eines analogen Werkes, der dessen Digitalisierung nicht verhindert - etwa einen Künstler, der nicht verhindert, dass sein Gemälde digital fotografiert wird und diese digitale Vervielfältigung in das Internet gestellt wird - an der unterbliebenen Verhinderung als Anknüpfungspunkt für eine Einwilligung in eine spätere Suchmaschinennutzung festhalten. Dass eine solche Annahme die Einwilligungslehre nicht nur überdehnt, sondern mit deren Grundgedanken unvereinbar ist, liegt auf der Hand.

674 Also ein niemals mit Zustimmung des Urhebers/Rechteinhabers im Internet veröffentlichtes Werkexemplar.

675 Also ein andernorts mit Zustimmung des Urhebers/Rechteinhabers im Internet veröffentlichtes Werkexemplar, das ohne Zustimmung auf einer anderen Internetseite auffindbar ist.

676 Vgl. BGHZ 145, 343 (346 f.); BGHZ 185, 291 (305 f.) - Vorschaubilder; v.Ungern-Sternberg, GRUR 2009, 369 (370).

677 Vgl. BGHZ 185, 291 (306) - Vorschaubilder; Leistner/Stang, CR 2008, 499 (504 f.); Ott, Linking und Framing, S. 368; v.Ungern-Sternberg, GRUR 2009, $369(370)$. 
Bei dieser Sachlage lässt sich jedoch nicht zufriedenstellend erklären und erscheint es willkürlich, dass der Suchmaschinenbetreiber sich (nur) dann auf eine Einwilligung des Rechteinhabers verlassen können soll, wenn ein Werk ursprünglich mit Zustimmung des Rechteinhabers in das Internet gelangte, nicht hingegen bei einem „völlig“ ohne Zustimmung eingestellten Bild. Zur Vermeidung einer Haftung müsste der Suchmaschinenbetreiber also feststellen, ob es sich bei der über seine Suchmaschine auffindbaren und von dieser als Thumbnail angezeigten Vorlage um eine „ursprünglich illegale“ oder erst „,nachträglich illegale“ Vervielfältigung des Werkes handelt. Eine solche Unterscheidung ist zum einen technisch nicht möglich. Zum anderen verdeutlicht diese willkürliche Differenzierung die Schwäche der vom BGH herangezogenen Einwilligungslösung, die hier an ihre Grenzen gerät. Denn aus Sicht des Suchmaschinenbetreibers - als objektivem Erklärungsempfänger - ist der objektive Erklärungsgehalt in beiden Fällen gleich. Er findet (durch seine Crawler) jeweils ein Werkexemplar vor, das nicht mit Hilfe technischer Schutzmaßnahmen gegen einen Zugriff geschützt ist. Unterscheidet sich jedoch der „Erklärungsgehalt " 678 bei der (maßgeblichen) Betrachtung vom objektiven Empfängerhorizont tatsächlich nicht, so kann sich auch für die Beurteilung der Annahme einer mutmaßlichen Einwilligung sinnvollerweise kein Unterschied ergeben.

Dies verdeutlicht, dass der BGH mit der Vorschaubilder II-Entscheidung den Boden der traditionellen zivilrechtlichen Einwilligungslehre weitgehend verlässt und diese zu einer „Allzweckwaffe“679 zur Rettung erhaltenswerter Geschäftsmodelle erweitert, die in Verbindung mit dem Rückgriff auf das Argument widersprüchlichen Verhaltens eine äußerst flexible Anwendung und insbesondere auch die Berücksichtigung von Praktikabilitäts-, Tranksaktionskosten- und Gemeinnutzgesichtspunkte ermöglicht. ${ }^{600}$ Zugleich zeigen die dogmatischen Schwächen eindrucksvoll, dass sich die vom BGH vorgenommene Überdehnung der Einwilligungslehre als „Notanker“ zur Ermöglichung oder Erhaltung wünschenswerter

678 Hier in Anführungszeichen gesetzt, da im Falle „ursprünglich illegaler“ Inhalte bereits jegliche Erklärung fehlt.

679 Spindler, GRUR 2010, 785 (789).

680 Thum, GRUR-Prax 2012, 215 stellt insoweit (unter Hinweis auf Spindler, GRUR 2010, 785 (790)) zutreffend fest, auf der Basis der Rechtsfigur der (schlichten) Einwilligung habe sich ,eine von den Gerichten flexibel handhabbare „QuasiFair-Use-Regelung" im deutschen Recht etabliert". 
neuer Formen der Werknutzung letztlich als Offenbarungseid darstellt, der einmal mehr verdeutlicht, wie dringend eine Flexibilisierung der urheberrechtlichen Schranken erforderlich ist. ${ }^{681}$ Eine dringend erforderliche Schrankengeneralklausel sollte dabei so ausgestaltet werden, dass gerade auch die vom BGH in jüngerer Zeit insbesondere in Bezug auf InternetNutzungssachverhalte immer offener zur Begründung herangezogenen (Transaktions-)Kosten- und Nutzenaspekte ${ }^{682}$ bei der Frage der Rechtfertigung einer Werknutzung Berücksichtigung finden können. ${ }^{683}$ So können auf Basis einer Schrankengeneralklausel Entscheidungen getroffen werden, die nicht nur im Ergebnis, sondern auch in der Herleitung und Begründung überzeugen. Dies würde es dem BGH ersparen, sich zur Erreichung richtiger Ergebnisse fragwürdiger Konstruktionen zu bedienen, mit denen er selbst teilweise nicht im Reinen zu sein scheint. Darauf dass auch der BGH mit seiner Lösung im Vorschaubilder II-Urteil nicht vollständig zufrieden zu sein scheint, deutet jedenfalls der den Überlegungen zur Einwilligung angefügte (selbstverständliche) Hinweis hin, dem Rechteinhaber bleibe es ,allerdings unbenommen, diejenigen wegen einer Verletzung seiner nach dem Urheberrechtsgesetz geschützten Rechte an der Fotografie in Anspruch zu nehmen, die Abbildungen der Fotografie unberechtigt ins Internet eingestellt haben“. 684

\section{c) Untersagung künftiger Nutzungen}

Kommt man zu dem - hier vertretenen - Ergebnis, dass im ungeschützten Einstellen urheberrechtlich geschützter Werke grundsätzlich eine konkludente (schlichte) Einwilligung in deren Nutzung in einem für die effektive Bildersuche erforderlichen Umfang zu sehen ist, so stellt sich die Frage, ob und wie der Urheber beziehungsweise Rechteinhaber, der mit der Nutzung - entgegen des von ihm objektiv erzeugten Rechtsscheins - tatsäch-

681 So i.E. auch Spindler, MMR 2012, 386 (387).

682 Siehe bereits BGH, GRUR 2003, 958 (961) - Paperboy sowie die Praktikabilitäts- und Zumutbarkeitsüberlegungen in der Rechtsprechung zur Störerhaftung, etwa BGH, GRUR 2007, 708 (712) - Internet-Versteigerung II; GRUR 2009, 597 (598 f.) - Halzband; GRUR 2010, 633 (635 f.) - Sommer unseres Lebens; GRUR 2012, 304 (307 f.) - Basler Haar-Kosmetik.

683 Siehe zu Möglichkeiten der Ausgestaltung einer Schrankengeneralklausel im deutschen und europäischen Recht unten 7. Kapitel, A. und B.

684 BGH, GRUR 2012, 602 (605, Rn. 29) - Vorschaubilder II. 
lich nicht einverstanden ist, die künftige Nutzung untersagen kann. Die Einwilligung ist grundsätzlich mit Wirkung für die Zukunft frei widerruflich, ${ }^{685}$ das heißt der „Erklärende“ kann der Annahme einer konkludenten Einwilligung durch eine ausdrückliche gegenteilige Erklärung entgegentreten. Unter dem Gesichtspunkt der protestatio facto contraria räumt der BGH jedoch in seiner Vorschaubilder-Entscheidung dem sozialtypischen Verhalten des Einstellenden sogar im Konfliktfall den Vorrang vor dessen tatsächlich erklärtem Willen ein und nimmt an, die Einwilligung könne nur spiegelbildlich zu ihrer Erklärung widerrufen werden. ${ }^{686}$ Selbst ein ausdrücklich gegenüber einem Suchmaschinenbetreiber geäußerter Widerspruch soll demnach unbeachtlich sein, wenn der Erklärende sein Verhalten, dem objektiv die Einwilligungserklärung entnommen wurde, nicht ändert. Die stillschweigende (schlichte) Einwilligungserklärung könne im konkreten Fall folglich nur widerrufen werden, indem der „Erklärende“ die entsprechenden Sicherungen seiner eingestellten Werke gegen das Auffinden beziehungsweise Verwenden durch die Bildersuchmaschinen vornimmt. ${ }^{687}$

Diese Auffassung mag aus Transaktionskostengesichtspunkten auf den ersten Blick ihren Reiz haben, da der dem Rechteinhaber durch die Einrichtung technischer Schutzmaßnahmen entstehende Aufwand in aller Regel tatsächlich deutlich niedriger ist, als der Aufwand für die Suchmaschinenbetreiber, auf eine Vielzahl einzelner, uneinheitlicher und zu überprüfender (Widerrufs-)Erklärungen zu reagieren. Bei genauerer rechtlicher Betrachtung ist die Ansicht des BGH dennoch aus mehreren Gründen abzulehnen. Misst man einem bestimmten Verhalten - hier dem ungeschützten Einstellen eines Werkes in das Internet - einen gewissen Erklärungswert zu, so kann es nicht überzeugen, diesen weiterhin anzunehmen, wenn der Erklärende tatsächlich widersprochen hat. Den Erklärenden trotz eines ausdrücklich und deutlich erklärten Widerspruchs an seinem sozialtypischen Verhalten festzuhalten, widerspräche dem allgemeinen zivilrechtlichen Grundsatz, dass in der Regel der wahre Wille maßgeblich ist, wenn er erkennbar ist. ${ }^{688}$ Die Beschränkung der Gestaltungsfreiheit des Einzelnen durch die Annahme eines Vorranges des Erklärungsgehalts eines sozi-

685 Vgl. nur Ohly, Volenti non fit iniuria, S. 177 f. m.w.N.

686 Siehe BGHZ 185, 291 (308) - Vorschaubilder.

687 Vgl. BGHZ 185, 291 (308) - Vorschaubilder.

688 Vgl. grundlegend Staudinger/Singer, § 133 BGB Rn. 17 m.w.N. Vgl. auch Medicus/Petersen, Bürgerliches Recht, Rn. 191. 
altypischen Verhaltens gegenüber der ausdrücklichen Erklärung muss daher die begründungsbedürftige Ausnahme bleiben. ${ }^{689}$ Legt man die (stillschweigende) Einwilligungserklärung vom objektiven Empfängerhorizont aus - im Fall der Bildersuche also aus der Sicht der Suchmaschinenbetreiber - so erscheint es inkonsequent, bei einem tatsächlich erfolgten Widerruf an einen oder alle Suchmaschinenbetreiber nicht mehr auf diese Empfänger abzustellen, die ja nun tatsächlich Kenntnis vom Widerspruch des Einstellenden haben, sondern stattdessen einen Widerruf gegenüber der Allgemeinheit durch ein geändertes Sozialverhalten zu fordern. ${ }^{690}$

Eine Änderung des „Sozialverhaltens“ im Sinne der Einfügung wirksamer Schutzmechanismen gegen die Erfassung durch Bildersuchmaschinen zu verlangen, kann zudem im Einzelfall den Interessen des Einstellenden entgegenlaufen. Dieser mag tatsächlich ein Interesse daran haben, von den „Massensuchmaschinen“ nicht gefunden zu werden und deshalb der Nutzung durch diese widersprechen. Zugleich möchte der Urheber oder Rechteinhaber jedoch unter Umständen gerade keine erhöhten Sicherheitsvorkehrungen, etwa einen Passwortschutz und Mitgliederbereich für die eingestellten Werke verwenden, um den problemlosen Zugang für andere Nutzer sicher zu stellen, beispielsweise für den Freundeskreis oder ein Fachpublikum, das die Internetseite nicht aufgrund einer Suche mit einer Bildersuchmaschine erreicht, sondern deren Adresse gezielt eingibt oder die Seite durch das Anklicken eines Links aufruft.

Es ist zudem nicht ersichtlich, weshalb ein Urheber oder Rechteinhaber daran gehindert sein sollte, die Nutzung seiner Werke - aus welchen Gründen auch immer - beispielsweise nur einem bestimmten Suchmaschinenbetreiber mit Wirkung für die Zukunft zu untersagen. Dies wäre ihm aber nicht möglich, wollte man - wie der $\mathrm{BGH}^{691}$ - stets ein gegenläufiges Verhalten durch Erklärung gegenüber der Allgemeinheit als Wirksamkeitsvoraussetzung eines Widerrufs verlangen. Bei konsequenter Anwendung der Argumentation des Senats müsste nämlich auch ein Widerruf durch ein geändertes Sozialverhalten in Form der - technisch ohne Weiteres möglichen - Einfügung wirksamer Schutzmechanismen gegen die Er-

689 Vgl. Teichmann, in: FS Michaelis, S. 294 (315).

690 Vgl. Hüsch, CR 2010, 452 (456).

691 Vgl. BGHZ 185, 291 (308) - Vorschaubilder. 
fassung durch einen oder bestimmte Bildersuchmaschinenanbieter ${ }^{692}$ rechtlich unbeachtlich bleiben, da sich eine solche Erklärung gerade an einzelne Suchmaschinenbetreiber und somit nicht - spiegelbildlich zur zunächst erklärten (mutmaßlichen) Einwilligung - an die Allgemeinheit richtet. Die Folge der Vorschaubilder-Rechtsprechung wäre somit in Bezug auf die Möglichkeit einer einmal erklärten Einwilligung ein interessenwidriges „Alles oder Nichts“. Trotz zahlreicher, zumeist leicht zu realisierender technischer Möglichkeiten zur - auch nachträglichen - Differenzierung und Steuerung der Suchmaschinennutzung könnte ein Widerruf aufgrund des Erfordernisses eines spiegelbildlich zur gegenüber der Allgemeinheit erklärten Einwilligung auch nur durch einen entsprechenden Widerruf gegenüber der Allgemeinheit rechtlich beachtlich erklärt werden. Der Urheber oder Rechteinhaber, der einmal seine Einwilligung in die Suchmaschinennutzung (konkludent) erklärt hat, wäre folglich daran gehindert, diese mit Wirkung für die Zukunft einzelnen Suchmaschinenbetreibern gegenüber wirksam zu widerrufen.

Nur die Anerkennung der Möglichkeit eines ausdrücklichen Widerrufs trägt zudem der Tatsache Rechnung, dass tatsächlich bei weitem nicht jeder, der ein Bild auf einer eigenen oder fremden Webseite ins Internet einstellt, die Möglichkeiten kennt oder technisch umzusetzen weiß, um Suchmaschinen die Nutzung dieses Werkes zu untersagen. ${ }^{693}$ Dieses Unwissen muss er aufgrund einer entsprechenden Verkehrssitte im Internet bei der Ermittlung des Erklärungsinhaltes aus Sicht eines objektiven Empfängers zu seinen Lasten im Sinne einer Einwilligung in die übliche Nutzung hinnehmen. Kennt der Einstellende jedoch die technischen Möglichkeiten eines Opt Out tatsächlich nicht, so ist er auch nicht - oder zumindest nicht ohne erheblichen Aufwand, etwa durch die Beauftragung eines Webdesigners - in der Lage, diese nachträglich vorzunehmen, nachdem er Kenntnis von der seinem tatsächlichen Willen widersprechenden Nutzung durch die Suchmaschine erlangt hat. Macht der Urheber oder Rechteinhaber auf „traditionellem“ Wege durch einen ausdrücklichen Widerruf einer aufgrund der Verkehrssitte angenommenen Einwilligungserklärung deutlich, nicht mit der Nutzung einverstanden zu sein, so muss dies Beachtung finden.

692 Siehe zu den technischen Möglichkeiten, den Zugriff durch SuchmaschinenCrawler auf einzelne Anbieter zu beschränken oder bestimmten Suchmaschinen zu untersagen oben 3. Kapitel, B.

693 Vgl. Omsels, jurisPR-WettbR 7/2010 Anm. 1. 
Schließlich besteht auch kein tatsächliches Bedürfnis, den Widerruf gegenüber dem Einzelnen auszuschließen. Die Annahme einer konkludenten Einwilligung beruht letztlich auf einer - wesentlich durch Transaktionskostenüberlegung gesteuerten - Interessenabwägung zwischen den Belangen der Suchmaschinenbetreiber und deren Nutzern auf der einen Seite und den Interessen der Urheber beziehungsweise Rechteinhaber auf der anderen Seite. ${ }^{694}$ Hier kommt man grundsätzlich zu dem Ergebnis, dass letztere gewisse Einschnitte in ihre Ausschließlichkeitsbefugnisse hinnehmen müssen, da sie sich die Vorteile des Mediums Internet zu Nutzen machen und ihnen unschwer eine Sicherung ihrer Inhalte gegen ungewollte Nutzungen möglich ist, während dem Suchmaschinenbetreiber eine individuelle Lizenzierung und Überprüfung der Rechte im Einzelfall nicht möglich oder zumindest nicht zumutbar ist. ${ }^{695}$ Dieses Abwägungsergebnis entspricht in aller Regel auch den tatsächlichen Interessen der Beteiligten, insbesondere auch denen der Urheber und Rechteinhaber, die gerade ein Interesse an einer besseren Auffindbarkeit ihrer Inhalte und gesteigertem traffic auf ihrer Webseite haben. Die Interessenlage ändert sich aber entscheidend, wenn der Urheber oder Rechteinhaber der Nutzung tatsächlich widersprochen hat. Dann ist kein Raum mehr für Mutmaßungen über dessen Willen und der Suchmaschinenbetreiber ist in seinen Interessen an einer möglichst einfachen und effektiven Ermöglichung der Bildersuche nicht mehr schutzbedürftig. Ein schutzwürdiges Vertrauen dahingehend, der Urheber oder Rechteinhaber sei bereit, Einschränkungen seiner Ausschließlichkeitsrechte durch die Nutzung seiner Werke im Rahmen der Bildersuche hinzunehmen, besteht gerade nicht mehr. Sobald der Suchmaschinenbetreiber Kenntnis von einem Widerspruch erlangt hat, ist es ihm ohne unzumutbaren Aufwand möglich, die entsprechenden Thumbnails aus seiner Datenbank zu entfernen und die entsprechende Website in $\mathrm{Zu}$ kunft nicht mehr von den Crawlern durchsuchen zu lassen, so dass die entsprechenden Bilder nicht mehr auf Suchanfragen der Nutzer angezeigt werden. Ein solches nachträgliches Opt Out ist somit in rein tatsächlicher Hinsicht nicht problematisch und zudem bei Online-Diensten auch nicht unüblich. So wird auch von zahlreichen anderen Online-Diensteanbietern, etwa von Verkaufsplattformen, verlangt, dass diese nach einem entsprechenden Hinweis rechtsverletzende Angebote entfernen und Maßnahmen

694 Vgl. Götting, LMK 2010, 309481; Spindler, GRUR 2010, 785 (790).

695 Vgl. BGHZ 185, 291 (307 f.) - Vorschaubilder; Schulze, ZUM 2011, 2 (11 f.); Spindler, GRUR 2010, 785 (790). 
zur zukünftigen Verhinderung solcher Rechtsverletzungen treffen. ${ }^{696} \mathrm{Zu}$ bedenken ist zudem, dass dem Dritten - hier also dem Suchmaschinenbetreiber - durch die (schlichte) Einwilligung gerade kein durchsetzbarer Anspruch auf eine Nutzung eingeräumt wird. Wenn aber kein Anspruch einzelner Mitglieder der Allgemeinheit begründet wird, sondern lediglich die Rechtswidrigkeit ihrer Handlung ausgeschlossen wird, so kann es auch keinen Vertrauensschutz der Allgemeinheit geben, der die Interessen des Rechteinhabers überragt. ${ }^{697}$ Es muss dem Urheber oder Rechteinhaber deshalb möglich sein, gegenüber einem bestimmten Dritten oder allen Mitgliedern der Allgemeinheit die Wirkung der Einwilligung durch ausdrückliche Erklärung zu vernichten. 698

Die tatsächliche Erklärung eines Widerrufs gegenüber einem oder allen Bildersuchmaschinenbetreibern ohne eine gleichzeitige Modifikation der eigenen Website grundsätzlich als treuwidriges Verhalten zu deklarieren und daher für unbeachtlich zu halten, kann somit im Ergebnis nicht überzeugen. Ist derjenige, der durch das freie Einstellen eines Webseiten-Inhaltes objektiv eine Einwilligung erklärt hat, tatsächlich mit der Nutzung im Rahmen der Bildersuche nicht einverstanden, so kann er dies durch die Änderung seines Verhaltens, das heißt durch die Verwendung geeigneter Schutzmechanismen, verdeutlichen und so die zukünftige Nutzung verhindern. Er muss die Nutzung aber für die Zukunft auch durch einen ausdrücklichen Widerruf an einen oder mehrere Bildersuchmaschinenbetreiber beseitigen können. Ein solcher Widerruf ist meines Erachtens (spätestens) auch in der Erhebung einer Klage gegen die Nutzung zu sehen, da der Rechteinhaber hiermit eindeutig zum Ausdruck bringt, mit der (weiteren) Nutzung seiner urheberrechtlich geschützten Inhalte nicht einverstanden zu sein.

696 Vgl. BGHZ 172, 119 (132) - Internet-Versteigerung II; BGHZ 173, 188 (194 ff.) - Jugendgefährdende Medien bei eBay; BGH, GRUR 2008, 702 (706) - InternetVersteigerung III. Zur (auch nachträglichen) Opt Out-Möglichkeit im Rahmen der Google Buchsuche, siehe oben 3. Kapitel, A. Ebenfalls möglich ist ein Opt Out etwa bei dem umstrittenen Dienst Google Street View, bei dem auch nach der Veröffentlichung der Bilder im Internet eine Unkenntlichmachung einzelner Gebäude möglich bleibt; vgl. https://streetview-deutschland.appspot.com/submission [zuletzt abgerufen am 26.5.2013]. Zu den rechtlichen Problemen von Google Street View siehe etwa Dreier/Spiecker gen. Döhmann, Systematische Aufnahme des Straßenbildes, S. 19 ff.; Hoffmann, CR 2010, 514 ff.

697 Vgl. Omsels, jurisPR-WettbR 7/2010 Anm. 1.

698 Ebenso i.E. Ohly, GRUR 2012, 983 (990 f.). 
d) Zwischenergebnis

Hat der Urheber oder Rechteinhaber seine urheberrechtlich geschützten Werke ungeschützt und somit für jedes Mitglied der Öffentlichkeit frei zugänglich auf einer Internetseite eingestellt, so stellt die Annahme einer konkludenten (schlichten) Einwilligung in die Nutzung durch Bildersuchmaschinen in Form von Vorschaubildern einen dogmatisch tragfähigen Weg zur Rechtfertigung von Eingriffen in die Verwertungsrechte dar, der zu interessengerechten Ergebnissen führen kann. Der Erklärende kann seine stillschweigende Einwilligung in die Nutzung mit Wirkung für die $\mathrm{Zu}-$ kunft entweder durch ein gegenläufiges Verhalten oder durch eine ausdrückliche Erklärung gegenüber einem Suchmaschinenbetreiber widerrufen. Aus den dargestellten Voraussetzungen der Einwilligungslösung ergeben sich jedoch auch deren Grenzen. Grundsätzlich ausscheiden muss die Annahme einer rechtfertigenden Einwilligung in die Thumbnail-Nutzung durch Bildersuchmaschinen nämlich dann, wenn der Urheber seine Werke nicht selbst auf einer Webseite zum Abruf durch die Öffentlichkeit bereitgestellt und auch Dritten die erforderlichen Nutzungsrechte nicht eingeräumt hat. In solchen Konstellationen einer „Drittinhaberschaft“ der erforderlichen Nutzungsbefugnisse kommt eine Einwilligungslösung nicht in Betracht, da es schon an einer anknüpfungsfähigen Handlung des Rechteinhabers fehlt.

3. Haftungsprivilegierung des Suchmaschinenbetreibers unter Anwendung des Art. 14 Abs. 1 E-Commerce-Richtlinie

Obwohl die Konstellation der „Drittinhaberschaft“ des Urheberrechts nicht Gegenstand der ersten „Vorschaubilder"-Entscheidung des BGH war, hat dieser in einem obiter dictum Überlegungen angestellt, die nach allen zuvor dargestellten Lösungsansätzen nicht zu legitimierenden Fälle der Verwendung von Werken, die von dazu nicht berechtigten Personen in das Internet eingestellt wurden, durch eine Anwendung der Haftungsprivilegierung des Art. 14 Abs. 1 der Richtlinie 2000/31/EG ${ }^{699}$ (sog. E-Com-

699 Richtlinie 2000/31/EG des Europäischen Parlaments und des Rates vom 8. Juni 2000 über bestimmte rechtliche Aspekte der Dienste der Informationsgesellschaft, insbesondere des elektronischen Geschäftsverkehrs, im Binnenmarkt, ABl. Nr. L 178 v. 17.7.2000, S. 1. 
merce-Richtlinie) zu erfassen. So soll die Haftung der Suchmaschinenbetreiber auf solche Verstöße begrenzt werden, die begangen werden, nachdem die Betreiber Kenntnis von einer klaren Rechtsverletzung erlangt haben. ${ }^{700}$ In Anlehnung an die jüngste Rechtsprechung des EuGH zur Benutzung fremder Marken als sogenannte Keywords im Rahmen der OnlineWerbung ${ }^{701}$ soll Art. 14 Abs. 1 E-Commerce-RL auch auf die Bereitstellung der Dienstleistungen von Suchmaschinen anwendbar sein, wenn die betreffende Tätigkeit des Suchmaschinenbetreibers rein technischer, automatischer und passiver Art ist und er weder Kenntnis noch Kontrolle über die von ihm gespeicherte oder weitergeleitete Information besitzt.

Diese Überlegungen des BGH überraschen in vielerlei Hinsicht und können im Ergebnis nicht überzeugen. ${ }^{702}$ Bei der Regelung des Art. 14 Abs. 1 E-Commerce-RL handelt es sich um eine Haftungsprivilegierung für Host Provider. Diese wurde durch $\S 10 \mathrm{TMG}$ in deutsches Recht umgesetzt. Warum der BGH nicht auf diese nationale Regelung, sondern unmittelbar auf die Richtlinien-Vorschrift abstellt, ist bereits die erste Ungereimtheit in diesem Teil der Entscheidung. Unabhängig davon ist jedoch entgegen des Eindrucks, den der Hinweis des Senats vermittelt - auch nicht eindeutig, ob diese Haftungsregel ohne weiteres auf Suchmaschinenbetreiber anwendbar ist. Die in Art. 14 Abs. 1 E-Commerce-RL vorgesehene Beschränkung der Verantwortlichkeit gilt im Fall eines „Dienstes der Informationsgesellschaft, der in der Speicherung von durch einen Nutzer eingegebenen Informationen besteht". Der Anbieter eines solchen Dienstes kann nicht für die im Auftrag eines Nutzers gespeicherten Informationen zur Verantwortung gezogen werden, es sei denn, er hat die Informationen nicht unverzüglich entfernt oder den Zugang zu ihnen gesperrt,

700 BGHZ 185, 291 (309) - Vorschaubilder; dem ohne Begründung folgend Schricker/Loewenheim/v.Ungern-Sternberg, § 19a Rn. 47.

701 Siehe EuGH, Urt. v. 23.3.2010, C-236/08 bis C-238/08, GRUR 2010, 445 Google France SARL, Google Inc../. Louis Vuitton Malletier SA u.a. Zu diesen Urteilen und zur markenrechtlichen Zulässigkeit der Verwendung fremder Kennzeichen im Rahmen des Keyword-Advertising, siehe etwa Eichelberger, EuZW 2010, 731 ff.; Ohly, GRUR 2010, 776 ff.; Ott/Schubert, MarkenR 2010, 160 ff.; Spindler/Prill, CR 2010, 303 ff.; Splittgerber, NJW 2010, 2014 ff.; ausführlich Hühner, Domain-Parking, S. 175 ff.

702 Ebenfalls kritisch zu diesem Aspekt der Vorschaubilder-Entscheidung des BGH Conrad, ZUM 2010, 585 (587); Eichelberger, GB 2010, 212 (214); Leistner, IIC 2011, 417 (433 f.); Niemann, K\&R 2010, 507 (508); Roggenkamp, jurisPR-ITR 14/2008 Anm. 2; Rössel, MMR 480 (481 f.); Spindler, GRUR 2010, 785 (792). 
nachdem er durch eine geschädigte Person oder auf andere Weise von der Rechtswidrigkeit dieser Informationen oder Tätigkeiten des Nutzers Kenntnis erlangt hat. Es stellt sich also die Frage, ob eine Suchmaschine als ein solcher „Dienst der Informationsgesellschaft“ einzustufen ist, der in der Speicherung von durch den Werbenden eingegebenen Informationen besteht, so dass diese Daten Gegenstand von „Hosting” im Sinne des Art. 14 Abs. 1 E-Commerce-RL sind und die Verantwortlichkeit des Suchmaschinenanbieters nicht geltend gemacht werden kann, solange er von dem rechtswidrigen Verhalten des Dritten keine Kenntnis hat. ${ }^{703}$

Zur Frage der Anwendbarkeit der Haftungsprivilegierungen der ECommerce-Richtlinie beziehungsweise des TMG auf Suchmaschinen hat der BGH bisher nicht Stellung genommen. Der BGH hat jedoch bislang eine Anwendung der Haftungsprivilegierungen des TMG auf Hyperlinks abgelehnt. ${ }^{704}$ Gegen die Anwendung der $\S \S 7 \mathrm{ff}$. TMG auf Hyperlinks wurde insbesondere angeführt, der Wortlaut der Normen sei auf Provider zugeschnitten und passe nicht auf den Fall eines bloßen Seitenverweises. ${ }^{705}$ Zudem lasse die E-Commerce-RL in Art. 21 Abs. 2 die Frage der Haftung für Hyperlinks ausdrücklich offen und auch der deutsche Gesetzgeber habe bei der Umsetzung der Richtlinie in nationales Recht bewusst auf eine Regelung des ihm bekannten Problems der Haftung für Links verzichtet. ${ }^{706}$ Diese Argumente ließen sich auch auf die Frage der Anwendbarkeit der Haftungsprivilegierungen auf Suchmaschinen übertragen, weshalb bisher zumeist auch davon ausgegangen wurde, die Regelungen der $\S \S 7 \mathrm{ff}$. TMG seien auf diese ebenfalls nicht anwendbar. ${ }^{707}$

Der EuGH hat jedoch zuletzt im Zusammenhang mit der Frage der Haftung von Suchmaschinen für fremde Markenrechtsverletzungen durch Keyword-Advertising angedeutet, dass er die Anwendung der Haftungsprivilegierung des Art. 14 Abs. 1 E-Commerce-RL auf Suchmaschinen als „Referenzierungsdienste“ in dieser Konstellation prinzipiell für möglich

703 Vgl. EuGH, GRUR 2010, 445 (450) - Google France./. Louis Vuitton.

704 Siehe BGHZ 158, 343 (349) - Schöner Wetten.

705 Vgl. Härting, Internetrecht, Rn. 1689 f.; Spindler, MMR 2002, 495 (496); ders., NJW 2002, 921 (924).

706 Vgl. Gegenäußerung der Bundesregierung, BT-Drs. 14/6098, S. 37; Ernst/Seichter, WRP 2006, 810 (811); Koch, CR 2004, 213 (214); Ott, WRP 2006, 691 (693); Spindler, NJW 2002, 921 (924); ders., MMR 2004, 440.

707 Vgl. Gegenäußerung der Bundesregierung, BT-Drs. 14/6098, S. 37; Härting, Internetrecht, Rn. 1691; Spindler, MMR 2004, 440. 
hält. ${ }^{708}$ Zugleich hat das Gericht jedoch einschränkend festgestellt, die Speicherung der Information durch den Suchmaschinenbetreiber falle nur dann unter die Regelung des Art. 14 Abs. 1 E-Commerce-RL, wenn das Verhalten des Anbieters auf das eines „Vermittlers“ beschränkt sei, dieser die Informationen also für einen Dritten auf dessen Veranlassung speichere. ${ }^{709}$ Aus Erwägungsgrund 42 der E-Commerce-RL ergibt sich, dass dies nur der Fall ist, wenn die Tätigkeit des Suchmaschinenbetreibers rein technischer, automatischer und passiver Art ist und dieser weder Kenntnis noch Kontrolle über die weitergeleitete oder gespeicherte Information besitzt. ${ }^{710} \mathrm{Ob}$ der Suchmaschine im konkreten Fall eine derartige neutrale Rolle zukam, hat der EuGH nicht entschieden, sondern dem nationalen Gericht zur Feststellung überlassen. ${ }^{711}$ Demnach ist bereits für die vom EuGH behandelte Konstellation - die im Wesentlichen die Verwendung sogenannter AdWords durch ,traditionelle“ Suchmaschinen und gerade nicht deren Suchfunktion selbst betraf - bisher nicht festgestellt worden, ob diese tatsächlich rein technische, automatische und passive Dienstleistungen erbringen und weder Kenntnis noch Kontrolle über die weitergeleiteten oder gespeicherten Informationen haben. Bei den vom EuGH zu bewertenden Suchmaschinen-Dienstleistungen mag dies vertretbar sein, da es um die Störerhaftung aufgrund der Mitwirkung von Google an einer von einem Dritten vorgenommenen Rechtsverletzung durch die Zurverfügungstellung der erforderlichen Infrastruktur geht, Google als reiner Dienstleister die Daten also nur auf Anfrage des Werbenden verarbeitet und speichert. ${ }^{712}$ Auf das Geschäftsmodell der Bildersuchmaschinen ist die Regelung des Art. 14 Abs. 1 E-Commerce-RL hingegen unanwendbar, da diese in keiner Weise eine dem klassischen Host Provider vergleichbare Tätigkeit durchführen.

Die Tätigkeit des Bildersuchmaschinenbetreibers ist gerade nicht rein technischer, automatischer und passiver Art, denn der Betreiber hat Kenntnis und Kontrolle über die weitergeleitete und gespeicherte Information. Der Suchmaschinenbetreiber nimmt durch das Erstellen und Speichern verkleinerter Vorschaubilder der von den eigenen Crawlern aufge-

708 Vgl. EuGH, GRUR 2010, 445 (451) - Google France./. Louis Vuitton.

709 Vgl. EuGH, GRUR 2010, 445 (451) - Google France./. Louis Vuitton.

710 Vgl. EuGH, GRUR 2010, 445 (451) - Google France./. Louis Vuitton; BGHZ 185, 291 (310) - Vorschaubilder.

711 Siehe EuGH, GRUR 2010, 445 (451) - Google France./. Louis Vuitton.

712 Vgl. EuGH, GRUR 2010, 445 (451) - Google France./. Louis Vuitton. 
fundenen Bilddateien und das Vorhalten dieser Thumbnails für spätere Suchanfragen eigene Nutzungshandlungen vor. ${ }^{713}$ Dies hat der BGH auch selbst bei der Qualifizierung des Eingriffs in urheberrechtliche Verwertungsrechte festgestellt und ausdrücklich betont, der Bildersuchmaschinenbetreiber stelle nicht lediglich die technischen Mittel zur Verfügung, sondern übe vielmehr die Kontrolle über die Bereithaltung der Werke aus. Die Tatsache, dass der einzelne Suchmaschinennutzer den Abruf der vorgehaltenen Thumbnails durch die Eingabe eines bestimmten Suchbegriffes bewirke, berühre die Eigenschaft des Suchmaschinenbetreibers als Werknutzer gerade nicht. ${ }^{714}$ Diesen Überlegungen ist zuzustimmen, da der Bildersuchmaschinenbetreiber die Suche nach Bilddateien im Internet unabhängig von einer konkreten Anfrage durchführt und die gefundenen Bilder indexiert und in verkleinerter Form für einen späteren Abruf speichert. Die Feststellungen des BGH vertragen sich jedoch nicht mit der Annahme einer Haftungsprivilegierung des Bildersuchmaschinenbetreibers nach Art. 14 Abs. 1 E-Commerce-RL. Die Werknutzung erfolgt nicht im Auftrag oder auf Veranlassung der Inhalteanbieter oder der Suchmaschinennutzer, sondern aus eigenem Antrieb und Interesse des Suchmaschinenbetreibers. Es handelt sich um eigene Werknutzungen durch den Suchmaschinenanbieter - dieser ist also nicht lediglich Störer, sondern selbst $T \ddot{a}$ ter einer Urheberrechtsverletzung. Art. 14 Abs. 1 E-Commerce-RL soll hingegen ausdrücklich nur die Haftung beseitigen, wenn ein neutraler Anbieter wegen einer mittelbaren Rechtsverletzung hinsichtlich solcher Inhalte, die auf Veranlassung Dritter gespeichert und gegebenenfalls zugänglich gemacht werden, zur Verantwortung gezogen werden soll. Aus diesem Grund kann die Regelung des Art. 14 Abs. 1 E-Commerce-RL keine Anwendung auf Bildersuchmaschinen finden.

Auch ein weiterer Aspekt des Verweises des Senats auf Art. 14 Abs. 1 E-Commerce-RL und die neue EuGH-Rechtsprechung überrascht. Nach bisheriger Rechtsprechung des BGH finden die im TMG geregelten Haftungsprivilegierungen für Host Provider keine Anwendung auf Unterlassungsansprüche. ${ }^{715}$ Durch $\S 10$ TMG sollen demnach lediglich die strafrechtliche Verantwortlichkeit und die Schadensersatzhaftung begrenzt

713 Siehe dazu oben 4. Kapitel, A.I.1.

714 Siehe BGHZ 185, 291 (297f.) - Vorschaubilder.

715 Vgl. BGHZ 158, 236 (246 f.) - Internet-Versteigerung I; BGHZ 172, 119 (126) Internet-Versteigerung II; BGHZ 173, 188 (193 f.) - Jugendgefährdende Medien bei eBay. 
werden. ${ }^{716}$ Im „Vorschaubilder“-Verfahren wurde Google jedoch gerade auf Unterlassung in Anspruch genommen. Die Verweisung des Senats auf die Regelung der E-Commerce-Richtlinie wirft somit die Frage auf, ob der BGH tatsächlich Abstand von seiner bisherigen Rechtsprechung zur Anwendbarkeit der Haftungsprivilegierung auf Unterlassungsansprüche nimmt, oder ob es sich insoweit um ein „Versehen“ handelt. Es spricht einiges dafür, dass die Äußerungen des BGH zur Haftungsprivilegierung nach Art. 14 Abs. 1 E-Commerce-RL tatsächlich lediglich einen (missglückten) Versuch darstellen, eine Lösung für die äußerst problematischen Fälle der Verwendung von Werken, die von dazu nicht berechtigten Personen in das Internet eingestellt wurden, zu finden. Dabei mag das Gericht tatsächlich übersehen haben, dass es sich mit seinen Äußerungen in einen Widerspruch zur bisherigen Rechtsprechung zu Haftungsprivilegierungen zum TMG begibt. ${ }^{717}$

Selbst wenn man jedoch dem Vorschlag des BGH folgen und die Haftung der Betreiber von Bildersuchmaschinen auf solche Verstöße beschränken wollte, die begangen werden, nachdem dieser auf eine klare Rechtsverletzung hingewiesen worden sind, offenbart sich eine weitere Schwäche des „Vorschaubilder“-Urteils. Einerseits soll für die Untersagung der künftigen Werknutzung ein ausdrücklicher Widerruf der konkludenten Einwilligung gegenüber dem Suchmaschinenbetreiber nicht ausreichen, sondern vielmehr eine Erklärung an die Allgemeinheit in Form einer Änderung des „Einstellverhaltens“ erforderlich sein, da es für den Suchmaschinenbetreiber für unzumutbar gehalten wird, auf einen einzelnen Widerruf zu reagieren. ${ }^{718}$ Andererseits hält es der BGH jedoch offensichtlich für den Suchmaschinenbetreiber für durchaus zumutbar, auf Mitteilungen zu reagieren, in denen er auf bestimmte rechtswidrig in das Internet eingestellte Bilder hingewiesen wird. Eine Haftungsprivilegierung des Bildersuchmaschinenbetreibers setzt also voraus, dass es diesem - was tatsächlich auch zutreffend sein wird - möglich ist, die Erfassung einzelner Internetseiten durch seine Crawler und die Anzeige der Thumbnails von dort eingestellten Bildern mit Wirkung für die Zukunft zu unterlassen, sobald der Betreiber Kenntnis davon erlangt hat, dass Inhalte unberechtigt eingestellt wurden. Diese Annahme lässt sich im Verhältnis zur Ablehnung einer ausdrücklichen Widerrufsmöglichkeit für denjenigen, der In-

716 Vgl. BGHZ 173, 188 (193) - Jugendgefährdende Medien bei eBay.

717 So die Vermutung von Hüttner, WRP 2010, 1008 (1015).

718 Zur Möglichkeit des Widerrufs der Einwilligung siehe oben 4. Kapitel, B.I.2.c). 
halte berechtigt ins Internet stellt, jedoch nicht ohne Wertungswiderspruch aufrechterhalten. ${ }^{719}$ Es spricht vielmehr deutlich dafür, im Falle einer Haftungsprivilegierung des Suchmaschinenbetreibers zumindest - wie zuvor befürwortet $^{720}$ - auch den Widerruf einer konkludenten Einwilligung in die Werknutzung durch ausdrückliche Erklärung gegenüber dem Suchmaschinenbetreiber zuzulassen, da auch ein solcher dem Suchmaschinenbetreiber keinen unzumutbaren Aufwand aufbürdet.

Aus der vom BGH vorgeschlagenen Anwendung der Regelungen zur Haftungsprivilegierung auf die Konstellation der „Drittinhaberschaft“ der Urheberrechte bei der Bildersuche ergibt sich schließlich ein weiteres Folgeproblem: In ständiger Rechtsprechung zur Störerhaftung verlangt der BGH, dass nach dem Hinweis auf eine Verletzung zumutbare Vorkehrungen getroffen werden, um vergleichbare Verletzungen künftig zu vermeiden. ${ }^{721}$ Solche Vorkehrungen müssten folglich konsequenterweise auch von den Betreibern der Bildersuchmaschinen gefordert werden. ${ }^{722} \mathrm{Be}-$ denkt man jedoch, dass es sich bei der Konstruktion der Rechtfertigung der Werknutzung im Rahmen der Bildersuche durch eine Einwilligung letztlich um eine Lösung handelt, die der Tatsache Rechnung tragen soll, dass eine Überprüfung der Berechtigung zur Bildnutzung im Einzelfall den Suchmaschinen gerade nicht möglich ist, so ist nicht ersichtlich, wie ausreichende Vorkehrungen zur Vermeidung zukünftiger Rechtsverletzungen im Einzelnen ausgestaltet werden sollten, ohne dabei das Geschäftsmodell der Bildersuche tatsächlich in Frage zu stellen.

719 Vgl. auch die Kritik von Omsels, jurisPR-WettbR 7/2010 Anm. 1; Spindler, GRUR 2010, 785 (792).

720 Siehe oben 4. Kapitel, B.I.2.c).

721 Siehe BGHZ 172, 119 (132) - Internet-Versteigerung II; BGHZ 173, 188 (194 ff.) - Jugendgefährdende Medien bei eBay; BGH, GRUR 2008, 702 (706) Internet-Versteigerung III. Vgl. auch Bornkamm, GRUR Int. 2007, 642 (644). Zum Folgeproblem der Ausgestaltung derartiger Prüf- und Vorkehrungspflichten in Abgrenzung zu dem in Art. 15 Abs. 1 E-Commerce-RL und $\S 7$ Abs. 2 S. 1 TMG vorgesehenen Verbot allgemeiner Überwachungspflichten GRUR 2007, 890 (894) - Jugendgefährdende Medien bei eBay; Leistner/Stang, WRP 2008, 533 (541 ff.); sowie zuletzt ausführlich Leistner, GRUR-Beil. 2010, 1 (27 ff.) m.w.N. Zur Störerhaftung bei nicht gewerblichem Handeln (privater WLAN-Anschlussinhaber) und in diesem Fall zumutbaren Prüfungspflichten BGHZ 185, 330 (335 ff.) - Sommer unseres Lebens, mit Anm. Stang/Hühner, GRUR 2010, $636 \mathrm{f}$.

722 Vgl. auch Niemann, K\&R 2010, 507 (508). 
4. Zusammenfassung zur Rechtfertigung der Thumbnail-Nutzung

Es ist vielfach versucht worden, die Thumbnail-Nutzung durch die erweiternde Auslegung oder analoge Anwendung der urheberrechtlichen Schrankenbestimmungen zu legitimieren, wobei zum Teil abenteuerlich anmutende Konstruktionen oder Begründungen bemüht worden sind. Im Ergebnis erscheint auf der Ebene der Schrankenregelungen jedoch allenfalls ein Umkehrschluss zu $\S 12$ Abs. 2 UrhG als praktikabler Lösungsweg, der allerdings mit nicht unerheblichen dogmatischen Zweifeln belastet ist. Einen dogmatisch überzeugenderen Weg zur Rechtfertigung von Eingriffen in die Verwertungsrechte stellt die Annahme einer konkludenten (schlichten) Einwilligung in die Nutzung durch Bildersuchmaschinen dar. Diese vermag allerdings - ebenso wie ein Umkehrschluss zu $\S 12$ Abs. 2 UrhG - die Thumbnail-Nutzung nur dann zu rechtfertigen und kann nur dann zu interessengerechten Ergebnissen führen, wenn der Urheber selbst seine urheberrechtlich geschützten Werke ungeschützt auf einer Internetseite eingestellt oder die dazu erforderlichen Rechte einem Dritten eingeräumt hat. Grundsätzlich ausscheiden muss die Einwilligungslösung hingegen dann, wenn der Urheber seine Werke nicht selbst in das Internet gestellt und auch Dritten die erforderlichen Nutzungsrechte nicht eingeräumt hat. In solchen Konstellationen einer „Drittinhaberschaft“ der erforderlichen Nutzungsbefugnisse fehlt es für die Annahme einer Einwilligung schon an einer anknüpfungsfähigen Handlung des Rechteinhabers. Der Versuch, Fälle der Verwendung von Werken, die von dazu nicht berechtigten Personen in das Internet eingestellt wurden, durch die Anwendung der Haftungsprivilegierung des Art. 14 Abs. 1 der E-CommerceRichtlinie zu erfassen, ist abzulehnen. Die Werknutzung erfolgt bei der Bildersuche nicht im Auftrag oder auf Veranlassung der Inhalteanbieter oder der Suchmaschinennutzer, sondern aus eigenem Antrieb und Interesse des Suchmaschinenbetreibers. Es handelt sich um eigene Werknutzungen durch den Suchmaschinenanbieter - dieser ist also nicht lediglich Störer, sondern selbst Täter einer Urheberrechtsverletzung, so dass Art. 14 Abs. 1 E-Commerce-RL keine Anwendung finden kann.

De lege lata lässt sich die Verwendung solcher Werke, die ohne $\mathrm{Zu}-$ stimmung des Urhebers und ohne entsprechende Rechtseinräumung an Dritte in das Internet gestellt wurden - was bei einem nicht unerheblichen Anteil der Nutzungen der Fall sein wird - also nicht rechtfertigen. Tatsächlich ist es in diesen Fällen auch berechtigt, dem Urheber oder Rechteinhaber einen Unterlassungsanspruch zuzugestehen, da eine unerlaubte 
Nutzung seiner Werke stattfindet, die er nicht hinzunehmen braucht. Selbst wenn man jedoch eine - wie auch immer ausgestaltete - Haftungsprivilegierung der Suchmaschinenbetreiber annehmen wollte, nach der diese erst dann haften, wenn sie von einer klaren Rechtsverletzung Kenntnis erlangt haben, droht im Falle zahlreicher entsprechender Mitteilungen eine empfindliche Erschwerung der Dienstleistung „Bildersuche“.

Obwohl es sich bei der Bildersuche um eine Dienstleistung handelt, die allgemein als äußerst nützlich und deshalb erhaltenswert angesehen wird, lässt sich diese nach geltendem Recht nur schwer gesetzeskonform ausgestalten. Insgesamt zeigen die vorhergehenden Überlegungen, dass sich die Verwendung urheberrechtlich geschützter Werke in Form von Thumbnails im Rahmen der Bildersuche de lege lata nur dann rechtfertigen lässt, wenn die verwendeten Werke mit Zustimmung des Urhebers im Internet veröffentlicht wurden. Auch die Rechtfertigung dieser Nutzung erfordert jedoch erheblichen Begründungsaufwand und die Heranziehung „wackeliger" Hilfskonstruktionen. Dies zeigt, dass von der regelmäßig als entscheidendes Argument zugunsten eines detaillierten Schrankenkataloges ins Feld geführten Rechtssicherheit oftmals nicht viel übrig bleibt, da bis zu einer höchstrichterlichen Entscheidung - oder sogar noch danach - tatsächlich keine Klarheit herrscht, ob eine neuartige Nutzungsform geschützter Werke Urheberrechte verletzt. Diese Probleme und die durch die Heranziehung zum Teil ,abenteuerlicher“ Hilfskonstruktionen erzeugte Rechtsunsicherheit zeigen, dass mehr Flexibilität bei den urheberrechtlichen Schranken dringend erforderlich ist.

Durch den Rückgriff auf die flexible zivilrechtliche Einwilligungslösung wird zwar die begrüßenswerte Berücksichtigung zusätzlicher interessengerechter Aspekte, etwa auch die den urheberrechtlichen Schranken weitestgehend fremde Beachtung von Tranksaktionskostengesichtspunkten, ermöglicht. Zugleich ist jedoch zu bedenken, dass der Rückgriff auf die im Richterrecht ausgestaltete und damit wenig vorhersehbare und wenig „nutzerfreundliche“ Einwilligungslösung letztlich allein dazu dient, (urheber-)rechtlich das zu erreichen, was derzeit auf Grundlage des zu starren Schrankenkatalogs nicht möglich ist: Eingriffe in urheberrechtliche Ausschließlichkeitsrechte durch neuartige Formen der Werknutzung, die wünschens- und fördernswerte Allgemeinwohlwirkungen entfalten, sollen jedenfalls dann urheberrechtlich rechtfertigbar sein, wenn sie die Urheber und Rechteinhaber nicht oder jedenfalls nicht ungebührlich beeinträchtigen. Der Rückgriff auf die zivilrechtliche Einwilligungslösung dient somit letztlich zur Überwindung der sich mit fortschreitender technischer Ent- 
wicklung immer deutlicher aufdrängenden Schwächen des geltenden Urheberrechts.

Vor diesem Hintergrund mag die Anwendung der Einwilligungslösung durch die Rechtsprechung für einige Zeit als „Brückentechnologie“ geeignet und hinnehmbar sein; auf Dauer verfestigen sollte sich eine solche „urheberrechtsexterne“" Lösung jedoch nicht. Auf längere Sicht erscheint es vielmehr nicht nur zur „Rettung“ bestimmter (neuer) Geschäftsmodelle, sondern - wie insbesondere Hilty zu Recht angemerkt hat ${ }^{723}$ - auch aus Gründen der Methodenehrlichkeit erstrebenswert, das deutsche (und europäische) Urheberrecht durch die Schaffung einer flexiblen Schrankengeneralklausel oder zumindest durch die Implementierung flexiblerer Elemente in den bestehenden Schrankenkatalog zukunftsfähig zu machen. ${ }^{724}$ Die Einführung einer hinreichend konkret und dennoch flexibel ausgestalteten, im Urheberrecht verankerten Schrankengeneralklausel ermöglicht die erstrebenswerte „urheberrechtsinterne“ Lösung, die einen - zwar (teilweise) zielführenden, jedoch methodisch fragwürdigen - Rückgriff auf die gegenüber einer etwaigen Schrankengeneralklausel noch deutlich vagere zivilrechtliche Einwilligungslösung in Zukunft erübrigen würde und zugleich eine Möglichkeit für die Urheber vorsehen könnte, an den Einnahmen aus der Nutzung ihrer Werke angemessen zu partizipieren..

\section{Rechtfertigung der Google Buchsuche nach deutschem Urheberrecht}

Der allgemein als äußerst nützlich angesehene Buchsuche-Dienst von Google greift - wie gezeigt ${ }^{725}$ - in die ausschließlichen Verwertungsrechte der Urheber ein, namentlich in das Vervielfältigungsrecht ( $\$ 16 \mathrm{UrhG}$ ) und das Recht der öffentlichen Zugänglichmachung (§ 19a UrhG). Lässt sich die Werknutzung nach geltendem Recht nicht durch die Schrankenregelungen des Urheberrechtsgesetzes rechtfertigen, so liegt eine Verletzung des Urheberrechts vor, die gemäß den $\S \S 97$ ff. UrhG grundsätzlich Ansprüche auf Unterlassung, Schadensersatz und Vernichtung der Werkstü-

723 Vgl. Hilty, wiedergegeben von Geiger/Engelhardt/Hansen/Markowski, GRUR Int. 2006, 475 (493).

724 Zur Zulässigkeit und zu den Möglichkeiten einer Flexibilisierung der urheberrechtlichen Schranken im deutschen und europäischen Recht, siehe unten 7. Kapitel.

725 Siehe oben 4. Kapitel, A.II. 
cke nach sich zieht und gegebenenfalls sogar eine nach den $\S \S 106,108 \mathrm{a}$ UrhG strafbare Handlung darstellt. Greifen die Schrankenregelungen nicht ein, müsste Google sich zur Vermeidung dieser Rechtsfolgen individuell die erforderlichen Rechte zur Nutzung einräumen lassen.

\section{Anwendung des $\S 44 \mathrm{a} U \mathrm{UrhG}$}

Nach § 44a UrhG sind Vervielfältigungshandlungen zulässig, die lediglich vorübergehend, flüchtig oder begleitend sind, einen integralen und wesentlichen Teil eines technischen Verfahrens darstellen und keine eigenständige wirtschaftliche Bedeutung haben. Zur Ermöglichung eines effizienten Funktionierens von Übertragungssystemen sollen derartige für den Benutzer nicht verwertbare Vervielfältigungen, die rein technisch bedingt sind, der Verfügungsbefugnis des Rechtsinhabers entzogen sein. ${ }^{726}$

Die Regelung des $\S 44 a$ UrhG vermag die Werknutzung im Rahmen der Google Buchsuche nicht zu rechtfertigen. Soweit es um die öffentliche Zugänglichmachung der Werke gemäß §19a UrhG geht, greift §44a UrhG schon nicht ein, da er ausschließlich Vervielfältigungshandlungen im Sinne von $\S 16$ UrhG zu privilegieren vermag. ${ }^{727}$ Auch die für die Buchsuche vorgenommenen Vervielfältigungen können jedoch nicht nach $\S 44 a$ UrhG gerechtfertigt werden, da es sich gerade nicht um flüchtige Vervielfältigungen handelt, die einen integralen und wesentlichen Teil eines technischen Verfahrens darstellen. ${ }^{728}$ Die digitalisierten Bücher werden vielmehr dauerhaft sowohl als Bilddatei als auch als maschinenlesbare Textdatei gespeichert und zum Abruf bereitgehalten.

726 Vgl. Dreier/Schulze, §44a Rn. 1; Schricker/Loewenheim/Loewenheim, §44a Rn. 1.

727 Vgl. BGHZ 185, 291 (299) - Vorschaubilder; HK-UrhR/Dreyer, § 44a Rn. 3; Schack, Urheberrecht, Rn. 419 f.; Schricker/Loewenheim/Loewenheim, §44a Rn. 1; Spindler, GRUR 2010, 785 (787).

728 Im Ergebnis ebenso Heckmann, AfP 2007, 314 (317); Kubis, ZUM 2006, 370 (375). 


\section{Anwendung des $\S 51 \mathrm{UrhG}$}

Nach der durch den „Zweiten Korb“ der Urheberrechtsreform neu eingefügten Generalklausel in $\S 51 \mathrm{~S} .1 \mathrm{UrhG}$ ist das Zitatrecht nun nicht mehr auf bestimmte Zitatarten beschränkt, sondern ein veröffentlichtes Werk darf ganz generell zitatweise genutzt werden, sofern die Nutzung in ihrem Umfang durch den besonderen Zweck gerechtfertigt ist. Entscheidende Voraussetzung für die Anwendung des $\S 51 \mathrm{UrhG}$ ist somit der für den zulässigen Umfang des Zitats entscheidende Zitatzweck. ${ }^{729} \S 51$ UrhG setzt zudem auch nach der vorsichtigen Erweiterung durch den „zweiten Korb“ nach richtiger Ansicht weiterhin einen selbständigen Werkcharakter der Leistung voraus, in der zitiert wird. ${ }^{730}$ Erfüllt die Werknutzung diese Voraussetzungen, so sind sowohl die Vervielfältigung und Verbreitung als auch die öffentliche Zugänglichmachung zulässig. ${ }^{731}$

Die Regelung des $\S 51$ UrhG ist seit ihrer vorsichtigen Erweiterung nicht mehr auf das Zitieren in bestimmten Werkarten begrenzt. Als zitierendes Werk könnte im Falle der Buchsuche daher grundsätzlich die von Google zur Ermöglichung des Buchsuche-Dienstes erstellte Datenbank in Betracht kommen, wenn diese als Datenbankwerk im Sinne des $\S 4$ Abs. 2 UrhG einzustufen ist. Nach $\S 4$ Abs. 2 S. 1 UrhG sind Datenbankwerke Sammelwerke, deren Elemente systematisch oder methodisch angeordnet und einzeln mit Hilfe elektronischer Mittel oder auf andere Weise zugänglich sind. Da es sich bei den Datenbankwerken um einen Unterfall der Sammelwerke gemäß $\S 4$ Abs. 1 UrhG handelt, gilt auch für Datenbankwerke als Schutzvoraussetzung, dass es sich um eine persönliche geistige Schöpfung handeln muss. ${ }^{732}$ Aufgrund der aufwendigen Gestaltung der Buchsuche-Datenbank, wie sie insbesondere etwa in der Anordnung und Verknüpfung der Bild- und Textdateien, der Festlegung des Anzeigeumfangs im Einzelfall, der Verknüpfung mit bestimmten bibliographischen Angaben, der Suchoptionen und Abfragemöglichkeiten, der Verknüpfung der verschiedenen Werke untereinander und der mit diesen verbundenen

729 Vgl. BGHZ 85, 1 (10 f.) - Presseberichterstattung und Kunstwerkwiedergabe I; GRUR 1986, 59 (60) - Geistchristentum; Dreier/Schulze, § 51 Rn. 3; Fromm/ Nordemann/Dustmann, § 51 Rn. 16.

730 Vgl. oben 4. Kapitel, B.I.1.c).

731 Vgl. Schricker/Loewenheim/Schricker/Spindler, § 51 Rn. 10 m.w.N.

732 Vgl. nur Dreier/Schulze, § 4 Rn. 16, 19 sowie ausführlich und mit zahlreichen Nachweisen Leistner, Rechtsschutz von Datenbanken, S. 264 ff. 
Links zum Ausdruck kommt, sprechen im Ergebnis gute Gründe dafür, die Buchsuche-Datenbank als Datenbankwerk im Sinne des $\S 4$ Abs. 2 UrhG anzusehen. ${ }^{733}$ Selbst wenn die Buchsuche-Datenbank jedoch ein Datenbankwerk gemäß $§ 4$ Abs. 2 UrhG ist, fehlt es für die Anwendung der Zitatschranke des $\S 51$ UrhG dennoch an einer entscheidenden weiteren Voraussetzung - der Selbständigkeit des zitierenden Werkes. Durch die Auswahl und Anordnung von Zitaten kann zwar ein als Datenbankwerk schutzfähiges Werk geschaffen werden, das gegenüber jedem einzelnen verwendeten Werk selbständig ist, da die Urheberrechtsschutzfähigkeit nicht von dessen Verwendung abhängt. ${ }^{734}$ Dennoch kann es an der nach $\S 51$ UrhG erforderlichen Selbständigkeit fehlen, wenn die Gesamtheit der Zitate dergestalt im Mittelpunkt des zitierenden Werkes steht, dass Letzteres ohne die Zitate kein für sich existenzfähiges Werk mehr darstellen würde. ${ }^{735}$ Entscheidend ist für die Beurteilung also, ob eine eigenständige individuelle Schöpfung übrig bliebe, wenn man sich die übernommenen Werke wegdenkt. ${ }^{736}$ Denkt man sich bei der für die Google Buchsuche erstellten Datenbank die zitierten Datenbankelemente, also alle Vervielfältigungsstücke der Originalwerke in Form der Bild- und Textdateien, weg, so bleibt letztlich kein schutzfähiges Werk übrig. Ist dies der Fall, so verdient die Werknutzung jedoch keine Privilegierung durch das Zitatrecht, da letztlich nur eine Mehrzahl fremder Werke ohne wesentliche eigene Leistung wiedergegeben wird. ${ }^{737}$ Insbesondere nicht von der Schrankenregelung des $\S 51$ UrhG erfasst ist daher das bloße Aneinanderreihen fremder Werke oder Werkteile ohne eigene schöpferische Leistung. ${ }^{738}$ Schon aus diesem Grund scheidet daher die Privilegierung der Werknutzung bei der Google Buchsuche durch die Zitatschranke aus.

Selbst wenn man jedoch annehmen wollte, dass nach der Änderung des $\S 51$ UrhG im Rahmen des „Zweiten Korbs“ der Urheberrechtsreform das

733 Ausführlich zur Einordnung der Buchsuche-Datenbank als Datenbankwerk Lucke, Google Buchsuche, S. 54 ff.

734 Vgl. BGH, GRUR 1973, 216 (217 f.) - Handbuch moderner Zitate.

735 Vgl. BGHZ 116, 136 (141) - Leitsätze; BGHZ 126, 313 (320) - Museumskatalog; HK-UrhR/Dreyer, § 51 Rn. 12; Loewenheim/Götting, § 31 Rn. 168 f. m.w.N.

736 Vgl. BGH, GRUR 1973, 216 (217) - Handbuch moderner Zitate; GRUR 1986, 59 (60) - Geistchristentum; BGHZ 116, 136 (141 f.) - Leitsätze; Fromm/Nordemann/Dustmann, § 51 Rn. 19; Schricker/Loewenheim/Schricker/Spindler, § 51 Rn. 22.

737 Vgl. Ulmer, S. 314.

738 Vgl. BGH, GRUR 1973, 216 (218) - Handbuch moderner Zitate. 
Zitieren in einem selbständigen Werk nicht mehr zwingend erforderlich ist, ${ }^{739}$ so lässt sich die Werknutzung im Rahmen der Buchsuche dennoch nicht nach $\S 51$ UrhG rechtfertigen. Unstrittig ist die zitatweise Nutzung eines Werkes nur zu einem besonderen Zweck und in einem durch diesen gerechtfertigten Umfang zulässig. Dies erfordert, dass der Zitierende die fremden Werkteile erkennbar als solche nutzt, dabei jedoch eine innere Verbindung zwischen dem eigenen und dem fremden Werk herstellt. ${ }^{740}$ Das Zitat soll dem Zitierenden also nicht lediglich dazu dienen, sich eigene Ausführungen zu ersparen, sondern vielmehr die Erörterungsgrundlage für selbständige Ausführungen bilden und durch diese Belegfunktion die geistige Auseinandersetzung ermöglichen oder erleichtern. ${ }^{741}$ Einem solchen legitimen Zitatzweck dient die Werknutzung im Rahmen der Google Buchsuche gerade nicht. Eine geistige Auseinandersetzung mit den verwendeten Werken findet durch den „Zitierenden“ selbst, den BuchsucheAnbieter, nicht statt. Zwar wird oftmals der Nutzer des Dienstes die mit Hilfe der Buchsuche aufgefundenen Werke zur Grundlage eigener Überlegungen machen, doch ist eine solche „Vermittlerrolle“ zur Ermöglichung der geistigen Auseinandersetzung eines Dritten mit einem Werk von $\S 51$ UrhG nicht privilegiert. ${ }^{742}$

Auch eine erweiternde Auslegung oder analoge Anwendung des $\S 51$ UrhG vermag die Werknutzung durch Google nicht zu rechtfertigen. Die Werke werden von Google lediglich mit dem Ziel in die Datenbank aufgenommen, eine möglichst umfassende Dienstleistung zu erbringen - und somit letztlich zu kommerziellen Zwecken, da durch die besondere Attraktivität des umfassenden Dienstes die Möglichkeit begründet werden soll, Gewinne zu erzielen. ${ }^{743}$ Diese Interessenlage ist jedoch mit der vom Gesetzgeber privilegierten Förderung der geistigen Auseinandersetzung und

739 Vgl. zu dieser Ansicht die Nachweise oben Fn. 571.

740 Vgl. BGHZ 28, 234 (240) - Verkehrskinderlied; BGH, GRUR 1987, 362 (364) Filmzitat [insoweit nicht abgedruckt in BGHZ 99, 162]; BGHZ 175, 135 (147) TV-Total; BGHZ 185, 291 (300) - Vorschaubilder; KG, ZUM 2010, 883 (884) Bild im Bild; Fromm/Nordemann/Dustmann, § 51 Rn. 16 m.w.N.

741 Vgl. BGHZ 50, 147 (154) - Kandinsky I; BGH, GRUR 1986, 59 (60) - Geistchristentum; GRUR 1987, 34 (35) - Liedtextwiedergabe I; BGHZ 175, 135 (147) - TV-Total; BGHZ 185, 291 (300) - Vorschaubilder; Schricker/Loewenheim/ Schricker/Spindler, § 51 Rn. 16 m.w.N.

742 Vgl. zur insoweit vergleichbaren Situation bei der Bildersuche Schack, MMR 2008, 414 (415); siehe dazu auch bereits oben 4. Kapitel, B.I.1.c).

743 So auch Kubis, ZUM 2006, 370 (376); Lucke, Google Buchsuche, S. 87. 
schöpferischen Tätigkeit durch die Möglichkeit der unentgeltlichen Nutzung urheberrechtlich geschützter Werke oder Werkteile nicht vergleichbar.

Eine Privilegierung der Werknutzung im Rahmen der Google Buchsuche durch die Schrankenregelung des $\S 51$ UrhG scheidet somit im Ergebnis aus. ${ }^{744}$

\section{Anwendung des $\S 52 \mathrm{a} \mathrm{UrhG}$}

Die Regelung des § 52a UrhG wurde im Rahmen der Umsetzung der InfoSoc-Richtlinie (RL 2001/29/EG) in das Urheberrechtsgesetz eingefügt, um in einem eng begrenzten Umfang den berechtigten Interessen von Wissenschaft und Unterricht an der Nutzung moderner Kommunikationsformen Rechnung zu tragen. ${ }^{745} \mathrm{Zu}$ diesem Zweck gestattet $§ 52 \mathrm{a}$ UrhG die öffentliche Zugänglichmachung veröffentlichter (kleiner) Teile eines Werkes, von Werken geringen Umfangs sowie einzelner Beiträge aus Zeitungen und Zeitschriften für einen abgegrenzten Personenkreis. Privilegiert ist nach $\S 52 \mathrm{a}$ Abs. 1 UrhG zum einen die Nutzung zum Zwecke der Veranschaulichung im Unterricht in Schulen und weiteren genannten Bildungseinrichtungen (Nr.1) und zum anderen die öffentliche Zugänglichmachung zum Zwecke der eigenen wissenschaftlichen Forschung (Nr. 2). In beiden Fällen ist die Nutzung jedoch nur zulässig, soweit sie zu einem der privilegierten Zwecke geboten und zur Verfolgung nicht kommerzieller Zwecke gerechtfertigt ist. Nach §52a Abs. 3 UrhG ist auch die Herstellung der für die öffentliche Zugänglichmachung erforderlichen Vervielfältigungen erlaubt.

Im Rahmen der Google Buchsuche werden den Nutzern auf ihre Suchanfragen hin lediglich einzelne Auszüge aus den urheberrechtlich geschützten Werken zugänglich gemacht. Gewiss wird der Dienst auch von zahlreichen Personen genutzt, die die aufgefundenen Informationen für die eigene wissenschaftliche Forschung verwenden. Es kann und soll jedoch

744 So im Ergebnis - jedoch zumeist ohne nähere Begründung - ebenfalls Bohne/ Elmers, WRP 2009, 586 (588); Heckmann, AfP 2007, 314 (317); Kubis, ZUM 2006, 370 (376); Lucke, Google Buchsuche, S. 85 ff., 113 ff.; Ott, GRUR Int. 2007, 562 (565); Rath/Swane, K\&R 2009, 225 (228); Schricker/Loewenheim/ Schricker/Spindler, § 51 Rn. 54.

745 Vgl. Amtl. Begr., BT-Drs. 15/38, S. 20. 
bei der Google Buchsuche, die das Ziel hat, möglichst sämtliche veröffentlichte Bücher zu erfassen, gerade nicht ausgeschlossen werden, dass auch eine Nutzung zu beliebigen anderen Zwecken erfolgt. § 52a UrhG soll jedoch zur Vermeidung einer unzumutbaren Beeinträchtigung der (wissenschaftlichen) Verleger die öffentliche Zugänglichmachung nur für einen bestimmten abgegrenzten Personenkreis ermöglichen. ${ }^{746}$ In Bezug auf die Nutzung zur eigenen wissenschaftlichen Forschung muss die Nutzung also in einem Personenkreis erfolgen, dessen Angehörige selbst das Ziel der Gewinnung neuer wissenschaftlicher Erkenntnisse verfolgen - die Einbeziehung von Personen, bei denen das nicht der Fall ist, ist unzulässig. ${ }^{77}$ Die Zugänglichmachung muss zudem zur Verfolgung nicht kommerzieller Zwecke gerechtfertigt sein. Auch aus diesem Grund ist eine Rechtfertigung der Google Buchsuche nach § 52a UrhG ausgeschlossen. Für die Beurteilung des kommerziellen Charakters ist nämlich sowohl entscheidend, ob die konkrete Forschungstätigkeit einem kommerziellen Zweck dient, als auch die Frage, ob mit der Zurverfügungstellung selbst bereits ein kommerzieller Zweck verfolgt wird. ${ }^{748} \mathrm{Da}$ eine Beschränkung der Nutzung bei der Buchsuche nicht auf eine solche zu Forschungszwecken erfolgt, etwa durch eine Identifizierung des Nutzers als Mitglied einer bestimmten (Forschungs-)Institution, ist schon nicht ausgeschlossen, dass durch einzelne Nutzer eine Verwendung zu kommerziellen Zwecken erfolgt. Entscheidend ist jedoch, dass Google selbst die Buchsuche mit Gewinnerzielungsabsicht betreibt. Die Buchsuche wird zwar als für die Nutzer kostenlose Dienstleistung angeboten, Google generiert jedoch auf unterschiedliche Weise, insbesondere durch die Verknüpfung des Suchangebots mit Werbung und Links zu Online-Buchhändlern, bei denen der Erwerb eines Werkes möglich ist, Einnahmen. Durch die Implementierung der Buchsuche in das sonstige Suchmaschinenangebot von Google wird zudem deutlich, dass eine besonders umfassende Buchsuche gerade auch den Zweck hat, durch das Angebot umfassender Dienstleistungen die Popularität des kommerziellen Unternehmens Google insgesamt zu fördern.

746 Vgl. Dreier/Schulze, §52a Rn. 2 f.; Schricker/Loewenheim/Loewenheim, § 52a Rn. 1.

747 Vgl. Schricker/Loewenheim/Loewenheim, § 52a Rn. 11.

748 Vgl. Dreier/Schulze, § 52a Rn. 13; Fromm/Nordemann/Dustmann, § 52a Rn. 16; Schricker/Loewenheim/Loewenheim, § 52a Rn. 15. 
Im Ergebnis scheidet daher eine Privilegierung der Google Buchsuche als Nutzung zur eigenen wissenschaftlichen Forschung nach § 52a Abs. 1 Nr. 2, Abs. 3 UrhG aus. ${ }^{749}$

\section{Anwendung des $\S 53 \mathrm{UrhG}$}

Nach $§ 53$ Abs. 1 S. 1 UrhG ist die Herstellung einzelner Vervielfältigungsstücke eines Werkes zustimmungsfrei zulässig, wenn der Gebrauch durch eine natürliche Person in der Privatsphäre zur Befriedigung rein persönlicher Bedürfnisse der eigenen Person oder der mit ihr durch ein persönliches Band verbundenen Personen erfolgt. ${ }^{750}$ Die Vervielfältigung darf dabei auf beliebigen Trägern, also sowohl mit analogen als auch mit digitalen Mitteln, stattfinden. ${ }^{751}$ Anders als der sonstige eigene Gebrauch im Sinne des $\S 53$ Abs. 2 UrhG darf der private Gebrauch jedoch weder mittelbar noch unmittelbar Erwerbszwecken dienen.

Wie gezeigt wird die Buchsuche von Google jedoch zu kommerziellen Zwecken angeboten. Google kann sich somit keinesfalls unmittelbar als privilegierter Nutzer auf die Schrankenbestimmung des $\S 53$ UrhG berufen. In Betracht kommt eine Anwendung des $\S 53$ UrhG allenfalls dann, wenn Google nicht als Werknutzer, sondern als reiner Dienstleister einzustufen wäre, der die Vervielfältigung lediglich für einen Dritten - den Nutzer der Buchsuche - anfertigt.

Der nach $\S 53$ Abs. 1 S. 1 UrhG zur Vervielfältigung Berechtigte muss die Vervielfältigungsstücke nicht zwingend eigenhändig herstellen, sondern kann sie nach $\S 53$ Abs. 1 S. 2 UrhG auch durch einen Anderen her-

749 So im Ergebnis auch Heckmann, AfP 2007, 314 (317); Kubis, ZUM 2006, 370 (376); Ott, GRUR Int. 2007, 562 (564).

750 St. Rspr., vgl. BGH, GRUR 1978, 474 (475) - Vervielfältigungsstücke (noch zum insoweit entsprechenden Begriff des ,persönlichen Gebrauchs“ in $\S 53$ UrhG a.F.); BGHZ 134, 250 (256 f.) - CB-Infobank I; OLG München, GRUR-RR 2003, 365 (366) - CD-Münzkopierautomaten; vgl. aus dem Schrifttum statt vieler Schricker/Loewenheim/Loewenheim, § 53 Rn. 14 m.w.N.

751 Vgl. Amtl. Begr., BT-Drs. 15/38, S. 20; Schricker/Loewenheim/Loewenheim, $\S 53$ Rn. 18. 
stellen lassen, solange dies unentgeltlich ${ }^{752}$ geschieht oder es sich lediglich um analoge Vervielfältigungen handelt. „Anderer“ im Sinne dieser Norm kann dabei jeder Dritte sein. ${ }^{753}$ Es stellt sich somit auch hier die Frage der Abgrenzung zwischen Werknutzer und bloßem Dienstleister. ${ }^{754}$ Die Werknutzung gemäß $\S 53$ Abs. 1 S. 2 UrhG ist nur dann dem Auftraggeber und nicht dem Hersteller selbst zuzurechnen, wenn dessen Beitrag sich bei wertender Betrachtung darauf beschränkt, gleichsam ,an die Stelle des Vervielfältigungsgeräts" zu treten und somit bei normativer Betrachtung als ,notwendiges Werkzeug” des anderen tätig zu werden. ${ }^{755}$

Ein solches „notwendiges Werkzeug“ des anderen stellt Google als Anbieter der Buchsuche jedoch gerade nicht dar. Ein zulässiges „Herstellenlassen" im Sinne des §53 UrhG kann nämlich dann nicht mehr angenommen werden, wenn nicht der privilegierte Nutzer selbst die Auswahl der zu vervielfältigenden Werke trifft, sondern der Dritte die Vervielfältigungsstücke unabhängig von einer konkreten Anfrage auf der Grundlage eigener Recherchen erstellt. ${ }^{756} \mathrm{Im}$ Falle der Buchsuche digitalisiert Google aus eigenem Antrieb und eigenem (wirtschaftlichem) Interesse sämtliche Bücher aus den Kooperations-Bibliotheken. Nur auf diese zuvor digitalisierten Werke kann der Nutzer der Buchsuche zugreifen. Die Vervielfältigungen finden also keinesfalls aufgrund konkreter Nutzeranfragen statt, sondern erfolgen völlig unabhängig davon. Dies wird schon dadurch deutlich, dass sich in der Buchsuche-Datenbank etliche Werke finden dürften, die tatsächlich nie aufgerufen werden. Zudem wird von Google auch nicht ausgeschlossen, dass die Verwendung durch die Nutzer ebenfalls zu mittelbaren oder unmittelbaren Erwerbszwecken erfolgt. Diesen Nutzern käme aber selbst schon die Regelung des $\S 53$ Abs. 1 UrhG nicht zugute, so dass auch ein Herstellenlassen der Vervielfältigungsstücke durch einen Dritten nicht zulässig wäre. Auch aus diesem Grund kann die Schranken-

752 Die Herstellung eines Vervielfältigungsstückes durch einen Dritten ist auch dann noch als unentgeltlich i.S.d. §53 Abs. 1 S. 2 UrhG anzusehen, wenn ein Entgelt verlangt wird, das lediglich der Kostendeckung dient. Ist die Tätigkeit hingegen auf Gewinnerzielung ausgerichtet, so ist sie nicht mehr unentgeltlich im Sinne der Norm; vgl. Begr. RegE, BT-Drs. 15/38, S. 20 f.; bestätigt und präzisiert durch BGH, GRUR 2009, 845 (850) - Internet-Videorecorder.

753 Vgl. Schricker/Loewenheim/Loewenheim, § 53 Rn. 25.

754 Vgl. dazu bereits oben 4. Kapitel, A.I.1.

755 Vgl. BGH, GRUR 2009, 845 (846) - Internet-Videorecorder; OLG Köln, GRUR 2000, 414 (417) - GRUR/GRUR Int.

756 Vgl. BGHZ 141, 13 (20 ff.) - Kopienversanddienst. 
regelung des $\S 53$ Abs. 1 UrhG nicht zur Rechtfertigung der Google Buchsuche dienen.

Letztlich ist für eine Anwendung des $\S 53$ UrhG auf die Google Buchsuche auch deswegen kein Raum, weil $\S 53$ Abs. 4 lit. b UrhG ausdrücklich regelt, dass die vollständige oder im Wesentlichen vollständige Vervielfältigung von Büchern oder Zeitschriften grundsätzlich die Einwilligung des Berechtigten voraussetzt, sofern sie nicht durch Abschreiben erfolgt. Zwar erfordert ein Abschreiben im Sinne des $\S 53$ Abs. 4 UrhG nicht die handschriftliche Übernahme des Textes, sondern erfasst auch die Textverarbeitung mittels eines Computers, eine unmittelbare Übertragung des Textes mittels digitaler Technik wie im Falle des Scannens unterfällt jedoch nicht mehr dem Abschreiben im Sinne der Norm. ${ }^{757}$ Vom Verbot der vollständigen Vervielfältigung eines Werkes nach $\S 53$ Abs. 4 lit.b UrhG ausgenommen ist jedoch auch die Vervielfältigung zum Zwecke der Aufnahme in ein Archiv gemäß $§ 53$ Abs. 2 S. 1 Nr. 2 UrhG. Unter einem Archiv im Sinne dieser Norm versteht der BGH eine unter sachlichen Gesichtspunkten geordnete Sammlung vorhandener Werke zum internen Gebrauch. ${ }^{758}$ Die Ausnahme zugunsten von Archiven kommt demnach nur dann zur Anwendung, wenn die vollständige Vervielfältigung dem reinen Zweck der Archivierung dient. Es darf also gerade keine zusätzliche Verwertung des Werkes erfolgen. ${ }^{759} \mathrm{Zu}$ diesem Zweck beschränkt $\S 53$ Abs. 2 S. 1 Nr. 2 UrhG die Ausnahme auf eine Archivierung unter Benutzung eines eigenen Werkstückes als Vorlage. Schließlich darf die Vervielfältigung auch bei der Aufnahme in ein Archiv nicht gewerblichen Zwecken dienen. ${ }^{760}$ Alle diese Voraussetzungen erfüllt die Google Buchsuche nicht. Es handelt sich bei der Buchsuche-Datenbank schon nicht um ein internes Archiv. Die Vervielfältigung der Bücher erfolgt zudem von fremden Vorlagen und gerade nicht zum Zwecke der Archivierung, sondern um diese den Nutzern zur weiteren Verwendung zugänglich zu machen. Schließlich dient die Nutzung wie gezeigt auch Erwerbszwecken. Auch die Ausnahme zugunsten von Archiven kommt Google somit im Ergebnis nicht zugute.

Wie zuvor gezeigt, stellt zudem der Abruf der Textausschnitte durch den Nutzer im Rahmen der Suchergebnisse einen Eingriff in das Vervielfältigungsrecht des $\S 16$ UrhG dar. Diese Vervielfältigungshandlung wird

757 Vgl. Schricker/Loewenheim/Loewenheim, § 53 Rn. 75.

758 Vgl. BGHZ 134, 250 (257) - CB-Infobank I.

759 Vgl. Amtl. Begr., BT-Drs. IV/270, S. 73.

760 Vgl. Fromm/Nordemann/W.Nordemann, § 53 Rn. 23. 
jedoch in aller Regel von der Schrankenregelung des $\S 53$ Abs. 1 S. 1, Abs. 2 UrhG als Vervielfältigung zum privaten Gebrauch oder als Vervielfältigung zum eigenen wissenschaftlichen Gebrauch (§53 Abs. 2 S. 1 Nr. 1 UrhG) privilegiert sein. ${ }^{761}$ Es ist jedoch auch nicht auszuschließen, dass die Buchsuche vom Nutzer mittelbar oder unmittelbar zu Erwerbszwecken verwendet wird.

Im Ergebnis kann $\S 53$ UrhG in Bezug auf die Google Buchsuche somit allenfalls solche Vervielfältigungshandlungen rechtfertigen, die durch den Nutzer beim Abruf der Suchergebnisse erstellt werden. Allerdings sind auch diese nur nach $\S 53$ UrhG zulässig, wenn sie nicht mittelbar oder unmittelbar Erwerbszwecken dienen. Alle sonstigen Eingriffe in das Vervielfältigungsrecht gemäß $\S 16$ UrhG durch das Digitalisieren geschützter Werke und deren Umwandlung in eine Textdatei für die Nutzung im Rahmen der Google Buchsuche lassen sich hingegen keinesfalls nach $\S 53$ UrhG rechtfertigen. ${ }^{762}$ Beeinträchtigungen des Rechts der öffentlichen $\mathrm{Zu}$ gänglichmachung gemäß § $19 \mathrm{a}$ UrhG durch die Buchsuche lassen sich zudem grundsätzlich nicht nach $\S 53$ UrhG rechtfertigen, der ausdrücklich nur auf das Vervielfältigungsrecht Anwendung findet.

\section{Anwendung des $\S 53 \mathrm{a}$ UrhG}

Nach §53a UrhG ist die Vervielfältigung und Übermittlung einzelner in Zeitungen und Zeitschriften erschienener Beiträge und kleiner Teile eines erschienenen Werkes durch öffentliche Bibliotheken im Wege des Postoder Faxversands oder in sonstiger elektronischer Form zulässig. Die Anwendung dieser Regelung auf die Google Buchsuche scheidet jedoch im Ergebnis aus mehreren Gründen aus. Zum einen erscheint schon zweifelhaft, ob sich die Google Buchsuche als öffentliche Bibliothek im Sinne der Schrankenregelung einordnen lässt. Die „Öffentlichkeit“ einer Bibliothek erfordert zwar nicht, dass diese von der öffentlichen Hand getragen wird, sondern kann auch bei einer privaten Einrichtung vorliegen. ${ }^{763} \mathrm{Er}-$ forderlich ist jedoch, dass die Bibliothek und ihre Buchbestände öffentlich

761 So auch Bohne/Elmers, WRP 2009, 586 (588); Kubis, ZUM 2006, 370 (376 f.); Meyer, K\&R 2007, 177 (183); Ott, GRUR Int. 2007, 562 (564).

762 So im Ergebnis - ohne nähere Begründung - auch Heckmann, AfP 2007, 314 (317); Kubis, ZUM 2006, 370 (376); Lucke, Google Buchsuche, S. 71 ff.

763 Vgl. Fromm/Nordemann/Nordemann-Schiffel, § 53a Rn. 5. 
zugänglich sind. ${ }^{764}$ Dies ist zwar auch bei einer reinen Zugriffsmöglichkeit über das Internet nicht ausgeschlossen, ${ }^{765}$ trifft aber auf die Google Buchsuche nicht zu. Dem Nutzer ist nicht der vollständige Bibliotheksbestand zugänglich, sondern gerade nur eine begrenzte Snippet-Vorschau auf die in der Datenbank enthaltenen Werke. Die Google Buchsuche dient also gerade nicht als Bibliothek im klassischen Sinne, sondern vielmehr als Register oder „Wegweiser“ zu den Büchern, die der Anfrage des Nutzers entsprechen. Um den vollständigen Inhalt eines Werkes zu sehen, muss der Nutzer - bei urheberrechtlich geschützten Werken - daher das mit Hilfe der Buchsuche aufgefundene Werk andernorts, etwa in einer „echten“ Bibliothek, einsehen. Dieses „Selbstverständnis“ der Google Buchsuche als reiner Hinweisdienst zeigt sich gerade auch darin, dass neben der Snippet-Anzeige Hinweise auf mögliche Fundstellen und Kaufmöglichkeiten des gefundenen Buches präsentiert werden. § 53a Abs. 1 UrhG setzt zudem voraus, dass die öffentliche Bibliothek auf Grundlage einer Einzelbestellung handelt und die daraufhin erstellte Kopie durch Post- oder Faxversand oder in sonstiger elektronischer Form an den Besteller übermittelt wird. Einen Post- oder Faxversand der vom Nutzer gefundenen Werkteile bietet Google nicht an. In Betracht kommt daher allenfalls eine Einstufung der Snippet-Darstellung als Übermittlung in sonstiger elektronischer Form. Eine Übermittlung in sonstiger elektronischer Form ist zulässig, soweit sie funktional an die Stelle der Einzelübermittlung in körperlicher Form tritt. ${ }^{766}$ Sie unterliegt jedoch zusätzlichen Einschränkungen gemäß $\S 53 \mathrm{a}$ Abs. 1 S. 2 und 3 UrhG. Diese einschränkenden Voraussetzungen erfüllt die Google Buchsuche keinesfalls, denn es erfolgt - wie zuvor gezeigt - keine Beschränkung auf solche Kopien, die der Veranschaulichung des Unterrichts oder Zwecken der wissenschaftlichen Forschung dienen. Schließlich ist festzuhalten, dass die Schrankenregelung des $\S 53 \mathrm{a}$ UrhG nur das Vervielfältigungsrecht gemäß $\S 16$ UrhG einschränkt. Eine Be-

764 Vgl. Dreier/Schulze, §53a Rn. 7; Schricker/Loewenheim/Loewenheim, §53a Rn. 9.

765 Vgl. HK-UrhR/Dreyer, § 53a Rn. 7.

766 Vgl. Begr. zum Entwurf eines Zweiten Gesetzes zur Regelung des Urheberrechts in der Informationsgesellschft, BT-Drs. 16/1828, S. 27. 
schränkung des Rechts der öffentlichen Zugänglichmachung ist ausdrücklich nicht erwünscht. ${ }^{767}$

Die Google Buchsuche lässt sich somit im Ergebnis nicht aufgrund der Schrankenregelung des § 53a UrhG rechtfertigen. ${ }^{768}$

\section{Einwilligung}

Die zuvor ausführlich dargestellte Annahme einer konkludenten Einwilligung, ${ }^{769}$ die hinsichtlich der Thumbnail-Nutzung (teilweise) einen dogmatisch tragfähigen Weg zur Rechtfertigung der Nutzung urheberrechtlich geschützter Werke darstellt, kann für die Google Buchsuche nicht als Lösung herangezogen werden. Bei der Bildersuche kann eine konkludente Einwilligung des Urhebers oder Rechteinhabers deshalb angenommen werden, weil dieser sein geschütztes Werk frei zugänglich in das Internet eingestellt hat. Diesem Verhalten lässt sich bei Betrachtung vom objektiven Empfängerhorizont die Erklärung entnehmen, der Einstellende sei mit der üblichen Nutzung durch (Bilder-)Suchmaschinen einverstanden. ${ }^{770}$

In Bezug auf die Google Buchsuche fehlt jedoch jegliches Verhalten des Rechteinhabers, dem der für die Annahme einer Einwilligung erforderliche Erklärungswert beigemessen werden könnte, er sei mit der Nutzung im Rahmen der Buchsuche einverstanden. Google verwendet für seine Buchsuche diejenigen Werke, die in den Partner-Bibliotheken enthalten sind. Es handelt sich also ausschließlich um Werke, die offline veröffentlicht wurden. Der Veröffentlichung und Verbreitung eines Buches in gedruckter Form kann jedoch keinesfalls eine Einwilligung in die kommerzielle Online-Nutzung durch einen Dritten entnommen werden. ${ }^{771}$ Eine Einwilligung in die Werknutzung durch Google für die Buchsuche kann auch deshalb nicht angenommen werden, weil die dafür erforderlichen Rechte vielfach gar nicht bei dem Verleger liegen mögen, der das Werk in gedruckter Form verbreitet hat. Hat sich der Urheber etwa die Rechte zur

767 Vgl. Begr. zum Entwurf eines Zweiten Gesetzes zur Regelung des Urheberrechts in der Informationsgesellschft, BT-Drs. 16/1828, S. 27; Schricker/Loewenheim/ Loewenheim, § 53a Rn. 13.

768 So auch Lucke, Google Buchsuche, S. 122 f.

769 Siehe oben 4. Kapitel, B.I.2.

770 Siehe dazu ausführlich oben 4. Kapitel, B.I.2.b).

771 So auch Ott, GRUR Int. 2007, 562 (565). 
Online-Nutzung ausdrücklich vorbehalten oder diese bereits einem anderen Verleger eingeräumt, so kann der Verleger der von Google digitalisierten Offline-Veröffentlichung schon rein rechtlich nicht in die Online-Nutzung einwilligen. Selbst wenn jedoch die Rechte für die Online-Nutzung bei demselben Verleger liegen und selbst wenn der Rechteinhaber das Werk auch online veröffentlicht haben sollte, ändert sich die Bewertung jedoch nicht. Denn selbst einer solchen Handlung könnte eine Einwilligung in die Nutzung im Rahmen der Buchsuche nicht entnommen werden. Durch eine eigene Online-Veröffentlichung macht der Rechteinhaber vielmehr deutlich, dass er diese Art der Werkverwertung selbst nutzen möchte und somit keinesfalls mit einer möglicherweise konkurrierenden kommerziellen Nutzung durch einen Dritten einverstanden ist.

Die Rechtswidrigkeit der Werknutzung im Rahmen der Google Buchsuche kann somit auch nicht durch die Annahme einer Einwilligung ausgeschlossen werden.

\section{Zusammenfassung zur Rechtfertigung der Google Buchsuche}

Die vorstehenden Ausführungen haben gezeigt, dass die allgemein als äußerst nützlich und deshalb erhaltenswert erachtete Google Buchsuche in ihrer derzeitigen Ausgestaltung nicht mit geltendem Recht vereinbar ist. Die Werknutzung greift in das Vervielfältigungsrecht gemäß $\S 16$ UrhG und das Recht der öffentlichen Zugänglichmachung gemäß § 19a UrhG ein. Die Digitalisierung vollständiger Werke zu kommerziellen Zwecken und die Anzeige einzelner Ausschnitte mit Werkqualität lässt sich de lege lata auch nicht rechtfertigen. Die Werknutzung kann nicht durch die Schranken des Urheberrechtsgesetzes erfasst werden und - anders als bei der Thumbnail-Nutzung im Rahmen der Bildersuche - kann auch eine Einwilligung des Rechteinhabers nicht angenommen werden, da es an einer anknüpfungsfähigen Handlung fehlt, der ein entsprechender Erklärungswert beigemessen werden könnte. Es liegt somit eine Urheberrechtsverletzung vor, die gemäß $\S \S 97$ ff. UrhG grundsätzlich Ansprüche auf Unterlassung, Schadensersatz und Vernichtung der Werkstücke nach sich zieht und gegebenenfalls sogar eine nach den $\S \S 106,108$ a UrhG strafbare Handlung darstellt. 


\section{Zwischenergebnis}

Die Überlegungen zur Rechtfertigung der Thumbnail-Nutzung bei der Bildersuche und zur Werknutzung im Rahmen der Google Buchsuche haben gezeigt, vor welche erheblichen Schwierigkeiten der technische Fortschritt und auf diesem basierende neue Geschäftsmodelle das deutsche Urheberrecht stellen. Selbst allgemein als äußerst nützlich anerkannten und aufgrund ihres erheblichen Wertes für die Allgemeinheit für erhaltenswert gehaltenen Geschäftsmodellen, die die eigene Werkverwertung durch den Urheber oder Rechteinhaber nicht beeinträchtigen oder diese sogar fördern, droht das „Aus“, weil sie sich im Rahmen des starren Schrankenkataloges des Urheberrechtsgesetzes nicht rechtfertigen lassen. Um dieses unerwünschte Ergebnis zu vermeiden, wird oftmals versucht, die innovativen Nutzungsformen durch eine extensive Auslegung der bestehenden Schranken, deren analoge Anwendung oder den Rückgriff auf die allgemeine zivilrechtliche Einwilligungslehre zu rechtfertigen. Dabei werden bisweilen abenteuerlich anmutende Konstruktionen oder Begründungen bemüht, deren dogmatische Tragfähigkeit bezweifelt werden darf. Trotz dieser Anstrengungen lassen sich jedoch nicht alle Geschäftsmodelle rechtfertigen.

Die Anzeige von Vorschaubildern unter Nutzung urheberrechtlich geschützter Werke lässt sich etwa nur dann durch die Annahme einer konkludenten (schlichten) Einwilligung in die Werknutzung oder einen Umkehrschluss zu $§ 12$ Abs. 2 UrhG rechtfertigen, wenn die Ursprungswerke vom Urheber selbst oder zumindest mit dessen Zustimmung in das Internet eingestellt wurden. Im Fall der „Drittinhaberschaft“ der Urheberrechte, wenn Werke also ohne Zustimmung des Urhebers und ohne entsprechende Rechtseinräumung an Dritte in das Internet gestellt wurden, ist dieser Lösungsweg hingegen versperrt. Die vom BGH für diese Fälle erwogene Anwendung der Haftungsprivilegierung des Art. 14 Abs. 1 der E-CommerceRichtlinie ist abzulehnen, da eine eigenständige Nutzungshandlung des Suchmaschinenbetreibers stattfindet, so dass dieser Täter einer Urheberrechtsverletzung ist. Für die Konstellation der „Drittinhaberschaft" bleibt es somit de lege lata bei dem Ergebnis, dass das Vorgehen der Suchmaschinenbetreiber die Rechte des Urhebers und/oder Rechteinhabers verletzt.

Auch die Google Buchsuche lässt sich in ihrer derzeitigen Ausgestaltung nicht mit deutschem Urheberrecht vereinbaren. Noch deutlicher als im Falle der Thumbnail-Nutzung bei der Bildersuche greifen zugunsten 
des Anbieters Google keine urheberrechtlichen Schrankenbestimmungen ein. Auch die für die Bildersuche zumindest teilweise tragfähige Annahme einer (konkludenten) Einwilligung in die Werknutzung scheidet hier aus. Dem inzwischen weltweit angebotenen Buchsuche-Dienst droht daher in Deutschland aufgrund der mangelnden Flexibilität der Schrankenregelungen das Aus.

Die dogmatischen „Verbiegungen“, die unternommen wurden und werden, um innovative, auf zuvor unbekannten Geschäftsmodellen basierende Nutzungsformen urheberrechtlich geschützter Werke de lege lata zu rechtfertigen, erzeugen jedoch nicht nur praktische Probleme bei der Rechtsanwendung. Sie zeigen auch deutlich, dass die Rechtssicherheit, die regelmäßig als wesentlicher Vorteil des enumerativen Schrankenkataloges des deutschen Urheberrechtsgesetzes gepriesen wird, tatsächlich ganz erheblich leidet, sobald sich das deutsche Recht mit neuen Geschäftsmodellen konfrontiert sieht. Es scheint daher nicht nur zur „Rettung“ bestimmter neuer Geschäftsmodelle, sondern auch aus Gründen der Methodenehrlichkeit notwendig, das deutsche Recht durch die Schaffung einer flexiblen Schrankengeneralklausel oder durch die Implementierung flexiblerer Elemente in den bestehenden Schrankenkatalog zukunftsfähig zu machen.

\section{Verletzung von (Urheber-)Persönlichkeitsrechten?}

Neben den dargestellten Verwertungsrechten könnten durch die Verwendung von Thumbnails im Rahmen der Bildersuche und durch das Geschäftsmodell der Google Buchsuche in Einzelfällen auch persönlichkeitsrechtliche Aspekte betroffen sein; es könnte insbesondere eine Verletzung des Urheberpersönlichkeitsrechts vorliegen. Derartige Verletzungen sind im Hinblick auf die Zulässigkeit der genannten neuen Verwertungsformen urheberrechtlich geschützter Werke besonders problematisch, da eine Rechtfertigung durch Schrankenregelungen von vorneherein nicht in Betracht kommt. Lediglich ein Ausschluss der Rechtswidrigkeit aufgrund einer Einwilligung kommt unter bestimmten - strengen - Voraussetzungen möglicherweise in Betracht. 


\section{Anerkennung der Urheberschaft - $\$ 13$ UrhG}

Nach $\S 13$ S. 1 UrhG hat der Urheber das Recht auf Anerkennung seiner Urheberschaft; er hat somit zum einen positiv das Recht, sich jederzeit zu seiner Urheberschaft zu bekennen, zum anderen auch negativ, beeinträchtigende Verhaltensweisen Dritter zu untersagen. ${ }^{772}$ Gemäß § 13 S. 2 UrhG kann er zudem bestimmen, ob das Werk mit einer Urheberbezeichnung zu versehen und welche Bezeichnung zu verwenden ist. Das Recht auf Anerkennung der Urheberschaft nach $\S 13$ UrhG stellt einen Schwerpunkt des Schutzes der persönlichen und geistigen Interessen des Urhebers dar. ${ }^{773}$ Neben dem Schutz der ideellen Interessen kommt der Namensnennung jedoch oftmals auch eine erhebliche wirtschaftliche Bedeutung zu. Zumeist ermöglicht erst die Urhebernennung die Zuordnung eines Werkes zu einem bestimmten Autor. Nur so kann das Werk dem Autor daher als Referenz und Werbung dienen und ihm zugleich auch etwa zum Zwecke der Abrechnung über eine Verwertungsgesellschaft sicher zugerechnet werden. ${ }^{774} \S 13$ UrhG gewährt dem Urheber deshalb ein Recht, grundsätzlich bei jeder Nutzung seines Werkes genannt zu werden. ${ }^{775}$ Dies folgt aus seinem Persönlichkeitsrecht auf Anerkennung seiner Urheberschaft. ${ }^{776}$ Unabhängig von Nutzungshandlungen kann der Urheber jeder Darstellung, die seine Urheberschaft in Frage stellt oder das Werk einer anderen Person zuweist, entgegentreten. Auch bei Vervielfältigungen und Bearbeitungen behält der Urheber des Ausgangswerkes daher sein Recht auf Anerkennung

772 Vgl. Hock, Namensnennungsrecht, S. 32.

773 Vgl. BGHZ 126, 245 (248f.) - Namensnennungsrecht des Architekten; Schricker/Loewenheim/Dietz/Peukert, § 13 Rn. 1.

774 Vgl. zur Zuordnungsfunktion der Urhebernennung Dreier/Schulze, § 13 Rn. 7; Hoeren/Sieber/Decker, 7.2 Rn. 10.

775 St. Rspr. und h.M., siehe nur BGH, GRUR 1963, 40 (43) - Straßen - gestern und morgen; BGHZ 126, 245 (247f.) - Namensnennungsrecht des Architekten; Dreier/Schulze, § 13 Rn. 8; Schricker/Loewenheim/Dietz/Peukert, § 13 Rn. 6, jeweils m.w.N.; a.A. die Amtl. Begr., BT-Drs. IV/270, S. 44, wonach der Urheber kein allgemeines Recht haben soll, die Angabe seines Namens bei jeder Nutzung seines Werkes verlangen zu können.

776 Vgl. BGH, GRUR 1963, 40 (43) - Straßen - gestern und morgen; GRUR 1972, 713 (714) - Im Rhythmus der Jahrhunderte; Dreier/Schulze, § 13 Rn. 3; Möhring/ Nicolini/Kroitzsch, § 13 Rn. 1, 6. 
der Urheberschaft und ist als Urheber des (bearbeiteten) Werks zu nennen. ${ }^{777}$

\section{Thumbnails}

Eine Verletzung des in $\S 13$ UrhG gewährten Rechtes auf Anerkennung der Urheberschaft bei der Nutzung von Thumbnails im Rahmen der Bildersuche käme zunächst dann in Betracht, wenn für den Nutzer nicht hinreichend erkennbar wäre, dass es sich bei den Thumbnails um Darstellungen beziehungsweise Bearbeitungen fremder Werke handelt. Dies dürfte allerdings - zumindest bei allen derzeitig gängigen Gestaltungen der Bildersuche - stets ausgeschlossen sein. Regelmäßig befindet sich unterhalb der angezeigten Thumbnails ein Link zu der Website, die das Originalbild enthält, so dass der Nutzer eindeutig die Ursprungsseite identifizieren kann. Aufgrund der Funktion der Thumbnails als „Wegweiser“ zu solchen Bildern, die für die Anfrage des Nutzers relevant sind, wird diesem zudem bewusst sein, dass die Thumbnails fremde Werke möglichst detailgetreu und lediglich aus Praktikabilitätsgründen verkleinert darstellen.

Eine Verletzung des Rechts auf Anerkennung der Urheberschaft könnte jedoch auch darin liegen, dass zwar die Internetadresse der Ursprungsseite, die sogenannte URL, ${ }^{778}$ genannt wird, nicht jedoch eine namentliche Nennung des Urhebers des Originalbildes erfolgt. ${ }^{779}$ Enthält das verkleinert dargestellte Bild selbst einen Urhebervermerk, so scheidet eine Verletzung des Namensnennungsrechts aus, da die Urheberkennung zwar ver-

777 Vgl. BGHZ 151, 15 (20) - Stadtbahnfahrzeug; Dreier/Schulze, § 13 Rn. 12; Möhring/Nicolini/Kroitzsch, § 13 Rn. 13; Schricker/Loewenheim/Dietz/Peukert, § 13 Rn. 18; Wandtke/Bullinger/Bullinger $\S 13$ Rn. 8.

778 Die Abkürzung URL steht für Uniform Resource Locator. URLs stellen eine Unterart von Uniform Resource Identifiern (URIs) dar und identifizieren und lokalisieren innerhalb eines Computernetzwerkes eine Ressource über das verwendete Netzwerkprotokoll (beispielsweise HTTP oder FTP) und den Ort der Ressource. Da URLs die erste und häufigste Form von URIs darstellen, wird der Begriff URL üblicherweise als Synonym für die Internetadresse verwendet.

779 Im belgischen Verfahren Google, Inc. v. Copiepresse SCRL, Urt. v. 13.2.2007, 06/10.928/C vertrat das Tribunal de Première Instance de Bruxelles die Auffassung, Google verletze im Rahmen des Dienstes Google News (auch) das Recht des Autors auf Namensnennung, indem dieser auf der Website des Nachrichtendienstes bei der Darstellung von Abstracts der ursprünglichen Nachrichtenartikel nicht genannt werde; ebenda, S. 34. Kritisch dazu Klein, IIC 2008, 451 (476). 
kleinert, jedoch letztlich unverändert erhalten bleibt und somit vom Betrachter gesehen wird, wenn dieser das Bild betrachtet oder weiterverwendet. ${ }^{780}$ Enthält jedoch das Bild nicht selbst einen Hinweis auf den Urheber, sondern ist ein solcher - und so wird es in der Regel sein, wenn überhaupt ein Urheber benannt ist - lediglich auf der Ursprungsseite, etwa in einer Textdatei neben dem Bild oder am unteren Ende der Website, enthalten, so ist die Beurteilung nicht so eindeutig, da diese Informationen von den Bildersuchmaschinen (derzeit) nicht übernommen und den Bildern zugeordnet werden. Dem Nutzer ist zwar ersichtlich, dass es sich bei den als Thumbnails dargestellten Bildern um fremde Werke handelt. Dies allein schließt jedoch eine Verletzung des $\S 13$ UrhG nicht aus, denn der Nutzer kann nicht ohne weiteres erkennen, wer konkret der Urheber eines Werkes ist. Der Urheber ist jedoch grundsätzlich bei jeder Nutzung seines Werkes ausdrücklich zu benennen. Dabei muss in jedem Fall eine eindeutige $\mathrm{Zu}$ ordnung des Werkes zu seinem Urheber möglich sein. ${ }^{781}$ Nur so ist ein Schutz der neben den immateriellen Interessen ebenfalls relevanten materiellen Belange möglich. Die Herstellung und Speicherung der Thumbnails stellt - wie gezeigt ${ }^{782}$ - eine eigene urheberrechtlich relevante Nutzungshandlung dar, da eine Vervielfältigung einer Bearbeitung gemäß den $\S \S 16,23 \mathrm{~S} .1$ UrhG und eine öffentliche Zugänglichmachung dieser Bearbeitungen ( $\S 19 \mathrm{a}, 23 \mathrm{~S} .1 \mathrm{UrhG})$ vorliegt. Da die ausdrückliche Urhebernennung bei dieser Werknutzung unterbleibt, erscheint auf den ersten Blick die Annahme einer Verletzung des Rechts aus $\S 13$ UrhG unausweichlich.

Etwas anderes könnte sich jedoch ergeben, wenn man annimmt, dass bei Bildersuchmaschinen eine Urhebernennung ausnahmsweise nicht stattfinden muss oder zumindest beschränkt werden kann. Ein vollständiger und dauerhafter Verzicht auf das Namensnennungsrecht ist nicht möglich, da das Recht auf Urhebernennung einen Ausfluss des Urheberpersönlichkeitsrechts darstellt und daher im Kern unverzichtbar ist. ${ }^{783}$ Dem Urheber steht es jedoch grundsätzlich frei, auf die Ausübung seines Namensnennungsrechts vorübergehend oder auch dauerhaft zu verzichten. ${ }^{784}$ Ein Ver-

780 So auch Schaefer, Bildersuchmaschinen, S. 84.

781 Vgl. Dreier/Schulze, § 13 Rn. 21.

782 Siehe oben 4. Kapitel, A.I.1.

783 Vgl. OLG München, ZUM 2003, 964 (967) - Pumuckl; Schricker/Loewenheim/ Dietz/Peukert, Vor $\S \S 12$ ff. Rn. 28 m.w.N.

784 Vgl. Fromm/Nordemann/Dustmann, § 13 Rn. 12. 
zicht auf die Urhebernennung oder deren Beschränkung kommt - wie sich aus $\S 39$ Abs. 1 UrhG ergibt - in erster Linie durch eine ausdrückliche Vereinbarung etwa im Rahmen von Lizenzverträgen in Betracht. Eine derartige ausdrückliche Vereinbarung über den Verzicht auf die Urhebernennung wird jedoch im Hinblick auf die Nutzung im Internet durch Suchmaschinen in aller Regel fehlen.

In Betracht käme daher allenfalls die Annahme einer Beschränkung oder eines Verzichts auf die Urhebernennung aufgrund einer entsprechenden Verkehrssitte oder Branchengepflogenheit. Eine solche soll nach verbreiteter Auffassung unter gewissen Umständen ebenfalls geeignet sein, einen Verzicht auf das Namensnennungsrecht oder dessen Beschränkung zu begründen. Innerhalb dieser Auffassung ist wiederum die dogmatische Einordnung einer solchen Beschränkung umstritten. Zum Teil wird angenommen, die Verkehrssitten oder Branchengepflogenheiten schränkten das Recht auf Namensnennung bereits tatbestandlich ein. ${ }^{785}$ Zumeist wird hingegen vertreten, der Anspruch auf Namensnennung bestehe grundsätzlich unbeschränkt fort, könne aber durch entsprechende Branchenübung eingeschränkt werden, wenn diese ausdrücklich oder stillschweigend Vertragsinhalt geworden sei. ${ }^{786}$ Unabhängig von der dogmatischen Begründung ist jedoch bei einer solchen Annahme Vorsicht geboten und ein strenger Maßstab anzulegen. Es ist insbesondere genau zu prüfen, ob sich in dem fraglichen Bereich tatsächlich eine entsprechende Verkehrssitte herausgebildet hat oder ob es sich eher um eine „Unsitte“ handelt, die etwa auf mangelndem Interesse oder Bequemlichkeit beruht. ${ }^{787}$ Eine Verkehrssitte kann deshalb nur dann zu einer Entbehrlichkeit der Urheberbezeichnung führen, wenn der Urheber dabei nicht unangemessen benachteiligt wird, da bei drohender unangemessener Benachteiligung der unverzichtbare Kern des Urheberpersönlichkeitsrechts betroffen ist und das so-

785 Vgl. v.Gamm, UrhG, § 13 Rn. 14; ders., NJW 1959, 318 (319) (noch zu $\$ 9$ LUG); Ulmer, S. 214 f.; Rehbinder, ZUM 1991, 220 (224 ff.).

786 Vgl. BGHZ 126, 245 (249f.) - Namensnennungsrecht des Architekten; LG Hamburg, ZUM 2004, 675 (678); Dreier/Schulze, § 13 Rn. 26; Fromm/Nordemann/ Dustmann, § 13 Rn. 14; Haberstumpf, Handbuch, S. 117; Rehbinder, Urheberrecht, Rn. 406; Schricker/Loewenheim/Dietz/Peukert, Vor $\S 112$ ff. Rn. 24. Unentschlossen Möhring/Nicolini/Kroitzsch, § 13 Rn. 20 f., der sowohl eine tatbestandliche als auch eine vertragliche Einschränkung für möglich hält.

787 Vgl. BGHZ 126, 245 (249f.) - Namensnennungsrecht des Architekten; OLG Düsseldorf, GRUR-RR 2006, 393 (395); Loewenheim/Dietz/Peukert, § 16 Rn. 77. 
ziale Ungleichgewicht zwischen Verwertern und Urhebern droht, zu Lasten der Letzteren perpetuiert zu werden. ${ }^{788} \mathrm{Im}$ Zweifel wird man daher eher ein Namensnennungsrecht annehmen müssen. ${ }^{789}$

Mangels ausdrücklicher Vereinbarung über die Nutzung von Bildern als Thumbnails im Rahmen der Bildersuche, kommt hier allenfalls eine stillschweigende Einbeziehung einer entsprechenden Branchenübung in Betracht. Im Fall der Bildersuche könnte für eine Branchenübung, nach der das Namensnennungsrecht beschränkt wird, die Tatsache sprechen, dass die Thumbnails als „Wegweiser“ zu den aufgefundenen Bildern dienen. Die gängigen Bildersuchmaschinen lassen durch die Anzeige der Internetadresse der Ursprungsseite unterhalb der Thumbnails und auch durch die Art der graphischen Darstellung deutlich erkennen, dass es sich um fremde Inhalte handelt. Der Bildersuchdienst liefert also nur eine Art „Vorverzeichnis“, in dem schon aus Gründen der Übersichtlichkeit nicht alle Angaben zu den aufgefundenen Bildern enthalten sein können. Es ist dabei jedem Nutzer möglich, die auf der Ursprungsseite enthaltenen vollständigen Informationen zu jedem Bild zu erhalten, indem er dem Link folgt und das Bild im ursprünglichen Kontext sieht. Nimmt man - wie hier vertreten - durch das ungeschützte Einstellen von Bilddateien in das Internet eine stillschweigende Einwilligung in die übliche Nutzung der Bilder durch Bildersuchmaschinen an, so kann als Teil dieser Einwilligung auch der Verzicht auf die Namensnennung beziehungsweise eine Beschränkung auf den üblichen Umfang angesehen werden, da die vollständige Namensnennung im Rahmen der Thumbnail-Darstellung eben nicht üblich und technisch auch nur schwerlich möglich ist. Üblich ist insoweit bei Bildersuchmaschinen eine Reduzierung auf die deutliche Kenntlichmachung als Fremdinhalt und die Anzeige der URL der Ursprungsseite. Genügt die Bildersuchmaschine diesen Anforderungen, so sprechen gute Argumente dafür, eine Verletzung des Rechts auf Urhebernennung nicht anzunehmen.

Es ist jedoch nicht von der Hand zu weisen, dass sich die gegenteilige Auffassung ebenfalls vertreten lässt. Derjenige, der eine Bilddatei frei zugänglich in das Internet einstellt, hat - aus der Sicht eines objektiven Beobachters - ein Interesse daran, dass diese Bilddatei auch von anderen Nutzern gefunden werden kann. Der Einstellende willigt somit (stillschweigend) in die Nutzung durch Bildersuchmaschinen ein. Dies muss

788 Vgl. Dreier/Schulze, § 13 Rn. 26; Schricker/Loewenheim/Dietz/Peukert, § 13 Rn. 25; Schack, Urheberrecht, Rn. 377.

789 Vgl. Rehbinder, Urheberrecht, Rn. 406. 
jedoch nicht bedeuten, dass der Einstellende auch auf die Urhebernennung verzichten möchte. Enthält die Ursprungsseite etwa einen deutlichen Hinweis auf den Urheber eines Werkes, üblicherweise in Textform unmittelbar unterhalb oder neben der Bilddatei, so zeigt dies, dass der Urheber auf die namentliche Nennung gerade nicht verzichten möchte. In diesem Fall kann daher auch nicht ohne weiteres davon ausgegangen werden, die Einwilligung des Urhebers umfasse den Verzicht auf die Namensnennung im Rahmen der Bildersuche. Ein Verzicht auf die Namensnennung durch eine (konkludente) Einwilligung beziehungsweise eine Beschränkung auf den im Rahmen der Bildersuche üblichen Umfang scheidet jedoch aus, wenn der Urheber das Werk nicht selbst in das Internet eingestellt hat und auch keinem Dritten die dafür erforderlichen Rechte eingeräumt hat, da es in diesem Fall an einer anknüpfungsfähigen Handlung eines Berechtigten fehlt.

Es zeigt sich im Ergebnis, dass die rechtliche Bewertung der Nutzung urheberrechtlich geschützter Werke im Rahmen der Bildersuche in Bezug auf eine Verletzung des Rechts auf Urhebernennung gemäß $§ 13$ UrhG unsicher ist. Es ist zumindest nicht ausgeschlossen, dass im Einzelfall eine Verletzung angenommen werden kann oder muss. Ein letzter Zweifel lässt sich somit nach der derzeitigen Rechtslage nicht ausräumen - ein weiterer Beleg dafür, dass eine flexiblere und daher rechtssicherere Lösung anzustreben ist.

\section{Google Buchsuche}

Eine Verletzung des in $\S 13$ UrhG gewährten Rechtes auf Anerkennung der Urheberschaft ist bei der Werknutzung im Rahmen der Google Buchsuche in ihrer derzeitigen Gestaltung grundsätzlich nicht anzunehmen. Regelmäßig befinden sich oberhalb der angezeigten Snippets gut und deutlich sichtbar die bibliographischen Angaben zum Originalwerk, aus dem die Textausschnitte stammen, so dass der Nutzer eindeutig deren Ursprung ermitteln und das Werk einem bestimmten Autor zuordnen kann. Zudem ist zu bedenken, dass der Nutzer die Buchsuche gerade verwendet, um Informationen aus fremden Werken zu finden. Die Buchsuche erfüllt somit gerade den Zweck eines „Wegweisers“ zu solchen Werken, die der Anfrage des Nutzers entsprechen. Dabei ist sich der Nutzer im Klaren, dass es sich nicht um eigene Inhalte des Buchsuche-Dienstes handelt. 
Das Urhebernennungsrecht könnte ausnahmsweise dann verletzt sein, wenn die bibliographischen Angaben zu einem Buch falsch sind, so dass der Urheber falsch benannt ist. Die Falschbenennung des Autors stellt nämlich als Unterfall der fehlerhaften Urhebernennung einen schwerwiegenden Eingriff in das Recht auf Anerkennung der Urheberschaft dar. ${ }^{790}$ Durch Fehler bei der Erfassung und Verarbeitung der Metadaten ist dies in drei Formen denkbar. Zum einen kann es zu einer falschen Erfassung des Urhebernamens kommen, so dass dieser im Rahmen der Buchsuche anschließend fehlerhaft angezeigt wird. Zum anderen ist denkbar, dass durch einen Fehler eine Urhebernennung vollständig unterbleibt, so dass die bibliographischen Angaben keinen Urheber ausweisen. Schließlich - und dies stellt zweifelsohne die schwerwiegendere Beeinträchtigung dar könnte es zu einer falschen Zuordnung eines Werkes zu einem Urheber kommen, so dass nicht der richtige Urheber fehlerhaft benannt, sondern das Werk allein oder zusätzlich einem anderen Urheber zugeschrieben wird. Dass alle diese genannten Fehler in den Metadaten in der Google Buchsuche tatsächlich nicht ausgeschlossen sind, ergeben stichprobenartige Suchen, etwa nach besonders bekannten Persönlichkeiten, deren Namen oftmals fälschlich in der Rubrik „Autoren“ auftauchen, wenn ein Buch tatsächlich über diese Personen handelt. ${ }^{791}$

In der falschen, insbesondere schreibfehlerhaften Namenswiedergabe kann eine Verletzung des $\S 13$ UrhG liegen. Nach $\S 13$ S. 2 UrhG darf der Urheber bestimmen, ob und wie seine Urheberschaft kenntlich zu machen ist. Hat er sich für eine bestimmte Form der Urheberbezeichnung entschieden, so ist diese am Original und allen Vervielfältigungsstücken so anzubringen, dass das Werk eindeutig und unmissverständlich seinem Urheber zugeordnet werden kann. ${ }^{792}$ Dies ist bei einer orthographisch fehlerhaften Namenswiedergabe nicht immer der Fall. So ist beispielsweise im Wissenschaftsbereich, in dem die eindeutige Zuordnung eines Werkes zu einem bestimmten Autor besondere Bedeutung hat, da die Anerkennung in der

790 Vgl. LG Berlin, ZUM-RD 2006, 443.

791 Als besonders plakative Beispiele mögen hier das 1961 erschienene Werk „Hitler's conservative opponents in Bavaria 1930-1945“von James Donohoe und das Buch „Adolf Hitler als Maler und Zeichner“ von Billy F. Price aus dem Jahr 1983 dienen, als deren Autoren die Google Buchsuche neben Donohoe und Price jeweils auch Adolf Hitler selbst benennt [Suchabfragen vom 2.3.2011 und 8.6.2012; bzgl. des Buches von Donohoe wurde der Fehler inzwischen von Google korrigiert].

792 Vgl. nur Schricker/Loewenheim/Dietz/Peukert, § 13 Rn. 12 m.w.N. 
„Scientific Community“ hier eine ganz entscheidende Rolle für das Werkschaffen spielt, denkbar, dass gerade ein kurzer Nachname durch das Weglassen oder Ändern schon eines einzelnen Buchstabens so verändert wird, dass eine Zuordnung eines Werkes zu einer bestimmten Person nicht mehr ohne weiteres möglich ist. Dies ist insbesondere der Fall, wenn es etwa tatsächlich mehrere Personen mit ähnlichem Namen gibt, die ähnliche Werke veröffentlichen beziehungsweise in demselben Wissenschaftsbereich tätig sind. ${ }^{793}$ Die Falschbenennung kann entweder - wie auch im Fall des vollständigen Fehlens der Urheberbezeichnung - dazu führen, dass es dem Betrachter oder Leser nicht oder nur schwer möglich ist, sich eine Vorstellung über die Urheberschaft zu bilden, oder es kann sogar eine irrige Vorstellung über die Urheberschaft im Sinne einer Zuordnung zu einem anderen Urheber erzeugen. ${ }^{794}$ In diesem Fall sind nicht nur immaterielle Interessen des Urhebers im Sinne einer Anerkennung seiner konkreten Leistung betroffen, die Urhebernennung kann auch nicht mehr ihre Zuordnungs- und Werbefunktion erfüllen. ${ }^{795}$

Sind die bibliographischen Angaben zu einem Buch tatsächlich fehlerhaft und lässt sich deshalb das Werk nicht mehr eindeutig einem Urheber zuordnen, so liegt darin ein Eingriff in das Recht auf Anerkennung der Urheberschaft gemäß $\S 13$ UrhG.

793 Etwa im Falle verschiedener Autoren desselben Fachgebiets mit den Namen „Meier", „Meyer", „Maier“, „Mayer“ und „Mayr".

794 Diese Problematik wird dadurch verstärkt, dass oftmals die Jahresangaben der Werke falsch sind [Bspw. ergibt eine Suche nach dem Begriff „Microsoft" in Werken aus der Zeit vor 1950 1.160 Treffer und eine Suche nach „Internet“ vor 1950

33.000 Treffer; dies lässt sich mit (fast) beliebigen Suchbegriffen verifizieren, z.B. einer Suche nach „Andy Warhol“ vor seinem Geburtsjahr 1928, nach „Angela Merkel“" vor 1954, etc.]. Eine eindeutige Zuordnung zu einem bestimmten Autor ist aber dann erst recht nicht mehr sicher möglich, wenn dieser zusätzlich falsch bezeichnet ist.

Sämtliche Verfahrensdokumente, darunter zahlreiche Letters of Objection einzelner Rechteinhaber und Amicus Curiae Briefs, sind abrufbar unter: http:// dockets.justia.com/docket/new-york/nysdce/1:2005cv 08136/273913/ [zuletzt abgerufen am 26.5.2013].

795 Vgl. Spieker, GRUR 2006, 118 (120). 


\section{Entstellung des Werkes - 14 UrhG}

Als Ausdruck des Urheberpersönlichkeitsrechts verbietet § 14 UrhG eine Entstellung oder eine andere Beeinträchtigung des Werkes, die geeignet ist, berechtigte geistige oder persönliche Interessen des Urhebers an seinem Werk zu gefährden. Dabei genügt die Möglichkeit einer Verletzung; eine konkrete Gefährdung oder der Eintritt eines Schadens sind nicht erforderlich. ${ }^{796}$ Während also das Veröffentlichungsrecht des $\S 12$ UrhG dem Urheber ermöglicht, zu bestimmen, in welcher konkreten Form er sein Werk an die Öffentlichkeit entlassen möchte, schützt § 14 UrhG den Bestand dieser konkreten Form und des darin zum Ausdruck gelangenden konkreten geistig-ästhetischen Gesamteindrucks des Werkes. ${ }^{797}$ Jede objektiv nachweisbare Änderung dieses Gesamteindrucks ist dabei eine Beeinträchtigung, wobei diese sowohl in einem Eingriff in die körperliche Substanz des Werkexemplars als auch in einem solchen in die geistige Substanz des Werkes liegen kann. ${ }^{798}$ Ist eine Beeinträchtigung festgestellt, so ist auf einer zweiten Stufe zu prüfen, ob diese geeignet ist, die berechtigten Interessen des Urhebers zu gefährden. Aufgrund des grundsätzlichen Interesses des Urhebers an der Unversehrtheit seines Werkes, indiziert dessen Beeinträchtigung eine Eignung zur Interessengefährdung. ${ }^{799}$ In einem dritten Schritt ist schließlich eine Abwägung des Bestands- und Integritätsinteresses des Urhebers mit den Interessen seines Gegenübers vorzunehmen. ${ }^{800}$ Dabei müssen übertriebene Empfindlichkeiten oder eine übersteigerte Eitelkeit des Urhebers außer Betracht bleiben; maßgeblich ist vielmehr das Urteil eines unvoreingenommenen, für Kunst empfänglichen und mit Kunstdingen einigermaßen vertrauten Durchschnittsbetrachters. ${ }^{801}$

796 Vgl. Fromm/Nordemann/Dustmann, § 14 Rn. 15.

797 Vgl. Dreier/Schulze, § 14 Rn. 1.

798 Vgl. Dreier/Schulze, § 14 Rn. 10 f.; Schricker/Loewenheim/Dietz/Peukert, § 14 Rn. $21 \mathrm{ff}$.

799 Vgl. Fromm/Nordemann/Dustmann, § 14 Rn. 15; Loewenheim/Dietz/Peukert, $\S 16$ Rn. 109.

800 Vgl. Schricker/Loewenheim/Dietz/Peukert, § 14 Rn. 28 ff.

801 Vgl. BGH, GRUR 1989, 106 (108) - Oberammergauer Passionsspiele II; GRUR 1999, 230 (232) - Treppenhausgestaltung; Möhring/Nicolini/Kroitzsch, § 14 Rn. 20; Schricker/Loewenheim/Dietz/Peukert, § 14 Rn. 29. 
Dieses Recht gegen Entstellungen des Werkes könnte sowohl durch die Google Buchsuche als auch durch die Darstellung von Bildern als Thumbnails beeinträchtigt sein.

\section{Thumbnails}

Durch die Verwendung von Thumbnails als Vorschaubilder im Rahmen der Bildersuche könnte ebenfalls das in $\S 14$ UrhG geschützte Urheberpersönlichkeitsrecht beeinträchtigt sein. In Betracht kommt a) eine Beeinträchtigung durch die gegenüber dem Originalbild stark verminderte Qualität der Thumbnails, b) durch das Herausreißen des Originalwerkes aus seinem ursprünglichen Kontext sowie c) durch die Herabstufung des Werkes auf eine rein funktionale Nutzung und die damit einhergehende Verminderung des Werkgenusses.

a) Beeinträchtigung durch Verringerung der Auflösung/Qualität des Originalbildes?

$\S 14$ UrhG schützt den Bestand der konkreten Form eines Werkes und dessen darin zum Ausdruck gelangenden konkreten geistig-ästhetischen Gesamteindruck. Dieser Gesamteindruck könnte durch die erhebliche Reduzierung der Datenmenge bei der Erstellung der Thumbnails beeinträchtigt werden, da diese zu einer deutlich geringeren Auflösung und Schärfe der Bilder führt. Es ist jedoch zu beachten, dass die Betreiber der Bildersuchmaschinen nur deshalb verkleinerte Vorschaubilder verwenden, da diese aufgrund der starken Komprimierung den Vorteil einer gegenüber den Originalbildern vielfach höheren Anzeigegeschwindigkeit haben. Eine Verringerung der Bildqualität erfolgt also aus rein technischen Gründen. Eine Beeinträchtigung des Gesamteindrucks der so dargestellten Werke soll hingegen gerade soweit wie möglich vermieden werden. Die Betreiber bemühen sich um eine möglichst originalgetreue Abbildung der Originalwerke, da nur so dem Nutzer ein ausreichender Eindruck vom Aussehen des Originalwerkes vermittelt werden kann und dieser so in der Lage ist, festzustellen, welches der als Thumbnail angezeigten Bilder seiner Suchanfrage am ehesten entspricht. In der Regel wird daher eine Beeinträchtigung des Werkes, die geeignet ist, berechtigte geistige oder persönliche Interessen des Urhebers zu gefährden, allein durch die Verringerung der 
Bildqualität ausscheiden. ${ }^{802}$ Der geistig-ästhetische Gesamteindruck des Originalwerkes bleibt somit in aller Regel gerade erhalten. ${ }^{803}$ Es ist jedoch auch nicht auszuschließen, dass im Einzelfall eine Verletzung des Urheberpersönlichkeitsrechts bereits durch die starke Verminderung der Bildqualität anzunehmen sein wird. Dies kommt insbesondere dann in Betracht, wenn das verkleinerte Werk auf der Ursprungsseite ganz gezielt in einer besonders hohen Auflösung dargestellt ist, da nur so die vom Urheber gewollte ästhetische Wirkung erzielt werden kann. Dieser Gesamteindruck mag durch die erhebliche Verkleinerung vollständig verloren gehen, so dass das Vorschaubild durch den starken Qualitätsverlust nicht mehr als eine „plumpe“ Version des Originals ist. 804

b) Beeinträchtigung durch Herausreißen aus dem Kontext bei isolierter Anzeige des Bildes in Originalgröße?

Neben den zuvor beschriebenen Funktionen bietet die Google Bildsuche eine zusätzliche Suchfunktion, die eine isolierte Anzeige des Originalbildes in voller Größe durch einen Link nur auf das Bild, nicht aber auf die es enthaltende Website ermöglicht. Der Nutzer wird nach dem Anklicken eines in der Trefferliste angezeigten Thumbnails auf die Website weitergeleitet, die das verkleinert dargestellte Bild in Originalgröße enthält. In einem Frame oberhalb der Originalwebsite wird allerdings erneut der Thumbnail isoliert angezeigt mit der Möglichkeit, das verkleinert dargestellte Originalbild als Vollbild - losgelöst von der aufgefundenen Website - anzeigen zu lassen. Auch diese isolierte Anzeige des Bildes in Originalgröße könnte im Einzelfall als urheberpersönlichkeitsrechtlich relevante Beeinträchtigung des Originalwerkes zu bewerten sein. ${ }^{805}$ Eine Beeinträchtigung liegt nämlich nicht erst vor, wenn in die körperliche Substanz

802 A.A. Wandtke/Dietz, Urheberrecht, Kapitel 3 Rn. 51.

803 Im Ergebnis ebenso Schrader/Rautenstrauch, UFITA 2007, 761 (764 f.). Allgemein zur technisch bedingten Veränderung der Auflösung digitaler Fotografien für die Verwendung im Internet auch Fromm/Nordemann/Dustmann, § 14 Rn. 62; Wandtke/Bullinger/Bullinger, $\S 14$ Rn. 65.

804 Vgl. Fromm/Nordemann/Dustmann, § 14 Rn. 62 unter Verweis auf OLG Hamburg, ZUM 1995, 430.

805 Vgl. Berberich, CR 2007, 393 (394); zur Entstellung eines Werkes durch das Verwenden von Inline-Links und Frames allgemein, vgl. Plaß, WRP 2000, 599 (602, 604); Schack, MMR 2001, 9 (14). 
des Werkexemplars eingegriffen wird, sondern auch bereits bei einem Eingriff in die geistige Substanz des Werkes. ${ }^{806}$ Die urheberpersönlichkeitsrechtlichen Interessen können daher auch durch die Form und Art der Werkwiedergabe und -nutzung beeinträchtigt werden, etwa durch die Verwendung in einem anderen Sachzusammenhang, der sich auf den geistigästhetischen Gesamteindruck des Werkes auswirkt, indem der Betrachter es anders als geplant wahrnimmt. ${ }^{807}$ Das ist insbesondere bei Websites mit künstlerischer oder besonderer inhaltlicher Tendenz denkbar, etwa wenn einzelne Bilder als Teil einer Bildserie nur im Zusammenhang mit weiteren Bildern oder nur in Verbindung mit dem Design der Website betrachtet werden sollen, da sich erst in einer Gesamtschau der vom Künstler oder Websitebetreiber gewünschte Eindruck ergibt. Zwar ermöglichen alle gängigen Browser ebenfalls eine isolierte Anzeige solcher Bilder, die der Nutzer auf einer Website (ungeschützt) auffindet, allerdings muss dafür der Nutzer zunächst das Bild auf der Website auffinden - er nimmt es also zunächst (zwangsläufig) in dem vom Websitebetreiber erwünschten Kontext wahr. Lässt er sich ein Bild anschließend isoliert anzeigen, so ist dies eine bewusste Entscheidung über die Art der Darstellung. Diesen Schritt überspringt eine Bildersuche, welche dem Nutzer das Auffinden und Ansehen des Bildes im Originalzusammenhang „erspart“. Zu beachten ist jedoch, dass inzwischen beim Einstellen von Bilddateien in das Internet die Möglichkeit besteht, diese gegen eine isolierte Anzeige mit den gängigen Browsern zu schützen. Nimmt der Berechtigte diese einfache Schutzmöglichkeit nicht wahr, so müssen seine durch das Anzeigen der Bilder außerhalb des Originalkontextes möglicherweise im Einzelfall beeinträchtigten urheberpersönlichkeitsrechtlichen Interessen letztlich zumindest auf der Ebene der bei $\S 14$ UrhG stets durchzuführenden Interessenabwägung 808 zurücktreten. Eine Beeinträchtigung der durch $\S 14$ UrhG geschützten urheberpersönlichkeitsrechtlichen Interessen durch das isolierte Anzeigen

806 Vgl. Dreier/Schulze, § 14 Rn. 11.

807 Vgl. BGHZ 150, 32 (41 f.) - Unikatrahmen; BGH, GRUR 2009, 395 (397) Klingeltöne für Mobiltelefone; Bettinger/Leistner/Leistner, Teil 1 B Rn.72; Schricker/Loewenheim/Dietz/Peukert, § 14 Rn. 23; Wandtke/Bullinger/Bullinger, $\S 14$ Rn. 49.

808 Vgl. dazu statt aller Schricker/Loewenheim/Dietz/Peukert, § 14 Rn. 28 ff. Ggfs. könnte man aus diesem Gesichtspunkt auch bereits eine Entkräftung der Vermutung einer Eignung zur Gefährdung der berechtigten Urheberinteressen annehmen, da der Urheber die vorgenommene Beeinträchtigung gestattet habe. 
der Originalbilder außerhalb des Website-Kontextes ist somit nicht grundsätzlich ausgeschlossen, wird aber in aller Regel ausscheiden.

c) Beeinträchtigung durch Herausreißen aus ursprünglichem Kontext und Darstellung in neuem Zusammenhang

Eine Verletzung urheberpersönlichkeitsrechtlicher Interessen durch die Darstellung von Bildern als Thumbnails in der Ergebnisliste einer Bildersuchmaschine kommt aber auch dann in Betracht, wenn ein Bild aus seinem ursprünglichen Zusammenhang gerissen und in der Ergebnisliste in einen neuen, „Zwielichtigen“ Zusammenhang gestellt wird. Dies kann im Einzelfall dazu geeignet sein, die berechtigten Interessen des Urhebers zu beeinträchtigen. So ist etwa vorstellbar, dass ein auf einer Website enthaltenes Foto des Autors eines Beitrages aufgrund der Schlagwörter, die diesem von der Suchmaschine basierend auf dem umliegenden Text zugeordnet werden, in einem völlig anderen, persönlichkeitsbeeinträchtigenden Zusammenhang in der Trefferliste der Suchmaschine angezeigt wird. ${ }^{809}$ Hat der Autor etwa einen historischen Beitrag über die Machtergreifung der Nationalsozialisten oder einen Nachrichtenbeitrag über das Terrornetzwerk Al-Qaida verfasst, so könnte das Autorenfoto im Rahmen der Bildersuche nach Eingabe von Suchworten wie „Nazi“ oder „Terrorist" in der Trefferliste erscheinen und so möglicherweise beim Betrachter einen falschen Eindruck vom Autor, insbesondere etwa von dessen (politischer) Gesinnung, vermitteln. In der Darstellung in diesem neuen (Sach-)Zusammenhang kann durchaus eine Beeinträchtigung des Werkes liegen, auch wenn dessen Substanz nicht tangiert ist.

d) Beeinträchtigung durch Herabstufung des Werkes auf rein funktionale Nutzung und der Verminderung des Werkgenusses?

Schließlich kommt eine urheberpersönlichkeitsrechtsverletzende Beeinträchtigung eines Werkes noch unter dem Gesichtspunkt der Herabstufung des Werkes auf eine rein funktionale Nutzung als Vorschau beziehungsweise „Wegweiser“ im Rahmen der Bildersuche in Betracht. So wurde die

809 Vgl. Ott, ZUM 2009, 345 (346). 
Verwendung eines - nicht für diesen Zweck geschaffenen - Musikwerkes als Klingelton für (Mobil-)Telefone von der Rechtsprechung als eine Verletzung des $\S 14$ UrhG eingestuft. ${ }^{810}$ Eine Beeinträchtigung im Sinne dieser Bestimmung setzt schließlich nicht notwendig voraus, dass das Werk selbst verändert wird; vielmehr genügt es, dass die urheberpersönlichkeitsrechtlichen Interessen des Urhebers an seinem Werk - ohne dessen inhaltliche Änderung - durch Form und Art der Werkwiedergabe und -nutzung beeinträchtigt werden können. Dies ist bei der Zweckentfremdung eines Musikstücks zu einem Klingelton der Fall, da bei der Nutzung als rein funktionaler - oftmals als störend empfundener - Signalton nicht mehr das individuell-künstlerische, sinnlich-klangliche Erlebnis im Vordergrund steht, sondern der Werkgenuss völlig in den Hintergrund tritt. Das Musikwerk wird nicht mehr - wie vom Urheber erhofft - bewusst gehört, sondern erklingt zu allen (un)möglichen Zeiten und an beliebigen Orten, wobei der in der Komposition angelegte Spannungsbogen regelmäßig durch das Annehmen oder Wegdrücken des Gesprächs zerstört wird. ${ }^{811}$

Diese Wertungen lassen sich jedoch auf die Darstellung urheberrechtlich geschützter Werke im Rahmen der Bildersuche grundsätzlich nicht übertragen. Zwar verändert sich auch bei der Thumbnail-Nutzung der Nutzungszweck des Werkes, da dieses rein funktional verwendet wird, nämlich als eine Art „Wegweiser“ zum Originalwerk. Dabei wird jedoch gerade versucht, den Gesamteindruck des Werkes und somit auch den Werkgenuss weitestgehend unverändert zu lassen, um dem Nutzer eine möglichst komfortable Identifizierung solcher Bilder zu ermöglichen, die zu seiner Suchanfrage passen. Abgesehen von der Komprimierung und Verkleinerung wird das Originalwerk bei der Nutzung als Thumbnail deshalb gerade nicht weiter verändert. Anders als dies oftmals bei Handy-Klingeltönen der Fall sein wird, wird das als Thumbnail dargestellte Werk im Rahmen der Bildersuche zudem nicht als störend empfunden. Der Werk,ggenuss“ wird hier - anders als bei Klingeltönen - niemandem gegen

810 Siehe BGH, GRUR 2009, 395 (397) - Klingeltöne für Mobiltelefone I (siehe dazu die Anmerkungen von Weller, jurisPR-ITR 8/2009 Anm. 4, und Prill, CR 2009, 239); BGH, GRUR 2010, 920 (921) - Klingeltöne für Mobiltelefone II; OLG Hamburg, GRUR-RR 2002, 249 (251, 253) - Handy-Klingeltöne; OLG Hamburg, GRUR 2006, 323 - Handy-Klingeltöne II (mit Anm. Dehmel, MMR 2006, 318); OLG Hamburg, GRUR-RR 2008, 282 (284) - Anita.

811 Ausführlich zur Verletzung von Urheberpersönlichkeitsrechten durch die Verwendung eines Musikwerkes als Klingelton für Mobiltelefone Landfermann, Handy-Klingeltöne, S. 66 ff.; Prill, Urheberrecht und Klingeltöne, S. 41 ff. 
seinen Willen aufgedrängt und auch nicht - wie beim Annehmen des Gesprächs bei einem Mobiltelefon - abrupt unterbrochen. Die Thumbnails werden gerade nur demjenigen angezeigt, der den Suchdienst nutzt und durch seine Eingabe steuert, der also die verkleinerten Bilder gerade sehen möchte, um die gewünschten Bildinformationen zu finden. Tatsächlich mag der Werkgenuss somit vermindert sein. Dies entspricht jedoch dem Willen des Nutzers, da es der Übersichtlichkeit dient. Aus der Sicht eines unvoreingenommenen Betrachters kann daher - anders als im Fall der Handy-Klingeltöne - in der Regel gerade keine Verletzung des Urheberpersönlichkeitsrechts aufgrund der Herabstufung auf eine rein funktionale Nutzung als Thumbnail angenommen werden. ${ }^{812}$

e) Einwilligung in die urheberpersönlichkeitsrechtsverletzende Nutzung?

Kommt es im Rahmen der Thumbnail-Nutzung durch Bildersuchmaschinen tatsächlich im Einzelfall zu Eingriffen in das Urheberpersönlichkeitsrecht, so könnte auch hier die Rechtswidrigkeit ausgeschlossen sein, wenn diese Beeinträchtigung - ebenso wie der Eingriff in ein Verwertungsrecht $^{813}$ - durch die stillschweigende Einwilligung des Urhebers oder Rechteinhabers in die Werknutzung gedeckt ist. Auch ein Eingriff in urheberpersönlichkeitsrechtliche Interessen kann durch eine Einwilligung gerechtfertigt werden. ${ }^{814}$ An eine stillschweigende Einwilligung, die urheberpersönlichkeitsrechtliche Interessen berührt, sind allerdings generell strenge Anforderungen zu stellen. ${ }^{815}$ Es müssen sich grundsätzlich konkrete Hinweise finden, dass auch solche Eingriffe, die das Urheberpersönlichkeitsrecht beeinträchtigen, von der Einwilligung erfasst sein sollen. ${ }^{816} \mathrm{Im}$ Hinblick auf die Beeinträchtigung des Rechts aus §14 UrhG durch die Werknutzung im Rahmen der Bildersuche ist wohl anzunehmen, dass eine solche nicht durch eine etwaige stillschweigende Einwilligung des Urhe-

812 Im Ergebnis ebenso Ott, ZUM 2009, 345 (346); Schrader/Rautenstrauch, UFITA 2007, 761 (765).

813 Siehe dazu oben 4. Kapitel, B.I.2.

814 Vgl. BGH, GRUR 1986, 458 (459) - Oberammergauer Passionsspiele; GRUR 1999, 230 (232) - Treppenhausgestaltung; Metzger, GRUR Int. 2003, 9 (12); Schricker/Loewenheim/Dietz/Peukert, § 14 Rn. 11 m.w.N.

815 Vgl. Loewenheim, GRUR 1989, 108 (110).

816 Vgl. OLG München, GRUR 1986, 460 (463) - Die unendliche Geschichte; Metzger, GRUR Int. 2003, 9 (12) m.w.N. 
bers gerechtfertigt ist. Der Urheber willigt wie gezeigt nur in die zum Zwecke einer sinnvollen Suche notwendigen und üblichen Nutzungshandlungen ein. Diese verletzen allerdings in der Regel gerade nicht das Urheberpersönlichkeitsrecht. Liegt aufgrund besonderer Umstände im Einzelfall eine Urheberpersönlichkeitsrechtsverletzung vor, so bewegt sich das Vorgehen des Suchmaschinenbetreibers diesbezüglich zumeist gerade nicht mehr im Rahmen des Erforderlichen und Üblichen. Die schlichte Einwilligung des Urhebers durch das ungeschützte Einstellen eines Werkes in das Internet geht also nicht so weit, diese verletzenden Nutzungen zu erfassen. Selbst wenn man jedoch die konkludente Einwilligung so weit auslegen wollte, dass auch Beeinträchtigungen des Urheberpersönlichkeitsrechts erfasst werden, so findet diese Gestattung ihre Grenzen dort, wo es zu schwerwiegenden Eingriffen in das Urheberpersönlichkeitsrecht kommt. Zum Teil wird angenommen, bezüglich schwerwiegender Entstellungen des geistig-ästhetischen Gesamteindrucks eines Werkes komme eine stillschweigende Einwilligung schon nicht in Betracht. ${ }^{817}$ Zumindest ist jedoch anerkannt, dass der Urheber gegen gröbliche Entstellungen unter Berufung auf $\S 14$ UrhG vorgehen kann, selbst wenn er dem Werknutzer zunächst eine Nutzung oder Änderungen des Werkes gestattet hatte. ${ }^{818}$

Hat der Urheber das im Rahmen der Bildersuche verwendete Werk nicht selbst in das Internet eingestellt und auch keinem Dritten die dafür erforderlichen Rechte eingeräumt, so muss - ebenso wie hinsichtlich der Verwertungsrechte - die Annahme einer Rechtfertigung aufgrund einer Einwilligung von vornherein ausscheiden, da es an einer anknüpfungsfähigen Handlung eines Berechtigten fehlt. In diesen Fällen ergibt sich im Hinblick auf das Urheberpersönlichkeitsrecht zudem eine Besonderheit. Hat der Urheber einer Verwertung seines Werkes im Internet nicht nur nicht zugestimmt, sondern einer solchen sogar ausdrücklich widersprochen, so droht durch die Nutzung dieser Werke im Rahmen der Bildersuche gerade eine Verletzung urheberpersönlichkeitsrechtlicher Interessen, da die Nutzung den (berechtigten) Interessen des Urhebers eindeutig zuwider läuft.

817 Vgl. BGH, GRUR 1986, 458 (459) - Oberammergauer Passionsspiele; GRUR 1999, 230 (232) - Treppenhausgestaltung.

818 Vgl. LG Berlin, GRUR 2007, 964 (967); Metzger, GRUR Int. 2003, 9 (12f.); Schricker/Loewenheim/Dietz/Peukert, § 14 Rn. 11. 


\section{Google Buchsuche}

Durch die Werknutzung im Rahmen der Google Buchsuche könnte ebenfalls das durch § 14 UrhG geschützte Recht gegen Entstellungen des Werkes beeinträchtigt sein. Denkbar ist eine Verletzung des Urheberpersönlichkeitsrechts durch Fehler, die bei der OCR-Texterkennung entstehen (aa)), durch eine schlechte Qualität oder Lückenhaftigkeit der Scans (bb)), durch die Darstellung der Werke in Form von Snippets (cc)) und durch fehlerhafte Metadaten (dd)).

\section{a) Beeinträchtigung durch Fehler bei der Texterkennung (OCR)}

Eine Entstellung des Werkes im Rahmen der Google Buchsuche kommt zunächst unter dem Gesichtspunkt der Fehlerhaftigkeit der OCR-Texterkennung in Betracht. Zwar sind die Programme zur Texterkennung inzwischen so ausgereift, dass eine weitgehend fehlerfreie Texterfassung möglich ist. Selbst gute Programme erzielen jedoch keine vollständig fehlerfreie Texterkennung - erst Recht nicht bei der Erkennung weniger üblicher oder alter Schriftarten oder einem schlechten Zustand beziehungsweise einer schlechten Druckqualität der gescannten Vorlage. ${ }^{819}$ Es ist somit davon auszugehen, dass auch die im Rahmen der Buchsuche erfassten Texte bei der Texterkennung insoweit verändert werden, als Fehler hinzugefügt werden, die im Originalwerk nicht enthalten waren. Rechnet der Nutzer diese Fehler dem Urheber und nicht Google zu, so könnte der Urheber in seinen berechtigten Interessen am Werk verletzt sein. Es ist jedoch zu beachten, dass der Nutzer bei urheberrechtlich geschützten Werken die indizierte Textdatei selbst nicht sieht, sondern ihm ausschließlich die jeweilige Buchseite als grafische Datei angezeigt wird. ${ }^{820}$ Hierbei han-

819 Siehe näher zur Qualität der OCR-Texterkennung inbesondere im Falle alter Vorlagen Holley, 15 D-Lib Magazine 2009.

820 Bei gemeinfreien Werken wird dem Nutzer hingegen die Möglichkeit angeboten, anstelle der Bilddatei nur die mittels Texterkennung erstellte Textdatei anzuzeigen (Ansicht „Nur Text“). Diese Ansicht offenbart auch die tatsächlich große Anzahl von Erkennungsfehlern, insbesondere etwa bei Büchern, die in Frakturschrift gedruckt sind. Vgl. etwa das „Deutsche Staats-Wörterbuch, Achter Band“ (1864) von Johann Caspar Bluntschli und Karl Brater [insbes. etwa Seite $128 \mathrm{f}$. zur „Polizei“] oder das Buch „Die Stadt und Universität Bonn am Rhein“ (1832) 
delt es sich um eine 1:1-Kopie des Originalwerkes, so dass die Fehler in der Texterkennung nicht sichtbar werden. Mit diesen Bilddateien ist die Textdatei lediglich verbunden, um eine Volltextsuche zu ermöglichen. Entspricht die Textdatei aufgrund fehlerhafter OCR-Erkennung also nicht vollständig dem Originalwerk, so ist dies für den Nutzer nicht sichtbar, sondern wirkt sich lediglich auf die Genauigkeit der Suche aus, da tatsächlich im Text enthaltene Ausdrücke aufgrund der fehlerhaften Texterkennung nicht aufgefunden werden können. Eine Beeinträchtigung des Urheberpersönlichkeitsrechts aufgrund von Konvertierungsfehlern ist daher nicht anzunehmen, solange dem Nutzer die fehlerhafte Textdatei nicht zugänglich ist. ${ }^{821}$

b) Beeinträchtigung durch schlechte Scanqualität oder lückenhafte Scans

Anders kann sich dies hingegen unter Umständen darstellen, wenn bereits die Qualität des ersten Scans, das heißt der grafischen Datei, so schlecht ist, dass der Werkgenuss ganz erheblich beeinträchtigt oder gar unmöglich wird. Dies ist etwa bei der lückenhaften Digitalisierung eines Werkes vorstellbar, bei der einzelne Seiten vollständig fehlen oder für den Nutzer unlesbar sind, etwa weil der Ausschnitt falsch gewählt ist, so dass Teile des Textes abgeschnitten sind. Ein Fehler, der gerade in den Anfängen der Google Buchsuche ebenfalls häufiger zu finden war und weiterhin teilweise zu finden ist, ist die Überlagerung einzelner Textteile durch störende Fremdkörper, insbesondere Hände einer Person oder Teile der technischen Apparatur, die den Scan durchführt. Es ist nicht ausgeschlossen, dass in einer solchen „Verstümmelung“ des Werkes durch störende „Fremdeinflüsse" oder durch grob fehler- oder lückenhafte Kopien im Einzelfall eine Entstellung des Werkes zu sehen sein kann. Es muss jedoch bezweifelt werden, ob diese Werkbeeinträchtigung tatsächlich geeignet ist, die Interessen des Urhebers zu gefährden. Dies würde voraussetzen, dass der Betrachter diese Mängel nicht der unzureichenden Digitalisierungstechnik,

von Bernhard Hundeshagen, welche auf jeder Seite zahlreiche Konvertierungsfehler enthalten, die teilweise so weit reichen, dass sie zur Unlesbarkeit der Textdatei führen.

821 Im Ergebnis ebenso Heckmann, AfP 2007, 314 (315); Hüttner, WRP 2009, 422 (425); Kubis, ZUM 2006, 370 (374); Lucke, Google Buchsuche, S. 132; Ott, GRUR Int. 2007, 562 (564). 
sondern einer mangelnden Fähigkeit oder minderwertigen Leistung des Urhebers zurechnet. ${ }^{822}$ Alle vorgenannten Fehler sind jedoch eindeutig Ergebnisse einer mangelhaften Digitalisierung und dem Betrachter unzweideutig auch als solche zu erkennen. Der Nutzer, der die Anzeige des (fehlerhaften) Textausschnittes zudem durch seine Suchanfrage selbst veranlasst, verwendet den Buchsuche-Dienst in aller Regel dazu, um Informationen über den Inhalt einzelner Bücher aufzufinden. Er verwendet die Buchsuche somit als Werkzeug zur Auffindung bestimmter Inhalte, ist sich dabei jedoch bewusst, dass mögliche Fehler in der Darstellung nicht auf eine mangelnde Qualität des Originalwerkes zurückzuführen sind, sondern ihren Grund vielmehr in der noch nicht vollständig ausgefeilten Technik der Digitalisierung haben. Eine Entstellung gemäß $§ 14$ UrhG durch die mangelhafte Qualität der digitalen grafischen Vervielfältigungsstücke scheidet daher - abgesehen von im Einzelfall möglichen ganz gröblichen Entstellungen des Werkes, die der Urheber nicht hinzunehmen braucht - in der Regel aus. ${ }^{823}$

c) Beeinträchtigung durch Darstellung in Form von Snippets

Auch die Darstellung eines Werkes in Form einzelner Sätze oder kurzer Ausschnitte losgelöst von ihrem Kontext könnte als Entstellung oder Beeinträchtigung des Werkes anzusehen sein. Grundsätzlich stellt jede objektiv nachweisbare Änderung des geistig-ästhetischen Gesamteindrucks, den der Urheber für sein Werk bestimmt hat, eine Beeinträchtigung des Werkes dar. ${ }^{824}$ Eine solche Abweichung vom Gesamteindruck liegt zweifelsohne vor, wenn lediglich einige kurze Fragmente aus diesem Werk „herausgeschnitten" und dem Nutzer der Google Buchsuche angezeigt werden. Eine vollständige Betrachtung des Werkes in der ihm vom Urheber gegebenen Gestalt ist gerade nicht möglich. Aufgrund des generell anzunehmenden Interesses des Urhebers an Bestand und Unversehrtheit seines

822 Vgl. (zum Schutz des ausübenden Künstlers) BGH, GRUR 1987, 814 (816) - Die Zauberflöte; insoweit zustimmend Schack, GRUR 1987, 817 (818).

823 So im Ergebnis auch Kubis, ZUM 2006, 370 (374 f.); Ott, GRUR Int. 2007, 562 (564); a.A. Bohne/Elmers, WRP 2009, 586 (588); Heckmann, AfP 2007, 314 (315).

824 Vgl. BGH, GRUR 1989, 106 (107) - Oberammergauer Passionsspiele II; Dreier/ Schulze, § 14 Rn. 10 m.w.N. 
Werkes $^{825}$ erscheint es auch noch vertretbar, dieser Beeinträchtigung eine Eignung zur Interessengefährdung zuzusprechen. Jedenfalls die abschlieBende Interessenabwägung ergibt jedoch meines Erachtens, dass eine Verletzung des Rechts aus $\S 14$ UrhG allein durch die Anzeige in SnippetForm in der Regel nicht anzunehmen ist. ${ }^{826} \mathrm{Zu}$ beachten ist zum einen, dass die verkürzte Anzeige gerade im Interesse des Urhebers erfolgt und letztlich dem Schutz seines Bestands- und Integritätsinteresses dient. Dem Nutzer soll kein vollständiger Werkgenuss ermöglicht werden, der die Lektüre des Werkes ersetzt, sondern lediglich ein Werkzeug zum Auffinden einzelner Inhalte an die Hand gegeben werden. Dies fördert letztlich die Bekanntheit und möglicherweise auch den Absatz des Werkes. Es wird durch die Snippet-Ansicht zugleich verhindert, dass eine unkontrollierte, gegebenenfalls entstellende Nutzung durch den einzelnen Nutzer erfolgt, die aufgrund der digitalen Form deutlich leichter fallen würde. Zum anderen ist zu bedenken, dass der jeweilige Textausschnitt erst auf die Anfrage des Nutzers hin automatisch erzeugt und angezeigt wird. Die Textschnipsel sind also gerade nicht bereits in verkürzter und möglicherweise entstellender Form in der Datenbank von Google gespeichert. ${ }^{827}$ Schließlich bietet Google jedem Urheber, der mit der Snippet-Nutzung seines Werkes nicht einverstanden ist, in Form des Opt Out auch die Möglichkeit, die zukünftige Anzeige von Textausschnitten zu verhindern oder sein Werk ganz aus der Buchsuche-Datenbank zu löschen.

\section{d) Beeinträchtigung durch fehlerhafte Metadaten}

Eine Entstellung des Werkes ist schließlich im Einzelfall auch durch die im Hinblick auf eine Verletzung des Rechts auf Anerkennung der Urheberschaft gemäß $\S 13$ UrhG bereits problematisierte Fehlerhaftigkeit der von Google gespeicherten bibliographischen Angaben und Metadaten zu einzelnen Büchern ${ }^{828}$ denkbar. $§ 14$ UrhG schützt den Urheber in seinem geistigen und persönlichen Interesse, dass die Öffentlichkeit das Werk nur so zu sehen bekommt, wie er es zur Veröffentlichung vorgesehen hat. ${ }^{829}$

825 Vgl. Schricker/Loewenheim/Dietz/Peukert, § 14 Rn. 27.

826 A.A. Heckmann, AfP 2007, 314 (316); Lucke, Google Buchsuche, S. 139.

827 So der zutreffende Hinweis von Peifer, ZGE 2010, 351 (353).

828 Siehe oben 4. Kapitel, C.I.2.

829 Vgl. Fromm/Nordemann/Dustmann, § 14 Rn. 1. 
Dieser Integritätsschutz des Urhebers könnte aber dann beeinträchtigt sein, wenn im Einzelfall fehlerhafte bibliographische Angaben dazu führen, dass ein völlig falsches Bild des Urhebers und seines Werkes gezeichnet wird, etwa weil der Autor durch die fehlerhaften Metadaten in einem herabwürdigenden Zusammenhang erscheint. Es liegt in einem solchen Fall zumindest eine Beeinträchtigung der Urheberinteressen vor. Ob diese auch geeignet ist, die berechtigten Interessen des Urhebers zu gefährden, ist eine Frage des Einzelfalls, deren Bejahung in besonders extrem gelagerten Fällen jedoch wohl nicht ausgeschlossen werden kann. ${ }^{830}$

\section{Allgemeines Persönlichkeitsrecht}

Das Urheberpersönlichkeitsrecht wird allgemein als rechtlich selbständige Erscheinungsform des aus Art. 1 Abs. 1 und Art. 2 Abs. 1 GG abgeleiteten allgemeinen Persönlichkeitsrechts ${ }^{831}$ verstanden. ${ }^{832}$ Als Spezialregelung geht das Urheberpersönlichkeitsrecht dem allgemeinen Persönlichkeitsrecht vor. ${ }^{833}$ Soweit die spezialgesetzlichen Voraussetzungen des Urheberpersönlichkeitsrechts jedoch nicht erfüllt sind, dieses besondere Persönlichkeitsrecht also nicht eingreift, kann daher grundsätzlich auf das allgemeine Persönlichkeitsrecht zurückgegriffen werden. ${ }^{834}$ Besondere Bedeutung kommt dem allgemeinen Persönlichkeitsrecht dabei dann zu, wenn ein Urheberschutz - und somit auch ein urheberpersönlichkeitsrechtlicher Schutz - wegen fehlender Werkqualität ausscheidet. ${ }^{835}$ Auch Individualinteressen des Urhebers, die sich nicht auf ein einzelnes Werk beziehen,

830 Beispielsweise im Falle des bereits oben (Fn. 790) erwähnten Buches „Hitler's conservative opponents in Bavaria 1930-1945“ von James Donohoe, als dessen Autor die Google Buchsuche neben Donohoe auch Adolf Hitler benennt, oder in ähnlich gelagerten Fällen, ist dies denkbar, da der Betrachter den Eindruck bekommen könnte, der Urheber habe mit seinem vermeintlichen Co-Autor zusammengearbeitet und stehe diesem nahe oder teile unter Umständen dessen (politische) Ansichten.

831 Ausführlich zu den normativen Grundlagen und der Entwicklung des allgemeinen Persönlichkeitsrechts MünchKomm-BGB/Rixecker, Anhang zu § 12 BGB, Allg. PersönlR, Rn. 1 ff.

832 Vgl. nur Dreier/Schulze, Vor $§ 12$ Rn. 5.

833 Siehe nur Schricker/Loewenheim/Dietz/Peukert, Vor $\S \S 12$ ff. Rn. 15 m.w.N.

834 Vgl. v.Gamm, UrhG, Einf. Rn. 93; Krüger-Nieland, in: FS Hauß, S. 215 (221 ff.); Schricker/Loewenheim/Dietz/Peukert, Vor $\S \S 12$ ff. Rn. 15 m.w.N.

835 Vgl. Schack, Urheberrecht, Rn. 48. 
sondern auf die Gesamtheit seines Werkschaffens, werden nicht durch das Urheberpersönlichkeitsrecht geschützt, können jedoch auf Grundlage des allgemeinen Persönlichkeitsrechts des Urhebers Schutz genießen. ${ }^{836}$ Durch das allgemeine Persönlichkeitsrecht wird das Recht des Einzelnen auf Achtung seiner personalen und sozialen Identität, seiner Entfaltung und Entwicklung einer individuellen Persönlichkeit geschützt. ${ }^{837}$

Hinsichtlich der Thumbnail-Nutzung erscheint eine Verletzung des allgemeinen Persönlichkeitsrechts eher fernliegend. Im Hinblick auf die Google Buchsuche ist jedoch überlegt worden, ob das allgemeine Persönlichkeitsrecht dadurch beeinträchtigt ist, dass durch die Digitalisierung und die Möglichkeit einer Volltextsuche eine Nutzung der Werke ermöglicht wird, die zuvor nicht bekannt war und die der Urheber somit zuvor nicht hinnehmen musste. ${ }^{838}$ Eine Beeinträchtigung des allgemeinen Persönlichkeitsrechts käme dann in Betracht, wenn durch die Google Buchsuche die Gefahr bestünde, dass das Bild der Öffentlichkeit bezüglich eines bestimmten Urhebers negativ beeinflusst wird. Durch die Google Buchsuche ist eine gezielte Suche nach einzelnen Begriffen, aber auch nach ganzen Sätzen oder Satzteilen möglich. Es ist daher in nur wenigen Schritten zu erkennen, ob mehrere Werke in Teilen übereinstimmen, so dass etwa Plagiate leicht ermittelt werden können. Durch die gezielte Suche nach einem bestimmten Autor lassen sich zudem ohne Aufwand sämtliche Werke dieses Autors ermitteln (sofern sie von der Buchsuche erfasst sind), so dass der Nutzer möglicherweise auch auf vergessene oder vergriffene Werke aufmerksam wird. Die Ermittlung von Plagiaten oder auch längst vergessenen Äußerungen eines Autors, etwa aus seinem vergriffenen Frühwerk, mag tatsächlich die öffentliche Wahrnehmung des Autors verändern. Allein die Tatsache, dass durch neue technische Möglichkeiten der Nachweis unlauterer Methoden oder das Wiederauffinden vergessener Äußerungen erleichtert wird, verletzt jedoch das allgemeine Persönlichkeitsrecht des Autors noch nicht. Diese Schwächen oder Tatsachen hätten auch vorher schon aufgedeckt werden können, entweder zufällig oder durch eine zwar aufwändigere, jedoch mögliche gezielte Recherche. Hat der Urheber sich für eine Veröffentlichung seines Werkes entschieden, so muss er grundsätzlich die damit verbundenen Konsequenzen tragen, auch wenn diese in einer kritischen Auseinandersetzung mit seinem Werk und seinen

836 Vgl. Schricker/Loewenheim/Dietz/Peukert, Vor $\S § 12$ ff. Rn. 16 m.w.N.

837 Vgl. Palandt/Sprau, BGB, § 823 Rn. 86 m.w.N.

838 Kubis, ZUM 2006, 370 (375). 
Methoden liegen. Dies soll gerade nicht durch eine Berufung auf das allgemeine Persönlichkeitsrecht verhindert werden, da der Autor insoweit nicht schutzbedürftig ist. ${ }^{839}$ Entspricht ein (altes) Werk nicht mehr der Überzeugung des Urhebers, so kann er es zudem grundsätzlich unter den Voraussetzungen des $\S 42$ UrhG zurückrufen. ${ }^{840}$ Eine Verletzung des allgemeinen Persönlichkeitsrechts durch die Google Buchsuche scheidet daher in aller Regel aus. Anders mag dies im Einzelfall jedoch dann zu bewerten sein, wenn - wie zuvor dargestellt ${ }^{841}$ - durch Fehler in den Metadaten ein völlig verzerrtes Bild des Urhebers gezeichnet wird, beispielsweise weil dieser in Verbindung mit einem falschen (Co-)Autor genannt oder ihm fälschlich ein fremdes Werk zugeschrieben wird.

\section{Zwischenergebnis}

Die Untersuchung hat gezeigt, dass sich die Verwendung von Thumbnails im Rahmen der Bildersuche stets in einem „Grenzbereich“ der Verletzung urheberpersönlichkeitsrechtlicher Interessen bewegt. Die Nutzung kann sowohl in das Recht auf Anerkennung der Urheberschaft gemäß $\S 13$ UrhG als auch in das Recht gegen Entstellungen des Werkes nach $\S 14$ UrhG eingreifen. Auch wenn im Ergebnis eine Rechtsverletzung oftmals ausscheiden wird, kann eine solche nicht grundsätzlich und insbesondere nicht von vorneherein ausgeschlossen werden. Im Einzelfall - etwa bei Thumbnails von künstlerischen Werken oder dem Verweis auf Bilder, die sich auf einer Website mit künstlerisch anspruchsvollem Gesamtkonzept befinden - erscheint zudem eine Urheberpersönlichkeitsrechtsverletzung durchaus möglich. Insbesondere in Fällen, in denen der Rechteinhaber einer öffentlichen Zugänglichmachung seines Werkes im Internet von vorneherein nicht zugestimmt hat, können urheberpersönlichkeitsrechtliche Interessen betroffen sein, da hier eine Rechtfertigung eines Eingriffs aufgrund einer (konkludenten) Einwilligung ausscheidet.

839 Vgl. Kubis, ZUM 2006, 370 (375).

840 Dem Rückruf wegen gewandelter Überzeugung gemäß $§ 42$ UrhG könnte tatsächlich in Zukunft eine wachsende Bedeutung zukommen, da Urheber aufgrund der neuen Nutzungsmöglichkeiten gerade im Internet mit völlig neuen Formen der Nutzung ihrer Werke und einer erheblich weiteren, unkontrollierbaren Verbreitung konfrontiert sind; siehe dazu Rauda, GRUR 2010, $22 \mathrm{ff}$.

841 Siehe oben 4. Kapitel, C.I.2. und 4. Kapitel, C.II.2.d). 
Auch im Rahmen der Google Buchsuche ist - wie gezeigt - die Verletzung urheberpersönlichkeitsrechtlicher Interessen keinesfalls ausgeschlossen. Eine Rechtsverletzung ist insbesondere als Folge einer schlechten Scan-Qualität und der daraus resultierenden fehler- und lückenhaften Wiedergabe des Werkes denkbar. Auch durch die Verwendung fehlerhafter (Meta-)Daten im Zusammenhang mit einem Werk kann dieses in persönlichkeitsrechtsverletzender Weise dargestellt sein. Gerade im letzteren Fall kann auch eine Beeinträchtigung des allgemeinen Persönlichkeitsrechts nicht ausgeschlossen werden.

Es zeigt sich somit hinsichtlich der urheberpersönlichkeitsrechtlichen Bewertung der neuen Nutzungsformen urheberrechtlich geschützter Werke insgesamt eine erhebliche Rechtsunsicherheit, die zugleich ein nicht unerhebliches Prozessrisiko verdeutlicht. Oftmals lässt sich nicht von vorneherein und nicht mit Sicherheit ausschließen, dass durch eine neue Form der Online-Nutzung Urheberpersönlichkeitsrechte verletzt werden. Flexiblere Schrankenregelungen, die auch in persönlichkeitsrechtlicher Hinsicht für mehr Klarheit sorgen, können hier Abhilfe schaffen.

\section{Exkurs: Anwendbares Recht und internationale Zuständigkeit}

Es wurde festgestellt, dass die Nutzung urheberrechtlich geschützter Werke im Rahmen der Bildersuche in Form von Thumbnails und die Digitalisierung und Anzeige von Büchern im Rahmen der Google Buchsuche nach deutschem Recht erheblichen urheberrechtlichen Bedenken ausgesetzt sind. Zumindest hinsichtlich gewisser Rechtsverletzungen ist jedoch aufgrund der internationalen Dimension, die diese Nutzungshandlungen aufgrund des globalen Charakters des Internet haben, fraglich, ob sich die Urheber vor deutschen Gerichten gegen diese zur Wehr setzen können und ob gegebenenfalls in der Sache deutsches Urheberrecht anzuwenden ist. Da die Fragen des anwendbaren Rechts (sogleich 1.) und der internationalen Zuständigkeit (sodann 2.) für die Möglichkeiten der Rechteinhaber zur Durchsetzung ihrer durch die neuen Nutzungsformen betroffenen Rechte entscheidend ist, sollen diese im Folgenden im Rahmen eines Exkurses geklärt werden. 


\section{Anwendbares Recht}

Berührt ein urheberrechtlicher Sachverhalt mehrere Rechtsordnungen, so bestimmt das zuständige Gericht mit Hilfe der Regeln des eigenen internationalen Privatrechts, der sogenannten lex fori, das konkret anzuwendende nationale Recht. In der deutschen Rechtsordnung findet sich allerdings ebenso wie in vielen anderen Staaten - keine gesetzliche Regelung, welche die Frage nach dem anzuwendenden Urheberrecht bei internationalen urheberrechtlichen Sachverhalten beantwortet. Da eine geschriebene Kollisionsnorm fehlte, folgte die Rechtsprechung und ganz herrschende Meinung für das Urheberrecht seit jeher dem - aus dem Territorialitätsprinzip hergeleiteten - Schutzlandprinzip. Danach richten sich Entstehung, Inhalt und Umfang, Übertragbarkeit und Schutzdauer des Urheberrechts ebenso wie Ansprüche wegen Urheberrechtsverletzungen nach dem Recht desjenigen Staates, für dessen Gebiet der Schutz beansprucht wird, der sogenannten lex loci protectionis, nicht also nach dem Recht des Landes, vor dessen Gerichten um Schutz nachgesucht wird. ${ }^{842}$ Auf europäischer Ebene ist das Schutzlandprinzip nun für das Immaterialgüterrecht ausdrücklich in Art. 8 Abs. 1 der seit dem 11. Januar 2009 geltenden EG-Verordnung über das auf außervertragliche Schuldverhältnisse anzuwendende Recht ${ }^{843}$ (sog.

842 St. Rspr., siehe etwa BGHZ 118, 394 (397) - ALF; BGHZ 136, 380 (387) Spielbankaffaire; BGHZ 152, 317 (321) - Sender Felsberg; BGH, GRUR 2007, 691 (692) - Staatsgeschenk; BGHZ 171, 151 (157 f.) - Wagenfeld-Leuchte; vgl. auch BVerfGE 81, 208 (223 f.) - Bob Dylan. Aus dem Schrifttum siehe statt vieler Dreier/Schulze, Vor $\S \S 120$ ff. Rn. 28; Fromm/Nordemann/Nordemann-Schiffel, Vor $\S \S 120$ ff. Rn. 59 ff.; MünchKomm-BGB/Drexl, 4. Aufl., IntImmGR, Rn. 10; Schricker/Loewenheim/Katzenberger, Vor $\S \S 120 \mathrm{ff}$. Rn. 124, 129, Ulmer, S 80 ff., jeweils m.w.N.; a.A. vor allem Schack, Urheberrecht, Rn. 1019 ff.; ders., JZ 1998, 753 (761); ders., MMR 2000, 59 (60 ff.); ders., IPRax 2003, 141 (141 f.), der das sog. Universalitätsprinzip befürwortet, das davon ausgeht, dass das Urheberrecht als eigentumsähnliches Recht ähnlich wie im internationalen Sachenrecht hinsichtlich seiner Entstehung und Inhaberschaft allein derjenigen Rechtsordnung untersteht, in der das Werk erstmals mit Zustimmung des Urhebers veröffentlicht wurde. Ausführlich zum Schutzlandprinzip zuletzt Beckstein, Einschränkungen des Schutzlandprinzips, S. 80 ff.

843 Verordnung (EG) Nr. 864/2007 des Europäischen Parlaments und des Rates vom 11. Juli 2007 über das auf außervertragliche Schuldverhältnisse anzuwendende Recht („Rom II“), AB1. Nr. L 199 v. 31.7.2007, S. 40. 
„Rom II-Verordnung“) kodifiziert. ${ }^{844}$ Voraussetzung für die Anwendung des deutschen Urheberrechtsgesetzes auf Urheberrechtsverletzungen ist aufgrund dieser Anknüpfung an den Handlungsort, dass die verletzende Benutzungshandlung in Deutschland stattgefunden hat, da das inländische Urheberrecht auch nur durch eine im Inland begangene Handlung verletzt werden kann. ${ }^{845}$ Dabei ist jede einzelne Verletzungshandlung gesondert zu betrachten, so dass gegebenenfalls für verschiedene Verletzungshandlungen unterschiedliches nationales Recht zur Anwendung kommen kann. ${ }^{846}$

Für Beeinträchtigungen des Vervielfältigungsrechts ist weitgehend unumstritten, dass als Handlungsort zum einen die Standorte der beteiligten Rechner mit dauerhafter Speicherfunktion - insbesondere also Standorte zentraler Server - in Betracht kommen, zum anderen die Orte, von denen aus die Speicherung auf diesen stattfindet. ${ }^{847}$ Ansprüche wegen der Verletzung des Vervielfältigungsrechts sind demnach nur dann nach deutschem Recht, also nach $\S 16$ UrhG, zu bewerten, wenn die Vervielfältigungshandlung selbst - also die Speicherung auf einem Rechner oder Server - von Deutschland aus gesteuert wird oder zumindest der entsprechende Servercomputer auf deutschem Boden steht.

Weniger eindeutig stellt sich dies bei der Beurteilung der Verletzung des Rechts der öffentlichen Zugänglichmachung dar. Aufgrund der weltweiten Zugriffsmöglichkeit auf einen im Internet verfügbaren (verletzenden) Inhalt, führt eine uneingeschränkte Anwendung des Schutzlandprinzips hier zur Anwendbarkeit einer unüberschaubaren Vielzahl von Rechtsordnungen, da sich der Ort der unerlaubten Handlung in diesen Fällen

844 Art. 8 Abs. 1 der Rom II-VO lautet: „Auf außervertragliche Schuldverhältnisse aus einer Verletzung von Rechten des geistigen Eigentums ist das Recht des Staates anzuwenden, für den der Schutz beansprucht wird.“ Siehe auch Erwägungsgrund 26 der Rom II-VO: „Bei einer Verletzung von Rechten des geistigen Eigentums gilt es, den allgemein anerkannten Grundsatz der lex loci protectionis zu wahren. Im Sinne dieser Verordnung sollte der Ausdruck „Rechte des geistigen Eigentums" dahin interpretiert werden, dass er beispielsweise Urheberrechte, verwandte Schutzrechte, das Schutzrecht sui generis für Datenbanken und gewerbliche Schutzrechte umfasst.".

845 Vgl. BGHZ 126, 252 (254 ff.) - Folgerecht bei Auslandsbezug m.w.N.

846 Vgl. Fromm/Nordemann/Nordemann-Schiffel, Vor $\S \S 120$ ff. Rn. 65 f.; Schricker/ Loewenheim/Katzenberger, Vor $\S \S 120 \mathrm{ff}$. Rn. 126, jeweils m.w.N.

847 Vgl. Dreier/Schulze, Vor $\S \S 120$ ff. Rn. 33, Ensthaler/Weidert/Gesmann-Nuissl, Handbuch, Kap. 8 Rn. 26 f.; Intveen, Internationales Urheberrecht und Internet, S. 31; Muth, Urheberrechtsverletzungen im Internet, S. 79; Schricker/Loewenheim/Katzenberger, Vor $\S \S 120$ ff. Rn. 145, jeweils m.w.N. 
kaum eingrenzen lässt. Als Handlungsorte kommen hier neben dem Serverstandort und dem Ort der Einspeisung insbesondere auch alle diejenigen Länder in Betracht, in denen Nutzer die verletzenden Inhalte abrufen können oder zumindest tatsächlich abrufen. Als Folge droht aufgrund dieser unüberschaubaren (Rechts-)Situation zum einen der Schutz der Urheber ausgehöhlt zu werden, zum anderen ist es für einen Verwerter äußerst umständlich oder sogar faktisch unmöglich, die Rechtmäßigkeit solcher „Multi-State-Verwertungshandlungen“ sicher zu bestimmen. Zunächst müssten sie alle anwendbaren Urheberrechtsordnungen ermitteln, um sich dann in diesen Ländern die entsprechenden Rechte einräumen zu lassen und aus dem Kreis der anwendbaren Rechtsordnungen diejenige mit den strengsten Anforderungen zu ermitteln. ${ }^{848}$ Erst nach einer solchen weltweiten Rechteklärung und nur wenn die fragliche Verwertungshandlung mit den Anforderungen der strengsten Rechtsordnung im Einklang stünde, könnte der Verwerter das Werk also auf die gewünschte Art und Weise rechtssicher im Internet verwerten.

Aufgrund dieser Probleme mit der teilweise als unerträglich empfundenen Kumulation der anwendbaren Rechtsordnungen ist verschiedentlich versucht worden, deren Kreis mit Hilfe internetspezifischer Anknüpfungsregeln einzuschränken. Auch wenn sich die vorgeschlagenen Lösungsansätze im Detail zum Teil stark unterscheiden, lassen sie sich im Wesentlichen in zwei Kategorien aufteilen: Zum einen wird befürwortet, die öffentliche Zugänglichmachung auf einen einzigen Ort zu beschränken, zum anderen wird eine Mehrzahl von Rechtsordnungen für anwendbar gehalten, jedoch versucht, diese Anzahl sachgerecht einzugrenzen. ${ }^{849}$

Unter den Befürwortern der Anwendung nur einer Rechtsordnung finden sich Überlegungen, an das Recht der Verletzungshandlung, des Serverstandortes, des Ursprungslandes sowie das Recht der Staatsangehörig-

848 Vgl. Klett, Urheberrecht im Internet, S. 57 f.; Thum, GRUR Int. 2001, 9 (20); Sack, WRP 2008, 1405 (1414); Schulze, ZUM 2000, 432 (453); Spindler, IPRax 2003, 412 (413 f.).

849 Die beiden Ansätze können hier allenfalls in Grundzügen dargestellt werden, da eine umfassende Auseinandersetzung mit dieser Problematik den Rahmen der vorliegenden Untersuchung überschreiten würde. Für eine gute Übersicht über die vertretenen Lösungsansätze siehe Dreier/Schulze, Vor $\S \S 120 \mathrm{ff}$. Rn. $40 \mathrm{ff}$; MünchKomm-BGB/Drexl, 4. Aufl., IntImmGR, Rn. 206 ff.; ausführlich zu den verschiedenen Lösungsansätzen Beckstein, Einschränkungen des Schutzlandprinzips, S. 147 ff.; Junker, Anwendbares Recht und internationale Zuständigkeit, S. $204 \mathrm{ff}$. 
keit oder des gewöhnlichen Aufenthalts des Rechtsinhabers anzuknüpfen. Am weitesten verbreitet ist dabei wohl - oftmals in Anlehnung an die Regelung des Art. 1 Abs. 2 lit. b der Satellitenrundfunk-Richtlinie ${ }^{850}$ - die Anknüpfung an den Ort, von welchem der urheberrechtlich geschützte Inhalt in das Internet eingespeist wurde, das heißt an den Ort, von dem der Inhalt an den Betreiber des Servers, auf dem dieser Inhalt gehostet wird, übertragen wurde. ${ }^{851}$ Dieser Vorschlag erscheint auf den ersten Blick attraktiv, da er eine nachvollziehbare und einfache Lösung zu bieten scheint, durch die eine Kumulation nationaler Rechte vermieden würde. Bei genauerer Betrachtung hat dieser Ansatz jedoch insbesondere eine ganz erhebliche Schwäche, die nicht zu überwinden ist, solange eine umfassende Angleichung des urheberrechtlichen Schutzniveaus nicht innerhalb der EU und erst Recht nicht weltweit erfolgt ist: (Professionellen) Verletzern würde durch die Anknüpfung an das „Sende“-Land ermöglicht, Werke aus sogenannten „Urheberrechtsoasen“, also Ländern mit möglichst niedrigen Schutzstandards, ${ }^{852}$ in das Internet einzuspeisen. 853 Durch derartiges „Country Shopping“ könnten die Verletzer die Gefahr einer Haftung deutlich senken oder oftmals einer Haftung gar vollständig entgehen. Durch den Anreiz, sich in Staaten mit niedrigen Schutzstandards niederzulassen, liefe dieses System zudem Gefahr, einem „race to the bottom" Vorschub

850 Richtlinie 93/83/EWG des Rates vom 27.9.1993 zur Koordinierung bestimmter urheber- und leistungsschutzrechtlicher Vorschriften betreffend Satellitenrundfunk und Kabelweiterverbreitung, ABl. Nr. L 248 v. 6.10.1993, S. 15. Art. 1 Abs. 2 lit. b lautet: „Die öffentliche Wiedergabe über Satellit findet nur in dem Mitgliedstaat statt, in dem die programmtragenden Signale unter der Kontrolle des Sendeunternehmens und auf dessen Verantwortung in eine ununterbrochene Kommunikationskette eingegeben werden, die zum Satelliten und zurück zur Erde führt.“.

851 So (mit im Einzelnen unterschiedlicher Begründung) etwa Bachmann, IPRax 1998, 179 (183); Ginsburg, 42 J. Copyright Soc'y U.S.A. 318, 335 ff. (1995); Handig, GRUR Int. 2007, 206 (217 f.); Lucas, Private International Law Aspects, S. 22.

852 Für einen kurzen Überblick über einige solcher Urheberrechtsoasen für die Verwertung urheberrechtlich geschützter Werke im Internet, siehe Hoeren, MMR 1998, $297 \mathrm{f}$.

853 Vgl. Thum, in: Neues Recht für neue Medien, S. 117 (137), die zu Recht darauf hinweist, dass gerade im Internet die Gefahr der Flucht in Urheberrechtsoasen besonders hoch ist, da eine Relokalisierung hier - anders als etwa im Bereich des traditionellen Rundfunks oder Satellitenfernsehens - keinen oder nur einen geringen technischen Aufwand erfordert. 
zu leisten. ${ }^{854}$ Eine Anknüpfung an das „Sende“-Land erscheint daher allenfalls innerhalb eines weitgehend vereinheitlichten Rechts- und Wirtschaftsraumes tragbar, kann allerdings vor dem Hintergrund des derzeitigen Harmonisierungsstandes selbst innerhalb der EU nicht überzeugen. ${ }^{855}$ Aus demselben Grund kann auch die ebenfalls vertretene Anknüpfung an den Serverstandort für die Lokalisierung der Verwertungshandlung nicht überzeugen.

Aufgrund dieser Schwächen ist von einer derart starren Anknüpfung Abstand zu nehmen. Zur Vermeidung einer exorbitanten Ausweitung der anwendbaren Rechtsordnungen erscheint es jedoch sinnvoll, gewisse Einschränkungen vorzunehmen. Aufgrund der engen Anlehnung des Rechts der öffentlichen Zugänglichmachung an das Senderecht ( $\$ 20$ UrhG) ist mehrfach vorgeschlagen worden, die für das Senderecht entwickelte sogenannte „Bogsch-Theorie“ auch auf die Verbreitung urheberrechtlicher Inhalte im Internet anzuwenden. ${ }^{856}$ Nach dieser - nach dem früheren langjährigen Generaldirektor der WIPO benannten - Lehre gelten als Handlungsort für das urheberrechtliche Senderecht neben dem Ausstrahlungsland auch alle weiteren Länder, in denen die Fernseh- oder Hörfunksendung empfangen werden kann. ${ }^{857}$ Diese Überlegungen bilden tatsächlich

854 Vgl. Handig, GRUR Int. 2007, 206 (213); Mankowski, GRUR Int. 1999, 909 (914, 921); Schack, MMR 2000, 59 (63); Spindler, IPRax 2003, 412 (418).

855 Kritisch ebenfalls Dreier/Schulze, Vor $\S \S 120$ ff. Rn. 41; Geller, 20 Colum.-VLA J.L. \& Arts 571, 595 f. (1996); Klett, Urheberrecht im Internet, S. 59 f.; Lucke, Google Buchsuche, S. 92 f.; MünchKomm-BGB/Drexl, 4. Aufl., IntImmGR, Rn. 206 ff.; Schack, MMR 2000, 59 (63); Schønning, ZUM 1997, 34 (38); Schricker, MMR 1998, 39; Spindler, ZUM 1996, 533 (563); ders., GRUR 2002, 105 (109); ders., IPRax 2003, 412 (418); Thum, GRUR Int. 2001, 9 (22 f.). Vgl. auch Vorschlag für eine Richtlinie des Europäischen Parlaments und des Rates zur Harmonisierung bestimmter Aspekte des Urheberrechts und der verwandten Schutzrechte in der Informationsgesellschaft, KOM(1997) 628 endg., S. $11 \mathrm{f}$.

856 Vgl. etwa LG Hamburg, GRUR-RR 2004, 313 (315); Dreier/Schulze, Vor $\S \S 120$ ff. Rn. 42; Ensthaler/Weidert/Gesmann-Nuissl, Handbuch, Kap. 8 Rn. 33 f.; Junker, Anwendbares Recht und internationale Zuständigkeit, S. 215 ff.; v.Lewinski, MMR 1998, 115 (116); Loewenheim/Walter, § 58 Rn. 78, 89; MünchKomm-BGB/Drexl, 4. Aufl., IntImmGR, Rn. 165 ff.; Reinbothe, GRUR Int. 2001, 733 (736); Sack, WRP 2000, 269 (277f.); ders., WRP 2008, 1405 (1415 f.); Schack, MMR 2000, 59 (63 f.); Schønning, ZUM 1997, 34 (38 f.); Schricker/Loewenheim/Katzenberger, Vor $\S \S 120 \mathrm{ff}$. Rn. 145.

857 Zur „Bogsch-Theorie“ siehe statt vieler Bornkamm, in: FS GRUR, S. 1349 (1395 ff.); Schricker/Loewenheim/Katzenberger, Vor $\S \S 120$ ff. Rn. 141, jeweils mit zahlreichen weiteren Nachweisen. 
einen geeigneten Ausgangspunkt für die Feststellung des Handlungsortes bei der öffentlichen Zugänglichmachung urheberrechtlich geschützter Werke im Internet. Es sind demnach grundsätzlich nur diejenigen Rechtsordnungen zu beachten, in deren Geltungsbereich ein Abruf möglich ist. ${ }^{858}$ Man spricht insofern auch von einer kollisionsrechtlichen „Mosaikbetrachtung ". ${ }^{859}$ Anders als im Rahmen des Senderechts gemäß § 20 UrhG, bei dem der Sendende zumeist die Reichweite seiner Funksendung technisch bestimmen und beschränken kann, sind jedoch Inhalte, die im Internet verfügbar sind, grundsätzlich weltweit abrufbar. Um den Kreis der anzuwendenden Rechtsordnungen überschaubarer zu gestalten, erscheint es daher sinnvoll, den Maßstab im Hinblick auf die öffentliche Zugänglichmachung urheberrechtlich geschützter Inhalte im Sinne einer Weiterentwicklung der „Bogsch-Theorie“ weiter einzuschränken. Dabei bietet sich eine Betrachtung an, die danach fragt, ob es sich um eine bestimmungsgemäße Abrufbarkeit handelt, ob also die fragliche Dienstleistung, beziehungsweise die Website oder der konkrete Inhalt, auf den Abruf in einem bestimmten Land oder mehreren Ländern ausgerichtet ist. ${ }^{860} \mathrm{Ob}$ die konkrete Internetseite auf den Abruf im Schutzland ausgerichtet ist, muss anhand einer Gesamtschau der Umstände des Einzelfalls erfolgen. Als sinnvolle objektive Indizien für einen solchen Inlandsbezug können etwa die Sprache des Web-Angebotes, die verwendete Top-Level-Domain, die Sperrung des Angebotes für bestimmte (andere) Länder, auf der Website angebrachte Disclaimer, die konkret beworbenen Produkte oder Leistungen, auf der Website geschaltete Werbung und auch der Sitz des Anbieters herangezogen werden.

Eine solche Beschränkung ist interessengerecht, da sie den Schutz des Urhebers nicht unnötig beschränkt, den Urheber insbesondere nicht zum Opfer einer Abwanderung von Anbietern in „Urheberrechtsoasen“ werden lässt, und zugleich die Verwerter weder ungerechtfertigt privilegiert noch diese durch übermäßig weitreichende und letztlich unerfüllbare Prüfungs-

858 Vgl. Spindler, IPRax 2003, 412 (418 f.).

859 Vgl. MünchKomm-BGB/Drexl, 4. Aufl., IntImmGR, Rn. 165; Schack, MMR 2000, 59 (64).

860 Im Ergebnis ebenso oder ähnlich Dreier/Schulze, Vor $\S \S 120 \mathrm{ff}$. Rn. 42; Fromm/ Nordemann/Nordemann-Schiffel, Vor $\S 1120$ ff. Rn. 77 ff.; Härting, Internetrecht, Rn. 1868 f.; Junker, Anwendbares Recht und internationale Zuständigkeit, S. 215 ff.; Lucke, Google Buchsuche, S. 100; Schricker/Loewenheim/Katzenberger, Vor $\S \S 120$ ff. Rn. 145. 
pflichten benachteiligt. ${ }^{861}$ Ein Verwerter, der sich das Internet zu Nutze macht, um eine Vielzahl von Märkten und Nutzern zu bedienen, muss die mit einem solchen Vorhaben verbundenen Beschwernisse grundsätzlich hinnehmen. Durch die Beschränkung beziehungsweise den gezielten $\mathrm{Zu}-$ schnitt des Internetangebotes auf gewisse Märkte ist dem Verwerter zumindest eine gewisse Kontrolle der Rechtmäßigkeit seines Internetangebotes möglich.

Die Beschränkung auf eine bestimmungsgemäße Abrufbarkeit steht zudem im Einklang mit Lösungen, wie sie für andere Bereiche des Zivilrechts - etwa für das internationale Privatrecht des Wettbewerbs-, Kennzeichen- und Produkthaftungsrechts - entwickelt wurden. Im Recht des unlauteren Wettbewerbs wird bei „Multi-State-Wettbewerbshandlungen“ nur auf diejenigen Orte abgestellt, an denen die fragliche Handlung geeignet ist, spürbar auf den relevanten Markt einzuwirken. ${ }^{862}$ In Bezug auf Internetangebote bedeutet dies, dass eine relevante Verletzung überall dort anzunehmen ist, wo die wettbewerbswidrige Internetseite bestimmungsgemäß abgerufen werden kann. ${ }^{863}$ Im Kennzeichenrecht wird von der herrschenden Meinung zur Begrenzung einer ansonsten bestehenden Vielzahl von Gerichtsständen bei einer Kennzeichenverletzung im Internet entsprechend gefordert, dass ein wirtschaftlich relevanter Inlandsbezug besteht, sich der Internetauftritt also bestimmungsgemäß (auch) an Verkehrskreise im fraglichen Land richtet. ${ }^{864}$ Auch im internationalen Produkthaftungsrecht wird bei der Bewertung der Verhaltenspflichten des Herstellers auf die Rechtsordnungen abgestellt auf deren Märkte der Hersteller abzielt. ${ }^{865}$

861 Vgl. Junker, Anwendbares Recht und internationale Zuständigkeit, S. $216 \mathrm{f}$.

862 Vgl. BGHZ 167, 91 (98) - Arzneimittelwerbung im Internet; Dethloff, NJW 1998, 1596 (1599 f.); Mankowski, GRUR Int. 1999, 909 (915 ff.); Sack, WRP 2000, 269 (278), jeweils m.w.N. Ausführlich zur Behandlung von Multi-StateSachverhalten im Wettbewerbsrecht Höder, Kollisionsrechtliche Behandlung unteilbarer Multistate-Verstöße, insbes. S. $60 \mathrm{ff}$.

863 Vgl. BGHZ 167, 91 (98) - Arzneimittelwerbung im Internet; OLG Frankfurt, ZUM-RD 1999, 455; Köhler/Bornkamm, UWG, Einl. UWG Rn. 5.8, 5.39 ff.; Hoeren, MMR 2006, 464.

864 Vgl. nur BGH, GRUR 2005, 431 (432) - HOTEL MARITIME; Bettinger/Thum, GRUR Int. 1999, 659 (665 ff.); Fezer, MarkenG, Einl. H Rn. 39 ff.; Kur, WRP 2000, 935 (936 ff.), jeweils mit zahlreichen Nachweisen zu den vertretenen Auffassungen.

865 Vgl. Spindler/Leistner, GRUR Int. 2005, 773 (795) m.w.N. 
Die Überlegungen zur Bestimmung des anwendbaren Rechts bei der öffentlichen Zugänglichmachung eines Werkes im Internet lassen sich auch auf damit verbundene Verletzungen urheberpersönlichkeitsrechtlicher Interessen durch die Entstellung des Werkes oder die Unterlassung der Namensnennung übertragen. Der Täter - also der Verwertende - muss in der Lage sein, das anwendbare Recht vorherzusehen beziehungsweise - bei einer Mehrzahl anwendbarer Rechtsordnungen - diese zumindest einzugrenzen, um sein Verhalten daran ausrichten zu können. Denn eine unvorhersehbare oder zufällige Anknüpfung könnte für den Handelnden eine wesentliche Einbuße seiner Meinungs- und Handlungsfreiheit bedeuten. ${ }^{866}$ Daher kann es nicht auf den (zufälligen) Wohn- oder Aufenthaltsort des Verletzten ankommen. ${ }^{867}$ Zugleich darf das Opfer der Persönlichkeitsverletzung aber auch nicht schutzlos gestellt werden, etwa indem dem Täter ein Ausweichen in „Haftungsparadiese“ ermöglicht wird. 868 Bei (Urheber-)Persönlichkeitsrechtsverletzungen im Internet droht ein ineffektiver Schutz etwa, wenn man für die Feststellung des Handlungs- und Erfolgsortes an den Standort des Servers, auf dem die verletzende Information gespeichert ist, oder an den Ort der Einspeisung der Information anknüpfen wollte. Dann könnte der Betroffene nämlich Schutz nur auf dem Schutzniveau eines rein zufällig festgelegten Staates erlangen - was in vielen Fällen, insbesondere beim Ausweichen auf Rechtsoasen, dazu führen würde, dass der Betroffene schutzlos gestellt wäre. Sinnvoll erscheint daher eine Anknüpfung an jeden Ort, an dem die verletzende Handlung empfangen werden kann. ${ }^{869}$ Die persönlichkeitsrechtsverletzende Wirkung entfaltet sich schließlich nicht durch das Abspeichern der verletzenden Information als solcher, sondern durch deren öffentliche Zugänglichmachung, also die Verbreitung beziehungsweise Übermittlung an den Empfänger. ${ }^{870}$ Auch hier empfiehlt sich - ebenso wie im Rahmen des Rechts der öffentlichen Zugänglichmachung - eine Begrenzung der anwendbaren Rechtsordnung durch eine Beschränkung auf den bestimmungsgemäßen Empfang der ur-

866 Vgl. Schack, Int. Zivilverfahrensrecht, S. $84 \mathrm{f}$.

867 So aber für (traditionelle) grenzüberschreitende Rundfunksendungen Hohloch, ZUM 1986, 165 (178 f.).

868 Vgl. Schack, UFITA 108 (1988), 51 (63).

869 Vgl. Spindler, ZUM 1996, 533 (559 f.), allerdings ohne die hier - sogleich - vertretene Beschränkung auf einen bestimmungsgemäßen Empfang.

870 So in Bezug auf Verletzungen des Persönlichkeitsrechts durch traditionelle Massenmedien wie Printpublikationen und Funksendungen schon Schack, UFITA 108 (1988), 51 (64 f.). 
heberrechtsverletzenden Information vorzunehmen. ${ }^{871}$ Dabei können auch die zuvor genannten Indizien für die Bewertung der Ausrichtung des konkreten Internetangebotes herangezogen werden. Nur so ist für den Verwertenden (annähernd) bestimm- und vorhersehbar, an welchen Rechtsordnungen er sein Verhalten ausrichten muss. Dass dies unter Umständen eine erhebliche Anzahl von Rechtsordnungen sein kann, ist hinzunehmen, denn derjenige, der sich bewusst für die Vorteile einer globalen Verbreitung entscheidet, muss auch die damit verbundenen rechtlichen Konsequenzen tragen. Zugleich wird durch die hier vertretene Differenzierung dem Schutzbedürfnis des Betroffenen ausreichend Rechnung getragen, da er überall dort gegen die Verletzung vorgehen kann, wo eine solche auch tatsächlich erfolgt oder zumindest mit gewisser Wahrscheinlichkeit zu erwarten ist.

\section{Google Buchsuche}

Durch die Google Buchsuche kann es bei der derzeitigen Ausgestaltung durch das Scannen und Digitalisieren der Bücher zu einer Verletzung des Vervielfältigungsrechts nach $\S 16$ UrhG und durch die Ermöglichung der Volltextsuche und die Anzeige der Suchergebnisse in Form von Snippets zu Verletzungen des Rechts der öffentlichen Zugänglichmachung gemäß $\S 19$ a UrhG kommen.

Ansprüche wegen der Verletzung des Vervielfältigungsrechts durch die Google Buchsuche wären - wie gezeigt - nur dann nach $\S 16$ UrhG zu bewerten, wenn die Vervielfältigungshandlung in Deutschland stattfände. ${ }^{872}$ Daran fehlt es bei der derzeitigen Ausgestaltung der Buchsuche jedoch, da die Vervielfältigung sämtlicher urheberrechtlich geschützter Werke nicht in Deutschland stattfindet. Würden jedoch (in Zukunft) Kopien der in den USA oder im sonstigen Ausland digitalisierten urheberrechtlich geschütz-

871 So im Ergebnis auch Junker, Anwendbares Recht und internationale Zuständigkeit, S. 222 f. Vgl. auch Schack, UFITA 108 (1988), 51 (65 f.).

$872 \mathrm{Zu}$ einem anderen Ergebnis kam nach französischem Recht das Tribunal de Grande Instance de Paris in der Rechtssache Éditions du Seuil SAS et a. c/ Google Inc. et Google France, Urt. v. 18.12.2009, Az. 09/00540 [abgedruckt in ZUMRD 2010, 518]. Das Gericht wandte auch in Bezug auf das Vervielfältigungsrecht französisches Recht an, da Frankreich das Land sei, das die engsten Beziehungen zu dem Rechtsstreit aufweise. 
ten Werke auf in Deutschland belegenen Servern abgelegt, so wäre auf diese Vervielfältigungshandlungen deutsches Recht anwendbar.

Hinsichtlich der Verletzung des Rechts der öffentlichen Zugänglichmachung ist hingegen deutsches Recht, also §19a UrhG als Recht des Schutzlandes, maßgeblich. ${ }^{873}$ Der Buchsuche-Dienst, in dessen Rahmen die urheberrechtlich geschützten Werke öffentlich zugänglich gemacht werden, ist von Deutschland aus abrufbar. Der Dienst ist auch erkennbar auf die Nutzung aus Deutschland ausgerichtet. Im Rahmen der Google Buchsuche werden zum einen (auch) deutschsprachige Bücher angeboten, was nahe legt, dass deutsche Nutzer zur Zielgruppe des Dienstes gehören. Zum anderen - und dies kann ohne Zweifel als wesentliches Indiz für eine bestimmungsgemäße Abrufbarkeit dienen - ist das Buchsuche-Angebot in deutscher Sprache und unter der deutschen Top-Level-Domain ,.de“ verfügbar (books.google.de). Zudem ist das Buchsuche-Angebot inzwischen in Googles deutschen Suchmaschinendienst eingebunden, der ebenfalls unter einer deutschen Top-Level-Domain zu erreichen ist (www.google.de).

Auch hinsichtlich möglicher Verletzungen des Urheberpersönlichkeitsrechts durch die Google Buchsuche ist somit deutsches Recht anwendbar, da der Dienst eindeutig auf Deutschland beziehungsweise deutsche Nutzer ausgerichtet ist.

\section{Thumbnails}

Ansprüche wegen der Verletzung des Vervielfältigungs- und Bearbeitungsrechts durch die Erstellung verkleinerter Vorschaubilder der urheberrechtlich geschützten Werke sind nur dann nach $\S 16$ beziehungsweise $\S \S 16,23 \mathrm{~S} .1$ UrhG zu bewerten, wenn die Vervielfältigungshandlung in Deutschland stattfindet. Erfolgt die den Vorschaubildern zu Grunde liegende körperliche Festlegung hingegen - wie etwa von Google im „Vorschaubilder"-Verfahren behauptet und von der Klägerseite nicht bezweifelt ${ }^{874}$ - ausschließlich auf im Ausland belegenen Servercomputern, so scheidet die Anwendung deutschen Rechts aus. Bei anderen Bildersuchmaschinenbetreibern mag dies jedoch anders sein. Findet die Speicherung

873 Im Ergebnis ebenso Kubis, ZUM 2006, 370 (378); Lucke, Google Buchsuche, S. 101; Schricker/Loewenheim/Katzenberger, Vor $\S 120$ ff. Rn. 177.

874 Vgl. BGHZ 185, 291 (296) - Vorschaubilder. 
auf in Deutschland belegenen Speichermedien statt, so ist deutsches Recht anwendbar.

Jedenfalls hinsichtlich der Verletzung des Rechts der öffentlichen Zugänglichmachung ist jedoch deutsches Urheberrecht, also § 19a UrhG als Recht des Schutzlandes, anwendbar. Die Bildersuchdienste sind von Deutschland aus abrufbar und zudem erkennbar auf die Nutzung aus Deutschland ausgerichtet. Die Bildersuchdienste aller großen Suchmaschinen sind in deutscher Sprache verfügbar und unter einer deutschen TopLevel-Domain (,.de“) abrufbar (etwa www.bing.de/images oder images.google.de). Zudem wird das Bildersuch-Angebot zunehmend in die „herkömmlichen“ Suchmaschinendienste integriert, so dass den Nutzern sogenannte Universal Search-Ergebnisse präsentiert werden, das heißt Listen, die sowohl Ergebnisse der Websuche als auch etwa solche der Bilder-, Landkarten- und Produktsuche enthalten. ${ }^{875}$ Die „Hauptsuche“, die die Bildersuche beinhaltet oder zumindest auf diese verweist, ist in aller Regel ebenfalls unter einer deutschen Top-Level-Domain zu erreichen (etwa www.bing.de oder www.google.de).

Aus denselben Gründen sind auch mögliche Verletzungen des Urheberpersönlichkeitsrechts nach deutschem Recht zu beurteilen.

\section{Internationale Zuständigkeit}

Durch die Feststellung des anwendbaren materiellen Rechts ist allerdings noch nicht entschieden, ob auch ein deutsches Gericht für dessen Anwendung zuständig ist. Eine selbständige und im Rahmen ihres Anwendungsbereichs gegenüber den Regelungen der ZPO vorrangige Regelung der in-

875 Dem Marktführer Google wird vorgeworfen, durch die Verknüpfung seiner Dienste im Rahmen des Universal Search die eigene Marktmacht im Suchmaschinenbereich zu missbrauchen und so sein Monopol auf andere Bereiche auszudehnen, insbesondere etwa auf den Markt für Stadtpläne und Landkarten. Entsprechende Beschwerden von Wettbewerbern wurden beim Bundeskartellamt eingereicht; vgl. Wirtschaftswoche vom 21.8.2010, „Neue Vorwürfe gegen Google“, abrufbar unter: http://www.wiwo.de/unternehmen-maerkte/neue-vorwuerfe-gegen-Google-438976/ [zuletzt abgerufen am 26.5.2013]. Allgemein zu kartellrechtlichen Problemen im Zusammenhang mit der Marktmacht des Marktführers Google, siehe etwa Danckert/Mayer, MMR 2010, $219 \mathrm{ff}$.; Kühling/Gauß, MMR 2007, 751 ff.; Ott, MMR 2006, 195 ff.; ders., MMR-Aktuell 2010, 301459. 
ternationalen Zuständigkeit enthält die am 1. März $2002^{876}$ in Kraft getretene EuGVVO. $877 \mathrm{Zu}$ den Zivil- und Handelssachen im Sinne der EuGVVO zählen auch zivilrechtliche Streitigkeiten über das Urheberrecht und die verwandten Schutzrechte. ${ }^{878}$ Zeitlich ist die EuGVVO auf alle Klagen anwendbar, die nach ihrem Inkrafttreten erhoben werden. ${ }^{879}$ Räumlich findet die EuGVVO auf alle Klagen Anwendung, bei denen der Beklagte - ohne Rücksicht auf die Staatsangehörigkeit - seinen (Wohn-)Sitz in einem EU-Mitgliedstaat hat. ${ }^{880}$ Nicht erfasst sind daher reine Inlandssachverhalte oder Sachverhalte, bei denen der Beklagte keinen Sitz in der EU hat. Für alle diese nicht von der EuGVVO erfassten Sachverhalte bestimmt sich die internationale Zuständigkeit nach der ZPO. Bei Streitigkeiten wegen der Verletzung urheberrechtlicher Ausschließlichkeitsrechte kommt regelmäßig dem sogenannten Tatortgerichtsstand besondere Bedeutung zu. Nach $\S 32$ ZPO beziehungsweise Art. 5 Nr. 3 EuGVVO besteht für unerlaubte Handlungen ein besonderer Gerichtsstand am Tatort der Handlung. Dem Tatortgerichtsstand kommt dabei eine doppelte Funktion als Regelung der örtlichen und der internationalen Zuständigkeit zu. ${ }^{881}$ Für die Begründung der internationalen Zuständigkeit eines deutschen Gerichts ist es demnach erforderlich, dass eine Verletzungshandlung im Inland stattgefunden hat beziehungsweise schlüssig dargelegt wird. ${ }^{882}$ Begehungsort der deliktischen Handlung ist dabei sowohl der Handlungs- als auch der Erfolgsort, so dass eine Zuständigkeit wahlweise dort gegeben ist, wo die Verletzungshandlung begangen wurde, oder dort, wo in ein geschütztes Rechtsgut eingegriffen wurde, also der Schaden entstanden ist. ${ }^{883}$ Für den Fall der Verletzung von Persönlichkeitsrechten hat der EuGH (zum Art. 5 Nr. 3 EuGVVO entsprechenden

876 Für Dänemark in Kraft getreten am 1.7.2007.

877 Verordnung (EG) Nr. 44/2001 des Rates vom 22.12.2000 über die gerichtliche Zuständigkeit und die Anerkennung und Vollstreckung von Entscheidungen in Zivil- und Handelssachen, ABl. Nr. L 12 v. 16.1.2001, S. 1.

878 Vgl. Loewenheim/Walter, § 59 Rn. 167.

879 Siehe Art. 66 Abs. 1 EuGVVO.

880 Siehe Art. 2 Abs. 1, Art. 60 EuGVVO.

881 Vgl. BGH, GRUR 1978, 194 (195) - profil; BGHZ 184, 313 (316f.) - The New York Times; Prütting/Gehrlein/Wern, ZPO, § 32 Rn. 13, 16; Thomas/Putzo/Hüßtege, ZPO, § 32 Rn. 5 ff., jeweils m.w.N.

882 Vgl. BGHZ 184, 313 (317) - The New York Times m.w.N.

883 Vgl. BGHZ 132, 105 (110 ff.); Dreier/Schulze, Vor $§ 120$ ff. Rn. 61. 
Art. 5 Nr. 3 EuGVÜ) ${ }^{884}$ zunächst vertreten, der gesamte durch die Rechtsverletzung entstandene Schaden könne - neben dem allgemeinen Gerichtsstand - nur vor dem Gericht des Ortes des ursächlichen Geschehens geltend gemacht werden. ${ }^{885}$ Diese Rechtsprechung hat der EuGH in jüngerer Zeit speziell für Internetsachverhalte fortgeschrieben beziehungsweise geändert. Auf Vorlage des Bundesgerichtshofs ${ }^{886}$ und des Tribunal de Grande Instance de Paris ${ }^{87}$ hat die Große Kammer des EuGH entschieden, Art. 5 Nr. 3 EuGVVO sei dahingehend auszulegen, dass im Falle einer Verletzung des allgemeinen Persönlichkeitsrechts durch Veröffentlichungen im Internet das mutmaßliche Opfer nicht nur bei den Gerichten des Mitgliedstaates, in dem der Urheber der im Internet veröffentlichten Inhalte niedergelassen ist, sondern auch in dem Mitgliedstaat, in dem sich der Mittelpunkt der Interessen des Verletzten befindet, auf Ersatz des gesamten im EU-Gebiet entstandenen Schadens klagen könne. ${ }^{88}$ Dieser Ort entspreche im Allgemeinen dem gewöhnlichen Aufenthalt. ${ }^{889}$ Zur Begründung führt der EuGH aus, Internetveröffentlichungen könnten anders als Druckerzeugnisse, die gebietsabhängig verbreitet würden, von einer unbestimmten Zahl von Internetnutzern überall auf der Welt unmittelbar abgerufen werden. Die weltumspannende Verbreitung könne dabei zum einen die Schwere der Verletzungen von Persönlichkeitsrechten erhöhen. Zum anderen sei es nicht immer technisch möglich, diese Verbreitung sicher und zuverlässig für einen konkreten Mitgliedstaat zu quantifizieren und so den ausschließlich in diesem Mitgliedstaat verursachten Schaden zu beziffern. ${ }^{890}$ Schließlich könne das Gericht an dem Ort, an dem das mutmaßliche Opfer den Mittelpunkt seiner Interessen hat, die Auswirkungen einer

884 Übereinkommen über die gerichtliche Zuständigkeit und die Vollstreckung gerichtlicher Entscheidungen in Zivil- und Handelssachen vom 27.9.1968.

885 Vgl. EuGH, Urt. v. 7.3.1995, C-68/93, Slg. 1995, I-415, Rn. 24 = GRUR Int. 1998, 298 (299) - Fiona Shevill et al../. Presse Alliance SA; ebenso für das Patentrecht LG Düsseldorf, GRUR Int. 1999, 455 (457) - Schußfadengreifer.

886 Siehe BGH, GRUR 2010, 261 - www.rainbow.at.

887 Siehe ABl. EU 2010, C 148/21.

888 Siehe EuGH, Urt. v. 25.10.2011, C-509/09 und C-161/10, AB1. EU 2011, C 370/09, Rn. 48, 52 = GRUR 2012, 300 (302) - eDate Advertising GmbH./. X und Martinez./. MGN Ltd.

889 Siehe EuGH, a.a.O., Rn. 49 - eDate Advertising und Martinez. Zum Problem der Bestimmung des in der EuGVVO nicht definierten und im europäischen Prozessrecht nicht abschließend konkretisierten Begriffs des ,gewöhnlichen Aufenthaltsortes" siehe Hess, JZ 2012, 189 (191 f.); Spindler, AfP 2012, 114 (117).

890 Siehe EuGH, a.a.O., Rn. 45 f. - eDate Advertising und Martinez. 
Internetveröffentlichung auf dessen Persönlichkeitsrechte auch am besten beurteilen. ${ }^{891}$ Einschränkend hält der EuGH allerdings fest, der Betreiber einer Webseite, für die die E-Commerce-Richtlinie 2000/31/EG gelte, dürfe jedoch bei einer Klage in dem Staat, in dem der Geschädigte seinen Interessenmittelpunkt habe, keinen strengeren Anforderungen unterworfen werden als in seinem Sitzmitgliedstaat. ${ }^{892}$

Dem (mutmaßlich) Verletzten bietet sich somit nun bei Online-Sachverhalten eine weitreichende Wahlmöglichkeit: Er hat die Wahl zwischen einer Klage auf Ersatz aller Schäden am Beklagtensitz, auf nationale Teilschäden beschränkten Einzelklagen in jedem Mitgliedstaat, ,in dessen Hoheitsgebiet ein im Internet veröffentlichter Inhalt zugänglich ist oder war", und einer Klage auf Ersatz des gesamten Schadens an seinem eigenen Interessenmittelpunkt, also seinem gewöhnlichen Aufenthalt oder gegebenenfalls beruflichen Tätigkeitsort. ${ }^{893}$ Auch wenn der EuGH dies in seinem Urteil nicht ausdrücklich ausführt, gilt die Gerichtszuständigkeit am gewöhnlichen Aufenthaltsort konsequenterweise nicht nur für Schadensersatzklagen, sondern auch für Unterlassungsklagen wegen Persönlichkeitsrechtsverletzungen. ${ }^{894}$

Die Entscheidung wirft die Folgefrage auf, ob sich diese für Verletzungen des Persönlichkeitsrechts entwickelte Rechtsprechung auf das Immaterialgüterrecht, im hier interessierenden Zusammenhang also auf Verletzungen des Urheberpersönlichkeitsrechts und Verletzungen der urheberrechtlichen Ausschließlichkeitsrechte durch Internetdelikte, übertragen lässt. Das Urteil lässt insoweit unterschiedliche Interpretationen zu. Erblickt man das entscheidende Begründungselement der EuGH-Entscheidung in der Ubiquität der Internetinhalte, so ließe sich folgern, dass die vom EuGH entwickelten Zuständigkeitsregeln auch für alle anderen Internetdelikte - unabhängig vom konkret verletzten Recht - gelten müssten, da die weltweite Abrufbarkeit allen Verletzungshandlungen im Internet gemein ist. Es erscheint jedoch fraglich, ob eine so weitreichende Wende

891 Siehe EuGH, a.a.O., Rn. 48 - eDate Advertising und Martinez.

892 Siehe EuGH, a.a.O., Rn. 68 - eDate Advertising und Martinez.

893 Vgl. Heinze, EuZW 2011, 947 (949), der deshalb zu dem Schluss kommt, die Zuständigkeitsordnung komme nun für den Verletzten ,der besten aller Welten nahe".

894 Siehe Hess, JZ 2012, 189 (191) mit dem Hinweis, dass auch die Vorlage des BGH im Ausgangsverfahren eine Unterlassungsklage betraf; ebenso Spindler, AfP 2012, 114 (117). 
in der europäischen Zuständigkeitsordnung tatsächlich mit der Entscheidung bezweckt war. ${ }^{895}$ Im Kern ging es hier um den effektiven Schutz des Persönlichkeitsrechts, der gerade durch das Internet vor besondere Herausforderungen gestellt wird. So hat der EuGH maßgeblich mit der durch die Ubiquität der Internetinhalte drohenden besonderen Schwere der Persönlichkeitsrechtsverletzungen ${ }^{896}$ und den damit verbundenen Schwierigkeiten der konkreten Schadensbezifferung argumentiert. Diese Argumente lassen sich nicht deckungsgleich auf die Verletzung anderer Rechte im Internet, insbesondere auch nicht auf die Verletzung von Immaterialgüterrechten, übertragen. Zwar sind auch andere Rechtsverletzungen, wenn sie im Internet erfolgen, weltweit abrufbar. Sie wiegen jedoch in aller Regel nicht so schwer wie eine in diesem Medium erfolgte Persönlichkeitsverletzung, die - wenn sie einmal geschehen ist - kaum effektiv zu beschränken und dauerhaft zu beseitigen oder gutzumachen ist. Auch hinsichtlich der Bezifferung eines Schadens stellen Internetsachverhalte die Verletzten im Falle von Immaterialgüterrechtsverletzungen nicht vor vergleichbare Schwierigkeiten wie im Falle von Persönlichkeitsrechtsverletzungen. Gegen eine Ausdehnung des „fliegenden Gerichtsstands“ auf sonstige Sachverhalte spricht schließlich auch der Gleichlauf zwischen der EuGVVO und der Rom II-Verordnung, die bei Immaterialgüterrechtsdelikten vom klassischen Territorialitätsverständnis ausgeht, so dass hier nach wie vor das Schutzlandprinzip greift. ${ }^{897}$

Anders könnte sich die Situation jedoch hinsichtlich der Verletzung von Urheberpersönlichkeitsrechten darstellen. Auf diese Fälle lassen sich sowohl das Argument der Ubiquität der Internetinhalte als auch die weiteren Besonderheiten von Verletzungen des allgemeinen Persönlichkeitsrechts deutlich eher übertragen. Hier ähnelt die Interessenlage - jedenfalls bei schwerwiegenden Eingriffen in das Urheberpersönlichkeitsrecht, die geeignet sind, die Reputation des Urhebers erheblich zu beeinträchtigen der vom EuGH in der Entscheidung eDate Advertising und Martinez ${ }^{898}$ beurteilten Interessenlage bei der Verletzung des allgemeinen Persönlich-

895 So auch Heinze, EuZW 2011, 947 (950).

896 Hess, JZ 2012, 189 (191) weist insofern zu Recht darauf hin, dass der EuGH nicht etwa (neutral) vom „Verletzten“, sondern explizit vom „Opfer einer mittels des Internet begangenen Persönlichkeitsverletzung" spricht.

897 So auch Heinze, EuZW 2011, 947 (950); Spindler, AfP 2012, 114 (118).

898 EuGH, Urt. v. 25.10.2011, C-509/09 und C-161/10, AB1. EU 2011, C 370/09 = GRUR 2012, 300 - eDate Advertising GmbH./. X und Martinez./. MGN Ltd. 
keitsrechts. Es ist daher nicht auszuschließen, dass der EuGH - im Falle einer entsprechenden Vorlagefrage - mit einer der Entscheidung eDate Advertising und Martinez vergleichbaren Argumentation auch für solche Sachverhalte eine weitgehende Wahlfreiheit des (mutmaßlich) Verletzten hinsichtlich des Gerichtsstands statuieren würde.

Für das Vervielfältigungsrecht bedeutet dies, dass eine Verfolgung grundsätzlich am Ort der Herstellung des Vervielfältigungsstückes erfolgen muss. ${ }^{899}$ Hinsichtlich der Verletzung des Rechts der öffentlichen $\mathrm{Zu}-$ gänglichmachung nach § 19a UrhG und einer möglichen Verletzung von Urheberpersönlichkeitsrechten etwa durch die Entstellung eines Werkes lässt sich hingegen bei Internetsachverhalten aufgrund der weltweiten Verfügbarkeit der Werke die internationale Zuständigkeit nicht so klar bestimmen. Als zuständigkeitsbegründender Tatort im Sinne des $\S 32$ ZPO beziehungsweise Art. 5 Nr. 3 EuGVVO kommt diesbezüglich nämlich nicht nur der Ort in Betracht, an dem das Werk in das Internet eingestellt wurde, sondern grundsätzlich jeder Ort, an dem das Werk oder der Werkteil abgerufen werden kann. ${ }^{900}$ Im Falle der Online-Verfügbarkeit eines Werkes ließe sich somit letztlich eine Zuständigkeit an jedem Ort begründen, an dem ein Internetzugang besteht und somit ein Aufruf der Internetseite möglich ist. ${ }^{901}$ Einschränkend ist von den Gerichten - ähnlich wie bei der Bestimmung des anwendbaren Rechts - mehrfach darauf abgestellt worden, ob es sich im konkreten Fall um eine bestimmungsgemäße Abrufbarkeit handele, also eine tatsächliche Ausrichtung auf eine bestimmte Rechtsordnung bestehe. ${ }^{902} \mathrm{Um}$ einem übermäßig weiten Ausufern der $\mathrm{Zu}$ ständigkeiten Einhalt zu gebieten, erscheint dies als sinnvolle Einschränkung. Die internationale Zuständigkeit deutscher Gerichte wegen der Verletzung des Rechts der öffentlichen Zugänglichmachung ist somit jeden-

899 Vgl. Dreier/Schulze, § 105 Rn. 15; Fromm/Nordemann/J.B.Nordemann, § 105 Rn. 8; Schricker/Loewenheim/Wild, § 105 Rn. 9.

900 Vgl. Schricker/Loewenheim/Katzenberger, Vor $\S \S 120$ ff. Rn. 172.

901 Vgl. Dreier/Schulze, § 105 Rn. 9; Fromm/Nordemann/J.B.Nordemann, § 105 Rn. 10; Loewenheim/Walter, §58 Rn. 133; Schricker/Loewenheim/Wild, § 105 Rn. 9. Zu den mit diesem sog. „fliegenden Gerichtsstand“ verbundenen Problemen siehe statt vieler Schack, MMR 2000, 135.

902 So bezüglich der Abrufbarkeit von Thumbnails ausdrücklich BGHZ 185, 291 (295) - Vorschaubilder; LG Hamburg, GRUR-RR 2004, 313 (314); LG Hamburg, ZUM 2009, 315 (317f.). Allgemein hinsichtlich der bestimmungsgemäßen Abrufbarkeit bestimmter Internetseiten auch BGHZ 167, 91 (98 f.) - Arzneimittelwerbung im Internet; OLG Köln, GRUR-RR 2008, 71 - Internet-Fotos. 
falls dann zu bejahen, wenn eine ein Ausschließlichkeitsrecht verletzende Werknutzung in Deutschland möglich ist und eine Einzelfallbetrachtung einen zusätzlichen Bezug zu Deutschland ergibt, so dass eine bestimmungsgemäße Abrufbarkeit vorliegt.

\section{Google Buchsuche}

Da die Digitalisierung der Bücher für die Google Buchsuche - mit Ausnahme der von der Bayerischen Staatsbibliothek zur Verfügung gestellten gemeinfreien Werke - nach Angaben von Google nicht in Deutschland, sondern in den USA und in einigen weiteren Ländern erfolgt, scheidet für die Geltendmachung von Ansprüchen wegen der Verletzung des Vervielfältigungsrechts des $\S 16 \mathrm{UrhG}$ eine internationale Zuständigkeit deutscher Gerichte nach § 32 ZPO aus. ${ }^{903}$ Würden hingegen - etwa zum Zwecke der schnelleren Abrufbarkeit - Vervielfältigungsstücke der beim Scannen und Digitalisieren erstellten Bild- und Textdateien auf in Deutschland belegenen Server abgespeichert, so wäre die internationale Zuständigkeit deutscher Gerichte wegen Verletzung des Vervielfältigungsrechts gegeben. ${ }^{904}$

Hinsichtlich der Verletzung des Rechts der öffentlichen Zugänglichmachung lässt sich hingegen die internationale Zuständigkeit deutscher Gerichte begründen. Die digitalisierten Buchinhalte beziehungsweise Auszüge aus den Büchern in Form von Snippets werden jedem Nutzer auf seine Anfrage angezeigt. Ein Abruf ist somit grundsätzlich von jedem beliebi-

903 Im Ergebnis ebenso Kubis, ZUM 2006, 370 (377); Schricker/Loewenheim/Katzenberger, Vor $\S \S 120 \mathrm{ff}$. Rn. 177. Denkbar wäre zudem grundsätzlich auch eine Anknüpfung an den allgemeinen Gerichtsstand von Googles deutscher Tochtergesellschaft, der Google Germany GmbH. Nach §§12, 17 Abs. 1 ZPO wäre dies Hamburg als Sitz der Gesellschaft. Dies erscheint allerdings im Ergebnis nicht vielversprechend, da ein solches Vorgehen voraussetzen würde, dass es sich bei der Verletzung um eine solche der beklagten Gesellschaft selbst handelt bzw. die Verletzung der Muttergesellschaft dieser zugerechnet werden müsste; vgl. Prütting/Gehrlein/Wern, ZPO, § 17 Rn. 12. Dies erscheint bzgl. der Verletzung des Vervielfältigungsrechts durch das Scannen und Digitalisieren der Werke in den USA durch Google, Inc. eher unwahrscheinlich.

904 Bekannt ist, dass Google aus Gründen der Sicherheit, Stabilität und Abrufgeschwindigkeit seiner Dienstleistungen weltweit Rechenzentren betreibt. Die genauen Standorte der Rechenzentren sind jedoch streng geheim, so dass der Nachweis einer solchen auf einem deutschen Server hinterlegten Kopie eines urheberrechtlich geschützten Werkes wohl kaum zu erbringen ist. 
gen Ort (in Deutschland) möglich, an dem ein Internetanschluss zur Verfügung steht. Es ist auch nicht daran zu zweifeln, dass es sich dabei um eine bestimmungsgemäße Abrufbarkeit handelt, wie sie teilweise einschränkend gefordert wird. Der Buchsuche-Dienst umfasst (auch) deutsche Bücher, wird in deutscher Sprache angeboten und ist nicht zuletzt unter einer deutschen Top-Level-Domain (,.de“) zu erreichen. Da die Dienstleistung erkennbar (auch) auf Nutzer in Deutschland ausgerichtet ist, können deutsche Gerichte somit bei Streitigkeiten über die Verletzung des Rechts der öffentlichen Zugänglichmachung durch die Google Buchsuche - ebenso wie bei Streitigkeiten wegen der Verletzung von Urheberpersönlichkeitsrechten, die insofern gleich zu behandeln sind - international zuständig sein. ${ }^{905}$

\section{Thumbnails}

Erfolgt die Erstellung und Speicherung der verkleinerten Vorschaubilder für den späteren Abruf nicht in Deutschland, sondern - wie etwa im Falle von Google - in den USA oder anderen Ländern, so scheidet für die Geltendmachung von Ansprüchen wegen der Verletzung des Vervielfältigungs- und Bearbeitungsrechts gemäß $\S \S 16,23$ S. 1 UrhG eine internationale Zuständigkeit deutscher Gerichte nach $\S 32$ ZPO aus. Werden die Thumbnails hingegen auf in Deutschland belegenen Server abgespeichert, etwa um deren schnelle und sichere Abrufbarkeit zu gewährleisten, so ist die internationale Zuständigkeit deutscher Gerichte wegen Verletzung des Vervielfältigungs- und Bearbeitungsrechts begründet.

Ebenso wie bei der Google Buchsuche lässt sich jedoch jedenfalls hinsichtlich der Verletzung des Rechts der öffentlichen Zugänglichmachung und möglicher Verletzungen des Urheberpersönlichkeitsrechts durch die Nutzung urheberrechtlich geschützter Werke in Thumbnail-Form die internationale Zuständigkeit deutscher Gerichte begründen. Die Werke werden jedem Nutzer auf seine Anfrage hin in Form kleiner Vorschaubilder angezeigt. Ein Abruf ist somit grundsätzlich von jedem beliebigen Ort (in Deutschland) möglich, an dem ein Internetanschluss zur Verfügung steht. Aufgrund der gezielten Ausrichtung der Dienstleistung „Bildersuche“ auf

$905 \mathrm{Im}$ Ergebnis ebenso Schricker/Loewenheim/Katzenberger, Vor $\S \S 120 \mathrm{ff}$. Rn. 177. 
deutsche Nutzer ist auch nicht daran zu zweifeln, dass es sich dabei um eine bestimmungsgemäße Abrufbarkeit handelt, wie sie teilweise einschränkend gefordert wird.

\section{E. Zusammenfassung für das deutsche Recht}

Die Untersuchung der urheberrechtlichen Probleme der Werknutzung im Rahmen der Google Buchsuche und in Form von Thumbnails bei der Bildersuche hat exemplarisch gezeigt, dass das deutsche Urheberrecht regelmäßig an seine Grenzen stößt, wenn es mit neuen Geschäftsmodellen und auf diesen basierenden innovativen Nutzungsformen urheberrechtlich geschützter Werke konfrontiert ist. Eingriffe in die ausschließlichen Verwertungsrechte des Urhebers lassen sich im Rahmen des starren Schrankenkataloges entweder gar nicht oder nur mit erheblichem und teilweise dogmatisch äußerst zweifelhaftem Begründungsaufwand rechtfertigen. Neben den Problemen bei der Rechtfertigung von Eingriffen in die ausschließlichen Verwertungsrechte und der mit diesen Problemen einhergehenden nicht unerheblichen Rechtsunsicherheit, stellen jedoch gerade auch die urheberpersönlichkeitsrechtlichen Interessen, deren Schutz in Deutschland und Kontinentaleuropa besonders ausgeprägt ist, eine wesentliche Hürde für diese Geschäftsmodelle dar, da eine Rechtfertigung von Eingriffen in diese anhand von Schrankenbestimmungen grundsätzlich ausscheidet und unter strengen Voraussetzungen allenfalls eine Einwilligung in Betracht kommt. Flexiblere Schrankenregelungen, die idealerweise auch in persönlichkeitsrechtlicher Hinsicht für mehr Klarheit sorgen, können hier Abhilfe schaffen. 


\section{Kapitel: Länderbericht USA: Urheberrechtliche Probleme der Google Buchsuche und der Bildersuche im Internet nach US-amerikanischem Copyright}

Die zuvor dargestellten neuen Nutzungsformen urheberrechtlich geschützter Werke stellen auch für das US-amerikanische Urheberrecht eine Herausforderung dar. Während ein Eingriff in zumindest eines der exclusive rights der Rechteinhaber zumeist recht eindeutig vorliegt (dazu sogleich A.), ist die Rechtfertigung dieser Eingriffe unter Anwendung der flexiblen Fair Use-Schranke teilweise mit einigen Unwägbarkeiten und einigem Begründungsaufwand verbunden (unten B.). Die Brisanz dieses Themas zeigt sich nicht zuletzt darin, dass sowohl die Verwendung von Thumbnails im Rahmen der Bildersuche als auch die Google Buchsuche bereits zu mehreren gerichtlichen Verfahren mit zum Teil divergierenden Entscheidungen und zudem $\mathrm{zu}$ einer wissenschaftlichen Auseinandersetzung in einer Vielzahl von Beiträgen geführt haben. Für besondere „Furore" hat dabei der Rechtsstreit um die Google Buchsuche und insbesondere das Tauziehen um das Google Book Settlement gesorgt. Diesem und seinen möglichen Folgen widmet sich die Untersuchung deshalb im Rahmen eines Exkurses (B.II.2.).

\section{A. Betroffene Verwertungsrechte der Urheberrechtsinhaber}

Der Copyright Act of 1976 benennt in 17 U.S.C. § 106 die dem Urheberrechtsinhaber zustehenden Ausschließlichkeitsrechte. Danach hat der Rechtsinhaber das ausschließliche right to reproduce ${ }^{906}$ (Vervielfältigungsrecht), right to prepare derivative works ${ }^{907}$ (Bearbeitungsrecht), right to distribute ${ }^{908}$ (Verbreitungsrecht), right to display publicly ${ }^{909}$ (Recht zur öffentlichen Darbietung/Vorführung) sowie das right to per-

90617 U.S.C. $\S 106(1)$.

907 17 U.S.C. $\$ 106(2)$.

90817 U.S.C. $\$ 106(3)$.

90917 U.S.C. $§ 106(5)$. 
form publicly ${ }^{910}$ (Recht der öffentlichen Aufführung/Wiedergabe). Durch die zuvor dargestellte Verwendung urheberrechtlich geschützter Werke im Rahmen der Buch- und Bildersuche können insbesondere das reproduction right, das distribution right und das right to display publicly betroffen sein. 911

\section{Reproduction right}

Nach 17 U.S.C § 106 (1) hat der Urheberrechtsinhaber das ausschließliche Recht, , [...] to reproduce the copyrighted work in copies or phonorecords". Nach der Definition des 17 U.S.C. § 101 sind copies körperliche Gegenstände, in beziehungsweise auf denen das Werk mit einer bereits bekannten oder auch jeder in Zukunft entwickelten Methode fixiert wird und von denen das Werk unmittelbar oder mit Hilfe von Maschinen oder anderen Einrichtungen wahrnehmbar gemacht, kopiert oder anderweitig kommuniziert werden kann. ${ }^{912}$ Neben der Reproduktion in Form von exakten Kopien umfasst dieses Recht des Urheberrechtsinhabers auch das Recht, die Herstellung solcher Kopien zu untersagen, die qualitativ und quantitativ ,substantially similar" sind, also im Wesentlichen mit dem Originalwerk übereinstimmen. ${ }^{913}$ Eine Urheberrechtsverletzung liegt immer dann

91017 U.S.C. $\$ 106$ (4) und (6).

911 Eine Verletzung des right to prepare derivative works ist ebenfalls unter bestimmten Umständen denkbar. Dies soll an dieser Stelle jedoch nicht vertieft werden, da sich auch die Klageverfahren in den USA und die dortige Diskussion um die Rechtmäßigkeit der Buchsuche auf eine Verletzung der hier ausführlicher dargestellten Ausschließlichkeitsrechte konzentrieren und der Schwerpunkt der Darstellung ohnehin bei der Frage des Fair Use liegen soll.

912 Obgleich der Gesetzestext den Plural „copies” verwendet, besteht weitestgehend Einigkeit darüber, dass auch der Singular erfasst ist, so dass das reproduction right auch durch die Herstellung nur eines einzelnen Vervielfältigungsstückes verletzt sein kann; vgl. Sony Corp. of Am. v. Universal City Studios, Inc., 464 U.S. 417, 465 (1984); Nimmer/Nimmer, On Copyright, § 8.02 [D].

913 Vgl. Nichols v. Universal Pictures Corp., 45 F.2d 119 (2d Cir. 1930), cert. denied, 282 U.S. 902 (1931); Arnstein v. Porter, 154 F.2d 464 (2d Cir. 1946), cert. denied, 330 U.S. 851 (1947); Sid \& Marty Krofft Television Productions, Inc. v. McDonald's Corp., 562 F.2d 1157 (9 ${ }^{\text {th }}$ Cir. 1977); Castle Rock Entertainment, Inc. v. Carol Publishing Group, Inc., 150 F.3d 132, 138 (2d Cir. 1998). Ausführlich zu den Schwierigkeiten der genauen Bestimmung der substantial similarity siehe auch Clarida, Copyright, S. 276 ff.; Merges/Menell/Lemley, Intel- 
vor, wenn der Rechtsinhaber seine Urheberrechtsinhaberschaft belegen kann, er nachweisen kann, dass ,original elements“ seines Werkes kopiert wurden und ihm auch keine defense, also kein Ausnahmetatbestand, zugute kommt. ${ }^{914}$

\section{Thumbnails}

Durch das Erstellen und Speichern von Thumbnails für die spätere Verwendung im Rahmen der Bildersuche ist das right to reproduce des Urheberrechtsinhabers betroffen. ${ }^{915}$ Sobald Google die verkleinerten Bilddateien auf seinen Servern speichert sind sie auf einem körperlichen Gegenstand fixiert, von dem aus sie wahrgenommen und erneut vervielfältigt werden können, so dass eine copy im Sinne des 17 U.S.C § 101, § 106 (1) vorliegt. ${ }^{916}$ Dass die als Thumbnail abgespeicherten Kopien eine gegenüber dem Original (zumeist) stark verminderte Qualität aufweisen, führt zu keiner anderen Bewertung. Um dem Nutzer einen möglichst guten Eindruck vom Originalwerk zu vermitteln und so eine effektive Bildersuche zu ermöglichen, bemüht Google sich gerade um eine möglichst originalge-

lectual Property, S. 475 ff.; Nimmer/Nimmer, On Copyright, § 13.03 [A]; Schechter/Thomas, Intellectual Property, S. 177 ff.; Costantino, 17 Fordham Intell. Prop. Media \& Ent. L.J. 235, 248 f. (2006).

914 Vgl. Feist Publications, Inc. v. Rural Telephone Service Co., Inc., 499 U.S. 340, 361 (1991).

915 So auch Kelly v. Arriba Soft Corp., 336 F.3d 811, 817 (9th Cir. 2003) (Arriba Soft erkannte allerdings im Laufe des Verfahrens das Vorliegen eines Eingriffs in das reproduction right an, so dass diesem Teil der Entscheidung keine Präjudizwirkung für zukünftige Entscheidungen zukommt.); Perfect 10 v. Google, Inc., 416 F.Supp.2d 828, 851 (C.D. Cal. 2006) (Im Rahmen der Verhandlung der Klage von Perfect 10 gegen Google vor dem Court of Appeals war eine Verletzung des reproduction right hingegen nicht (mehr) Verfahrensgegenstand; Perfect 10 stützte seine Klage ausschließlich auf eine Verletzung des display right und des distribution right durch die Verwendung von Bildern in Form von Thumbnails, vgl. Perfect 10, Inc. v. Amazon.com, Inc., et al., 508 F.3d 1146, 1159 (9th Cir. 2007)). Vgl. auch Ayazi, 7 N. C. J. L. \& Tech. 367, 375 (2006); Ding, 23 Berkeley Tech. L.J. 373, 394 f. (2008); Goryunov, 41 J. Marshall L. Rev. 487, 498 ff. (2008); K. Olson, 14 Comm. L. \& Pol'y 153, 161 ff. (2009); Stokes, Digital Copyright, S. 139 ff.; ders., EIPR 2000, 22(12), 599, 600.

916 Vgl. Perfect 10, Inc. v. Amazon.com, Inc., et al., 508 F.3d 1146, 1160 (9th Cir. 2007); McFarlane, 38 Golden Gate U. L. Rev. 381, 385 f. (2008). Vgl. auch Klett, Urheberrecht im Internet, S. 101. 
treue Abbildung. Es werden daher gerade die "original elements" des Werkes kopiert, so dass jedenfalls eine ,substantially similar copy“ erstellt wird.

\section{Google Book Search}

Eine Urheberrechtsverletzung durch Google kommt auf drei Stufen der Verwendung der Werke im Rahmen der Buchsuche in Betracht - durch die Digitalisierung der Bücher und Speicherung in einer Datenbank, das Anzeigen von Snippets auf die Anfragen der Nutzer hin und durch die Übergabe einer digitalen Fassung an die Bibliothek, aus deren Bestand das jeweilige Werk gescannt wurde.

Das reproduction right kann dabei insbesondere durch das Einscannen und Speichern der urheberrechtlich geschützten Werke für die Google Buchsuche verletzt sein. Das Einscannen von Büchern, deren Urheberrechtsschutz noch nicht abgelaufen ist, erfolgt in den USA, so dass USamerikanisches Recht auf mögliche Rechtsverletzungen im Zusammenhang mit diesem Vorgang anwendbar ist. ${ }^{917}$

Google scannt die gesamten Bücher und speichert deren Inhalt in Form von Bilddateien in seiner Datenbank. Dass es sich dabei um eine digitale Kopie eines analogen Mediums handelt, ist nach 17 U.S.C. § 101 für die Einordnung als copy unerheblich. Eine Reproduktion stellt auch dann eine copy im Sinne dieser Norm dar, wenn sie in einem anderen Medium erstellt wird als das Original, solange sie fixiert und wahrnehmbar ist. ${ }^{918}$ Durch das Scannen der Buchinhalte werden die durch das Copyright geschützten „original elements“ eines jeden Werkes kopiert und in der Datenbank verkörpert. Es handelt sich dabei auch nicht nur um Kopien geringfügiger Teile der Werke, da Google zum Zwecke der späteren Volltextsuche stets das gesamte Werk digitalisiert. Andernfalls hätte Google möglicherweise zu seinen Gunsten geltend machen können, dass es sich

917 Ausführlich zur Frage des anwendbaren Rechts siehe Adolphsen/Mutz, GRUR Int. 2009, 789 (790 f.).

918 Vgl. oben 5. Kapitel, A.I.1. sowie Kelly v. Arriba Soft Corp., 336 F.3d 811, 819 (9th Cir. 2003); Costantino, 17 Fordham Intell. Prop. Media \& Ent. L.J. 235, 265 (2006); Hanratty, 2005 Duke L. \& Tech. Rev. 10, Rn. 4. 
lediglich um de minimis-Eingriffe handele. ${ }^{919}$ Solche werden jedoch von der US-amerikanischen Rechtsprechung nach dem sogenannten Ordinary Observer Test grundsätzlich nur dann angenommen, wenn lediglich kleine, unbedeutende Teile eines Werkes kopiert werden, so dass der durchschnittliche Leser beziehungsweise Betrachter die Verwendung nicht erkennt. ${ }^{920}$ Sinn und Zweck der Digitalisierung durch Google ist es aber gerade, später das Auffinden der gescannten Werke zu ermöglichen. Aus diesem Grund wird jedes Werk vollständig digitalisiert, so dass die Annahme von de minimis-Kopien ausscheiden muss und ein Eingriff in das reproduction right durch das Einscannen und Speichern der Werke vorliegt. ${ }^{921}$ Zudem greift auch das Fixieren einer digitalen Kopie eines jeden gescannten Werkes auf einem Speichermedium zur Weitergabe an die Bibliothek aus deren Bestand es gescannt wurde, in das reproduction right ein. ${ }^{922}$

919 Ausführlich zur Anwendung der Maxime de minimis non curat lex im US-amerikanischen Copyright siehe Inesi, 21 Berkeley Tech. L.J. 945 (2006) und Nimmer/ Nimmer, On Copyright, $\S 8.01$ [G].

920 Vgl. Newton v. Diamond, 388 F.3d 1189, 1193 (9th Cir. 2003) [,A taking is considered de minimis only if it is so meager and fragmentary that the average audience would not recognize the appropriation"]; Nihon Keizai Shimbum, Inc. v. Comline Bus. Data, Inc., 166 F.3d 65, 70 (2d Cir. 1999); Warner Bros. Inc. v. American Broadcasting Companies, Inc., 720 F.2d 231, 242 (2d Cir. 1983) [,... allowing the copying of a small and usually insignificant portion of the (...) work."']. Siehe auch Clarida, Copyright, S. 276 ff.; Hanratty, 2005 Duke L. \& Tech. Rev. 10, Rn. 6 f.; Merges/Menell/Lemley, Intellectual Property, S. 488 ff.; Nimmer/Nimmer, On Copyright, § 8.01 [G].

921 So im Ergebnis auch Adler, Google Library Project, S. 7; Band, 3 J. Bus. \& Tech. L. 1, 19 (2008); ders., Google Library Project, S. 10; Bisk, 17 Alb. L.J. Sci. \& Tech. 271, 287 (2007); Costantino, 17 Fordham Intell. Prop. Media \& Ent. L.J. 235, 264 (2006); Ganley, 10 No. 5 J. Internet L. 1, 10 (2006); Grimmelmann, Google Book Search Settlement, S. 3; Hanratty, 2005 Duke L. \& Tech. Rev. 10, Rn. 7; Hetcher, 13 Mich. Telecomm. \& Tech. L. Rev. 1, 22 (2006); Kohler, 2007 Duke L. \& Tech. Rev. 5, Rn. 17; Okano, 3 Shidler J. L. Com. \& Tech. 13 (2007), Rn. 19; Proskine, 21 Berkeley Tech. L.J. 213, 223 (2006); Rogers, 10 Tul. J. Tech. \& Intell. Prop. 1, 8 (2007); Romman, 43 Hous. L. Rev. 807, 839 f. (2006); Sag, 55 N.Y.L. Sch. L. Rev. 19, 25 (2010); Vaidhyanathan, 40 U.C. Davis L. Rev. 1207, 1217 f. (2007). Auf die Verletzung des reproduction right durch das Einscannen und Speichern der Werke stützt sich auch die Class Action-Klage der Authors Guild und weiterer Autoren, vgl. The Authors Guild, et al. v. Google Inc., No. 05 CV 8136, 2005 WL 2463899 (S.D.N.Y. Sept. 20, 2005).

922 Vgl. Tushnet, 53 UCLA L. Rev. 977, 1020 (2006). 
Eine Rechtsverletzung scheidet jedoch aus, wenn Google im Rahmen eines Ausnahmetatbestandes handelt. Neben dem möglichen Fair UseEinwand ${ }^{923}$ käme eine Rechtfertigung nach 17 U.S.C. $§ 108$ in Betracht, wonach Bibliotheken und Archive unter bestimmten Voraussetzungen Kopien urheberrechtlich geschützter Werke anfertigen dürfen. Diese sogenannte Library Exemption kommt Google jedoch letztlich jedenfalls deshalb nicht zugute, weil die Kopien zu kommerziellen Zwecken angefertigt werden. ${ }^{924}$

\section{Distribution right}

Die Regelung des 17 U.S.C. § 106 (3) gewährt dem Urheberrechtsinhaber das ausschließliche Recht, die (Erst-)Verbreitung jeder Verkörperung eines Werkes durch Verkauf oder anderweitige Eigentumsübertragung, durch Vermietung, Verleih oder Pacht zu kontrollieren. Erfasst sind jedoch nur solche Verbreitungshandlungen, die das Werk der Öffentlichkeit

923 Zur Frage der Einordnung als Fair Use sogleich unten 5. Kapitel, B.II.1.

924 Vgl. 17 U.S.C. § 108 (a) (1). Ausführlich zur Einschlägigkeit der Library Exemption im Zusammenhang mit der Google Buchsuche Hanratty, 2005 Duke L. \& Tech. Rev. 10, Rn. 8 ff. Vgl. auch Adolphsen/Mutz, GRUR Int. 2009, 789 (793); Bisk, 17 Alb. L.J. Sci. \& Tech. 271, 287 f. (2007); Ganley, 10 No. 5 J. Internet L. 1, 10 (2006); Givler, 14 No. 2 NYSBA Bright Ideas 23, 25 (2005); Na, 16 Cornell J. L. \& Pub. Pol'y 417, 433 f. (2007); Okano, 3 Shidler J. L. Com. \& Tech. 13 (2007), Rn. 17; Shah, 15 CommLaw Conspectus 569, 582 (2007); Wilhelm, 33 Rutgers Computer \& Tech. L.J. 107, 114 f. (2006). Zudem werden in der Praxis auch die übrigen Voraussetzungen der Library Exemption sehr eng ausgelegt, so dass selbst im Falle einer Verneinung des kommerziellen Charakters der Google Buchsuche (etwa aufgrund einer entsprechenden Umgestaltung der Website) der Ausnahmetatbestand aus anderen Gründen - insbesondere wegen des systematischen Kopierens zum Aufbau einer umfassenden digitalen Datenbank, in der Werke aus mehreren ,physischen“ Bibliotheken gesammelt sind, und wegen des Erstellens einer Mehrzahl digitaler Kopien - ebenfalls nicht zur Anwendung käme, vgl. Hanratty, a.a.O., Rn. 9 ff.; Knutson, 24 Berkeley Tech. L.J. 437, 452 ff. (2009); Merges/Menell/Lemley, Intellectual Property, S. 499; Schechter/Thomas, Intellectual Property, S. 116 ff.; Tushnet, 53 UCLA L. Rev.977, 1007 (2006); Wilhelm, 33 Rutgers Computer \& Tech. L.J. 107, 115 (2006). 
zugänglich machen. ${ }^{925}$ Nach der sog. first sale doctrine kann der Urheberrechtsinhaber allerdings die Weiterverbreitung beziehungsweise den Weiterverkauf eines einmal mit seiner Zustimmung in den öffentlichen Verkehr gelangten Werkexemplars nicht mehr kontrollieren, so dass diesbezüglich Verletzungen des distribution right grundsätzlich ausgeschlossen sind. ${ }^{926}$ Das distribution right bezieht sich auf jegliche Werkstücke; es sind also neben solchen Exemplaren, die legal hergestellt und verbreitet wurden, auch illegal hergestellte Werkexemplare erfasst. ${ }^{927}$ Im Falle der Verbreitung eines nicht autorisierten Werkexemplars tritt daher neben die Verletzung des reproduction right stets eine Verletzung des distribution right. ${ }^{928}$

\section{Thumbnails}

Bei den auf Googles eigenen Servern gespeicherten Thumbnails handelt es sich - wie zuvor gezeigt - um illegal, unter Verletzung des reproduction right hergestellte Vervielfältigungsstücke der Originalwerke. Diese werden den Nutzern auf ihre Suchanfrage hin in Form der Anzeige auf dem jeweiligen Bildschirm zugänglich gemacht. Aufgrund der unüberschauund unkontrollierbaren Zahl von Nutzern, ist auch an der Öffentlichkeit der distribution nicht zu zweifeln. Das Anzeigen der Thumbnails im Rah-

925 Grundlegend zur Frage, wann eine Verbreitung an die „Öffentlichkeit“ vorliegt, vgl. Encyclopaedia Britannica Educ. Corp. v. Crooks, 558 F. Supp. 1247 (W.D.N.Y. 1983); Obolensky v. G.P. Putnam's Sons, 628 F. Supp. 1552 (S.D.N.Y. 1986); vgl. auch Nimmer/Nimmer, On Copyright, § 8.11 [A].

926 Der Gedanke der heute in 17 U.S.C. $\$ 109$ (a) kodifizierten first sale doctrine wurde vom U.S. Supreme Court erstmals in der Entscheidung Bobbs-Merrill Co. v. Straus, 210 U.S. 339 (1908) erörtert. Ausführlich zu 17 U.S.C. § 109 (a) siehe Nimmer/Nimmer, On Copyright, §8.12 und Schechter/Thomas, Intellectual Property, S. $126 \mathrm{ff}$.

927 Vgl. Nimmer/Nimmer, On Copyright, § 8.11 [A].

928 Vgl. Hotaling v. Church of Jesus Christ of Latter-Day Saints, 118 F.3d 199, 203 (4th Cir. 1997); Merges/Menell/Lemley, Intellectual Property, S. 510 f.; Nimmer/ Nimmer, On Copyright, $\S 8.12$ [A], [B](4). Dem Urheberrechtsinhaber stehen daher im Falle der Verbreitung nicht autorisierter Werkexemplare aufgrund der Verletzung beider Ausschließlichkeitsrechte zwei unabhängige Ansprüche zu, die sich sowohl gegen dieselbe Person (Herstellung und Verbreitung des Werkstückes durch eine Person) als auch gegen unterschiedliche Personen richten können. 
men der Bildersuche stellt daher eine Beeinträchtigung des distribution right dar. ${ }^{929}$

\section{Google Book Search}

Das distribution right könnte auch durch die Verwendung der urheberrechtlich geschützten Werke durch Google im Rahmen der Buchsuche betroffen sein. Sowohl die Anzeige von Snippets als Suchergebnisse als auch die Weitergabe von digitalen Kopien der gescannten Werke an die Ursprungsbibliothek kann eine public distribution im Sinne des 17 U.S.C. $\S 106$ (3) darstellen. In beiden Fällen werden - wie zuvor gezeigt - ohne Autorisation durch den Urheberrechtsinhaber Werkstücke hergestellt.

Bei der Anzeige der Snippets könnte man bereits daran zweifeln, ob diese einen für eine public distribution ausreichenden Umfang haben oder aber eine Verletzung des Ausschließlichkeitsrechtes aufgrund der Kürze der dargestellten Ausschnitte ausscheidet. Anders als im Rahmen des reproduction right ist eine ,eigenständige“ de minimis-Ausnahme bezüglich des distribution right jedoch nicht anerkannt, so dass auch die ungenehmigte Verbreitung von kleinen Werkteilen das ausschließliche Recht des Urheberrechtsinhabers beeinträchtigt. Der geringe Umfang der dargestellten Werkstücke kann jedoch Berücksichtigung im Rahmen der Fair UsePrüfung finden. ${ }^{930}$ Daran, dass eine Verbreitung an die Öffentlichkeit vorliegt, ist aufgrund der unüberschaubaren und unkontrollierbaren Zahl von Nutzern nicht zu zweifeln. Das Anzeigen der Snippets beeinträchtigt somit das distribution right.

Durch die Übergabe einer digitalen Kopie eines jeden gescannten Werkes an die Ursprungsbibliothek wird ebenfalls ohne Zustimmung des Urheberrechtsinhabers ein Werkexemplar verbreitet. Fraglich ist allerdings, ob auch ein Zugänglichmachen an die Öffentlichkeit im Sinne des 17 U.S.C. § 106 (3) vorliegt. Dies hängt letztendlich von der Art der Nutzung durch die jeweilige Bibliothek ab. Werden die digitalen Kopien lediglich zu Zwecken der Archivierung des Bibliotheksbestandes in digitaler Form verwendet, scheidet eine public distribution wohl aus. Werden die Werke hingegen - wie es voraussichtlich zumeist der Fall sein wird - den Nut-

929 So auch Perfect 10 v. Google, Inc., 416 F.Supp.2d 828, 844 (C.D. Cal. 2006).

930 Vgl. Inesi, 21 Berkeley Tech. L.J. 945, 970 ff. (2006); Nimmer/Nimmer, On Copyright, $\S 8.01[\mathrm{G}]$. 
zern der jeweiligen Bibliothek beispielsweise an Leseplätzen zugänglich gemacht oder gar zum Download auf den eigenen Computer oder zum Ausdrucken angeboten, so ist ebenfalls das Verbreitungsrecht betroffen. ${ }^{931}$ Diesbezüglich käme jedoch allenfalls eine Haftung Googles nach den Grundsätzen des contributory infringement, also wegen einer mittelbaren Urheberrechtsverletzung, in Betracht, da eine public distribution durch die Bibliotheken selbst stattfände, die die Werke den Nutzern zugänglich machen. Eine Haftung für contributory infringement setzt jedenfalls einen gewissen Tatbeitrag und ein Wissenselement voraus, wobei grundsätzlich jede Form der Teilnahme ausreicht ${ }^{932}$ und auch ein „Wissenmüssen“ (,constructive knowledge") genügen kann. ${ }^{933934}$ Daran wäre hier grundsätzlich nicht zu zweifeln, da die den Nutzern zugänglichgemachten Digitalisate von Google stammen und ohne diese die dargestellte Nutzung durch die Bibliotheken nicht ohne Weiteres möglich wäre. In der Entscheidung Sony v. Universal ${ }^{935}$ stellte der Supreme Court jedoch einschränkend fest, eine mittelbare Haftung für eine Urheberrechtsverletzung müsse in aller Regel ausscheiden, wenn die Werknutzer die Werkkopien ganz überwiegend zu nicht urheberrechtsverletzenden Zwecken einsetzten. ${ }^{936}$ Eine Verletzung des distribution right würde diesbezüglich folglich ausscheiden, wenn die Nutzung der Vervielfältigungsstücke durch die Nutzer ihrerseits keine Ur-

931 Vgl. Tushnet, 53 UCLA L. Rev. 977, 1020 f. (2006); Vaidhyanathan, 40 U.C. Davis L. Rev. 1207, 1229 f. (2007).

932 Vgl. Gershwin Pub. Corp. v. Columbia Artists Management, Inc., 443 F.2d 1159, 1162 (2d Cir. 1971): ,[O]ne who, with knowledge of the infringing activity, induces, causes or materially contributes to the infringing conduct of another, may be held liable as a 'contributory' infringer." [Hervorhebungen durch den Verfasser].

933 Vgl. A\&M Records, Inc. v. Napster, Inc., 239 F.3d 1004, 1020 (9th Cir. 2001): „Contributory liability requires that the infringer 'know or have reason to know' of direct infringement".

934 Ausführlich zu den Voraussetzungen des „contributory infringement“ Nimmer/ Nimmer, On Copyright, § 12.04 [A][3]; Patry, On Copyright, § 21:42-61, jeweils m.w.N. Aus der deutschen Literatur siehe Spindler/Leistner, GRUR Int. 2005, 773 (775 ff.).

935 Sony Corporation of America v. Universal City Studios, Inc., 464 U.S. 417 (1984); siehe dazu ausführlich oben 2. Kapitel, C.I.2.b)aa).

936 Siehe Sony v. Universal, 464 U.S. 417, 441 f. (1984). 
heberrechtsverletzung darstellt, insbesondere weil sie als Fair Use zu betrachten oder nach der Library Exemption zulässig wäre. ${ }^{937}$

\section{Right to publicly display}

Neben dem reproduction und distribution right kommt auch ein Eingriff in das dem Urheberrechtsinhaber nach 17 U.S.C. § 106 (5) ausschließlich zustehende right to publicly display in Betracht. Nach der Legaldefinition des 17 U.S.C. $\S 101$ liegt ein display des Werkes in jedem Fall einer Darstellung eines Vervielfältigungsstückes, gleich in welchem Zusammenhang, vor. Das unbefugte Darstellen eines urheberrechtlich geschützten Werkes verletzt das display right aber nur dann, wenn dies öffentlich ( $p u$ blicly) geschieht. Nach 17 U.S.C. § 101 liegt ein public display vor, wenn die Kopie des Werkes an einem beliebigen Ort oder mehreren Orten durch beliebige Medien einer beträchtlichen Zahl von Personen außerhalb des Kreises der Familie und Bekannten zugänglich gemacht wird. ${ }^{938}$ Entscheidend ist die Möglichkeit der Wahrnehmung durch eine ausreichende Zahl von Mitgliedern der Öffentlichkeit; einer tatsächlichen Wahrnehmung bedarf es hingegen nicht. ${ }^{939}$ Erheblich eingeschränkt wird das display right allerdings - ähnlich der Beschränkung des distribution right durch die first sale doctrine - durch 17 U.S.C. § 109 (c), wonach der Eigentümer eines rechtmäßig hergestellten und erlangten Werkstückes dieses der Öffentlichkeit ohne weitere Zustimmung des Urheberrechtsinhabers zugänglich machen darf.

937 Siehe dazu näher unten 5. Kapitel, B.II.1. Zur vergleichbaren Argumentation des Supreme Court in der Entscheidung Sony v. Universal siehe oben 2. Kapitel, C.I. 2.b)aa).

938 Ausführlich zum Erfordernis des public display, insbesondere zur Frage, wann eine „substantial number of persons" im Sinne dieser Definition vorliegt, siehe Streeter v. Rolfe, 491 F. Supp. 416 (W.D. La. 1980); Thomas v. Pansy Ellen Prods., Inc., 672 F. Supp. 237, 240 (W.D.N.C. 1987); Nimmer/Nimmer, On Copyright, § 8.14 [C].

939 Vgl. H.R. Rep. No. 94-1476 (1976), S. 64 f.; Los Angeles News Service v. Reuters Television International, Ltd., 942 F. Supp. 1265, 1270 (C.D. Cal. 1996); Merges/Menell/Lemley, Intellectual Property, S. 515. 


\section{Thumbnails}

Im Rahmen der Bildersuche werden dem Nutzer auf seine Suchanfragen hin die von Google erstellten und in einer Datenbank gespeicherten Thumbnails angezeigt, die der jeweiligen Suchanfrage am besten entsprechen. Mit einem weiteren Klick auf die Thumbnails kann der Nutzer unmittelbar die Website erreichen, auf der sich das urheberrechtlich geschützte Originalwerk in seiner ursprünglichen Größe befindet. Durch diese Vorgehensweise könnte das right to publicly display aus zwei Gründen beziehungsweise durch zwei Vorgänge verletzt sein.

Zunächst kommt eine Rechtsverletzung durch die Anzeige der auf Googles eigenen Servern gespeicherten Thumbnails auf die Nutzeranfrage hin in Betracht. Bei den Thumbnails handelt es sich, wie zuvor gezeigt, um nicht autorisierte Vervielfältigungsstücke der Originalwerke. Diese werden auch öffentlich im Sinne der 17 U.S.C. § 101, § 106 (5) dargestellt, da sie allen Nutzern des Suchdienstes - und somit einer unkontrollierbar großen Zahl von Personen an (fast) beliebigen Orten weltweit - auf ihren Computerbildschirmen angezeigt und somit zugänglich gemacht werden. Das Anzeigen der auf den Servern von Google gespeicherten Thumbnails stellt daher einen Eingriff in das dem Urheberrechtsinhaber zustehende right to publicly display dar. ${ }^{940}$

Zusätzlich könnte das display right auch durch das Setzen sogenannter In-Line Links zu den fremden Inhalten beziehungsweise durch das sogenannte Framing durch Google beeinträchtigt sein. Auch bei diesem Vorgang werden den Nutzern Vervielfältigungsstücke der Originalwerke zugänglich gemacht. ${ }^{941}$ Anders als die dem Nutzer präsentierten Thumbnails sind die so angezeigten Bilddateien jedoch niemals auf Googles Servern gespeichert. Nach dem vom District Court in der Entscheidung Perfect 10

940 Ebenso Kelly v. Arriba Soft Corp., 336 F.3d 811, 816 (9th Cir. 2003): Ein Eingriff in das display right wurde von Arriba Soft nicht bestritten. Perfect $10 \mathrm{v}$. Google, Inc., 416 F.Supp.2d 828, 844 (C.D. Cal. 2006); Perfect 10, Inc. v. Amazon.com, Inc., et al., 508 F.3d 1146, 1148 (9th Cir. 2007); Goryunov, 41 J. Marshall L. Rev. 487, 501 (2008); McFarlane, 38 Golden Gate U. L. Rev. 381, 386 f. (2008); Nimmer/Nimmer, On Copyright, § 12B.01 [2]. Siehe auch K. Olson, 14 Comm. L. \& Pol'y 153, 161 (2009).

941 Im Arbeitsspeicher der Computer der Nutzer kommt es zunächst zur Speicherung und somit zu einer Fixierung einer Kopie des Originalwerkes, die anschließend auf dem Computerbildschirm angezeigt werden kann. 
v. Google entworfenen ${ }^{942}$ und vom Court of Appeals for the Ninth Circuit in der zweiten Instanz übernommenen ${ }^{943}$ sogenannten „Server Test" ist jedoch gerade dieser Unterschied für die Zurechenbarkeit des Eingriffes in das display right entscheidend: Im Falle des In-Line Linkings wird dem Nutzer lediglich ein Pfad zum Auffinden des Originalwerkes aufgezeigt. Ein Vervielfältigungsstück dieses Werkes in Originalgröße befindet sich jedoch - anders als das verkleinerte Thumbnail Image - nicht auf Googles eigenen Servern. Google macht dem Nutzer daher das Bild in Originalgröße nicht im Sinne des Copyright Act zugänglich. Ein Eingriff in das display right scheidet somit in diesem Fall aus. ${ }^{944}$

\section{Google Book Search}

Die genannten Eingriffsvoraussetzungen könnte auch die Google Buchsuche durch die Darstellung von Snippets auf die Suchanfrage der Nutzer hin erfüllen und somit eine Beeinträchtigung des display right darstellen.

Da an der Öffentlichkeit der Darstellung aufgrund der unüberschaubaren und unkontrollierbaren Zahl von Nutzern nicht zu zweifeln ist, käme lediglich in Betracht, eine Verletzung des display right aufgrund des geringen Umfanges der angezeigten Textauszüge als de minimus ausschei-

942 Siehe Perfect 10 v. Google, Inc., 416 F.Supp.2d 828, 839, 843 f. (C.D. Cal. 2006).

943 Siehe Perfect 10, Inc. v. Amazon.com, Inc., et al., 508 F.3d 1146, 1159 ff. (9th Cir. 2007).

944 Vgl. Perfect 10 v. Google, Inc., 416 F.Supp.2d 828, 844 (C.D. Cal. 2006); Perfect 10, Inc. v. Amazon.com, Inc., et al., 508 F.3d 1146, $1160 \mathrm{f}$. (9th Cir. 2007); McFarlane, 38 Golden Gate U. L. Rev. 381, 386 f. (2008). Anderer Ansicht war zunächst der Court of Appeals for the Ninth Circuit in seiner ersten Entscheidung des Falles Kelly v. Arriba Soft Corp., 280 F.3d 934, 947 (9th Cir. 2002). Diesen Teil der Entscheidung widerrief das Gericht jedoch in der zweiten, endgültigen Entscheidung und erklärte, dass der ersten Entscheidung insoweit keine Präjudizwirkung zukomme, vgl. Kelly v. Arriba Soft Corp., 336 F.3d 811, 815 (9th Cir. 2003): „The Opinion filed February 6, 2002 [...] is withdrawn. It may not be cited as precedent [...].“. Siehe auch Cohen/Loren/Okediji/O'Rourke, Copyright, S. 433 ff.; Gray/Kissman, 19 No. 10 Intell. Prop. \& Tech. L.J. 12, 13 (2007); Goryunov, 41 J. Marshall L. Rev. 487, 515 f. (2008); Westin, 2007 Duke L. \& Tech. Rev. 2, Rn. 16. 
den zu lassen. ${ }^{945}$ Von der ganz überwiegenden Auffassung wird jedoch die Annahme einer eigenständigen de minimis-Ausnahme im Rahmen der Verletzung des display rights - ebenso wie bezüglich des distribution rights ${ }^{946}$ - abgelehnt und für eine Berücksichtigung des geringen Umfanges und damit einer möglicherweise geringen Intensität des Eingriffes im Rahmen der anschließenden Fair Use-Rechtfertigungsprüfung plädiert. ${ }^{947}$ Letzterer Ansicht ist zuzustimmen, da nur so eine klare und „saubere“ Prüfung zu gewährleisten ist, die nicht die Grenzen zwischen Eingriff und Rechtfertigung verwischt. Andernfalls würde der dritte Fair Use-Faktor (,The Amount and Substantiality of the Portion Used") letztlich überflüssig.

Die Darstellung von Auszügen der gescannten Werke in Form von Snippets stellt daher einen Eingriff in das dem Urheberrechtsinhaber vorbehaltene right to publicly display dar. ${ }^{948}$

\section{B. Google Book Search und Darstellung von Thumbnails als Fair Use?}

Sowohl durch die Verwendung und Darstellung von Thumbnails bei der Bildersuche als auch im Rahmen der Buchsuche wird - wie zuvor dargestellt - in durch 17 U.S.C. § 106 gewährte urheberrechtliche Ausschließlichkeitsrechte eingegriffen. Diese Eingriffe müssten die jeweiligen Rechteinhaber jedoch hinnehmen, wenn die Verwendung ihrer urheberrechtlich geschützten Werke durch Google (oder andere Betreiber) durch die defense des Fair Use gerechtfertigt wäre.

Die Frage der Rechtfertigung der Verwendung von Thumbnails ist bereits Gegenstand von Entscheidungen verschiedener US-amerikanischer Gerichte gewesen und dabei (zunächst) unterschiedlich beantwortet worden. Eine höchstrichterliche Klärung ist noch nicht erfolgt und in näherer Zukunft auch nicht zu erwarten.

945 So Band, 9 J. Marshall Rev. Intell. Prop. L. 227, 235 (2009); ders., 3 J. Bus. \& Tech. L. 1, 19 (2008); ders., Google Library Copyright Debate, S. 4.

946 Vgl. oben 5. Kapitel, A.II.

947 Siehe statt vieler Inesi, 21 Berkeley Tech. L.J. 945, 970 ff. (2006) und Nimmer/ Nimmer, On Copyright, $\S 8.01$ [G], jeweils m.w.N.

948 Im Ergebnis ebenso Ganley, 10 No. 5 J. Internet L. 1, 10 (2006); Na, 16 Cornell J. L. \& Pub. Pol'y 417, 435 (2007). 
Zur Frage der Rechtmäßigkeit der Google Buchsuche ist hingegen noch keine Rechtsprechung ergangen. $\mathrm{Ob}$ es zu einer solchen überhaupt oder zumindest in absehbarer Zeit kommen wird, ist angesichts des im Rahmen der Class Action-Klage vor dem District Court for the Southern District of New York vorgeschlagenen Vergleichs, dem Google Book Search Settlement, nicht absehbar. Dennoch ist eine Auseinandersetzung mit der Möglichkeit der Rechtfertigung der Google Buchsuche durch die Fair UseDoktrin für die hier interessierende Frage der Erfassung neuer, innovativer Geschäftsmodelle und damit einhergehender neuer Nutzungsformen urheberrechtlich geschützter Werke durch verschiedenartige Schrankensysteme von großem Interesse. Es soll daher im Folgenden trotz des zwischenzeitlich vorgeschlagenen - im Rahmen eines Exkurses dargestellten ${ }^{949}$ Buchsuche-Vergleichs geprüft werden, ob Googles Vorgehen als Fair Use zu rechtfertigen wäre. Da in der Diskussion um die Zulässigkeit der Google Buchsuche im US-amerikanischen Urheberrecht vielfach auf die Gerichtsentscheidungen zur Rechtmäßigkeit der Darstellung von Thumbnails rekurriert wird, erscheint es sinnvoll, die Anwendung der Fair Use-Doktrin auf die beiden Geschäftsmodelle separat darzustellen und mit den Überlegungen zur Zulässigkeit von Thumbnails nach US-amerikanischem Copyright Law zu beginnen.

\section{Thumbnails}

Die Frage der Zulässigkeit der Verwendung fremder urheberrechtlich geschützter Werke als Thumbnails im Rahmen von Bildersuchmaschinen war Gegenstand zweier Verfahren im Neunten Gerichtsbezirk der USA. Bereits im Jahr 1999 befasste sich der U.S. District Court for the Central District of California in der Rechtssache Kelly v. Arriba Soft Corp. mit der Thumbnail-Nutzung. Die Entscheidung wurde schließlich im Jahr 2003 durch den U.S. Court of Appeals for the Ninth Circuit bestätigt (dazu sogleich 1.). In den Jahren 2006 und 2007 mussten sich dieselben Gerichte in der Rechtssache Perfect 10 v. Google erneut mit der Rechtmäßigkeit der Bildersuche befassen (sodann 2.).

949 Siehe unten 5. Kapitel, B.II.2. 


\section{Kelly v. Arriba Soft Corp.}

Das erste US-amerikanische Verfahren, das die Rechtmäßigkeit der Thumbnail-Nutzung durch Bildersuchmaschinen betraf, war die Rechtssache Kelly v. Arriba Soft Corp. Die damals völlig neuartige Suchmaschine des Unternehmens Arriba Soft Corp. durchsuchte mit Hilfe von Crawlern das Internet nach Bilddateien, erstellte von diesen stark verkleinerte Vorschaubilder und zeigte diese Thumbnails dem Nutzer auf seine Suchanfrage hin an. Im Jahr 1999 verklagte der professionelle Fotograf Leslie A. Kelly das Unternehmen Arriba Soft als Betreiber der Bildersuchmaschine wegen der Verletzung seiner Urheberrechte durch die Erstellung und Anzeige der Thumbnails. In erster Instanz wurde diese Klage vom U.S. District Court for the Central District of California vollumfänglich abgewiesen, da das Gericht die Thumbnail-Nutzung als Fair Use einstufte. ${ }^{950}$ Gegen diese Entscheidung legte Kelly Berufung zum U.S. Court of Appeals for the Ninth Circuit ein. ${ }^{951}$ Das Berufungsgericht überprüfte die Entscheidung des Gerichts erster Instanz vollständig und befasste sich dabei umfassend mit der Frage des Fair Use.

Hinsichtlich des ersten Fair Use-Faktors, der Frage nach dem „Purpose and character of the use" stellte das Gericht zunächst fest, dass Arriba seine Suchmaschine zweifellos zu kommerziellen Zwecken betreibe und somit auch die in Thumbnail-Form verwendeten fremden Bilder kommerziell nutze. ${ }^{952}$ Im Anschluss an die Supreme Court-Entscheidung Campbell v. Acuff-Rose ${ }^{953}$ stellte das Gericht jedoch fest, dass die kommerzielle Werknutzung eine faire Nutzung nicht bereits grundsätzlich ausschließe. Vielmehr sei im Rahmen des ersten Faktors maßgeblich zu berücksichtigen, ob die konkrete Nutzung umgestaltend (,transformative“) sei. Je transformativer eine Nutzung sei, desto größer sei letztlich die Wahrscheinlichkeit, dass es sich um einen Fair Use handele. Das Gericht stellte diesbezüglich fest, Arriba erstelle zwar identische Vervielfältigungsstücke, dennoch sei diese Werknutzung transformativ, da die Thumbnails einem völlig anderen Zweck dienten als die vervielfältigten Originalbilder. Bei Kellys Originalbildern handele es sich um künstlerische Werke, die äs-

950 Leslie A. Kelly v. Arriba Soft Corp., 77 F.Supp.2d 1116 (C.D. Cal. 1999).

951 Leslie A. Kelly v. Arriba Soft Corp., 336 F.3d 811 (9th Cir. 2003).

952 Vgl. Kelly v. Arriba Soft, 336 F.3d 811, 818 (9th Cir. 2003).

953 Luther R. Campbell v. Acuff-Rose Music, Inc., 510 U.S. 569 (1994). Siehe zu dieser Entscheidung bereits oben 2. Kapitel, C.I.2.b)cc). 
thetischen Zwecken dienten. Arribas Werknutzung hingegen verfolge keinerlei ästhetische Zwecke, sondern diene allein als „Werkzeug“, das zum öffentlichen Nutzen den Zugang zu Werken im Internet erleichtere. Für einen ästhetischen Werkgenuss seien die Thumbnails zudem aufgrund ihrer geringen Auflösung weder bestimmt noch geeignet. Trotz der identischen Werknutzung durch Arriba sei diese im Ergebnis transformativ, da dem Werk als Thumbnail eine neue Bedeutung beziehungsweise ein neuer Zweck zukomme. ${ }^{954}$ Aufgrund des öffentlichen Nutzens dieser neuen Zweckgebung durch die Suchmaschine wertete das Gericht den ersten Faktor im Ergebnis trotz der kommerziellen Nutzung zugunsten von Arriba. ${ }^{955}$

Den zweiten Faktor („Nature of the copyrighted work“) wertete das Gericht im Ergebnis nur leicht zugunsten des Klägers. ${ }^{956}$ Zwar handele es sich bei den künstlerischen Fotografien um kreative Werke, die grundsätzlich einen stärkeren Urheberrechtsschutz genießen als reine Tatsachendarstellungen, jedoch sei zu beachten, dass Kelly seine Werke bereits im Internet veröffentlicht habe. Bei der Verwendung veröffentlichter Werke sei aber - wie bereits der Supreme Court in seiner Entscheidung Harper \& Row v. Nation ${ }^{957}$ festgestellt habe - wahrscheinlicher, dass die Nutzung einen Fair Use darstelle.

Hinsichtlich des dritten Faktors (,Amount and substantiality of the portion used") stellte das Gericht fest, Arriba habe Kellys Werke zwar vollständig kopiert, auch ein vollständiges Kopieren schließe jedoch die Annahme eines Fair Use nicht generell aus. Vielmehr bestimme die konkrete Art der Verwendung den zulässigen Umfang der Nutzung. Kopiere der Nutzer nur soviel, wie für die fragliche Nutzung zwingend erforderlich sei, so spreche der dritte Faktor nicht gegen den Nutzer, selbst wenn eine vollständige Kopie des Originalwerkes angefertigt werde. Dies sei bei der Thumbnail-Nutzung der Fall, denn ohne eine vollständige Kopie des Originalwerkes sei eine sinnvolle Gestaltung der Bildersuche nicht denkbar. Den dritten Faktor wertete das Gericht daher im Ergebnis weder zugunsten des Klägers noch zugunsten des Beklagten. ${ }^{958}$

954 Vgl. Kelly v. Arriba Soft, 336 F.3d 811, 818 f. (9th Cir. 2003).

955 Siehe Kelly v. Arriba Soft, 336 F.3d 811, 820 (9th Cir. 2003).

956 Siehe Kelly v. Arriba Soft, 336 F.3d 811, 820 (9th Cir. 2003).

957 Harper \& Row, Publishers, Inc. v. Nation Enterprises, 471 U.S. 539 (1985).

Siehe zu dieser Entscheidung oben 2. Kapitel, C.I.2.b)bb).

958 Siehe Kelly v. Arriba Soft, 336 F.3d 811, 820 f. (9th Cir. 2003). 
Den vierten Faktor (,Effect of the use upon the potential market for or value of the copyrighted work") wertete das Gericht schließlich wieder zugunsten von Arriba. Generell seien bei transformativer Werknutzung negative Auswirkungen auf den Marktwert des Originalwerkes unwahrscheinlich. So sei es auch im Falle der Thumbnail-Nutzung bei der Bildersuche. Die Suchmaschine leite die Nutzer lediglich zu Kellys Webseite, so dass diesen ermöglicht werde, die Originalwerke in voller Auflösung aufzufinden. Durch die geringe Auflösung eigneten sich die Thumbnails zudem nicht dazu, die Originalbilder zu ersetzen, so dass ein Besuch der Ursprungswebsite unumgänglich sei, um das Bild in voller Auflösung anzusehen und gegebenenfalls weiter zu verwenden. Der Bildersuchdienst verringere somit nicht den wirtschaftlichen Wert der Originalwerke, sondern fördere allenfalls deren Bekanntheit und Verkauf, da Internetnutzer auf diese aufmerksam gemacht würden. ${ }^{959}$

Nach Ansicht des Gerichts waren insgesamt zwei Faktoren zugunsten von Arriba, einer neutral und lediglich einer leicht zugunsten des Klägers zu werten, so dass die Thumbnail-Nutzung im Ergebnis als Fair Use anzusehen sei. ${ }^{960}$

\section{Perfect 10 v. Google, Inc.}

Drei Jahre nach dem Urteil des Court of Appeals musste sich der District Court for the Central District of California erneut mit der urheberrechtlichen Zulässigkeit der Bildersuche beschäftigen. Geklagt hatte Perfect 10, $I n c$., Herausgeber eines Erotikmagazins und Betreiber einer entsprechenden Internetseite, gegen die Bildersuchmaschinenbetreiber Google, Inc. und Amazon.com, Inc. ${ }^{961}$ Der District Court verband die beiden Verfahren und setzte sich umfassend mit der Fair Use-Doktrin und deren Anwendung auf Bildersuchmaschinen in der Rechtssache Kelly v. Arriba Soft auseinander, verneinte jedoch im Ergebnis - entgegen seiner vorherigen Entscheidung und der Berufungsentscheidung des Court of Appeals in Kelly v. Arriba Soft - deren Anwendung auf die Bildersuche im konkreten Fall. ${ }^{962}$ Die Berufung gegen dieses Urteil zum Court of Appeals for the

959 Siehe Kelly v. Arriba Soft, 336 F.3d 811, 821 f. (9th Cir. 2003).

960 Siehe Kelly v. Arriba Soft, 336 F.3d 811, 822 (9th Cir. 2003).

961 Amazon.com, Inc. wurde als Betreiber der Bildersuchmaschine A9.com verklagt.

962 Siehe Perfect 10 v. Google, Inc., 416 F.Supp.2d 828 (C.D. Cal. 2006). 
Ninth Circuit hatte jedoch Erfolg; das Gericht hob die Entscheidung auf und stufte die Thumbnail-Nutzung im Ergebnis auch in diesem Fall als Fair Use ein. ${ }^{963}$

\section{a) Erste Instanz: District Court for the Central District of California}

Die Tatsache, dass der District Court in Perfect $10 v$. Google zu einer anderen Beurteilung der Rechtslage kam als in Kelly v. Arriba Soft hat seinen Grund zum einen in der abweichenden Sachverhaltsgestaltung, zum anderen aber auch in einer abweichenden Bewertung der Marktsituation. Anders als im Verfahren Kelly v. Arriba Soft, in dem sich Kelly ausschließlich gegen die Thumbnail-Nutzung solcher Bilder wandte, die er auf seiner eigenen Webseite eingestellt hatte, stützte Perfect 10 seine Klage gegen die Suchmaschinenbetreiber auch wesentlich darauf, dass diese solche Bilder in Thumbnail-Form anzeigten, die nicht von Perfect 10 selbst und auch nicht mit deren Zustimmung in das Internet gestellt worden waren, sondern als „Raubkopien“ aus dem geschützten Mitgliederbereich von Perfect $10 \mathrm{~s}$ Webseite auf anderen Internetseiten veröffentlicht worden waren. Es lag dem Verfahren somit eine Konstellation der - bereits zuvor geschilderten ${ }^{964}$ - „Drittinhaberschaft“ der Urheberrechte zu Grunde. Die Sachverhalte unterschieden sich zudem insoweit entscheidend, als Perfect 10 seine Bilder tatsächlich selbst ebenfalls in ThumbnailGröße verwendete und zu diesem Zweck einen Lizenzvertrag mit einem Dritten über den Verkauf und Vertrieb der Miniaturbilder für die Nutzung auf Mobiltelefonen abgeschlossen hatte. ${ }^{965}$ Anders als im Falle von Kelly

963 Siehe Perfect 10, Inc. v. Amazon.com, Inc., et al., 508 F.3d 1146 (9th Cir. 2007).

964 Siehe zum deutschen Recht und zum entsprechenden Sachverhalt des Verfahrens vor dem LG Hamburg (ZUM 2009, 315) oben 4. Kapitel, B.I.2.b).

965 Der Lizenzvertrag zwischen Perfect 10 und dem Unternehmen Fonestarz Media Limited über die Verwendung der Bilder in Miniaturgröße für Mobiltelefone wurde allerdings erst nach Erhebung der Klage gegen Google geschlossen, so dass vermutet wurde, dieser Lizenzvertrag sei nur abgeschlossen worden, um die Erfolgsaussichten der Klage zu erhöhen; siehe von Lohmann, Perfect 10 v. Google: More Smooth Than Crunchy, EFF Deeplinks v. 22.2.2006: „As for Fonestarz, I don't think the court was adequately sensitive to indications that the arrangement was a sham concocted for this litigation (the court notes that the license was not entered into until after Perfect 10 sued Google)“; abrufbar unter: http:// www.eff.org/deeplinks/2006/02/perfect-10-v-Google-more-smooth-crunchy [zuletzt abgerufen am 26.5.2013]. 
kam somit in der Tat eine andere Bewertung des Kriteriums der transformativen Nutzung und der Marktauswirkungen in Betracht. Im Einzelnen führte der District Court zur Fair Use-Analyse Folgendes aus:

Den ersten Faktor wertete das Gericht leicht zugunsten des Klägers Perfect 10. Bereits im Verfahren Kelly v. Arriba Soft hatten die Gerichte festgestellt, dass die Werknutzung durch den Bildersuchmaschinenbetreiber kommerzieller Natur sei. In Bezug auf Google stellte der District Court fest, das Unternehmen nutze die Thumbnails sogar noch deutlich stärker kommerziell, als dies bei Arriba der Fall gewesen sei. Google profitiere nämlich gleich in zweifacher Hinsicht von der Thumbnail-Nutzung. Zum einen steigere eine umfassende Bildersuche die Attraktivität des Bildersuchdienstes von Google allgemein, wodurch ein gesteigerter Traffic und somit gesteigerte Werbeeinnahmen auf der eigenen Website erzeugt würden. Zudem profitiere Google mit Hilfe seines AdSense-Werbeprogramms jedoch - anders als Arriba - erneut, wenn Nutzer durch die Thumbnails auf solche Internetseiten verwiesen würden, auf denen AdSense-Werbung geschaltet sei, so dass Google ein besonders starkes Interesse habe, auf möglichst viele fremde Internetseiten zu verweisen - darunter gegebenenfalls auch solche, auf denen illegale Inhalte angezeigt würden. ${ }^{966}$ Ebenso wie im Verfahren Kelly v. Arriba Soft hielt das Gericht bei seiner Bewertung des ersten Fair Use-Faktors die Kommerzialität der Nutzung allein jedoch nicht für ausschlaggebend, sondern widmete sich auch ausführlich der Frage, ob eine transformative Nutzung vorliege. $\mathrm{Zu}$ nächst stellte das Gericht fest, die Thumbnail-Nutzung durch den Suchmaschinenbetreiber sei insofern als sehr transformativ anzusehen, als sie den Bildern eine völlig neue Funktion als schneller und effizienter Wegweiser zu Bildinformationen gebe, die auch keinesfalls den Genuss der Bilder von Perfect 10 in Originalgröße ersetze. ${ }^{967}$ Dennoch sei Googles Werknutzung nicht ausschließlich transformativ. Hinsichtlich der von Perfect 10 ebenfalls vermarkteten Bilder in Miniaturgröße für die Mobiltelefonnutzung stelle sich die Thumbnail-Nutzung nämlich nicht als transformativ dar, sondern trete vielmehr in unmittelbaren Wettbewerb zu diesen. Nicht wenige Nutzer würden voraussichtlich eher die kostenlos verfügbaren Thumbnails aus dem Bildersuchdienst herunterladen, um diese auf dem Mobiltelefon zu verwenden, als für Bilder in demselben Format bei

966 Siehe Perfect 10 v. Google, Inc., 416 F.Supp.2d 828, 846 f. (C.D. Cal. 2006).

967 Siehe Perfect 10 v. Google, Inc., 416 F.Supp.2d 828, 847 f. (C.D. Cal. 2006). 
Perfect 10 Geld zu bezahlen. ${ }^{968}$ Dieser „consumptive use“ hinsichtlich der Miniaturbilder und die Tatsache, dass Google erhebliche eigene kommerzielle Interessen mit der Bildersuche verfolgte, sprachen nach Auffassung des Gerichts im Ergebnis (leicht) gegen die Annahme eines Fair Use.

Bei der Beurteilung des zweiten Fair Use-Faktors schloss sich das Gericht vollständig der Analyse des Court of Appeals in Kelly v. Arriba Soft an und stellte fest, dieser wiege nur leicht zugunsten der Klägerin, da die Fotografien zwar kreative Werke darstellten, jedoch bereits zuvor veröffentlicht waren, sowohl online als auch in Print-Form. ${ }^{969}$

Auch hinsichtlich des dritten Faktors stellte das Gericht keine Abweichung zur Entscheidung Kelly v. Arriba Soft fest und kam daher zu dem Ergebnis, dass dieser Faktor zugunsten keiner der Parteien zu werten sei, weil einerseits vollständige Kopien der Originalwerke angefertigt würden, andererseits jedoch nicht mehr kopiert werde, als für die sinnvolle Nutzung im Rahmen der Bildersuche zwingend erforderlich sei. Dabei lehnte das Gericht die von der Klägerin als Alternative zur Thumbnail-Darstellung vorgeschlagene Beschreibung der Suchergebnisse in Textform als für eine sinnvolle und effektive Bildersuche unbrauchbar und keinesfalls gleichwertig ab. ${ }^{970}$

Bei der Prüfung des vierten Fair Use-Faktors kam das Gericht ebenso wie im Verfahren Kelly v. Arriba Soft zu dem Ergebnis, dass eine Beeinträchtigung des Marktes für die Bilder in Originalgröße durch deren Thumbnail-Nutzung höchst unwahrscheinlich sei. Anders stelle sich dies jedoch erneut in Bezug auf die Auswertung der Bilder in Miniaturgröße für die Nutzung auf Mobiltelefonen dar. Dieser Markt werde mit großer Wahrscheinlichkeit durch die Vorschaubilder bei der Bildersuche negativ beeinträchtigt, da Nutzer eher die kostenlos verfügbaren Thumbnails für die Nutzung auf dem Mobiltelefon herunterladen würden, als für Bilder in derselben Qualität bei Perfect 10 beziehungsweise dessen Lizenznehmer zu bezahlen. ${ }^{971}$ Googles Argument, eine negative Marktauswirkung sei nicht festzustellen, da der Markt für Handybilder nachweislich gewachsen

968 Siehe Perfect 10 v. Google, Inc., 416 F.Supp.2d 828, 849 (C.D. Cal. 2006).

969 Siehe Perfect 10 v. Google, Inc., 416 F.Supp.2d 828, 849 f. (C.D. Cal. 2006).

970 Siehe Perfect 10 v. Google, Inc., 416 F.Supp.2d 828, 850 (C.D. Cal. 2006).

971 Kritisch zur Bestimmung des relevanten Marktes durch den District Court in diesem Fall Patry, Fair Use (2009), § 3:50 mit dem Hinweis, dass die Lizenznehmerin Fonestarz Media Limited ein britisches Unternehmen gewesen sei, das die Bilder für die Handynutzung im Vereinigten Königreich lizenziert habe. 
sei, lehnte das Gericht ab. Diese Tatsache verdeutliche lediglich, dass tatsächlich ein beträchtlicher Markt für die Miniaturbilder bestehe, der jedoch möglicherweise noch mehr gewachsen wäre, wenn die Bilder nicht kostenlos als Thumbnails bei Bildersuchmaschinen verfügbar gewesen wären. In Bezug auf die Bilder in Miniaturgröße wertete das Gericht den vierten Faktor somit im Ergebnis zugunsten von Perfect 10.972

Zusammenfassend hielt das Gericht fest, dass der erste, zweite und vierte Fair Use-Faktor im konkreten Fall zugunsten der Klägerin zu werten seien, während der dritte Faktor insoweit keinerlei Aufschluss ermögliche. Das Gericht sah sich somit gezwungen, das Vorliegen eines Fair Use im konkreten Fall zu verneinen - nicht ohne jedoch festzuhalten, dass es aufgrund des erheblichen öffentlichen Nutzens der Bildersuche und des möglichen negativen Effekts für den technologischen Fortschritt bei einer Untersagung dieser Technologie gerne anders entschieden hätte. ${ }^{973}$

\section{b) Zweite Instanz: Court of Appeals for the Ninth Circuit}

Gegen dieses Urteil legten sowohl Google als auch Perfect 10 Berufung beim Court of Appeals for the Ninth Circuit ein. ${ }^{974}$ Der Court of Appeals lobte ausdrücklich die gründliche und umfassende Fair Use-Analyse des District Court, ${ }^{975}$ vertrat jedoch bei der eigenen Nachprüfung in Bezug auf den ersten und vierten Faktor eine abweichende Auffassung und kam daher nach Abwägung der einzelnen Faktoren zu dem Ergebnis, auch die Thumbnail-Nutzung durch Google sei im konkreten Fall als Fair Use anzusehen.

Hinsichtlich des ersten Faktors stellte das Berufungsgericht fest, Googles Werknutzung in Form von Thumbnails sei hoch transformativ (,highly transformative“), da die Suchmaschine den Bildern eine völlig

972 Siehe Perfect 10 v. Google, Inc., 416 F.Supp.2d 828, 850 f. (C.D. Cal. 2006).

973 Siehe Perfect 10 v. Google, Inc., 416 F.Supp.2d 828, 851 (C.D. Cal. 2006).

974 Siehe Perfect 10, Inc. v. Amazon.com, Inc., et al., 508 F.3d 1146, 1157 (9th Cir. 2007). Perfect 10 legte Berufung gegen das Urteil des District Court ein, da das Gericht der Klage nicht vollumfänglich stattgegeben hatte, insbesondere Google nicht das Setzen von Inline-Links zu solchen Internetseiten untersagt hatte, auf denen urheberrechtsverletzende Kopien der Originalbilder in voller Größe zu finden waren.

975 Siehe Perfect 10, Inc. v. Amazon.com, Inc., et al., 508 F.3d 1146, 1155 (9th Cir. 2007). 
neue Funktion zuweise. Es stehe nicht mehr der ästhetische oder unterhaltende Genuss des Werkes im Vordergrund, sondern das Werk werde zu einem ,Zeiger" transformiert, der die Nutzer zu bestimmten Informationsquellen leite. Das Bild werde folglich einer völlig neuen Nutzung zugeführt, da es zum Teil eines elektronischen Referenzwerkzeuges werde, das erheblichen sozialen Nutzen habe. Insofern sei die Thumbnail-Nutzung der Bildersuchmaschine sogar noch transformativer als die vom Supreme Court als äußerst transformativ eingestufte Parodie, da dem Werk nicht lediglich etwas hinzugefügt werde und so im neuen Zusammenhang unter Beibehaltung desselben (Unterhaltungs-)Zwecks dessen Bedeutung geändert werde, sondern das Bild sogar zu einem völlig anderen Zweck genutzt werde. ${ }^{976}$ Aufgrund dieser erheblichen Transformativität und des damit verbundenen hohen Nutzens für die Allgemeinheit verlor nach Ansicht des Gerichts auch die Tatsache, dass es sich um eine kommerzielle Nutzung handelte, ganz erheblich an Gewicht. Der soziale Nutzen der Suchmaschine und die stark transformative Nutzung verdrängten letztlich selbst die Gefahr, dass die Thumbnails zu den von Perfect 10 für die Nutzung auf Mobiltelefonen vermarkteten Bildern in Miniaturgröße in unmittelbaren Wettbewerb treten könnten. Dass eine solche Nutzung der Thumbnails tatsächlich erfolgt sei und die Thumbnails somit tatsächlich in Wettbewerb zur kostenpflichtigen Nutzung der Bilder für Mobiltelefone getreten sei, habe Perfect 10 zudem nicht dargelegt. Die notwendig flexible Analyse des ersten Fair Use-Faktors unter besonderer Berücksichtigung der Umstände des Einzelfalls und insbesondere der Transformativität und des sozialen Nutzens der Werkverwertung führte nach Ansicht des Gerichts im Ergebnis zu der Bewertung, dass der erste Faktor im konkreten Fall stark zugunsten von Google zu werten sei. ${ }^{977}$

In der Bewertung des zweiten und dritten Faktors stimmte der Court of Appeals dem District Court zu. Bei den streitgegenständlichen Bildern handele es sich um eher kreative Werke, die jedoch zuvor bereits im Internet veröffentlicht worden waren, so dass der zweite Faktor nur leicht zugunsten von Perfect 10 zu werten sei. ${ }^{978}$ Da zwar vollständige Kopien der

976 Siehe Perfect 10, Inc. v. Amazon.com, Inc., et al., 508 F.3d 1146, 1165 (9th Cir. 2007).

977 Siehe Perfect 10, Inc. v. Amazon.com, Inc., et al., 508 F.3d 1146, 1166 f. (9th Cir. 2007).

978 Siehe Perfect 10, Inc. v. Amazon.com, Inc., et al., 508 F.3d 1146, 1167 (9th Cir. 2007). 
Werke angefertigt wurden, jedoch auch nur soviel kopiert worden sei, wie für die beabsichtigte Nutzung unumgänglich war, spreche der dritte Faktor weder für noch gegen den Verwender. 979

Hinsichtlich des vierten Faktors, der Frage nach den Auswirkungen auf den Markt beziehungsweise Marktwert des verwendeten Werkes, wich der Court of Appeals hingegen - mit erstaunlich knapper Begründung - von der Auffassung des erstinstanzlichen Gerichts ab. Der District Court habe zwar zutreffend angenommen, dass die Thumbnails den Markt für die Bilder in Originalgröße nicht negativ beeinträchtigten, das Gericht habe sich jedoch in seiner Bewertung der Auswirkungen auf den Markt für die Bilder in Miniaturgröße für die Mobiltelefonnutzung geirrt. Die Feststellung, dass Nutzer eher die kostenlosen Thumbnails für die Nutzung auf dem Mobiltelefon herunterladen würden, als für Bilder in derselben Qualität zu bezahlen, sei rein hypothetisch. Der District Court habe nicht festgestellt und Perfect 10 nicht dargelegt, dass eine derartige Nutzung der Thumbnails tatsächlich erfolge und somit eine tatsächliche negative Marktbeeinträchtigung festzustellen sei. Die rein potentielle Gefahr für den Markt für Bilder in Miniaturgröße reiche jedoch nicht aus, um den vierten Faktor zugunsten von Perfect $10 \mathrm{zu}$ werten. Im Ergebnis wertete das Gericht diesen Faktor daher als neutral. 980

Eine Abwägung aller vier Fair Use-Faktoren im Lichte der Umstände des Einzelfalls und unter besonderer Berücksichtigung des erheblichen Nutzens der Suchmaschinen für die Allgemeinheit und der stark transformativen Art der Nutzung ergab somit nach Ansicht des Court of Appeals in Abweichung von der Entscheidung der Vorinstanz -, dass die Werknutzung in Form von Thumbnails durch Google im Rahmen der Bildersuche als Fair Use anzusehen sei. ${ }^{981}$

979 Siehe Perfect 10, Inc. v. Amazon.com, Inc., et al., 508 F.3d 1146, 1167 f. (9th Cir. 2007).

980 Siehe Perfect 10, Inc. v. Amazon.com, Inc., et al., 508 F.3d 1146, 1168 (9th Cir. 2007).

981 Siehe Perfect 10, Inc. v. Amazon.com, Inc., et al., 508 F.3d 1146, 1168 (9th Cir. 2007). 
3. Rezeption der Entscheidungen in der US-amerikanischen Literatur

Die dargestellten „Thumbnail“-Entscheidungen der Gerichte des Neunten Gerichtsbezirks haben in der US-amerikanischen rechtswissenschaftlichen Literatur ein breites Echo erzeugt, wobei sie im Ergebnis ganz überwiegend begrüßt, ihre Begründungen jedoch oftmals kritisch hinterfragt wurden. ${ }^{982}$ Gerade die Entscheidungen des District Court und des Court of Appeals for the Ninth Circuit in der Rechtssache Perfect 10 v. Googlel Amazon sind vielfach besonders kritisch beurteilt worden. Zentrale Kritikpunkte stellen dabei die (Über-)Betonung der Transformativität der Nutzung bei der Prüfung des ersten Fair Use-Faktors und der Gesamtabwägung, die Bestimmung des relevanten Marktes und die Analyse eines möglichen negativen Einflusses auf diesen im Rahmen des vierten Faktors dar.

Im Rahmen des ersten Faktors - „Purpose and character of the use“ erfolgt eine Betrachtung des Zwecks der fraglichen Nutzungshandlung. Eine ganz wesentliche Rolle spielte dabei traditionell die Frage der Kommerzialität der Nutzung. Handelt es sich um eine kommerzielle Nutzung, so spricht dies zunächst generell gegen die Annahme eines Fair Use. Bereits der Supreme Court hat jedoch in seiner Entscheidung Campbell $v$. Acuff-Rose $e^{983}$ den Schwerpunkt der Prüfung innerhalb des ersten Fair Use-Faktors verschoben. Die Bewertung einer auch kommerziellen Nutzung kann sich insbesondere dann zugunsten des Nutzenden verschieben, wenn ein „transformative use" vorliegt, das Originalwerk also durch die neue Nutzung nicht lediglich substituiert wird, sondern diesem etwas Neues hinzugefügt wird, etwa durch die Verwendung in einem neuen Zusam-

982 Siehe etwa Ayazi, 7 N.C. J. L. \& Tech. 367, 377 ff. (2006); Band, 3 J. Bus. \& Tech. L. 1, 7 ff. (2008); Bongiorno, 12 Touro Int'l L. Rev. 107, 121 ff. (2009); Carnevale, 14 B.U. J. Sci. \& Tech. L. 132, 138 ff. (2008); Dang, 18 Santa Clara Computer \& High Tech. L.J. 389, 394 ff. (2002); Ding, 23 Berkeley Tech. L.J. 373, 388 ff. (2008); Goldstein, IIC 2008, 216 (220 f.); Goryunov, 41 J. Marshall L. Rev. 487, 501 ff. (2008); Gray/Kissman, 19 No. 10 Intell. Prop. \& Tech. L.J. 12, 14 ff. (2007); Kociubinski, 12 B.U. J. Sci. \& Tech. L. 372, 378 ff. (2006); McFarlane, 38 Golden Gate U. L. Rev. 381, 387 ff. (2008); Nimmer/Nimmer, On Copyright, § 13:05 [G]; A. Olson, 44 Jurimetrics J. 487, 496 ff. (2004); K. Olson, 14 Comm. L. \& Pol'y 153, 160 ff. (2009); Patry, Fair Use (2009), § 3:50; Payne, 17 Fordham Intell. Prop. Media \& Ent. L.J. 279, 286 ff. (2006); Reese, 31 Colum. J.L. \& Arts 467, 483 ff. (2008); Staples, 18 Berkeley Tech. L.J. 69, 84 ff. (2003).

983 Luther R. Campbell v. Acuff-Rose Music, Inc., 510 U.S. 569 (1994). 
menhang, so dass sich Charakter, Wirkung, Aussage oder Bedeutung des Werkes ändern. Je transformativer und somit kreativer die Nutzung des Originalwerkes erfolgt, desto wahrscheinlich ist, dass eine faire Benutzung vorliegt. Dass die Gerichte in den dargestellten „Thumbnail"s-Entscheidungen im Rahmen des ersten Fair Use-Faktors ganz wesentlich auf die Transformativität der Nutzung abstellen, steht somit zumindest auf den ersten Blick im Einklang mit der Rechtsprechung des Supreme Court. Dennoch sind die Entscheidungen zur Thumbnail-Nutzung in Bezug auf die Prüfung des ersten Faktors in mehrfacher Hinsicht kritisiert worden. Zum Teil ist bereits die Richtigkeit der Feststellung, dass überhaupt eine transformative Nutzung vorliegt, in Frage gestellt worden. Die ThumbnailNutzung sei schon nicht mit der parodistischen Nutzung eines Werkes vergleichbar, in deren Zusammenhang der Supreme Court das Kriterium der Transformativität in die Rechtsprechung eingeführt habe. Die grundlegende Begründung der Rechtmäßigkeit einer Parodie habe der Supreme Court gerade darin gesehen, dass das Originalwerk bei der Schaffung des neuen Werkes gerade ,physisch“ geändert werde, dem Originalwerk also neue, eigene Werkteile durch den Urheber der Parodie hinzugefügt würden. An einer solchen Eigenleistung fehle es bei den Thumbnails gerade. Eine reine identische Kopie des Originalwerkes, die lediglich in einem anderen Zusammenhang verwendet werde, stelle gerade keine transformative Nutzung dar. ${ }^{984}$ Zudem sei zweifelhaft, ob sich der Verwendungszweck des Originalbildes und des Vorschaubildes tatsächlich unterscheide. Zwar dienten die Thumbnails insoweit einem anderen Zweck als die Originalwerke, als sie als Wegweiser zu Informationsquellen dienten. Dennoch sei der hinter der Verwendung stehende Gedanke und somit der Hauptnutzungszweck derselbe: Sowohl die Ursprungswebsite als auch die Suchmaschine erzielen Gewinne durch den Verkauf von Werbeflächen, Produkten und Dienstleistungen. Sie verwenden die Bilder daher jeweils zu dem Zweck, um ihre Internetseite attraktiv zu gestalten und somit um Nutzer zu gewinnen. Die identische Kopie des Ursprungsbildes und dessen Verwendung auf einer eigenen Webseite, um diese für Nutzer besonders attraktiv zu gestalten, stelle daher keine transformative Nutzung dar. ${ }^{985}$

Der überwiegende Teil der Kommentatoren hat den Gerichten hingegen im Hinblick auf die Feststellung der Transformativität der Nutzung zuge-

984 Vgl. Bongiorno, 12 Touro Int'l L. Rev. 107, 127 f., 135 (2009); Williams, 25 Cardozo Arts \& Ent. L.J. 303, 318 (2007).

985 Vgl. Ayazi, 7 N.C. J. L. \& Tech. 367, 381 ff. (2006). 
stimmt. Als problematisch stellt sich jedoch aus Sicht mehrerer Autoren die ganz zentrale Betonung des Kriteriums der transformativen Nutzung bei der Gesamtabwägung der vier Fair Use-Faktoren und insbesondere in ihrem Verhältnis zum vierten Faktor dar. Wie sich insbesondere im Urteil des Court of Appeals for the Ninth Circuit in Perfect 10 v. Google/Amazon zeigt, überlagert die Transformativität die gesamte sonstige Fair Use-Prüfung. Nachdem das Gericht das Vorliegen einer transformativen Nutzung durch den geänderten Verwendungszweck bejaht hat, verlieren sämtliche weiteren Überlegungen, selbst wenn sie deutlich gegen die Annahme eines Fair Use sprechen, im Ergebnis (fast) vollständig an Gewicht. ${ }^{986}$ Als besonders problematisch ist insofern die Feststellung des Gerichts betrachtet worden, dass bereits eine teilweise transformative Nutzung (im Hinblick auf die Bilder in Originalgröße) eine ebenfalls vorliegende „gefährdende“ Nutzung (bezüglich der Miniaturbilder für Mobiltelefone) in der Gesamtschau unerheblich werden lässt, selbst wenn dieser "superseding use“ tatsächlich das Potential hat, in unmittelbaren Wettbewerb zu einer Nutzung des Originalwerkes auf einem potentiellen oder gar tatsächlich schon bedienten Markt zu treten. ${ }^{987}$ Letztlich kommt das Gericht trotz deutlicher Hinweise auf eine Marktbeeinträchtigung oder -gefährdung und trotz der vollständigen Kopie eines kreativen Werkes zu dem Ergebnis, dass eine für die Allgemeinheit wertvolle Nutzung allein aufgrund ihrer Transformativität als Fair Use zu qualifizieren sei. Diese „Degradierung“ des vierten Fair Use-Faktors, der vom Supreme Court sogar als ,undoubtedly the single most important element of fair use" bezeichnet worden ist ${ }^{988}$ und die Bestimmung des relevanten Marktes beziehungsweise einer relevanten Marktbeeinträchtigung durch das Gericht im konkreten Fall, ist erheblich kritisiert worden. Der Court of Appeals lehnte eine Wertung des vierten Faktors zugunsten von Perfect 10 gerade deshalb ab, weil ein tatsächlicher Schaden nicht nachgewiesen worden war, so dass eine Beeinträchtigung hypothetisch sei. Nach dem vierten Fair Use-Faktor sollen jedoch aus-

986 Vgl. Ayazi, 7 N.C. J. L. \& Tech. 367, 390 f. (2006); Staples, 18 Berkeley Tech. L.J. 69, 83 ff. (2003); Williams, 25 Cardozo Arts \& Ent. L.J. 303, 319 (2007). Ausführlich zum Problem der Überbetonung des "transformative use" durch die Gerichte nach der Campbell-Entscheidung Bunker, 7 Comm. L. \& Pol'y 1, 17 ff. (2002); Kudon, 80 B.U. L. Rev. 579, 597 ff. (2000).

987 Vgl. Ayazi, 7 N.C. J. L. \& Tech. 367, 388 (2006); Bongiorno, 12 Touro Int'1 L. Rev. 107, 127 (2009).

988 Harper \& Row v. Nation Enterprises, 471 U.S. 539, 566 (1985) unter Hinweis auf Nimmer/Nimmer, On Copyright, § 13.05 [A]. 
drücklich auch potentielle Markteinflüsse Berücksichtigung finden, die sich letztlich stets als ",hypothetische“ Effekte charakterisieren ließen.989 Es ist zudem zu bedenken, dass es in diesem Fall nicht um einen rein hypothetischen zukünftigen Markt ging, sondern um eine lediglich nicht nachgewiesene Beeinträchtigung eines bereits tatsächlich bedienten Marktes. Die Auseinandersetzung mit dem vierten Faktor durch den Court of Appeals ist insofern als wenig überzeugend angesehen worden. ${ }^{990}$ Letztlich ist sie jedoch - wie auch die im Anschluss an die Prüfung der vier Faktoren vom Gericht vorgenommene allgemeine Interessenabwägung deutlich zeigt - vor dem Hintergrund zu verstehen, dass das Gericht sein Ziel - die Legalisierung der als unverzichtbar angesehenen Bildersuche „um jeden Preis“ erreichen wollte und zu diesem Zweck bereit war, die Fair Use-Doktrin äußerst großzügig anzuwenden.991

\section{Ergebnis: Thumbnail-Nutzung als Fair Use}

Die US-amerikanische Rechtsprechung ist bisher in zwei großen Verfahren mit der Frage der urheberrechtlichen Zulässigkeit der Thumbnail-Nutzung konfrontiert worden. Während die erstinstanzlichen Gerichte diese Frage zunächst uneinheitlich beantwortet haben, hat der Court of Appeals for the Ninth Circuit die Thumbnail-Nutzung durch Bildersuchmaschinen in beiden Verfahren im Ergebnis als Fair Use eingestuft.

Einen ganz wesentlichen Aspekt aller Entscheidungen stellt die Frage der transformativen Nutzung dar. Anders als in vorherigen Urteilen wird im Ergebnis allein aufgrund eines unterschiedlichen Verwendungszwecks von Originalwerk und identischer (verkleinerter) Kopie - ästhetische und unterhaltende Zwecke einerseits und eine rein funktionale Verwendung als „Wegweiser" zu Online-Inhalten andererseits - eine transformative Nutzung bejaht, die letztlich in allen Urteilen entscheidend für die Bejahung des Fair Use war. Dabei hat das Gericht sowohl die Nutzung solcher Bil-

989 Vgl. Nimmer/Nimmer, On Copyright, § 13.05 [G].

990 Vgl. Ayazi, 7 N.C. J. L. \& Tech. 367, 385 ff. (2006); Bongiorno, 12 Touro Int'1 L. Rev. 107, 126 f. (2009); Nimmer/Nimmer, On Copyright, § 13.05 [G].

991 Diese flexible Handhabung der Fair Use-Doktrin im Hinblick auf neue Nutzungsformen im Internet begrüßend Goryunov, 41 J. Marshall L. Rev. 487, 523 (2008); McFarlane, 38 Golden Gate U. L. Rev. 381, 405 f. (2008); Payne, 17 Fordham Intell. Prop. Media \& Ent. L.J. 279, 292 f. (2006); Staples, 18 Berkeley Tech. L.J. 69, 83 (2003). 
der behandelt, die vom Urheber selbst beziehungsweise mit dessen $\mathrm{Zu}$ stimmung im Internet veröffentlicht wurden, als auch die - nach deutschem Recht besonders schwer zu erfassende ${ }^{992}$ - Konstellation der „Drittinhaberschaft" der Urheberrechte, in der die Werke ohne Zustimmung des Urhebers von Dritten im Internet zur Verfügung gestellt werden. Die Rechtslage hinsichtlich der Thumbnail-Nutzung durch Bildersuchmaschinen kann somit in den USA - trotz der zum Teil erheblichen Kritik an der Rechtsprechung - als geklärt gelten. Die Verwendung fremder Werke in Form von Thumbnails im Rahmen der Bildersuche lässt sich von der flexiblen Fair Use-Doktrin erfassen und ist somit zulässig, jedenfalls solange nicht im Einzelfall nachteilige Auswirkungen auf den Markt für das Originalwerk beziehungsweise auf dessen Marktwert tatsächlich nachgewiesen werden.

\section{Google Book Search}

Die Frage der urheberrechtlichen Zulässigkeit der Google Buchsuche war ebenfalls bereits Gegenstand gerichtlicher Verfahren in den USA. Im Herbst 2005 reichten in kurzem zeitlichen Abstand sowohl der US-amerikanische Autorenverband Authors Guild 993 als auch der Verlegerverband Association of American Publishers (AAP) beim U.S. District Court for the Southern District of New York Klagen gegen Google ein. ${ }^{994}$ Die Kläger machten „massive Urheberrechtsverletzungen“ durch Googles Vorgehen im Rahmen des Library Projects geltend. Die zentrale Frage, ob die massenhafte Digitalisierung von Büchern und deren Zurverfügungstellung im Internet als Fair Use anzusehen ist, ist von der Rechtsprechung jedoch bisher nicht geklärt worden, da ein gerichtlicher Vergleich vorgeschlagen wurde, dessen Inhalt und Folgen im Rahmen eines Exkurses dargestellt werden (unten 2.). Zunächst soll jedoch die Rechtslage ermittelt werden, die derzeit - ohne den Abschluss eines Buchsuche-Vergleichs - besteht.

992 Siehe oben 4. Kapitel, B.I.2.b).

993 Die Authors Guild vertritt mehr als 8.000 Autoren und ist damit die größte USamerikanische Vereinigung von Autoren; siehe The Authors Guild, „History“, abrufbar unter: http://www.authorsguild.org/about/history.html [zuletzt abgerufen am 26.5.2013].

994 Siehe The Authors Guild, et al. v. Google Inc., No. 05 CV 8136 (S.D.N.Y. Sept. 20, 2005) und The McGraw-Hill Companies, Inc. et al. v. Google Inc., No. 05 CV 8881 (S.D.N.Y. Oct. 19, 2005). 
Daher ist zu prüfen, ob Googles Vorgehen als Fair Use zu rechtfertigen ist.

\section{Fair Use-Analyse}

Google macht geltend, die Nutzung fremder Werke im Rahmen der Buchsuche sei als Fair Use zulässig, da eine Dienstleistung mit enormem Nutzen für die Öffentlichkeit ebenso wie für die Urheberrechtsinhaber angeboten würde. Die Rechte der Urheber und Rechteinhaber würden nicht negativ beeinflusst, da Nutzern nur kleine Teile eines mit Hilfe der Suchfunktion aufgefundenen Werkes angezeigt würden, solange an diesem noch Urheberrechte bestehen und der Urheberrechtsinhaber einer weitergehenden Nutzung nicht zugestimmt hat. Zudem ermögliche die Google Buchsuche eine Steigerung der Bekanntheit und Auffindbarkeit der einzelnen Werke, wovon letztlich die Rechteinhaber insbesondere auch in Form gesteigerter Einnahmen aus zusätzlichen Verkäufen profitieren könnten. ${ }^{995}$

$\mathrm{Ob}$ die massenhafte Digitalisierung der Bücher durch Google und die Anzeige einzelner Ausschnitte aus dem gespeicherten Text auf Suchanfragen der Nutzer tatsächlich als Fair Use zulässig ist, ist eine der in den letzten Jahren wohl meistdiskutierten Fragen in der US-amerikanischen urheberrechtlichen Literatur, aber auch in den Massenmedien. Die vielstimmige Diskussion zeigt zum einen, dass die Rechtslage insoweit tatsächlich nicht eindeutig ist, insbesondere da die von Google vorgenommene Art der Nutzung völlig neu ist und somit vergleichbare Urteile, die als Leitbild dienen könnten, weitgehend fehlen. Die tatsächlich bestehende Unsicherheit über den Ausgang eines gerichtlichen Verfahrens, in dessen Mittelpunkt die Frage des Fair Use stünde, spiegelt sich nicht zuletzt darin, dass die Parteien sich auf einen Vergleich geeinigt haben. ${ }^{996}$ Zum anderen zeigt der Umfang der Debatte und auch die Emotionalität, mit der diese teilweise geführt wird, welche Bedeutung dem Projekt „Google Buchsuche“ selbst beigemessen wird und welche Reichweite eine entsprechende Entscheidung zugunsten oder zuungunsten von Google für die Entwicklung des gesamten US-amerikanischen Urheberrechts im Hinblick auf den Umgang mit neuen Nutzungsformen urheberrechtlich geschützter Werke ha-

995 Vgl. „Google Books - Legal Analysis“, abrufbar unter: http://www.google.com/ googlebooks/legal.html [zuletzt abgerufen am 26.5.2013].

996 Zum Google Book Settlement siehe ausführlich unten 5. Kapitel, B.II.2. 
ben könnte. Die Frage der Zulässigkeit der Google Buchsuche im Rahmen der Fair Use-Doktrin entwickelt sich somit letztlich auch zu einer rechtspolitischen Frage, deren Antwort davon abhängt, welche Reichweite man der Fair Use-Doktrin zukommen lassen möchte und welche Funktion dem Urheberrecht bei der Gestaltung der technologischen Entwicklung zukommen soll. Diese rechtspolitischen Überlegungen sollen hier allerdings (zunächst) weitestgehend außer Betracht bleiben. Es soll vielmehr anhand der einzelnen Fair Use-Faktoren geprüft werden, ob die Google Buchsuche nach dem in der bisherigen US-amerikanischen Rechtsprechung entwickelten Verständnis der Fair Use-Doktrin als zulässig anzusehen ist. Urheberrechtlich relevant und somit bei der Fair Use-Prüfung zu beachten sind drei Vorgänge: Die Digitalisierung vollständiger Bücher und deren Erfassung in einer Datenbank, die Anzeige von Auszügen aus diesen Werken in Snippet-Form als Antwort auf Nutzeranfragen und die Weitergabe einer digitalen Kopie jedes digitalisierten Werkes an die Bibliothek, aus deren Bestand das gescannte Werk stammt. ${ }^{997}$

\section{a) Die Präambel}

Auch wenn die Aufzählung der Präambel nur beispielhaft ist und selbst für die dort genannten Fälle eine Ablehnung eines Fair Use möglich ist, kommt den in der Präambel genannten Nutzungszwecken durchaus eine Bedeutung zu: Dient die fragliche Nutzung einem der genannten Zwecke, so kann dies insbesondere im Rahmen des ersten Faktors als Argument zugunsten des Nutzers gelten, da die aufgelisteten Zwecke in der Regel wünschenswert sind. In Bezug auf die Google Buchsuche käme eine Kategorisierung der Nutzung zu Zwecken der Wissenschaft oder Forschung (,scholarship or research“) im Sinne der Präambel in Betracht. Tatsächlich wird die Buchsuche in einer Vielzahl der Fälle Zwecken des wissenschaftlichen Arbeitens dienen, insbesondere da es sich bei den beteiligten Bibliotheken ganz überwiegend um akademische Bibliotheken handelt, deren Bestände zu einem Großteil aus wissenschaftlicher oder wissenschaftlich relevanter Literatur bestehen werden. Durch die Google Buchsuche wird in ihrer derzeitigen Gestaltung jedoch auch nicht garantiert, dass eine

997 Die Klagen der Authors Guild und $A A P$ beziehen sich allerdings nur auf die Digitalisierung vollständiger Bücher durch Google und deren Speicherung in einer Datenbank. 
Nutzung zu Zwecken der Wissenschaft und Forschung erfolgt. Es werden nicht nur wissenschaftliche Werke, sondern grundsätzlich alle Werke der beteiligten Bibliotheken digitalisiert. Zudem wird bisher der Zugang nicht auf solche Nutzer beschränkt, die die Dienstleistung zu wissenschaftlichen Zwecken nutzen. Ob die Werknutzung im Rahmen der Buchsuche den ausdrücklich in der Präambel des 17 U.S.C. § 107 genannten Zwecken „scholarship or research“ unterfällt, lässt sich folglich nicht pauschal beantworten. Oftmals wird jedoch eine Nutzung zu einem dieser Zwecke erfolgen, was im Rahmen der Prüfung der Fair Use-Faktoren Berücksichtigung finden kann.

b) Erster Faktor: "The Purpose and Character of the Use"

Der erste Fair Use-Faktor betrifft den Zweck und Charakter der Nutzung einschließlich der Frage, ob ihr Gebrauch kommerzieller Natur ist oder gemeinnützigen Erziehungs- beziehungsweise Unterrichtszwecken dient. Zentral sind dabei zwei Fragestellungen: Ob die Nutzung zu kommerziellen Zwecken erfolgt und ob die Nutzung transformativ ist.

Es steht außer Frage, dass Google ein kommerzielles Unternehmen ist, das in erster Linie zu kommerziellen Zwecken und mit Gewinnerzielungsabsicht handelt. Google profitiert jedoch nicht unmittelbar finanziell von der Nutzung der fremden Werke im Rahmen der Buchsuche, da es die vollständigen Kopien der Werke beziehungsweise die Snippets (bisher) nicht an die Nutzer verkauft und für den Suchdienst auch keine Bezahlung verlangt. Dennoch verfolgt Google mit der Buchsuche zumindest mittelbar kommerzielle Interessen. Das Unternehmen digitalisiert die Bücher und nimmt diese in eine Datenbank auf, um später eine Volltextsuche zu ermöglichen. Im Zusammenhang mit den Suchergebnissen werden den Nutzern Werbebanner und Links zu anderen Internetangeboten, insbesondere solchen zum Kauf des gefundenen Buches, angezeigt. Google generiert mit diesen Werbebannern und Links Einnahmen. Ein umfassendes Buchsuche-Angebot steigert zudem allgemein die Attraktivität des Dienstleisters Google. Durch die Verbindung der Buchsuche mit den anderen (Such-)Angeboten von Google kann zudem zusätzlicher Traffic für die weiteren Angebote generiert werden. All dies führt zu gesteigerten Werbeeinnahmen bei Google. Die Tatsache, dass Google die Buchsuche (bisher) kostenlos anbietet, ändert an dieser Beurteilung nichts. Relevant ist für die Beurteilung der Kommerzialität lediglich, ob der Nutzende überhaupt von 
der Nutzung des fremden Werkes finanziell profitiert, auch wenn dies wie hier und auch im Falle der Thumbnail-Nutzung 998 - nur mittelbar erfolgt. ${ }^{999}$ Gerade die Gerichte des Second Circuit, in dem auch die Klagen gegen Googles Buchsuche erhoben wurden, haben diesbezüglich bisher stets ein weites Verständnis der Kommerzialität der Nutzung vertreten. ${ }^{1000}$ Auch wenn der kommerzielle Charakter der Nutzung hier nicht so ausgeprägt ist wie im Falle der unmittelbaren kommerziellen Verwertung eines Werkes, liegt im Ergebnis eine kommerzielle Nutzung vor, die grundsätzlich gegen die Annahme eines Fair Use spricht. ${ }^{1001}$

Der erste Fair Use-Faktor ist jedoch auch bei kommerzieller Nutzung nicht automatisch gegen den Nutzenden zu werten. ${ }^{1002}$ Der Supreme Court hat im Urteil Campbell v. Acuff-Rose ausdrücklich festgestellt, dass die Annahme einer unfairen Benutzung insbesondere dann widerlegt sein kann, wenn ein transformative use erfolgt. Die Nutzung ist dann als umge-

998 Vgl. Perfect 10, Inc. v. Amazon.com, Inc., et al., 508 F.3d 1146, 1166 (9th Cir. 2007); Perfect 10 v. Google, Inc., 416 F.Supp.2d 828, 846 f. (C.D. Cal. 2006). Siehe dazu oben 5. Kapitel, B.I.

999 Vgl. Harper \& Row, Publishers, Inc. v. Nation Enterprises, 471 U.S. 539, 562 (1985); Kelly v. Arriba Soft Corp., 336 F.3d 811, 818 (9th Cir. 2003).

1000 Vgl. Roy Export Co. Establishment v. Columbia Broadcasting Sys. Inc., 503 F.Supp. 1137, 1144 (S.D.N.Y. 1980); bestätigt durch Roy Export Co. Establishment v. Columbia Broadcasting Sys. Inc., 672 F.2d 1095 (2d Cir. 1982); Lish v. Harper's Magazine Foundation, 807 F.Supp. 1090, 1101 (S.D.N.Y. 1992); zu dieser Rechtsprechung siehe Shah, 15 CommLaw Conspectus 569, $584 \mathrm{f}$. (2007).

1001 So im Ergebnis auch Adler, Google Library Project, S. 11 f.; Band, Google Library Project, S. 4; Bisk, 17 Alb. L.J. Sci. \& Tech. 271, 289 (2007); Gamble, 9 Tul. J. Tech. \& Intell. Prop. 365, 378 f. (2007); Ganley, 10 No. 5 J. Internet L. 1, 12 (2006); Glorioso, 38 Hofstra L. Rev. 971, 984 (2010); Hanratty, 2005 Duke L. \& Tech. Rev. 10, Rn. 19; Hetcher, 13 Mich. Telecomm. \& Tech. L. Rev. 1, 32 f. (2006); Lichtman, Copyright as Innovation Policy, S. 10; Manuel, Google Library Project, S. 5; Okano, 3 Shidler J. L. Com. \& Tech. 13 (2007), Rn. 39 ff.; Proskine, 21 Berkeley Tech. L.J. 213, 226 (2006); Romman, 43 Hous. L. Rev. 807, 828 (2006); Shah, 15 CommLaw Conspectus 569, 584 f. (2007); Travis, 61 U. Miami L. Rev. 87, 126 f. (2006); Varian, Google Library Project, S. 9; Westin, 2007 Duke L. \& Tech. Rev. 2, Rn. 48, 56 ff.; Wilhelm, 33 Rutgers Computer \& Tech. L.J. 107, 123 f. (2006); a.A. Na, 16 Cornell J. L. \& Pub. Pol'y 417, 436 f. (2007).

1002 So aber noch die frühere Rechtsprechung; siehe Sony v. Universal, 464 U.S. 417, 451 (1984): ,[E]very commercial use of copyrighted material is presumptively an unfair exploitation of the monopoly privilege that belongs to the owner of the copyright $[\ldots] .$. . 
staltend im Sinne der Rechtsprechung anzusehen, wenn dem genutzten Werk durch die Nutzung etwas Neues hinzugefügt wird, etwa durch die Nutzung in einem neuen Zusammenhang, so dass sich Charakter, Wirkung, Aussage oder Bedeutung des Werkes ändern. ${ }^{1003}$ Je transformativer die Nutzung, desto wahrscheinlicher ist, dass dieser Aspekt die Kommerzialität überwiegt und die Nutzung somit als fair anzusehen ist. ${ }^{1004}$ Für die Google Buchsuche werden identische Kopien der Originalwerke angefertigt, denen keine neuen, eigenen Werkteile hinzugefügt werden, so dass keine Transformativität im ursprünglich von der Rechtsprechung verlangten Sinne vorliegt. Dennoch könnte die Nutzung als transformativ anzusehen sein, soweit die Vervielfältigungsstücke in der Buchsuche einem völlig anderen Zweck dienen als die Originalwerke.

Dies ist zumindest bei solchen Werken anzunehmen, bei denen - wie insbesondere bei belletristischen Werken - in aller Regel nur ein Interesse an der vollständigen Lektüre oder jedenfalls der Lektüre längerer zusammenhängender Abschnitte besteht. Insofern lässt sich die Google Buchsuche gut mit der zuvor dargestellten Nutzung urheberrechtlich geschützter Werke als Thumbnails im Rahmen der Bildersuche vergleichen, bei der von den Gerichten eine transformative Nutzung allein aufgrund eines geänderten Nutzungszwecks angenommen wurde. ${ }^{1005}$ In den Urteilen Kelly v. Arriba Soft und Perfect 10 v. Google/Amazon stuften die Gerichte des Ninth Circuit die Werknutzung sogar als äußerst transformativ ein, obwohl identische Vervielfältigungsstücke hergestellt wurden. Die Werknutzung sei dennoch transformativ, da die Thumbnails einem völlig anderen Zweck dienten als die vervielfältigten Originalbilder. Bei den Originalbildern handele es sich um künstlerische Werke, die ästhetischen Zwecken dienten. Die Nutzung durch die Suchmaschinen hingegen verfolge keinerlei ästhetische Zwecke, sondern diene allein als „Werkzeug“, das zum öffentlichen Nutzen den Zugang zu Werken im Internet erleichtere. Für einen ästhetischen Werkgenuss seien die Thumbnails zudem aufgrund ihrer geringen Auflösung weder bestimmt noch geeignet. Trotz der identischen Werknutzung sei diese im Ergebnis transformativ, da dem Werk als Thumbnail eine neue Bedeutung beziehungsweise ein neuer Zweck zu-

1003 Vgl. Campbell v. Acuff-Rose, 510 U.S. 569, 579 (1994).

1004 Vgl. Campbell v. Acuff-Rose, 510 U.S. 569, 580 (1994). So auch ausdrücklich der Court of Appeals for the Second Circuit in der Entscheidung Bill Graham Archives v. Dorling Kindersley Ltd., 448 F.3d 605, 608 ff. (2d Cir. 2006).

1005 Siehe dazu oben 5. Kapitel, B.I. 
komme. ${ }^{1006}$ Auch die Google Buchsuche ermöglicht keinen vollständigen Werkgenuss - das Lesen vollständiger urheberrechtlich geschützter Bücher ist nicht möglich. Von diesen werden nur Snippets angezeigt, die den vom Nutzer gesuchten Text enthalten. Die Buchsuche dient folglich nicht als Werkzeug zum Lesen von Büchern in digitaler Form, sondern ausschließlich als äußerst nützliches Werkzeug zum Auffinden von Büchern beziehungsweise bestimmten Buchinhalten. Google gibt die Werke also nicht lediglich in einem anderen Medium wieder, ${ }^{1007}$ sondern bietet ein durchsuchbares Verzeichnis, das das Lesen eines vollständigen Buches gerade nicht ersetzt. Die Buchsuche verknüpft das Originalwerk zudem mit weiteren Funktionen, zum Beispiel mit Hinweisen auf Bibliotheken, in deren Bestand sich das Buch befindet, oder mit Vorschlägen zu ähnlichen Titeln, die für den Nutzer ebenfalls interessant sein könnten. Die von Google angefertigten vollständigen Werkkopien dienen somit bei diesen Werken - ähnlich wie die Thumbnails - einem völlig neuen Zweck: der Informationsgewinnung und -lokalisierung.

Tatsächlich ist hier die Werknutzung in Form von Snippets sogar von deutlich geringerer Intensität als die Thumbnail-Nutzung. Im Gegensatz zu den verkleinerten Vorschaubildern bei der Bildersuche, die das jeweilige

1006 Vgl. Kelly v. Arriba Soft, 336 F.3d 811, 818 f. (9th Cir. 2003); Perfect 10, Inc. v. Amazon.com, Inc., et al., 508 F.3d 1146, 1155 (9th Cir. 2007). Auch der Court of Appeals for the First Circuit und der Court of Appeals for the Second Circuit haben anerkannt, dass allein die Änderung des Verwendungszwecks einen transformative use darstellen kann; siehe Núñez v. Caribbean Int'l News Corp., 235 F.3d 18, 22 f. (1st Cir. 2000) [Abdruck von Fotografien aus einem ModelPortfolio der „Miss Puerto Rico“ in einer Zeitung im Rahmen der Berichterstattung über eine diese betreffende Kontroverse als transformative Nutzung]; Bill Graham Archives v. Dorling Kindersley Ltd., 448 F.3d 605, 608 ff. (2d Cir. 2006) [Stark verkleinerte, chronologisch geordnete Darstellung von Konzertpostern der Rockband Grateful Dead in einem biographischen Buch über die Musikgruppe als transformative Nutzung der geschützten Bildwerke]. Siehe auch Field v. Google, Inc., 412 F.Supp.2d 1106, 1118 ff. (D. Nev. 2006) [Vervielfältigung und Speicherung der auf Internetseiten aufgefundenen Werke im CacheSpeicher einer Suchmaschine ist transformative use].

1007 Ein solches reines „medium-shifting“" haben Gerichte des Second Circuit bisher gerade nicht als transformative use anerkannt; vgl. Infinity Broadcast Corp. v. Kirkwood, 150 F.3d 104, 108 f. (2d Cir. 1998) [Erneute Übertragung einer Radiosendung über eine Telefonleitung nicht transformativ]; UMG Recordings, Inc. v. MP3.com, Inc., 92 F.Supp.2d 349, 351 (S.D.N.Y. 2000) [Übertragung einer Musik-CD in MP3-Format zum späteren Abruf der Musikstücke über das Internet keine transformative Werknutzung]. 
Bild zwar in verminderter Qualität, jedoch in seiner Gesamtheit erkennen lassen, ermöglichen die Snippets gar keinen vollständigen Werkgenuss. Anders als die Thumbnails bei der Bildersuche können außerdem die dargestellten Textausschnitte bei der Buchsuche auch nicht heruntergeladen oder kopiert werden. Die Werknutzung im Rahmen der Buchsuche ist aufgrund dieses völlig veränderten Werknutzungszwecks und der geringen Eingriffsintensität somit als äußerst transformativ anzusehen. ${ }^{1008}$ Der mit dieser hoch-transformativen Nutzung einhergehende Nutzen für die Allgemeinheit - die Möglichkeit in Millionen Büchern nach Begriffen oder Textteilen zu suchen - rechtfertigt es, das Gewicht der Kommerzialität der Nutzung zurücktreten zu lassen, denn letztlich entsteht dieser positive Effekt für die Allgemeinheit völlig unabhängig davon, ob die Dienstleistung von einem kommerziellen oder nicht-kommerziellen Anbieter erbracht wird, solange diese für den Nutzer kostenlos angeboten wird. ${ }^{1009}$

Trotz der kommerziellen Natur der Nutzung gibt es somit im Ergebnis deutliche Indizien für die Annahme, dass ein Gericht den ersten Fair UseFaktor aufgrund der Transformativität der Werknutzung im Rahmen der Buchsuche und deren erheblichem Nutzen für die Allgemeinheit zugunsten von Google werten würde.

Deutlich anders könnte die Beurteilung durch ein Gericht allerdings ausfallen, soweit es die Digitalisierung wissenschaftlicher Werke und deren Nutzung im Rahmen der Google Buchsuche zu beurteilen hätte. Denn hier gelten die vorherigen Ausführungen zur Transformativität der Werknutzung allenfalls mit deutlichen Einschränkungen. Den Nutzern wissenschaftlicher Literatur wird nicht selten bereits ein Kurzeinblick in das Werk in Form eines oder weniger Snippets genügen, wenn der Ausschnitt die gesuchte Aussage oder Information vollständig enthält und daher die Lektüre eines längeren Abschnittes ersetzt. Dies ist in vielen Fällen vor-

1008 So auch Costantino, 17 Fordham Intell. Prop. Media \& Ent. L.J. 235, 269 ff. (2006); Ganley, 10 No. 5 J. Internet L. 1, 12 (2006); Hetcher, 13 Mich. Telecomm. \& Tech. L. Rev. 1, 37 (2006); Lichtman, Copyright as Innovation Policy, S. 10 f.; Lundeen, 75 UMKC L. Rev. 265, 273 (2006); Na, 16 Cornell J. L. \& Pub. Pol'y 417, 437 ff. (2007); Okano, 3 Shidler J. L. Com. \& Tech. 13 (2007), Rn. 36 ff.; Proskine, 21 Berkeley Tech. L.J. 213, 227 (2006); Romman, 43 Hous. L. Rev. 807, 831 (2006); Sag, 55 N.Y.L. Sch. L. Rev. 19, 27 f. (2010); Travis, 61 U. Miami L. Rev. 87, 126 ff. (2006); a.A. Adler, Google Library Project, S. 12 f.; Glorioso, 38 Hofstra L. Rev. 971, 984 (2010); Hanratty, 2005 Duke L. \& Tech. Rev. 10, Rn. 21.

1009 Vgl. Lee, 83 S. Cal. L. Rev. 797, 848 f., 861 (2010). 
stellbar, in denen die Buchsuche - vergleichbar einer anderen (Fach-) Datenbank - nur zum Auffinden einzelner Belegstellen genutzt wird, um diese anschließend - etwa in einem Schriftsatz - zur Untermauerung der eigenen Auffassung zu zitieren, ohne dass eine vertiefte Auseinandersetzung mit den zu der gefundenen Aussage führenden Überlegungen des Urhebers erforderlich oder gewünscht ist. Auch hier ermöglichen die Snippets zwar keinen vollständigen Werkgenuss. Der „Genuss“ der Snippets ersetzt jedoch in diesen Fällen gerade die - gar nicht vollständig gewünschte weitere Werkwahrnehmung, da die gesuchte Passage bereits in den Snippets enthalten ist. Hier tritt die Dienstleistung des kommerziellen Anbieters Google folglich in unmittelbare Konkurrenz zu den Angeboten anderer kommerzieller Anbieter von wissenschaftlichen Datenbanken mit Volltextsuche, mit dem Unterschied, dass letztere sich für ihre Dienstleistungen die erforderlichen Rechte einräumen lassen haben.

Stellte ein Gericht bei der Fair Use-Prüfung (auch) auf diese Art der Werknutzung ab oder wäre es gar gezwungen, diese schwerpunktmäßig zu berücksichtigen, etwa weil als Kläger wissenschaftliche Verlage auftreten, so ist anzunehmen, dass das Gericht den ersten Fair Use-Faktor aufgrund der fehlenden Transformativität der Werknutzung zu Googles Ungunsten werten würde.

\section{c) Zweiter Faktor: "The Nature of the Copyrighted Work"}

Als zweiten Faktor nennt 17 U.S.C. $§ 107$ die „Nature of the copyrighted

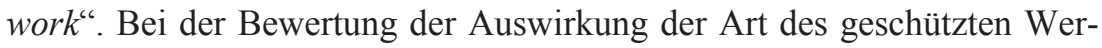
kes auf die Fair Use-Prüfung wird zumeist zunächst auf den Grad der im Originalwerk zum Ausdruck kommenden Kreativität abgestellt. Zeichnet sich das verwendete Werk durch besondere Kreativität aus, so genießt es grundsätzlich einen weiterreichenden Schutz gegen Übernahmen, als ein eher faktisches Werk. ${ }^{1010}$ Neben diesem qualitativen Merkmal kommt zudem der Frage, ob das verwendete Werk zum Zeitpunkt der Benutzung bereits veröffentlicht war, besondere Bedeutung zu. ${ }^{1011}$

Google vervielfältigt für die Buchsuche sämtliche von den Vereinbarungen mit den beteiligten Bibliotheken erfassten Bücher. Eine Auswahl

1010 Vgl. Campbell v. Acuff-Rose, 510 U.S. 569, 586 (1994).

1011 Vgl. Harper \& Row v. Nation Enterprises, 471 U.S. 539, 564 (1985). 
nach Werkarten erfolgt dabei grundsätzlich nicht. Die Buchsuche-Datenbank enthält daher sämtliche denkbaren „Stufen“ von Werktypen: Von rein fakten-basierten, wenig kreativen Darstellungen, deren urheberrechtliche Schutzbedürftigkeit als eher gering angesehen wird, bis zu besonders kreativen und rein fiktionalen Werken, deren Schutz ein besonderes Ziel des US-amerikanischen Urheberrechts ist. Sämtliche von Google digitalisierten Bücher sind jedoch bereits veröffentlicht, da sie sich bereits im Bestand mindestens einer der teilnehmenden Bibliotheken befinden. Bei veröffentlichten Werken ist die Hürde für die Annahme eines Fair Use grundsätzlich weniger hoch als bei unveröffentlichten Werken. Werden solche veröffentlichte Werke verwendet, die nicht mehr gedruckt werden und nicht mehr über ,gewöhnliche Kanäle“ bezogen werden können, so liegt die Annahme eines Fair Use zudem nahe. ${ }^{1012}$ Wie die Diskussion um die Orphan Works und um ein (vermeintliches) diesbezügliches Monopol von Google ${ }^{1013}$ zeigt, trifft dies auf einen nicht unerheblichen Teil der von Google für die Buchsuche digitalisierten Werke zu. Die Tatsachen, dass sämtliche verwendeten Werke bereits publiziert sind, eine erhebliche Zahl bereits „out of print" ist und ein Großteil der aus akademischen Bibliotheken stammenden Bücher eher faktischer Natur sein wird, sprechen zunächst dafür, den zweiten Faktor als neutral oder sogar leicht zugunsten von Google zu werten. ${ }^{1014}$ Werden hingegen besonders kreative Werke im Rahmen der Buchsuche genutzt, die zudem noch ,im Druck“ sind, so spricht der zweite Faktor eher gegen die Annahme eines Fair Use. ${ }^{1015}$ Hat ein Gericht über die Google Buchsuche als Ganzes zu entscheiden, so

1012 Vgl. Senate Report No. 94-473, S. 64 (1975) [„A key, though not necessarily determinative, factor in fair use is whether or not the work is available to the potential user. If the work is "out of print" and unavailable for purchase through normal channels, the user may have more justification for reproducing it than in the ordinary case, but the existence of organizations licensed to provide photocopies of out-of-print works at reasonable cost is a factor to be considered."]; siehe auch Harper \& Row v. Nation Enterprises, 471 U.S. 539, 553 (1985).

1013 Zur Problematik des Entstehens eines Orphan Works-Monopols durch das Google Book Settlement siehe unten 5. Kapitel, B.II.2.

1014 Vgl. Hetcher, 13 Mich. Telecomm. \& Tech. L. Rev. 1, 40 (2006); Lundeen, 75 UMKC L. Rev. 265, 275 (2006); Sag, 55 N.Y.L. Sch. L. Rev. 19, 24 (2010); Travis, 61 U. Miami L. Rev. 87, 128 f. (2006).

1015 Vgl. Bisk, 17 Alb. L.J. Sci. \& Tech. 271, 294 (2007); Ganley, 10 No. 5 J. Internet L. 1, 12 (2006); Na, 16 Cornell J. L. \& Pub. Pol'y 417, 442 (2007); Proskine, 21 Berkeley Tech. L.J. 213, 228 (2006); Romman, 43 Hous. L. Rev. 807, 833 (2006). 
sprechen gute Argumente dafür, den zweiten Faktor eher zuungunsten von Google zu bewerten, da keine Einzelauswahl der Werke erfolgt und somit auch kreative Werke gescannt werden, die als besonders schutzbedürftig angesehen werden. ${ }^{1016}$ Unabhängig vom Grad der Kreativität des jeweiligen Werkes ist zudem zu bedenken, dass die von Google digitalisierten Werke zwar bereits veröffentlicht, allerdings - anders als im Falle der Darstellung von Webinhalten als Thumbnails - bisher in der Regel nicht in digitaler Form und nicht im Internet verfügbar waren. ${ }^{1017}$ Google ändert folglich im Rahmen des Buchsuche-Projekts die „Natur“ der zuvor nur in analoger Form zugänglichen Werke. Diese Übertragung in ein neues Medium spricht dafür, den Werken einen gesteigerten Schutz gegen eine ungenehmigte Verwendung zu gewähren, da diese Art der Werknutzung nicht der Form der vom Urheberrechtsinhaber konsentierten Veröffentlichung entspricht. Ein mit der Frage des Fair Use befasstes Gericht könnte daher die Werknutzung im Rahmen der Buchsuche eher so bewerten wie die Nutzung unveröffentlichter Werke. Auch bei diesen ist die Annahme eines Fair Use nicht grundsätzlich ausgeschlossen, sie bedarf jedoch einer besonders starken Legitimation durch die übrigen Fair Use-Faktoren. ${ }^{1018}$ Im Ergebnis spricht der zweite Faktor der Fair Use-Analyse somit eher (leicht) gegen die Annahme einer fairen Benutzung. ${ }^{1019}$

d) Dritter Faktor: "The Amount and Substantiality of the Portion Used"

Im Rahmen der Prüfung des dritten Faktors der Fair Use-Prüfung sind Umfang und Bedeutung des übernommenen Werkteils (,Amount and substantiality of the portion used") ins Verhältnis zum gesamten Originalwerk zu setzen, wobei sowohl eine quantitative als auch eine qualitative Betrachtung vorzunehmen sind. Werden nur minimale Teile des Originalwerkes übernommen, so liegt die Möglichkeit einer fairen Benutzung grundsätzlich näher als bei einer Übernahme in einem quantitativ größeren Um-

1016 Vgl. Glorioso, 38 Hofstra L. Rev. 971, 984 f. (2010).

1017 Vgl. Wilhelm, 33 Rutgers Computer \& Tech. L.J. 107, 127 f. (2006).

1018 Vgl. oben 2. Kapitel, C.I.2.b)bb).

1019 So im Ergebnis ebenfalls Bisk, 17 Alb. L.J. Sci. \& Tech. 271, 294 (2007); Gamble, 9 Tul. J. Tech. \& Intell. Prop. 365, 380 (2007); Ganley, 10 No. 5 J. Internet L. 1, 12 (2006); Na, 16 Cornell J. L. \& Pub. Pol'y 417, 442 (2007); Okano, 3 Shidler J. L. Com. \& Tech. 13 (2007), Rn. 46; Romman, 43 Hous. L. Rev. 807, 833 f. (2006); Wilhelm, 33 Rutgers Computer \& Tech. L.J. 107, 128 (2006). 
fang. Die vollständige Übernahme eines fremden Werkes ist zwar ein deutliches Indiz gegen die Annahme eines Fair Use, schließt diese aber auch nicht grundsätzlich aus. ${ }^{1020}$

Google kopiert den vollständigen Text von Millionen Büchern und speichert diesen in seiner Datenbank. Es wird somit zwangsläufig auch das „Herz“ eines jeden Werkes, das heißt der qualitativ wesentlichste Teil, kopiert. Eine rein quantitative und qualitative Betrachtung spräche somit eindeutig gegen die Annahme einer fairen Benutzung. ${ }^{1021}$ Der dritte Faktor ist jedoch auch im Lichte des Zwecks der Vervielfältigung zu betrachten. ${ }^{1022}$ Den Endnutzern werden bei der Google Buchsuche nicht die vollständigen urheberrechtlich geschützten Werke angezeigt, sondern nur kurze Textauszüge, die den Suchbegriff enthalten. Diese Snippet-Anzeige erfordert jedoch eine vollständige Durchsuchbarkeit des Originalwerkes. Ohne eine vollständige Kopie der Werke könnte Google die Buchsuche in ihrer derzeitigen Form daher nicht anbieten, da eine Volltextsuche ohne die Digitalisierung der Werke und deren Überführung in einen maschinenlesbaren Text nicht möglich wäre. Google kopiert daher nur so viel wie zwingend erforderlich ist. Ebenso wie in der „Thumbnail"-Rechtsprechung scheint es daher naheliegend, den dritten Faktor auch hinsichtlich der Buchsuche neutral zu werten. ${ }^{1023}$ Bei genauerer Betrachtung unterscheiden sich die Sachverhalte bei der Google Buchsuche und den bisherigen Urteilen, insbesondere auch denen zur Thumbnail-Nutzung, jedoch erheblich: In den Fällen, in denen bisher trotz der vollständigen Übernahme eines Werkes zu kommerziellen Zwecken ein Fair Use anerkannt wurde, wurden stets nur vorübergehend vollständige Kopien des Originalwerkes in Originalgröße und -qualität erstellt, die anschließend wieder gelöscht wurden.. ${ }^{1024}$ Anders als in diesen Fällen bleiben für die Google Buchsuche

1020 Vgl. Hustler Magazine Inc. v. Moral Majority Inc., 796 F.2d 1148, 1155 (9th Cir. 1986); Worldwide Church of God v. Philadelphia Church of God, Inc., 227 F.3d 1110, 1118 (9th Cir. 2000).

1021 Vgl. Sony v. Universal, 464 U.S. 417, 449 f. (1984).

1022 Vgl. Kelly v. Arriba Soft Corp., 336 F.3d 811, 820 (9th Cir. 2003).

1023 So etwa Band, Google Library Project, S. 5; Costantino, 17 Fordham Intell. Prop. Media \& Ent. L.J. 235, 272 f. (2006); Okano, 3 Shidler J. L. Com. \& Tech. 13 (2007), Rn. 47; Proskine, 21 Berkeley Tech. L.J. 213, 228 (2006); Varian, Google Library Project, S. $11 \mathrm{f}$.

1024 Siehe Sega Enterprises Ltd. v. Accolade, Inc., 977 F.2d 1510, 1526 f. (9th Cir. 1992) und Sony Computer Entertainment, Inc. v. Connectix Corp., 203 F.3d 596, 606 (9th Cir. 2000) [Vorübergehende vollständige Vervielfältigung eines 
jedoch dauerhaft die vollständigen Kopien in ihrer ursprünglichen Qualität in der Datenbank, da nur so eine Volltextsuche und die Anzeige der korrespondierenden Snippets möglich ist. Auch hier ist jedoch zu bedenken, dass der dritte Faktor im Lichte des ersten Fair Use-Faktors, insbesondere also des Zwecks der Werknutzung, zu betrachten ist. Ist die vollständige Vervielfältigung des Originalwerkes aus technischen Gründen notwendig, da ohne diesen Zwischenschritt die neue Nutzungsform nicht realisierbar wäre, so kann ein Fair Use allein aufgrund der Anfertigung einer - auch dauerhaften - Kopie nicht ausgeschlossen sein. ${ }^{1025}$ Dies muss inbesondere gelten, wenn die endgültige „sichtbare“ Nutzung - wie im Falle der Google Buchsuche, bei der den Nutzern letztlich nur Snippets der vollständig vervielfältigten Werke angezeigt werden - äußerst begrenzt ist. ${ }^{1026}$ Es sprechen demnach trotz der dauerhaften Speicherung vollständiger Vervielfältigungsstücke der Originalwerke gute Gründe dafür, auch im Fall der Google Buchsuche den dritten Fair Use-Faktor als neutral zu werten.

Von diesen Überlegungen nicht erfassen lässt sich allerdings die Weitergabe einer digitalen Kopie des Werkes von Google an die jeweilige Bibliothek, aus deren Bestand das Buch stammte. Die Anfertigung vollständiger Kopien soll nach Auffassung der Rechtsprechung im Rahmen der Fair Use-Doktrin die seltene Ausnahme bleiben und ist daher nur unter besonderen, engen Voraussetzungen als gerechtfertigt angesehen worden. Bei einer Betrachtung des dritten Fair Use-Faktors im Lichte des ersten Faktors kann dieser erhebliche Eingriff - wie gezeigt - insbesondere dann gerechtfertigt sein, wenn die vollständige Vervielfältigung zur Erreichung

Computerprogrammes zum Zwecke des Reverse Engineering]; Ty, Inc. v. Publications Intern. Ltd., 292 F.3d 512, 522 (7th Cir. 2002) [Vervielfältigung eines dreidimensionalen Originalwerkes in Form eines zweidimensionalen Bildes zum Abdruck in einem Katalog bzw. Sammlerleitfaden]; Kelly v. Arriba Soft Corp., 336 F.3d 811, 815 (9th Cir. 2003); Perfect 10, Inc. v. Amazon.com, Inc., et al., 508 F.3d 1146 (9th Cir. 2007) [Dauerhafte Speicherung eines Vervielfältigungsstücks in verminderter Qualität, aber zur Erstellung der Thumbnails erforderliche Kopie des Originalwerkes in voller Größe anschließend wieder aus dem (Zwischen)Speicher gelöscht].

1025 So auch Patry, Fair Use (2009), § 5:3; Sag, 55 N.Y.L. Sch. L. Rev. 19, 32 f. (2010).

1026 Vgl. Glorioso, 38 Hofstra L. Rev.971, 985 (2010); Hetcher, 13 Mich. Telecomm. \& Tech. L. Rev. 1, 51 f. (2006); Lee, 83 S. Cal. L. Rev. 797, 845 f. (2010); Travis, 84 Notre Dame L. Rev 331, 395 f. (2008). 
eines als wünschenswert angesehenen Nutzungszweckes technisch zwingend notwendig ist. Die von Google weitergegebenen "Library Copies" sind für die Durchführung der Buchsuche jedoch nicht technisch zwingend erforderlich. Das Angebot einer Volltextsuche in den Büchern und deren Verknüpfung mit weiteren Dienstleistungen wäre auch ohne die Weitergabe der digitalen Kopien an die beteiligten Bibliotheken technisch möglich. Dass der Erhalt einer digitalen Kopie der Bibliotheksbestände tatsächlich ein entscheidender Grund für die Teilnahme einiger Bibliotheken am Bibliotheksprogramm sein mag, muss insofern außer Betracht bleiben. Letztlich handelt es sich bei den „Library Copies“ um eine geldwerte Gegenleistung für die Teilnahme am Bibliotheksprogramm. Eine solche „Bezahlung" mit Kopien fremder Werke für deren Ausleihe stellt jedoch keinesfalls eine als Fair Use privilegierenswerte Handlung dar. Der Copyright Act enthält in 17 U.S.C. $§ 108$ eine ausdrückliche und äußerst detaillierte Regelung für die Vervielfältigung urheberrechtlich geschützter Werke durch Bibliotheken zu Zwecken der Archivierung. ${ }^{1027}$ Die Erstellung (digitaler) Archivkopien setzt voraus, dass diese zur Erhaltung beziehungsweise Ersetzung eines Werkes erforderlich ist, da das im Bestand der Bibliothek befindliche Exemplar beschädigt ist und ein anderes Exemplar nicht zu einem fairen Preis beschafft werden kann. ${ }^{1028}$ Diese engen Voraussetzungen mögen bei den von Google erstellten digitalen Kopien in wenigen Einzelfällen erfüllt sein, in aller Regel werden sie jedoch nicht vorliegen. Es ist sogar davon auszugehen, dass besonders stark beschädigte Werke gerade nicht von Google gescannt werden, da diese aufgrund ihres schlechten Zustandes entweder bereits unbrauchbar sind oder jedenfalls nicht weiter beschädigt werden sollen. Zudem ist bisher unklar, wie genau die teilnehmenden Bibliotheken die erhaltenen digitalen Kopien verwenden werden. Es ist zumindest nicht ausgeschlossen, dass - insbesondere im Falle eines Fair Use-Urteils zugunsten von Google - weitergehende Nutzungen als die reine Verwendung zur Archivierung erfolgen würden, so dass durch die von Google weitergegebenen Vervielfältigungsstücke weitere Beeinträchtigungen der Rechte der Urheberrechtsinhaber drohen. Hinsichtlich der Weitergabe der digitalen Kopien an die Biblio-

1027 Zum Verhältnis der in 17 U.S.C. § 108 ausdrücklich normierten Library Exemption zur Generalklausel des Fair Use und der Gefahr der Umgehung der spezifischen Vorgaben des 17 U.S.C. § 108 durch eine überdehnende Anwendung des Fair Use, siehe unten 5. Kapitel, B.II.1.g).

1028 Siehe 17 U.S.C. $§ 108(c)(1)$, (e). 
theken spricht der dritte Faktor somit (stark) gegen die Annahme eines Fair Use. ${ }^{1029}$

e) Vierter Faktor: "The Effect of the Use upon the Potential Market for or Value of the Copyrighted Work"

Ziel des vierten Faktors ist es, die nach der incentive-Theorie durch die Gewährung eines Urheberrechts gesetzten finanziellen Anreize für kreatives Schaffen zu schützen. ${ }^{1030} \mathrm{Zu}$ diesem Zweck sind im Rahmen des vierten Fair Use-Faktors die Auswirkungen der Werknutzung auf den Marktwert des genutzten Werkes zu bewerten, wobei sowohl tatsächliche Effekte auf bereits bestehende Märkte als auch mögliche Auswirkungen auf potentielle Märkte zu beachten sind, insbesondere auch solche, die durch eine künftige weite Verbreitung der fraglichen Nutzung entstehen könnten. ${ }^{1031}$ Entscheidende Bedeutung für das Ergebnis der Fair Use-Analyse kommt somit der Definition der relevanten Märkte zu, denn bei einer eher engen Bestimmung ist die Annahme einer fairen Benutzung deutlich wahrscheinlicher als bei einer sehr weiten Definition der Märkte. In Fällen wie diesem, in denen aufgrund des technischen Fortschritts neue Formen der Werknutzung entstehen, stellt sich diese Analyse oftmals als besonders schwierig dar, da sich entsprechende Märkte entweder gerade erst entwickeln oder noch nicht einmal absehbar sind, so dass sich auch ein tatsächlicher oder möglicher Schaden insbesondere in Form entgangener Lizenzeinnahmen kaum zweifelsfrei nachweisen oder begründen lässt. Einen entscheidenden Anhaltspunkt kann insoweit auch für den vierten Fair Use-Faktor die Frage der Transformativität der Nutzung darstellen. Je transformativer die Nutzung, desto unwahrscheinlicher ist grundsätzlich ein nachteiliger Einfluss auf bestehende Märkte und auch auf potentielle

1029 So im Ergebnis auch Lee, 83 S. Cal. L. Rev. 797, 863 (2010); Manuel, Google Library Project, S. 8; Vaidhyanathan, 40 U.C. Davis L. Rev. 1207, $1229 \mathrm{f}$. (2007); a.A. Hetcher, 13 Mich. Telecomm. \& Tech. L. Rev. 1, 57 (2006), der davon ausgeht, die Weitergabe einer vollständigen digitalen Kopie an die Bibliotheken verhindere die Entstehung eines Buch-Monopols von Google und sei daher im Lichte des ersten Faktors gerechtfertigt.

1030 Vgl. Lichtman, Copyright as Innovation Policy, S. 14.

1031 Vgl. Harper \& Row v. Nation Enterprises, 471 U.S. 539, 568 (1985). 
Märkte, da transformative Formen der Werknutzung in der Regel nicht im Wettbewerb mit bestehenden Nutzungsformen stehen. ${ }^{1032}$

In Bezug auf die Google Buchsuche in ihrer derzeitigen Ausgestaltung ${ }^{1033}$ kommen insbesondere vier Märkte in Betracht, die durch die Nutzung urheberrechtlich geschützter Werke beeinträchtigt sein könnten: (1) der Markt für den Verkauf kompletter Bücher in Print- oder digitaler Form, (2) der Markt für kommerzielle (Fach-)Datenbanken mit Volltextsuchangeboten insbesondere für wissenschaftliche Werke, (3) der Markt für die Lizenzierung von Buchauszügen für die Verwendung in Suchmaschinen und (4) der Markt für den Verkauf digitaler Werkexemplare an Bibliotheken zum Zwecke der Archivierung.

aa) Beeinträchtigung des bestehenden Buchmarktes

Bei dem erstgenannten Markt für den Verkauf von Büchern als „Hard Copy" oder in digitaler Form an Endnutzer handelt es sich um den (derzeitigen) Hauptmarkt für Druckerzeugnisse. Gegen eine Rechtfertigung der Werknutzung im Rahmen der Buchsuche als Fair Use würden demnach jedenfalls dann ganz erhebliche Bedenken bestehen, wenn dieser Markt negativ beeinflusst würde, die Verleger und Autoren also aufgrund der Verfügbarkeit ihrer Werke in der Buchsuche geringere Einnahmen hätten. ${ }^{1034}$ Ein solcher Effekt erscheint jedoch jedenfalls im Hinblick auf den Markt für belletristische Werke tatsächlich fernliegend. Die Google Buchsuche ermöglicht den Nutzern kein vollständiges Lesen der Bücher, sondern gewährt lediglich in Form von Snippets Einblicke in urheberrechtlich geschützte Werke. Zwar entsprechen die angezeigten Snippets insofern genau dem „Bedürfnis“ des Nutzers, als sie die von ihm gesuchten Worte enthalten. Dennoch wird in aller Regel der so aufgefundene kurze Textausschnitt den Bedarf des Nutzers nicht vollständig decken, sondern diesem lediglich zeigen, ob das aufgefundene Buch inhaltlich relevant ist.

1032 Vgl. Campbell v. Acuff-Rose, 510 U.S. 569, 591 (1994); Kelly v. Arriba Soft Corp., 336 F.3d 811, 821 (9th Cir. 2003).

$1033 \mathrm{Zu}$ möglichen Änderungen aufgrund des Google Book Settlements siehe unten 5. Kapitel, B.II.2.

1034 Für eine umfassende Analyse der ökonomischen Auswirkungen der Google Buchsuche auf die Umsätze und Gewinne von Verlegern siehe Travis, 57 J. Copyright Soc'y U.S.A. 907, 929 ff. (2010). 
Um das ganze Buch oder längere Abschnitte zu lesen, muss der Nutzer es weiterhin kaufen oder in einer Bibliothek einsehen. Entscheidet der Nutzer sich aufgrund des bereits Gesehenen gegen den Kauf eines Buches, so kann dies nicht als negative Auswirkung auf den Markt betrachtet werden. Auch in einer Buchhandlung hätte ein potentieller Käufer

beispielsweise die Möglichkeit, zunächst einige Passagen des Buches zu ,überfliegen“ und sich dann gegen einen Kauf zu entscheiden. Tatsächlich wird jedoch das Gegenteil oftmals die Folge der durch die Buchsuche ermöglichten Vorschau sein. Nicht selten wird sich ein Nutzer gerade aufgrund der mit Hilfe der Buchsuche aufgefundenen interessanten Stellen in einem Werk für den Kauf eines Buches entscheiden. ${ }^{1035}$ So zeigen etwa erste Erfahrungen mit dem Google Partnerprogramm oder der von Amazon in Kooperation mit einigen Verlagen angebotenen Buchvorschau Search Inside!, dass diese den Verkauf eher fördern als ihn zu bremsen. ${ }^{1036}$ Diese Erfahrungen stehen auch im Einklang mit Erkenntnissen aus verhaltensökonomischen Untersuchungen, die ergeben haben, dass die Nachfrage nach einem Produkt und somit auch die Wahrscheinlichkeit, dieses $\mathrm{zu}$ kaufen, mit dem Umfang der einem Verbraucher zu diesem Produkt zur Verfügung stehenden Informationen steigt, wobei gerade den Möglichkeiten, das Produkt anzuschauen, zu untersuchen oder zu testen, erhebliche Bedeutung zukam. ${ }^{1037}$ Anders als bei Online-Buchhändlern, auf deren Webseiten der Nutzer ein Buch in der Regel nur bei (relativ) genauer Suche nach Autor und/oder Titel finden wird, ermöglicht die Google Buchsuche zudem nicht selten echte "Zufallsfunde“. Oftmals wird der Nutzer durch die Volltextsuche in allen in der Datenbank enthaltenen Büchern auf Werke aufmerksam gemacht, die seinem Suchbegriff genau entsprechen, ihm aber vorher vollkommen unbekannt waren, etwa weil sie in seinem Land gewöhnlich nicht im Handel erhältlich sind. Gerade bei diesen Wer-

1035 Vgl. Romman, 43 Hous. L. Rev. 807, 839 f. (2006).

1036 Laut Ganley, 10 No. 5 J. Internet L. 1, 13 (2006) (unter Hinweis auf AmazonGründer Jeff Bezos) und Proskine, 21 Berkeley Tech. L.J. 213, 229 (2006) hat Amazons Search Inside!-Programm zu einem Verkaufsanstieg um neun Prozent bei den durchsuchbaren Büchern im Vergleich zu nicht durchsuchbaren Büchern geführt. Siehe auch die von Google zum Buchsuche Partner-Programm veröffentlichten „Erfolgsgeschichten von Partnern“, abrufbar unter: http:// www.google.com/intl/de/googlebooks/success.html [zuletzt abgerufen am 26.5.2013].

1037 Vgl. Pasquale, 55 Case W. Res. L. Rev. 777, 806 f. (2005); Romman, 43 Hous. L. Rev. 807, 825 ff. (2006), jeweils m.w.N. 
ken wird durch einen kurzen Snippet-Einblick oftmals ein gegenüber dem Zustand ohne Einblickmöglichkeit deutlich gesteigerter Kaufanreiz festzustellen sein. ${ }^{1038}$ In Verbindung mit den von Google angebotenen Links zu Internetseiten von Anbietern, bei denen das gefundene Buch gekauft werden kann, wird es für den Nutzer zudem besonders einfach und verlockend gestaltet, ein Buch schnell und unkompliziert zu bestellen. ${ }^{1039}$ Es sprechen somit gute Gründe dafür, dass die Buchsuche aufgrund der transformativen Art der Werknutzung eher einen Werbeeffekt zugunsten der Verleger und Autoren hat und den Verkauf von Büchern fördern wird, als diesen zu verringern.

Auch im Falle der Thumbnails haben die Gerichte angenommen, dass diese aufgrund ihrer stark verminderten Qualität gegenüber dem Originalwerk nicht geeignet sind, um dieses zu ersetzen und somit den Markt für dieses negativ zu beeinträchtigen. Bei der Google Buchsuche werden die Originalwerke bei der endgültigen Anzeige in Form von Snippets sogar noch in deutlich geringerem Umfang genutzt, da ein Genuss des gesamten Werkes nicht möglich ist. Die Google Buchsuche verringert oder ersetzt vielfach nicht den Bedarf nach ganzen Büchern, sondern fügt diesen durch die Indexierung und das Durchsuchbarmachen neue Funktionen hinzu, ohne dem Nutzer in aller Regel das Lesen des vollständigen Buches zu ,ersparen". ${ }^{1040}$ Es ist daher davon auszugehen, dass die Gerichte negative Auswirkungen auf den bestehenden Buchmarkt durch die Google Buchsuche nicht feststellen werden, so dass im Hinblick auf diesen Markt der vierte Fair Use-Faktor zugunsten der Annahme einer fairen Benutzung spricht. ${ }^{1041}$

1038 Vgl. Band, 3 J. Bus. \& Tech. L. 1, 21 (2008).

1039 Einen nicht unerheblichen Einfluss mag insofern auch die Tatsache haben, dass Bücher im Internet oftmals deutlich schneller und ,unüberlegter“ gekauft werden als in einem Ladengeschäft.

1040 Es ist jedoch - neben den Fällen der gesondert zu betrachtenden wissenschaftlichen Werke (dazu unten 5. Kapitel, B.II.1.e)bb)) - auch in anderen Einzelfällen denkbar, dass ein Snippet tatsächlich das Lesen des gesamten Werkes oder größerer Teile des Originalwerkes ersetzt, etwa bei Wörterbüchern oder Zitatesammlungen, bei denen tatsächlich die gesamte Information, die der Nutzer sucht, in einem Snippet angezeigt wird.

1041 So auch Bisk, 17 Alb. L.J. Sci. \& Tech. 271, 296 (2007); Costantino, 17 Fordham Intell. Prop. Media \& Ent. L.J. 235, 275 f. (2006); Ganley, 10 No. 5 J. Internet L. 1, 13 (2006); Glorioso, 38 Hofstra L. Rev. 971, 987 (2010); Hetcher, 
Anders wäre dies allerdings zu bewerten, wenn aufgrund von Sicherheitslücken beim Scannen oder Speichern der vollständigen digitalen Kopien der Bücher auf Googles Servern oder durch mangelnde Absicherung der Buchsuche-Webseite gegen den Download ganzer Bücher ${ }^{1042}$ diese Vervielfältigungsstücke in die Hände Dritter gelangten, die diese beispielsweise in Peer-to-Peer-Tauschnetzwerken zugänglich machten. Dann bestünde eine reale Gefahr und Wahrscheinlichkeit, dass (zumindest) der Markt für den Verkauf digitaler Kopien und e-Books negativ beeinflusst würde. ${ }^{1043}$

bb) Beeinträchtigung des Marktes für die Lizenzierung zur digitalen Werknutzung in kommerziellen (Fach-)Datenbanken mit Volltextsuchangeboten insbesondere für wissenschaftliche Werke

Deutlich anders kann sich die Bewertung der Marktfolgen jedoch - ebenso wie hinsichtlich des ersten Faktors ${ }^{1044}$ - bei der Beurteilung der Auswirkungen der Google Buchsuche auf den Markt für die kommerzielle Online-Vermarktung wissenschaftlicher Werke im Rahmen von (Fach-)Datenbanken mit Volltextsuchangeboten darstellen. Hier stellt sich die durch Google angebotene Form der Werknutzung im Wesentlichen nicht als transformativ dar, da den Nutzern wissenschaftlicher Literatur nicht selten bereits ein Kurzeinblick in das Werk in Form eines oder weniger Snippets zur Befriedigung ihres Werkinteresses genügt. In Bezug gerade auf wissenschaftliche Werke wird die Google Buchsuche nicht selten nur zum Auffinden einzelner Belegstellen genutzt werden, um diese anschließend in einem eigenen (wissenschaftlichen) Werk zu zitieren, ohne dass eine vertiefte Auseinandersetzung mit den zu der gefundenen Aussage führenden Überlegungen des Urhebers erforderlich oder gewünscht ist. Enthält der mittels der Buchsuche aufgefundene Werkausschnitt die gesuchte

13 Mich. Telecomm. \& Tech. L. Rev. 1, 45 f. (2006); Na, 16 Cornell J. L. \& Pub. Pol'y 417, 445 (2007); Proskine, 21 Berkeley Tech. L.J. 213, 229 f. (2006); Romman, 43 Hous. L. Rev. 807, 837 ff. (2006); Shah, 15 CommLaw Conspectus 569, 607 (2007); Suarez, 55 N.Y.L. Sch. L. Rev. 175, 186 f. (2010); Travis, 57 J. Copyright Soc'y U.S.A. 907, 929 ff. (2010); Varian, Google Library Project, S. 9 f.; Wilhelm, 33 Rutgers Computer \& Tech. L.J. 107, 131 (2006).

1042 Siehe zu derartigen Bedenken oben Fn. 451 und 541.

1043 Vgl. Lichtman, Copyright as Innovation Policy, S. 15.

1044 Siehe dazu oben 5. Kapitel, B.II.1.b). 
Aussage oder Information vollständig, so ersetzt das Snippet die weitere Lektüre des Werkes oder eines längeren Abschnittes.

Hier tritt die Dienstleistung des (kommerziellen) Anbieters Google somit in unmittelbare Konkurrenz zu den Angeboten anderer kommerzieller Anbieter wissenschaftlicher (Fach-)Datenbanken mit der Möglichkeit einer Volltextsuche. Anders als die derzeit am Markt aktiven Anbieter derartiger Datenbanken ${ }^{1045}$ hat Google jedoch gerade nicht von den Verlagen die Rechte für eine solche Dienstleistung erworben. Würde die Werknutzung durch Google im Rahmen der Buchsuche als Fair Use anerkannt, so drohten folglich ganz erhebliche Auswirkungen auf den (bereits bestehenden) Markt für die Werklizenzierung für die Nutzung in Fachdatenbanken. Wissenschaftliche Fachverlage wären dann voraussichtlich nicht mehr in der Lage, die derzeit aufgrund der Exklusivität ihrer Angebote erzielten (oftmals hohen) Preise für die Möglichkeit der Werknutzung zu erzielen und dementsprechend nicht bereit, entgeltliche Lizenzen einzuholen.

Auch wenn man eine solche Belebung des in vielen Bereichen der Wissenschaft - gerade in den Naturwissenschaften - fast vollständig fehlenden Wettbewerbs auf Anbieterseite begrüßen mag, ${ }^{1046}$ so ist jedenfalls nicht auszuschließen, dass ein mit der Fair Use-Prüfung befasstes Gericht den vierten Fair Use-Faktor aufgrund der direkten Konkurrenz der Buchsuche zu einem tatsächlich bereits bestehenden Markt für die kommerzielle Online-Vermarktung wissenschaftlicher Werke im Rahmen von (Fach-)Datenbanken mit Volltextsuchangeboten (deutlich) zu Googles Ungunsten werten würde. Ebenso denkbar ist jedoch auch, dass das Gericht die dargestellten Auswirkungen als willkommenes Mittel zur Steuerung eines Marktes sehen würde, auf dem aufgrund eines fehlenden Anbieterwettbewerbs und der Exklusivität der angebotenen Leistungen ein (teilweises) Marktversagen festzustellen ist - und damit eher zu Googles Gunsten werten könnte.

1045 Im juristischen Bereich sind dies für den amerikanischen Markt insbesondere WestLaw und LexisNexis, für den deutschen Markt insbesondere beck-online und juris.

1046 Kritisch zu der derzeit zu beobachtenden Abnahme der Verfügbarkeit wissenschaftlicher Werke für wissenschaftliche Nutzer durch überhöhte Preise aufgrund des fehlenden Wettbewerbs auf Anbieterseite im Bereich wissenschaftlicher Online-Angebote Hilty, GRUR 2009, 633 ff. 
cc) Beeinträchtigung des (potentiellen) Marktes für die Lizenzierung digitaler Werkexemplare zur Verwendung im Rahmen der Volltextsuche in Suchmaschinen

Auch wenn der bestehende Buchmarkt nicht durch die Google Buchsuche beeinträchtigt wird, könnte ein anderer Markt durch diese negativ beeinflusst werden. $\mathrm{Zu}$ denken ist hier insbesondere an die von den Urheberrechtsinhabern geltend gemachte Beeinträchtigung des von Google mit der Buchsuche betretenen Marktes zur Ermöglichung von Volltextsuchen in Büchern und eine anschließende (Snippet-)Vorschau. Eine Volltextsuche ist - wie gezeigt - nur möglich, wenn der Suchanbieter den vollständigen Text eines Werkes in maschinenlesbarer Schrift in seiner Datenbank gespeichert oder zumindest Zugriff auf diesen Volltext hat, denn nur dann können einzelne Suchanfragen mit dem Inhalt des Buches abgeglichen werden. Die Rechteinhaber könnten ein rechtlich beachtliches Interesse daran haben, ihre Werke für eine derartige Nutzung im Rahmen von Suchmaschinen zu lizenzieren. Ein Markt für den Verkauf von Snippets besteht (bisher) nicht. Dass jedoch eine Lizenzierung vollständiger Werke für die Ermöglichung einer Volltextsuche und die anschließende vollständige oder beschränkte Darstellung der Bücher nicht nur einen potentiellen, sondern tatsächlich einen realen und auch lukrativen Markt bildet, zeigt die Tatsache, dass bereits mehrere solcher Angebote bestehen, die - abgesehen von der Google Buchsuche - alle auf Kooperationen mit den Rechteinhabern basieren ${ }^{1047}$ oder von den Rechteinhabern selbst betrieben werden. ${ }^{1048}$ Diesen Markt könnte die Buchsuche beeinträchtigen, denn wenn alle oder viele Bücher eines Verlegers bereits in Googles Angebot im Volltext durchsuchbar sind, wird sich zumeist für einen Dritten eine Lizenzierung der Werke für eine entsprechende Volltextsuche und die Anzeige von Textauszügen ebenso wenig lohnen wie die (kostenintensive) Etablierung einer eigenen Volltextsuchmaschine durch einen oder mehrere

1047 Etwa Amazons Search Inside!-Programm, das Partner-Programm bei der Google Buchsuche, das europäische Projekt Europeana (das neben gemeinfreien Werken auch Werke enthält, deren Rechteinhaber der Nutzung zugestimmt haben) und das Project Gutenberg (das ebenfalls Bücher enthält, die mit Zustimmung der Rechteinhaber zugänglich gemacht werden, und Bücher, deren Copyright in den USA abgelaufen ist).

1048 Etwa die Plattform libreka! des Börsenvereins des Deutschen Buchhandels e.V., die Volltextsuche des Langenscheidt Verlags und der „Buchscanner“ von Galileo Press. 
Rechteinhaber selbst. Auch wenn einem Dritten durch die Erteilung einer Lizenz eine weitergehende Vorschau erlaubt würde als die Snippet-Anzeige bei Google - etwa die Anzeige mehrerer zusammenhängender vollständiger Seiten eines Buches wie bei Amazons Search Inside! -, droht dennoch eine Marktbeeinträchtigung durch die Google Buchsuche. Allein die Tatsache, dass ein bestimmtes Buch bereits im Volltext durchsuchbar und ein Vorschau in gewissem Umfang möglich ist, nimmt dem Angebot eines möglichen Lizenznehmers die Exklusivität, die oftmals gerade ein entscheidender Grund für den Abschluss einer Lizenz ist. Es erscheint daher wahrscheinlich, dass zumindest der vom Rechteinhaber für die Lizenzierung zu erzielende Preis durch die Aufnahme seines Werkes in die Google Buchsuche negativ beeinflusst wird. Es ist insoweit auch unerheblich, dass Rechteinhaber teilweise bereit sein mögen, ihre Werke - wie im Falle des Buchsuche Partner-Programms - ohne die Zahlung einer unmittelbaren Lizenzgebühr für die Volltextsuche zur Verfügung zu stellen, denn die Teilnahme an allen derartigen Modellen wird zumindest mittelbar in Form der Partizipation an Verkäufen oder Werbeeinnahmen vergütet. Diese Partizipationsmöglichkeit besteht im Falle der zustimmungslosen Verwendung fremder Werke in der Google Buchsuche nicht. Ein Rechteinhaber kann sich zwar auch nachträglich noch für eine Teilnahme am PartnerProgramm entscheiden und somit an den mit seinen Werken erzielten Erlösen partizipieren; an bereits erzielten Erlösen partizipiert er jedoch in diesem Fall nicht rückwirkend. Zudem ist zu bedenken, dass bei einem Rechteinhaber, der nur an Googles Partner-Programm teilnimmt, um überhaupt ein „Stück vom Kuchen“ zu bekommen, die Entscheidungsfreiheit hinsichtlich der Art der Verwertung seiner Werke am Markt erheblich beeinträchtigt wird. Gerade das „Ob“ und „Wie“ der Werkverwertung stellt jedoch einen wesentlichen Schutzaspekt des Urheberrechts dar. ${ }^{1049}$ Durch die Schaffung von Tatsachen in Form der Digitalisierung fremder Werke ohne Zustimmung der Rechteinhaber wird diese Freiheit ganz erheblich beschränkt.

1049 Vgl. BMG Music v. Gonzalez, 430 F.3d 888, 891 (7th Cir. 2005): „Copyright law lets authors make their own decisions about how best to promote their works; copiers [...] cannot ask courts (and juries) to second-guess the market and call wholesale copying "fair use" if they think that authors err in understanding their own economic interests or that Congress erred in granting authors the rights in the copyright statute.". 
Die Google Buchsuche beeinträchtigt den bereits existierenden und sich weiter entwickelnden Markt für die Lizenzierung von Werken für die Volltextsuche und Anzeige von Textauszügen als Teil von Suchmaschinen- oder anderen Internetangeboten. ${ }^{1050}$

dd) Beeinträchtigung des Marktes für den Verkauf digitaler Werkexemplare an Bibliotheken und Archive

Die Weitergabe einer digitalen Kopie des Werkes von Google an die Bibliothek, aus deren Bestand das digitalisierte Buch stammte, könnte zudem negative Auswirkungen auf den Markt für den Verkauf digitaler Werkexemplare durch Verlage an Bibliotheken und Archive haben. Viele Verlage bieten Bibliotheken beim Erwerb neuer Bücher bereits auch den Erwerb digitaler Werkexemplare an. Neben dem Verkauf aktueller Werke in digitaler Form gehen jedoch auch immer mehr Verlage dazu über, alte Werke zu digitalisieren und diese digitalen Kopien an Bibliotheken zu verkaufen. Für die Bibliotheken ist der Erwerb digitaler Werkfassungen interessant, um diese einerseits den Bibliotheksnutzern zugänglich zu machen, andererseits um Werke zu archivieren. Der Erwerb digitaler Fassungen ist auch für beide Seiten finanziell interessant, weshalb davon ausgegangen werden kann, dass dieser Markt in Zukunft eher wachsen wird. Bei den Verlagen entstehen die digitalen Versionen - zumindest bei neueren Büchern - in der Regel automatisch als „Vorprodukt" gedruckter Werke. Bei den Bibliotheken schafft der Erwerb digitaler Werkexemplare von den Verlagen einerseits Rechtssicherheit hinsichtlich der Vervielfältigung und Verwendung der Werke, ${ }^{1051}$ andererseits wird der Kauf in der Regel deutlich günstiger sein als die zeit- und kostenintensive eigenständige Digitalisierung der Bibliotheksbestände.

Diesen (wachsenden) Markt droht die Google Buchsuche zu beeinträchtigen. Es erscheint äußerst wahrscheinlich, dass Bibliotheken, die digitale

1050 So auch Adler, Google Library Project, S. 21; Bisk, 17 Alb. L.J. Sci. \& Tech. 271, 296 f. (2007); Gamble, 9 Tul. J. Tech. \& Intell. Prop. 365, 382 (2007); Hanratty, 2005 Duke L. \& Tech. Rev. 10, Rn. 30 f.; Hetcher, 13 Mich. Telecomm. \& Tech. L. Rev. 1, 42 f. (2006); Lichtman, Copyright as Innovation Policy, S. 16; Nimmer, CRi 2006, 1 (5); a.A. Proskine, 21 Berkeley Tech. L.J. 213, $231 \mathrm{f}$. (2006).

1051 Zur unklaren Rechtslage aufgrund der problematischen Library Exemption vgl. oben 5. Kapitel, A.I.2. 
Kopien ihrer Bestände kostenlos von Google als Gegenleistung für die Teilnahme am Bibliotheksprogramm erhalten, diese Werke nicht mehr in digitaler Form von den Rechteinhabern gegen Bezahlung erwerben werden. ${ }^{1052}$ Zugleich mag die Aussicht auf eine kostenlose Digitalisierung der gesamten Bestände einen deutlichen Anreiz für weitere Bibliotheken bilden, an Googles Bibliotheksprogramm teilzunehmen. Würden zudem vergleichbare Buchprojekte anderer Anbieter dieses „Vergütungsmodell“" übernehmen, so droht ein ganz erheblicher Schaden für den entsprechenden Markt der Rechteinhaber oder gar dessen vollständige Zerstörung. Auch ein solcher negativer Markteffekt durch die zukünftige weitere Verbreitung der fraglichen Praxis ist von den Gerichten im Rahmen der Analyse des vierten Fair Use-Faktors zu beachten. ${ }^{1053}$ Die Weitergabe der Digitalisate an die teilnehmenden Bibliotheken als Gegenleistung für das Zurverfügungstellen der Bücher beeinträchtigt somit den Markt für den Verkauf digitaler Werkexemplare und droht, diesen weiter negativ zu beeinträchtigen oder gar vollständig zum Erliegen zu bringen.

\section{ee) Ergebnis zum vierten Fair Use-Faktor}

Eine Beeinträchtigung des bestehenden Hauptmarktes für Bücher, den Markt für den Verkauf vollständiger Bücher in gedruckter oder digitaler Form an Endnutzer, droht durch die transformative Nutzung in Form des Angebots einer Volltextsuche mit Snippet-Vorschau - wie gezeigt - nicht. Im Gegenteil, es erscheint deutlich wahrscheinlicher, dass die Google Buchsuche einen Werbeeffekt hat, der den Absatz von Büchern unterstützen kann und so den Buchmarkt eher stärken als schwächen wird.

Die Google Buchsuche beeinträchtigt hingegen den bereits existierenden und sich weiter entwickelnden Markt für die Volltextsuche und das Anzeige von Textauszügen als Teil von Suchmaschinen- oder anderen Internetangeboten. Durch das kostenlose Angebot des Buchsuche-Dienstes ohne die Zustimmung der Rechteinhaber beeinträchtigt Google nicht uner-

1052 So auch Adler, Google Library Project, S. 20 f.; Hetcher, 13 Mich. Telecomm. \& Tech. L. Rev. 1, 57 (2006); Lee, 83 S. Cal. L. Rev. 797, 865 (2010); Nimmer, CRi 2006, 1 (5).

1053 Siehe Sony v. Universal, 464 U.S. 417, 451 (1984); Harper \& Row v. Nation Enterprises, 471 U.S. 539, 568 (1985); Campbell v. Acuff-Rose, 510 U.S. 569, 590 (1994). 
heblich deren Möglichkeit, durch die Lizenzierung von Werken für die Verwendung in einem vergleichbaren Dienst Einnahmen zu generieren.

Die Weitergabe der Digitalisate an die teilnehmenden Bibliotheken als Gegenleistung für das Zurverfügungstellen der Bücher beeinträchtigt zudem den (wachsenden) Markt für den Verkauf digitaler Werkexemplare an Bibliotheken oder Archive, da diese auf einen kostenpflichten Erwerb vom Rechteinhaber verzichten werden, wenn die Möglichkeit besteht, kostenlose digitale Werkexemplare von Google zu erhalten.

Auch wenn der (derzeitige) Hauptmarkt für den Verkauf von Büchern durch die Google Buchsuche nicht beeinträchtigt ist, spricht der vierte Fair Use-Faktor aufgrund (möglicher) negativer Auswirkungen auf die genannten Nebenmärkte im Ergebnis (zumindest leicht) gegen die Annahme einer fairen Benutzung.

\section{f) Berücksichtigung weiterer Umstände?}

Die in 17 U.S.C. $\S 107$ ausdrücklich genannten Faktoren sind nicht abschließend. Die Gerichte können daher nach freiem Ermessen auch weitere Überlegungen und Wertungen im Rahmen der Fair Use-Prüfung heranziehen und ihnen bei der Entscheidung über die Frage des Vorliegens einer fairen Benutzung das im konkreten Fall als angemessen empfundene Gewicht beimessen. ${ }^{1054}$

Eine Überlegung, die in der Vergangenheit mehrfach zusätzlich von den Gerichten angestrengt wurde, ist die Frage nach dem ,good faith" des Nutzers, also eine moralische Beurteilung seines Handelns. ${ }^{1055}$ Zuletzt hat sich der District Court for the District of Nevada in der Rechtssache Field

1054 Vgl. Patry, Fair Use (2009), § 7:1 m.w.N.

1055 Vgl. etwa Harper \& Row v. Nation Enterprises, 471 U.S. 539, 540 (1985) („Fair use presupposes good faith"); Campbell v. Acuff-Rose, 510 U.S. 569, 585 (Fn. 18) (1994); Marcus v. Rowley, 695 F.2d 1171, 1175 (9th Cir. 1983) (,,[F]air use presupposes that the defendant has acted fairly and in good faith [...]"); zustimmend Fisher v. Dees, 794 F.2d 432, 436 (9th Cir. 1986); Bill Graham Archives, LLC. v. Dorling Kindersley Ltd., 386 F.Supp.2d 324, 333 (S.D.N.Y. 2005); Kane v. Comedy Partners, 2003 WL 22383387, Rn. 7 (S.D.N.Y. 2003); zustimmend Samuelson, 77 Fordham L. Rev. 2537, 2614 (2009); kritisch zu "good faith"-Überlegungen im Rahmen der Fair Use-Analyse Leval, 103 Harv. L. Rev. 1105, 1126 f. (1990). 
v. Google ${ }^{1056}$ im Zusammenhang mit der Nutzung urheberrechtlich geschützter Werke durch eine Internetsuchmaschine im Rahmen des $\mathrm{Ca}$ ching ausführlich mit der Berücksichtigung des ,good faith" des Nutzers im Rahmen der Fair Use-Analyse auseinandergesetzt. Im Ergebnis nahm das Gericht an, dieser "fünfte Faktor“ spreche deutlich für die Annahme eines Fair Use, da Google „Industriestandards" für einen Ausschluss bestimmter Inhalte aus dem Suchmaschinenangebot beachtet und möglicherweise rechtsverletzende Inhalte umgehend entfernt habe, während der Rechteinhaber sich durch die Erhebung einer Klage in Widerspruch zu seinem tatsächlichen Verhalten begeben habe, da er zunächst auf seiner Internetseite Maßnahmen zur Suchmaschinenoptimierung vorgenommen hatte. ${ }^{1057}$

Es ist erwogen worden, diese Überlegungen auf die Google Buchsuche zu übertragen. ${ }^{1058}$ Die Buchsuche erzeugt erhebliche positive Effekte für die Allgemeinheit, indem der Zugang zu Informationen, die andernfalls in Büchern „,versteckt“ wären, deutlich erleichtert wird. Zugleich bietet Google die Möglichkeit eines Opt Out, das heißt allen Rechteinhabern, die sich als solche identifizieren, wird ermöglicht, ihre Bücher vom Scannen auszunehmen beziehungsweise aus den Suchergebnissen der Google Buchsuche entfernen zu lassen. Anstelle eines Opt Out besteht weiterhin die Möglichkeit, am „Partner-Programm“ teilzunehmen und so an den mit Hilfe der Buchsuche erzielten Umsätzen durch die Nutzung eines Werkes zu partizipieren. Teilweise werden diese Optionen als Hinweis für den „guten Willen“ Googles gewertet. Google wolle die Rechteinhaber nicht benachteiligen, sondern tatsächlich lediglich eine Dienstleistung mit Nutzen sowohl für die Rechteinhaber als auch für die Nutzer anbieten, die Bekanntheit und Absatz von Büchern fördert und zugleich den Zugang zum „gesamten Wissen der Menschheit“" ermöglicht. Das Opt Out-Modell verdeutliche, dass Google keine Bücher habe scannen wollen, mit deren Nutzung die Rechteinhaber nicht einverstanden gewesen seien, und stelle demnach ein Entgegenkommen von Google dar, da eine Rechteklärung vor der Digitaliserung aufgrund der unüberschaubaren Anzahl von Büchern und Rechteinhaber gar nicht möglich gewesen sei. ${ }^{1059}$

1056 Field v. Google Inc., 412 F.Supp.2d 1106 (D.Nev. 2006).

1057 Siehe Field v. Google Inc., 412 F.Supp.2d 1106, 1122 f. (D.Nev. 2006).

1058 Vgl. Gamble, 9 Tul. J. Tech. \& Intell. Prop. 365, 382 f. (2007); Shah, 15 CommLaw Conspectus 569, 594 ff., 609 (2007).

1059 So Shah, 15 CommLaw Conspectus 569, 609 (2007). 
Tatsächlich vereinfacht eine solche Betrachtung jedoch die komplexe Problematik der Google Buchsuche zu sehr und übersieht wesentliche Aspekte. Zunächst ist zu beachten, dass sich der Sachverhalt, der dem Verfahren Field v. Google zugrunde lag, von der Sachlage im Falle der Goolge Buchsuche in einem erheblichen Punkt unterscheidet. Im Falle Field v. Google handelte es sich bei den streitgegenständlichen urheberrechtlich geschützten Werken um solche Werke, die vom Rechteinhaber bereits willentlich in das Internet eingestellt worden waren. Diese vervielfältigte Google im Rahmen des Caching. Auf Hinweise von Rechteinhabern, dass diese nicht mit der Nutzung ihrer Werke in diesem Umfang einverstanden waren, reagierte Google umgehend durch deren Entfernung, was einem Standard entsprach, der sich insofern in der Suchmaschinenlandschaft entwickelt hatte. Mit anderen Worten: Google nutzte die Werke nur in einem allgemein üblichen Umfang, mit dem ein Rechteinhaber grundsätzlich rechnen musste, und tat bei Beanstandungen dieser Nutzung lediglich das, was ohnehin üblich war und somit erwartet werden konnte. Bei der Google Buchsuche liegen die Dinge anders. Google digitalisiert Werke von analogen Vorlagen und macht diese erstmalig im Internet zugänglich. Diese Art der Nutzung ist zweifelsohne deutlich intensiver als die Erfassung solcher Daten, die ohnehin im Internet verfügbar sind und vom Rechteinhaber selbst eingestellt wurden. Der Google Buchsuche vergleichbare Nutzungen ohne Zustimmung der Rechteinhaber durch andere Anbieter bestehen zudem nicht, so dass sich auch noch kein Standard zum Umgang mit den genutzten Werken bei Einwänden der Rechteinhaber herausgebildet hat oder herausbilden konnte. Zudem ist zu bedenken, dass Google - abgesehen von der Möglichkeit einer Teilnahme am Partner-Programm - gar nicht erst versucht hat, die Rechtslage zu klären oder die Rechte für die Buchsuche zu erwerben. ${ }^{1060} \mathrm{Im}$ Gegenteil, Google hat sich entschieden, zunächst Tatsachen zu schaffen, um sich so ein ,first mover advantage“ zu sichern. Ein primäres Ziel scheint dabei gewesen zu sein, zunächst die tatsächliche Kontrolle über eine Vielzahl urheberrechtlich geschützter Werke zu erlangen, um anschließend aus einer „komfortablen“ Position heraus zu (ver)handeln. Die Möglichkeit eines Opt Out erscheint daher bei genauerer Betrachtung nicht als Ausdruck eines „guten Willens“ von Google, sondern eher als Versuch, in einer rechtlich unsicheren Situation

1060 Dies übersieht Shah, 15 CommLaw Conspectus 569, 609 (2007). 
möglichen Ansprüchen und Klagen von Rechteinhabern zu entgehen. ${ }^{1061}$ Schließlich ist auch weiterhin unklar, was genau mit den urheberrechtlich geschützten Werken nach deren Digitalisierung und Aufnahme in die Buchsuche-Datenbank geschieht, wenn der Rechteinhaber der Nutzung in der Buchsuche widerspricht. Google formuliert insoweit (bewusst) offen, es bestehe jederzeit die Möglichkeit, ein Buch aus den Suchergebnissen zu entfernen, ${ }^{1062}$ was nahe legt, dass die digitale Kopie nicht aus der Buchsuche-Datenbank gelöscht wird. ${ }^{1063}$ Die Strategie von Google ist somit keinesfalls mit dem vom District Court for the District of Nevada in der Rechtssache Field v. Google zur Begründung einer fairen Benutzung ergänzend herangezogene , good faith" vergleichbar. ${ }^{1064}$

Auch ein weiterer Aspekt lässt die Opt Out-Möglichkeit bei der Google Buchsuche als Argument für einen Fair Use zumindest zweifelhaft erscheinen: Wie gezeigt ist im Rahmen der Fair Use-Prüfung auch entscheidend $\mathrm{zu}$ berücksichtigen, welche Folgen das strittige Verhalten hätte, wenn es - aufgrund der Einstufung als Fair Use - weite Verbreitung fände. ${ }^{1065}$ Das Opt Out-Modell mag gut funktionieren, wenn ein Opt Out für jedermann verständlich, ohne großen Aufwand und vor allem kostengünstig möglich ist - dies jedenfalls, solange Google der einzige Anbieter einer Buchsuche oder einer vergleichbaren Dienstleistung ist. Hier kann der Rechteinhaber (relativ) problemlos die erforderlichen Informationen sammeln und einer Nutzung seiner Werke widersprechen. ${ }^{1066}$ In einem sol-

1061 Ähnlich Gamble, 9 Tul. J. Tech. \& Intell. Prop. 365, 383 (2007).

1062 Siehe „Wie gehe ich vor, wenn ich eines meiner Bücher in Google Buchsuche finde und es entfernen möchte?", abrufbar unter: http://support.google.com/ books/bin/answer.py?hl=de\&answer=43756 [zuletzt abgerufen am 26.5.2013].

1063 Anders ist dies interessanterweise hinsichtlich des ebenfalls erheblich umstrittenen Google-Dienstes Street View. Hier hat Google nach zahlreichen Protesten erklärt, nach Einsprüchen gegen die Veröffentlichung von Aufnahmen nicht nur die online verfügbaren Bilder durch das Verpixeln unkenntlich zu machen, sondern in diesem Falle auch die ursprünglichen Aufnahmen, die sog. Rohdaten, zu löschen. Die Gebäude erscheinen im Dienst Street View somit unwiderruflich bzw. jedenfalls bis zu einer (derzeit nicht geplanten) erneuten Aufnahme durch Google - verpixelt; vgl. König, c’t 26/2010, 42 (43).

1064 So im Ergebnis auch Gamble, 9 Tul. J. Tech. \& Intell. Prop. 365, 383 (2007).

1065 Siehe Sony v. Universal, 464 U.S. 417, 451 (1984); dazu oben 2. Kapitel, C.I. 2.b)cc).

$1066 \mathrm{Ob}$ dies bei der Google Buchsuche derzeit tatsächlich gewährleistet ist, mag man angesichts der recht umfangreichen und umständlichen Erfordernisse für die Registrierung und Identifizierung als Rechteinhaber durchaus bezweifeln. 
chen Szenario ist das Opt Out-Modell auch effizient, da die für den Rechteinhaber mit dem Opt Out verbundenen Kosten deutlich niedriger sein werden als die Kosten, die Google bei der Identifizierung jedes Rechteinhabers und einer individuellen Rechteklärung entstehen würden. Dieses Verhältnis ändert sich jedoch entscheidend, sobald weitere Anbieter den Markt betreten und sich der Rechteinhaber mit einer Vielzahl von Projekten mit Opt Out-Modellen konfrontiert sieht. Der Rechteinhaber wäre in diesem Fall gezwungen, erhebliche Zeit und Kosten zu investieren, um die Details jedes Opt Out-Systems zu ermitteln und jedem Anbieter die weitere Werknutzung zu untersagen. Diese Überlegungen zeigen, dass ein $O p t$ Out-Modell, welches vom Rechteinhaber verlangt, aktiv zu werden, um seine Recht geltend zu machen, bei einer wachsenden Zahl von Anbietern vergleichbarer Dienste schnell an Effektivität verlieren und somit letztlich die Bürde einer umständlichen Rechteklärung unbillig vom Nutzer auf den Rechteinhaber verlagern würde. ${ }^{1067}$

\section{g) Abwägung der Faktoren und Ergebnis}

Die Fair Use-Doktrin als „equitable rule of reason“ verlangt zur Erreichung eines fairen Ausgleichs die Beachtung sämtlicher Umstände des Einzelfalls und deren sorgfältige Abwägung. ${ }^{1068}$ Die vier im Gesetz genannten Fair Use-Faktoren können insoweit wesentliche Anhaltspunkte bieten, sie geben jedoch das Ergebnis keinesfalls vor und können nach freiem Ermessen der Richter im Einzelfall gewichtet werden. ${ }^{1069}$

Die Analyse der einzelnen Fair Use-Faktoren im Hinblick auf die Werknutzung durch Google im Rahmen der Buchsuche hat hinsichtlich der Digitalisierung vollständiger Bücher und deren Erfassung in einer Datenbank sowie der Anzeige von Auszügen aus diesen Werken in SnippetForm als Antwort auf Nutzeranfragen ergeben, dass bei der Beurteilung des ersten Faktors (,Purpose and Character of the Use") zu differenzieren ist. In Bezug auf solche Bücher, deren Lektüre nicht durch die Nutzung der Buchsuche ersetzt wird, ist davon auszugehen, dass von einem Gericht mit großer Wahrscheinlichkeit trotz der dahinter stehenden kommerziellen Interessen aufgrund der Transformativität der Werknutzung und des er-

1067 Vgl. Lichtman, Copyright as Innovation Policy, S. 18.

1068 Vgl. Sony v. Universal, 464 U.S. 417, 448 (1984).

1069 Vgl. Patry, Fair Use (2009), § 7:1 m.w.N. 
heblichen Nutzens der Buchsuche für die Allgemeinheit der erste Faktor zugunsten von Google gewertet würde. Anders dürfte die Beurteilung hinsichtlich solcher Werke ausfallen, bei denen die Buchsuche von den Nutzern derart als (wissenschaftliches) Recherchewerkzeug verwendet wird, dass bereits die Snippet-Anzeige die weitere Lektüre des Werkes ersetzt. Hier fehlt weitgehend die Transformativität der Nutzung, so dass der erste Faktor zu Googles Ungunsten zu werten wäre. ${ }^{1070}$ Der zweite Faktor („Nature of the Copyrighted Work") spricht eher (leicht) gegen die Annahme einer fairen Benutzung, da Google (auch) besonders kreative Werke scannt, die im US-amerikanischen Copyright Law als besonders schutzbedürftig angesehen werden. Diese sind zwar bereits veröffentlicht, jedoch überführt Google die bisher (nur) in analoger Form verfügbaren Werke in ein digitales Format und ändert somit die „Natur“ der Werke. ${ }^{1071}$ Der dritte Faktor (,Amount and Substantialitly of the Portion Used") spricht im Ergebnis weder für noch gegen die Annahme eines Fair Use, da einerseits die verwendeten Werke dauerhaft vollständig vervielfältigt werden, andererseits jedoch die vollständige Vervielfältigung des Originalwerkes aus technischen Gründen notwendig ist, da ohne diesen Zwischenschritt die neue Nutzungsform nicht realisierbar wäre. Zudem wird bei der Google Buchsuche letztlich nur ein sehr kleiner Teil jedes Werkes dem Nutzer in Form von Snippets zugänglich gemacht. ${ }^{1072}$ Hinsichtlich des vierten Faktors („Effect of the Use upon the Market") erscheint es wahrscheinlich, dass ein Gericht diesen (zumindest leicht) zuungunsten von Google werten würde, da zwar nicht der (derzeitige) Hauptmarkt für den Verkauf von Büchern, jedoch der wachsende Nebenmarkt für die Lizenzierung digitaler Werkexemplare zur Verwendung im Rahmen der Volltextsuche in Suchmaschinen durch die Google Buchsuche zu beeinträchtigt werden droht. ${ }^{1073}$ Somit sprechen zwei Faktoren (leicht) gegen die Annahme eines Fair Use, während ein Faktor als neutral zu bewerten ist und ein Faktor zugunsten des Nutzers und somit für die Annahme einer fairen Benutzung spricht.

Das Ergebnis einer gerichtlichen Entscheidung hängt folglich ganz wesentlich davon ab, welches Gewicht das Gericht den einzelnen Faktoren, jedoch insbesondere dem ersten und vierten Faktor, beimisst. Einerseits ist

1070 Vgl. oben 5. Kapitel, B.II.1.b).

1071 Vgl. oben 5. Kapitel, B.II.1.c).

1072 Vgl. oben 5. Kapitel, B.II.1.d).

1073 Vgl. oben 5. Kapitel, B.II.1.e). 
denkbar, dass ein mit der Frage der Zulässigkeit der Google Buchsuche befasstes Gericht - ebenso wie der Court of Appeals for the Ninth Circuit in den Thumbnail-Verfahren ${ }^{1074}$ und im Einklang mit einer weit verbreiteten Praxis ${ }^{1075}$ - ganz wesentlich auf den Aspekt der Transformativität abstellt und aufgrund der neuen Funktionalität und des erheblichen Nutzens für die Allgemeinheit alle weiteren Faktoren in den Hintergrund treten lässt. Insofern könnte es für das Gericht auch erheblich sein, dass durch die Werknutzung jedenfalls der Hauptmarkt für die Originalwerke nicht negativ, sondern durch die Steigerung der Bekanntheit und die Ermöglichung neuer und zusätzlicher Vermarktungsmöglichkeiten allenfalls positiv beeinflusst wird. Es erscheint daher keinesfalls ausgeschlossen, dass ein Gericht im Ergebnis zugunsten von Google und somit für die Annahme eines Fair Use entscheiden würde. ${ }^{1076}$

Ebenfalls möglich erscheint jedoch, dass ein Gericht die gegenteilige Auffassung vertreten und die Werknutzung durch Google im Rahmen der Buchsuche nicht als Fair Use kategorisieren würde. ${ }^{1077}$ Misst das Gericht der Frage der Transformativität keine so (vor)entscheidende Bedeutung $\mathrm{zu}$, so würde sich das Blatt schnell zuungunsten von Google wenden. Die Nutzung erfolgt zu kommerziellen Zwecken und geht durch die Digitalisierung vormals analoger Werke und deren Zugänglichmachung im Internet deutlich über das von den Rechteinhabern durch die Verbreitung der Werke in analoger Form gewünschte beziehungsweise absehbare Maß hinaus. Google geht somit durch das Kopieren der Werke und deren Überführung in ein neues Medium einen Schritt weiter als in den Fällen der

1074 Siehe ausführlich oben 5. Kapitel, B.I.2.

1075 Siehe dazu und zur Kritik an dieser Praxis oben 5. Kapitel, B.I.3.

1076 Eine Fair Use-Entscheidung zugunsten von Google nehmen an: Band, Google Library Project, S. 14; Costantino, 17 Fordham Intell. Prop. Media \& Ent. L.J. 235, 276 f. (2006); Ganley, 10 No. 5 J. Internet L. 1, 13 f. (2006); Lee, 83 S. Cal. L. Rev. 797, 865. (2010); Lundeen, 75 UMKC L. Rev. 265, 281 (2006); Na, 16 Cornell J. L. \& Pub. Pol'y 417, 446 (2007); Okano, 3 Shidler J. L. Com. \& Tech. 13 (2007), Rn. 56 f.; Romman, 43 Hous. L. Rev. 807, 839 f. (2006); Travis, 84 Notre Dame L. Rev 331, 395 f. (2008); Varian, Google Library Project, S. 12; Wilhelm, 33 Rutgers Computer \& Tech. L.J. 107, 134 (2006); vorsichtig in diese Richtung auch Sag, 55 N.Y.L. Sch. L. Rev. 19, 36 f. (2010).

1077 Eine Entscheidung gegen Google nehmen an: Adler, Google Library Project, S. 21 f.; Hetcher, 13 Mich. Telecomm. \& Tech. L. Rev. 1, 58 (2006); Lucke, Google Buchsuche, S. 270; Nimmer, CRi 2006, 1 (6); Shah, 15 CommLaw Conspectus 569, 612 f. (2007); Vaidhyanathan, 40 U.C. Davis L. Rev. 1207, 1229 f. (2007). 
Werknutzung durch Suchmaschinen für die Bildersuche oder im Rahmen des Caching. Die Werknutzung im Rahmen der Google Buchsuche hat zudem das Potential, in manchen Bereichen in unmittelbare Konkurrenz zu (Fach-)Datenbanken anderer kommerzieller Anbieter zu treten und zudem den (wachsenden) Nebenmarkt für die Lizenzierung digitaler Werkexemplare zur Verwendung im Rahmen der Volltextsuche in Suchmaschinen deutlich zu beeinträchtigen oder gar zum Erliegen zu bringen. Zudem könnte die Überlegung, dass eine Fair Use-Entscheidung zur Erhaltung der sozial nützlichen Dienstleistung „Buchsuche“ tatsächlich nicht notwendig ist, das Gericht zu einer Entscheidung zuungunsten von Google leiten. Google macht geltend, ein Opt In- anstelle des bisherigen Opt OutModells sei aufgrund der erheblichen Transaktionskosten nicht möglich oder zumindest nicht praktikabel. Die Tatsache, dass tatsächlich mit zahlreichen Verlegern und weiteren Rechteinhabern im Rahmen des PartnerProgramms und ähnlicher Vereinbarungen Einigungen über die Werknutzung erzielt werden konnten, könnte jedoch als Indiz gewertet werden, dass eine Gerichtsentscheidung zuungunsten von Google nicht tatsächlich das Ende der Buchsuche bedeuten würde. Insbesondere in Verbindung mit festgeschriebenen Sorgfaltsstandards für die Ermittlung der Rechteinhaber und für den Umgang mit Orphan Works, deren Rechteinhaber sich nicht ermitteln lassen, erscheint ein umfassendes Buchsuche-Angebot auch auf Basis eines Opt In-Systems durchaus vorstellbar. Alle diese Überlegungen könnten dafür sprechen, dass ein Gericht letztlich die Werknutzung durch Google im Rahmen der Buchsuche nicht als Fair Use ansehen würde.

Letztlich sprechen meines Erachtens die stärkeren Indizien dafür, dass ein Gericht im Einklang mit der in der Rechtsprechung des U.S. Supreme Court und insbesondere in der neueren Rechtsprechung der Instanzgerichte zu erkennenden Tendenz, die Entwicklung neuartiger und für die Allgemeinheit besonders nützlicher (Internet-)Dienste, die urheberrechtlich geschützte Werke äußerst transformativ verwenden, durch die Annahme von Fair Use zu erhalten beziehungsweise zu fördern, ${ }^{1078}$ auch die Google

1078 Vgl. insbesondere die bereits dargestellte „Sony-Betamax“-Rechtsprechung des U.S. Supreme Court (Sony v. Universal, 464 U.S. 417 (1984)) sowie die ausführlich besprochenen instanzgerichtlichen Urteile zur Rechtmäßigkeit der Thumbnail-Nutzung im Rahmen der Bildersuche (Kelly v. Arriba Soft, 336 F.3d 811 (9th Cir. 2003) und Perfect 10, Inc. v. Amazon.com, Inc., et al., 508 F.3d 1146 (9th Cir. 2007)) und zur Zulässigkeit der Werknutzung im Rahmen des Caching (Field v. Google, 412 F.Supp.2d 1106 (D. Nev. 2006)). 
Buchsuche als Fair Use anerkennen würde. Die dargestellten Argumente zeigen jedoch, dass es sich dabei letztlich nur um eine weitere unter vielen (zumeist) begründeten Annahmen handelt. Tatsächlich ist der Ausgang eines Gerichtsverfahrens über die Frage des Fair Use im Falle der Google Buchsuche kaum vorhersehbar, ${ }^{1079}$ da er wesentlich von der Nuancierung der einzelnen Aspekte durch das Gericht und nicht zuletzt von den persönlichen Überzeugungen der entscheidenden Richter hinsichtlich der Rolle des Urheberrechts im Spannungsverhältnis zwischen Rechteinhabern und der Entwicklung neuer Technologien abhängt. Für beide Sichtweisen - die Annahme oder die Ablehnung einer fairen Benutzung - sprechen gewichtige Argumente, die von dem mit der Frage befassten Gericht jeweils im Einklang mit älterer Rechtsprechung für die Entscheidung herangezogen werden könnten.

Diese Beurteilung betrifft jedoch nur die Digitalisierung vollständiger Bücher und deren Erfassung in einer Datenbank sowie der Anzeige von Auszügen aus diesen Werken in Snippet-Form als Antwort auf Nutzeranfragen. Allenfalls diese Form der Werknutzung ließe sich mit den vorgenannten Argumenten als Fair Use anerkennen. Die Weitergabe von digitalen Kopien der Werke an die teilnehmenden Bibliotheken lässt sich hingegen nicht als Fair Use rechtfertigen. ${ }^{1080}$ Diesbezüglich sprechen zumindest der erste, dritte und vierte Fair Use-Faktor gegen die Annahme einer fairen Benutzung, da vollständige Kopien der urheberrechtlich geschützten Werke erstellt werden, die keiner transformativen Nutzung zugeführt werden und den Markt für den Verkauf digitaler Kopien zu Archivierungszwecken beeinträchtigen können. Dieses Ergebnis stützt auch folgende Überlegung: In 17 U.S.C. $§ 108$ ist ausdrücklich eine spezifische Library Exemption ${ }^{1081}$ kodifiziert, nach der die systematische Digitalisierung von Bibliotheksbeständen unter anderen als den ausdrücklich genannten Voraussetzungen gerade nicht zulässig sein soll. Die speziellen

1079 Eine Vorhersage hinsichtlich des Ausgangs eines Verfahrens für nicht möglich halten aus diesem Grund etwa Bisk, 17 Alb. L.J. Sci. \& Tech. 271, 297 f. (2007); Gamble, 9 Tul. J. Tech. \& Intell. Prop. 365, 383 f. (2007); Glorioso, 38 Hofstra L. Rev. 971, 988 f. (2010); Hanratty, 2005 Duke L. \& Tech. Rev. 10, Rn. 33 f.; Jordan, 86 Michigan Bar Journal 32, 34 (2007); Lichtman, Copyright as Innovation Policy, S. 18 f.; Proskine, 21 Berkeley Tech. L.J. 213, 232, 239 (2006);

1080 So auch Band, 9 J. Marshall Rev. Intell. Prop. L. 227, 257 (2009); Hetcher, 13 Mich. Telecomm. \& Tech. L. Rev. 1, 58 (2006); Vaidhyanathan, 40 U.C. Davis L. Rev. 1207, 1229 f. (2007).

1081 Siehe dazu bereits oben 5. Kapitel, A.I.2. 
Anforderungen dieser Vorschrift für die Anfertigung von Kopien durch Bibliotheken und Archive würden letztlich umgangen, wollte man die Weitergabe vollständiger Kopien von Google an Bibliotheken als „Vergütung" für deren Teilnahme am Bibliotheksprogramm als Fair Use einstufen. ${ }^{1082}$ Die ganz besondere Brisanz der Weitergabe der "Library Copies“ durch Google offenbart auch die Tatsache, dass die Authors Guild und weitere Rechteinhabervereinigungen am 12. September 2011 eine Klage beim U.S. District Court for the Southern District of New York gegen fünf der am Library Program beteiligten Bibliotheken eingereicht haben, die die Unzulässigkeit der Verwendung der von Google erhaltenen digitalen Buchexemplare zum Gegenstand hat. ${ }^{1083}$

\section{Exkurs: Das Google Book Settlement und seine Folgen}

Die vorhergehende Betrachtung hat gezeigt, dass ingesamt erhebliche Unsicherheit bezüglich der Bewertung der Google Buchsuche im Lichte der Fair Use-Doktrin besteht und dass der Ausgang eines entsprechenden Gerichtsverfahrens kaum sicher vorhergesagt werden kann. Diese Unsicherheit sowohl auf Seiten der Kläger als auch der Beklagten war letztlich wohl auch einer der maßgeblichen Gründe dafür, dass über die Klage nicht inhaltlich entschieden wurde, sondern von den Parteien eine Einigung angestrebt wurde. ${ }^{1084}$ Diese Einigung und die dazu führenden Entwicklungen sollen im Folgenden dargestellt werden.

Im Herbst 2005 reichten in kurzem zeitlichem Abstand sowohl der USamerikanische Autorenverband Authors Guild als auch der Verlegerverband Association of American Publishers (AAP) beim U.S. District Court for the Southern District of New York Klagen gegen Google ein. ${ }^{1085}$ Die

1082 Vgl. Adler, Google Library Project, S. 4.

1083 Siehe Authors Guild, et al. v. HathiTrust, et al., 11 CIV 6351 (S.D.N.Y., Sep. 12, 2011).

1084 Zudem dürfte für Google die Aussicht auf einen verglichen mit einer Fair UseEntscheidung deutlich vorteilhafteren Vergleich (siehe dazu unten 5. Kapitel, B.II.2.b)) ein weiterer entscheidender Grund für die Bemühung um eine Streitbeilegung durch einen Vergleich gewesen sein; vgl. Samuelson, 2011 Wis. L. Rev. 479, $504 \mathrm{ff}$.

1085 Siehe The Authors Guild, et al. v. Google Inc., No. 05 CV 8136 (S.D.N.Y. Sept. 20, 2005) und The McGraw-Hill Companies, Inc. et al. v. Google Inc., No. 05 CV 8881 (S.D.N.Y. Oct. 19, 2005). 
Kläger machten im Wege einer Class Action, das heißt stellvertretend für alle Mitglieder der Gruppe (class) ${ }^{1086}$ der Autoren und Herausgeber, massive Urheberrechtsverletzungen durch Googles Vorgehen im Rahmen des Library Projects geltend. Nach dreijährigen gerichtlichen Verhandlungen verkündeten die Authors Guild, die AAP und Google am 28. Oktober 2008, dass sie eine „bahnbrechende“ Vergleichsvereinbarung (Settlement Agreement) erzielt hätten, mit der die Sammelklage gegen die Google Buchsuche beigelegt werden solle. ${ }^{1087}$ Über die Klagen der Authors Guild und der $A A P$ wird somit nicht mehr inhaltlich vom Gericht entschieden, so dass auch die zentrale Frage des Fair Use nicht mehr vom Gericht zu klären ist. Das Gericht hat lediglich über die Genehmigung des Vergleichs zu entscheiden. Diese ist zu erteilen, wenn das Gericht den Vergleichsvorschlag als ,fair, reasonable, and adequate“ bewertet. ${ }^{1088}$ Nach mehr als einjährigen Verhandlungen über die Genehmigung des hochkomplexen ersten Settlement Agreement ${ }^{1089}$ und zahlreichen Einwendungen und Bedenken von Rechteinhabern, rechtswissenschaftlichen Autoren, Institutio-

1086 Vgl. Federal Rules of Civil Procedure, Rule 23. Bei einer Class Action wird die Klage durch einen oder mehrere namentlich benannte Kläger stellvertretend für eine Gruppe (class) erhoben. Die class besteht dabei aus Personen oder Institutionen, die die Verletzung eines jeweils gleichartigen Rechts oder von Rechte aus einem gleichartigen Sachverhalt geltend machen. Prozessbeteiligt sind nur die Repräsentanten, von denen zumindest einer Mitglied der class sein muss. Das Gericht klärt jedoch die Rechts- und Tatfragen bindend für alle class members, selbst wenn diese nicht unmittelbar am Prozess beteiligt waren. Von der Bindungswirkung ausgenommen sind lediglich solche (potentiellen) Gruppenmitglieder, die von der Möglichkeit eines Opt Out Gebrauch gemacht haben. Alle durch das Urteil gebundenen class members sind aus diesem berechtigt und auch verpflichtet, d.h. sie können den Gegenstand des Verfahrens nicht noch einmal gerichtlich geltend machen (sog. res judicata-Wirkung). Ausführlich zur Class Action im US-amerikanischen Recht aus der deutschen Literatur siehe etwa Beuchler, Class Actions, S. 27 ff.; Eichholtz, Class Action, S. 29 ff.; Hoppe, Einbeziehung ausländischer Beteiligter in US-amerikanische class actions, S. $35 \mathrm{ff}$; aus der US-amerikanischen Literatur grundlegend und umfassend zur Class Action statt vieler Nagareda, The Law of Class Actions, 2009.

1087 Siehe Google Press Center, Meldung vom 28.10.2008: „Authors, Publishers, and Google Reach Landmark Settlement", abrufbar unter: http://www.google.com/intl/en/press/pressrel/20081027_booksearchagreement.html [zuletzt abgerufen am 26.5.2013].

1088 Siehe Federal Rules of Civil Procedure, Rule 23(e)(2).

1089 Siehe The Authors Guild, Inc., Association of American Publishers, Inc., et al. v. Google Inc., Case No. 05 CV 8136-JES, Settlement Agreement. 
nen und Regierungen präsentierten die Parteien schließlich am 13. November 2009 einen geänderten und ergänzten Vergleichsvertrag, das Amended Settlement Agreement (ASA), ${ }^{1090}$ dem jedoch am 22. März 2011 durch den mit dem Verfahren vor dem U.S. District Court for the Southern District of New York befassten Richter Denny Chin ${ }^{1091}$ die Genehmigung versagt wurde. ${ }^{1092} \mathrm{Im}$ Laufe des Jahres 2011 fanden zahlreiche sogenannte "Status Conferences" der beteiligten Parteien mit dem Ziel statt, den abgelehnten Vergleich erneut zu überarbeiten und dem Gericht einen geänderten Vergleichsvorschlag zur Genehmigung vorzulegen. Dazu ist es bisher jedoch nicht gekommen. Ein endgültiges Scheitern der Vergleichsverhandlungen erscheint keinesfalls ausgeschlossen. Für diesen Fall hat Judge Chin eine Wiederaufnahme des streitigen Verfahrens und ein baldiges Urteil in Aussicht gestellt. ${ }^{1093}$ Am 4.10.2012 haben sich nach siebenjährigem Rechtsstreit überraschend die AAP und Google geeinigt. ${ }^{1094}$ Eine richterliche Zustimmung war nicht erforderlich, da die Einigung lediglich zwischen den Parteien gilt. Nach der Einigung können die Verleger nun darüber entscheiden, ob sie die von Google digitalisierten Bücher aus der Google Buchsuche entfernen oder diese über die Google-Plattform Google Play zum Verkauf freigeben. Bei Freigabe erhält der Verlag eine digitale Kopie zum eigenen Gebrauch. Im Rahmen der Buchsuche können die Nutzer nun bis zu 20 Prozent der vom Vergleich erfassten Bücher lesen und dieses dann als Digitalversion über Google Play erwerben. Durch

1090 Siehe The Authors Guild, Inc., Association of American Publishers, Inc., et al. v. Google Inc., Case No. 05 CV 8136-DC, Amended Settlement Agreement.

1091 Richter Chin ist mit Wirkung zum 22. April 2010 zum Richter am U.S. Court of Appeals for the Second Circuit ernannt worden. Er ist jedoch weiterhin für das von ihm zuvor beim U.S. District Court for the Southern District of New York betreute Verfahren zum Google Book Settlement zuständig; siehe Dokument 1:10-CV-02977-DC Doc. 17 vom 23.9.2010 (zum inzwischen mit dem Hauptverfahren verbundenen Verfahren The American Society of Media Photographers, Inc. et al v. Google, Inc.), unterzeichnet von Richter Chin ,sitting by designation".

1092 Siehe The Authors Guild et al. v. Google Inc., Case No. 05 CV 8136-DC, Opinion, Doc. 971 (S.D.N.Y. March 22, 2011).

1093 Siehe The Entertainment, Arts and Sports Law Blog, "Update on Google Books Settlement" vom 19.9.2011, abrufbar unter: http://nysbar.com/blogs/EASL/ 2011/09/update_on_Google_books_settlem.html [zuletzt abgerufen am 26.5.2013].

1094 Siehe Pressemeldung der AAP vom 4.10.2012, abrufbar unter: http://publishers.org/press/85/. 
den Vergleich nicht beendet ist jedoch die Klage der Autorenvereinigung Authors Guild. Diese ist weiterhin als Class Action-Klage anhängig. Ein Ende ist nicht in Sicht. Es haben sich zudem jüngst weitere Kläger dieser Klage angeschlossen, u.a. die National Press Photographers Association (NPPA), die American Society of Media Photographers (ASMP) und die Graphic Artists Guild, die die Verletzung ihrer Bildrechte durch die Google Buchsuche geltend machen. ${ }^{1095}$

Eine Beendigung des Rechtsstreits durch einen Vergleich hätte ganz erhebliche Auswirkungen auf die zukünftige Gestaltung nicht nur der Google Buchsuche, sondern auch vergleichbarer Projekte, denn ein solcher entfaltet durch die Besonderheiten des Class Action-Verfahrens seine Wirkung nicht nur für US-amerikanische Rechteinhaber, sondern auch für Autoren und Verleger aus anderen Ländern, deren Werke vom Vergleich erfasst werden. Mehrere Millionen Rechteinhaber, etliche Millionen Werke und mindestens hunderte Millionen US-Dollar Umsatz - allein diese Zahlen zeigen die Bedeutung, die dem Vergleich in Bezug auf die Google Buchsuche zukommt. Die reinen Zahlen sind jedoch allenfalls eine Seite der Medaille. Zugleich stellt der Vergleichsvertrag ein Novum dar, da der Class Action-Vergleich erstmalig nicht nur herangezogen wird, um strittige neue Geschäftsmodelle zu legalisieren, sondern auch, um diese detailliert inhaltlich auszugestalten. Der Inhalt der beiden Vergleichsvorschläge und insbesondere die Änderungen im Zuge des Amended Settlement Agreement (ASA) sollen aufgrund dieser erheblichen Bedeutung und weitreichenden Konsequenzen im Folgenden überblicksartig dargestellt und kritisch betrachtet werden (sogleich a)). Auf Grundlage dieser Darstellung erfolgt schließlich eine Gegenüberstellung der Rechtslage nach einer Genehmigung des ASA mit der Rechtslage, die bestehen wird, wenn kein Vergleich geschlossen wird und stattdessen eine Fair Use-Entscheidung eines Gerichts zugunsten von Google erginge (unten b)).

\section{a) Inhalt des Google Book Settlement}

Sowohl die ursprüngliche Fassung des Google Book Settlement (GBS) als auch die geänderte und ergänzte Fassung (ASA) sind äußerst komplex und

1095 Siehe Pressemeldung der NPPA vom 15.4.2013, abrufbar unter: https:// nppa.org/node/60890; Pressemeldung der ASMP vom 7.4.2010, abrufbar unter: http://asmp.org/articles/press-release-10-04-07.html. 
werfen eine Vielzahl einzelner Probleme und Fragen auf, die weit über die hier besonders interessierenden urheberrechtlichen Fragestellungen hinausgehen. Die umfassende Darstellung und Klärung dieser Aspekte würde den Rahmen dieser Untersuchung sprengen. Es sollen deshalb im Folgenden nur die wesentlichen Inhalte der Vergleichsvorschläge und die damit verbundenen Hauptprobleme und -kritikpunkte skizziert werden, deren Kenntnis für ein besseres Verständnis der Google Book Search-Debatte sinnvoll und für den anschließenden Vergleich mit einer möglichen Fair Use-Entscheidung erforderlich erscheint.

aa) Die erste Fassung des Google Book Settlement

(1) Wesentliche Regelungen des GBS

Der für Nutzer, Rechteinhaber und Google wohl wesentlichste Punkt des ursprünglichen Vergleichsvertrages war, dass Google danach weiterhin berechtigt sein sollte, urheberrechtlich (noch) geschützte Werke zu digitalisieren und in die Buchsuche-Datenbank aufzunehmen, um so eine Volltextsuche innerhalb dieser Werke zu ermöglichen. ${ }^{1096}$ Zugleich würde Google gegenüber sämtlichen Mitgliedern der class von einer (möglichen) Haftung für das bisherige Einscannen, Durchsuchen und öffentliche $\mathrm{Zu}$ gänglichmachen im Rahmen der Google Buchsuche freigestellt. ${ }^{1097}$ Als Gegenleistung für diese Haftungsfreistellung sollte Google einmalig mindestens 45 Millionen US-Dollar an die Rechteinhaber, ${ }^{1098}$ 34,5 Millionen US-Dollar für bisher angefallene Verwaltungs- und Verfahrenskosten 1099 und 30 Millionen US-Dollar für Anwaltskosten der Gegenseite ${ }^{1100}$ zahlen. Neben der (erwartungsgemäßen) Klärung dieser Punkte überraschte das

1096 Siehe § 3.1(a) GBS.

1097 Siehe §10.2(a) GBS. Diese Haftungsfreistellung gilt allerdings ausdrücklich nicht für Ansprüche nach ausländischem Recht; siehe § 10.2(h).

1098 Siehe $\S 2.1$ (b) i.V.m. $\S 5.1$ GBS. Diese Summe setzt sich wie folgt zusammen: Google zahlt in den Settlement Fund mindestens 60 US-Dollar für jedes vollständig digitalisierte Werk („Principal Work“, vgl. § 1.111 GBS), 15 US-Dollar für jeden selbständigen Buchteil (,Insert“, vgl. § 1.72 GBS) und 5 US-Dollar für sonstige Werkteile („Partial Inserts“, vgl. § 1.100 GBS). Diese Beträge werden an die jeweiligen Rechteinhaber ausgeschüttet.

1099 Siehe $\$ 2.1$ (c) i.V.m. § 5.2 GBS.

1100 Siehe $\S 2.1(\mathrm{~d})$ i.V.m. $\S 5.5$ GBS. 
GBS jedoch durch zahlreiche weitere Regelungen mit weitreichenden Auswirkungen. Gegenstand des ursprünglichen Google Library Projects war die Erstellung eines Index sämtlicher Bücher der beteiligten Bibliotheken und die Ermöglichung der Volltext-Durchsuchbarkeit dieser Bücher, wobei die Vorschau bei urheberrechtlich geschützten Werken auf maximal drei Snippets begrenzt sein sollte. Durch das GBS hingegen wären im Falle der gerichtlichen Anerkennung diese Grundfunktionen deutlich erweitert und Google zahlreiche weitere kommerzielle Nutzungen ermöglicht worden, unter anderem auch Angebote zur Volltextanzeige einer Vielzahl von Büchern gegen Bezahlung. Im Einzelnen enthält das GBS folgende wesentlichen Regelungen: ${ }^{101}$

Google wäre durch das GBS auch zukünftig die Digitalisierung vollständiger Bücher und in gewissem Umfang deren öffentliche Zugänglichmachung gestattet, unabhängig davon, ob die Bücher (noch) urheberrechtlich geschützt sind oder nicht. Dazu werden Google durch das GBS einfache Nutzungsrechte eingeräumt. ${ }^{1102}$ Der Umfang der zulässigen Vorschau im Rahmen der Google Buchsuche richtet sich nach dem Verfügbarkeitsstatus des jeweiligen Buches. Zu diesem Zweck unterteilt das GBS sämtliche Bücher in drei Kategorien: ${ }^{1103}$ Bücher, die urheberrechtlich geschützt und in den USA weiterhin zum Kauf erhältlich sind („Commercially

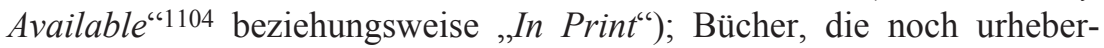
rechtlich geschützt, jedoch in den USA nicht mehr über übliche Kanäle neu zum Kauf erhältlich sind (,Not Commercially Available“ beziehungsweise „Out of Print"); und Bücher, die nach dem US-amerikanischen Copyright Act gemeinfrei sind (,Public Domain Books"). ${ }^{1105}$ Die Kategorisierung der Bücher erfolgt zunächst durch Google anhand bestehender Da-

1101 Das GBS kann hier aufgrund des erheblichen Umfangs (134 Seiten Vergleichstext zuzüglich 15 Attachments) und der enthaltenen detaillierten Einzelregelungen keinesfalls vollständig dargestellt werden. Die Darstellung beschränkt sich daher auf solche Aspekte, die dem Verfasser für das Verständnis des GBS und der damit verbundenen Probleme besonders wesentlich erscheinen und die auf besonders starke Kritik gestoßen sind. Einen guten Überblick über das gesamte GBS bietet Band, A Guide for the Perplexed I, S. 2 ff. Eine äußerst ausführliche Analyse des vollständigen GBS findet sich bei Band, 9 J. Marshall Rev. Intell. Prop. L. 227, 260 ff. (2009).

$1102 \S 3.1$ (a) GBS.

1103 Siehe $\$ 3.2(d)$ GBS.

1104 Siehe die Definition in $\S 1.28$ GBS.

1105 Siehe die Definition in $\S 1.116$ GBS. 
tenbanken und Internetrecherchen, ${ }^{1106}$ sie kann jedoch durch den Rechteinhaber angefochten und geändert werden. ${ }^{1107}$ Alle Bücher sind im Volltext durchsuchbar; die Kategorisierung entscheidet jedoch über den standardmäßigen Umfang der für den Nutzer verfügbaren Buchvorschau. Gemeinfreie Werke und Bücher, die „Not Commercially Available“ sind, werden für sogenannte „Display Uses" ${ }^{\prime 108}$ freigeschaltet, die eine Vorschau auf das Buch ermöglichen, während für urheberrechtlich geschützte Werke, die "Commercially Available“ sind, keine Freischaltung erfolgt (,Non-Display Uses“). ${ }^{1109}$ Der Umfang des „Display Uses“ wiederum unterscheidet sich nach Werkkategorien. Bei Public Domain Books ist ein Abruf des vollständigen Textes möglich. Von nicht mehr verfügbaren, aber noch urheberrechtlich geschützten Büchern (,Not Commercially Available") werden hingegen - ohne Zustimmung der Rechteinhaber standardmäßig bis zu $20 \%$ des Buchtextes zugänglich gemacht, wobei die Vorschau jedoch grundsätzlich auf maximal fünf zusammenhängende Seiten begrenzt ist. ${ }^{110}$ Hinsichtlich dieser „Out of Print"-Bücher erfolgt somit durch das GBS eine ganz erhebliche Erweiterung des Vorschauumfanges gegenüber der vorher verwendeten Snippet-Vorschau, die zudem auf maximal drei Ausschnitte pro Buch begrenzt war. Für urheberrechtlich geschützte Bücher, die „Commercially Available“ sind, wird durch das GBS hingegen der Umfang der Darstellung im Rahmen der Google Buchsuche verringert. Standardmäßig werden von diesen Büchern nicht einmal mehr Snippets angezeigt, sondern in der Regel nur noch bibliographische Angaben, Schlüsselwörter und gegebenenfalls ungeschützte Werkteile wie Titelblatt, Inhalts- oder Stichwortverzeichnis. ${ }^{1111}$ Die Rechteinhaber können den Vorschauumfang jedoch durch die Änderung der Klassifizierung ihrer Werke weitgehend frei verändern, also etwa ein „No Display Book“ in ein „Display Book" umwandeln und den Umfang des „Display Uses“ bestimmen oder umgekehrt ein bisher als „Display Book“" qualifiziertes Werk in die Kategorie der „No Display Books“ aufnehmen lassen. ${ }^{1112}$ Jeder Rechteinhaber kann zudem grundsätzlich von der Möglichkeit eines Opt Out

1106 Siehe $\S 3.2(\mathrm{~d})(\mathrm{i})$ GBS und Attachment E zum GBS.

1107 Siehe $\$ 3.2(d)($ iii) GBS.

1108 Siehe die Definition in $\S 1.48$ GBS.

1109 Siehe die Definition in $\S 1.91$ GBS.

1110 Siehe $\S$ 4.3(b)(i)(1) GBS und Attachment $F$ zum GBS.

1111 Siehe $\S \S 1.57,1.91,3.4($ a) GBS.

1112 Siehe $\S 3.2(\mathrm{e})$ (i) GBS. 
Gebrauch machen und die vollständige Entfernung seines bereits digitalisierten Werkes aus der Google Buchsuche oder das Unterlassen der Digitalisierung bisher nicht erfasster Bücher beantragen. ${ }^{1113}$

Neben diesen „Grundeinstellungen“ regelt das GBS jedoch auch zahlreiche weitere Neuerungen, die ganz erheblichen Einfluss auf die Gestaltung der Google Buchsuche und den Umfang der zugänglichen Werkteile haben. Google wird gestattet, Nutzern gegen Bezahlung einen Zugang zum Volltext von als „Display Books“ kategorisierten Werken zu gewähren. ${ }^{1114}$ Dieser sogenannte „Consumer Purchase ${ }^{\text {" } 115}$ ermöglicht dem Nutzer einen dauerhaften Zugang zu einem Werk, der nicht auf das Lesen beschränkt ist, sondern auch das digitale Kopieren (,copy/paste“) des Buchtextes, ${ }^{1116}$ das Ausdrucken des Buches ${ }^{1117}$ sowie das Hinzufügen von Anmerkungen und Kommentaren zum Buch ${ }^{1118}$ umfasst. Den Preis für den „Consumer Purchase“ legt grundsätzlich der Rechteinhaber fest. Er kann sich dabei entweder dafür entscheiden, einen spezifischen Preis zu bestimmen (sog. ,Specified Price" ${ }^{1119}$ oder diesen durch Google mittels eines Preisalgorithmus' festlegen lassen, dessen Ziel die Ermittlung des optimalen Preises eines Buches zur Maximierung der Einnahmen für den jeweiligen Rechteinhaber ist (sog. „Settlement Controlled Price“). ${ }^{1120}$ Legt ein

1113 Siehe § 3.5(a)(i) GBS. Die vollständige Entfernung aus der Google Buchsuche kann allerdings nur innerhalb der ersten 27 Monate nach Schluss des Vergleichs verlangt werden. Nach Ablauf dieses Zeitraums kann lediglich der Ausschluss von „Display Uses“ erreicht werden; § 3.5(a)(iii) GBS.

1114 Siehe $\S 4.2$ GBS.

1115 Siehe die Definition in $\S 1.32$ GBS.

1116 Nach § 4.2(a) GBS ist zwar durch einen einzelnen „,copy/paste“-Befehl stets maximal das Kopieren von vier Buchseiten möglich, eine Begrenzung der Anzahl der ,copy/paste“-Vorgänge erfolgt durch das GBS jedoch nicht, so dass durch viele Kopiervorgänge auch das gesamte Werk kopiert werden kann.

1117 Nach § 4.2(a) GBS ist auch das Ausdrucken eines Buches insoweit beschränkt, als durch einen einzelnen Druckbefehl höchstens zwanzig Seiten eines Buches

1118 Siehe $\S \S 1.17,4.2$ (a) GBS.

ausgedruckt werden können. Durch mehrere Druckbefehle ist jedoch auch hier die Vervielfältigung des gesamten Buchtextes möglich. Alle ausgedruckten Seiten werden jedoch von Google mit einem Wasserzeichen versehen, das eine Identifikation des ausdruckenden Nutzers ermöglicht.

1119 Siehe $\S 4.2(\mathrm{~b})(\mathrm{i})(1) \mathrm{GBS}$.

1120 Siehe $\$ 4.2($ b)(i)(2) GBS. Zur genauen Berechnung des „Settlement Controlled

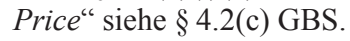


Rechteinhaber keinen spezifischen Preis fest, so wird der Zugang zu seinem Werk zum „Settlement Controlled Price“" verkauft. ${ }^{1121}$

Neben dem „Consumer Purchase" gestattet das GBS Google eine weitere Art der kommerziellen Werknutzung. Im Rahmen sogenannter „Institutional Subscriptions" können Einrichtungen gegen Bezahlung für einen bestimmten Zeitraum den Zugang zum Volltext aller Bücher erhalten, die Teil der „Institutional Subscription Database“ (ISD) sind. ${ }^{1122}$ Diese Datenbank umfasst sämtliche gemeinfreien Werke, Bücher, die urheberrechtlich noch geschützt aber „Not Commercially Available“ sind, und InPrint-Werke, deren Rechteinhaber der Aufnahme in die ISD ausdrücklich zugestimmt haben. Neben öffentlichen Einrichtungen und Bildungseinrichtungen wie Universitäten und Schulen können auch gewerbliche Unternehmen Zugänge kaufen. ${ }^{1123}$ Der Preis für das „Abonnement“ variiert jedoch nach Einrichtung und Zahl der zugangsberechtigten Personen. ${ }^{1124}$ Allen Zugangsberechtigten wird eine Werknutzung in demselben Umfang wie im Rahmen des „Consumer Purchase“ ermöglicht, das heißt neben dem reinen Lesen ist auch das Kopieren, Ausdrucken und Hinzufügen von Anmerkungen möglich. ${ }^{1125}$

Wie gezeigt wird Google durch die im GBS vorgesehenen erweiterten Werknutzungsmöglichkeiten in die Lage versetzt, durch Werbung und durch den Verkauf kostenpflichtiger Zugänge zur Volltextansicht zusätzliche Einnahmen zu erzielen. An diesen Einnahmen im Zusammenhang mit der Werknutzung im Rahmen der Google Buchsuche sollen die Rechteinhaber beteiligt werden. $37 \%$ der durch die Google Buchsuche erzielten Einnahmen behält Google, während die restlichen $63 \%$ an die Rechteinhaber verteilt werden sollen. ${ }^{1126} \mathrm{Zu}$ diesem Zweck wird durch das GBS auf Kosten von Google eine Registrierungs- und Verwaltungsstelle, die

1121 Siehe $\S 4.2(\mathrm{~b})($ iii) GBS.

1122 Siehe $\S 4.1(\mathrm{a})(\mathrm{v})$ GBS. Neben dem vollständigen Zugang zur gesamten ISD kann Google auch Zugänge zu fachspezifischen Teilen der Datenbank gewähren.

1123 Vgl. § 4.1(a)(iv) GBS.

1124 Siehe im Einzelnen $\S 4.1$ (a)(iv)-(viii) GBS.

1125 Siehe $\S 4.1(\mathrm{~d})$, (e) GBS. Insoweit bestehen dieselben Beschränkungen wie beim „Consumer Purchase“: Das Kopieren im Wege des „copy/paste“ ist auf maximal vier Seiten je Kopiervorgang beschränkt und das Ausdrucken auf zwanzig Seiten je Druckauftrag.

1126 Siehe § 2.1(a) GBS. 
sogenannte Book Rights Registry (BRR), gegründet, ${ }^{127}$ die als Vermittler zwischen Google und den Rechteinhabern Rechte der class members verwaltet und wahrnimmt, Einnahmen aus der Google Buchsuche sammelt und diese an die Rechteinhaber ausschüttet und zu diesem Zweck versucht, Rechteinhaber zu ermitteln und eine Datenbank über Rechtsinhaberschaft an den in der Google Buchsuche verfügbaren Werken führt. Die BRR verteilt zudem die von Google vorab gezahlten 45 Millionen USDollar für die bereits digitalisierten Werke an deren Rechteinhaber. Können Rechteinhaber nicht lokalisiert werden, so werden diesen zustehende Einnahmen zunächst für fünf Jahre treuhänderisch von der BRR verwahrt und nach Ablauf dieser Frist nach einem gesonderten Verteilungsschlüssel (,Plan of Allocation") ${ }^{1128}$ zur Deckung von Kosten der BRR verwendet und an registrierte Rechteinhaber ausgeschüttet. ${ }^{1129}$

\section{(2) Kritik am GBS}

Während das ursprüngliche Google Buchsuche-Projekt hauptsächlich auf Widerstand von Autoren und Verlegern gestoßen war, stieß das GBS aufgrund seiner Breite und weit über die urheberrechtlichen Fragestellungen hinausgehenden Konsequenzen auf Kritik und Widerstand aus deutlich weiteren Kreisen, zu denen neben Rechteinhabern insbesondere Vertreter der Wissenschaft, aber auch nationale und internationale staatliche Stellen wie die Antidrust Division des U.S. Department of Justice und die deutsche Bundesregierung gehörten. Anders als die ursprüngliche Kritik betraf die neue Kritik am GBS jedoch nicht mehr nur noch die ungenehmigte Verwendung fremder Werke durch Google, sondern bezog sich ganz wesentlich auf die Art der Regelung dieser Aspekte durch das GBS im Rahmen einer Class Action und auf einzelne Inhalte des GBS.

Ein zentraler Kritikpunkt betraf die Reichweite des GBS. Obwohl die Kläger nur eine kleine Gruppe von Autoren und Verlegern vertraten, erfasste das GBS aufgrund der enthaltenen weitreichenden Definitionen und der Besonderheiten der Class Action-Klage eine kaum überschaubare Anzahl von Büchern und somit eine kaum feststellbare Anzahl von Rechteinhabern. Die Class umfasste zum einen alle Rechteinhaber mit einem

1127 Siehe im Einzelnen $\S \S 6.1-6.7$ GBS.

1128 Siehe Attachment $C$ zum GBS.

1129 Siehe $\S 6.3($ a) GBS. 


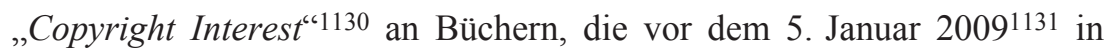
den USA veröffentlicht und beim U.S. Copyright Office registriert wurden, unabhängig von der Nationalität der Autoren oder der Sprache der Veröffentlichung, zum anderen auch ausländische Rechteinhaber, die an Werken, die in diesem Zeitraum veröffentlicht, jedoch nicht in den USA registriert wurden, ein "Copyright Interest" haben. ${ }^{132}$ Ein solches ist bei einem Großteil der ausländischen Rechteinhaber anzunehmen, da jedenfalls Autoren in Mitgliedstaaten der RBÜ mit Entstehung eines inländischen Urheberrechts gemäß 17 U.S.C. § 104 grundsätzlich auch ein USamerikanisches Urheberrecht erwerben. Diese ausländischen Autoren wären also - oftmals unwissentlich - vom GBS erfasst worden, obwohl ihre Werke nicht in den USA registriert und möglicherweise nicht einmal dort veröffentlicht wurden. ${ }^{1133}$ Dies hätte besonders weitreichende Folgen gehabt, weil ein erheblicher Teil der Bücher ausländischer Autoren als „Not Commercially Available" eingestuft worden wäre, da nach dem GBS für eine solche Kategorisierung ausreichen soll, dass ein Buch nicht über übliche Kanäle in den USA zum Kauf erhältlich ist. ${ }^{1134}$ Sämtliche Bücher, die nicht in den USA zum Kauf angeboten werden, im Extremfall also sogar Bücher, die in einem anderen Land ein Bestseller sind oder waren, würden im Hinblick auf die Nutzung für die Google Buchsuche als „Not Commercially Available" kategorisiert, so dass sie als „Display Books" eingestuft und folglich standardmäßig für sämtliche „Display Uses“ freigeschaltet würden. Aufgrund dieser großen Reichweite des GBS formierte sich erheblicher Widerstand insbesondere von ausländischen Rechteinhabern ${ }^{1135}$

1130 Siehe die Definition in $\S 1.38$ GBS.

1131 Der 5. Januar 2009 wurde von den Parteien gemäß $§ 1.97$ des Amended Settlement Agreement als „Notice Commencement Date“ im Sinne von $\S 1.16$ i.V.m. $\S 1.94$ GBS festgelegt.

1132 Siehe $\S 1.16$ GBS.

1133 Vgl. (im Hinblick auf die Erfassung deutscher Bücher) die ausführliche Darstellung von Brägelmann, KUR 2009, 135 (139 ff.).

1134 Vgl. §§ 1.28, 3.2(d) GBS.

1135 Siehe etwa Börsenverein des Deutschen Buchhandels, Schweizer Buchhändlerund Verleger-Verband, Hauptverband des Österreichischen Buchhandels, Svenska Förläggareföreningen, et al., Letter of Objection to the Proposed Settlement Agreement, Doc. 167, Authors Guild et al. v. Google Inc., No. 05 CV 8136-DC (S.D.N.Y. Aug. 31, 2009); Editions Larousse SAS (France), Letter of Objection, Doc. 558, Authors Guild et al. v. Google Inc., No. 05 CV 8136-JES (S.D.N.Y. Sept. 11, 2009); Japanese Publishers, Letter of Objection, Doc. 497, Authors Guild et al. v. Google Inc., No. 05 CV 8136-DC (S.D.N.Y. Sept. 10, 2009). 
und staatlichen Stellen, ${ }^{1136}$ die eine Einschränkung der class unter Herausnahme der ausländischen Rechteinhaber forderten. Der Vergleich berücksichtige die Interessen ausländischer Rechteinhaber nicht hinreichend, obwohl er die selbstbestimmte Werkverwertung durch Rechteinhaber weltweit ganz erheblich beeinträchtige. ${ }^{1137}$ Durch die weltweite Abrufbarkeit des Google Buchsuche-Dienstes könne eine Werknutzung im durch das GBS zugelassenen Umfang auch aus anderen Ländern als den USA nicht (wirksam) ausgeschlossen werden, wodurch erhebliche Eingriffe in Ausschließlichkeitsrechte der Urheber drohten. ${ }^{1138}$ Die Erstreckung eines von einigen wenigen Interessenvertretern in einem Land verhandelten privatrechtlichen Vergleichs mit derartig weitreichenden Folgen auf eine so große Anzahl von Rechteinhabern, ohne dass diese am Verfahren beteiligt waren, benachteilige ausländische Urheber unangemessen. ${ }^{1139}$ Zudem verstoße der Vergleichsvorschlag durch das Opt Out-Erfordernis für Rechteinhaber, die nicht durch den Vergleich gebunden werden wollen, gegen internationales Recht. ${ }^{1140}$ Der Vergleich sei folglich nicht ,fair, reasonable,

1136 Siehe etwa Federal Republic of Germany, Memorandum of Law in Opposition to the Settlement Proposal, Doc. 179, Authors Guild et al. v. Google Inc., No. 05 CV 8136-DC (S.D.N.Y. Aug. 31, 2009); French Republic, Memorandum of Law in Opposition to the Settlement Proposal, Doc. 287, Authors Guild et al. v. Google Inc., No. 05 CV 8136-DC (S.D.N.Y. Sept. 8, 2009).

1137 Vgl. Federal Republic of Germany, Memorandum of Law in Opposition to the Settlement Proposal, Doc. 179, Authors Guild et al. v. Google Inc., No. 05 CV 8136-DC (S.D.N.Y. Aug. 31, 2009), S. 1 f.; French Republic, Memorandum of Law in Opposition to the Settlement Proposal, Doc. 287, Authors Guild et al. v. Google Inc., No. 05 CV 8136-DC (S.D.N.Y. Sept. 8, 2009), S. 9, 17 ff.

1138 Vgl. Federal Republic of Germany, Memorandum of Law in Opposition to the Settlement Proposal, Doc. 179, Authors Guild et al. v. Google Inc., No. 05 CV 8136-DC (S.D.N.Y. Aug. 31, 2009), S. 6.

1139 Vgl. Börsenverein des Deutschen Buchhandels, Schweizer Buchhändler- und Verleger-Verband, Hauptverband des Österreichischen Buchhandels, Svenska Förläggareföreningen, et al., Letter of Objection to the Proposed Settlement Agreement, Doc. 167, Authors Guild et al. v. Google Inc., No. 05 CV 8136-DC (S.D.N.Y. Aug. 31, 2009), S. 21 ff., 25; French Republic, Memorandum of Law in Opposition to the Settlement Proposal, Doc. 287, Authors Guild et al. v. Google Inc., No. 05 CV 8136-DC (S.D.N.Y. Sept. 8, 2009), S. 21 ff.

1140 Vgl. Börsenverein des Deutschen Buchhandels, Schweizer Buchhändler- und Verleger-Verband, Hauptverband des Österreichischen Buchhandels, Svenska Förläggareföreningen, et al., Letter of Objection to the Proposed Settlement Agreement, Doc. 167, Authors Guild et al. v. Google Inc., No. 05 CV 8136-DC (S.D.N.Y. Aug. 31, 2009), S. 17 ff.; Federal Republic of Germany, Memorandum of Law in Opposition to the Settlement Proposal, Doc. 179, Authors Guild 
and adequate" und deshalb vom Gericht abzulehnen. Die zahlreiche internationale Kritik am GBS veranlasste schließlich auch das U.S. Department of Justice dazu, besondere Zweifel an der hinreichenden Berücksichtigung der Belange ausländischer Rechteinhaber durch das GBS und somit an der Erfüllung der zur Genehmigung eines Vergleichs erforderlichen Kriterien ,fair, reasonable, and adequate" zu äußern. ${ }^{1141}$

Nicht nur von ausländischen Rechteinhabern wurde jedoch erhebliche Kritik am von den Parteien beschrittenen Weg zur Streitbeilegung geäuBert. Auch von Beteiligten in den USA wurde das Vorgehen im Wege einer Class Action vielfach als ungeeignet oder gar unzulässig angesehen. Die vom Vergleich erfasste Class sei zu weit gefasst. Aufgrund der daraus folgenden Diversität der Betroffenen seien die namentlich genannten Kläger nicht geeignet, die Class angemessen zu repräsentieren. ${ }^{1142}$ Zudem sei eine hinreichende Information aller betroffenen Class Members aufgrund ihrer unüberschaubaren Zahl nicht gewährleistet und tatsächlich auch nicht erfolgt. ${ }^{1143}$ Schließlich gehe das GBS durch die umfassende Rege-

et al. v. Google Inc., No. 05 CV 8136-DC (S.D.N.Y. Aug. 31, 2009), S. 12; French Republic, Memorandum of Law in Opposition to the Settlement Proposal, Doc. 287, Authors Guild et al. v. Google Inc., No. 05 CV 8136-DC (S.D.N.Y. Sept. 8, 2009), S. 10 ff., mit dem Hinweis, das Opt Out-Modell verstoße gegen internationales Recht, da es eine nach Art. 5 Abs. 2 RBÜ für die Erlangung und Ausübung von Urheberrechtsschutz unzulässige Förmlichkeit darstelle. Siehe aber die umfassende Prüfung der Vereinbarkeit des GBS mit der RBÜ bei Ricketson, Google Book Settlement, S. 4 ff., der zu dem Ergebnis kommt, ein Opt Out-Erfordernis stelle keinen Verstoß gegen Art. 5 Abs. 2 RBÜ dar. Zur international-rechtlichen Bewertung des GBS siehe auch Gervais, 2011 Stan. Tech. L. Rev. 1.

1141 Siehe United States of America, Statement of Interest Regarding Proposed Class Settlement, Doc. 720, Authors Guild et al. v. Google Inc., No. 05 CV 8136-DC (S.D.N.Y. Sept. 18, 2009), S. 5.

1142 Vgl. Science Fiction and Fantasy Writers of America, Inc., and American Society of Journalists and Authors, Inc., Objections to the Amended Settlement Agreement, Doc. 864, Authors Guild et al. v. Google Inc., No. 05 CV 8136-DC (S.D.N.Y. Jan. 28, 2010), S. 4 ff.; United States of America, Statement of Interest Regarding Proposed Class Settlement, Doc. 720, Authors Guild et al. v. Google Inc., No. 05 CV 8136-DC (S.D.N.Y. Sept. 18, 2009), S. 8 ff.; Samuelson, 52 No. 7 Comm. ACM 28, 30 (2009).

1143 Vgl. Science Fiction and Fantasy Writers of America, Inc., and American Society of Journalists and Authors, Inc., Objections to the Amended Settlement 
lung zukünftiger Sachverhalte und kommerzieller Geschäftsmodelle inhaltlich deutlich über die Entscheidung der dem Gericht im Prozess vorgelegten Fragen hinaus ${ }^{1144}$ und sei deshalb unzulässig. ${ }^{1145}$

Neben dieser Kritik an der Reichweite des GBS wurden weitere Bedenken insbesondere hinsichtlich der wettbewerbs- und kartellrechtlichen Implikationen des GBS und wegen Fragen des Datenschutzes, des Schutzes der Privatsphäre und des Schutzes der Meinungsfreiheit geäußert. Die Darstellung dieser Problematik würde den Rahmen dieser Untersuchung bei weitem überschreiten. Es sollen daher nur überblicksartig die wesentlichen Kritikpunkte dargestellt werden. ${ }^{1146}$

Aus kartell- und wettbewerbsrechtlicher Sicht sind im Wesentlichen zwei Aspekte des GBS kritisiert worden, die Verstöße gegen Regelungen des US-amerikanischen Kartell- oder Wettbewerbsrechts, ${ }^{1147}$ insbesondere gegen den Sherman Act ${ }^{1148}$ darstellen könnten. Nach Section 1 des Sherman Act, 15 U.S.C. § 1, ist der Abschluss von Verträgen untersagt, die den Handel oder geschäftlichen Verkehr unangemessen beschränken. Solche Beschränkungen wurden zum einen durch die Einrichtung und die vorgeschlagene Ausgestaltung der Book Rights Registry befürchtet. Insbesondere aufgrund der Befugnis der BRR, Preise für den Online-Zugriff auf Bücher festzusetzen, bestehe die Gefahr, dass der Preiswettbewerb auf die-

Agreement, Doc. 864, Authors Guild et al. v. Google Inc., No. 05 CV 8136-DC (S.D.N.Y. Jan. 28, 2010), S. 7; Scott E. Gant, Objection to Proposed Settlement, Doc. 143, Authors Guild et al. v. Google Inc., No. 05 CV 8136-DC (S.D.N.Y. Aug. 20, 2009), S. $13 \mathrm{ff}$.

$1144 \mathrm{Zu}$ den Unterschieden zu einer möglichen Fair Use-Entscheidung des Gerichts siehe unten 5. Kapitel, B.II.2.b).

1145 Vgl. Amazon.com, Inc., Objection to Proposed Settlement, Doc. 206, Authors Guild et al. v. Google Inc., No. 05 CV 8136-DC (S.D.N.Y. Sept. 1, 2009), S. 34 ff.; AT\&T Corp., Objections to Class Action Settlement, Doc. 863, Authors Guild et al. v. Google Inc., No. 05 CV 8136-DC (S.D.N.Y. Jan. 28, 2010), S. 7 ff.; Microsoft Corp., Objections to Proposed Settlement, Doc. 276, Authors Guild et al. v. Google Inc., No. 05 CV 8136-DC (S.D.N.Y. Sept. 8, 2009), S. $20 \mathrm{ff}$.

1146 Ein guter Überblick über die gegen das GBS vorgebrachten wesentlichen Bedenken findet sich bei Grimmelmann, Objections and Responses, S. 4 ff.

1147 Für eine überblicksartige Betrachtung des GBS nach deutschem Kartellrecht siehe Rath/Swane, K\&R 2009, 225 (227).

1148 Sherman Antitrust Act vom 2. Juli 1890, 15 U.S.C. $\S \S 1-7$. 
sem Markt erheblich beeinflusst werde. ${ }^{149}$ Die Problematik würde dadurch noch verschärft, dass Google zumindest faktischen Einfluss auf die selbst finanzierte BRR erhalten würde. ${ }^{1150}$ Zum anderen wurde vielfach kritisiert, dass Google durch den Vergleich eine monopolistische Stellung auf dem Markt für den Verkauf digitaler Zugänge zu Bibliotheksbeständen und abhängigen Produkten sowie auf dem Markt für vergriffene und verwaiste Werke erlangen könnte, da Google - und nur Google - durch das GBS eine Haftungsfreistellung für die Verwendung von Büchern erhalte, deren Rechteinhaber nicht auffindbar sind oder ihre Rechte nicht geltend machen. ${ }^{1151}$ Auch Wettbewerbern könnte die BRR zwar Lizenzen für die Werknutzung erteilen. Für diese bestünde jedoch, anders als für Google, nicht die Sicherheit, dass sie sich durch die Werkverwertung nicht haftbar machen, da die rechtliche Bewertung der Werknutzung durch das GBS gerade nicht geklärt worden wäre. Die BRR könnte Wettbewerbern folglich tatsächlich keine Lizenzen erteilen, die eine rechtssichere Nutzung in demselben Umfang wie Google garantieren. ${ }^{1152}$ Als besonders brisant stellte sich zudem die im GBS enthaltene sogenannte ,most favored nation clause" dar, nach der die BRR oder eine von Rechteinhabern ins Leben gerufene vergleichbare Einrichtung, die Daten oder Materialien von Goog-

1149 Vgl. Amazon.com, Inc., Objection to Proposed Settlement, Doc. 206, Authors Guild et al. v. Google Inc., No. 05 CV 8136-DC (S.D.N.Y. Sept. 1, 2009), S. $18 \mathrm{ff}$; United States of America, Statement of Interest Regarding Proposed Class Settlement, Doc. 720, Authors Guild et al. v. Google Inc., No. 05 CV 8136-DC (S.D.N.Y. Sept. 18, 2009), S. 17 ff., 21 f.; Fraser, 2010 Stan. Tech. L. Rev. 1, 9 ff.; Picker, 5 J. Competition L. \& Econ. 383, 403 ff. (2009); Suarez, 55 N.Y.L. Sch. L. Rev. 175, 190 ff. (2010).

1150 Vgl. Samuelson, AMI 2010, 50 (52).

1151 Siehe zu diesbezüglichen wettbewerbs- und kartellrechtlichen Bedenken United States of America, Statement of Interest Regarding Proposed Class Settlement, Doc. 720, Authors Guild et al. v. Google Inc., No. 05 CV 8136-DC (S.D.N.Y. Sept. 18, 2009), S. 23 ff.; Fraser, 2010 Stan. Tech. L. Rev. 1, 17 ff.; Glorioso, 38 Hofstra L. Rev. 971, 994 ff. (2010); Grimmelmann, Google Book Search Settlement, S. 5 ff.; Müller-Langer/Scheufen, 8 Rev. Econ. Research on Copyright 7, 26 ff. (2011); Picker, 5 J. Competition L. \& Econ. 383, 394 ff. (2009); Samuelson, 52 No. 7 Comm. ACM 28, 30 (2009); Suarez, 55 N.Y.L. Sch. L. Rev. 175, $204 \mathrm{ff}$. (2010). Siehe aber auch Elhauge, 2 J. Legal Analysis, 1, $7 \mathrm{ff}$. (2010) und Lemley, AMI 2010, 55 ff., die das Google Book Settlement für wettbewerbsfördernd halten.

1152 Siehe United States of America, Statement of Interest Regarding Proposed Class Settlement, Doc. 720, Authors Guild et al. v. Google Inc., No. 05 CV 8136-DC (S.D.N.Y. Sept. 18, 2009), S. 23. 
le verwendet, Google stets mindestens ebenso gute Konditionen einräumen müsste wie seinen Wettbewerbern. ${ }^{1153}$ Diese Regelung hätte zweifelsohne eine erhebliche Marktzutrittsschranke für Wettbewerber dargestellt, die Google in den Markt für digitale Bibliotheksangebote folgen wollten.

In Bezug auf den Datenschutz ist vielfach kritisiert worden, dass Google durch das GBS in die Lage versetzt worden wäre, eine Vielzahl von Informationen über die Nutzer zu sammeln, ${ }^{1154}$ deren Sicherheit und (Weiter-)Verwendung nicht ausreichend geregelt und geklärt sei. ${ }^{1155}$ Im Rahmen der Buchsuche speichert Google unter anderem die IP-Adresse jedes Nutzers, Informationen über den verwendeten Browser und das verwendete Betriebssystem, den Inhalt der Suchanfragen sowie Informationen über aufgerufene Bücher und Buchseiten sowie über den Ort und Zeitpunkt des Abrufs. ${ }^{1156}$ Google könnte so detaillierte Nutzerprofile erstellen und diese

1153 Siehe §3.8(a) GBS; siehe dazu Grimmelmann, 12 No. 10 J. Internet L. 1, 15 (2009); Hausman/Sidak, 5 J. Competition L. \& Econ. 411, 429 f. (2009); Picker, 5 J. Competition L. \& Econ. 383, 400 ff. (2009).

1154 Ironischerweise sind Google und die teilnehmenden Bibliotheken nach dem GBS zur Einhaltung der dort geregelten Sicherheitsstandards sogar dazu verpflichtet, umfassende Daten über das Nutzungsverhalten zu sammeln und zu speichern; siehe Attachment $D$ zum GBS.

1155 Vgl. Center for Democracy \& Technology, Brief Amicus Curiae in Support of Approval of the Settlement and Protection of Reader Privacy, Doc. 314, Authors Guild et al. v. Google Inc., No. 05 CV 8136-DC (S.D.N.Y. Sept. 9, 2009), S. 4 ff.; Consumer Watchdog, Brief Amicus Curiae in Opposition to the Proposed Settlement Agreement, Doc. 313, Authors Guild et al. v. Google Inc., No. 05 CV 8136-DC (S.D.N.Y. Sept. 9, 2009), S. 7 ff.; Electronic Privacy Information Center, Objection to the Proposed Settlement, Doc. 748, Authors Guild et al. v. Google Inc., No. 05 CV 8136-DC (S.D.N.Y. Oct. 2, 2009), S. 3 ff.; Privacy Authors and Publishers, Objection to Proposed Settlement, Doc. 325, Authors Guild et al. v. Google Inc., No. 05 CV 8136-DC (S.D.N.Y. Sept. 9, 2009), S. 10 ff. Siehe auch Band, 9 J. Marshall Rev. Intell. Prop. L. 227, 306 ff. (2009); D'Andrade, Don't Let Google Close the Book on Reader Privacy!, EFF Deeplinks v. 23.7.2009 (abrufbar unter: http://www.eff.org/deeplinks/2009/07/ take-action-dont-let-google [zuletzt abgerufen am 26.5.2013]); Friedman, 17 Vill. Sports \& Ent. L.J. 637, 669 ff. (2010); Grimmelmann, 12 No. 10 J. Internet L. 1, 16 (2009); Klinefelter, 11 N.C. J. L. \& Tech. 553 (2010); Ozer/Lynch, Protecting Reader Privacy, S. 2 ff.; Pasquale, 104 Nw. U. L. Rev. 105, 144 ff. (2010); Samuelson, 94 Minn. L. Rev. 1308, 1346 ff. (2010). Ausführlich zu datenschutzrechtlichen Problemen der Google Buchsuche zuletzt Jones/Janes, 2 Policy \& Internet 43, 45 ff. (2010).

1156 Vgl. Ozer/Lynch, Protecting Reader Privacy, S. 3. 
etwa für gezielte Werbung oder weitere kommerzielle Zwecke verwenden. Alle diese Vorgänge haben das Potential, die ,intellektuelle Privatsphäre" ${ }^{\text {"1157 }}$ und letztlich auch die Meinungsbildung der Nutzer ganz erheblich zu beeinträchtigen. Als besonders problematisch wurde insofern gesehen, dass Google als Monopolist und als kommerzieller Anbieter in die Lage versetzt werde, den Zugang zu Informationen zu kontrollieren und so die Freiheit der Meinungsbildung zu beeinflussen. ${ }^{158}$ Auch durch Formen der Zensur, etwa durch das Herausnehmen bestimmter Werke aus der Datenbank und/oder die „bevorzugte“ Behandlung bestimmter Werke aufgrund kommerzieller Interessen oder auf politischen Druck, könnte ein derartiger Monopolist Einfluss auf die Meinungsbildung erlangen. ${ }^{1159}$

\section{bb) Das Amended Settlement Agreement (ASA)}

Die erhebliche Kritik am ursprünglichen Google Book Settlement führte dazu, dass Google, die Authors Guild und die AAP am 13. November 2009 bei dem zuständigen Gericht einen geänderten und ergänzten Vergleichsvertrag, das Amended Settlement Agreement (ASA), einreichten. ${ }^{1160}$ Besondere Berücksichtigung fanden durch das ASA die Kritik internationaler Rechteinhaber und die Bedenken des U.S. Department of Justice, die jedoch auch durch den geänderten Vergleichsvorschlag nicht vollständig ausgeräumt werden konnten. In den wesentlichen Grundzügen blieb der Vergleichsvorschlag unverändert. Auch nach dem ASA bleibt Google weiterhin berechtigt, urheberrechtlich (noch) geschützte Werke zu digitalisieren und in die Buchsuche-Datenbank aufzunehmen, um so eine Volltextsuche innerhalb dieser Werke zu ermöglichen und die Werke in durch das ASA näher bestimmtem Umfang den Nutzern zugänglich zu

1157 Siehe dazu ausführlich Richards, 87 Texas L. Rev. 387 ff. (2008), der den Begriff der „Intellectual Privacy“ geprägt hat. Vgl. auch Grimmelmann, 19 Widener L.J. 793, 813 ff. (2010); Jones/Janes, 2 Policy \& Internet 43, 50 ff. (2010).

1158 Vgl. Pamela Samuelson et al., Academic Author Objections to the Google Book Search Settlement, Doc. 336, Authors Guild et al. v. Google Inc., No. 05 CV 8136-DC (S.D.N.Y. Sept. 9, 2009), S. 12.

1159 Vgl. Pamela Samuelson et al., Academic Author Objections to the Google Book Search Settlement, Doc. 336, Authors Guild et al. v. Google Inc., No. 05 CV 8136-DC (S.D.N.Y. Sept. 9, 2009), S. 9 f.

1160 Siehe The Authors Guild, Inc., Association of American Publishers, Inc., et al. v. Google Inc., Case No. 05 CV 8136-DC, Amended Settlement Agreement. 
machen. ${ }^{1161}$ Google ist zudem weiterhin berechtigt, Abonnements für die elektronische Buchsuche-Datenbank an Institutionen zu verkaufen (,Institutional Subscriptions"), Online-Zugänge für einzelne Bücher zu verkaufen („Consumer Purchase"), Werbung auf den Seiten der Bücher zu verkaufen und Auszüge aus Büchern in einem „Vorschau“-Format zu zeigen, um Online-Zugangsverkäufe zu Büchern zu fördern. ${ }^{1162}$ Zugleich wird Google weiterhin gegenüber sämtlichen Mitgliedern der class von einer (möglichen) Haftung für das bisherige Einscannen, Durchsuchen und öffentliche Zugänglichmachen im Rahmen der Google Buchsuche freigestellt. ${ }^{1163}$ Die wesentlichen Änderungen des Vergleichsvorschlags gegenüber dem GBS sollen im Folgenden überblicksartig dargestellt werden. ${ }^{1164}$

\section{(1) Wesentliche Änderungen gegenüber dem ursprünglichen GBS}

Die - im Hinblick auf die Rechte ausländischer Rechteinhaber - entscheidendste Neuerung des ASA gegenüber dem GBS betrifft dessen veränderte Reichweite. Durch eine deutliche Verengung der Definition des „Book“ in $§ 1.19$ ASA sind viele der zuvor noch erfassten ausländischen Werke nicht mehr vom Vergleich erfasst, so dass deren Rechteinhaber auch nicht mehr Mitglieder der durch den Vergleich betroffenen Class sind. ${ }^{1165}$ Anders als vom GBS, das auch (fast) sämtliche im Ausland erschienenen Bücher erfasste, ${ }^{1166}$ werden vom ASA neben Büchern, die in den USA veröffentlicht wurden, ${ }^{1167}$ nur noch solche Werke erfasst, die entweder vor dem

1161 Vgl. § 3.1(a) ASA.

1162 Vgl. $\S \S 2.1(\mathrm{a}), 2.2$ ASA.

1163 Vgl. § 10.2(a) ASA.

1164 Eine vollständige Darstellung des ASA und der enthaltenen Änderungen gegenüber dem GBS würde auch hier den Rahmen sprengen. Es sollen daher nur einige ganz wesentliche Aspekte kurz dargestellt werden. Eine Verfolgung sämtlicher Änderungen des ASA gegenüber dem GBS ermöglicht eine auf der Internetseite zum Google Buchsuche-Vergleich abrufbare Version des ASA, in der alle Änderungen im „Änderungsmodus“ sichtbar gemacht sind; abrufbar unter: http://www.googlebooksettlement.com/agreement.html [zuletzt abgerufen am 26.5.2013]. Einen guten Überblick über wesentliche Aspekte des ASA bietet Band, A Guide for the Perplexed III, S. 2 ff.

1165 Vgl. die Definition der Amended Settlement Class in $\S 1.13$ ASA.

1166 Siehe oben 5. Kapitel, B.II.2.a)aa)(a).

1167 Nach $\S 1.19$ ASA sind United States Works im Sinne von 17 U.S.C. § 101 erfasst. 
5. Januar 2009 in Kanada, Australien oder dem Vereinigten Königreich erschienen sind oder bis zum 5. Januar 2009 beim U.S. Copyright Office registriert wurden. ${ }^{1168}$ Ziel dieser Beschränkung war es, die Settlement Class im Wesentlichen auf solche Rechteinhaber zu beschränken, die aus Ländern mit vergleichbaren Rechtssystemen und vergleichbaren Buchmärkten stammen. ${ }^{1169}$ Zumindest auf den ersten Blick scheint somit ein Großteil der nicht aus den genannten Ländern stammenden ausländischen Werke aus dem Vergleich auszuscheiden. Eine genauere Betrachtung ergibt jedoch, dass auch weiterhin ein nicht unerheblicher Teil ausländischer, insbesondere auch deutscher Werke vom Vergleich erfasst sein wird. Bis zum Inkrafttreten des Copyright Act of 1976 am 1. Januar 1978 war Voraussetzung für die Erlangung (effektiven) Urheberrechtsschutzes in den USA die Registrierung des Werkes beim Copyright Office. ${ }^{1170}$ Ausländische Werke wurden deshalb in der Zeit vor 1978 von vielen Verlagen standardmäßig auch im U.S. Copyright-Register eingetragen, um auf dem

$1168 \S 1.19$ ASA lautet: “'Book’ means a written or printed work that as of January 5, 2009 (a) had been published or distributed to the public or made available for public access as a set of written or printed sheets of paper bound together in hard copy form under the authorization of the work's U.S. copyright owner, (b) was subject to a Copyright Interest, and (c) (1) if a 'United States work', as defined in 17 U.S.C. $\$ 101$, was registered with the United States Copyright Office, and (2) if not a United States work, either (x) was registered with the United States Copyright Office, or (y) had a place of publication in Canada, the United Kingdom or Australia, as evidenced by information printed in or on a hard copy of the work. Relevant information printed in or on a hard copy of the work may include, for example, a statement that the book was 'Published in [Canada] or [the UK] or [Australia]', or the location or address of the publisher in one of those three countries. [...]" [Hervorhebungen durch den Verfasser].

1169 Vgl. AAP, The Revised Google Books Settlement Agreement, S. 1, abrufbar unter: http://publishers.org/main/Copyright/CopyKey/documents/SettlementModificationsOverview.pdf [zuletzt abgerufen am 26.5.2013].

1170 Nach $\S 13$ des Copyright Act of 1909 war die Registrierung eines Werkes zwingend erforderlich, um das Urheberrecht an diesem vor einem Gericht geltend zu machen. Nach $\S 24$ Copyright Act of 1909 betrug die urheberrechtliche Schutzdauer nach US-amerikanischem Recht zudem zunächst nur 28 Jahre ab der Erstveröffentlichung. Der Schutz konnte jedoch durch eine rechtzeitige Registrierung des Werkes beim Copyright Office um weitere 28 Jahre verlängert werden. 
US-amerikanischen Markt Schutz zu erlangen. ${ }^{1171}$ Auch nach der Änderung der Gesetzeslage dürften noch etliche ausländische Werke beim Copyright Office registriert worden sein, unter anderem da die Registrierung auch heute noch Voraussetzung für die prozessuale Geltendmachung eines pauschalierten Schadensersatzes wegen Urheberrechtsverletzungen und für den Ersatz von Anwaltsgebühren aus einem solchen Prozess ist. ${ }^{1172}$ Es ist somit insgesamt davon auszugehen, dass eine nicht unerhebliche Anzahl von Werken, die auf den ersten Blick nicht mehr vom ASA erfasst werden, tatsächlich doch zu den in $\S 1.19$ ASA definierten „Books“ zu rechnen sind, da sie beim Copyright Office registriert wurden. ${ }^{1173}$ Selbst solche ausländischen Bücher, die nicht beim Copyright Office registriert wurden, können jedoch auch weiterhin vom Buchsuche-Vergleich erfasst werden. Neben solchen Werken, die im Copyright-Register eingetragen sind, sind nach §1.19 ASA nämlich auch solche Werke als „Books" im Sinne des Vergleichs anzusehen, die bis zum 5. Januar 2009 in Kanada, Australien oder dem Vereinigten Königreich erschienen sind. Eine nähere Definition, wann ein solches „Erscheinen“ vorliegt, liefert das ASA nicht. $\S 1.19$ ASA formuliert lediglich, dass eine Hinweisfunktion insoweit auf oder in einem Buch enthaltenen gedruckten Informationen über den Erscheinungsort zukommen kann. ${ }^{1174}$ Nach dieser offenen Definition ist nicht auszuschließen, dass auch zahlreiche Bücher vom Vergleich erfasst werden, die zwar nur in einem oder mehreren anderen als den im ASA genannten Ländern veröffentlicht wurden, deren Verlage jedoch - wie vielfach üblich - als Verlagsorte sämtliche Städte angeben, in denen sie zen-

1171 Siehe Syndicat National de l'Édition, Objection to Amended Settlement Agreement, Doc. 836, Authors Guild et al. v. Google Inc., No. 05 CV 8136-DC (S.D.N.Y. Jan. 28, 2010), S. 2; VG Wort, Objection to Amended Settlement Agreement, Doc. 857, Authors Guild et al. v. Google Inc., No. 05 CV 8136-DC (S.D.N.Y. Jan. 28, 2010), S. 3.

1172 Siehe 17 U.S.C. § 412. Siehe dazu oben Fn. 121.

1173 So auch Brägelmann, KUR 2009, 187 (189 f.).

1174 Vgl. § 1.19 ASA: "[...] had a place of publication in Canada, the United Kingdom or Australia, as evidenced by information printed in or on a hard copy of the work. [...]". 
trale Dependancen betreiben. ${ }^{1175} 1176$ Eine sichere Bestimmung der vom ASA erfassten Werke ist somit für die Rechteinhaber oftmals nicht möglich.

Auch nicht vom ASA erfasste Bücher will Google jedoch weiterhin digitalisieren, in die Buchsuche-Datenbank aufnehmen und wie bisher in Snippet-Form zugänglich machen. ${ }^{1177}$ Diesbezüglich wird also letztlich das bisherige Bibliotheksprogramm fortgesetzt. Da diese Werke jedoch nicht vom ASA erfasst werden, wird Google diesbezüglich auch keine Haftungsfreistellung erteilt, so dass die Rechteinhaber grundsätzlich weiterhin klageweise gegen Google wegen Urheberrechtsverletzungen durch die Digitalisierung und weitere Werknutzung im Rahmen der Google Buchsuche vorgehen könnten.

Neben der Kritik internationaler Rechteinhaber wurden zum GBS im Wesentlichen kartell- und wetttbewerbsrechtliche Bedenken in Bezug auf die Entstehung einer privilegierten Stellung von Google geäußert, insbesondere hinsichtlich der kommerziellen Verwertung solcher Bücher, deren Rechteinhaber ihre Rechte nicht geltend machen und die sich auch nicht ermitteln lassen. ${ }^{1178}$ Auf die kartell- und wettbewerbsrechtlichen Bedenken reagierten die Parteien durch einige Änderungen des Vergleichsvorschlags. Die sogenannte ,most favored nation clause“, die auf erhebliche Kritik gestoßen war, wurde vollständig aus dem Vergleichsvertrag gestrichen. Zudem wurden die Bestimmungen zur Berechnung und Festlegung des „Settlement Controlled Pricing“ für den „Consumer Purchase“ modi-

1175 Im Springer Verlag erschienene Bücher tragen etwa üblicherweise die Information ,Springer Verlag - Berlin Heidelberg New York“ und sind zudem nicht selten mit zwei ISBN-Nummern versehen - eine für den deutschsprachigen und eine für den englischsprachigen Raum; siehe etwa Ulmer, Urheber- und Verlagsrecht, 3. Aufl., Springer-Verlag Berlin Heidelberg New York 1980, ISBN 3-540-10367-8 und ISBN 0-387-10367-8.

1176 Vgl. VG Wort, Objection to Amended Settlement Agreement, Doc. 857, Authors Guild et al. v. Google Inc., No. 05 CV 8136-DC (S.D.N.Y. Jan. 28, 2010), S. 5 mit weiteren Beispielen. Siehe auch U.S. District Court for the Southern District of New York, Supplemental Notice to Authors, Publishers and other Book Rightsholders about the Google Book Settlement, Attachment $N$ zum ASA, S. $1 \mathrm{f}$.

1177 Vgl. Google Buchsuche-Vergleich, Häufig gestellte Fragen, Frage 21: „Was geschieht mit den Büchern von Autoren und Verlegern, die Widerspruch gegen den ergänzten Vergleich einlegen?“", abrufbar unter: http://www.googlebooksettlement.com/help/bin/answer.py?answer=118704\&hl=de\#q18a [zuletzt abgerufen am 26.5.2013].

1178 Siehe oben 5. Kapitel, B.II.2.a)aa)(b). 
fiziert. ${ }^{1179}$ Außerdem verpflichtet das ASA Google dazu, auch Dritten als „Reseller“ die Möglichkeit zu gewähren, Einzelzugänge zu Buchinhalten der Google Buchsuche im Rahmen des „Consumer Purchase“ zu verkaufen, wobei diese Wiederverkäufer den Großteil der auf Google entfallenden $37 \%$ der Gesamteinnahmen erhalten sollen. ${ }^{1180}$ Schließlich wurde eine im GBS enthaltene und vom U.S. Department of Justice besonders kritisierte Regelung deutlich eingeschränkt, nach der die Book Rights Registry ermächtigt wurde, Google zukünftig den Ausbau des Buchsuche-Angebotes um nicht näher spezifizierte, zusätzliche kommerzielle Dienste zu genehmigen. Das ASA gestattet lediglich die zukünftige Entwicklung von drei ausdrücklich benannten zusätzlichen Einnahmemodellen: (1) Das Angebot eines „Print on Demand“"-Dienstes, bei dem Käufer eine gedrucktes Exemplar eines Buches, das als „Not Commercially Available“ kategorisiert ist, erhalten; ${ }^{1181}$ (2) das Angebot eines „File Download“, das heißt die Ermöglichung des vollständigen Herunterladens eines für den Käufer im Rahmen des „Consumer Purchase“ zugänglichen Buches in einem Format, das die Nutzung auf einem e-Book-Lesegerät, einem Mobiltelefon oder ähnlichen elektronischen Geräten ermöglicht; ${ }^{1182}$ (3) das Angebot sogenannter „Consumer Subscription Models“, bei denen einzelne Nutzer ei-

1179 Siehe §4.2(c) ASA. Das ASA gibt vor, dass der von Google entwickelte Preisalgorithmus zur Berechnung des ,Settlement Controlled Price“ so auszugestalten ist, dass dieser die Preise eines wettbewerberlichen Marktes simuliert und der Preis für ein Buch ohne Rücksicht auf Preisänderungen bei anderen Büchern zu bestimmen ist. Die Preise werden also nicht mehr wie nach dem GBS für ähnliche Bücher automatisch einheitlich festgesetzt. Der aufgrund der neuen Berechnungsmethode bestimmte Preis für ein Buch wird zudem nur den Rechteinhabern des jeweiligen Buches offengelegt.

1180 Siehe $\S 4.5(\mathrm{~b})(\mathrm{v})(2)$ ASA.

1181 Siehe $\S 4.7$ (a) ASA. Die Tatsache, dass ein Buch, welches zuvor nicht kommerziell verfügbar war, in diesem Fall im Wege des ,Print on Demand“" kommerziell verfügbar gemacht wird, soll nach dieser Regelung keinen Einfluss auf dessen Kategorisierung als „Not Commercially Available“ haben.

1182 Siehe § 4.7(b) ASA. Diesen Service plant Google im Rahmen des Anfang 2010 unter dem Namen Google Editions angekündigten Dienstes anzubieten, der im Dezember 2010 unter dem Namen Google eBooks startete und derzeit nur gemeinfreie Werke und solche Werke umfasst, die mit Zustimmung von Verlagen angeboten werden. Googles eBookstore ist abrufbar unter: http://books.google.com/ebooks [zuletzt abgerufen am 26.5.2013]. Näher zur Funktionsweise von Google eBooks, siehe die Informationen von Google, „Getting started with Google eBooks“, abrufbar unter: http://books.google.com/support/partner/bin/ answer.py?hl=en\&answer=167975 [zuletzt abgerufen am 26.5.2013]. 
nen Zugang zur gesamten „Institutional Subscription Database“ oder Teilen davon erwerben können. ${ }^{1183}$ An allen diesen Modellen sollen die Rechteinhaber - wenn keine gegenteiligen Einzelvereinbarungen bestehen - nach demselben System beteiligt werden, das im ASA für den „Consumer Purchase“ beziehungsweise die "Institutional Subscriptions" festgeschrieben ist. ${ }^{1184}$ Die Befugnisse der BRR wurden zudem im Hinblick auf Orphan Works beschränkt. Nach dem ASA wird eine unabhängige Treuhandstelle, die sogenannte Unclaimed Works Fiduciary (UWF), eingerichtet, die mit zahlreichen Befugnissen ausgestattet ist, um stellvertretend für die nicht identifizierten Rechteinhaber zu handeln, insbesondere um die aus der Verwertung von Orphan Works erzielten Einnahmen treuhänderisch für deren Rechteinhaber zu verwalten und zu verteilen. ${ }^{185}$ Nicht beanspruchte Einnahmen sollen von der UWF für die Auszahlung an Rechteinhaber mindestens fünf Jahre vorgehalten werden, bevor sie zu anderen Zwecken, insbesondere für die Lokalisierung von Rechteinhabern, aufgewendet werden können. ${ }^{1186}$ Den Bedenken des Department of Justice trägt schließlich noch eine weitere Regelung Rechnung, die eine wesentliche Änderung gegenüber dem GBS darstellt: Nach $\S 17$ des Attachment $L$ zum ASA wird durch die gerichtliche Anerkennung des Vergleichs ausdrücklich nicht eine kartellrechtliche Verantwortung der beteiligten Parteien ausgeschlossen. Ohne eine derartige Regelung könnten sich die Vergleichsparteien möglicherweise darauf berufen, nach der sogenannten Noerr-Pennington-Doktrin ${ }^{1187}$ von einer solchen Haftung befreit zu sein. ${ }^{1188}$ Nach dieser Doktrin kann grundsätzlich auf Grundlage einer Vereinbarung, die mit Zustimmung einer Regierungsstelle oder eines Gerichts geschlossen wurde, kein späteres kartellrechtliches Verfahren angestrengt werden. ${ }^{1189}$ Durch den „Noerr-Pennington-Ausschluss“ in $\S 17$ Attach-

1183 Siehe $\S 4.7(\mathrm{c})$ ASA.

1184 Siehe $\S 4.7$ ASA.

1185 Siehe $\$ 6.2(\mathrm{~b})$ (iii) ASA.

1186 Vgl. § 6.3(a)(i) ASA.

1187 Die Doktrin ist benannt nach zwei Urteilen des U.S. Supreme Court aus den 1960er Jahren, Eastern Railroad Presidents Conference v. Noerr Motor Freight, Inc., 365 U.S. 127 (1961) und United Mine Workers of America v. Pennington, 381 U.S. 657 (1965).

1188 Vgl. Picker, 5 J. Competition L. \& Econ. 383, 387, 407 ff. (2009).

1189 Vgl. Professional Real Estate Investors, Inc. v. Columbia Pictures Industries, Inc., 508 U.S. 49 (1991); Holmes, Antitrust Law, § 8:8; ausführlich Schmidt, Noerr-Pennington Doctrine, S. 5 f., 31 ff., 77 ff. m.w.N. 
ment L bleibt für das U.S. Department of Justice die Möglichkeit gewahrt, im Falle einer Genehmigung des Vergleichs die Entwicklung der Google Buchsuche zu beobachten und gegebenenfalls zu einem späteren Zeitpunkt aufgrund kartellrechtlicher Bedenken gegen die Preispolitik oder gegen eine Monopolbildung einzuschreiten. ${ }^{1190}$

\section{(2) Kritik am ASA}

Trotz der genannten Änderungen gegenüber dem ursprünglichen Vergleichsvorschlag stieß auch das ASA weiterhin auf Kritik. Insbesondere internationale Rechteinhaber kritisierten die neue, engere Definition der „Books“ und somit der Vergleichsteilnehmer als ungeeignet und unzureichend. Zum einen sei die Anknüpfung an die Registrierung eines Werkes beim U.S. Copyright Office zur effektiven Begrenzung der „Settlement Class" ungeeignet, da es für Rechteinhaber kaum möglich sei festzustellen, ob ihre Werke vom Vergleich erfasst würden. Informationen über eine solche Registrierung lägen den Rechteinhabern oftmals nicht mehr vor und seien nur unter erheblichem Kosten- und Zeitaufwand zu beschaffen. ${ }^{1191}$ Tatsächlich sind die Registrierungsdaten aus der Zeit vor 1978 nicht einmal in einer Online-Datenbank, sondern nur in einem etwa 45 Millionen Einträge umfassenden Karteikastensystem des U.S. Copyright

1190 Vgl. Band, A Guide for the Perplexed III, S. 11; Picker, 5 J. Competition L. \& Econ. 383, 407 ff. (2009).

1191 Siehe Börsenverein des Deutschen Buchhandels, Schweizer Buchhändler- und Verleger-Verband, Hauptverband des Österreichischen Buchhandels, Associazione Italiana Editori, and the New Zealand Society of Authors, Letter of Objection to Amended Settlement Agreement, Doc. 868, Authors Guild et al. v. Google Inc., No. 05 CV 8136-DC (S.D.N.Y. Jan. 28, 2010), S. 5 ff.; Japan P.E.N. Club, Amicus Curiae Brief in Opposition to Amended Settlement Agreement, Doc. 848, Authors Guild et al. v. Google Inc., No. 05 CV 8136-DC (S.D.N.Y. Jan. 28, 2010), S. 4; Syndicat National de l'Édition, Objection to Amended Settlement Agreement, Doc. 836, Authors Guild et al. v. Google Inc., No. 05 CV 8136-DC (S.D.N.Y. Jan. 28, 2010), S. 3 f.; VG Wort, Objection to Amended Settlement Agreement, Doc. 857, Authors Guild et al. v. Google Inc., No. 05 CV 8136-DC (S.D.N.Y. Jan. 28, 2010), S. 3 ff. 
Office verfügbar. ${ }^{1192}$ Eine Auskunft kann daher nur durch eigene Suche in den Archiven des Copyright Office oder im Wege eines Suchauftrages beim Copyright Office erlangt werden, für den nicht unerhebliche Kosten anfallen. ${ }^{1193}$ Zudem würde durch ein solches Erfordernis die Möglichkeit einer kollektiven Wahrnehmung der Rechte durch Verwertungsgesellschaften erheblich erschwert oder gar unmöglich gemacht. ${ }^{1194}$ Auch das zweite Kriterium zur Eingrenzung der vom ASA erfassten Werke - die Beschränkung auf Werke, die in den USA, Kanada, Australien und dem Vereinigten Königreich veröffentlicht wurden - wurde als willkürlich und ungeeignet kritisiert. ${ }^{1195}$ Tatsächlich erscheint dieses Kriterium zum einen willkürlich, da nicht ersichtlich ist, weshalb gerade die Veröffentlichung in einem dieser Länder über die Teilnahme am Buchsuche-Vergleich entscheiden soll. Zum anderen ist das Kriterium - wie gezeigt - mangels näherer Angaben zu den Voraussetzungen einer „Veröffentlichung“ im Sinne der Definition des „Book“ in $\S 1.19$ ASA wenig hilfreich zur Begrenzung der Gruppe der vom Vergleich Betroffenen. Zudem ist davon auszugehen, dass bei einer weiten Auslegung des Kriteriums im Sinne einer reinen Betrachtung anhand der in einem Werk angeführten Verlagsorte ${ }^{1196}$ in Zeiten global agierender Verlage tatsächlich eine Vielzahl von Werken

1192 Vgl. die Informationen des U.S. Copyright Office unter: http://www.copyright.gov/records/ und die Informationsschrift „The Copyright Card Catalog and the Online Files of the Copyright Office", abrufbar unter: http://www.copyright.gov/circs/circ23.pdf [jeweils zuletzt abgerufen am 26.5.2013].

1193 Siehe „Obtaining Access to and Copies of Copyright Office Records and Deposits“, abrufbar unter: http://www.copyright.gov/circs/circ06.pdf; nach der Gebührenauskunft des Copyright Office entstehen für eine entsprechende Suche Kosten von 165 US-Dollar pro Arbeitsstunde, d.h. pro Buch ca. Gebühren in Höhe von 115 US-Dollar, zuzüglich etwaiger Gebühren für Kopien des Registereintrags o.ä.; siehe „Copyright Office Fees“, S. 2 f., abrufbar unter: http:// www.copyright.gov/circs/circ04.pdf [zuletzt abgerufen am 26.5.2013].

1194 Siehe Börsenverein des Deutschen Buchhandels, Schweizer Buchhändler- und Verleger-Verband, Hauptverband des Österreichischen Buchhandels, Associazione Italiana Editori, and the New Zealand Society of Authors, Letter of Objection to Amended Settlement Agreement, Doc. 868, Authors Guild et al. v. Google Inc., No. 05 CV 8136-DC (S.D.N.Y. Jan. 28, 2010), S. 8 ff.; VG Wort, Objection to Amended Settlement Agreement, Doc. 857, Authors Guild et al. v. Google Inc., No. 05 CV 8136-DC (S.D.N.Y. Jan. 28, 2010), S. 2 f.

1195 Siehe VG Wort, Objection to Amended Settlement Agreement, Doc. 857, Authors Guild et al. v. Google Inc., No. 05 CV 8136-DC (S.D.N.Y. Jan. 28, 2010), S. $4 \mathrm{f}$.

1196 Siehe oben 5. Kapitel, B.II.2.a)bb)(a). 
vom ASA erfasst werden, selbst wenn sie keinesfalls für einen der genannten englischsprachigen Märkte konzipiert sind. ${ }^{1197}$ Auch unter weiteren Gesichtspunkten wurde das ASA schließlich von internationalen Rechteinhabern und Rechteinhabervereinigungen kritisiert. Der Vergleichsvertrag verstoße weiterhin gegen internationales Recht ${ }^{1198}$ und benachteilige ausländische Rechteinhaber. Eine Benachteiligung liege zum einen darin, dass das ASA nicht in anderen Sprachen als Englisch zur Verfügung gestellt würde, wodurch eine umfassende Überprüfung möglicher Folgen für Rechteinhaber aus nicht-englischsprachigen Ländern mit erheblichem Aufwand verbunden sei. ${ }^{1199}$ Zum anderen seien die ausländischen Rechteinhaber nicht ausreichend über ihre Möglichkeiten zur Teilnahme am ASA und zum Ausstieg aus dem Vergleich informiert worden. ${ }^{1200}$ Schließlich würden Rechteinhaber aus anderen als den in $\S 1.19$ ASA genannten Ländern (USA, Kanada, Australien und Vereinigtes Königreich) benachteiligt, da sie nicht im Board of Directors der Book Rights Registry repräsentiert seien, obwohl ihre Werke vielfach dem ASA unter-

1197 So könnte - wie gezeigt (siehe oben S. 260 f.) - etwa auch ein in deutscher Sprache verfasstes Lehrbuch zum deutschen Urheberrechtsgesetz vom Vergleich erfasst werden, obwohl dessen Veröffentlichung offensichtlich auf den deutschen Markt abzielt.

1198 Vgl. Börsenverein des Deutschen Buchhandels, Schweizer Buchhändler- und Verleger-Verband, Hauptverband des Österreichischen Buchhandels, Associazione Italiana Editori, and the New Zealand Society of Authors, Letter of Objection to Amended Settlement Agreement, Doc. 868, Authors Guild et al. v. Google Inc., No. 05 CV 8136-DC (S.D.N.Y. Jan. 28, 2010), S. 10 ff.

1199 Vgl. Börsenverein des Deutschen Buchhandels, Schweizer Buchhändler- und Verleger-Verband, Hauptverband des Österreichischen Buchhandels, Associazione Italiana Editori, and the New Zealand Society of Authors, Letter of Objection to Amended Settlement Agreement, Doc. 868, Authors Guild et al. v. Google Inc., No. 05 CV 8136-DC (S.D.N.Y. Jan. 28, 2010), S. 22; Japan P.E.N. $C l u b$, Amicus Curiae Brief in Opposition to Amended Settlement Agreement, Doc. 848, Authors Guild et al. v. Google Inc., No. 05 CV 8136-DC (S.D.N.Y. Jan. 28, 2010), S. 4; Syndicat National de l'Édition, Objection to Amended Settlement Agreement, Doc. 836, Authors Guild et al. v. Google Inc., No. 05 CV 8136-DC (S.D.N.Y. Jan. 28, 2010), S. 8; VG Wort, Objection to Amended Settlement Agreement, Doc. 857, Authors Guild et al. v. Google Inc., No. 05 CV 8136-DC (S.D.N.Y. Jan. 28, 2010), S. 6.

1200 Vgl. Japan P.E.N. Club, Amicus Curiae Brief in Opposition to Amended Settlement Agreement, Doc. 848, Authors Guild et al. v. Google Inc., No. 05 CV 8136-DC (S.D.N.Y. Jan. 28, 2010), S. 4. 
fielen. ${ }^{1201}$ Aus allen diesen Gründen wurde im Ergebnis von sämtlichen internationalen Rechteinhabern, die sich zum ASA geäußert haben, die Ablehnung des Vergleichsvorschlags durch das zuständige Gericht gefordert.

Von Betroffenen in den USA wird der Vergleich ebenso kritisiert. Insbesondere das Vorgehen im Wege einer Class Action wird vielfach weiterhin als ungeeignet oder gar unzulässig angesehen. Im Hinblick auf USamerikanische Rechteinhaber sei keine Einschränkung der Class erfolgt. Weiterhin sei die Class daher zu weit gefasst und durch die namentlich genannten Kläger nicht angemessen repräsentiert. ${ }^{1202}$

Auch die kartell- und wettbewerbsrechtlichen Bedenken konnten durch die im Rahmen des ASA vorgenommenen Änderungen und den „NoerrPennington-Ausschluss“ in $\S 17$ Attachment $L$ nicht vollständig ausgeräumt werden. Weiterhin kritisiert werden insbesondere die Festlegung des „Settlement Controlled Pricing“ durch Google ${ }^{1203}$ und die Gefahr eines durch das ASA erzeugten de facto-Monopols von Google in Bezug auf die kommerzielle Verwertung von Orphan Works, da nur Google durch den Vergleich in die Lage versetzt würde, diese rechtssicher zu nutzen. ${ }^{1204}$

Trotz einiger Änderungen gegenüber dem GBS ist das ASA - wie gezeigt - erheblichen Zweifeln ausgesetzt. Aus den dargestellten Gründen ist es letztlich nicht überraschend, dass sich auch das zuständige Gericht der

1201 Vgl. Syndicat National de l'Édition, Objection to Amended Settlement Agreement, Doc. 836, Authors Guild et al. v. Google Inc., No. 05 CV 8136-DC (S.D.N.Y. Jan. 28, 2010), S. 8.

1202 Vgl. Samuelson, 53 No. 7 Comm. ACM 32, 33 (2010).

1203 Vgl. Amazon.com, Inc., Objection to Proposed Amended Settlement, Doc. 823, Authors Guild et al. v. Google Inc., No. 05 CV 8136-DC (S.D.N.Y. Jan. 27, 2010), S. 10 ff.; AT\&T Corp., Objections to Class Action Settlement, Doc. 863, Authors Guild et al. v. Google Inc., No. 05 CV 8136-DC (S.D.N.Y. Jan. 28, 2010), S. 13 ff.; Open Book Alliance, Supplemental Memorandum of Amicus Curiae, Doc. 840, Authors Guild et al. v. Google Inc., No. 05 CV 8136-DC (S.D.N.Y. Jan. 28, 2010), S. 6 ff.; Wang, Antitrust Analysis of the GBS, S. $14 \mathrm{ff}$.

1204 Vgl. AT\&T Corp., Objections to Class Action Settlement, Doc. 863, Authors Guild et al. v. Google Inc., No. 05 CV 8136-DC (S.D.N.Y. Jan. 28, 2010), S. $17 \mathrm{ff}$; Microsoft Corp., Objections to Proposed Amended Settlement, Doc. 874, Authors Guild et al. v. Google Inc., No. 05 CV 8136-DC (S.D.N.Y. Jan. 28, 2010), S. 15 ff.; Open Book Alliance, Supplemental Memorandum of Amicus Curiae, Doc. 840, Authors Guild et al. v. Google Inc., No. 05 CV 8136DC (S.D.N.Y. Jan. 28, 2010), S. 8 f.; Picker, 5 J. Competition L. \& Econ. 383, 402 ff. (2009); 
zahlreichen und vielstimmigen Kritik an den Vergleichsvorschlägen angeschlossen und dem ASA die Genehmigung versagt hat. Die in einem erneut überarbeiteten Vergleichsvorschlag vorgenommenen Änderungen dürfen daher mit Spannung erwartet werden. $\mathrm{Zu}$ beachten ist jedoch auch, dass selbst im Falle der Genehmigung eines Vergleichs durch das zuständige Gericht keine völlig umfassende Regelung der Google Buchsuche erfolgt. Nicht ausgeschlossen ist einerseits weiterhin ein klageweises Vorgehen solcher Rechteinhaber, die nicht vom Vergleich erfasst werden, andererseits ein Vorgehen aufgrund kartell- oder wettbewerbsrechtlicher Bedenken, die sich durch den Betrieb der Buchsuche und der Book Rights Registry bestätigen oder neu ergeben.

b) Unterschiede zu einer (möglichen) Fair Use-Entscheidung

Die Fair Use-Analyse der Google Buchsuche hat gezeigt, dass sich der Ausgang des von der Authors Guild und der Association of American Publishers gegen Google beim U.S. District Court for the Southern District of New York angestrengten Gerichtsverfahrens kaum sicher vorhersagen ließ.1205 Die Parteien haben sich (daher) schließlich auf einen Vergleich geeinigt. Dieser ist jedoch - wie gezeigt - in vielerlei Hinsicht durchaus problematisch und entfaltet insbesondere durch die weite Definition der Class und die Besonderheiten des Class Action-Verfahrens sehr weitreichende Wirkungen. Der Vergleichsvorschlag geht zudem inhaltlich deutlich über die Beantwortung der Fragen hinaus, die Gegenstand einer Entscheidung des zuständigen Gerichts im dargestellten Prozess gewesen wären.

Hätte das angerufene Gericht im streitigen Verfahren die Werknutzung durch Google im Rahmen der Buchsuche nicht als Fair Use angesehen, so wäre dies möglicherweise das Ende des gesamten Projekts „Google Buchsuche“" gewesen. Jedenfalls hätte Google im Falle einer solchen Entscheidung seinen Dienst für den weiteren Betrieb ganz erheblich modifizieren müssen. Selbst bei einer Fair Use-Entscheidung zugunsten von Google

1205 Siehe oben 5. Kapitel, B.II.1.g). 
wäre jedoch lediglich - erstinstanzlich ${ }^{1206}$ - geklärt gewesen, dass die Google Buchsuche in der streitgegenständlichen, vor dem Vergleich bestehenden Form mit dem US-amerikanischen Urheberrecht vereinbar ist. Nur die streitgegenständlichen Nutzungsformen hätte Google folglich rechtssicher weiterführen können. Durch den Vergleich werden hingegen die Möglichkeiten von Google deutlich erweitert und zudem zusätzliche, zukünftige Sachverhalte umfassend geregelt. Google könnte somit im Ergebnis durch den Vergleich deutlich besser darstehen, als im Falle einer Fair Use-Entscheidung im Gerichtsverfahren. Inwieweit sich die Rechtslage nach dem Vergleich im Einzelnen von der rechtlichen Situation unterscheidet, die bestanden hätte, wenn kein Vergleich geschlossen worden und stattdessen von einem Gericht eine Fair Use-Entscheidung zugunsten von Google ergangen wäre, soll im Folgenden kurz dargestellt werden. Dieser Vergleich erfordert dabei einen Blick auf mehr als die reinen Rechte und Freiheiten für Google, die eine Fair Use-Entscheidung erzeugt hätte. Es erscheint vielmehr sinnvoll zu überlegen, welche Auswirkungen eine solche Entscheidung auf die Verhandlungsposition von Rechteinhabern, Google und auch Konkurrenzunternehmen in Bezug auf die weitere Ausgestaltung der Google Buchsuche oder ähnlicher Projekte gehabt hätte.

Eine Fair Use-Entscheidung zugunsten von Google hätte Google in die Lage versetzt, die Buchsuche in ihrer bisherigen Ausgestaltung weiterzuführen, das heißt weiterhin Bücher ohne Zustimmung der Rechteinhaber $\mathrm{zu}$ digitalisieren, in die Buchsuche-Datenbank aufzunehmen, für eine Volltextsuche zugänglich zu machen und einzelne kurze Ausschnitte der Werke auf die Suchanfragen der Nutzer hin anzuzeigen. Jede weiterreichende Nutzung wäre hingegen nicht von der Gerichtsentscheidung erfasst worden, so dass etwa eine Ausweitung der Vorschauansichten oder deren Ergänzung um neue Verwertungsformen ohne Zustimmung der Rechteinhaber nicht möglich beziehungsweise mit dem Risiko erneuter Gerichtsverfahren behaftet gewesen wäre. Die Fair Use-Entscheidung hätte somit zur Vermeidung weiterer kostenintensiver Auseinandersetzungen aufgrund dieser Bindungswirkung die Ausgestaltung der Google Buchsuche

1206 Aufgrund der mit der Google Buchsuche verbundenen erheblichen finanziellen Interessen sowohl auf Seiten von Google als auch auf der Seite der Gegner und aufgrund der Bedeutung des Dienstes für die Allgemeinheit, erscheint es äußerst wahrscheinlich, dass - je nach Entscheidung des erstinstanzlichen Gerichts - die unterliegende Partei in Berufung gegangen wäre. 
voraussichtlich gewissermaßen im status quo des Urteilszeitpunkts „eingefroren". Für die vom Gericht als Fair Use anerkannten Nutzungsformen hätte Google jedoch weder für die Vergangenheit noch in Zukunft eine Vergütung an die Rechteinhaber zahlen müssen. ${ }^{1207}$

Diese durch ein Fair Use-Urteil gezogenen relativ engen Grenzen der Werknutzung sprengt der von den Parteien geschlossene Vergleich. Das ASA erlaubt Google in erheblichem Maße solche Nutzungen, die über die Fair Use-Entscheidung hinausgehen. Der Vergleich ermöglicht Google insbesondere die umfassende Nutzung verwaister und vergriffener Werke. So überschreiten etwa die im ASA enthaltenen Regelungen zu Buchvorschauen den zunächst streitgegenständlichen Snippet-Umfang deutlich. Im Rahmen der „Standardvorschau“ für urheberrechtlich noch geschützte verwaiste und vergriffene Werke werden bis zu $20 \%$ eines Buches angezeigt, wobei auch längere Abschnitte zusammenhängend dargestellt werden. $\mathrm{Zu}$ sätzlich werden Google durch das ASA zahlreiche Optionen zur kommerziellen Nutzung fremder Werke eingeräumt. Im Rahmen kostenpflichtiger Abonnements kann Einzelnutzern oder institutionellen Nutzern der $\mathrm{Zu}$ gang zum Volltext vieler verwaister und vergriffener Werke gewährt werden. Diese Werke darf Google nach dem ASA zudem durch weitere zukünftige Einnahmemodelle noch umfassender kommerziell verwerten. Von diesen durch das ASA eingeräumten umfassenden Nutzungsmöglichkeiten profitiert jedoch nicht ausschließlich Google. Der Buchsuche-Vergleich bringt auch einen erheblichen Nutzen für die Allgemeinheit, da Nutzern in einem deutlich größeren Umfang der Zugang zu sonst oftmals kaum zugänglichen vergriffenen Werken und Orphan Works ermöglicht wird als dies im Falle einer Fair Use-Entscheidung denkbar gewesen wäre. ${ }^{1208}$

Neben dieser inhaltlichen Ausgestaltung der Google Buchsuche enthält der Buchsuche-Vergleich jedoch weitere Bestimmungen, die den wesentlichsten Unterschied zu einer Fair Use-Entscheidung erzeugen: Durch das ASA wird der Google Buchsuche ein institutioneller Rahmen gegeben, der das Verhältnis von Google zu den vom Vergleich erfassten Rechteinhabern umfassend regeln und zukünftige Probleme vermeiden und gegebenenfalls lösen soll. Zur Verwaltung von Rechten und Einnahmen wird von

1207 Zum „Alles oder Nichts“ als Rechtsfolge des Fair Use siehe oben 2. Kapitel, C.I.3.

1208 Vgl. Sag, 55 N.Y.L. Sch. L. Rev. 19, 70 f. (2010); Travis, 11 Yale J.L. \& Tech. 209, 215 (2009). 
den Parteien eine eigene Institution, die Book Rights Registry, mit weitreichenden Befugnissen geschaffen. Durch den Vergleich werden zudem konkrete Mechanismen und Formalia für den Umgang von Google und Rechteinhabern mit urheberrechtlich geschützten Werken festgelegt, zum Beispiel konkrete Regelungen zum vollständigen Opt Out oder zur Änderung der Präferenzen eines Rechteinhabers etwa im Hinblick auf den Verfügbarkeitsstatus eines Werkes. Durch diese Institutionalisierung sollen letztlich alle diejenigen Transaktionen, die zwar auch im Falle einer Fair Use-Entscheidung grundsätzlich denkbar gewesen wären, jedoch nur durch kostspielige Verhandlungen im Einzelfall hätten ermöglicht werden können, durch die Etablierung konkreter Rahmenbedingungen kostengünstiger ausgestaltet werden. ${ }^{1209}$

Einen weiteren ganz entscheidenden Unterschied gegenüber einer Fair Use-Entscheidung und den für Google möglicherweise tatsächlich maßgeblichen Beweggrund für die Beendigung des Rechtsstreits im Wege eines Vergleichs stellt schließlich die Reichweite seiner rechtlichen Bindungswirkung dar. Nur für die Parteien des Rechtsstreits sind die Regelungen des Vergleichs bindend. Berechtigt und verpflichtet sind folglich einerseits Google und andererseits die Kläger. Durch die Besonderheiten der Class Action-Klage werden jedoch auf Klägerseite neben den namentlich auftretenden Klägern sämtliche Class Members, die nicht von ihrer $O p t$ Out-Möglichkeit Gebrauch gemacht haben, von der Bindungswirkung des Vergleichs erfasst. ${ }^{1210}$ Das Rechtsverhältnis zwischen Google und sämtlichen Mitgliedern der Vergleichsgruppe ist somit verbindlich geklärt. Daraus folgt, dass Google zwar einerseits gegenüber allen Mitgliedern der Class zur Einhaltung der im ASA festgelegten Vorgaben und Standards verpflichtet ist, insbesondere also den dort genannten Zahlungsverpflichtungen für die Nutzung nachkommen muss. Andererseits gibt das ASA Google im Verhältnis zu allen vom Vergleich erfassten Rechteinhabern die (Rechts-) Sicherheit, sämtliche im Vergleich vorgesehenen Formen der Werknutzung - insbesondere die intensive kommerzielle Nutzung verwaister und vergriffener Werke - fortsetzen oder künftig aufnehmen zu können, ohne diesbezüglich der Gefahr weiterer (kostspieliger) Rechtsstreitigkeiten ausgesetzt zu sein. Eine Verhandlung mit Rechteinhabern über die Erteilung entsprechender Lizenzen ist für Google folglich nicht

1209 Vgl. Sag, 55 N.Y.L. Sch. L. Rev. 19, 69 f. (2010).

1210 Vgl. oben Fn. 1029 und zugehörigen Text. 
mehr erforderlich. Für die Rechteinhaber wird dadurch die Verwertung ihrer Werke einerseits erleichtert, da ihnen ohne jeglichen eigenen Aufwand neue Einnahmemöglichkeiten entstehen. Zugleich wird die Verhandlungsposition für den Abschluss individueller, möglicherweise vorteilhafterer oder restriktiverer Lizenzen für solche Rechteinhaber durch den Vergleich stark verschlechtert, die lieber eigenverantwortlich ihre Werke verwerten würden, jedoch entweder unwissentlich durch den Vergleich gebunden sind oder aber von einem Opt Out Gebrauch gemacht haben. Keine Bindungswirkung entfaltet der Vergleich hingegen für unbeteiligte Dritte und somit auch insbesondere nicht für mögliche Konkurrenten von Google, die am Aufbau vergleichbarer Datenbanken, Suchmaschinen oder Abonnementdienste interessiert sein könnten. Dritte können zwar ebenfalls in gewissem Umfang von den durch das ASA geschaffenen Bedingungen und neuen Institutionen profitieren, sie erhalten jedoch nicht dieselbe rechtliche Sicherheit wie Google, da Rechteinhaber weiterhin Klagen gegen sie anstrengen könnten. Im Falle eines Fair Use-Urteils wäre hingegen vom Gericht allgemein die Rechtmäßigkeit der Werknutzung im Rahmen der Google Buchsuche geklärt worden, so dass auch für Wettbewerber klar gewesen wäre, in welchen Grenzen ein Einstieg in das Geschäft mit der Buchsuche ohne rechtliches Risiko möglich wäre. ${ }^{1211}$ Die Begründung derartiger allgemeingültiger Fair Use-Prinzipien und somit letztlich die Fortentwicklung des Urheberrechts in Bezug auf die Ermöglichung neuartiger Nutzungsformen wird folglich durch den BuchsucheVergleich gerade nicht erreicht, beziehungsweise - aus Googles Sicht vermieden. ${ }^{1212}$

\section{Zusammenfassung für das US-amerikanische Copyright}

Die Untersuchung der urheberrechtlichen Zulässigkeit der Verwendung von Thumbnails durch Bildersuchmaschinen nach US-amerikanischem Recht hat gezeigt, dass sich diese Art der Werknutzung - anders als nach deutschem Urheberrecht - durch die flexible Fair Use-Doktrin legitimieren lässt. Auch wenn keine höchstrichterlichen Entscheidungen zu dieser

1211 Vgl. Grimmelmann, 12 No. 10 J. Internet L. 1, 12 (2009): „Google would have opened the book search business to anyone if it prevailed on the fair use issue.".

1212 Vgl. Picker, 5 J. Competition L. \& Econ. 383, 385 (2009); Samuelson, 52 No. 7 Comm. ACM 28, 30 (2009). 
Frage vorliegen, kann die Frage der Rechtmäßigkeit der Thumbnail-Nutzung in den USA als geklärt gelten. Den wesentlichen Aspekt aller Thumbnail-Entscheidungen stellte die Frage des transformative use dar. Anders als in vorherigen Urteilen wurde im Ergebnis trotz der Anfertigung einer identischen (verkleinerten) Kopie des Originalwerkes allein aufgrund eines unterschiedlichen Verwendungszwecks - ästhetische und unterhaltende Zwecke des Originalwerkes einerseits und eine rein funktionale Verwendung der Thumbnails als „Wegweiser“ zu Online-Inhalten andererseits - eine transformative Nutzung bejaht. Diese war letztlich in allen Urteilen entscheidend für die Bejahung des Fair Use, da aufgrund des hohen Grades der Transformativität den weiteren Fair Use-Faktoren geringere Bedeutung beigemessen wurde und insbesondere negative Auswirkungen auf den Markt für das Originalwerk verneint wurden. Dabei hat der Court of Appeals for the Ninth Circuit sowohl die Nutzung solcher Bilder behandelt, die vom Urheber selbst, beziehungsweise mit dessen $\mathrm{Zu}$ stimmung, im Internet veröffentlicht wurden, als auch die - nach deutschem Recht nicht zu legitimierende ${ }^{1213}$ - Konstellation der „Drittinhaberschaft" der Urheberrechte, in der die Werke ohne Zustimmung des Urhebers von Dritten im Internet zur Verfügung gestellt wurden. Insgesamt zeigt die Auseinandersetzung mit der Zulässigkeit der Thumbnail-Nutzung deutlich die Flexibilitätsvorteile der Fair Use-Doktrin aufgrund der von der Rechtsprechung vorzunehmenden Einzelfallbetrachtung und Gewichtung der verschiedenen Faktoren. Diese ermöglichen eine interessengerechte Lösung urheberrechtlicher Konfliktfälle, die auf neuartigen Geschäftsmodellen beruhen.

Nicht gerichtlich geklärt ist in den USA hingegen die urheberrechtliche Zulässigkeit der Verwendung fremder Werke im Rahmen der Google Buchsuche. Zwar war der District Court for the Southern District of New York in dieser Sache mit Klagen gegen Google befasst, doch kam es bisher nicht zu einer Gerichtsentscheidung, da sich die Parteien auf einen gerichtlichen Vergleich einigten (dessen Schicksal derzeit jedoch ungewiss ist). Dieser Vergleich war letztlich wohl ganz wesentlich auch eine Reaktion der Beteiligten auf den unsicheren Ausgang eines gerichtlichen Verfahrens. Wie die Fair Use-Analyse gezeigt hat, lassen sich sowohl für als auch gegen ein Fair Use-Urteil zugunsten von Google zahlreiche gewichtige Argumente und gerichtliche Präjudizien anführen, auch wenn im Er-

1213 Siehe näher oben 4. Kapitel, B.I.11. 
gebnis einige Indizien eine Entscheidung zugunsten von Google naheliegender erscheinen lassen. Wesentlich könnte insofern sein, dass durch die Google Buchsuche jedenfalls der Hauptmarkt für die verwendeten Originalwerke nicht negativ, sondern durch die Steigerung der Bekanntheit und die Ermöglichung neuer und zusätzlicher Vermarktungsmöglichkeiten allenfalls positiv beeinflusst wird. Eine gegenteilige Entscheidung des Gerichts wäre jedoch auch keinesfalls ausgeschlossen gewesen. Die letztlich auch aufgrund der Unsicherheit erzielte Einigung regelt aber nicht nur den Streitgegenstand des Gerichtsverfahrens, sondern geht - wie gezeigt - inhaltlich weit über eine mögliche gerichtliche Entscheidung hinaus. Aus diesem Grund ist der Vergleich von vielen Seiten scharf kritisiert worden. Es droht insbesondere eine Benachteiligung ausländischer Urheber und Rechteinhaber und die Entstehung eines Monopols für die Verwertung verwaister und vergriffener Werke. 
Ergebnis zu Teil 2 der Untersuchung - Vor- und Nachteile eines enumerativen Schrankenkataloges und einer Generalklausel im digitalen Kontext

Die Untersuchung hat gezeigt, dass auf neuen Geschäftsmodellen basierende neuartige Formen der Werknutzung das deutsche Urheberrecht aufgrund seines wenig flexiblen Schrankenkataloges vor erhebliche - oftmals unlösbare - (methodische) Probleme stellen. Selbst innovativen Nutzungsformen urheberrechtlich geschützter Werke, die - wie Buch- und Bildersuchdienste - einen erheblichen Wert für die Allgemeinheit haben und die die eigene Werkverwertung durch den Urheber oder Lizenznehmer nicht beeinträchtigen oder diese sogar fördern, werden durch die fehlende Rechtfertigungsmöglichkeit im Rahmen des starren und „trägen“, oftmals technologiespezifischen Schrankenkataloges des Urheberrechtsgesetzes immer wieder Grenzen gesetzt. ${ }^{1214}$ Das wenig flexible deutsche Urheberrecht droht so, den technischen Fortschritt einzuschränken.

Anders stellt sich die (Rechts-)Lage in den USA dar. Die Schrankengeneralklausel des Fair Use im US-amerikanischen Copyright Law ermöglicht - wie die Untersuchung der Thumbnail-Nutzung gezeigt hat ${ }^{1215}$ - einen flexiblen Umgang (auch) mit neuartigen Nutzungsformen. Anders als im deutschen Recht muss nicht versucht werden, eine innovative Form der Werknutzung unter den Wortlaut einer engen und detaillierten Schrankenregelung zu subsumieren, bei deren Schaffung der Gesetzgeber einen völlig anderen Stand der Technologie vor Augen hatte und zukünftige Entwicklungen zumeist noch nicht absehen konnte. Anhand eines offenen Kriterienkataloges ermöglicht die Fair Use-Doktrin den Gerichten eine flexible Handhabung neuer Sachverhalte unter Heranziehung gefestigter Rechtsprechung und Abwägung der beteiligten Interessen im Einzelfall und somit - unabhängig vom Stand der technischen Entwicklung im Zeitpunkt der Gesetzgebung - letztlich zumeist die Erzielung interessen- und einzelfallgerechter Ergebnisse.

1214 Siehe oben 4. Kapitel, B.III. und 4. Kapitel, C.IV.

1215 Siehe oben 5. Kapitel, B.I.4. 
Dieser unstreitige Vorteil deutlich größerer Flexibilität wird jedoch - so das übliche Gegenargument ${ }^{1216}$ - durch erhebliche Rechtsunsicherheit teuer erkauft. Anders als bei einem enumerativen Schrankenkatalog sei für den Rechtsanwender nicht mehr ohne weiteres zu erkennen, welche Nutzungshandlungen unter welchen Voraussetzungen zulässig sind. ${ }^{1217}$ Die Stichhaltigkeit dieses Standardarguments ist allerdings bei einem Blick auf die Entwicklung des Urheberrechts in Kontinentaleuropa und in den USA im Zusammenhang mit neuartigen Technologien tatsächlich zu bezweifeln. Zum einen hat sich in den USA ein Grundkonsens über die Bedeutung und Reichweite der Fair Use-Doktrin entwickelt, auf dessen Grundlage eine über Jahrzehnte in einer Vielzahl von Entscheidungen gefestigte Rechtsprechung zur Generalklausel des Fair Use entstanden ist. ${ }^{1218}$ Die Tradition der Formulierung oftmals umfangreicher obiter dicta und dissenting opinions, die gerade bei späteren Entscheidungen ähnlich gelagerter Fälle als Argumentations- und Abgrenzungsgrundlage herangezogen werden können, ${ }^{1219}$ hat zudem zusätzlich zur Entwicklung und Ausformung der Fair Use-Doktrin und somit letztlich zu größerer Vorhersehbarkeit beigetragen. Schließlich entsteht durch das Zusammen- und Gegenspiel verschiedener (Bezirks-)Gerichte eine Art „Signalsystem“ gegenläufiger Rechtsansichten und Entscheidungen, die ,reif“ für eine Überprüfung durch den Supreme Court sind. ${ }^{1220}$ Die mit Hilfe dieses „Werkzeugkastens" zahlreich entwickelten Kriterien, Regeln und Prinzipien für die

1216 Vgl. etwa Cohen Jehoram, AMI 1998, 174; ders., GRUR Int. 2001, 807 (808 f.); Dreier, in: Schricker, Informationsgesellschaft, S. 154 f.; ders., CR 2000, 45 (49); Förster, Fair Use, S. 220; Janssens, in: Derclaye, Research Handbook on the Future of EU Copyright, S. 317 (337 f.); Kubis, ZUM 2006, 370 (373); Nordemann/Conrad, GRUR Int. 2010, 953 (969); Schack, in: FS Schricker II, S. 511 (513); ders., ZEuP 2000, 799 (812); Spindler, GRUR 2002, 105 (115).

1217 Förster, Fair Use, S. 220; Reschke, Verfassungs- und dreistufentestkonforme Auslegung, S. 21.

1218 Vgl. Samuelson, 77 Fordham L. Rev. 2537, 2540 f. (2009).

$1219 \mathrm{Zu}$ Rolle und Einfluss von dissenting opinions in der US-Rechtsprechung siehe Ginsburg, 95 Minn. L. Rev. 1 (2010) m.w.N.

1220 Zum ,signaling system“ solcher „circuit splits“ am Beispiel der Frage der Auslegung des vierten Fair Use-Faktors durch die Urteile Kelly v. Arriba Soft (336 F.3d 811 (9th Cir. 2003)) und Video Pipeline, Inc. v. Buena Vista Home Entertainment (342 F.3d 191 (3d Cir. 2003)) siehe Pasquale, 60 Vand. L. Rev. 135, 182 ff. (2007). Allgemein zu diesem „Kontrollmechanismus“ im US-amerikanischen Recht (am Beispiel des US-amerikanischen Patentverfahrenssystems) auch Leistner/Kleinemenke, ZGE 2010, 273 (287, 290). 
Auslegung und Ausfüllung der Fair Use-Doktrin werden von den Gerichten tatsächlich in aller Regel bei ihren Fair Use-Entscheidungen beachtet, so dass die Rechtsprechung keinesfalls bei jeder neuen Entscheidung ,im Dunkeln stochern" und ohne Leitlinie völlig frei anhand der weiten (und nicht abschließenden) Kriterien des 17 U.S.C. § 107 entscheiden müsste. Tatsächlich werden daher nur selten völlig überraschende, kaum vorhersehbare Urteile gefällt. ${ }^{1221}$

Das regelmäßig maßgeblich ins Feld geführte Argument der größeren Rechtssicherheit eines enumerativen Kataloges urheberrechtlicher Schranken gegenüber einer Schrankengeneralklausel vermag zudem jedenfalls dann nicht mehr zu überzeugen, wenn die technologische Entwicklung so schnell abläuft, dass der Gesetzgeber mit diesem keinesfalls Schritt halten kann. Ebendies ist jedoch derzeit im deutschen und europäischen Urheberrecht zu beobachten. Der technische Fortschritt verläuft immer schneller, während Gesetzgebungsprozesse in ihrer Geschwindigkeit allenfalls gleich, eher jedoch aufgrund der europarechtlichen „Einkleidung“ und wachsender Zahlen von beteiligten Interessengruppen langsamer werden. ${ }^{1222}$ Die im Rahmen des abgeschlossenen deutschen Schrankenkataloges zur rechtlichen Erfassung neuer Sachverhalte herangezogenen Analogien und äußerst extensiven Auslegungen bestehender Schrankenregelungen bis hin zu einer vollständigen „Verbiegung“ unter Abkehr vom Wortlaut und von etablierten Auslegungsmethoden und -ergebnissen, ${ }^{1223}$ kann jedenfalls eine größere Rechtssicherheit nicht für sich reklamieren. Wird unter Abkehr von etablierter Methodik krampfhaft versucht, einen neuen Sachverhalt unter die bestehenden Schranken zu subsumieren, kann kei-

1221 Ähnlich Griffiths, JIPITEC 2010, 87 (92); Leistner, IIC 2011, 417 (436); Metzger, in: Europäische Perspektiven des Geistigen Eigentums, S. 101 (120 f.); Netanel, 15 Lewis \& Clark L. Rev. 715, 768 ff. (2011); Samuelson, 77 Fordham L. Rev. 2537, 2540 f., 2621 (2009); Senftleben, AMI 2009, 1 (2). Dieses Ergebnis stützen auch neuere, umfassende empirische Studien von Barton Beebe und Matthew Sag. Beide kommen zu dem Schluss, die verbreitete Wahrnehmung, Fair Use-Entscheidungen seien äußerst wechselhaft und daher kaum vorhersehbar, lasse sich anhand empirischer Daten deutlich widerlegen; siehe Beebe, U. Pa. L. Rev. 549, 621 f (2008) und Sag, 73 Ohio St. L.J. 47, 72 ff. (2012).

1222 Ähnlich Dreier, CR 2000, 45 (49); Hugenholtz, EIPR 2000, 22(11), 499 (501); Hugenholtz/Senftleben, Fair Use in Europe, S. 29.

1223 Vgl. etwa die Versuche, die Bildersuche durch eine erheblich erweiternde Auslegung des Zitatrechts unter Überdehnung des Zitatzwecks zu rechtfertigen; siehe dazu oben 4. Kapitel, B.I.3. 
nesfalls mehr behauptet werden, der Rechtsanwender könne ,in allen Fällen aus dem Gesetzestext erkennen, welche Nutzungshandlungen unter welchen Voraussetzungen zulässig" sind. ${ }^{1224}$ Diese Funktion einer schnellen, zuverlässigen und verständlichen Information der Rechteinhaber und Nutzer über ihre (urheberrechtlichen) Rechte und Pflichten erfüllt das deutsche und europäische Recht jedenfalls im Hinblick auf die urheberrechtlichen Schranken tatsächlich nicht mehr. ${ }^{1225}$ So zeigen etwa die vielfältigen Lösungsvorschläge und Spekulationen zur Zulässigkeit der Thumbnail-Nutzung nach deutschem Recht, ${ }^{1226}$ ebenso wie die Tatsache, dass die Entscheidungen des Bundesgerichtshofs in dieser Frage allseits „mit Spannung erwartet"1227 wurden, dass der bestehende, wenig flexible Schrankenkatalog tatsächlich keine sichere Vorhersage über die urheberrechtliche Zulässigkeit neuer Nutzungsformen ermöglicht und somit auch keine größere Rechtssicherheit bietet als eine - durch eine gefestigte Rechtsprechung ausgeformte - offene Schrankengeneralklausel. Auch der letztlich vom Bundesgerichtshof zur Lösung der Thumbnail-Problematik gewählte Weg über eine (konkludente beziehungsweise schlichte) Einwilligung ${ }^{1228}$ verdeutlicht dies und zeigt mangelnde Methodenehrlichkeit. Unter Rückgriff auf die Figur der Einwilligung aus dem allgemeinen Zivilrecht wird versucht, die den Schranken fehlende Flexibilität zu erreichen und auf Grundlage einer Interessenabwägung zu einem interessengerechten Ergebnis zu gelangen. Dabei wird jedoch über den „Umweg“ der Einwilligungslösung letztlich gerade eine - vom BGH für die Auslegung der Schranken ausdrücklich abgelehnte ${ }^{1229}$ - ,freischwebende“ Güter- und Interessenabwägung vorgenommen, ${ }^{1230}$ welche sicherlich ein hohes Maß an Rechtssicherheit nicht für sich reklamieren kann.

1224 So aber zugunsten eines geschlossenen Schrankenkataloges argumentierend Förster, Fair Use, S. 220.

1225 Ähnlich Schack, ZGE 2009, 275 (280).

1226 Vgl. die ausführliche Darstellung oben 4. Kapitel, B.I.

1227 Spindler, GRUR 2010, 785 (786).

1228 Siehe dazu oben 4. Kapitel, B.I.9.

1229 Siehe BGHZ 154, 260 (266) - Gies-Adler; Z 185, 291 (301) - Vorschaubilder. Siehe auch oben Fn. 323 und zugehörigen Text.

1230 Vgl. Leistner, IIC 2011, 417 (428); Spindler, GRUR 2010, 785 (791). Metzger, in: Europäische Perspektiven des Geistigen Eigentums, S. 101 (114) verwendet das treffende Bild, die Gerichte hätten durch den Rückgriff auf die Lösung über die konkludente Einwilligung „Notventile geöffnet, um die mangelnde Flexibilität der Schranken auf andere Weise auszugleichen“". 
Je weiter ,veraltete“ Schrankenregelungen von der (technischen) Realität abweichen, desto mehr verlagert sich auch im deutschen Recht die Entscheidungskompetenz tatsächlich vom Gesetzgeber auf den Richter. So hat sich in Fällen, in denen der Gesetzestext zur Erfassung neuartiger Nutzungsformen zu eng und daher kaum hilfreich ist, auch das deutsche Recht deutlich an ein System des Case Law angenähert. Oftmals wird versucht, eine Lösung unter Rückgriff auf Vorgaben und Überlegungen aus früheren Entscheidungen nicht nur deutscher, sondern auch ausländischer Gerich$t^{1231} \mathrm{zu}$ erreichen und eine für richtig und gerecht erachtete Lösung „krampfhaft" in Einklang mit dem zu unflexiblen Gesetz zu bringen. Ist das Urheberrecht jedoch in Fällen der Konfrontation mit neuen Geschäftsmodellen derart ,überfordert“, so stellt eine Schrankengeneralklausel, die sich anhand etablierter Faktoren und Methoden und unter Rückgriff auf eine gefestigte Rechtsprechung mit Leben füllen lässt, ohne eine „Überdehnung“ und „Verbiegung“ des bestehenden Rechts unter vollständiger Abkehr vom Wortlaut zu erfordern, den deutlich methodenehrlicheren und somit möglicherweise sogar rechtssichereren Weg zur Erreichung interessengerechter Ergebnisse dar. Es kann folglich mit guten Gründen bezweifelt werden, ob eine Generalklausel wie die des Fair Use tatsächlich mit größerer Rechtsunsicherheit verbunden ist als eine veraltete und daher oftmals unpassende und „träge“ abschließende Aufzählung der Schranken.

Nicht von der Hand zu weisen ist jedoch selbstverständlich, dass ebenso wie bei anderen Schrankenregelungen - auch mit der Fair UseDoktrin und deren Anwendung durch die Gerichte eine gewisse Rechtsunsicherheit verbunden ist. Dies zeigt sich gerade bei der rechtlichen Bewertung neuer Sachverhalte, zu denen noch kein Präjudiz besteht. Aufgrund der Weite der Generalklausel des Fair Use und deren Eignung, grundsätzlich (fast) jede Form der Werknutzung zu erfassen, solange diese nicht ganz offensichtlich einseitig die Rechteinhaber benachteiligt, ohne zumindest einen gewissen Nutzen für die Allgemeinheit zu haben, ist eine Einstufung als Fair Use beinahe nie bereits grundsätzlich ausgeschlossen. Ebenso lässt sich allerdings in diesen Fällen kaum ausschließen, dass ein Gericht im Streitfall diese Bewertung nicht teilen wird. Für die Beteiligten ist der Ausgang eines möglichen Fair Use-Verfahrens daher nicht immer

1231 Siehe etwa die Entscheidung des LG Hamburg, ZUM 2009, 315 (319, 323), in der sich die Kammer im Zusammenhang mit der Frage der Zulässigkeit der Google Bildersuche mehrfach mit der parallelen Entscheidung des U.S. Court of Appeals for the Ninth Circuit auseinandersetzt. 
sicher zu ermitteln. ${ }^{1232}$ Dies hat die Fair Use-Analyse der Google Buchsuche bestätigt. ${ }^{1233}$

Eine Generalklausel wie die des Fair Use aufgrund dieser Unsicherheit bereits grundsätzlich abzulehnen, wäre jedoch falsch und kurzsichtig. Zum einen ist zu bedenken, dass es eine Lösung, die zugleich weitreichende Flexibilität und vollständige Rechtssicherheit bietet, nicht geben kann. Ein gewisser Grad an Unvorhersehbarkeit ist stets in Kauf zu nehmen, wenn das Recht überhaupt in die Lage versetzt werden soll, auf neue, unvorhergesehene Entwicklungen zu reagieren. ${ }^{1234}$ Zum anderen erscheint es - wie gezeigt - wenig überzeugend, anzunehmen, die von einer Generalklausel ausgehende Rechtsunsicherheit sei per se größer als bei einem detaillierten Schrankenkatalog. Jedenfalls wenn dieser - wie im Fall des deutschen Urheberrechtsgesetzes - zu starr ist, um mit der technischen Entwicklung und einer daraus resultierenden geänderten Werknutzungsrealität Schritt zu halten, hat diese Argumentation keine Gültigkeit mehr. Ist die erzeugte Rechtsunsicherheit aber tatsächlich nicht größer, sondern allenfalls gleich groß, so ist im Ergebnis die Methodik der richterlichen Ausfüllung einer flexiblen Generalklausel gegenüber der unsicheren und methodisch unsauberen Erweiterung bestehender enger Schranken und gegenüber dem Rückgriff auf „urheberrechtsexterne“ Rechtsinstitute und deren Überdehnung vorzugswürdig.

Es ist sogar argumentiert worden, die durch die weite Fair Use-Doktrin entstehende Unsicherheit könne in einigen Fällen gar als Vorteil gesehen werden. ${ }^{1235}$ Die Weite der Fair Use-Schranke, die hinsichtlich vieler neuartiger Geschäftsmodelle (auch) eine Deutung zulässt, diese als urheberrechtlich zulässig anzusehen, mag nicht selten gerade erst der Grund sein, dass derartige innovative Geschäftsmodelle zunächst überhaupt verwirklicht werden und nicht bereits im Keim erstickt werden. Die Unsicherheit über den Ausgang eines möglichen gerichtlichen Fair Use-Verfahrens und die drastische „Alles-oder-Nichts-Folge“ des Fair Use-Einwandes erzeu-

1232 Lawrence Lessig, der zu den besonders entschiedenen Kritikern des status quo des US-amerikanischen Copyright Law und insbesondere auch der Fair UseDoktrin zählt, hat aufgrund der mit der Fair Use-Schranke verbundenen Unsicherheit den Satz geprägt: ,[F]air use in America simply means the right to hire a lawyer [...].“; siehe Lessig, Free Culture, S. 187.

1233 Siehe oben 5. Kapitel, B.II.1.g).

1234 So auch Griffiths, JIPITEC 2010, 87 (91).

1235 In diese Richtung Sag, 55 N.Y.L. Sch. L. Rev. 19, 36 f. (2010); Samuelson, 2011 Wis. L. Rev. 479, $504 \mathrm{ff}$. 
gen - wie etwa der Fall der Google Buchsuche zeigt - jedoch zugleich gerade in Fällen, in denen sich ein neues Geschäftsmodell als erfolgreich erweist - einen deutlich gesteigerten Einigungsdruck für die Parteien. ${ }^{1236}$ Wäre die Rechtslage im Falle der Google Buchsuche für eine der Parteien eindeutig gewesen, wäre es wohl nicht zu den ausgiebigen Verhandlungen über ein Settlement Agreement gekommen, mit dessen Hilfe die Parteien eine umfassende Regelung des Sachverhalts anstreben. Der bestehenden Unsicherheit über den Ausgang eines Fair Use-Verfahrens ist es folglich zum einen (mit) zu ,verdanken“, dass die Google Buchsuche überhaupt realisiert wurde, zum anderen, dass die Parteien hinsichtlich dieses Geschäftsmodells eine für beide Seiten ${ }^{1237}$ akzeptable Einigung suchen.

Schließlich ist in der US-amerikanischen Literatur, namentlich etwa von Patry und Posner, ${ }^{1238}$ argumentiert worden, die von den Gerichten flexibel anzuwendende und auszufüllende Generalklausel des Fair Use habe gegenüber einer detaillierten legislativen Lösung einen weiteren entscheidenden Vorteil: Sie sei durch die Verlagerung der Entscheidungskompetenz vom Gesetzgeber auf die Gerichte nicht in demselben Maße für Lobbying der betroffenen Interessengruppen anfällig und daher letztlich besser geeignet, interessengerechte Ergebnisse zu erzielen. ${ }^{1239}$ Tatsächlich erscheint dieses Argument gerade im Hinblick auf den Umgang des Urheberrechts mit solchen neuen Technologien stichhaltig, hinter denen - wie etwa im Falle der Geschäftsmodelle der internetbasierten Buchoder Bildersuche - erhebliche wirtschaftliche Interessen stehen. In allen diesen Fällen würden einflussreiche und finanzstarke Interessengruppen (wohl mit recht guten Erfolgsaussichten) versuchen, entscheidenden Einfluss auf ein entsprechendes Gesetzgebungsvorhaben zu nehmen. Nicht selten droht das Ergebnis des legislativen Prozesses daher nicht den tatsächlich sinnvollsten und gerechtesten Interessenausgleich, sondern vielmehr den Einfluss der beteiligten Lobbygruppen widerzuspiegeln. ${ }^{1240}$ Die langwierigen Verhandlungen auf europäischer Ebene über die Harmoni-

1236 Vgl. dazu näher oben 5. Kapitel, B.II.2.

1237 Dass es sich im konkreten Fall um ein Class Action-Verfahren handelte, durch das auch zahlreiche „Unbeteiligte“ gebunden wurden, soll hier außer Betracht bleiben; siehe dazu aber ausführlich oben 5. Kapitel, B.II.2.

1238 Patry/Posner, 92 Cal. L. Rev. 1639 (2004).

1239 Siehe Patry/Posner, 92 Cal. L. Rev. 1639, 1645 (2004); zustimmend Brannon, 14. J. Intell. Prop. L. 145, 170 (2006).

1240 Vgl. Litman, 96 Iowa L. Rev. 1, 25 f. (2010). 
sierung der urheberrechtlichen Schranken und über deren Umsetzung in nationales Recht sowie in jüngerer Zeit die Diskussionen über die Einführung eines Leistungsschutzrechtes für Verleger ${ }^{1241}$ verdeutlichen dies ebenso eindrucksvoll wie die im US-amerikanischen Copyright Act aufgenommenen sogenannten Statutory Exceptions ${ }^{1242}$ (17 U.S.C. §§ 108-122). Eine vergleichbare (und erfolgreiche) Einflussnahme auf unabhängige - in Deutschland zudem anders als in den USA verbeamtete und nicht gewählte - Richter bei der Anwendung und Auslegung einer Generalklausel, erscheint hingegen deutlich unwahrscheinlicher.

Diese positiven Aspekte der flexiblen Fair Use-Doktrin sollten jedoch nicht den Blick dafür versperren, dass die Fair Use-Schranke aufgrund der mit ihr verbundenen Unsicherheiten tatsächlich gerade in der US-amerikanischen Literatur seit jeher erheblich kritisiert worden ist und vielfach Vorschläge zur Konkretisierung und „Verbesserung“ der Doktrin oder aber auch zu deren Abschaffung unterbreitet wurden. ${ }^{1243}$ Einen wesentli-

1241 Siehe dazu aus neuerer Zeit etwa die Überblicksdarstellungen von Frey, MMR 2010, 291; Nolte, ZGE 2010, 165; Ohly, WRP 2012, 41 sowie ausführlich Szilágyi, Leistungsschutzrecht für Verleger, 2011. Siehe auch die „Stellungnahme der GRUR zur Anhörung des BMJ am 28.6.2010 zum Thema ,Leistungsschutzrecht für Verleger'“, abgedruckt in: GRUR 2010, 808 ff.; die „Stellungnahme zu Überlegungen zu Einführungen eines urheberrechtlichen Leistungsschutzrechtes für Presseverleger" des Bundesverbandes Informationswirtschaft, Telekommunikation und neue Medien e.V. (BITKOM), abrufbar unter: http:// www.bitkom.org/files/documents/100624_Stellungnahme_BITKOM_Verleger

LSR_final.pdf; die „Gemeinsame Verbändeerklärung gegen das ,Leistungs schutzrecht für Presseverleger'“, abrufbar unter: http://www.btw.de/cms/upload/ Publikationen/Leistungsschutzrecht_Presseverleger_Verbaendeerklaerung.pdf. Siehe auch das umfangreiche Online-Informationsangebot der Initiative gegen ein Leistungsschutzrecht (IGEL), abrufbar unter: http://leistungsschutzrecht.info/ [jeweils zuletzt abgerufen am 26.5.2013]. Das Leistungsschutzrecht für Presseverlage tritt am 1.8.2013 in Kraft, siehe BGBl. 2013 I, S. 1161.

1242 Siehe dazu oben 2. Kapitel, C.II.

1243 Siehe etwa die grundlegenden und umfassenden kritischen Beiträge von Brannon, 14. J. Intell. Prop. L. 145 (2006); Carroll, 85 N.C. L. Rev. 1087 (2007); Fisher, 101 Harv. L. Rev. 1659 (1988); Goldstein, 31 Colum. J.L. \& Arts 433 (2008); Gordon, 82 Colum. L. Rev. 1600 (1982); dies., 50 J. Copyright Soc'y U.S.A. 149 (2003); Hartnett, 34 N.Y.L. Sch. L. Rev. 267 (1989); Lee, 83 S. Cal. L. Rev. 797 (2010); Lemley/Weiser, 85 Tex. L. Rev. 783 (2007); Leval, 36 J. Copyright Soc'y U.S.A. 167 (1989); Liu, 31 Colum. J.L. \& Arts 571 (2008); Lockridge, 24 Santa Clara Computer \& High Tech. L.J. 31 (2007); Madison, 23 Cardozo Arts \& Ent. L.J. 391 (2005); Moore, 82 N.Y.U. L. Rev. 944 (2007); 
chen Kritikpunkt stellen die nicht unerheblichen Transaktionskosten dar, die die Fair Use-Doktrin erzeugt. Insbesondere die für die Klärung der Rechtslage - unter Auswertung der 170-jährigen Rechtsprechung ${ }^{1244}$ und einen eventuellen Fair Use-Prozess anfallenden Kosten machen es gerade für private Nutzer und weniger finanzstarke Unternehmen oftmals umständlich und unattraktiv, sich auf den Fair Use-Einwand zu verlassen oder die Frage, ob eine bestimmte Nutzung als Fair Use anzusehen ist, tatsächlich gerichtlich klären zu lassen. ${ }^{1245}$ Dieses Kostenproblem wird im US-amerikanischen System dadurch verstärkt, dass im Falle eines Unterliegens im Prozess nicht nur ein Ersatz des tatsächlichen Schadens, sondern auch die Verurteilung zur Zahlung hoher pauschalierter Schadensersatzbeträge, sogenannter statutory damages, und erheblicher Anwaltskosten droht, die nicht selten den Streitwert - und somit auch eine mögliche Lizenzgebühr für die Werknutzung - bei Weitem überschreiten. ${ }^{1246}$ Finanzstarken Rechteinhabern kann dieses Kostenrisiko oftmals gar als ausreichende Drohkulisse dienen, um (möglicherweise) als Fair Use zu qualifizierende unliebsame Werknutzungen durch die Drohung mit einem Pro-

Nimmer, 66 Law \& Contemp. Probs. 263 (2003); Okediji, 53 Fla. L. Rev. 107 (2001); Patry/Perlmutter, 11 Cardozo Arts \& Ent. L.J. 667 (1993); Patry/ Posner, 92 Cal. L. Rev. 1639 (2004); Samuelson, 77 Fordham L. Rev. 2537 (2009); Timberg, 75 Nw. U. L. Rev. 193 (1980); Weinreb, 103 Harv. L. Rev. 1137 (1990); Wu, 31 Colum. J.L. \& Arts 617 (2008).

1244 Auch wenn die Bezeichnung „Fair Use“ im Jahre 1841 im Urteil Folsom v. Marsh, 9 F.Cas. 342, 348 (C.C.D. Mass. 1841), noch nicht verwendet wurde, kann dieses dennoch als Ursprung und Grundlage der US-amerikanischen Fair Use-Doktrin gelten; vgl. oben 2. Kapitel, C.I.1.

1245 Vgl. Barker, 83 Tex. L. Rev. 525, 526 f. (2004); Carroll, 85 N.C. L. Rev. 1087, 1096 (2007); Depoorter, 157 U. Pa. L. Rev. 1831, 1859 f. (2009); Gibson, 116 Yale L.J. 882, 888 f. (2007); Lemley, 22 U. Dayton L. Rev. 547, 566 (1997); Lessig, Free Culture, S. 186 f.; Litman, 75 Or. L. Rev. 19, 45 f. (1996); Samuelson/Wheatland, 51 Wm. \& Mary L. Rev. 439, 443 (2009); Wagner, 74 Fordham L. Rev. 423, 429 (2005).

1246 Nach 17 U.S.C. § 505 kann der unterliegenden Partei neben einer Schadensersatzpflicht auch die Pflicht zur Zahlung der (gesamten) Anwaltskosten der Gegenseite auferlegt werden. Diese übersteigen die (in der Regel bereits äußerst großzügig bemessenen) Schadensersatzbeträge nicht selten um ein Vielfaches; siehe etwa Wall Data Inc. v. Los Angeles County Sheriff's Dept., 447 F.3d 769, 776, 787 (9th Cir. 2006) [Ablehnung des Fair Use-Einwandes und Verpflichtung des Werknutzers zur Zahlung von Schadensersatz i.H.v. 210.000 US-Dollar und zur Übernahme der Anwaltskosten des Rechteinhabers i.H.v. 516.271 US-Dollar]. 
zess zu unterbinden. Ist der Nutzende grundsätzlich risikoscheu ${ }^{1247}$ oder finanziell nicht in der Lage, das Risiko einer Prozessniederlage einzugehen, so wird er entweder vollständig auf die Werknutzung verzichten oder aber versuchen, eine Lizenz zu erhalten. ${ }^{1248}$ Verzichtet aber ein Nutzer, obwohl er tatsächlich gute Gründe hat anzunehmen, im Rahmen der Fair Use-Schranke zu handeln, sicherheitshalber auf die zukünftige Nutzung oder zahlt er für diese freiwillig eine Lizenzgebühr, so zeigen sich die deutlichen Chilling-Effekte, die die Unsicherheit und das erhebliche Kostenrisiko in Bezug auf die schöpferische Tätigkeit unter Verwendung vorbestehender Werke haben können. ${ }^{1249}$

Einen gemeinsamen Schwachpunkt teilen schließlich die in Deutschland derzeit als „Notventil“"1250 zur Bewältigung des durch neue Technologien erzeugten Drucks auf das Urheberrecht herangezogene Einwilligungslösung und die US-amerikanische Fair Use-Doktrin: Beide Lösungswege sind zwar ausreichend flexibel, um zahlreiche urheberrechtliche Probleme im Zusammenhang mit neuen Nutzungsformen zu bewältigen, nicht hinreichend flexibel sind hingegen beide Modelle im Hinblick auf die Rechtsfolge - es fehlt eine Regelung zur Zahlung eines angemessenen Ausgleichs für die Möglichkeit der Werknutzung.

Lässt sich eine Nutzung als Fair Use einordnen, so kommt es zu einer Situation des „Alles oder Nichts“ - die (vergütungs-)freie Nutzung ist die

1247 Verhaltensökonomische Studien kommen zu dem Schluss, dass Entscheidungsträger in der Kreativwirtschaft typischerweise eher risikoavers sind. Gerade bei der Schaffung neuer Werke, die - wie beispielsweise Spielfilme - erhebliche Vorabinvestitionen erfordern und Gewinne allenfalls nach ihrer Fertigstellung erwarten lassen, werden die Werkschaffenden in der Regel versuchen, rechtliche Risiken und somit unerwünschte „Überraschungen“ zu vermeiden, da urheberrechtliche Klagen - gerade auch im einstweiligen Rechtsschutz - das Potential haben, eine solche Produktion erheblich zu verlangsamen oder gar vollständig zum Erliegen zu bringen. Siehe dazu Gibson, 116 Yale L.J. 882, $891 \mathrm{ff.}$ (2007).

$1248 \mathrm{Zu}$ dieser „license, don't litigate“-Tendenz Gibson, 116 Yale L.J. 882, 889 ff. (2007). Vgl. auch Litman, 75 Or. L. Rev. 19, 45 f. (1996); D. Olson, 52 Wm. \& Mary L. Rev. 537, 541 (2010).

1249 Vgl. Beldiman, in: Hilty/Peukert, Interessenausgleich, S. 187 (194); Depoorter, 157 U. Pa. L. Rev. 1831, 1859 f. (2009); Lessig, Free Culture, S. 188 ff.; Netanel, Copyright's Paradox, S. 66; D. Olson, 52 Wm. \& Mary L. Rev. 537, 605 (2010); Samuelson/Wheatland, 51 Wm. \& Mary L. Rev. 439, 442 f., 480 ff. (2009); Tushnet, 42 B.C. L. Rev. 1, 20 f., 24 f. (2000).

1250 Metzger, in: Europäische Perspektiven des Geistigen Eigentums, S. 101 (114). 
zwingende Folge. ${ }^{1251}$ Auch in dem Fall, dass eine Nutzung im deutschen Recht durch eine (konkludente) Einwilligung gedeckt ist, fehlt eine konkrete Vergütungsregelung. Zunächst hatte der BGH gar angenommen, die unterstellte Einwilligung in die Vervielfältigung solle zugleich einen Verzicht auf jegliche Vergütung enthalten, so dass eine Nutzung ohne die Zahlung einer urheberrechtlichen Vergütung erfolgen könnte. ${ }^{1252}$ Diese unflexible Rechtsfolge erschien jedoch in vielen Fällen unangemessen oder zumindest willkürlich. So ist etwa kaum einsichtig, warum der Rechteinhaber einen Anspruch auf eine angemessene Vergütung für Kopien haben soll, die mit Hilfe eines Vervielfältigungsgerätes erstellt werden, für das nach den $\S \S 54 \mathrm{ff}$. UrhG eine Vergütungspflicht besteht, nicht jedoch für solche Vervielfältigungen, die - wie im Fall der Bildersuche - durch ein kommerzielles Unternehmen für die Nutzung im Internet angefertigt werden und die nur über die Hilfskonstruktion der mutmaßlichen Einwilligung gerechtfertigt sind. ${ }^{1253} \mathrm{Zu}$ Recht hat daher auch der BGH im Rahmen zweier Vorlagebeschlüsse an den $\mathrm{EuGH}^{1254}$ verdeutlicht, an seiner ursprünglichen Rechtsprechung nicht festhalten zu wollen. ${ }^{1255}$ Der BGH

1251 Zum Ergebnis des „Alles oder Nichts“ nach der US-amerikanischen Fair UseDoktrin, siehe oben 2. Kapitel, C.I.3.

1252 Vgl. BGHZ 174, 359 (366f.) - Drucker und Plotter; BGH, GRUR 2009, 53 (55) $-P C$.

1253 Kritisch zur früheren Rechtsprechung des BGH auch BVerfG, GRUR 2010, 999 (1002) - Drucker und Plotter mit dem Hinweis, die Annahme des BGH, dass die unterstellte Einwilligung in die Vervielfältigung zugleich einen Verzicht auf jegliche Vergütung enthalten solle, begegne im Hinblick auf die verfassungsrechtlich gebotene grundsätzliche Zuordnung des vermögenswerten Ergebnisses der schöpferischen Leistung an den Urheber erheblichen Bedenken. Kritisch auch Dreier, GRUR 2010, 1002 (1003); Müller, GRUR 2011, 26 (28 f.); Schulze, ZUM 2011, 2 (11); Wandtke/Dietz, ZUM 2009, 155 (159); Winghardt, ZUM 2002, 349 (357 f.). Peifer, jurisPR-WettbR 12/2010 Anm. 2, hielt dieses Ergebnis hingegen für „kurios, aber keineswegs systemwidrig“.

1254 BGH, GRUR 2011, 1007 - Drucker und Plotter II und BGH, GRUR 2011, $1012-P C$ II.

1255 Siehe BGH, GRUR 2011, 1012 (1016f.) - PC II. Unmittelbare Bedeutung haben die BGH-Vorlage und die ausstehende EuGH-Entscheidung nur für die Durchsetzung der Vergütungsansprüche für PCs nach altem Recht gemäß § 54 Abs. 1 UrhG a.F. Die vom BGH dargestellten Grundsätze dürften jedoch - jedenfalls im Falle einer Bestätigung durch den EuGH - auch für die Durchsetzung von Vergütungsansprüchen nach dem seit dem 1.1.2008 geltenden Recht Geltung beanspruchen. 
hat den EuGH insoweit gebeten, nach der Padawan-Entscheidung ${ }^{1256}$ weiter offene Fragen zum ,gerechten Ausgleich“ zu klären. In dieser habe der EuGH ausgeführt, aus den Erwägungsgründen 35 und 38 zur InfoSocRichtlinie ergebe sich, dass der gerechte Ausgleich den Urhebern die „ohne ihre Genehmigung" erfolgte Nutzung ihrer geschützten Werke angemessen vergüten solle. Dies könne dahin verstanden werden, dass die Bedingung eines gerechten Ausgleichs oder die Möglichkeit eines gerechten Ausgleichs nicht bestehe, soweit der Rechtsinhaber eine Nutzung seines Werkes genehmigt hat. Dem könnte die Überlegung zu Grunde liegen, dass die Vervielfältigung eines geschützten Werkes in einem solchen Fall bereits auf Grund der Genehmigung des Rechtsinhabers und nicht erst auf Grund einer von den Mitgliedstaaten nach Art. 5 Abs. 2 und 3 der Richtlinine vorgesehenen Ausnahme oder Beschränkung in Bezug auf das Vervielfältigungsrecht zulässig ist und dem Rechtsinhaber daher kein Schaden durch die in der nationalen Regelung vorgesehene Einschränkung seines Vervielfältigungsrechts entsteht. ${ }^{1257}$ Der Senat legte jedoch dar, dass nach seiner Ansicht die in Art. 5 Abs. 2 und 3 der Richtlinie vorgesehenen Ausnahmen oder Beschränkungen in Bezug auf das Vervielfältigungsrecht gegenüber einer ausdrücklichen oder konkludenten Genehmigung einer solchen Vervielfältigung durch den Rechtsinhaber vorrangig seien. Soweit solche Einschränkungen des Vervielfältigungsrechts reichten, nehmen sie dem Rechtsinhaber die Möglichkeit, Vervielfältigungen zu verbieten oder zu gestatten. Eine Genehmigung der bereits auf Grund der Einschränkungen des Vervielfältigungsrechts zulässigen Vervielfältigungen durch den Rechtsinhaber gehe somit - entgegen der in den Entscheidungen Drucker und Plotter I und PC I vertretenen Ansicht - ins Leere und lasse die Bedingung oder die Möglichkeit eines gerechten Ausgleichs unberührt. ${ }^{1258}$ Selbst wenn Ausnahmen oder Beschränkungen in Bezug auf das Vervielfältigungsrecht gegenüber einer Genehmigung des Rechtsinhabers nicht als vorrangig anzusehen wären, sei die Entscheidung des EuGH in der Sache Padawan jedenfalls nicht dahin zu verstehen, dass eine Genehmigung der Vervielfältigung durch den Rechtsinhaber - ohne gleichzeitige Vergütungsabrede - einen gerechten Ausgleich nach der Richtlinie ausschlösse. Erwägungsgrund 35 der Richtlinie besage lediglich, dass in Fällen, in de-

1256 EuGH, Urt. v. 21.10.2010, C-467/08, ABl. EU 2010, C 346/05 = GRUR 2011, 50 - Padawan./. Sociedad General de Autores y Editores de España [SGAE].

1257 Siehe BGH, GRUR 2011, 1012 (1016 f., Rn. 51 f.) - PC II.

1258 Siehe BGH, a.a.O., S. 1017, Rn. 53 - PC II. 
nen Rechtsinhaber bereits Zahlungen in anderer Form erhalten haben, z.B. als Teil einer Lizenzgebühr, gegebenenfalls keine spezifische oder getrennte Zahlung fällig sein kann. ${ }^{1259}$

Demnach ist nunmehr nach Ansicht des BGH - jedenfalls wenn die Nutzung im Rahmen einer Schranke liegt - auch im Falle einer aufgrund einer ausdrücklichen oder konkludenten Einwilligung zulässigen Nutzungshandlung für diese eine angemessene Vergütung zu zahlen. Klarheit darüber, ob, wann und in welchem Umfang im Falle einer Einwilligung des Rechteinhabers in die Nutzung eine Vergütung zu zahlen ist, wird letztlich (frühestens) durch die EuGH-Entscheidung erreicht werden. Derartige Unklarheiten im Hinblick auf die Rechtsfolge sollten bei der Flexibilisierung der deutschen Urheberrechtsschranken de lege ferenda dringend vermieden werden. 1260

1259 Siehe BGH, a.a.O., S. 1017, Rn. 54 - PC II unter Bezugnahme auf BVerfG, GRUR 2011, 223 (225) - Drucker und Plotter.

1260 Siehe dazu unten 7. Kapitel. 


\section{Teil 3 Flexibilisierung der Urheberrechtsschranken de lege ferenda}

Die Untersuchung hat anhand zweier Beispiele aus der Praxis deutlich gezeigt, vor welche massiven rechtsdogmatischen und -praktischen Schwierigkeiten neue (kommunikations-)technische Entwicklungen und auf diesen basierende neue Formen der Werknutzung das deutsche Urheberrecht stellen. In den vergangenen Jahrzehnten mag es zumeist noch mit einzelnen Retouchen am geltenden Recht durch den Gesetzgeber oder durch Heranziehung mehr oder minder überzeugender rechtlicher Konstruktionen durch die Rechtsprechung gelungen sein, die urheberrechtlichen Schrankenregelungen neuen Entwicklungen anzupassen. ${ }^{1261}$ Die zuvor dargestellten Problemfälle, die sich problemlos um weitere Beispiele ergänzen lassen, haben jedoch gezeigt, dass nun aufgrund der immer rasanter fortschreitenden technischen Entwicklung und aufgrund der damit einhergehenden ständig wachsenden Herausforderungen für das Urheberrecht ein Punkt erreicht ist, an dem eine solche rechtliche „Flickschusterei“ nicht einmal mehr die zweitbeste, sondern gar keine befriedigende Lösung darstellt. Eine zukunftsoffene Flexibilisierung der deutschen und/oder europäischen urheberrechtlichen Schrankenregelungen de lege ferenda ist daher dringend erforderlich.

Die rechtsvergleichende Untersuchung der Nutzung urheberrechtlich geschützter Werke im Rahmen der Google Buchsuche und in Form von Thumbnails durch Bildersuchmaschinen hat zugleich gezeigt, welche Flexibilitätsvorteile das US-amerikanische Urheberrecht im Umgang mit derartigen Herausforderungen durch die Fair Use-Generalklausel bietet. Die US-amerikanische Fair Use-Doktrin als Grundlage heranzuziehen, um die Schrankenregelungen des deutschen und europäischen Urheberrechts $\mathrm{zu}$ flexibilisieren und dieses zukunftsfähig zu gestalten, drängt sich daher förmlich auf.

Den Möglichkeiten, das europäische und deutsche Urheberrecht derart umzugestalten, widmet sich der dritte Teil dieser Untersuchung. Zunächst werden zu diesem Zweck die Vorgaben für die gesetzgeberische Ausge-

1261 Vgl. Hilty, ZUM 2003, 983 (984). 
Teil 3 Flexibilisierung der Urheberrechtsschranken de lege ferenda

staltung der Urheberrechtsschranken durch inter- und supranationales Recht sowie durch das deutsche (Verfassungs-)Recht untersucht (sogleich 6. Kapitel). Das 7. Kapitel widmet sich schließlich möglichen legislativen Maßnahmen zur Flexibilisierung der Schranken des Urheberrechts und ihrer Vereinbarkeit mit den rechtlichen Vorgaben. 


\section{Kapitel Vorgaben für die gesetzgeberische Ausgestaltung der Urheberrechtsschranken durch inter- und supranationales Recht sowie durch das deutsche (Verfassungs-)Recht}

Die erstrebenswerte Flexibilisierung der Urheberrechtsschranken de lege ferenda kann nur dann erfolgreich umgesetzt werden, wenn sie im Einklang mit geltendem höherrangigem Recht oder jedenfalls im Bewusstsein der bestehenden gesetzlichen Grenzen und möglicherweise erforderlicher Gesetzesänderungen erfolgt. Eine entscheidende Frage ist daher, welche Handlungsspielräume dem deutschen und europäischen Gesetzgeber bei der Ausgestaltung der Schranken des Urheberrechts vor allem im Hinblick auf Vorgaben aus dem internationalen Konventionsrecht (sogleich A.), dem europäischen Gemeinschaftsrecht (sodann B.) und dem nationalen Verfassungsrecht (unten D.) verbleiben. Dabei soll nachfolgend aufgezeigt werden, dass der rechtlich vorgegebene Rahmen - entgegen des oftmals erweckten Eindrucks - keinesfalls so eng ist, dass grundlegende Veränderungen bereits per se ausgeschlossen wären, und dass gerade hinsichtlich der Ausgestaltung der Schranken recht erhebliche Spielräume bestehen.

\section{A. Konventionsrecht als Grenze der gesetzgeberischen Gestaltungsfreiheit}

Die Bundesrepublik Deutschland (und auch die Europäische Union) ist Vertragspartei mehrerer internationaler Abkommen, die völkerrechtliche Verpflichtungen für den Bereich des Urheberrechts enthalten. Durch die Transformation in deutsches Recht in Form eines Vertragsgesetzes kommt diesen völkerrechtlichen Verträgen der Rang einfachen Bundesrechtes zu. ${ }^{1262}$ Durch diese Übereinkommen geschützte Interessen sind somit bei

1262 Gemäß Art. 25 GG gilt ein Vorrang von Völkerrechtsnormen gegenüber einfachem nationalem Recht nur für die allgemeinen Regeln des Völkerrechts. Völkervertragsrechtliche normative Verpflichtungen werden hingegen nach ganz h.M. durch ein Vertragsgesetz in innerstaatliches Recht auf die Ebene eines Bundesgesetzes transformiert (vgl. BVerfGE 1, 372 (389) - Deutsch-Französi- 
der Änderung bestehender oder Einführung neuer Schrankenregelungen des Urheberrechts zu berücksichtigen. Die wichtigsten dieser internationalen Verträge und ihre jeweilige Reichweite sollen daher im Folgenden kurz dargestellt werden. Der in mehreren der Verträge enthaltene Dreistufentest als zentrale konventionsrechtliche Vorgabe und Beschränkung der Urheberrechtsgesetzgebung im Bereich der Schranken wird dabei zunächst weitgehend ausgeklammert. Dem Dreistufentest in seiner Ausformung durch das Konventionsrecht und durch das europäische Gemeinschaftsrecht widmet sich die Arbeit aufgrund seiner grundlegenden Bedeutung für die vorliegende Untersuchung in einem eigenen Abschnitt (unten C.) im Anschluss an den Überblick über die Grenzen gesetzgeberischer Gestaltungsfreiheit, die das Konventions- und europäische Gemeinschaftsrecht ziehen.

\section{Allgemeine Erklärung der Menschenrechte (AEMR)}

Das Urheberrecht wird sehr selten ausdrücklich in Verfassungen oder verfassungsähnlichen Rechtsnormen genannt. Die wohl prominenteste Ausnahme bildet die Allgemeine Erklärung der Menschenrechte (AEMR) von

sches Wirtschaftsabkommen; E 42, 263 (284) - Contergan; E 63, 343 (354) Rechtshilfevertrag zwischen Deutschland und Österreich). Folglich gehen sie zwar landesgesetzlichen Bestimmungen vor, sind im Vergleich mit anderen bundesgesetzlichen Regelungen allerdings grundsätzlich dem lex posterior-Grundsatz unterworfen, könnten also unter Umständen hinter neueren bundesgesetzlichen Regelungen zurücktreten. Dieser Grundsatz wird allerdings durch den Grundsatz der völkerrechtsfreundlichen Auslegung des deutschen Rechts eingeschränkt (vgl. BVerfGE 74, 358 (370) - Unschuldsvermutung). Soweit der Vertrag transformierbares Recht enthält, erlangt dieses die Qualität innerstaatlichen Rechts durch das Zustimmungsgesetz. Das Vertragsgesetz enthält den Rechtsanwendungsbefehl; sein Inkrafttreten ist jedoch aufschiebend bedingt und hängt davon ab, ob und wann der Vertrag selbst verbindlich wird. Erst mit dem Inkrafttreten des Vertrags werden seine Bestimmungen als innerstaatliches Recht wirksam (vgl. BVerfGE 29, 348 (360) Deutsch-Niederländischer Finanzvertrag; E 42, 263, (284) - Contergan; E 90, 286 (364) - Bundeswehreinsatz). Ausführlich zur Frage, welche innerstaatlichen Rechtswirkungen einem zu vollziehenden völkerrechtlichen Vertrag zukommen, Maunz/Dürig/Nettesheim, GG, Art. 59 Rn. 181 ff. m.w.N. 
1948, ${ }^{1263}$ nach deren Art. 27 Abs. 2 jeder das Recht auf Schutz der geistigen und materiellen Interessen hat, die ihm als Urheber von Werken der Wissenschaft, Literatur oder Kunst erwachsen und das Urheberrecht somit gar in den Kreis der Menschenrechte aufgenommen wird. Noch vor dem Schutz der Urheber nach Absatz 2 gewährleistet die Norm in ihrem Absatz 1 das Recht eines jeden, am kulturellen Leben der Gemeinschaft frei teilzunehmen, sich an den Künsten zu erfreuen und am wissenschaftlichen Fortschritt und dessen Errungenschaften teilzuhaben.

Die AEMR hat als Resolution der Generalversammlung der Vereinten Nationen keine unmittelbare völkerrechtliche Bindungswirkung, sondern ist - wie alle Resolutionen der Generalversammlung - grundsätzlich nur eine Empfehlung. ${ }^{1264} \mathrm{Ihr}$ außerordentlich hoher Stellenwert spiegelt sich jedoch in der Tatsache wider, dass die AEMR in zahlreichen amtlichen Erklärungen, einigen nationalen Verfassungen ${ }^{1265}$ und anderen supranationalen Menschenrechtskonventionen ${ }^{1266}$ in Bezug genommen wurde und inzwischen als Definition und zur Auslegung der Rechte anerkannt ist, die die Vereinten Nationen und deren Mitgliedstaaten nach Art. 55 und 56 der UN-Charta fördern wollen. ${ }^{1267}$ Zudem ist der Wortlaut des Art. 27 Abs. 2 AEMR fast identisch in Art. 15 Abs. 1 lit. c des Internationalen Paktes über wirtschaftliche, soziale und kulturelle Rechte (ICESCR) ${ }^{1268}$ übernommen worden. Dieser Pakt trat 1976, nachdem er 1973 auch von Deutschland ratifiziert worden war, als völkerrechtlich verbindlicher Ver-

1263 Resolution 217 A (III) der Generalversammlung der Vereinten Nationen vom 10.12.1948. Im offiziellen Wortlaut in den fünf Amtssprachen der Vereinten Nationen (Chinesisch, Englisch, Französisch, Russisch und Spanisch) abgedruckt in: United Nations, General Assembly, Official Records, Third Session (Part I) Resolutions (Doc. A/810) S. 71). Eine nicht verbindliche deutsche Fassung der AEMR ist auf der Internetseite des Office of the High Commissioner for Human Rights der Vereinten Nationen abrufbar unter: http:// www.ohchr.org/EN/UDHR/Documents/UDHR_Translations/ger.pdf [zuletzt abgerufen am 26.5.2013].

1264 Bindende Willensakte der Generalversammlung werden als Beschluss (decision) verabschiedet; vgl. Herdegen, Völkerrecht, § 47 Rn. 3; Hobe, Völkerrecht, S. 425.

1265 Vgl. etwa die Präambel der französischen Verfassung vom 4. Oktober 1958.

1266 Vgl. etwa die Präambel der Europäischen Menschenrechtskonvention vom 4. November 1950.

1267 Vgl. Vitzthum/Hailbronner, Völkerrecht, 3. Abschnitt Rn. 223.

1268 International Covenant on Economic, Social and Cultural Rights vom 19. Dezember 1966. 
trag in Kraft. ${ }^{1269}$ Trotz der grundsätzlichen Verbindlichkeit als völkerrechtlicher Vertrag enthält auch der ICESCR keine unmittelbar anwendbaren Rechtspflichten, sondern knüpft bei den wirtschaftlichen, sozialen und kulturellen Rechten an die Verfügbarkeit der Ressourcen an. ${ }^{1270}$ So enthält Art. 2 Abs. 1 ICESCR lediglich die Verpflichtung der Vertragsstaaten, unter Ausschöpfung aller ihrer Möglichkeiten Maßnahmen zu ergreifen, um nach und nach mit allen geeigneten Mitteln, vor allem durch gesetzgeberische Maßnahmen, die volle Verwirklichung der in diesem Pakt anerkannten Rechte zu erreichen. Trotz dieser „weichen“ Formulierung als Staatszielbestimmungen haben die Kodifikation der aus Art. 27 Abs. 2 AEMR übernommenen Gewährleistung des Urheberrechts im ICESCR und die zahlreichen Bezugnahmen auf die AEMR in anderen Erklärungen und in gerichtlichen Entscheidungen dazu geführt, dass letztlich auch Art. 27 Abs. 2 AEMR selbst eine (zumindest) völkergewohnheitsrechtliche Bindungswirkung nicht mehr abgesprochen werden kann ${ }^{1271}$ und dem geistigen Eigentum somit menschenrechtlicher Schutz zukommt, soweit die Gewährleistungen der AEMR reichen.

Die AEMR enthält in ihrem Art. 17 eine allgemeine Gewährleistung des Eigentumsschutzes. In Art. 19 AEMR wird zudem die Meinungs- und Meinungsäußerungsfreiheit garantiert. Im Rahmen der Verhandlungen zur AEMR wurde daher von einigen Delegierten der Standpunkt vertreten, die Anerkennung des Urheberschutzes und die Garantie der Teilnahme am kulturellen Leben in Art. 27 AEMR seien überflüssig. ${ }^{1272}$ Diese Kritik kann jedoch aus zwei Gründen nicht überzeugen: Zum einen erfasst Art. 27 Abs. 2 AEMR ausdrücklich auch die persönlichen, ,geistigen Interessen" des Urhebers an seinem Werk. Diese persönlichkeitsrechtlichen Aspekte unterfallen jedoch nicht dem Eigentumsschutz des Art. 17 AEMR, so dass ein Schutz des Urhebers ausschließlich über Art. 17 AEMR gegenüber der Garantie des Art. 27 AEMR unvollständig wäre.

1269 Die Bundesrepublik Deutschland hat den Vertrag am 9. Oktober 1968 unterzeichnet, vgl. BGBl. 1973 II, S. 1570, und am 17. Dezember 1973 die Ratifikationsurkunde beim Generalsekretär der Vereinten Nationen hinterlegt, vgl. BGBl. 1976 II, S. 428. Seit dessen Inkrafttreten am 3. Januar 1976 ist Deutschland völkerrechtlich an den Pakt gebunden.

1270 Vgl. Herdegen, Völkerrecht, § 48 Rn. 6; Vitzthum/Hailbronner, Völkerrecht, 3. Abschnitt Rn. 226.

1271 Vgl. Herdegen, Völkerrecht, § 47 Rn. 3; Hobe, Völkerrecht, S. 425; Vitzthum/ Hailbronner, Völkerrecht, 3. Abschnitt Rn. 223.

1272 Siehe Chapman, Human Rights Perspective on IP, S. 7. 
Zudem ist die Normierung des Urheberrechtsschutzes nach Art. 27 AEMR systematisch im Zusammenhang mit den wirtschaftlichen, kulturellen und sozialen Rechten verortet. Aus dieser systematischen Stellung lässt sich folgern, dass die Regelung des Art. 27 AEMR gegenüber dem in Art. 17 AEMR geregelten allgemeinen Schutz des Eigentums und der in Art. 19 AEMR garantierten Meinungsfreiheit eine Spezialvorschrift darstellt. Der Anwendungsbereich des Art. 17 AEMR muss daher bereits aus systematischen Überlegungen auf das Sacheigentum beschränkt sein, so dass eine Berufung auf den Schutz des Urheberrechts als Eigentum im Sinne dieser Norm ausscheidet. ${ }^{1273}$ Diese Überlegungen stützt auch ein Blick auf die Folgen, die eine solche Möglichkeit der Berufung auf Art. 17 AEMR hätte: Das durch Art. 27 Abs. 1 AEMR etablierte Recht, am kulturellen Leben der Gemeinschaft frei teilzunehmen, würde seiner Bedeutung weitgehend beraubt, könnte sich der Urheber stets auch auf den Schutz des Eigentums nach Art. 17 AEMR berufen, da diese Norm - anders als etwa das deutsche Grundgesetz in Art. 14 Abs. 2 S. $2^{1274}$ - eine Berücksichtigung von Allgemeininteressen nicht vorsieht. ${ }^{1275}$ Auch die durch Art. 19 AEMR gewährte Meinungsfreiheit in ihrer Ausformung als Informationsfreiheit wird - bezogen auf urheberrechtlich geschützte Werke - durch Art. 27 AEMR als Spezialvorschrift verdrängt, die den Schutz der freien Teilhabe am kulturellen Leben besonders hervorhebt. ${ }^{1276}$

Über die innere Systematik des Art. 27 AEMR und mögliche Rückschlüsse für den Ausgleich der in Absatz 1 und 2 geregelten konfligierenden Interessen der freien Teilhabe am kulturellen Leben einerseits und dem Schutz der Urheber andererseits ist ebenfalls vielfach diskutiert worden. ${ }^{1277}$ So wurde zum Teil davon ausgegangen, die Erwähnung des Rech-

1273 Ebenso Fechner, Geistiges Eigentum und Verfassung, S. 86; Hohagen, Vervielfältigung zum eigenen Gebrauch, S. 126; Yu, 23 Ga. St. U. L. Rev. 709, 732, 734 (2007).

1274 Zur Sozialbindung des Eigentums nach dem deutschen Grundgesetz, siehe ausführlich unten 6. Kapitel, D.I.1.

1275 So auch Hohagen, Vervielfältigung zum eigenen Gebrauch, S. 126.

1276 Ebenso Fischman Afori, 14 Fordham Intell. Prop. Media \& Ent. L.J. 497, 526 ff. (2004).

1277 Vgl. etwa Wong, 26 Cardozo Arts \& Ent. L.J. 775, 807, 817, 822 (2009), die das Spannungsverhältnis zwischen den beteiligten Interessen hervorhebt. Für eine ausführliche Darstellung der langwierigen und spannungsgeladenen Entstehungsgeschichte des Art. 27 AEMR siehe Yu, 40 U.C. Davis L. Rev. 1039, $1050 \mathrm{ff}$. (2007). 
tes der freien Teilhabe am kulturellen Leben in Art. 27 Abs. 1 AEMR und somit vor der Normierung des Urheberschutzes in Art. 27 Abs. 2 AEMR - sei Ausdruck einer den Urheberschutz übersteigenden Bedeutung der aktiven Teilhabe am Kulturleben. ${ }^{1278}$ Nach anderer Ansicht existiert ein solches Spannungsverhältnis zwischen den beiden Absätzen der Norm hingegen nicht beziehungsweise nur scheinbar und sollte daher nicht überinterpretiert werden. ${ }^{1279}$ Insbesondere wenn man den langwierigen Entstehungsprozess der Norm und die darin reflektierten Kompromisse berücksichtigt, erscheint es unangemessen, durch den Versuch einer übermäßigen Interpretation der Systematik des Art. 27 AEMR einem der dort genannten Interessen der Vorrang einzuräumen. Vielmehr lässt sich Art. 27 AEMR als Ausdruck des gemeinsamen Willens der beteiligten Parteien verstehen, die überragende Bedeutung der Interessen der Allgemeinheit und des Einzelnen an einer möglichst ungehinderten Teilhabe am kulturellen Leben herauszustellen und zugleich - zur Erreichung dieses Ziels - auf die Notwendigkeit eines gerechten Interessenausgleichs zwischen Urhebern und Allgemeinheit hinzuweisen. Diesen „Balanceakt" in Art. 27 kodifiziert und somit in den Rang von Menschenrechten erhoben zu haben, ist - in Bezug auf das Urheberrecht - das wesentliche Verdienst der Allgemeinen Erklärung der Menschenrechte. Trotz der grundsätzlichen rechtlichen Unverbindlichkeit der AEMR ist die von der Statuierung ausgehende Symbolwirkung nicht zu unterschätzen, da zumindest die meisten der UN-Mitgliedstaaten Menschenrechtsverstöße zu vermeiden versuchen werden.

\section{Europäische Menschenrechtskonvention (EMRK)}

Erhebliche Bedeutung bei der Ausgestaltung und Anwendung des Urheberrechts kommt der Europäischen Konvention zum Schutze der Men-

1278 Vgl. etwa Kéréver, DdA 1990, 138 (146).

1279 So etwa Hohagen, Vervielfältigung zum eigenen Gebrauch, S. 127, der der ausdrücklichen Anerkennung berechtigter Nutzerinteressen in der AEMR einerseits besondere Bedeutung beimisst, jedoch vor einer Überinterpretation der systematischen Vorrangstellung des Rechts auf freie Teilnahme am kulturellen Leben warnt. Ähnlich Wong, 26 Cardozo Arts \& Ent. L.J. 775, 817, 835 (2009), die zwar ein deutliches Spannungsverhältnis zwischen den beiden Absätzen sieht, jedoch keinem der beteiligten Interessen den Vorrang einräumen will; in diese Richtung auch Woods, 37 AIPLA Q.J. 347, 385 (2009). 
schenrechte und Grundfreiheiten (EMRK) ${ }^{1280}$ von $1950^{1281} \mathrm{zu}$, die spätestens durch den Vertrag von Lissabon endgültig zur Grundlage eines gemeineuropäischen Mindeststandards für den Individualschutz geworden ist. ${ }^{1282}$ Als Kontrollorgan zur Durchsetzung und zum Schutz der gewährten Grund- und Menschenrechte wurde der Europäische Gerichtshof für Menschenrechte (EGMR) mit Sitz in Straßburg geschaffen, ${ }^{1283}$ an den sich betroffene Einzelne oder auch Staaten bei Verletzung der Konventionsrechte wenden können. ${ }^{1284}$

Eine Art. 17 AEMR vergleichbare Vorschrift zum Schutz des Eigentums allgemein oder gar eine Art. 27 AEMR vergleichbare Bestimmung zu den Rechten der Urheber und zu den Rechten der Allgemeinheit an der freien Teilhabe am kulturellen Leben enthält die EMRK nicht. Erst durch

1280 Konvention zum Schutz der Menschenrechte und Grundfreiheiten vom 4.11.1950 (BGB1. 1952 II, S. 686) in Fassung der Bekanntmachung vom 17.5.2002 (BGB1. 2002 II, S. 1054), zuletzt geändert durch Bekanntmachung über die vorläufige Anwendung von Bestimmungen des Protokolls Nr. 14 zur Konvention zum Schutz der Menschenrechte und Grundfreiheiten über die Änderung des Kontrollsystems der Konvention vom 6.7.2009 (BGB1. 2009 II, S. 823).

1281 Die Konvention wurde am 4. November 1950 in Rom von Mitgliedern des Europarates unterzeichnet und trat am 3. September 1953 nach der Ratifizierung durch 10 Mitgliedstaaten in Kraft. Die EMRK kann als sog. geschlossene Konvention nur von Mitgliedern des Europarates unterzeichnet werden, vgl. Art. 59 Abs. 1 EMRK. Mittlerweile haben alle 47 Mitgliedstaaten des Europarates die EMRK ratifiziert. Als einzige europäische Staaten sind somit der Vatikan und Weißrussland nicht an die EMRK gebunden. Völkerrechtlich verbindlich ist allein die englische und französische Sprachfassung, vgl. Art. 59 Abs. 4 EMRK.

1282 Die Europäische Union ist der EMRK zwar bisher noch nicht beigetreten, jedoch haben alle Unionsmitgliedstaaten die EMRK ratifiziert. Art. 6 Abs. 2 des EU-Vertrags schafft zudem die für den Beitritt der EU zur EMRK erforderliche Kompetenz. Nach Art. 6 Abs. 3 EUV sind die Grund- und Menschenrechte der EMRK bereits jetzt als allgemeine Grundsätze Teil des Unionsrechts. Zudem sah der EGMR die EU bereits vorher als an die EMRK gebunden an, vgl. EGMR, Urt. v. 30.6.2005 (GrK), Nr. 45036/98 = NJW 2006, 197 - Bosphorus./. Irland.

12831954 wurde zunächst die Europäische Kommission für Menschenrechte (EKMR) als Untersuchungs- und Vermittlungsorgan errichtet, um die Einhaltung der EMRK durch ihre Unterzeichner zu gewährleisten. Ihre Aufgabe wurde 1998 durch den EGMR übernommen, vgl. Art. 19 EMRK in der Fassung des Protokolls Nr. 11.

1284 Vgl. Art. 33, 34 EMRK in der Fassung des Protokolls Nr. 11. 
Art. 1 des ersten Zusatzprotokolls zur Konvention vom 20.3.1952 $2^{1285}$ wurde jeder natürlichen oder juristischen Person das Recht auf Achtung ihres Eigentums als europäisches Menschenrecht garantiert. Die Vorschrift enthält drei unterschiedliche Regelungen. ${ }^{1286}$ Absatz 1 Satz 1 verankert allgemein den Grundsatz des Rechts auf Achtung des Eigentums. Absatz 1 Satz 2 und Absatz 2 der Bestimmung regeln Sonderfälle für Eingriffe in das Eigentum. So macht die Regelung des Absatzes 1 Satz 2 die Enteignung von bestimmten Voraussetzungen abhängig. Absatz 2 schließlich erkennt an, dass die Konventionsstaaten dazu berechtigt sind, die Benutzung des Eigentums im Allgemeininteresse zu regeln. ${ }^{1287}$ Aufgrund des Fehlens einer ausdrücklichen Aussage in der EMRK und in den Zusatzprotokollen war lange nicht eindeutig geklärt, ob vom Eigentumsbegriff im Sinne dieser Norm auch das Urheberrecht als geistiges Eigentum erfasst wird. Gestützt auf eine Entscheidung der Europäischen Kommission für Menschenrechte (EKMR), die das Patentrecht dem Eigentumsschutz des Art. 1 des 1. Zusatzprotokolls zuordnete, ${ }^{1288}$ wurde in der Literatur schon früh ganz überwiegend angenommen, dass alle Immaterialgüterrechte dem konventionsrechtlichen Eigentumsschutz unterfallen. ${ }^{1289}$ In jüngerer Zeit hat der Europäische Gerichtshof für Menschenrechte sich nun im Rahmen einer markenrechtlichen Streitigkeit erstmals grundlegend zur Reichweite des Eigentumsschutzes nach der EMRK in Bezug auf Immaterialgüterrechte geäußert ${ }^{1290}$ und sich der herrschenden Auffassung in der Literatur

1285 Zusatzprotokoll zur Konvention zum Schutz der Menschenrechte und Grundfreiheiten in seiner durch das Protokoll Nr. 11 vom 11.5.1994 geänderten Fassung, BGBl. 2002 II, S. 1072.

1286 St. Rspr., grundlegend EGMR, Urt. v. 23.9.1982, Nr. 7151/75, Rn. 61, EGMR-E 2, 148 = EuGRZ 1983, 523 - Sporrong und Lönnroth./. Schweden; vgl. auch Urt. v. 5.1.2000 (GrK), Nr. 32202/96 = NJW 2003, 645 - Beyerler./. Italien.

1287 Vgl. ausführlich zu den drei in Art. 1 des 1. Zusatzprotokolls zur EMRK enthaltenen Prinzipien, Meyer-Ladewig, EMRK, Art. 1 ZP 1 Rn. 2 f.

1288 EKMR, Entsch. v. 4.10.1990, Beschwerde Nr. 12633/87, DR 66 (1990), 70 (79) - Smith Kline and French Laboratories Ltd... Niederlande.

1289 Vgl. etwa Frowein/Peukert, EMRK, 2. Aufl., Art. 1 1. ZP Rn. 6; Gelinsky, Schutz des Eigentums gemäß Art. 1 des Ersten Zusatzprotokolls, S. 32; v.Milczewski, Grundrechtlicher Schutz des Eigentums im Europäischen Gemeinschaftsrecht, S. 217; Müller-Michaels, Grundrechtlicher Eigentumsschutz in der EU, S. 65; Peukert, EuGRZ 1981, 97 (103); Riedel, EuGRZ 1988, 333 (334). Ausführlich Mittelberger, Eigentumsschutz, S. 22 f. m.w.N.

1290 EGMR, Urt. v. 11.1.2007 (GrK), Nr. 73049/01 = GRUR 2007, 696 - AnheuserBusch Inc../. Portugal. 
angeschlossen. Die Große Kammer stellte fest, der Begriff „Eigentum“ nach Art. 1 des 1. Zusatzprotokolls habe autonome Bedeutung, beschränke sich also nicht auf das Eigentum an Sachen und sei unabhängig von der formalen Einordnung im innerstaatlichen Recht zu beurteilen. Bestimmte andere Rechte und Interessen, die Vermögenswerte darstellen, könnten daher ebenfalls als „Eigentumsrechte” und darum als „Eigentum” im Sinne dieser Norm angesehen werden. ${ }^{1291}$ Somit sei auch das gesamte ,geistige Eigentum" als Eigentum im Sinne des Art. 1 des 1. Zusatzprotokolls anzusehen und nach der EMRK geschützt. ${ }^{1292}$ Diese Position hat der EGMR im Jahr 2008 auch noch einmal ausdrücklich in Bezug auf das Urheberrecht bestätigt, ${ }^{1293}$ so dass nun unzweifelhaft davon auszugehen ist, dass das Urheberrecht als Eigentum im Sinne des Art. 1 des 1. Zusatzprotokolls Schutz nach der EMRK genießt.

Nationale Bestimmungen des urheberrechtlichen Schutzes müssen im Einklang mit dieser Vorschrift stehen. Dabei ist die Regelung des Art. 1 Abs. 2 des 1. Zusatzprotokolls zur EMRK von besonderer Bedeutung, die - anders als die Eigentumsgewährleistung der AEMR ${ }^{1294}$ - ausdrücklich Einschränkungsmöglichkeiten des Eigentumsschutzes zugunsten von Allgemeininteressen vorsieht. ${ }^{1295}$ Der EGMR hat bei der Auslegung dieser Regelung explizit gefordert, dass ein gerechter Ausgleich zwischen dem Allgemeininteresse und den Rechten des Einzelnen herzustellen ist. ${ }^{1296}$ Bei der Ausgestaltung des Urheberrechts, insbesondere der urheberrechtlichen Schranken, müssen somit das Interesse der Allgemeinheit am $\mathrm{Zu}$ gang zu urheberrechtlich geschützten Werken und an deren Nutzung im Einklang mit dieser Vorschrift berücksichtigt werden. Als gewichtiges Allgemeininteresse, dem ebenfalls Schutz nach der EMRK zukommt, ist in diesem Zusammenhang insbesondere die durch Art. 10 Abs. 1 EMRK

1291 EGMR, GRUR 2007, 696 (697) - Anheuser-Busch Inc../. Portugal.

1292 EGMR, GRUR 2007, 696 (698) - Anheuser-Busch Inc../. Portugal.

1293 EGMR, Urt. v. 29.1.2008, Nr. 19247/03 (Rn. 34 ff.) - Balan./. Moldova.

1294 Siehe dazu oben 6. Kapitel, A.I.

1295 Art. 1 Abs. 2 des 1. Zusatzprotokolls zur EMRK lautet: „Absatz 1 beeinträchtigt jedoch nicht das Recht des Staates, diejenigen Gesetze anzuwenden, die er für die Regelung der Benutzung des Eigentums im Einklang mit dem Allgemeininteresse oder zur Sicherung der Zahlung der Steuern oder sonstigen Abgaben oder von Geldstrafen für erforderlich hält." [Hervorhebung durch den Verfasser].

1296 Vgl. EGMR, Urt. v. 15.2.2001, Nr. $37095 / 97$ (Rn. 57) - Pialopoulos./. Griechenland. 
garantierte - nach Abs. 2 jedoch durch notwendige gesetzliche Regelungen einschränkbare - Informationsfreiheit zu beachten. ${ }^{1297}$

\section{Charta der Grundrechte der Europäischen Union}

\section{Anwendbarkeit und Bedeutung der Charta der Grundrechte}

Ebenfalls bei der Ausgestaltung und Anwendung des Urheberrechts zu beachten ist die Charta der Grundrechte der Europäischen Union (GRC) vom 7. Dezember 2000, ${ }^{1298}$ die durch den Verweis in Art. 6 Abs. 1 EUV nun rechtsverbindlich geworden ist. ${ }^{1299}$ Sowohl ein Textvergleich als auch ein Blick in die Präambel der Grundrechte-Charta zeigen deutlich, dass die EMRK in wesentlichen Teilen Pate für Inhalt und Formulierung der Charta gestanden hat: ${ }^{1300}$ Zum einen finden sich in der GRC nahezu sämtliche Artikel der EMRK - oftmals fast wortgleich - wieder. Zum anderen wird in Absatz 5 der Präambel ausdrücklich auf die EMRK und die Rechtsprechung des EGMR als mitkonstituierende Elemente des Inhalts der Gemeinschaftsgrundrechte Bezug genommen.

Dies wirft die Frage nach dem Verhältnis der beiden Grundrechtskataloge zueinander auf. Eine Regelung für Konfliktfälle enthalten die Artikel

1297 Ausführlich zum Schutz der Meinungs- und Informationsfreiheit nach Art. 10 EMRK Grabenwarter, EMRK, § 23 Rn. 1 ff.; Hohagen, Vervielfältigung zum eigenen Gebrauch, S. $131 \mathrm{ff}$.

1298 ABl. EG 2007, C 303/01 (offizieller Text der Charta in der Fassung von 2007, auf die Art. 6 EUV seit 1.12.2009 verweist; für die ursprüngliche Fassung, siehe AB1. EG 2000, C 364/01).

1299 Die Charta der Grundrechte wurde zur Eröffnung der Regierungskonferenz von Nizza am 7. Dezember 2000 feierlich proklamiert, erlangte jedoch nach dem Scheitern des Europäischen Verfassungsvertrages erst am 1. Dezember 2009 gemeinsam mit dem Inkrafttreten des Vertrags von Lissabon verbindliche Rechtskraft für die Mitgliedstaaten. Für Großbritannien, Polen und Tschechien gelten jedoch Sonderregeln, vgl. Protokoll über die Anwendung der Charta der Grundrechte der Europäischen Union auf Polen und das Vereinigte Königreich, AB1. EG 2007, C 306/156; erstreckt auf die Tschechische Republik gemäß Protokoll über die Anwendung der Charta der Grundrechte der Europäischen Union auf die Tschechische Republik, Schlussfolgerungen des Vorsitzes, Europäischer Rat vom 29./30.10.2009, Anlage I, EU-Nachrichten, Dokumentation Nr. 3/2009, S. 12 f.; Rat der EU, Dok. 13840/11 vom 6.9.2011.

1300 Ausführlich zur Entstehung der Charta der Grundrechte Barriga, Die Entstehung der Charta, S. $20 \mathrm{ff}$. 
52 und 53 GRC. Art. 52 Abs. 3 GRC ordnet für die Rechte der Charta, die jenen der EMRK entsprechen, an, dass ihnen mindestens die Bedeutung und Tragweite zugemessen werden muss, die ihnen nach der EMRK zukommt. Die EMRK wurde somit vom Grundrechte-Konvent als Mindeststandard festgelegt, das heißt der durch die Charta gewährleistete Schutz darf niemals geringer sein als der durch die EMRK gewährte Schutz. ${ }^{1301}$ Die Möglichkeit eines weitergehenden Schutzes durch Unionsrecht bleibt hierdurch hingegen unberührt. In Anlehnung an Art. 53 EMRK regelt Art. 53 GRC, dass keine Bestimmung der Charta als eine Einschränkung oder Verletzung von Menschenrechten und Grundfreiheiten auszulegen ist, die in der EMRK oder in den Verfassungen der Mitgliedstaaten anerkannt werden. Es treffen im Ergebnis also drei Günstigkeitsprinzipien aufeinander: jenes zugunsten eines weiterreichenden Unionsgrundrechts in Art. 52 Abs. 3 GRC, und jenes in Art. 53 GRC zugunsten von Rechten aus der EMRK und nationalstaatlichen Grundrechten. Für Mitgliedstaaten kommt das Günstigkeitsprinzip des Art. 53 EMRK hinzu, das sich auf günstigere Rechte nach Unionsrecht erstreckt. Im Verhältnis Staat-Bürger führen diese Günstigkeitsregelungen zu einer Steigerung des Schutzes auf das jeweils höchste Niveau. Gegenüber der unionalen Hoheitsgewalt oder gegen Akte der Mitgliedstaaten bei der Durchführung des Unionsrechts findet hingegen eine solche automatische „Hochzonung“ der Chartarechte auf das jeweils höchste Schutzniveau nicht statt. Es bleibt ein geringerer Grundrechtsschutz zulässig, als ihn etwa nationale Verfassungen gegenüber der staatlichen Hoheitsgewalt gewähren, wenn und soweit der nationale Grundrechtsschutz ganz zurücktritt, mithin nur die Charta zur Anwendung gelangt. ${ }^{1302}$

1301 Vgl. Meyer/Borowsky, Charta der Grundrechte, Art. 53 Rn. 9. Zur Problematik der genauen Definition und Abgrenzung der Begriffe „Bedeutung und Tragweite" sowie zur Frage, wann ein Recht der Charta einem Recht der EMRK im Sinne dieser Norm „entspricht“, siehe Kober, Grundrechtsschutz in der EU, S. 203 ff.; Meyer/Borowsky, Charta der Grundrechte, Art. 52 Rn. 29 ff. Für eine Vielzahl von Grundrechten der Charta bestimmen jedoch ausdrücklich die Erläuterungen zur Charta der Grundrechte, ABl. EG 2007, C 303/17 (33 f.), dass ihnen dieselbe Bedeutung und Tragweite zukommt wie den in den entsprechenden Artikeln der EMRK gewährleisteten Rechten.

1302 Vgl. ausführlich zu den Günstigkeitsprinzipien und deren Wirkung Grabenwarter, EMRK, § 4 Rn. 11 ff.; Meyer/Borowsky, Charta der Grundrechte, Art. 53 Rn. 9. 
2. Inhaltliche Relevanz der Charta für das Urheberrecht

Die Charta der Grundrechte der Europäischen Union enthält in Art. 17 Abs. 1 eine ausdrückliche Regelung zum Schutz des Eigentums. Trotz der stark von Art. 1 des 1. Zusatzprotokolls zur EMRK abweichenden Formulierung lassen sich Art. 17 Abs. 1 GRC ebenfalls drei Grundprinzipien entnehmen. ${ }^{1303}$ Art. 17 Abs. 1 S. 1 GRC gewährleistet die Ausübung der mit dem Eigentum wesensmäßig verbundenen Rechte und betont so allgemein die freiheitsschützende Funktion der Eigentumsgarantie. Die zweite Grundregel, Art. 17 Abs. 1 S. 2 GRC, stellt bestimmte Bedingungen auf, unter denen eine Eigentumsentziehung zulässig ist. Als drittes erkennt Art. 17 Abs. 1 S. 3 GRC die Kompetenz des Gesetzgebers an, die Nutzung des Eigentums zu regeln, soweit dies für das Wohl der Allgemeinheit erforderlich ist. Art. 17 Abs. 2 GRC hebt schließlich hervor, dass das geistige Eigentum als Eigentum im Sinne des Art. 17 GRC anzusehen ist und grundrechtlichen Schutz genießt. ${ }^{1304}$ Die spezielle Hervorhebung des geistigen Eigentums als Schutzgegenstand der Eigentumsgarantie stellt lediglich eine ausdrückliche Anerkennung der Rechtsprechung des EGMR zur Eigentumsgarantie der EMRK dar ${ }^{1305}$ und wird mit der zunehmenden Bedeutung des geistigen Eigentums und dem abgeleiteten Gemeinschaftsrecht begründet. ${ }^{1306}$ Der Gewährleistungsgehalt stimmt jedoch trotz der gesonderten Erwähnung mit demjenigen des Art. 17 Abs. 1 GRC überein. ${ }^{1307}$ Die Gewährleistung des Art. 17 Abs. 1 GRC wiederum entspricht in Bedeutung und Tragweite dem Eigentumsschutz nach Art. 1 des 1. Zusatzprotokolls zur EMRK. ${ }^{1308}$ Bei der Ausformung des Schutzbereichs der

$1303 \mathrm{Zu}$ den drei in Art. 1 des 1. Zusatzprotokolls zur EMRK enthaltenen Grundprinzipien, siehe bereits oben 6. Kapitel, A.II.

1304 Kritisch zum (unglücklichen) offenen Wortlaut des Art. 17 Abs. 2 GRC, der anders als Art. 17 Abs. 1 GRC - die Grenzen der Gewährleistung des geistigen Eigentums nicht explizit nennt, Geiger, EIPR 2009, 31(3), 113 (115).

1305 Vgl. Meyer/Bernsdorff, Charta der Grundrechte, Art. 17 Rn. 15.

1306 Vgl. Erläuterungen zur Charta der Grundrechte, ABl. EG 2007, C 303/17 (23).

1307 Vgl. Frenz, Europäische Grundrechte, Rn. 2852; Tettinger/Stern/Depenheuer, GK Grundrechte-Charta, Art. 17 Rn. 29.

1308 Die Erläuterungen zur Charta der Grundrechte, ABl. EG 2007, C 303/17 (23), heben ausdrücklich hervor, dass der Eigentumsschutz nach Art. 17 GRC im Sinne des Art. 52 Abs. 3 GRC trotz des geänderten Wortlauts die gleiche Bedeutung und die gleiche Tragweite wie das in der EMRK garantierte Recht hat, wo- 
Eigentumsgarantie des Art. 17 GRC geben somit wesentlich die in der Rechtsprechung des EGMR entwickelten Grundsätze zu Umfang und Grenzen des Eigentumsschutzes nach der EMRK den Bedeutungsgehalt vor. Zudem dient die Rechtsprechung des EuGH, über die die gemeinsamen Verfassungsüberlieferungen der Mitgliedstaaten in der durch den EuGH judizierten Weise auf das Eigentumsrecht einwirken als Rechtserkenntnisquelle. ${ }^{1309}$

Unter Zugrundelegung des so vorgeprägten Schutzbereichs definiert Frenz Eigentum im Sinne des Art. 17 GRC als ,,jedes kraft eigener Leistung entstandene und nach den Rechtsvorschriften der Mitgliedstaaten einer Person zugeordnete oder in seiner Entstehung rechtlich abgesicherte Vermögensrecht einer jeden natürlichen oder juristischen Person, das die Substanz wirtschaftlicher Selbstbestimmung konstituiert und damit Grundlage wirtschaftlichen Freiheit ist". ${ }^{1310}$ Art. 17 GRC benennt zudem ausdrücklich den positiven Schutzbereich des Eigentumsrechts im Sinne einer aktiven Grundrechtsausübung. Danach hat jede Person das Recht, ihr rechtmäßig erworbenes Eigentum zu besitzen, zu nutzen, darüber zu verfügen und es zu vererben. Die positive Freiheit des Eigentumsrechts ergibt sich damit - anders als etwa bei Art. 14 GG - bereits aus der Charta selbst und muss nicht erst in den Umfang des Schutzbereichs des Eigentums hineindefiniert werden. ${ }^{1311}$

Ebenso wie Art. 1 des 1. Zusatzprotokolls zur EMRK sieht die Charta in ihrem Art. 17 Abs. 1 S. 3 ausdrücklich die Möglichkeit einer gesetzlichen Beschränkung des Eigentums aus Gründen des Allgemeinwohls vor. Nach dem Wortlaut des Art. 17 Abs. 1 S. 3 GRC müssen Nutzungsbeschränkungen ,nur“ zum Wohl der Allgemeinheit erforderlich sein. Nach ständiger Rechtsprechung des EuGH werden hingegen an die Zulässigkeit bloßer Nutzungsbeschränkungen des Eigentums strengere Anforderungen gestellt. Danach sind bloße Nutzungsbeschränkungen des Eigentums nur rechtmäßig, „sofern diese Beschränkungen tatsächlich dem Gemeinwohl dienenden Zielen der Europäischen Gemeinschaft entsprechen und nicht einen im Hinblick auf den verfolgten Zweck unverhältnismäßigen, nicht

bei nicht über die in der EMRK vorgesehenen Einschränkungen hinausgegangen werden darf. Die Formulierung sollte lediglich zeitgemäßer gestaltet werden.

1309 Vgl. dazu Frenz, Europäische Grundrechte, Rn. 2775 ff., 2819 f.

1310 Frenz, Europäische Grundrechte, Rn. 2864.

1311 Vgl. Frenz, Europäische Grundrechte, Rn. 2868. 
tragbaren Eingriff darstellen, der die so gewährleisteten Rechte in ihrem Wesensgehalt antastet". 1312 Dieser Formel entspricht die Formulierung der allgemeinen Schrankenregelung des Art. 52 Abs. 1 GRC. Diese ist daher zur Vermeidung von Wertungswidersprüchen bei der Einschränkung des Eigentumsrechts nach Art. 17 GRC mitzulesen. ${ }^{1313}$

Neben der Eigentumsgarantie des Art. 17 GRC kann als Schutzrecht zugunsten der Urheber bei der Ausgestaltung von Schrankenregelungen durch den Gesetzgeber insbesondere die durch Art. 13 GRC gewährte Freiheit der Kunst und Wissenschaft zu beachten sein. Diese leitet sich im Wesentlichen aus der Gedankenfreiheit und Freiheit der Meinungsäußerung ab und steht insofern in einem engen Zusammenhang mit den Gewährleistungen der Art. 10 („Gedanken-, Gewissens- und Religionsfreiheit") und Art. 11 GRC (,Freiheit der Meinungsäußerung und Informationsfreiheit"). ${ }^{1314}$ Die Rechtsprechung des EGMR zu Art. 10 EMRK kann daher zur Auslegung des Schutzbereichs der Kunst- und Wissenschaftsfreiheit nach Art. 13 GRC herangezogen werden. ${ }^{1315}$ Eine Einschrän-

1312 St. Rspr., vgl. nur EuGH, Urt. v. 28.4.1998, C-200/96, Slg. 1998, I-1953, Rn. 21 = GRUR Int. 1998, 596 (597) - Metronome Musik; Urt. v. 3.12.1998, C-368/96, Slg. 1998, I-7967, Rn. 79 - Generics.

1313 Ebenso Calliess/Ruffert/Calliess, EUV/AEUV, Art. 17 GRCh, Rn. 26; Ehlers/ Calliess, Europäische Grundrechte, § 16.4 Rn. 42; Frenz, Europäische Grundrechte, Rn. 2978; Jarass, EU-Grundrechte, § 22 Rn. 27; Rengeling/Szczekalla, Charta der Grundrechte, §20 Rn. 823; a.A. Meyer/Bernsdorff, Charta der Grundrechte, Art. 13 Rn. 19.

1314 Vgl. Erläuterungen zur Charta der Grundrechte, ABl. EG 2007, C 303/17 (22); Frenz, Europäische Grundrechte, Rn.2310; Meyer/Bernsdorff, Charta der Grundrechte, Art. 13 Rn. 12.

1315 Auch wenn die EMRK keine ausdrückliche Regelung zum Schutz der Kunst und Wissenschaft enthält, so ist doch allgemein anerkannt, dass von Art. 10 EMRK alle Kommunikationsformen geschützt sind und es so sehr weitgehende Überschneidungen zwischen den Schutzbereichen der Art.10 EMRK und Art. 13 GRC gibt. Nach Art. 10 EMRK ist etwa die Freiheit sich durch Mittel der Kunst auszudrücken ebenso geschützt wie die wissenschaftliche Lehre und Meinungsäußerung, etwa in Form der Freiheit (wissenschaftliche) Informationen aller Art zu empfangen und weiterzugeben, am wissenschaftlichen Diskurs frei teilzunehmen und sich in Form wissenschaftlicher Bücher und Beiträge auszudrücken und diese zu verbreiten; vgl. EGMR, Urt. v. 24.5.1988, Nr. 10737/84 = NJW 1989, 379 - Müller u.a../. Schweiz (Freiheit künstlerischer Meinungsäußerungen); Urt. v. 25.8.1998, Nr. 25181/94 - Hertel./. Schweiz (Freie Publikation einer Minderheitenmeinung in der Wissenschaft); Urt. v. 28.10.1999 (GrK), 
kungsmöglichkeit der in Art. 13 GRC garantierten Grundrechte sieht die Norm selbst nicht vor. Soweit sich jedoch die Gewährleistungen des Art. 13 GRC mit denjenigen der EMRK ,überschneiden“, ist der Maßstab für einschränkende Regelungen der speziellen Grundrechtsschranke des Art. 52 Abs. 3 S. 1 GRC zu entnehmen. ${ }^{1316}$ Da der Kunst- und Wissenschaftsfreiheit weitgehend die gleiche Bedeutung und Tragweite zukommt wie den entsprechenden Aspekten der durch die EMRK garantierten Freiheit der Meinungsäußerung, dürfen die möglichen Einschränkungen somit grundsätzlich nicht über die in Art. 10 Abs. 2 EMRK vorgesehenen Einschränkungen hinausgehen. ${ }^{1317}$ Außerhalb dieses Bereichs gilt Art. 52 Abs. 1 GRC, wonach unter Wahrung des Grundsatzes der VerhältnismäBigkeit und des Wesensgehaltes der nach der Charta anerkannten Rechte und Freiheiten gesetzliche Einschränkungen vorgenommen werden dürfen, wenn sie erforderlich sind und den von der Union anerkannten, dem Gemeinwohl dienenden Zielsetzungen oder den Erfordernissen des Schutzes der Rechte und Freiheiten Anderer tatsächlich entsprechen. ${ }^{1318}$

Nationale Vorschriften zur Ausgestaltung des Urheberrechts, insbesondere die Schrankenregelungen, müssen im Einklang mit der nun verbindlichen Charta der Grundrechte stehen, die das Eigentum - und ausdrücklich auch das geistige Eigentum - als europäisches Grundrecht schützt. Zudem enthält die Charta weitere Grundrechte, die den Urheber in seinem Schaf-

Nr. 28396/95 = NJW 2001, 1195 - Wille./. Liechtenstein (Freiheit der wissenschaftlichen Lehre); Urt. v. 10.5.2001 (GrK), Nr. 25781/94 - Zypern/Türkei (Zensur wissenschaftlicher Bücher); vgl. aus der Literatur Frenz, Europäische Grundrechte, Rn. 2319 ff.; Grabenwarter, EMRK, § 23 Rn. 2 ff.; Meyer-Ladewig, EMRK, Art. 10 Rn. 4 ff., 11 ff.

1316 Zum Verhältnis der beiden Grundrechtskataloge zueinander, siehe oben 6. Kapitel, A.III.1.

1317 Vgl. Erläuterungen zur Charta der Grundrechte, ABl. EG 2007, C 303/17 (21); Meyer/Bernsdorff, Charta der Grundrechte, Art. 13 Rn. 13.

1318 Die Formulierung des Art. 52 Abs. 1 GRC entspricht der Formel der st. Rspr. des EuGH, wonach bloße Nutzungsbeschränkungen aufgrund allgemeiner Grundsätze des Gemeinschaftsrechts gewährleisteter Rechtspositionen rechtmäBig sind, „sofern diese Beschränkungen tatsächlich dem Gemeinwohl dienenden Zielen der Europäischen Gemeinschaft entsprechen und nicht einen im Hinblick auf den verfolgten Zweck unverhältnismäßigen, nicht tragbaren Eingriff darstellen, der die so gewährleisteten Rechte in ihrem Wesensgehalt antastet", vgl. nur EuGH, Urt. v. 28.4.1998, C-200/96, Slg. 1998, I-1953, Rn. $21=$ GRUR Int. 1998, 596 (597) - Metronome Musik; Urt. v. 3.12.1998, C-368/96, Slg. 1998, I-7967, Rn. 79 - Generics. 
fen oder auch in der Verbindung zu seinem Werk schützen. Alle in der Charta anerkannten Freiheitsrechte sind jedoch entweder ausdrücklich so etwa das Eigentumsrecht des Art. 17 GRC $^{1319}$ - oder aber zumindest über die Regelung des Art. 52 GRC einschränkbar, wenn die Einschränkungen unter Wahrung des Grundsatzes der Verhältnismäßigkeit erforderlich sind und den von der Union anerkannten, dem Gemeinwohl dienenden Zielsetzungen oder den Erfordernissen des Schutzes der Rechte und Freiheiten Anderer tatsächlich entsprechen. Die Charta der Grundrechte steht daher einer (Neu-) Gestaltung der urheberrechtlichen Schranken nicht entgegen, solange diese sowohl die Interessen der Urheber als auch die Interessen der Allgemeinheit am Zugang zu urheberrechtlich geschützten Werken und an deren Nutzung berücksichtigt. Die in der Charta gewährten Rechte sind dabei zu einem möglichst schonenden Ausgleich zu bringen, wo sich verschiedene Interessen, denen Schutz nach der Charta zukommt, gegenüber stehen. Eine Einschränkung der Rechte der Urheber und auch der Werkmittler zugunsten der Allgemeinheit können insbesondere deren nach Art. 11 GRC geschützte Interessen der freien Meinungsäußerung und Information und auch das Recht auf Bildung nach Art. 14 GRC erforderlich machen.

\section{Revidierte Berner Übereinkunft (RB̈̈)}

Der älteste und zugleich wohl bedeutendste ${ }^{1320}$ Staatsvertrag auf dem Gebiet des (internationalen) Urheberrechts ist die Berner Übereinkunft zum Schutz von Werken der Literatur und Kunst vom 9. September 1886, die auch im Rahmen der Ausgestaltung der urheberrechtlichen Schranken entscheidend zu beachten ist. Die Berner Übereinkunft wurde mit dem Ziel einer kontinuierlichen Verbesserung des Urheberschutzes ${ }^{1321}$ mehrfach ergänzt und revidiert, weshalb sie üblicherweise als Revidierte Berner Über-

1319 Das Eigentumsrecht des Art. 17 GRC stellt neben Art. 8 GRC („Schutz personenbezogener Daten") das einzige Freiheitsrecht dar, das eine spezifische Schrankenregelung im Text der Vorschrift enthält.

1320 Die große Bedeutung der RBÜ spiegelt sich neben der Anzahl der Unterzeichnerstaaten auch in den zahlreichen Verweisungen in anderen internationalen Verträgen wider, insbesondere etwa in Art. 9 Abs. 1 TRIPS, durch den die urheberrechtlichen Bestimmungen der RBÜ pauschal in das TRIPS-Abkommen inkorporiert werden.

1321 Vgl. Art. 27 Abs. 1 RBÜ. 
einkunft (RBÜ) bezeichnet wird. ${ }^{1322}$ Eine Besonderheit der Konvention ist die Gründung eines Verbandes mit eigener Rechtspersönlichkeit ${ }^{1323}$ und eigenen Verwaltungsorganen. ${ }^{13241325}$ Seit Gründung der World Intellectual Property Organization (WIPO) im Jahre 1967 hat diese die Verwaltungsaufgaben der Union übernommen. ${ }^{1326}$ Während neben Deutschland nur Belgien, Frankreich, Großbritannien, Italien, die Schweiz, Spanien und Tunesien von Beginn an Mitglieder waren, gehören mittlerweile 166 Staaten der Revidierten Berner Übereinkunft an. ${ }^{1327}$

1322 Die ursprüngliche Fassung der Berner Übereinkunft (RGB1. 1887, S. 493) wurde erstmals am 4.5.1896 in Paris vervollständigt. Seit der ersten Revisionskonferenz in Berlin („Berliner Fassung vom 13.11.1908; RGB1. 1910, S. 965 (987)) wird allgemein von der „Revidierten Berner Übereinkunft“ gesprochen. Anschließend wurde die RBÜ erneut am 20.3.1914 in Bern vervollständigt (RGB1. 1920, S. 31 (137)) und am 2.6.1928 in Rom (RGBl. 1933 II, S. 889), am 26.6.1948 in Brüssel (BGBl. 1965 II, S. 1213), am 14.7.1967 in Stockholm (BGB1. 1970 II, S. 293 (348)) und zuletzt am 24.7.1971 in Paris (BGB1. 1973 II, S. 1069 (1071); BGB1. 1974 II, S. 165 und S. 1079) revidiert. Die Pariser Fassung der RBÜ trat am 10.10.1974 in Kraft. Dieser Darstellung wird - soweit nicht anders vermerkt - die Pariser Fassung von 1971 zugrunde gelegt. Zu den Änderungen durch die einzelnen Revisionskonferenzen, vgl. Delp, Recht des geistigen Schaffens, S. 346 ff. m.w.N.

1323 Vgl. Art. 1 RBÜ. Siehe ausführlich Ricketson/Ginsburg, International Copyright I, $5.69 \mathrm{ff}$.

1324 Vgl. Art. 22 ff. RBÜ.

1325 Die RBÜ folgt insofern dem Vorbild der Pariser Verbandsübereinkunft zum Schutz des gewerblichen Eigentums (PVÜ) vom 20.3.1883 (RGB1. 1903, S. 147), nach deren Art. 1 Abs. 1 ebenfalls ein Verband gegründet wurde. Zweck der Verbandskonzeption war es, die Konventionsgeltung unabhängig vom Bei- und Austritt einzelner Staaten zu gewährleisten; vgl. Ricketson/Ginsburg, International Copyright I, $5.60 \mathrm{ff}$.

1326 Vgl. Art. 4, 9 WIPO Convention, Art. 24 RBÜ.

1327 Stand: Mai 2013. Eine aktuelle Aufstellung der Verbandsländer findet sich auf der Website der WIPO unter http://www.wipo.int/treaties/en/ShowResults.jsp? treaty_id=15 [zuletzt abgerufen am 26.5.2013]. Da nicht alle Konventionsstaaten die Pariser Fassung ratifiziert haben, gilt im Verhältnis zweier Vertragsstaaten untereinander stets die jüngste gemeinsam ratifizierte Fassung, vgl. Art. 32 Abs. 1 S. 2 RBÜ. 


\section{Schutzsystem und Anwendungsbereich der RBÜ}

Ziel der RBÜ ist es, die Rechte der Urheber von Werken der Literatur und Kunst möglichst wirksam und gleichmäßig in allen Verbandsstaaten zu schützen. ${ }^{1328}$ Der Anwendungsbereich der Übereinkunft ist dabei zunächst allgemein durch urheber- und werkbezogene Anknüpfungspunkte bestimmt. Nach Art. 3 Abs. 1 RBÜ genießen Urheber, die einem Verbandsland angehören, Konventionsschutz für alle ihre Werke, gleich ob veröffentlicht oder unveröffentlicht. Urheber, die keinem Verbandsland angehören, genießen den Schutz hingegen nur für ihre zum ersten Mal in einem Verbandsland veröffentlichten Werke. Dass die Bezeichnung „Werke der Literatur und Kunst" im Sinne der Konvention weit zu verstehen ist, verdeutlicht Art. 2 Abs. 1 RBÜ, der beispielhaft die wesentlichen geschützten Werkarten aufzählt, ohne jedoch den Kreis der geschützten Werke auf die ausdrücklich genannten Werkarten zu begrenzen. ${ }^{1329}$ Der Werkbegriff ist vielmehr technologieneutral auszulegen und somit auch neueren Entwicklungen gegenüber offen. ${ }^{1330}$

Die Verbandsländer verpflichten sich nach Art. 36 Abs. 1 RBÜ, die notwendigen Maßnahmen zu ergreifen, um die Anwendung der Übereinkunft zu gewährleisten. Wie sie diese Verpflichtung erfüllen, ist ihnen jedoch freigestellt. Ein effektiver Schutz der Urheber soll im Wesentlichen durch zwei Grundprinzipien erreicht werden: den Grundsatz der Inländerbehandlung und die Gewährung konventionsrechtlicher Mindestrechte. Nach Art. 5 RBÜ werden die Urheber konventionsgeschützter Werke (Art. 3 RBÜ) in den Verbandsländern hinsichtlich des Schutzumfangs grundsätzlich inländischen Urhebern gleichgestellt. Der Verbandsschutz passt sich dabei flexibel der Fortentwicklung der nationalen Urheberrechte an, indem Art. 5 Abs. 1 RBÜ die Pflicht zur Inländerbehandlung explizit auch auf in

1328 Vgl. die Präambel der RBÜ.

1329 Vgl. Drexl, Entwicklungsmöglichkeiten, S. 49 ff.; Goldstein/Hugenholtz, International Copyright, S. 39 f.; Loewenheim/v.Lewinski, § 57 Rn.22; Ricketson/ Ginsburg, International Copyright I, $8.08 \mathrm{ff}$; Strömholm, Conflict of Laws, S. $15 \mathrm{ff}$. Es war und ist etwa streitig, ob auch Computerprogramme durch die RBÜ geschützt werden, bzw. ob die RBÜ die Mitgliedstaaten zum urheberrechtlichen Schutz von Computerprogrammen verpflichtet. Der Streit hat jedoch seit der ausdrücklichen Einbeziehung der Computerprogramme in Art. 10 TRIPS erheblich an praktischer Bedeutung verloren, vgl. dazu Dreier/Schulze, § 121 Rn. 7; Fromm/Nordemann/Nordemann-Schiffel, Vor $\S \S 120$ ff. Rn. 13.

1330 Vgl. v.Lewinski, International Copyright Law, 5.75. 
Zukunft gewährte Rechte bezieht. ${ }^{1331}$ Die RBÜ geht grundsätzlich davon aus, so einen angemessenen Schutz der Urheber in den Verbandsländern zu erreichen. Ist der Schutz dennoch nicht ausreichend, sollen die sogenannten Mindestrechte ${ }^{1332}$ ein gewisses Schutzniveau garantieren. ${ }^{1333}$

Die Urheber genießen für die konventionsgeschützten Werke in allen Verbandsländern, mit Ausnahme des Ursprungslandes, die von der Übereinkunft gewährten Rechte. Ein wesentliches Charakteristikum der RBÜ ist dabei, dass sich die Konventionsvorgaben auf das Urheberrecht für internationale Sachverhalte beschränken. Die RBÜ regelt den Schutz von Werken ausländischer Urheber und von Werken mit einem ausländischen Ursprungsland und ist daher auf rein inländische Sachverhalte nicht (unmittelbar) anwendbar. ${ }^{1334}$ Der Konventionsschutz durch Inländerbehand-

1331 Vgl. ausführlich zur Inländerbehandlung nach der RBÜ, Drexl, Entwicklungsmöglichkeiten, S. 44 ff.; Schack, Urheberrecht, Rn. 959 ff.

1332 Die RBÜ selbst verwendet den Begriff der „Mindestrechte“ nicht. Die in der RBÜ garantierten Ausschließlichkeitsrechte wurden jedoch stets als Garantie von Mindeststandards und nicht etwa im Sinne eines Maximalschutzes verstanden. Zur Klarstellung wurde im Rahmen der Berliner Revision von 1908 Art. 19 RBÜ eingefügt, der einen weitergehenden nationalen Schutz ausdrücklich zulässt. Vgl. ausführlich zu den durch die RBÜ garantierte „minimum rights“, v.Lewinski, International Copyright Law, 5.94 ff. m.w.N.

1333 Das Prinzip der Inländerbehandlung verhindert grundsätzlich lediglich eine Schlechterbehandlung in- und ausländischer Rechteinhaber. Einen adäquaten Schutz der Urheber in allen Verbandsstaaten vermag die Inländerbehandlung allein jedoch nicht zu gewährleisten, solange das nationale Recht einzelner Staaten auch die Inländer nur unzulänglich schützt. Zur Erreichung eines materiell gleichmäßigen und somit gerechten (Mindest-) Schutzes in allen Verbandsstaaten ist daher eine Ergänzung durch materielle Schutzprinzipien (hier die Mindestrechte) erforderlich. Ausführlich zum Prinzip der Inländerbehandlung und dessen Unvollkommenheit, Drexl, Entwicklungsmöglichkeiten, S. 21 f.

1334 Vgl. Fromm/Nordemann/Nordemann-Schiffel, Vor $\S 120$ ff. Rn. 10; Katzenberger, GRUR Int. 1995, 447 (454); Nordemann/Vinck/Hertin, Internationales Urheberrecht, Art. 5 RBÜ Rn. 3; Riesenhuber, ZUM 2003, 333 (335); Ulmer, GRUR Int. 1972, 429; Wandtke/Dietz, Urheberrecht, Kapitel 13 Rn. 21. Inländer können sich nach deutschem Recht somit nicht unmittelbar auf für sie gegenüber dem deutschen UrhG günstigeres Konventionsrecht berufen. Es ist jedoch auch bei der Anwendung und Auslegung nationalen Rechts in rein nationalen Sachverhalten davon auszugehen, dass der Gesetzgeber das innerstaatliche Recht dem Standard des Konventionsrechts zumindest angleichen wollte, um eine Benachteiligung von Inländern gegenüber konventionsgeschützten Ausländern zu vermeiden. Das nationale Recht ist daher auch bei rein inländischen Sachverhalten zumindest konventionsfreundlich auszulegen; vgl. Dreier/ 
lung und Mindestrechte gilt nach Art. 5 Abs. 1 RBÜ nicht im Ursprungsland; derjenige nur durch Inländerbehandlung aber auch im Ursprungsland, wenn der Urheber diesem Land nicht angehört (Art. 5 Abs. 3 S. 2 RBÜ). Art. 5 Abs. 3 S. 1 RBÜ stellt insoweit klar, dass es im Ursprungsland des Werkes im Übrigen bei der Anwendung der innerstaatlichen Rechtsvorschriften bleibt.

\section{Inhaltliche Relevanz der RBÜ für die Untersuchung}

Die als völkerrechtlicher Vertrag geschlossene Berner Übereinkunft begründet innerstaatlich kein übergeordnetes internationales Gemeinschaftsrecht, sondern hat den Rang eines einfachen Gesetzes. ${ }^{1335}$ Dennoch sind die Vorgaben der RBÜ bei der Anwendung und Ausgestaltung des deutschen Urheberrechts entscheidend zu beachten, insbesondere da das inländische Urheberrecht grundsätzlich konventionsfreundlich auszulegen ist. ${ }^{1336}$ Relevante Vorgaben enthält die RBÜ zum einen hinsichtlich des zu gewährenden Mindestbestandes und -standards von Ausschließlichkeitsrechten, zum anderen auch in Bezug auf deren Einschränkungsmöglichkeiten.

Als Mindestrechte gewährleistet die RBÜ unter anderem das Urheberpersönlichkeitsrecht in Form eines Namensnennungs- und Werkintegritätsrechts (Art. $6^{\text {bis }}$ RBÜ), das Übersetzungsrecht (Art. 8 RBÜ), das Vervielfältigungsrecht (Art. 9 Abs. 1 RBÜ), das Aufführungs-, Sende- und Vortragsrecht (Art. 11, 11 $1^{\text {bis }}, 11^{\text {ter }}$ RBÜ) und das Bearbeitungsrecht (Art. 12, 14 RBÜ). ${ }^{1337}$ Die Regelungen der RBÜ zu den Mindestrechten enthalten dabei nicht lediglich völkerrechtliche Verpflichtungen der Ver-

Schulze, Vor $\S \S 120$ ff. Rn. 25; Fromm/Nordemann/Nordemann-Schiffel, Vor $\S \S 120$ ff. Rn. 10; Riesenhuber, ZUM 2003, 333 (335 f.); Schricker/Loewenheim/Katzenberger, Vor $\S \S 120$ ff. Rn. 119, jeweils m.w.N.

1335 Vgl. BGHZ 64, 183 (191) - August Vierzehn; Z 72, 63 (67) - Jeannot; Ulmer, S. 66 f., 93; Nordemann/Vinck/Hertin, Internationales Urheberrecht, Einl. Rn. 15, 35.

1336 Vgl. dazu bereits oben Fn. 1331 sowie BGHZ 141, 13 (34) - Kopienversanddienst; Bornkamm, in: FS Erdmann, S. 29 (36); Nordemann/Vinck/Hertin, Internationales Urheberrecht, Einl. Rn. 35; Schricker/Loewenheim/Katzenberger, Vor $\S \S 120$ ff. Rn. 118 m.w.N.

1337 Ausführlich zu den einzelnen Mindestrechten, Drexl, Entwicklungsmöglichkeiten, S. 111 ff.; Katzenberger, in: FS Beier, S. 379 (382 ff.). 
bandsstaaten, sondern zugleich auch privatrechtliche Rechtssätze, die unmittelbare Grundlage individueller Rechte sein können, soweit sie nach ihrem Inhalt und ihrer Fassung hinreichend bestimmt sind, um von den nationalen Gerichten auf die privaten Rechtsbeziehungen zwischen Bürgern angewandt zu werden. ${ }^{1338}$ Man spricht daher auch von einem Schutz ,iure conventionis" ${ }^{1339}$ Eine solche unmittelbare Berufung auf die Mindestrechte der RBÜ erlangt insbesondere dann Relevanz, wenn der nationale Urheberrechtsschutz verglichen mit der RBÜ lückenhaft ist und so hinter den durch die RBÜ garantierten Rechten zurückbleibt. ${ }^{1340}$

1338 Vgl. BGHZ 11, 135 (138) - Lautsprecherübertragung; Baum, GRUR 1950, 437 (458 f.); Drexl, Entwicklungsmöglichkeiten, S. 28 f.; Fromm/Nordemann/Nordemann-Schiffel, Vor $\S \S 120$ ff. Rn. 11 m.w.N.

1339 Vgl. etwa Baum, GRUR 1949, 1 (9 ff.); Nordemann/Vinck/Hertin, Internationales Urheberrecht, Einl. Rn.21; Strömholm, Conflict of Laws, S. 24; Ulmer, S. 67.

1340 So könnte beispielsweise eine unmittelbare Berufung auf die urheberpersönlichkeitsrechtlichen Mindestrechte der RBÜ im Hinblick auf deren lückenhaften Schutz in den USA relevant werden. Nach der Regelung des $\$ 2$ (1), (2) des Berne Convention Implementation Act (BCIA) von 1988 und 17 U.S.C. $\S 104$ (c) soll jedoch eine unmittelbare innerstaatliche Anwendbarkeit der RBÜ und somit eine unmittelbare Berufung auf die Mindestrechte der RBÜ in den USA ausdrücklich ausgeschlossen sein. Ein ausreichender Schutz soll ausschließlich nach US-amerikanischem Bundes- und Landesrecht erfolgen, das nach Ansicht des US-amerikanischen Gesetzgebers ausreicht, um die Mindeststandards der RBÜ zugewährleisten. Entgegen der ausdrücklichen Feststellung in $\S 2$ (3) BCIA, das US-amerikanische Urheberrecht erfülle bereits alle Anforderungen der RBÜ, wird das Urheberpersönlichkeitsrecht in den USA jedoch tatsächlich nicht ausreichend, d.h. nicht entsprechend der Anforderungen des Art. $6^{\text {bis }}$ RBÜ, geschützt. Zur unzureichenden Umsetzung des urheberpersönlichkeitsrechtlichen Schutzes der RBÜ in den USA, siehe aus dem deutschen Schrifttum Baumgarten/Meyer, GRUR Int. 1989, 620 (622 f.); Dietz, GRUR Int. 1989, 627 (628 ff.); Peifer, ZUM 1993, 325 (329 ff.); Schack, Urheberrecht, Rn. 963 (der die Regelung des 17 U.S.C. $\$ 104$ (c) ausdrücklich für völkerrechtswidrig hält); aus dem amerikanischen Schrifttum ausführlich zur unzureichenden Umsetzung des Urheberpersönlichkeitsrechtsschutzes nach der RBÜ, siehe etwa Austin, 61 N.Y.U. Ann. Surv. Am. L. 111, 115 ff. (2005); Belanger, 3 Geo. Mason Independent L. Rev. 373, 387 ff. (1995); Brooks, 77 Cal. L. Rev. 1431, 1439 ff. (1989); Carpenter, 63 Wash. \& Lee L. Rev. 1601, 1612 ff. (2006); Chinni, 14 W. New Eng. L. Rev. 145, 161 ff. (1992); Ginsburg, 19 Cardozo Arts \& Ent. L.J. 9, 10 ff. (2001); Ginsburg/Kernochan, 13 Colum.-VLA J.L. \& Arts 1, 27 ff. (1989); Karakis, 5 Touro Int'l L. Rev. 105, 119 ff. (1994); Ludolph/Merenstein, 19 Stetson L. Rev. 201, 222 ff. (1989); Patry, On Copy- 
Auch die konventionseigenen Mindestrechte werden jedoch nicht schrankenlos gewährt. Erst aus einer Gesamtschau der Schranken und der Mindestrechte ergibt sich daher das dem Urheber durch die RBÜ gewährte (Mindest-)Schutzniveau. Jede Schrankenregelung legt fest, wie weit der Gesetzgeber bei der Schaffung von Schranken gehen darf. Geht er darüber hinaus, entfalten die konventionsrechtlichen Mindestrechte ihre Wirkung. ${ }^{1341}$ Die RBÜ enthält eine Vielzahl historisch gewachsener ${ }^{1342}$ und infolge dessen größtenteils unsystematischer und kaum aufeinander abgestimmter Schrankenbestimmungen, die entweder unmittelbar konventionsrechtlich geregelt oder der Gesetzgebung der Verbandsländer vorbehalten

right, § 16:3; Ross, 68 N.C. L. Rev. 363, 364 ff. (1990). Die urheberpersönlichkeitsrechtlichen Schutzlücken wurden auch durch den in Anlehnung an die einzelstaatlichen Gesetze zum Schutz der moral rights erlassenen Visual Artists Rights Act (VARA) von 1990 (siehe dazu bereits oben 1. Kapitel, B.) nicht (vollständig) geschlossen; vgl. Baucks, ZUM 1992, 72 (76); Damich, 39 Cath. U. L. Rev. 945, 996 (1990); Dieselhorst, GRUR Int. 1992, 902 (909 f.); Ginsburg, GRUR Int. 1991, 593 (598 ff.); Laky, 14 Seton Hall J. Sports \& Ent. L. 441, 448 ff., 470 ff. (2004); Peifer, ZUM 1993, 325 (351 f.). Durch die Entscheidung des U.S. Supreme Court in der Rechtssache Dastar Corp. v. Twentieth Century Fox Film Corp. (539 U.S. 23 (2003)) ist die Schutzlücke des US-amerikanischen Urheberrechts gegenüber der RBÜ sogar erneut vergrößert worden, da das Gericht den Anwendungsbereich der Regelung des § 43(a) des Lanham Act deutlich einschränkte. §43(a) Lanham Act regelt einen (lauterkeitsrechtlichen) Anspruch wegen irreführender Herkunftsangaben, der bis zur Entscheidung des U.S. Supreme Court (auch bereits vor dem Beitritt der USA zur RBÜ) von der instanzgerichtlichen Rechtsprechung zum Schutz gewisser (urheber-)persönlichkeitsrechtlicher Interessen im Hinblick auf die Namensnennung herangezogen wurde; siehe etwa Smith v. Montoro, 648 F.2d 602, 603 (9th Cir. 1981); Waldman Publishing Corp. v. Landoll, Inc., 43 F.3d 775, 781 (2d Cir. 1994); Batiste v. Island Records, Inc., 179 F.3d 217, 225 (5th Cir. 1999); Murray Hill Publications, Inc. v. ABC Communications, Inc., 264 F.3d 622, 634 (6th Cir. 2001); Lipscher v. LRP Publications, Inc., 266 F.3d 1305, 1313 (11th Cir. 2001). Vgl. zur Entscheidung Dastar v. Twentieth Century Fox und deren Folgen für die Übereinstimmung des US-amerikanischen Rechts mit den Vorgaben der RBÜ, Goldstein, IIC 2008, 216 (218) und ausführlich Davidson, 38 Cornell Int'1 L.J. 583, 614 ff. (2005); Hughes, 2007 Utah L. Rev. 659, 678 ff.; Laky, 14 Seton Hall J. Sports \& Ent. L. 441, 462 ff. (2004); Landau, 61 N.Y.U. Ann. Surv. Am. L. 273, 289 ff. (2005).

1341 Vgl. Rehbinder, in: FS 100 Jahre RBÜ, S. 357 (358).

1342 Zur historischen Entwicklung der Schrankentatbestände der RBÜ, siehe Cohen Jehoram, EIPR 2005, 27(10), 359 (359 ff.). 
sind. ${ }^{1343}$ Die Schrankenregelungen lassen sich dabei am ehesten in drei Kategorien systematisieren: ${ }^{1344}$ Zum einen enthält die RBÜ eine Reihe einzeln aufgezählter und größtenteils genau definierter Beschränkungen der Urheberrechte. ${ }^{1345}$ Diese sollen hier aufgrund ihrer zumeist spezifischen Anwendungsbereiche nicht näher dargestellt werden. Spezifische Vorgaben hinsichtlich der Einschränkung von Ausschließlichkeitsrechten der Urheber im digitalen Kontext enthalten diese Regelungen zudem nicht, da die letzte Revision 1971 - und somit im Wesentlichen vor dem „Aufstieg“ der digitalen Technologie - stattfand. Zweitens wurden einige generalklauselartige ,allgemeine Billigkeitsregeln“1346 in die RBÜ aufgenommen. Drittens schließlich enthält die RBÜ einige ungeschriebene, stillschweigend vereinbarte Schranken, die es den Verbandsstaaten erlauben, in bestimmten Fällen urheberrechtliche Schranken vorzusehen. ${ }^{1347}$ Auch Letztere sollen hier nicht weiter vertieft werden. Von Interesse für die vorliegende Untersuchung sind hingegen die zweitgenannten, generalklauselartigen Schrankenregelungen der RBÜ.

Art. 10 Abs. 1 RBÜ regelt das Zitatrecht unter Verwendung offener Rechtsbegriffe. Die Norm erklärt Zitate für zulässig, sofern sie „anständigen Gepflogenheiten“ entsprechen und hinsichtlich ihres Umfangs „durch den Zweck gerechtfertigt" sind. Der bei der Revision in Stockholm 1967 eingefügte Begriff der ,anständigen Gepflogenheiten“ ist der deutschen Rechtssprache fremd und bedarf daher der Auslegung. Offensichtlich ist

1343 Ein Überblick und eine Kategorisierung der Schrankenregelungen der RBÜ finden sich bei Dreier, in: Schricker, Informationsgesellschaft, S. 143 ff. Für eine ausführliche Darstellung der Schrankenregelungen der RBÜ, vgl. Rehbinder, in: FS 100 Jahre RBÜ, S. 357 ff.; Ricketson/Ginsburg, International Copyright I, $13.01 \mathrm{ff}$.

1344 Ähnlich Rehse, Ungeschriebene Schranken, S. $144 \mathrm{f}$.

1345 Vgl. etwa die Beschränkungen der urheberrechtlichen Ausschließlichkeitsrechte hinsichtlich politischer Reden und Reden in Gerichtsverhandlungen, Art. $2^{\text {bis }}$ RBÜ, zugunsten von Presse und Rundfunk, Art. $10^{\text {bis }}$ Abs. 1 RBÜ, oder anlässlich der Berichterstattung über Tagesereignisse, Art. $10^{\text {bis }}$ Abs. 2 RBÜ. Ausführlich zu diesen und weiteren Schrankenregelungen der RBÜ, Ricketson/Ginsburg, International Copyright I, $13.47 \mathrm{ff}$.

1346 Cohen Jehoram, GRUR Int. 2001, 807 (807 f.).

1347 Ausführlich zu diesen üblicherweise als ,implied exceptions“ oder „minor reservations" bezeichneten Ausnahmen v.Lewinski, International Copyright Law, 5.199 ff.; Nordemann/Vinck/Hertin, Internationales Urheberrecht, Art. 8 RBÜ Rn. 3; Ricketson, IPQ 1999, 56 (72 f.); Ricketson/Ginsburg, International Copyright I, $13.78 \mathrm{ff}$. 
jedoch, dass die Formulierung den nationalen Gesetzgebern und auch den Gerichten einen erheblichen Spielraum bei der Beurteilung des zulässigen Umfangs eines Zitats belässt. ${ }^{1348}$ Etwas deutlicher werden Sinn und Inhalt der Regelung des Art. 10 Abs. 1 RBÜ bei Betrachtung der englischen Sprachfassung, nach der eine ,fair practice" verlangt wird, womit die Regelung deutlich in die Nähe des US-amerikanischen Fair Use gerückt wird. ${ }^{1349}$ Es verwundert somit nicht, dass auch die in der Literatur zur Bestimmung der ,anständigen Gepflogenheiten“ beziehungsweise der ,fair practice" vorgeschlagenen Kriterien den im Rahmen der Fair Use-Prüfung $\mathrm{zu}$ berücksichtigenden Kriterien weitgehend entsprechen. ${ }^{1350}$ Die zweite ausdrücklich in Art. 10 Abs. 1 RBÜ normierte Voraussetzung - die Rechtfertigung des Umfangs „durch den Zweck“ - stellt keine Beschränkung mit eigenständiger Bedeutung dar. Vielmehr handelt es sich dabei letztlich lediglich um die Festschreibung eines im Rahmen der Einzelfallbewertung der „Anständigkeit“ zu berücksichtigenden Faktors. ${ }^{1351}$ Ein-

1348 Vgl. Masouyé, RBÜ, Art. 10 Rn. 10.4; Ricketson, IPQ 1999, 56 (64); vgl. auch Nordemann/Vinck/Hertin, Internationales Urheberrecht, Art. 10 RBÜ Rn. 1, die allerdings die Wortwahl der deutschen Sprachfassung kritisieren und zudem diese generalklauselartige Regelung aus Gründen mangelnder Rechtssicherheit für misslungen halten. Zum - zweifelhaften - Argument der fehlenden Rechtssicherheit von Generalklauseln siehe bereits oben S. $279 \mathrm{ff}$.

1349 Ein Blick auf den gesamten Wortlaut des Art. 10 Abs. 1 RBÜ verdeutlicht die Nähe dieser Regelung zum US-amerikanischen Konzept des Fair Use: "It shall be permissible to make quotations from a work which has already been lawfully made available to the public, provided that their making is compatible with fair practice, and their extent does not exceed that justified by the purpose, including quotations from newspaper articles and periodicals in the form of press summaries." [Hervorhebungen durch den Verfasser]. Zum zulässigen Umfang von Zitaten im Rahmen des Fair Use nach US-amerikanischem Copyright, vgl. Harper \& Row v. Nation Enterprises, 471 U.S. 539 (1985); siehe dazu bereits oben 2. Kapitel, C.I.2.b)bb).

1350 Nordemann/Vinck/Hertin, Internationales Urheberrecht, Art. 10 RBÜ Rn. 1 etwa nennen als zu berücksichtigende Faktoren die (potentielle) Beeinträchtigung der normalen Auswertung des Werkes, das Potential eines Zitates, das zitierte Werk zu ersetzen, sowie den Umfang der zitierten Passage im Verhältnis zum Gesamtwerk. Ähnlich Ricketson, IPQ 1999, 56 (65); Ricketson/Ginsburg, International Copyright I, 13.41, die zur Auslegung von Art. 10 Abs. 1 RBÜ ausdrücklich die im Dreistufentest des Art. 9 Abs. 2 RBÜ genannten Kriterien heranziehen wollen; zustimmend Cohen Jehoram, EIPR 2005, $27(10), 359$ (361); v.Lewinski, International Copyright Law, 5.165.

1351 Ebenso Nordemann/Vinck/Hertin, Internationales Urheberrecht, Art. 10 RBÜ Rn. 1. 
schränkend wirkt jedoch das Erfordernis, dass lediglich aus einem „der Öffentlichkeit erlaubterweise zugänglich gemachten Werk" zitiert werden kann. Dies setzt entsprechend dem deutschen Zitatrecht eine vorherige Veröffentlichung des Werkes voraus. ${ }^{1352}$ Die in Art. 10 Abs. 2 RBÜ geregelte Schranke zugunsten einer Benutzung von Werken zur Veranschaulichung des (schulischen) Unterrichts ist in vergleichbarer Weise offen formuliert. Auch hier wird auf die ,,anständigen Gepflogenheiten“ und einen „durch den Zweck gerechtfertigten Umfang“ der Nutzung abgestellt.

Die für diese Untersuchung wichtigste, als umfassende Generalklausel ausgestaltete flexible Schrankenregelung der RBÜ findet sich schließlich in Art. 9 Abs. 2 RBÜ, der die erste - allerdings auf die Einschränkung des Vervielfältigungsrechts beschränkte - Kodifizierung des urheberrechtlichen Dreistufentests darstellt. Nach Art. 9 Abs. 2 RBÜ kommt es nicht in erster Linie auf den Zweck einer Beschränkung, sondern auf deren Umstände an. ${ }^{1353}$ Das Vervielfältigungsrecht kann danach in gewissen Sonderfällen unter der Voraussetzung beschränkt werden, dass weder die normale Auswertung des Werkes beeinträchtigt noch die berechtigten Interessen des Urhebers unzumutbar verletzt werden. Auf die Regelung des Art. 9 Abs. 2 RBÜ wird später näher zurückzukommen sein. ${ }^{1354}$

Alle vorgenannten Schrankenregelungen der RBÜ sind jedoch, abgesehen vom Zitatrecht, ${ }^{1355}$ nicht als zwingende Vorgaben zur Beschränkung des Urheberrechts ausgestaltet, sondern eröffnen den Verbandsstaaten lediglich die Möglichkeit, Urheberrechtsschranken einzuführen und so in die Mindestrechte der RBÜ einzugreifen. ${ }^{1356}$ Somit lässt die RBÜ dem

1352 Vgl. Nordemann/Vinck/Hertin, Internationales Urheberrecht, Art. 10 RBÜ Rn. 1. Das Erfordernis der vorherigen Veröffentlichung stellt eine deutliche Abweichung vom US-amerikanischen Fair Use dar. Nach 17 U.S.C. $\$ 107$ a.E. schließt die Tatsache, dass das verwendete Werk unveröffentlicht war, die Anerkennung eines Fair Use nicht per se aus; vgl. grundlegend Harper \& Row v. Nation Enterprises, 471 U.S. 539 (1985); siehe dazu bereits oben 2. Kapitel, C.I. 2.b)bb).

1353 Vgl. Ricketson, IPQ 1999, 56 (69).

1354 Siehe dazu ausführlich unten 6. Kapitel, C.

1355 Zum zwingenden Charakter des Zitatrechts, vgl. v.Lewinski, International Copyright Law, 5.163; Nordemann/Vinck/Hertin, Internationales Urheberrecht, Art. 10 RBÜ Rn. 3; Ricketson/Ginsburg, International Copyright I, 13.38.

1356 Vgl. Rehbinder, in: FS 100 Jahre RBÜ, S. 357 (358). Diese Regelungstechnik wird im Anschluss an Hoffmann, Berner Übereinkunft, S. 12, auch als „,halbstarres System“ bezeichnet, vgl. Nordemann/Vinck/Hertin, Internationales Urheberrecht, Einl. Rn. 24; Rehbinder, in: FS 100 Jahre RBÜ, S. 357 (358). 
Gesetzgeber trotz festgeschriebener Mindestrechte und der Schrankenvorgaben nicht unerheblichen Spielraum bei der Ausgestaltung des Urheberrechts und seiner Schranken. Insbesondere wird ein bestimmtes Modell jeweils nicht vorgeschrieben. Es ist dem nationalen Gesetzgeber freigestellt, wie er die aus dem Vertrag erwachsenden Verpflichtungen erfüllt. Bei Einhaltung der durch die RBÜ vorgegebenen Rahmenbedingungen steht diese der Einführung einer Schrankengeneralklausel oder der Verknüpfung eines Kataloges von Urheberrechtsschranken mit einer generalklauselartigen Regelung daher nicht grundsätzlich entgegen. ${ }^{1357}$

\section{Welturheberrechtsabkommen (WUA)}

Vorgaben zu Umfang und Reichweite des urheberrechtlichen Schutzes enthält ebenfalls das nach dem Zweiten Weltkrieg auf Betreiben der UNESCO zustande gekommene Welturheberrechtsabkommen (WUA) vom 6. September 1952. ${ }^{1358}$ Dem Vorbild der RBÜ folgend, basiert dieser völkerrechtliche Vertrag auf dem Prinzip der Inländerbehandlung und der Gewährleistung von Mindestrechten, ${ }^{1359}$ gewährt den Vertragsstaaten jedoch auch erheblichen Spielraum in Bezug auf deren Beschränkung. ${ }^{1360}$ Das WUA kann in der vorliegenden Untersuchung allerdings außer Betracht bleiben, da es sowohl hinsichtlich des etablierten Schutzniveaus als auch hinsichtlich seiner praktischen Bedeutung deutlich hinter der RBÜ zurückbleibt. Ziel des WUA war es, Staaten, die nicht Verbandsmitglieder der RBÜ waren und die das hohe Schutzniveau der RBÜ nicht erreichten, in ein internationales Schutzsystem einzubinden. Mit dem Beitritt der USA, der Sowjetunion und auch der Volksrepublik China zur RBÜ hat

1357 So auch Rehse, Ungeschriebene Schranken, S. 145; Reinbothe, in: FS Dittrich, S. 251 (254).

1358 BGB1. 1955 II, S. 101; für die Bundesrepublik Deutschland in Kraft seit dem 16.9.1955, BGBl. 1955 II, S. 892. Das WUA wurde in Paris am 24.7.1971 revidiert; BGBl. 1973 II, S. 1111, für die Bundesrepublik Deutschland in Kraft seit dem 10.7.1974, BGB1. 1974 II, S. 1309.

1359 Ausführlich zum Inländerbehandlungsgrundsatz und den Mindestschutzrechten des WUA, Drexl, Entwicklungsmöglichkeiten, S. 166 ff., 181 ff.

1360 Als zentrale Norm enthält Art. IV ${ }^{\text {bis }}$ Abs. 2 WUA eine generalklauselartige Schrankenermächtigung; vgl. Dreier, in: Schricker, Informationsgesellschaft, S. 145; Nordemann/Vinck/Hertin, Internationales Urheberrecht, Art. IV ${ }^{\text {bis }}$ WUA Rn. 5; Ulmer, S. 309. 
das WUA seine praktische Bedeutung jedoch weitestgehend verloren. ${ }^{1361}$ Im Verhältnis der RBÜ-Verbandsstaaten untereinander genießt die RBÜ nach Art. XVII WUA ohnehin Vorrang vor den Regelungen des WUA.

\section{Rom-Abkommen (RA)}

Als Ergänzung zu RBÜ und WUA, die ausschließlich den Schutz der Rechte der Urheber zum Gegenstand haben, wurde am 26. Oktober 1961 das sogenannte Rom-Abkommen (RA) ${ }^{1362}$ als erstes mehrseitiges internationales Übereinkommen zum Schutz der ausübenden Künstler, Tonträgerhersteller und Sendeunternehmen verabschiedet. Das Rom-Abkommen war das Ergebnis mehr als 35-jähriger zäher Verhandlungen über die Rechtsnatur und Angemessenheit des Schutzes der Leistungen der vorgenannten Gruppen ${ }^{1363}$ und trat schließlich am 18. Mai 1964 in Kraft. ${ }^{1364}$ Der Beitritt zum Rom-Abkommen ist gemäß Art. 23, 24 Abs. 2 RA nur solchen Staaten gestattet, die den Urhebern bereits als Mitglieder der RBÜ oder des WUA gewisse Rechte zugestehen. Scheidet ein Staat aus der

1361 Vgl. Schack, Urheberrecht, Rn. 967; zustimmend Hohagen, Vervielfältigung zum eigenen Gebrauch, S. $49 \mathrm{f}$.

1362 Internationales Abkommen über den Schutz der ausübenden Künstler, der Hersteller von Tonträgern und der Sendeunternehmen vom 26.10.1961, BGB1. 1965 II, S. 1245.

1363 Vgl. zur Entstehungsgeschichte des Rom-Abkommens Kaminstein, UFITA 40 (1963), 99 ff.; Straus, GRUR Int. 1985, 19 (21 f.); Ulmer, GRUR Int. 1961, $569 \mathrm{ff}$.

1364 Am 17.2.1964 hinterlegte Mexiko als sechstes Land seine Ratifikationsurkunde, so dass das RA gemäß seines Art. 25 am 18.5.1964 in Kraft trat. Deutschland hat das Rom-Abkommen mit Wirkung zum 21.10.1966 ratifiziert, BGB1. 1966 II, S. 1473. Dem RA gehören mittlerweile 91 Staaten an (Stand: Mai 2013; die aktuelle Zahl der Mitgliedstaaten ist unter http://www.wipo.int/ treaties/en/ip/rome/index.html abrufbar [zuletzt abgerufen am 26.5.2013]). Viele (wirtschaftlich) bedeutsame Staaten, insbesondere die USA, sind dem RA jedoch bislang ferngeblieben. Da ein Beitritt in näherer Zukunft zudem unwahrscheinlich erscheint, bestehen im Bereich der Leistungsschutzrechte auf internationaler Ebene weiterhin deutlich größere Schutzlücken als auf dem Gebiet des Urheberrechts. Ausführlich zum lückenhaften Schutz in- und ausländischer ausübender Künstler und Tonträgerhersteller in den USA, siehe Wagner-Silva Tarouca, Urheberschutz der ausübenden Künstler und Tonträgerhersteller in den USA (1983) sowie die neuere Darstellung von Apel, Der ausübende Musiker im Recht Deutschlands und der USA (2011). 
RBÜ oder dem WUA aus, so endet nach Art. 28 Abs. 4 RA auch seine Mitgliedschaft im Rom-Abkommen. So soll eine Schlechterstellung von Urhebern gegenüber den ausübenden Künstlern durch das Abkommen verhindert werden. Dies verdeutlicht auch Art. 1 RA, der bestimmt, dass das Rom-Abkommen den Schutz der Urheberrechte unberührt lässt und ihn in keiner Weise beeinträchtigt. ${ }^{1365}$

Ähnlich wie die RBÜ und das WUA beruht das Schutzsystem des Rom-Abkommens im Wesentlichen auf dem Grundsatz der Inländerbehandlung 1366 und der Gewährung gewisser Mindestschutzrechte. ${ }^{1367}$ Parallel zur Regelung des Art. 20 RBÜ gestattet Art. 22 RA den Vertragsstaaten untereinander Zusatz- und Erweiterungsabkommen abzuschließen, die über die im Rom-Abkommen gewährten Rechte hinausgehende Rechte gewähren können, jedoch nicht im Widerspruch zu den Gewährleistungen des Rom-Abkommens stehen dürfen. Es ist dabei jedoch zu beachten, dass die Mindestrechte im Rom-Abkommen deutlich schwächer ausgestaltet sind als in der RBÜ. Zwar sind die gewährten Verwertungsrechte grundsätzlich als ausschließliche Rechte konzipiert, Art. 15 RA gewährt den nationalen Gesetzgebern jedoch weitreichenden Spielraum bei der Ausgestaltung der Beschränkungen der Verwertungsrechte. ${ }^{1368}$ Zum einen ist es dem Gesetzgeber überlassen, Schranken zugunsten der in Art. 15 Abs. 1 RA explizit genannten Nutzungen - etwa der privaten Benutzung oder der Benutzung zu Forschungs- und Unterrichtszwecken - einzuführen, zum anderen sieht Art. 15 Abs. 2 RA die Möglichkeit weitergehender Schranken vor: Jedem Vertragsstaat wird zugestanden, für den Schutz der ausübenden Künstler, der Tonträgerhersteller und der Sendeunternehmen die gleichen Beschränkungen vorzusehen, wie sie in seiner Gesetzgebung für

1365 Vgl. Möhring/Nicolini/Hartmann, Vor $\S 120$ ff. Rn. 80; Rehbinder, Urheberrecht, Rn. 994.

1366 Das Rom-Abkommen knüpft jedoch im Gegensatz zu den urheberrechtlichen Konventionen nicht an die Staatsangehörigkeit des ausübenden Künstlers, sondern in erster Linie an den Ort der Darbietung an, vgl. Art. 4 lit. a RA.

1367 Ausführlich zur Inländerbehandlung nach dem Rom-Abkommen und zu den gewährten Mindestrechten, vgl. Beining, Schutz ausübender Künstler, S. 74, 76 ff.; Dreier, GRUR Int. 1988, 753 (756 ff.); Drexl, Entwicklungsmöglichkeiten, S. 211 ff., 220 ff.; Knies, Rechte der Tonträgerhersteller, S. 7 ff., 12 ff.; Straus, GRUR Int. 1985, 19 (23 ff.); Ulmer, GRUR Int. 1961, 569 (576 ff.).

1368 Zur Entstehungsgeschichte und zur Diskussion über die Gesetzestechnik des Art. 15 RA, vgl. Ulmer, GRUR Int. 1961, 569 (590 f.). 
den Schutz des Urheberrechts vorgesehen sind. ${ }^{1369}$ Anders als in der RBÜ werden für diese Schranken keine unmittelbaren materiellen Voraussetzungen festgelegt. Lediglich über die Verweisung auf die in den Urheberrechtsgesetzen vorgesehenen Ausnahmen kommen mittelbar die Voraussetzungen der RBÜ zur Anwendung. ${ }^{1370}$ Zusammenfassend lässt sich somit festhalten, dass im nationalen Recht nur solche Schranken des durch das Rom-Abkommen gewährten Schutzes zulässig sind, die entweder eine Parallele im nationalen Recht zum Schutze der Urheber finden oder die sich unter eine der in Art. 15 Abs. 1 RA explizit genannten Ausnahmen subsumieren lassen. ${ }^{1371}$

\section{TRIPS-Übereinkommen}

Das Übereinkommen über handelsbezogene Aspekte der Rechte des geistigen Eigentums (TRIPS), ${ }^{1372}$ das am 15. April 1994 als integraler Bestandteil des Übereinkommens zur Errichtung der Welthandelsorganisation $^{1373}$ in Marrakesch unterzeichnet wurde und am 1. Januar 1995 für Deutschland in Kraft trat, ${ }^{1374}$ stellt neben der RBÜ - gemessen an der An-

1369 Für Zwangslizenzen enthält allerdings Art. 15 Abs. 2 S. 2 RA eine Ausnahme. Deren Zulässigkeit kann nicht alleine mit entsprechenden Vorschriften im nationalen Urheberrecht begründet werden.

1370 Dieser Regelung liegt der Gedanke zugrunde, dass das Urheberrecht systematisch den Leistungsschutzrechten vorrangig sei und diesen daher kein höherrangiger Schutz gewährt werden könne. Konfligieren jedoch Urheberrechte mit Rechten der durch das Rom-Abkommen geschützten Interessengruppen, so setzen sich aufgrund des in Art. 1 RA statuierten absoluten Vorrangs des Urheberrechts vor den verwandten Schutzrechten letztlich stets die Interessen der Urheber durch. Vgl. dazu Drexl, Entwicklungsmöglichkeiten, S. 232; Knies, Rechte der Tonträgerhersteller, S. 17.

1371 Vgl. Drexl, Entwicklungsmöglichkeiten, S. 233.

1372 Agreement on Trade-Related Aspects of Intellectual Property Rights, BGB1. 1994 II, S. 1565 (englisch), S. 1730 (deutsch).

1373 Agreement establishing the World Trade Organisation vom 15.4.1994, BGBl. 1994 II, S. 1442 (englisch), S. 1625 (deutsch).

1374 Vgl. Art. 1 und Art. 10 des Gesetzes zu dem Übereinkommen vom 15. April 1994 zur Errichtung der Welthandelsorganisation und zur Änderung anderer Gesetze vom 30.8.1994, BGBl. 1994 II, S. 1438 und Bekanntmachung vom 18. Mai 1995, BGB1. 1995 II, S. 456. Die BRD hat damit nicht von der in Art. 65 Abs. 1 TRIPS vorgesehenen Möglichkeit Gebrauch gemacht, das Abkommen erst nach einer Übergangsfrist von einem Jahr nach dem Inkrafttreten 
zahl der Unterzeichnerstaaten ${ }^{1375}$ und dem gewährleisteten Schutzniveau die bedeutendste internationale Vereinbarung auf dem Gebiet des Immaterialgüterrechts dar. Ziel des TRIPS-Übereinkommens ist es, Verzerrungen und Behinderungen des internationalen Handels durch die Anerkennung der wachsenden internationalen Bedeutung der Rechte des geistigen Eigentums und durch Maßnahmen zur Sicherstellung, dass die Ausübung dieser Rechte nicht zu einer Behinderung des Handels werden kann, zu verringern. ${ }^{1376}$ Der Schutz und die Durchsetzung von Rechten des geistigen Eigentums sollen dabei sowohl zur Förderung der technischen Innovation als auch zur Weitergabe und Verbreitung von Technologie beitragen. Sie sollen dem beiderseitigen Vorteil der Erzeuger und der Nutzer technischen Wissens dienen, in einer dem gesellschaftlichen und wirtschaftlichen Wohl zuträglichen Weise erfolgen und einen Ausgleich zwischen Rechten und Pflichten herstellen. ${ }^{1377}$ Diese Zielbestimmungen sind bei der Auslegung des TRIPS-Übereinkommens zu beachten. ${ }^{1378}$

\section{Schutzsystem und Anwendungsbereich des TRIPS-Übereinkommens}

In einem ersten Teil regelt das TRIPS-Übereinkommen einige allgemeine Bestimmungen und Grundprinzipien als Grundlage des Schutzes der Immaterialgüterrechte (Art. 1 bis 8 TRIPS). Auch dem TRIPS-Übereinkommen liegt nach Art. 3 TRIPS der Grundsatz der Inländerbehandlung zugrunde, wobei gemäß Art. 3 Abs. 1 S. 1 TRIPS die Inländerbehandlung nach TRIPS denselben Ausnahmen unterliegt wie diejenige nach der RBÜ. Der Inländerbehandlungsgrundsatz entfaltet dabei sowohl Wirkung

des WTO-Übereinkommens zum 1.1.1996 in Kraft zu setzen; zum Streit über den Zeitpunkt des Inkrafttretens des TRIPS, vgl. nur Braun, GRUR Int. 1997, 427 (427 f.) m.w.N.

1375 Derzeit gehören der WTO 159 Mitgliedstaaten an (Stand: Mai 2013), für die somit auch das TRIPS-Übereinkommen verbindlich ist. Eine aktuelle Liste aller Mitgliedstaaten ist abrufbar unter: http:/www.wto.org/english/thewto_e/ whatis_e/tif_e/org6_e.htm [zuletzt abgerufen am 26.5.2013]. Neben Deutschland ist auch die Europäische Union als solche Mitglied der WTO.

1376 Vgl. die Präambel zum TRIPS-Übereinkommen. Ausführlich zum Zweck des TRIPS-Übereinkommens Frankel, 1 WIPO J. 2009, 35 (39 ff.).

1377 Vgl. Art. 7 TRIPS.

1378 Ausführlich zu den bei der Auslegung und Anwendung der TRIPS-Bestimmungen zu berücksichtigenden Interessen Haas, TRIPS-Abkommen, S. 104 ff. 
für die materiellen Rechte des TRIPS als auch für die TRIPS-Regelungen zur Rechtsdurchsetzung. ${ }^{1379}$ Ein Novum auf dem Gebiet des internationalen Immaterialgüterrechtsschutzes durch multilaterale Abkommen stellt die Implementierung des Meistbegünstigungsgrundsatzes in Art. 4 TRIPS nach dem Vorbild des Art. I Abs. 1 GATT ${ }^{1380}$ dar. ${ }^{1381}$ Danach sind alle TRIPS-Mitgliedstaaten verpflichtet, allen Ausländern aus TRIPS-Staaten den jeweils national höchsten Ausländern gewährten Schutz zu sichern. So soll die willkürliche Diskriminierung eines ausländischen Urhebers gegenüber einem aus einem anderen Staat stammenden Urheber verhindert werden. ${ }^{1382}$ Art. 1 Abs. 1 S. 2 TRIPS schließlich verdeutlicht, dass die Regelungen des TRIPS-Übereinkommens als zwingende Mindestschutzvorschriften ausgestaltet sind, über die die Mitgliedstaaten hinausgehen dürfen, soweit dies nicht den Zielen des Übereinkommens zuwiderläuft.

In seinem zweiten Teil enthält das TRIPS-Übereinkommen „Normen betreffend die Verfügbarkeit, den Umfang und die Ausübung von Rechten des geistigen Eigentums“; es regelt also detailliert die Mindeststandards

1379 Vgl. Duggal, TRIPs-Übereinkommen, S. 65; Katzenberger, GRUR Int. 1995, 447 (460); Reichman, 29 Int'l Law. 345, 348 ff. (1995), jeweils m.w.N.

1380 Zur Meistbegünstigungsklausel des Art. I Abs. 1 GATT siehe statt vieler ausführlich Drexl, Entwicklungsmöglichkeiten, S. 257 ff. sowie Hufbauer/Shelton Erb/Starr, 12 Law \& Pol'y Int'l Bus. 59, 62 ff. (1980), jeweils m.w.N.

$1381 \mathrm{Zu}$ Meistbegünstigungsklauseln in früheren bilateralen Abkommen zum Schutz des geistigen Eigentums Dölemeyer, UFITA 123 (1993), 53 (60); Drexl, Entwicklungsmöglichkeiten, S. 341 f., jeweils m.w.N.

1382 Vgl. ausführlich zum Zweck des Meistbegünstigungsgrundsatzes in TRIPS, Elfring, Geistiges Eigentum in der Welthandelsordnung, S. $66 \mathrm{ff}$.; Gervais, TRIPS Agreement, 2.48 ff.; Stoll/Busche/Arend/Elfring/Arend, WTO, Art. 4 TRIPS Rn. 5 f., jeweils m.w.N. Lückenlos durchgeführt würde das Meistbegünstigungsprinzip jedoch dazu führen, dass TRIPS-Mitglieder am höchsten Schutzniveau aller bestehenden und zukünftigen Urheberrechtsabkommen partizipieren würden, an denen auch nur ein einziger anderer TRIPS-Mitgliedstaat beteiligt ist, ohne diesen Abkommen selbst beitreten und ohne selbst einen weitergehenden Schutz als den TRIPS-Mindestschutz gewähren zu müssen. Eine solche ausnahmslose Anwendung des Meistbegünstigungsprinzips könnte wegen eines möglichen Trittbrettfahrereffekts zu einem nicht unerheblichen Hindernis für den Abschluss zukünftiger Abkommen werden. Zum ,free riding“ als Gefahr des Meistbegünstigungsprinzips, vgl. Buck, Geistiges Eigentum und Völkerrecht, S. 87 f.; Drexl, Entwicklungsmöglichkeiten, S. 355 f.; Dünnwald, ZUM 1996, 725 (726); Duggal, TRIPs-Übereinkommen, S. 67; Howard/Reinbothe, EIPR 1991, 13(5), 157 (159); Katzenberger, GRUR Int. 1995, 447 (461); Rehbinder/Staehelin, UFITA 127 (1995), 5 (14); Reinbothe, GRUR Int. 1992, 707 (713); ders., ZUM 1996, 735 (740 f.); Ullrich, GRUR Int. 1995, 623 (633). 
für einzelne Schutzkategorien. Das Urheberrecht und bestimmte verwandte Schutzrechte werden in Art. 9 bis 14 TRIPS geregelt. Art. 9 Abs. 1 S. 1 TRIPS inkorporiert ausdrücklich die zentralen Bestimmungen der Art. 1 bis 21 RBÜ (in der Pariser Fassung) und verpflichtet so die Mitgliedstaaten zur Einhaltung des hohen Schutzniveaus der materiellen Bestimmungen der RBÜ. Nach Art. 9 Abs. 1 S. 2 TRIPS umfasst diese Verpflichtung jedoch nicht das in Art. $6^{\text {bis }}$ RBÜ geregelte Urheberpersönlichkeitsrecht. ${ }^{1383}$ Ergänzend zur Übernahme des materiellen Gehalts der RBÜ werden in den Art. 10 bis 12 TRIPS darüber hinausgehende Mindestrechte eingeführt. Man spricht insoweit allgemein von einem „Bern-Plus“-Ansatz. ${ }^{1384}$

2. Inhaltliche Relevanz des TRIPS-Übereinkommens für die Untersuchung

Besondere Relevanz für die vorliegende Untersuchung erlangt das TRIPSÜbereinkommen aufgrund der Schrankenregelung des Art. 13 TRIPS. Nach Art. 13 TRIPS ist es den Mitgliedstaaten gestattet, die durch TRIPS gewährleisteten Mindestrechte in bestimmten Sonderfällen zu beschränken, soweit dadurch weder die normale Auswertung des Werkes beeinträchtigt, noch die berechtigten Interessen des Rechtsinhabers unzumutbar verletzt werden. TRIPS übernimmt somit die Voraussetzungen des auf das Vervielfältigungsrecht bezogenen Dreistufentests des Art. 9 Abs. 2 RBÜ, erweitert dessen Anwendungsbereich jedoch horizontal auf die Beschränkung aller durch TRIPS und RBÜ gewährleisteten Verwertungsrechte. Art. 13 TRIPS stellt dabei keine unabhängige Ausnahme zu den in der RBÜ enthaltenen Beschränkungsmöglichkeiten der Mindestrechte dar, sondern ist - um eine Aushöhlung der spezifischen Schrankenvorgaben der RBÜ zu vermeiden - vielmehr als zusätzliches Erfordernis für alle

1383 Nach Art. 2 Abs. 2 TRIPS bleiben die Verpflichtungen der TRIPS- und WTOMitglieder untereinander aus der RBÜ durch die materiellen Bestimmungen des TRIPS-Übereinkommens unberührt. Die RBÜ bleibt daher ausdrücklich neben TRIPS wirksam und anwendbar; vgl. dazu Katzenberger, GRUR Int. 1995, 447 (456). Die Verpflichtung der RBÜ-Verbandsstaaten zum Schutz des Urheberpersönlichkeitsrechts nach Art. $6^{\text {bis }}$ RBÜ wird somit durch das TRIPS-Übereinkommen nicht eingeschränkt; vgl. Reinbothe, ZUM 1996, 735 (736).

1384 Siehe statt vieler Reinbothe, GRUR Int. 1992, 707 (709). 
Ausnahmen zu verstehen, die bereits unter der RBÜ bestehen. ${ }^{1385}$ In einem ersten Schritt ist daher zu prüfen, ob eine nationale Beschränkung mit der RBÜ vereinbar ist. Entspricht die nationale Regelung diesen Anforderungen, ist sie in einem zweiten Schritt zusätzlich an den Vorgaben des Dreistufentests des Art. 13 TRIPS zu messen. ${ }^{1386}$ Auf die Vorgaben des Dreistufentests wird im Einzelnen zurückzukommen sein. ${ }^{1387}$ Neben der Erstreckung des Dreistufentest auf alle Verwertungsrechte geht Art. 13 TRIPS auch noch in einem weiteren Aspekt über die Schrankenbestimmungen der RBÜ hinaus: Anders als im Rahmen der RBÜ, über deren Einhaltung die Verbandsländer selbst wachen, können die urheberrechtlichen Bestimmungen des TRIPS-Übereinkommens zum Gegenstand eines WTO-Streitbeilegungsverfahrens nach Art. 63, 64 TRIPS gemacht werden. ${ }^{1388}$ Weitere Vorgaben für die Beschränkung der urheberrechtlichen Ausschließlichkeitsrechte enthält das TRIPS-Übereinkommen nicht.

1385 Vgl. Cohen Jehoram, GRUR Int. 2001, 807 (808); ders., EIPR 2005, 27(10), 359 (361); Gervais, TRIPS Agreement, 2.119; Hohagen, Vervielfältigung zum eigenen Gebrauch, S. 87; Oliver, 25 Colum. J.L. \& Arts 119, 135 f. (2002); Ricketson, IPQ 1999, 56 (80); Sattler, Status quo, S. 49; Senftleben, GRUR Int. 2004, 200 (203); ders., Three-Step Test, S. 89 f.

1386 Vgl. Senftleben, GRUR Int. 2004, 200 (203) m.w.N.

1387 Siehe unten 6. Kapitel, C.

1388 Vgl. Bornkamm, in: FS Erdmann, S. 29 (39f.) m.w.N.; ausführlich (allgemein) zum WTO-Streitschlichtungsverfahren Dörmer, GRUR Int. 1998, 919 (920 ff.); Fromm-Russenschuck/Duggal, WTO und TRIPs, S. 30 ff.; Gervais, TRIPS Agreement, $2.468 \mathrm{ff}$.

Gegenstand des - von der EG anhängig gemachten - ersten (und bisher einzigen) urheberrechtlichen Schlichtungsverfahrens war die Frage der Vereinbarkeit der US-amerikanischen Schrankenregelung des 17 U.S.C. $§ 110$ (5) (A) und (B) zugunsten der vergütungsfreien öffentlichen Wiedergabe von Musikwerken durch ein einzelnes Radiogerät (sog. ,homestyle exemption") und in Restaurantund Geschäftsräumen (sog. „business exemption“) mit Art.9 Abs. 1 TRIPS i.V.m. Art. 11 und $11^{\text {bis }}$ RBÜ. Während die Schiedsstelle die sog. ,homestyle exemption" für mit dem Dreistufentest in Art. 13 TRIPS vereinbar hielt, befand sie, die Regelung des 17 U.S.C. $§ 110$ (5) (B) sei mit dem Dreistufentest unvereinbar, und empfahl den USA daher eine entsprechende Änderung des Copyright Act; vgl. WTO-Panel Report, WT/DS160/R vom 15.6.2000, § 7.1-2. Nachgekommen sind die USA dieser Aufforderung allerdings bis heute nicht. Dies verdeutlicht sowohl die Stärken als auch die Grenzen und Schwächen derartiger Schlichtungsverfahren: Zum einen hat das Verfahren maßgeblich zur Klärung der Reichweite und Bedeutung der Einzelkriterien des Dreistufentests nach TRIPS beigetragen (siehe dazu näher unten 6. Kapitel, C.), zum anderen hat die Entscheidung der Schiedsstelle lediglich Empfehlungscharakter, so dass 
Die Vorgaben des TRIPS-Übereinkommens sind bei der Ausgestaltung und Auslegung des deutschen Urheberrechts zwingend zu beachten. Zum einen hat das TRIPS-Übereinkommen - wie die RBÜ - aufgrund des Zustimmungsgesetzes innerstaatlich den Rang eines einfachen Gesetzes. Die urheberrechtlichen Bestimmungen stellen unmittelbar geltendes Recht dar, an dem sich auch die Schrankenbestimmungen des deutschen Urheberrechtsgesetzes messen lassen müssen, da die urheberrechtlichen Regelungen des TRIPS-Übereinkommens nach Inhalt, Zweck und Fassung hinreichend bestimmt sind. ${ }^{1389}$ Zum anderen ist zu beachten, dass die Europäische Union - neben ihren Mitgliedstaaten - selbst Vertragspartei des WTO-Abkommens ist, so dass die Bestimmungen des TRIPS-Übereinkommens - und somit über die Verweisung des Art. 9 Abs. 1 S. 1 TRIPS auch die Regelungen der Art. 1 bis 21 RBÜ (mit Ausnahme des Art. $6^{\text {bis }}$ RBÜ) - unmittelbar anwendbares Gemeinschaftsrecht geworden sind, das

kein Mitgliedstaat zu einer erforderlichen Rechtsänderung gezwungen werden kann. Die Entscheidung über die Befolgung einer Panel-Entscheidung bleibt somit letztlich eine solche des rationalen, politischen Willens und der Interessen des ,verurteilten“ Staates, der ja ebenfalls aus eigenem Interesse und auf eigenes Betreiben Unterzeichner des TRIPS-Übereinkommens ist. Gerade politisch und wirtschaftlich mächtigere Staaten haben daher letztlich auch eine größere „Freiheit“, Entscheidungen nicht zu befolgen, ohne Konsequenzen befürchten zu müssen; siehe dazu grundlegend Goldsmith/Posner, The Limits of International Law, S. 185 ff. sowie speziell zur Befolgung von WTO-Entscheidungen Bello, 90 Am. J. Int'l L. 416, 417 f. (1996); Hudec, 8 Minn. J. Global Trade 1, 11 ff. (1999) und ders., 13 Cornell Int'1 L.J. 145, 159 f. (1980) (zum früheren GATTStreitschlichtungsverfahren). Zur mangelnden Durchsetzbarkeit der Entscheidungen der WTO-Schiedsstelle siehe auch Cohen Jehoram, EIPR 2005, 27(10), 359 (361 f.); Lee, 18 J. Intell. Prop. L. 401, 406 ff. (2011); v.Lewinski, International Copyright Law, 10.129 ff.; Poeppel, Neuordnung, S. 109; Schack, Urheberrecht, Rn. 1002. Ausführlich zum WTO-Verfahren „United States - Section 110(5) of the US Copyright Act" siehe etwa Brennan, IPQ 2002, 212; Christakos, 17 Berkeley Tech. L.J. 595, 600 ff. (2002); Dinwoodie, 62 Ohio St. L.J. 733, 748 ff. (2001); Gervais, TRIPS Agreement, 2.125 ff.; Ginsburg, RIDA 187 (2001), 3 (7 ff.); Goldmann, GRUR Int. 1999, 504 (507 ff.); dies., IIC 2001, 412 ff.; Helfer, 80 B.U. L. Rev. 93 (2000); Landau, 23 Ga. St. U. L. Rev. 847, 883 ff. (2007); sowie Oliver, 25 Colum. J.L. \& Arts 119, 125 ff., 139 ff. (2002) mit ausführlicher (und kritischer) Würdigung des von der EG eingeleiteten Verfahrens und dessen (möglicher) Folgen.

1389 Vgl. BGHZ 141, 13 (35) - Kopienversanddienst; Denkschrift der Bundesregierung zum WTO-Abkommen, BT-Drs. 12/7655 (neu), S. 335 (345); Bornkamm, in: FS Erdmann, S. 29 (40); Duggal, TRIPs-Übereinkommen, S. 103. 
Anwendungsvorrang vor nationalem Recht beansprucht und der Auslegungskompetenz des EuGH unterliegt. ${ }^{1390}$

\section{WIPO-,,Internet Treaties “ WCT und WPPT}

Von unmittelbarer Bedeutung für die vorliegende Untersuchung sind zudem der am 20. Dezember 1996 in Genf verabschiedete WIPO-Urheberrechtsvertrag (WCT) ${ }^{1391}$ und der am selben Tag verabschiedete WIPOVertrag über Darbietungen und Tonträger (WPPT). ${ }^{1392}$ Die beiden Übereinkommen stellen einen ersten bedeutenden Schritt auf dem Weg zu einem an die Herausforderungen moderner digitaler Technologien angepassten internationalen Schutz der Urheber- und Leistungsschutzrechte dar. Die Bedeutung der beiden oftmals zusammen als WIPO-,Internet Treaties“ bezeichneten ${ }^{1393}$ Vertragswerke spiegelt sich deutlich in dem Einfluss wider, den die Regelungen und Wertungen von WCT und WPPT auf spätere Gesetzgebungsaktivitäten im Bereich des Urheber- und Leistungsrechtsschutzes auf internationaler und nationaler Ebene hatten - insbesondere etwa auf die Gestaltung der InfoSoc-Richtlinie. ${ }^{1394}$

1390 Vgl. Drexl, GRUR Int. 1994, 777 (783, 787); ders., in: FS Dietz, S. 461 (476 f.); Schack, Urheberrecht, Rn. 1000.

1391 WIPO Copyright Treaty (WCT), BGBl. 2003 II, S. 755. Der WCT ist gemäß Art. 20 WCT mit der Hinterlegung der 30. Ratifikationsurkunde am 6.3.2002 in Kraft getreten. Derzeit haben 90 Staaten den WCT ratifiziert (Stand: Mai 2013; die aktuelle Zahl der Unterzeichnerstaaten ist unter http://www.wipo.int/ treaties/en/ip/wct/ abrufbar [zuletzt abgerufen am 26.5.2013]). Im Gegensatz zur RBÜ, der nur Staaten angehören können, steht nach Art. 17 Abs. 3 WCT der Beitritt zum WCT ausdrücklich auch der EG offen. Die EG hat den WCT nach Umsetzung der InfoSoc-Richtlinie in allen Mitgliedstaaten am 14.12.2009 ratifiziert. Am 14.3.2010 ist der WCT für die bisher noch fehlenden 16 Mitgliedstaaten der EU und für die EU selbst in Kraft getreten; siehe dazu v.Lewinski, GRUR-Prax. 2010, $49 \mathrm{ff}$.

1392 WIPO Performances and Phonograms Treaty (WPPT), BGB1. 2003 II, S. 770. Der WPPT ist gemäß Art. 29 WPPT mit der Hinterlegung der 30. Ratifikationsurkunde am 20.5.2002 in Kraft getreten. Derzeit haben 91 Staaten den WPPT ratifiziert (Stand: Mai 2013; die aktuelle Zahl der Unterzeichnerstaaten ist unter http://www.wipo.int/treaties/en/ip/wppt/ abrufbar [zuletzt abgerufen am 26.5.2013]). Am 14.3.2010 ist der WPPT für die bisher noch fehlenden 16 Mitgliedstaaten der EU und für die EU selbst in Kraft getreten.

1393 Siehe statt vieler Seville, EU IP Law, S. 19.

1394 Siehe dazu unten 6. Kapitel, B.III. 


\section{Schutzsystem und Anwendungsbereich von WCT und WPPT}

Da zum einen eine Anpassung der RBÜ an die seit ihrer letzten Revision im Jahre 1971 stark veränderten Herausforderungen für das Urheberrecht insbesondere durch die digitale Technologie notwendig erschien, zum anderen jedoch die für eine solche Revision nach Art. 27 Abs. 3 RBÜ erforderliche Einstimmigkeit aller Verbandsmitglieder unerreichbar schien, ${ }^{1395}$ wurde als Weg zur Anpassung des Urheberrechts an die neuen technischen und wirtschaftlichen Entwicklungen der Abschluss eines Sonderabkommens im Sinne des Art. 20 RBÜ gewählt. Der WCT sollte somit als de facto-Revision der RBÜ der Sicherung effektiven und angemessenen Urheberrechtschutzes, insbesondere der Modernisierung des Schutzes nach der RBÜ durch Anpassung an die digitalen Verwertungstechniken, dienen und zugleich einen Ausgleich zwischen den Interessen der Urheber und denjenigen der Gesellschaft schaffen. ${ }^{1396}$ Als Sonderabkommen nach Art. 20 RBÜ konnten dabei Schutzniveau und Schutzumfang der RBÜ durch den WCT lediglich erhöht werden. ${ }^{1397}$ Als inhaltliche Ergänzung zur RBÜ gewährt der WCT in den Artikeln 6 bis 8 die konventionseigenen Mindestrechte der Verbreitung, der gewerblichen Vermietung und als zentralen Punkt das Recht der öffentlichen Zugänglichmachung, einschließlich der Online-Übermittlung.

Der ähnlich aufgebaute WPPT, dessen Ziel die Anpassung des Rechtsschutzes der ausübenden Künstler und der Tonträgerhersteller an die geänderten Rahmenbedingungen durch weitreichende Ergänzungen des RomAbkommens ist, enthält im Vergleich zum vorbestehenden internationalen Recht sogar deutlich weitergehende Neuerungen. Der WPPT gewährt den ausübenden Künstlern (erstmals) konventionseigene Mindestrechte, insbesondere die selbständigen Verwertungsrechte der Verbreitung, Vermietung und Online-Übermittlung. Zudem finden durch Art. 5 WPPT Künstlerpersönlichkeitsrechte erstmals auf internationaler Ebene ausdrückliche

1395 Ausführlich zur Entstehungsgeschichte des WCT, insbesondere zur entscheidenden „Diplomatischen Konferenz zu bestimmten Fragen des Urheberrechts und verwandter Schutzrechte“, siehe v.Lewinski, GRUR Int. 1997, 667 (667ff.); v.Lewinksi/Gaster, ZUM 1997, 607 (608 ff.), jeweils m.w.N.

1396 Vgl. die Präambel des WCT. Siehe auch Reinbothe, ZEuP 2000, 5 (25).

1397 Vgl. die Klarstellung in Art. 1 Abs. 2 und 4 WCT. 
Anerkennung nach dem Vorbild des Art. $6^{\text {bis }}$ RBÜ. ${ }^{1398}$ Auch die Ausschließlichkeitsrechte der Tonträgerhersteller sind in den Artikeln 11 bis 14 WPPT deutlich ausführlicher geregelt als im Rom-Abkommen. ${ }^{1399}$

\section{Inhaltliche Relevanz von WCT und WPPT für die Untersuchung}

Den durch WCT und WPPT gewährten Rechten werden - anders als in der RBÜ oder im Rom-Abkommen - keine konkreten Schrankenvorgaben gegenübergestellt. Stattdessen soll der nach dem Muster von Art. 9 Abs. 2 RBÜ als generalklauselartige Schrankenregelung in Art. 10 WCT und Art. 16 WPPT $^{1400}$ aufgenommene Dreistufentest einen angemessenen Ausgleich zwischen den Interessen der Urheber beziehungsweise ausübenden Künstler und Tonträgerhersteller einerseits und denjenigen der Allgemeinheit andererseits herbeiführen. Anders als in der RBÜ ist der Dreistufentest in WCT und WPPT jedoch nicht auf die Beschränkung des Vervielfältigungsrechts begrenzt, sondern als allgemeine Schrankenregelung konzipiert. ${ }^{1401}$

Nach Art. 10 WCT ist es den Vertragsstaaten überlassen, über die Regelungen der RBÜ hinaus Schranken für das digitale Umfeld zu schaffen, solange diese den Vorgaben des Dreistufentests genügen. Während Art. 10

1398 Vgl. dazu und zu den einzelnen Ausschließlichkeitsrechten Beining, Schutz ausübender Künstler, S. 115 ff.; Brunner, Musikdistribution im Internet, S. 76 ff.; Kloth, Schutz der ausübenden Künstler, S. 205 ff.

1399 Ausführlich zu den Neuerungen hinsichtlich des Schutzes der ausübenden Künstler und der Tonträgerhersteller durch den WPPT v.Lewinksi/Gaster, ZUM 1997, 607 (620 ff.); v.Lewinski/Reinbothe, EIPR 2002, 24(4), 199 (201 f.); Reinbothe, EIPR 1997, 19(4), 171 (174 f.), jeweils m.w.N.

1400 Anders als Art. 14 Abs. 4 TRIPS, der zur Begrenzung der in Art. 14 Abs. 1 bis 3 TRIPS geregelten verwandten Schutzrechte auf die nach dem Rom-Abkommen zulässigen inhaltlichen Schranken Bezug nimmt, enthält der WPPT keinen Verweis auf das Rom-Abkommen. Art. 16 Abs. 1 WPPT folgt jedoch bezüglich der Bestimmung der zulässigen Beschränkungen dem Ansatz des Art. 15 Abs. 2 RA. So können die Rechte der ausübenden Künstler und Tonträgerhersteller in der Weise eingeschränkt werden, wie es das nationale Recht für die Rechte der Urheber vorsieht. Durch die Implementierung des Dreistufentests in Art. 16 Abs. 2 WPPT wird diese Befugnis allerdings eingeschränkt und so das Lösungsmodell des Art. 15 RA zumindest teilweise aufgegeben; vgl. v.Lewinksi/Gaster, ZUM 1997, 607 (618).

1401 Ausführlich zum Dreistufentest unten 6. Kapitel, C. 
Abs. 1 WCT dies in Bezug auf die durch den WCT selbst gewährten konventionseigenen Mindestrechte anordnet, beinhaltet Art. 10 Abs. 2 WCT die Verpflichtung, auch alle bei Anwendung der RBÜ zulässigen Schranken an diesem Maßstab zu messen. ${ }^{1402}$ Demnach muss der Dreistufentest des WCT bei der Schaffung neuer Schranken zusätzlich zu den Schrankenvorgaben der RBÜ eingehalten werden. ${ }^{1403}$ Zugleich kommt der Ausdehnung des Dreistufentests auf die RBÜ insofern Bedeutung zu, als dadurch eine übermäßig weite Auslegung und Ausdehnung der ausdrücklich in der RBÜ vorgesehenen Schranken verhindert wird. ${ }^{1404}$ Als Interpretationshilfe zu den einzelnen Bestimmungen des WCT wurden diesem von den Vertragsstaaten mehrere „vereinbarte Erklärungen“ angefügt. Die Erklärung zu Art. 10 WCT konkretisiert die vertraglichen Vorgaben für die Schrankengestaltung wie folgt: 1405

„Die Bestimmungen des Artikels 10 erlauben den Vertragsparteien, die in ihren Rechtsvorschriften bestehenden Ausnahmen und Beschränkungen, die nach der Berner Übereinkunft als zulässig angesehen werden, auf digitale Technologien anzuwenden und in angemessener Form auszudehnen. Diese Bestimmungen sind gleichermaßen dahin auszulegen, dass sie den Vertragsparteien erlauben, neue Ausnahmen und Beschränkungen zu konzipieren, die für Digitalnetze angemessen sind.

Der Anwendungsbereich der nach der Berner Übereinkunft zulässigen Ausnahmen und Beschränkungen wird durch Artikel 10 Absatz 2 weder reduziert noch erweitert."

Die Erklärung verdeutlicht, dass die Vertragsstaaten eine übermäßige Einengung ihres Spielraumes bei der Ausgestaltung von Schrankenregelungen im digitalen Umfeld und somit eine zu weitgehende Bindungswirkung des Dreistufentests vermeiden wollten. ${ }^{1406}$ Alle nach der RBÜ für die analoge Verwertung urheberrechtlich geschützter Werke zulässigen Schranken können auch im Bereich der digitalen Nutzungen vorgesehen werden, darüber hinaus dürfen die Vertragsstaaten aber die digitale Nutzung sogar

1402 Der Regelungsgehalt des Art. 10 Abs. 2 WCT entspricht somit Art. 13 TRIPS; vgl. Bornkamm, in: FS Erdmann, S. 29 (41); v.Lewinski, CR 1997, 438 (441); Poeppel, Neuordnung, S. 110; Reinbothe, in: FS Dittrich, S. 251 (262 ff.).

1403 Reinbothe, in: FS Dittrich, S. 251 (264 f.); zustimmend Poeppel, Neuordnung, S. 110; Schippan, Harmonisierung des Urheberrechts, S. 128.

1404 Vgl. v.Lewinski, CR 1997, 438 (441); v.Lewinski/Reinbothe, EIPR 2002, 24(4), 199 (201).

1405 Zitiert nach der deutschen Übersetzung in BGB1. 2003 II, S. 755 (769).

1406 Vgl. auch Geiger, EIPR 2007, 29(12), 486 (487 f.); ders., IIC 2009, 627 (640). 
noch großzügiger regeln. Es gilt jedoch zu beachten, dass der WCT das Schutzniveau der RBÜ nicht senken darf. Solche im digitalen Zusammenhang angemessenen neuen Schranken müssen deshalb stets im Einklang mit den Vorgaben des Dreistufentests des Art. 10 Abs. 1 WCT stehen. Die Ausdehnung des Dreistufentests auf sämtliche in der RBÜ vorgesehenen Ausnahmen kann daher nicht als Grundlage für weitere, nicht in der RBÜ vorgesehene Ausnahmen dienen. ${ }^{1407}$

\section{B. Schrankenvorgaben durch das europäische Gemeinschaftsrecht}

Neben den dargestellten konventionsrechtlichen Grenzen sind aufgrund der unionsrechtlichen Harmonisierungsbestrebungen im Urheberrecht bei der Ausgestaltung europäischer und nationaler urheberrechtlicher Schranken maßgeblich die Vorgaben des europäischen Gemeinschaftsrechts zu beachten.

Die Grenzen des gesetzgeberischen Ausgestaltungsspielraums in Bezug auf urheberrechtliche Schrankenregelungen definieren dabei zum einen die Kompetenzbestimmungen des Vertrags von Lissabon, zum anderen im Wesentlichen vier der inzwischen zahlreichen europäischen Richtlinien, namentlich die Computerprogramm-Richtlinie, die Vermiet- und Verleihrechts-Richtlinie, die Datenbank-Richtlinie und die InfoSoc-Richtlinie. Den genannten Richtlinien kommt neben dem durch sie vorgegebenen rechtlichen Rahmen für die Neugestaltung urheberrechtlicher Regelungen auch aufgrund des Gebots der richtlinienkonformen Auslegung des auf Richtlinien beruhenden nationalen Rechts besondere Bedeutung zu. Neben den drei erstgenannten Richtlinien, die auf einzelne Schutzgegenstände oder Verwertungsrechte beschränkt sind und somit lediglich bestimmte Teilaspekte des Urheberrechts oder einzelner Leistungsschutzrechte regeln, verdient die als übergreifende und umfassende Richtlinie ausgestaltete sogenannte InfoSoc-Richtlinie ein besonderes Augenmerk.

Durch seine Entscheidungen zur Auslegung des europäischen Primärund Sekundärrechts hat schließlich der EuGH ganz wesentlich zur europäischen Harmonisierung des Urheberrechts beigetragen. Seine Entscheidun-

1407 Vgl. Cohen Jehoram, EIPR 2005, 27(10), 359 (363); v.Lewinksi, GRUR Int. 1997, 667 (676); Oliver, 25 Colum. J.L. \& Arts 119, 137 (2002); Reinbothe, in: FS Dittrich, S. 251 (265 f.); Reinbothe/v.Lewinski, WIPO Treaties, Art. 10 WCT Rn. 31, 34 . 
gen zu den Grundfreiheiten und zum Diskriminierungsverbot ebenso wie zur Auslegung des Sekundärrechts, die den acquis communautaire im Urheberrecht maßgeblich geprägt haben, sind daher bei der Gestaltung des nationalen Rechts ebenfalls zu beachten.

\section{Gemeinschaftskompetenz zur Harmonisierung des Urheberrechts}

Auch wenn eine ausdrückliche entsprechende Kompetenznorm fehlte, war bereits vor der Verabschiedung des AEUV ${ }^{1408}$ anerkannt, dass die Europäische Gemeinschaft auch im Bereich des geistigen Eigentums über eine Zuständigkeit zum Erlass der zur Verwirklichung des Binnenmarktkonzeptes erforderlichen Maßnahmen einer Rechtsangleichung verfügte. ${ }^{1409}$ Als Rechtsgrundlagen für die bisherige schrittweise Harmonisierung des nationalen Urheberrechts durch europäische Richtlinien wurden - allein oder kumulativ - die Regelungen zur Dienstleistungsfreiheit (ex-Art. 47 Abs. 2 i.V.m. ex-Art. 55 EGV (Art. 53 Abs. 2 i.V.m. Art. 62 AEUV)), zum Gemeinsamen Markt (ex-Art. 94 EGV (Art. 115 AEUV)) und nach seiner Einfügung insbesondere ex-Art. 95 EGV (Art. 114 AEUV) herangezogen. ${ }^{1410}$ Eine ausdrückliche Kompetenzgrundlage für eine europäische Rechtsvereinheitlichung - die Ergänzung oder vollständige Ersetzung des nationalen Urheberrechts durch die Schaffung eines originären europäischen Gemeinschaftsurheberrechts - enthielt der EGV hingegen nicht. Dennoch wäre auch eine europäische Vollharmonisierung des Urheber-

1408 Vertrag über die Arbeitsweise der Europäischen Union (AEUV), AB1. Nr. C 115 v. 9.5.2008, S. 47-199.

1409 Siehe Grabitz/Hilf/Nettesheim/Stieper, Recht der EU, Art. 118 AEUV Rn. 2; Reinbothe, ZEuP 2000, 5 (9); Streinz, in: Systembildung im Europäischen Urheberrecht, S. 11 (13 ff., 32 ff.), jeweils m.w.N.

1410 Siehe Streinz, in: Systembildung im Europäischen Urheberrecht, S. 11 (32). Auch der EuGH hat betont, dass diese Rechtsgrundlagen für die Harmonisierung und Ergänzung der nationalen Schutzmechanismen des geistigen Eigentums genutzt werden können; siehe grundlegend EuGH, Urt. v. 13.7.1995, C-350/92, Slg. 1995, I-1985, Rn. 25 ff. = GRUR Int. 1995, 906 (907 f.) - Königreich Spanien./. Rat der Europäischen Union sowie die Tabakwerbeverbot-Entscheidung, EuGH, Urt. v. 5.10.2000, C-376/98, Slg. 2000, I-8419, Rn. 76 ff. = NJW 2000, 3701 (3702 f.) - Bundesrepublik Deutschland./. Europäisches Parlament und Rat der EU. Zur Kompetenzgrundlage für den Erlass der InfoSocRL siehe EuGH, Urt. v. 12.9.2006, C-479/04, Slg. 2006, I-8089, Rn. 29 ff. = GRUR Int. 2007, 237 (239) - Laserdisken ApS./. Kulturministeriet. 
rechts durch die Ersetzung nationaler Urheberrechtsregelungen durch eine oder mehrere EG-Verordnungen nach richtiger Auffassung als Maßnahme der Rechtsangleichung nach ex-Art. 95 EGV zulässig gewesen. ${ }^{1411}$

Eine ausdrückliche Kompetenzgrundlage für die Schaffung „europäischer Rechtstitel über einen einheitlichen Schutz der Rechte des geistigen Eigentums" besteht im europäischen Gemeinschaftsrecht nun erstmals mit der Regelung des Art. 118 AEUV, die weder im EGV noch im EUV eine Vorgängerregelung hat. ${ }^{1412}$ Art. 118 Abs. 1 AEUV ermächtigt den europäischen Gesetzgeber zum Erlass derjenigen Maßnahmen, die zur Schaffung eines entsprechenden europäischen Rechtstitels erforderlich sind. Zur Anwendung kommt das ordentliche Gesetzgebungsverfahren gemäß Art. 289 Abs. 1, 294 AEUV i.V.m. Art. 16 Abs. 3 EUV, nach dem eine qualifizierte Mehrheit im Rat ausreicht. Grundsätzlich kann die Rechtsvereinheitlichung im Wege sämtlicher in Art. 288 AEUV vorgesehener Rechtsakte (Verordnungen, Richtlinien, Beschlüsse, Empfehlungen und Stellungnahmen) erfolgen. Praktikabel erscheint die Einführung eines einheitlichen europäischen urheberrechtlichen Schutzrechtssystems jedoch nur im Wege einer Verordnung, da diese gemäß Art. 288 Abs. 2 AEUV unmittelbare Geltung in den Mitgliedstaaten entfalten würde. ${ }^{1413}$

Eine europäische Urheberrechtsverordnung böte die Gelegenheit, durch die vollständige Vereinheitlichung des materiellen europäischen Urheberrechts ein weiteres Anwachsen des bisher durch die nur bereichsspezifische Harmonisierung im Wege der Richtlinien entstandenen „kreuz und quer und schräg gewebten Flickenteppichs"1414 zu verhindern und die bisher in diesem „Teppich“ - etwa im Bereich des Schutzes der Urheberper-

1411 So auch Drasch, ZEuP 1998, 123 (132); Kaiser, Geistiges Eigentum und Gemeinschaftsrecht, S. 73; Leistner, Konsolidierung und Entwicklungsperspektive, S. 74 f.; Peifer, ZUM 2006, 1 (4 f.); Schack, ZGE 2009, 275 (283); a.A. Grabitz/ Hilf/Nettesheim/Stieper, Recht der EU, Art. 118 AEUV Rn. 2; Reinbothe, ZEuP 2000, 5 (8); Schieble, Kompetenz der EG, S. 146 f., 227.

1412 Siehe Calliess/Ruffert/Wichard, EUV/AEUV, Art. 118 AEUV Rn. 1; Grabitz/ Hilf/Nettesheim/Stieper, Recht der EU, Art. 118 AEUV Rn. 1.

1413 So auch Grabitz/Hilf/Nettesheim/Stieper, Recht der EU, Art. 118 AEUV Rn. 24; Schack, ZGE 2009, 275 (284). Siehe zur Opportunität der Einführung einer Schrankengeneralklausel im europäischen Recht im Rahmen einer Urheberrechtsverordnung näher unten 7. Kapitel, A.

1414 Schack, ZGE 2009, 275 (276). 
sönlichkeitsrechte - verbliebenen „Löcher“ zu stopfen. ${ }^{1415}$ Bis zu einer solchen - wünschenswerten und zugleich zur Erreichung eines funktionierenden Binnenmarktes unumgänglichen - Vereinheitlichung der Schutzvoraussetzungen, des Inhalts, der Inhaberschaft, der Dauer und auch der Schranken des Urheberrechts dürften jedoch selbst bei einem entsprechenden politischen Willen sicherlich noch Jahre oder Jahrzehnte vergehen. ${ }^{1416}$ Bis dahin müssen die nationalen Gesetzgeber den ihnen belassenen Gestaltungsspielraum unter Berücksichtigung der gemeinschaftsrechtlichen Vorgaben nutzen, um das Urheberrecht zukunftsfähig zu machen.

\section{Computerprogramm-Richtlinie, Vermiet- und Verleihrechts-Richtlinie und Datenbank-Richtlinie}

Die Ober- und Untergrenzen einer gesetzgeberischen Ausgestaltung des nationalen Urheberrechts werden maßgeblich durch europäische Richtlinien festgelegt. Neben der aufgrund ihrer zentralen Bedeutung für die Gestaltung urheberrechtlicher Schranken näher zu betrachtenden sogenannten InfoSoc-Richtlinie (unten III.) seien zunächst drei der InfoSoc-Richtli-

1415 Ebenfalls befürwortet von Grabitz/Hilf/Nettesheim/Stieper, Recht der EU, Art. 118 AEUV Rn. 37; Haedicke, Patente und Piraten, S. 99 f.; Hilty, IIC 2004, 760 (774 f.); Kreile/Becker, GRUR Int. 1994, 901 (904); Leistner, Konsolidierung und Entwicklungsperspektive, S. 64 ff.; ders., CMLR 46 (2009), 847 (883 f.); Lucas, in: FS Schricker II, S. 435 (444 f.); Schack, ZGE 2009, 275 (286 ff.); zurückhaltender v.Eechoud/Hugenholtz/v.Gompel/Guibault/Helberger, Harmonizing European Copyright Law, S. 316 ff.; Gaster, ZUM 2006, 8 (14); Hugenholtz/v.Eechoud/v.Gompel/Guibault/u.a., Recasting of Copyright, S. $218 \mathrm{ff}$; ablehnend v.Lewinski, in: Systembildung im Europäischen Urheberrecht, S. 215 (244); v.Lewinski/Walter, in: Walter/v.Lewinski, European Copyright Law, 16.0.147 f. Für einen Vorschlag für ein einheitliches europäisches Urheberrecht, siehe den im April 2010 vorgestellten Entwurf eines „European Copyright Code" des von namhaften europäischen Rechtswissenschaftlern ins Leben gerufenen „Wittem Project“, abrufbar unter: <www.copyrightcode.eu>; siehe dazu näher unten 7. Kapitel, A.II.1.

1416 Grabitz/Hilf/Nettesheim/Stieper, Recht der EU, Art. 118 AEUV Rn. 41 nimmt an, dass eine Kodifizierung frühestens in zehn Jahren Realität werden könnte. Schack, ZGE 2009, 275 (289) hält eine Realisierung eines einheitlichen europäischen Urheberrechts bis zum Jahre 2025 für möglich. Dreier, in: FS Loschelder, S. 47 (48) meint, der politische Wille und die Kraft reichten in der EU derzeit für eine weitreichende Harmonisierung des Urheberrechts im Wege einer Verordnung nicht aus. 
nie zeitlich vorausgehende Richtlinien erwähnt, die einzelne Teilaspekte der Schranken des Urheberrechtsschutzes regeln und die daher im Zusammenhang mit der vorliegenden Untersuchung ebenfalls relevant sind.

Mit der Richtlinie 91/250/EWG des Rates vom 14. Mai 1991 über den Rechtsschutz von Computerprogrammen (Computerprogramm-RL) ${ }^{1417}$ wurde der europäische Gesetzgeber erstmals auf dem Gebiet des Urheberrechts harmonisierend tätig. Die Richtlinie beinhaltete die Verpflichtung der Mitgliedstaaten, Computerprogramme dem urheberrechtlichen Schutz als Werke der Literatur zu unterstellen. ${ }^{1418} \mathrm{Zu}$ diesem Zweck harmonisierte die Richtlinie neben der Schutzvoraussetzung der „eigenen geistigen Schöpfung"1419 den Inhalt, die Schutzdauer und auch die Schranken des Urheberrechts an Computerprogrammen. ${ }^{1420}$ Durch die Richtlinie 2009/24/EG des Europäischen Parlaments und des Rates vom 23. April 2009 über den Rechtsschutz von Computerprogrammen wurde die ursprüngliche Computerprogramm-RL zwischenzeitlich aufgehoben, teilweise an die veränderte Rechtslage angepasst und in geänderter Form kodifiziert. ${ }^{1421}$ Die für die vorliegende Untersuchung relevanten Schrankenbestimmungen der Artikel 5 und 6 der Richtlinie blieben jedoch unverändert. Art. 5 Computerprogramm-RL räumt dem rechtmäßigen Erwerber eines Computerprogramms das (nicht disponible) ${ }^{1422}$ Recht ein, ohne die Zustimmung des Rechteinhabers Handlungen durchzuführen, die zur bestimmungsgemäßen Benutzung des Computerprogramms einschließlich der Fehlerbeseitigung erforderlich sind, sowie Sicherungskopien zu erstellen und das Funktionieren des Programms zu beobachten, zu untersuchen und zu testen. Der ebenfalls nicht disponible Art. 6 ComputerprogrammRL enthält Vorgaben zur Dekompilierung von Computerprogrammen zum Zwecke der Sicherung der Interoperabilität. ${ }^{1423}$

Die zweite europäische Richtlinie auf dem Gebiet des Urheberrechts mit Relevanz für die (Neu-)Regelung der urheberrechtlichen Schranken ist

1417 AB1. Nr. L 122 v. 17.5.1991, S. 42-46.

1418 Siehe Erw.-Grd. 6 zur Computerprogramm-RL.

1419 Siehe Art. 1 Abs. 3 Computerprogramm-RL.

$1420 \mathrm{Zu}$ Entstehungsgeschichte und Inhalt der Computerprogramm-RL siehe statt vieler Lehmann, GRUR Int. 1991, 327 ff.

1421 ABl. Nr. L 111 v. 5.5.2009, S. 16-22.

1422 Siehe Art. 8 S. 2 (vormals: Art. 9 Abs. 1 S. 2) Computerprogramm-RL.

1423 Für eine detaillierte Analyse der Art. 5 und 6 Computerprogramm-RL siehe statt vieler Blocher/Walter, in: Walter/v.Lewinski, European Copyright Law, 5.5.6 ff.; 5.6.20 ff. 
die Richtlinie 92/100/EWG des Rates vom 19. November 1992 zum Vermietrecht und Verleihrecht sowie zu bestimmten dem Urheberrecht verwandten Schutzrechten im Bereich des geistigen Eigentums (Vermiet- und Verleihrechts-RL). ${ }^{1424}$ Artikel 10 der Richtlinie regelt die Schranken des Schutzes der ausübenden Künstler, Tonträgerhersteller, Sendeunternehmen und Filmhersteller. Art. 10 Vermiet- und Verleihrechts-RL entspricht der Regelung des Art. 15 des Rom-Abkommens ${ }^{1425}$ und erlaubt den Mitgliedstaaten, Schranken für die private Nutzung, für die Benutzung von Auszügen für die Berichterstattung über Tagesereignisse, für ephemere Aufzeichnungen durch Sendeunternehmen mit eigenen Mitteln und für die Nutzung zum Zwecke der wissenschaftlichen Forschung und des Unterrichts vorzusehen. Nach Art. 10 Abs. 2 Vermiet- und VerleihrechtsRL können Mitgliedstaaten zudem die Schranken, die das nationale Recht für das Urheberrecht vorsieht, auch für die genannten verwandten Schutzrechte vorsehen. Durch Art. 11 Abs. 1 lit. b der InfoSoc-Richtlinie wurde schließlich Art. 10 Abs. 3 Vermiet- und Verleihrechts-RL dahingehend geändert, dass dieser nun den Dreistufentest ${ }^{1426}$ enthält. Sämtliche in der Vermiet- und Verleihrechts-Richtlinie genannten Schrankenbestimmungen sind jedoch optional, so dass eine unionsweite Harmonisierung der Schranken der verwandten Schutzrechte durch die Richtlinie nicht erfolgte. Mitgliedstaaten können frei entscheiden, ob und gegebenenfalls welche Schrankenbestimmungen sie einführen wollen. Werden jedoch Schrankenregelungen zu Lasten der Inhaber verwandter Schutzrechte im nationalen Recht verankert, so müssen sie den Voraussetzungen des Art. 10 Vermietund Verleihrechts-RL entsprechen und dürfen nicht über diese hinausgehen. ${ }^{1427}$ Die Vermiet- und Verleihrechts-RL beschränkt somit jedoch nicht die Möglichkeiten der Mitgliedstaaten, neue Schrankenbestimmungen einzuführen, die lediglich das Urheberrecht und nicht auch die verwandten Schutzrechte betreffen. ${ }^{1428}$ Die Einführung neuer Urheberrechtsschranken

1424 ABl. Nr. L 346 v. 27.11.1992, S. 61-66.

1425 Siehe zum Rom-Abkommen und zum Inhalt des Art. 15 RA oben 6. Kapitel, A.VI.

1426 Zum Dreistufentest siehe sogleich unten 6. Kapitel, C.

1427 Siehe v.Lewinski, in: Walter/v.Lewinski, European Copyright Law, 6.10.1. Zu Entstehungsgeschichte, Inhalt und Umsetzung der Vermiet- und VerleihrechtsRL in nationales Recht siehe v.Lewinski, GRUR Int. 1991, 104 ff.; dies., ZUM 1995, $442 \mathrm{ff}$.

1428 Vgl. Hugenholtz/v.Eechoud/v.Gompel/Guibault/u.a., Recasting of Copyright, S. 65 . 
steht allerdings unter dem Vorbehalt der Vereinbarkeit mit der InfoSocRichtlinie. ${ }^{1429}$

Als dritte relevante Harmonisierungsmaßnahme ist schließlich die Richtlinie 96/9/EG des Europäischen Parlaments und des Rates vom 11. März 1996 über den rechtlichen Schutz von Datenbanken (DatenbankRL) ${ }^{1430}$ zu nennen. Vorgaben für die Ausgestaltung von Schranken enthält die Datenbank-Richtlinie in Art. 6 Abs. 2. Bei den vier dort genannten Beschränkungen des Urheberrechts an einer Datenbank handelt es sich um eine abschließende Aufzählung optionaler Schrankentatbestände. ${ }^{1431}$ Diese können demnach vom nationalen Gesetzgeber vorgesehen werden, sind jedoch nicht zwingend in das nationale Recht zu übernehmen. Mitgliedstaaten können insoweit also frei wählen; andere als die aufgezählten Schrankentatbestände darf das nationale Recht hingegen grundsätzlich nicht enthalten. ${ }^{1432}$ Ergänzend regelt Art. 6 Abs. 3 Datenbank-RL in enger Anlehnung an den Dreistufentest der RBÜ, ${ }^{1433}$ dass die vorgesehenen Schrankenbestimmungen nicht in einer Weise angewendet werden dürfen, die die rechtmäßigen Interessen des Rechteinhabers unzumutbar verletzt oder die normale Nutzung der Datenbank beeinträchtigt.

\section{InfoSoc-Richtlinie 2001/29/EG}

Von den vorgenannten sektoralen Richtlinien, die auf einzelne Schutzgegenstände oder Verwertungsrechte beschränkt sind und somit lediglich bestimmte Teilaspekte des Urheberrechts oder einzelner Leistungsschutzrechte regeln, unterscheidet sich die Richtlinie 2001/29/EG des Europäischen Parlaments und des Rates zur Harmonisierung bestimmter Aspekte des Urheberrechts und der verwandten Schutzrechte in der Informations-

1429 Dazu sogleich unten 6. Kapitel, B.III.

1430 ABl. Nr. L 77 v. 27.3.1996, S. 20-28.

$1431 \mathrm{Zu}$ den Schrankenregelungen des Art. 6 Abs. 2 Datenbank-RL siehe nur Leistner, Rechtsschutz von Datenbanken, S. 117 ff.; v.Lewinski, in: Walter/v.Lewinski, European Copyright Law, 9.6.21 ff., jeweils mit detaillierter Analyse der einzelnen Schrankenoptionen und zahlreichen weiteren Nachweisen.

1432 Vgl. Erw.-Grd. 35 zur Datenbank-RL. Zur problematischen Regelung des Art. 6 Abs. 2 lit. d Datenbank-RL und der erforderlichen restriktiven Auslegung siehe Gaster, Rechtsschutz von Datenbanken, Art. 6 Rn. 405 ff.

1433 Siehe dazu bereits oben 6. Kapitel, A.IV.2. sowie ausführlich unten 6. Kapitel, C. 
gesellschaft (sog. InfoSoc-Richtlinie) $)^{1434}$ entscheidend: Sie verfolgt - in Umsetzung der Verpflichtungen aus den WIPO-,Internet Treaties“ WCT und WPPT, ${ }^{1435}$ aber auch über diese hinaus - einen horizontalen Harmonisierungsansatz und zielt auf eine unionsweite Anpassung und Ergänzung des Urheberrechtsschutzes, um den neuen wirtschaftlichen und technischen Gegebenheiten in angemessener Weise Rechnung zu tragen. ${ }^{1436}$ Ein zentraler Zweck der Richtlinie ist die Erreichung beziehungsweise Gewährleistung eines einheitlich hohen Schutzniveaus im Bereich des geistigen Eigentums zur Förderung von Kreativität und von Investitionen in Kreativität und Innovation als Beitrag zu Wachstum und erhöhter Wettbewerbsfähigkeit der europäischen (Kreativ-)Industrie. ${ }^{1437}$

Der Erreichung dieses Zweckes dienen die drei Regelungsabschnitte der Richtlinie: Den ersten Regelungsgegenstand bildet die Harmonisierung der wichtigsten Verwertungsrechte der Inhaber von Urheberrechten und verwandten Schutzrechten (Art. 2 bis 4 InfoSoc-RL). Der zweite Abschnitt widmet sich (dem Versuch) der Harmonisierung der urheberrechtlichen Schrankenbestimmungen (Art. 5 InfoSoc-RL). Der dritte Abschnitt schließlich befasst sich mit der Regelung des Zusammenspiels von Urheberrechten und verwandten Schutzrechten mit technischen Schutzmaßnahmen (Art. 6 und 7 InfoSoc-RL). ${ }^{1438}$

Obwohl die mit der Nutzung neuer Medien verbundenen Rechtsprobleme den Anstoß zum Erlass der Richtlinie gaben und der Titel der Richtlinie auf eine Ausrichtung auf die Gestaltung des europäischen Urheberrechts in der Informationsgesellschaft hinzudeuten scheint, beschränkt diese sich tatsächlich nicht auf die Erfassung der damit verbundenen Rechtsprobleme. ${ }^{1439}$ In der Richtlinie werden vielmehr durch die Festschreibung von Verwertungsrechten und deren Schranken Grundprinzipien des Urheberrechts und der verwandten Schutzrechte nicht nur in Bezug auf die di-

1434 AB1. Nr. L 167 v. 22.6.2001, S. 10-19.

1435 Siehe zu deren Inhalt und Relevanz bereits oben 6. Kapitel, A.VIII.

1436 Vgl. Erw.-Grd. 5 zur InfoSoc-RL.

1437 Vgl. Erw.-Grd. 4 und 9 zur InfoSoc-RL.

$1438 \mathrm{Zu}$ den Regelungen der Richtlinie zum Rechtsschutz technischer Maßnahmen siehe die kritische Betrachtung bei Leistner, Konsolidierung und Entwicklungsperspektive, S. 36 ff. m.w.N.

1439 Siehe Art. 1 Abs. 1 InfoSoc-RL: ,Gegenstand dieser Richtlinie ist der rechtliche Schutz des Urheberrechts ..., insbesondere in Bezug auf die Informationsgesellschaft." [Hervorhebung durch den Verfasser]; siehe auch Bayreuther, ZUM 2001, 828 (829). 
gitale, sondern auf jegliche Werknutzung formuliert und in den Erwägungsgründen näher erläutert. ${ }^{1440}$

Ausdrücklich unangetastet bleibt durch die InfoSoc-Richtlinie gemäß deren Art. 1 Abs. 2 der durch die bereits erlassenen Richtlinien mit Urheberrechtsbezug bisher erreichte urheberrechtliche acquis communautaire. Wenn und soweit Vorschriften der vorbestehenden Richtlinien durch die InfoSoc-Richtlinie abgeändert werden sollen, ist dies - wie in Art. 11 InfoSoc-RL - ausdrücklich geregelt. ${ }^{141}$ Nach Art. 9 InfoSoc-RL bleiben zudem die anderen nicht urheberrechtsbezogenen Richtlinien ausdrücklich unberührt. Außerhalb des Anwendungsbereichs der InfoSoc-Richtlinie bleiben schließlich auch Regelungen zum Urheberpersönlichkeitsrecht. ${ }^{1442}$

Um die internationalen Verpflichtungen aus der Ratifizierung der WIPO-,,Internet Treaties“ umzusetzen, ${ }^{1443}$ die kommerziellen Verwertungsrechte der Urheber und Inhaber verwandter Schutzrechte zu harmonisieren und mehr Rechtssicherheit für die Begünstigten zu erreichen, werden in den Artikeln 2 bis 4 der InfoSoc-Richtlinie die Verwertungsrechte der Vervielfältigung, öffentlichen Wiedergabe und Zugänglichmachung sowie der Verbreitung definiert und bewusst weit gefasst. ${ }^{1444}$

Zur Sicherung eines angemessenen Rechts- und Interessenausgleichs zwischen den verschiedenen Kategorien von Rechteinhabern untereinander und zwischen Rechteinhabern und Nutzern von Schutzgegenständen

1440 Vgl. Bornkamm, in: FS Erdmann, S. 29 (43); Reinbothe, GRUR Int. 2001, 733 (735); Spindler, GRUR 2002, 105. Zur Rolle der Erwägungsgründe bei der Auslegung europäischen Rechts siehe Leistner, Rechtsschutz von Datenbanken, S. 37 ff. m.w.N.

1441 Siehe Reinbothe, GRUR Int. 2001, 733 (735). Zu den drohenden Unstimmigkeiten zwischen den Regelungen einzelner Richtlinien siehe mit detaillierter Analyse und Kritik Hugenholtz/v.Eechoud/v.Gompel/Guibault/u.a., Recasting of Copyright, S. $64 \mathrm{ff}$.

1442 Siehe Erw.-Grd. 19 zur InfoSoc-RL. Zum Spannungsverhältnis aufgrund der fehlenden Harmonisierung des Urheberpersönlichkeitsrechts in der EU und dessen grundsätzlicher Anerkennung als Schutzgegenstand des Urheberrechts durch den EuGH (siehe EuGH, Urt. v. 20.10.1993, C-92/92 und C-326/92, Slg. 1993, I-5145 Rn. 20 = NJW 1994, 375 (376) - Phil Collins./. Imtrat Handelsgesellschaft $\mathrm{mbH}$ und Patricia Im- und Export Verwaltungsgesellschaft mbH, Leif Emanuel Kraul./. EMI Electrola GmbH) siehe Leistner, CMLR 46 (2009), 847 (850 f.) sowie die ausführliche Bestandsaufnahme und Kritik von Metzger, in: FS Schricker II; S. 455 (457 ff.). Vgl. auch die Kritik von Schack, Urheberrecht, Rn. 143; ders., ZGE 2009, 275 (278 f.).

1443 Siehe Erw.-Grd. 15 zur InfoSoc-RL und oben 6. Kapitel, A.VIII.

1444 Vgl. Erw.-Grd. 21 und 23 zur InfoSoc-RL. 
sieht die InfoSoc-Richtlinie in ihrem zweiten Regelungsabschnitt die Einschränkung der zuvor geregelten Ausschließlichkeitsrechte durch detaillierte Bestimmungen zu den Ausnahmen vor. Ziel dieses - nicht durch WCT und WPPT vorgegebenen - Teils der Richtlinie war es, die auf dem Gebiet der Schrankenbestimmungen zuvor bestehenden, teils ganz erheblich abweichenden nationalen Bestimmungen ${ }^{1445}$ unionsweit $\mathrm{zu}$ harmonisieren. ${ }^{1446}$ Die Absätze 1 und 2 enthalten dazu Schrankenbestimmungen des in Artikel 2 geregelten Vervielfältigungsrechts, Absatz 3 weitere Ausnahmebestimmungen, die auf das Recht der öffentlichen Zugänglichmachung und Wiedergabe Anwendung finden, und Absatz 4 eine Ausnahme zum Verbreitungsrecht. ${ }^{1447}$ Absatz 5 schließlich macht den für alle in den Absätzen 1 bis 4 aufgelisteten Schrankenregelungen geltenden Dreistufentest $^{1448}$ zum Teil des europäischen acquis.

Drei der in Art. 5 Abs. 2 aufgeführten Schrankentatbestände enthalten zudem die ausdrückliche Vorgabe, dass diese Regelungen von den Mitgliedstaaten nur unter der Voraussetzung angewendet werden können, dass „die Rechtsinhaber einen gerechten Ausgleich erhalten“. ${ }^{1449}$ Auch für andere nach der Richtlinie zulässige Schrankenbestimmungen, die einen „gerechten Ausgleich“ nicht zwingend vorschreiben, können die Mitgliedstaaten einen solchen jedoch vorsehen. ${ }^{1450}$ Eine Auslegungshilfe für den im Rahmen der Beratungen zur Richtlinie neu eingeführten Begriff des „gerechten Ausgleichs“1451 liefert Erwägungsgrund 35 zur InfoSoc-Richtlinie: Danach ist der Begriff so auszulegen, dass den Rechteinhabern unter

$1445 \mathrm{Zu}$ den mehr als 130 unterschiedlichen Schrankenbestimmungen innerhalb der EU vor Umsetzung der InfoSoc-Richtlinie siehe Decker/Hoeren, EIPR 1998, 20(7), 256 (257 ff.); Hoeren, MMR 2000, 515 (517 ff.).

1446 Vgl. Erw.-Grd. 31 zur InfoSoc-RL. Zu den politischen Schwierigkeiten und zähen Verhandlungen um einen Kompromiss zur Harmonisierung der Schrankenbestimmungen siehe Bayreuther, ZUM 2001, 828 (829); Hoeren, MMR 2000, 515 ff.; Reinbothe, GRUR Int. 2001, 733 (734 f.); Spindler, GRUR 2002, 105 (106, $110 \mathrm{f}$.$) .$

1447 Ausführlich zum Inhalt der einzelnen Schrankenvorgaben in Art. 5 Abs. 1-4 InfoSoc-RL statt vieler Reinbothe, GRUR Int. 2001, 733 (738 ff.).

$1448 \mathrm{Zu}$ den verschiedenen Erscheinungsformen des Dreistufentests und seiner Auslegung sogleich ausführlich 6. Kapitel, C.

1449 Siehe Art. 5 Abs. 2 lit. a InfoSoc-RL (Reprographie), Art. 5 Abs. 2 lit. b InfoSoc-RL (private Vervielfältigung); Art. 5 Abs. 2 lit. e InfoSoc-RL (Vervielfältigung in nicht-kommerziellen sozialen Einrichtungen).

1450 Siehe Erw.-Grd. 36 zur InfoSoc-RL.

1451 Siehe dazu Reinbothe, GRUR Int. 2001, 733 (738). 
Berücksichtigung der besonderen Umstände eines jeden Einzelfalls grundsätzlich die Nutzung ihrer geschützten Werke angemessen vergütet wird. Als brauchbares Kriterium zur Ermittlung der Form und Höhe des Ausgleichs nennt die Richtlinie den sich aus der Nutzungshandlung ergebenden etwaigen Schaden für den Rechteinhaber. Diese Vorgaben der Richtlinie hat der EuGH in seiner Padawan-Entscheidung ${ }^{1452}$ näher konkretisiert. Der EuGH betonte, der Begriff des ,gerechten Ausgleichs“ in der Richtlinie 2001/29/EG sei ein autonomer Begriff des Unionsrechts, der in allen Mitgliedstaaten einheitlich auszulegen sei. ${ }^{1453}$ Eine Auslegung der Erwägungsgründe 35 und 38 zur Richtlinie ergebe, dass der Begriff zwingend auf dem Begriff des Schadens beruhe. ${ }^{1454}$ Diesen hat der EuGH als den Nachteil definiert, „der sich für den Urheber aus der Vervielfältigung seines geschützten Werkes ergibt, wenn sie ohne seine Genehmigung für den privaten Gebrauch erfolgt". ${ }^{1455}$ Ergänzend hat der EuGH nun festgestellt, dass grundsätzlich die Person eine angemessene Vergütung schulde, die ohne vorherige Genehmigung des Rechteinhabers eine Vervielfältigung des geschützten Werkes für ihren privaten Gebrauch vornimmt und somit beim Rechteinhaber einen Schaden verursacht. ${ }^{1456}$ Die Mitgliedstaaten treffe jedoch in Bezug auf die Gewährleistung einer effektiven Erhebung des gerechten Ausgleichs eine „Ergebnispflicht“, so dass es den Mitgliedstaaten aufgrund der praktischen Schwierigkeiten bei der Ermittlung der privaten Nutzer letztlich frei stehe, eine Vergütungsregelung einzuführen,

1452 EuGH, Urt. v. 21.10.2010, C-467/08, ABl. EU 2010, C 346/05 = GRUR 2011, 50 - Padawan./. Sociedad General de Autores y Editores de España [SGAE].

1453 Siehe EuGH, a.a.O., Rn. 37 - Padawan.

1454 Siehe EuGH, a.a.O., Rn. 42, 50 - Padawan; bestätigt durch EuGH, Urt. v. 16.6.2011, C-462/09, Rn. 24 - Stichting de Thuiskopie./. Opus Supplies Deutschland GmbH. Das Abstellen auf den „Schaden“ ist mit der Begründung kritisiert worden, dass allein durch die Einführung der Privatkopieausnahme als solcher ein konkreter Schaden bei einem bestimmten Urheber noch nicht entstanden sein dürfte; siehe Frank, CR 2011, 1 (4 f.); Paulus/Wesche, GRUR 2012, 112 (115). Dreier, ZUM 2011, 281 (283) weist allerdings zutreffend darauf hin, dass der EuGH zwar in der deutschen Sprachfassung von „Schaden“ spreche, in der englischen Sprachfassung allerdings nicht etwa der Begriff ,damage“, sondern „harm“ verwendet werde. „Harm“ ziele im Gegensatz zum Begriff ,damage“ weniger auf den konkreten Schaden als vielmehr allgemeiner auf einen Nachteil, eine Beeinträchtigung von Interessen ab.

1455 EuGH, Urt. v. 21.10.2010, C-467/08, Rn. 40 - Padawan./. SGAE.

1456 Siehe EuGH, Urt. v. 16.6.2011, C-462/09, Rn. 35 - Stichting de Thuiskopie./. Opus Supplies Deutschland GmbH. 
nach der die Hersteller oder Importeure zur Zahlung des angemessenen Ausgleichs verpflichtet sind. ${ }^{1457}$ Diese „Ergebnispflicht" hat der EuGH zuletzt ausdrücklich dahingehend konkretisiert, dass sichergestellt werden müsse, dass der (von den Verwertungsgesellschaften erhobene) gerechte Ausgleich tatsächlich den Rechteinhabern zufließt, da unmittelbar und originär Berechtigter des Anspruchs auf gerechten Ausgleich - unabhängig von der konkreten Ausgestaltung der Erhebung - die Urheber beziehungsweise Rechteinhaber bleiben. ${ }^{1458}$

Trotz dieser Konkretisierung durch den EuGH erfolgt eine europäische Harmonisierung der Vergütungsansprüche zum Ausgleich erlaubter Nutzungen durch die InfoSoc-Richtlinie nicht. ${ }^{1459}$ Vorgegeben ist nunmehr nur, anhand welcher Kriterien ein ,gerechter Ausgleich“ auszugestalten ist, wenn dieser vom Gesetzgeber vorgesehen wird, und wer (grundsätzlich) Schuldner eines solchen Anspruches ist. Die Frage, in welchen Fällen ein Vergütungsanspruch vorzusehen ist, regelt die Richtlinie jedoch gerade nicht abschließend. Die Richtlinie schreibt lediglich vor, dass die Umstände des Einzelfalls zu berücksichtigen sind. Insbesondere etwaige bereits erhaltene Zahlungen oder ein nur geringfügiger Nachteil können auch dazu führen, dass in bestimmten Situationen gar keine Vergütungspflicht für die Nutzung entsteht. ${ }^{1460}$

Die - auf Regelungen in den nationalen Urheberrechtsordnungen der Mitgliedstaaten zurückgehende - Liste der Ausnahmen in Artikel 5 der InfoSoc-Richtlinie ist abschließend und erschöpfend, ${ }^{1461}$ jedoch (abgesehen von der vorübergehende Vervielfältigungen betreffenden Regelung des Art. 5 Abs. 1 InfoSoc-RL) nicht bindend und ohne Rangfolge, so dass Mitgliedstaaten in dem derart vorgegebenen Rahmen nach freiem Ermessen im nationalen Recht Schrankenbestimmungen vorsehen dürfen. Nicht nur das „Ob“ der Richtlinienumsetzung steht den Mitgliedstaaten insoweit frei, sondern auch das „Wie“, denn für die konkrete Ausgestaltung der na-

1457 Siehe EuGH, Urt. v. 16.6.2011, C-462/09, Rn. 34, 37 - Stichting de Thuiskopie./. Opus Supplies Deutschland GmbH; Kröber, GRUR 2011, 911 (912); Müller, ZUM 2011, $631 \mathrm{ff}$.

1458 Siehe EuGH, Urt. v. 9.2.2012, C-277/10, Rn. 88 ff., 95, ABl. EU 2012, C 80/04 = GRUR 2012, 489 (493) - Luksan./. van der Let; dazu Obergfell, GRUR 2012, 494 (496).

1459 Gefordert von Dieselhorst, GRUR Int. 1994, 788 (792 ff.); Schack, ZGE 2009, 275 (278).

1460 Vgl. Erw.-Grd. 35 zur InfoSoc-RL.

1461 Siehe Erw.-Grd. 32 zur InfoSoc-RL: „erschöpfend aufgeführt“. 
tionalen Schranken macht die Richtlinie keine Vorgaben. Die Regelung des Art. 5 Abs. 3 lit. o InfoSoc-RL untergräbt eine umfassendere Harmonisierung der mitgliedstaatlichen Schrankenregelungen in Form einer tatsächlich abschließenden Liste von zulässigen Schrankenregelungen zusätzlich, indem sie es jedem Mitgliedstaat erlaubt, sonstige bisher bestehende nationale Schranken in „Fällen von geringer Bedeutung“ aufrecht zu erhalten, sofern diese nur analoge Nutzungen betreffen und den freien Waren- und Dienstleistungsverkehr der Gemeinschaft nicht berühren. ${ }^{1462}$ Auch wenn der Richtliniengeber eine Anwendung der Schrankenbestimmungen der Richtlinie durch die Mitgliedstaaten ,,in kohärenter Weise“ erhofft, ${ }^{1463}$ ist es zu einer Harmonisierung der urheberrechtlichen Schrankenbestimmungen in der Europäischen Union durch die Regelungen der InfoSoc-Richtlinie tatsächlich nicht gekommen. ${ }^{1464}$ Bei der Einführung neuer oder Änderung bestehender Schrankenregelungen sind die Vorgaben des Art. 5 InfoSoc-Richtlinie als „Höchstgrenzen“1465 der Schrankenausgestaltung jedoch zwingend zu beachten. Sie begrenzen den gesetzgeberischen Spielraum entscheidend, da sie jedenfalls der Einführung völlig neuer, im Katalog des Art. 5 InfoSoc-RL nicht vorgesehener Schrankenbestimmungen grundsätzlich entgegenstehen. ${ }^{1466}$

$\mathrm{Zu}$ Recht ist die Entscheidung für die Aufnahme eines geschlossenen Schrankenkataloges in die InfoSoc-Richtlinie deshalb auf Kritik in der

1462 Siehe auch die deutliche Kritik an dieser Regelung bei Hoeren, MMR 2000, 515 (519) („Persil-Schein“) und Schippan, ZUM 2001, 116 (127) (,stauseegroße Auffangschranke").

1463 Siehe Erw.-Grd. 32 zur InfoSoc-RL.

1464 Deutlich Leistner, IIC 2011, 417 (436) („,... the 'harmonisation', which should have been reached by the Information Society Directive, is purely virtual.") sowie Schack, ZGE 2009, 275 (278) (,... hat die Harmonisierungs-RL die Schranken gerade nicht harmonisiert, sondern nach dem Motto „Schranken aller Länder vereinigt euch" alle bisher bekannten Schranken für zulässig erklärt."). Für einen kritischen Überblick über den Grad der aufgrund der InfoSoc-RL tatsächlich eingetretenen Harmonisierung der Schranken siehe Guibault, JIPITEC 2010, 55 (59 ff.). Eine detaillierte Analyse der Umsetzung der Schrankenvorgaben der InfoSoc-RL in den einzelnen Mitgliedstaaten findet sich bei Westkamp, Implementation of Directive 2001/29/EC, S. 84 ff., $108 \mathrm{ff}$.

1465 Bayreuther, ZUM 2001, 828 (829).

1466 Leistner, CMLR 46 (2009), 847 (851 f.) sieht ein gewisses Verdienst des (ansonsten kritisch betrachteten) umfassenden Schrankenkataloges der InfoSocRichtlinie deshalb darin, dass sie zumindest einer zukünftigen weiteren Disharmonisierung im Bereich der urheberrechtlichen Schrankenbestimmungen vorbeugt. 
Wissenschaft gestoßen. ${ }^{1467}$ Eben diese Beschränkung der zukünftigen Gesetzgebung durch eine abschließende Liste möglicher Schranken ist im Bereich der urheberrechtlichen Schranken äußerst problematisch, da sie die erforderliche flexible Anpassung der Schranken an neue technologische Entwicklungen nicht unerheblich einschränkt. Der Neugestaltung urheberrechtlicher Schranken wurde eine „Obergrenze“ gesetzt, die sich am damaligen Stand der Technik und am status quo der Schranken in den Mitgliedstaaten orientiert und zukünftigen Entwicklungen und darauf beruhenden unvorhergesehenen Formen der Nutzung urheberrechtlich geschützter Werke gegenüber nicht hinreichend offen ist. Führt die technologische Entwicklung - wie es bereits zu beobachten und zweifelsohne weiterhin zu erwarten ist - zur Entstehung neuer Nutzungsformen, die unter Berücksichtigung der beteiligten Interessen wünschenswert und daher grundsätzlich „schrankenwürdig“ erscheinen, sich jedoch nicht unter den bestehenden Katalog von Schranken fassen lassen, so lässt sich aufgrund der Festschreibung des Schrankenkataloges in der InfoSoc-Richtlinie dieses Ergebnis möglicherweise nicht ohne eine Änderung der bestehenden oder den Erlass einer weiteren Richtlinie in einem schwerfälligen legislativen Prozess auf europäischer Ebene erreichen. Denn sind die äußersten Grenzen der de lege lata nach dem Richtlinienrahmen möglichen und zulässigen nationalen Schrankenbestimmungen erreicht, so kann nur auf der europäischen Ebene zusätzlich erforderlicher Spielraum für den nationalen Gesetzgeber geschaffen werden. ${ }^{1468}$ Neben der erhofften Harmonisierung der Schranken innerhalb der EU hat die Richtlinie so in Bezug auf die urheberrechtlichen Schranken letztlich gerade auch ihr zentrales Ziel - die Gewährleistung der Zukunftsfähigkeit des europäischen Urheberrechts durch dessen Anpassung an die Herausforderungen der Informationsgesellschaft - verfehlt.

1467 Siehe etwa Dreier/Euler/Fischer/v.Raay, ZUM 2012, 273 (278 ff.); Guibault, JIPITEC 2010, 55 (64); Hugenholtz, EIPR 2000, 22(11), 499 (501); Hugenholtz/ v.Eechoud/v.Gompel/Guibault/u.a., Recasting of Copyright, S. 66; Janssens, in: Derclaye, Research Handbook on the Future of EU Copyright, S. 317 (332 f.); Leistner, Konsolidierung und Entwicklungsperspektive, S. 29; ders., CMLR 46 (2009), 847 (852); ders., IIC 2011, 417 (436); Linnenborn, K\&R 2001, 394 (396 f.). Mit vorsichtiger Kritik auch Bornkamm, in: FS Erdmann, S. 29 (48).

$1468 \mathrm{Zu}$ den Möglichkeiten und (politischen) Chancen einer Flexibilisierung der Schranken durch eine Änderung der InfoSoc-RL siehe unten 7. Kapitel, A. 


\section{Der Dreistufentest}

Im Rahmen der Konferenz zur Revision der Berner Übereinkunft in Stockholm im Jahr 1967 wurde der sogenannte Dreistufentest als Kompromissformel, die im Grunde zwei entgegengesetzte Aufgaben erfüllen sollte, in das internationale Urheberrecht eingeführt. Einerseits sollte durch seine Einführung der Weg für die erstmalige formale Anerkennung eines allgemeinen und umfassenden Vervielfältigungsrechts iure conventionis geebnet werden, ohne jedoch dieses weit angelegte Exklusivrecht schutzlos den vielfältigen nationalen Schrankenbestimmungen preiszugeben, die zur damaligen Zeit bereits bestanden. ${ }^{1469}$ Daher wurde dem schließlich in Art. 9 Abs. 2 RBÜ kodifizierten Dreistufentest die Funktion übertragen, Beschränkungen des in Art. 9 Abs. 1 RBÜ gewährten Vervielfältigungsrechts zu begrenzen. ${ }^{1470}$ Andererseits sollte der Befürchtung vieler Mitgliedstaaten der Berner Union Tribut gezollt werden, die neu zu schaffende Bestimmung könne den Freiraum der nationalen Gesetzgeber für die Berücksichtigung berechtigter sozialer, kultureller und ökonomischer Belange zu sehr einengen. Dies sollte durch die Wahl eines offenen, durch unbestimmte Rechtsbegriffe geprägten Wortlauts der Regelung gewährleistet werden. ${ }^{1471}$ Auch bei der späteren Einfügung beziehungsweise Übernahme des Dreistufentests in das TRIPS-Übereinkommen und in die WIPO-,Internet Treaties“ WCT und WPPT blieb diese Grundkonzeption ausdrücklich unangetastet. Der Dreistufentest wurde als eine Art Materialisierung des in der RBÜ erreichten Schutzstandards begriffen ${ }^{1472}$ und seine Interpretation sollte ausdrücklich der gängigen Auslegung des Art. 9 Abs. 2 RBÜ folgen. ${ }^{1473}$

1469 Ausführlich zu den Verhandlungen zur Einführung des Dreistufentests Ricketson/Ginsburg, International Copyright I, 13.03-13.09; Senftleben, Three-Step Test, S. $47 \mathrm{ff}$. Speziell zu den unterschiedlichen nationalen Schrankenregelungen zur damaligen Zeit Senftleben, a.a.O., S. 52 ff.

1470 Siehe Senftleben, Three-Step Test, S. 52.

1471 Vgl. zum Ganzen WIPO, Records of the IP Conference at Stockholm, S. 113, 857 und 883 ff. sowie Geiger, e-Copyright Bulletin 2007, S. 3; Ricketson, IPQ 1999, 56 (69).

1472 Vgl. GATT-Dokumente MTN.GNG/NG11/W/17/Add. 1, S. 6, und MTN.GNG/ NG11/W/14/Rev. 1, S. 8. Vgl. Reinbothe, GRUR Int. 1992, 707 (711).

1473 Vgl. WIPO-Dokumente CRNR/DC/4, § 12.05, und CRNR/DC/5, § 13.04, abrufbar unter: http://www.wipo.org [zuletzt abgerufen am 26.5.2013]. 
Die enge Verknüpfung aller internationalen Kodifikationen des Dreistufentests wird auch durch deren nahezu identischen Wortlaut verdeutlicht: Nach Art. 9 Abs. 2 RBÜ ist es der Gesetzgebung der Verbandsländer vorbehalten, „die Vervielfältigung in gewissen Sonderfällen unter der Voraussetzung zu gestatten, dass eine solche Vervielfältigung weder die normale Auswertung des Werkes beeinträchtigt noch die berechtigten Interessen des Urhebers unzumutbar verletzt". Diese Formulierung wurde in Art. 13 TRIPS fast wörtlich übernommen; ${ }^{1474}$ jedoch wurde der in der RBÜ nur das Vervielfältigungsrecht betreffende Dreistufentest horizontal auf alle Verwertungsrechte erstreckt und damit zu einer allgemeinen, für alle Beschränkungen der urheberrechtlichen Ausschließlichkeitsrechte geltenden Regelung erweitert. ${ }^{1475}$ Die WIPO-,Internet Treaties“ enthalten in Art. 10 WCT beziehungsweise Art. 16 WPPT ebenfalls generelle, für sämtliche Verwertungsrechte geltende Schrankenregelungen nach diesem Muster. Schließlich wurde auch in Art. 5 Abs. 5 der InfoSoc-Richtlinie 2001/29/EG der Dreistufentest fast wortgleich eingeführt und so die Kontinuität unterstrichen, in der die neue Bestimmung steht. ${ }^{1476}$ Trotz der Ähnlichkeit zwischen den konventionsrechtlichen Ausformungen des Dreistufentests und seiner Kodifizierung in der Richtlinie 2001/29/EG ergeben sich dennoch grundlegende Unterschiede hinsichtlich der Bedeutung und Wirkung des Dreistufentests. Auf diese soll im Folgenden eingegangen werden.

\section{Funktion und Wirkung des konventionsrechtlichen Dreistufentests}

Der Dreistufentest wurde, wie zuvor dargestellt, als Kompromissformel in das Konventionsrecht aufgenommen. Zum einen stellt der Test eine Vorgabe für die Ausgestaltung von urheberrechtlichen Schranken dar, die weit genug formuliert sein sollte, um allen bestehenden, mehr oder weniger weit reichenden nationalen Beschränkungen (im Rahmen der RBÜ zu-

1474 Art. 13 TRIPS lautet: „Die Mitglieder begrenzen Beschränkungen und Ausnahmen von ausschließlichen Rechten auf bestimmte Sonderfälle, die weder die normale Auswertung des Werkes beeinträchtigen noch die berechtigten Interessen des Rechtsinhabers unzumutbar verletzen." [Hervorhebungen durch den Verfasser].

1475 Bornkamm, in: FS Erdmann, S. 29 (39).

1476 Vgl. Bornkamm, in: FS Erdmann, S. 29 (44). 
nächst nur des Vervielfältigungsrechts) in den Verbandsstaaten - unabhängig von deren Regelungstechnik - Rechnung zu tragen, ohne Gesetzesänderungen notwendig zu machen. Zugleich sollten die Rechte der Urheber durch das Aufstellen einer Schranken-Schranke vor einer weiteren Aushöhlung geschützt werden. ${ }^{1477}$ Adressat des konventionsrechtlichen Dreistufentests ist stets der nationale Gesetzgeber der Vertragsstaaten. ${ }^{1478}$ Dessen Gestaltungsfreiheit bei der Ausgestaltung der Schranken des Urheberrechts wird durch den Dreistufentest eingeschränkt. Schranken dürfen demnach nur für gewisse/bestimmte Sonderfälle unter der Voraussetzung vorgesehen werden, dass weder die normale Auswertung des Werkes beeinträchtigt noch die berechtigten Interessen des Urhebers unzumutbar verletzt werden. Neben dieser kompetenzbegrenzenden Funktion für den Gesetzgeber kommt dem konventionsrechtlichen Dreistufentest jedoch eine weitere entscheidende Funktion zu: Auch bei der Anwendung des Urheberrechtsgesetzes durch die nationalen Gerichte ist seinen Anforderungen Rechnung zu tragen. Da das inländische Urheberrecht nach allgemeiner Meinung konventionsfreundlich auszulegen ist, ist dem Dreistufentest der entscheidende Maßstab für die Anwendung der einschlägigen Vorschriften des Urheberrechtsgesetzes zu entnehmen. ${ }^{1479}$

\section{Funktion und Wirkung des gemeinschaftsrechtlichen Dreistufentests}

Art. 5 Abs. 5 der InfoSoc-Richtlinie hat den Wortlaut des Dreistufentests der RBÜ fast wortgleich übernommen und unterstreicht so die Kontinuität, in der die Regelung steht. ${ }^{1480}$ Dennoch geht seine Wirkung weit über diejenige des konventionsrechtlichen Dreistufentests hinaus. Zum einen gilt der gemeinschaftsrechtliche Dreistufentest in Art. 5 Abs. 5 der Richtlinie abweichend von Art. 9 Abs. 2 RBÜ (aber ebenso wie Art. 13 TRIPS und Art. $10 \mathrm{WCT}$ ) nicht lediglich für das Vervielfältigungsrecht, sondern

1477 Vgl. Geiger, EIPR 2007, 29(12), 486 (487) m.w.N.

1478 Vgl. die einleitende Formulierung der einzelnen Regelungen: Art. 9 Abs. 2 RBÜ: „It shall be a matter for legislation in the countries of the Union to permit ...“; Art. 13 TRIPS: „Members shall confine limitations or exceptions to exclusive rights to ..."; Art. 10 WCT: „Contracting Parties may, in their national legislation, provide for ..." [Hervorhebungen durch den Verfasser].

1479 Vgl. BGHZ 141, 13 (34) - Kopienversanddienst; sowie oben Fn. 1331 und 1333.

1480 Vgl. Bornkamm, in: FS Erdmann, S. 29 (44). 
bezieht sich auf alle durch die Artikel 2 bis 4 der InfoSoc-Richtlinie harmonisierten Verwertungsrechte. Zudem wird nicht lediglich auf die Urheber und deren berechtigte Interessen abgestellt, sondern es werden alle Rechteinhaber erfasst. Anders als im Konventionsrecht stellt der Dreistufentest in der InfoSoc-Richtlinie allerdings keine eigenständige Ermächtigung zur Einschränkung dieser Verwertungsrechte dar. Er fußt vielmehr ausweislich seines Wortlauts auf den in Art. 5 Abs. 1 bis 4 InfoSoc-RL abschließend aufgezählten Schrankenbestimmungen, die er als zusätzliche Schranken-Schranke begrenzt. ${ }^{1481}$ Ebenso wie der konventionsrechtliche Dreistufentest wirkt auch Art. 5 Abs. 5 InfoSoc-RL somit als Kompetenzbegrenzung für den Gesetzgeber bei der Schaffung und Ausgestaltung urheberrechtlicher Schranken im Rahmen der Vorgaben des Art. 5 Abs. 1 bis 4 InfoSoc-RL. So ist der europäische Gesetzgeber seiner völkerrechtlichen Verpflichtung ${ }^{1482}$ nachgekommen, die Schrankenbestimmungen im europäischen Recht im Einklang mit den Vorgaben des TRIPS-Übereinkommens und der WIPO-,Internet Treaties“" auszugestalten. ${ }^{1483}$

Neben der begrenzenden Wirkung für den Gesetzgeber könnte dem gemeinschaftsrechtlichen Dreistufentest jedoch eine weitere, über die Tragweite seiner konventionsrechtlichen Ausformung hinausgehende Wirkung zukommen: Anders als im Konventionsrecht, das stets die Gesetzgeber der Vertragsparteien als Adressaten des Dreistufentests kennzeichnet, ${ }^{1484}$ wird der Adressat des Dreistufentests in der InfoSoc-Richtlinie nicht ausdrücklich benannt. Art. 5 Abs. 5 InfoSoc-RL regelt vielmehr nur, dass die in dessen Absätzen 1 bis 4 genannten Ausnahmen und Beschränkungen nur unter den Voraussetzungen des Dreistufentests angewandt werden dürfen. Es liegt somit nahe, die Norm nicht als reine Anweisung an den Gesetzgeber zu verstehen, sondern dieser zusätzlich einen Auftrag an den Rechtsanwender zu entnehmen. Auch der Wortlaut des Erwägungsgrundes 44 der Richtlinie stützt diese Ansicht, da ausdrücklich auf die Anwen-

1481 Vgl. Bayreuther, ZUM 2001, 828 (839); Bornkamm, in: FS Erdmann, S. 29 (44); Heide, EIPR 1999, 21(3), 105 (108); Schack, Urheberrecht, Rn. 535; Westkamp, 56 J. Copyright Soc'y U.S.A. 1, 25 (2008).

1482 Die EU ist sowohl Vertragspartei des TRIPS-Übereinkommens als auch der WIPO-,Internet Treaties"; vgl. oben 6. Kapitel, A.VII. und VIII.

1483 Vgl. Bayreuther, ZUM 2001, 828 (839); Bornkamm, in: FS Erdmann, S. 29 (44); Geiger, e-Copyright Bulletin 2007, S.3; Reinbothe, ZUM 1998, 429 (434 f.); ders., GRUR Int. 2001, 733 (740).

1484 Vgl. oben Fn. 1475. 
dung der Ausnahmen und Beschränkungen abgestellt wird. ${ }^{1485}$ Ein solches Verständnis des gemeinschaftsrechtlichen Dreistufentests birgt jedoch dann ein nicht unerhebliches Risiko in sich, wenn man der Richtlinie einen unmittelbaren Auftrag an den Rechtsanwender entnehmen wollte. ${ }^{1486}$ Die gesetzgeberische Entscheidung hinter einzelnen Schranken des Urheberrechts wäre so ständig durch die Einzelfallüberprüfung der Vereinbarkeit mit dem Dreistufentest durch die Gerichte in Frage gestellt, ${ }^{1487}$ was

1485 Erwägungsgrund 44 der Richtlinie 2001/29/EG lautet: „Bei der Anwendung der Ausnahmen und Beschränkungen im Sinne dieser Richtlinie sollten die internationalen Verpflichtungen beachtet werden. Solche Ausnahmen und Beschränkungen dürfen nicht auf eine Weise angewandt werden, dass die berechtigten Interessen der Rechtsinhaber verletzt werden oder die normale Verwertung ihrer Werke oder sonstigen Schutzgegenstände beeinträchtigt wird. Die von den Mitgliedstaaten festgelegten Ausnahmen oder Beschränkungen sollten insbesondere die gesteigerte wirtschaftliche Bedeutung, die solche Ausnahmen oder Beschränkungen im neuen elektronischen Umfeld erlangen können, angemessen berücksichtigen. Daher ist der Umfang bestimmter Ausnahmen oder Beschränkungen bei bestimmten neuen Formen der Nutzung urheberrechtlich geschützter Werke und sonstiger Schutzgegenstände möglicherweise noch enger zu begrenzen." [Hervorhebungen durch den Verfasser].

1486 So aber Cohen Jehoram, in: FS Schricker II, S. 249 (258); ders., EIPR 2005, 27(10), 359 (364); ders., EIPR 2009, 31(8), 408 (409); Geiger, CRi 2005, 7 (11); ders., IIC 2006, 74 (80); ders., IIC 2006, 683 (689f.); ders., e-Copyright Bulletin 2007, S. 13 ff.; ders., IIC 2008, 178 (194 ff.); ders., EIPR 2008, 30(4), 121 (127); Ghidini, Innovation, Competition and Consumer Welfare, S. 112 f.; Mazziotti, EU Digital Copyright Law, S. 85 f.; Oliver, 25 Colum. J.L. \& Arts 119, 139 (2002); Senftleben, Three-Step Test, S. 281.

1487 So geschehen in der Entscheidung des französischen Cour de Cassation, Urt. v. 28.2.2006, IIC 2006, 760 - DVD Copy III, in der das Gericht die private Kopie einer DVD als Beeinträchtigung der normalen Verwertung des geschützten Werkes ansah und daher die Schrankenregelung des Art. L.122-5 des Code de la propriété intellectuelle (CPI) zugunsten der Privatkopie für mit der zweiten Stufe des Dreistufentests unvereinbar erklärte. Das Gericht wandte den Dreistufentest an, obwohl zum Zeitpunkt der Entscheidung die InfoSoc-Richtlinie (und somit Art. 5 Abs. 5) in Frankreich noch nicht in nationales Recht umgesetzt war. Da allerdings die Umsetzungsfrist bereits abgelaufen war, sah sich das Gericht gezwungen, das nationale Recht im Einklang mit der Richtlinie anzuwenden. Ausführlich zur Entscheidung des Cour de Cassation, siehe die Besprechungen von Geiger, IIC 2006, 683; Griffiths, IPQ 2009, 428 (433 f.); Ngombe, EIPR 2007, 29(2), 61 und Senftleben, JIPITEC 2010, 67 (71). Siehe auch die Entscheidung der Rechtbank Den Haag, Urt. v. 25.6.2008, No. 246698, LJN BD5690 - Thuiskopie, in der das Gericht den Dreistufentest unmittelbar anwandte und zu dem Ergebnis kam, das Anfertigen privater Kopien von einer illegalen Vorlage sei mit dem Dreistufentest unvereinbar und könne daher 
insbesondere vor dem Hintergrund der weiterhin uneinheitlichen Auslegung der Tatbestandsmerkmale und der Reichweite des Dreistufentests problematisch erscheint. Eine erhebliche Rechtsunsicherheit wäre die Konsequenz. ${ }^{1488}$ So könnte etwa ein Nutzer nicht mit Sicherheit davon ausgehen, dass eine gesetzlich gewährte Ausnahme zu seinen Gunsten auch in einem Prozess Bestand hätte. ${ }^{1489}$

Auch wenn der Wortlaut des Art. 5 Abs. 5 InfoSoc-RL nahe legt, dass nicht ausschließlich der Gesetzgeber zur Beachtung des Dreistufentests angehalten werden soll, kann diese Ansicht letztlich nicht überzeugen. Eine Richtlinie stellt gemäß Art. 288 Abs. 3 AEUV (ex-Art. 249 Abs. 3 EGV) stets ein an die nationalen Gesetzgeber gerichtetes Harmonisierungsinstrument dar, dem grundsätzlich ein unmittelbarer Auftrag an den Rechtsanwender nicht entnommen werden kann. ${ }^{1490}$ Auch den Materialien zur InfoSoc-Richtlinie lassen sich keine Anhaltspunkte dafür entnehmen, dass eine unmittelbare Anwendbarkeit des Dreistufentests durch die nationalen Gerichte gewünscht gewesen wäre. Hätte der Richtliniengeber jedoch eine derart weitreichende Neuerung hinsichtlich der Wirkung des Dreistufentests bezweckt, so erscheint es wahrscheinlich, dass sich ausdrückliche Hinweise darauf zumindest in den Gesetzgebungsmaterialien finden würden. ${ }^{1491}$ Es erscheint daher überzeugender, dem Dreistufentest

nicht von der gesetzlichen Regelung des Art. 16c des niederländischen Urheberrechtsgesetzes (Auteurswet) erfasst sein. Bemerkenswert ist, dass das Gericht in diesem Fall zum einen eine detaillierte Analyse der einzelnen Tatbestandsmerkmale vermissen lässt, zum anderen nicht einmal offenbart, gegen welche der drei Stufen die fragliche Handlung nach seiner Auffassung verstößt; siehe dazu kritisch Senftleben, AMI 2009, 1 (3); ders., JIPITEC 2010, 67 (70 f.).

1488 Vgl. Brinkel, Filesharing, S. 71; Dusollier, IRDI 2005, 212 (215); Geiger, EIPR 2007, 29(12), 486 (489); ders., EIPR 2008, 30(4), 121 (127); Ghidini, Innovation, Competition and Consumer Welfare, S. 213; Senftleben, AMI 2009, 1 (3 f.).

1489 Vgl. etwa die Urteile des Cour de Cassation, IIC 2006, 760 - DVD Copy III und der Rechtbank Den Haag, Urt. v. 25.6.2008, No. 246698, LJN BD5690 - Thuiskopie; siehe dazu bereits oben Fn. 1484.

1490 Vgl. Wandtke/Bullinger/v.Welser, Vor $\S \S 120$ ff. Rn. 56 m.w.N.

1491 Siehe auch. Hart, EIPR 2002, 24(2), 58 (61), der darauf hinweist, dass die endgültige Formulierung des Art. 5 Abs. 5 InfoSoc-RL (,,angewandt") von der ursprünglich - in Anlehnung an Art. 6 Abs. 3 Computerprogramm-RL - vorgeschlagenen Formulierung abweicht. Der ursprüngliche Vorschlag lautete: „The exceptions and limitations provided for in paragraphs 1, 2 and 3 shall only be applied to certain specific cases and shall not be interpreted in such a way as to allow their application to be used in a manner which unreasonably prejudices 
in seiner Ausformung durch die InfoSoc-Richtlinie einen unmittelbaren Auftrag an den Gesetzesanwender nicht zu entnehmen, sondern ihn als an die nationalen Gesetzgeber gerichtet anzusehen. ${ }^{1492}$ Dies bedeutet jedoch nicht, dass die nationalen Gerichte den Dreistufentest völlig unbeachtet lassen können. Bei der fraglichen Formulierung des Dreistufentests in der Richtlinie handelt es sich vielmehr letztlich um eine Klarstellung und Festschreibung der Verpflichtung der Gerichte zur Anwendung und Auslegung der nationalen Gesetze nach den etablierten Grundsätzen der richtlinienkonformen Auslegung. ${ }^{14931494}$ Art. 5 Abs. 5 InfoSoc-RL verdeutlicht

the right holders' legitimate interests or conflicts with the normal exploitation of their works or other subject matter." [Hervorhebung durch den Verfasser]. Die Streichung der Formulierung ,shall not be interpreted" kann als Indiz dafür angesehen werden, dass der Richtliniengeber eine unmittelbare Anwendung des richtlinienrechtlichen Dreistufentests gerade nicht bezweckt hat.

1492 So auch Bechtold, in: Dreier/Hugenholtz, Concise Copyright, Information Society Dir., Art. 5 Rn. 6 b; Berger, CR 2004, 360 (364); Brinkel, Filesharing, S. 72; Burrell/Coleman, Copyright Exceptions, S. 298; Dusollier, IRDI 2005, 212 (216); Hart, EIPR 2002, 24(2), 58 (61); Griffiths, IPQ 2009, 428 (456); Guntrum, Zukunft der Privatkopie, S. 56; Hugenholtz/Okediji, Limitations and Exceptions, S. 18; Koelman, EIPR 2006, 28(8), 407 (408 f.); Leistner, CMLR 46 (2009), 847 (852); v.Lewinski/Walter, in: Walter/v.Lewinski, European Copyright Law, 11.5.78; Westkamp, 56 J. Copyright Soc'y U.S.A. 1, 26 f. (2008).

1493 Es kommt dabei nicht darauf an, ob die mitgliedstaatlichen Vorschriften vor oder nach der Richtlinie erlassen wurden. Das Gebot richtlinienkonformer Auslegung betrifft zwar typischerweise Gesetze, die die Richtlinie umsetzen (vgl. BGH, GRUR 2007, 691 (692) - Staatsgeschenk), erfasst wird aber auch das sonstige mitgliedstaatliche Recht; st. Rspr. des EuGH, siehe EuGH, Urt. v. 14.7.1994, C-91/92, Slg. 1994, I-3325 = NJW 1994, 2473 - Paola Faccini Dori; Urt. v. 7.3.1996, C-192/94, Slg. 1996, I-1281 = NJW 1996, $1401-E l$ Corte Inglés. Der Gerichtshof formuliert in seiner ELOG-Entscheidung (Urt. v. 4.7.2006, C-212/04, Slg. 2006, I-6057 = NJW 2006, 2465 - Konstantinos Adeneler u.a... Ellinikos Organismos Galaktos [ELOG]) unmissverständlich: „Es ist daran zu erinnern, dass die nationalen Gerichte bei der Anwendung des innerstaatlichen Rechts dieses so weit wie möglich anhand des Wortlauts und des Zweckes der fraglichen Richtlinie auslegen müssen, um das in ihr festgelegte Ergebnis zu erreichen und so Artikel 249 Absatz 3 EG nachzukommen. Diese Pflicht zur gemeinschaftsrechtskonformen Auslegung betrifft das gesamte nationale Recht, unabhängig davon, ob es vor oder nach der Richtlinie, um die es geht, erlassen wurde.“ Umfassend zur richtlinienkonformen Auslegung, siehe statt vieler Streinz/Schroeder, EUV/EGV, Art. 249 EGV Rn. 125 ff. m.w.N.

1494 So ausdrücklich die belgische amtliche Begründung zum Gesetz zur Umsetzung der InfoSoc-Richtlinie, Doc. 51-1137/001, Chambre des Représentantes de Bel- 
somit, dass der Dreistufentest die äußerste Grenze des gesetzgeberischen Gestaltungsspielraumes hinsichtlich der urheberrechtlichen Schranken darstellt. Eine Auslegung des nationalen Rechts im Lichte des gemeinschaftsrechtlichen Dreistufentests in diesem Sinne wurde auch bereits von mehreren mitgliedstaatlichen Gerichten angestrengt. ${ }^{1495}$ Dies trifft so freilich nur in Mitgliedstaaten zu, die sich gegen eine unmittelbare Übernahme des Dreistufentests in nationales Recht entschieden haben. ${ }^{1496}$ In Mitgliedstaaten, die den Dreistufentest zu einem Bestandteil ihres nationalen

gique, Projet de Loi transposant en droit belge la directive européenne 2001/29/CE du 22 mai 2001 sur l'harmonisation de certains aspects du droit d'auteur et des droits voisins dans la société de l'information, S. 15: „Le test en trois étapes, tel qu'il est repris dans l'article 5.5 de la directive est donc destiné avant tout au législateur, ce qui n'empêche toutefois pas qu'il peut servir de ligne directrice pour les Cours et tribunaux lors de l'application de la loi.“ [Hervorhebungen durch den Verfasser]. Vgl. auch OLG Dresden, ZUM 2010, 362 (364) - Urheberrechtsschutz für programmbegleitendes Material. Ähnlich die deutsche amtl. Begr. zum ,zweiten Korb“, BT-Drs. 16/1828, S. 21. Vgl auch die amtl. Begr. zum ersten Gesetz zur Regelung des Urheberrechts in der Informationsgesellschaft, BT-Drs. 15/38, S. 15. Vgl. außerdem die in Fn. 1426 genannten Stimmen aus der Literatur.

1495 Vgl. etwa für Belgien Tribunal de Première Instance de Bruxelles, Urt. v. 13.2.2007, 06/10.928/C - Google, Inc. v. Copiepresse SCRL; siehe dazu Klein, IIC 2008, 451 ff.; Turner/Callaghan, EIPR 2008, 30(1), 34 ff. Vgl. für die Niederlande Rechtbank Den Haag, Urt. v. 2.3.2005, No. 192880, LJN AS8778 Uitgevers/De Staat; dazu Anm. Koelman, Computerrecht 2005, 143 ff. und Anm. Sujecki, MR-Int. 2005, 40 f.; sowie Rechtbank Den Haag, Urt. v. 25.6.2008, No. 246698, LJN BD5690 - Thuiskopie. Zur Anwendung des richtlinienrechtlichen Dreistufentests durch deutsche Gerichte, siehe BGHZ 151, 300 (315f.) - Elektronischer Pressespiegel; KG Berlin, GRUR 2010, 64 (67) - Gerechter Ausgleich; OLG Dresden, ZUM 2010, 362 (364) - Urheberrechtsschutz für programmbegleitendes Material; OLG Frankfurt a.M., GRUR-RR 2010, 1 (3) - Elektronische Leseplätze; LG Frankfurt a.M., GRUR-RR 2009, 330 (331) - Elektronische Leseplätze. Zur Anwendung des konventionsrechtlichen Dreistufentests durch deutsche Gerichte, vgl. BGHZ 141, 13 (30 ff.) - Kopienversanddienst; OLG Dresden, ZUM 2007, 203 (206) - Online-Videorekorder.

1496 So - neben Deutschland - etwa Belgien, Dänemark, Großbritannien, die Niederlande und Österreich. Für eine vollständige Übersicht über die Umsetzung des Art. 5 Abs. 5 InfoSoc-RL in den Mitgliedstaaten, siehe Westkamp, Implementation of Directive 2001/29/EC, S. $92 \mathrm{ff}$. 
Rechts gemacht haben, ${ }^{1497}$ stellt dieser selbstverständlich unmittelbar anwendbares Recht dar, an dem sich nationale Schrankenregelungen in jedem Einzelfall messen lassen müssen. ${ }^{1498}$ Gerade vor dem Hintergrund der unterschiedlichen nationalen Regelungen und des daraus resultierenden unterschiedlichen Ranges des Dreistufentests auch innerhalb der europäischen Union ist es geboten, für den gemeinschaftsrechtlichen Dreistufentest eine einheitliche Auslegung zu finden, die den beteiligten Interessen gerecht wird.

Eine weitere Besonderheit des Dreistufentests in seiner Ausformung durch Art. 5 Abs. 5 InfoSoc-RL besteht schließlich darin, dass der EU-Gesetzgeber diesen durch die Aufnahme in die Richtlinie zu einem durch den EuGH überprüfbaren Bestandteil des urheberrechtlichen acquis communautaire gemacht hat. ${ }^{1499}$ Eine Auslegung und Konkretisierung der unbestimmten Rechtsbegriffe des Dreistufentests kann somit nun durch den EuGH - anders als etwa durch die WTO-Schiedsstelle ${ }^{1500}$ - für alle Mitgliedstaaten verbindlich erfolgen. ${ }^{1501}$

1497 So etwa Frankreich (Art. L.122-5 a.E. Code de la propriété intellectuelle; zur Umsetzung der InfoSoc-Richtlinie in Frankreich, siehe Geiger, AMI 2008, $1 \mathrm{ff}$.), Italien (Art. 71-nonies Legge 22 aprile 1941 n. 633 sul diritto d'autore), Griechenland (Art. 28(c) Griechisches Urheberrechtsgesetz, eingefügt durch Gesetz 3057/2002, JO A/239 vom 10.10.2002), Luxemburg (Art. 10 Abs. 2 Loi du 18 avril 2001 sur les droits d'auteur, les droits voisins et les bases de données), Portugal (Art. 75(4) Código do Direito de Autor e dos Direitos Conexos (Lei $n^{\circ}$ 45/85)) und Spanien (Art. 40bis Ley de propiedad intelectual).

1498 Vgl. v.Eechoud/Hugenholtz/v.Gompel/Guibault/Helberger, Harmonizing European Copyright Law, S. 114; Geiger, IIC 2006, 683 (690); ders., EIPR 2008, 30(4), 121 (127); Griffiths, IPQ 2009, 428 (433); Hugenholtz/Okediji, Limitations and Exceptions, S. 18.

1499 Vgl. Dreier/Schulze, Vor $\S \S 44$ aff. Rn. 21; Schack, Urheberrecht, Rn. 535; Westkamp, 56 J. Copyright Soc'y U.S.A. 1, 33 (2008).

1500 Zur mangelnden Bindungswirkung der Entscheidungen der WTO-Schiedsstelle siehe bereits oben Fn. 1385.

1501 Vgl. Cohen Jehoram, EIPR 2005, 27(10), 359 (364), Koelman, EIPR 2006, 28(8), 407 (408) Mazziotti, EU Digital Copyright Law, S. 86. Bisher hat der EuGH den Dreistufentest in keinem Urteil ausgelegt, obwohl er zuletzt in der Infopaq-Entscheidung (EuGH, Urt. v. 16.7.2009, C-5/08, Slg. 2009, I-6569 = GRUR 2009, 1041 - Infopaq International A/S./. Danske Dagblades Forening) Gelegenheit dazu gehabt hätte; vgl. die Schlussanträge der Generalanwältin Trstenjak vom 12.2.2009, Rs. C-5/08, Rn. 134 ff. Siehe dazu Derclaye, EIPR 2010, 32(5), 247 (251) und Griffiths, IPQ 2009, 428 (456), die es begrüßen, dass der EuGH von einer Auslegung des Dreistufentests bisher Abstand genommen hat, da sie die Zeit für ein derartiges Urteil aufgrund der weiterhin sehr lebhaften 


\section{Auslegung der drei Stufen}

Der Dreistufentest hat sich von einem nur für Beschränkungen des Vervielfältigungsrechts geltenden Schrankenvorbehalt in der RBÜ zu einer oder gar der zentralen Schrankenvorschrift des internationalen und insbesondere europäischen Rechts in Bezug auf die Begrenzung urheberrechtlicher Verwertungsbefugnisse entwickelt. ${ }^{1502}$ Nach dem übereinstimmenden Willen der Vertragsstaaten der WIPO-,Internet Treaties“ stellt der Dreistufentest auch im digitalen Kontext den entscheidenden Maßstab für die Beschränkung der urheberrechtlichen Ausschließlichkeitsrechte dar. ${ }^{1503}$ Aufgrund dieser herausragenden Bedeutung ist es wenig verwunderlich, dass die Auslegung des Dreistufentests bereits Gegenstand einer Vielzahl von Beiträgen der wissenschaftlichen Literatur war. ${ }^{1504}$ Umso erstaunli-

wissenschaftlichen Debatte noch nicht für reif halten. Vgl. auch die Schlussanträge der Generalanwältin Stix-Hackl vom 8.6.2004 in den Rechtssachen C-444/02, Rn. 136 ff. - Fixtures Marketing und C-203/02, Rn. 115 ff. - The British Horseracing Board, in denen sich die Generalanwältin im Zusammenhang mit der dem Dreistufentest nachempfundenen Regelung des Art. 7 Abs. 5 RL 96/9/EG mit der Auslegung des konventionsrechtlichen Dreistufentests auseinandersetzt.

1502 Aufgrund des enormen Bedeutungszuwachses des Dreistufentests durch seine Verankerung in diversen völkerrechtlichen Verträgen und die Übernahme in die Richtlinie 2001/29/EG ist wohl zu Recht von der „Karriere eines Begriffs“ (Bornkamm, in: FS Erdmann, S. 29), einem „,beispiellosen Siegeszug durch das internationale Urheberrecht" (Senftleben, in: Hilty/Peukert, Interessenausgleich, S. 159 (171)) oder dem „mittlerweile berühmten“ Dreistufentest (Schricker/ Loewenheim/Melichar, Vor $\S \S 44$ a ff. Rn. 12) gesprochen worden.

1503 Vgl. Absatz 1 der vereinbarten Erklärung zu Art. 10 WCT (wiedergegeben oben S. 319). So auch Hohagen, Vervielfältigung zum eigenen Gebrauch, S. 92.

1504 Nachdem der Dreistufentest lange Zeit erstaunlich wenig wissenschaftliche Beachtung gefunden hat, ist er in jüngerer Zeit - insbesondere nach der Entscheidung des WTO-Panels in der Angelegenheit „United States - Section 110(5) of the US Copyright Act" (siehe dazu oben Fn. 1385) und seiner Aufnahme in die InfoSoc-Richtlinie - Gegenstand einer großen Zahl nationaler und internationaler wissenschaftlicher Beiträge gewesen; siehe insbesondere die Monographie von Senftleben, Three-Step Test; sowie ders., in: Hilty/Peukert, Interessenausgleich, S. 159 ff.; ders., CR 2003, 914; ders., GRUR Int. 2004, 200; ders., IIC 2006, 407; außerdem etwa Berger, CR 2004, 360; Bornkamm, in: FS Erdmann, S. 29 ff.; Cohen Jehoram, GRUR Int. 2001, 807; Geiger, CRi 2005, 7; ders., IIC 2006, 683; ders., e-Copyright Bulletin 2007, S. 2 ff.; ders., EIPR 2007, 29(12), 486; ders., GRUR Int. 2008, 459; Geiger/Griffiths/Hilty, IIC 2008, 707; Ginsburg, RIDA 187 (2001), 3; He, IIC 2009, 274; Heide, EIPR 1999, 21(3), 105; 
cher ist es jedoch, dass sich eine einheitliche Auslegung des konventionsrechtlichen Dreistufentests bisher nicht etablieren lassen hat. Im Folgenden soll daher die Systematik der Norm und der Inhalt der einzelnen Tatbestandsmerkmale beleuchtet werden, um eine eigene Stellungnahme zu ermöglichen. Dabei können die Kriterien des Dreistufentests für sämtliche konventionsrechtlichen Vorschriften und auch für das europäische Recht grundsätzlich einheitlich interpretiert werden. ${ }^{1505}$ Lediglich im Rahmen des dritten Prüfungsschrittes ergibt sich insoweit eine Abweichung, als hinsichtlich der Regelung des Art. 13 TRIPS die unzumutbare Verletzung der Interessen der Rechteinhaber allein auf deren vermögensrechtliche Interessen gestützt werden kann, da - anders als durch die RBÜ, die WIPO„Internet Treaties“ und das europäische Urheberrecht - persönlichkeitsrechtliche Interessen durch das TRIPS-Übereinkommen ausdrücklich nicht geschützt sind. ${ }^{1506}$

\section{Zur Methode der Auslegung des Dreistufentests}

Die Regelungen der Art. 9 Abs. 2 RBÜ, Art. 13 TRIPS und Art. 10 WCT legen für die Ausgestaltung urheberrechtlicher Schranken ein positives und zwei negative Kriterien fest: So sind Schranken des Urheberrechts zulässig, wenn sie (1) für gewisse $e^{1507}$ beziehungsweise bestimmte ${ }^{1508}$ Sonderfälle vorgesehen werden, (2) die normale Auswertung des Werkes

Hugenholtz/Okediji, Limitations and Exceptions, S. 16 ff., Katzenberger, GRUR Int. 2004, 739 (743 ff.); Koelman, EIPR 2006, 28(8), 407; Kur, 8 Rich. J. Global L. \& Bus. 287, 305 ff. (2009); Lucas, in: FS Dietz, S. 423 ff.; ders., EIPR 2010, 32(6), 277; Newby, 51 Stan. L. Rev. 1633 (1999); Oliver, 25 Colum. J.L. \& Arts 119, 133 ff. (2002); Poll/Braun, ZUM 2004, 266 (271 ff.); Ricketson, WIPOStudy, S. 65 ff.; Runge, GRUR Int. 2007, 130; Sun, 5 Nw. J. Tech. \& Intell. Prop. 265 (2007); Ullrich, GRUR Int. 2009, 283; Westkamp, 56 J. Copyright Soc'y U.S.A. 1 (2008).

1505 Die Kriterien des Dreistufentests in seiner Ausformung durch die Richtlinie 2001/29/EG entsprechen denen der konventionsrechtlichen Vorschriften, denen sie nachgebildet sind. Lediglich in Bezug auf die Wirkung des Dreistufentests ergeben sich für das europäische Recht deutliche Abweichungen zum Konventionsrecht; siehe dazu oben 6. Kapitel, C.II. und zugehörige Fußnoten.

1506 Siehe Art. 9 Abs. 1 S. 2 TRIPS i.V.m. Art. $6^{\text {bis }}$ RBÜ; siehe dazu oben 6. Kapitel, A.VII.

1507 So die Formulierung in Art. 9 Abs. 2 RBÜ.

1508 So die Formulierung in Art. 13 TRIPS und Art. 10 WCT. 
durch die Beschränkung nicht beeinträchtigt wird und (3) die berechtigten Interessen des Urhebers ${ }^{1509}$ beziehungsweise des Rechteinhabers ${ }^{1510}$ nicht unzumutbar verletzt werden. Es besteht weitestgehendes Einvernehmen, dass die drei Voraussetzungen des Dreistufentests kumulativ erfüllt sein müssen, damit sich eine Schranke im Rahmen des Zulässigen bewegt. ${ }^{1511}$ Kann eine der Stufen nicht überwunden werden, ist die Schrankenbestimmung folglich grundsätzlich unzulässig. Insbesondere vor dem Hintergrund dieser rigiden Folge ist eine angemessene Auslegung und gegebenenfalls Eingrenzung der einzelnen Tatbestandsmerkmale daher entscheidend, um zu gewährleisten, dass der Dreistufentest seine Funktion als Grundlage und Grenze der Ausgestaltung, Einführung und Auslegung zukunftsfähiger urheberrechtlicher Schranken erfüllen kann.

Die Auslegung internationaler Verträge richtet sich in erster Linie nach den Regeln des Völkergewohnheitsrechts, die in den Artikeln 31 bis 33 des Wiener Übereinkommens über das Recht der Verträge (WÜV) ${ }^{1512}$ vom 23. Mai 1969 kodifiziert sind. ${ }^{1513}$ Im Fall der RBÜ ist jedoch zu beachten, dass diese vor dem Inkrafttreten des WÜV geschlossen wurde und daher grundsätzlich lediglich nach den allgemeinen Grundsätzen des Völkergewohnheitsrechts auszulegen ist. ${ }^{1514}$ Auch hinsichtlich des TRIPSÜbereinkommens und der WIPO-,,Internet Treaties“ ist umstritten, ob diese auf Grundlage des WÜV auszulegen sind. Zum einen ist der Verweis in

1509 So die Formulierung in Art. 9 Abs. 2 RBÜ und Art. 10 WCT.

1510 So die Formulierung in Art. 13 TRIPS.

1511 Vgl. WTO-Panel Report, WT/DS160/R vom 15.6.2000, § 6.97: "The three conditions apply on a cumulative basis, each being a separate and independent requirement that must be satisfied. Failure to comply with any one of the three conditions results in the Article 13 exception being disallowed."; ebenso die ganz h.L., vgl. nur Busche/Stoll/Füller, TRIPs, Art. 13 Rn. 7; Maus, Digitale Kopie, S. 132 f.; Reinbothe, in: FS Dittrich, S. 251 (256); Reinbothe/v.Lewinski, WIPO Treaties, Art. 10 WCT Rn. 14; Ricketson, Berne Convention, S. 482; Senftleben, Three-Step Test, S. 125, jeweils m.w.N.; a.A. Hugenholtz/Okediji, Limitations and Exceptions, S. 21.

1512 BGB1. 1985 II, S. 927.

1513 Ausführlich zur Auslegung völkerrechtlicher Verträge Buck, Geistiges Eigentum und Völkerrecht, S. 117 ff.; umfassend zur Auslegung des Dreistufentests Senftleben, Three-Step Test, S. $99 \mathrm{ff}$.

1514 Nach Art. 4 WÜV findet dieses nur auf solche Verträge Anwendung, die nach Inkrafttreten der Wiener Vertragskonvention geschlossen wurden. Das Übereinkommen entfaltet keine rückwirkende Geltungskraft; vgl. Aust, Modern Treaty Law, S. 8. Umfassend zur Frage der Auslegung der RBÜ nach Völkergewohnheitsrecht und/oder WÜV, Dittrich, in: FS 50 Jahre UrhG, S. 63 (67 ff.). 
Art. 3 Abs. 2 S. 2 TRIPS insoweit nicht eindeutig. Zum anderen ist hinsichtlich der Auslegung von WCT und WPPT zu beachten, dass diese zwar formal dem WÜV unterfallen, jedoch wichtige Vertragsstaaten - wie etwa die USA - dem WÜV nicht beigetreten sind. ${ }^{1515}$ Allerdings ist allgemein anerkannt, dass das WÜV auch dann zur Auslegung eines internationalen Vertragswerkes herangezogen werden kann, wenn dieses formal nicht dem WÜV unterfällt, da das WÜV inhaltlich die Vorgaben des Völkergewohnheitsrechts widerspiegelt. ${ }^{1516}$ Folglich können die Regelungen des WÜV als Richtschnur für die Auslegung des Dreistufentests in allen seinen konventionsrechtlichen Verkörperungen dienen.

Nach Art. 31 Abs. 1 WÜV ist ein Vertrag grundsätzlich nach Treu und Glauben in Übereinstimmung mit der gewöhnlichen, seinen Bestimmungen in ihrem Zusammenhang zukommenden Bedeutung und im Lichte seines Zieles und Zweckes auszulegen. Diese "gewöhnliche Bedeutung“ kann dabei nicht isoliert, sondern nur im Rahmen des gesamten Übereinkommens - insbesondere mit Rücksicht auf dessen Gesamtinhalt, den Zweck und die Entstehungsgeschichte - ermittelt werden. ${ }^{1517}$ Zusätzlich sind nach Art. 31 Abs. 3 WÜV ,in gleicher Weise“ auch spätere Entwicklungen im Zusammenhang mit dem Vertrag - etwa spätere Übereinkünfte zwischen den Vertragsparteien über die Auslegung des Vertrags oder spätere Übungen bei der Anwendung des Vertrags - zu berücksichtigen. Die Panel Reports des WTO-Streitbeilegungsgremiums, in denen sich teilweise ausführliche Überlegungen zur Auslegung des Dreistufentests in seiner TRIPS-Variante finden, ${ }^{1518}$ stellen keine ,späteren Übungen“ oder ,späteren Übereinkünfte“ im Sinne des Art. 31 Abs. 3 WÜV dar. ${ }^{1519}$ Die Panel Reports haben daher keine für die Auslegung bindende Wirkung, sondern können allenfalls als Anknüpfungspunkte für die Auslegung des TRIPSÜbereinkommens herangezogen werden. ${ }^{1520}$ Nach Art. 31 Abs. 3 lit.c

1515 Vgl. Ricketson, WIPO-Study, S. 5.

1516 Vgl. dazu Aust, Modern Treaty Law, S. 10 ff.; Buck, Geistiges Eigentum und Völkerrecht, S. 126 f.; Lennard, 5 J. Int'l Econ. L. 17, 18 f. (2002); Netanel, 37 Va. J. Int'l L. 441, 449 f. (1997); Ricketson/Ginsburg, International Copyright I, 5.15; Sinclair, Vienna Convention, S. 10 ff., jeweils m.w.N.

1517 Vgl. Buck, Geistiges Eigentum und Völkerrecht, S. $128 \mathrm{f}$.

1518 Vgl. insbesondere WTO-Panel Report, WT/DS160/R, dazu oben Fn. 1385.

1519 Vgl. Gray/Cameron, ICLQ 2001, 50(2), 248 (274); Kur, 8 Rich. J. Global L. \& Bus. 287, 328 f. (2009); Senftleben, Three-Step Test, S. 107 ff.

1520 Vgl. Jackson, GATT and WTO, S. 128 f.; Senftleben, Three-Step Test, S. 109 f.; zustimmend Förster, Fair Use, S. 192 f. 
WÜV sind zudem alle zwischen den Vertragsparteien anwendbaren einschlägigen Völkerrechtssätze für die Auslegung heranzuziehen. So kommt etwa eine Heranziehung der Allgemeinen Erklärung der Menschenrechte (AEMR) ${ }^{1521}$ für die Auslegung in Betracht. ${ }^{1522}$ Führt die Auslegung anhand der Kriterien des Art. 31 WÜV zu einem mehrdeutigen oder offensichtlich sinnwidrigen Ergebnis, so können nach Art. 32 WÜV als ergänzende Auslegungsmittel etwa die vorbereitenden Arbeiten und die Umstände des Vertragsabschlusses zur Auslegung herangezogen werden. Art. 33 WÜV schließlich enthält eine Sonderregelung für die Auslegung von Verträgen mit zwei oder mehr authentischen Sprachen. ${ }^{1523}$

\section{Die drei Stufen des Dreistufentests}

Trotz der zentralen Verankerung des Dreistufentests im internationalen und europäischen Urheberrecht und seiner prominenten Rolle bei der Ausgestaltung und Auslegung urheberrechtlicher Schrankenbestimmungen sind weder die einzelnen Tatbestandsmerkmale der drei Teststufen, noch deren genaue Bedeutung und ihr Zusammenspiel bisher abschließend und befriedigend geklärt. Solange die Voraussetzungen des Dreistufentests jedoch derart ungeklärt sind, kann dieser seine Funktion als zentrale Vorschrift für die Gestaltung von Beschränkungen des Urheberrechts nicht wahrnehmen. Im Folgenden sollen daher im Rahmen eines Überblicks über die auslegungsbedürftigen Merkmale der einzelnen Stufen die zu deren Auslegung vertretenen Auffassungen nachgezeichnet und - wo dies sinnvoll erscheint - nach deren kritischer Würdigung eigene Positionen entwickelt werden.

$1521 \mathrm{Zu}$ Inhalt und Bedeutung der AEMR in Bezug auf das Urheberrecht siehe oben 6. Kapitel, A.I.

1522 Vgl. etwa Geiger, IIC 2009, 627 (629 ff.), der sogar die Einfügung eines ausdrücklichen Verweises auf die AEMR im TRIPS-Übereinkommen befürwortet, um so das Übereinkommen zu „konstitutionalisieren“.

1523 Die Auslegungsregel des Art. 33 WÜV könnte hinsichtlich der für die vorliegende Untersuchung relevanten Konventionen etwa bei der Auslegung des TRIPS-Übereinkommens, dessen englische, französische und spanische Sprachfassung verbindlich sind, oder bei der Auslegung des WCT (verbindlich in englischer, arabischer, chinesischer, französischer, russischer und spanischer Sprache) herangezogen werden. Siehe dazu umfassend Linderfalk, Interpretation of Treaties, S. 355 ff. 
a) Bestimmte Sonderfälle

Hinsichtlich der ersten Stufe des Dreistufentests, der Frage nach dem Vorliegen eines „bestimmten Sonderfalls“, drängen sich zwei Auslegungsfragen auf: Auslegungsbedürftig ist zum einen das Kriterium der „Bestimmtheit“, zum anderen der Begriff des ,Sonderfalls“. Dem vorgelagert stellt sich jedoch aufgrund der verglichen mit den beiden anderen Stufen deutlich allgemeineren Natur der ersten Stufe die Frage, ob ihr überhaupt eine eigenständige Bedeutung als „vollwertiges“ Prüfungselement zukommt oder ob sich die Prüfung tatsächlich - wie teilweise in der Literatur vertreten - eher auf einen ,Zweistufentest" reduziert.

\section{aa) Bedeutung der ersten Stufe}

Die Überlegung, dass der ersten Stufe eine eigenständige Bedeutung nicht zukomme, beruht zum einen auf der Tatsache, dass dem ersten Prüfungskriterium bei der Stockholmer Revisionskonferenz, in deren Rahmen der Dreistufentest in die RBÜ aufgenommen wurde, nur wenig Beachtung geschenkt wurde. ${ }^{1524}$ Diese Haltung spiegelt sich auch in der Rezeption des neuen Schrankeninstruments in der frühen Literatur zum Dreistufentest wider, ${ }^{1525}$ so dass die Annahme nahe liegt, dem ersten Prüfungsschritt nicht das gleiche Gewicht beizumessen wie den beiden folgenden Bedingungen.

Eine derartige Reduzierung der Konventionsvorschriften zur Schrankenausgestaltung auf lediglich zwei Bedingungen kann jedoch letztlich

1524 In den Konferenzmaterialien ist die Verpflichtung, Schranken auf bestimmte Sonderfälle zu begrenzen, zwar am Rande erwähnt, es findet sich jedoch keine nähere Auseinandersetzung mit dieser Prüfungsstufe; siehe WIPO, Records of the IP Conference at Stockholm, Report of the Work of Main Committee I, S. 1145; vgl. auch den Konferenzbericht von Reimer/Ulmer, GRUR Int. 1967, 431 (444), in dem Ulmer lediglich den zweiten und dritten Prüfungsschritt näher erläutert.

1525 Vgl. etwa Masouyé, RBÜ, Art. 9 Rn.9.6, der von „zwei kumulativ anwendbare[n] Voraussetzungen" spricht [Hervorhebung durch den Verfasser]; sowie Desbois/Françon/Kéréver, Conventions Internationales, $§ 137$ und Nordemann/ Vinck/Hertin, Internationales Urheberrecht, Art. 9 RBÜ Rn. 3 f., die das erste Kriterium nicht erwähnen. Auch Drexl, Entwicklungsmöglichkeiten, S. 115 f. erwähnt das erste Kriterium nicht. 
nicht überzeugen. Bereits der Wortlaut der Normen und deren Entstehungsgeschichte streiten für eine eigenständige Bedeutung der ersten Stufe. Wäre dieser keinerlei Bedeutung beizumessen, so hätten die Vertragsparteien ohne größeren Aufwand auf eine andere Formulierung zurückgreifen können, die eine Beschränkung auf bestimmte Sonderfälle nicht beinhaltete, ${ }^{1526}$ oder aber erst recht bei der Übernahme der „Ursprungsregelung" aus der RBÜ in weitere Abkommen diesen Passus streichen können. Auch aus systematischer Sicht ist es gerade in Bezug auf die Regelung des Art. 9 Abs. 2 RBÜ sinnvoll, der ersten Stufe eigenständige Bedeutung beizumessen. In Art. 9 Abs. 1 RBÜ wird dem Urheber das ausschließliche Vervielfältigungsrecht eingeräumt. Das erste Kriterium der unmittelbar anschließenden Schrankenregelung in Absatz 2 stellt somit klar, dass das gewährte Mindestrecht nicht etwa in beliebigen Fällen, sondern nur unter besonderen Voraussetzungen eingeschränkt werden darf. Dies setzt in der Regel das Vorliegen eines bestimmten Sonderfalles voraus. ${ }^{1527}$ Es hat sich daher inzwischen allgemein die Überzeugung durchgesetzt, dass im Rahmen des konventionsrechtlichen Dreistufentests der erste Prüfungsschritt als Grundregel und somit als „Eintrittstor zum Abwägungsvorgang " ${ }^{\prime 1528}$ zu den darauf folgenden Stufen nicht etwa eine untergeordnete Rolle spielt, sondern diesem eigenständige Bedeutung zukommt. ${ }^{1529}$ Diese Auffassung spiegelt letztlich auch die internationale Durchsetzung der Bezeichnung „Dreistufentest" beziehungsweise ,threestep test" wider.

Ein abweichender Befund lässt sich jedoch im Hinblick auf den Dreistufentest in seiner Ausformung durch die Richtlinie 2001/29/EG vertreten. In der InfoSoc-Richtlinie findet sich der Dreistufentest im Anschluss an den enumerativen Katalog von Schrankenvorgaben in Art. 5 Abs. 1 bis Abs. 5. Dreier hat daher geltend gemacht, dem Erfordernis eines bestimm-

1526 So auch Frotz, in: FS 50 Jahre UrhG, S. 119 (122); Senftleben, GRUR Int. 2004, 200 (206).

1527 Vgl. Frotz, in: FS 50 Jahre UrhG, S. 119 (122 f.); Senftleben, Three-Step Test, S. 127.

1528 Senftleben, GRUR Int. 2004, 200 (205).

1529 Siehe etwa Bornkamm, in: FS Erdmann, S. 29 (34); Frotz, in: FS 50 Jahre UrhG, S. 119 (124 f.); He, IIC 2009, 274 (279 f.); Katzenberger, GRUR Int. 2004, 739 (744); Maus, Digitale Kopie, S. 132; Nolte, Informationsmehrwertdienste, S. 290; Poeppel, Neuordnung, S. 112; Rehse, Ungeschriebene Schranken, S. 139 f.; Ricketson, Three-Step Test, S. 27; Sattler, Status quo, S. 60; Senftleben, Three-Step Test, S. 126 f.; ders., GRUR Int. 2004, 200 (206). 
ten Einzelfalles komme in diesem Rahmen keine eigenständige Bedeutung zu, da der EU-Gesetzgeber in der Richtlinie die Ausnahmen von den Ausschließlichkeitsrechten bereits auf Einzelfälle beschränkt habe. ${ }^{1530}$ Einer Einschränkung auf faktische Einzelfälle innerhalb der bereits durch die einzelne Schrankenbestimmung festgelegten Einzelfälle bedürfe es angesichts der zwei weiteren Stufen des Dreistufentests auch gar nicht. Die logische Konsequenz sei daher in diesem Rahmen die Reduzierung des Dreistufentests auf einen Zweistufentest. ${ }^{1531}$ Diese Auffassung hat im Hinblick auf den Dreistufentest in seiner Ausformung durch die InfoSocRichtlinie vielfach Zustimmung erfahren. ${ }^{1532}$ Es wäre widersinnig, die nationalen Gesetzgeber zu einer weiteren Konkretisierung zu verpflichten, die die Bildung von Sonderfällen der in den Absätzen 1 bis 4 aufgelisteten Schranken erfordern und somit eine doppelte Beschränkung darstellen würde. Gerade im Hinblick auf die durch Art. 5 Abs. 1 InfoSoc-RL privilegierten ephemeren Vervielfältigungen würde das Ziel einer europäischen Harmonisierung wohl verfehlt, wäre der nationale Gesetzgeber verpflichtet, innerhalb der Kriterien des Art. 5 Abs. 1 InfoSoc-RL bestimmte Sonderfälle zu bilden. Diese Auffassung stützt auch Erwägungsgrund 44 zur Richtlinie, in dessen Satz 2 lediglich das zweite und dritte Kriterium des Dreistufentests erwähnt werden, was nahe legt, dass auch der Richtliniengeber selbst die einzelnen Schranken des Art. 5 Abs. 1 bis 4 InfoSocRL bereits als „bestimmte Sonderfälle“ im Sinne des Dreistufentests verstand. Richtlinienintern kommt der ersten Teststufe somit keine eigenständige Bedeutung zu. Dennoch ist die erste Teststufe auch im Rahmen der InfoSoc-Richtlinie nicht völlig sinnentleert. Durch die (wortgleiche) Übernahme des Dreistufentests in europäisches Richtlinienrecht ist der europäische Gesetzgeber zugleich seiner völkerrechtlichen Verpflichtung ${ }^{1533}$ nachgekommen, die Schrankenbestimmungen im europäischen Recht im Einklang mit den Vorgaben des TRIPS-Übereinkommens und der WIPO-

1530 Siehe Dreier, ZUM 2002, 28 (35).

1531 Siehe Dreier, ZUM 2002, 28 (35).

1532 Siehe etwa Bornkamm, in: FS Erdmann, S. 29 (43); Brinkel, Filesharing, S. 69; Findeisen, Auslegung, S. 166; Freiwald, Private Vervielfältigung, S. 90; Nolte, Informationsmehrwertdienste, S. 290; Rehse, Ungeschriebene Schranken, S. 139; Sattler, Status quo, S. 60 f.; Senftleben, CR 2003, 914 (915); ders., GRUR Int. 2004, 200 (206); Westkamp, 56 J. Copyright Soc'y U.S.A. 1, 25 ff. (2008).

1533 Die EU ist sowohl Vertragspartei des TRIPS-Übereinkommens als auch der WIPO-,,Internet Treaties“; vgl. oben 6. Kapitel, A.VII. und 6. Kapitel, A.VIII. 
„Internet Treaties“ zu begrenzen. ${ }^{1534}$ Auch Erwägungsgrund 44 der Richtlinie hebt die Beachtung der internationalen Verpflichtungen ausdrücklich hervor. Im Konventionsrecht besteht der Dreistufentest jedoch, wie gezeigt, aus drei gleichberechtigten Prüfungsstufen. Nur die vollständige Übernahme des Dreistufentests in die Richtlinie garantiert daher die sichere Einhaltung der internationalen Verpflichtungen. Der Dreistufentest in der Richtlinie kann somit als eine Art „Platzhalter“ für die bestehenden internationalen Verpflichtungen verstanden werden. ${ }^{1535}$ Auch wenn der europäische Gesetzgeber durch die Verwendung eines enumerativen Schrankenkataloges in Art. 5 Abs. 1 bis 4 der Richtlinie bereits den Vorgaben der ersten Teststufe - der Beschränkung von Ausnahmen auf bestimmte Sonderfälle - Rechnung getragen hat, ist jeder einzelne Mitgliedstaat bei der Umsetzung in nationales Recht letztlich dazu aufgerufen, selbst nachzuprüfen, ob eine nach Art. 5 erlaubte Schranke tatsächlich die internationalen Vorgaben erfüllt. ${ }^{1536}$ Der ersten Stufe des Dreistufentests kommt somit innerhalb der InfoSoc-Richtlinie zum einen eine klarstellende Funktion in Bezug auf die Umsetzung konventionsrechtlicher Verpflichtungen zu, zum anderen dient sie als Richtschnur für die nationalen Gesetzgeber bei der konventionskonformen Umsetzung der Schrankenvorgaben der Richtlinie in nationales Recht.

bb) Anforderungen an die Bestimmtheit

Während Art. 9 Abs. 2 RBÜ als erstes Kriterium eine Beschränkung auf „gewisse Sonderfälle“ vorschreibt, wurde von dieser Formulierung in den deutschen Fassungen der nachfolgenden Festschreibungen des Dreistufentests abgewichen und fortan eine Beschränkung auf „,bestimmte Sonderfäl-

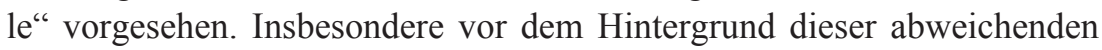
Formulierungen ist in der Literatur über das Kriterium der Bestimmtheit kontrovers diskutiert worden.

1534 Vgl. Bayreuther, ZUM 2001, 828 (839); Reinbothe, ZUM 1998, 429 (434 f.); ders., GRUR Int. 2001, 733 (740).

1535 So anschaulich Senftleben, CR 2003, 914 (915).

1536 Vgl. Brinkel, Filesharing, S. 69; Senftleben, CR 2003, 914 (915). 
Teilweise wird angenommen, das Merkmal sei restriktiv im Sinne eines gesonderten Bestimmtheitsgebotes zu verstehen. ${ }^{1537}$ Ein bestimmter Sonderfall setze klar definierte Ausnahmefälle und einen spezifischen Nutzungszweck voraus, der präzise und eng festgelegt und somit klar identifizierbar sei. ${ }^{1538}$ Ausgeschlossen wären demnach grundsätzlich pauschalierte Beschränkungen der Urheberrechte wie die US-amerikanische Fair Use-Schranke, ${ }^{1539}$ bei denen ein bestimmter Privilegierungszweck nicht erkennbar ist. ${ }^{1540}$

Eine derartige restriktive Auslegung des Bestimmtheitsmerkmals ist jedoch aus mehreren Gründen abzulehnen. Zum einen vermag sie bereits auf Grundlage einer Wortlautauslegung nicht zwingend zu überzeugen. An-

1537 So WTO-Panel Report, WT/DS160/R vom 15.6.2000, § 6.108; Ficsor, Law of Copyright, C10.03; Maus, Digitale Kopie, S. 134 f.; Reinbothe, in: FS Dittrich, S. 251 (257); Reinbothe/v.Lewinski, WIPO Treaties, Art. 10 WCT Rn. 15.

1538 Vgl. WTO-Panel Report, WT/DS160/R vom 15.6.2000, § 6.108: “[A]n exception or limitation in national legislation must be clearly defined"; Ficsor, Law of Copyright, C10.03: "[T]he use to be covered must be specific - precisely and narrowly determined [...] no broadly determined cases are acceptable."; zustimmend Berger, CR 2004, 360 (365); Bornkamm, in: FS Erdmann, S. 29 (46); Busche/Stoll/Füller, TRIPs, Art. 13 Rn. 8; Dusollier, IRDI 2005, 212 (218); Förster, Fair Use, S. 196 f.; Fromm-Russenschuck/Duggal, WTO und TRIPs, S. 54; Reinbothe, in: FS Dittrich, S. 251 (257); Reinbothe/v.Lewinski, WIPO Treaties, Art. 10 WCT Rn. 15; Ricketson, Three-Step Test, S. 29; wohl auch Hohagen, Vervielfältigung zum eigenen Gebrauch, S.96. Vgl. auch Schweizerisches Bundesgericht, Urt. v. 26.6.2007, Az. 4C.73/2007 = GRUR Int. 2007, 1046 (1049) - Elektronische Pressespiegel; siehe dazu die kritische Anmerkung von Born, MR-Int. 2007, $148 \mathrm{ff}$.

1539 Zur Vereinbarkeit der Fair Use-Schranke mit dem Dreistufentest siehe unten 6. Kapitel, C.IV.

1540 Einige Befürworter einer restriktiven Auslegung des Bestimmtheitserfordernisses versuchen jedoch, diese insoweit ,abzufedern“, als sie es als hinreichend bestimmt ansehen, wenn nicht alle denkbaren Ausnahmen explizit geregelt sind, sondern eine Abwägung anhand nachvollziehbarer Kriterien erfolgt, z.B. - wie im Falle der US-amerikanischen Fair Use-Doktrin - durch eine gefestigte Rechtsprechung; vgl. etwa Busche/Stoll/Füller, TRIPs, Art. 13 Rn. 9 (der jedoch wenig überzeugend zum einen ausdrücklich fordert, nationale Beschränkungen dürften nicht pauschal gefasst sein, sondern müssten eindeutig formuliert und definiert sein, zum anderen aber eine transparente Interessenabwägung als hinreichend bestimmt verstehen will und deshalb die Fair Use-Doktrin für mit der ersten Stufe des Dreistufentests vereinbar hält); ähnlich Förster, Fair Use, S. 197. Derartige systematisch nicht überzeugende (Hilfs-)Konstruktionen werden überflüssig, wenn man - wie hier vertreten - eine übermäßige Betonung des Bestimmtheitserfordernisses ablehnt. 
ders als in den deutschen Sprachfassungen des Dreistufentests findet sich etwa in den (verbindlichen) ${ }^{1541}$ englischen Sprachfassungen keine Abweichung zwischen den einzelnen Konventionen. Sowohl in Art. 9 Abs. 2 RBÜ als auch in Art. 13 TRIPS, Art. 10 WCT, Art. 16 WPPT und Art. 5 Abs. 5 der InfoSoc-Richtlinie wird einheitlich die Formulierung „,ertain special cases" verwendet. Diese Formulierung vermag aber eine besondere Betonung des „Bestimmten“, die man in die deutsche Fassung durchaus hineininterpretieren könnte, nicht zu stützen. Vielmehr kann die englische Formulierung ebenso gut in dem Sinne verstanden werden, dass Ausnahmen lediglich in „einigen“ oder ,gewissen“ Sonderfällen zulässig sein sollen. ${ }^{1542}$ Letztlich ist die besondere Hervorhebung dieses Merkmals gerade in der deutschen Sprachfassung das Ergebnis einer unglücklichen Übersetzung, die trotz gleichbleibenden Wortlauts in den Originalfassungen bis heute überlebt hat. Auch die Entstehungs- und Entwicklungsgeschichte des Dreistufentests stützt diesen Befund. Ein früher, von den USA eingebrachter Entwurf für das TRIPS-Übereinkommen etwa enthielt die Vorgabe, Schranken sollten auf ,clearly and carefully defined special cases“ beschränkt sein. ${ }^{1543}$ Diese oder ähnliche Formulierungen konnten sich allerdings letztlich gerade aufgrund der damit verbundenen einschränkenden Wirkung nie durchsetzen und wurden stets im Zuge der Verhandlungen zugunsten der Formulierung ,certain special cases“ gestrichen. ${ }^{1544}$

1541 Englisch stellt nach Art. 24 Abs. 1 WCT, Art. 32 Abs. 1 WPPT und der Schlusspassage des Übereinkommens zur Errichtung der Welthandelsorganisation, dessen Annex 1C das TRIPS-Übereinkommen ist, eine authentische und somit für die Auslegung verbindliche Sprache für Art.10 WCT, Art. 16 WPPT und Art. 13 TRIPS dar. Für die Auslegung der RBÜ hat nach Art. 37 Abs. 1 lit. c RBÜ im Zweifel der französische Text Vorrang. Allerdings ergeben sich aus der französischen Sprachfassung des Art. 9 Abs. 2 RBÜ, die von „,certains cas spéciaux" spricht, keine abweichenden Schlussfolgerungen, so dass der englische Text nach Art. 37 Abs. 1 lit. a RBÜ gleichermaßen verbindlich ist.

1542 Vgl. Senftleben, GRUR Int. 2004, 200 (206). Diese Auslegung stützt auch die französische Sprachfassung. Die Wortwahl „,certains cas spéciaux“ spricht deutlich dafür, dass dem Begriff „,certains“ keine eigenständige Bedeutung im Sinne eines zusätzlichen Bestimmtheitserfordernisses zukommen sollte. Andernfalls hätte die Formulierung „cas certains et spéciaux“ nahegelegen. Vgl. ausführlich zu dieser Argumentation und insgesamt zur Auslegung der Formulierung unter Rückgriff sowohl auf die englische als auch auf die französische Sprachfassung Senftleben, Three-Step Test, S. 133 ff.; ders., GRUR Int. 2004, 200 (206 f.).

1543 Siehe Draft Agreement on the Trade-Related Aspects of Intellectual Property Rights, GATT-Dokument MTN.GNG/NG11/W/70, S. 6.

1544 Vgl. Senftleben, Three-Step Test, S. 134 m.w.N. 
Schließlich sprechen auch teleologische Überlegungen gegen ein zu restriktives Verständnis des Bestimmtheitsmerkmals. Durch ein enges Bestimmtheitserfordernis würde letztlich die kontinentaleuropäische Regelungstechnik der enumerativen Kataloge von Einzeltatbeständen mit begrenztem Anwendungsbereich auf Grundlage des Konventionsrechts für (einzig) maßgeblich erklärt. ${ }^{1545}$ Dies kann und sollte jedoch nicht der Zweck der ersten Stufe des Dreistufentests sein, wie ein Blick auf die Konsequenzen eines solch engen Verständnisses verdeutlicht: Zum einen wäre in diesem Fall die US-amerikanische Fair Use-Doktrin wohl nicht mit dem Dreistufentest vereinbar. Die Geschichte der Entstehung des Dreistufentests und seiner Implementierung in das Konventionsrecht zeigt jedoch, dass der flexible Wortlaut des Dreistufentests sich gerade deshalb durchsetzen konnte, weil auf diese Weise die internationalen Vereinbarungen neben dem kontinentaleuropäischen Ansatz gerade auch andere Regelungstechniken, insbesondere die angloamerikanischen Schrankengeneralklauseln mit generellem Anwendungsbereich und weitgehend unbestimmten Tatbestandsmerkmalen, zu legitimieren vermochten. ${ }^{1546}$ Die Zulässigkeit offener Schrankengeneralklauseln wie der Fair Use-Doktrin sollte also gerade nicht in Frage gestellt werden. ${ }^{1547}$ Zum anderen würde durch eine enge Auslegung des Bestimmtheitserfordernisses auch der Weg für die zukünftige Einfügung flexiblerer Schranken oder Schrankenelemente weitgehend verbaut. Dass flexiblere Elemente im Bereich der Schranken des Urheberrechts jedoch dringend erforderlich sind, hat diese Untersuchung bereits gezeigt. ${ }^{1548}$

Zusammenfassend lässt sich somit festhalten, dass eine enge Auslegung des Bestimmtheitserfordernisses der ersten Teststufe im Sinne eines echten Bestimmtheitsgebotes, das eine präzise und enge Umschreibung einzelner Schrankenvorschriften erfordert, nicht überzeugen kann. Wie die

1545 Vgl. Nolte, Informationsmehrwertdienste, S. 291; Poeppel, Neuordnung, S. 113; Senftleben, Three-Step Test, S. 135.

1546 So wurde die letztlich bei der Stockholmer Konferenz angenommene finale Formulierung des Art. 9 Abs. 2 RBÜ von der Delegation Großbritanniens vorgeschlagen, einem Land, das traditionell auch einer generalklauselartigen Schrankentechnik folgt und dessen zentrales Schrankenkonzept das fair dealing darstellt.

1547 So auch Geiger, EIPR 2007, 29(12), 486 (487); ders., IIC 2009, 627 (633 f.); Ginsburg, RIDA 187 (2001), 3 (35 f.), jeweils m.w.N.

1548 Siehe zur Notwendigkeit, mehr Flexibilität im Bereich der urheberrechtlichen Schranken zu schaffen, oben S. $279 \mathrm{ff}$. 
Auslegung des Bestimmtheitsmerkmals gezeigt hat, ist eine übermäßige Betonung der „Bestimmtheit“ im Rahmen der ersten Stufe des Dreistufentest weder erforderlich noch geboten und daher abzulehnen. Glücklicher und deutlicher wäre insofern die einheitliche Verwendung der Formulierung ,gewisse Sonderfälle“ auch in allen deutschen Sprachfassungen des Dreistufentests, da so das Augenmerk im Rahmen der ersten Teststufe schwerpunktmäßig auf das Erfordernis des „Sonderfalls“ gelenkt würde. Durch dieses Verständnis wird zugleich sichergestellt, dass der Dreistufentest den Gesetzgeber nicht daran hindert, offene Beschränkungen beizubehalten oder einzuführen, solange die Reichweite derartiger Beschränkungen hinreichend vorhersehbar ist. Eine hinreichende Vorhersehbarkeit ist auch dann gegeben, wenn eine Abwägung anhand etablierter und nachvollziehbarer Kriterien erfolgt - etwa solchen, die in gefestigter Rechtsprechung entwickelt wurden. ${ }^{1549}$

\section{cc) Vorliegen eines Sonderfalls}

Auch das zweite Merkmal der ersten Teststufe ist jedoch auslegungsbedürftig. Im Hinblick auf die Frage, wann ein „Sonderfall“ im Sinne des Dreistufentests vorliegt, werden im Wesentlichen zwei Ansätze vertreten.

Zum einen wird der Begriff im Sinne eines quantitativen Kriteriums verstanden. Die Zulässigkeit einer urheberrechtlichen Schranke soll demnach wesentlich davon abhängen, wie groß die zu erwartende Zahl der privilegierten Nutzungshandlungen ist. Wird lediglich eine begrenzte Anzahl von Verwertungsvorgängen erfasst oder lediglich eine kleine Nutzergruppe angesprochen, so würde ein Sonderfall gegenüber den Fällen der normalen Verwertung vorliegen. ${ }^{1550}$ Ein solcher rein quantitativer Ansatz kann jedoch aus verschiedenen Gründen nicht überzeugen. Es kann nicht darauf ankommen, wie groß die (potentielle) Nutzergruppe einer Schran-

1549 So etwa bei der durch die US-amerikanische Rechtsprechung detailliert ausgeformten Fair Use-Doktrin; siehe dazu unten 6. Kapitel, C.IV.

1550 Vgl. WTO-Panel Report, WT/DS160/R vom 15.6.2000, § 6.109, § 6.111-112; zustimmend Ginsburg, RIDA 187 (2001), 3 (41 f.); Reinbothe, in: FS Dittrich, S. 251 (257); Ricketson, WIPO-Study, S. 22; Ricketson/Ginsburg, International Copyright I, 13.11. Unklar Reinbothe/v.Lewinski, WIPO Treaties, Art. 10 WCT Rn. 15, die zum einen eine ,limited application“" verlangen, zum anderen jedoch einen Sonderfall anhand eines ,specific and sound policy objective“ messen wollen. 
kenregelung oder wie hoch die zu erwartende Zahl der Nutzungshandlungen ist. Eine solche Betrachtung ist zwangsläufig zu starr, um den hinter der Einführung einer Schrankenvorschrift stehenden komplexen Überlegungen zum Ausgleich berechtigter Interessen gerecht zu werden. ${ }^{1551}$ Auch aus systematischen Gründen sieht sich eine quantitative Betrachtung Bedenken ausgesetzt. Art. 31 WÜV fordert eine Auslegung völkerrechtlicher Bestimmungen ,in ihrem Zusammenhang“. Das Merkmal des „Sonderfalls" darf daher nicht isoliert betrachtet werden, sondern muss auch mit Rücksicht auf die weiteren Stufen des Dreistufentests ausgelegt werden. ${ }^{1552}$ Eine quantitative Betrachtung der Beschränkung erfolgt jedoch bereits auf der zweiten Stufe des Dreistufentests bei der Frage nach einer Beeinträchtigung der normalen Werkverwertung. Betrifft eine Schrankenbestimmung lediglich eine geringe Zahl von Nutzungshandlungen, so wird in der Regel eine Beeinträchtigung der normalen Auswertung ausscheiden. Ist hingegen eine Vielzahl von Nutzungshandlungen privilegiert oder eine (besonders) große Nutzergruppe angesprochen, so ist eine Beeinträchtigung der normalen Werkverwertung wahrscheinlicher. Wären bereits auf der ersten Stufe allein quantitative Aspekte maßgeblich, würde die zweite Stufe weitgehend sinnentleert. ${ }^{1553}$ Schließlich wäre eine rein quantitative Betrachtung auch aus praktischer Sicht zweifelhaft. Gerade im „digitalen Zeitalter" wird es aufgrund des schnellen Wandels des sozialen, ökonomischen und technologischen Umfeldes aufwendig oder oftmals unmöglich sein, einen Überblick über den Nutzerkreis oder gar die Zahl der Nutzungshandlungen zu erlangen. ${ }^{1554}$ Zudem mag die Zahl der Nutzer etwa durch die weltweite Online-Verbreitung eines Werkes enorm hoch sein, ohne dass sich daraus zwingend Rückschlüsse auf die Erheblichkeit der Nutzung und somit auf die Frage des Vorliegens eines Sonderfalles ziehen ließen.

1551 Senftleben, in: Hilty/Peukert, Interessenausgleich, S. 159 (178) verwendet in Anlehnung an die Entscheidung des Bundesverfassungsgerichts in der Rechtssache Germania 3 (GRUR 2001, 149) das treffende Beispiel, dass es im Rahmen des Zitatrechts für die Qualifikation als Sonderfall unmöglich von Belang sein könne, wie oft eine Textstelle eines gewissen Umfangs ohne Zustimmung des Urhebers genutzt werden kann.

1552 Auf diesen Aspekt weist zutreffend Förster, Fair Use, S. 194 hin.

1553 So auch Senftleben, Three-Step Test, S. 144; ders., GRUR Int. 2004, 200 (207); zustimmend He, IIC 2009, 274 (292 f.); Nolte, Informationsmehrwertdienste, S. 292; Poeppel, Neuordnung, S. 114; Sattler, Status quo, S. 64.

1554 Vgl. He, IIC 2009, 274 (289); Senftleben, GRUR Int. 2004, 200 (207). 
Nach der Gegenansicht ist nicht eine quantitative Betrachtung, sondern eine qualitative Bewertung vorzunehmen. Es soll demnach für die Bewertung als Sonderfall entscheidend darauf abgestellt werden, welchem Zweck eine Beschränkung des Urheberrechts dient. ${ }^{1555}$ Dient die Schrankenbestimmung der Durchsetzung von Grundrechten, wie der Informations- oder Meinungsfreiheit oder anderen hochrangigen Allgemeinwohlbelangen, so soll von einem Sonderfall auszugehen sein. ${ }^{1556}$ Anhaltspunkte für eine ausreichende qualitative Fundierung einer Schrankenregelung soll dabei das internationale Urheberrecht bieten, etwa der Schrankenkatalog der RBÜ oder die Präambel des WCT. ${ }^{15571558}$ Ein Sonderfall soll indes nicht vorliegen, wenn die Rechtfertigung für eine Schranke so schwach ist, dass eine sinnvolle Abwägung gegen berechtigte Interessen des Urhebers ausgeschlossen erscheint. ${ }^{1559}$ Auch diese rein qualitative Betrach-

1555 So erstmals Ricketson, Berne Convention, S. 482, der allerdings in jüngerer Zeit von diesem Standpunkt abgewichen ist, siehe Ricketson, WIPO-Study, S. 22 (,[T] he phrase 'certain special cases' should not be interpreted as requiring that there should also be some 'special purpose' underlying it."); ders., ThreeStep Test, S. 31 („There is no further requirement at this stage of the analysis to point to some specific public policy or exceptional circumstance justifying the exception.") sowie Ricketson/Ginsburg, International Copyright I, 13.14. Die ursprüngliche qualitative Betrachtung von Ricketson hat jedoch vielfach Zustimmung erfahren, siehe etwa Bornkamm, in: FS Erdmann, S. 29 (45 f.); Ficsor, Law of Copyright, C10.03; Goldstein, International Copyright, S. 295; Hohagen, Vervielfältigung zum eigenen Gebrauch, S. 96; Lucas, in: FS Dietz, S. 423 (429 f.); Sattler, Status quo, S. 64; Senftleben, Three-Step Test, S. 144 ff.

1556 Vgl. Ficsor, Law of Copyright, 5.55 und C10.03; ders., RIDA 192 (2002), 111 (129); Goldstein, International Copyright, S. 295; Koelman, EIPR 2006, 28(8), 407 (409); Nolte, Informationsmehrwertdienste, S. 292; Rehse, Ungeschriebene Schranken, S. 141; Reinbothe/v.Lewinski, WIPO Treaties, Art. 10 WCT Rn. 15; Ricketson, Berne Convention, S. 482; Runge, GRUR Int. 2007, 130 (134); Sattler, Status quo, S. 64; Senftleben, Three-Step Test, S. 144 ff.; ders., in: Hilty/ Peukert, Interessenausgleich, S. 159 (178 f.); ders., CR 2003, 914 (916); ders., GRUR Int. 2004, 200 (207 f.).

1557 Die Präambel des WCT hebt als wichtigen Belang allgemein das „öffentliche Interesse, insbesondere Bildung, Forschung und Zugang zu Informationen, zu wahren" hervor.

1558 Siehe Ficsor, Law of Copyright, 5.55 und C10.03; ders., RIDA 192 (2002), 111 (129); Reinbothe/v.Lewinski, WIPO Treaties, Art. 10 WCT Rn. 15; Senftleben, Three-Step Test, S. 144 f.; ders., in: Hilty/Peukert, Interessenausgleich, S. 159 (179); zustimmend Lüghausen, Auslegung von § 53 I S. 1 UrhG, S. 159.

1559 Siehe Senftleben, GRUR Int. 2004, 200 (207). 
tungsweise ist jedoch Bedenken ausgesetzt. ${ }^{1560}$ So greift eine Prüfung der (grund-)rechtlichen Fundierung und des Zwecks einer Schrankenregelung teilweise der Prüfung der dritten Stufe vor und läuft daher Gefahr, die Konturen des Dreistufentests zu verwischen. Ob eine ungebührliche Verletzung der Urheberinteressen vorliegt, hängt schließlich nicht zuletzt davon ab, welches Gewicht den hinter einer Beschränkung stehenden (Allgemein-)Interessen zukommt und ob die Schrankenregelung somit einem legitimen Zweck dient. Auch ein Rückgriff auf den Schrankenkatalog der RBÜ oder die Präambel des WCT als Anhaltspunkte für „qualitativ hochwertige" Zwecke erscheint letztlich nicht weiterführend. Zum einen betreffen die in der RBÜ ausdrücklich zugelassenen Schranken spezielle Nutzungsformen, die gerade in der Zeit der Entstehung beziehungsweise Revisionen der RBÜ für relevant gehalten wurden. Anhaltspunkte für neue Nutzungsarten und somit für die gerade im Zeitalter digitaler Nutzung problematischen Fälle enthält der Schrankenkatalog der RBÜ deshalb nicht. Die in der Präambel des WCT hervorgehobenen Interessen der Allgemeinheit etwa am „Zugang zu Informationen“ sind hingegen so weit und offen gefasst, dass sie eine echte Leitlinie für den Gesetzgeber oder Rechtsanwender kaum darstellen können. Da die Schranken gerade das entscheidende Rechtsinstrument darstellen, um das Urheberrecht mit den individuellen und kollektiven Interessen der Allgemeinheit in Einklang zu bringen, ist die Einführung einer Urheberrechtsschranke, die nicht einem der in der Präambel genannten Interessen dient, kaum vorstellbar.

Trotz dieser Schwächen erscheint ein qualitativer Ansatz zur Bestimmung von „Sonderfällen“ letztlich vorzugswürdig. Entgegen entsprechender Bedenken in der Literatur wird die erste Stufe bei qualitativer Ermittlung des Vorliegens eines „Sonderfalles“ weder inhaltsleer ${ }^{1561}$ noch nimmt sie den weiteren Stufen der Prüfung ihre Bedeutung. Der ersten Stufe kommt tatsächlich die wichtige Aufgabe zu, die hinter einer Schrankenregelung stehenden Belange zu bestimmen und so den Weg für eine vertiefende Überprüfung einer Schrankenbestimmung auf den folgenden Stufen zu ebnen. Durch ein derartiges Verständnis der ersten Prüfungsstufe wird die dreistufige Prüfung insgesamt entzerrt und somit letztlich übersichtlich und nachvollziehbar gestaltet. Insbesondere die auf der dritten Stufe vorzunehmende Abwägung der beteiligten Interessen wird so deut-

1560 Auch He, IIC 2009, 274 (291 f.) und Poeppel, Neuordnung, S. 115 machen auf die Schwächen dieses Ansatzes aufmerksam.

1561 So aber Poeppel, Neuordnung, S. 115. 
lich erleichtert. Eine allein quantitative Bewertung ist hingegen keinesfalls geeignet, den hinter der Einführung einer Schrankenvorschrift stehenden Überlegungen zum Ausgleich berechtigter Interessen gerecht zu werden. Zugleich würde durch ein derartiges Vorgehen der zweiten Prüfungsstufe weitgehend die Bedeutung genommen.

\section{b) Beeinträchtigung der normalen Auswertung}

Die zweite Stufe des Dreistufentests legt fest, dass eine urheberrechtliche Beschränkung die normale Auswertung des Werkes nicht beeinträchtigen darf. Die Formulierung stellt klar, dass im Bereich der normalen Auswertung des Werkes Ausnahmen grundsätzlich unzulässig sein sollen. ${ }^{1562}$ Eine Aussage darüber, was die „,normale Auswertung“ eines Werkes ist und wann diese „beeinträchtigt“ ist, enthält der Dreistufentest nicht.

Die „Auswertung“ beziehungsweise „Verwertung“ eines urheberrechtlich geschützten Werkes lässt sich als die Erzielung eines wirtschaftlichen Nutzens mittels einer Nutzungsrechtseinräumung auf der Grundlage der urheberrechtlichen Ausschließlichkeitsrechte definieren. ${ }^{1563}$ Durch die Beschränkung auf die „,normale“ Auswertung wird deutlich, dass im Rahmen der zweiten Teststufe eine gewisse Einschränkung erfolgen muss, so dass nicht jede Form der Auswertung urheberrechtlich geschützten Materials erfasst wird. ${ }^{1564}$ Wann in diesem Zusammenhang allerdings von einer „normalen“ Verwertung gesprochen werden kann, bleibt bei dieser Definition offen. Eine sachgerechte Auslegung und Eingrenzung dieses Kriteriums ist jedoch gerade für die Anwendung des Dreistufentests im Hinblick auf neue Nutzungsarten insbesondere im digitalen Umfeld von entscheidender Bedeutung, da die von mangelnder Flexibilität gekennzeichnete zweite Prüfungsstufe das „Potential“ hat, eine erhebliche Hürde für die Zulässigkeit neuer ebenso wie bestehender Schrankenregelungen darzustellen. Insofern ist zu beachten, dass - anders als auf der dritten Prüfungs-

1562 Vgl. Desbois/Françon/Kéréver, Conventions Internationales, §173; Reimer/ Ulmer, GRUR Int. 1969, 431 (444).

1563 Siehe WTO-Panel Report, WT/DS160/R, § 6.165; ähnlich Gervais, 9 Marq. Intell. Prop. L. Rev. 1, 16 (2005).

1564 Würde die ,normale“ Auswertung mit der vollständigen Auswertung der urheberrechtlichen Ausschließlichkeitsrechte gleichgesetzt, bliebe letztlich kein Raum für zulässige Beschränkungen der ausschließlichen Verwertungsrechte; vgl. WTO-Panel Report, WT/DS160/R, § 6.167. 
stufe - auch die Zahlung einer angemessenen Vergütung keinerlei Einfluss auf die Bewertung dieser Stufe haben soll. ${ }^{1565}$ Bereits diese starre Folge verdeutlicht die Notwendigkeit einer sachgerechten Auslegung und Einschränkung der zweiten Teststufe. Verstärkt wird dieses Bedürfnis durch die Notwendigkeit einer Berücksichtigung neuer technischer Entwicklungen, insbesondere im digitalen Umfeld: Während sich eine Trennlinie zwischen „normaler“ und „nicht-normaler“ Auswertung eines Werkes zur Zeit der Entstehung des Dreistufentests zumeist noch relativ scharf ziehen ließ, verschwimmen derartige Konturen im digitalen Kontext zwangsläufig immer mehr. So konnte im ,analogen Zeitalter“ eine gewöhnliche Verwertungsform zumeist recht eindeutig identifiziert werden, insbesondere da für viele Werke lediglich ein klar definier- und abgrenzbarer (Haupt-)Markt bestand. Im digitalen Umfeld, in dem ständig neue Verwertungsmöglichkeiten entstehen oder sich bestehende Auswertungsformen durch den Einsatz digitaler Technologie - etwa technischer Schutzmaßnahmen - ändern und dabei häufig einander annähern, ist eine (sinnvolle) Abgrenzung von „normaler“ und „nicht-normaler“ Verwertung aufgrund der sich verschiebenden oder der neu entstehenden Märkte hingegen zumeist kaum noch möglich. Ein zu weites Verständnis der „normalen Auswertung" birgt daher die Gefahr, die Schrankenregelungen zu stark zugunsten der Urheber auszugestalten und so die Interessen der Allgemeinheit zu vernachlässigen. Vor diesem Hintergrund ist bereits vielfach versucht worden, sinnvolle Ansätze zur Auslegung und Eingrenzung des Anwendungsbereichs der zweiten Teststufe zu entwickeln. Anhand dieser Ansätze soll im Folgenden überlegt werden, wie das zweite Prüfungskrite-

1565 Siehe WIPO, Records of the IP Conference at Stockholm, Report of the Work of Main Committee I, S. 1145 f. Diese Annahme wird auch von der ganz h.M. in der Literatur geteilt, siehe etwa Berger, CR 2004, 360 (365); Bornkamm, in: FS Erdmann, S. 29 (47); Geiger, EIPR 2007, 29(12), 486 (490); Nolte, Informationsmehrwertdienste, S. 298; Ricketson, Berne Convention, S. 484; ders., IPQ 1999, 56 (70); Ricketson/Ginsburg, International Copyright I, 13.25; Senftleben, Three-Step Test, S. 170; ders., in: Hilty/Peukert, Interessenausgleich, S. 159 (179 f.). A.A. aber wohl der BGH, der in seiner Entscheidung zum „Kopienversanddienst" die zweite Teststufe des Dreistufentests vollständig überspringt und lediglich feststellt: ,Die Vorschrift des Art. 9 Abs. 2 RBÜ läßt es - in ihrem auf Sonderfälle beschränkten Anwendungsbereich - zu, eine unzumutbare Verletzung der berechtigten Interessen des Urhebers ebenso wie eine - etwa gegebene - Beeinträchtigung der normalen Auswertung des Werkes, die mit der Freistel- 
rium eingegrenzt und zugleich für den auf der dritten Prüfungsstufe folgenden umfassenden Interessenausgleich dienstbar gemacht werden kann.

aa) Historische Auslegung

Als Ausgangspunkt mögen hierbei die Überlegungen der zuständigen Kommission im Rahmen der Stockholmer Revisionskonferenz zur Berner Übereinkunft dienen, in deren Rahmen der Dreistufentest in die RBÜ aufgenommen wurde. Zur Erläuterung des Dreistufentests findet sich in den Tagungsberichten folgendes Anwendungsbeispiel, das sich auf das damals besonders aktuelle Problem der Vervielfältigung von urheberrechtlich geschützten Materialien zu verschiedenen Zwecken im Wege der Fotokopie bezog:

„A practical example might be photocopying for various purposes. If it consists of producing a very large number of copies, it may not be permitted, as it conflicts with a normal exploitation of the work. If it implies a rather large number of copies for use in industrial undertakings, it may not unreasonably prejudice the legitimate interests of the author, provided that, according to national legislation, an equitable remuneration is paid. If a small number of copies is made, photocopying may be permitted without payment, particularly for individual or scientific use." 1566

Das Anwendungsbeispiel verdeutlicht anhand einer Abstufung nach der Anzahl der gefertigten Vervielfältigungsstücke, dass der Intensität, mit der in das Ausschließlichkeitsrecht des Rechteinhabers eingegriffen wird, entscheidende Bedeutung für die Abgrenzung der einzelnen Stufen des Dreistufentests zukommt. Unter Bezugnahme auf diese Erwägungen bei der Stockholmer Revisionskonferenz und insbesondere unter Rückgriff auf

lung vom Ausschließlichkeitsrecht des Urhebers verbunden wäre, durch die Zuerkennung eines Vergütungsanspruchs zu beseitigen."; siehe BGHZ 141, 13 (33) - Kopienversanddienst unter Bezugnahme auf Reimer/Ulmer, GRUR Int. 1969, 431 (444). Dem vom BGH zitierten Beitrag lässt sich diese Aussage jedoch tatsächlich nicht entnehmen. Ulmer schreibt im Rahmen eines Beispiels zur gewerblichen Fotokopie: „Auch hier kann aber der Gesichtspunkt, daß dem Urheber ein unzumutbarer Schaden zugefügt wird, entfallen, wenn die nationale Gesetzgebung wenigstens eine angemessene Vergütung vorsieht.“ Diese Aussage, die sich bei näherer Betrachtung eindeutig auf die dritte Prüfungsstufe bezieht, missversteht der BGH.

1566 WIPO, Records of the IP Conference at Stockholm, Report of the Work of Main Committee I, S. 1145 f. [Hervorhebungen durch den Verfasser]. 
den Konferenzbericht von Ulmer, ${ }^{1567}$ der der zuständigen Kommission vorsaß, vertritt Bornkamm deshalb die Auffassung, für eine sinnvolle Abgrenzung der zweiten Stufe zur dritten Stufe sei es erforderlich, eine Beeinträchtigung der normalen Auswertung nur dann anzunehmen, wenn die fragliche Nutzung in unmittelbaren Wettbewerb zu herkömmlichen Formen der Werknutzung tritt. ${ }^{1568}$ Mittelbare nachteilige Effekte auf die herkömmliche Verwertung sollen hingegen erst im Rahmen des dritten Prüfungsschrittes $\mathrm{zu}$ beachten sein. ${ }^{1569}$ Der Wirkungsbereich der zweiten Teststufe wäre demnach auf direkte Eingriffe in traditionelle Primärverwertungsformen eines Werkes beschränkt.

Während diese historische Betrachtungsweise Bornkamms den Vorteil einer klaren Trennung der zweiten und dritten Teststufe für sich reklamieren kann, kann sie aus anderen Gründen nicht überzeugen. Die inhaltliche Beschränkung der zweiten Teststufe auf traditionelle Verwertungsformen vermag dem technischen Wandel und der damit einhergehenden Veränderung der Nutzung urheberrechtlich geschützter Werke nicht gerecht zu werden. Zum einen wird es gerade im digitalen Umfeld zunehmend schwieriger, überhaupt eine oder gar die ,herkömmliche“ Verwertung eines Werkes zu definieren, insbesondere dann, wenn neue Technologien ganz neue Märkte entstehen lassen oder neue Arten der Werkverwertung neben die traditionellen Formen treten und so zu zusätzlichen Optionen für die Rechteinhaber führen, ohne eine herkömmliche Verwertungsform vollständig zu ersetzen. ${ }^{1570}$ Selbst wenn jedoch eine ,normalen Verwertung" in diesem Sinne ermittelt werden kann, erscheint die Prüfung, ob im konkreten Fall ein „unmittelbares Konkurrenzverhältnis“ vorliegt, als wei-

1567 Reimer/Ulmer, GRUR Int. 1969, 431. Ulmer vertritt die Auffassung, dass etwa die Vervielfältigung literarischer Werke durch den Buchdruck oder die Veranstaltung einer Neuauflage im Wege der fotomechanischen Vervielfältigung dem Bereich der normalen Auswertung zuzuordnen seien. Keine normale Verwertungsart sei hingegen beispielsweise die Herstellung einzelner Fotokopien. Hier komme es vielmehr darauf an, ob den berechtigten Interessen der Urheber ein unzumutbarer Schaden zugefügt werde, wobei man davon ausgehen könne, dass die Herstellung einzelner Fotokopien, die zu rein persönlichen oder wissenschaftlichen Zwecken erfolgt, nicht als unzumutbarer Schaden anzusehen sei und daher von den nationalen Gesetzgebern gestattet werden könne; siehe Reimer/Ulmer, a.a.O., S. 444.

1568 Siehe Bornkamm, in: FS Erdmann, S. 29 (34, 47); zustimmend Grassmann, Elektronischer Kopienversand, S. 155.

1569 Vgl. Bornkamm, in: FS Erdmann, S. 29 (34).

1570 So auch Nolte, Informationsmehrwertdienste, S. 299. 
tere teilweise nur schwer zu ermittelnde Vorgabe. Der entscheidende Makel dieses Ansatzes ist jedoch darin zu sehen, dass die zweite Teststufe des Dreistufentests bei einer derartigen historischen Herangehensweise aufgrund ihres statischen Charakters mit fortschreitender Entwicklung der Verwertungsarten zwangsläufig ihre Bedeutung verlieren würde. Das Ergebnis wäre letztlich eine Reduzierung des Dreistufentests auf einen Zweistufentest, ${ }^{1571}$ die im Widerspruch zum Anspruch eines effektiven Urheberschutzes durch die Konventionen und das europäische Recht stünde. ${ }^{1572}$

In Anbetracht der vielfältigen Kritik an der mangelnden Flexibilität der zweiten Teststufe mag ein derartiges Ergebnis von vielen Kritikern als „kleineres Übel“ gegenüber einer zu engen Auslegung der zweiten Stufe akzeptiert werden. Es erscheint dennoch unglücklich, eine Auslegung zu wählen, die letztlich einer der Stufen des Dreistufentests zumindest „schleichend“ die Bedeutung entzieht. Vielmehr erscheint es vorzugswürdig, eine Auslegung zu finden, die weder einzelne Stufen des Dreistufentests überbetont und diese zu Ausschlusskriterien im Rahmen der dreistufigen Prüfung werden lässt, noch einzelne Stufen völlig inhaltsleer werden lässt.

Letztlich lässt sich in Fällen, in denen sich eine herkömmliche Auswertungsform eindeutig ermitteln lässt und eine privilegierte Handlung in unmittelbare Konkurrenz zu eben dieser Primärverwertung tritt, bereits mit Hilfe der historischen Herangehensweise begründen, dass eine Beeinträchtigung der normalen Auswertung im Sinne der zweiten Teststufe vorliegt und die Schrankenregelung somit wegen Verstoßes gegen den Dreistufentest unzulässig sein muss. Wenn jedoch - wie es aufgrund technologischer Neuerungen und der damit verbundenen Verschiebung und Neuentstehung von Märkten häufig der Fall sein wird - eine „,normale“, herkömmliche Verwertungsform in diesem Sinne nicht eindeutig zu ermitteln ist, scheitert der historische Ansatz aufgrund seines zu statischen Charakters.

1571 Ebenso Senftleben, Three-Step Test, S. 170; ders., CR 2003, 914 (917).

1572 Siehe auch Hohagen, Vervielfältigung zum eigenen Gebrauch, S. 101 f., der diesen historischen Ansatz einerseits - zu Recht - als zu statisch kritisiert, andererseits jedoch - letztlich kaum weniger statisch - die „,normale Auswertung“ unter Einbeziehung der modernen Formen der Werkverwertung im digitalen Kontext als diejenigen Hauptverwertungsformen definiert, denen gegenwärtig eine wichtige wirtschaftliche und praktische Bedeutung zukommt. 
bb) Normative Auslegung

Einen völlig anderen und deutlich weitergehenden Ansatz zur Auslegung der zweiten Teststufe wählte das WTO-Panel im Streitbeilegungsverfahren „United States - Section 110(5) of the US Copyright Act ${ }^{\prime 1}{ }^{1573}$ Es ist dabei allerdings auch zu beachten, dass die Auslegung des WTO-Panels sich ausschließlich auf die Regelung des Art. 13 TRIPS bezog. Das TRIPS-Übereinkommen verfolgt - anders als die anderen Konventionen und insbesondere auch die InfoSoc-Richtlinie - in erster Linie ökonomische Ziele, so dass auch die Auslegung des WTO-Panels in diesem Lichte zu sehen ist. Das Ergebnis des WTO-Panels muss bereits aus diesem Grund hinsichtlich seiner Übertragbarkeit auf die anderen Erscheinungsformen des Dreistufentests, insbesondere in seiner Ausformung durch die InfoSoc-Richtlinie, die auch wesentlich auf die soziale und kulturelle Dimension des Urheberrechts fokussiert ist, kritisch betrachtet werden. ${ }^{1574}$

Auf Basis einer sorgfältigen Wortlautauslegung unter Heranziehung von Wörterbuchdefinitionen vertrat das WTO-Panel die Auffassung, der Begriff ,normal“ könne in der englischen Sprache auf zwei unterschiedliche Arten verstanden werden. Zum einen komme dem Begriff eine eher empirische Bedeutung im Sinne von "regular, usual, typical or ordinary" zu. Zum anderen könne der Begriff jedoch auch als ,conforming to a type or standard" und somit in einem eher normativen und dynamischeren Sinne interpretiert werden. ${ }^{1575} \mathrm{Da}$ das Panel sich nicht gezwungen sah, zu entscheiden, welche der beiden Bedeutungen des Begriffs im konkreten Fall maßgeblich sei, bemühte es sich unter Hinweis auf die Auslegungsregel des Art. 31 WÜVV ${ }^{1576}$ um eine Auslegung, die beiden Konnotationen des Begriffs gerecht würde.

1573 WTO-Panel Report, WT/DS160/R vom 15.6.2000; zum Gegenstand und Inhalt des Streitbeilegungsverfahrens siehe bereits oben Fn. 1385.

1574 So auch Geiger, e-Copyright Bulletin 2007, S. 6.

1575 Siehe WTO-Panel Report, WT/DS160/R, § 6.166. Ähnlich auch bereits die Entscheidung des WTO-Panels im Streitbeilegungsverfahren „Canada - Patent Protection of Pharmaceutical Products", in der das Panel in Bezug auf die (dem Art. 13 TRIPS ähnliche) für Patente geltende Regelung des Art. 30 TRIPS dieselbe Auffassung vertrat; siehe WTO-Panel Report, WT/DS114/R vom 17.3.2000, § 7.54.

1576 Siehe dazu oben 6. Kapitel, C.III.1. 
Im Hinblick auf die erste, empirische Bedeutung der Formulierung nimmt das Panel in Anlehnung an Ricketson ${ }^{1577}$ an, die ,normale Auswertung" sei dann betroffen, wenn es sich um eine Form der Auswertung handelt, die im Falle des normalen Laufes der Dinge vernünftigerweise auch vom Urheber hätte erwartet werden können. ${ }^{1578}$ Zusätzlich sei aber auch die zweite, dynamisch-normative Bedeutung zu beachten, die die Berücksichtigung von technologischen Entwicklungen und Marktgesichtspunkten ermögliche. ${ }^{1579}$ Das Panel kommt dabei zu dem Ergebnis, die „,normale Auswertung" in diesem zweiten, normativen Sinne umfasse neben den Auswertungsformen, die derzeit bereits erhebliche oder spürbare Einnahmen erzeugten, auch solche Nutzungsformen, die - mit einem gewissen Grad an Wahrscheinlichkeit - zukünftig beachtliche ökonomische oder praktische Bedeutung erlangen könnten. ${ }^{1580}$ Die normale Auswertung sei demnach letztlich immer dann betroffen, wenn eine Nutzung in einen wirtschaftlichen Wettbewerb zu den Nutzungsformen trete, die den Rechten eines Rechteinhabers gewöhnlich einen wirtschaftlichen Wert gäben, so dass der Rechteinhaber letztlich um einen erheblichen oder spürbaren wirtschaftlichen Gewinn gebracht werde. ${ }^{1581}$

Das Panel stellt somit bei der Ermittlung der „,normalen Auswertung“ zentral auf ökonomische Gesichtspunkte ab. Entscheidend ist demnach die ökonomische Relevanz der fraglichen Verwertung im Rahmen der Gesamtverwertung beziehungsweise Gesamtverwertungsmöglichkeit aus

1577 Ricketson, Berne Convention, S. 483.

1578 Siehe WTO-Panel Report, WT/DS160/R, §6.176: „[...] the ways in which an author might reasonably be expected to exploit his work in the normal course of events.".

1579 Vgl. WTO-Panel Report, WT/DS160/R, § 6.178.

1580 WTO-Panel Report, WT/DS160/R, § 6.180: „Thus it appears that one way of measuring the normative connotation of normal exploitation is to consider, in addition to those forms of exploitation that currently generate significant or tangible revenue, those forms of exploitation which, with a certain degree of likelihood and plausibility, could acquire considerable economic or practical importance.".

1581 Siehe WTO-Panel Report, WT/DS160/R, § 6.183: „We believe that an exception or limitation to an exclusive right [...] rises to the level of a conflict with a normal exploitation of the work [...] if uses [...] enter into economic competition with the ways that right holders normally extract economic value from that right to the work (i.e., the copyright) and thereby deprive them of significant or tangible commercial gains."; zustimmend Gervais, TRIPS Agreement, 2.121; ders., 9 Marq. Intell. Prop. L. Rev. 1, 16 f. (2005.). 
Sicht des Rechteinhabers. Diese rein ökonomisch fokussierte Betrachtungsweise weist jedoch - neben der Unsicherheit, die jedem Wahrscheinlichkeitsurteil über mögliche zukünftige Marktentwicklungen anhaftet eine erhebliche Schwäche auf: Betrachtet man im Sinne des WTO-Panels unter ausschließlicher Beachtung ökonomischer Interessen der Rechteinhaber alle diejenigen Verwertungsformen als "normale Auswertung“, denen aktuell oder potentiell eine gewisse wirtschaftliche oder praktische Bedeutung zukommt, und lässt man - wie das Panel - bereits eine auch nur geringe ökonomische Bedeutung genügen, droht die zweite Teststufe gerade im digitalen Verwertungsumfeld aufgrund der ständig wachsenden Möglichkeiten zur Werkauswertung und zu deren Kontrolle zu einer (fast) unüberwindbaren Hürde für die Prüfung zu werden. ${ }^{1582}$ So müssten alle erdenklichen aktuell bestehenden oder zukünftig - insbesondere auch durch neue Möglichkeiten des Einsatzes von DRM-Systemen - zu erwartenden Verwertungsformen - unabhängig von den möglicherweise dahinter stehenden öffentlichen Interessen - der „,normalen Auswertung“ zugerechnet werden und demnach einen Verstoß gegen die zweite Stufe des Dreistufentests darstellen, da sie dem Rechteinhaber einen derzeit oder zukünftig realisierbaren Gewinn entziehen. ${ }^{1583}$ Die Prüfung wäre somit notwendig an dieser Stelle ,abgeschnitten“, da nach h.M. auf der zweiten Stufe auch eine „Heilung“ durch die Zahlung einer angemessenen Vergütung nicht möglich ist. ${ }^{15841585}$ Selbst traditionell privilegierte Nutzungsfor-

1582 Heide, EIPR 1999, 21(3), 105 (106) weist zutreffend darauf hin, dass durch die Weiterentwicklung der technischen Möglichkeiten insbesondere auf dem Gebiet der DRM-Systeme bereits heute und erst recht in absehbarer Zukunft beinahe jede Nutzung eines urheberrechtlich geschützten Werkes unter den Vorbehalt des Abschlusses einer (Einzel-)Lizenz gestellt werden kann.

1583 Vgl. Griffiths, IPQ 2009, 428 (441); ähnlich Senftleben, Three-Step Test, S. 181. Eine theoretische Grundlage für diese Auffassung, die auf neoklassizistischen ökonomischen Theorien basiert, liefern etwa Bell, 76 N.C. L. Rev. 557, 567 ff. (1998); Gordon, 82 Colum. L. Rev. 1600, 1605 ff. (1982); Merges, 12 Berkeley Tech. L.J. 115, 130 ff. (1997).

1584 Siehe dazu oben S. 352 f. sowie die Nachweise in Fn. 1562.

$1585 \mathrm{Vgl}$. Heide, EIPR 1999, 21(3), 105 (106): „In an environment where few, if any, practical problems prevent contracting directly with the end user for the user's desired use of a work and where on-line contracts and technological devices enable an author to monitor the use of his work, such an interpretation potentially transforms the three-step test into a one-step test, and in the process renders it, depending on the perspective taken, either totally effective or completely ineffective.". 
men - beispielsweise eine Nutzung zu privaten Studien- und Forschungszwecken oder im Rahmen einer Parodie - müssten demnach zukünftig dann zur „normalen Auswertung“ gezählt werden, wenn die Rechteinhaber transaktionskostenarme Möglichkeiten - etwa durch die Verwendung technischer Schutzmaßnahmen - entwickelten, um derartige Nutzungen unter den Vorbehalt einer Lizenzerteilung zu stellen und so für diese eine Bezahlung zu verlangen. ${ }^{1586}$

Um zu verhindern, dass der Dreistufentest regelmäßig bereits auf der zweiten Stufe scheitert, bedarf die rein ökonomische Herangehensweise des WTO-Panels einer Korrektur. Nur wenn die zweite Teststufe „überwunden" wird, kann die - entscheidende - auf der dritten Stufe des Dreistufentests angelegte umfassende Abwägung der konfligierenden Interessen erfolgen und insbesondere auch die Möglichkeit der Zahlung einer angemessenen Vergütung in den Abwägungsvorgang einbezogen werden.

Es ist deshalb vorgeschlagen worden, dem Bereich der ,normalen Auswertung" nur den ökonomischen Kern des Urheberrechts zuzurechnen und somit nur solche Schrankenbestimmungen als Beeinträchtigung der normalen Auswertung anzusehen, die dem Urheber oder Rechteinhaber eine aktuelle oder potentielle Einnahmequelle entziehen, die typischerweise von ganz erheblichem Gewicht innerhalb der Gesamtverwertung der betroffenen Werkart ist. ${ }^{1587}$ Verstehe man den gesamten Dreistufentest als verfeinerte Verhältnismäßigkeitsprüfung, so komme der zweiten Teststufe die Funktion zu, Fälle evidenter Unverhältnismäßigkeit bereits im Vorfeld der eigentlichen Verhältnismäßigkeitsprüfung der dritten Stufe auszusondern. ${ }^{1588}$ Der Schwerpunkt der Betrachtung liegt somit auch nach dieser Ansicht auf den ökonomischen Interessen der Urheber.

Aufgrund der nicht ausschließlich ökonomischen Fokussierung der anderen Erscheinungsformen des Dreistufentests scheint es jedoch sinnvoll, im Rahmen der zweiten Teststufe ausgehend vom entscheidenden Faktor der ökonomischen Relevanz der fraglichen Verwertungsform Abstand von

1586 Siehe Ginsburg, RIDA 187 (2001), 3 (49 f.); zustimmend Geiger, e-Copyright Bulletin 2007, S. 6; Griffiths, IPQ 2009, 428 (441); He, IIC 2009, 274 (284); weitgehend zustimmend Senftleben, in: Hilty/Peukert, Interessenausgleich, S. 159 (180).

1587 Vgl. Senftleben, Three-Step Test, S. 193 f.; ders., GRUR Int. 2004, 200 (209); zustimmend Rehse, Ungeschriebene Schranken, S. 142; Runge, GRUR Int. 2007, 130 (134).

1588 Senftleben, in: Hilty/Peukert, Interessenausgleich, S. $181 \mathrm{f}$. 
der reinen Fokussierung auf den Rechteinhaber zu nehmen und zusätzlich weitere normative, nicht-ökonomische Aspekte zu berücksichtigen. Es kann durchaus auf der zweiten Stufe danach gefragt werden, ob eine bestimmte Verwertungsart tatsächlich ausschließlich dem Rechteinhaber zugeordnet werden sollte. ${ }^{1589}$ So können bereits auf dieser Stufe auch übergeordnete Allgemeininteressen Beachtung finden. ${ }^{1590}$ Zur ,normalen Auswertung" sollten demnach solche Formen der Werkverwertung nicht gezählt werden, mit deren wirtschaftlicher Auswertung der Rechteinhaber vernünftiger Weise nicht rechnen darf. ${ }^{1591}$ Dies sollte jedoch keinesfalls in dem Sinne verstanden werden, dass automatisch alle Verwertungshandlungen, zu deren Gunsten bereits Schrankenregelungen bestehen, außerhalb des Bereichs liegen, mit dessen Auswertung der Rechteinhaber rechnen darf. Andernfalls wäre die logische Konsequenz der automatische Schutz des status quo der Schrankenregelungen. ${ }^{1592}$ Vielmehr sollte zusätzlich zu der stets zu ermittelnden wirtschaftlichen Bedeutung einer Verwertungsform anhand von normativen, über die Bestimmung des rein ökonomischen Umfangs der Verwertungsform hinausgehenden Aspekten für jeden Einzelfall ermittelt werden, ob diese dem Rechteinhaber tatsächlich

1589 So auch Ricketson, WIPO Study, S. 24: ,[...] considerations as to what the copyright owner's market should cover [...]" [Hervorhebung im Original]; zustimmend Nolte, Informationsmehrwertdienste, S. 303.

1590 Vgl. Ginsburg, RIDA 187 (2001), 3 (51); He, IIC 2009, 274 (285).

1591 Vgl. Ricketson, IPQ 1999, 56 (70). Diese Ansicht stützt auch der Bericht der sog. Swedish/BIRPI Study Group, einer 1963 ins Leben gerufenen Gruppe von Vertretern der schwedischen Regierung und des United International Bureau for the Protection of Intellectual Property (BIRPI), die mit der Vorbereitung der Stockholmer Revisionskonferenz von 1967 betraut war. In ihrem Bericht äußerte die Swedish/BIRPI Study Group im Hinblick auf die zweite Teststufe: "[A]ll the forms of exploiting a work, which had, or were likely to acquire, considerable economic or practical importance, must in principle be reserved to the authors"; BIRPI, General Report of the Swedish/BIRPI Study Group Established at 1 July 1964, Doc. DA/22/2, S. 47 f. [Hervorhebung durch den Verfasser]; siehe auch Doc. S/1, WIPO, Records of the IP Conference at Stockholm, S. $111 \mathrm{f}$. Dies legt den Schluss nahe, dass auch die Study Group davon ausging, dass durchaus Verwertungsformen denkbar sind, denen eine ökonomische oder praktische Bedeutung für den Urheber oder derivativen Rechteinhaber zukommt und die dennoch nicht zum Bereich der ,normalen Auswertung“ zu zählen sind.

1592 Auf die Gefahr einer derartig zirkelschlüssigen Argumentation weist Goldstein, International Copyright, S. 295 f. überzeugend hin; zustimmend Ginsburg, RIDA 187 (2001), 3 (45); Senftleben, Three-Step Test, S. 172. 
ausschließlich zugeordnet werden sollte, oder ob dies etwa aus Sicht der Gesamtwohlfahrt zu untragbaren Ergebnissen, etwa aufgrund eines Marktversagens, führen würde oder etwa gegen Grundrechte Dritter verstieBe. ${ }^{1593}$

Wie gezeigt wurde, droht sowohl eine zu enge als auch eine zu weite Definition der „,normalen Auswertung“ im Rahmen der zweiten Prüfungsstufe den gesamten Dreistufentest aus dem Gleichgewicht zu bringen. Es gilt jedoch auch zu beachten, dass im Rahmen der dritten Teststufe, nach der eine ungebührliche Verletzung berechtigter Interessen der Rechteinhaber verboten ist, aufgrund des offenen Wortlauts Raum für eine umfassende Abwägung und einen Ausgleich der widerstreitenden Interessen bleibt. Wesentliches Ziel der Auslegung der zweiten Prüfungsstufe muss es daher sein, zum einen ein vorzeitiges „Abbrechen“ der Prüfung und daraus resultierende ungerechte Ergebnisse zu vermeiden, zum anderen aber auch, die zweite Stufe nicht durch eine allzu umfassende Prüfung zu überfrachten, die die der dritten Stufe vorbehaltene umfassende Interessenabwägung weitgehend vorwegnehmen würde. Ausgangspunkt für die Bestimmung der ,normalen Auswertung“ eines Werkes auf der zweiten Teststufe muss weiterhin die ökonomische Bedeutung einer Verwertungsform sein. Dies erfordert eine Identifizierung der betroffenen Märkte und deren genaue Analyse sowie eine Folgenbetrachtung unter besonderer Berücksichtigung der Auswirkungen einer Schrankenbestimmung auf die ökonomischen Interessen des Rechteinhabers. ${ }^{1594}$ Ein alleiniges Abstellen auf die Interessen der Rechteinhaber auf der zweiten Teststufe kann dem Dreistufentest als Abwägungsvorgang zwischen den Interessen der Rechteinhaber und denen der Nutzer beziehungsweise der Allgemeinheit jedoch nicht gerecht werden. Andernfalls wäre die Prüfung stets bereits dann auf der zweiten Stufe beendet, wenn eine Schrankenregelung einen Marktbereich beträfe, der tatsächlich oder potentiell von einigem Gewicht für den Rechteinhaber ist. $\mathrm{Zu}$ einer Abwägung der beteiligten Interessen auf der (entscheidenden) dritten Stufe käme es in diesem Fall nicht. Aufgrund der fortschreitenden technischen Entwicklung und der damit verbundenen stetigen - zumindest potentiellen - Erschließung zusätzlicher Märkte würde so auf längere Sicht die dritte Stufe als Beschränkung funktionslos. Ein solches Ergebnis

1593 So auch Ginsburg, RIDA 187 (2001), 3 (51 f.); zustimmend He, IIC 2009, 274 (285); Nolte, Informationsmehrwertdienste, S. 303. Ähnlich Hilty, in: FS Schricker II, S. 325 (344).

1594 Vgl. Senftleben, GRUR Int. 2004, 200 (209). 
ließe aber die Tatsache außer Betracht, dass zahlreiche Schrankenbestimmungen denkbar sind, die zwar einen ökonomisch gewichtigen Verwertungsmarkt betreffen, jedoch zu keinen oder lediglich zu marginalen finanziellen Verlusten für die Rechteinhaber führen, etwa weil die privilegierten Handlungen bei genauerer Betrachtung auch den Interessen der Rechteinhaber dienen mögen ${ }^{1595}$ - insbesondere wenn nicht ökonomische Interessen des Urhebers im Vordergrund stehen - oder weil die Zahlung einer (auf der dritten Teststufe zu berücksichtigenden) angemessenen Vergütung die Interessen der Rechteinhaber ebenso oder gar besser zu wahren vermag als ein Verbotsrecht. ${ }^{1596}$ Es ist somit auf der zweiten Stufe zu beurteilen, wem bei wertender Betrachtung der beteiligten widerstreitenden Interessen ein Markt im konkreten Fall zuzuordnen ist. Unter Berücksichtigung der beteiligten Interessen, insbesondere auch von Grundrechten Dritter, kann so verhindert werden, dass die zweite Teststufe des Dreistufentests aufgrund eines zu engen Verständnisses des Kriteriums der „,normalen Auswertung“ zu unerwünschten oder gar untragbaren Ergebnissen führt. Gleichzeitig kann die zweite Teststufe bei einem solchen Verständ-

1595 So etwa in dem im 4. Kapitel ausführlich dargestellten Fall der Nutzung fremder Werke als Thumbnails im Rahmen eines Bildersuchdienstes. Die Werknutzung durch die Bildersuchmaschine führt in aller Regel zu keinem (spürbaren) finanziellen Nachteil der Rechteinhaber und ermöglicht zugleich eine Steigerung der Bekanntheit der verwendeten Werke durch eine verbesserte (oder gar erstmalige) Auffindbarkeit und gesteigerten traffic der jeweiligen Internetseite.

1596 Letzteres ist insbesondere denkbar, wenn ein Urheber - wie vielfach üblich seine Rechte umfassend einem Primärverwerter eingeräumt hat. In diesem Fall profitiert von einem Verbotsrecht hinsichtlich einer möglichen Sekundärverwertung nur der mit umfassenden Rechten ausgestattete Primärverwerter, nicht jedoch der Urheber. Bei einer die Sekundärverwertung zulassenden Schrankenregelung, die einen gesetzlichen Vergütungsanspruch vorsieht, partizipiert der Urheber hingegen wenigstens anteilmäßig am Verwertungserlös; vgl. dazu die entsprechenden Überlegungen des Schweizerischen Bundesgerichts, Urt. v. 26.6.2007, Az. 4C.73/2007 = GRUR Int. 2007, 1046 (1050) - Elektronische Pressespiegel; siehe auch Geiger, e-Copyright Bulletin 2007, S. 8; Hilty, GRUR 2005, 819 (820); Hohagen, Vervielfältigung zum eigenen Gebrauch, S. 109; Reinbothe/v.Lewinski, WIPO Treaties, Art. 10 WCT Rn. 21; kritisch aber Reschke, Verfassungs- und dreistufentestkonforme Auslegung, S. 80. Ähnlich BGHZ 151, 300 (311 f.) - Elektronischer Pressespiegel (der BGH rechtfertigt die ausnahmsweise extensive Auslegung einer Schrankenbestimmung damit, dass die Anwendung der Schranke den Urheber günstiger stelle als die Geltung des Ausschließlichkeitsrechts). Vgl. auch bezüglich gesetzlicher Lizenzen die Überlegungen von Hilty, in: FS Schricker II, S. 325 (345). 
nis dazu dienen, Fälle von evidenter Unverhältnismäßigkeit bereits vor dem Eintritt in eine auf der dritten Teststufe vorzunehmende umfassende Interessenabwägung auszusondern. ${ }^{1597}$

Ein solches Verständnis der zweiten Teststufe nähert sich deutlich der US-amerikanischen Fair Use-Prüfung an, in deren Rahmen die betroffenen ökonomischen Interessen des Rechteinhabers insbesondere bei der Prüfung der vierten Stufe zwar ein zentrales Kriterium darstellen, jedoch keinesfalls einzig entscheidend für die Zulässigkeit einer urheberrechtlichen Schrankenregelung sind. ${ }^{1598}$ Die für die Bestimmung des Fair Use entwickelten Kriterien der Rechtsprechung und die ebenfalls zu beachtenden weiteren Faktoren mögen gar geeignet sein, als Leitlinie für die Bestimmung der „normalen Auswertung“ eines Werkes im Rahmen des Dreistufentests zu dienen. ${ }^{1599}$ Auch die von Wissenschaftlern des MaxPlanck-Instituts für Geistiges Eigentum, Wettbewerbs- und Steuerrecht und der School of Law at Queen Mary, University of London, erarbeitete „Declaration on a Balanced Interpretation of the ,Three-Step Test' in Copyright Law"1600 ähnelt diesen Überlegungen. Es wird vorgeschlagen, Schranken dann als nicht mit der normalen Auswertung konkurrierend anzusehen, wenn sie auf wichtigen konkurrierenden Erwägungen beruhen oder den Effekt haben, unangemessenen Einschränkungen des Wettbewerbs, namentlich auf Sekundärmärkten, entgegenzuwirken. ${ }^{1601}$ Schließlich soll nach der „Declaration“ der Dreistufentest ausdrücklich in einer Weise ausgelegt werden, welche die berechtigten Interessen Dritter berücksichtigt. ${ }^{1602}$ Das Vorliegen ,wichtiger konkurrierender Erwägungen“ und „,berechtigter Interessen Dritter“ sind Überlegungen, die auch im Rah-

1597 Vgl. Senftleben, CR 2003, 914 (918).

1598 Siehe zur Fair Use-Prüfung und zur Auslegung deren vierter Stufe oben 2. Kapitel, C.I. und 5. Kapitel, B.II.1.e).

1599 Ähnlich Nolte, Informationsmehrwertdienste, S. 305. Deutlich weitergehend $\mathrm{He}$, IIC 2009, 274 (294ff.), der ausdrücklich alle vier Fair Use-Faktoren (unter leichter Abwandlung des vierten Faktors) zum Prüfungsmaßstab der zweiten Stufe des Dreistufentests erheben möchte.

1600 Abgedruckt in IIC 2008, 707 [im Folgenden: Geiger/Griffiths/Hilty, IIC 2008, 707]; eine (nicht maßgebliche) deutsche Übersetzung der Erklärung ist abgedruckt in GRUR Int. 2008, 822.

1601 Siehe Geiger/Griffiths/Hilty, IIC 2008, 707 (711).

1602 Siehe Geiger/Griffiths/Hilty, IIC 2008, 707 (712). 
men der Fair Use-Prüfung, insbesondere auf deren erster Stufe, ${ }^{1603}$ angestellt werden. Die Frage nach dem „Effekt, unangemessenen Einschränkungen des Wettbewerbs entgegenzuwirken“, ähnelt ebenfalls der Fair Use-Prüfung, insbesondere deren vierter Stufe. ${ }^{1604}$

\section{c) Ungebührliche Verletzung berechtigter Interessen}

Auf der dritten Stufe des Dreistufentests ist schließlich zu prüfen, ob die berechtigten Interessen des Urhebers beziehungsweise Rechteinhabers unzumutbar beziehungsweise ungebührlich ${ }^{1605}$ verletzt werden. Nicht jede Beeinträchtigung von Interessen des Urhebers beziehungsweise Rechteinhabers stellt demnach automatisch einen Verstoß gegen die dritte Prüfungsstufe dar. Es wird vielmehr anerkannt, dass jede Beschränkung die Interessen des Urhebers beziehungsweise Rechteinhabers in gewisser Weise beeinträchtigt, eine Schrankenbestimmung jedoch nur dann an der dritten Teststufe scheitern soll, wenn dadurch solche Interessen betroffen werden, die bei wertender Betrachtung als „berechtigt“ anzusehen sind, und wenn deren Verletzung ,ungebührlich“ erscheint. ${ }^{1606}$ Dieser wertungsoffene Wortlaut gibt der dritten Stufe den nötigen Spielraum für eine umfassende Abwägung, mit deren Hilfe ein sachgerechter Ausgleich zwi-

$1603,[$ T] commercial nature or is for nonprofit educational purposes"; eingehend zur ersten Stufe der Fair Use-Prüfung siehe oben 2. Kapitel, C.I. und 5. Kapitel, B.II. 1.b).

$1604,[$,T]he effect of the use upon the potential market for or value of the copyrighted work"; zur vierten Stufe der Fair Use-Prüfung siehe oben 2. Kapitel, C.I.2.c) und 5. Kapitel, B.II.1.e).

1605 Diese Abweichung im Wortlaut (,unzumutbar“ in Art. 9 Abs. 2 RBÜ, Art. 13 TRIPS und Art. 10 WCT - „ungebührlich“ in Art. 5 Abs. 5 InfoSoc-RL) findet sich nur in den deutschen Sprachfassungen. In allen englischen Fassungen wird die Formulierung „... do not unreasonably prejudice..." verwendet. Es erscheint daher vorzugswürdig, auch in der deutschen Sprache durchgehend das Wort „ungebührlich“ anstelle von „unzumutbar“ zu verwenden, da dieses dem (maßgeblichen) englischen Wortlaut näher kommt; so auch Senftleben, CR 2003, 914 (Fn. 3) unter Hinweis auf Bornkamm, in: FS Erdmann, S. 29 (47), der auf diese Abweichung aufmerksam macht.

1606 Vgl. Gervais, TRIPS Agreement, 2.122; Ricketson, Berne Convention, S. 483 f. 
schen den widerstreitenden Interessen gefunden werden kann. ${ }^{1607}$ Als Leitlinie einer solchen umfassenden Abwägung bietet sich der - in unterschiedlichen Ausprägungen - in vielen Rechtsordnungen und insbesondere auch im EG-Recht anerkannte ${ }^{1608}$ Grundsatz der Verhältnismäßigkeit an. 1609

Dabei bedürfen auf dieser Teststufe insbesondere drei Aspekte der näheren Erörterung: Erstens enthalten die unterschiedlichen Erscheinungsformen des Dreistufentests abweichende Formulierungen hinsichtlich des Personenkreises, auf dessen Interessen abzustellen ist. Art. 9 Abs. 2 RBÜ sowie die WIPO-,,Internet Treaties“ sprechen von den „berechtigten Interessen des Urhebers", nach Art. 13 TRIPS und Art. 5 Abs. 5 InfoSoc-RL ist hingegen auf die „berechtigten Interessen des Rechtsinhabers“ abzustellen. Zweitens ist zu erörtern, wann Interessen als „,berechtigt" im Sinne dieser Stufe des Dreistufentests anzusehen sind. Drittens stellt sich schließlich die Frage, wann eine Verletzung ,ungebührlich“ ist, wobei insbesondere die Verhinderung beziehungsweise Beseitigung einer ungebührlichen Verletzung durch die Zahlung einer angemessenen Vergütung zu diskutieren sein wird.

aa) Auswirkung der Wortlautabweichung „Urheber“ - „Rechtsinhaber“

Die verschiedenen Erscheinungsformen des Dreistufentests unterscheiden sich in Bezug auf den Wortlaut der jeweiligen dritten Stufe. Während nach der ursprünglichen Fassung des Dreistufentests in Art. 9 Abs. 2 RBÜ und ebenso nach Art. 10 WCT und Art. 16 Abs. 2 WPPT auf die „berechtigten Interessen des Urhebers" abzustellen ist, sind nach Art. 13 TRIPS und nach Art. 5 Abs. 5 InfoSoc-RL die „berechtigten Interessen des Rechtsinhabers" zu beachten.

Die Formulierung des Art. 9 Abs. 2 RBÜ, der auf die Interessen des Urhebers abstellt, entspricht dem Sprachgebrauch der gesamten Berner Über-

1607 Vgl. Gervais, 9 Marq. Intell. Prop. L. Rev. 1, 18 f. (2005); Ginsburg, RIDA 187 (2001), 3 (55 f.); Ricketson, Berne Convention, S. 484.

1608 Vgl. dazu grundlegend Emmerich-Fritsche, Grundsatz der Verhältnismäßigkeit, insbes. S. $96 \mathrm{ff}$.

1609 So etwa auch Dusollier, IRDI 2005, 212 (221); Geiger, IIC 2006, 683 (696); ders., e-Copyright Bulletin 2007, S. 18; Senftleben, in: Hilty/Peukert, Interessenausgleich, S. 159 (183); ders., GRUR Int. 2004, 200 (210 f.). 
einkunft, in der stets auf den Urheber verwiesen wird, da das Ziel der Übereinkunft der möglichst wirksame und gleichmäßige Schutz der Rechte der Urheber von Werken der Literatur und Kunst in allen Verbandsstaaten ist. ${ }^{1610}$ Durch Art. 2 Abs. 6 RBÜ werden auch die Rechtsnachfolger und die Inhaber ausschließlicher Nutzungsrechte in den Schutzbereich einbezogen. Es sind somit sowohl die Interessen der eigentlichen Urheber als auch die - möglicherweise gegenläufigen ${ }^{1611}$ - Interessen der Werkverwerter zu berücksichtigen. Der Wortwahl des Art. 9 Abs. 2 RBÜ schließen sich die als Sonderabkommen nach Art. 20 RBÜ abgeschlossenen WIPO„Internet Treaties“ konsequenterweise an.

Nach Art. 13 TRIPS sollen hingegen die „berechtigten Interessen des Rechtsinhabers" maßgeblich sein. Diese Wortlautabweichung gegenüber der RBÜ überrascht auf den ersten Blick, da es gerade das ausdrückliche Ziel des TRIPS-Übereinkommens war, die Mitgliedstaaten zur Einhaltung des hohen Schutzniveaus der materiellen Bestimmungen der RBÜ zu verpflichten, ${ }^{1612}$ so dass eine wortgleiche Übernahme des Dreistufentests naheliegend erscheint. Es ist allerdings zu beachten, dass nach Art. 9 Abs. 1 TRIPS ausdrücklich die durch Art. $6^{\text {bis }}$ RBÜ gewährten Urheberpersönlichkeitsrechte vom Schutz durch das TRIPS-Übereinkommen ausgenommen sind. Vor dem Hintergrund dieser Regelung ist auch der abweichende Wortlaut des Art. 13 TRIPS zu verstehen. Hätte das TRIPS-Übereinkommen den Dreistufentest der RBÜ wortgleich übernommen und ebenfalls auf die „,berechtigten Interessen des Urhebers“ abgestellt, so hätte dies als Indiz verstanden werden können, dass alle im Rahmen des Dreistufentests der Berner Übereinkunft im Rahmen der dritten Teststufe zu berücksichtigenden Interessen auch unter dem TRIPS-Übereinkommen Berücksichtigung finden müssten. Für Art. 9 Abs. 2 RBÜ ist allerdings anerkannt, dass als derartige Interessen neben den ökonomischen Interessen auch urheberpersönlichkeitsrechtliche Aspekte erfasst sind. ${ }^{1613}$ Die neutralere Formulierung unter Bezugnahme auf die „berechtigten Interessen des Rechtsinhabers" in Art. 13 TRIPS ist somit als Klarstellung zu verstehen, dass wie im gesamten TRIPS-Übereinkommen - auch im Rahmen des Dreistufentests urheberpersönlichkeitsrechtliche Interessen keine Berücksichti-

1610 Vgl. die Präambel der RBÜ.

1611 Vgl. dazu unten 6. Kapitel, D.II. sowie ausführlich zur tripolaren Interessenlage im Urheberrecht Hilty, GRUR 2005, 819 (820 ff.); ders., Urheberrecht, S. 25 ff.

1612 Vgl. dazu bereits oben 6. Kapitel, A.VII.

1613 Siehe Ricketson, IPQ 1999, 56 (70). 
gung finden sollen. ${ }^{1614}$ Eine ungebührliche Verletzung der Interessen der Rechtsinhaber kann somit im Rahmen des Dreistufentests nach dem TRIPS-Übereinkommen allein auf deren vermögensrechtliche Interessen gestützt werden.

Ebenfalls auf die Interessen der Rechtsinhaber stellt Art. 5 Abs. 5 der InfoSoc-Richtlinie ab. Im Rahmen der Richtlinie resultiert die Verwendung des Begriffs „Rechtsinhaber“ allerdings in erster Linie daraus, dass die Richtlinie neben Urheberrechten ausdrücklich auch verwandte Schutzrechte erfasst und somit die Inhaber dieser Schutzrechte ebenfalls in den Schutzbereich des Dreistufentests einbezogen werden. ${ }^{1615}$ Die wörtliche Übernahme der Formulierung des Dreistufentests des WCT und WPPT, deren Umsetzung die Richtlinie (auch) diente, wäre somit schlichtweg nicht ausreichend gewesen, um alle zu berücksichtigenden Interessengruppen zu erfassen. Ebenso wie beim TRIPS-Übereinkommen müssen zudem auch im Rahmen der Auslegung des Dreistufentests in seiner Ausformung durch die InfoSoc-Richtlinie urheberpersönlichkeitsrechtliche Interessen ausweislich des neunzehnten Erwägungsgrundes zur Richtlinie letztlich außer Betracht bleiben.

\section{bb) Berechtigte Interessen}

Die dritte Stufe des Dreistufentests spricht von den „berechtigten Interessen“ des Urhebers beziehungsweise Rechtsinhabers. Es ist somit zu klären, wann die betroffenen Interessen des Urhebers oder Rechteinhabers als „berechtigt" im Sinne dieser Stufe anzusehen sind. Als Ausgangspunkt für diese Überlegung bieten sich die Feststellungen des WTO-Panels im Streitbeilegungsverfahren „United States - Section 110(5) of the US Copyright Act"1616 an. Das Panel ging zunächst von einer rechtlich-positivistischen Sichtweise aus und stellte fest, eine Möglichkeit sei es, das „berechtigte Interesse" als den ökonomischen Wert der Ausschließlichkeitsrechte zu definieren, die dem Rechteinhaber durch das Urheberrecht gewährt

1614 Vgl. Hohagen, Vervielfältigung zum eigenen Gebrauch, S. 110; Senftleben, Three-Step Test, S. 225.

1615 Vgl. Senftleben, GRUR Int. 2004, 200 (209).

1616 WTO-Panel Report, WT/DS160/R vom 15.6.2000; zum Gegenstand und Inhalt des Streitbeilegungsverfahrens siehe bereits oben Fn. 1385. 
werden. ${ }^{1617}$ „Berechtigte Interessen“ wären nach dieser Ansicht also letztlich gleichbedeutend mit „rechtlichen Interessen“.1618 Das Panel stellte jedoch weiterhin fest, dass der Begriff „berechtigt“ auch anders, im Sinne eines normativen Erfordernisses, verstanden werden könne. Diesbezüglich griff das Panel auf die Entscheidung eines früheren WTO-Panels zurück, das sich im Rahmen eines Streitbeilegungsverfahrens zum Patentschutz von pharmazeutischen Produkten in Kanada ${ }^{1619}$ mit der an den Dreistufentest angelehnten Bestimmung des Art. 30 TRIPS auseinandersetzte. Art. 30 TRIPS verbietet die ungebührliche Verletzung von berechtigten Interessen des Patentinhabers unter Berücksichtigung der berechtigten Interessen Dritter ${ }^{1620}$ und bietet somit einen größeren Abwägungsspielraum als die starrere Formulierung des Dreistufentests in Art. 13 TRIPS. Trotz dieser Abweichung nahm das WTO-Panel in der Rechtssache „United States - Section 110(5)“" ausdrücklich Bezug auf die Ausführungen des patentrechtlichen Panel Reports zur Identifizierung berechtigter Interessen. ${ }^{1621}$ Das Patent-Panel war zu Art. 30 TRIPS zu der Überzeugung gelangt, der Ausdruck ,berechtigte Interessen“ stelle ein normatives Erfordernis dar, das „den Schutz von Interessen verlangt, die in dem Sinne „gerechtfertigt" sind, dass sie auf relevanten politischen Wertentscheidungen oder anderen sozialen Normen beruhen“. ${ }^{1622}$ Übertragen auf das Urheberrecht vertrat das WTO-Panel in der Rechtssache „United States - Section 110(5)“ die Auffassung, es könnten demnach solche Interessen als „berechtigt" angesehen werden, die im Lichte der kulturellen, ökonomischen oder sozialen Überzeugungen, die die Einräumung von Urheberrechten tragen, gerechtfertigt erscheinen. ${ }^{1623}$

1617 Vgl. WTO-Panel Report, WT/DS160/R, § 6.227.

1618 Vgl. Ficsor, RIDA 192 (2002), 111 (141); Gervais, 9 Marq. Intell. Prop. L. Rev. 1, 17 f. (2005); Senftleben, Three-Step Test, S. 228, 230.

1619 WTO-Panel Report „Canada - Patent Protection of Pharmaceutical Products“, WT/DS114/R vom 17.3.2000.

1620 Art. 30 TRIPS lautet: „Members may provide limited exceptions to the exclusive rights conferred by a patent, provided that such exceptions do not unreasonably conflict with a normal exploitation of the patent and do not unreasonably prejudice the legitimate interests of the patent owner, taking account of the legitimate interests of third parties.".

1621 Siehe WTO-Panel Report, WT/DS160/R, § 6.224 und 6.227.

1622 Siehe WTO-Panel Report, WT/DS114/R, § 7.69.

1623 Siehe WTO-Panel Report, WT/DS160/R, § 6.224; zustimmend Senftleben, Three-Step Test, S. 230 f.; ders., GRUR Int. 2004, 200 (210). 
Trotz des traditionell fehlenden Konsenses über die hinter der Gewährung des Urheberrechtsschutzes stehenden Wertentscheidungen ${ }^{1624}$ besteht inzwischen insbesondere aufgrund des hohen Schutzniveaus internationaler Verträge weitgehende Einigkeit hinsichtlich Umfang und Ausgestaltung des urheberrechtlichen Schutzes, so dass diese Herangehensweise gewisse Aussagen über die Berechtigung eines Interesses ermöglicht. Jedenfalls das ökonomische Interesse des Urhebers an der Geltendmachung international anerkannter Ausschließlichkeitsrechte wird demnach als berechtigtes Interesse im Sinne des Dreistufentests anzusehen sein. ${ }^{1625} \mathrm{Ne}-$ ben diesen ökonomischen Interessen kommen als berechtigte Interessen im Sinne des Dreistufentests ebenfalls urheberpersönlichkeitsrechtliche Interessen in Betracht, jedenfalls soweit der in Art. $6^{\text {bis }}$ RBÜ manifestierte diesbezügliche Minimalkonsens ${ }^{1626}$ reicht. ${ }^{1627}$ Ausscheiden muss die Berücksichtigung persönlichkeitsrechtlicher Interessen jedoch - wie bereits gezeigt - im Hinblick auf Art. 13 TRIPS und Art. 5 Abs. 5 InfoSoc-RL.

\section{cc) Ungebührliche Verletzung}

Schließlich stellt sich die Frage, wann diese berechtigten Interessen der Urheber beziehungsweise Rechteinhaber ungebührlich verletzt werden. Ausgangspunkt des abschließend vorzunehmenden Abwägungsvorganges sind die berechtigten Belange der genannten Interessengruppen. (Berechtigte) Interessen der Allgemeinheit oder bestimmter Nutzergruppen finden hingegen im Dreistufentest - anders als etwa in Art. 30 TRIPS ${ }^{1628}$ - keine ausdrückliche Erwähnung. Jedoch bedarf es für die Frage, ob eine Interessenbeeinträchtigung als ungebührlich einzustufen ist, notwendigerweise einer Abwägung. Diese Abwägung wiederum erfordert einen Bezugspunkt, den sinnvollerweise nur Interessen außerhalb des Interessenkreises der ausdrücklich genannten Gruppen (Urheber und Rechteinhaber), insbesondere also wichtige Interessen der Allgemeinheit oder bestimmter Nut-

$1624 \mathrm{Zu}$ den unterschiedlichen Grundansätzen der copyright- und droit d'auteur-Systeme vgl. bereits oben 1. Kapitel, A. und B.

1625 Vgl. Senftleben, GRUR Int. 2004, 200 (210); zustimmend Nolte, Informationsmehrwertdienste, S. 307.

1626 Vgl. dazu Dietz, 19 Colum.-VLA J.L. \& Arts 199, 200 ff. (1995).

1627 Vgl. Ricketson, IPQ 1999, 56 (70); Senftleben, GRUR Int. 2004, 200 (210).

1628 Vgl. dazu oben Fn. 1617. 
zergruppen darstellen können. ${ }^{1629}$ Eine derartige Interessenabwägung unter Gegenüberstellung der Interessen der Urheber und Rechteinhaber einerseits und Interessen der Allgemeinheit an der Nutzung der urheberrechtlichen Verwertungsgegenstände andererseits steht auch im Einklang mit neueren Entwicklungen im internationalen (Urheber-) Recht, wonach die Interessen der Allgemeinheit eine deutlich stärkere Betonung gefunden haben. ${ }^{1630}$

Als Grundregel lässt sich demnach festhalten, dass ein Eingriff als ungebührlich anzusehen ist, wenn im konkreten Fall die betroffenen berechtigten Interessen der Urheber oder Rechteinhaber schwerer wiegen als die Interessen der Allgemeinheit. ${ }^{1631}$ Verwendet man - wie hier befürwortet den Grundsatz der Verhältnismäßigkeit als Leitbild dieses Abwägungsvorganges, so lässt sich dies weiter präzisieren. Eine Verletzung der berechtigten Interessen des Urhebers oder Rechteinhabers darf unter Berücksichtigung der Zwecke, denen die Beschränkung dient, nicht unverhältnismäßig sein. ${ }^{1632}$ Eine Schrankenregelung muss demnach zur Erreichung der Zwecke geeignet, erforderlich und angemessen sein. ${ }^{1633}$ Die Geeignetheit einer Regelung erfordert nicht, dass das Regelungsziel in jedem Einzelfall tatsächlich erreicht wird, mit seiner Hilfe muss jedoch der ge-

1629 Vgl. Ginsburg, RIDA 187 (2001), 3 (57).

1630 Vgl. die Präambel des WCT, die explizit die Notwendigkeit anerkennt, „ein Gleichgewicht zwischen den Rechten der Urheber und dem umfassenderen öffentlichen Interesse, insbesondere Bildung, Forschung und Zugang zu Informationen, zu wahren, wie dies in der Berner Übereinkunft zum Ausdruck kommt"; siehe dazu bereits oben 6. Kapitel, A.VIII. sowie Hohagen, Vervielfältigung zum eigenen Gebrauch, S. 111 f. Vgl. zudem etwa das Menschenrecht auf kulturelle Teilhabe gemäß Art. 27 Abs. 1 der Allgemeinen Erklärung der Menschenrechte, wonach jeder das Recht hat, am kulturellen Leben der Gemeinschaft frei teilzunehmen, sich an den Künsten zu erfreuen und am wissenschaftlichen Fortschritt und dessen Errungenschaften teilzuhaben; siehe dazu bereits oben 6 . Kapitel, A.I. sowie Runge, GRUR Int. 2007, 130 (135).

1631 Vgl. Runge, GRUR Int. 2007, 130 (134 f.).

1632 Vgl. Senftleben, GRUR Int. 2004, 200 (211).

1633 Diese Kriterien entsprechen der st. Rspr. des BVerfG zum Verhältnismäßigkeitsgrundsatz; siehe statt vieler aus jüngerer Zeit etwa BVerfGE 109, 279 (335 ff.) - Großer Lauschangriff; E 115, 320 (345) - Rasterfahndung; E 118, 168 (193) - Kontenabfrage; E 120, 274 (318f.) - Online-Durchsuchung; zuletzt grundlegend zum Grundsatz der Verhältnismäßigkeit BVerfGE 125, 260 (316 ff.) - Vorratsdatenspeicherung. 
wünschte Erfolg zumindest gefördert werden. ${ }^{1634}$ Das gewählte Mittel ist erforderlich, wenn der Gesetzgeber nicht ein anderes, gleich wirksames, aber weniger fühlbar einschränkendes Mittel hätte wählen können. ${ }^{1635}$ Angemessen - oder auch verhältnismäßig im engeren Sinn - ist eine Maßnahme nur dann, wenn eine Abwägung sämtlicher Vor- und Nachteile ergibt, dass die Nachteile, die mit der Maßnahme verbunden sind, nicht völlig außer Verhältnis zu den Vorteilen stehen, die diese bewirkt. ${ }^{1636}$ Übertragen auf die Vereinbarkeit einer Schrankenregelung mit dem Dreistufentest bedeutet dies, dass die konkrete Schrankenregelung dazu geeignet sein muss, die Zwecke zu fördern, um deretwillen sie eingeführt worden ist. Zudem muss die gewählte Beschränkung erforderlich sein, also das relativ mildeste Mittel zur Erreichung dieser Ziele darstellen. Eine Beschränkung verletzt die berechtigten Interessen der Urheber oder Rechteinhaber somit ungebührlich, wenn sie nutzlos ist oder wenn dem Gesetzgeber ein ebenso effektives, aber weniger einschneidendes Mittel zur Zweckerreichung zur Verfügung gestanden hätte. ${ }^{1637}$

Auch wenn dies dem Wortlaut der dritten Stufe des Dreistufentests nicht unmittelbar zu entnehmen ist, ist anerkanntermaßen als Mittel zur (Wieder-)Herstellung eines angemessenen Verhältnisses zwischen den berechtigten Interessen des Urhebers oder Rechteinhabers und den Belangen, deren Förderung die Schrankenregelung dient, insbesondere an die Zahlung einer angemessenen Vergütung zu denken. ${ }^{1638}$ Denn mit Hilfe einer

1634 St. Rspr., siehe z.B. BVerfGE 63, 88 (115) - Versorgungsausgleich; E 67, 157 (175) - Telefonüberwachung; E 96, 10 (23) - Räumliche Aufenthaltsbeschränkung; E 103, 293 (307) - Urlaubsanrechnung.

1635 St. Rspr., vgl. etwa BVerfGE 30, 292 (316) - Erdölbevorratung; E 40, 196 (222) - Güterkraftverkehrsgesetz.

1636 St. Rspr., siehe etwa BVerfGE 90, 145 (173) - Cannabis; E 109, 279 (349 ff.) Großer Lauschangriff; E 113, 348 (382) - Telekommunikationsüberwachung; E 120, 274 (318 f.) - Online-Durchsuchung.

1637 Vgl. Senftleben, Three-Step Test, S. 230 f., 236 f.

1638 Die Möglichkeit, auf der dritten Teststufe die Zahlung einer angemessenen Vergütung vorzusehen, entspricht - auch ohne einen ausdrücklichen Hinweis im Wortlaut - eindeutig der Intention der „Schöpfer“ des Dreistufentests. Bereits bei der Stockholmer Revisionskonferenz war dies Teil des getroffenen Konsenses, vgl. WIPO, Records of the IP Conference at Stockholm, Report of the Work of Main Committee I, S. 1145 f.; vgl. dazu Reimer/Ulmer, GRUR Int. 1967, 431 (444). Auch in der InfoSoc-Richtlinie findet sich ein ausdrücklicher Anspruch auf eine Vergütung nicht, jedoch spricht Erwägungsgrund 35 von einem ,gerechten Ausgleich“, den die Rechtsinhaber erhalten sollen, damit die Nutzung 
angemessenen Vergütungszahlung kann eine zunächst ungebührlich erscheinende Interessenverletzung auf ein für den Urheber oder Rechtsinhaber annehmbares, ,gebührliches“ Maß reduziert werden. ${ }^{1639}$ Welche Vergütungssumme im konkreten Fall angemessen ist, hängt maßgeblich von der Rechtfertigung ab, auf der die fragliche Schrankenbestimmung beruht. ${ }^{1640}$ Sind berechtigte Belange der Allgemeinheit von ganz erheblicher Bedeutung der Beweggrund zur Einführung einer Schranke, so müssen Urheber und Rechteinhaber tendenziell Eingriffe in ihre Rechte in deutlich größerem Umfang hinnehmen, als dies bei weniger wesentlichen Belangen der Allgemeinheit oder bei Interessen nur einer bestimmten Nutzergruppe der Fall sein wird. Eine demnach vorzusehende Vergütung des Urhebers beziehungsweise Rechteinhabers ist dabei nicht erst dann angemessen, wenn sie die durch die Schrankenregelung entstehenden Einbußen vollständig ausgleicht und der Schranke somit jegliche Spürbarkeit nimmt. Eine angemessene Vergütung entspricht also nicht einer „vollständigen Vergütung“. Vielmehr muss es ausreichen, wenn die Höhe der Ausgleichszahlung so bemessen ist, dass die Beeinträchtigung aus dem Bereich des Unzumutbaren auf ein (gerade noch) zumutbares Niveau abgemildert wird. ${ }^{1641}$ Die Vergütung kann somit als angemessen angesehen werden, wenn sie dazu geeignet ist, den für die Einführung einer Schrankenregelung maßgeblichen Erwägungen Vorschub zu leisten, und zugleich ausreichend hoch ist, um weiterhin ausreichende Anreize für die Schöpfung und Verbreitung urheberrechtlicher Werke unter den bestehenden sozialen und wirtschaftlichen Bedingungen $\mathrm{zu}$ bieten. ${ }^{1642}$ Dabei kann im Einzelfall auch eine Vergütung unterhalb des Marktpreises angemessen sein, insbesondere dann, wenn die Differenz zwischen tatsächlicher Vergütung unterhalb des Marktpreises und der theoretischen Marktpreisvergütung durch Drittinteressen gerechtfertigt ist. ${ }^{1643}$ So entsteht auf der dritten Prüfungsstufe ein flexibles System, das einen fließenden Übergang von Konstella-

ihrer Werke ,angemessen vergütet“ wird; zur Auslegung des „gerechten Ausgleiches" durch den EuGH, siehe oben 6. Kapitel, B.III.

1639 Vgl. Senftleben, Three-Step Test, S. 239.

1640 Vgl. Senftleben, GRUR 2004, 200 (211). Nach Erwägungsgrund 35 zur InfoSoc-RL soll zudem auch der Grad des Einsatzes technischer Schutzmaßnahmen Berücksichtigung finden. Allgemein zum Problem einer den Umständen nach angemessenen Vergütung Schricker, GRUR 2002, 737.

1641 Ebenso He, IIC 2009, 274 (300 f.).

1642 So auch Geiger/Griffiths/Hilty, IIC 2008, 707 (710); He, IIC 2009, 274 (303).

1643 Vgl. Geiger/Griffiths/Hilty, IIC 2008, 707 (710). 
tionen ermöglicht, in denen eine Vergütungszahlung - aufgrund des Gewichts der geförderten Interessen oder aufgrund der Geringfügigkeit des Eingriffs - gar nicht erforderlich ist, bis hin zu Fällen, in denen aufgrund der Erheblichkeit des Eingriffs in die urheberrechtlichen Ausschließlichkeitsrechte nur relativ große Summen eine ungebührliche Verletzung zu verhindern vermögen. ${ }^{1644}$ Insoweit gewährt der Dreistufentest sowohl dem nationalen Gesetzgeber als auch der Rechtsprechung ${ }^{1645}$ erheblichen Spielraum bei der Ausgestaltung einzelner Vergütungsansprüche beziehungsweise der Festlegung einer angemessenen Vergütungshöhe.

\section{Zusammenfassende Stellungnahme}

Die vorgehenden Überlegungen haben gezeigt, dass die einzelnen Tatbestandsmerkmale der drei Stufen des Dreistufentests sich zwar durch Auslegung mit „Leben“ füllen lassen, eine trennscharfe Abgrenzung der einzelnen Tatbestandsmerkmale und auch der einzelnen Stufen jedoch nicht immer möglich ist. Eine solche ist allerdings auch nicht zwingend erforderlich, damit der Dreistufentest seinen Zweck als Grundlage und Grenze der Ausgestaltung, Einführung und Auslegung von urheberrechtlichen Schranken erfüllen kann. Es erscheint im Gegenteil sogar vorzugswürdig, keine der Stufen überzubetonen und keiner Stufe den Vorrang vor den anderen einzuräumen. Vielmehr sollten anstelle eines strikt auf die einzelnen Stufen fokussierten Vorgehens die Vorgaben des Dreistufentests im Sinne einer umfassenden Gesamtprüfung umgesetzt werden. ${ }^{1646}$ So kann verhindert werden, dass eine einzelne Prüfungsstufe zur „Sackgasse“ für die gesamte Prüfung wird und daher Ergebnisse erzielt werden, die möglicherweise berechtigte Interessen der Allgemeinheit, der Urheber oder der derivativen Rechteinhaber nicht hinreichend berücksichtigen. Diese Gefahr droht - wie gezeigt wurde - insbesondere bei einer zu engen Interpretation der zweiten Teststufe.

1644 Vgl. Senftleben, Three-Step Test, S. 239. Vgl. auch Erwägungsgrund 35 zur InfoSoc-RL.

1645 Siehe etwa die Überlegungen des BGH zur Ermittlung eines angemessenen Vergütungsbetrages in der Kopienversanddienst-Entscheidung, BGHZ 141, 13 (28ff.). Zur Kritik an der mangelnden Genauigkeit dieser Entscheidung im Hinblick auf die Prüfung des Dreistufentests siehe bereits oben Fn. 1562.

1646 Ähnlich Geiger/Griffiths/Hilty, IIC 2008, 707 (709 ff.). 
Es erscheint jedoch auch nicht gewinnbringend, von einem Vorgehen anhand der einzelnen Stufen vollständig Abstand zu nehmen. ${ }^{1647}$ Eine reine Gesamtbetrachtung ohne Beachtung der einzelnen Stufen birgt die Gefahr einer vagen, wenig nachvollziehbaren und kaum vorhersehbaren Prüfung. Die in den einzelnen Stufen enthaltenen Tatbestandsmerkmale ermöglichen die notwendige Orientierung und bieten wichtige Anhaltspunkte für die Prüfung einzelner Schranken und deren Auslegung. Sie sollten daher als Leitlinien der Prüfung weiter eingehalten werden. Es erscheint daher insgesamt angemessen, die vom Dreistufentest vorgeschriebenen Prüfungskriterien im Sinne einzelner Faktoren zu verstehen, die - ähnlich der Fair Use-Prüfung im US-amerikanischen Recht - bei der Überprüfung einer Schrankenbestimmung zu beachten sind, wobei jedoch keinem der einzelnen Faktoren eine abschließende Bedeutung zukommen darf, die regelmäßig einen vorzeitigen Abbruch der Prüfung herbeiführen könnte. ${ }^{1648}$ So ist es etwa sinnvoll, den ökonomischen Nachteilen für den Rechteinhaber bei der Überprüfung einer Schrankenregelung große Beachtung zu schenken. Diese tatsächlich schwer zu ermittelnde Größe sollte jedoch auch nicht (wie es bei einem zu engen Verständnis der zweiten Teststufe droht) zu einem allein entscheidenden Ausschlusskriterium werden. Vielmehr müssen stets auch die berechtigten Interessen Dritter in die Betrachtung einbezogen werden. Nur so bleibt die Möglichkeit erhalten, gegebe-

1647 In diese Richtung aber Geiger/Griffiths/Hilty, IIC 2008, 707 (711); dazu ebenfalls kritisch $\mathrm{He}$, IIC 2009, 274 (280).

1648 Für einen geänderten Dreistufentest in Anlehnung an den US-amerikanischen Fair Use spricht sich ausdrücklich Gervais, 9 Marq. Intell. Prop. L. Rev. 1, $28 \mathrm{f}$. (2005) aus. Einen ähnlichen Vorschlag macht Koelman, EIPR 2006, 28(8), 407 (410), der aber letztlich eine Reduzierung auf einen ,Zweistufentest" nach dem Vorbild der für das Patentrecht in das TRIPS-Übereinkommen aufgenommenen Regelung des Art. 30 TRIPS als Ideallösung bevorzugt. Art. 30 TRIPS gewährt einen größeren Abwägungsspielraum als der Dreistufentest, da er Beschränkungen des Ausschließlichkeitsrechts für zulässig erklärt, solange sichergestellt ist, dass diese "do not unreasonably conflict with a normal exploitation of the patent and do not unreasonably prejudice the legitimate interests of the patent owner, taking account of the legitimate interests of third parties". Die tatsächliche Durchsetzbarkeit einer entsprechenden Änderung des internationrechtlichen Dreistufentests hält aber auch Koelman letztlich für wenig realistisch, siehe EIPR 2006, 28(8), 407 (411). Bedenken hinsichtlich der Praktikabilität jeglicher Reform des Dreistufentests, die eine Änderung des Wortlauts voraussetzt, haben auch Geiger, IIC 2009, 627 (641); Gervais, 9 Marq. Intell. Prop. L. Rev. 1, 28 (2005) und Griffiths, IPQ 2009, 428 (442 f.). 
nenfalls einem überragenden, etwa aus Menschenrechten oder Grundfreiheiten abgeleiteten Allgemeininteresse durch die Etablierung einer Schrankenregelung Vorschub zu leisten, selbst wenn dadurch nicht unerhebliche Nachteile für den Rechteinhaber entstehen sollten. Diese müssen jedoch - anders als im Rahmen der insoweit unflexiblen US-amerikanischen Fair Use-Regelung ${ }^{1649}$ - gegebenenfalls durch eine angemessene Vergütung abgefedert werden.

Nur eine ausgewogene Gesamtbetrachtung aller durch den Dreistufentest vorgegebenen Kriterien ermöglicht es, dass dieser seinen Zweck als Grundlage und Grenze der Ausgestaltung, Einführung und Auslegung gerechter und zukunftsoffener urheberrechtlicher Schranken erfolgreich erfüllen kann. Ein derartiges Verständnis stellt auch keinesfalls einen Systembruch dar. Vielmehr steht es sogar im Einklang mit der ursprünglichen Intention hinter der Einführung des Dreistufentests. Bei der Revisionskonferenz in Stockholm 1967 konnte der Dreistufentest seinen „Siegeszug“ gerade deshalb antreten, weil er von den Beteiligten als flexibler Rahmen angesehen wurde, der den nationalen Gesetzgebern ausreichende Freiräume bei der Ausgestaltung urheberrechtlicher Schrankenregelung unter Berücksichtigung nationaler Besonderheiten und sozialer, kultureller und ökonomischer Bedürfnisse gewährte. ${ }^{1650}$

\section{Exkurs: Vereinbarkeit der Fair Use-Doktrin mit dem Dreistufentest}

Es drängt sich - wie bereits im Rahmen der Auslegung der einzelnen Teststufen angedeutet - die Frage der Vereinbarkeit der offenen US-amerikanischen Fair Use-Generalklausel mit dem im internationalen Recht verankerten Dreistufentest auf. Da auch eine in das deutsche oder europäische Recht aufgenommene generalklauselartige Schrankenregelung in Anlehnung an die Fair Use-Doktrin den Vorgaben des Dreistufentests genügen müsste, soll die Frage der Vereinbarkeit im Folgenden kurz geklärt werden.

Die Zulässigkeit einer offenen Schrankengeneralklausel unter dem Dreistufentest ist in der rechtswissenschaftlichen Literatur zum Teil be-

1649 Zum unflexiblen „Alles oder Nichts“ als Rechtsfolge des Fair Use-Einwandes siehe oben 2. Kapitel, C.I.3.

1650 Siehe WIPO, Records of the IP Conference at Stockholm, S. 81; Ricketson, Berne Convention, S. $484 \mathrm{f}$. 
jaht, ${ }^{1651}$ überwiegend jedoch bezweifelt worden. ${ }^{1652}$ Diese Zweifel an der Vereinbarkeit beruhen zumeist auf einem - anders als hier vertretenen engeren Verständnis der ersten Teststufe, insbesondere auf einer rein quantitativen Auslegung des Kriteriums des „Sonderfalles“ und/oder einer Überbetonung des Bestimmtheitserfordernisses.

\section{Hinreichende Bestimmtheit der Fair Use-Schranke}

Nimmt man an, das auf der ersten Teststufe des Dreistufentests vorgegebene Kriterium der „Bestimmtheit“ sei restriktiv im Sinne eines gesonderten Bestimmtheitsgebotes zu verstehen und ein bestimmter Sonderfall setze klar definierte Ausnahmefälle und einen spezifischen Nutzungszweck voraus, der präzise und eng festgelegt und somit klar identifizierbar sei, ${ }^{1653}$ so wäre eine generalklauselartige Beschränkung der Urheberrechte

1651 Siehe etwa Newby, 51 Stan. L. Rev. 1633, 1662 f. (1999); Patry, Fair Use (2009), § 8:12, § 8:2; Poeppel, Neuordnung, S. 499; Schack, in: FS Schricker II, S. 512 f.; Senftleben, Three-Step Test, S. 162 ff.; ders., GRUR Int. 2004, 200 (206 f.); im Ergebnis auch Busche/Stoll/Füller, TRIPs, Art. 13 Rn. 9; Förster, Fair Use, S. 201.

1652 Ablehnend oder zweifelnd etwa Bornkamm, in: FS Erdmann, S. 29 (46); Brenncke, Fair Use, S. 14 f.; Burrell/Coleman, Copyright Exceptions, S. 270 ff.; Cohen Jehoram, GRUR Int. 2001, 807 (808); ders., EIPR 2005, 27(10), 359 (360, 362); Coombe, 52 DePaul L. Rev. 1171, 1182 f. (2003); Dreyfuss/Lowenfeld, 37 Va. J. Int'1 L. 275, 305 (1997); Leaffer, 62 Ohio St. L.J. 849, 859 ff. (2001); Leistner, Konsolidierung und Entwicklungsperspektive, S. 33; Lucas, EIPR 2010, 32(6), 277 (278 f.); Okediji, 39 Colum. J. Transnat'l L. 75, 126 ff. (2000); Reichman, 29 Int'l Law. 345, 368 (1995); Ricketson, Three-Step Test, S. 150 ff.; ders., WIPO-Study, S. 67 ff.; Sun, 5 Nw. J. Tech. \& Intell. Prop. 265, 291 (2007).

1653 So etwa WTO-Panel Report, WT/DS160/R vom 15.6.2000, § 6.108: "[A]n exception or limitation in national legislation must be clearly defined"; Ficsor, Law of Copyright, C10.03: "[T] he use to be covered must be specific-precisely and narrowly determined [...] no broadly determined cases are acceptable."; zustimmend Berger, CR 2004, 360 (365); Bornkamm, in: FS Erdmann, S. 29 (46); Busche/Stoll/Füller, TRIPs, Art. 13 Rn. 8; Dusollier, IRDI 2005, 212 (218); Förster, Fair Use, S. 196 f.; Fromm-Russenschuck/Duggal, WTO und TRIPs, S. 54; Reinbothe, in: FS Dittrich, S. 251 (257); Reinbothe/v.Lewinski, WIPO Treaties, Art. 10 WCT Rn. 15; Ricketson, Three-Step Test, S.29; 
wie die US-amerikanische Fair Use-Schranke wohl tatsächlich mit dem Dreistufentest unvereinbar. Eine konkrete Definition der zulässigen Nutzungsformen und -zwecke erfolgt hier nicht. Gerade aus diesem „Mangel“ folgt jedoch die besondere - wünschenswerte - Flexibilität der Schrankenregelung.

Folgt man hingegen der hier befürworteten Auslegung der ersten Stufe des Dreistufentests, nach der eine enge Auslegung des Bestimmtheitserfordernisses der ersten Teststufe im Sinne eines echten Bestimmtheitsgebotes abzulehnen ist, so steht die Fair Use-Schranke oder eine vergleichbare offene Schrankenregelung nicht im Widerspruch zum Erfordernis der Bestimmtheit, solange die Reichweite der Beschränkung hinreichend vorhersehbar ist. Eine hinreichende Vorhersehbarkeit ist aber auch dann gegeben, wenn eine Abwägung anhand etablierter und nachvollziehbarer Kriterien erfolgt und die Schranke somit ein ausreichendes Maß an Rechtssicherheit vermittelt. Eine solche hinreichende Vorhersehbarkeit und genügende Rechtssicherheit bietet die US-amerikanische Fair UseDoktrin durch ein Zusammenspiel des gesetzlichen Kriterienkataloges mit einer diesen ausfüllenden gefestigten Rechtsprechung und deren Bindungswirkung für unterinstanzliche Gerichte.

In den USA ist über Jahrzehnte in einer Vielzahl von Entscheidungen eine gefestigte Rechtsprechung zur Generalklausel des Fair Use entstanden, aus der (zumindest in der Rechtsprechung) ein weitestgehender Konsens über Bedeutung und Reichweite der Fair Use-Doktrin abzulesen ist. ${ }^{1654}$ Wesentliche „Eckpunkte“ der Fair Use-Rechtsprechung sind im Jahr 1976 in der gesetzlichen Regelung des 17 U.S.C. § 107 festgeschrieben worden. Diese Regelung bietet einen Ausgangspunkt und eine Leitlinie für eine jede Fair Use-Prüfung. Es findet also schon allein aufgrund der gesetzlichen Fundierung keinesfalls eine völlig „freischwebende“ Interessenabwägung mit unvorhersehbarem Ausgang statt. Ausgehend von der gesetzlichen Regelung hat die Rechtsprechung zudem in den Jahren nach 1976 die Fair Use-Kriterien in zahlreichen Entscheidungen weiter-

wohl auch Hohagen, Vervielfältigung zum eigenen Gebrauch, S. 96. Vgl. auch Schweizerisches Bundesgericht, Urt. v. 26.6.2007, Az. 4C.73/2007 = GRUR Int. 2007, 1046 (1049) - Elektronische Pressespiegel; siehe dazu die kritische Anmerkung von Born, MR-Int. 2007, $148 \mathrm{ff}$.

1654 Vgl. Samuelson, 77 Fordham L. Rev. 2537, 2540 f. (2009). 
entwickelt, stetig ,verfeinert“ und teilweise ergänzt. ${ }^{1655}$ Gerade die jüngere Rechtsprechung wird neben den Entscheidungen der majority geprägt durch die Tradition der Formulierung oftmals umfangreicher obiter dicta und dissenting opinions, die bei späteren Entscheidungen als Argumentations- und Abgrenzungsgrundlage dienen können. ${ }^{1656}$ Auch dies hat zusätzlich zur Entwicklung und Ausformung der Fair Use-Doktrin und somit letztlich zu größerer Vorhersehbarkeit beigetragen. Schließlich entsteht durch das Zusammen- und Gegenspiel verschiedener (Bezirks-)Gerichte eine Art „Signalsystem“ gegenläufiger Rechtsansichten und Entscheidungen, die „reif" für eine Überprüfung durch den Supreme Court sind. ${ }^{1657}$

Auf diesen etablierten „Werkzeugkasten“ aus vielfältigen Kriterien, Regeln und Prinzipien für die Auslegung und Ausfüllung der Fair Use-Doktrin kann die Rechtsprechung in den USA zurückgreifen, wenn sie mit Fragen der urheberrechtlichen Zulässigkeit neuer Formen der Werknutzung konfrontiert wird, die bisher nicht Gegenstand gerichtlicher Auseinandersetzungen waren. Es fehlt der Fair Use-Schranke nach alledem keinesfalls an der für eine Vereinbarkeit mit dem Bestimmtheitserfordernis des Dreistufentests erforderlichen Vorhersehbarkeit. Werden die in gefestiger Rechtsprechung entwickelten Kriterien von den Gerichten beachtet wie dies in den USA bei Fair Use-Entscheidungen regelmäßig der Fall ist - so mögen Entscheidungen der Gerichte im Zusammenhang mit neuen urheberrechtlichen Nutzungsformen gar besser vorhersehbar sein als im Falle eines geschlossenen Kataloges von Schrankenregelungen, der notwendig nicht jede nur denkbare (Nutzungs-)Situation vorhersehen und beinhalten kann und somit regelmäßig an seine Grenzen stoßen wird. ${ }^{1658}$

1655 Siehe etwa zur gelegentlich als weiterem Fair Use-Kriterium herangezogenen Frage des „Good Faith“ oben 5. Kapitel, B.II.1.f).

$1656 \mathrm{Zu}$ Rolle und Einfluss von dissenting opinions in der US-Rechtsprechung siehe Ginsburg, 95 Minn. L. Rev. 1 (2010) m.w.N.

1657 Zum „signaling system“ solcher „circuit splits“ am Beispiel der Frage der Auslegung des vierten Fair Use-Faktors durch die Urteile Kelly v. Arriba Soft (336 F.3d 811 (9th Cir. 2003)) und Video Pipeline, Inc. v. Buena Vista Home Entertainment (342 F.3d 191 (3d Cir. 2003)) siehe Pasquale, 60 Vand. L. Rev. 135, 182 ff. (2007). Allgemein zu diesem „Kontrollmechanismus“ im US-amerikanischen Recht (am Beispiel des US-amerikanischen Patentverfahrenssystems) auch Leistner/Kleinemenke, ZGE 2010, 273 (287, 290).

1658 Siehe zu dieser Kritik am geschlossenen Schrankenkatalog des deutschen UrhG bereits zusammenfassend oben S. 202 ff., $279 \mathrm{ff}$. 
2. Vorliegen eines „Sonderfalles“

Auch zu dem weiteren Erfordernis der ersten Teststufe des Dreistufentests steht die US-amerikanische Fair Use-Doktrin oder eine vergleichbare Schrankengeneralklausel jedenfalls dann nicht im Widerspruch, wenn man der hier vertretenen Auslegung folgt, nach der das Kriterium des ,Sonderfalles" nicht überbetont werden sollte und keinesfalls eine rein quantitative Betrachtung vorzunehmen ist. Vorzugswürdig ist ein qualitativer Ansatz zur Bestimmung von „Sonderfällen“, nach dem die erste Stufe im Wesentlichen dazu dient, den hinter einer Schrankenregelung stehenden Zweck und die geförderten Interessen zu bestimmen und so den Weg für eine vertiefende Überprüfung der Schrankenbestimmung auf den beiden folgenden Stufen zu ebnen.

Den richtigerweise eher niedrig anzusetzenden qualitativen Anforderungen an das Vorliegen eines ,Sonderfalles“ genügt die Fair Use-Schranke zweifelsohne. Das gesamte US-amerikanische Urheberrecht basiert auf einem utilitaristischen Verständnis, wonach oberstes Ziel der Gewährung des Urheberrechtsschutzes die Förderung der Wissenschaft und Künste ist. ${ }^{1659}$ Dem Urheber oder Rechteinhaber soll jedoch nur insoweit ein Monopol in Form urheberrechtlicher Ausschließlichkeitsbefugnisse eingeräumt werden als dieses als Anreiz und zur Marktsteuerung erforderlich ist. Sind die durch das Monopol verursachten Nachteile geringer als die gesamtwirtschaftlichen Vorteile, so sind sie als „notwendiges Übel“ zur Korrektur eines Marktversagens in Kauf zu nehmen. Das urheberrechtliche Monopol wird jedoch dann durch die Fair Use-Schranke durchbrochen, wenn die gesamtwohlfahrtlichen Vorteile einer bestimmten Nutzungsform aufgrund des mit dieser verbundenen sozialen, kulturellen oder politischen Nutzens die Beeinträchtigungen des Urhebers oder Rechteinhabers überwiegen.

Die Anerkennung einer Nutzungsform als Fair Use stellt somit gerade immer einen „Sonderfall“ dar, dem die Annahme zugrunde liegt, dass besondere Belange einzelner Nutzergruppen oder schützenswerte Allgemeininteressen im konkreten Fall Vorrang vor dem urheberrechtlichen Ausschließlichkeitsrecht verdienen. Die Präambel des 17 U.S.C. § 107 listet sogar ausdrücklich einige solcher Belange auf, die aufgrund eines üblicherweise mit ihnen verbundenen besonderen sozialen, politischen oder

1659 Siehe dazu bereits oben 1. Kapitel, B. 
kulturellen Nutzens typischerweise „fördernswert“ erscheinen. ${ }^{1660}$ Als „fair" anzusehende Nutzungsformen sind folglich in aller Regel gerade solche Nutzungen, die - qualitativ verstandene - „Sonderfälle“ darstellen, so dass die Fair Use-Schranke insofern im Einklang mit der ersten Stufe des Dreistufentest steht. ${ }^{1661}$

\section{Historische Betrachtung der Vereinbarkeit}

Dieses Ergebnis lässt sich durch eine historische Betrachtung zusätzlich stützen. Es steht im Einklang mit der Entstehungsgeschichte des urheberrechtlichen Dreistufentests und dem Willen der Vertragsparteien von RBÜ, TRIPS und WCT, Schrankengeneralklauseln und insbesondere die US-amerikanische Fair Use-Doktrin als mit den Anforderungen des Dreistufentests vereinbar anzusehen. Der Dreistufentest konnte seinen „Siegeszug"1662 durch das internationale Urheberrecht gerade deshalb antreten und fortsetzen, weil er von den Vertragsparteien als hinreichend flexible Regelung angesehen wurde, die den Freiraum der nationalen Gesetzgeber für die Berücksichtigung berechtigter sozialer, kultureller und ökonomischer Belange nicht übermäßig einengen und sowohl der kontinentaleuropäischen als auch der angloamerikanischen Urheberrechtstradition mit ihren unterschiedlichen Schrankenmethodiken gerecht werden sollte. ${ }^{1663}$ Die Zulässigkeit offener Schrankengeneralklauseln wie der auch bereits damals für das US-amerikanische Urheberrecht prägenden Fair Use-Doktrin sollte also durch die Einführung des Dreistufentests gerade nicht in Frage gestellt werden. ${ }^{1664}$

166017 U.S.C. $\S 107$ nennt als fördernswerte Belange ausdrücklich criticism, comment, news reporting, teaching, scholarship und research. Siehe näher zu Inhalt und Bedeutung der Präambel oben 2. Kapitel, C.I.2.a)aa).

1661 So auch Förster, Fair Use, S. 195; Schack, in: FS Schricker II, S. 513; Senftleben, Three-Step Test, S. $166 \mathrm{f}$.

1662 Senftleben, in: Hilty/Peukert, Interessenausgleich, S. 159 (171).

1663 Siehe WIPO, Records of the IP Conference at Stockholm, S. 81; Ricketson, Berne Convention, S. 484 f. sowie oben Fn. 1468 und zugehöriger Text.

1664 So auch Geiger, EIPR 2007, 29(12), 486 (487); ders., IIC 2009, 627 (633 f.); Ginsburg, RIDA 187 (2001), 3 (35 f.); Schack, in: FS Schricker II, S. 513; Senftleben, Three-Step Test, S. 167 f. 
4. Ergebnis: Vereinbarkeit der Fair Use-Doktrin mit dem Dreistufentest

Folgt man der hier vertretenen Interpretation des urheberrechtlichen Dreistufentests, nach der dessen erste Stufe kein gesondertes Bestimmtheitserfordernis aufstellt und das Vorliegen eines Sonderfalles qualitativ zu ermitteln ist, so ist eine Schrankengeneralklausel wie die des Fair Use mit dem Dreistufentest vereinbar. Dies muss jedenfalls dann gelten, wenn die Generalklausel vom Gesetzgeber und/oder - wie in den USA - von der Rechtsprechung anhand nachvollziehbarer Kriterien so ausgeformt wird, dass eine hinreichende Vorhersehbarkeit gewährleistet ist.

\section{Der verfassungsrechtliche Rahmen gesetzgeberischer Gestaltungsfreiheit}

Besondere Bedeutung bei der Neu- oder Umgestaltung der Schranken des Urheberrechts auf nationaler Ebene kommt neben dem Konventions- und Gemeinschaftsrecht schließlich dem deutschen Verfassungsrecht zu, das dem Gesetzgeber einen verbindlichen Rahmen für die Ausgestaltung des deutschen Urheberrechts vorgibt.

An urheberrechtlich geschützten Werken besteht eine Vielzahl von zum Teil gegenläufigen Interessen, die jeweils durch eine Reihe von Verfassungsbestimmungen Schutz genießen. Die an der urheberrechtlichen Verwertung Beteiligten - Urheber, Verwerter und Endnutzer - sind alle Träger von Grundrechten, deren Schutzbereiche mit den Grundrechten anderer Beteiligter oder mit sonstigen Verfassungszielen kollidieren können. ${ }^{1665}$ Der Gesetzgeber muss deshalb die Gesamtheit der betroffenen Verfassungswerte bei der Einführung neuer oder Anpassung bestehender urheberrechtlicher Schrankenregelungen beachten und versuchen, einen verhältnismäßigen, möglichst schonenden Ausgleich der gegenläufigen, gleichermaßen verfassungsrechtlich geschützten Interessen mit dem Ziel ihrer Optimierung zu finden. ${ }^{1666}$

Das Urheberrecht basiert dabei in seiner Konzeption seit jeher und nach wie vor auf der Fiktion eines bipolaren Interessengegensatzes, nämlich dem zwischen den Rechteinhabern auf der einen und den Nutzern (als Teil der Allgemeinheit) auf der anderen Seite. In Wahrheit sieht sich der Ge-

1665 Vgl. Poeppel, Neuordnung, S. 133.

1666 Vgl. BVerfGE 81, 278 (292 f.) - Bundesflagge; E 93, 1 (21) - Kruzifix. 
setzgeber heute jedoch bei der Ausgestaltung des Urheberrechts mit einer tripolaren Interessenlage konfrontiert, da die gesetzlich dem Urheber zuerkannten Ausschließlichkeitsrechte tatsächlich kaum mehr vom Kreativen selbst, sondern in der Regel von einem Verwerter wahrgenommen werden. ${ }^{1667}$ Der grundrechtliche Schutz der Interessen der Urheber (der originären Rechteinhaber) und ihrer Werke (sogleich I.) muss deshalb in einen interessengerechten Ausgleich mit den Interessen der derivativen Rechteinhaber (der Werkmittler) (sodann II.) sowie den verfassungsrechtlich anerkannten Interessen Dritter oder der Allgemeinheit an einer möglichst freien Werknutzung und -verwertung (unten III.) gebracht werden. Dabei besteht - entgegen des häufig erweckten Eindrucks - ein besonderes Spannungsverhältnis nicht etwa zwischen den Interessen der Allgemeinheit und denen der originären Rechteinhaber, sondern vielmehr zwischen den Interessen der Allgemeinheit und denen der Verwerter. ${ }^{1668}$

\section{Verfassungsrechtlicher Schutz der Interessen der Urheber}

Anders als die Weimarer Reichsverfassung von 1919, die das Urheberrecht als Programmsatz anführte, ${ }^{1669}$ erwähnt das Grundgesetz das Urheberrecht ausdrücklich lediglich in Art. 73 Abs. 1 Nr. 9 GG als Gegenstand der ausschließlichen Gesetzgebung des Bundes. Dennoch besteht Einigkeit, dass der Urheber sich auf grundrechtlichen Schutz berufen kann, so dass die Regelungen des Grundgesetzes eine entscheidende Rolle bei der Bestimmung der Grenzen des Urheberrechts und seiner Einschränkungen spielen. Ein umfassender verfassungsrechtlicher Schutz geistiger Leistungen erfolgt nach dem Grundgesetz durch ein Zusammenspiel der Gewährleistungen verschiedener Einzelgrundrechte. Für die vorliegende Untersuchung ist daher von Interesse, welche Grundrechtspositionen des Urhebers durch die Einführung oder Änderung von Urheberrechtsschranken konkret

1667 Ausführlich zu den involvierten Interessen dieser drei Gruppen Geiger, Droit d'auteur, Rn. 19-97; Hilty, ZUM 2003, 983 (985 ff.); ders., GRUR 2005, 819 (820, 824); ders., in: FS Schricker II, S. 325 (329 f.). Für eine quadrupolare Auffächerung der beteiligten Interessen (Urheber, Rechteinhaber, Wettbewerber und Endnutzer) Dreier, in: Torremans, Copyright Law, S. $232 \mathrm{ff}$.

1668 Vgl. Hilty, GRUR 2005, 819 (824).

1669 Art. 158 Abs. 1 WRV lautete: „Die geistige Arbeit, das Recht der Urheber, Erfinder und Künstler genießt den Schutz und die Fürsorge des Reiches.“. 
betroffen sind und in welchem Verhältnis die Grundrechtspositionen zueinander stehen.

Da sich die Interessen der Urheber in Bezug auf ihre Werke je nach „Urhebertyp“, Werkkategorie und Motiven für das Schaffen erheblich unterscheiden können, ${ }^{1670}$ lassen sie sich - jedenfalls im Rahmen dieser Arbeit - nicht erschöpfend darstellen. Im Wesentlichen können die Interessen jedoch in zwei Kategorien eingeteilt werden: Zum einen die materiellen Interessen, insbesondere also das Interesse an Amortisation getätigter Investitionen und ein mögliches Interesse an der Gewinnerzielung zur Sicherung oder Ergänzung des Lebensunterhaltes. Zum anderen die persönlichkeitsrechtlich geprägten ideellen Interessen, die sich etwa im Bedürfnis nach Kontrolle über die Werkveröffentlichung, Darstellungsform und Urhebernennung widerspiegeln. Was die materiellen Interessen des Urhebers betrifft, so steht der verfassungsrechtliche Schutz durch die Eigentumsgarantie (sogleich 1.) im Vordergrund. Die ideellen Interessen des Urhebers hingegen schützen vorwiegend die Kunst- und Wissenschaftsfreiheit (unten 2.) sowie das Persönlichkeitsgrundrecht (unten 3.).

\section{Art. $14 \mathrm{GG}$ - Eigentumsschutz}

Das Urheberrecht genießt als absolutes Recht hinsichtlich seiner vermögenswerten Befugnisse in Deutschland den Schutz der Eigentumsgarantie des Grundgesetzes. Insbesondere in den beiden Grundsatzurteilen zum Kirchen- und Schulgebrauch ${ }^{1671}$ sowie zur Kirchenmusik ${ }^{1672}$ hat das Bundesverfassungsgericht herausgestellt, dass das vom Urheber geschaffene Werk und die darin verkörperte geistige Leistung in vermögensrechtlicher Hinsicht Eigentum des Urhebers im Sinne des Art. 14 Abs. 1 S. 1 GG sind; sie gehören zu dem ,durch Arbeit und Leistung erworbenen Bestand an vermögenswerten Gütern““ ${ }^{1673}$ Prüfungsmaßstab und Grenze der Zulässigkeit gesetzlicher Regelungen, die sich auf die wirtschaftliche Verwertung

1670 Siehe dazu näher Schweikart, Interessenlage, S. 24 ff.; Stang, Das urheberrechtliche Werk, S. 61 ff. m.w.N.

1671 BVerfGE 31, 229.

1672 BVerfGE 49, 382.

1673 Siehe BVerfGE 31, 229 (238 f.) - Kirchen- und Schulgebrauch; E 49, 382 (392) - Kirchenmusik; vgl. auch BVerfGE 77, 263 - Zeitschriftenauslage; E 81, 12 Vermietungsvorbehalt; ausführlich Badura, in: FS Maunz, S. 1 (11 ff.); KrügerNieland, in: FS Oppenhoff, S. 173 (177). 
der in einem Werk verkörperten Leistung des Urhebers beziehen - insbesondere also gerade gesetzlicher Schranken der Befugnisse des Urhebers -, ist daher primär die Eigentumsgarantie des Grundgesetzes. ${ }^{1674}$ Dieser kommt im Gesamtgefüge der Verfassung zunächst die Aufgabe zu, dem Träger des Grundrechts durch Zubilligung und Sicherung von Herrschafts-, Nutzungs- und Verfügungsrechten einen Freiheitsraum im vermögensrechtlichen Bereich zu gewährleisten und ihm damit die Entfaltung und eigenverantwortliche Gestaltung des Lebens zu ermöglichen. Insoweit steht sie in einem inneren Zusammenhang mit der Garantie der persönlichen Freiheit. Darüber hinaus bewahrt die Eigentumsgarantie den konkreten, vor allem den durch Arbeit und Leistung erworbenen Bestand an vermögenswerten Gütern vor ungerechtfertigten Eingriffen durch die öffentliche Gewalt. ${ }^{1675}$ Das Bundesverfassungsgericht sieht den verfassungsrechtlich geschützten Kern des Urheberrechts also in einem Doppelten: in der Zuordnung des Vermögenswertes an den Urheber und in der Verfügungsfreiheit des Urhebers. ${ }^{1676}$

Nach Art. 14 Abs. 1 S. 1 GG wird das Eigentum gewährleistet; Satz 2 ermächtigt und verpflichtet den Gesetzgeber, Inhalt und Schranken des Eigentums zu bestimmen. Art. 14 Abs. 1 GG enthält somit eine Bestandsund eine Institutsgarantie. Während die Bestandsgarantie im Hinblick auf Immaterialgüterrechte vergleichsweise unproblematisch ist, ${ }^{1677}$ wirft die Institutsgarantie vielfach Probleme auf, da es einen (naturrechtlich) vorgegebenen und absoluten Begriff des Eigentums nicht gibt und sich so die genaue Reichweite der Eigentumsgarantie im Bereich des Urheberrechts nicht von vorneherein präzise festlegen lässt. ${ }^{1678}$ Vielmehr ist dem Gesetz-

1674 Vgl. Melichar, Schranken, S. 11.

1675 BVerfGE 31, 229 (239) - Kirchen- und Schulgebrauch.

1676 Grzeszick, ZUM 2007, 344 (350).

1677 Der Gesetzgeber darf, wenn er das Urheberrechte einmal in bestimmter Weise ausgestaltet hat, bereits entstandene Rechte nachträglich nur beschneiden, wenn es dafür sachliche Gründe gibt, die einer Verhältnismäßigkeitsprüfung standhalten; vgl. BVerfGE 31, 275 (289 f., 294) - Bearbeiter-Urheberrechte.

1678 Zur Problematik der „Grundrechte aus der Hand des Gesetzgebers" siehe Her$z o g$, in: FS Zeidler, S. 1415 ff. In Fällen, in denen das Schutzobjekt - hier das Eigentum - nicht der Tatsachenwelt entnommen, sondern selbst ein Produkt der Rechtsordnung ist, tut sich der Widerspruch auf, dass Grundrechte bestimmte Güter gegen den Staat schützen sollen, es diese Güter aber ohne den Staat, der sie durch seine Rechtsordnung erst geschaffen hat, überhaupt nicht gäbe. Der Grundrechtscharakter reicht daher grundsätzlich nicht weiter als der gesetzge- 
geber im Rahmen des in Art. 14 Abs. 1 S. 2 GG enthaltenen Regelungsauftrags, Inhalt und Schranken des Urheberrechts zu bestimmen, ein grundsätzlich weiter Spielraum zur gesetzlichen Ausgestaltung dieser Regelungen gelassen. ${ }^{1679}$ Der Gesetzgeber darf dabei jedoch zum einen die grundsätzliche Zuordnung des vermögenswerten Ergebnisses der geistig-schöpferischen Leistung an den Urheber nicht in Frage stellen; er ist dazu aufgefordert, den Grundsatz durchzusetzen, dass der Urheber „tunlichst an dem wirtschaftlichen Nutzen zu beteiligen ist, der aus seinem Werk gezogen wird". 1680 Zum anderen muss er die Allgemeinwohlbindung des Eigentums nach Art. 14 Abs. 2 GG beachten. ${ }^{1681}$ Schließlich hat der Gesetzgeber bei der Inhalts- und Schrankenbestimmung des Eigentums den verfassungsrechtlichen Grundsatz der Verhältnismäßigkeit zu berücksichtigen.

\section{a) Institutsgarantie}

Der Gesetzgeber ist - wie bereits dargestellt - nach Art. 14 Abs. 1 S. 2 GG ausdrücklich dazu aufgefordert, dem grundgesetzlich verbürgten Eigentum seine konkrete Form zu geben. Gerade das Urheberrecht bedarf dabei in besonderer Weise der Ausgestaltung durch positives Recht, weil es erst dadurch nutzbar und wirtschaftlich verwertbar wird. ${ }^{1682}$ Das Bundesverfassungsgericht betont jedoch zugleich, dass die grundsätzliche Zuord-

berische Schutz. Dieses lässt sich gerade anhand des Urheberrechts nahezu lupenrein zeigen: Schreibt das Gesetz - wie derzeit - eine siebzigjährige Schutzfrist p.m.a. vor, so wirkt der Grundrechtsschutz grundsätzlich ebenfalls 70 Jahre p.m.a. Verlängert das Gesetz die Schutzfrist, so verlängert sich auch der Grundrechtsschutz; vgl. Herzog, a.a.O., S. 1417 f. Siehe zu dieser Problematik auch Maunz/Dürig/Papier, GG, Art. 14 Rn. 35 ff.; Timmann, Patentrecht im Lichte von Art. 14 GG, S. 49 ff.

1679 Vgl. BVerfGE 79, 29 (40)-Vollzugsanstalten; Geiger, GRUR Int. 2008, 459 (465); Grzeszick, ZUM 2007, 344 (350); Paulus/Wesche, ZGE 2010, 385 (392); Schack, Urheberrecht, Rn. $91 \mathrm{f}$.

1680 St. Rspr., vgl. BGHZ 11, 135 (143) - Lautsprecherübertragung; Z 97, 37 (43) Filmmusik; Z 116, 305 (308) - Altenwohnheim II; Z 129, 66 (72) - Mauer-Bilder.

1681 Vgl. Dreier/Schulze, Einl. Rn. 39. Zur Sozialbindung des geistigen Eigentums und zur Beachtung der Interessen der Allgemeinheit siehe bereits oben 2. Kapitel, B.

1682 Vgl. BVerfGE 31, 275 (286) - Bearbeiter-Urheberrechte; Krause, JZ 1984, 711 (715). 
nung der vermögenswerten Seite des Urheberrechts nicht bedeutet, dass damit jede nur denkbare Verwertungsmöglichkeit urheberrechtlich geschützter Werke verfassungsrechtlich gesichert ist. ${ }^{1683}$ Die Freiheit der Konkretisierung findet vielmehr ihre Grenze in der sogenannten Institutsgarantie des Art. 14 Abs. 1 S. 1 GG. Danach enthält die Gewährleistung des Eigentums auch die konstitutionelle Zusicherung, dass das Privateigentum als Rechtseinrichtung erhalten bleibt; es muss also stets ein elementarer Bestand an Eigentumsrechten erhalten bleiben. ${ }^{1684}$ Dem Gesetzgeber ist es demnach verwehrt, solche Sachbereiche der Privatrechtsordnung vorzuenthalten oder zu entziehen, die zum elementaren Bestand einer Betätigung im vermögensrechtlichen Bereich gehören und ohne die vom Eigentum im Rechtssinn nicht mehr gesprochen werden könnte. ${ }^{1685}$ Was nicht zu diesem elementaren Bestand gehört, ist nicht von der Institutsgarantie erfasst. Es kann daher grundsätzlich ohne Grundrechtsverletzung aufgehoben oder eingeschränkt werden. ${ }^{1686}$ Die Institutsgarantie stellt somit selbst keine Anspruchsgrundlage für den Einzelnen dar, sondern beschränkt die gesetzgeberische Befugnis zur Inhalts- und Schrankenbestimmung des Eigentums. Ihr kommt die Funktion einer „Schranken-Schranke“" der Inhalts- und Schrankenbestimmung und der Enteignung zu. ${ }^{1687}$

Die Institutsgarantie erlangt daher erhebliche Bedeutung für die Frage der Rechtmäßigkeit der Änderung bestehender oder Schaffung neuer urheberrechtlicher Schrankenbestimmungen sowie für die Auslegung dieser Schranken durch die Gerichte. Sie steht jedoch nicht etwa der Schaffung neuer Schranken grundsätzlich entgegen. Die gesetzlichen Schranken des Urheberrechts sind Ausdruck der Ausgleichsregelung zwischen dem Schutz des Urhebers und den Interessen der Allgemeinheit und Dritter, für die sich der Gesetzgeber einmal entschieden hat. Sie spiegeln aber nicht die schlechthin verfassungsrechtlich gebotene, allein mögliche Entscheidung des Gesetzgebers wider und stellen auch nicht etwa die allein mögli-

1683 Vgl. BVerfGE 31, 229 (241) - Kirchen- und Schulgebrauch.

1684 Vgl. BVerfGE 58, 300 (339) - Nassauskiesung; Fechner, Geistiges Eigentum und Verfassung, S. 210; Kreile, in: FS Lerche, S. 251 ff.; Maunz, GRUR 1973, 107 ff.; Maunz/Dürig/Papier, GG, Art. 14 Rn. 11.

1685 Vgl. BVerfGE 20, 351 (355) - Tollwut; E 24, 367 (389) - Hamburger Deichordnungsgesetz; E 31, 229 (241) - Kirchen- und Schulgebrauch; E 58, 300 (338 ff.) - Nassauskiesung.

1686 Vgl. Maunz, GRUR 1973, 107 (108).

1687 Vgl. Pieroth/Schlink, Grundrechte, Rn. 1022. 
che oder äußerste Grenze der gesetzlichen Ausgestaltung des Ausgleichs der beteiligten Interessen dar. ${ }^{1688}$ Vielmehr definiert die Institutsgarantie die äußerste Grenze des Zulässigen: Der Gesetzgeber ist in der Ausgestaltung der Nutzung des geistigen Eigentums frei, solange er die typusbestimmenden Grundstrukturen und institutsbewahrenden Leitlinien beachtet. ${ }^{1689}$ Die Nutzung des geistigen Eigentums durch seinen Urheber darf deshalb keinesfalls soweit beschränkt werden, dass dem Rechtsinhaber faktisch kein Gegenwert für seine Leistung zukommt oder verbleibt.

Markiert die Institutsgarantie jedoch die äußerste Grenze des Zulässigen, so kann sie sich auch zu einer Pflicht des Gesetzgebers konkretisieren, (erneut) regulierend einzugreifen, wenn sich Intensität oder Ausmaß einer auf urheberrechtliche Schranken gestützten Nutzung durch eine geänderte Nutzungsrealität so sehr verändern, dass sich die Beeinträchtigung gegenüber der ursprünglichen Situation so erheblich zu Ungunsten des Urhebers verstärkt hat, dass der grundgesetzlich geschützte Kern des Urheberrechts berührt ist. ${ }^{1690}$ Der grundrechtliche Schutzauftrag des Gesetzgebers endet somit nicht mit dem (einmaligen) Erlass eines verfassungsgemäßen Urheberrechts beziehungsweise einzelner verfassungsgemäßer Schrankenbestimmungen, sondern kann auch eine Anpassung an geänderte Umstände erfordern. ${ }^{1691}$ Aus der Eigentumsgarantie des Grundgesetzes ergibt sich somit auch eine Pflicht des Gesetzgebers, die tatsächlichen (insbesondere technischen) Entwicklungen im Auge zu behalten und bestehende Gesetze bei faktischen Veränderungen zu überprüfen und gegebenenfalls zu korrigieren. ${ }^{1692}$ Gleiches gilt auch für die Rechtsprechung. In seiner Entscheidung zur Vergütungspflicht für Drucker und Plotter 1693 hat das Bundesverfassungsgericht zuletzt ausdrücklich betont, die Gerichte seien nicht nur befugt, sondern auch verpflichtet, Gesetze durch Ausle-

1688 Badura, ZUM 1984, 552 (555 f.); zustimmend Hohagen, Vervielfältigung zum eigenen Gebrauch, S. 278.

1689 Vgl. Badura, in: FS Maunz, S. 1 (7f.); Grzeszick, ZUM 2007, 344 (353); Fechner, Geistiges Eigentum und Verfassung, S. 215.

1690 Vgl. Badura, ZUM 1984, 552 (557); Fechner, Geistiges Eigentum und Verfassung, S. 216; Kreile, in: FS Lerche, S. 251 (257).

1691 Siehe Badura, in: FS Maunz, S. 1 (10); Kreile, in: FS Lerche, S. 251 (257); zustimmend Reschke, Verfassungs- und dreistufentestkonforme Auslegung, S. 34.

1692 Siehe Fechner, Geistiges Eigentum und Verfassung, S. 216, mit Nachweisen zur streitigen Frage, ob ein gerichtlich durchsetzbarer Anspruch auf derartiges gesetzgeberisches Tätigwerden besteht.

1693 BVerfG, GRUR 2010, 999 - Drucker und Plotter. 
gung an die aktuellen Gegebenheiten anzupassen, wenn ehemals eindeutige und vollständige gesetzliche Regelungen auf Grund eines durch die technische Entwicklung bedingten „Alterungsprozesses“ lückenhaft, ergänzungsbedürftig und zugleich ergänzungsfähig würden. ${ }^{1694}$

\section{b) Sozialpflichtigkeit, Art. 14 Abs. 2 GG}

Der Generalklausel der Eigentumsgewähr stellt das Grundgesetz in Art. 14 Abs. 2 GG eine zweite Generalklausel gegenüber - die der Sozialbindung. Jenseits der Institutsgarantie ist das Wohl der Allgemeinheit die wesentliche Leitlinie der zulässigen Ausgestaltung des Urheberrechts. ${ }^{1695}$ Interessen der „Allgemeinheit“ können dabei nach hier vertretenem Verständnis nicht lediglich gesamtgesellschaftliche Interessen sein, sondern auch solche einzelner Individuen oder einzelner Interessengruppen wie etwa der Werkverwerter. Das subjektive Recht des Urhebers findet seine Grenzen in sämtlichen grundrechtlich gewährleisteten, berechtigten Interessen Dritter und muss mit diesen in Einklang gebracht werden. ${ }^{1696}$ Die Bindung an das Allgemeinwohl bedeutet folglich, dass sich der Träger eines vermögenswerten Rechts solche Beschränkungen gefallen lassen muss, die in Bezug auf sein Recht üblich, sozialadäquat und zumutbar sind. ${ }^{1697}$ Eine Sozialbindung kann daher stets dann nicht mehr vorliegen, wenn die Grenze zur entschädigungspflichtigen Enteignung im Sinne des Art. 14 Abs. 3 GG überschritten ist. ${ }^{1698}$

1694 Siehe BVerfG, GRUR 2010, 999 (1002) - Drucker und Plotter.

1695 Vgl. BVerfGE 81, 208 (220) - Bob Dylan.

1696 So auch Stieper, Schranken, S. 27.

1697 Vgl. Maunz, GRUR 1973, 107 (108).

1698 Eine Enteignung im Sinne des Art. 14 Abs. 3 GG liegt vor, wenn der Staat auf das Eigentum des Einzelnen zugreift. Sie ist auf die vollständige oder teilweise Entziehung konkreter subjektiver, durch Art. 14 Abs. 1 S. 1 GG gewährleisteter Rechtspositionen zur Erfüllung bestimmter öffentlicher Aufgaben gerichtet (st. Rspr. des BVerfG, siehe nur BVerfGE 72, 66 (76) - Flughafen Salzburg; E 101, 239 (259) - Stichtagregelung im Vermögensgesetz; E 102, 1 (15 f.) - Altlasten). Die Enteignung setzt den Entzug konkreter Rechtspositionen voraus, aber nicht jeder Entzug ist eine Enteignung im Sinne von Art. 14 Abs. 3 GG. Diese ist beschränkt auf solche Fälle, in denen Güter hoheitlich beschafft werden, mit denen ein konkretes, der Erfüllung öffentlicher Aufgaben dienendes Vorhaben durchgeführt werden soll (vgl. BVerfGE 38, 175 (179 f.) - Rückenteignung; E 115, 97 (111 f.) - Halbteilungsgrundsatz). Ist mit dem Entzug bestehender Rechtsposi- 
Dem Kriterium der Sozialbindung kommt somit hinsichtlich des Urheberrechts die Aufgabe zu, einen Ausgleich zwischen den Individualinteressen der Rechteinhaber und den Interessen der Allgemeinheit an einer umfassenden und möglichst kostengünstigen Nutzung sowie den Interessen der Werkverwerter und auch der einzelnen Nutzer herbeizuführen. ${ }^{1699}$ Die Individualinteressen der Urheber beanspruchen dabei keinen unbedingten Vorrang vor den Interessen der Gemeinschaft oder Einzelner. Der Gesetzgeber muss dem Urheber nicht jede denkbare Verfügungs- und Verwertungsmöglichkeit garantieren, sondern nur eine grundsätzliche Zuordnung seiner Leistung vornehmen. ${ }^{1700}$ Verfassungsrechtlich ist der Gesetzgeber also nur verpflichtet, eine angemessene Verwertung sicherzustellen, die der Natur der sozialen Bedeutung des Rechts entspricht. Wie der Urheber das Werk verwertet und ihm ermöglicht wird, aus diesem eine Vergütung zu erzielen, wird jedoch nicht zwangsläufig vorgeschrieben. ${ }^{1701}$ Bei der Festlegung des Angemessenen bleibt dem Gesetzgeber grundsätzlich ein weiter Gestaltungsspielraum, wobei das Gemeinwohl nicht nur Grund, sondern auch Grenze für die dem Urheber aufzuerlegenden Beschränkungen ist. ${ }^{1702}$ Die Beschränkungen dürfen deshalb nicht weiter gehen, als es das Allgemeinwohl gebietet. ${ }^{1703}$

\section{c) Grundsatz der Verhältnismäßigkeit}

Die widerstreitenden Belange der Urheber und der Allgemeinheit und ihrer Mitglieder muss der Gesetzgeber in Anwendung des Grundsatzes der

tionen der Ausgleich privater Interessen beabsichtigt, kann es sich nur um eine Inhalts- und Schrankenbestimmung des Eigentums handeln (vgl. BVerfGE 104, 1 (10) - Baulandumlegung). Ausführlich zur wechselhaften Entwicklung des Enteignungsbegriffs, zur Abgrenzung zur Sozialbindung und zur Problematik der entschädigungspflichtigen Sozialbindung, Maunz/Dürig/Papier, GG, Art. 14 Rn. 343 ff.; Fechner, Geistiges Eigentum und Verfassung, S. 230 ff., 248 ff., jeweils m.w.N.

1699 Vgl. Fechner, Geistiges Eigentum und Verfassung, S. 241; Stieper, Schranken, S. 27.

1700 Vgl. BVerfGE 79, 1 (25) - Urheberrechtliche Vergütung; E 79, 29 (40) - Vollzugsanstalten.

1701 Siehe Geiger, GRUR Int. 2008, 459 (465).

1702 Vgl. BVerfGE 72, 66 (78) - Flughafen Salzburg; E 81, 208 (220) - Bob Dylan.

1703 Vgl. BVerfGE 79, 29 (40) - Vollzugsanstalten. 
Verhältnismäßigkeit ${ }^{1704}$ und unter Beachtung des Gleichheitsgebotes zu einem ausgewogenen Ausgleich bringen.

Der Verhältnismäßigkeitsgrundsatz besagt, dass eine Maßnahme zur Erreichung des angestrebten Zweckes geeignet und erforderlich sein muss. Sie ist geeignet, wenn der gewünschte Erfolg mit ihrer Hilfe gefördert werden kann, und erforderlich, wenn der Gesetzgeber kein anderes, das betreffende Grundrecht nicht oder doch weniger fühlbar einschränkendes Mittel hätte wählen können. ${ }^{1705}$ Der mit der Maßnahme verbundene Eingriff darf zudem nicht außer Verhältnis zur Bedeutung der Sache stehen. ${ }^{1706}$ Der Gesetzgeber darf somit weder die Eigentumsfreiheit mehr als verhältnismäßig verkürzen noch die Sozialbindung unverhältnismäßig vernachlässigen. In den Grenzen des danach Zumutbaren muss der Urheber die zur Pflege und Förderung des sozialen Zusammenlebens gebotenen Schranken hinnehmen. ${ }^{1707}$

Aus verfassungsrechtlicher Sicht ist somit eine völlig schrankenlose Ausgestaltung des subjektiven Urheberrechts im Sinne eines uneingeschränkten ausschließlichen Verwertungsrechts des Urhebers grundsätzlich nicht denkbar. Dies könnte allenfalls möglich sein, wenn die berechtigten Interessen der Allgemeinheit bereits auf Tatbestandsebene bei der Formulierung der Reichweite der Verwertungsbefugnisse berücksichtigt würden. ${ }^{1708}$ Ebenso wenig lässt sich jedoch ein grundsätzliches Zurücktreten der Urheberinteressen zugunsten der Allgemeinheit rechtfertigen. Einschränkungen bedürfen regelmäßig einer besonderen Begründung und sind möglichst milde auszugestalten. ${ }^{1709}$ Als Mittel der Intensitätssteuerung kann dabei insbesondere die Gewährung einer angemessen entschä-

1704 Zum Streit über die Rechtsgrundlage des Verhältnismäßigkeitsprinzips, siehe Maunz/Dürig/Grzeszick, GG, Art. 20 Rn. 108 m.w.N.

1705 St. Rspr., vgl. BVerfGE 21, 150 (159) - Weinwirtschaftsgesetz; E 30, 292 (316) - Erdölbevorratung; E 63, 88 (115) - Versorgungsausgleich; E 96, 10 (23) Räumliche Aufenthaltsbeschränkung; E 103, 293 (307) - Urlaubsanrechnung; zuletzt BVerfGE 125, 260 (317 f.) - Vorratsdatenspeicherung.

1706 St. Rspr., vgl. BVerfGE 27, 344 (352 f.) - Scheidungsakte; E 65, 1 (54) - Volkszählung; E 70, 278 (286) - Lohnsteuererstattung.

1707 Vgl. BVerfGE 31, 229 (242) - Kirchen- und Schulgebrauch; E 79, 29 (40) Vollzugsanstalten.

1708 Siehe zu derartigen Gestaltungsmöglichkeiten des Urheberrechts Hohagen, Vervielfältigung zum eigenen Gebrauch, S. $13 \mathrm{f}$.

1709 Vgl. Dreier, in: Schricker, Informationsgesellschaft, S. 139; Kröger, Informationsfreiheit und Urheberrecht, S. 159. Zur abgestuften Intensität der Schranken des deutschen UrhG siehe oben 2. Kapitel, B.I.1. 
digenden Vergütung wirken. ${ }^{1710}$ Der vollständige und entschädigungslose Verlust sämtlicher urheberrechtlicher Befugnisse ${ }^{1711}$ kommt folglich vor dem Hintergrund des Verhältnismäßigkeitsgrundsatzes allenfalls in besonderen Ausnahmefällen in Betracht, in denen ein ganz erhebliches öffentliches Interesse nicht nur am Zugang zu einem geschützten Werk, sondern gerade auch an dessen vergütungsfreier Nutzung besteht. ${ }^{1712}$

Der Grundsatz der Verhältnismäßigkeit ist jedoch nicht nur durch den Gesetzgeber bei der Ausgestaltung der urheberrechtlichen Schranken besonders zu beachten. Auch für die Rechtsprechung bildet der Verhältnismäßigkeitsgrundsatz eine entscheidende Richtschnur und Grenze bei der (verfassungskonformen) Auslegung oder richterlichen Fortentwicklung gesetzlicher Schranken. Auch die Gerichte müssen folglich darauf achten, unverhältnismäßige, einseitige Belastungen zu vermeiden und die erweiternde Anwendung einer Schrankenregelung zu Lasten des Rechteinhabers so milde wie möglich auszugestalten, etwa indem sie von der Gewährung eines angemessenen finanziellen Ausgleichs abhängig gemacht wird. ${ }^{1713}$ Insbesondere die erweiternde Auslegung oder analoge Anwendung von Schrankentatbeständen, die die Zahlung einer angemessenen Vergütung nicht vorsehen, muss daher mit besonderer Vorsicht erfolgen. ${ }^{1714}$

1710 Zur Gewährung einer Entschädigung als Mittel zur Wahrung der Verhältnismäßigkeit und Vermeidung einer ungebührlichen Verletzung berechtigter Urheberinteressen im Sinne des Dreistufentests siehe bereits oben 6. Kapitel, C.III. 2.c)cc).

1711 Zum „Alles oder Nichts“ als Rechtsfolge des US-amerikanischen Fair Use-Einwandes siehe oben 2. Kapitel, C.I.3.

1712 Vgl. Dreier/Schulze, Vor §§ 44a ff. Rn. 10; Grzeszick, ZUM 2007, 344 (350 f.).

1713 Vgl. die entsprechenden Überlegungen des BGH in seiner KopienversanddienstEntscheidung (BGHZ 141, 13 (28 ff.)) sowie in der Rechtssache Elektronischer Pressespiegel (BGHZ 151, 300), in der der BGH die ausnahmsweise extensive Auslegung einer Schrankenbestimmung damit rechtfertigte, dass die Anwendung der Schranke den Urheber günstiger stelle als die Geltung des Ausschließlichkeitsrechts (siehe BGH, a.a.O., S. $311 \mathrm{f}$.).

1714 Siehe die diesbezügliche Kritik an einer übermäßigen Ausdehnung des Zitatrechts und der weitreichenden Anwendung der zivilrechtlichen Einwilligungslehre oben 4. Kapitel, B.I. 
2. Art. 5 Abs. 3 S. 1 GG - Kunst- und Wissenschaftsfreiheit

Neben der Eigentumsgarantie des Art. 14 GG kann bei der Ausgestaltung von Schrankenregelungen für den Gesetzgeber auch die durch Art. 5 Abs. 3 S. 1 GG gewährte Kunstfreiheit von Bedeutung sein. Sinn und Aufgabe der Kunstfreiheitsgarantie ist es vor allem, die auf der Eigengesetzlichkeit der Kunst beruhenden, von ästhetischen Rücksichten bestimmten Prozesse, Verhaltensweisen und Entscheidungen von jeglicher Ingerenz öffentlicher Gewalt freizuhalten. ${ }^{1715}$ Die Kunstfreiheit verbietet es, auf Methoden, Inhalte und Tendenzen der künstlerischen Tätigkeit einzuwirken, allgemein verbindliche Regeln für den Schaffensprozess vorzuschreiben oder den Raum künstlerischer Betätigung einzuengen. ${ }^{1716}$ Sofern die Tätigkeit des Urhebers dem verfassungsrechtlichen Kunstbegriff unterfällt - wenn sich also im konkreten Fall der urheberrechtliche Werk- und der verfassungsrechtliche Kunstbegriff ${ }^{1717}$ inhaltlich decken ${ }^{1718}$-, schützt Art. 5 Abs. 3 S. 1 GG den Urheber sowohl bei der Erschaffung des (Kunst-)Werkes (sog. Werkbereich) als auch hinsichtlich der Darbietung, Vervielfältigung und Verbreitung des Werkes (sog. Wirkbereich). ${ }^{1719}$

„Konkret" hat sich das Bundesverfassungsgericht - wie es selbst betont - zum Verhältnis von Urheberrecht und Kunstfreiheit noch nicht geäuBert. ${ }^{1720}$ Es hat bisher die Kunstfreiheit zwar mehrfach in die Abwägung der Zulässigkeit einer Schrankenregelung einbezogen, sie letztlich jedoch nie als Argument gegen eine bestimmte Schranke gelten lassen, da das Bundesverfassungsgericht von einem Vorrang der Eigentumsgarantie ausgeht, sofern die verwertungsrechtliche Seite des Urheberrechts betroffen ist. ${ }^{1721}$ Weil das Urheberrecht Eigentum im Sinne des Art. 14 Abs. 1 GG ist, kann Art. 5 Abs. 3 GG nach Auffassung des Bundesverfassungsgerichts allenfalls dann einmal eingreifen, wenn die wirtschaftliche Auswer-

1715 BVerfGE 31, 229 (238) - Kirchen- und Schulgebrauch.

1716 BVerfGE 31, 229 (238) - Kirchen- und Schulgebrauch; vgl. auch BVerfGE 119, 1 (21 f.) - Esra.

1717 Ausführlich zum verfassungsrechtlichen Kunstbegriff siehe statt vieler v.Münch/Kunig/Wendt, GG, Art. 5 Rn. 89 m.w.N.

1718 Vgl. Wandtke/Bullinger/Wandtke, Einl. Rn. 31.

1719 Vgl. BVerfGE 30, 173 (189) - Mephisto; Schack, Urheberrecht, Rn. 96. Ausführlich Dreier/Pernice, GG, Art. 5 III (Kunst) Rn. 24 ff.

1720 BVerfG, GRUR 2001, 149 (151) - Germania 3.

1721 Vgl. BVerfGE 31, 229 (238) - Kirchen- und Schulgebrauch; E 49, 382 (392) Kirchenmusik; Schricker/Loewenheim/Melichar, Vor $\S \S 44$ ff. Rn. 7. 
tung des Werkes durch ein Gesetz derart beschränkt würde, dass die freie künstlerische Betätigung praktisch nicht mehr möglich wäre. ${ }^{1722}$ Dies erscheint in der Praxis allerdings kaum vorstellbar. ${ }^{1723}$ Berührt ein die Rechte des Urhebers beschränkendes Gesetz hingegen über die Beeinträchtigung der vermögenswerten Befugnisse hinaus die Eigengesetzlichkeit der Kunst und die Freiheit der künstlerischen Betätigung, so kommt der Kunstfreiheit neben der Eigentumsgarantie eigene Bedeutung zu. ${ }^{1724}$

Erheblichere Relevanz in Bezug auf die urheberrechtlichen Schrankenregelungen erlangt die Kunstfreiheit hingegen bei deren Auslegung. ${ }^{1725}$ So hat das Bundesverfassungsgericht ausdrücklich darauf hingewiesen, dass die Schrankenbestimmungen gegebenenfalls im Lichte der Kunstfreiheit auszulegen seien. ${ }^{1726}$ Etwa im Rahmen der Anwendung des Zitatrechts des $\S 51$ UrhG zugunsten von Kunstwerken sei aufgrund von Art. 5 Abs. 3 S. 1 GG eine kunstspezifische Betrachtung angebracht, ${ }^{1727}$ die einen Ausgleich ermögliche zwischen dem Interesse der Urheberrechtsinhaber vor Ausbeutung ihrer Werke ohne Genehmigung zu fremden kommerziellen Zwecken und dem durch die Kunstfreiheit geschützten Interesse anderer Künstler, ohne die Gefahr von Eingriffen finanzieller oder inhaltlicher Art in einen künstlerischen Dialog und Schaffungsprozess zu vorhandenen Werken treten zu können. ${ }^{1728}$

Die ebenfalls durch Art. 5 Abs. 3 S. 1 GG garantierte Freiheit der Wissenschaft, Forschung und Lehre sichert als Abwehrrecht jedem, der sich wissenschaftlich betätigt oder wissenschaftlich tätig werden will, Freiheit von staatlicher Beschränkung zu. ${ }^{1729}$ Die Wissenschaftsfreiheit erfasst alles, was nach Inhalt und Form als ernsthafter und planmäßiger Versuch zur Ermittlung der Wahrheit anzusehen ist, ${ }^{1730}$ und schützt die auf wissen-

1722 BVerfGE 31, 229 (240) - Kirchen- und Schulgebrauch.

1723 So auch Schricker/Loewenheim/Melichar, Vor $\S \S 44 a$ ff. Rn. 7. Maunz, GRUR 1973, 107 (111) sieht in der Beeinträchtigung der künstlerischen Eigenart einer Schöpfung durch deren Aufnahme in eine Sammlung gemäß $§ 46$ UrhG zumindest einen denkbaren Fall, in dem der Kunstfreiheit eine eigenständige Bedeutung in diesem Sinne zukommen könnte.

1724 Ebenso Badura, in: FS Maunz, S. 1 (11).

1725 Zur Auslegung von Schrankenbestimmungen, siehe oben 2. Kapitel, B.I.2.

1726 BVerfG, GRUR 2001, 149 (151) - Germania 3.

1727 BVerfG, GRUR 2001, 149 (152) - Germania 3.

1728 BVerfG, GRUR 2001, 149 (151) - Germania 3.

1729 Vgl. BVerfGE 15, 256 (263 f.) - Universitäre Selbstverwaltung.

1730 Vgl. BVerfGE 35, 79 (113) - Hochschulurteil. 
schaftlicher Eigengesetzlichkeit beruhenden Prozesse, Verhaltensweisen und Entscheidungen beim Auffinden von Erkenntnissen, ihrer Deutung und Wiedergabe. ${ }^{1731}$ Somit kommt auch dem wissenschaftlich tätigen Urheber in seiner Arbeit verfassungsrechtlicher Schutz nach Art. 5 Abs. 3 S. 1 GG zu.

Sowohl die Kunstfreiheit als auch die Wissenschaftsfreiheit sind nominell vorbehaltlos gewährleistete Grundrechte. Eine unmittelbare oder analoge Anwendung der Schranken des Art. 5 Abs. 2 GG oder Art. 2 Abs. 1 2. Hs. GG auf die Kunstfreiheit lehnt das Bundesverfassungsgericht aus systematischen Gründen ausdrücklich ab. ${ }^{1732}$ Die Kunst- und Wissenschaftsfreiheit finden ihre Grenzen daher nur in verfassungsimmanenten Schranken, also kollidierenden Verfassungswerten; das heißt sie dürfen nur durch Gesetze beschränkt werden, die anderen verfassungsrechtlich geschützten Interessen dienen und dem Grundsatz der Verhältnismäßigkeit genügen. ${ }^{1733}$ Kollidieren von der Kunst- oder Wissenschaftsfreiheit geschützte Interessen der Urheber mit Verfassungsgütern Dritter - insbesondere also solchen der Werkmittler, Nutzer oder der Allgemeinheit -, so müssen die Interessen daher im Wege einer Abwägung zu einem gerechten und verhältnismäßigen Ausgleich gebracht werden.

\section{Art. 1 und Art. 2 Abs. 1 GG - Persönlichkeitsgrundrecht}

Neben den heute aufgrund der wirtschaftlichen Dimension des Urheberrechts oftmals dominierenden vermögensrechtlichen Interessen verbinden den Urheber mit seinem Werk auch ideelle Interessen. Die hieraus abgeleiteten Befugnisse werden zumeist unter dem Begriff des Urheberpersön-

1731 Vgl. BVerfGE 47, 327 (367) - Hessisches Universitätsgesetz; E 90, 1 (12) Jugendgefährdende Schriften. Ausführlich zum umstrittenen Begriff der Wissenschaft im Sinne des Art. 5 Abs. 3 GG Maunz/Dürig/Scholz, GG, Art. 5 Rn. 86 ff. m.w.N.

1732 St. Rspr., siehe etwa BVerfGE 30, 173 (191) - Mephisto; E 67, 213 (228) Anachronistischer Zug; E 83, 130 (139) - Josefine Mutzenbacher. Ebenso die h.L., siehe nur v.Mangoldt/Klein/Starck/Starck, GG, Art. 5 Abs. 3 Rn. 328; Maunz/Dürig/Scholz, GG, Art. 5 Abs. 3 Rn. 14, jeweils m.w.N.

1733 Vgl. BVerfGE 67, 213 (228) - Anachronistischer Zug; Jarass/Pieroth, GG, Art. 5 Rn. 113 f. m.w.N. 
lichkeitsrechts zusammengefasst. ${ }^{1734}$ Es ist dabei jedoch näher zwischen Urheberpersönlichkeitsrecht und allgemeinem Persönlichkeitsrecht zu differenzieren: Das Urheberpersönlichkeitsrecht wird allgemein als rechtlich selbständige Erscheinungsform des aus Art. 1 Abs. 1 und Art. 2 Abs. 1 GG abgeleiteten allgemeinen Persönlichkeitsrechts ${ }^{1735}$ verstanden. ${ }^{1736}$ Als Spezialregelung geht das Urheberpersönlichkeitsrecht dem allgemeinen Persönlichkeitsrecht vor. ${ }^{1737}$ Soweit die spezialgesetzlichen Voraussetzungen des Urheberpersönlichkeitsrechts jedoch nicht erfüllt sind, dieses besondere Persönlichkeitsrecht also nicht eingreift, kann grundsätzlich auf das allgemeine Persönlichkeitsrecht zurückgegriffen werden. ${ }^{1738}$ Besondere Bedeutung kommt dem allgemeinen Persönlichkeitsrecht dabei dann zu, wenn ein Urheberschutz - und somit auch ein urheberpersönlichkeitsrechtlicher Schutz - wegen fehlender Werkqualität ausscheidet. ${ }^{1739}$ Auch Individualinteressen des Urhebers, die sich nicht auf ein einzelnes Werk beziehen, sondern auf die Gesamtheit seines Werkschaffens, werden nicht durch das Urheberpersönlichkeitsrecht geschützt, können jedoch auf Grundlage des allgemeinen Persönlichkeitsrechts des Urhebers Schutz genießen. ${ }^{174}$ Durch das allgemeine Persönlichkeitsrecht wird das Recht des Einzelnen auf Achtung seiner personalen und sozialen Identität, seiner Entfaltung und Entwicklung einer individuellen Persönlichkeit sowie die Selbstbestimmung des Trägers über seine Person und ihr Erscheinungsbild in der Öffentlichkeit geschützt. ${ }^{1741}$ Das allgemeine Persönlichkeitsrecht gewährleistet folglich den Schutz der Persönlichkeit hinsichtlich solcher Elemente, die nicht Gegenstand der besonderen Freiheitsgarantien des

1734 Vgl. Ulmer, S. 208. Zur Beeinträchtigung des Urheberpersönlichkeitsrechts durch die Digitalisierung und Online-Nutzung urheberrechtlich geschützter Werke siehe bereits oben 4. Kapitel, C.

1735 Ausführlich zu den normativen Grundlagen und der Entwicklung des allgemeinen Persönlichkeitsrechts MünchKomm-BGB/Rixecker, Anhang zu § 12 BGB, Allg. PersönlR, Rn. 1 ff.

1736 Siehe nur BGHZ 13, 334 (339) - Leserbrief (Hjalmar Schacht) sowie Dreier/ Schulze, Vor $\S 12$ Rn. 5.

1737 Siehe nur Schricker/Loewenheim/Dietz/Peukert, Vor $\S \S 12$ ff. Rn. 15 m.w.N.

1738 Vgl. v.Gamm, UrhG, Einf. Rn. 93; Krüger-Nieland, in: FS Hauß, S. 215 (221 ff.); Schricker/Loewenheim/Dietz/Peukert, Vor $\S \S 12$ ff. Rn. 15 m.w.N.

1739 Vgl. Schack, Urheberrecht, Rn. 48.

1740 Vgl. Schricker/Loewenheim/Dietz/Peukert, Vor $\S \S 12$ ff. Rn. 16 m.w.N.

1741 Vgl. BVerfGE 35, 202 (220 f.) - Lebach; E 63, 131 (142) - Gegendarstellung; E 101, 361 (380f.) - Caroline von Monaco II; Palandt/Sprau, BGB, § 823 Rn. 86 m.w.N. 
Grundgesetzes sind, diesen aber in ihrer konstituierenden Bedeutung für die Persönlichkeit nicht nachstehen. ${ }^{1742}$ Es kann somit der Konfliktfall auftreten, dass - wenn dies von Verfassungs wegen zum Schutz der Person geboten ist, wenn also mit dem urheberrechtlich geschützten Werk zugleich eine Verletzung des allgemeinen Persönlichkeitsrechts verbunden ist - dieses verfassungsrechtlich Vorrang vor dem Urheberrecht beansprucht. ${ }^{1743}$ In diesen Fällen muss der Urheber oder Rechteinhaber Eingriffe in sein Werk beziehungsweise Änderungen an diesem oder Unterlassungs-beziehungsweise Schadensersatzansprüche hinnehmen. ${ }^{1744}$ Das Persönlichkeitsrecht wiederum findet seine Schranken nach Art. 2 Abs. 1 GG in der verfassungsmäßigen Ordnung. ${ }^{1745}$

\section{Verfassungsrechtlicher Schutz der Interessen der Werkmittler}

Während zunächst bei der verfassungsgerichtlichen Kontrolle der urheberrechtlichen Schranken der Eigentumsschutz der Urheber nach Art. 14 GG und eine Zurückdrängung zu weit gezogener Schranken auf dieser Grundlage ganz im Vordergrund standen, hat sich dieses Augenmerk spätestens seit der Germania 3-Entscheidung des Bundesverfassungsgerichts geändert. Diese Entscheidung hat die Aufmerksamkeit verstärkt darauf gelenkt, dass auch die gegenläufigen Interessen der Werkmittler, anderer Künstler, der Verbraucher und der Allgemeinheit grundrechtsrelevant und somit bei der verfassungskonformen Auslegung und Ausgestaltung der Schranken $\mathrm{zu}$ beachten sind.

Der Kreis der Werkmittler lässt sich (grob) in zwei Kategorien aufteilen: Zum einen die sogenannten organisatorischen Werkmittler oder auch Erstverwerter urheberrechtlich geschützter Werke, die die geistige Leistung auswählen und mit organisatorischem und geschäftlichem Talent unter Einsatz von Kapital für deren Verbreitung sorgen ${ }^{1746}$ - etwa Verleger, Tonträgerhersteller und Filmproduzenten -, zum anderen die Zweitver-

1742 St. Rspr., siehe BVerfGE 101, 361 (380) - Caroline von Monaco II; BVerfG, NJW 2005, 883 (884).

1743 Vgl. Lettl, WRP 2005, 1045 (1060).

1744 Wandtke/Bullinger/Wandtke, Einl. Rn. 34.

1745 Vgl. Jarass, NJW 1989, 857 (861).

1746 Vgl. Schmieder, Das Recht des Werkmittlers, S. 12 ff., der zwischen sog. organisatorischen, technischen und künstlerischen Werkmittlern unterscheidet. 
werter, beispielsweise Fernseh- und Rundfunksender oder Konzertveranstalter, die ein eigenes werkvermittelndes Angebot aus dem Fundus der von anderen erschaffenen und produzierten urheberrechtlich geschützten Werke erstellen. Beiden Gruppen der Werkmittler ist gemein, dass ihre Tätigkeit im Wesentlichen von vermögensrechtlichen Interessen geprägt ist; sie handeln (in der Regel) mit dem Ziel, aus der Vermittlung der Werke ihre Investitionen zu amortisieren und einen Gewinn zu erzielen. ${ }^{1747}$

\section{Art. $14 \mathrm{GG}$ - Eigentumsschutz}

Ebenso wie bei den originären Rechteinhabern, also den „Kreativen“ selbst, stellt sich auch hinsichtlich der Werkmittler die Frage nach der Reichweite der Eigentumsgarantie. Art. 14 Abs. 1 S. 1 GG schützt nicht bloße Gewinnchancen, Verdiensterwartungen und Zukunftshoffnungen, ${ }^{1748}$ sondern den durch Leistung erworbenen Bestand konkreter vermögenswerter privatrechtlicher Rechtspositionen in der Hand der Werkmittler sowie die Nutzung und Verfügung über derartige Rechtspositionen. ${ }^{1749}$ Eine derartige als Eigentum grundrechtsgeschützte Rechtsposition stellt etwa das in $\S 85$ Abs. 1 S. 1 UrhG geregelte ausschließliche Recht der Tonträgerhersteller zur Vervielfältigung, Verbreitung und öffentlichen Zugänglichmachung der Tonträger dar. ${ }^{1750}$ Gleiches dürfte für die anderen dem Urheberrecht verwandten Schutzrechte - etwa das den Sendeunternehmen in $\S 87$ UrhG oder den Datenbankherstellern in $\S 87$ a UrhG eingeräumte Ausschließlichkeitsrecht - gelten. ${ }^{1751}$ Auch die Verleger, denen zwar (noch) kein eigenes Leistungsschutzrecht zusteht, ${ }^{1752}$ können sich

1747 Vgl. Rehbinder, Urheberrecht, Rn. 82; Schweikart, Interessenlage, S. 35 ff.; Stang, Das urheberrechtliche Werk, S. $64 \mathrm{f}$.

1748 St. Rspr., vgl. BVerfGE 28, 119 (142) - Spielbank; E 30, 292 (335) - Erdölbevorratung; E 45, 272 (296); E 68, 193 (222) - Zahntechniker-Innung.

1749 Vgl. Jarass/Pieroth, GG, Art. 14 Rn. 22 m.w.N.

1750 So ausdrücklich das Bundesverfassungsgericht, BVerfGE 81, 12 (16) - Vermietungsvorbehalt.

1751 Vgl. BVerfGE 81, 12 (16ff.) - Vermietungsvorbehalt.

1752 Zur Diskussion um ein Leistungsschutzrecht für Verleger siehe etwa Frey, MMR 2010, 291 ff.; Kauert, Das Leistungschutzrecht des Verlegers (2008); Nolte, ZGE 2010, 165 ff.; Ohly, WRP 2012, 41; Schwarz, GRUR-Prax. 2010, 283 ff.; Wieduwilt, K\&R 2010, 555 ff. sowie das umfangreiche Online-Informationsangebot der Initiative gegen ein Leistungsschutzrecht (IGEL), abrufbar unter: http://leistungsschutzrecht.info/ [zuletzt abgerufen am 26.5.2013]. 
bei der Beeinträchtigung der vom Urheber abgeleiteten ausschließlichen Verwertungsrechte auf durch Art. 14 Abs. 1 GG geschützte eigentumsrechtliche Positionen berufen.

Folglich sind auch die Interessen der derivativen Rechteinhaber grundsätzlich bei der Ausgestaltung des Urheberrechts durch den Gesetzgeber angemessen $\mathrm{zu}$ berücksichtigen. ${ }^{1753}$ Es gilt allerdings $\mathrm{zu}$ beachten, dass den Werkmittlern als nachfolgend Berechtigten aus der verfassungsrechtlichen Eigentumsgarantie keine weitergehenden Befugnisse zustehen können als den Urhebern selbst. Hat also der Urheber aufgrund eines berechtigten und überwiegenden Allgemeininteresses Beschränkungen seiner ausschließlichen Befugnisse hinzunehmen, so kann auch der verfassungsrechtliche Schutz der Werkmittler - der im Wesentlichen auf finanziellen Interessen basiert und sich weniger auf den künstlerisch-schöpferischen Bereich bezieht - in aller Regel nicht dazu führen, dass diese berechtigten Allgemeininteressen zurückgestellt werden müssen. ${ }^{1754}$ Der verfassungsrechtliche Schutz der Werkmittler auf Grundlage der Eigentumsgarantie erzeugt somit hinsichtlich der Ausgestaltung des Urheberrechts zugunsten der Interessen der Nutzer und der Allgemeinheit an einem möglichst freien Zugang zu urheberrechtlich geschützten Werken keine über den verfassungsrechtlichen Schutz der Urheber hinausgehende Beschränkungswirkung. ${ }^{1755}$

Die Eigentumsgarantie des Art. 14 Abs. 1 GG schützt somit die Werkmittler in ihren erworbenen Rechten ebenso wie die Urheber. Dies sagt jedoch nichts darüber aus, ob hinsichtlich der den Werkmittlern eingeräumten verwandten Schutzrechte dieser Schutz als Eigentum auch garantiert werden muss. Es sprechen vielmehr gute Gründe dafür, dass eine Rechtsänderung, die diese Rechte - etwa durch die Einführung oder den Wegfall von Schranken - beschneiden oder gar streichen würde, letztlich keinen Verstoß gegen die Eigentumsgarantie des Art. 14 Abs. 1 GG darstellen würde, da der elementare Kern des Eigentums der Werkmittler im Sinne eines vermögenswerten Ergebnisses der geistig-schöpferischen Leistung nicht betroffen wäre. ${ }^{1756}$ Dies zeigt schon die Überlegung, dass derartige

1753 Vgl. BVerfGE 81, 12 (17f.) - Vermietungsvorbehalt.

1754 So hinsichtlich der Interessen der Tonträgerhersteller im Verhältnis zu den Interessen der Urheber und der Allgemeinheit das Bundesverfassungsgericht, vgl. BVerfGE 81, 12 (19) - Vermietungsvorbehalt.

1755 Siehe Hohagen, Vervielfältigung zum eigenen Gebrauch, S. 304 f.

1756 Vgl. Hohagen, Vervielfältigung zum eigenen Gebrauch, S. 304 f. 
abgeleitete (Schutz-)Rechte lange Zeit nicht bestanden und es sich dabei wohl kaum um einen verfassungswidrigen Zustand handelte.

\section{Art. $12 \mathrm{GG}$ - Berufsfreiheit}

Im Hinblick auf die Werkmittler stellt sich zudem die Frage, wie weit deren Schutz durch die in Art. 12 GG geregelte Berufsfreiheit reicht und inwieweit dieses Grundrecht bei der Ausgestaltung urheberrechtlicher Schranken zu beachten ist. Art. 12 Abs. 1 GG enthält ein einheitliches Grundrecht, das die Wahl des Berufes und dessen Ausübung einschließlich der freien Wahl des Arbeitsplatzes schützt. ${ }^{1757}$ Der Begriff des Berufes im Sinne des Art. 12 Abs. 1 GG ist nach allgemeiner Ansicht weit auszulegen. Erfasst ist jede auf die Dauer berechnete und nicht nur vorübergehende, der Schaffung und Erhaltung einer Lebensgrundlage dienende Betätigung. ${ }^{1758}$ In diesen weiten Schutzbereich fallen in aller Regel auch Werkmittler wie Hersteller, Händler oder Importeure.

Eine Beeinträchtigung der Berufsfreiheit käme - jedenfalls auf den ersten Blick - beispielsweise durch die Einbeziehung gewisser Werkmittler in Schrankenregelungen als Schuldner von Vergütungsansprüchen, insbesondere etwa für Leerträgermedien, in Betracht. Im Ergebnis scheidet ein Eingriff in die Berufsfreiheit der Hersteller von Vervielfältigungsgeräten oder Leermedien oder ähnlicher vergütungsverpflichteter Werkmittler durch solche Vergütungspflichten jedoch aus. Bei derartigen Verpflichtungen, wie sie etwa in der Vorschrift des $\S 54$ UrhG geregelt sind, handelt es sich nicht um Berufsausübungsregelungen im Sinne des Art. 12 Abs. 1 S. 2 GG, da ihr Ziel nicht ist, den Herstellern bei der Ausübung ihres Berufes im öffentlichen Interesse Schranken zu ziehen oder Gemeinwohlbelange durchzusetzen; es handelt sich vielmehr um interessenausgleichende Normen des Privatrechts. ${ }^{1759}$

1757 Siehe nur BVerfGE 7, 377 (401 ff.) - Apothekenurteil.

1758 Siehe nur Maunz/Dürig/Scholz, GG, Art. 12 Rn. 28 f. m.w.N.

1759 BVerfGE 31, 255 (265 f.) - Tonbandvervielfältigung (zur Vereinbarkeit des $§ 53$ Abs. 5 UrhG (a.F.) mit Art. 12 Abs. 1 GG); vgl. auch Claussen, Vergütung für die Überspielung zum privaten Gebrauch, S. $15 \mathrm{f}$. 
III. Verfassungsrechtliche Anerkennung der Interessen der Kulturverbraucher, einzelner Nutzergruppen oder der Allgemeinheit an der Werknutzung

Neben den bereits dargestellten verfassungsrechtlich verankerten Interessen der Urheber und Werkmittler sind bei der Ausgestaltung des Urheberrechts schließlich jedenfalls solche Interessen einzelner Nutzergruppen oder der Allgemeinheit am Zugang zu urheberrechtlich geschützten Werken gleichrangig zu beachten, die ebenfalls grundrechtlich fundiert sind. Ebenso wie bei der Gruppe der Werkmittler handelt es sich jedoch auch beim Kreis der Nutzer nicht um eine homogene Gruppe. Die konkreten Interessen unterscheiden sich vielmehr üblicherweise je nach der Art der Nutzung urheberrechtlich geschützter Werke. ${ }^{1760}$ Nutzer, die die urheberrechtlich geschützte Leistung zum eigenen Bedarf rein passiv „,konsumieren" wollen, ${ }^{1761}$ haben in der Regel im Wesentlichen ein Interesse an einem möglichst breiten, möglichst einfach und kostengünstig zugänglichen Angebot an Werken. ${ }^{1762}$ Hiervon unterscheiden sich teilweise die Interessen derjenigen Nutzer, die fremde Werke ,aktiv“ konsumieren, um - wie etwa üblicherweise Wissenschaftler - auf Grundlage dieser Auseinandersetzung eine eigene schöpferischer Tätigkeit zu entfalten. Ebenso wie die rein passiven „Kulturverbraucher" haben auch diese aktiven „Kulturverwender" ein Interesse an möglichst ungehindertem und idealerweise kostengünstigem Zugang zu urheberrechtlich geschützten Werken. Über den reinen Zugang zu den Werken hinaus ist es für diese Nutzergruppe jedoch von besonderem Interesse, die eigene Kreativität unter (Weiter-) Verwendung der fremden Vorleistung ausleben zu können; urheberrechtlich geschützte Werke also etwa zitieren, bearbeiten oder parodieren zu dürfen. ${ }^{1763}$ Von diesen Interessen der einzelnen (aktiven und passiven) Nutzer zu unterscheiden sind schließlich die überindividuellen Interessen der Allgemeinheit. Zentrales Interesse der Allgemeinheit als Gesamtgebilde aller Interessenträger - erfasst sind somit sowohl sämtliche Nutzer als auch

1760 Zur folgenden Kategorisierung der Interessen der Nutzer und der Allgemeinheit siehe näher Stang, Das urheberrechtliche Werk, S. 66 ff.

1761 Rehbinder, Urheberrecht, Rn. 81, bezeichnet diese Interessengruppe treffend als „Kulturverbraucher".

1762 Siehe Stang, Das urheberrechtliche Werk, S. 66.

1763 Vgl. Raue, Nachahmungsfreiheit, S. 30 f.; Stang, Das urheberrechtliche Werk, S. $68 \mathrm{f}$. 
Werkmittler und Urheber selbst ${ }^{1764}$ - ist in erster Linie die Ermöglichung und Erhaltung einer reichhaltigen kulturellen Produktion und eines reichhaltigen Kulturlebens. ${ }^{1765}$ Neben den Interessen des Einzelnen an der kulturellen Teilhabe und der Möglichkeit einer Information aus möglichst zahlreichen Quellen, gehört zu diesem Interessenkomplex auch das gesamtstaatliche Interesse an Schutz und Förderung des Kulturbesitzes und des kulturellen und technologischen Fortschritts der Nation. ${ }^{1766}$

Zentrale Bedeutung zum Schutz der vorgenannten, zum Teil überlappenden, zum Teil abweichenden Nutzer- und Allgemeininteressen kommt insbesondere der Informationsfreiheit zu, da neues geistiges Schaffen in aller Regel von der Möglichkeit einer Unterrichtung über Vorbestehendes aus (allgemein) zugänglichen Quellen lebt. ${ }^{1767}$ Auch in den Schutzbereich der Kunst- und Wissenschaftsfreiheit können Interessen der Nutzer oder der Allgemeinheit an der Nutzung urheberrechtlich geschützter Werke fallen. Schließlich sind bei der Ausgestaltung urheberrechtlicher Schranken das Sozialstaats- und Kulturstaatsprinzip zu berücksichtigen. ${ }^{1768}$

1764 Ein solches Verständnis der „Allgemeinheit“ als Gesamtgebilde aller Interessenträger erscheint vorzugswürdig, da nur so eine Abgrenzung der individuellen Interessen der die Allgemeinheit ausmachenden Interessenträger von den überindividuellen Interessen, die erstgenannten Interessen sogar widersprechen können, möglich ist. Häufig werden jedoch unter dem Schlagwort der „Interessen der Allgemeinheit" wenig präzise lediglich die Interessen der Nutzer zusammengefasst; vgl. etwa Rehbinder, Urheberrecht, Rn. 79; Schricker/Loewenheim/ Melichar, Vor $\S \S 44 a$ ff. Rn. 4. Wie hier Hansen, Warum Urheberrecht, S. 313; Schack, Urheberrecht, Rn. 17; Schweikart, Interessenlage, S. 46 f.; Stang, Das urheberrechtliche Werk, S. 69.

1765 Vgl. Schack, Urheberrecht, Rn. 17; Schricker, GRUR 1992, 242 (245).

1766 Vgl. Rehbinder, Urheberrecht, Rn. 79; Schweikart, Interessenlage, S. 46; Stang, Das urheberrechtliche Werk, S. 69 f. m.w.N.

1767 Siehe Delp, Recht des geistigen Schaffens, S. 58.

1768 Diesen Staatsprinzipien lassen sich jedoch keine konkreten Aussagen im Hinblick auf die gesetzliche Ausgestaltung des urheberrechtlichen Schutzes entnehmen. Aufgrund ihrer Unbestimmtheit bedürfen sie in besonderem Maße der Konkretisierung und gewähren regelmäßig keine subjektiven Rechte. Sie sind jedoch jedenfalls als Leitlinien bei der Ausgestaltung des Urheberrechtsschutzes zu berücksichtigen. Ihre konkrete Bedeutung für den Schutz urheberrechtlicher Interessen soll im Rahmen der vorliegenden Untersuchung nicht näher erörtert werden; siehe dazu Fechner, Geistiges Eigentum und Verfassung, S. 354 ff.; Hohagen, Vervielfältigung zum eigenen Gebrauch, S. 300 ff.; Poeppel, Neuordnung, S. 153. 
1. Art. 5 Abs. $1 \mathrm{~S} .1 \mathrm{GG}$ - Informationsfreiheit

Art. 5 Abs. 1 S. 1 GG gewährleistet jedermann das Recht, seine Meinung in Wort, Schrift und Bild frei zu äußern und zu verbreiten und sich aus allgemein zugänglichen Quellen ungehindert zu unterrichten. Diese Gewährleistungen ergänzt Art. 5 Abs. 1 S. 2 GG um den Schutz der Pressefreiheit und der Freiheit der Berichterstattung durch Rundfunk und Film, da das Recht, sich ungehindert zu informieren voraussetzt, dass entsprechende Informationsquellen überhaupt bestehen.

\section{a) Schutzbereich des Art. 5 Abs. 1 S. 1 2. Hs. GG}

Die Vorschrift des Art. 5 Abs. 1 S. 1 GG enthält zwei eigenständige Gewährleistungen: Die der sogenannten Meinungs(äußerungs)freiheit (Art. 5 Abs. 1 S. 1 1. Hs. GG) und die der sogenannten Informationsfreiheit (Art. 5 Abs. 1 S. 1 2. Hs. GG). Bei der Ausgestaltung des Urheberrechts zu berücksichtigende Interessen der Nutzer oder der Allgemeinheit an der Werknutzung von Verfassungsrang können insbesondere auf der in Art. 5 Abs. 1 S. 1 2. Hs. GG geregelten Informationsfreiheit beruhen. Die Informationsfreiheit schützt die aktive Informationsbeschaffung durch den Bürger ebenso wie die schlichte Entgegennahme von Informationen. ${ }^{1769}$ Anders als es die Reihenfolge, in der Art. 5 Abs. 1 S. 1 GG die beiden Grundrechte nennt, vermuten lässt, ist die Informationsfreiheit daher keine Folge, sondern eine Voraussetzung der Meinungs(äußerungs)freiheit. ${ }^{1770}$

Zugesichert ist der Zugriff auf solche Inhalte, die aus einer (Informations-)Quelle stammen, die wiederum allgemein zugänglich ist. Eine Einschränkung auf bestimmte Arten von Information ist der Vorschrift des Art. 5 Abs. 1 S. 1 2. Hs. GG nicht zu entnehmen. ${ }^{1771}$ Quelle der Information kann jeder nur denkbare Träger von Information sein. ${ }^{1772}$ Der Begriff der Informationsquelle ist insoweit nach allgemeiner Meinung im weites-

1769 Siehe BVerfGE 27, 71 (82) - Leipziger Volkszeitung; E 27, 88 (98) - Überwachungsgesetz.

1770 Maunz/Dürig/Herzog, GG, Art. 5 Abs. 1, 2 Rn. 82.

1771 Siehe BVerfGE 90, 27 (32) - Parabolantenne I.

1772 Vgl. Jarass/Pieroth, GG, Art. 5 Rn. 15; v.Mangoldt/Klein/Starck/Starck, GG, Art. 5 Abs. 1, 2 Rn. 42 f. 
ten Sinne des Wortes zu verstehen. ${ }^{1773}$ Nur eine solche offene Definition wird den ständigen Veränderungen in der Kommunikationstechnologie und einem sich ändernden Nutzerverhalten bei der Informationsbeschaffung gerecht, da sie ausdrücklich auch Raum lässt, neue Kommunikationstechniken einzubeziehen. ${ }^{1774}$ Auch urheberrechtlich geschützte Werke kommen somit als Informationsquelle in Betracht beziehungsweise das Vorliegen einer urheberrechtlich geschützten Ausdrucksform steht einer Einordnung des Werkes als Informationsquelle im Sinne des Art. 5 Abs. 1 GG nicht entgegen. ${ }^{1775}$

Die Informationsquelle muss jedoch allgemein zugänglich sein. Das Kriterium verleiht dem Grundrecht der Informationsfreiheit Konturen, indem es die notwendige Weite des Quellenbegriffs relativiert und so den Schutzbereich begrenzt. ${ }^{1776}$ Nach heute allgemeiner Ansicht darf eine Definition der ,allgemeinen Zugänglichkeit“ entsprechend dem Sinn und Zweck des Grundrechts der Informationsfreiheit weder durch den Gesetzgeber noch durch sonstige staatliche Instanzen erfolgen. ${ }^{1777}$ Rechtsnormen, die den Informationszugang regulieren, umgrenzen daher nicht den Schutzbereich der Informationsfreiheit, sondern sind als grundrechtsbeschränkende Normen an der Verfassung zu messen. ${ }^{1778}$ Allgemein zugänglich ist nach Auffassung des Bundesverfassungsgerichts eine Informationsquelle, wenn sie (technisch) geeignet und dazu bestimmt ist, der Allgemeinheit, also einem individuell nicht bestimmbaren Personenkreis, Informationen $\mathrm{zu}$ verschaffen. ${ }^{1779}$ Die Allgemeinzugänglichkeit richtet sich somit nach der durch den Bestimmungswillen des Informierenden geprägten objektiven Tatsachenlage. ${ }^{1780}$

1773 Siehe Degenhart, in: Bonner Kommentar GG, Art. 5 Rn. 247; Jarass/Pieroth, GG, Art. 5 Rn. 15; v.Mangoldt/Klein/Starck/Starck, GG, Art. 5 Abs. 1, 2 Rn. 42; Maunz/Dürig/Herzog, GG, Art. 5 Abs. 1, 2 Rn. 87, jeweils m.w.N.

1774 Vgl. v.Mangoldt/Klein/Starck/Starck, GG, Art. 5 Abs. 1, 2 Rn. 42; Zahrt, Der urheberrechtliche Schutz elektronischer Printmedien, S. 64.

1775 Hohagen, Vervielfältigung zum eigenen Gebrauch, S. 283.

1776 Vgl. Maunz/Dürig/Herzog, GG, Art. 5 Abs. 1, 2 Rn. 88.

1777 Vgl. Maunz/Dürig/Herzog, GG, Art. 5 Abs. 1, 2 Rn. 89.

1778 BVerfGE 90, 27 (32) - Parabolantenne I.

1779 St. Rspr., vgl. BVerfGE 27, 71 (83 f.) - Leipziger Volkszeitung; E 33, 52 (65) Verbringungsgesetz; E 90, 27 (32) - Parabolantenne I.

1780 Vgl. BVerfGE 27, 71 (83) - Leipziger Volkszeitung; E 90, 27 (32) - Parabolantenne I; E 103, 44 (59 f.) - Gerichtsfernsehen; v.Mangoldt/Klein/Starck/Starck, 
Bezogen auf urheberrechtlich geschützte Werke ergibt sich daraus, dass jedenfalls Werke, die mit Zustimmung des Urhebers und im Rahmen seiner Verfügungsbefugnis der Öffentlichkeit zugänglich gemacht und somit im Sinne des $\S 6$ Abs. 1 UrhG veröffentlicht wurden, als allgemein zugängliche Quellen im Sinne des Art. 5 Abs. 1 S. 12 . Hs. GG zu qualifizieren sind. ${ }^{1781}$ Auf welchem Wege das Werk veröffentlicht wurde, ist unerheblich; traditionelle Medien sind somit ebenso erfasst wie neue Kommunikationswege. Unschädlich ist es insoweit, wenn das Werk - wie etwa bei der Online-Veröffentlichung in einem Social Network oder Internetforum - nur an einen (nicht explizit beziehungsweise von vornherein abgegrenzten) Ausschnitt der Allgemeinheit gerichtet ist. ${ }^{1782}$ Unveröffentlichte oder nur einem ausdrücklich eng abgegrenzten Personenkreis - und somit nicht der Öffentlichkeit - zugänglich gemachte Werke stellen hingegen keine allgemein zugänglichen Quellen dar, da sie nach dem Willen des Urhebers gerade (noch) nicht dazu bestimmt sind, als Informationsquelle zu dienen.

Keine echte Hürde für die Allgemeinzugänglichkeit stellt schließlich nach richtigem Verständnis das von der Rechtsprechung aufgestellte Erfordernis der „technischen Eignung“ zum Empfang durch die Allgemeinheit dar. Es kann insbesondere nicht darauf ankommen, ob für den Zugang zu der Information ein erheblicher technischer Aufwand, etwa eine besondere technische Ausrüstung, erforderlich ist. ${ }^{1783}$ Vielmehr muss maßgeblich sein, ob unter Berücksichtigung der Adressierung der Information durch deren Urheber an irgendeinem Ort technische Allgemeinzugänglichkeit besteht. ${ }^{1784}$ Eine tatsächliche Erreichbarkeit für Jedermann ist folglich nicht erforderlich.

GG, Art. 5 Abs. 1, 2 Rn. 44; Maunz/Dürig/Herzog, GG, Art. 5 Abs. 1, 2 Rn. 90. Ausführlich zur Entwicklung des Begriffs der Allgemeinzugänglichkeit und unterschiedlichen Definitionsansätzen Langer, Informationsfreiheit als Grenze informationeller Selbstbestimmung, S. $128 \mathrm{ff}$.

1781 So auch Hohagen, Vervielfältigung zum eigenen Gebrauch, S. 284.

1782 Vgl. Lerche, Jura 1995, 561 (565) (,sektorale Allgemeinheit"); zustimmend Hohagen, Vervielfältigung zum eigenen Gebrauch, S. 284; Kröger, Informationsfreiheit und Urheberrecht, S. 199.

1783 In diese Richtung aber im Zusammenhang mit der Empfangbarkeit von Kabelund Satellitenfernsehen vertreten von BVerfGE 73, 118 (197) - Niedersächsisches Landesrundfunkgesetz. Siehe auch die Nachweise bei Degenhart, in: Bonner Kommentar GG, Art. 5 Rn. 257 ff.

1784 Siehe Lerche, Jura 1995, 561 (565 f.); zustimmend Hohagen, Vervielfältigung zum eigenen Gebrauch, S. 285; Kröger, Informationsfreiheit und Urheberrecht, S. 200. 
Art. 5 Abs. 1 S. 1 2. Hs. GG garantiert ein ,ungehindertes Unterrichten“ aus diesen allgemein zugänglichen Quellen. Grundsätzlich sind dabei alle menschlichen Verhaltensweisen, etwa das Hören, Lesen und Sehen, geschützt, die nach der Natur der Sache der Information aus einer der oben umschriebenen Informationsquellen dienen. ${ }^{1785}$ Die Garantie einer ,ungehinderten" Informationsbeschaffung verdeutlicht, dass es sich bei der Informationsfreiheit in erster Linie um ein klassisches Abwehrrecht des Bürgers gegen den Staat handelt. ${ }^{1786}$ Der Bürger soll sich der bereits bestehenden allgemein zugänglichen Informationsquellen bedienen können, ohne dabei mittelbar oder unmittelbar durch staatliche Maßnahmen behindert zu werden. ${ }^{1787}$ Einen Anspruch des Bürgers gegen den Staat auf Einrichtung allgemein zugänglicher Informationsquellen begründet Art. 5 Abs. 1 S. 1 2. Hs. GG hingegen nicht. ${ }^{1788}$ Ebenso wenig begründet die Garantie einer „ungehinderten Unterrichtung" einen Anspruch des Bürgers auf unentgeltliche Informationsbeschaffung. ${ }^{1789}$ Keine staatliche Behinderung der Informationsbeschaffung stellt es deshalb dar, wenn die Nutzung urheberrechtlich geschützter Informationsquellen von der Zahlung einer (angemessenen) Vergütung an den Urheber abhängig gemacht wird.

\section{b) Einschränkung der Informationsfreiheit}

Die in Art. 5 Abs. 1 S. 1 GG festgeschriebene Informationsfreiheit wird nicht schrankenlos gewährleistet. Sie steht gemäß Art. 5 Abs. 2 GG unter dem Vorbehalt der allgemeinen Gesetze. „Allgemeine Gesetze“ sind nach ständiger Rechtsprechung des Bundesverfassungsgerichts solche Gesetze, die nicht eine Meinung als solche verbieten oder sich gegen die Äußerung der Meinung als solcher richten, sondern dem Schutz eines schlechthin, ohne Rücksicht auf eine bestimmte Meinung zu schützenden Rechtsguts

1785 Siehe Maunz/Dürig/Herzog, GG, Art. 5 Abs. 1, 2 Rn. 95.

1786 Vgl. Jarass/Pieroth, GG, Art. 5 Rn. 20; v.Mangoldt/Klein/Starck/Starck, GG, Art. 5 Abs. 1, 2 Rn. 52.

1787 Vgl. BVerfGE 103, 44 (59f.) - Gerichtsfernsehen; v.Mangoldt/Klein/Starck/ Starck, GG, Art. 5 Abs. 1, 2 Rn. 52; Maunz/Dürig/Herzog, GG, Art. 5 Abs. 1, 2 Rn. $97 \mathrm{f}$.

1788 Siehe BVerfGE 103, 44 (59 f.) - Gerichtsfernsehen; Jarass/Pieroth, GG, Art. 5 Rn. 20 m.w.N.

1789 Vgl. BVerwGE 29, 214 (218); v.Mangoldt/Klein/Starck/Starck, GG, Art. 5 Abs. 1, 2 Rn. 53, 58. 
dienen; dem Schutze eines Gemeinschaftswertes, der gegenüber der Betätigung der Meinungsfreiheit den Vorrang hat. ${ }^{1790}$

Das Urheberrechtsgesetz ist in erster Linie dazu bestimmt, dem Schutz der Urheber zu dienen, ${ }^{1791}$ und verbietet nicht etwa eine bestimmte Art oder Form der Meinungsäußerung. Das Urheberrechtsgesetz ist daher als allgemeines Gesetz in diesem Sinne zu qualifizieren. ${ }^{1792}$ Auch durch ein allgemeines Gesetz kann jedoch die Informationsfreiheit nicht beliebig eingeschränkt werden. Um ein Leerlaufen oder eine Aushöhlung der Informationsfreiheit zu vermeiden, findet nach der vom Bundesverfassungsgericht entwickelten sogenannten Wechselwirkungslehre eine Wechselwirkung in dem Sinne statt, dass die allgemeinen Gesetze zwar dem Wortlaut nach der Informationsfreiheit Schranken setzen, ihrerseits aber im Lichte der Informationsfreiheit auszulegen und in ihrer das Grundrecht begrenzenden Wirkung selbst wieder einzuschränken sind. ${ }^{1793}$ Als Folge dieser Lehre ist eine Güterabwägung zwischen der Informationsfreiheit und dem Rechtsgut vorzunehmen, dessen Schutz das jeweils einschränkende Gesetz dient. ${ }^{1794}$ Im Falle des Urheberrechtsgesetzes sind somit im Rahmen der Güterabwägung die ebenfalls verfassungsrechtlich fundierten Interessen der Urheber mit den durch die Informationsfreiheit geschützten Interessen der Nutzer und der Allgemeinheit in Einklang zu bringen. ${ }^{1795}$

In Bezug auf die Nutzung urheberrechtlich geschützter Werke durch die Allgemeinheit ist die Möglichkeit einer freien Information aus allgemein zugänglichen Quellen in doppelter Hinsicht von zentraler Bedeutung: Zum einen ist der ungehinderte Zugang zu urheberrechtlich geschützten Werken oftmals Voraussetzung neuer schöpferischer Tätigkeit, da die Schaffung neuer Werke vielfach auf Vorbekanntem aufbaut. Zum anderen ist auch die rein passive Teilnahme am kulturellen und gesellschaftlichen Leben in Form des Genusses und der Nutzung von (urheberrechtlich geschützten) Kulturgütern durch die Informationsfreiheit geschützt. Aus

1790 Siehe nur BVerfGE 7, 198 (209) - Lüth. Ausführlich zur Vorgeschichte der Regelung des Art. 5 Abs. 2 GG und zum Streit um den Begriff des allgemeinen Gesetzes siehe statt vieler Maunz/Dürig/Herzog, GG, Art. 5 Abs. 1, 2 Rn. 249 ff.

1791 Vgl. Amtl. Begr., BT-Drs. IV/270, S. 27.

1792 So auch Hohagen, Vervielfältigung zum eigenen Gebrauch, S. 290; Niggemann, Informationsfreiheit und Urheberrecht, S. 35. Vom BVerfG ebenfalls bejaht für die Vorschriften der $\S \S 22,23$ KUG, siehe BVerfGE 35, 202 (224) - Lebach.

1793 Vgl. BVerfGE 7, 198 (208) - Lüth; E 20, 162 (177) - Spiegel-Urteil.

1794 Vgl. Maunz/Dürig/Herzog, GG, Art. 5 Abs. 1, 2 Rn. 258.

1795 Vgl. Hohagen, Vervielfältigung zum eigenen Gebrauch, S. 290. 
Art. 5 Abs. 1 S. 1 2. Hs. GG ergibt sich folglich eine Schutzpflicht des Staates gegenüber dem Bürger, den Kommunikationsprozess grundsätzlich offen zu halten und gesellschaftlichen Informationsungleichgewichten entgegenzuwirken. ${ }^{1796}$ Es besteht somit ein Anspruch des Bürgers gegen den Staat auf Beachtung der verfassungsrechtlich gewährten Informationsfreiheit bei der gesetzgeberischen oder auch richterlichen Ausgestaltung oder Auslegung der urheberrechtlichen Ausschließlichkeitsrechte und ihrer Schranken. Wird der Zugang zu (veröffentlichten) Werken durch die Gewährung urheberrechtlicher Ausschließlichkeitsrechte beschränkt, so stellt dies grundsätzlich eine Beeinträchtigung der Informationsfreiheit dar, die einer besonderen Rechtfertigung bedarf. ${ }^{1797}$ Im Rahmen einer Güterabwägung ist sicher zu stellen, dass die Beeinträchtigung der Informationsfreiheit durch staatliche Maßnahmen nur so weit geht, wie dies zum Ausgleich etwaiger Konflikte mit den (grundsätzlich gleichrangigen) Grundrechten der Urheber oder Werkmittler erforderlich ist. Hier kommt insbesondere auch die Festschreibung einer Pflicht des Nutzers zur Zahlung einer angemessenen Vergütung für die Nutzung des urheberrechtlichen Werkes als milderes Mittel gegenüber einer vollständigen Untersagung der Nutzung in Betracht.

\section{Art. 5 Abs. 3 S. 1 GG - Kunst- und Wissenschaftsfreiheit}

Die durch Art. 5 Abs. 3 S. 1 GG gewährleistete Kunst- und Wissenschaftsfreiheit schützt - wie gezeigt - die schöpferische Tätigkeit wissenschaftlich oder künstlerisch tätiger Urheber gegenüber staatlichen Beschränkungen ihrer Betätigung. ${ }^{1798}$ Ebenso dem Schutz unterfällt deshalb die - im Sinne des Art. 5 Abs. 3 S. 1 GG wissenschaftliche oder künstlerische ${ }^{1799}$ schöpferische Tätigkeit Dritter, wenn sie an vorbestehende Werke anknüpft. Aus Sicht dieser Künstler und Wissenschaftler besteht folglich ein ebenfalls verfassungsrechtlich fundiertes Interesse an einer möglichst freien Entfaltung, die auch möglichst weitgehende und ungestörte Zugriffs-

1796 Vgl. Kröger, Informationsfreiheit und Urheberrecht, S. 203.

1797 So auch Hohagen, Vervielfältigung zum eigenen Gebrauch, S. 286 f.; a.A. wohl v.Mangoldt/Klein/Starck/Starck, GG, Art. 5 Abs. 1, 2 Rn. 58.

1798 Siehe oben 6. Kapitel, D.I.2.

1799 Zur Reichweite des Schutzbereiches der Kunst- und Wissenschaftsfreiheit in Bezug auf urheberrechtsschutzfähige Schöpfungen siehe oben 6. Kapitel, D.I.2. 
möglichkeiten auf urheberrechtlich geschützte Werke voraussetzt. Dieses grundrechtliche Interesse anknüpfender Werkschöpfung ist bei der Ausgestaltung der urheberrechtlichen Ausschließlichkeitsrechte und ihrer Schranken zu berücksichtigen.

Aus der Funktion der Kunst- und Wissenschaftsfreiheit als Abwehrrechte gegenüber dem Staat ergibt sich zugleich, dass aus diesen Grundrechten keine Rechte der (nicht künstlerisch oder wissenschaftlich tätigen) Allgemeinheit an einer ungehinderten Nutzung urheberrechtlicher Werke abgeleitet werden können. ${ }^{1800}$ Die Interessen an ungehindertem Zugang zu Kulturgütern und Informationen sind jedoch im Rahmen der Schutzgebotsfunktion der Informationsfreiheit zu berücksichtigen. ${ }^{1801}$

Die Kunst- und Wissenschaftsfreiheit werden - wie gezeigt ${ }^{1802}$ - grundsätzlich vorbehaltlos gewährleistet. Sie können jedoch durch kollidierendes Verfassungsrecht beschränkt werden, wobei Eingriffe grundsätzlich einer gesetzlichen Grundlage bedürfen. ${ }^{1803}$ Im Rahmen einer Abwägung unter Heranziehung des Verhältnismäßigkeitsgrundsatzes sind die kollidierenden verfassungsrechtlich festgelegten Rechte und allgemeinen Verfassungsgüter mit der Kunstfreiheit zu einem angemessenen Ausgleich zu bringen. ${ }^{1804}$

\section{Zusammenfassung zu den verfassungsrechtlichen Vorgaben}

Die voranstehenden Ausführungen zum verfassungsrechtlichen Rahmen gesetzgeberischer Gestaltungsfreiheit bei der Ausgestaltung urheberrechtlicher Ausschließlichkeitsrechte und ihrer Schranken haben gezeigt, dass die teilweise einheitlichen, zumeist jedoch gegenläufigen Interessen aller an der Schöpfung, Verwertung und Nutzung urheberrechtlich geschützter Werke beteiligten Personengruppen verfassungsrechtlichen Schutz genießen. Die von einer (Neu-)Gestaltung urheberrechtlicher Schrankenbestimmungen betroffenen grundrechtlich fundierten Interessen der am Kommunikationskreislauf beteiligten Gruppen müssen deshalb vom Gesetzgeber

1800 Vgl. Fechner, Geistiges Eigentum und Verfassung, S. 297.

1801 Vgl. oben 6. Kapitel, D.III.1.

1802 Siehe oben 6. Kapitel, D.I.2.

1803 Vgl. BVerfGE 67, 213 (228) - Anachronistischer Zug; Jarass/Pieroth, GG, Art. 5 Rn. 113.

1804 Vgl. v.Mangoldt/Klein/Starck/Starck, GG, Art. 5 Abs. 3 Rn. 334. 
und auch von den Gerichten beachtet und im Falle einer Kollision zu einem angemessenen Ausgleich gebracht werden.

In Bezug auf den Urheber ist im Wesentlichen sicherzustellen, dass es bei der grundsätzlichen Zuordnung des dem Schutzbereich des Art. 14 GG unterfallenden vermögenswerten Ergebnisses der geistig-schöpferischen Leistung an den Urheber bleibt. ${ }^{1805}$ Die Einordnung der vermögensrechtlichen Interessen der Urheber unter Art. 14 GG eröffnet zugleich für den Gesetzgeber die Möglichkeit und Pflicht, Inhalt und Schranken des Rechtes insbesondere zum Wohl der Allgemeinheit in verhältnismäßiger Weise näher zu bestimmen. Neben den (zentralen) materiellen Belangen sind die persönlichkeitsrechtlichen Interessen des Urhebers an dem von ihm geschaffenen Werk zu berücksichtigen.

Auch die Interessen der Werkmittler genießen verfassungsrechtlichen Schutz. Insbesondere die Eigentumsgarantie des Art. 14 Abs. 1 GG schützt diese Interessengruppe in ihren erworbenen Rechten ebenso wie die Urheber. Schließlich sind bei der Ausgestaltung der Schranken maßgeblich die Interessen einzelner Nutzergruppen sowie die überindividuellen Belange der Allgemeinheit als Gesamtgebilde aller Interessengruppen zu berücksichtigen. Die Interessen an einem möglichst ungehinderten Zugang zu urheberrechtlich geschützten Werken finden ihre grundrechtliche Grundlage insbesondere in den durch Art. 5 GG gewährleisteten Freiheiten der Information, Kunst und Wissenschaft.

1805 Vgl. BGHZ 11, 135 (143) - Lautsprecherübertragung; Z 97, 37 (43) - Filmmusik; Z 116, 305 (308) - Altenwohnheim II; Z 129, 66 (72)-Mauer-Bilder. 


\section{Kapitel Mögliche legislative Maßnahmen zur Flexibilisierung der Schranken des Urheberrechts und ihre Vereinbarkeit mit den rechtlichen Vorgaben}

Überlegungen zur Erforderlichkeit und Ausgestaltung legislativer Maßnahmen zur Flexibilisierung der urheberrechtlichen Schranken sind keine Neuheit. In der rechtswissenschaftlichen Literatur ist in den vergangenen Jahren und Jahrzehnten vielfach eine Flexibilisierung der Schranken angemahnt und - zumeist nur in Umrissen - über unterschiedliche Flexibilisierungsmodelle nachgedacht worden. ${ }^{1806}$ Gerade in jüngerer Zeit hat diese Diskussion jedoch insbesondere auch auf politischer Ebene neuen Schwung erhalten. ${ }^{1807}$ Es scheint sich dabei in Europa nicht nur in der

1806 Siehe aus der Vielzahl etwa Bernhöft, Digitale Aufzeichnung, S. 307 ff.; Dreier, Urheberrecht und digitale Werkverwertung, S. 24 ff.; ders., in: FS Loschelder, S. 47 ff.; ders., JIPITEC 2010, 50 ff.; Dreier/Euler/Fischer/v.Raay, ZUM 2012, 273 (280 f.); Förster, Fair Use, S. 211 ff.; Geiger, IIC 2008, 178 (184 ff.); Geiger/Griffiths/Hilty, IIC 2008, 707 ff.; Griffiths, JIPITEC 2010, 87 (89 ff.); Hansen, Warum Urheberrecht, S. 401 ff.; Hilty, JIPITEC 2010, 83 (84 ff.); Hoeren, GRUR 1997, 866 (871 ff.); ders., MMR 2000, 3 (5); ders., in: FS Sandrock, S. 357 (370 f.); IGCollaboratory, Regelungssysteme für informationelle Güter, S. 109 ff., 131 f.; Janssens, in: Derclaye, Research Handbook on the Future of EU Copyright, S. 317 (332 ff.); Klass, ZUM 2013, 1 (9 f.); Koch, Auswirkungen der digitalen Informationstechnologie, S. 258 ff.; Kur, in: Geistiges Eigentum im Dienst der Innovation, S. 23 (49 f.); Leistner, Konsolidierung und Entwicklungsperspektive, S. 33 ff.; ders., IIC 2011, 417 (435 ff.); Metzger, in: Europäische Perspektiven des Geistigen Eigentums, S. 101 (121 ff.); Nolte, Informationsmehrwertdienste, S. 257 ff.; Poeppel, Neuordnung, S. 489 ff.; Schack, in: FS Schricker II, S. 511 ff.; Schaefer, Bildersuchmaschinen, S. 147 ff.; Senftleben, AMI 2009, 1 (7); ders., 57 J. Copyright Soc'y U.S.A. 521, 538 ff. (2010); ders., JIPITEC 2010, 67 (73 ff.); Spindler, GRUR 2010, 785 (791); Wandtke, GRUR 2002, 1 (5 ff.); Wiebe, GRUR 2011, 888 (893 f.) sowie die Vorschläge der aus europäischen Wissenschaftlern bestehenden Wittem Group zu einem „European Copyright Code" (dazu näher unten 7. Kapitel, A.II.1.).

1807 Siehe aus neuerer Zeit beispielsweise die Überlegungen zur Aufnahme einer Schranke zugunsten ,kreativer nutzergenerierter Adaptionen oder abgeleiteter Werke“ im Grünbuch „Urheberrechte in der wissensbestimmten Wirtschaft" der Europäischen Kommission (KOM(2008) 466/3, S. 19 ff.), die Überlegungen zur Einführung einer Fair Use-Ausnahme im Vereinigten Königreich in dem im Auftrag der britischen Regierung erstellten sog. Hargreaves-Report (Hargrea- 
Wissenschaft, sondern auch in der Politik ein wachsender Konsens dahingehend herauszubilden, dass eine Flexibilisierung der Schrankenbestimmungen de lege ferenda erforderlich ist, damit das Urheberrecht den Anschluss an die schnelle und oftmals unvorhersehbare technische Entwicklung nicht vollends verliert, so weiter an Akzeptanz einbüßt und zu einem Wettbewerbsnachteil für den europäischen Rechtsraum wird. Darüber, wie diese Flexibilisierung auszugestalten ist, herrscht hingegen weiterhin weitgehende Uneinigkeit.

Als wohl radikalste Abkehr von der derzeitigen Schrankendogmatik des deutschen und kontinentaleuropäischen Urheberrechts käme eine Streichung des gesamten bestehenden Schrankenkataloges und dessen vollständige Ersetzung durch eine einzige Schrankengeneralklausel in Betracht. Ein solcher Schnitt wäre auf zwei Ebenen denkbar: Er könnte entweder im europäischen Recht angesetzt werden (sogleich A.I.) oder sich auf das deutsche Recht beschränken (unten B.I.). Als Vorbild einer Generalklausel böten sich insbesondere die US-amerikanische Fair Use-Schranke oder aber auch der völker- und europarechtlich verankerte Dreistufentest an.

Als weniger einschneidende Veränderung ist die weitgehende Beibehaltung des Systems enumerativer Schrankenkataloge und deren Ergänzung um eine Generalklausel in Form eines Auffangtatbestandes denkbar wiederum sowohl auf europäischer (unten A.II.) als auch auf nationaler Ebene (unten B.II.).

Eines ist jedoch allen diesen Rechtsetzungsvarianten gemein: Vorschläge zur Einführung einer Schrankengeneralklausel sehen sich stets dem „Standardgegenargument“ mangelnder Rechtssicherheit ${ }^{1808}$ ausgesetzt und

ves, Digital Opportunity, S. 41 ff.); den Dritten Zwischenbericht der EnqueteKommission des Deutschen Bundestags „Internet und digitale Gesellschaft“" vom 23.11.2011, BT-Drs. 17/7899, S. 18 ff. sowie Hugenholtz/Senftleben, Fair Use in Europe, S. 4, $10 \mathrm{ff}$. mit Nachweisen zu aktuellen Bestrebungen in den Niederlanden und weiteren europäischen Staaten zur Flexibilisierung der Urheberrechtsschranken. Nach jüngsten Presseberichten hat die niederländische Regierung sich gar entschieden, nicht auf eine einheitliche europäische Schrankenflexibilisierung zu warten, sondern im Rahmen des geltenden europäischen Rechts die Einführung einer Fair Use-Regelung im nationalen Recht zu wagen; siehe „Niederländische Regierung will Fair-Use-Vorstoß wagen“, heise online vom 16.2.2012, abrufbar unter: http://www.heise.de/tp/artikel/36/36423/1.html [zuletzt abgerufen am 26.5.2013].

1808 Siehe für diese Auffassung die Nachweise oben Fn. 1213. Kritisch zur Validität dieses Standardargumentes gegen generalklauselartige Schrankenregelungen bereits oben S. $279 \mathrm{ff}$. 
müssen sich gegen diese Widerstände durchsetzen. In gewissen Konstellationen mögen derartige Zweifel tatsächlich begründet sein, ${ }^{1809}$ in aller Regel lässt sich die Behauptung, eine Generalklausel vermittle geringere Rechtssicherheit als ein geschlossener Schrankenkatalog, hingegen widerlegen. ${ }^{1810}$ Grundsätzlich zu bedenken ist zudem, dass es eine Lösung, die zugleich weitreichende Flexibilität und vollständige Rechtssicherheit bietet, nicht geben kann. Ein gewisser Grad an Unvorhersehbarkeit ist stets in Kauf zu nehmen, wenn das Recht überhaupt in die Lage versetzt werden soll, auf Veränderungen der Werknutzungsrealität zu reagieren. ${ }^{1811}$ Dies verdeutlichen eindrucksvoll die Versuche der deutschen Rechtsprechung, unvorhergesehene technische Entwicklungen im Rahmen des geltenden Schrankenkataloges im Wege der Analogie oder unter Rückgriff auf die Einwilligungslehre $\mathrm{zu}$ erfassen. Auch in diesen Fällen richterlicher „Kunstgriffe“ war und ist für Rechteinhaber, Nutzer und Verwerter - jedenfalls bis zu einer höchstrichterlichen Entscheidung ${ }^{1812}$ - trotz eines vermeintlich klaren Schrankenkataloges keinesfalls ersichtlich, ob eine neuartige Nutzungsform urheberrechtlich zulässig ist. Vor diesem Hintergrund ist es bereits ein Gebot der Methodenehrlichkeit, die im europäischen Rechtsraum weit verbreitete grundsätzlich ablehnende Haltung gegenüber urheberrechtlichen Schrankengeneralklauseln wie dem Fair Use kritisch zu hinterfragen und zu überdenken. Dies erscheint umso mehr geboten, als es sich zum einen bei der weiterhin überwiegenden grundsätzlichen Ablehnung einer Schrankengeneralklausel um ein europäisches Phänomen handelt, das dem in anderen Rechtskreisen auszumachenden Trend hin zur Einführung neuer urheberrechtlicher Schrankengeneralklauseln widerspricht. ${ }^{1813}$ Zum anderen handelt es sich selbst in Europa im Wesent-

1809 Siehe zu Rechtssicherheitsproblemen bei Einführung einer alleinigen Schrankengeneralklausel im europäischen Recht unten 7. Kapitel, A.I.3.

1810 Siehe dazu bereits oben S. 279 ff. sowie unten 7. Kapitel, A.II.2.c) und 7. Kapitel, B.II.2.

1811 So auch Griffiths, JIPITEC 2010, 87 (91).

1812 Dass auch eine höchstrichterliche Entscheidung häufig nicht geeignet ist, die urheberrechtliche Zulässigkeit einer neuartigen Nutzungsform umfassend zu klären, zeigt die Vorschaubilder-Rechtsprechung des Bundesgerichtshofes (BGHZ 185, 291 - Vorschaubilder; BGH, GRUR 2012, 602 - Vorschaubilder II). Weiterhin nicht vollständig geklärt ist der Umgang mit Konstellationen der „Drittinhaberschaft“ der Urheberrechte; siehe oben 4. Kapitel, B.I.4.

1813 Fair Use-ähnliche Schrankengeneralklauseln wurden in jüngerer Zeit etwa in Israel (siehe Fischman Afori, EIPR 2008, 30(3), 85 f.) und Singapur (siehe $N g$ - 
lichen um ein urheberrechtliches Phänomen, denn in anderen Rechtsgebieten - etwa im Lauterkeitsrecht ${ }^{1814}$ - ist auch im europäischen und mitgliedstaatlichen Recht die Verwendung von Generalklauseln durchaus verbreitet und nicht etwa grundlegend umstritten.

Lehnt man die Einführung einer urheberrechtlichen Schrankengeneralklausel - unabhängig von der konkreten Form ihrer Ausgestaltung im europäischen oder nationalen Recht - hingegen vollständig ab, so muss dies nicht einer vollständigen Absage an eine Flexibilisierung der urheberrechtlichen Schranken gleichkommen. Auch eine flexiblere Ausgestaltung der bestehenden nationalen Schrankenregelungen ist möglich. Diese kann insbesondere durch die verstärkte Verwendung von unbestimmten Rechtsbegriffen und Regelbeispielen sowie durch die Einführung generalklauselartiger, weiter Formulierungen innerhalb einzelner Schrankentatbestände erreicht werden (unten C.).

\section{A. Einführung einer Schrankengeneralklausel im europäischen Recht}

Die Einführung einer Schrankengeneralklausel nach dem Vorbild des USamerikanischen Fair Use im europäischen Recht käme zur Flexibilisierung des Urheberrechts auf verschiedenen Ebenen und in unterschiedlicher Gestalt in Betracht. Eine Generalklausel könnte zum einen durch Änderung des Richtlinienrechts eingeführt werden und dabei den Schrankenkatalog der InfoSoc-Richtlinie entweder vollständig ersetzen oder aber lediglich ergänzend als Auffangtatbestand in das Richtlinienrecht eingefügt werden. Eine Schrankengeneralklausel könnte - ebenfalls als einzige Schranke oder als Auffangtatbestand - aber auch einen (zentralen) Bestandteil einer völligen Neugestaltung des europäischen Urheberrechts bilden und in eine europäische Urheberrechtsverordnung aufgenommen werden.

Loy, IPQ 2009, 162 (173 ff.)) eingeführt. Auch in Japan und Korea wird die Einführung einer Fair Use-Generalklausel diskutiert; siehe Chang, Do Japan and Korea need Fair use?, S. 6 ff.

1814 Siehe exemplarisch die weite Generalklausel des $\S 3$ Abs. 1 UWG, die in $\S 4$ UWG durch einen Katalog von Regelbeispielen ergänzt wird, die zumeist wiederum generalklauselartig ausgestaltet sind und so der Rechtsprechung erhebliche Auslegungs- und Gestaltungsspielräume belassen (z.B. §4 Nr. 10 UWG: „Unlauter handelt insbesondere, wer Mitbewerber gezielt behindert.“). 


\section{Alleinige Schrankengeneralklausel im europäischen Recht}

Eine äußerst weitreichende Flexibilisierung der urheberrechtlichen Schranken in der gesamten Europäischen Union könnte durch die gemeinschaftsrechtliche Ausgestaltung der Urheberrechtsschranken als Generalklausel nach dem Vorbild der US-amerikanischen Fair Use-Doktrin erreicht werden.

\section{1. Änderung des Richtlinienrechts}

Denkbar ist eine solche Gestaltung zum einen in Form einer Änderung des Richtlinienrechts, insbesondere also der InfoSoc-Richtlinie, deren geltender - wenig geglückter - Katalog von Einzelausnahmen die Anpassung des Urheberrechts an sich wandelnde Rahmenbedingungen deutlich erschwert oder teilweise gar unmöglich macht. In einer Neuauflage der Richtlinie sollte daher gerade im Bereich der Schranken mehr Flexibilität ermöglicht werden. Dies könnte durch die vollständige Streichung der bisher in Art. 5 InfoSoc-RL aufgelisteten Ausnahmetatbestände und deren Ersetzung durch eine einzige Schrankengeneralklausel erreicht werden.

Eine solche Schrankengeneralklausel könnte in enger Anlehnung an die US-amerikanische Fair Use-Schranke beispielsweise wie folgt lauten:

Artikel 5 InfoSoc-RL (Entwurf): Beschränkung der Ausschließlichkeitsrechte

(1) Die den Rechteinhabern in dieser Richtlinie gewährten urheberrechtlichen Ausschließlichkeitsrechte können nach Maßgabe der Absätze 2 und 3 zum Zwecke der redlichen Nutzung eingeschränkt werden.

(2) ${ }^{1}$ Die redliche Nutzung eines veröffentlichten urheberrechtlich geschützten Werkes ist ohne Zustimmung des Rechteinhabers zulässig. ${ }^{2}$ Bei der Entscheidung, ob eine Nutzung redlich ist, sind insbesondere folgende Kriterien zu berücksichtigen:

1. der Zweck und der Charakter der Nutzung einschließlich der Frage, ob die Nutzung kommerzieller Natur ist; eine Nutzung kann insbesondere dann redlich sein, wenn ssie zum Zwecke des kritischen Kommentars, der Berichterstattung über aktuelle Ereignisse von öffentlichem Interesse, der Veranschaulichung 
des Unterrichts, der Lehre, der Forschung, der Zugänglichmachung für Menschen mit Behinderungen, der Förderung des Wettbewerbs, insbesondere auf Sekundärmärkten, oder der kreativen Weiterverwendung im Rahmen eigener Werkschöpfung erfolgt;

2. die Art des urheberrechtlich geschützten Werkes;

3. der Umfang und die Bedeutung des verwendeten Werkteils im Verhältnis zum urheberrechtlich geschützten Werk als Ganzem und

4. die Auswirkung der Nutzung auf den aktuellen und potentiellen Verwertungsmarkt und auf den Wert des urheberrechtlich geschützten Werkes.

(3) ${ }^{1}$ Für die redliche Nutzung nach Absatz 2 ist dem Urheber ein gerechter Ausgleich zu leisten. ${ }^{2}$ Auf seinen Anspruch auf einen gerechten Ausgleich kann der Urheber nicht verzichten. ${ }^{3}$ Der Anspruch kann nur durch eine Verwertungsgesellschaft geltend gemacht werden. ${ }^{4}$ Die Pflicht zur Zahlung eines gerechten Ausgleichs kann entfallen, wenn ein gesteigertes öffentliches Interesse nicht nur am freien Zugang, sondern auch an der Unentgeltlichkeit der Nutzung besteht.

Absatz 2 des Vorschlages übernimmt zunächst weitgehend die von Poeppel für die Neuregelung einer Schrankengeneralklausel im deutschen Urheberrecht in enger Anlehnung an die US-amerikanische Fair UseSchranke des 17 U.S.C. § 107 vorgeschlagene Formulierung. ${ }^{1815}$ Poeppel nimmt überzeugend keine wörtliche Übersetzung der Fair Use-Klausel vor, sondern versucht, die Schrankengeneralklausel in gewissem Umfang der deutschen beziehungsweise kontinentaleuropäischen Schrankentradition anzupassen. Insbesondere ist der Vorschlag daher zur Berücksichtigung urheberpersönlichkeitsrechtlicher Interessen auf die Nutzung veröffentlichter Werke beschränkt. Poeppel wählt in seinem Vorschlag die Formulierung „redliche Verwertung“ anstelle von „faire Verwertung“ mit dem Ziel, eine eigenständige Auslegung und Anwendung gegenüber der USamerikanischen Interpretation der „Fairness“ zu gewährleisten. ${ }^{1816}$ Dem ist grundsätzlich zuzustimmen. Vorzugswürdig erscheint jedoch die hier

1815 Siehe Poeppel, Neuordnung, S. 491 f., der die vorgeschlagene Generalklausel letztlich aber verwirft.

1816 Siehe Poeppel, Neuordnung, S. 492. 
gewählte Formulierung „redliche Nutzung“, um eine Einengung des Anwendungsbereichs auf Formen der wirtschaftlichen Verwertung zu vermeiden und $\mathrm{zu}$ verdeutlichen, dass die Schranke auch alle ,nicht-wirtschaftlichen" Formen der Werknutzung erfassen kann, die sich - wie etwa das künstlerische Zitat - nur schwerlich zwanglos unter den Begriff der „Verwertung“ einordnen lassen. Klarstellend wurde Absatz 2 Satz 1 hier gegenüber Poeppels Vorschlag zudem um die Worte „ohne Zustimmung des Rechteinhabers“ ergänzt. Durch die Formulierung „....sind insbesondere folgende Kriterien zu berücksichtigen" wird klargestellt, dass sämtliche genannten Kriterien regelmäßig Berücksichtigung finden sollten, jedoch keinesfalls abschließend sind. Es verbleibt somit Raum für eine zukunftsoffene Berücksichtigung weiterer Aspekte.

Die in der US-amerikanischen Fair Use-Schranke im Rahmen der Präambel beispielhaft aufgezählten Nutzungszwecke werden aus systematischen Gründen nicht in Satz 1, sondern in Satz 2 Nr. 1 erwähnt. Dies entspricht auch der tatsächlichen Praxis im US-amerikanischen Recht, die die in der Präambel aufgeführten Nutzungszwecke im Wesentlichen im Rahmen des ersten Fair Use-Faktors berücksichtigt. ${ }^{1817}$ Ergänzt wurden die in Satz 2 Nr. 1 aufgeführten Nutzungszwecke durch den Zweck der „Berichterstattung über Tagesereignisse" und die weder im US-amerikanischen Recht noch in Poeppels Vorschlag aufgeführte „Zugänglichmachung für Menschen mit Behinderungen“, zum Zwecke der „Förderung des Wettbewerbs“ oder zur „kreativen Weiterverwendung im Rahmen eigener Werkschöpfung“".

Die ausdrückliche Aufnahme der „Zugänglichmachung für Menschen mit Behinderungen" steht im Einklang mit der besonderen Berücksichtigung der Interessen dieser Nutzergruppe durch den europäischen Gesetzgeber. ${ }^{1818}$ Die Aufnahme in die Schrankengeneralklausel verdeutlicht zudem, dass Rechteinhaber zur Verwirklichung dieses wichtigen - im europäischen Recht unter anderem auch durch Art. 26 der GrundrechteCharta hervorgehobenen - Zwecks gegebenenfalls besonders weitgehende Beschränkungen ihrer Ausschließlichkeitsrechte hinnehmen müssen. Schließlich erscheint die ausdrückliche Aufnahme in die Schrankengeneralklausel auch aus rein praktischen Gesichtspunkten sinnvoll: Gerade die Sicherung einer angemessenen Informationsversorgung von Menschen mit

1817 Vgl. oben 2. Kapitel, C.I.2. So auch Förster, Fair Use, S. 215.

1818 Vgl. etwa Grünbuch „Urheberrechte in der wissensbestimmten Wirtschaft“ der Europäischen Kommission, KOM(2008) 466/3, S. 13 ff. 
Behinderungen, die oftmals eine „Übersetzung“ beziehungsweise Umformatierung oder etwa die Intonation von Werken erfordert, steht regelmäBig dann vor besonderen (rechtlichen) Herausforderungen, wenn sich neue Formen der Werkverbreitung und -nutzung etablieren. Durch eine Schrankengeneralklausel kann auch hier gewährleistet werden, dass alle zur $\mathrm{Zu}$ gänglichmachung für Menschen mit Behinderungen notwendigen Maßnahmen ergriffen werden können, um mit dieser Entwicklung Schritt zu halten.

Die ausdrückliche Erwähnung der Berücksichtigung von Auswirkungen auf den Wettbewerb, insbesondere auf Sekundärmärkten, hebt einen Aspekt hervor, der in der US-amerikanischen Fair Use-Rechtsprechung regelmäßig Beachtung findet, in der Regelung des 17 U.S.C. § 107 jedoch nicht erwähnt ist. Die Hervorhebung möglicher positiver Wettbewerbseffekte trägt zudem dem Bedürfnis Rechnung, gerade solche Werknutzungen zu ermöglichen, die in wettbewerblicher Sicht wünschenswert erscheinen, weil sie solchen wettbewerbswidrigen Praktiken entgegenwirken, die auf der im urheberrechtlichen Ausschließlichkeitsrecht begründeten starken oder gar beherrschenden Marktposition des Rechteinhabers beruhen. ${ }^{1819}$

Zusätzlich wurde in Satz 2 Nr. 1 als Kriterium einer redlichen Nutzung ausdrücklich die - der im deutschen Recht in $\S 24$ UrhG geregelten freien Benutzung vergleichbare - Werknutzung als Grundlage kreativer Weiterverarbeitung im Rahmen eigenen Werkschaffens aufgenommen. Dies entspricht zum einem dem vorzugswürdigen Verständnis der freien Benutzung als Schrankenbestimmung des Urheberrechts ${ }^{1820}$ und steht zum anderen im Einklang mit der US-amerikanischen Fair Use-Rechtsprechung, die der Frage, ob eine Werknutzung zum Zwecke der Anregung für selbständiges Werkschaffen erfolgt, im Rahmen der Fair Use-Prüfung, insbesondere unter dem Aspekt der Transformativität, wesentliche Bedeutung beimisst. ${ }^{1821}$ Durch die Wortwahl ,kreative Weiterverwendung im Rahmen eigener Werkschöpfung" wird zudem die zwanglose Anknüpfung an die Rechtsprechung des EuGH zur „eigenen geistigen Schöpfung“ als

1819 Vgl. zu diesem Aspekt auch Geiger/Griffiths/Hilty, IIC 2008, 707 (710) („Declaration on a Balanced Interpretation of the ,Three-Step Test' in Copyright Law").

1820 Siehe zum Streit um die dogmatische Einordnung des $\S 24$ UrhG oben 2. Kapitel, B.I.3.a).

1821 Vgl. dazu näher oben 2. Kapitel, C.I.2. 
Ausgangspunkt der Auslegung des urheberrechtlichen Werkbegriffes ${ }^{1822}$ ermöglicht.

Die Generalklausel bietet schließlich durch ihren offenen Wortlaut die Möglichkeit, neben den genannten (ökonomischen) Aspekten auch weitere Faktoren zur Erreichung einer optimalen Balance zwischen den Interessen der Werkschaffenden und der Nutzbarkeit der Werke für Dritte zu erreichen. Sie ist somit hinreichend zukunftsoffen, um etwa auch eine Berücksichtigung neuer wissenschaftlicher Erkenntnisse zu ermöglichen, beispielsweise auf dem Gebiet der für die Rechtswissenschaften und gerade auch für den Bereich des Urheberrechts zunehmend fruchtbar gemachten verhaltensökonomischen und -psychologischen Forschung. ${ }^{1823}$

1822 Siehe dazu näher oben 4. Kapitel, A.II.2.

1823 Insbesondere in der US-amerikanischen Literatur sind sowohl Fragen der Gewährung von Urheberrechtsschutz als auch der Grenzen des Urheberrechtsschutzes bereits seit längerer Zeit Gegenstand wissenschaftlicher Abhandlungen zur ökonomischen Analyse des Rechts; siehe grundlegend aus der US-amerikanischen Literatur etwa Besen/Kirby/Salop, 78 Va. L. Rev. 383 (1992); Besen/ Raskind, 5 J. Econ. Persp. 3 (1991); Landes/Posner, 18 J. Legal Stud. 325 (1989); dies., Economic Structure, S. 37 ff.; Lemley, 71 U. Chi. L. Rev. 129 (2004); ders., 83 Tex. L. Rev. 1031 (2005). In jüngerer Zeit ist jedoch auch verstärkt in der deutschen Wissenschaft untersucht worden, welchen Beitrag die ökonomische Forschung zur grundsätzlichen Rechtfertigung und zur Ausgestaltung des urheberrechtlichen Schutzes leisten kann und sollte; siehe aus der deutschen urheberrechtlichen Literatur etwa Bechtold, GRUR Int. 2008, 484 ff.; Eger/Scheufen, in: Ökonomik als allgemeine Theorie menschlichen Verhaltens, S. 151 (152 ff.); Hansen, Warum Urheberrecht, S. 107 ff.; Hansen/Schmidt-Bischoffshausen, GRUR Int. 2007, 461 (462 ff.); Hardege, Informationstechnologische Entwicklungen; Jänich, Geistiges Eigentum, S. 249 ff.; Leistner, ZGE 2009, 403 (405 ff.); Leistner/Hansen, GRUR 2008, 479 ff.; Ohly, in: Geistiges Eigentum - Schutzrecht oder Ausbeutungstitel?, S. 143 ff.; Peukert, in: Hilty/ Peukert, Interessenausgleich, S. 11 (12 ff.); Reich, Ökonomische Analyse, S. 231 ff. und passim; Schack, in: Geistiges Eigentum - Schutzrecht oder Ausbeutungstitel?, S. 123 ff. Dennoch hat - soweit ersichtlich - eine vertiefte Auseinandersetzung mit (verhaltens-)ökonomischen Überlegungen zur Ausgestaltung der urheberrechtlichen Schranken und insbesondere eine Untermauerung geäußerter Vermutungen durch empirische Forschungsarbeiten bisher nicht stattgefunden. Sie würde auch den Rahmen dieser Untersuchung sprengen und muss daher späteren wissenschaftlichen Arbeiten überlassen bleiben. Einen im Hinblick auf die vorliegende Untersuchung besonders interessanten Ansatzpunkt bilden insoweit verhaltensökonomische und -psychologische Überlegungen zur Rezeption und Akzeptanz unterschiedlicher Schrankenmodelle durch den Rechtsanwender; siehe zu derartigen Überlegungen und weiteren Ansatzpunkten für die ökonomische Forschung im Bereich des Urheberrechts bereits 
Absatz 2 wird in Absatz 3 - in Anlehnung an die von Förster für eine Generalklausel im nationalen Recht vorgeschlagene Formulierung ${ }^{1824}$ um eine Rechtsfolgenregelung ergänzt. Danach soll ein Rechteinhaber die zustimmungsfreie Nutzung seines Werkes üblicherweise nur gegen Zahlung eines angemessenen Ausgleichs hinnehmen müssen. Anstelle des von Förster vorgeschlagenen, im deutschen Urheberrechtsgesetz verwendeten Begriffs der „,angemessenen Vergütung“ wurde hier jedoch der im europäischen Richtlinienrecht (inzwischen) etablierte Begriff des „gerechten Ausgleichs“ gewählt. Die Regelung fügt sich so in das europäische urheberrechtliche Regelungssystem ein. Zugleich ermöglicht sie es, zur näheren Bestimmung des „gerechten Ausgleichs“ auf die in jüngerer Zeit zur Auslegung dieses Begriffs in der InfoSoc-Richtlinie und der Vermiet- und Verleihrechts-Richtlinie ergangene Rechtsprechung des Gerichtshofs der Europäischen Union ${ }^{1825}$ und des Bundesgerichtshofs ${ }^{1826}$ zurückzugreifen.

Leistner, ZGE 2009, 403 (430 ff.) m.w.N. Hier böte sich etwa eine experimentelle verhaltensökonomische Gegenüberstellung der Auswirkungen eines offenen „Designs“ urheberrechtlicher Schranken einerseits und geschlossener Schrankenkataloge andererseits auf das "Gerechtigkeitsempfinden“ und das Nutzungsverhalten einzelner Nutzergruppen, insbesondere etwa in Bezug auf die Nutzung neuer technischer Möglichkeiten, an. Derartige Forschung könnte dringend erforderliche Aufklärungsarbeit darüber leisten, ob aus Sicht der Rechtsanwender mit der Einführung von Schrankengeneralklauseln oder der Verwendung offener Rechtsbegriffe und der damit verbundenen Übertragung größerer Entscheidungsspielräume auf die Rechtsprechung tatsächlich eine größere Rechtsunsicherheit einhergeht oder aber dieses Standardargument gegen generalklauselartige Schranken weiter entkräften. Dies würde wertvolle Erkenntnisse für die gesetzgeberische Ausgestaltung der urheberrechtlichen Schranken im Sinne einer idealen Balance zwischen ausreichender Flexibilität und Zukunftsoffenheit einerseits und der zur Vermeidung unerwünschter chilling effects erforderlichen hinreichenden Vorhersehbarkeit und Rechtssicherheit andererseits ermöglichen.

1824 Siehe Förster, Fair Use, S. 215.

1825 Siehe EuGH, Urt. v. 21.10.2010, C-467/08, AB1. EU 2010, C 346/05 = GRUR 2011, 50 - Padawan./. Sociedad General de Autores y Editores de España [SGAE]; EuGH, Urt. v. 16.6.2011, C-462/09, AB1. EU 2011, C 232/07 = GRUR 2011, 909 - Stichting de Thuiskopie./. Opus Supplies Deutschland GmbH; EuGH, Urt. v. 30.6.2011, C-271/10, AB1. EU 2011, C 252/05 = GRUR 2011, 913 - Vereniging van Educatieve en Wetenschappelijke Auteurs [VEWA]./. Belgische Staat; EuGH, Urt. v. 9.2.2012, C-277/10, AB1. EU 2012, C 80/04 = GRUR 2012, 489 - Luksan./. van der Let. Siehe zu dieser Rechtsprechung bereits oben 2. Kapitel, B.I.1.b) und 6. Kapitel, B.III.

1826 Siehe BGH, GRUR 2011, 1007 - Drucker und Plotter II; GRUR 2011, 1012 - 
Im Einklang mit der jüngsten EuGH-Rechtsprechung ${ }^{1827}$ wird zudem in Absatz 3 Satz 1 und 2 klargestellt, dass Inhaber des gesetzlichen Vergütungsanspruches der Urheber und dieser zu seinem Schutz unverzichtbar ist. Eine Abtretung des Anspruchs auf einen gerechten Ausgleich im Einzelfall wird durch die Bestimmung hingegen nicht grundsätzlich ausgeschlossen. Auch dies steht im Einklang mit der Luksan-Entscheidung, in der der EuGH lediglich eine unwiderlegbare gesetzliche Vermutung der Abtretung der dem Urheber zustehenden Vergütungsansprüche an einen Dritten für mit den Vorgaben des europäischen Richtlinienrechts unvereinbar erklärte, da andernfalls dem Urheber die Zahlung des in Art. 5 Abs. 2 lit. b der InfoSoc-Richtlinie (zwingend) vorgesehenen gerechten Ausgleichs vorenthalten bliebe. ${ }^{1828}$ Dies schließt jedoch nicht eine Abtretung von Vergütungsansprüchen durch eine widerlegbare Vermutung 1829 oder durch Parteivereinbarung im Einzelfall aus - jedenfalls solange diese sich nicht als reine Umgehung der grundsätzlichen Zuordnung des Vergütungsanspruchs zum Urheber darstellen. Dies verdeutlicht auch Absatz 3 Satz 3 der Regelung, nach dem der Anspruch nur durch eine Verwertungsgesellschaft geltend gemacht werden kann. Denn die verwertungsgesellschaftliche Geltendmachung setzt die Abtretung beziehungsweise Abtretbarkeit des Vergütungsanspruchs voraus. Insoweit sind also die vom EuGH als zwingend angesehene Inhaberschaft des Vergütungsanspruchs und die Frage seiner Geltendmachung strikt auseinanderzuhalten. ${ }^{1830}$

Die in der Regelung vorgeschlagene Verwertungsgesellschaftspflichtigkeit des Anspruchs steht auch im Einklang mit der neueren Rechtsprechung des EuGH, nach der die Mitgliedstaaten in Bezug auf die Gewährleistung einer effektiven Erhebung des gerechten Ausgleichs eine „Ergebnispflicht" trifft, nach der sichergestellt werden muss, dass der gerechte Ausgleich tatsächlich den Urhebern als unmittelbar und originär Berech-

PC II; GRUR 2012, 705 - PC als Bild- und Tonaufzeichnungsgerät. Siehe zu dieser Rechtsprechung auch oben S. $287 \mathrm{f}$.

1827 Siehe EuGH, Urt. v. 9.2.2012, C-277/10, Rn. 96 ff., ABl. EU 2012, C 80/04 = GRUR 2012, 489 (493 f.) - Luksan./. van der Let.

1828 Vgl. EuGH, a.a.O., Rn. 108 - Luksan./. van der Let.

1829 So auch Obergfell, GRUR 2012, 494 (496).

1830 Vgl. Flechsig, MMR 2012, 293 (297). 
tigten des Anspruchs auf gerechten Ausgleich zufließt. ${ }^{1831}$ Auch wenn die Verwertungsgesellschaften in der Praxis auch hier nur schematisierte Vergütungslösungen anbieten können werden, erscheint die vorgeschlagene Regelung einer Verwertungsgesellschaftspflichtigkeit hier zur Gewährleistung dieser „Ergebnispflicht“ angemessen. Eine kollektive Wahrnehmung der Vergütungsansprüche erscheint in diesem Zusammenhang als einzig praktikable Lösung. Aufgrund des stetig voranschreitenden technischen und wirtschaftlichen Wandels ist es den einzelnen Rechteinhabern - trotz der Möglichkeiten des Einsatzes von technischen Schutzmaßnahmen und DRM-Systemen - heute kaum noch möglich, die vielfältigen Nutzungen ihrer Werke effektiv zu verfolgen und zu kontrollieren. Zugleich ist es den Nutzern oftmals nicht oder nicht mit zumutbarem Aufwand möglich, für jede Nutzungshandlung vom jeweiligen Rechteinhaber selbst die Rechte einzuholen. Beides - eine effektive Kontrollmöglichkeit der Rechteinhaber und die Möglichkeit der Lizenzierung zu angemessenen Bedingungen im Einzelfall - wären jedoch zwingende Voraussetzungen, um ohne Verwertungsgesellschaften eine effektive Erhebung des gerechten Ausgleichs zu gewährleisten. ${ }^{1832}$ Zudem sprechen neben diesen Praktikabilitätserwägungen auch andere Aspekte für eine verwertungsgesellschaftspflichtige Ausgestaltung. Diese erscheint hier geeignet, sicherzustellen, dass der gerechte Ausgleich - wie vom EuGH gefordert - tatsächlich den Urhebern zufließt. Die kollektive Wahrnehmung reduziert die Gefahr erheblich, dass der Urheber als regelmäßig wirtschaftlich schwächere Vertragspartei durch eine umfassende Abtretung seiner Rechte an die Verwerter im Rahmen nachteiliger Individualverträge um seine angemessene Beteiligung gebracht wird. ${ }^{1833}$ Soweit die Verwertungsgesellschaft Rechte der Urheber wahrnimmt, ist ihnen für die Nutzung dieser Rechte eine angemessene Vergütung gesichert.

In Absatz 3 Satz 4 sieht der Entwurf schließlich die Möglichkeit eines vollständigen Wegfalls der Vergütungspflicht für Fälle vor, in denen ein

1831 Vgl. EuGH, Urt. v. 16.6.2011, C-462/09, Rn. 34, 37 - Stichting de Thuiskopie./. Opus Supplies Deutschland GmbH; EuGH, Urt. v. 9.2.2012, C-277/10, Rn. 88 ff., 95, AB1. EU 2012, C 80/04 = GRUR 2012, 489 (493) - Luksan./. van der Let.

1832 Siehe ausführlich zu den ökonomischen Funktionen der Verwertungsgesellschaften und zur kollektiven Wahrnehmung im Lichte der Transaktionskostenökonomik Hansen/Schmidt-Bischoffshausen, GRUR Int. 2007, 461 (466 ff.).

1833 Vgl. Dreier/Schulze, Vorbemerkung vor $\S 1$ ff. WahrnG Rn. 10. 
öffentliches Interesse an der kostenfreien Nutzung besteht, das das Vergütungsinteresse des Rechteinhabers überwiegt. Dies ist insbesondere in den - auch in Absatz 2 Satz 2 Nr. 1 angeführten - Fällen denkbar, in denen ein Werk lediglich als Ausgangspunkt oder Anregung für eigene kreative schöpferische Tätigkeit genutzt wird und das neu geschaffene Werk einen hinreichenden (kreativen) Abstand zum genutzten Werk aufweist. ${ }^{1834}$ Dass jedoch die Zahlung einer Vergütung der Regelfall des „gerechten Ausgleichs" und die Unentgeltlichkeit die Ausnahme sein soll, verdeutlicht der Entwurf - in Abweichung von Försters Vorschlag - durch die Ersetzung des Wortes „entfällt“ durch die Formulierung „kann entfallen“, die Satz 4 noch deutlicher von der ,ist"-Vorschrift des Satzes 1 abgrenzt. Dies trägt der Tatsache Rechnung, dass den erheblichen Zugangsinteressen Dritter und der Allgemeinheit aus Sicht der Rechteinhaber häufig eher ein Partizipations- und weniger ein echtes Kontrollinteresse gegenübersteht. ${ }^{1835}$ Ein gerechter Interessenausgleich lässt sich deshalb häufig durch die Zahlung einer angemessenen Vergütung erreichen. Eine für die jeweils betroffene Interessengruppe besonders nachteilige, einseitige Entscheidung zwischen gänzlicher Freistellung und Zustimmungsvorbehalt kann somit in aller Regel vermieden werden.

Die an die US-amerikanische Fair Use-Schranke angelehnte und um eine Vergütungspflicht ergänzte Vorschrift ist schließlich ergänzt um einen einleitenden Absatz 1, der diese Regelung in den Kontext der (überarbeiteten) InfoSoc-Richtlinie einfügt. Anstelle eines einleitenden Absatzes wäre auch ein entsprechender Erwägungsgrund zur Richtlinie denkbar.

Um der Schrankengeneralklausel die erforderliche Effektivität zu verleihen, innerhalb der europäischen Union einen möglichst einheitlichen (hohen) Grad an Flexibilität im Bereich der Schranken zu erreichen und eine der derzeit hinsichtlich des europarechtlichen Dreistufentests bestehenden Unklarheit über die Adressaten der Norm ${ }^{1836}$ vergleichbare Situation zu vermeiden, sollte zudem sichergestellt werden, dass die Generalklausel tatsächlich in allen Mitgliedstaaten möglichst einheitlich Anwendung findet. Wäre den nationalen Gesetzgebern die Wahl freigestellt, wie sie das nationale Recht im Einklang mit der richtlinienrechtlichen Generalklausel ausgestalten, so könnten diese sich dazu entscheiden, alles beim

1834 Siehe zum vergleichbaren, vom BGH in Bezug auf $\S 24$ UrhG entwickelten Kriterium des „Verblassens“" näher oben 2. Kapitel, B.I.3.a) und 4. Kapitel, A.I.2.

1835 Vgl. Dreier, in: FS Loschelder, S. 47 (59).

1836 Siehe dazu oben S. $334 \mathrm{ff}$. 
Alten zu belassen und bestehende Schrankenkataloge unverändert zu erhalten - da diese zweifelsohne mit den Vorgaben der Generalklausel vereinbar wären. Zudem wäre das Problem nicht gelöst, dass jede neue, im Rahmen bestehender Schranken nicht erfassbare Form der Werknutzung weiterhin ein - zeitaufwändiges und für Lobbyeinflüsse anfälliges - Tätigwerden der Legislative erforderte.

Beließe man den nationalen Gesetzgebern eine so weitreichende Freiheit bei der Umsetzung, so ließe sich die erforderliche Klarheit wohl allenfalls durch eine ausdrückliche Klarstellung im Richtlinienrecht dahingehend erreichen, dass Adressaten der richtlinienrechtlichen Generalklausel neben den nationalen Gesetzgebern auch unmittelbar die nationalen Gerichte sind. Neben den dogmatischen Bedenken, die gegen eine solche ausdrückliche Ermächtigung der nationalen Gerichte im Richtlinienrecht bestehen, könnte eine solche Regelung jedoch auch nicht die Probleme beseitigen, die sich aus dem Nebeneinander nationaler, die Richtlinie umsetzender gesetzlicher Regelungen und der unmittelbaren Heranziehung der Generalklausel durch die nationalen Gerichte ergäben. ${ }^{1837}$

Erfolgversprechend erscheint daher allenfalls eine Ausgestaltung auf Richtlinienebene, bei der den mitgliedstaatlichen Gesetzgebern die Umsetzung durch die Aufnahme einer Generalklausel in das nationale Recht zwingend vorgeschrieben würde. Eine solche Vorgabe für die Mitgliedstaaten könnte - dem Vorbild der Richtlinie über unlautere Geschäftspraktiken ${ }^{1838}$ folgend - insbesondere in den Erwägungsgründen näher dargelegt und ausgestaltet werden. ${ }^{1839}$ Sie könnte dabei entweder als Pflicht zur Einführung einer alleinigen Schrankengeneralklausel und Streichung bestehender Schrankenkataloge im nationalen Recht oder aber lediglich als Pflicht zur Ergänzung der bestehenden nationalen Schrankenregelungen

1837 Siehe zu dieser Problematik bei der Anwendung des europarechtlichen Dreistufentests oben S. $334 \mathrm{ff}$.

1838 Richtlinie 2005/29/EG des Europäischen Parlaments und des Rates vom 11. Mai 2005 über unlautere Geschäftspraktiken im binnenmarktinternen $\mathrm{Ge}$ schäftsverkehr zwischen Unternehmen und Verbrauchern und zur Änderung der Richtlinie 84/450/EWG des Rates, der Richtlinien 97/7/EG, 98/27/EG und 2002/65/EG des Europäischen Parlaments und des Rates sowie der Verordnung (EG) Nr. 2006/2004 des Europäischen Parlaments und des Rates (sog. UGP-Richtlinie).

1839 Vgl. Erwägungsgründe zur UGP-Richtlinie, insbesondere Erw.-Grd. 13. 
um eine im Einklang mit der Richtlinie stehende Generalklausel ${ }^{1840}$ ausgestaltet werden.

2. Schrankengeneralklausel als Teil einer europäischen Urheberrechtsverordnung

Ebenfalls denkbar ist die Einführung einer alleinigen Schrankengeneralklausel als Teil einer europäischen Urheberrechtsverordnung, mit der unmittelbar ein einheitliches europäisches Urheberrecht begründet würde. ${ }^{1841}$ Aufgrund der unmittelbaren Geltung der Verordnung in allen Mitgliedstaaten gemäß Artikel 288 Abs. 2 AEUV bedürfte es einer Umsetzung der Schrankenvorgaben in nationales Recht nicht. Die genannten Probleme, die sich aus dem Nebeneinander nationaler gesetzlicher Schrankenregelungen und der unmittelbaren Heranziehung einer Generalklausel durch die Gerichte ergeben können, könnten so vermieden werden. Würde in der Urheberrechtsverordnung als einzige Schrankenregelung eine Generalklausel nach dem Vorbild der US-amerikanischen Fair Use-Schranke oder des Dreistufentests aufgenommen, so obläge ihre Ausgestaltung allein den europäischen und nationalen Gerichten. Diese erhielten folglich ganz erhebliche Spielräume für die nähere Gestaltung der urheberrechtlichen Schranken - und damit einhergehend ganz erhebliche Flexibilität bei deren Anwendung.

In Anlehnung an die Fair Use-Doktrin könnte eine solche alleinige Schrankengeneralklausel in einer europäischen Urheberrechtsverordnung ebenso lauten wie der zuvor dargestellte Entwurf einer alleinigen Schrankengeneralklausel in einer überarbeiteten InfoSoc-Richtlinie. ${ }^{1842}$ Auf den einleitenden, klarstellenden Absatz 1 könnte dabei freilich verzichtet werden. Es böte sich daher etwa folgende Schrankenregelung an:

1840 Dies wäre der in der sog. Klausel-Richtlinie 93/13/EWG gewählten Regelungstechnik vergleichbar, die für einige Bereiche zwingende (Mindest-)Standards festlegte, daneben aber auch enumerative Konkretisierungen im nationalen Recht weiterhin zuließ; vgl. Erwägungsgründe zur Richtlinie 93/13/EWG des Rates vom 5. April 1993 über mißbräuchliche Klauseln in Verbraucherverträgen.

1841 Siehe zur Gemeinschaftskompetenz zur Errichtung einer solchen Urheberrechtsverordnung bereits oben 6 . Kapitel, B.I.

1842 Siehe oben 7. Kapitel, A.I.1. 
Artikel x: Beschränkung der Ausschließlichkeitsrechte

(1) ${ }^{1}$ Die redliche Nutzung eines veröffentlichten urheberrechtlich geschützten Werkes ist ohne Zustimmung des Rechteinhabers zulässig. ${ }^{2}$ Bei der Entscheidung, ob eine Nutzung redlich ist, sind insbesondere folgende Kriterien zu berücksichtigen:

1. der Zweck und der Charakter der Nutzung einschließlich der Frage, ob die Nutzung kommerzieller Natur ist; eine Nutzung kann insbesondere dann redlich sein, wenn sie zum Zwecke des kritischen Kommentars, der Berichterstattung über aktuelle Ereignisse von öffentlichem Interesse, der Veranschaulichung des Unterrichts, der Lehre, der Forschung, der Zugänglichmachung für Menschen mit Behinderungen, der Förderung des Wettbewerbs, insbesondere auf Sekundärmärkten, oder der kreativen Weiterverwendung im Rahmen eigener Werkschöpfung erfolgt;

2. die Art des urheberrechtlich geschützten Werkes;

3. der Umfang und die Bedeutung des verwendeten Werkteils im Verhältnis zum urheberrechtlich geschützten Werk als Ganzem und

4. die Auswirkung der Nutzung auf den aktuellen und potentiellen Verwertungsmarkt und auf den Wert des urheberrechtlich geschützten Werkes.

(2) ${ }^{1}$ Für die redliche Nutzung nach Absatz 1 ist dem Urheber ein gerechter Ausgleich zu leisten. ${ }^{2}$ Auf seinen Anspruch auf einen gerechten Ausgleich kann der Urheber nicht verzichten. ${ }^{3}$ Der Anspruch kann nur durch eine Verwertungsgesellschaft geltend gemacht werden. ${ }^{4}$ Die Pflicht zur Zahlung eines gerechten Ausgleichs kann entfallen, wenn ein gesteigertes öffentliches Interesse nicht nur am freien Zugang, sondern auch an der Unentgeltlichkeit der Nutzung besteht.

\section{Opportunität und Umsetzbarkeit der Rechtsetzungsvarianten}

Das größte Maß an Flexibilität bei der Ausgestaltung der Schranken würde den nationalen Gesetzgebern und Gerichten durch die vollständige Streichung des bisherigen Schrankenkataloges der InfoSoc-Richtlinie und dessen Ersetzung durch eine alleinige Schrankengeneralklausel gewährt. 
Eine solche könnte - wie dargestellt - etwa dem Vorbild des Fair Use folgen. ${ }^{1843}$

Eine solche Neuregelung der urheberrechtlichen Schranken könnte und sollte - anders als derzeit Artikel 5 der InfoSoc-Richtlinie ${ }^{1844}$ - auch als ausdrücklich vorrangig gegenüber den vorbestehenden bereichsspezifischen Richtlinien - namentlich insbesondere der Computerprogramm- und Datenbank-Richtlinie - ausgestaltet werden. Die sich derzeit aufgrund der teilweise bestehenden Unklarheiten hinsichtlich des Verhältnisses der Richtlinien zueinander beziehungsweise der diesbezüglich zum Teil mangelhaften Abstimmung bestehenden Probleme ${ }^{1845}$ könnten so weitgehend beseitigt werden.

Die Ersetzung des bisherigen Schrankenkataloges der InfoSoc-Richtlinie durch eine alleinige Schrankengeneralklausel auf Ebene des Richtlinienrechts ist jedoch ganz erheblichen Bedenken ausgesetzt. Durch diese Rechtsetzungsvariante könnte zwar die gewünschte Flexibilisierung der urheberrechtlichen Schranken erreicht werden, sie wäre jedoch nicht geeignet, hinreichende Rechtssicherheit zu bieten, und schösse voraussichtlich deutlich über das erstrebte Ziel hinaus beziehungsweise verfehlte dieses. Die konkrete Umsetzung der Richtlinienvorgaben bliebe den nationalen Gesetzgebern der Mitgliedstaaten überlassen, so dass durch unterschiedliche Formen der nationalen Umsetzung eine ganz erhebliche weitere Disharmonisierung im europäischen Urheberrecht drohte. Ob tatsächlich eine deutliche Flexibilisierung im Bereich der urheberrechtlichen Schranken erreicht würde, hinge zudem davon ab, ob die nationalen Gesetzgeber von der durch die Generalklausel im Richtlinienrecht eröffneten Möglichkeit einer flexibleren Ausgestaltung der Schranken überhaupt Gebrauch machten. Würde die Umsetzung in Form der Aufnahme einer Generalklausel in das nationale Recht nicht zwingend vorgeschrieben, so wä-

1843 Siehe den Formulierungsvorschlag oben 7. Kapitel, A.I.1.

1844 Siehe Art. 1 Abs. 2 InfoSoc-RL, wonach diese Richtlinie die bestehenden gemeinschaftsrechtlichen Bestimmungen u.a. über den Schutz von Computerprogrammen und Datenbanken „unberührt“ lässt und diesen „,in keiner Weise beeinträchtigt".

1845 Siehe bereits oben 6. Kapitel, B.II. und III. sowie Commission Staff Working Paper on the review of the EC legal framework in the field of copyright and related rights vom 19.7.2004, SEC(2004) 995, S. 6 ff., abrufbar unter: http:// ec.europa.eu/internal_market/copyright/docs/review/sec-2004-995_en.pdf [zuletzt abgerufen am 26.5.2013]; dazu Leistner, Konsolidierung und Entwicklungsperspektive, S. 20. 
re es auch möglich - und im Rahmen einer weiten Generalklausel weiterhin zulässig - die bestehenden geschlossenen Schrankenkataloge beizubehalten. Auch dann könnten diese Schrankentatbestände zwar gegebenenfalls durch die Rechtsprechung vor dem Hintergrund der Generalklausel des Richtlinienrechts im Einzelfall ergänzend und erweiternd ausgelegt werden, so dass jedenfalls eine gewisse Flexibilisierung der Schranken erreicht würde. Diese Einzelfallkontrolle festgeschriebener Schrankentatbestände anhand einer Generalklausel durch die Gerichte hätte jedoch die derzeit in einigen Mitgliedstaaten schon bei der Anwendung des Dreistufentests der InfoSoc-Richtlinie zu beobachtende ${ }^{1846}$ - negative Konsequenz erheblich gesteigerter Rechtsunsicherheit. Es drohte ein „Worst Case"-Szenario, in dem die Schranken grundsätzlich weiterhin in Form starrer Kataloge ausgestaltet wären, deren (erhoffter) Vorteil größerer Vorhersehbarkeit und Rechtssicherheit jedoch durch die Einzelfallüberprüfung durch die Gerichte anhand einer Generalklausel vollends zunichte gemacht würde. Nutzer könnten letztlich nicht einmal mehr sicher darauf vertrauen, dass selbst durch die Schranken ausdrücklich vorgesehene Ausnahmen im Einzelfall auch vor Gericht Bestand hätten. ${ }^{1847}$

Eine weitere Disharmonisierung der Schranken in Europa und die dargestellte gesteigerte Rechtsunsicherheit könnten freilich vermieden werden, wenn eine Schrankengeneralklausel nicht durch Änderung des Richtlinienrechts, sondern im Rahmen einer Urheberrechtsverordnung eingeführt würde, da diese gemäß Artikel 288 Abs. 2 AEUV unmittelbare Geltung in den Mitgliedstaaten beanspruchte. Die im Falle der Regelung in einer Richtlinie drohende Gefahr unterschiedlicher Formen der Umsetzung im nationalen Recht bestünde somit nicht. Auch das geschilderte „Worst Case"-Szenario eines Zusammen- beziehungsweise Gegenspiels von Rechtsprechung und Gesetzgebung und die daraus resultierende Rechtsunsicherheit ließen sich vermeiden. Zugleich erhielten die Gerichte ganz erhebliche Spielräume für die nähere Ausgestaltung der urheberrechtlichen Schranken und deren Anwendung.

Beide Rechtsetzungsvarianten - alleinige Generalklausel im Richtlinienrecht oder in einer Urheberrechtsverordnung - sehen sich jedoch einem weiteren, erheblichen Kritikpunkt ausgesetzt: Insbesondere von Leistner sind zu Recht weitere Bedenken hinsichtlich der rechtssicheren Umset-

1846 Siehe zu den unerwünschten Folgen einer unmittelbaren Anwendung des Dreistufentests durch die Rechtsprechung bereits oben 6. Kapitel, C.II.

1847 Vgl. zu dieser Kritik auch bereits oben 6. Kapitel, C.II. m.w.N. 
zung und Ausgestaltung einer solchen Fair Use-Generalklausel in Europa geäußert worden. ${ }^{1848}$

In ihrer Ausgestaltung im US-amerikanischen Recht und durch die dortige Rechtsprechung ist die Fair Use-Generalklausel - wie gezeigt - keinen durchgreifenden Rechtssicherheitsbedenken ausgesetzt. Im Gegenteil, der durch eine langjährige gefestigte Rechtsprechung, die Methodik der Formulierung ausführlicher obiter dicta und dissenting opinions und das Zusammen- und Gegenspiel verschiedener (Bezirks-)Gerichte zur Verfügung stehende „Fair Use-Werkzeugkasten“ vermag gar mehr Rechtssicherheit zu erzeugen, als dies derzeit im europäischen Recht der Fall ist, wo „krampfhaft" versucht wird, auf Grundlage beziehungsweise durch Umgehung des veralteten Schrankenkataloges Lösungen für neuartige Rechtsprobleme zu finden. ${ }^{1849}$

Auf das europäische Recht lässt sich die Erkenntnis, dass mit der Einführung einer Schrankengeneralklausel gar ein Rechtssicherheitsgewinn einhergehen kann, dennoch nicht zwanglos übertragen. Es muss insbesondere mit Blick auf die Rolle des Gerichtshofs der Europäischen Union bezweifelt werden, ob eine Schrankengeneralklausel nach dem Vorbild des Fair Use im Rahmen des europäischen Gerichtssystems ebenso erfolgreich und rechtssicher ausgestaltet und ausgefüllt werden könnte wie in den USA. Bedenken bestehen insoweit zum einen deshalb, weil durch das System der Vorabentscheidungsverfahren durch den EuGH nach Artikel 267 AEUV nur eine relativ geringe Zahl von Fällen zur höchstrichterlichen Entscheidung kommt. ${ }^{1850}$ Auch wenn in jüngerer Zeit zu beobachten ist, dass die mitgliedstaatlichen Gerichte gerade auch im Hinblick auf urheberrechtliche Fragen weniger zögerlich von der Möglichkeit der Vorlage an den EuGH Gebrauch machen, ${ }^{1851}$ hängt die Möglichkeit des EuGH zur Klärung und Weiterentwicklung des europäischen Urheberrechts weiterhin maßgeblich davon ab, welche Fragen die nationalen Gerichte ihm zur Vorabentscheidung vorlegen. ${ }^{1852}$ Nur sehr langsam würde deshalb voraussichtlich eine „Anreicherung“ der Schrankengeneralklausel mit dem für hinreichende Rechtssicherheit erforderlichen Fallrecht erfol-

1848 Siehe Leistner, IIC 2011, 417 (437 f.).

1849 Siehe zu dieser Kritik am Standardargument mangelnder Rechtssicherheit bereits oben S. $279 \mathrm{ff}$.

1850 Siehe Leistner, IIC 2011, 417 (437).

1851 Vgl. Metzger, GRUR 2012, $118(119,125)$ m.w.N.

1852 Vgl. Metzger, GRUR 2012, 118 (119). 
gen. Zum anderen erscheint auch die vom EuGH angewandte Methodik bisher kaum geeignet, den zur Ausfüllung einer Generalklausel erforderlichen „Werkzeugkasten“ mit den benötigten Werkzeugen zu bestücken. ${ }^{1853}$ Anders als in der US-amerikanischen Rechtsprechungspraxis üblich, nimmt der EuGH nur in seltenen Fällen eine Abgrenzung zu seinen vorherigen Entscheidungen vor. ${ }^{1854}$ Einer solchen bedarf es jedoch, um das zur Ausfüllung einer Generalklausel erforderliche Herausbilden von Fallgruppen zu ermöglichen. In der Regel entscheidet der EuGH zudem nicht sämtliche zur Vorabentscheidung vorgelegten Fragen „durch“, sondern gibt lediglich Leitlinien für die Auslegung gesetzlicher Bestimmungen vor und verweist zur weiteren Entscheidung an das vorlegende nationale Gericht zurück. Selbst im Falle einer Vorlage an den EuGH wäre daher die abschließende Klärung einer Auslegungsfrage im Zusammenhang mit der Ausfüllung der Generalklausel ebenso wenig sichergestellt, wie die europaweit einheitliche Anwendung der Schrankenbestimmung. Schließlich werden immer wieder auch Zweifel an der spezifischen Kompetenz des EuGH und der fachlichen Qualität seiner Entscheidungen laut, insbesondere unter Hinweis darauf, der Stand der wissenschaftlichen Diskussion werde teilweise nicht hinreichend berücksichtigt ${ }^{1855}$ und die Konsequenzen für die Praxis würden verkannt. ${ }^{1856}$ Diese - tatsächlich jedenfalls vereinzelt auszumachenden - Schwächen von EuGH-Entscheidungen haben ihren Grund im Wesentlichen wohl darin, dass der EuGH zugleich als Verfassungs- und oberstes Fachgericht fungiert, jedoch ohne Spezialkammern und feste Geschäftsverteilung arbeitet und die meisten Richter einen europa- oder völkerrechtlichen Hintergrund haben. ${ }^{1857}$ Es ist deshalb mehrfach über die Einrichtung einer Spezialkammer für Urheberrechtsfra-

1853 Zweifelnd auch Leistner, IIC 2011, 417 (437 f.); Metzger, in: Europäische Perspektiven des Geistigen Eigentums, S. 101 (121 f.).

1854 Vgl. Leistner, IIC 2011, 417 (437).

1855 Siehe etwa die Kritik an der Rechtsprechung des EuGH in Bezug auf die (zu) enge Auslegung von Schrankenbestimmungen in der Infopaq-Entscheidung (EuGH, Urt. v. 16.7.2009, C-5/08, Slg. 2009, I-6569 = GRUR 2009, 1041 - Infopaq International A/S./. Danske Dagblades Forening.) bei Hugenholtz/Senftleben, Fair Use in Europe, S. 25; Leistner, GRUR 2010, 987 (988); ders., JZ 2011, 1140 (1145); Metzger, GRUR 2012, 118 (123); ders., in: Europäische Perspektiven des Geistigen Eigentums, S. 101 (116 ff.) sowie oben 2. Kapitel, B.I.2.b).

1856 Vgl. Metzger, GRUR 2012, 118 (126).

1857 Vgl. Metzger, GRUR 2012, 118 (119); Paulus/Wesche, GRUR 2012, 112 (113). 
gen oder gar die Schaffung eines spezialisierten europäischen Urheberrechtsgerichtes nachgedacht worden. ${ }^{1858}$

Unabhängig davon, ob man eine derartige Spezialisierung auf europäischer Ebene letztlich für sinnvoll erachtet, leistet jedenfalls der status quo Zweifeln daran Vorschub, ob sich eine urheberrechtliche Schrankengeneralklausel im europäischen Recht sinnvoll durch das erforderliche Fallrecht mit Leben füllen ließe. Vor dem Hintergrund der europäischen Entscheidungspraxis und der Rolle des EuGH muss dies derzeit verneint werden. Jedenfalls eine alleinige Schrankengeneralklausel auf europäischer Ebene - egal ob im Richtlinienrecht oder in einer Verordnung verankert wird ohne eine hinreichende und zügige Ausfüllung durch die Rechtsprechung den beteiligten Interessen nicht gerecht, da sie die erforderliche Rechtssicherheit nicht zu erzeugen vermag. Derzeit kann eine solche Ausgestaltung der urheberrechtlichen Schranken auf europäischer Ebene daher nicht empfohlen werden.

\section{Schrankengeneralklausel als Auffangtatbestand}

Aufgrund der aufgezeigten Bedenken, die gegen eine alleinige Schrankengeneralklausel im europäischen Recht bestehen, ist mehrfach eine vermittelnde Lösung erwogen worden, bei der eine Generalklausel in einen Schrankenkatalog integriert beziehungsweise diesem als Auffangtatbestand angefügt würde. ${ }^{1859}$ Denkbar ist eine solche Flexibilisierung zum einen durch Änderung des Richtlinienrechts in Form der Ergänzung eines gegenüber der derzeitigen InfoSoc-Richtlinie deutlich gestrafften und verbindlich ausgestalteten - Schrankenkataloges um eine generalklauselartige „Auffangschranke“. Zum anderen könnte ein um einen generalklauselartigen Auffangtatbestand ergänzter Schrankenkatalog in eine europäische Urheberrechtsverordnung aufgenommen werden.

1858 Siehe Schack, ZGE 2009, 275 (287); Tilmann, GRUR 2011, 1096 ff.

1859 Siehe etwa Förster, Fair Use, S. $218 \mathrm{ff}$; Hansen, Warum Urheberrecht, S. $404 \mathrm{ff}$; Hilty, wiedergegeben von Geiger/Engelhardt/Hansen/Markowski, GRUR Int. 2006, 475 (493); ders., JIPITEC 2010, 83 (84); Leistner, Konsolidierung und Entwicklungsperspektive, S. 28 ff.; ders., IIC 2011, 417 (441 f.); Poeppel, Neuordnung, S. 503; Senftleben, JIPITEC 2010, 67 (76 ff.) sowie den Vorschlag der Wittem Group zu einer Auffanggeneralklausel im „European Copyright Code“" (dazu sogleich 7. Kapitel, A.II.1.). 
Die Einführung einer Auffanggeneralklausel auf der Ebene des Richtlinienrechts hätte den Vorteil, dass sie den nationalen Gesetzgebern neben den Vorgaben zur Umsetzung eines - idealerweise obligatorisch ausgestalteten - Schrankenkataloges auch ein begrenztes Feld zum „Experimentieren" mit neuartigen Schrankenregelungen belassen würde. ${ }^{1860}$ Diesem Vorteil stehen letztlich dieselben Bedenken gegenüber, die auch gegen die Einführung einer alleinigen Schrankengeneralklausel im Rahmen einer europäischen Richtlinie sprechen: ${ }^{1861}$ Würde die Umsetzung in Form der Aufnahme einer Generalklausel in das nationale Recht nicht zwingend vorgeschrieben und bliebe die konkrete Umsetzung der Richtlinienvorgaben den nationalen Gesetzgebern der Mitgliedstaaten überlassen, so hinge es maßgeblich vom Willen der mitgliedstaatlichen Gesetzgeber und der jeweils gewählten Form der Umsetzung ab, ob das Ziel gesteigerter Flexibilität tatsächlich erreicht würde. Durch unterschiedliche Formen nationaler Umsetzung drohte dann zudem eine wenig wünschenswerte weitere Disharmonisierung im europäischen Urheberrecht. Erfolgversprechend erscheint daher auch hier allenfalls eine Ausgestaltung auf Richtlinienebene, bei der den mitgliedstaatlichen Gesetzgebern die Umsetzung durch die Aufnahme einer Generalklausel in das nationale Recht zwingend vorgeschrieben würde. Eine solche Vorgabe für die Mitgliedstaaten könnte wie dargestellt ${ }^{1862}$ - etwa dem Vorbild der UGP-Richtlinie folgen und die Einführung einer Generalklausel in den Erwägungsgründen zur Richtlinie für verpflichtend erklären.

Umsetzungsprobleme würden vermieden, wenn neben einem Schrankenkatalog ein generalklauselartiger Auffangtatbestand in das europäische Urheberrecht im Wege einer Urheberrechtsverordnung eingeführt würde. Durch die Schaffung eines einheitlichen europäischen Urheberrechts wäre aufgrund der unmittelbaren Geltung sichergestellt, dass tatsächlich europaweit einheitliche Schrankenbestimmungen mit demselben Maß an Flexibilität Anwendung fänden.

1860 Siehe Hansen, Warum Urheberrecht, S. 406.

1861 Siehe dazu bereits oben 7. Kapitel, A.I.3.

1862 Siehe oben 7. Kapitel, A.I.1. 
1. Der Entwurf einer generalklauselartigen Öffnungsklausel in Anlehnung an den Dreistufentest im „European Copyright Code“

Den bisher bei Weitem detailliertesten Vorschlag eines um eine Generalklausel ergänzten Schrankenkataloges im europäischen Urheberrecht liefert der im Jahr 2010 als Ergebnis der Arbeit der sogenannten Wittem Group vorgestellte Entwurf eines European Copyright Code. ${ }^{1863}$ Im Rahmen des Wittem Project setzten sich Urheberrechtswissenschaftler aus verschiedenen europäischen Staaten ausgiebig mit Fragen der Schaffung eines zukunftsfähigen, vereinheitlichten europäischen Urheberrechts auseinander. ${ }^{1864}$ Ziel des Projektes war nicht die grundlegende Neuordnung des europäischen Urheberrechts, sondern im Wesentlichen, den Kern des derzeitigen europäischen Urheberrechts $\mathrm{zu}$ ermitteln und auf dieser Grundlage einen Ausgangspunkt für die weitere Diskussion um die Fortschreibung des Urheberrechts in Europa zu schaffen. ${ }^{1865}$ Auch wenn der Entwurf in Form eines „Code“ ausgestaltet ist, enthalten sich die Verfasser ausdrücklich einer Aussage darüber, ob und inwieweit sie einen einheitlichen europäischen Urheberrechtsrahmen für erstrebenswert halten. ${ }^{1866}$

\section{a) Ausgestaltung der Schranken im European Copyright Code-Entwurf}

Nach vier Abschnitten, die die schutzfähigen Werke, die Urheber- und Rechteinhaberschaft, das Urheberpersönlichkeitsrecht und die urheberrechtlichen Ausschließlichkeitsrechte betreffen, widmet sich der umfangreiche fünfte Abschnitt des European Copyright Code (ECC) den Schranken des Urheberrechts. In zum Teil enger Anlehnung an den derzeitigen

1863 Abrufbar unter: http://www.copyrightcode.eu/Wittem_European_copyright code_21 april 2010.pdf [zuletzt abgerufen am 26.5.2013].

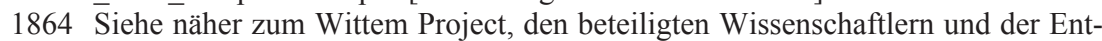
stehungsgeschichte des ECC Dreier, in: FS Loschelder, S. 47 (49 f.).

1865 Vgl. den vorletzten Erwägungsgrund zum ECC: „Believing that the design of a European Copyright Code might serve as an important reference tool for future legislatures at the European and national levels" sowie Absatz 2 der "Introduction" zum ECC. Vgl. auch Dreier, in: FS Loschelder, S. 47 (47, 51); Kuhlen, JIPITEC 2011, 18.

1866 Vgl. Absatz 2 der "Introduction” zum ECC, abrufbar unter: http://www.copyrightcode.eu/ [zuletzt abgerufen am 26.5.2013]; Dreier, in: FS Loschelder, S. 47 (60). 
Schrankenkatalog der InfoSoc-Richtlinie ist eine Reihe spezifischer - im Gegensatz zur InfoSoc-Richtlinie jedoch verbindlich ausgestalteter Schrankenregelungen vorgesehen. Diese sind unterteilt in Schranken zugunsten von Nutzungen mit minimaler wirtschaftlicher Bedeutung (Art. 5.1 ECC), ${ }^{1867}$ Nutzungen, die der Verwirklichung der Meinungsäußerungs- und Informationsfreiheit dienen (Art. 5.2 ECC), ${ }^{1868}$ Nutzungen, die der Förderung politischer, sozialer und kultureller Zwecke dienen (Art. 5.3 ECC), ${ }^{1869}$ sowie Nutzungen, die geeignet sind, den Wettbewerb zu fördern (Art. 5.4 ECC). ${ }^{1870}$ Die Regelungen der Artikel 5.1 bis 5.3 und des Artikel 5.4 Abs. 1 ECC entsprechen dabei weitgehend den bereits in der InfoSoc-Richtlinie vorzufindenden Schrankenbestimmungen. Bereits durch die gegenüber dem Schrankenkatalog der InfoSoc-Richtlinie vorgenommene Straffung und die teilweise vorsichtige Öffnung der Tatbestände durch offenere Formulierungen wird hier jedoch eine größere Flexiblität der urheberrechtlichen Schranken erreicht. ${ }^{1871}$

Echtes „Neuland“1872 im Bereich der urheberrechtlichen Schranken betritt der ECC-Entwurf hingegen mit der Regelung des Artikel 5.4 Abs. 2 ECC. ${ }^{1873}$ Zur Förderung beziehungsweise Öffnung des Wettbewerbs sieht die Regelung für bestimmte Fälle eine genehmigungsfreie - jedoch nicht kostenlose - Nutzung näher benannter Werkarten vor. Die Nutzung soll zulässig sein, wenn ein Wettbewerb dadurch unterbunden würde, dass der Rechteinhaber zu einer Rechteeinräumung zu angemessenen Konditionen nicht bereit ist, obwohl seine Interessen durch die Lizenzvergabe nicht unzumutbar beeinträchtigt würden. Letztlich handelt es sich somit um die Einräumung einer Zwangslizenz, für deren Beurteilung kartellrechtliche

1867 "Uses with minimal economic significance".

1868 "Uses for the purpose of freedom of expression and information".

1869 "Uses Permitted to Promote Social, Political and Cultural Objectives".

1870 "Uses for the purpose of enhancing competition".

1871 Vgl. Dreier, JIPITEC 2010, 50 (53).

1872 Kuhlen, JIPITEC 2011, 18.

1873 Art. 5.4 Abs. 2 ECC lautet: "Uses of news articles, scientific works, industrial designs, computer programs and databases are permitted without authorisation, but only against payment of a negotiated remuneration, and to the extent justified by the purpose of the use, provided that: (i) the use is indispensable to compete on a derivative market; (ii) the owner of the copyright in the work has refused to license the use on reasonable terms, leading to the elimination of competition in the relevant market and (iii) the use does not unreasonably prejudice the legitimate interests of the owner of the copyright in the work.". 
Kriterien in das Urheberrecht eingeführt werden. ${ }^{1874}$ Diese ausdrückliche Berücksichtigung wettbewerblicher Gesichtspunkte stellt freilich nur für das europäische Urheberrecht eine - begrüßenswerte - Neuheit dar. Im Rahmen des US-amerikanischen Fair Use finden vergleichbare Kriterien bereits regelmäßig Berücksichtigung.

Eine weitere Besonderheit des Artikel 5.4 Abs. 2 ECC ist, dass die in der Regelung vorgesehene Vergütung zwischen den Parteien frei ausgehandelt werden soll. ${ }^{1875} \mathrm{Ob}$ diese Gestaltung letztlich praktikabel wäre, erscheint zumindest zweifelhaft. Schließlich sieht die Regelung eine gesetzliche Lizenz gerade für solche Fälle vor, in denen sich die Parteien zunächst nicht auf eine Rechteeinräumung zu angemessenen Bedingungen haben einigen können. Weshalb sie daher im Rahmen der gesetzlichen Lizenz zu einer - vorher nicht möglichen - Einigung über eine „faire und angemessene"1876 Vergütung kommen sollen, erschließt sich nicht. Es kann insofern auch nicht Zweck der Regelung sein, den Nutzer gegenüber dem Rechteinhaber in eine bessere Verhandlungsposition zu versetzen, die es dem Nutzenden ermöglicht, regelmäßig eine besonders niedrige Lizenzgebühr zu erzielen. Dann bestünde für den Nutzenden nämlich stets ein Interesse, eine Einigung über die Lizenzeinräumung nicht vorab herbeizuführen, sondern sich in der Hoffnung auf günstigere Konditionen auf die Möglichkeit einer gesetzlichen Lizenzeinräumung nach Artikel 5.4 Abs. 2 ECC „zurückzuziehen“. Die Verhandlungsposition des Rechteinhabers in Lizenzverhandlungen würde so ohne hinreichenden Grund regelmäßig erheblich geschwächt.

Neben den in den Artikeln 5.1 bis 5.4 ECC ausdrücklich aufgezählten Schrankenregelungen soll zusätzliche Flexibilität schließlich dadurch erreicht werden, dass diesem Schrankenkatalog in Art. 5.5 ECC eine generalklauselartige Öffnungsklausel zur Seite gestellt wird. Die Regelung lautet:

Art. 5.5 - Further Limitations:

"Any other use that is comparable to the uses enumerated in art. 5.1 to 5.4(1) is permitted provided that the corresponding requirements of the relevant limitation are met and the use does not conflict with the normal exploitation of the work and does not unreasonably prejudice the legitimate interests of the

1874 Vgl. Dreier, in: FS Loschelder, S. 47 (58).

1875 Vgl. Fußnote 54 zum ECC.

1876 Art. 5.7 Abs. 1 ECC regelt ausdrücklich: "Any remuneration provided for under this chapter shall be fair and adequate.". 
author or rightholder, taking account of the legitimate interests of third parties."

Nach dieser „Analogie-Öffnungsklausel“ sollen folglich auch solche Nutzungen zulässig sein, die mit den in den Artikeln 5.1 bis 5.4 Abs. 1 ECC aufgezählten Nutzungsformen vergleichbar sind. ${ }^{1877}$ Dies allerdings nur dann, wenn die entsprechenden Voraussetzungen der vergleichbaren Schrankenregelung erfüllt sind. Weiter eingeschränkt wird der Anwendungsbereich schließlich in Anlehnung an den Dreistufentest durch die Voraussetzungen, dass die Nutzung die normale Auswertung des Werkes nicht beeinträchtigt und die berechtigten Interessen des Rechteinhabers nicht ungebührlich beeinträchtigt werden, wobei - wie es Artikel 30 TRIPS ebenfalls vorsieht ${ }^{1878}$ - ausdrücklich auch berechtigte Interessen Dritter Berücksichtigung finden sollen.

b) Kritische Bewertung der vorgeschlagenen Auffanggeneralklausel

Die Stärke dieser flexibilisierenden Auffangregelung ist zugleich eine ihrer wesentlichen Schwächen: Ob beziehungsweise wie viel Flexibilität tatsächlich erreicht wird, hängt nämlich entscheidend davon ab, wie weit der Begriff ,comparable“ verstanden wird - wann neue Nutzungsformen also für mit den ausdrücklich normierten Nutzungen vergleichbar gehalten werden. Leitlinien für die Ermittlung der Vergleichbarkeit liefert der ECC-Vorschlag jedoch nicht. Insoweit wird lediglich ausgeführt, dass eine Vergleichbarkeit sich nicht allein im Wege der Kumulierung unterschiedlicher Zwecke der in den Artikeln 5.1 bis 5.4 Abs. 1 ECC geregelten Schrankenbestimmungen ergeben darf. ${ }^{1879}$ Nähere Anhaltspunkte - oder besser: ein Katalog von Kriterien - zur Ermittlung der Vergleichbarkeit erscheinen jedoch notwendig, um neben der Möglichkeit größerer Flexibilität auch eine gewisse Vorhersehbarkeit und somit das erforderliche Mindestmaß an Rechtssicherheit zu erreichen. Andernfalls liefe gerade das re-

1877 Die bereits präzise umschriebene Schrankenregelung des Art. 5.4 Abs. 2 ECC zur Ermöglichung des Wettbewerbs ist vom Anwendungsbereich dieser „Analogie-Schranke“ bewusst ausgenommen; vgl. Dreier, in: FS Loschelder, S. 47 (58).

1878 Siehe dazu näher oben 6. Kapitel, C.III.2.c)bb).

1879 Siehe Fußnote 55 zum ECC: „See note 48. Note that art. 5.5 does not allow new limitations by blending the criteria of articles 5.1 to 5.3.". 
gelmäßig zur Begründung der - auch im ECC-Entwurf vorgesehenen detaillierten Festschreibung urheberrechtlicher Schranken angeführte (zweifelhafte) Argument gesteigerter Rechtssicherheit letztlich leer. Denn die Flexibilität im Bereich der Schranken wird gerade für die ,interessanten“ beziehungsweise ,kritischen“ Fälle benötigt, in denen über die urheberrechtliche Zulässigkeit neuer Nutzungsformen zu entscheiden ist, die sich nicht im Rahmen des bestehenden Schrankenkataloges erfassen lassen. Dann böte der Schrankenkatalog jedoch allenfalls insofern einen Anhaltspunkt, als feststünde, dass die fragliche Nutzung von keinem der festgeschriebenen Tatbestände erfasst wird. Rechteinhabern, Nutzern und somit auch der Rechtssicherheit ist jedoch nicht geholfen, wenn die Zulässigkeit der neuartigen Nutzung letztlich allein davon abhängt, ob ein mit der Sache befasstes Gericht diese für mit einem der gesetzlichen Schrankentatbestände vergleichbar hält - und für diese Beurteilung nicht einmal nachvollziehbare Kriterien festgeschrieben sind. ${ }^{1880}$ Durch die Verlagerung auf die Frage einer Analogiemöglichkeit ergäbe sich somit letztlich dasselbe Dilemma, das unter der Geltung des derzeitigen Schrankenkataloges besteht, der die Gerichte teilweise dazu zwingt, unter methodischen „Verbiegungen“ Tatbestände extrem weit auszulegen oder zweifelhafte Analogien zu ziehen, nur um eine wünschenswerte Nutzungsform zu ermöglichen. ${ }^{1881}$

Die im ECC-Entwurf in Anlehnung an den Dreistufentest ergänzend vorgesehene Berücksichtigung der berechtigten Interessen der Rechteinhaber und der Auswirkungen auf die normale Werkverwertung hilft insofern in zweierlei Hinsicht nicht weiter: Zum einen greift diese „SchrankenSchranke" nach dem ECC-Entwurf erst auf einer zweiten Stufe ein, wenn bereits festgestellt wurde, dass ein Sachverhalt einer der Regelungen der Artikel 5.1 bis 5.4 Abs. 1 ECC vergleichbar ist. ${ }^{1882}$ Zum anderen löst sie durch die (fast) wörtliche Übernahme des Dreistufentests der InfoSoc-

1880 Weshalb Dreier, in: FS Loschelder, S. 47 (58f.) es ausdrücklich für einen Vorteil hält, dass durch die gewählte Ausgestaltung des Art. 5.5 ECC ,ein Rückgriff auf die zumeist eher vagen Kriterien einer ,fair use'-Bestimmung vermieden“ wird, kann nicht nachvollzogen werden. Gerade ein Fair Use-ähnlicher Katalog mit vorhersehbaren - wenn auch evtl. vagen - Kriterien für die Rechtsprechung bietet die Möglichkeit, eine flexible Generalklausel mit der erforderlichen Rechtssicherheit auszugestalten.

1881 Siehe zu dieser Kritik am Beispiel der urheberrechtlichen Bewertung der Bildersuche im Internet bereits ausführlich oben 4. Kapitel, B.I.

1882 Siehe Art. 5.5 ECC: ,...provided that...". 
Richtlinie die existierenden Probleme der Definition und Auslegung der einzelnen Tatbestandsmerkmale des Dreistufentests ${ }^{1883}$ nicht und birgt so zumindest die Gefahr zusätzlicher Rechtsunsicherheit in sich.

Neben diesen dogmatischen Bedenken kann die im ECC-Entwurf vorgesehene Festschreibung eines "Vergleichbarkeits-Erfordernisses“ schließlich auch aus rechtspolitischer Sicht nicht vollständig überzeugen. Es erscheint keinesfalls ausgeschlossen, dass durch neue, unabsehbare technische Entwicklungen auch neue Formen der Werknutzungen entstehen, die tatsächlich nicht mit irgendwelchen derzeit bekannten - im ECCEntwurf festgeschriebenen - Nutzungsformen vergleichbar sind und die dennoch wünschenswert erscheinen und daher urheberrechtlich zulässig sein sollen. Durch die Normierung der Vergleichbarkeit als zwingender „Eintrittshürde“ für die Anwendung der Schrankengeneralklausel würde deren Zukunftsoffenheit somit unnötig beschnitten. Früher oder später wäre erneut ein Einschreiten des Gesetzgebers erforderlich.

\section{c) Fazit zum ECC-Entwurf}

Eines der wesentlichen Verdienste des European Copyright Code der Wittem-Gruppe ist es sicherlich, der Diskussion um die Modernisierung und weitergehende Harmonisierung des europäischen Urheberrechts durch die weite und „medienwirksame“ Vorstellung und Verbreitung des Entwurfes auf Fachveranstaltungen, in zahlreichen Fachpublikationen und im Internet neuen Schwung und eine detaillierte Diskussionsgrundlage verliehen zu haben. Gerade im Bereich der Schranken überzeugt der Vorschlag jedoch letztlich nicht vollständig. Die erforderliche Flexibilität im Bereich der urheberrechtlichen Schranken könnte im Rahmen des ECC-Vorschlages zwar erreicht werden. Jedenfalls bis zu einer (europäischen) höchstrichterlichen Konkretisierung des Tatbestandsmerkmals der „Vergleichbarkeit" im Sinne des Artikels 5.5 ECC würde diese Flexibilität jedoch auf

1883 Siehe zu den Streitfragen im Zusammenhang mit der Auslegung des Dreistufentests, insbesondere zur Frage, wann eine „,normale Auswertung“ vorliegt, ausführlich oben 6. Kapitel, C.III.2. 
Kosten erheblicher Rechtsunsicherheit erkauft. ${ }^{1884}$ Diese Rechtsunsicherheit könnte durch die Ergänzung der Regelung um einen - beispielsweise an den Fair Use-Tatbestand angelehnten - Katalog von Prüfungskriterien deutlich abgemildert werden. Insofern wäre insbesondere auch eine Kombination des urheberrechtlichen Dreistufentests mit einem Kriterienkatalog denkbar.

\section{Auffangtatbestand nach dem Vorbild des Dreistufentests und des Fair} Use

Die vorstehenden Überlegungen haben gezeigt, dass die ergänzende Einfügung einer Schrankengeneralklausel als Auffangtatbestand im europäischen Recht - bevorzugt im Rahmen einer Urheberrechtsverordnung grundsätzlich erstrebenswert erscheint, da diese Regelungsvariante weitreichende Flexibilität im Bereich der urheberrechtlichen Schranken ermöglichen würde und zugleich die wesentlichen Nachteile einer alleinigen Schrankengeneralklausel im europäischen Recht vermeiden könnte.

Hinreichende Rechtssicherheit kann jedoch auch eine als Auffangtatbestand ausgestaltete Generalklausel nur erzeugen, wenn die Anwendung der Schrankenbestimmung durch gewisse Leitlinien für die Prüfung nachvollziehbar und somit zugleich vorhersehbar ausgestaltet ist. ${ }^{1885}$ Als Vorbild einer solchen ,gelenkten“ Generalklausel bietet sich die US-amerikanische Fair Use-Schranke an, die - wie gezeigt - eine sehr flexible Anwendung ermöglicht und zugleich aufgrund eines Kataloges ausdrücklich aufgezählter Prüfungskriterien deutlich größere Vorhersehbarkeit gewährleistet. Dass auch solche Tatbestandsmerkmale letztlich einer Auslegung durch die Rechtsprechung bedürfen, sollte dabei nicht als Argument gegen eine derartige Regelung dienen. Als auslegungsbedürftig erweist sich schließlich letztlich jede (neue) gesetzliche Regelung - unabhängig davon, ob sie sehr detailliert oder wenig detailreich ausgestaltet ist. Bis zu einer umfassenden höchstrichterlichen Klärung der einzelnen Tatbestandsmerk-

1884 Zur Problematik der durch das System der Vorabentscheidungsverfahren durch den EuGH nach Art. 267 AEUV nur langsamen und ggfs. unvollständigen höchstrichterlichen Klärung von Auslegungsfragen, siehe bereits oben 7. Kapitel, A.I.3.

1885 Vgl. zu der Kritik an dieser Schwäche des European Copyright Code-Entwurfes der Wittem-Gruppe oben 7. Kapitel, A.II.1.b). 
male - wie dies heute hinsichtlich der Fair Use-Klausel in den USA weitgehend der Fall ist - ermöglicht jedoch ein Katalog von Prüfungskriterien jedenfalls eine gewisse Orientierung für Rechteinhaber und Nutzer ebenso wie für die Rechtsprechung. Dies belegen auch Erkenntnisse aus der USamerikanischen Forschung, die die Anwendung der Fair Use-Schranke selbst in Fällen der Konfrontation mit neuen Technologien und Nutzungsformen aufgrund des Kriterienkataloges für weitestgehend vorhersehbar halten, so dass nur sehr selten überraschende Entscheidungen der Gerichte ergehen. ${ }^{1886}$ Das „Standardargument" mangelnder Rechtssicherheit von Generalklauseln ${ }^{1887}$ lässt sich durch eine solche Ausgestaltung somit bereits im Ansatz deutlich entkräften.

Bei der Einführung eines generalklauselartigen Auffangtatbestandes nach dem Vorbild der Fair Use-Schranke in einer europäischen Urheberrechtsverordnung sollte jedoch eine Besonderheit Beachtung finden: Der europäische Gesetzgeber hat sich dafür entschieden, den urheberrechtlichen Dreistufentest ausdrücklich im europäischen Recht zu verankern. Durch die Aufnahme in die InfoSoc-Richtlinie wurde nicht nur die Umsetzung international-rechtlicher Verpflichtungen garantiert und offenkundig gemacht, sondern der Dreistufentest auch zu einem durch den EuGH überprüfbaren Bestandteil des urheberrechtlichen acquis communautaire aufgewertet. ${ }^{1888}$ Diese Grundsatzentscheidung des europäischen Gesetzgebers für die Aufnahme des Dreistufentests ist sinnvoll und sollte respektiert werden. Eine Auffanggeneralklausel in Anlehnung an den Fair Use muss ihr daher gerecht werden.

Zugleich erscheint es jedoch nicht zweckmäßig, parallel sowohl den generalklauselartigen Dreistufentest als auch eine Fair Use-Generalklausel in eine europäische Urheberrechtsverordnung aufzunehmen. Eine sinnvolle Lösung könnte hier anstelle eines „Entweder-Oder“ ein Mittelweg bieten - die Schaffung einer neuartigen Schrankengeneralklausel, die beide Regelungen „verschmelzen“ lässt und so das „Beste beider Welten“

1886 Siehe Beebe, U. Pa. L. Rev. 549, 621 f (2008); Sag, 73 Ohio St. L.J. 47, 72 ff. (2012); siehe dazu auch bereits oben Fn. 1218 und zugehöriger Text.

1887 Siehe dazu bereits oben S. 279 ff. sowie die Nachweise oben Fn. 1213.

1888 Vgl. dazu bereits oben 6. Kapitel, C.II. 
vereint. ${ }^{1889}$ So könnte der - in der hier befürworteten Auslegung ohnehin deutlich an eine faktorbasierte Fair Use-Prüfung angenäherte ${ }^{1890}$ - Dreistufentest seinen „Siegeszug“1891 fortsetzen und zugleich - ergänzt um nachvollziehbare Prüfungskriterien - zu einer handhabbaren und zudem hinreichende Rechtssicherheit vermittelnden generalklauselartigen Auffangschranke ausgebaut werden.

\section{a) Formulierungsvorschlag}

Eine solche - einen Katalog urheberrechtlicher Schrankenregelungen ergänzende - Auffanggeneralklausel in Anlehnung an den Dreistufentest und die Fair Use-Doktrin könnte beispielsweise wie folgt lauten:

Kapitel x: Beschränkungen der Ausschließlichkeitsrechte Artikel y: Weitere Beschränkungen der Ausschließlichkeitsrechte

(1) Die Nutzung eines veröffentlichten urheberrechtlich geschützten Werkes, die nicht dem Anwendungsbereich einer der speziellen Schrankenbestimmungen dieses Kapitels unterfällt, ist ohne $\mathrm{Zu}-$ stimmung des Rechteinhabers zulässig, wenn sie die normale Verwertung des Werkes nicht ungebührlich beeinträchtigt und die berechtigten Interessen des Rechteinhabers nicht ungebührlich verletzt.

(2) Bei der Beurteilung, ob die Nutzung die normale Verwertung des Werkes ungebührlich beeinträchtigt, sind insbesondere die Auswirkungen der Nutzung auf den aktuellen und potentiellen Verwertungsmarkt, auf den Wert des urheberrechtlich geschützten Werkes und berechtigte Interessen Dritter zu berücksichtigen.

(3) ${ }^{1}$ Bei der Beurteilung, ob die Nutzung berechtigte Interessen des Rechteinhabers ungebührlich verletzt, sind auch die berechtigten Interessen Dritter zu berücksichtigen. ${ }^{2}$ Bei der Abwägung der Be-

1889 Ähnlich im Ansatz, jedoch jeweils ohne nähere Darstellung und konkrete Formulierungsvorschläge, Gervais, 9 Marq. Intell. Prop. L. Rev. 1, 28 ff. (2005); Griffiths, JIPITEC 2010, 87 (93); Senftleben, AMI 2009, 1 (7); ders., 57 J. Copyright Soc'y U.S.A. 521, 541 ff. (2010).

1890 Vgl. oben 6. Kapitel, C.III.3.

1891 Senftleben, in: Hilty/Peukert, Interessenausgleich, S. 159 (171). 
einträchtigung der beteiligten Interessen sind insbesondere folgende Kriterien zu berücksichtigen:

1. der Zweck und der Charakter der Nutzung einschließlich der Frage, ob die Nutzung kommerzieller Natur ist; eine Nutzung kann insbesondere dann zulässig sein, wenn sie zum Zwecke des kritischen Kommentars, der Berichterstattung über aktuelle Ereignisse von öffentlichem Interesse, der Veranschaulichung des Unterrichts, der Lehre, der Forschung, der Zugänglichmachung für Menschen mit Behinderungen, der Förderung des Wettbewerbs, insbesondere auf Sekundärmärkten, oder der kreativen Weiterverwendung im Rahmen eigener Werkschöpfung erfolgt;

2. die Art des urheberrechtlich geschützten Werkes;

3. der Umfang und die Bedeutung des verwendeten Werkteils im Verhältnis zum urheberrechtlich geschützten Werk als Ganzem;

4. die Möglichkeit einer Kompensation durch die Zahlung eines gerechten Ausgleichs.

(4) ${ }^{1}$ Für eine nach Absatz 1 zulässige Nutzung ist dem Urheber ein gerechter Ausgleich zu leisten. ${ }^{2}$ Auf seinen Anspruch auf einen gerechten Ausgleich kann der Urheber nicht verzichten. ${ }^{3}$ Der Anspruch kann nur durch eine Verwertungsgesellschaft geltend gemacht werden. ${ }^{4}$ Die Pflicht zur Zahlung eines gerechten Ausgleichs kann entfallen, wenn ein gesteigertes öffentliches Interesse nicht nur am freien Zugang, sondern auch an der Unentgeltlichkeit der Nutzung besteht.

b) Erläuterung des Formulierungsvorschlags

Die vorgeschlagene Regelung gestaltet den urheberrechtlichen Dreistufentest in eine generalklauselartige Auffangschranke um. Die Funktion und Zielrichtung des Dreistufentests im europäischen Recht würde sich somit maßgeblich ändern. Aus der derzeitigen Schranken-Schranke der enumerierten Schrankentatbestände würde durch die vorgeschlagene Ausgestaltung eine flexible, eigenständige (Auffang-)Schrankengeneralklausel, die nicht lediglich der Kontrolle und Begrenzung bestehender Schrankenbestimmungen diente, sondern gerade eine erweiterte Rechtfertigungsmöglichkeit in Bezug auf neue, vom Schrankenkatalog nicht erfasste Formen 
der Werknutzung bezweckt. ${ }^{1892}$ Was für das europäische Recht eine Neuerung darstellt, wäre freilich im Hinblick auf die Geschichte des Dreistufentests eher eine Rückbesinnung auf dessen ursprüngliche Funktion. Bei der Revisionskonferenz in Stockholm 1967 konnte der Dreistufentest seinen „Siegeszug“ gerade deshalb antreten, weil er von den Beteiligten als flexibler Rahmen angesehen wurde, der den nationalen Gesetzgebern ausreichende Freiräume bei der Ausgestaltung urheberrechtlicher Schrankenregelung unter Berücksichtigung nationaler Besonderheiten und sozialer, kultureller und ökonomischer Bedürfnisse gewährte. ${ }^{1893}$ Der Dreistufentest sollte somit zugleich als Grundlage und Grenze der Ausgestaltung, Einführung und Auslegung urheberrechtlicher Schranken dienen. ${ }^{1894}$ Auf diese ursprüngliche Funktion, auch neue Formen der Werknutzung zu ermöglichen, ${ }^{1895}$ würde der Dreistufentest durch die vorgeschlagene Ausgestaltung als Auffanggeneralklausel zurückgeführt beziehungsweise erweitert.

Im hiesigen Vorschlag wird dabei in Absatz 1 nur die zweite und dritte Stufe des Dreistufentests übernommen. Dies trägt der Tatsache Rechnung, dass der ersten Teststufe - nach hier vertretener Ansicht - im europäischen Recht bereits heute keine wesentliche Bedeutung zukommt. ${ }^{1896}$ Die in Bezug auf das Richtlinienrecht verbleibende Funktion als Richtschnur für die nationalen Gesetzgeber bei der konventionskonformen Umsetzung der Richtlinienvorgaben in nationales Recht entfiele bei der hier vorgesehenen Positionierung der Schrankenregelung in einer unmittelbar geltenden Urheberrechtsverordnung ebenfalls. Die Verkürzung des Dreistufentests auf einen Zweistufentest hat folglich keine Auswirkung auf dessen Anwendung. Ihr kommt vielmehr nur eine bereinigende beziehungsweise klarstellende Funktion zu.

Der Vorschlag modifiziert zudem die zweite Stufe des Dreistufentests geringfügig, indem er darauf abstellt, ob die normale Verwertung des Werkes ungebührlich beeinträchtigt wird. Diese Formulierung trägt zum einen dem Bedürfnis der Rechteinhaber Rechnung, vor solchen Nutzungen

1892 Ähnlich Senftleben, 57 J. Copyright Soc'y U.S.A. 521, 543 (2010).

1893 Siehe WIPO, Records of the IP Conference at Stockholm, S.81; Ricketson, Berne Convention, S. $484 \mathrm{f}$.

1894 Vgl. oben 6. Kapitel, C.I. und 6. Kapitel, C.III.3.

1895 Näher zu dieser ,enabling function“ des konventionsrechtlichen Dreistufentests, siehe Senftleben, 57 J. Copyright Soc'y U.S.A. 521, 544 ff. (2010).

1896 Vgl. oben 6. Kapitel, C.III.2.a)aa). 
geschützt zu werden, die erhebliche negative Auswirkungen auf die eigene Werkverwertung haben. Zum anderen verdeutlicht sie, dass sich diese Teststufe nicht in einer rein empirisch auswertungsbezogenen Sicht auf die Auswirkungen der Werknutzung auf bestehende und potentielle Märkte erschöpfen kann, sondern auch bereits auf dieser Stufe notwendig in gewissem Umfang eine wertende Entscheidung über die Marktzuordnung getroffen werden muss. So berücksichtigt die Regelung - unter Betonung der berechtigten Interessen Dritter in den Absätzen 2 und 3 - auch, dass nicht jede Beeinträchtigung der ökonomischen Interessen des Rechteinhabers automatisch zur Unzulässigkeit einer Werknutzung führen darf. Andernfalls drohte aufgrund der fortschreitenden technischen Entwicklung und der damit verbundenen stetigen - zumindest potentiellen - ErschlieBung zusätzlicher Märkte auf längere Sicht die dritte Stufe des Dreistufentests (hier: zweite Teststufe des Absatzes 1) als Beschränkung funktionslos zu werden. ${ }^{1897}$ Ein solches Ergebnis ließe aber die Tatsache außer Betracht, dass zahlreiche Formen der Werknutzung denkbar sind, die zwar die ökonomischen Interessen des Rechteinhabers tangieren, jedoch durch die Zahlung einer angemessenen Vergütung ebenso gut oder gar besser kompensiert werden können als durch ein Verbotsrecht. ${ }^{1898}$

Absatz 1 stellt zudem klar, dass der Anwendungsbereich der Auffangschranke stark begrenzt ist. Zum einen ist er zur Berücksichtigung grundlegender urheberpersönlichkeitsrechtlicher Interessen auf die Nutzung veröffentlichter Werke beschränkt, zum anderen kommt ein Eingreifen nur dann in Betracht, wenn keine der Schrankenregelungen des in der (fiktiven) Urheberrechtsverordnung enthaltenen Schrankenkataloges einschlägig ist. Die Regelung kann und soll somit gerade nicht als Auffangtatbestand in dem Sinne dienen, dass sämtliche Nutzungen, die zwar in den Anwendungsbereich einer konkreten Schrankenregelung fallen, nach dieser jedoch nicht zulässig sind, einer ergänzenden Einzelfallprüfung anhand des Kriterienkataloges unterzogen werden. Die im Schrankenkatalog aufgeführten Schranken gingen der Auffangschranke vielmehr als leges speciales zwingend vor - ein Rückgriff auf die Auffangklausel wäre somit gesperrt, sobald der Anwendungsbereich einer anderen Schrankenregelung

1897 Siehe zu dieser Kritik an der Auslegung der zweiten Teststufe des Dreistufentests oben 6. Kapitel, C.III.2.b).

1898 Vgl. oben 6. Kapitel, C.III.2.b). 
einmal eröffnet wäre. ${ }^{1899}$ Es würde daher nicht an der Grundentscheidung des Gesetzgebers gerüttelt, bestimmte Nutzungsformen zu privilegieren und für diese Privilegierungen konkrete Bedingungen vorzuschreiben. $\mathrm{Zu}-$ gleich könnten ohne erneutes Tätigwerden des Gesetzgebers solche Formen der Werknutzung ermöglicht werden, die im Schrankenkatalog (noch) keine Berücksichtigung gefunden haben, insbesondere weil sie zur Zeit der Gesetzgebung noch nicht bekannt waren oder berücksichtigenswert erschienen.

Die Absätze 2 und 3 des Entwurfes konkretisieren die Vorgaben des in Absatz 1 enthaltenen ,Zweistufentests“ mit Hilfe eines an die Fair UseDoktrin angelehnten Kataloges von Prüfungskriterien.

Absatz 2 lässt den vierten Fair Use-Faktor in die Regelung einfließen. Die Bestimmung stellt klar, dass bei der Beurteilung, ob eine Nutzung die normale Verwertung des Werkes beeinträchtigt, insbesondere die Auswirkungen der Nutzung auf den aktuellen und potentiellen Verwertungsmarkt und auf den Wert des urheberrechtlich geschützten Werkes zu berücksichtigen sind. Die Formulierung ,,insbesondere“ verdeutlicht dabei, dass die genannten Kriterien keinesfalls abschließend sind, sondern auch weitere Auswirkungen auf die normale Nutzung des Werkes Beachtung finden können. Durch die offene Formulierung, die allein auf „Auswirkungen“ abstellt und nicht etwa auf „Nachteile“ oder einen „Schaden“, und durch die ausdrückliche Erwähnung der berechtigten Interessen Dritter ist zudem die - auch im Rahmen der Fair Use-Prüfung anerkannte ${ }^{1900}$ - Möglichkeit eröffnet, auch positive Effekte auf den Markt zu berücksichtigen und gegebenenfalls als Indiz zugunsten der Zulässigkeit einer Nutzung zu werten.

Absatz 3 des Entwurfes stellt zum einen in Anlehnung an Artikel 30 TRIPS klar, dass auch die berechtigten Interessen Dritter zu berücksichtigen sind, zum anderen, dass eine Abwägung der beteiligten Interessen vorzunehmen ist. Zur Erleichterung und Strukturierung der Prüfung werden in Anlehnung an die Faktoren eins bis drei der Fair Use-Prüfung (nicht abschließende) Kriterien für die Beurteilung der Interessenbeein-

1899 So generell in Bezug auf Auffangklauseln bzw. in Bezug auf anders ausgestaltete Auffangschranken auch Hansen, Warum Urheberrecht, S. 410; Poeppel, Neuordnung, S. 503; Schack, in: FS Schricker II, S. 511 (513); wohl auch Förster, Fair Use, S. $221 \mathrm{f}$.

1900 Vgl. Leval, 103 Harv. L. Rev. 1105, 1124 (Fn. 85) (1990); ders., 44 UCLA L. Rev. 1449, 1459 (1997); Patry, Fair Use (2009), § 6:11 sowie oben 2. Kapitel, C.I.2.c). 
trächtigung aufgestellt. Die Nummern 1 bis 3 entsprechen insoweit dem zuvor dargestellten Entwurf einer alleinigen Schrankengeneralklausel. ${ }^{1901}$ Der Verwirklichung vieler der in Absatz 3 Satz 2 Nr. 1 genannten Nutzungszwecke dienen bereits konkrete Schrankentatbestände des Schrankenkataloges. Sie sind hier dennoch aufgeführt, da durchaus neue, heute noch nicht bekannte Formen der Werknutzung vorstellbar sind, die keiner Schrankenregelung unterfallen und dennoch einem der genannten Nutzungszwecke dienen. Zudem verdeutlicht die Aufzählung, welche Zwecke der Werknutzung generell privilegierungswürdig erscheinen. Ergänzend zu den aus der Fair Use-Prüfung bekannten Kriterien stellt Absatz 3 Satz 2 Nr. 4 ausdrücklich klar, dass insbesondere die Zahlung eines gerechten Ausgleichs geeignet sein kann, eine ungebührliche Beeinträchtigung auf ein „gebührliches“, das heißt hinnehmbares, Maß zu reduzieren. Dies ist für den Dreistufentest allgemein anerkannt, auch wenn es sich dem Wortlaut der dritten Stufe nicht unmittelbar entnehmen lässt. ${ }^{1902}$

Absatz 4 ergänzt die Vorschrift schließlich um eine Rechtsfolgenregelung, ${ }^{1903}$ die klarstellt, dass der Rechteinhaber die Nutzung seines Werkes im Regelfall nur gegen Zahlung eines gerechten (Geld-)Ausgleichs hinnehmen muss. Besteht jedoch ausnahmsweise ein so erhebliches öffentliches Interesse an der kostenfreien Nutzung, dass dieses das Vergütungsinteresse des Rechteinhabers überwiegt, so kann die Vergütungspflicht im Einzelfall vollständig entfallen.

\section{c) Opportunität der vorgeschlagenen Schrankenbestimmung}

Die dargestellte Ausgestaltung einer Auffanggeneralklausel nach dem Vorbild des urheberrechtlichen Dreistufentests und die Ergänzung um an die US-amerikanische Fair Use-Schranke angelehnte Kriterien, vermag gleich mehrere Vorteile zu vereinen: Durch die Anlehnung an den bereits im europäischen Recht enthaltenen Dreistufentest erscheint die Schrankenbestimmung nicht als Fremdkörper. Sie bietet zugleich hinreichende Flexibilität, um einer neuen Nutzungsrealität gerecht zu werden und die

1901 Siehe zur Erläuterung des insoweit gleichlautenden Entwurfs oben 7. Kapitel, A.I.1.

1902 Siehe oben 6. Kapitel, C.III.2.c)cc).

1903 Siehe zur näheren Erläuterung oben 7. Kapitel, A.I.1. zum insoweit gleichlautenden Absatz 3 des Entwurfes einer alleinigen Schrankengeneralklausel. 
urheberrechtliche Zulässigkeit neuartiger Formen der Werknutzung zu beurteilen. Die Prüfung solcher Sachverhalte erfolgt jedoch nicht „freischwebend", sondern anhand nachvollziehbarer Kriterien, die das erforderliche Maß an Vorhersehbarkeit und somit Rechtssicherheit gewährleisten. Durch die allmähliche richterrechtliche Ausdifferenzierung der einzelnen Prüfungskriterien lässt sich diese Rechtssicherheit durch die Bildung von Fallgruppen weiter ausbauen. Derart durch die Rechtsprechung etablierte Fallgruppen könnten zudem durch den Gesetzgeber zur Steigerung der „Nutzerfreundlichkeit“ und Rechtssicherheit durch die Aufnahme in den Schrankenkatalog gesetzlich festgeschrieben werden. 1904

Anders als bei der vollständigen Ersetzung des Schrankenkataloges durch eine einzige Schrankengeneralklausel, werden jedoch bekannte Formen der Werknutzung, für deren Zulässigkeit bereits Kriterien in einer Schrankenbestimmung explizit ausdifferenziert sind, nicht der Unsicherheit einer Einzelfallprüfung anhand einer alleinigen Generalklausel preisgegeben. So kann nicht nur Unsicherheit hinsichtlich etablierter Nutzungsformen vermieden werden, sondern gar die Rechtssicherheit erhöht werden. Durch die Reduzierung der Anwendung der einzelnen Schrankentatbestände auf die vom Gesetzgeber tatsächlich vorgesehenen Sachverhalte und die Ergänzung des Schrankenkataloges um eine Auffanggeneralklausel werden methodische „Verbiegungen“ und richterliche „Kunstgriffe“, wie sie derzeit im Umgang mit neuen Nutzungsformen zu beobachten sind, überflüssig. So kann der Katalog von Schrankenbestimmungen seine eigentliche Stärke zurückgewinnen - es wird für den Rechtsanwender wieder besser zu erkennen, welche Nutzungshandlungen unter welchen Voraussetzungen im Rahmen der Schrankenregelungen zulässig sind. Zugleich würde die Frage, ob für die Nutzung eine Vergütung zu zahlen ist anders als bei einer alleinigen Generalklausel -, nicht in jedem Einzelfall zum Gegenstand der Prüfung, da es für die festgeschriebenen Schrankentatbestände bei einer gesetzlichen Bestimmung der Vergütungspflicht bliebe. Bei Nutzungshandlungen, die keiner Schrankenbestimmung unterfallen, ist es hingegen nicht mehr erforderlich, „krampfhaft“ zu überlegen, von welchem Schrankentatbestand diese sich möglicherweise im Wege der erweiternden Auslegung oder Analogie erfassen ließen. Vielmehr ist für den Rechtsanwender ersichtlich, dass sich diese Nutzungen allein am

1904 Ähnlich Metzger, in: Europäische Perspektiven des Geistigen Eigentums, S. 101 (121 f.). 
Maßstab der Schrankengeneralklausel messen lassen müssen, deren grundlegende Kriterien sich ebenfalls aus dem Gesetz ergeben, so dass in aller Regel jedenfalls eine Abschätzung der Zulässigkeit möglich sein wird.

Es handelt sich somit bei der vorgeschlagenen Regelung nicht um eine umfassende „Megaschranke“, 1905 sondern vielmehr um eine vorsichtige und zugleich zukunftsoffene Flexibilisierung der Schrankenbestimmungen, die durch die Verbindung eines Schrankenkataloges mit einem Auffangtatbestand auf Grundlage des Dreistufentests mit Fair Use-Kriterien ein - in Anbetracht der notwendigen Offenheit - größtmögliches Maß an Vorhersehbarkeit und Rechtssicherheit gewährleistet. Gerade in dem Nebeneinander eines Schrankenkataloges und der nur subsidiär anwendbaren Schrankengeneralklausel liegt dabei die Stärke dieser Rechtsetzungsvariante, da das „Wechselspiel“ zwischen Einzeltatbeständen und Schrankengeneralklausel die „Nutzerfreundlichkeit“, Vorhersehbarkeit und Rechtssicherheit der urheberrechtlichen Schranken steigert.

Die explizit im Gesetz aufgeführten Schrankentatbestände werden gewissermaßen „entschlackt“, da ihr Anwendungsbereich auf das vom Gesetzgeber vorgesehene Maß reduziert wird. Finden die Schrankenbestimmungen nur auf vom Wortlaut (offensichtlich) erfasste Nutzungshandlungen Anwendung, so vermögen diese Regelungen tatsächlich die Vorhersehbarkeit und Rechtssicherheit zu gewährleisten, die regelmäßig als wesentlicher Vorteil eines enumerativen Schrankenkataloges angeführt werden.

Die gegebenenfalls durch die Schrankengeneralklausel erzeugte Unsicherheit wird durch die Ergänzung um einen Kriterienkatalog und die nur nachrangige Anwendung hingegen erheblich reduziert. Die Generalklausel findet schließlich gerade nur in solchen Fällen Anwendung, in denen sich die fragliche Nutzung nicht von einer konkreten Schrankenregelung erfassen lässt. Gäbe es keine Auffanggeneralklausel, so bewegte man sich bei diesen Nutzungen folglich ohnehin stets in dem Bereich, in dem sich eine Rechtfertigung allenfalls im Wege der erweiternden Auslegung oder Analogie oder unter Rückgriff auf ,urheberrechtsexterne“ Lösungen begründen ließe. Dass derartige Entscheidungen jedoch von weitgehender Unvorhersehbarkeit und dadurch begründeter erheblicher Rechtsunsicherheit geprägt sind, hat die Untersuchung der Thumbnail-Nutzung und der Google

1905 Hoeren, MMR 2000, 3 (5); ders., in: FS Sandrock, S. 357 (370 f.). 
Buchsuche gezeigt. Diese Probleme entschärft die Auffanggeneralklausel erheblich, denn gerade für die nicht vom Schrankenkatalog erfassten Konstellationen gibt sie der Prüfung durch einen Kriterienkatalog zusätzliche Leitlinien und erhöht somit die Vorhersehbarkeit für Rechteinhaber und Nutzer gleichermaßen.

Die Stärke des Auffangtatbestandes liegt folglich in einem Doppelten: Gerade für die Fälle, in denen die Zulässigkeit einer neuen, zuvor unbekannten Form der Werknutzung in Frage steht, schafft sie die Flexibilität, die die starren - in diesen Fällen unanwendbaren - Einzeltatbestände nicht bieten können. Durch die klaren Prüfungskriterien in Anlehnung an die Fair Use-Schranke ist die Prüfung dabei selbst bei völlig neuen Nutzungsformen klar strukturiert und somit nachvollziehbar. Nicht die oftmals propagierte Rechtsunsicherheit, sondern ein Mehr an Rechtssicherheit ist deshalb bei richtiger Ausgestaltung die Folge der Einführung einer Schrankengeneralklausel als Auffangtatbestand.

\section{Zusammenfassung und Bewertung}

Gegen die Einführung einer alleinigen Schrankengeneralklausel im europäischen Recht bestehen - wie gezeigt - sowohl im Rahmen des Richtlinienrechts als auch in einer europäischen Urheberrechtsverordnung erhebliche Bedenken. Diese Maßnahmen könnten zwar erhebliche Flexibilität im Bereich der urheberrechtlichen Schranken erzeugen, sie ginge jedoch zu Lasten der Rechtssicherheit und im Falle der Änderung des Richtlinienrechts zusätzlich zu Lasten einer weiteren Disharmonisierung des europäischen Urheberrechts. Die dargestellten Formen der Flexibilisierung erscheinen somit nicht wünschenswert.

Erstrebenswert erscheint hingegen eine Änderung des europäischen Rechts, in deren Rahmen einem Katalog urheberrechtlicher Schranken ergänzend eine Generalklausel als Auffangtatbestand zur Seite gestellt wird. Um ein möglichst großes Maß an Rechtssicherheit zu gewährleisten, sollte eine solche Auffanggeneralklausel jedoch nicht eine völlig ,freischwebende“ Abwägung erfordern, sondern - etwa dem Vorbild des US-amerikanischen Fair Use folgend - anhand nachvollziehbarer Prüfungskriterien eine gewisse Vorhersehbarkeit ermöglichen. Zugleich erscheint es wenig wünschenswert, eine solche Generalklausel neben dem urheberrechtlichen Dreistufentest einzuführen. Die gesetzgeberische Entscheidung für die ausdrückliche Aufnahme des Dreistufentests in das europäische Urheber- 
recht sollte zugleich respektiert werden. Es bietet sich daher - wie dargestellt - eine Lösung an, die das „Beste beider Welten“ vereint: Eine Auffanggeneralklausel nach dem Vorbild des (auf zwei Stufen reduzierten) Dreistufentests, die um Fair Use-artige Prüfungskriterien ergänzt ist.

Denkbar ist auch eine solche Flexibilisierung sowohl durch Änderung des Richtlinienrechts als auch im Rahmen einer europäischen Urheberrechtsverordnung. Überzeugend erscheint sie letztlich jedoch nur innerhalb einer Urheberrechtsverordnung. Durch die Schaffung eines gemäß Artikel 288 Abs. 2 AEUV unmittelbar in sämtlichen Mitgliedstaaten geltenden, einheitlichen europäischen Urheberrechts wäre in Bezug auf die Urheberrechtsschranken sichergestellt, dass tatsächlich europaweit ein einheitlicher „Schranken-Standard“ mit demselben Maß an Flexibilität gelten würde. Im Falle einer entsprechenden Änderung des Richtlinienrechts bliebe die konkrete Umsetzung der Richtlinienvorgaben hingegen den nationalen Gesetzgebern der Mitgliedstaaten überlassen, so dass durch unterschiedliche Formen der nationalen Umsetzung eine weitere Disharmonisierung im europäischen Urheberrecht drohte.

Auch wenn eine Flexibilisierung der urheberrechtlichen Schranken auf europäischer Ebene nicht nur denkbar, sondern - bei richtiger Ausgestaltung - auch erstrebenswert erscheint, ist stets zu bedenken, dass alle vorgenannten Regelungsoptionen eine ganz erhebliche Schwäche teilen: Ihre Umsetzung setzt die Änderung europäischen Richtlinienrechts beziehungsweise eine grundlegende Neuorientierung und -ordnung des europäischen Urheberrechts voraus. Weder das Eine noch das Andere erscheint derzeit realistisch.

Im Bereich des Richtlinienrechts sind in näherer Zukunft allenfalls geringfügige Veränderungen zu erwarten, wie sie sich insbesondere aus der teilweisen „Überlagerung“ der InfoSoc-Richtlinie durch neue bereichsspezifische Regelungen, etwa zur Lösung des Orphan Works-Problems ergeben könnten. ${ }^{1906}$ Eine Neufassung der InfoSoc-Richtlinie selbst erscheint derzeit hingegen äußerst unwahrscheinlich. ${ }^{1907} \mathrm{Bis}$ zu einer - wünschenswerten und zugleich auf längere Sicht zur Erreichung eines funktionierenden Binnenmarktes unumgänglichen - echten Harmonisierung des Urheberrechts durch eine europäische Urheberrechtsverordnung, für die nun mit Art. 118 Abs. 1 AEUV auch eine ausdrückliche Ermächtigungsgrund-

1906 Siehe Hilty, JIPITEC 2010, 83 (85); Leistner, IIC 2011, 417 (440).

1907 So auch Griffiths, JIPITEC 2010, 87 (89); Hilty, JIPITEC 2010, 83 (85). 
lage besteht, dürften selbst bei einem entsprechenden politischen Willen ebenfalls noch etliche Jahre oder Jahrzehnte vergehen. ${ }^{1908}$ So lange kann allerdings mit der erforderlichen Flexibilisierung der urheberrechtlichen Schranken nicht gewartet werden. Es muss daher über Lösungen nachgedacht werden, die bereits im Rahmen des geltenden Rechts oder jedenfalls mit weniger gesetzgeberischem „Aufwand“ umgesetzt werden können. Es ist daher insbesondere auch über Flexibilisierungsmaßnahmen auf Ebene des mitgliedstaatlichen Rechts nachzudenken, die den den nationalen Gesetzgebern belassenen Gestaltungsspielraum unter Berücksichtigung der gemeinschaftsrechtlichen Vorgaben nutzen, um das Urheberrecht zukunftsfähig zu machen, und die idealerweise keine Änderung des europäischen Rechts voraussetzen.

\section{B. Einführung einer Schrankengeneralklausel im deutschen Urheberrecht}

An der zeitnahen Realisierbarkeit einer wünschenswerten grundlegenden Umgestaltung der Schranken des europäischen Urheberrechts bestehen wie gezeigt - erhebliche Zweifel. Mehr Flexibilität im Bereich der urheberrechtlichen Schrankenregelungen muss jedoch möglichst schnell erreicht werden, damit das Urheberrecht den Anschluss an die im Wesentlichen durch technische Veränderungen erzeugte geänderte Werknutzungsrealität nicht verpasst und dadurch weiter an Akzeptanz verliert. Auch wenn ein nationales Voranschreiten zur Lösung der Schrankenproblematik die dahinter stehenden, grundlegenderen Probleme auf europäischer Ebene nicht beseitigen und somit letztlich allenfalls die zweitbeste Lösung darstellen würde, sollen im Folgenden die Möglichkeiten einer Flexibilisierung der Schranken des deutschen Urheberrechtsgesetzes de lege ferenda aufgezeigt und auf ihre Vereinbarkeit mit den rechtlichen Vorgaben überprüft werden. Erstrebenswert erscheinen insbesondere Flexibilisierungsmaßnahmen, die den dem nationalen Gesetzgeber derzeit belassenen Gestaltungsspielraum ausnutzen, um das Urheberrecht zukunftsfähig zu machen, da eine Flexibilisierung, die lediglich eine Änderung nationalen Rechts und nicht des europäischen Rechts erfordert, größere Chancen auf eine zeitnahe Realisierung hätte. Im Erfolgsfall könnte ein solches nationales Voranschreiten zudem gegebenenfalls dem europäischen Gesetzge-

1908 Siehe oben 6. Kapitel, B.I. und Nachweise in Fn. 1412 f. 
ber als Vorlage und „Ansporn“ für die erforderlichen unionsweiten Maßnahmen dienen.

Ebenso wie auf Ebene des europäischen Rechts käme auch im deutschen Recht eine Streichung des gesamten bestehenden Schrankenkataloges und dessen vollständige Ersetzung durch eine einzige Schrankengeneralklausel (sogleich I.) in Betracht. Ebenfalls denkbar ist die weitgehende Beibehaltung des enumerativen Schrankenkataloges und dessen Ergänzung um eine Generalklausel in Form eines Auffangtatbestandes (sodann II.).

\section{Vollständige Ersetzung des Schrankenkataloges des deutschen Urheberrechtsgesetzes durch eine Generalklausel}

\section{Formulierungsvorschlag und Erläuterung}

Ebenso wie auf Ebene des europäischen Rechts ${ }^{1909}$ ist auch für eine Flexibilisierung der Schranken des deutschen Urheberrechtsgesetzes die Streichung des gesamten Schrankenkataloges und die Einführung einer alleinigen Schrankengeneralklausel denkbar. Auch für eine solche ,große Lösung"1910 einer alleinigen Schrankengeneralklausel böte sich eine Ausgestaltung in Anlehnung an den im Europa- und Völkerrecht verankerten urheberrechtlichen Dreistufentest und die US-amerikanische Fair Use-Doktrin an.

Eine alleinige Schrankengeneralklausel könnte etwa wie folgt formuliert werden:

$\S 45$ UrhG-E: ${ }^{1911}$ Beschränkung der Ausschließlichkeitsrechte

(1) Die Nutzung eines veröffentlichten urheberrechtlich geschützten Werkes ist ohne Zustimmung des Rechteinhabers zulässig, wenn

1909 Siehe dazu oben 7. Kapitel, A.I.

1910 Förster, Fair Use, S. 213.

1911 Da der hiesige Vorschlag die Streichung des gesamten Schrankenkataloges und deren Ersetzung durch einige alleinige Generalklausel vorsieht, könnte die Schrankengeneralklausel als $\S 45$ UrhG-E in das Gesetz aufgenommen werden. Auch § 44a UrhG soll jedoch selbstverständlich gestrichen werden. Die Einführung als $\S 45$ UrhG-E erscheint lediglich gegenüber einer dann nicht notwendigen Bezeichnung als $\S 44 \mathrm{a}$ UrhG-E vorzugswürdig. 
sie die normale Verwertung des Werkes nicht ungebührlich beeinträchtigt und die berechtigten Interessen des Rechteinhabers nicht ungebührlich verletzt.

(2) Bei der Beurteilung, ob die Nutzung die normale Verwertung des Werkes ungebührlich beeinträchtigt, sind insbesondere die Auswirkungen der Nutzung auf den aktuellen und potentiellen Verwertungsmarkt, auf den Wert des urheberrechtlich geschützten Werkes und berechtigte Interessen Dritter zu berücksichtigen.

(3) ${ }^{1}$ Bei der Beurteilung, ob die Nutzung berechtigte Interessen des Rechteinhabers ungebührlich verletzt, sind auch die berechtigten Interessen Dritter zu berücksichtigen. ${ }^{2}$ Bei der Abwägung der Beeinträchtigung der beteiligten Interessen sind insbesondere folgende Kriterien zu berücksichtigen:

1. der Zweck und der Charakter der Nutzung einschließlich der Frage, ob die Nutzung kommerzieller Natur ist; eine Nutzung kann insbesondere dann zulässig sein, wenn sie zum Zwecke des kritischen Kommentars, der Berichterstattung über aktuelle Ereignisse von öffentlichem Interesse, der Veranschaulichung des Unterrichts, der Lehre, der Forschung, der Zugänglichmachung für Menschen mit Behinderungen, der Förderung des Wettbewerbs, insbesondere auf Sekundärmärkten, oder der kreativen Weiterverwendung im Rahmen eigener Werkschöpfung erfolgt;

2. die Art des urheberrechtlich geschützten Werkes;

3. der Umfang und die Bedeutung des verwendeten Werkteils im Verhältnis zum urheberrechtlich geschützten Werk als Ganzem;

4. die Möglichkeit einer Kompensation durch die Zahlung eines gerechten Ausgleichs;

5. die Auswirkungen der Nutzung auf die berechtigten geistigen oder persönlichen Interessen des Urhebers an seinem Werk.

(4) ${ }^{1}$ Für eine nach Absatz 1 zulässige Nutzung ist dem Urheber ein gerechter Ausgleich zu leisten. ${ }^{2}$ Auf seinen Anspruch auf einen gerechten Ausgleich kann der Urheber nicht verzichten. ${ }^{3}$ Der Anspruch kann nur durch eine Verwertungsgesellschaft geltend gemacht werden. ${ }^{4}$ Die Pflicht zur Zahlung eines gerechten Ausgleichs kann entfallen, wenn ein gesteigertes öffentliches Interesse nicht nur am freien Zugang, sondern auch an der Unentgeltlichkeit der Nutzung besteht. 
(5) ${ }^{1}$ Bei einer nach Absatz 1 zulässigen Nutzung kann die Verpflichtung zur Nennung des Urhebers entfallen, soweit die Urhebernennung nach den Umständen des Einzelfalls nicht zu erwarten oder nicht möglich ist. ${ }^{2}$ Die Verpflichtung zur Kennzeichnung der Fremdheit und Herkunft des Werkes entfällt nicht.

Dieser Formulierungsvorschlag entspricht weitgehend dem für das europäische Recht als Auffanggeneralklausel dargestellten Entwurf. ${ }^{1912}$ Zur Erläuterung kann insoweit auf die dortigen Ausführungen verwiesen werden.

Ergänzt wird dieser Entwurf hier jedoch durch eine besondere Betonung urheberpersönlichkeitsrechtlicher Interessen. Eine Hervorhebung der urheberpersönlichkeitsrechtlichen Interessen entspricht deren auch in Zeiten gesteigerter wirtschaftlicher Interessen an urheberrechtlichen Werken weiterhin starken Stellung im deutschen Urheberrecht. Im Vorschlag für das europäische Recht wurden diese Interessen hingegen ausdrücklich weitgehend ausgespart, ${ }^{1913}$ um der Tatsache Rechnung zu tragen, dass in einigen europäischen Mitgliedstaaten - insbesondere im Vereinigten Königreich - Urheberpersönlichkeitsrechte (traditionell) weniger ausgeprägt sind als im deutschen Recht.

Der Vorschlag für einen $\S 45$ UrhG-E spiegelt die zentralen Normen des Urheberrechtsgesetzes zum Schutz der Urheberpersönlichkeitsrechte, die $\S \S 12-14$ UrhG, wider und betont so deren Bedeutung. Zum einen ist die Schrankenbestimmung - ebenso wie im Entwurf für das europäische Recht - auf die Nutzung veröffentlichter Werke beschränkt. Das durch $\S 12$ UrhG garantierte Recht des Urhebers, über das Ob und Wie der Veröffentlichung zu bestimmen, bleibt somit ausdrücklich unangetastet. Im Rahmen der Prüfung, ob die Nutzung berechtigte Interessen des Rechteinhabers ungebührlich verletzt, wurden als Kriterium zudem die Auswirkungen der Nutzung auf die berechtigten geistigen oder persönlichen Interessen des Urhebers an seinem Werk aufgenommen. Dies hebt durch die Übernahme des Wortlautes des $\S 14$ UrhG die Bedeutung des Schutzes des geistig-ästhetischen Gesamteindrucks des Werkes vor Entstellungen

1912 Siehe dazu oben 7. Kapitel, A.II.2.a).

1913 Durch die jeweils vorgesehene Beschränkung auf veröffentlichte Werke finden jedoch auch im Formulierungsvorschlag für das europäische Recht urheberpersönlichkeitsrechtliche Interessen eine gewisse Berücksichtigung; siehe oben 7. Kapitel, A.I.1. 
hervor und verdeutlicht, dass die urheberpersönlichkeitsrechtlichen Interessen mit in die Interessenabwägung einfließen sollen. Durch die Übernahme des Wortlautes des $\S 14$ UrhG ist zudem klargestellt, dass bei der Auslegung dieses Prüfungskriteriums die Rechtsprechung zu dieser Norm herangezogen werden kann.

Absatz 5 des Entwurfes trägt schließlich einem praktischen Bedürfnis Rechnung, das die Untersuchung der Thumbnail-Nutzung exemplarisch offenbart hat: Die in $§ 13$ UrhG verankerte Pflicht zur (vollständigen) Urhebernennung ist mit der veränderten Nutzungsrealität gerade bei der Online-Nutzung urheberrechtlich geschützter Werke teilweise nicht mehr vereinbar. ${ }^{1914}$ Mit einem Wegfall der Urhebernennung geht jedoch zugleich vielfach keine wesentliche Beeinträchtigung der berechtigten Interessen des Urhebers einher. Insoweit ist den Interessen des Urhebers in aller Regel genüge getan, wenn die Fremdheit und Herkunft des Werkes deutlich gekennzeichnet ist ${ }^{1915}$ - etwa durch die deutliche Angabe eines Links auf die Ursprungsseite im Rahmen der Ergebnisliste einer (Bilder-)Suchmaschine.

\section{Opportunität des Vorschlags}

Die dargestellte Ausgestaltung einer Schrankengeneralklausel nach dem Vorbild des urheberrechtlichen Dreistufentests und die Ergänzung um an die US-amerikanische Fair Use-Schranke angelehnte Kriterien bietet erhebliche Flexibilität, die geeignet ist, einer neuen Nutzungsrealität gerecht zu werden und die urheberrechtliche Zulässigkeit neuartiger Formen der Werknutzung zu beurteilen. Die Prüfung erfolgt dabei - anders als etwa bei einer reinen Übernahme des Dreistufentests - nicht „freischwebend“, sondern anhand nachvollziehbarer Kriterien, die ein gewisses Maß an Vorhersehbarkeit und somit Rechtssicherheit gewährleisten. Durch die allmähliche richterrechtliche Ausdifferenzierung der einzelnen Prüfungskriterien lässt sich diese Rechtssicherheit durch die Bildung von Fallgruppen weiter ausbauen.

Eine vollständige Streichung des Schrankenkataloges ist jedoch auch erheblichen Bedenken ausgesetzt. Bereits die Opportunität einer derarti-

1914 Siehe zur Beeinträchtigung der urheberpersönlichkeitsrechtlichen Interessen durch die Thumbnail-Nutzung und die Google Buchsuche, oben 4. Kapitel, C.

1915 Vgl. zu diesem Aspekt auch Schaefer, Bildersuchmaschinen, S. 173 f. 
gen Umsetzung im deutschen Recht ist fraglich. Durch die vollständige Ersetzung des Schrankenkataloges durch eine einzige Schrankengeneralklausel würden die bisher anerkannten Formen der Werknutzung, für deren Zulässigkeit der Gesetzgeber bereits Kriterien in einer Schrankenbestimmung explizit ausdifferenziert und die Rechtsprechung diese ausgelegt hat, unnötig aufgegeben und der Unsicherheit einer Einzelfallprüfung anhand einer alleinigen Generalklausel unterworfen. Es ist zwar davon auszugehen, dass die nationalen Gerichte eine neue Schrankengeneralklausel von Anfang an im Sinne der bisherigen Rechtslage anwenden und ausgehend von den bisher anerkannten Schrankenbestimmungen auslegen würden, so dass ein Anfang bei „Null“ nicht erforderlich wäre. Ist dies jedoch ohnehin der Fall, so ist nicht ersichtlich, welchen Vorteil eine vollständige Streichung der anerkannten Schrankenregelungen haben sollte, der die Nachteile überwöge, die aus dem Wegfall der durch ausdifferenzierte Schrankenbestimmungen gewährleisteten Orientierungshilfe insbesondere für Urheber und Nutzer entstünden.

\section{Vereinbarkeit mit den rechtlichen Vorgaben}

Eine alleinige Schrankengeneralklausel im deutschen Urheberrechtsgesetz, die den gesamten Schrankenkatalog ersetzt, wäre aus diesem Grund auch nur schwerlich mit den verfassungsrechtlichen Vorgaben, insbesondere mit dem Gesetzesvorbehalt des Art. 14 Abs. 1 S. 2 GG und dem verfassungsrechtlichen Bestimmtheitsgebot, $\mathrm{zu}$ vereinbaren. ${ }^{1916}$ Der in Art. 14 Abs. 1 S. 2 GG verankerte Gesetzesvorbehalt verlangt, dass die materiell-rechtliche Inhaltsbestimmung des Eigentums grundsätzlich durch die Legislative erfolgt und nicht weitestgehend der Judikative überlassen wird. ${ }^{1917}$ Das Gebot der ausreichenden Bestimmtheit von Normen zielt darauf ab, dass dem Bürger die Möglichkeit gegeben wird, sein Verhalten auf die Rechtsnormen einzustellen. Die Normen müssen so bestimmt formuliert sein, dass die Folgen der Regelung für den Normadressat so vorhersehbar und berechenbar sind, dass er sein Verhalten danach ausrichten kann, dass der Verwaltung angemessen klare Handlungsmaßstäbe vorgegeben werden und dass eine hinreichende gerichtliche Kontrol-

1916 So im Ergebnis auch Poeppel, Neuordnung, S. 499 ff.

1917 Siehe Schack, in: FS Schricker II, S. 511. Siehe auch oben 6. Kapitel, D.I.1. 
le möglich ist. ${ }^{1918}$ Dies schließt jedoch eine Anwendung von Generalklauseln oder unbestimmten Rechtsbegriffen auch nicht grundsätzlich aus. Das Bundesverfassungsgericht nimmt an, die Anforderungen an die Bestimmtheit erhöhten sich mit der Intensität, mit der auf der Grundlage der betreffenden Regelung in grundrechtlich geschützte Bereiche eingegriffen werden kann. Dies habe jedoch nicht zur Folge, dass die Norm dann überhaupt keine Auslegungsprobleme aufwerfen dürfe. Dem Bestimmtheitserfordernis sei vielmehr genügt, wenn Auslegungsprobleme mit herkömmlichen juristischen Methoden bewältigt werden können. ${ }^{1919}$ Gerade in Fällen, in denen eine gesetzliche Bestimmung vielgestaltige Lebenssachverhalte regeln soll, hat das Bundesverfassungsgericht deshalb auch äußerst weite gesetzliche Regelungen für zulässig erachtet, die wesentliche Wertentscheidungen der Rechtsprechung überantworten. ${ }^{1920}$

Unter Hinweis auf die Vielgestaltigkeit der Nutzungssachverhalte und die sich ständig ändernde Werknutzungsrealität könnte somit auch eine urheberrechtliche Schrankengeneralklausel mit dem Bestimmtheitsgebot vereinbar sein. Dies allerdings nur dann, wenn keine weniger unvorhersehbare und gleich wirksame Rechtsetzungsvariante ersichtlich wäre. Eine gegenüber einer alleinigen Schrankengeneralklausel, deren Auslegung und Ausgestaltung allein der Rechtsprechung überlassen würde, deutlich vorhersehbarere und berechenbarere Variante stellt jedoch der - bereits für das europäische Recht dargestellte - Mittelweg eines um eine Auffanggeneralklausel ergänzten Schrankenkataloges dar. Für bereits bekannte Formen der Werknutzung könnten so die Grenzen der urheberrechtlichen Ausschließlichkeitsrechte in Form expliziter Schrankenbestimmungen gezogen werden. Nur in Ausnahmefällen käme es folglich zur Anwendung der (besonders) auslegungsbedürftigen Schrankengeneralklausel. ${ }^{1921}$ Die durch die Einfügung einer Generalklausel gegebenenfalls erzeugte Rechtsunsicherheit würde so für die Rechtsunterworfenen auf ein - mit dem Bestimmtheitsgebot vereinbares - Maß reduziert.

1918 Siehe nur Maunz/Dürig/Grzeszick, GG, Art. 20 Rn. 59 m.w.N.

1919 Siehe BVerfGE 83, 130 (145) - Josefine Mutzenbacher m.w.N.

1920 Vgl. unter Verweis auf die „Vielgestaltigkeit des Lebens“ oder die „Vielgestaltigkeit der Verhältnisse“ etwa BVerfGE 4, 352 (358); E 9, 137 (151) - Reuegeld; E 71, 108 (115) - Neutralität im Wahlraum; E 92, $1(12,19)$ - Sitzblockade III.

1921 Siehe näher unten 7. Kapitel, B.II. 
Die vollständige Streichung des bestehenden Schrankenkataloges und die Ersetzung durch eine alleinige Generalklausel stünden schließlich auch in einem Konflikt zu den Vorgaben des europäischen Richtlinienrechts. Es erscheint zwar nicht per se ausgeschlossen, auch unter der geltenden InfoSoc-Richtlinie im nationalen Recht eine Schrankengeneralklausel, wie die hier vorgeschlagene, einzuführen. Insbesondere steht diese - anders als möglicherweise eine reine Übernahme der US-amerikanischen Fair UseSchranke ${ }^{1922}$ - nicht im Widerspruch zum Dreistufentest. Gerade die - mit europäischem und nationalem Recht nicht vereinbare - „Alles oder Nichts"-Rechtsfolge des Fair Use wurde hier durch die Einführung einer Rechtsfolgenregelung ausgeglichen. Auch inhaltlich wäre die Schrankengeneralklausel mit der InfoSoc-Richtlinie zu vereinbaren, solange die nationalen Gerichte die Generalklausel - wie zu erwarten - im Sinne des derzeitigen Schrankenkataloges des Urheberrechtsgesetzes - und somit auch im Sinne der InfoSoc-Richtlinie - handhaben und auslegen würden. ${ }^{1923}$

Bedenken hinsichtlich der Vereinbarkeit mit den Richtlinienvorgaben bestehen jedoch im Hinblick auf das europarechtliche Effektivitätsgebot. Danach sind die Mitgliedstaaten angehalten, zur Umsetzung einer Richtlinie die Formen und Mittel zu wählen, die sich zur Gewährleistung der praktischen Wirksamkeit (effet utile) der Richtlinie unter Berücksichtigung des mit ihnen verfolgten Zwecks am besten eignen. ${ }^{1924} \mathrm{Ob}$ detaillierte Richtlinienvorgaben im Wege einer Generalklausel umgesetzt werden dürfen, die lediglich entsprechend den Vorgaben der Richtlinie ausgelegt werden, kann somit nicht allgemein, sondern nur durch eine Gesamtschau von Richtlinieninhalt und nationaler Auslegungspraxis beurteilt werden. ${ }^{1925}$ Das Effektivitätsgebot steht dabei der Umsetzung einer Richtlinienbestimmung durch eine Generalklausel nicht grundsätzlich entgegen. ${ }^{1926}$ Im Falle der Umsetzung der Schrankenbestimmungen der Info-

1922 Zur - hier bejahten - Vereinbarkeit der Fair Use-Doktrin mit dem urheberrechtlichen Dreistufentest, siehe oben 6. Kapitel, C.IV.

1923 Ähnlich Förster, Fair Use, S. 208.

1924 Vgl. EuGH, Urt. v. 8.4.1976, C-48/75, Slg. 1976, 497, Rn. 69/73 - Royer.

1925 Siehe Leible, EuZW 2001, 438 (438 f.); Poeppel, Neuordnung, S. 504.

1926 Vgl. EuGH, Urt. v. 26.10.1983, C-163/82, Slg. 1983, 3273, Rn. 9 - Kommission./. Italien zur - für zulässig befundenen - Umsetzung von Richtlinienvorgaben $\mathrm{zu}$ Arbeitsbedingungen durch eine Generalklausel. Für nicht ausreichend 
Soc-Richtlinie lässt es jedoch eine solche Ausgestaltung nicht zu. In der InfoSoc-Richtlinie hat sich der europäische Gesetzgeber für eine Ausgestaltung der urheberrechtlichen Schranken in Form eines grundsätzlich abschließenden Kataloges enumerativer Einzeltatbestände entschieden. Erwägungsgrund 32 zur InfoSoc-Richtlinie stellt insoweit unmissverständlich klar, dass die Schrankenbestimmungen jedenfalls in Bezug auf das Vervielfältigungsrecht und das Recht der öffentlichen Wiedergabe in der Richtlinie erschöpfend aufgeführt sind. Dies spiegelt hinsichtlich der Schranken das zentrale Ziel der InfoSoc-Richtlinie wider. Die auf dem Gebiet der Schrankenbestimmungen zuvor bestehenden, teils ganz erheblich abweichenden nationalen Bestimmungen sollten gerade unionsweit harmonisiert und eine weitere Auseinanderentwicklung der Schranken im mitgliedstaatlichen Recht unterbunden werden. ${ }^{1927}$ Auch wenn man am Erfolg dieses Harmonisierungsvorhabens zweifeln kann, ${ }^{1928}$ so sind die Vorgaben des Art. 5 InfoSoc-Richtlinie und die Entscheidung des europäischen Gesetzgebers für einen Katalog von Schrankentatbeständen bei der Einführung neuer oder der Änderung bestehender Schrankenregelungen jedenfalls als „Höchstgrenzen“1929 der Schrankenausgestaltung zwingend zu beachten. Sie begrenzen den gesetzgeberischen Spielraum insofern entscheidend, als sie jedenfalls der Einführung völlig neuer, im Katalog des Art. 5 InfoSoc-RL nicht vorgesehener Schrankenbestimmungen grundsätzlich entgegenstehen und so einer weiteren Disharmonisierung im Bereich der urheberrechtlichen Schrankenbestimmungen entgegenwirken sollen. ${ }^{1930}$ Die „Öffnungsklausel“ des Art. 5 Abs. 3 lit. o InfoSoc-RL hilft insofern nicht weiter, da sie den Mitgliedstaaten lediglich erlaubt, sonstige bisher bestehende nationale Schranken in „Fällen von geringer Bedeu-

befunden hat der EuGH hingegen die generalklauselartige Umsetzung verbraucherschützender Richtlinienvorgaben; vgl. EuGH, Urt. v. 10.5.2001, C-144/99, Slg. 2001, I-3541, Rn. 17 ff. - Kommission./. Niederlande. Vgl. auch Siems, ZEuP 2002, 747 (750 ff.); Streinz, JuS 2001, 1113 (1114).

1927 Vgl. Erw.-Grd. 31 zur InfoSoc-RL. Zu den politischen Schwierigkeiten und zähen Verhandlungen um einen Kompromiss zur Harmonisierung der Schrankenbestimmungen siehe Bayreuther, ZUM 2001, 828 (829); Hoeren, MMR 2000, 515 ff.; Reinbothe, GRUR Int. 2001, 733 (734 f.); Spindler, GRUR 2002, 105 (106, 110 f.).

1928 Zur Kritik an der Ausgestaltung der Schrankenbestimmungen durch die InfoSoc-Richtlinie, siehe oben 6. Kapitel, B.III.

1929 Bayreuther, ZUM 2001, 828 (829).

1930 Vgl. Leistner, CMLR 46 (2009), 847 (851 f.). 
tung“ aufrecht zu erhalten, und auch dies nur, wenn diese analoge Nutzungen betreffen und den freien Waren- und Dienstleistungsverkehr der Gemeinschaft nicht berühren.

Sinn und Zweck einer alleinigen Schrankengeneralklausel wäre es jedoch gerade, die Schrankenbestimmungen insbesondere im Hinblick auf den Umgang mit neuen Formen der Werknutzung zu flexibilisieren und auch solche Nutzungsformen zu erfassen, die bisher nicht in einer der enumerativen Schrankenbestimmungen der InfoSoc-Richtlinie erfasst sind. Durch die Ausgestaltung der nationalen Schrankenregelungen in Form einer Generalklausel bestünde somit - insbesondere dann, wenn mehrere Mitgliedstaaten diesen Weg beschritten - die Gefahr einer erheblichen weiteren Disharmonisierung, die dem Willen des europäischen Richtliniengebers gerade widerspricht. Die nationale Umsetzung der Richtlinienvorgaben durch eine alleinige Schrankengeneralklausel ist daher als nicht europarechtskonform anzusehen. ${ }^{1931}$

\section{Integration einer Generalklausel in den bestehenden Schrankenkatalog}

Aufgrund der aufgezeigten Bedenken, die gegen die Einführung einer alleinigen Schrankengeneralklausel im deutschen Urheberrechtsgesetz bestehen, erscheint auch für eine Flexibilisierung der Schranken auf Ebene des nationalen Rechts eine vermittelnde Lösung vorzugswürdig, bei der eine Generalklausel in den bestehenden Schrankenkatalog integriert beziehungsweise diesem als Auffangtatbestand angefügt würde.

\section{Formulierungsvorschlag und Erläuterung}

Für die Ausgestaltung einer Auffanggeneralklausel im deutschen Urheberrecht böte sich - ebenso wie auf Ebene des europäischen Rechts ${ }^{1932}$ - eine

1931 So im Ergebnis auch Bornkamm, in: FS Erdmann, S. 29 (46); v.Eechoud/Hugenholtz/v.Gompel/Guibault/Helberger, Harmonizing European Copyright Law, S. 128 f.; Förster, Fair Use, S. 209; Leistner, Konsolidierung und Entwicklungsperspektive, S. 33; Poeppel, Neuordnung, S. 504 f.; Schack, in: FS Schricker II, S. 511 (512); Wiebe, GRUR 2011, 888 (893 f.).

1932 Siehe dazu mit näherer Erläuterung oben 7. Kapitel, A.II.2. 
Ausgestaltung in Anlehnung an den im Europa- und Völkerrecht verankerten urheberrechtlichen Dreistufentest und die US-amerikanische Fair UseDoktrin an. Zugleich sollte ein Auffangtatbestand im nationalen Recht wie zuvor in Bezug auf eine alleinige Schrankengeneralklausel dargestellt ${ }^{1933}$ - der droit d'auteur-Tradition des deutschen Urheberrechts Rechnung tragen und urheberpersönlichkeitsrechtliche Interessen besonders berücksichtigen.

Eine solche Auffanggeneralklausel in Anlehnung an den Dreistufentest und die Fair Use-Doktrin könnte etwa wie folgt lauten:

$\S 61$ UrhG-E: 1934 Weitere Beschränkungen der Ausschließlichkeitsrechte

(1) Die Nutzung eines veröffentlichten urheberrechtlich geschützten Werkes, die nicht dem Anwendungsbereich einer der speziellen Schrankenbestimmungen dieses Kapitels unterfällt, ist ohne $\mathrm{Zu}-$ stimmung des Rechteinhabers zulässig, wenn sie die normale Verwertung des Werkes nicht ungebührlich beeinträchtigt und die berechtigten Interessen des Rechteinhabers nicht ungebührlich verletzt.

(2) Bei der Beurteilung, ob die Nutzung die normale Verwertung des Werkes ungebührlich beeinträchtigt, sind insbesondere die Auswirkungen der Nutzung auf den aktuellen und potentiellen Verwertungsmarkt, auf den Wert des urheberrechtlich geschützten Werkes und berechtigte Interessen Dritter zu berücksichtigen.

(3) ${ }^{1}$ Bei der Beurteilung, ob die Nutzung berechtigte Interessen des Rechteinhabers ungebührlich verletzt, sind auch die berechtigten Interessen Dritter zu berücksichtigen. ${ }^{2} \mathrm{Bei}$ der Abwägung der Beeinträchtigung der beteiligten Interessen sind insbesondere folgende Kriterien zu berücksichtigen:

1933 Siehe oben 7. Kapitel, B.I.

1934 Auch Poeppel, Neuordnung, S. 491, Förster, Fair Use, S. 214 und Hansen, Warum Urheberrecht, S. 409 sehen die von ihnen erwogenen Schrankengeneralklauseln als $\S 61$ UrhG de lege ferenda vor. Für eine Auffanggeneralklausel bietet sich $\S 61$ UrhG gesetzessystematisch an, da er unmittelbar an die letzte Schrankenbestimmung des Schrankenkataloges anschließt und durch die Aufhebung im Zuge des Gesetzes zur Regelung des Urheberrechts in der Informationsgesellschaft vom 10.9.2003 (BGB1. 2003 I, S. 1774) ,freigeworden“ ist. 
1. der Zweck und der Charakter der Nutzung einschließlich der Frage, ob die Nutzung kommerzieller Natur ist; eine Nutzung kann insbesondere dann zulässig sein, wenn sie zum Zwecke des kritischen Kommentars, der Berichterstattung über aktuelle Ereignisse von öffentlichem Interesse, der Veranschaulichung des Unterrichts, der Lehre, der Forschung, der Zugänglichmachung für Menschen mit Behinderungen,der Förderung des Wettbewerbs, insbesondere auf Sekundärmärkten, oder der kreativen Weiterverwendung im Rahmen eigener Werkschöpfung erfolgt;

2. die Art des urheberrechtlich geschützten Werkes;

3. der Umfang und die Bedeutung des verwendeten Werkteils im Verhältnis zum urheberrechtlich geschützten Werk als Ganzem;

4. die Möglichkeit einer Kompensation durch die Zahlung eines gerechten Ausgleichs;

5. die Auswirkungen der Nutzung auf die berechtigten geistigen oder persönlichen Interessen des Urhebers an seinem Werk.

(4) ${ }^{1}$ Für eine nach Absatz 1 zulässige Nutzung ist dem Urheber ein gerechter Ausgleich zu leisten. ${ }^{2}$ Auf seinen Anspruch auf einen gerechten Ausgleich kann der Urheber nicht verzichten. ${ }^{3}$ Der Anspruch kann nur durch eine Verwertungsgesellschaft geltend gemacht werden. ${ }^{4}$ Die Pflicht zur Zahlung eines gerechten Ausgleichs kann entfallen, wenn ein gesteigertes öffentliches Interesse nicht nur am freien Zugang, sondern auch an der Unentgeltlichkeit der Nutzung besteht.

(5) ${ }^{1}$ Bei einer nach Absatz 1 zulässigen Nutzung kann die Verpflichtung zur Nennung des Urhebers entfallen, soweit die Urhebernennung nach den Umständen des Einzelfalls nicht zu erwarten oder nicht möglich ist. ${ }^{2}$ Die Verpflichtung zur Kennzeichnung der Fremdheit und Herkunft des Werkes entfällt nicht.

Die vorgeschlagene Auffanggeneralklausel stellt eine Kombination aus dem hier für eine Auffangschranke im europäischen Recht unterbreiteten Vorschlag 1935 und dem Entwurf einer alleinigen Schrankengeneralklausel im nationalen Recht dar:

1935 Siehe oben 7. Kapitel, A.II.2.a). 
Der Auffangtatbestand ist in Anlehnung an den urheberrechtlichen Dreistufentest ausgestaltet und um der US-amerikanischen Fair UseSchranke ähnliche Prüfungskriterien ergänzt. Der Anwendungsbereich dieser - als Ergänzung eines überarbeiteten und gestrafften Kataloges urheberrechtlicher Schranken vorgesehenen - Generalklausel ist dabei deutlich begrenzt. Nicht jede Werknutzung wird zusätzlich zu den Regelungen des Schrankenkataloges einer Einzelfallüberprüfung anhand der Generalklausel unterzogen. Eine Anwendung des Auffangtatbestandes kommt vielmehr nur dann in Betracht, wenn der Anwendungsbereich keiner Schrankenbestimmung des Schrankenkataloges des Urheberrechtsgesetzes eröffnet ist. Die vom Gesetzgeber im Rahmen des Schrankenkataloges ausdifferenzierten Schranken gingen der Generalklausel folglich als leges speciales zwingend vor. ${ }^{1936}$

Die vorgeschlagene Regelung gestaltet den urheberrechtlichen Dreistufentest in eine generalklauselartige Auffangschranke um, die diesen - über seine europarechtliche Funktion als Schranken-Schranke hinaus - auf seine ursprüngliche (konventionsrechtliche) Funktion zurückführt, auch neue Formen der Werknutzung zu ermöglichen. ${ }^{1937}$ Zugleich verkürzt der vorgeschlagene $\S 61$ UrhG-E den Dreistufentest auf einen Zweistufentest. Dies hat jedoch nur eine klarstellende Funktion und keine Auswirkung auf dessen Anwendung. Den Anforderungen der ersten Teststufe des Dreistufentests genügen die anhand der vorgeschlagenen Generalklausel auf ihre Zulässigkeit zu überprüfenden Nutzungshandlungen ohnehin sowohl bei einem quantitativen als auch bei einem qualitativen Verständnis des „Sonderfalles". ${ }^{1938}$ Da die Bestimmung nur subsidiär Anwendung findet, wenn keine der ausdrücklich im Gesetz enthaltenen Schranken einschlägig ist, wird die Zahl der anhand der Generalklausel zu überprüfenden Nutzungshandlungen eher niedrig sein. Dass diese Nutzungshandlungen zugleich auch den - richtigerweise eher niedrig anzusetzenden ${ }^{1939}$ - qualitativen Anforderungen an einen ,Sonderfall“ genügen, wird durch die nähere

1936 Siehe zum derart beschränkten Anwendungsbereich der Auffangklausel näher oben 7. Kapitel, A.II.2.b).

1937 Siehe näher oben 7. Kapitel, A.II.2.b) sowie zu dieser ,enabling function“ des konventionsrechtlichen Dreistufentests, Senftleben, 57 J. Copyright Soc'y U.S.A. 521, 544 ff. (2010).

1938 Siehe zur Auslegung der ersten Teststufe des Dreistufentests oben 6. Kapitel, C.III.2.a).

1939 Vgl. zur hier vertretenen Auffassung näher oben 6. Kapitel, C.III.2.a)cc). 
Ausdifferenzierung der zweiten und dritten Teststufe anhand der vorgeschlagenen Fair Use-ähnlichen Prüfungskriterien garantiert, die zugleich sicherstellen, dass es sich um „bestimmte“ bzw. „bestimmbare“ Fälle im Sinne des Dreistufentests handelt. Auf die ausdrückliche Aufnahme der ersten Teststufe des Dreistufentests in eine nationale Schrankengeneralklausel kann deshalb - zum Wohle einer übersichtlicheren Prüfung - verzichtet werden, ohne dass eine Anwendung der Regelung entgegen der Vorgaben des konventions- und europarechtlichen Dreistufentests droht.

Ebenso wie für eine Schrankengeneralklausel in einer europäischen Urheberrechtsverordnung vorgeschlagen, modifiziert der Entwurf zudem die zweite Stufe des Dreistufentests geringfügig, indem er darauf abstellt, ob die normale Verwertung des Werkes ungebührlich beeinträchtigt wird. Diese Formulierung trägt zum einen dem Bedürfnis der Rechteinhaber Rechnung, vor solchen Nutzungen geschützt zu werden, die erhebliche negative Auswirkungen auf die eigene Werkverwertung haben. Zum anderen berücksichtigt die Regelung jedoch auch, dass nicht jede Beeinträchtigung der ökonomischen Interessen des Rechteinhabers automatisch zur Unzulässigkeit einer Werknutzung führen darf. Andernfalls drohte aufgrund der fortschreitenden technischen Entwicklung und der damit verbundenen stetigen - zumindest potentiellen - Erschließung zusätzlicher Märkte auf längere Sicht die dritte Stufe des Dreistufentests (hier: zweite Teststufe des Absatzes 1) als Beschränkung funktionslos zu werden. ${ }^{1940}$ Ein solches Ergebnis ließe aber die Tatsache außer Betracht, dass zahlreiche Formen der Werknutzung denkbar sind, die zwar die ökonomischen Interessen des Rechteinhabers tangieren, jedoch durch die Zahlung einer angemessenen Vergütung ebenso gut oder gar besser kompensiert werden können als durch ein Verbotsrecht. ${ }^{1941}$

Der für eine europäische Urheberrechtsverordnung unterbreitete Gesetzgebungsvorschlag wird jedoch - ebenso wie zuvor für eine alleinige Schrankengeneralklausel im deutschen Recht vorgeschlagen - um urheberpersönlichkeitsrechtliche Aspekte ergänzt. Der Entwurf nimmt daher ausdrücklich Bezug auf die zentralen Regelungen zum Schutz der Urheberpersönlichkeitsrechte im Urheberrechtsgesetz. Das Veröffentlichungsrecht des Urhebers wird berücksichtigt, indem die Anwendung der Schrankenbestimmung gemäß ihrem Absatz 1 auf Nutzungen veröffent-

1940 Siehe zu dieser Kritik an der Auslegung der zweiten Teststufe des Dreistufentests oben 6. Kapitel, C.III.2.b).

1941 Vgl. oben 6. Kapitel, C.III.2.b). 
lichter Werke beschränkt ist. Der Entwurf stellt in Absatz 3 Satz 2 Nr. 5 zudem in Anlehnung an $\S 14$ UrhG klar, dass eine ungebührliche Verletzung berechtigter Interessen des Rechteinhabers insbesondere auf einer Beeinträchtigung berechtigter geistiger oder persönlicher Interessen des Urhebers an seinem Werk - etwa durch dessen Entstellung - beruhen kann. Absatz 5 des Entwurfes strebt schließlich einen angemessenen Ausgleich zwischen dem durch $\S 13$ UrhG geschützten Recht auf Anerkennung der Urheberschaft und der veränderten Werknutzungsrealität an, mit der gerade bei der Online-Nutzung urheberrechtlich geschützter Werke eine vollständige Urhebernennung teilweise nicht mehr vereinbar ist. ${ }^{1942}$ Für Fälle, in denen eine vollständige Urhebernennung nicht möglich ist und mit einem Wegfall der Urhebernennung keine wesentliche Beeinträchtigung der berechtigten Interessen des Urhebers einhergeht, sieht $\S 61$ Abs. 5 UrhG-E deshalb nur eine Kennzeichnung der Fremdheit und Herkunft des Werkes vor.

In Absatz 4 enthält die Vorschrift eine Rechtsfolgenregelung, ${ }^{1943}$ die klarstellt, dass der Rechteinhaber die Nutzung seines Werkes im Regelfall nur gegen Zahlung eines gerechten Ausgleichs hinnehmen muss. Sie trägt dem Erfordernis Rechnung, dass der Urheber für die Werknutzung grundsätzlich eine angemessene Vergütung erhalten soll. Besteht jedoch ausnahmsweise ein so erhebliches öffentliches Interesse an der kostenfreien Nutzung, dass dieses das Vergütungsinteresse des Rechteinhabers überwiegt, so kann die Vergütungspflicht im Einzelfall vollständig entfallen.

\section{Opportunität des Vorschlags}

Die Auffanggeneralklausel des $\S 61$ UrhG-E nach dem Vorbild des urheberrechtlichen Dreistufentests und deren Ergänzung um an die US-amerikanische Fair Use-Schranke angelehnte Kriterien vereint gleich in mehrerlei Hinsicht „das Beste beider Welten“:

Durch den offenen Wortlaut in Anlehnung an den Dreistufentest bringt die Generalklausel die notwendige Flexibilität in die derzeit zu starren Schranken des Urheberrechtsgesetzes. Diese ist - wie die rechtsverglei-

1942 Vgl. näher oben 7. Kapitel, A.II.2.b).

1943 Siehe zur näheren Erläuterung oben 7. Kapitel, A.I.1. zum insoweit gleichlautenden Absatz 3 des Entwurfes einer alleinigen Schrankengeneralklausel im europäischen Recht. 
chende Untersuchung der Buch- und Bildersuche exemplarisch gezeigt hat - erforderlich, um der gewandelten Nutzungsrealität gerecht zu werden und die urheberrechtliche Zulässigkeit neuartiger Formen der Werknutzung zu beurteilen. Durch die Aufnahme eines gesetzlichen Auffangtatbestandes werden methodische „Verbiegungen“ und richterliche „Kunstgriffe" zur Erfassung neuer Nutzungsformen überflüssig.

Der Fair Use-ähnliche Kriterienkatalog minimiert zugleich die derzeit bei der unmittelbaren Anwendung des konventions- oder europarechtlichen Dreistufentests durch die Rechtsprechung bestehenden Unsicherheiten. So gewährleistet die Generalklausel des $\S 61$ UrhG-E neben erheblicher Flexibilität zugleich ein größtmögliches Maß an Rechtssicherheit. Die Regelung findet nur auf solche Sachverhalte Anwendung, die nicht bereits von einer der im Rahmen des Schrankenkataloges enthaltenen Schrankenbestimmungen erfasst werden. Kommt es zu einer Anwendung der Generalklausel, so erfolgt die Prüfung anhand der in den Absätzen 2 und 3 aufgezählten, nachvollziehbaren Kriterien, so dass der Gang und auch Ausgang der Prüfung in aller Regel weitgehend vorhersehbar sein werden. Die Vorhersehbarkeit wird im Laufe der Zeit weiter zunehmen, wenn eine Auslegung und Ausdifferenzierung der einzelnen Prüfungskriterien durch die Rechtsprechung stattgefunden hat. ${ }^{1944}$ Durch die Rechtsprechung in Anwendung der Generalklausel etablierte Fallgruppen könnten zudem durch den Gesetzgeber zur Steigerung der „Nutzerfreundlichkeit" und Rechtssicherheit durch die Aufnahme in den Schrankenkatalog gesetzlich festgeschrieben werden. ${ }^{1945}$ Eine solche Kodifizierung einzelner von der Rechtsprechung etablierter Fallgruppen könnte gegebenenfalls dazu beitragen, die langwierigen Gesetzgebungsprozesse zu verkürzen oder diese jedenfalls interessengerechter auszugestalten. Die einer ausgeglichenen und zügigen Gesetzgebung nicht immer förderlichen Einflussnahmeversuche von Lobbyverbänden, die bei einer Schrankenneuschöpfung durch den Gesetzgeber stets zu beobachten sind, könnten deutlich minimiert werden, wenn der Gesetzgeber lediglich eine allgemein anerkannte - weitgehend frei von Lobbyeinflüssen entstandene - Rechtsprechungspraxis in Gesetzesform gösse.

1944 Siehe näher zur Vorhersehbarkeit von Fair Use-Entscheidungen als Beispiel einer durch die Rechtsprechung ausdifferenzierten Schrankengeneralklausel, oben S. $279 \mathrm{ff}$.

1945 Vgl. dazu bereits oben 7. Kapitel, A.II.2.c); ähnlich Metzger, in: Europäische Perspektiven des Geistigen Eigentums, S. 101 (121 f.). 
Durch die Ergänzung des - idealerweise deutlich gestrafften, vereinfachten und bereinigten ${ }^{1946}$ - Kataloges von Schrankenbestimmungen um die vorgeschlagene Auffanggeneralklausel würde das Urheberrecht zudem anwenderfreundlicher: Der Schrankenkatalog könnte seine eigentliche Stärke - die Gewährung eines hohen Maßes an Rechtssicherheit - zurückgewinnen. Finden die einzelnen Schrankentatbestände tatsächlich nur noch Anwendung auf die vom Gesetzgeber vorgesehenen Sachverhalte, so ist für den Rechtsanwender in aller Regel - auch ohne nähere Kenntnis der Rechtsprechung zu den urheberrechtlichen Schranken - wieder ,durch einen Blick in das Gesetz“ zu erkennen, welche Nutzungshandlungen unter welchen Voraussetzungen im Rahmen der Schrankenregelungen zulässig sind, und ob für diese gegebenenfalls eine Vergütung zu zahlen ist. Bei allen anderen - insbesondere neuartigen - Formen der Werknutzung, die keiner Schrankenbestimmung unterfallen, ist hingegen für den Rechtsanwender ersichtlich, dass sich die Nutzungen allein am Maßstab der Schrankengeneralklausel messen lassen müssen. Die grundlegenden Voraussetzungen einer legalen Nutzung lassen sich dieser Bestimmung ebenfalls in Form des gesetzlichen Kriterienkataloges entnehmen, so dass dem Nutzer - auch ohne detaillierte Kenntnis der Rechtsprechung - in aller Regel jedenfalls eine Abschätzung der Zulässigkeit möglich sein wird.

Schließlich ermöglicht die Auffangschranke durch ihre Offenheit und die ausdrückliche Festschreibung gewisser Kriterien auch einen gerechten Ausgleich der beteiligten Interessen. Die Regelung betont ausdrücklich, dass bei der Prüfung der Zulässigkeit einer Werknutzung alle beteiligten Interessen zu berücksichtigen sind. Für das deutsche Recht neu wäre die hier ausdrücklich festgeschriebene Beachtung von Belangen des Wettbewerbs. Durch die Hervorhebung urheberpersönlichkeitsrechtlicher Interessen wird jedoch auch sichergestellt, dass die Frage der Zulässigkeit einer zustimmungsfreien Werknutzung nicht regelmäßig einer rein wirtschaftlichen Kosten-Nutzen-Rechnung gleichgesetzt wird, aufgrund derer ein Verbietungsrecht des Urhebers letztlich stets zu einem Anspruch auf angemessene Vergütung abgeschwächt würde. Zugleich trägt die Regelung der geänderten Werknutzungsrealität Rechnung, die im Einzelfall gewisse Einschränkungen urheberpersönlichkeitsrechtlicher Belange erfordern

1946 Siehe zu erstrebenswerten Maßnahmen der gesetzestechnischen Straffung und Bereinigung der Schrankenbestimmungen Hansen, Warum Urheberrecht, S. $401 \mathrm{ff}$. 
kann. Durch die Möglichkeit einer Abschwächung des Rechtes auf Urhebernennung wird auch hier ein interessengerechter Ausgleich ermöglicht.

\section{Vereinbarkeit mit den rechtlichen Vorgaben}

Die vorgeschlagene Auffanggeneralklausel wäre mit den zuvor dargestellten völker- und verfassungsrechtlichen Vorgaben zur Ausgestaltung der urheberrechtlichen Schranken vereinbar. Ebenso wie die Einführung einer alleinigen Schrankengeneralklausel im nationalen Recht, würde die Umsetzung des dargestellten Vorschlages jedoch eine Änderung des europäischen Rechts voraussetzen.

An der Völkerrechtskonformität einer auf dem Dreistufentest aufbauenden Auffanggeneralklausel kann kein ernstlicher Zweifel bestehen. Insbesondere hat der Dreistufentest im Konventionsrecht - anders als in seiner Ausgestaltung in der InfoSoc-Richtlinie - seit jeher nicht lediglich die Funktion, als Schranken-Schranke für bestehende Schrankenbestimmungen zu wirken, sondern auch als Rahmen für die Ermöglichung neuer Formen der Werknutzung zu dienen. ${ }^{1947}$ Mit den Vorgaben des konventionsrechtlichen Dreistufentests ist eine auf dessen Basis ausgestaltete eigenständige Schrankengeneralklausel somit vereinbar. Dies ändert sich insbesondere auch nicht durch dessen Ergänzung und nähere Ausgestaltung anhand von Kriterien der Fair Use-Doktrin, da diese keine unmittelbaren Auswirkungen auf den Anwendungsbereich des Dreistufentests haben, sondern lediglich als Kriterien für dessen Auslegung konzipiert sind.

Auch mit den Vorgaben des deutschen Verfassungsrechts wäre die Regelung zu vereinbaren. ${ }^{1948}$ Anders als eine alleinige Schrankengeneralklausel stünde eine Generalklausel als subsidiärer Auffangtatbestand insbesondere nicht im Widerspruch zum verfassungsrechtlichen Bestimmtheitsgebot. Eine Öffnung der urheberrechtlichen Schrankenbestimmungen im Hinblick auf die geänderte und sich ständig weiter ändernde Nutzungsrealität ist - wie gezeigt - dringend erforderlich. Eine solche kann sinnvoll nur durch eine technologieneutrale, zukunftsoffene und daher flexible Schrankenbestimmung erfolgen. Durch die Kombination eines verfassungsrechtlich gebotenen Kataloges von Einzelausnahmen mit einer Auf-

1947 Vgl. oben 6. Kapitel, C. und 7. Kapitel, A.II.2.b).

1948 So im Ergebnis auch Hansen, Warum Urheberrecht, S. 407 f.; Poeppel, Neuordnung, S. 503. 
fanggeneralklausel, die nur in wenigen Einzelfällen Anwendung findet und zudem durch den enthaltenen Kriterienkatalog deutliche Anhaltspunkte für eine Konkretisierung durch die Rechtsprechung liefert, würde der Gesetzgeber nicht etwa notwendige Entscheidungen ungebührlich auf die Rechtsprechung abwälzen, sondern dem Bestimmtheitsgebot soweit wie möglich Rechnung tragen. Nur in Fällen, in denen dem Gesetzgeber eine nähere gesetzliche Bestimmung der Zulässigkeitsvoraussetzungen einer Nutzung ohnehin (noch) nicht möglich war - etwa weil die fragliche Nutzungsform zum Zeitpunkt der Gesetzgebung noch unbekannt war -, käme die Auffangschranke zur Anwendung. In diesen Konstellationen stellt der Rückgriff auf eine mit Hilfe von Prüfungskriterien ausdifferenzierte Generalklausel jedoch - wie gezeigt - gegenüber der erweiternden Auslegung oder analogen Anwendung spezieller Schrankenbestimmungen den methodenehrlicheren und auch vorhersehbareren Weg dar, der ein hohes Maß an Rechtssicherheit zu erzeugen vermag und somit gerade im Einklang mit dem Zweck des verfassungsrechtlichen Bestimmtheitsgebotes steht.

Ebenso wie die vollständige Streichung des bestehenden Schrankenkataloges und die Ersetzung durch eine alleinige Generalklausel stünde jedoch auch die vorgeschlagene Auffanggeneralklausel in einem Konflikt zu den Vorgaben des europäischen Richtlinienrechts. Bedenken hinsichtlich der Vereinbarkeit mit den Richtlinienvorgaben bestehen auch hier insbesondere im Hinblick auf das europarechtliche Effektivitätsgebot. Danach sind die Mitgliedstaaten angehalten, zur Umsetzung einer Richtlinie die Formen und Mittel zu wählen, die sich zur Gewährleistung der praktischen Wirksamkeit (effet utile) der Richtlinie unter Berücksichtigung des mit ihnen verfolgten Zwecks am besten eignen. ${ }^{1949}$ Das Effektivitätsgebot steht zwar der Umsetzung einer Richtlinienbestimmung durch eine Generalklausel nicht grundsätzlich entgegen. ${ }^{1950}$ Im Falle der Umsetzung der Schrankenbestimmungen der InfoSoc-Richtlinie lässt es jedoch eine solche Ausgestaltung nicht zu. Erwägungsgrund 32 zur InfoSoc-Richtlinie

1949 Vgl. EuGH, Urt. v. 8.4.1976, C-48/75, Slg. 1976, 497, Rn. 69/73 - Royer.

1950 Vgl. EuGH, Urt. v. 26.10.1983, C-163/82, Slg. 1983, 3273, Rn. 9 - Kommission./. Italien zur - für zulässig befundenen - Umsetzung von Richtlinienvorgaben zu Arbeitsbedingungen durch eine Generalklausel. Für nicht ausreichend befunden hat der EuGH hingegen die generalklauselartige Umsetzung verbraucherschützender Richtlinienvorgaben; vgl. EuGH, Urt. v. 10.5.2001, C-144/99, Slg. 2001, I-3541, Rn. 17 ff. - Kommission./. Niederlande. Vgl. auch Siems, ZEuP 2002, 747 (750 ff.); Streinz, JuS 2001, 1113 (1114). Siehe auch näher oben 7. Kapitel, B.I.3. 
stellt unmissverständlich klar, dass die Schrankenbestimmungen jedenfalls in Bezug auf das Vervielfältigungsrecht und das Recht der öffentlichen Wiedergabe in der Richtlinie erschöpfend aufgeführt sind. Auch wenn die durch diese abschließende Regelung bezweckte Harmonisierung tatsächlich weitgehend ausgeblieben ist, ${ }^{1951}$ so sind die Vorgaben des Art. 5 InfoSoc-Richtlinie und die Entscheidung des europäischen Gesetzgebers für einen Katalog von Schrankentatbeständen bei der Einführung neuer oder Änderung bestehender Schrankenregelungen jedenfalls als „Höchstgrenzen" 1952 der Schrankenausgestaltung zwingend zu beachten. Sie stehen der Einführung völlig neuer, im Katalog des Art. 5 InfoSoc-RL nicht vorgesehener Schrankenbestimmungen entgegen.

Durch die ergänzende Einführung einer Schrankengeneralklausel würde jedoch der vom europäischen Gesetzgeber vorgegebene Rahmen für Schrankenbestimmungen überschritten. Durch die nur subsidiäre Anwendung der Auffanggeneralklausel würde diese gerade nur dann Anwendung finden, wenn eine (innovative) Form der Werknutzung sich im Rahmen des engen „Korsetts“ des Artikels 5 der InfoSoc-Richtlinie - beziehungsweise der in Umsetzung dieser Regelung erlassenen nationalen Bestimmungen - nicht rechtfertigen lässt. Nach § 61 UrhG-E für zulässig erachtete Nutzungshandlungen lägen folglich regelmäßig außerhalb des vom europäischen Gesetzgeber vorgesehenen (engen) Gestaltungsspielraums für den nationalen Gesetzgeber. Mit den geltenden Vorgaben der InfoSocRichtlinie wäre die vorgeschlagene Auffanggeneralklausel daher nicht vereinbar. ${ }^{1953}$

\section{Zusammenfassung und Bewertung}

Gegen die Einführung einer alleinigen Schrankengeneralklausel im deutschen Urheberrecht bestehen erhebliche Bedenken. Eine solche Regelung könnte zwar äußerst weitreichende Flexibilität im Bereich der urheberrechtlichen Schranken erzeugen. Ihre Einführung ginge jedoch zu Lasten der Rechtssicherheit, da die bisher anerkannten Formen der Werknutzung,

1951 Zur Kritik an der Ausgestaltung der Schrankenbestimmungen durch die InfoSoc-Richtlinie, siehe oben 6. Kapitel, B.III.

1952 Bayreuther, ZUM 2001, 828 (829).

1953 So in Bezug auf jeweils anders ausgestaltete Auffanggeneralklauseln im Ergebnis auch Hansen, Warum Urheberrecht, S. 409; Poeppel, Neuordnung, S. 505. 
für deren Zulässigkeit der Gesetzgeber bereits Kriterien in einzelnen Schrankenbestimmungen explizit ausdifferenziert und die Rechtsprechung diese ausgelegt hat, unnötig aufgegeben und der Unsicherheit einer Einzelfallprüfung anhand einer alleinigen Generalklausel unterworfen würden. Der unleugbare Vorteil eines - sinnvoll und übersichtlich gestalteten - Schrankenkataloges, eine Orientierungshilfe für Urheber und Nutzer zu bieten, würde ohne hinreichenden Grund aufgegeben, da eine vollständige Streichung der bestehenden Schrankenbestimmungen nicht erforderlich ist, um die notwendige Flexibilität im Bereich der urheberrechtlichen Schranken zu erreichen.

Dasselbe Maß an Flexibilität lässt sich nämlich auch unter Beibehaltung eines - idealerweise deutlich gestrafften und gekürzten - Kataloges urheberrechtlicher Schranken durch dessen Ergänzung um eine Generalklausel als Auffangtatbestand erreichen. Die vorgeschlagene Auffanggeneralklausel des $\S 61$ UrhG-E vereint die Flexibilität des urheberrechtlichen Dreistufentests und die Vorhersehbarkeit eines Kriterienkataloges in Anlehnung an die US-amerikanische Fair Use-Schranke. Durch die nur subsidiäre Anwendung in Fällen, in denen keine spezifische Schrankenregelung einschlägig ist, bietet diese Ausgestaltung ein größtmögliches Maß an Rechtssicherheit und Nutzerfreundlichkeit und ermöglicht einen gerechten Interessenausgleich. Für den Rechtsanwender ist durch die (gestrafften) Einzelschrankentatbestände, die nur noch auf die vom Gesetzgeber vorgesehenen Fälle Anwendung finden und keiner übermäßig weiten Ausdehnung auf vom Wortlaut nicht erfasste Formen der Werknutzung bedürfen, vielfach wieder deutlich leichter zu erkennen, welche Nutzungshandlungen im Rahmen der Schrankenregelungen zulässig sind, und ob für diese gegebenenfalls eine Vergütung zu zahlen ist. Unterfällt eine Werknutzung hingegen keiner Schrankenbestimmung, so ist für den Rechtsanwender ersichtlich, dass sich die Nutzung allein am Maßstab der Schrankengeneralklausel messen lassen muss. Aus dem an die Fair UseSchranke angelehnten gesetzlichen Kriterienkatalog lassen sich dabei die grundlegenden Voraussetzungen einer legalen Nutzung entnehmen, so dass dem Nutzer oftmals bereits eine Abschätzung der Zulässigkeit erleichtert wird. Mit zunehmender Konkretisierung des Kriterienkataloges durch die Rechtsprechung wird zudem insoweit die Vorhersehbarkeit wachsen.

Ein Wermutstropfen verbleibt jedoch auch bei diesem erstrebenswerten Flexibilisierungsinstrument: Die vorgeschlagene Auffanggeneralklausel ist zwar konventions- und verfassungsrechtskonform, sie lässt sich jedoch 
nicht mit geltendem europäischem Recht vereinbaren. Erwägungsgrund 32 zur InfoSoc-Richtlinie statuiert, dass die Schrankenbestimmungen in der Richtlinie jedenfalls in Bezug auf das Vervielfältigungsrecht und das Recht der öffentlichen Wiedergabe erschöpfend aufgeführt sind. Die Vorgaben der InfoSoc-Richtlinie stehen daher der - im Hinblick auf die sich stetig wandelnde Werknutzungsrealität dringend erforderlichen - Einführung völlig neuer, im Katalog des Art. 5 InfoSoc-RL nicht vorgesehener Schrankenbestimmungen entgegen. Dies verdeutlicht, wie der europäische Gesetzgeber den Gestaltungsspielraum der nationalen Gesetzgeber durch die InfoSoc-Richtlinie eingeengt hat, ohne jedoch die erhoffte Harmonisierung der urheberrechtlichen Schranken oder wenigstens deren $\mathrm{Zu}$ kunftsfähigkeit durch Anpassung an die Herausforderungen der Informationsgesellschaft erreicht zu haben. ${ }^{1954}$

Lässt sich im nationalen Recht jedoch weder eine alleinige Schrankengeneralklausel noch eine Auffanggeneralklausel im Rahmen des geltenden europäischen Rechts umsetzen, so begegnet sie letztlich denselben Zweifeln, wie die für das europäische Recht unterbreiteten Vorschläge: Ihre Einführung setzt die Änderung europäischen Richtlinienrechts beziehungsweise eine grundlegende Neuorientierung und -ordnung des europäischen Urheberrechts voraus. Beides erscheint derzeit leider nicht realistisch. Ließe sich hingegen tatsächlich die erforderliche Änderung des europäischen Urheberrechts erreichen, so erscheint letztlich die Einführung einer Auffanggeneralklausel in einer europäischen Urheberrechtsverordnung als Ergänzung eines gestrafften, zwingend ausgestalteten Schrankenkataloges gegenüber der Einführung einer Generalklausel im nationalen Recht vorzugswürdig, da so eine - zur Verwirklichung eines funktionierenden Binnenmarktes unumgängliche - tatsächliche Harmonisierung des Urheberrechts mit einem europaweit einheitlichen Schrankenstandard erreicht werden könnte.

\section{Ergänzung einzelner Urheberrechtsschranken um flexiblere Elemente}

Lehnt man die Einführung einer urheberrechtlichen Schrankengeneralklausel im deutschen Recht generell ab, oder zeigt sich - wie zu befürch-

1954 Vgl. näher zur Kritik an den Schrankenregelungen der InfoSoc-Richtlinie oben 6. Kapitel, B.III. 
ten ist -, dass die zur Einführung einer Generalklausel erforderlichen Änderungen des europäischen Urheberrechts in naher Zukunft nicht zu erzielen sind, so ist zumindest eine „kleine Lösung“1955 zur Erreichung größerer Schrankenflexibilität in Form einer flexibleren Ausgestaltung der bestehenden nationalen Schrankenregelungen erstrebenswert. Eine vorsichtige und partielle Öffnung einzelner Schrankentatbestände kann insbesondere durch die verstärkte Verwendung von unbestimmten Rechtsbegriffen und Regelbeispielen sowie durch die Einführung generalklauselartiger, weiter Formulierungen innerhalb einzelner Schrankentatbestände erreicht werden. Zudem ist zur Lösung spezifischer Probleme auch die Einführung spezieller Schrankentatbestände - etwa zur urheberrechtlichen Privilegierung von (Bilder-) Suchmaschinen - denkbar.

Derartige Maßnahmen zur Flexibilisierung der Schranken des deutschen Urheberrechtsgesetzes sind an anderer Stelle ausführlich erörtert worden, ${ }^{1956}$ weshalb eine detaillierte Auseinandersetzung nicht Gegenstand dieser Untersuchung sein soll. Einige Flexibilisierungsmöglichkeiten, von denen der deutsche Gesetzgeber bereits Gebrauch gemacht hat, sollen jedoch im Folgenden überblicksartig dargestellt werden.

\section{Die Einführung von Regelbeispielen}

Eine Möglichkeit, die urheberrechtlichen Schranken zu flexibilisieren, ist die Ausgestaltung der Schrankentatbestände unter Verwendung von Regelbeispielen, die - ähnlich wie die Fair Use-Kriterien - zum einen den erforderlichen Freiraum für die Anwendung der jeweiligen Schrankenbestimmung auf weitere, nicht ausdrücklich genannte Fälle ermöglichen, zum anderen durch die beispielhafte Aufzählung privilegierter Zwecke Anhaltspunkte für die Zulässigkeitsprüfung bieten und somit die Vorhersehbarkeit einer Schrankenregelung steigern. Von dieser Flexibilisierungsmöglichkeit, die im Urheberrechtsgesetz seit jeher in $\S 2$ UrhG in Bezug

1955 Förster, Fair Use, S. 216 f.

1956 Siehe insbesondere die detaillierte Analyse zur Umgestaltung und Weiterentwicklung der Schranken des Urheberrechtsgesetzes bei Poeppel, Neuordnung, S. 163 ff. Siehe auch Förster, Fair Use, S. 216 ff.; Hansen, Warum Urheberrecht, S. $360 \mathrm{ff}$. (Einfügung einer programmatischen Normzweckklausel); Schaefer, Bildersuchmaschinen, S. 165 ff. (Einführung einer speziellen Schrankenregelung für (Bilder-)Suchmaschinen). 
auf die geschützten Werke angewendet und auch in anderen Gesetzen, etwa dem UWG, ${ }^{1957}$ weit verbreitet ist, hat der deutsche Gesetzgeber in jüngerer Zeit auch in Bezug auf die urheberrechtlichen Schranken Gebrauch gemacht.

Prominentestes Beispiel einer solchen Flexibilisierung der Schranken des Urheberrechts ist die Neuregelung der Zitierfreiheit des § 51 UrhG im Rahmen des ,zweiten Korbes“ der Urheberrechtsreform. ${ }^{1958}$ Die Regelung des $\S 51$ UrhG a.F. sah sich aufgrund der drei abschließend aufgezählten Zitatkategorien (Groß-, Klein- und Musikzitat) der berechtigten Kritik ausgesetzt, keinen hinreichenden Raum für die Anpassung des Zitatrechts an die sich wandelnde Nutzungsrealität und technisch bedingte neue Formen des Zitierens zu bieten. ${ }^{1959}$ Diesen - trotz einer behutsamen Öffnung des Zitatrechts durch die Rechtsprechung 1960 - mit der fortschreitenden Veränderung der technologischen Gegebenheiten wachsenden Bedenken trug der Gesetzgeber Rechnung, indem er im Zuge des „Zweiten Korbes“ die Regelung des $\S 51$ UrhG unter Verwendung flexiblerer Elemente vorsichtig umgestaltete. Nach der neu eingefügten „kleinen“ Generalklausel in $\S 51 \mathrm{~S} .1$ UrhG darf ein veröffentlichtes Werk nun ganz generell zitatweise genutzt werden, sofern die Nutzung in ihrem Umfang durch den besonderen Zweck gerechtfertigt ist. Dieser Satz 1 wird ergänzt um eine beispielhafte Aufzählung von Fällen einer zulässigen Nutzung in Satz 2, bei denen der frühere Gesetzeswortlaut weitestgehend beibehalten wurde. Dies verdeutlicht zum einen, dass bisher zulässige Zitate auch weiterhin zulässig bleiben, zum anderen wird das Zitatrecht mit Blick auf weitere Werkarten vorsichtig geöffnet, ohne es jedoch grundlegend zu erweitern. ${ }^{1961}$ Neue oder bisher von der Rechtsprechung etwa durch Analogien anerkannte Formen des Zitats können so auf eine ausdrückliche gesetzliche Grundlage gestützt werden, wenn eine Auslegung ergibt, dass die "Nutzung in ihrem Umfang durch den besonderen Zweck gerechtfertigt“

1957 Vgl. etwa den Beispielkatalog unlauterer geschäftlicher Handlungen in $\S 4$ UWG.

1958 Siehe dazu auch bereits oben 4. Kapitel, B.I.1.c) und 4. Kapitel, B.II.2.

1959 Siehe statt vieler etwa die Kritik an $\S 51$ UrhG a.F. bei Fromm/Nordemann/ Vinck, 9. Aufl., § 51 Rn. 1; Schricker/Schricker, 3. Aufl., § 51 Rn. 5; Wandtke/ Bullinger/Lüft, 2. Aufl., § 51 Rn. 1.

1960 Siehe zur erweiternden Auslegung der Schrankenbestimmungen durch BGH und BVerfG näher oben 2. Kapitel, B.I.2.b).

1961 Vgl. BT-Drs. 16/1828, S. 25. 
ist, wobei insbesondere die aufgeführten Regelbeispiele als Vergleichsmaßstab dienen können.

\section{Die Einführung generalklauselartiger, weiter Formulierungen innerhalb einzelner Tatbestände}

Anstelle einer alleinigen Schrankengeneralklausel oder einer grundsätzlich für alle Formen der Werknutzung geltenden Auffanggeneralklausel kann auch durch die Einführung generalklauselartiger Formulierungen innerhalb einzelner Tatbestände eine Flexibilisierung der Schrankenbestimmungen erreicht werden. So können die bestehenden Schranken vorsichtig auf solche Formen der Werknutzung erweitert werden, die durch sich wandelnde technische Gegebenheiten ermöglicht werden. Anders als bei einer unabhängig von der Werkart oder Nutzungsform für sämtliche Sachverhalte geltenden (Auffang-)Generalklausel, ist der so erzielte Flexibilitätsgewinn freilich auf den in der jeweiligen Schranke konkret geregelten Nutzungssachverhalt beschränkt.

Derartige generalklauselartige Schrankenbestimmungen hat der deutsche Gesetzgeber in den vergangenen Jahren bereits in das Urheberrechtsgesetz eingefügt. Ein Beispiel einer solchen Flexibilisierung bildet der soeben dargestellte $\S 51$ S. 1 UrhG in seiner seit dem „Zweiten Korb“ der Urheberrechtsreform geltenden Fassung. Danach ist ein Zitat - unabhängig vom verwendeten Medium - zulässig, wenn die „Nutzung in ihrem Umfang durch den besonderen Zweck gerechtfertigt" ist. Dies nähert sich deutlich der US-amerikanischen Fair Use-Prüfung an, insbesondere deren erster und dritter Stufe, die für die Zulässigkeit einer Nutzung ebenfalls auf deren Zweck und Umfang abstellt. Auch zwei weniger prominente Regelungen des Urheberrechtsgesetzes sind generalklauselartig ausgestaltet die für Computerprogramme beziehungsweise Datenbanken geltenden $\S \S 69$ e Abs. 3 und 87b Abs. 1 S. 2 UrhG. In diesen Bestimmungen hat - in enger Anlehnung an den Dreistufentest - ausdrücklich eine Abwägung der Belange unter Berücksichtigung der jeweiligen Interessenlage im Einzelfall Eingang in das deutsche Urheberrecht gefunden. ${ }^{1962} \S 69 \mathrm{e}$ Abs. 3

1962 Vgl. Dreier/Schulze, §69e Rn. 22, § 87b Rn. 16; Lehmann, GRUR Int. 1991, 327 (334); Wandtke/Bullinger/Grützmacher, § 69e Rn. 24 (mit dem ausdrücklichen Hinweis, es fände eine ,letzte Kontrolle im Sinne des angloamerikanischen Fair-Use-Gedanken statt"); Wandtke/Bullinger/Thum, § 87b Rn. 68. 
UrhG begrenzt generalklauselartig die detaillierten Regelungen zur Zulässigkeit der Dekompilierung in den Absätzen 1 und 2 und regelt, diese Bestimmungen seien so auszulegen, dass ihre Anwendung ,weder die normale Auswertung des Werkes beeinträchtigt noch die berechtigten Interessen des Rechtsinhabers unzumutbar verletzt“". Ähnlich regelt $\S 87 \mathrm{~b}$ Abs. 1 S. 2 UrhG, dass der Verwendung eines nach Art oder Umfang wesentlichen Teils der Datenbank die wiederholte und systematische Vervielfältigung, Verbreitung oder öffentliche Wiedergabe von nach Art und Umfang unwesentlichen Teilen der Datenbank gleichkommt, „sofern diese Handlungen einer normalen Auswertung der Datenbank zuwiderlaufen oder die berechtigten Interessen des Datenbankherstellers unzumutbar beeinträchtigen“".

Auch wenn es sich bei $\S 69$ e Abs. 3 UrhG um eine Bestimmung zur Begrenzung der im Übrigen detailliert geregelten Zulässigkeit einer Nutzung und bei $\S 87 \mathrm{~b}$ Abs. 1 S. 2 UrhG um eine Regelung zur Begrenzung des Schutzes auf wesentliche (Werk-)Teile handelt und diese Bestimmungen folglich keine „klassischen“, mit den Regelungen der $\S \S 44$ a ff. UrhG vollständig vergleichbaren Schrankenbestimmungen darstellen, zeigen sie doch, dass auch im Urheberrecht dem deutschen Gesetzgeber eine (vorsichtige) Abstandnahme vom traditionellen deutschen System geschlossener Schrankentatbestände und eine Hinwendung zu generalklauselartigen Ausgestaltungen nicht völlig fremd ist.

Zudem enthält das Urheberrechtsgesetz mit der Regelung des §24 UrhG seit jeher eine nicht technologiespezifische generalklauselartige Schrankenregelung, ${ }^{1963}$ die im Interesse der wissenschaftlichen und künstlerischen Auseinandersetzung und unter Abwägung der sich gegenüber stehenden Belange im Einzelfall die Übernahme fremden individuellen Gedankengutes erlaubt. ${ }^{1964}$

Angesichts dieser Tatsache erstaunt es umso mehr, dass die Einführung einer für sämtliche Formen der Werknutzung geltenden Auffanggeneralklausel weiterhin vielfach ganz erheblichen Bedenken begegnet. Diese hätte jedoch gegenüber der generalklauselartigen Ausgestaltung nur einzelner Tatbestände den deutlichen Vorteil, dass sie - unabhängig von der

1963 Zur umstrittenen - hier bejahten - Frage, ob es sich bei der Regelung des $\S 24$ UrhG um eine Schranke des Urheberrechts oder lediglich um eine Schutzumfangsbestimmung bzw. negative Inhaltsabgrenzung zu $§ 23$ UrhG handelt, siehe bereits oben 2. Kapitel, B.I.3.a).

1964 Vgl. Haberstumpf, ZUM 2003, 83. 
konkreten Form der Nutzung oder des verwendeten Werkes - immer dann die erforderliche Flexibilität bieten könnte, wenn diese tatsächlich benötigt würde, um wünschenswerte Nutzungen zu ermöglichen. Die Vergangenheit hat jedoch gezeigt, dass sich solche neuen Formen der Werknutzung oftmals nicht vorhersehen lassen, so dass die generalklauselartige Ausgestaltung einzelner Schranken in aller Regel nur nachträglich erfolgen kann, wenn sich - wie etwa im Falle des Zitatrechts - bereits ein erheblicher Änderungsbedarf gezeigt hat. Bis zu dieser - zumeist langwierigen Gesetzesänderung besteht jedoch regelmäßig ein Zustand erheblicher Rechtsunsicherheit. Diesen könnte eine sinnvoll ausgestaltete Schrankengeneralklausel als subsidiärer Auffangtatbestand verhindern. Zugleich hätte eine für alle Formen der Werknutzung geltende Auffangschranke den erheblichen Vorteil, für nicht von den bestehenden Schrankenbestimmungen erfasste Nutzungshandlungen einen einheitlichen Zulässigkeitsmaßstab zu bieten.

\section{Fazit und Perspektive zur Flexibilisierung der urheberrechtlichen Schrankenbestimmungen in Deutschland und Europa}

Die Untersuchung hat anhand des Umgangs der deutschen und US-amerikanischen (Rechtsprechungs-)Praxis mit den Geschäftsmodellen der Thumbnail-Nutzung durch Bildersuchmaschinen und der Google Buchsuche gezeigt, vor welche enormen, zum Teil unüberwindbaren, rechtsdogmatischen und -praktischen Schwierigkeiten neue (kommunikations-)technische Entwicklungen und auf diesen basierende neue Formen der Werknutzung insbesondere das deutsche Urheberrecht mit seinen starren Schrankenbestimmungen stellen. ${ }^{1965}$ Während es im deutschen Recht in den vergangenen Jahrzehnten oftmals noch mit einzelnen Retouchen durch den Gesetzgeber oder durch Heranziehung mehr oder minder überzeugender rechtlicher Konstruktionen durch die Rechtsprechung gelungen ist, die urheberrechtlichen Schrankenregelungen neuen Entwicklungen anzupassen, haben die dargestellten Problemfälle - die sich mühelos um weitere Beispiele ergänzen ließen - gezeigt, dass nun aufgrund der immer rasanter fortschreitenden technischen Entwicklung und aufgrund der damit

1965 Siehe oben 4. Kapitel (zum deutschen Recht) und 5. Kapitel (zum US-amerikanischen Recht). 
einhergehenden veränderten Werknutzungsrealität ein Punkt erreicht ist, an dem eine solche rechtliche „Flickschusterei“ nicht einmal mehr die zweitbeste, sondern gar keine befriedigende Lösung darstellt. Eine zukunftsoffene Flexibilisierung der deutschen und/oder europäischen urheberrechtlichen Schrankenregelungen de lege ferenda ist daher dringend erforderlich.

Im US-amerikanischen Urheberrecht gelingt es hingegen aufgrund der flexiblen Fair Use-Schranke deutlich besser, auch neue urheberrechtliche Herausforderungen einer interessengerechten Lösung zuzuführen. Die Regelung des 17 U.S.C. $\S 107$ in ihrer Ausgestaltung durch eine langjährige Rechtsprechung bietet sich daher besonders als Ausgangspunkt einer Neugestaltung der urheberrechtlichen Schranken im deutschen und europäischen Recht an.

Die Überlegungen zur Ausgestaltung legislativer Maßnahmen zur Flexibilisierung der urheberrechtlichen Schranken auf Basis der Fair UseDoktrin haben gezeigt, dass es weder auf europäischer noch auf nationaler Ebene erstrebenswert erscheint, die bestehenden Schrankenkataloge vollständig zu streichen und durch eine alleinige Schrankengeneralklausel zu ersetzen. Dasselbe Maß an Flexibilität kann nämlich auch erreicht werden, ohne die Vorteile detaillierter Schrankenbestimmungen aufzugeben. Die Ergänzung eines - sinnvoll gestrafften - Schrankenkataloges um eine Schrankengeneralklausel als subsidiären Auffangtatbestand ermöglicht es, die Vorteile beider Systeme zu vereinen. Die Auffanggeneralklausel ermöglicht das Erfassen neuartiger Formen der Werknutzung und bringt so die notwendige Flexibilität in die zu starren Schrankenbestimmungen. Durch die Ergänzung des Kataloges von Schrankenbestimmungen um eine Auffanggeneralklausel würde das Urheberrecht zudem anwenderfreundlicher. Der Schrankenkatalog könnte seine eigentliche Stärke - die Gewährung eines hohen Maßes an Rechtssicherheit - zurückgewinnen. Finden die einzelnen Schrankentatbestände tatsächlich nur noch Anwendung auf die vom Gesetzgeber vorgesehenen Sachverhalte, so ist für den Rechtsanwender in aller Regel - auch ohne nähere Kenntnis der Rechtsprechung zu den urheberrechtlichen Schranken - wieder durch einen Blick in das Gesetz zu erkennen, welche Nutzungshandlungen unter welchen Voraussetzungen im Rahmen der Schrankenregelungen zulässig sind, und ob für diese gegebenenfalls eine Vergütung zu zahlen ist. Bei allen anderen insbesondere neuartigen - Formen der Werknutzung, die keiner Schrankenbestimmung unterfallen, ist hingegen für den Rechtsanwender ersicht- 
lich, dass sich die Nutzungen allein am Maßstab der Schrankengeneralklausel messen lassen müssen.

Besonders vielversprechend erscheint die Ausgestaltung einer solchen Auffanggeneralklausel in Anlehnung an den urheberrechtlichen Dreistufentest und dessen Ergänzung um einen an die US-amerikanische Fair Use-Schranke angelehnten Katalog von Prüfungskriterien. ${ }^{1966}$ Der im Völker- und Europarecht etablierte - auf einen Zweistufentest reduzierte Dreistufentest ermöglicht einen angemessenen Interessenausgleich und bietet durch den offenen Wortlaut weitreichende Flexibilität. Der Fair Use-ähnliche Kriterienkatalog minimiert zugleich die bei alleiniger Anwendung des konventions- oder europarechtlichen Dreistufentests bestehenden Unsicherheiten. So gewährleisten die für das europäische und deutsche Recht vorgeschlagenen Auffanggeneralklauseln neben erheblicher Flexibilität zugleich ein größtmögliches $\mathrm{Ma} ß$ an Rechtssicherheit. Durch die nur subsidiäre Anwendung der Regelungen finden diese nur auf solche Sachverhalte Anwendung, die nicht bereits von einer der im Rahmen des Schrankenkataloges enthaltenen Schrankenbestimmungen erfasst werden. Kommt es jedoch zu einer Anwendung der Generalklausel, so erfolgt die Prüfung anhand nachvollziehbarer, Fair Use-ähnlicher Kriterien, die die Prüfung so vorhersehbar wie möglich machen. Die Vorhersehbarkeit nimmt zudem im Laufe der Zeit weiter zu, wenn eine Auslegung und Ausdifferenzierung der einzelnen Prüfungskriterien durch die Rechtsprechung stattgefunden hat. Durch die Rechtsprechung in Anwendung der Generalklausel etablierte Fallgruppen könnten zudem durch den europäischen oder nationalen Gesetzgeber zur Steigerung der „Nutzerfreundlichkeit" und Rechtssicherheit in den Schrankenkatalog einer Urheberrechtsverordnung beziehungsweise des Urheberrechtsgesetzes aufgenommen werden. Eine solche Kodifizierung einzelner, von der Rechtsprechung etablierter Fallgruppen könnte gegebenenfalls dazu beitragen, die langwierigen Gesetzgebungsprozesse zu verkürzen oder diese jedenfalls interessengerechter auszugestalten. Die einer ausgeglichenen und zügigen Gesetzgebung nicht förderlichen Einflussnahmeversuche von Lobbyverbänden, die bei einer Schrankenneuschöpfung durch den Gesetzgeber stets zu beobachten sind, könnten deutlich minimiert werden, wenn der Gesetzgeber le-

1966 Siehe den Vorschlag für das europäische Recht, oben 7. Kapitel, A.II.2. und den Vorschlag für das deutsche Recht, oben 7. Kapitel, B.II. 
diglich eine allgemein anerkannte - von Lobbyeinflüssen vergleichsweise freier entstandene - Rechtsprechungspraxis in Gesetzesform gösse.

Die Untersuchung hat jedoch auch gezeigt, dass die Einführung einer solchen Auffanggeneralklausel im deutschen oder europäischen Recht die Änderung europäischen Richtlinienrechts beziehungsweise - im Falle einer Verwirklichung als Teil einer europäischen Urheberrechtsverordnung - eine grundlegende Neuorientierung und -ordnung des europäischen Urheberrechts voraussetzt. Es ist derzeit zu befürchten, dass weder das Eine noch das Andere zeitnah erfolgen wird. Lässt sich hingegen tatsächlich die erforderliche Änderung des europäischen Urheberrechts erreichen, so erscheint die Einführung einer Auffanggeneralklausel in einer europäischen Urheberrechtsverordnung als Ergänzung eines gestrafften, zwingend ausgestalteten Schrankenkataloges gegenüber der Einführung einer Generalklausel im nationalen Recht vorzugswürdig, da so eine - zur Verwirklichung eines funktionierenden Binnenmarktes unumgängliche - tatsächliche Harmonisierung des Urheberrechts mit einem europaweit einheitlichen Schrankenstandard erreicht werden könnte.

Allein die fehlende Aussicht auf einen zeitnahen Erfolg sollte jedoch nicht dazu führen, die Idee einer grundlegenden Änderung des europäischen Urheberrechts und einer dringend notwendigen Flexibilisierung der urheberrechtlichen Schranken zu verwerfen. Es sollte vielmehr Mut machen, dass sich gerade in jüngerer Zeit nicht nur in der Wissenschaft, sondern auch in der Politik jedenfalls ein Konsens dahingehend herausgebildet zu haben scheint, dass eine Flexibilisierung der Schrankenbestimmungen de lege ferenda erforderlich ist, damit das Urheberrecht nicht weiter an Akzeptanz einbüßt, indem es den Anschluss an die schnelle und oftmals unvorhersehbare technische Entwicklung vollends verliert. Diese wünschenswerte Entwicklung gilt es voranzutreiben und um Vorschläge zu ergänzen, die als Diskussionsgrundlage dafür dienen können, wie die notwendige Flexibilisierung der urheberrechtlichen Schrankenbestimmungen sinnvoll ausgestaltet werden kann. 


\section{Kapitel Zusammenfassung der wesentlichen Ergebnisse in} Thesen

1. Die Schrankensysteme der kontinentaleuropäischen Länder mit einer droit d'auteur-Tradition und des US-amerikanischen Copyright Law haben sich in den vergangenen Jahrzehnten insbesondere als Folge der Umsetzung konventionsrechtlicher Verpflichtungen und aufgrund europäischer Binnenharmonisierungsbestrebungen in einigen Bereichen deutlich angenähert. Trotz des stetigen Abbaus charakteristischer Elemente des traditionell ökonomisch-utilitaristisch begründeten US-amerikanischen Copyright und der Einführung einiger kontinentaleuropäischer Elemente bestehen jedoch auch weiterhin grundlegende Unterschiede $\mathrm{zu}$ den Rechtssystemen der Länder mit einer droit d'auteurTradition. Dies zeigt sich neben dem nur in begrenztem Umfang gewährten Schutz von moral rights, die weiterhin als Fremdkörper mit geringer praktischer Relevanz erscheinen, insbesondere im Bereich der urheberrechtlichen Schranken. Auch wenn das US-amerikanische Urheberrecht in 17 U.S.C. $\S \S 108-122$ einen Katalog von Schrankenbestimmungen, die sogenannten Statutory Exceptions, enthält, kommt im Hinblick auf die Einschränkung der urheberrechtlichen Ausschließlichkeitsrechte eine ganz zentrale Rolle weiterhin der Generalklausel des Fair Use zu.

2. Durch die Kodifizierung der von der Rechtsprechung entwickelten Fair Use-Doktrin in 17 U.S.C. § 107 im Jahre 1976 hat sich an der Auslegung und Anwendung der Doktrin durch die Gerichte grundsätzlich nichts geändert. Weiterhin ist daher zur Feststellung von Fair Use eine Einzelfallanalyse vorzunehmen. Diese erfolgt in der Regel anhand der vier im Gesetz genannten, nicht abschließenden Faktoren, kann jedoch auch einzelne Faktoren außer Betracht lassen oder weitere Kriterien heranziehen. Dies eröffnet den Gerichten ein erhebliches Maß an Flexibilität bei der Anwendung der Schrankenbestimmung.

3. Der Vorteil deutlich größerer Flexibilität der Generalklausel des Fair Use gegenüber einem geschlossenen Katalog urheberrechtlicher Schrankenbestimmungen zeigt sich insbesondere bei der Konfrontation 
mit durch technische Entwicklungen bedingten, neuartigen Formen der Werknutzung. Die vergleichende Untersuchung der Thumbnail-Nutzung durch Suchmaschinen und der Google Buchsuche hat gezeigt, dass sich Nutzungsformen, die zum Zeitpunkt der Gesetzgebung noch unbekannt und unabsehbar waren, im Rahmen eines geschlossenen Schrankenkataloges europäischen Zuschnitts - wenn überhaupt - oftmals nur unter Zuhilfenahme zum Teil fragwürdiger Analogien und äußerst extensiver Auslegungen bestehender Schrankenregelungen bis hin zu einer vollständigen Abkehr vom Wortlaut und von etablierten Auslegungsmethoden und -ergebnissen rechtfertigen lassen. Im Rahmen der technologieneutral und wertungsoffen ausgestalteten Fair Use-Schranke gelingt es hingegen deutlich problemloser, auch einer solchen veränderten Werknutzungsrealität gerecht zu werden und wünschenswerte neue Formen der Werknutzung zuzulassen.

4. Anhand der Beispiele der Thumbnail-Nutzung durch Suchmaschinen und der Google Buchsuche hat sich gezeigt, dass auch im deutschen und europäischen Urheberrecht mehr Flexibilität im Bereich der Schrankenbestimmungen dringend erforderlich ist. Als Vorbild einer Flexibilisierung der urheberrechtlichen Schranken de lege ferenda kann aufgrund der genannten Vorteile die Generalklausel des Fair Use dienen. Insbesondere bei einer Ausgestaltung, die sich ein Zusammenspiel von Fair Use-Erkenntnissen mit dem im internationalen und europäischen Urheberrecht etablierten Dreistufentest zunutze macht, kann eine Schrankengeneralklausel auch die erforderliche Vorhersehbarkeit und Rechtssicherheit gewährleisten und sich zugleich leichter in das europäische Urheberrecht einfügen.

5. Bei genauerer Betrachtung zeigt sich bereits, dass das regelmäßig gegen eine Schrankengeneralklausel angeführte Argument mangelnder Rechtssicherheit jedenfalls für die US-amerikanische Fair Use-Schranke in ihrer Ausgestaltung durch die Rechtsprechung keine Geltung beanspruchen kann. In den USA hat sich ein Grundkonsens über die Bedeutung und Reichweite der Fair Use-Doktrin entwickelt, auf dessen Grundlage eine über Jahrzehnte in einer Vielzahl von Entscheidungen gefestigte Rechtsprechung zur Generalklausel des Fair Use entstanden ist. Die Tradition der Formulierung oftmals umfangreicher obiter dicta und dissenting opinions, die gerade bei späteren Entscheidungen ähnlich gelagerter Fälle als Argumentations- und Abgrenzungsgrundlage 
herangezogen werden können, hat zudem zusätzlich zur Entwicklung und Ausformung der Fair Use-Doktrin und somit letztlich zu größerer Vorhersehbarkeit beigetragen. Schließlich entsteht durch das Zusammen- und Gegenspiel verschiedener (Bezirks-)Gerichte eine Art „Signalsystem" gegenläufiger Rechtsansichten und Entscheidungen, die „reif" für eine Überprüfung durch den Supreme Court sind. Die mit Hilfe dieses Fair Use-,,Werkzeugkastens“ zahlreich entwickelten Kriterien, Regeln und Prinzipien für die Auslegung und Ausfüllung der Fair Use-Schranke werden von den Gerichten tatsächlich in aller Regel bei ihren Fair Use-Entscheidungen beachtet, so dass die Rechtsprechung keinesfalls bei jeder neuen Entscheidung ,im Dunkeln stochern“ und ohne Leitlinie völlig frei anhand der weiten (und nicht abschließenden) Kriterien des 17 U.S.C. § 107 entscheiden müsste. Tatsächlich werden daher nur selten völlig überraschende, kaum vorhersehbare Urteile gefällt.

6. Die Erkenntnis, dass mit der Einführung einer Schrankengeneralklausel gar ein Rechtssicherheitsgewinn einhergehen kann, lässt sich jedoch auf das europäische Recht nicht zwanglos übertragen. Es muss insbesondere mit Blick auf die Rolle und Methodik des Gerichtshofs der Europäischen Union bezweifelt werden, ob eine Schrankengeneralklausel nach dem Vorbild des Fair Use im Rahmen des europäischen Gerichtssystems ebenso erfolgreich und rechtssicher ausgestaltet und ausgefüllt werden könnte wie in den USA. Durch das System der Vorabentscheidungsverfahren durch den EuGH nach Artikel 267 AEUV kommt nur eine relativ geringe Zahl von Fällen zur höchstrichterlichen Entscheidung. Die Möglichkeit des EuGH zur Klärung und Weiterentwicklung des europäischen Urheberrechts hängt somit maßgeblich davon ab, welche Fragen die nationalen Gerichte ihm zur Vorabentscheidung vorlegen. Nur langsam würde deshalb voraussichtlich eine „Anreicherung" der Schrankengeneralklausel mit dem für hinreichende Rechtssicherheit erforderlichen Fallrecht erfolgen. Zudem erscheint auch die vom EuGH angewandte Methodik bisher nicht hinreichend geeignet, den zur Ausfüllung einer Generalklausel erforderlichen „Werkzeugkasten“ mit den benötigten Werkzeugen zu bestücken.

7. Diese Schwäche ist jedoch kein Grund, vollständig von der Einführung einer Schrankengeneralklausel Abstand zu nehmen. Sie kann vielmehr behoben werden, indem nicht eine alleinige Generalklausel eingeführt 
wird, sondern eine Fair Use-ähnliche, subsidiäre Auffangschranke, die einen gestrafften Katalog von Einzelbeschränkungen ergänzt.

8. Eine solche Flexibilisierung de lege ferenda könnte entweder auf Ebene des europäischen Rechts - insbesondere im Rahmen einer wünschenswerten europäischen Urheberrechtsverordnung - oder im nationalen Recht durch Änderung des Urheberrechtsgesetzes erfolgen.

9. In beiden Fällen bietet sich eine Ausgestaltung der Auffanggeneralklausel in Anlehnung an den im Europa- und Völkerrecht verankerten urheberrechtlichen Dreistufentest und die US-amerikanische Fair UseDoktrin an. Durch die Anlehnung an den Dreistufentest brächte die Generalklausel die notwendige Flexibilität in die derzeit zu starren Schranken der InfoSoc-Richtlinie bzw. des Urheberrechtsgesetzes, ohne jedoch als Fremdkörper zu erscheinen. Der Fair Use-ähnliche Kriterienkatalog ermöglicht es zugleich, die bei der Anwendung einer Generalklausel ohne hinreichende Anhaltspunkte bestehenden Unsicherheiten zu reduzieren und ein größtmögliches $\mathrm{Ma} ß$ an Vorhersehbarkeit zu gewährleisten. Durch die Auslegung und Ausdifferenzierung der einzelnen Prüfungskriterien durch die Rechtsprechung nähme die Vorhersehbarkeit zudem stetig zu. Durch die Rechtsprechung in Anwendung der Generalklausel etablierte Fallgruppen könnten zudem durch den Gesetzgeber zur Steigerung der „Nutzerfreundlichkeit“ und Rechtssicherheit als Einzelschrankentatbestände gesetzlich festgeschrieben werden. Eine solche Kodifizierung einzelner von der Rechtsprechung etablierter Fallgruppen könnte gegebenenfalls dazu beitragen, die langwierigen Gesetzgebungsprozesse zu verkürzen oder diese jedenfalls interessengerechter auszugestalten.

10. Einer solchen, im Hinblick auf die sich stetig wandelnde Werknutzungsrealität dringend erforderlichen Flexibilisierung der urheberrechtlichen Schranken stehen jedoch derzeit die Schrankenbestimmungen der InfoSoc-Richtlinie entgegen, die jedenfalls in Bezug auf das Vervielfältigungsrecht und das Recht der öffentlichen Wiedergabe in der Richtlinie erschöpfend aufgeführt sind. Auch wenn die durch diese abschließende Regelung bezweckte Harmonisierung tatsächlich weitgehend ausgeblieben ist, lassen sie jedenfalls die Einführung völlig neuer, im Katalog des Artikel 5 der InfoSoc-Richtlinie nicht vorgesehener Schrankenbestimmungen nicht zu. Eine sinnvolle Umsetzung der drin- 
8. Kapitel Zusammenfassung der wesentlichen Ergebnisse in Thesen

gend gebotenen Flexibilisierung der Schranken des Urheberrechts de lege ferenda setzt daher auch eine Änderung des europäischen Richtlinienrechts voraus. 


\section{Literatur}

Sämtliche im Literaturverzeichnis zitierten Internetadressen wurden zuletzt abgerufen am 26.5.2013.

Adler, Allan R.: The Google Library Project, 2006, abrufbar unter: http://publishers.org/main/Copyright/CopyKey/documents/ARApaperforNAA-NAB-MLRCcon ferenceJuly2006-final.pdf

Zitiert: Adler, Google Library Project

Adolphsen, Jens / Mutz, Martina Das Google Book Settlement, in: Gewerblicher Rechtsschutz und Urheberrecht - Internationaler Teil (GRUR Int.) 2009, S. 789-799 Zitiert: Adolphsen/Mutz, GRUR Int. 2009, 789

Alexy, Robert Theorie der Grundrechte, Frankfurt a.M. 1986

Zitiert: Alexy, Theorie der Grundrechte

Allfeld, Philipp Das Urheberrecht an Werken der Literatur und der Tonkunst - Kommentar zu dem Gesetz vom 19. Juli 1901 sowie zu den internationalen Verträgen zum Schutze des Urheberrechtes, 2. Auflage, München 1928

Zitiert: Allfeld, Urheberrecht

Apel, Simon Der ausübende Musiker im Recht Deutschlands und der USA, Tübingen 2011

Zitiert: Apel, Der ausübende Musiker im Recht Deutschlands und der USA

Assmann, Heinz-Dieter / Bungert, Hartwin (Hrsg.) Handbuch des US-amerikanischen Handels-, Gesellschafts- und Wirtschaftsrechts, Band 1, München 2001

Zitiert: Bearbeiter, in: Assmann/Bungert, US-HGW

Aust, Anthony Modern Treaty Law and Practice, Cambridge 2000

Zitiert: Aust, Modern Treaty Law

Austin, Graeme W. The Berne Convention as a Canon of Construction: Moral Rights after Dastar, in: New York University Annual Survey of American Law, Vol. 61 (2005), S. 111-150

Zitiert: Austin, 61 N.Y.U. Ann. Surv. Am. L. 111 (2005)

Ayazi, Sara Search Engines Score Another Perfect 10: The Continued Misuse of Copyrighted Images on the Internet, in: North Carolina Journal of Law \& Technology, Vol. 7 (2006), S. 367-396

Zitiert: Ayazi, 7 N. C. J. L. \& Tech. 367 (2006)

Babiskin, Lisa M. Oh, Pretty Parody: Campbell v. Acuff-Rose Music, Inc., in: Harvard Journal of Law \& Technology, Vol. 8 (1994), S. 193-229

Zitiert: Babiskin, 8 Harv. J.L. \& Tech. 193 (1994)

Bachmann, Birgit Der Gerichtsstand der unerlaubten Handlung im Internet, in: Praxis des internationalen Privat- und Verfahrensrechts (IPRax) 1998, S. 179-187

Zitiert: Bachmann, IPRax 1998, 179 


\section{Literatur}

Badura, Peter Zur Lehre von der verfassungsrechtlichen Institutsgarantie des Eigentums, betrachtet am Beispiel des ,geistigen Eigentums“, in: Lerche, Peter/Zacher, Hans Friedrich/Badura, Peter (Hrsg.), Festschrift für Theodor Maunz zum 80. Geburtstag am 1. September 1981, München 1981, S. 1-16

Zitiert: Badura, in: FS Maunz

ders. Zur Lehre von der verfassungsrechtlichen Institutsgarantie des Eigentums, betrachtet am Beispiel des ,geistigen Eigentums“, in: Zeitschrift für Urheber- und Medienrecht (ZUM) 1984, S. 552-560

Zitiert: Badura, ZUM 1984, 552

Balganesh, Shyamkrishna Foreseeability and Copyright Incentives, in: Harvard Law Review, Vol. 122 (2009), S. 1569-1633

Zitiert: Balganesh, 122 Harv. L. Rev. 1569 (2009)

Ball, Horace G. The Law of Copyright and Literary Property, Albany 1944 Zitiert: Ball, Copyright

Band, Jonathan The Google Library Project: Both Sides of the Story, in: Plagiary Cross-Disciplinary Studies in Plagiarism, Fabrication, and Falsification, Vol. 1 (2006), No. 2, S. 1-17, abrufbar unter: http://www.policybandwidth.com/publicati ons/Google-Library-Project.pdf

Zitiert: Band, Google Library Project

ders. The Google Library Project: The Copyright Debate, OITP Technology Policy Brief, January 2006, abrufbar unter: http://www.ala.org/ala/issuesadvocacy/copyright/googlebooks/The Google Library Project policy brief.pdf

Zitiert: Band, Google Library Copyright Debate

ders. Google and Fair Use, in: Journal of Business \& Technology Law, Vol. 3 (2008), S. $1-28$

Zitiert: Band, 3 J. Bus. \& Tech. L. 1 (2008)

ders. A Guide for the Perplexed: Libraries and the Google Library Project Settlement, 13. November 2008, abrufbar unter: http://www.arl.org/bm doc/google-settlement-13nov 08.pdf

Zitiert: Band, A Guide for the Perplexed I

ders. A Guide for the Perplexed Part III: The Amended Settlement Agreement, 23. November 2009, abrufbar unter: http://www.arl.org/bm doc/guide_for the perplexed part3.pdf

Zitiert: Band, A Guide for the Perplexed III

ders. The Long and Winding Road to the Google Books Settlement, in: The John Marshall Review of Intellectual Property Law, Vol. 9 (2009), S. 227-329

Zitiert: Band, 9 J. Marshall Rev. Intell. Prop. L. 227 (2009)

Bappert, Walter Wege zum Urheberrecht - Die geschichtliche Entwicklung des Urheberrechtsgedankens, Frankfurt a.M. 1962

Zitiert: Bappert, Wege zum Urheberrecht

Barabash, Igor Das Bildzitat im Internet, Aachen 2010

Zitiert: Barabash, Bildzitat im Internet

Barker, J. Cam Grossly Excessive Penalties in the Battle Against Illegal File-Sharing: The Troubling Effects of Aggregating Minimum Statutory Damages for Copyright Infringement, in: Texas Law Review, Vol. 83 (2004), S. 525-559

Zitiert: Barker, 83 Tex. L. Rev. 525 (2004) 
Barriga, Stefan Die Entstehung der Charta der Grundrechte der Europäischen Union, Baden-Baden 2003

Zitiert: Barriga, Die Entstehung der Charta

Baucks, Eckhard Der US Visual Artists Rights Act of 1990 - Durchbruch zum droit moral?, in: ZUM 1992, S. 72-79

Zitiert: Baucks, ZUM 1992, 72

Baum, Alfred Die Brüsseler Konferenz zur Revision der Revidierten Berner Übereinkunft - Erlebnis und Ergebnis, in: Gewerblicher Rechtsschutz und Urheberrecht (GRUR) 1949, S. 1-44 Zitiert: Baum, GRUR 1949, 1

ders. Völkerrecht, Berner Konvention und Landesgesetze, in: GRUR 1950, S. 437-480 Zitiert: Baum, GRUR 1950, 437

Baumgarten, Jon A. / Meyer, Christopher A. Die Bedeutung des Beitritts der USA zur Berner Übereinkunft, in: GRUR Int. 1989, S. 620-627

Zitiert: Baumgarten/Meyer, GRUR Int. 1989, 620

Bayreuther, Frank Beschränkungen des Urheberrechts nach der neuen EU-Urheberrechtsrichtlinie, in: ZUM 2001, S. 828-839

Zitiert: Bayreuther, ZUM 2001, 828

Bechtold, Stefan Vom Urheber- zum Informationsrecht - Implikationen des Digital Rights Management, München 2002

Zitiert: Bechtold, Vom Urheber- zum Informationsrecht

ders. Zur rechtsökonomischen Analyse im Immaterialgüterrecht, in: GRUR Int. 2008, S. 484-488

Zitiert: Bechtold, GRUR Int. 2008, 484

Becker, Bernhard von Parodiefreiheit und Güterabwägung - Das „Gies-Adler”-Urteil des BGH, in: GRUR 2004, S. 104-109

Zitiert: v.Becker, GRUR 2004, 104

Beckstein, Frank Einschränkungen des Schutzlandprinzips - Die kollisionsrechtliche Behandlung von Immaterialgüterrechtsverletzungen im Internet, Tübingen 2010 Zitiert: Beckstein, Einschränkungen des Schutzlandprinzips

Beebe, Barton An Empirical Study of U.S. Copyright Fair Use Opinions, 1978-2005, in: University of Pennsylvania Law Review, Vol. 156 (2008), S. 549-624

Zitiert: Beebe, 156 U. Pa. L. Rev. 549 (2008)

Beier, Nils Die urheberrechtliche Schutzfrist. Eine historische, rechtsvergleichende und dogmatische Untersuchung der zeitlichen Begrenzung, ihrer Länge und ihrer Harmonisierung in der Europäischen Gemeinschaft, München 2001

Zitiert: Beier, Die urheberrechtliche Schutzfrist

Beining, Anke Der Schutz ausübender Künstler im internationalen und supranationalen Recht, Baden-Baden 2000

Zitiert: Beining, Schutz ausübender Künstler

Belanger, William U.S. Compliance with the Berne Convention, in: George Mason Independent Law Review, Vol. 3 (1995), S. 373-402

Zitiert: Belanger, 3 Geo. Mason Independent L. Rev. 373 (1995) 
Beldiman, Dana The Role of Copyright Limiting Doctrines in the Digital Age - Can their Vigor be Restored?, in: Hilty, Reto/Peukert, Alexander (Hrsg.), Interessenausgleich im Urheberrecht, Baden-Baden 2004, S. 187-206 Zitiert: Beldiman, in: Hilty/Peukert, Interessenausgleich

Bell, Tom W. Fair Use vs. Fared Use: The Impact of Automated Rights Management on Copyright's Fair Use Doctrine, in: North Carolina Law Review, Vol. 76 (1998), S. 557-619 Zitiert: Bell, 76 N.C. L. Rev. 557 (1998)

Bello, Judith H. The WTO Dispute Settlement Understanding: Less Is More, in: American Journal of International Law, Vol. 90 (1996), S. 416-418 Zitiert: Bello, 90 Am. J. Int'1 L. 416 (1996)

Bently, Lionel / Sherman, Brad Intellectual Property, Second Edition, Oxford 2004 Zitiert: Bently/Sherman, Intellectual Property

Berberich, Matthias Die urheberrechtliche Zulässigkeit von Thumbnails bei der Suche nach Bildern im Internet, in: Multimedia und Recht - Zeitschrift für Informations-, Telekommunikations- und Medienrecht (MMR) 2005, S. 145-148 Zitiert: Berberich, MMR 2005, 145

ders. Anmerkung zu LG Erfurt, Urt. v. 15.3.2007, 3 O 1108/05, in: Computer und Recht (CR) 2007, S. 393-394 Zitiert: Berberich, CR 2007, 393

Berger, Christian Elektronische Pressespiegel und Informationsrichtlinie - Zur Vereinbarkeit einer Anpassung des $\S 49$ UrhG an die Pressespiegel-Entscheidung des BGH mit europäischem Urheberrecht, in: CR 2004, S. 360-366 Zitiert: Berger, CR 2004, 360

ders. Verträge über unbekannte Nutzungsarten nach dem „Zweiten Korb“, in: GRUR 2005, S. 907-912 Zitiert: Berger, GRUR 2005, 907

ders. Aktuelle Entwicklungen im Urheberrecht - Der EuGH bestimmt die Richtung, in: ZUM 2012, S. 353-361 Zitiert: Berger, ZUM 2012, 353

Berger, Christian / Wündisch, Sebastian Urhebervertragsrecht - Handbuch, 1. Auflage, Baden-Baden 2008 Zitiert: Bearbeiter, in Berger/Wündisch, Urhebervertragsrecht

Bernhöft, Mirko Die urheberrechtliche Zulässigkeit der digitalen Aufzeichnung einer Sendung, Frankfurt a.M. u.a. 2009

Zitiert: Bernhöft, Digitale Aufzeichnung

Bernreuther, Friedrich Die suchmaschinenoptimierte Webseite - eine urheberrechtlich geschützte Unlauterkeit mit und ohne Markenverletzung: Zusammenhänge zwischen UWG einerseits und UrhG bzw. MarkenG andererseits, in: Wettbewerb in Recht und Praxis (WRP) 2008, S. 1057-1068

Zitiert: Bernreuther, WRP 2008, 1057

Besen, Stanley M./ Kirby, Sheila N. / Salop, Steven C. An Economic Analysis of Copyright Collectives, in: Virigina Law Review, Vol. 78 (1992), S. 383-411

Zitiert: Besen/Kirby/Salop, 78 Va. L. Rev. 383 (1992)

Besen, Stanley M. / Raskind, Leo J. An Introduction to the Law and Economics of Intellectual Property, in: Journal of Economic Perspectives, Vol. 5 (1991), S. 3-27

Zitiert: Besen/Raskind, 5 J. Econ. Persp. 3 (1991) 
Bettinger, Torsten / Leistner, Matthias (Hrsg.) Werbung und Vertrieb im Internet, Köln 2003

Zitiert: Bettinger/Leistner/Bearbeiter

Bettinger, Torsten / Thum, Dorothee Territoriales Markenrecht im Global Village Überlegungen zu internationaler Tatortzuständigkeit, Kollisionsrecht und materiellem Recht bei Kennzeichenkonflikten im Internet, in: GRUR Int. 1999, S. 659-681 Zitiert: Bettinger/Thum, GRUR Int. 1999, 659

Beuchler, Holger Class Actions und Securities - Class Actions in den Vereinigten Staaten von Amerika, Baden-Baden 2008 Zitiert: Beuchler, Class Actions

Bisges, Marcel Grenzen des Zitatrechts im Internet, in: GRUR 2009, S. 730-733 Zitiert: Bisges, GRUR 2009, 730

Bisk, Jennifer S. B. Book Search Is Beautiful? - An Analysis of weather Google Book Search Violates International Copyright Law, in: Albany Law Journal of Science and Technology, Vol. 17 (2007), S. 271-310

Zitiert: Bisk, 17 Alb. L.J. Sci. \& Tech. 271 (2007)

Bodewig, Theo Urhebervertragsrecht in ausgewählten Ländern: USA, in: Beier, Friedrich-Karl/Götting, Horst-Peter/Lehmann, Michael/Moufang, Rainer (Hrsg.), Urhebervertragsrecht, Festgabe für Gerhard Schricker zum 60. Geburtstag, München 1995, S. 833-883

Zitiert: Bodewig, in: FS Schricker I

Bohne, Michael / Elmers, Christine Die Digitalisierung von Wissen in der Informationsgesellschaft und ihre rechtliche Regulierung, in: WRP 2009, S. 586-599

Zitiert: Bohne/Elmers, WRP 2009, 586

Bohne, Michael / Krüger, Alexandra Denise Das „Settlement Agreement“ zwischen Google und der Author's Guild als Leitbild einer europäischen Regelung, in: WRP 2009, S. 599-607

Zitiert: Bohne/Krüger, WRP 2009, 599

Bongiorno, James Fair Use of Copyrighted Images After Perfect 10 v. Amazon.com: Diverging From Constitutional Principles \& United States Treaty Obligations, in: Touro International Law Review, Vol. 12 (2009), S. 107-156

Zitiert: Bongiorno, 12 Touro Int'l L. Rev. 107 (2009)

Bork, Reinhard Allgemeiner Teil des Bürgerlichen Gesetzbuchs, 2. Auflage, Tübingen 2006

Zitiert: Bork, BGB AT

Born, Christoph Anmerkung zu Schweizerisches Bundesgericht, Urt. v. 26.6.2007, Az. 4C.73/2007, in: Medien und Recht International (MR-Int.) 2007, S. 148-150

Zitiert: Born, MR-Int. 2007, 148

Bornkamm, Joachim Vom Detektorempfänger zum Satellitenrundfunk, in: Beier, Friedrich-Karl/Kraft, Alfons/Schricker, Gerhard/Wadle, Elmar (Hrsg.), Gewerblicher Rechtsschutz und Urheberrecht in Deutschland - Festschrift zum hundertjährigen Bestehen der Deutschen Vereinigung für gewerblichen Rechtsschutz und Urheberrecht und ihrer Zeitschrift, Band II, Weinheim 1991, S. 1349-1398

Zitiert: Bornkamm, in: FS GRUR 


\section{Literatur}

ders. Ungeschriebene Schranken des Urheberrechts?, in: Erdmann, Willi/Gloy, Wolfgang/Herber, Wolf (Hrsg.), Festschrift für Henning Piper zum 65. Geburtstag, München 1996, S. 641-653

Zitiert: Bornkamm, in: FS Piper

ders. Der Dreistufentest als urheberrechtliche Schrankenbestimmung - Karriere eines Begriffs, in: Ahrens, Hans-Jürgen/Bornkamm, Joachim/Gloy, Wolfgang/Starck, Joachim/v. Ungern-Sternberg, Joachim (Hrsg.), Festschrift für Willi Erdmann zum 65. Geburtstag, Köln u.a. 2002, S. 29-48

Zitiert: Bornkamm, in: FS Erdmann

ders. E-Commerce Directive vs. IP Rights Enforcement - Legal Balance Achieved?, in: GRUR Int. 2007, S. 642-644

Zitiert: Bornkamm, GRUR Int. 2007, 642

Brägelmann, Tom Warum erfasst das Google Book Settlement Bücher aus Deutschland?, in: Kunst und Recht (KUR) 2009, S. 135-144

Zitiert: Brägelmann, KUR 2009, 135

ders. Das Amended Google Book Settlement: Welche deutschen Bücher fallen immer noch darunter?, in: KUR 2009, S. 187-192

Zitiert: Brägelmann, KUR 2009, 187

Brannon, Pamela Reforming Copyright to Foster Innovation: Providing Access to Orphaned Works, in: Journal of Intellectual Property Law, Vol. 14 (2006), S. 145-171 Zitiert: Brannon, 14. J. Intell. Prop. L. 145 (2006)

Braun, Thorsten Der Schutz ausübender Künstler durch TRIPS, in: GRUR Int. 1997, S. 427-432

Zitiert: Braun, GRUR Int. 1997, 427

Brennan, David J. The Three Step Test Frenzy - Why the TRIPs Panel Decision might be Considered Per Incuriam, in: Intellectual Property Quarterly (IPQ) 2002, No. 2, S. 212-225

Zitiert: Brennan, IPQ 2002, 212

Brenncke, Martin Is „fair use“ an option for U.K. copyright legislation?, Halle (Saale) 2007

Zitiert: Brenncke, Fair Use

Brinkel, Guido Filesharing - Verantwortlichkeit in Peer-to-Peer-Tauschplattformen, Tübingen 2006

Zitiert: Brinkel, Filesharing

Brooks, Eric M. "Tilted" Justice: Site-Specific Art and Moral Rights after U.S. Adherence to the Berne Convention, in: California Law Review, Vol. 77 (1989), S. 1431-1482

Zitiert: Brooks, 77 Cal. L. Rev. 1431 (1989)

Brown, Ralph S. / Denicola, Robert C. Copyright - Cases on Copyright, Unfair Competition, and Related Topics Bearing on the Protection of Works of Authorship, Ninth Edition, New York 2005

Zitiert: Brown/Denicola, Copyright

Brunner, Richard Urheber- und leistungsschutzrechtliche Probleme der Musikdistribution im Internet - unter besonderer Berücksichtigung der Richtlinie 2001/29/EG und ihrer Umsetzung in deutsches Recht, Berlin 2004

Zitiert: Brunner, Musikdistribution im Internet 
Buck, Petra Geistiges Eigentum und Völkerrecht - Beiträge des Völkerrechts zur Fortentwicklung des Schutzes von geistigem Eigentum, Berlin, 1994

Zitiert: Buck, Geistiges Eigentum und Völkerrecht

Bull, Hans Joachim Der Gemeinnutz im Urheberrecht, in: Archiv für Urheber- und Medienrecht (UFITA) 7 (1934), S. 378-382

Zitiert: Bull, UFITA 7 (1934), 378

ders. Der Zweck im Urheberrecht, in: UFITA 8 (1935), S. 400-404

Zitiert: Bull, UFITA 8 (1935), 400

Bullinger, Winfried / Garbers-von Boehm, Katharina Google Bildersuche - Schlichte Einwilligung des Urhebers als Lösung?, in: Gewerblicher Rechtsschutz und Urheberrecht. Praxis im Immaterialgüter- und Wettbewerbsrecht (GRUR-Prax.) 2010, S. 257

Zitiert: Bullinger/Garbers-v.Boehm, GRUR-Prax. 2010, 257

Bunker, Matthew D. Eroding Fair Use: The "Transformative" Use Doctrine After Campbell, in: Communication Law and Policy, Vol. 7 (2002), S. 1-24

Zitiert: Bunker, 7 Comm. L. \& Pol'y 1 (2002)

Burrell, Robert / Coleman, Allison Copyright Exceptions: The Digital Impact, Cambridge 2005

Zitiert: Burrell/Coleman, Copyright Exceptions

Busche, Jan / Stoll, Peter-Tobias TRIPs - Internationales und europäisches Recht des geistigen Eigentums, Kommentar, Köln 2007

Zitiert: Busche/Stoll/Bearbeiter, TRIPs

Bydlinski, Franz Juristische Methodenlehre und Rechtsbegriff, 2. Auflage, Wien u.a. 1991

Zitiert: Bydlinski, Methodenlehre

Calliess, Christian / Ruffert, Matthias (Hrsg.) EUV/AEUV. Das Verfassungsrecht der Europäischen Union mit Europäischer Grundrechtecharta, 4. Auflage, München 2011

Zitiert: Calliess/Ruffert/Bearbeiter, EUV/AEUV

Canaris, Claus-Wilhelm Die Feststellung von Lücken im Gesetz, 2. Auflage, Berlin 1983

Zitiert: Canaris, Feststellung von Lücken im Gesetz

Carnevale, Eric Questions of Copyright in Google's Image Search: Developments in Perfect 10, Inc. v. Amazon.com, Inc., in: Boston University Journal of Science and Technology Law, Vol. 14 (2008), S. 132-143

Zitiert: Carnevale, 14 B.U. J. Sci. \& Tech. L. 132 (2008)

Carpenter, Clint A. Stepmother, May I?: Moral Rights, Dastar, and the False Advertising Prong of Lanham Act Section 43(A), in: Washington and Lee Law Review, Vol. 63 (2006), S. 1601-1648

Zitiert: Carpenter, 63 Wash. \& Lee L. Rev. 1601 (2006)

Carroll, Michael W. Fixing Fair Use, in: North Carolina Law Review, Vol. 85 (2007), S. 1087-1154

Zitiert: Carroll, 85 N.C. L. Rev. 1087 (2007)

Chakraborty, Martin Das Rechtsinstitut der freien Benutzung im Urheberrecht, BadenBaden 1997

Zitiert: Chakraborty, Freie Benutzung 


\section{Literatur}

Chang, Yeyoung Debates on Introduction of "Fair use" to the Copyright Act of Japan and Korea - Do Japan and Korea need Fair use?, Comparative IP Academic Workshop Working Paper No. 2, 2009, abrufbar unter: http://www.law.washington.edu/ Casrip/WWIP/Papers/2009/Debates on Introduction of Fair use to the Copyright Act of Japan and Korea - Do Japan and Korea need Fair use.pdf Zitiert: Chang, Do Japan and Korea need Fair use?

Chapman, Audrey R. A Human Rights Perspective on Intellectual Property, Scientific Progress, and Access to the Benefits of Science, Washington, D.C. 1999, abrufbar unter: http://www.wipo.int/tk/en/hr/paneldiscussion/papers/pdf/chapman.pdf Zitiert: Chapman, Human Rights Perspective on IP

Chinni, Christine L. Droit d'Auteur Versus the Economics of Copyright: Implications for American Law of Accession to the Berne Convention, in: Western New England Law Review, Vol. 14 (1992), S. 145-174

Zitiert: Chinni, 14 W. New Eng. L. Rev. 145 (1992)

Chisum, Donald S. Chisum on Patents - A Treatise on the Law of Patentability, Validity and Infringement, Menands, NY, Loseblattsammlung, Stand: März 2012 Zitiert: Chisum, On Patents

Christakos, Helen A. WTO Panel Report on Section 110(5) of the U.S. Copyright Act, in: Berkeley Technology Law Journal, Vol. 17 (2002), S. 595-611

Zitiert: Christakos, 17 Berkeley Tech. L.J. 595 (2002)

Clarida, Robert W. Copyright Law Deskbook, Arlington 2009 Zitiert: Clarida, Copyright

Claussen, Carl Albrecht Die Vergütung für die Überspielung zum privaten Gebrauch gemäß $§ 54$ Absatz 1 UrhG und ihre Verteilung unter die Berechtigten im Filmbereich, Frankfurt a.M. u.a. 1993

Zitiert: Claussen, Vergütung für die Überspielung zum privaten Gebrauch

Cohen, Julie E. / Loren, Lydia Pallas / Okediji, Ruth L. / O'Rourke, Maureen A. Copyright in a Global Information Economy, Second Edition, New York 2006

Zitiert: Cohen/Loren/Okediji/O'Rourke, Copyright

Cohen Jehoram, Herman The Evolution of Copyright Restrictions, in: Ohly, Ansgar/ Bodewig, Theo/Dreier, Thomas/Götting, Horst-Peter/Haedicke, Maximilian/ Lehmann, Michael (Hrsg.), Festschrift für Gerhard Schricker zum 70. Geburtstag, München 2005, S. 249-259

Zitiert: Cohen Jehoram, in: FS Schricker II

ders. Fair use - die ferne Geliebte, in: Tijdschrift Voor Auteurs-, Media \& Informatierecht (AMI) 1998, Heft 10, S. 174-175

Zitiert: Cohen Jehoram, AMI 1998, 174

ders. Einige Grundsätze zu den Ausnahmen im Urheberrecht, in: GRUR Int. 2001, S. $807-810$

Zitiert: Cohen Jehoram, GRUR Int. 2001, 807

ders. Restrictions on Copyright and their Abuse, in: European Intellectual Property Review (EIPR) 2005, 27(10), S. 359-364

Zitiert: Cohen Jehoram, EIPR 2005, 27(10), 359

ders. Is there a Hidden Agenda behind the General Non-Implementation of the EU Three-Step Test?, in: EIPR 2009, 31(8), S. 408-410

Zitiert: Cohen Jehoram, EIPR 2009, 31(8), 408 
Conrad, Albrecht Anmerkung zu BGH, Urt. v. 29.4.2010, I ZR 69/08 - Vorschaubilder; in: ZUM 2010, S. 585-587

Zitiert: Conrad, ZUM 2010, 585

ders. Anmerkung zu BGH, Urt. v. 19.10.2011, I ZR 140/10 - Vorschaubilder II, in: ZUM 2012, S. 480-482

Zitiert: Conrad, ZUM 2012, 480

Coombe, Rosemary J. Fear, Hope, and Longing for the Future of Authorship and a Revitalized Public Domain in Global Regimes of Intellectual Property, in: DePaul Law Review, Vol. 52 (2003), S. 1171-1191

Zitiert: Coombe, 52 DePaul L. Rev. 1171 (2003)

Cornish, William R. Das „Statute of Anne“ (8 Anne c. 19), in: Wadle, Elmar (Hrsg.), Historische Studien zum Urheberrecht in Europa - Entwicklungslinien und Grundfragen, Berlin 1993, S. 57-65

Zitiert: Cornish, in: Historische Studien

ders. The Statute of Anne 1709-1710: its historical setting, in: Bently, Lionel/Suthersanen, Uma/Torremans, Paul (Hrsg.), Global Copyright - Three Hundred Years Since the Statute of Anne, From 1709 to Cyberspace, Cheltenham (UK) u.a. 2010, S. 14-25

Zitiert: Cornish, in: Bently/Suthersanen/Torremans, Global Copyright

Cornish, William R / Llewelyn, David Intellectual Property: Patents, Copyright, Trade Marks and Allied Rights, Sixth Edition, London 2007

Zitiert: Cornish/Llewelyn, Intellectual Property

Costantino, Melanie Fairly Used: Why Google's Book Project Should Prevail under the Fair Use Defense, in: Fordham Intellectual Property, Media \& Entertainment Law Journal, Vol. 17 (2006), S. 235-277

Zitiert: Costantino, 17 Fordham Intell. Prop. Media \& Ent. L.J. 235 (2006)

Czernik, Ilja Die Collage in der urheberrechtlichen Auseinandersetzung zwischen Kunstfreiheit und Schutz des geistigen Eigentums, Berlin 2008

Zitiert: Czernik, Die Collage

Czychowski, Christian „Wenn der dritte Korb aufgemacht wird...“ - Das zweite Gesetz zur Regelung des Urheberechts in der Informationsgesellschaft, in: GRUR 2008, S. 586-591

Zitiert: Czychowski, GRUR 2008, 586

Czychowski, Christian / Nordemann, Jan Bernd Die Entwicklung der Gesetzgebung und Rechtsprechung des BGH und EuGH zum Urheberrecht in den Jahren 2008 und 2009, in: Neue Juristische Wochenschrift (NJW) 2010, S. 735-743

Zitiert: Czychowski/Nordemann, NJW 2010, 735

Damich, Edward J. The Visual Artists Rights Act of 1990: Toward a Federal System of Moral Rights Protection for Visual Art, in: Catholic University Law Review, Vol. 39 (1990), S. 945-998

Zitiert: Damich, 39 Cath. U. L. Rev. 945 (1990)

Danckert, Burkhard / Mayer, Frank Joachim Die vorherrschende Meinungsmacht von Google - Bedrohung durch einen Informationsmonopolisten?, in: MMR 2010, S. 219-222

Zitiert: Danckert/Mayer, MMR 2010, 219 


\section{Literatur}

Dang, Khoi D. Kelly v. Arriba Soft Corp.: Copyright Limitations on Technological Innovation on the Internet, in: Santa Clara Computer and High Technology Law Journal, Vol. 18 (2002), S. 389-403

Zitiert: Dang, 18 Santa Clara Computer \& High Tech. L.J. 389 (2002)

Daniels, Stacy Harper \& Row, Publishers, Inc. v. Nation Enterprises: Pirating Unpublished Copyrighted Works: Does the Fair Use Doctrine Vindicate First Amendment Rights?, in: John Marshall Law Review, Vol. 19 (1986), S. 501-522

Zitiert: Daniels, 19 J. Marshall L. Rev. 501 (1986)

Dannay, Richard Copyright Injunctions and Fair Use: Enter Ebay - Four-Factor Fatigue or Four-Factor Freedom?, in: Journal of the Copyright Society of the U.S.A, Vol. 55 (2008), S. 449-460

Zitiert: Dannay, 55 J. Copyright Soc'y U.S.A. 449 (2008)

Datta, Ritendra / Joshi, Dhiraj / Li, Jia / Wang, James Z. Image Retrieval: Ideas, Influences, and Trends of the New Age, in: ACM Computing Surveys, Vol. 40, No. 2 (2008), S. 5:1-60

Zitiert: Datta/Joshi/Li/Wang, 40 ACM Computing Surveys 5:1 (2008)

Davidson, Benjamin Lost in Translation: Distinguishing between French and AngloAmerican Natural Rights in Literary Property, and how Dastar Proves that the Difference Still Matters, in: Cornell International Law Journal, Vol. 38 (2005), S. 583-623

Zitiert: Davidson, 38 Cornell Int'1 L.J. 583 (2005)

Davies, Gillian The Convergence of Copyright and Authors' Rights - Reality or Chimera?, in: International Review of Intellectual Property and Competition Law (IIC) 1995, S. 964-989

Zitiert: Davies, IIC 1995, 964

dies. Copyright and the Public Interest, Second Edition, London 2002

Zitiert: Davies, Copyright and Public Interest

de Boor, Hans Otto Vom Wesen des Urheberrechts - Kritische Bemerkungen zum Entwurf eines Gesetzes über das Urheberrecht an Werken der Literatur, der Kunst und der Photographie, Marburg 1933

Zitiert: de Boor, Vom Wesen des Urheberrechts

ders. Konstruktionsfragen im Urheberrecht, in: UFITA 16 (1943/44), S. 345-363 Zitiert: de Boor, UFITA 16 (1943/44), 345

Deazley, Ronan What's new about the Statute of Anne? Or Six observations in search of an act, in: Bently, Lionel/Suthersanen, Uma/Torremans, Paul (Hrsg.), Global Copyright - Three Hundred Years Since the Statute of Anne, From 1709 to Cyberspace, Cheltenham (UK) u.a. 2010, S. 26-53

Zitiert: Deazley, in: Bently/Suthersanen/Torremans, Global Copyright

Decker, Ute / Hoeren, Thomas Electronic Archives and the Press: Copyright Problems of Mass Media in the Digital Age, in: EIPR 1998, 20(7), S. 256-266

Zitiert: Decker/Hoeren, EIPR 1998, 20(7), 256

Dehmel, Susanne Anmerkung zu OLG Hamburg, Urt. v. 18.1.2006, 5 U 58/05, in: MMR 2006, S. 318-321

Zitiert: Dehmel, MMR 2006, 318

Delp, Ludwig Das Recht des geistigen Schaffens in der Informationsgesellschaft, 2. Auflage, München 2003

Zitiert: Delp, Recht des geistigen Schaffens 
Depoorter, Ben Technology and Uncertainty: The Shaping Effect on Copyright Law, in: University of Pennsylvania Law Review, Vol. 157 (2009), S. 1831-1868

Zitiert: Depoorter, 157 U. Pa. L. Rev. 1831 (2009)

Derclaye, Estelle Infopaq International A/S v Danske Dagblades Forening (C-5/08): Wonderful or Worrisome? The Impact of the ECJ Ruling in Infopaq on UK Copyright Law, in: EIPR 2010, 32(5), S. 247-251

Zitiert: Derclaye, EIPR 2010, 32(5), 247

Desbois, Henri / Françon, André / Kéréver, André Les Conventions Internationales du Droit d'Auteur et des Droits Voisins, Paris 1976

Zitiert: Desbois/Françon/Kéréver, Conventions Internationales

DeSimone, David J. The Supreme Court Applies the Doctrines of Fair Use and Contributory Infringement to Home Videotaping, in: University of Missouri-Kansas City Law Review, Vol. 53 (1984), S. 126-144

Zitiert: DeSimone, 53 UMKC L. Rev. 126 (1984)

Dethloff, Nina Marketing im Internet und Internationales Wettbewerbsrecht, in: NJW 1998, S. 1596-1603

Zitiert: Dethloff, NJW 1998, 1596

Diemar, Undine von Die digitale Kopie zum privaten Gebrauch, Hamburg 2002 Zitiert: v.Diemar, Digitale Kopie zum privaten Gebrauch

Dieselhorst, Jochen Das Ende des „,amoralen“ Copyrights? - Der Visual Artists Rights Act der USA von 1990, in: GRUR Int. 1992, S. 902-910

Zitiert:dieselhorst, GRUR Int. 1992, 902

ders. Die Harmonisierung der Leerkassetten- und Geräteabgabe, in: GRUR Int. 1994, S. 788-798

Zitiert:dieselhorst, GRUR Int. 1994, 788

ders. Was bringt das Urheberpersönlichkeitsrecht? - Urheberpersönlichkeitsschutz im Vergleich: Deutschland - USA, Frankfurt a.M. 1995

Zitiert:dieselhorst, Urheberpersönlichkeitsrecht

Dietz, Adolf Das Urheberrecht in der Europäischen Gemeinschaft: Studie im Auftrag der Generaldirektion „Forschung, Wissenschaft und Bildung“ der Kommission der Europäischen Gemeinschaften, Baden-Baden 1978

Zitiert: Dietz, Urheberrecht in der EG

ders. Einige Aspekte der Urhebernachfolgevergütung (domaine public payant), in: Herschel, Wilhelm/Hubmann, Heinrich/Rehbinder, Manfred (Hrsg.), Festschrift für Georg Roeber zum 10. Dezember 1981. Freiburg i. Brsg. 1982, S. 45-52

Zitiert: Dietz, in: FS Roeber

ders. Die USA und das „droit moral“: Idiosynkrasie oder Annäherung? Anmerkungen zu einem Problemverhältnis anläßlich des Beitritts der Vereinigten Staaten zur Berner Konvention, in: GRUR Int. 1989, S. 627-634

Zitiert: Dietz, GRUR Int. 1989, 627

ders. The Moral Right of the Author: Moral Rights and the Civil Law Countries, in: Columbia-VLA Journal of Law and the Arts, Vol. 19 (1995), S. 199-227

Zitiert: Dietz, 19 Colum.-VLA J.L. \& Arts 199 (1995)

ders. Ein neuer Vorstoß für das domaine public payant auf Grund einer Initiative der deutschen IG Medien, in: Zeitschrift für Rechtsvergleichung, Internationales Privatrecht und Europarecht (ZfRV) 1999, S. 81-88

Zitiert: Dietz, ZfRV 1999, 81 


\section{Literatur}

ders. Einige Thesen zum Urhebergemeinschaftsrecht, in: ZUM 1991, S. 129-132 Zitiert: Dietz, ZUM 1991, 129

ders. Das Projekt Künstlergemeinschaftsrecht der IG Medien, in: Zeitschrift für Rechtspolitik (ZRP) 2001, S. 165-171

Zitiert: Dietz, ZRP 2001, 165

ders. Verfassungsklauseln und Quasi-Verfassungsklauseln zur Rechtfertigung des Urheberrechts - gestern, heute und morgen, in: GRUR Int. 2006, S. 1-9

Zitiert: Dietz, GRUR Int. 2006, 1

Dillenz, Walter Überlegungen zum Domaine Public Payant, in: GRUR Int. 1983, S. 920-926

Zitiert: Dillenz, GRUR Int. 1983, 920

Ding, Meng Perfect 10 v. Amazon.com: A Step Toward Copyright's Tort Law Roots, in: Berkeley Technology Law Journal, Vol. 23 (2008), S. 373-403

Zitiert: Ding, 23 Berkeley Tech. L.J. 373 (2008)

Dinwoodie, Graeme B. The Development and Incorporation of International Norms in the Formation of Copyright Law, in: Ohio State Law Journal, Vol. 63 (2001), S. $733-782$

Zitiert: Dinwoodie, 62 Ohio St. L.J. 733 (2001)

Dinwoodie, Graeme B. / Hennessey, William O. / Perlmutter, Shira / Austin, Graeme $W$. International Intellectual Property Law and Policy, Second Edition, Newark u.a. 2008

Zitiert: Dinwoodie/Hennessey/Perlmutter/Austin, International IP Law

Dittrich, Robert Der Grundsatz der Inländerbehandlung der RBÜ und die sogenannte soziale Hälfte - Zugleich ein Beitrag zur Methode, die RBÜ auszulegen, in: Dittrich, Robert (Hrsg.), Festschrift 50 Jahre Urheberrechtsgesetz, Wien 1986, S. 63-93

Zitiert: Dittrich, in: FS 50 Jahre UrhG

Dölemeyer, Barbara Der ,internationale Standard“ des Urheberschutzes - Internationale Urheberrechtsverträge im 19. Jahrhundert, in: UFITA 123 (1993), S. 53-67

Zitiert: Dölemeyer, UFITA 123 (1993), 53

Dölemeyer, Barbara / Klippel, Diethelm Der Beitrag der deutschen Rechtswissenschaft zur Theorie des gewerblichen Rechtsschutzes und Urheberrechts, in: Beier, Friedrich-Karl/Kraft, Alfons/Schricker, Gerhard/Wadle, Elmar (Hrsg.), Gewerblicher Rechtsschutz und Urheberrecht in Deutschland - Festschrift zum hundertjährigen Bestehen der Deutschen Vereinigung für gewerblichen Rechtsschutz und Urheberrecht und ihrer Zeitschrift, Band I, Weinheim 1991, S. 185-237

Zitiert: Dölemeyer/Klippel, in: FS GRUR

Dolzer, Rudolf / Kahl, Wolfgang / Waldhoff, Christian (Hrsg.) Bonner Kommentar zum Grundgesetz, Heidelberg, Loseblattsammlung, Stand: 156. EL, 02/2012 Zitiert: Bearbeiter, in: Bonner Kommentar GG

Dörmer, Sigrid Streitbeilegung und neue Entwicklungen im Rahmen von TRIPS: Eine Zwischenbilanz nach vier Jahren, in: GRUR Int. 1998, S. 919-934

Zitiert: Dörmer, GRUR Int. 1998, 919

Drasch, Wolfgang Anmerkung zu EuGH, Urt. v. 13.7.1995, C-350/92 - Königreich Spanien./. Rat der Europäischen Union, in: Zeitschrift für Europäisches Privatrecht (ZEuP) 1998, S. 123-139

Zitiert: Drasch, ZEuP 1998, 123 
Dreier, Horst (Hrsg.) Grundgesetz. Kommentar, 2. Auflage, Tübingen 2004 Zitiert: Dreier/Bearbeiter, GG

Dreier, Thomas Kabelrundfunk, Satelliten und das Rom-Abkommen zum Schutz der ausübenden Künstler, der Hersteller von Tonträgern und der Sendeunternehmen, in: GRUR Int. 1988, S. 753-763

Zitiert: Dreier, GRUR Int. 1988, 753

ders. Schrankenbestimmungen (5. Teil), in: Schricker, Gerhard (Hrsg.), Urheberrecht auf dem Weg zur Informationsgesellschaft, Baden-Baden 1997, S. 139-180

Zitiert: Dreier, in: Schricker, Informationsgesellschaft

ders. Urheberrecht und digitale Werkverwertung: die aktuelle Lage des Urheberrechts im Zeitalter von Internet und Multimedia, Bonn 1997

Zitiert: Dreier, Urheberrecht und digitale Werkverwertung

ders. Urheberrecht an der Schwelle des 3. Jahrtausends - Einige Gedanken zur Zukunft des Urheberrechts, in: CR 2000, S. 45-50

Zitiert: Dreier, CR 2000, 45

ders. Balancing Proprietary and Public Domain Interests: Inside or Outside of Proprietary Rights?, in: Dreyfuss, Rochelle C./Zimmerman, Diane L./First, Harry (Hrsg.), Expanding the Boundaries of Intellectual Property - Innovation Policy for the Knowledge Society, Oxford 2001

Zitiert: Dreier, in: Expanding the Boundaries

ders. Die Umsetzung der Urheberrechtsrichtlinie 2001/29/EG in deutsches Recht, in: ZUM 2002, S. 28-43

Zitiert: Dreier, ZUM 2002, 28

ders. Regulating competition by way of copyright limitations and exceptions, in: Torremans, Paul (Hrsg.), Copyright Law - A Handbook of Contemporary Research, Cheltenham (UK) 2007, S. 232-254

Zitiert: Dreier, in: Torremans, Copyright Law

ders. Thumbnails als Zitate? Zur Reichweite von $\S 51$ UrhG in der Informationsgesellschaft, in: Blaurock, Uwe/Bornkamm, Joachim/Kirchberg, Christian (Hrsg.), Festschrift für Achim Krämer zum 70. Geburtstag am 19. September 2009, Berlin 2009, S. 225-240

Zitiert: Dreier, in: FS Krämer

ders. Das WITTEM-Projekt eines „European Copyright Code“, in: Erdmann, Willi/ Leistner, Matthias/Rüffer, Wilfried/Schulte-Beckhausen, Thomas (Hrsg.), Festschrift für Michael Loschelder zum 65. Geburtstag, Köln 2010, S. 47-60

Zitiert: Dreier, in: FS Loschelder

ders. Limitations: The Centerpiece of Copyright in Distress. An Introduction, in: Journal of Intellectual Property, Information Technology and E-Commerce Law (JIPITEC) 2010, S. 50-54

Zitiert: Dreier, JIPITEC 2010, 50

ders. Anmerkung zu BVerfG, Urt. v. 30.8.2010, 1 BvR 1631/08 - Drucker und Plotter, in: GRUR 2010, S. 1002-1004

Zitiert: Dreier, GRUR 2010, 1002

ders. Padawan und die Folgen für die deutsche Kopiervergütung, in: ZUM 2011, S. 281-291

Zitiert: Dreier, ZUM 2011, 281 


\section{Literatur}

Dreier, Thomas / Euler, Ellen / Fischer, Veronika / van Raay, Anne Museen, Bibliotheken und Archive in der Europäischen Union - Plädoyer für die Schaffung des notwendigen urheberrechtlichen Freiraums, in: ZUM 2012, S. 273-281

Zitiert: Dreier/Euler/Fischer/v.Raay, ZUM 2012, 273

Dreier, Thomas / Hugenholtz, P. Bernt Concise European Copyright Law, Alphen aan den Rijn 2006 Zitiert: Bearbeiter, in: Dreier/Hugenholtz, Concise Copyright

Dreier, Thomas / Schulze, Gernot Urheberrechtsgesetz, Kommentar, 3. Auflage, München 2008 Zitiert: Dreier/Schulze [Bearbeiter kursiv hervorgehoben]

Dreier, Thomas / Spiecker genannt Döhmann, Indra Die systematische Aufnahme des Straßenbildes - Zur rechtlichen Beurteilung von Online-Diensten wie „Google Street View", Baden-Baden 2010

Zitiert: Dreier/Spiecker gen. Döhmann, Systematische Aufnahme des Straßenbildes

Drexl, Josef Entwicklungsmöglichkeiten des Urheberrechts im Rahmen des GATT, München 1990

Zitiert: Drexl, Entwicklungsmöglichkeiten

ders. Nach „GATT und WIPO“: Das TRIPs-Abkommen und seine Anwendung in der Europäischen Gemeinschaft, in: GRUR Int. 1994, S. 777-788

Zitiert: Drexl, GRUR Int. 1994, 777

ders. Europarecht und Urheberkollisonsrecht, in: Ganea, Peter/Heath, Christopher/ Schricker, Gerhard, Urheberrecht gestern - heute - morgen, Festschrift für Adolf Dietz zum 65. Geburtstag, München 2001, S. 461-479

Zitiert: Drexl, in: FS Dietz

Dreyer, Gunda / Kotthoff, Astrid / Meckel, Jost Heidelberger Kommentar zum Urheberrecht, 2. Auflage, Heidelberg 2009

Zitiert: HK-UrhR/Bearbeiter

Dreyfuss, Rochelle C. / Lowenfeld, Andreas F. Two Achievements of the Uruguay Round: Putting TRIPS and Dispute Settlement Together, in: Virginia Journal of International Law, Vol. 37 (1997), S. 275-333

Zitiert: Dreyfuss/Lowenfeld, 37 Va. J. Int'l L. 275 (1997)

Dünnwald, Rolf Die Leistungsschutzrechte im TRIPS-Abkommen, in: ZUM 1996, S. $725-734$

Zitiert: Dünnwald, ZUM 1996, 725

Duggal, Raoul TRIPs-Übereinkommen und internationales Urheberrecht - Neue Entwicklungen im internationalen Urheberrecht unter dem Einfluß multilateraler Übereinkünfte, Köln u.a. 2001

Zitiert: Duggal, TRIPs-Übereinkommen

Dusollier, Séverine L'encadrement des exceptions au droit d'auteur par le test des trois étapes, in: Intellectuele Rechten - Droits Intellectuels (IRDI) 2005, S. 212-222 Zitiert: Dusollier, IRDI 2005, 212

Dworkin, Gerald The Moral Right of the Author: Moral Rights and the Common Law Countries, in: Columbia-VLA Journal of Law and the Arts, Vol. 19 (1995), S. 229-266

Zitiert: Dworkin, 19 Colum.-VLA J.L. \& Arts 229 (1995) 
Eechoud, Mireille van / Hugenholtz, P. Bernt / Gompel, Stef van / Guibault, Lucie / Helberger, Natali Harmonizing European Copyright Law - The Challenges of Better Lawmaking, Alphen aan den Rijn 2009

Zitiert: v.Eechoud/Hugenholtz/v.Gompel/Guibault/Helberger, Harmonizing European Copyright Law

Eger, Thomas / Scheufen, Marc Das Urheberrecht im Zeitenwandel: Von Gutenberg zum Cyberspace, in: Müller, Christian/Trosky, Frank/Weber, Marion (Hrsg.), Ökonomik als allgemeine Theorie menschlichen Verhaltens. Grundlagen und Anwendungen, Stuttgart 2012, S. 151-179

Zitiert: Eger/Scheufen, in: Ökonomik als allgemeine Theorie menschlichen Verhaltens

Eggersberger, Michael Die Übertragbarkeit des Urheberrechts in historischer und rechtsvergleichender Sicht, München 1992

Zitiert: Eggersberger, Übertragbarkeit des Urheberrechts

Eggert, Astrid Der Rechtsschutz der Urheber in der römischen Antike, in: UFITA 138 (1999), S. 183-217

Zitiert: Eggert, UFITA 138 (1999), 183

Ehlers, Dirk (Hrsg.) Europäische Grundrechte und Grundfreiheiten, 3. Auflage, Berlin 2009

Zitiert: Ehlers/Bearbeiter, Europäische Grundrechte

Eichelberger, Jan Anmerkung zu BGH, Urt. v. 29.4.2010, I ZR 69/08 - Vorschaubilder, in: Grüner Bote (GB) 3/2010, S. 212-214

Zitiert: Eichelberger, GB 2010, 212

ders. Keyword-Advertising vor dem EuGH - Zur markenrechtlichen Zulässigkeit der Verwendung fremder Kennzeichen als Keyword - zugleich Anmerkung zu EuGH, C-236/08 bis C-238/08 - Google, C-278/08 - BergSpechte, C-91/09 - Eis.de und C-558/08 - Portakabin/Primakabin, in: Europäische Zeitschrift für Wirtschaftsrecht (EuZW) 2010, S. 731-734

Zitiert: Eichelberger, EuZW 2010, 731

Eichholtz, Stephanie Die US-amerikanische Class Action und ihre deutschen Funktionsäquivalente, Tübingen 2002

Zitiert: Eichholtz, Class Action

Elfring, Klaus Geistiges Eigentum in der Welthandelsordnung - Auswirkungen des TRIPS-Übereinkommens auf den internationalen Schutz geistigen Eigentums, Köln u.a. 2006

Zitiert: Elfring, Geistiges Eigentum in der Welthandelsordnung

Elhauge, Einer Why the Google Books Settlement Is Procompetitive, in: Journal of Legal Analysis, Vol. 2 (2010), S. 1-68

Zitiert: Elhauge, 2 J. Legal Analysis, 1 (2010)

Emmerich-Fritsche, Angelika Der Grundsatz der Verhältnismäßigkeit als Direktive und Schranke der EG-Rechtsetzung, Berlin 2000

Zitiert: Emmerich-Fritsche, Grundsatz der Verhältnismäßigkeit

Engels, Gabriele Anmerkung zu OLG Köln, Urt. v. 9.2.2010, 15 U 107/09, in: GRURPrax. 2010, S. 156

Zitiert: Engels, GRUR-Prax. 2010, 156

Engisch, Karl Einführung in das juristische Denken, 10. Auflage, Stuttgart 2005

Zitiert: Engisch, Einführung in das juristische Denken 


\section{Literatur}

Ensthaler, Jürgen / Weidert, Stefan (Hrsg.) Handbuch Urheberrecht und Internet, 2. Auflage, Frankfurt a.M. 2010

Zitiert: Ensthaler/Weidert/Bearbeiter, Handbuch

Erdmann, Willi Urheberrechtliche Grenzen der Informationsvermittlung, in: Keller, Erhard/Plassmann, Clemens/v.Falck, Andreas (Hrsg.), Festschrift für Winfried Tilmann zum 65. Geburtstag, Köln u.a. 2003, S. 21-36

Zitiert: Erdmann, in: FS Tilmann

Ernst, Stefan Urheberrechtliche Bedeutung der Verwendung von thumbnails in Trefferlisten einer Bildersuchmaschine, Anmerkung zu OLG Jena, Urt. v. 27.2.2008 - 2 U 319/07, in: jurisPR-WettbR 9/2008 Anm. 5

Zitiert: Ernst, jurisPR-WettbR 9/2008 Anm. 5

ders. Bildersuche bei Google, Anmerkung zu LG Hamburg, Urt. v. 26.9.2008 - 308 O 42/06, in: jurisPR-WettbR 11/2008 Anm.

Zitiert: Ernst, jurisPR-WettbR 11/2008 Anm. 4

\section{Ernst, Stefan}

Seichter, Dirk Die Verwertung von Domains durch Partnerprogramme und Domain-Parking, in: WRP 2006, S. 810-815

Zitiert: Ernst/Seichter, WRP 2006, 810

Fahl, Constantin Die Bilder- und Nachrichtensuche im Internet - Urheber-, persönlichkeits- und wettbewerbsrechtliche Aspekte, Göttingen 2010

Zitiert: Fahl, Bilder- und Nachrichtensuche

ders. Die Nutzung von Thumbnails in der Bildersuche, in: Kommunikation und Recht (K\&R) 2010, S. 437-441

Zitiert: Fahl, K\&R 2010, 437

ders. Anmerkung zu BGH, Urt. v. 19.10.2011, I ZR 140/10 - Vorschaubilder II, in: MMR-Aktuell 2012, 331727

Zitiert: Fahl, MMR-Aktuell 2012, 331727

Feather, John The Book Trade in Politics: The Making of the Copyright Act of 1710, in: Publishing History 8 (1980)

Zitiert: Feather, The Making of the Copyright Act of 1710

ders. A History of British Publishing, London u.a. 1988

Zitiert: Feather, History

Fechner, Frank Geistiges Eigentum und Verfassung - Schöpferische Leistungen unter dem Schutz des Grundgesetzes, Tübingen 1999

Zitiert: Fechner, Geistiges Eigentum und Verfassung

Feingold, Robin When 'Fair Is Foul': A Narrow Reading of the Fair Use Doctrine in Harper \& Row, Publishers, Inc. v. Nation Enterprises, in: Cornell Law Review, Vol. 72 (1986), S. 218-243

Zitiert: Feingold, 72 Cornell L. Rev. 218 (1986)

Fezer, Karl-Heinz Markenrecht - Kommentar zum Markengesetz, zur Paris Verbandsübereinkunft und zum Madrider Markenabkommen, 4. Auflage, München 2009

Zitiert: Fezer, MarkenG

Ficsor, Mihály The Law of Copyright and the Internet, Oxford 2002

Zitiert: Ficsor, Law of Copyright 
ders. How Much of What? The Three-Step Test and Its Application in Recent WTO Dispute Settlement Cases, in: Revue internationale du droit d'auteur (RIDA) 192 (2002), S. 111-251

Zitiert: Ficsor, RIDA 192 (2002), 111

Findeisen, Frank Die Auslegung urheberrechtlicher Schrankenbestimmungen, BadenBaden 2005

Zitiert: Findeisen, Auslegung

Fischman Afori, Orit Human Rights and Copyright: The Introduction of Natural Law Considerations into American Copyright Law, in: Fordham Intellectual Property, Media and Entertainment Law Journal, Vol. 14 (2004), S. 497-565

Zitiert: Fischman Afori, 14 Fordham Intell. Prop. Media \& Ent. L.J. 497 (2004)

dies. An open standard "fair use" doctrine: A welcome Israeli initiative, in: EIPR, 2008, 30(3), S. 85-86

Zitiert: Fischman Afori, EIPR 2008, 30(3), 85

Fisher, William W. Reconstructing the Fair Use Doctrine, in: Harvard Law Review, Vol. 101 (1988), S. 1659-1795

Zitiert: Fisher, 101 Harv. L. Rev. 1659 (1988)

Flechsig, Norbert P. Vorausabtretung gesetzlicher Vergütungsansprüche - Unionsrechtliche Auswirkungen der EuGH-Entscheidung Luksan auf Urheber, Verwerter und Intermediäre, in: MMR 2012, S. 293-300

Zitiert: Flechsig, MMR 2012, 293

Förster, Achim Fair Use - Ein Systemvergleich der Schrankengeneralklausel des USamerikanischen Copyright Act mit dem Schrankenkatalog des deutschen Urheberrechtsgesetzes, Tübingen 2008

Zitiert: Förster, Fair Use

Frank, Christian Urheberabgaben nach Padawan - Zur Vereinbarkeit von Urheberabgaben für Geräte und Medien mit einem ,gerechten Ausgleich“ im Sinne der Harmonisierungsrichtlinie, in: CR 2011, S. 1-6

Zitiert: Frank, CR 2011, 1

Frankel, Susy Some Consequences of Misinterpreting the TRIPs Agreement, in: WIPO Journal 2009, Heft 1, S. 35-42

Zitiert: Frankel, 1 WIPO J. 2009, 35

Franzen, Jan Helmut / Olenhusen, Albrecht Götz von Lichtbildwerke, Lichtbilder und Fotoimitate - Abhängige Bearbeitung oder freie Benutzung, in: UFITA 2007, S. $435-480$ Zitiert: Franzen/v.Olenhusen, UFITA 2007, 435

Fraser, Eric M. Antitrust and the Google Books Settlement: The Problem of Simultaneity, in: Stanford Technology Law Review, 2010, Vol. 4, S. 1-91

Zitiert: Fraser, 2010 Stan. Tech. L. Rev. 1

Frenz, Walter Handbuch Europarecht, Band 4: Europäische Grundrechte, Berlin 2009 Zitiert: Frenz, Europäische Grundrechte

Freiwald, Sven Die private Vervielfältigung im digitalen Kontext am Beispiel des Filesharing, Baden-Baden 2004

Zitiert: Freiwald, Private Vervielfältigung 


\section{Literatur}

Frey, Dieter Leistungsschutzrecht für Presseverleger - Überlegungen zur Struktur und $\mathrm{zu}$ den Auswirkungen auf die Kommunikation im Internet, in: MMR 2010, S. 291-295

Zitiert: Frey, MMR 2010, 291

Freys, Alexander F. J. „Freie Benutzung“ der Memoiren eines Präsidenten - Die Entscheidung des Supreme Court vom 20. Mai 1985 in Sachen Harper \& Row v. Nation Enterprises, in: ZUM 1985, S. 500-503

Zitiert: Freys, ZUM 1985, 500

ders. USA-Beitritt zur Revidierten Berner Übereinkunft, in: ZUM 1989, S. 125-128 Zitiert: Freys, ZUM 1989, 125

Friedman, Matthew Nine Years and Still Waiting: While Congress Continues to Hold Off on Amending Copyright Law for the Digital Age, Commercial Industry has Largely Moved On, in: Villanova Sports and Entertainment Law Journal, Vol. 17 (2010), S. 637-680

Zitiert: Friedman, 17 Vill. Sports \& Ent. L.J. 637 (2010)

Fromm, Friedrich Karl / Nordemann, Wilhelm Urheberrecht, Kommentar, 9. Auflage, Stuttgart 1998

Zitiert: Fromm/Nordemann/Bearbeiter, 9. Aufl.

Fromm, Friedrich Karl / Nordemann, Wilhelm Urheberrecht, Kommentar, 10. Auflage, Stuttgart 2008

Zitiert: Fromm/Nordemann/Bearbeiter

Fromm-Russenschuck, Viola / Duggal, Raoul WTO und TRIPs - Unmittelbare Auswirkungen auf die Rechtspraxis, Köln, Berlin, München 2004

Zitiert: Fromm-Russenschuck/Duggal, WTO und TRIPs

Frotz, Gerhard Zum Vervielfältigungsrecht des Urhebers und zu den konventionskonformen nationalen Beschränkungen - Ein Beitrag zur Fortentwicklung des UrhG, in: Dittrich, Robert (Hrsg.), Festschrift 50 Jahre Urheberrechtsgesetz, Wien 1986, S. 119-139

Zitiert: Frotz, in: FS 50 Jahre UrhG

Frowein, Jochen A. / Peukert, Wolfgang Europäische Menschenrechtskonvention, EMRK-Kommentar, 2. Auflage, Kehl 1996

Zitiert: Frowein/Peukert, EMRK, 2. Aufl. [Bearbeiter kursiv hervorgehoben]

dies. Europäische Menschenrechtskonvention, EMRK-Kommentar, 3. Auflage, Kehl 2009

Zitiert: Frowein/Peukert, EMRK, 3. Aufl. [Bearbeiter kursiv hervorgehoben]

Galloux, Jean-Christophe Beschränkungen und Ausnahmen des Urheberrechts in Frankreich: französische Ausnahme oder französisches Paradox?, in: Hilty, Reto/ Geiger, Christophe (Hrsg.), Impulse für eine europäische Harmonisierung des Urheberrechts - Urheberrecht im deutsch-französischen Dialog, Berlin u.a. 2007, S. 321-327

Zitiert: Galloux, in: Hilty/Geiger, Europäische Harmonisierung

Gamble, Aundrea Google's Book Search Project: Searching for Fair Use or Infringement, in: Tulane Journal of Technology and Intellectual Property, Vol. 9 (2007), S. $365-384$

Zitiert: Gamble, 9 Tul. J. Tech. \& Intell. Prop. 365 (2007)

Gamm, Otto-Friedrich von Urheberrechtsgesetz - Kommentar, München 1968

Zitiert: v.Gamm, UrhG 
ders. Urheberbenennung in Rechtsprechung und Praxis, in: NJW 1959, S. 318-320 Zitiert: v.Gamm, NJW 1959, 318

Ganley, Paul Google Book Search: Fair Use, Fair Dealing and the Case for Intermediary Copying, in: Journal of Internet Law, Vol. 10, No. 5 (2006), S. 1-22

Zitiert: Ganley, 10 No. 5 J. Internet L. 1 (2006)

Garloff, Peter Copyright und Kunstfreiheit - zur Zulässigkeit ungenehmigter Zitate in Heiner Müllers letztem Theaterstück, in: GRUR 2001, S. 476-482 Zitiert: Garloff, GRUR 2001, 476

Gaster, Jens L. Der Rechtsschutz von Datenbanken - Kommentar zur Richtlinie 96/9/EG mit Erläuterungen zur Umsetzung in das deutsche und österreichische Recht, Köln u.a. 1999

Zitiert: Gaster, Rechtsschutz von Datenbanken

ders. Das urheberrechtliche Territorialitätsprinzip aus Sicht des Europäischen Gemeinschaftsrechts, in: ZUM 2006, S. 8-15

Zitiert: Gaster, ZUM 2006, 8

Geiger, Christophe Droit d'auteur et droit du public à l'information, Paris 2004 Zitiert: Geiger, Droit d'auteur

ders. Die Schranken des Urheberrechts im Lichte der Grundrechte - Zur Rechtsnatur der Beschränkungen des Urheberrechts, in: Hilty, Reto/Peukert, Alexander (Hrsg.), Interessenausgleich im Urheberrecht, Baden-Baden 2004, S. 143-157

Zitiert: Geiger, in: Hilty/Peukert, Interessenausgleich

ders. Die Schranken des Urheberrechts in Frankreich - Kritische Analyse und Vorausschau, in: Hilty, Reto/Geiger, Christophe (Hrsg.), Impulse für eine europäische Harmonisierung des Urheberrechts - Urheberrecht im deutsch-französischen Dialog, Berlin u.a. 2007, S. 335-347

Zitiert: Geiger, in: Hilty/Geiger, Europäische Harmonisierung

ders. Irrtum: Schranken des Urheberrechts sind Ausnahmebestimmungen und sind restriktiv auszulegen, in: Berger, Mathis/Macciacchini, Sandro (Hrsg.), Populäre Irrtümer im Urheberrecht, Festschrift für Reto M. Hilty, Zürich u.a. 2008, S. 77-100

Zitiert: Geiger, in: FS Hilty

ders. Der urheberrechtliche Interessenausgleich in der Informationsgesellschaft - Zur Rechtsnatur der Beschränkungen des Urheberrechts, in: GRUR Int. 2004, S. 815-821

Zitiert: Geiger, GRUR Int. 2004, 815

ders. Right to Copy v. Three-Step Test - The Future of the Private Copy Exception in the Digital Environment, in: Computer Law Review International (CRi) 2005, S. 7-13

Zitiert: Geiger, CRi 2005, 7

ders. Creating Copyright Limitations without Legal Basis: The „Buren“ Decision, A Liberation?, in: IIC 2005, S. 842-850

Zitiert: Geiger, IIC 2005, 842

ders. The Private Copy Exception, an Area of Freedom (Temporarily) Preserved in the Digital Environment, in: IIC 2006, S. 74-81

Zitiert: Geiger, IIC 2006, 74

ders. The Three-Step Test, a Threat to a Balanced Copyright Law?, in: IIC 2006, S. 683-699

Zitiert: Geiger, IIC 2006, 683 


\section{Literatur}

ders. The Role of the Three-Step Test in the Adaptation of Copyright Law to the Information Society, in: e-Copyright Bulletin, January-March 2007, abrufbar unter: http://portal.unesco.org/culture/en/files/34481/ 11883823381 test trois_etapes_en.pdf/test trois_etapes_en.pdf Zitiert: Geiger, e-Copyright Bulletin 2007

ders. From Berne to National Law, via the Copyright Directive: The Dangerous Mutations of the Three-Step Test, in: EIPR 2007, 29(12), S. 486-491

Zitiert: Geiger, EIPR 2007, 29(12), 486

ders. The French Implementation of the Information Society Directive: A Disappointing Result of a Promising Debate, in: AMI 2008, Heft 1, S. 1-7

Zitiert: Geiger, AMI 2008, 1

ders. Flexibilising Copyright - Remedies to the Privatisation of Information by Copyright Law, in: IIC 2008, S. 178-197

Zitiert: Geiger, IIC 2008, 178

ders. The Answer to the Machine Should not be the Machine: Safeguarding the Private Copy Exception in the Digital Environment, in: EIPR 2008, 30(4), S. 121-129

Zitiert: Geiger, EIPR 2008, 30(4), 121

ders. Die Schranken des Urheberrechts als Instrument der Innovationsförderung Freie Gedanken zur Ausschließlichkeit im Urheberrecht, in: GRUR Int. 2008, S. $459-468$

Zitiert: Geiger, GRUR Int. 2008, 459

ders. Implementing an International Instrument for Interpreting Copyright Limitations and Exceptions, in: IIC 2009, S. 627-642

Zitiert: Geiger, IIC 2009, 627

ders. Intellectual Property shall be Protected!? Article 17(2) of the Charter of Fundamental Rights of the European Union: A Mysterious Provision with an Unclear Scope, in: EIPR 2009, 31(3), S. 113-117

Zitiert: Geiger, EIPR 2009, 31(3), 113

Geiger, Christophe / Engelhardt, Tim / Hansen, Gerd / Markowski, Kristina Urheberrecht im deutsch-französischen Dialog - Impulse für eine europäische Rechtsharmonisierung - Bericht von der Abschlussveranstaltung der deutsch-französischen Vortragsreihe zum Urheberrecht am 13. Januar 2006 im Europäischen Patentamt, München, in: GRUR Int. 2006, S. 475-496

Zitiert: Geiger/Engelhardt/Hansen/Markowski, GRUR Int. 2006, 475

Geiger, Christophe / Griffiths, Jonathan / Hilty, Reto M. Declaration on a Balanced Interpretation of the "Three-Step Test" in Copyright Law, in: IIC 2008, S. 707-712 Zitiert: Geiger/Griffiths/Hilty, IIC 2008, 707

Gelinsky, Katja Der Schutz des Eigentums gemäß Art. 1 des Ersten Zusatzprotokolls zur Europäischen Menschenrechtskonvention: Eine Analyse der Rechtsprechung der Straßburger Organe, Berlin 1996

Zitiert: Gelinsky, Schutz des Eigentums gemäß Art. 1 des Ersten Zusatzprotokolls

Geller, Paul Edward Conflicts of Law in Cyberspace: Rethinking International Copyright in a Digitally Networked World, in: Columbia-VLA Journal of Law \& the Arts, Vol. 20 (1996), S. 571-603

Zitiert: Geller, 20 Colum.-VLA J.L. \& Arts 571 (1996) 
Gervais, Daniel J. The TRIPS Agreement: Drafting History and Analysis, Third Edition, London 2008

Zitiert: Gervais, TRIPS Agreement

ders. Towards a New Core International Copyright Norm: The Reverse Three-Step Test, in: Marquette Intellectual Property Law Review, Vol. 9 (2005), S. 1-35

Zitiert: Gervais, 9 Marq. Intell. Prop. L. Rev. 1 (2005)

ders. The Google Book Settlement and the TRIPS Agreement, in: Stanford Technology Law Review 2011, S. 1-10

Zitiert: Gervais, 2011 Stan. Tech. L. Rev. 1

Gey, Michael Das Recht der öffentlichen Zugänglichmachung i.S.d. § 19a UrhG, Stuttgart u.a. 2009

Zitiert: Gey, Öffentliche Zugänglichmachung

Ghidini, Gustavo Innovation, Competition and Consumer Welfare in Intellectual Property Law, Cheltenham (UK) 2010

Zitiert: Ghidini, Innovation, Competition and Consumer Welfare

Gibson, James Risk Aversion and Rights Accretion in Intellectual Property Law, in: Yale Law Journal, Vol. 116 (2007), S. 882-951

Zitiert: Gibson, 116 Yale L.J. 882 (2007)

Gierke, Cornelie von Die Freiheit des Straßenbildes ( 59 UrhG), in: Ahrens, HansJürgen/Bornkamm, Joachim/Gloy, Wolfgang/Starck, Joachim/v. Ungern-Sternberg, Joachim (Hrsg.), Festschrift für Willi Erdmann zum 65. Geburtstag, Köln u.a. 2002, S. 103-115

Zitiert: v.Gierke, in: FS Erdmann

Gierke, Otto von Deutsches Privatrecht, Band 1: Allgemeiner Teil und Personenrecht, Leipzig u.a. 1895

Zitiert: v.Gierke, Deutsches Privatrecht I

Gieseke, Ludwig Die geschichtliche Entwicklung des deutschen Urheberrechts, Göttingen 1957

Zitiert: Gieseke, Geschichtliche Entwicklung

ders. Zensur und Nachdruckschutz in deutschen Staaten in den Jahren nach 1800, in: Wadle, Elmar (Hrsg.), Historische Studien zum Urheberrecht in Europa - Entwicklungslinien und Grundfragen, Berlin 1993, S. 21-31

Zitiert: Gieseke, in: Historische Studien

ders. Vom Privileg zum Urheberrecht - Die Entwicklung des Urheberrechts in Deutschland bis 1845, Göttingen 1995

Zitiert: Gieseke, Vom Privileg zum Urheberrecht

Ginsburg, Jane C. Urheberpersönlichkeitsrechte im Rechtssystem des Common Law, in: GRUR Int. 1991, S. 593-605

Zitiert: Ginsburg, GRUR Int. 1991, 593

dies. Global Use/Territorial Rights: Private International Law Questions of the Global Information Infrastructure, in: Journal of the Copyright Society of the U.S.A., Vol. 42 (1995), S. 318-338

Zitiert: Ginsburg, 42 J. Copyright Soc'y U.S.A. 318 (1995)

dies. Have Moral Rights Come of (Digital) Age in the United States?, in: Cardozo Arts and Entertainment Law Journal, Vol. 19 (2001), S. 9-17

Zitiert: Ginsburg, 19 Cardozo Arts \& Ent. L.J. 9 (2001) 


\section{Literatur}

dies. Toward Supranational Copyright Law? The WTO Panel Decision and the "ThreeStep Test" for Copyright Exceptions, in: RIDA 187 (2001), S. 3-65

Zitiert: Ginsburg, RIDA 187 (2001), 3

Ginsburg, Jane C. / Kernochan, John M. One Hundred and Two Years Later: The U.S. Joins the Berne Convention, in: Columbia-VLA Journal of Law \& the Arts, Vol. 13 (1988-1989), S. 1-38

Zitiert: Ginsburg/Kernochan, 13 Colum.-VLA J.L. \& Arts 1 (1989)

Ginsburg, Ruth Bader The Role of Dissenting Opinions, in: Minnesota Law Review, Vol. 95 (2010), S. 1-8

Zitiert: Ginsburg, 95 Minn. L. Rev. 1 (2010)

Givler, Peter Google and the Book Publishers: Testing the Limits of Fair Use in the Digital Environment, in: NYSBA Bright Ideas, Vol. 14, No. 2 (2005), S. 23-25, abrufbar unter: http://aaupnet.org/aboutup/issues/pgbrightideas.pdf Zitiert: Givler, 14 No. 2 NYSBA Bright Ideas 23 (2005)

Glorioso, Alessandra Google Books: An Orphan Works Solution?, in: Hofstra Law Review, Vol. 38 (2010), S. 971-1007

Zitiert: Glorioso, 38 Hofstra L. Rev. 971 (2010)

Goldmann, Bettina C. Der „Fairness in Music Licensing Act“ in den USA - Sperrstunde für das „Kneipenrecht“? - Zum WTO-Konflikt zwischen Europa und den USA über die Ausweitung der „homestyle exemption“ im US-Copyright Act, in: GRUR Int. 1999, S. 504-511

Zitiert: Goldmann, GRUR Int. 1999, 504

dies. Victory for Songwriters in WTO Music-Royalties Dispute Between U.S. and EU - Background of the Conflict Over the Extension of Copyright Homestyle Exemption, in: IIC 2001, S. 412-429

Zitiert: Goldmann, IIC 2001, 412

Goldsmith, Jack L. / Posner, Eric A. The Limits of International Law, Oxford u.a. 2005

Zitiert: Goldsmith/Posner, The Limits of International Law

Goldstein, Paul International Copyright: Principles, Law, and Practice, New York 2001

Zitiert: Goldstein, International Copyright

ders. Copyright, New York u.a., 2002 Supplement

Zitiert: Goldstein, Copyright

ders. Berne in the USA, in: IIC 2008, S. 216-221

Zitiert: Goldstein, IIC 2008, 216

ders. Fair Use in Context, in: Columbia Journal of Law \& the Arts, Vol. 31 (2008), S. 433-443

Zitiert: Goldstein, 31 Colum. J.L. \& Arts 433 (2008)

Goldstein, Paul / Hugenholtz, Bernt International Copyright: Principles, Law, and Practice, Second Edition, New York 2010

Zitiert: Goldstein/Hugenholtz, International Copyright

Gordon, Wendy J. Fair Use as Market Failure: A Structural and Economic Analysis of the Betamax Case and its Predecessors, in: Columbia Law Review, Vol. 82 (1982), S. $1600-1657$

Zitiert: Gordon, 82 Colum. L. Rev. 1600 (1982) 
dies. Excuse and Justification in the Law of Fair Use: Transaction Costs Have Always Been Only Part of the Story, in: Journal of the Copyright Society of the U.S.A., Vol. 50 (2003), S. 149-198

Zitiert: Gordon, 50 J. Copyright Soc'y U.S.A. 149 (2003)

Goryunov, Eugene All Rights Reserved: Does Google's Image Search Infringe Vested Exclusive Rights Granted under the Copyright Law?, in: John Marshall Law Review, Vol. 41 (2008), S. 487-526

Zitiert: Goryunov, 41 J. Marshall L. Rev. 487 (2008)

Götting, Horst-Peter Urheberrechtliche und vertragsrechtliche Grundlagen, in: Beier, Friedrich-Karl/Götting, Horst-Peter/Lehmann, Michael/Moufang, Rainer (Hrsg.), Urhebervertragsrecht, Festgabe für Gerhard Schricker zum 60. Geburtstag, München 1995, S. 53-75

Zitiert: Götting, in: FS Schricker I

ders. Anmerkung zu BGH, Urt. v. 29.4.2010, I ZR 69/08 - Vorschaubilder, in: LMK 2010, 309481

Zitiert: Götting, LMK 2010, 309481

Grabenwarter, Christoph Europäische Menschenrechtskonvention, 4. Auflage, München 2009

Zitiert: Grabenwarter, EMRK

Gräbig, Johannes Anmerkung zu LG Berlin, Urt. v. 14.7.2009, 16 O 67/08, in: MMR 2010, S. 47-48

Zitiert: Gräbig, MMR 2010, 47

Grabitz, Eberhard / Hilf, Meinhard / Nettesheim, Martin (Hrsg.) Das Recht der Europäischen Union, München, Loseblattsammlung, Stand: 49. EL, November 2012

Zitiert: Grabitz/Hilf/Nettesheim/Bearbeiter, Recht der EU

Grassmann, Ferdinand Der elektronische Kopienversand im Rahmen der Schrankenregelungen - Rechtsvergleich vor allem zwischen deutschem und englischem Urheberrecht, Baden-Baden 2006

Zitiert: Grassmann, Elektronischer Kopienversand

Gray, Kevin R. / Cameron, James Principles of International Law in the WTO Dispute Settlement Body, in: International \& Comparative Law Quarterly (ICLQ), 2001, 50(2), S. 248-298

Zitiert: Gray/Cameron, ICLQ 2001, 50(2), 248

Gray, Naomi Jane / Kissman, Lee The Future of Third-Party Content on the Internet, in: Intellectual Property \& Technology Law Journal, Vol. 19, No. 10 (2007), S. $12-16$

Zitiert: Gray/Kissman, 19 No. 10 Intell. Prop. \& Tech. L.J. 12 (2007)

Griffiths, Jonathan The "Three-Step Test" in European Copyright Law - Problems and Solutions, in: IPQ 2009, No. 4, S. 428-457

Zitiert: Griffiths, IPQ 2009, 428

ders. Unsticking the centre-piece - the liberation of European copyright law?, in: JIPITEC 2010, S. 87-95

Zitiert: Griffiths, JIPITEC 2010, 87 


\section{Literatur}

Grimmelmann, James The Google Book Search Settlement: Ends, Means, and the Future of Books, NYLS Legal Studies Research Paper No. 08/09 No. 32, abrufbar unter: http://ssrn.com/abstract=1388846

Zitiert: Grimmelmann, Google Book Search Settlement

ders. How to Fix the Google Book Search Settlement, in: Journal of Internet Law, Vol. 12, No. 10 (2009), S. 1-20

Zitiert: Grimmelmann, 12 No. 10 J. Internet L. 1 (2009)

ders. Objections and Responses to the Google Books Settlement: A Report, Version 2.0, May 2010, abrufbar unter: http://works.bepress.com/cgi/viewcontent.cgi?arti$\mathrm{cle}=1029 \&$ context $=$ james_grimmelmann Zitiert: Grimmelmann, Objections and Responses

ders. Privacy as Product Safety, in: Widener Law Journal, Vol. 19 (2010), S. 793-827

Zitiert: Grimmelmann, 19 Widener L.J. 793, 813 ff. (2010)

Grzeszick, Bernd Geistiges Eigentum und Art. 14 GG, in: ZUM 2007, S. 344-353 Zitiert: Grzeszick, ZUM 2007, 344

Guibault, Lucie Why Cherry-Picking Never Leads to Harmonisation - The Case of the Limitations on Copyright under Directive 2001/29/EC, in: JIPITEC 2010, S. 55-66 Zitiert: Guibault, JIPITEC 2010, 55

Guntrum, Sebastian Zur Zukunft der Privatkopie in der Informationsgesellschaft, Hamburg 2007

Zitiert: Guntrum, Zukunft der Privatkopie

Haas, Franz-Werner Das TRIPS-Abkommen: Geistiges Eigentum als Gegenstand des Welthandelsrechts, Baden-Baden 2004

Zitiert: Haas, TRIPS-Abkommen

Haberstumpf, Helmut Handbuch des Urheberrechts, 2. Auflage, Neuwied u.a. 2000 Zitiert: Haberstumpf, Handbuch

ders. Die Entlehnungsfreiheit im Urheberrechtsgesetz, in: ZUM 2003, S. 83 Zitiert: Haberstumpf, ZUM 2003, 83

ders. Anmerkung zu BGH, Urt. v. 1.12.2010, I ZR 12/08 - Perlentaucher, in: ZUM 2011, S. 158-161

Zitiert: Haberstumpf, ZUM 2011, 158

Hackemann, Martin Information und Dokumentation aus urheberrechtlicher Sicht Einige Anmerkungen zur gegenwärtigen und künftigen Rechtslage, in: GRUR 1982, S. 262-273

Zitiert: Hackemann, GRUR 1982, 262

Haedicke, Maximilian Patente und Piraten - Geistiges Eigentum in der Krise, München 2011

Zitiert: Haedicke, Patente und Piraten

Hamel, W. Warren Harper \& Row v. The Nation: A First Amendment Privilege for News Reporting of Copyrightable Material?, in: Columbia Journal of Law and Social Problems, Vol. 19 (1985), S. 253-303

Zitiert: Hamel, 19 Colum. J.L. \& Soc. Probs. 253 (1985)

Handig, Christian Urheberrechtliche Aspekte bei der Lizenzierung von Radioprogrammen im Internet, in: GRUR Int. 2007, S. 206-218

Zitiert: Handig, GRUR Int. 2007, 206 
Hanratty, Elisabeth Google Library - Beyond Fair Use?, in: Duke Law \& Technology Review 2005, No. 10

Zitiert: Hanratty, 2005 Duke L. \& Tech. Rev. 10

Hansen, Gerd Warum Urheberrecht? - Die Rechtfertigung des Urheberrechts unter besonderer Berücksichtigung des Nutzerschutzes, Baden-Baden 2009

Zitiert: Hansen, Warum Urheberrecht

Hansen, Gerd / Schmidt-Bischoffshausen, Albrecht Ökonomische Funktionen von Verwertungsgesellschaften - Kollektive Wahrnehmung im Lichte von Transaktionskosten- und Informationsökonomik, in: GRUR Int. 2007, S. 461-481

Zitiert: Hansen/Schmidt-Bischoffshausen, GRUR Int. 2007, 461

Hardege, Stefan Informationstechnologische Entwicklungen und der Schutz von Verfügungsrechten für Informationsgüter - Eine ökonomische Analyse zur Ausgestaltung des Urheberrechts, Frankfurt a.M. u.a. 2006

Zitiert: Hardege, Informationstechnologische Entwicklungen

Hargreaves, Ian Digital Opportunity - A Review of Intellectual Property and Growth, May 2011, abrufbar unter: http://www.ipo.gov.uk/ipreview-finalreport.pdf Zitiert: Hargreaves, Digital Opportunity

Hart, Michael The Copyright in the Information Society Directive: An Overview, in: EIPR 2002, 24(2), S. 58-64

Zitiert: Hart, EIPR 2002, 24(2), 58

Harte-Bavendamm, Henning / Jürgens, Uwe Suchmaschinen: Neue Angebote und alte Haftungsfragen?, in: Ohly, Ansgar/Bodewig, Theo/Dreier, Thomas/Götting, HorstPeter/Haedicke, Maximilian/Lehmann, Michael (Hrsg.), Festschrift für Gerhard Schricker zum 70. Geburtstag, München 2005, S. 33-52

Zitiert: Harte-Bavendamm/Jürgens, in: FS Schricker II

Härting, Niko Internetrecht, 3. Auflage, Köln 2008

Zitiert: Härting, Internetrecht, 3. Aufl.

ders. Internetrecht, 4. Auflage, Köln 2010

Zitiert: Härting, Internetrecht

Hartnett, Deborah A New Era for Copyright Law: Reconstituting the Fair Use Doctrine, in: New York Law School Law Review, Vol. 34 (1989), S. 267-302

Zitiert: Hartnett, 34 N.Y.L. Sch. L. Rev. 267 (1989)

Hasse, Anja Parodie versus Parody: Eine rechtsvergleichende Untersuchung zum Recht der Bundesrepublik Deutschland und der Vereinigten Staaten von Amerika, Göttingen 2001

Zitiert: Hasse, Parodie vs. Parody

Hausman, Jerry A. / Sidak, J. Gregory Google and the Proper Antitrust Scrutiny of Orphan Books, in: Journal of Competition Law \& Economics, Vol. 5 (2009), S. 411-438

Zitiert: Hausman/Sidak, 5 J. Competition L. \& Econ. 411 (2009)

He, Huaiwen Seeking a Balanced Interpretation of the Three-Step Test - An Adjusted Structure in View of Divergent Approaches, in: IIC 2009, S. 274-308

Zitiert: He, IIC 2009, 274

Heckmann, Jörn Zum Erfordernis der Einwilligung in eine retrospektive Digitalisierung von Printwerken zu Werbezwecken - Dargestellt am Dienst ,google book search“, in: Archiv für Presserecht (AfP) 2007, S. 314-319

Zitiert: Heckmann, AfP 2007, 314 


\section{Literatur}

Hefti, Ernst Das Urheberrecht im Nationalsozialismus, in: Dittrich, Robert (Hrsg.), Woher kommt das Urheberrecht und wohin geht es?, Wien 1988, S. 165-180

Zitiert: Hefti, in: Woher kommt das Urheberrecht

Heide, Thomas The Berne Three-Step Test and the Proposed Copyright Directive, in: EIPR 1999, 21(3), S. 105-109

Zitiert: Heide, EIPR 1999, 21(3), 105

Heinze, Christian Surf global, sue local! Der europäische Klägergerichtsstand bei Persönlichkeitsrechtsverletzungen im Internet, in: EuZW 2011, S. 947-951 Zitiert: Heinze, EuZW 2011, 947

Helfer, Laurence R. World Music on a U.S. Stage: A Berne/TRIPS and Economic Analysis of the Fairness in Music Licensing Act, in: Boston University Law Review, Vol. 80 (2000), S. 93-204

Zitiert: Helfer, 80 B.U. L. Rev. 93 (2000)

Herdegen, Matthias Völkerrecht, 8. Auflage, München 2009

Zitiert: Herdegen, Völkerrecht

Herzog, Roman Grundrechte aus der Hand des Gesetzgebers, in: Fürst, Walther/ Herzog, Roman/Umbach, Dieter C. (Hrsg.), Festschrift für Wolfgang Zeidler, Band 2, Berlin u.a. 1987, S. 1415-1428

Zitiert. Herzog, in: FS Zeidler

Hess, Burkhard Der Schutz der Privatsphäre im Europäischen Zivilverfahrensrecht Besprechung von EuGH, Urteil v. 25.10.2011, verb. Rs. C-509/09 und C-161/10 (eDateAdvertising u.a.), in: JZ 2012, S. 189-193

Zitiert: Hess, JZ 2012, 189

Hetcher, Steven The Half-Fairness of Google's Plan to Make the World's Collection of Books Searchable, in: Michigan Telecommunications and Techology Law Review, Vol. 13 (2006), S. 1-76

Zitiert: Hetcher, 13 Mich. Telecomm. \& Tech. L. Rev. 1 (2006)

Heymann, Britta / Nolte, Georg Blockiert das Urheberrecht sinnvolle Informationsdienste? - Zur rechtlichen Beurteilung der Bildersuche, in: K\&R 2009, S. 759-765 Zitiert: Heymann/Nolte, K\&R 2009, 759

Heymann, Laura A. Everything is Transformative: Fair Use and Reader Response, in: Columbia Journal of Law \& the Arts, Vol. 31 (2008), S. 445-466

Zitiert: Heymann, 31 Colum. J.L. \& Arts 445 (2008)

Hilty, Reto M. Das Basler Nachdrucksverbot von 1531 im Lichte der gegenwärtigen Entwicklungen des Urheberrechts, in: Dittrich, Robert (Hrsg.), Die Notwendigkeit des Urheberrechtsschutzes im Lichte seiner Geschichte, S. 20-45

Zitiert: Hilty, in: Notwendigkeit des Urheberrechtsschutzes

ders. Urheberrecht in der Informationsgesellschaft: „Wer will was von wem woraus?“ - Ein Auftakt zum ,zweiten Korb“, in: ZUM Sonderheft, 2003, S. 983-1005 Zitiert: Hilty, ZUM 2003, 983

ders. Intellectual Property and the European Community's Internal Market Legislation - Copyright in the Internal Market, in: IIC 2004, S. 760-775

Zitiert: Hilty, IIC 2004, 760

ders. Vergütungssystem und Schrankenregelungen - Neue Herausforderungen an den Gesetzgeber, in: GRUR 2005, S. 819-828

Zitiert: Hilty, GRUR 2005, 819 
ders. Verbotsrecht vs. Vergütungsanspruch: Suche nach den Konsequenzen der tripolaren Interessenlage im Urheberrecht, in: Ohly, Ansgar/Bodewig, Theo/Dreier, Thomas/Götting, Horst-Peter/Haedicke, Maximilian/Lehmann, Michael (Hrsg.), Perspektiven des Geistigen Eigentums und Wettbewerbsrechts, Festschrift für Gerhard Schricker zum 70. Geburtstag, München 2005, S. 325-352

Zitiert: Hilty, in: FS Schricker II

ders. Sündenbock Urheberrecht?, in: Ohly, Ansgar/Klippel, Diethelm (Hrsg.), Geistiges Eigentum und Gemeinfreiheit, Tübingen 2007, S. 107-144

Zitiert: Hilty, in: Ohly/Klippel, Geistiges Eigentum und Gemeinfreiheit

ders. Renaissance der Zwangslizenzen im Urheberrecht? - Gedanken zu Ungereimtheiten auf der urheberrechtlichen Wertschöpfungskette, in: GRUR 2009, S. 633-644 Zitiert: Hilty, GRUR 2009, 633

ders. Declaration on the "Three-Step Test" - Where do we go from here?, in: JIPITEC 2010, S. 83-86

Zitiert: Hilty, JIPITEC 2010, 83

ders. Urheberrecht, Bern 2011

Zitiert: Hilty, Urheberrecht

Hobe, Stephan Einführung in das Völkerrecht, Begründet von Otto Kimminich, 9. Auflage, Tübingen 2008

Zitiert: Hobe, Völkerrecht

Hock, Martin Das Namensnennungsrecht des Urhebers, Baden-Baden 1993

Zitiert: Hock, Namensnennungsrecht

Höder, Andreas Die kollisionsrechtliche Behandlung unteilbarer Multistate-Verstöße Das Internationale Wettbewerbsrecht im Spannungsfeld von Marktort-, Auswirkungs- und Herkunftslandprinzip, München 2002

Zitiert: Höder, Kollisionsrechtliche Behandlung unteilbarer Multistate-Verstöße

Hoebbel, Christoph Friedrich Der Schutz von Sammelwerken, Sachprosa und Datenbanken im deutschen und amerikanischen Urheberrecht, München 1994

Zitiert: Hoebbel, Schutz von Sammelwerken

Hoeren, Thomas Die Schranken des Urheberrechts in Deutschland, in: Hilty, Reto/ Geiger, Christophe (Hrsg.), Impulse für eine europäische Harmonisierung des Urheberrechts - Urheberrecht im deutsch-französischen Dialog, Berlin u.a. 2007, S. 265-290

Zitiert: Hoeren, in: Hilty/Geiger, Europäische Harmonisierung

ders. Multimedia als noch nicht bekannte Nutzungsart, in: CR 1995, S. 710-714

Zitiert: Hoeren, CR 1995, 710

ders. Urheberrecht in der Informationsgesellschaft - Überlegungen zu einem Rechtsgutachten von Gerhard Schricker et al., in: GRUR 1997, S. 866-875

Zitiert: Hoeren, GRUR 1997, 866

ders. Rechtsoasen im Internet - Eine erste Einführung, in: MMR 1998, S. 297-298

Zitiert: Hoeren, MMR 1998, 297

ders. Urheberrecht 2000 - Thesen für eine Reform des Urheberrechts, in: MMR 2000, S. 3-7

Zitiert: Hoeren, MMR 2000, 3 


\section{Literatur}

ders. Entwurf einer EU-Richtlinie zum Urheberrecht in der Informationsgesellschaft Überlegungen zum Zwischenstand der Diskussion, in: MMR 2000, S. 515-521

Zitiert: Hoeren, MMR 2000, 515

ders. Happy birthday to you: Urheberrechtliche Fragen rund um ein Geburtstagsständchen, in: Berger, Klaus Peter/Ebke, Werner F./Elsing, Siegfried/Großfeld, Bernhard/Kühne, Gunter (Hrsg.), Festschrift für Otto Sandrock zum 70. Geburtstag, Heidelberg 2000, S. 357-372

Zitiert: Hoeren, in: FS Sandrock

ders. Pressespiegel und das Urheberrecht - Eine Besprechung des Urteils des BGH „Elektronischer Pressespiegel“, in: GRUR 2002, S. 1022-1028

Zitiert: Hoeren, GRUR 2002, 1022

ders. Anmerkung zu BGH, Urt. v. 30.3.2006, I ZR 24/03, in: MMR 2006, S. 464

Zitiert: Hoeren, MMR 2006, 464

ders. Anmerkung zu LG Hamburg, Urt. v. 26.9.2008, 308 O 42/06, in: MMR 2009, S. 62

Zitiert: Hoeren, MMR 2009, 62

Hoeren, Thomas / Herring, Eva Maria WikiLeaks und das Erstveröffentlichungsrecht des Urhebers - Informationsfreiheit als externe Schranke des Urheberrechts?, in: MMR 2011, S. 500-504

Zitiert: Hoeren/Herring, MMR 2011, 500

Hoeren, Thomas / Sieber, Ulrich Handbuch Multimedia-Recht - Rechtsfragen des elektronischen Geschäftsverkehrs, 23. Auflage, München 2010

Zitiert: Hoeren/Sieber/Bearbeiter

Hofer, Walther Der Nationalsozialismus. Dokumente 1933-1945, Frankfurt a.M. 1957 Zitiert: Hofer, Der Nationalsozialismus

Hoffmann, Christian Die Verletzung der Vertraulichkeit informationstechnischer Systeme durch Google Sreet View, in: CR 2010, S. 514-518

Zitiert: Hoffmann, CR 2010, 514

Hoffmann, Willy Die Berner Übereinkunft zum Schutze von Werken der Literatur und Kunst, Berlin 1935

Zitiert: Hoffmann, Berner Übereinkunft

Höffner, Eckhard Geschichte und Wesen des Urheberrechts - Band I, München 2010 Zitiert: Höffner, Geschichte und Wesen des UrhR I

Hohagen, Gisbert Die Freiheit der Vervielfältigung zum eigenen Gebrauch, München 2004

Zitiert: Hohagen, Vervielfältigung zum eigenen Gebrauch

ders. Überlegungen zur Rechtsnatur der Kopierfreiheit, in: Ohly, Ansgar/Bodewig, Theo/Dreier, Thomas/Götting, Horst-Peter/Haedicke, Maximilian/Lehmann, Michael (Hrsg.), Perspektiven des Geistigen Eigentums und Wettbewerbsrechts, Festschrift für Gerhard Schricker zum 70. Geburtstag, München 2005, S. 353-368 Zitiert: Hohagen, in: FS Schricker II

Hohloch, Gerhard Neue Medien und Individualrechtsschutz - Kollisionsrechtliche Aspekte grenzüberschreitender Rundfunksendungen, in: ZUM 1986, S. 165-179

Zitiert: Hohloch, ZUM 1986, 165 
Holley, Rose How Good Can It Get? - Analysing and Improving OCR Accuracy in Large Scale Historic Newspaper Digitisation Programs, in: D-Lib Magazine, March/April 2009, Volume 15 Number 3/4, abrufbar unter: http://www.dlib.org/ dlib/march09/holley/03holley.html

Zitiert: Holley, 15 D-Lib Magazine 2009

Holmes, William C. Antitrust Law Handbook, Eagan, Minn. 2010

Zitiert: Holmes, Antitrust Law

Hoppe, Vera Die Einbeziehung ausländischer Beteiligter in US-amerikanische class actions - Unter Berücksichtigung des Class Action Fairness Act 2005, Frankfurt a.M. u.a. 2005

Zitiert: Hoppe, Einbeziehung ausländischer Beteiligter in US-amerikanische class actions

Howard, Anthony / Reinbothe, Jörg The State of Play in the Negotiations on TRIPS (GATT/Uruguay Round), in: EIPR 1991, 13(5), S. 157-164

Zitiert: Howard/Reinbothe, EIPR 1991, 13(5), 157

Hubmann, Heinrich Das Recht des schöpferischen Geistes - Eine philosophisch-juristische Betrachtung zur Urheberrechtsreform, Berlin 1954

Zitiert: Hubmann, Recht des schöpferischen Geistes

ders. Urheber- und Verlagsrecht, München 1959

Zitiert: Hubmann, Urheber- und Verlagsrecht

ders. Das Persönlichkeitsrecht, 2. Auflage, Köln 1967

Zitiert: Hubmann, Persönlichkeitsrecht

ders. Immanuel Kants Urheberrechtstheorie, in: UFITA 106 (1987), S. 145-154

Zitiert: Hubmann, UFITA 106 (1987), 145

Hudec, Robert E. GATT Dispute Settlement after the Tokyo Round: An Unfinished Business, in: Cornell International Law Journal, Vol. 13 (1980), S. 145-203

Zitiert: Hudec, 13 Cornell Int'l L.J. 145 (1980)

ders. The New WTO Dispute Settlement Procedure: An Overview of the First Three Years, in: Minnesota Journal of Global Trade, Vol. 8 (1999), S. 1-50

Zitiert: Hudec, 8 Minn. J. Global Trade 1 (1999)

Hufbauer, Gary C. / Shelton Erb, Joanna / Starr, H. P. The GATT Codes and the Unconditional Most-Favored-Nation Principle, in: Law and Policy in International Business, Vol. 12 (1980), S. 59-93

Zitiert: Hufbauer/Shelton Erb/Starr, 12 Law \& Pol'y Int'l Bus. 59 (1980)

Hugenholtz, P. Bernt Why the Copyright Directive is Unimportant, and Possibly Invalid, in: EIPR 2000, 22(11), S. 499-505

Zitiert: Hugenholtz, EIPR 2000, 22(11), 499

Hugenholtz, P. Bernt / Eechoud, Mireille van / Gompel, Stef van / Guibault, Lucie / Helberger, Natali / Rossini, Mara / Steijger, Lennert / Dufft, Nicole / Bohn, Philipp The Recasting of Copyright \& Related Rights for the Knowledge Economy, Final Report, Institute for Information Law, November 2006, abrufbar unter: http:// www.ivir.nl/publications/other/IViR_Recast_Final_Report_2006.pdf Zitiert: Hugenholtz/v.Eechoud/v.Gompel/Guibault/u.a., Recasting of Copyright 


\section{Literatur}

Hugenholtz, P. Bernt / Okediji, Ruth L. Conceiving an International Instrument on Limitations and Exceptions to Copyright, Final Report, March 06, 2008, abrufbar unter: http://www.ivir.nl/publications/hugenholtz/limitations_exceptions_copyright.pdf

Zitiert: Hugenholtz/Okediji, Limitations and Exceptions

Hugenholtz, P. Bernt / Senftleben, Martin Fair Use in Europe. In Search of Flexibilities, Amsterdam, November 2011, abrufbar unter: http://www.ivir.nl/publications/ hugenholtz/Fair Use Report PUB.pdf

Zitiert: Hugenholtz/Senftleben, Fair Use in Europe

Hughes, Justin American Moral Rights and Fixing the Dastar "Gap", in: Utah Law Review 2007, S. 659-714

Zitiert: Hughes, 2007 Utah L. Rev. 659

Hühner, Sebastian Domain-Parking - Vertrags- und Haftungsfragen unter zusätzlicher Berücksichtigung suchwortabhängiger Werbung, Köln 2012

Zitiert: Hühner, Domain-Parking

Hüsch, Moritz Thumbnails in Bildersuchmaschinen: Zur rechtfertigenden Einwilligung in die Nutzung von Thumbnails - zugleich eine Besprechung von BGH, Urt. v. 29.4.2010 - I ZR 69/08, in: CR 2010, S. 452-457

Zitiert: Hüsch, CR 2010, 452

Hüttner, Sabine 1, 2, 3, 4 Eckstein, keiner muss versteckt sein? - Wer sich im Internet präsentiert, muss mit Google rechnen! Zugleich eine Besprechung des Grundsatzurteils des Bundesgerichtshofes zum Thema Thumbnails, in: WRP 2010, S. 1008-1016

Zitiert: Hüttner, WRP 2010, 1008

Internet \& Gesellschaft Co:llaboratory (Hrsg.) Regelungssysteme für informationelle Güter - Urheberrecht in der digitalen Zukunft, Abschlussbericht April 2011, abrufbar unter: http://dl.collaboratory.de/reports/Ini3_Urheberrecht.pdf

Zitiert: IGCollaboratory, Regelungssysteme für informationelle Güter

Inesi, Andrew A Theory Of De Minimis And A Proposal For Its Application In Copyright, in: Berkeley Technology Law Journal, Vol. 21 (2006), S. 945-994

Zitiert: Inesi, 21 Berkeley Tech. L.J. 945 (2006)

Intveen, Carsten Internationales Urheberrecht und Internet - Zur Frage des anzuwendenden Urheberrechts bei grenzüberschreitenden Datenübertragungen, Baden-Baden 1999

Zitiert: Intveen, Internationales Urheberrecht und Internet

Jackson, John H. The Jurisprudence of GATT \& the WTO, Insights on Treaty Law and Economic Relations, Cambridge u.a. 2000

Zitiert: Jackson, GATT and WTO

Jacob, Jan Ausschließlichkeitsrechte an immateriellen Gütern - Eine kantische Rechtfertigung des Urheberrechts, Tübingen 2010

Zitiert: Jacob, Ausschließlichkeitsrechte

Jacobson, Nels Faith, Hope \& Parody: Campbell v. Acuff-Rose, 'Oh, Pretty Woman', and Parodists' Rights, in: Houston Law Review, Vol. 31 (1994), S. 955-1026

Zitiert: Jacobson, 31 Hous. L. Rev. 955 (1994)

Jänich, Volker M. Geistiges Eigentum - eine Komplementärerscheinung zum Sacheigentum?, Tübingen 2002

Zitiert: Jänich, Geistiges Eigentum 
Janssens, Marie-Christine The issue of exceptions: reshaping the keys to the gates in the territory of literary, musical and artistic creation, in: Derclaye, Estelle (Hrsg.), Research Handbook on the Future of EU Copyright, Cheltenham (UK) 2009, S. 317-348

Zitiert: Janssens, in: Derclaye, Research Handbook on the Future of EU Copyright

Jarass, Hans D. Das allgemeine Persönlichkeitsrecht im Grundgesetz, in: NJW 1989, S. 857-862

Zitiert: Jarass, NJW 1989, 857

ders. EU-Grundrechte, München 2005

Zitiert: Jarass, EU-Grundrechte

Jarass, Hans D. / Pieroth, Bodo Grundgesetz für die Bundesrepublik Deutschland, 11. Auflage, München 2011

Zitiert: Jarass/Pieroth, GG [Bearbeiter kursiv hervorgehoben]

Jones, Elisabeth A. / Janes, Joseph W. Anonymity in a World of Digital Books: Google Books, Privacy, and the Freedom to Read, in: Policy \& Internet, Vol. 2 (2010), Heft 4, S. 43-75

Zitiert: Jones/Janes, 2 Policy \& Internet 43

Jordan, Lawrence The Google Book Search Project Litigation: „Massive Copyright Infringement" or „Fair Use“?, in: Michigan Bar Journal, Vol. 86, No. 9 (2007), S. 32-34

Zitiert: Jordan, 86 Michigan Bar Journal 32 (2007)

Junker, Markus Anwendbares Recht und internationale Zuständigkeit bei Urheberrechtsverletzungen im Internet, Kassel 2002

Zitiert: Junker, Anwendbares Recht und internationale Zuständigkeit

Kaiser, Karen Geistiges Eigentum und Gemeinschaftsrecht - Die Verteilung der Kompetenzen und ihr Einfluß auf die Durchsetzbarkeit der völkerrechtlichen Verträge, Berlin 2004

Zitiert: Kaiser, Geistiges Eigentum und und Gemeinschaftsrecht

Kaminstein, Abraham L. Diplomatische Konferenz über den internationalen Schutz der ausübenden Künstler, der Hersteller von Tonträgern und der Sendeunternehmen (Rom, 10. bis 26. Oktober 1961), in: UFITA 40 (1963), S. 99-135

Zitiert: Kaminstein, UFITA 40 (1963), 99

Kant, Immanuel Von der Unrechtmäßigkeit des Büchernachdrucks, 1785, Nachdruck in: UFITA 106 (1987), S. 137-145

Zitiert: Kant, Von der Unrechtmäßigkeit des Büchernachdrucks (1785), Nachdruck in: UFITA 106 (1987), 137

Karakis, Bella Moral Rights: French, United States and Soviet Compliance with Article 6bis of the Berne Convention, in Touro International Law Review, Vol. 5 (1994), S. 105-138

Zitiert: Karakis, 5 Touro Int'1 L. Rev. 105 (1994)

Katzenberger, Paul Urheberrecht und UFO-Technik - Bewährung des Urheberrechts im Zeichen der digitalen Revolution, in: Straus, Joseph (Hrsg.), Aktuelle Herausforderungen des geistigen Eigentums, Festgabe von Freunden und Mitarbeitern für Friedrich-Karl Beier zum 70. Geburtstag, Köln u.a. 1996, S. 379-388

Zitiert: Katzenberger, in: FS Beier

ders. TRIPS und das Urheberrecht, in: GRUR Int. 1995, S. 447-468

Zitiert: Katzenberger, GRUR Int. 1995, 447 


\section{Literatur}

ders. Elektronische Pressespiegel aus der Sicht des urheberrechtlichen Konventionsrechts, in: GRUR Int. 2004, S. 739-745

Zitiert: Katzenberger, GRUR Int. 2004, 739

Kauert, Michael Das Leistungsschutzrecht des Verlegers: eine Untersuchung des Rechtsschutzes der Verleger unter besonderer Berücksichtigung von $\S 63 \mathrm{a}$ UrhG, Berlin 2008

Zitiert: Kauert, Das Leistungsschutzrecht des Verlegers

Kéréver, André Le droit d'auteur: Acquis et conditions du développement de la culture juridique européenne, in: Le droit d'auteur (DdA) 1990, S. 138-147

Zitiert: Kéréver, DdA 1990, 138

Klass, Nadine Neue Internettechnologien und das Urheberrecht: Die schlichte Einwilligung als Rettungsanker? - Zugleich Besprechung der Vorschaubilder I und II-Entscheidungen des BGH, in: ZUM 2013, S. 1-10

Zitiert: Klass, ZUM 2013, 1

Klein, Susanne Search Engines and Copyright - An Analysis of the Belgian Copiepresse Decision in Consideration of British and German Copyright Law, in: IIC 2008, S. 451-483

Zitiert: Klein, IIC 2008, 451

Kleinemenke, Manuel Anmerkung zu LG Hamburg, Urt. v. 26.9.2008, 308 O 42/06, in: CR 2009, S. 55-56

Zitiert: Kleinemenke, CR 2009, 55

Klett, Alexander Urheberrecht im Internet aus deutscher und amerikanischer Sicht, Baden-Baden 1998

Zitiert: Klett, Urheberrecht im Internet

Klett, Alexander / Apetz, Daja Die Entwicklung des Urheberrechts seit Januar 2009, in: K\&R 2010, S. 441-448

Zitiert: Klett/Apetz, K\&R 2010, 441

Klinefelter, Anne Library Standards for Privacy: A Model for the Digital World?, in: North Carolina Journal of Law \& Technology, Vol. 11 (2010), S. 553

Zitiert: Klinefelter, 11 N.C. J. L. \& Tech. 553 (2010)

Klippel, Diethelm Die Idee des geistigen Eigentums in Naturrecht und Rechtsphilosophie des 19. Jahrhunderts, in: Wadle, Elmar (Hrsg.), Historische Studien zum Urheberrecht in Europa - Entwicklungslinien und Grundfragen, Berlin 1993, S. 121-138 Zitiert: Klippel, in: Historische Studien

Kloth, Matthias Der Schutz der ausübenden Künstler nach TRIPs und WPPT, BadenBaden 2000

Zitiert: Kloth, Schutz der ausübenden Künstler

Knies, Bernhard Die Rechte der Tonträgerhersteller in internationaler und rechtsvergleichender Sicht, München 1999

Zitiert: Knies, Rechte der Tonträgerhersteller

Knutson, Alyssa N. Proceed With Caution: How Digital Archives Have Been Left in the Dark, in: Berkeley Technology Law Journal, Vol. 24 (2009), S. 437-473

Zitiert: Knutson, 24 Berkeley Tech. L.J. 437 (2009) 
Kober, Martin Der Grundrechtsschutz in der Europäischen Union. Bestandsaufnahme, Konkretisierung und Ansätze zur Weiterentwicklung der europäischen Grundrechtsdogmatik anhand der Charta der Grundrechte der Europäischen Union, München 2009

Zitiert: Kober, Grundrechtsschutz in der EU

Koch, Frank A. Perspektiven für die Link- und Suchmaschinen-Haftung - Kommissionsbericht zur Umsetzung der E-Commerce-Richtlinie und seine Konsequenzen für das TDG, in: CR 2004, S. 213-218

Zitiert: Koch, CR 2004, 213

Koch, Manuela Die Auswirkungen der digitalen Informationstechnologien auf die Schranken des Urheberrechts, Leipzig 2007

Zitiert: Koch, Auswirkungen der digitalen Informationstechnologie

Kociubinski, Ben Copyright and the Evolving Law of Internet Search: Field v. Google, Inc. and Perfect 10 v. Google, Inc., in: Boston University Journal of Science and Technology Law, Vol. 12 (2006), S. 372-387

Zitiert: Kociubinski, 12 B.U. J. Sci. \& Tech. L. 372 (2006)

Koelman, Kamiel J. Anmerkung zu Rechtbank Den Haag, Urt. v. 2.3.2005, Az. LJN AS8778 - Uitgevers/De Staat, in: Computerrecht 2005, S. 143-148, abrufbar unter: http://cli.vu/pubdirectory/230/manuscript.pdf

Zitiert: Koelman, Computerrecht 2005, 143

ders. Fixing the Three-Step Test, in: EIPR 2006, 28(8), S. 407-412

Zitiert: Koelman, EIPR 2006, 28(8), 407

Köhler, Helmut / Bornkamm, Joachim Gesetz gegen den unlauteren Wettbewerb, 28. Auflage, München 2010

Zitiert: Köhler/Bornkamm, UWG [Bearbeiter kursiv hervorgehoben]

Köhler, Marcus / Arndt, Hans-Wolfgang / Fetzer, Thomas Recht des Internet, 6. Auflage, Heidelberg 2008

Zitiert: Köhler/Arndt/Fetzer, Recht des Internet

Kohler, David 'This Town Ain't Big Enough for the Both of Us - Or Is It?' Reflections on Copyright, the First Amendment and Google's Use of Others' Content, in: Duke Law \& Technology Review 2007, No. 5

Zitiert: Kohler, 2007 Duke L. \& Tech. Rev. 5

Kohler, Josef Urheberrecht an Schriftwerken und Verlagsrecht, Stuttgart 1907 Zitiert: Kohler, Urheberrecht

König, Peter Sichtbar unscharf - Google Street View startet in Deutschland, in: Magazin für Computer und Technik (c't) 2010, Heft 26, S. 42-43

Zitiert: König, c’t 26/2010, 42

Krause, Peter Die Rechtsprechung des Bundesverfassungsgerichts zum Privatrecht, in: JuristenZeitung (JZ) 1984, S. 711-719

Zitiert: Krause, JZ 1984, 711

Kreile, Reinhold Die Sozialbindung des geistigen Eigentums, Ein Beitrag zur Lehre über die Schranken des Urheberrechts, in: Badura, Peter/Scholz, Rupert (Hrsg.), Wege und Verfahren des Verfassungslebens, Festschrift für Peter Lerche zum 65. Geburtstag, München, 1993, S. 251-266

Zitiert: Kreile, in: FS Lerche 
Kreutzer, Till Das Modell des deutschen Urheberrechts und Regelungsalternativen konzeptionelle Überlegungen zu Werkbegriff, Zuordnung, Umfang und Dauer des Urheberrechts als Reaktion auf den urheberrechtlichen Funktionswandel, BadenBaden 2008

Zitiert: Kreutzer, Modell des deutschen Urheberrechts

Kröber, Christian Anmerkung zu EuGH, Urt. v. 16.6.2011, C-462/09 - Stichting de Thuiskopie./. Opus Supplies Deutschland GmbH, in: GRUR 2011, S. 911-912 Zitiert: Kröber, GRUR 2011, 911

Kröger, Detlef Informationsfreiheit und Urheberrecht, München 2002 Zitiert: Kröger, Informationsfreiheit und Urheberrecht

ders. Enge Auslegung von Schrankenbestimmungen - wie lange noch?, in: MMR 2002, S. 18-21

Zitiert: Kröger, MMR 2002, 18

Krüger-Nieland, Gerda Das Urheberpersönlichkeitsrecht, eine besondere Erscheinungsform des allgemeinen Persönlichkeitsrechts?, in: v.Caemmerer, Ernst/Fischer, Robert (Hrsg.), Festschrift für Fritz Hauß zum 70. Geburtstag, Karlsruhe 1978, S. $215-224$

Zitiert: Krüger-Nieland, in: FS Hauß

dies. Der Urheberrechtsschutz im Spannungsfeld der Eigentumsgarantie der Verfassung, in: Jagenburg, Walter/Maier-Reimer, Georg/Verhoeven, Thomas (Hrsg.), Festschrift für Walter Oppenhoff zum 80. Geburtstag, München 1985, S. 173-192 Zitiert: Krüger-Nieland, in: FS Oppenhoff

Kubis, Sebastian Digitalisierung von Druckwerken zur Volltextsuche im Internet - die Buchsuche von Google (,Google Book Search“) im Konflikt mit dem Urheberrecht, in: ZUM 2006, S. 370-379

Zitiert: Kubis, ZUM 2006, 370

Kudon, Jeremy Form over Function: Expanding the Transformative Use Test for Fair Use, in: Boston University Law Review, Vol. 80 (2000), S. 579-611

Zitiert: Kudon, 80 B.U. L. Rev. 579 (2000)

Kuhlen, Rainer Richtungsweisend oder eine nur begrenzt wahrgenommene Chance? Der Copyright-Code des Wittem-Projekts, in: JIPITEC 2011, S. 18-25 Zitiert: Kuhlen, JIPITEC 2011, 18

Kühling, Jürgen / Gauß, Nicolas Expansionslust von Google als Herausforderung für das Kartellrecht, in: MMR 2007, S. 751-757 Zitiert: Kühling/Gauß, MMR 2007, 751

Kur, Annette Territorialität versus Globalität - Kennzeichenkonflikte im Internet, in: WRP 2000, S. 935-940

Zitiert: Kur, WRP 2000, 935

dies. Funktionswandel von Schutzrechten: Ursachen und Konsequenzen der inhaltlichen Annäherung und Überlagerung von Schutzrechtstypen, in: Schricker, Gerhard/ Dreier, Thomas/Kur, Annette (Hrsg.), Geistiges Eigentum im Dienst der Innovation, Baden-Baden 2001, S. 23-50

Zitiert: Kur, in: Geistiges Eigentum im Dienst der Innovation

dies. Of Oceans, Islands, and Inland Water - How much Room for Exceptions and Limitations under the Three-Step Test?, in: Richmond Journal of Global Law and Business, Vol. 8 (2009), S. 287-350

Zitiert: Kur, 8 Rich. J. Global L. \& Bus. 287 (2009) 
Laky, Teresa Dastar Corp. v. Twentieth Century Fox Film Corp.: Widening the Gap between United States Intellectual Property Law and Berne Convention Requirements, in: Seton Hall Journal of Sports and Entertainment Law, Vol. 14 (2004), S. 441-479

Zitiert: Laky, 14 Seton Hall J. Sports \& Ent. L. 441 (2004)

Landau, Michael Dastar v. Twentieth Century Fox: The Need for Stronger Protection of Attribution Rights in the United States, in: New York University Annual Survey of American Law, Vol. 61 (2005), S. 273-315

Zitiert: Landau, 61 N.Y.U. Ann. Surv. Am. L. 273 (2005)

ders. Fitting United States Copyright Law into the International Scheme: Foreign and Domestic Challenges to Recent Legislation, in: Georgia State University Law Review, Vol. 23 (2007), S. 847-892

Zitiert: Landau, 23 Ga. St. U. L. Rev. 847 (2007)

Landes, William M. / Posner, Richard A. An Economic Analysis of Copyright Law, in: Journal of Legal Studies, Vol. 18 (1989), S. 325-363

Zitiert: Landes/Posner, 18 J. Legal Stud. 325 (1989)

dies. The Economic Structure of Intellectual Property Law, Cambridge, Mass. u.a. 2003

Zitiert: Landes/Posner, Economic Structure

Landfermann, Richard Handy-Klingeltöne im Urheber- und Markenrecht, Göttingen 2006

Zitiert: Landfermann, Handy-Klingeltöne

Lange, Max Kritik der Grundbegriffe vom geistigen Eigentum, Schoenebeck 1858, Nachdruck in: UFITA 117 (1991), S. 169-248

Zitiert: Lange, Kritik der Grundbegriffe vom geistigen Eigentum (1858), Nachdruck in: UFITA 117 (1991), 169

Langer, Margit Informationsfreiheit als Grenze informationeller Selbstbestimmung Verfassungsrechtliche Vorgaben der privatrechtlichen Informationsordnung, Berlin 1992

Zitiert: Langer, Informationsfreiheit als Grenze informationeller Selbstbestimmung

Larenz, Karl Methodenlehre der Rechtswissenschaft, 6. Auflage, Berlin u.a. 1991 Zitiert: Larenz, Methodenlehre

ders. Zur Struktur „subjektiver Rechte“, in: Baur, /Larenz, /Wieacker, (Hrsg.), Beiträge zur europäischen Rechtsgeschichte und zum geltenden Zivilrecht, Festgabe für Johannes Sontis, München 1977, S. 129-148

Zitiert: Larenz, in: FG Sontis

Larenz, Karl / Canaris, Claus-Wilhelm Methodenlehre der Rechtswissenschaft, 3. Auflage, Berlin 1995

Zitiert: Larenz/Canaris, Methodenlehre

Larenz, Karl / Wolf, Manfred Allgemeiner Teil des Bürgerlichen Rechts, 9. Auflage, München 2004

Zitiert: Larenz/Wolf, Allgemeiner Teil des Bürgerlichen Rechts

Leaffer, Marshall The Uncertain Future of Fair Use in a Global Information Marketplace, in: Ohio State Law Journal, Vol. 62 (2001), S. 849-867

Zitiert: Leaffer, 62 Ohio St. L.J. 849 (2001) 


\section{Literatur}

Lee, Edward Technological Fair Use, in: Southern California Law Review, Vol. 83 (2010), S. 797-874

Zitiert: Lee, 83 S. Cal. L. Rev. 797 (2010)

ders. Measuring TRIPS Compliance and Defiance: The WTO Compliance Scorecard, in: Journal of Intellectual Property Law, Vol. 18 (2011), S. 401-445

Zitiert: Lee, 18 J. Intell. Prop. L. 401 (2011)

Lee, Jay Campbell v. Acuff-Rose Music: The Sword of the Parodist is Mightier than the Shield of the Copyright Holder, in: University of San Francisco Law Review, Vol. 29 (1994), S. 279-312

Zitiert: Lee, 29 U.S.F. L. Rev. 279 (1994)

Leible, Stefan Pflicht zur klaren und eindeutigen Umsetzung der Richtlinie 93/13/ EWG, Anmerkung zu EuGH, Urt. v. 10.5.2001, C-144/99 - Kommission./. Niederlande, in: EuZW 2001, S. 438-439

Zitiert: Leible, EuZW 2001, 438

Leible, Stefan / Sosnitza, Olaf „3 ... 2... 1... meins!“ und das TDG - Zur Haftung von Internetauktionshäusern für rechtswidrige Inhalte, in: WRP 2004, S. 592-599 Zitiert: Leible/Sosnitza, WRP 2004, 592

dies. Haftung von Internetauktionshäusern - reloaded, in: NJW 2007, S. 3324-3326 Zitiert: Leible/Sosnitza, NJW 2007, 3324

Leinemann, Felix Die Sozialbindung des geistigen Eigentums, Baden-Baden 1998 Zitiert: Leinemann, Sozialbindung

Leistner, Matthias Der Rechtsschutz von Datenbanken im deutschen und europäischen Recht - Eine Untersuchung zur Richtlinie 96/6/EG und zu ihrer Umsetzung in das deutsche Urheberrechtsgesetz, München 2000

Zitiert: Leistner, Rechtsschutz von Datenbanken

ders. Anmerkung zu BGH, Beschluß vom 28.9.2006, I ZR 261/03 - Sächsischer Ausschreibungsdienst, in: Zeitschrift für Gemeinschaftsprivatrecht (GPR) 4/2007, S. 190-194

Zitiert: Leistner, GPR 2007, 190

ders. Konsolidierung und Entwicklungsperspektive des Europäischen Urheberrechts, Zentrum für Europäisches Wirtschaftsrecht (Hrsg.), Vorträge und Berichte, Nr. 167, Bonn 2008

Zitiert: Leistner, Konsolidierung und Entwicklungsperspektive

ders. Copyright Law in the EC: Status Quo, Recent Case Law and Policy Perspectives, in: Common Market Law Review (CMLR), Vol. 46 (2009), S. 847-884

Zitiert: Leistner, CMLR 46 (2009), 847

ders. Der Beitrag ökonomischer Forschung zum Urheberrecht. Bestandsaufnahme und interdisziplinäre Ideenskizze, in: Zeitschrift für Geistiges Eigentum (ZGE) 2009, S. 403-456

Zitiert: Leistner, ZGE 2009, 403

ders. Der urheberrechtliche Schutz der Sendefolge - ein Plädoyer für methodische Ehrlichkeit, in: Erdmann, Willi/Leistner, Matthias/Rüffer, Wilfried/Schulte-Beckhausen, Thomas (Hrsg.), Festschrift für Michael Loschelder zum 65. Geburtstag, Köln 2010, S. 189-202

Zitiert: Leistner, in: FS Loschelder 
ders. Störerhaftung und mittelbare Schutzrechtsverletzung, in: GRUR-Beilage 2010, S. $1-32$

Zitiert: Leistner, GRUR-Beil. 2010, 1

ders. Buchbesprechung: Schricker, Gerhard/Loewenheim, Ulrich (Hrsg.): Urheberrecht, Kommentar, 4. neu bearbeitete Aufl., München 2010, in: GRUR 2010, S. 987-988

Zitiert: Leistner, GRUR 2010, 987

ders. The German Federal Supreme Court's Judgment on Google's Image Search - A Topical Example of the "Limitations" of the European Approach to Exceptions and Limitations, in: IIC 2011, S. 417-442

Zitiert: Leistner, IIC 2011, 417

ders. Bei Spielen nichts Neues? - Zugleich Besprechung von BGH, Urt. v. 1.6.2011 - I ZR 140/09 - Lernspiele, in: GRUR 2011, S. 761-767

Zitiert: Leistner, GRUR 2011, 761

ders. Das Murphy-Urteil des EuGH: Viel Lärm um nichts oder Anfang vom Ende des Territorialitätsgrundsatzes im Urheberrecht?, in: JZ 2011, S. 1140-1148

Zitiert: Leistner, JZ 2011, 1140

Leistner, Matthias / Hansen, Gerd Die Begründung des Urheberrechts im digitalen Zeitalter - Versuch einer Zusammenführung von individualistischen und utilitaristischen Rechtfertigungsbemühungen, in: GRUR 2008, S. 479-490

Zitiert: Leistner/Hansen, GRUR 2008, 479

Leistner, Matthias / Kleinemenke, Manuel The Impact of Institutional Design on the Development of Patent Law: Patentability of Computer Programs and Business Methods in Europe and the United States of America as a Topical Example, in: ZGE 2010, S. 273-313

Zitiert: Leistner/Kleinemenke, ZGE 2010, 273

Leistner, Matthias / Stang, Felix Die Bildersuche im Internet aus urheberrechtlicher Sicht, in: CR 2008, S. 499-507

Zitiert: Leistner/Stang, CR 2008, 499

dies. Die Neuerung der wettbewerbsrechtlichen Verkehrspflichten - Ein Siegeszug der Prüfungspflichten? Zugleich ein Beitrag zur dogmatischen Fortentwicklung des Maßstabs der Prüfungspflichten, in: WRP 2008, S. 533-555

Zitiert: Leistner/Stang, WRP 2008, 533

Lehmann, Matthias / Rein, Christian A. eBay: Haftung des globalen Basars zwischen Gemeinschaftsrecht und BGH, in: CR 2008, S. 97-103

Zitiert: Lehmann/Rein, CR 2008, 97

Lehmann, Michael Die Europäische Richtlinie über den Schutz von Computerprogrammen, in: GRUR Int. 1991, S. 327-336

Zitiert: Lehmann, GRUR Int. 1991, 327

ders. Die Krise des Urheberrechts in der digitalen Welt, in: Hilty, Reto M./Drexl, Josef/Nordemann, Wilhelm, Schutz von Kreativität und Wettbewerb, Festschrift für Ulrich Loewenheim zum 75. Geburtstag, München 2009, S. 167-173

Zitiert: Lehmann, in: FS Loewenheim

Lemley, Mark A. Dealing with Overlapping Copyrights on the Internet, in: University of Dayton Law Review, Vol. 22 (1997), S. 547-585

Zitiert: Lemley, 22 U. Dayton L. Rev. 547 (1997) 


\section{Literatur}

ders. Ex Ante versus Ex Post Justifications for Intellectual Property, in: University of Chicago Law Review, Vol. 71 (2004), S. 129-149

Zitiert: Lemley, 71 U. Chi. L. Rev. 129 (2004)

ders. Property, Intellectual Property, and Free Riding, in: Texas Law Review, Vol. 83 (2005), S. 1031-1075

Zitiert: Lemley, 83 Tex. L. Rev. 1031 (2005)

ders. An Antitrust Assessment of the Google Book Search Settlement, in: Tijdschrift voor Auteurs-, Media \& Informatierecht (AMI), 2010, Heft 2, S. 55-59

Zitiert: Lemley, AMI 2010, 55

Lemley, Mark A. / Weiser, Philip J. Should Property or Liability Rules Govern Information?, in: Texas Law Review, Vol. 85 (2007), S. 783-841

Zitiert: Lemley/Weiser, 85 Tex. L. Rev. 783 (2007)

Lennard, Michael Navigating by the Stars: Interpreting the WTO Agreements, in: Journal of International Economic Law, Vol. 5 (2002), S. 17-89

Zitiert: Lennard, 5 J. Int'l Econ. L. 17 (2002)

Lerche, Peter Aktuelle Grundfragen der Informationsfreiheit, in: Jura 1995, S. 561-566 Zitiert: Lerche, Jura 1995, 561

Lessig, Lawrence Free Culture - How Big Media Uses Technology and the Law to Lock Down Culture and Control Creativity, New York 2004

Zitiert: Lessig, Free Culture

Lettl, Tobias Allgemeines Persönlichkeitsrecht und Medienberichterstattung, in: WRP 2005, S. 1045-1086

Zitiert: Lettl, WRP 2005, 1045

Leval, Pierre N. Fair Use or Foul? The Nineteenth Donald C. Brace Lecture, in: Journal of the Copyright Society of the U.S.A., Vol. 36 (1989), S. 167-181

Zitiert: Leval, 36 J. Copyright Soc'y U.S.A. 167 (1989)

ders. Toward a Fair Use Standard, in: Harvard Law Review, Vol. 103 (1990), S. $1105-1136$

Zitiert: Leval, 103 Harv. L. Rev. 1105 (1990)

ders. Campbell v. Acuff-Rose: Justice Souter's Rescue of Fair Use, in: Cardozo Arts and Entertainment Law Journal, Vol. 13 (1994), S. 19-26

Zitiert: Leval, 13 Cardozo Arts \& Ent. L.J. 19 (1994)

ders. Fair Use Rescued, in: UCLA Law Review, Vol. 44 (1997), S. 1449-1466

Zitiert: Leval, 44 UCLA L. Rev. 1449 (1997)

Lew, Michael S. / Sebe, Nicu / Djeraba, Chabane / Jain, Ramesh Content-based Multimedia Information Retrieval: State of the Art and Challenges, in: ACM Transactions on Multimedia Computing, Communications, and Applications, Vol. 2 (2006), S. 1-19

Zitiert: Lew/Sebe/Djeraba/Jain, 2 ACM Transactions on Multimedia Computing, Communications, and Applications 1 (2006)

Lewinski, Silke von International Copyright Law and Policy, New York 2008 Zitiert: v.Lewinski, International Copyright Law

dies. Vermieten, Verleihen und verwandte Schutzrechte - Der zweite Richtlinienvorschlag der EG-Kommission, in: GRUR Int. 1991, S. 104-111

Zitiert: v.Lewinski, GRUR Int. 1991, 104 
dies. Die Umsetzung der Richtlinie zum Vermiet- und Verleihrecht, in: ZUM 1995, S. 442-450

Zitiert: v.Lewinski, ZUM 1995, 442

dies. Die diplomatische Konferenz der WIPO 1996 zum Urheberrecht und zu verwandten Schutzrechten, in: GRUR Int. 1997, S. 667-681

Zitiert: v.Lewinski, GRUR Int. 1997, 667

dies. Die WIPO-Verträge zum Urheberrecht und zu verwandten Schutzrechten vom Dezember 1996, in: CR 1997, S. 438-444

Zitiert: v.Lewinski, CR 1997, 438

dies. Die Multimedia-Richtlinie - Der EG-Richtlinienvorschlag zum Urheberrecht in der Informationsgesellschaft, in: MMR 1998, S. 115-119

Zitiert: v.Lewinski, MMR 1998, 115

dies. Rechtewahrnehmung: Urhebervertragsrecht und Verwertungsgesellschaftsrecht, in: Riesenhuber, Karl (Hrsg.), Systembildung im Europäischen Urheberrecht, INTERGU-Tagung 2006, Berlin 2007, S. 215-241

Zitiert: v.Lewinski, in: Systembildung im Europäischen Urheberrecht

dies. EU und Mitgliedstaaten ratifizieren WIPO-Internetverträge - Was ändert sich aus deutscher Sicht?, in: GRUR-Prax. 2010, S. 49-50

Zitiert: v.Lewinski, GRUR-Prax. 2010, 49

Lewinski, Silke von / Gaster, Jens L. Die Diplomatische Konferenz der WIPO 1996 zum Urheberrecht und zu verwandten Schutzrechten - Ergebnisse und Folgen, in: ZUM 1997, S. 607-625

Zitier: v.Lewinksi/Gaster, ZUM 1997, 607

Lewinski, Silke von / Reinbothe, Jörg The WIPO Treaties 1996: Ready to Come Into Force, in: EIPR 2002, 24(4), S. 199-208

Zitiert: v.Lewinski/Reinbothe, EIPR 2002, 24(4), 199

Lichtman, Douglas Copyright as Innovation Policy: Google Book Search from a Law and Economics Perspective, in: Lerner, Josh/Stern, Scott (Hrsg.), Innovation Policy and the Economy, Vol. 9 (2008), abrufbar unter: http://ssrn.com/abstract=1472167

Zitiert: Lichtman, Copyright as Innovation Policy

Limper, Josef / Musiol, Christian (Hrsg.) Handbuch des Fachanwalts Urheber- und Medienrecht, Köln 2011

Zitiert: Limper/Musiol/Bearbeiter, Urheber- und Medienrecht

Linderfalk, Ulf On The Interpretation of Treaties, The Modern International Law as Expressed in the 1969 Vienna Convention on the Law of Treaties, Dordrecht 2007 Zitiert: Linderfalk, Interpretation of Treaties

Lindhorst, Hermann Anmerkung zu BGH, Urt. v. 20.11.2008, I ZR 112/06 - Metall auf Metall, in: GRUR 2009, S. 406-407

Zitiert: Lindhorst, GRUR 2009, 406

Linnenborn, Oliver Europäisches Urheberrecht in der Informationsgesellschaft, in: K\&R 2001, S. 394-402

Zitiert: Linnenborn, K\&R 2001, 394

Litman, Jessica Revising Copyright Law for the Information Age, in: Oregon Law Review, Vol. 75 (1996), S. 19-48

Zitiert: Litman, 75 Or. L. Rev. 19 (1996) 


\section{Literatur}

dies. Real Copyright Reform, in: Iowa Law Review, Vol. 96 (2010), S. 1-55

Zitiert: Litman, 96 Iowa L. Rev. 1 (2010)

Liu, Joseph P. Two Factor Fair Use?, in: Columbia Journal of Law \& the Arts, Vol. 31 (2008), S. 571-585

Zitiert: Liu, 31 Colum. J.L. \& Arts 571 (2008)

Locke, John Two Treaties of Government by John Locke - A Critical Edition with an Introduction and Apparatus Criticus by Peter Laslett, Laslett, Peter (Hrsg.), 2. Auflage, Cambridge 1967

Zitiert: Locke, Two Treaties of Government

Lockridge, Lee Ann W. The Myth of Copyright's Fair Use Doctrine as a Protector of Free Speech, in: Santa Clara Computer and High Technology Law Journal, Vol. 24 (2007), S. 31-103

Zitiert: Lockridge, 24 Santa Clara Computer \& High Tech. L.J. 31 (2007)

Löffler, Martin Das Grundrecht auf Informationsfreiheit als Schranke des Urheberrechts, in: NJW 1980, S. 201-205

Zitiert: Löffler, NJW 1980, 201

Loewenheim, Ulrich (Hrsg.) Handbuch des Urheberrechts, 1. Auflage, München 2003 Zitiert: Loewenheim/Bearbeiter, 1. Aufl.

ders. (Hrsg.) Handbuch des Urheberrechts, 2. Auflage, München 2010

Zitiert: Loewenheim/Bearbeiter

ders. Anmerkung zu BGH, Urt. v. 13.10.1988, I ZR 15/87 - Oberammergauer Passionsspiele II, in: GRUR 1989, S. 108-110

Zitiert: Loewenheim, GRUR 1989, 108

Lohmann, Fred von Google Books Settlement 2.0: Evaluating Access, abrufbar unter: http://www.eff.org/deeplinks/2009/08/google-book-search-settlement-access Zitiert: v.Lohmann, GBS 2.0: Evaluating Access

Lucas, André Private International Law Aspects of the Protection of Works and of the Subject Matter of Related Rights Transmitted Over Digital Networks, WIPO-Document PIL/01/1 Prov., Geneva, December 17, 2000; abrufbar unter: http:// www.wipo.int/edocs/mdocs/mdocs/en/wipo_pil_01/wipo_pil_01_1_prov.pdf Zitiert: Lucas, Private International Law Aspects

ders. Le «triple test» de l'article 13 de l'Accord ADPIC à la lumière du rapport du Goupe spécial de l'OMC «Etats-Unis - Article 110-5 de la Loi sur le droit d'auteur», in: Ganea, Peter/Heath, Christopher/Schricker, Gerhard, Urheberrecht gestern - heute - morgen, Festschrift für Adolf Dietz zum 65. Geburtstag, München 2001, S. $423-433$

Zitiert: Lucas, in: FS Dietz

ders. Libres propos sur l'harmonisation communautaire du droit d'auteur et des droits voisins, in: Ohly, Ansgar/Bodewig, Theo/Dreier, Thomas/Götting, Horst-Peter/ Haedicke, Maximilian/Lehmann, Michael (Hrsg.), Perspektiven des Geistigen Eigentums und Wettbewerbsrechts, Festschrift für Gerhard Schricker zum 70. Geburtstag, München 2005, S. 435-445

Zitiert: Lucas, in: FS Schricker II

ders. For a Reasonable Interpretation of the Three-Step Test, in: EIPR 2010, 3(6), S. 277-282

Zitiert: Lucas, EIPR 2010, 32(6), 277 
Lucke, Bettina Die Google Buchsuche nach deutschem Urheberrecht und US-amerikanischem Copyright Law, Frankfurt a.M. 2010

Zitiert: Lucke, Google Buchsuche

Ludolph, Carol G / Merenstein, Gary E. Authors' Moral Rights in the United States and the Berne Convention, in: Stetson Law Review, Vol. 19 (1989), S. 201-243

Zitiert: Ludolph/Merenstein, 19 Stetson L. Rev. 201 (1989)

Luf, Gerhard Philosophische Strömungen in der Aufklärung und ihr Einfluß auf das Urheberrecht, in: Dittrich, Robert (Hrsg.), Woher kommt das Urheberrecht und wohin geht es?, Wien 1988, S. 9-19

Zitiert: Luf, in: Woher kommt das Urheberrecht

Lüghausen, Philip Die Auslegung von $§ 53$ I S. 1 UrhG am Beispiel virtueller Private Video Recorder, Aachen 2009

Zitiert: Lüghausen, Auslegung von § 53 I S. 1 UrhG

Lundeen, Kyle Searching for a Defense: The Google Library Litigation and the Fair Use Doctrine, in: University of Missouri-Kansas City Law Review, Vol. 75 (2006), S. 265-282

Zitiert: Lundeen, 75 UMKC L. Rev. 265 (2006)

Macciacchini, Sandro Urheberrecht und Meinungsfreiheit: Untersucht am Gegenstand der Verwendung urheberrechtlich geschützter Werke in der Berichterstattung der Medien, Bern 2000

Zitiert: Macciacchini, Urheberrecht und Meinungsfreiheit

ders. Urheberrecht und Meinungsfreiheit: Drei Thesen, in: UFITA 2000, S. 683-689 Zitiert: Macciacchini, UFITA 2000, 683

Madison, Michael J. Rewriting Fair Use and the Future of Copyright Reform, in: Cardozo Arts and Entertainment Law Journal, Vol. 23 (2005), S. 391-418

Zitiert: Madison, 23 Cardozo Arts \& Ent. L.J. 391 (2005)

Mangoldt, Hermann von / Klein, Friedrich / Starck, Christian (Hrsg.) Kommentar zum Grundgesetz, 6. Auflage, München 2010

Zitiert: v.Mangoldt/Klein/Starck/Bearbeiter, GG

Mankowski, Peter Internet und Internationales Wettbewerbsrecht, in: GRUR Int. 1999, S. 909-921

Zitiert: Mankowski, GRUR Int. 1999, 909

Manuel, Kate M. The Google Library Project: Is Digitization for Purposes of Online Indexing Fair Use Under Copyright Law?, Congressional Research Service, Doc. R40194 v. 27.11.2009, abrufbar unter: http://assets.opencrs.com/rpts/ R40194 20091127.pdf

Zitiert: Manuel, Google Library Project

Masouyé, Claude Kommentar zur Berner Übereinkunft zum Schutz von Werken der Literatur und Kunst, München u.a. 1981

Zitiert: Masouyé, RBÜ

Maunz, Theodor Das geistige Eigentum in verfassungsrechtlicher Sicht, in: GRUR 1973, S. 107-115

Zitiert: Maunz, GRUR 1973, 107

Maunz, Theodor / Dürig, Günther (Begr.) Grundgesetz, Kommentar, 56. Auflage, München 2009

Zitiert: Maunz/Dürig/Bearbeiter, GG 


\section{Literatur}

Maus, Joachim Die digitale Kopie von Audio- und Videoprodukten - Die Nutzung von Film und Musik im privaten Bereich und deren Behandlung im deutschen und internationalen Urheberrecht, Baden-Baden 1991

Zitiert: Maus, Digitale Kopie

Mazziotti, Giuseppe EU Digital Copyright Law and the End-User, Berlin, Heidelberg 2008

Zitiert: Mazziotti, EU Digital Copyright Law

McCambridge, Michael J. Contributory Infringement by Providing the Means: The Staple Article of Commerce Doctrine and an Alternative Analysis for Copyright Law, in: John Marshall Law Review, Vol. 18 (1985), S. 703-732

Zitiert: McCambridge, 18 J. Marshall L. Rev. 703 (1985)

McFarlane, Robert A. The Ninth Circuit Lands a „Perfect 10“ Applying Copyright Law To The Internet, in: Golden Gate University Law Review, Vol. 28 (2008), S. $381-407$

Zitiert: McFarlane, 38 Golden Gate U. L. Rev. 381 (2008)

Medicus, Dieter / Petersen, Jens Bürgerliches Recht - Eine nach Anspruchsgrundlagen geordnete Darstellung zur Examensvorbereitung, 22. Auflage, Köln 2009

Zitiert: Medicus/Petersen, Bürgerliches Recht

Meißner, E. Gemeinnutz und Eigennutz im Urheberrecht der Werkkunst, in: UFITA 7 (1934), S. 189-197

Zitiert: Meißner, UFITA 7 (1934), 189

Melichar, Ferdinand Schranken zugunsten der Allgemeinheit beim Urheberrechtsschutz von Sprachwerken und Werken der Musik, Freiburg 1987

Zitiert: Melichar, Schranken

ders. Private Vervielfältigung und Pauschalvergütungen im Referentenentwurf zum Zweiten Korb, in: ZUM 2005, S. 119-120

Zitiert: Melichar, ZUM 2005, 119

Merges, Robert P. The End of Friction? Property Rights and Contract in the "Newtonian" World of On-Line Commerce, in: Berkeley Technology Law Journal, Vol. 12 (1997), S. 115-136

Zitiert: Merges, 12 Berkeley Tech. L.J. 115 (1997)

Merges, Robert P. / Menell, Peter S. / Lemley, Mark A. Intellectual Property in the New Technological Age, Fourth Edition, New York 2007

Zitiert: Merges/Menell/Lemley, Intellectual Property

Mestmäcker, Ernst-Joachim / Schulze, Erich Kommentar zum deutschen Urheberrecht, München, Loseblattsammlung, Stand: 55. EL, September 2011

Zitiert: Mestmäcker/Schulze/Bearbeiter

Metzger, Axel „Germania 3 Gespenster am toten Mann“ oder Welchen Zweck darf ein Zitat gemäß $§ 51$ Nr. 2 UrhG verfolgen? - Zugleich ein Beitrag zur Grundrechtswirkung im Urheberrecht, in: ZUM 2000, S. 924-934

Zitiert: Metzger, ZUM 2000, 924

ders. Rechtsgeschäfte über das Urheberpersönlichkeitsrecht nach dem neuen Urhebervertragsrecht - Unter besonderer Berücksichtigung der französischen Rechtslage, in: GRUR Int. 2003, S. 9-23

Zitiert: Metzger, GRUR Int. 2003, 9 
ders. Europäisches Urheberrecht ohne Droit moral? - Status quo und Perspektiven einer Harmonisierung des Urheberpersönlichkeitsrechts, in: Ohly, Ansgar/Bodewig, Theo/Dreier, Thomas/Götting, Horst-Peter/Haedicke, Maximilian/Lehmann, Michael (Hrsg.), Perspektiven des Geistigen Eigentums und Wettbewerbsrechts, Festschrift für Gerhard Schricker zum 70. Geburtstag, München 2005, S. 455-471

Zitiert: Metzger, in: FS Schricker II

ders. Urheberrechtsschranken in der Wissensgesellschaft: „Fair use“ oder enge Einzeltatbestände?, in: Leistner, Matthias (Hrsg.), Europäische Perspektiven des Geistigen Eigentums, S. 101-122

Zitiert: Metzger, in: Europäische Perspektiven des Geistigen Eigentums

ders. Der Einfluss des EuGH auf die gegenwärtige Entwicklung des Urheberrechts, in: GRUR 2012, S. 118-126

Zitiert: Metzger, GRUR 2012, 118

Meyer, Jürgen (Hrsg.) Kommentar zur Charta der Grundrechte der Europäischen Union, 2. Auflage, Baden-Baden 2006

Zitiert: Meyer/Bearbeiter, Charta der Grundrechte

Meyer, Sebastian Google \& Co. - Aktuelle Rechtsentwicklungen bei Suchmaschinen, in: K\&R 2007, S. 177-183

Zitiert: Meyer, K\&R 2007, 177

Meyer-Ladewig, Jens Europäische Menschenrechtskonvention, Handkommentar, 2. Auflage, Baden-Baden 2006

Zitiert: Meyer-Ladewig, EMRK

Milczewski, Christine von Der grundrechtliche Schutz des Eigentums im Europäischen Gemeinschaftsrecht, Frankfurt a.M./Berlin u.a. 1994

Zitiert: v.Milczewski, Grundrechtlicher Schutz des Eigentums im Europäischen Gemeinschaftsrecht

Miller, Arthur R.

Davis, Michael H. Intellectual Property. Patents, Trademarks, and Copyright in a Nutshell, St. Paul 2000

Zitiert: Miller/Davies, Intellectual Property

Miner, Roger J. Exploiting Stolen Text: Fair Use or Foul Play?, in: Journal of the Copyright Society of the U.S.A., Vol. 37 (1990), S. 1-11

Zitiert: Miner, 37 J. Copyright Soc'y U.S.A. 1 (1990)

Mittelberger, Philipp Der Eigentumsschutz nach Art. 1 des Ersten Zusatzprotokolls zur EMRK im Lichte der Rechtsprechung der Strassburger Organe, Bern 2000 Zitiert: Mittelberger, Eigentumsschutz

Möhring, Philip / Nicolini, Käte / Ahlberg, Hartwig / Urheberrechtsgesetz. Kommentar, 2. Auflage, München 2000

Zitiert: Möhring/Nicolini/Bearbeiter

Mönninger, Michael Die Google-Bibliothek, in: ZEIT Online, 32/2005, S. 40

Abrufbar unter: http://www.zeit.de/2005/32/Google-Bibliothek

Zitiert: Mönninger, ZEIT Online, 32/2005, S. 40

Moore, Robin A. Fair Use and Innovation Policy, in: New York University Law Review, Vol. 82 (2007), S. 944-973

Zitiert: Moore, 82 N.Y.U. L. Rev. 944 (2007) 


\section{Literatur}

Morrill, Stephen S. Harper \& Row, Publishers v. Nation Enterprises: Emasculating the Fair Use Accommodation of Competing Copyright and First Amendment Interests, in: Northwestern University Law Review, Vol. 79 (1984), S. 587-622

Zitiert: Morrill, 79 Nw. U. L. Rev. 587 (1984)

Müller, Georg Eyke von Repgow als Urheber, in: UFITA 10 (1937), S. 383-422 Zitiert: Müller, UFITA 10 (1937), 383

Müller, Stefan Der Verzicht auf technische Schutzmaßnahmen: kein Verzicht auf die gesetzliche Vergütung für private Vervielfältigung, in: GRUR 2011, S. 26-31 Zitiert: Müller, GRUR 2011, 26

ders. Die Ergebnispflicht des deutschen Gesetzgebers zur Gewährleistung der praktischen Durchsetzung von Ansprüchen nach den $\S \S 54 \mathrm{ff}$. UrhG - Zugleich Anmerkung zu EuGH, Urt. v. 16.6.2011, C-462/09 - Stichting de Thuiskopie./. Opus Supplies Deutschland GmbH, in: ZUM 2011, S. 631-634

Zitiert: Müller, ZUM 2011, 631

Müller-Langer, Frank / Scheufen, Marc The Google Book Search Settlement: A Law and Economics Analysis, in: Review of Economic Research on Copyright Issues, Vol. 8 (2011), S. 7-50

Zitiert: Müller-Langer/Scheufen, 8 Rev. Econ. Research on Copyright 7 (2011)

Müller-Michaels, Olaf Grundrechtlicher Eigentumsschutz in der Europäischen Union: Das Eigentumsgrundrecht in der Rechtsordnung der EU, in der EMRK und in den Verfassungen Deutschlands, Italiens und Irlands, Berlin 1997

Zitiert: Müller-Michaels, Grundrechtlicher Eigentumsschutz in der EU

Münch, Ingo von / Kunig, Philip Grundgesetz-Kommentar, Band 1: Präambel bis Art. 19, 5. Auflage, München 2000

Zitiert: v.Münch/Kunig/Bearbeiter, GG

Müsse, Hans-Gabriel Das Urheberpersönlichkeitsrecht unter besonderer Berücksichtigung der Veröffentlichung und der Inhaltsmitteilung, Freiburg i. Brsg. 1999 Zitiert: Müsse, Urheberpersönlichkeitsrecht

Muth, Susanne Die Bestimmung des anwendbaren Rechts bei Urheberrechtsverletzungen im Internet, Frankfurt a.M. 2000

Zitiert: Muth, Urheberrechtsverletzungen im Internet

Na, Nari Testing the Boundaries of Copyright Protection: The Google Books Library Project and the Fair Use Doctrine, in: Cornell Journal of Law and Public Policy, Vol. 16 (2007), S. 417-448

Zitiert: Na, 16 Cornell J. L. \& Pub. Pol'y 417 (2007)

Nagareda, Richard A. The Law of Class Actions and Other Aggregate Litigation, St. Paul 2009

Zitiert: Nagareda, The Law of Class Actions

Netanel, Neil $W$. The Next Round: The Impact of the WIPO Copyright Treaty on TRIPS Dispute Settlement, in: Virginia Journal of International Law, Vol. 37 (1997), S. 441-497

Zitiert: Netanel, 37 Va. J. Int'1 L. 441 (1997)

ders. Copyright's Paradox, New York 2008

Zitiert: Netanel, Copyright's Paradox

ders. Making Sense of Fair Use, in: Lewis \& Clark Law Review, Vol. 15 (2011), S. 715-771

Zitiert: Netanel, 15 Lewis \& Clark L. Rev. 715 (2011) 
Newby, Tyler G. What's Fair Here is Not Fair Everywhere: Does the American Fair Use Doctrine Violate International Copyright Law?, in: Stanford Law Review, Vol. 51 (1999), S. 1633-1663

Zitiert: Newby, 51 Stan. L. Rev. 1633 (1999)

Newman, Jon O. Not the End of History: The Second Circuit Struggles with Fair Use, in: Journal of the Copyright Society of the U.S.A., Vol. 37 (1990), S. 12-18

Zitiert: Newman, 37 J. Copyright Soc'y U.S.A. 12 (1990)

Ng-Loy, Wee Loon Exploring flexibilities within the global IP standards, in: IPQ 2009, Heft 2, S. 162-184

Zitiert: $N g$-Loy, IPQ 2009, 162

Ngombe, Laurier Yvon Technical Measures of Protection versus Copyright for Private Use. Is the French Legal Saga Over?, in: EIPR 2007, 29(2), S. 61-65

Zitiert: Ngombe, EIPR 2007, 29(2), 61

Nielen, Michael Interessenausgleich in der Informationsgesellschaft - Die Anpassung der urheberrechtlichen Schrankenregelungen im digitalen Bereich, Frankfurt a.M. 2009

Zitiert: Nielen, Interessenausgleich

Niemann, Fabian Schrankenlose Bildersuche? Zur entsprechenden Anwendung von $\S 49$ UrhG auf Bildersuchmaschinen, in: CR 2009, S. 97-103

Zitiert: Niemann, CR 2009, 97

ders. Shift der urheberrechtlichen Verwertungsrechte in der arbeitsteiligen digitalen Welt - Auswirkungen der BGH-Entscheidungen zu Online-Videorekordern (shift.tv, safe.tv) auf Outsourcing, Virtualisierung und Web 2.0 Dienste, in: CR 2009, S. 661-666

Zitiert: Niemann, CR 2009, 661

ders. Anmerkung zu BGH, Urt. v. 29.4.2010, I ZR 69/08 - Vorschaubilder, in: K\&R 2010, S. 507-509

Zitiert: Niemann, K\&R 2010, 507

Niggemann, Michael Informationsfreiheit und Urheberrecht - Pressedatenbanken im Internet, Hamburg 2003

Zitiert: Niggemann, Informationsfreiheit und Urheberrecht

Nimmer, David „Fairest of Them All“ and Other Fairy Tales of Fair Use, in: Law and Contemporary Problems, Vol. 66 (2003), S. 263-287

Zitiert: Nimmer, 66 Law \& Contemp. Probs. 263 (2003)

Nimmer, Melville B. / Nimmer, David Nimmer on Copyright, New York, Loseblattsammlung, Stand: 03/2011

Zitiert: Nimmer/Nimmer, On Copyright

Nimmer, Raymond T. „Google Print Library Project“ - Unfair Use of Copyright, in: CRi 2006, S. 1-6

Zitiert: Nimmer, CRi 2006, 1

Nolte, Georg Informationsmehrwertdienste und Urheberrecht, Baden-Baden 2009

Zitiert: Nolte, Informationsmehrwertdienste

ders. Paperboy oder die Kunst den Informationsfluss zu regulieren - von Datenbanken, Links und Suchmaschinen, in: ZUM 2003, S. 540-549

Zitiert: Nolte, ZUM 2003, 540 
ders. Zur Forderung der Presseverleger nach Einführung eines speziellen Leistungsschutzrechts. Eine kritische Auseinandersetzung, in: ZGE 2010, S. 165-195 Zitiert: Nolte, ZGE 2010, 165

Nordemann, Axel / Scheuermann, Andreas Der Beitritt der USA zur Revidierten Berner Übereinkunft - Bericht über ein Berliner Urheberrechts-Symposium, in: GRUR Int. 1990, S. 945-954 Zitiert: Nordemann/Scheuermann, GRUR Int. 1990, 945

Nordemann, Jan Bernd / Conrad, Albrecht Internationale Vereinigung für den Schutz des Geistigen Eigentums (AIPPI) - Berichte der Deutschen Landesgruppe für die Sitzung des Geschäftsführenden Ausschusses der AIPPI vom 3. bis 6. Oktober 2010 in Paris - Ausnahmen vom Urheberrechtsschutz und erlaubte Benutzungsformen urheberrechtlich geschützter Werke in den Branchen der Hochtechnologie und der Digitaltechnologie (Q216), in: GRUR Int. 2010, S. 953-970 Zitiert: Nordemann/Conrad, GRUR Int. 2010, 953

Nordemann, Wilhelm / Nordemann, Jan Bernd Die US-Doktrin des ,work made for hire" im neuen deutschen Urhebervertragsrecht - ein Beitrag insbesondere zum Umfang der Rechtseinräumung für Deutschland, in: Ohly, Ansgar/Bodewig, Theo/ Dreier, Thomas/Götting, Horst-Peter/Haedicke, Maximilian/Lehmann, Michael (Hrsg.), Perspektiven des Geistigen Eigentums und Wettbewerbsrechts, Festschrift für Gerhard Schricker zum 70. Geburtstag, München 2005, S. 473-482

Zitiert: W.Nordemann/J.B.Nordemann, in: FS Schricker II

Nordemann, Wilhelm / Vinck, Kai / Hertin, Paul W. Internationales Urheberrecht und Leistungsschutzrecht der deutschsprachigen Länder unter Berücksichtigung auch der Staaten der Europäischen Gemeinschaft - Kommentar, Düsseldorf 1977 Zitiert: Nordemann/Vinck/Hertin, Internationales Urheberrecht

Obergfell, Eva Inés Konkretisierung der urheberrechtlichen Bewertung von Abstracts durch den BGH, in: GRUR 2011, S. 208-210

Zitiert: Obergfell, GRUR 2011, 208

dies. Anmerkung zu EuGH, Urt. v. 9.2.2012, C-277/10 - Luksan./. van der Let, in: GRUR 2012, S. 494-496

Zitiert: Obergfell, GRUR 2012, 494

O'Connor, Robert B. Rap Parodies? An In-Depth Look at Acuff-Rose Music, Inc. v. Campbell, in: Fordham Entertainment, Media and Intellectual Property Law Forum, Vol. 2 (1992), S. 239

Zitiert: O'Connor, 2 Fordham Ent. Media \& Intell. Prop. L.F. 239 (1992)

Oddi, A. Samuel Contributory Infringement/Patent Misuse: Metaphysics and Metamorphosis, in: University of Pittsburgh Law Review, Vol. 44 (1982), S. 73-137

Zitiert: Oddi, 44 U. Pitt. L. Rev. 73 (1982)

Ohly, Ansgar „Volenti non fit iniuria“ - Die Einwilligung im Privatrecht, Tübingen 2002

Zitiert: Ohly, Volenti non fit iniuria

ders. Urheberrecht zwischen Innovationsstimulierung und -verhinderung, in: Eifert, Martin/Hoffmann-Riem, Wolfgang (Hrsg.), Geistiges Eigentum und Innovation Innovation und Recht I, Berlin 2008, S. 279-297

Zitiert: Ohly, in: Geistiges Eigentum und Innovation 
ders. Urheberrecht als Wirtschaftsrecht, in: Depenheuer, Otto/Peifer, Karl-Nikolaus (Hrsg.), Geistiges Eigentum - Schutzrecht oder Ausbeutungstitel?, Berlin u.a. 2008, S. 141-161

Zitiert: Ohly, in: Geistiges Eigentum - Schutzrecht oder Ausbeutungstitel?

ders. Keyword Advertising auf dem Weg zurück von Luxemburg nach Paris, Wien, Karlsruhe und Den Haag, in: GRUR 2010, S. 776-785

Zitiert: Ohly, GRUR 2010, 776

ders. Ein Leistungsschutzrecht für Presseverleger?, in: WRP 2012, S. 41-48 Zitiert: Ohly, WRP 2012, 41

ders. Zwölf Thesen zur Einwilligung im Internet - Zugleich Besprechung zu BGH, Urt. v. 19.10.2011, I ZR 140/10 - Vorschaubilder II, in: GRUR 2012, S. 983-993 Zitiert: Ohly, GRUR 2012, 983

Okano, Ari Digitized Book Search Engines and Copyright Concerns, in: Shidler Journal of Law, Commerce \& Technology, Vol. 3 (2007), Beitrag 13

Zitiert: Okano, 3 Shidler J. L. Com. \& Tech. 13 (2007)

Okediji, Ruth Toward an International Fair Use Doctrine, in: Columbia Journal of Transnational Law, Vol. 39 (2000), S. 75-175

Zitiert: Okediji, 39 Colum. J. Transnat'1 L. 75 (2000)

dies. Givers, Takers, and Other Kinds of Users: A Fair Use Doctrine For Cyberspace, in: Florida Law Review, Vol. 53 (2001), S. 107-182

Zitiert: Okediji, 53 Fla. L. Rev. 107 (2001)

Oliver, Jo Copyright in the WTO: The Panel Decision on the Three-Step Test, in: Columbia Journal of Law \& the Arts, Vol. 25 (2002), S. 119-170

Zitiert: Oliver, 25 Colum. J.L. \& Arts 119 (2002)

Olson, Adam B. Why Kelly v. Arriba Soft Corp., 336 F.3d 811 (9th Cir. 2003), Does and Doesn't Matter, in: Jurimetrics Journal, Vol. 44 (2004), S. 487-498

Zitiert: A. Olson, 44 Jurimetrics J. 487 (2004)

Olson, David S. First Amendment Based Copyright Misuse, in: William and Mary Law Review, Vol. 52 (2010), S. 537-606

Zitiert: D. Olson, 52 Wm. \& Mary L. Rev. 537 (2010)

Olson, Kathleen $K$. Transforming Fair Use Online: The Ninth Circuit's Productive-Use Analysis of Visual Search Engines, in: Communication Law and Policy, Vol. 14 (2009), S. 153-176

Zitiert: K. Olson, 14 Comm. L. \& Pol'y 153 (2009)

Omsels, Hermann-Josef Die Einwilligung im Internet als Rechtfertigungsgrund, Anmerkung zu BGH, Urt. v. 29.4.2010, I ZR 69/08 - Vorschaubilder, in: jurisPRWettbR 7/2010 Anm. 1

Zitiert: Omsels, jurisPR-WettbR 7/2010 Anm. 1

Ott, Stephan Urheber- und wettbewerbsrechtliche Probleme von Linking und Framing, Stuttgart u.a. 2004

Zitiert: Ott, Linking und Framing

ders. Haftung für Hyperlinks - Eine Bestandsaufnahme nach 10 Jahren, in: WRP 2006, S. 691-703

Zitiert: Ott, WRP 2006, 691 


\section{Literatur}

ders. Ich will hier rein! Suchmaschinen und das Kartellrecht, in: MMR 2006, S. 195-202

Zitiert: Ott, MMR 2006, 195

ders. Die Google Buchsuche - Eine massive Urheberrechtsverletzung?, in: GRUR Int. 2007, S. 562-569

Zitiert: Ott, GRUR Int. 2007, 562

ders. Zulässigkeit der Erstellung von Thumbnails durch Bilder- und Nachrichtensuchmaschinen?, in: ZUM 2007, S. 119-128

Zitiert: Ott, ZUM 2007, 119

ders. Anmerkung zu OLG Jena, Urt. v. 27.2.2008, 2 U 319/07, in: K\&R 2008, S. 306-308

Zitiert: Ott, K\&R 2008, 306

ders. Bildersuchmaschinen und Urheberrecht - Sind Thumbnails unerlässlich, sozial nützlich, aber rechtswidrig?, in: ZUM 2009, S. 345-354

Zitiert: Ott, ZUM 2009, 345

ders. Die vorherrschende Meinungsmacht von Google - Eine Replik zu Danckert/ Mayer, MMR 2010, 219 ff., in: MMR-Aktuell 2010, 301459

Zitiert: Ott, MMR-Aktuell 2010, 301459

Ott, Stephan / Schubert, Maximilian Fremde Marken als Keywörter - Orakelsprüche des EuGH als Antwort auf biblische Fragen, in: MarkenR 2010, S. 160-166

Zitiert: Ott/Schubert, MarkenR 2010, 160

Ozer, Nicole A. / Lynch, Jennifer A. Protecting Reader Privacy in Digital Books, Association for the Advancement of Artificial Intelligence Privacy 2010 Symposium, abrufbar unter: http://ssrn.com/abstract $=1588187$

Zitiert: Ozer/Lynch, Protecting Reader Privacy

Pahlow, Louis Das einfache Nutzungsrecht als schuldrechtliche Lizenz, in: ZUM 2005, S. 865-874

Zitiert: Pahlow, ZUM 2005, 865

Pahud, Eric Die Sozialbindung des Urheberrechts, Bern 2000 Zitiert: Pahud

ders. Zur Begrenzung des Urheberrechts im Interesse Dritter und der Allgemeinheit, in: UFITA 2000, S. 99-137

Zitiert: Pahud, UFITA 2000, 99

Palandt, Otto (Begr.) Bürgerliches Gesetzbuch, 71. Auflage, München 2012 Zitiert: Palandt/Bearbeiter, BGB

Pasquale, Frank Breaking the Vicious Circularity: Sony's Contribution to the Fair Use Doctrine, in: Case Western Reserve Law Review, Vol. 55 (2005), S. 777-811 Zitiert: Pasquale, 55 Case W. Res. L. Rev. 777 (2005)

ders. Copyright in an Era of Information Overload: Toward the Privileging of Categorizers, in: Vanderbilt Law Review, Vol. 60 (2007), S. 135-194

Zitiert: Pasquale, 60 Vand. L. Rev. 135 (2007)

ders. Beyond Innovation and Competition: The Need for Qualified Transparency in Internet Intermediaries, in: Northwestern University Law Review, Vol. 104 (2010), S. $105-173$

Zitiert: Pasquale, 104 Nw. U. L. Rev. 105 (2010) 
Patry, William F. Patry on Copyright, Eagan, Minn., Loseblattsammlung, Stand: 09/2009

Zitiert: Patry, On Copyright

ders. The Fair Use Privilege in Copyright, Washington, D.C. 1985

Zitiert: Patry, Fair Use (1985)

ders. Patry on Fair Use, Eagan, Minn. 2009

Zitiert: Patry, Fair Use (2009)

Patry, William F. / Perlmutter, Shira Fair Use Misconstrued: Profit Presumptions, and Parody, in: Cardozo Arts \& Entertainment Law Journal, Vol. 11 (1993), S. 667-719 Zitiert: Patry/Perlmutter, 11 Cardozo Arts \& Ent. L.J. 667 (1993)

Patry, William F. / Posner, Richard A. Fair Use and Statutory Reform in the Wake of Eldred, in: California Law Review, Vol. 92 (2004), S. 1639-1661

Zitiert: Patry/Posner, 92 Cal. L. Rev. 1639 (2004)

Patterson, Lyman Ray Copyright in Historical Perspective, Nashville 1968 Zitiert: Patterson, Copyright in Historical Perspective

Paulus, Andreas / Wesche, Steffen Urheberrecht und Verfassung, in: ZGE 2010, S. 385-397

Zitiert: Paulus/Wesche, ZGE 2010, 385

dies. Rechtsetzung durch Rechtsprechung fachfremder Gerichte, in: GRUR 2012, S. $112-118$

Zitiert: Paulus/Wesche, GRUR 2012, 112

Payne, Britton Imperfect 10: Digital Advances and Market Impact in Fair Use Analysis, in: Fordham Intellectual Property, Media and Entertainment Law Journal, Vol. 17 (2006), S. 279-298

Zitiert: Payne, 17 Fordham Intell. Prop. Media \& Ent. L.J. 279 (2006)

Peifer, Karl Nikolaus Moral Rights in den USA, in: ZUM 1993, S 325-352 Zitiert: Peifer, ZUM 1993, 325

ders. Das Territorialitätsprinzip im Europäischen Gemeinschaftsrecht vor dem Hintergrund der technischen Entwicklungen, in: ZUM 2006, S. 1-8

Zitiert: Peifer, ZUM 2006, 1

ders. Buchbesprechung: Bettina Lucke, Die Google Buchsuche nach deutschem Urheberrecht und US-amerikanischem Copyright Law, in: ZGE 2010, S. 351-355 Zitiert: Peifer, ZGE 2010, 351

ders. Gerechter Ausgleich und Kopiervergütung bei eindeutig beruflichen digitalen Vervielfältigungen - Anmerkung zu EuGH, Urt. v. 21.10.2010, C-467/08 - Padawan/SGAE, in: jurisPR-WettbR 12/2010 Anm. 2

Zitiert: Peifer, jurisPR-WettbR 12/2010 Anm. 2

Perry, Greg A. Copyright and the First Amendment: Nurturing the Seeds for Harvest Harper \& Row, Publishers v. Nation Enterprises, in: Nebraska Law Review, Vol. 65 (1986), S. 631-653

Zitiert: Perry, 65 Neb. L. Rev. 631 (1986)

Peukert, Alexander Der Schutzbereich des Urheberrechts und das Werk als öffentliches Gut - Insbesondere: Die urheberrechtliche Relevanz des privaten Werkgenusses, in: Hilty, Reto/Peukert, Alexander (Hrsg.), Interessenausgleich im Urheberrecht, Baden-Baden 2004, S. 11-46

Zitiert: Peukert, in: Hilty/Peukert, Interessenausgleich 


\section{Literatur}

Peukert, Wolfgang Der Schutz des Eigentums nach Art. 1 des Ersten Zusatzprotokolls zur Europäischen Menschenrechtskonvention, in: EuGRZ 1981, S. 97-114 Zitiert: Peukert, EuGRZ 1981, 97

Pichlmaier, Tobias Abschied von der Privatkopie? - Von der Zukunft einer Institution, in: CR 2003, S. 910-914 Zitiert: Pichlmaier, CR 2003, 910

Picker, Randal C. The Google Book Search Settlement: A New Oprhan-Works Monopoly?, in: Journal of Competition Law \& Economics, Vol. 5 (2009), S. 383-409

Zitiert: Picker, 5 J. Competition L. \& Econ. 383 (2009)

Pieroth, Bodo / Schlink, Bernhard Grundrechte - Staatsrecht II, 26. Auflage, München 2010

Zitiert: Pieroth/Schlink, Grundrechte

Plaß, Gunda Hyperlinks im Spannungsfeld von Urheber-, Wettbewerbs- und Haftungsrecht, in: WRP 2000, S. 599-610

Zitiert: Plaß, WRP 2000, 599

Poeppel, Jan Die Neuordnung der urheberrechtlichen Schranken im digitalen Umfeld, Göttingen 2005

Zitiert: Poeppel, Neuordnung

Pohl, Bettina Abstracts und andere Inhaltsmitteilungen im Urheberrecht, Osnabrück 2006

Zitiert: Pohl, Abstracts

Pohlmann, Hansjörg Privilegienwesen und Urheberrecht, in: UFITA 33 (1961), S. $169-204$

Zitiert: Pohlmann, UFITA 33 (1961), 169

ders. Die Frühgeschichte des musikalischen Urheberrechts (ca. 1400-1800), Kassel 1962

Zitiert: Pohlmann, Frühgeschichte, S. 19 ff.

ders. Zur notwendigen Revision unseres bisherigen Geschichtsbildes auf dem Gebiet des Urheberrechts und des gewerblichen Rechtsschutzes - Zugleich: Widerlegung von Bapperts Behauptung einer urheberrechtlichen Unmündigkeit der „Privilegienzeit", in: GRUR 1962, S. 9-25

Zitiert: Pohlmann, GRUR 1962, 9

Poll, Günter / Braun, Thorsten Privatkopien ohne Ende oder Ende der Privatkopie?, in: ZUM 2004, S. 266-279

Zitiert: Poll/Braun, ZUM 2004, 266

Prill, Aileen Urheberrecht und Klingeltöne - Die Lizenzierung von Ruftonmelodien und Ringbacktones und das Bearbeitungsrecht gemäß $\S 23$ i.V.m. 14 und 39 UrhG, Baden-Baden 2006

Zitiert: Prill, Urheberrecht und Klingeltöne

dies. Anmerkung zu BGH, Urt. v. 18.12.2008, I ZR 23/06, in: CR 2009, S. 239-240

Zitiert: Prill, CR 2009, 239

Proskine, Emily Anne Google's Technicolor Dreamcoat: A Copyright Analysis of the Google Book Search Library Project, in: Berkeley Technology Law Journal, Vol. 21 (2006), S. 213-239

Zitiert: Proskine, 21 Berkeley Tech. L.J. 213 (2006) 
Prütting, Hanns / Gehrlein, Markus (Hrsg.) ZPO, Kommentar, 2. Auflage, Köln 2010 Zitiert: Prütting/Gehrlein/Bearbeiter, ZPO

Rath, Michael Das Recht der Internet-Suchmaschinen, Stuttgart u.a. 2005 Zitiert: Rath, Internet-Suchmaschinen

Rath, Michael / Swane, Torben Google Buchsuche - digitale Weltbibliothek und globale Buchhandlung, in: K\&R 2009, S. 225-228

Zitiert: Rath/Swane, K\&R 2009, 225

Rauda, Christian Der Rückruf wegen gewandelter Überzeugung nach $\S 42$ UrhG Von Web 2.0 aus dem Dornröschenschlaf geweckt?, in: GRUR 2010, S. 22-27

Zitiert: Rauda, GRUR 2010, 22

Raue, Peter Zum Dogma von der restriktiven Auslegung der Schrankenbestimmungen des Urheberrechtsgesetzes, in: Loewenheim, Ulrich (Hrsg.), Urheberrecht in der Informationsgesellschaft - Festschrift für Wilhelm Nordemann zum 70. Geburtstag am 8. Januar 2004, München 2004, S. 327-339

Zitiert: Raue, in: FS Nordemann

ders. Das kleinste Kleinzitat, in: GRUR 2011, S. 1088-1090

Zitiert: Raue, GRUR 2011, 1088

Re, Joseph $R$. The Stage of Publication as a 'Fair Use' Factor: Harper \& Row, Publishers, Inc. v. Nation Enterprises, in: Saint John's Law Review, Vol. 58 (1984), S. 597-615

Zitiert: Re, 58 St. John's L. Rev. 597 (1984)

Rebmann, Kurt / Säcker, Franz Jürgen / Rixecker, Roland (Hrsg.) Münchener Kommentar zum Bürgerlichen Gesetzbuch, 4. Auflage, München

Zitiert: MünchKomm-BGB/Bearbeiter, 4. Aufl.

Rebmann, Kurt / Säcker, Franz Jürgen / Rixecker, Roland (Hrsg.) Münchener Kommentar zum Bürgerlichen Gesetzbuch, 5. Auflage, München

Zitiert: MünchKomm-BGB/Bearbeiter

Reese, R. Anthony Transformativeness and the Derivative Work Right, in: Columbia Journal of Law \& the Arts, Vol. 31 (2008), S. 467-495

Zitiert: Reese, 31 Colum. J.L. \& Arts 467 (2008)

Rehbinder, Manfred Kein Urheberrecht ohne Gesetzesrecht - Zum Urheberschutz um die Mitte des 19. Jahrhunderts, in: Dittrich, Robert (Hrsg.), Woher kommt das Urheberrecht und wohin geht es?, Wien 1988, S. 99-116

Zitiert: Rehbinder, in: Woher kommt das Urheberrecht

ders. Die Beschränkung des Urheberrechts zugunsten der Allgemeinheit in der Berner Übereinkunft, in: Schweizerische Vereinigung für Urheberrecht (Hrsg.), Die Berner Übereinkunft und die Schweiz, Schweizerische Festschrift zum einhundertjährigen Bestehen der Berner Übereinkunft zum Schutze von Werken der Literatur und Kunst, Bern 1986, S. 357-376

Zitiert: Rehbinder, in: FS 100 Jahre RBÜ

ders. Das Namensnennungsrecht des Urhebers, in: ZUM 1991, S. 220-228

Zitiert: Rehbinder, ZUM 1991, 220

ders. Johann Caspar Bluntschlis Beitrag zur Theorie des Urheberrechts, in: UFITA 123 (1993), S. 29-51

Zitiert: Rehbinder, UFITA 123 (1993), 29 


\section{Literatur}

ders. Felix Dahn und Karl Gareis zur Theorie des Urheberrechts, in: UFITA 129 (1995), S. 69-81

Zitiert: Rehbinder, UFITA 129 (1995), 69

ders. Urheberrecht - Ein Studienbuch, 16. Auflage, München 2010

Zitiert: Rehbinder, Urheberrecht

Rehbinder, Manfred / Klingner, Norbert Die Urhebernachfolgevergütung - Ein aktuelles Bedürfnis?, in: UFITA 137 (1998), S. 5-24

Zitiert: Rehbinder/Klingner, UFITA 137 (1998), 5

Rehbinder, Manfred / Staehelin, Alesch Das Urheberrecht im TRIPs-Abkommen Entwicklungsschub durch die New Economic World Order, in: UFITA 127 (1995); S. 5-34 Zitiert: Rehbinder/Staehelin, UFITA 127 (1995), 5

Rehse, Mario Zulässigkeit und Grenzen ungeschriebener Schranken des Urheberrechts, Hamburg 2008

Zitiert: Rehse, Ungeschriebene Schranken

Reich, Michael Mark Die ökonomische Analyse des Urheberrechts in der Informationsgesellschaft, München 2006

Zitiert: Reich, Ökonomische Analyse

Reichman, Jerome H. Universal Minimum Standards of Intellectual Property Protection under the TRIPS Component of the WTO Agreement, in: International Lawyer, Vol. 29 (1995), S. 345-388

Zitiert: Reichman, 29 Int'1 Law. 345 (1995)

Reimer, Dietrich / Ulmer, Eugen Die Reform der materiellrechtlichen Bestimmungen der Berner Übereinkunft, in: GRUR Int. 1967, S. 431-454

Zitiert: Reimer/Ulmer, GRUR Int. 1967, 431

Reinbothe, Jörg Der Schutz des Urheberrechts und der Leistungsschutzrechte im Abkommensentwurf GATT/TRIPs, in: GRUR Int. 1992, S. 707-715

Zitiert: Reinbothe, GRUR Int. 1992, 707

ders. TRIPS und die Folgen für das Urheberrecht, in: ZUM 1996, S. 735-741

Zitiert: Reinbothe, ZUM 1996, 735

ders. The New WIPO Treaties: A First Resume, in: EIPR 1997, 19(4), S. 171-184

Zitiert: Reinbothe, EIPR 1997, 19(4), 171

ders. Der EU-Richtlinienentwurf zum Urheberrecht und zu den Leistungsschutzrechten in der Informationsgesellschaft, in: ZUM 1998, S. 429-437

Zitiert: Reinbothe, ZUM 1998, 429

ders. Geistiges Eigentum und die Europäische Gemeinschaft, in: ZEuP 2000, S. 5-28

Zitiert: Reinbothe, ZEuP 2000, 5

ders. Die EG-Richtlinie zum Urheberrecht in der Informationsgesellschaft, in: GRUR Int. 2001, S. 733-745

Zitiert: Reinbothe, GRUR Int. 2001, 733

ders. Beschränkungen und Ausnahmen von den Rechten im WIPO-Urheberrechtsvertrag, in: Tades, Helmuth/Danzl, Karl-Heinz/Graninger, Gernot (Hrsg.), Ein Leben für Rechtskultur: Festschrift Robert Dittrich zum 75. Geburtstag, Wien 2000, S. 251-268

Zitiert: Reinbothe, in: FS Dittrich 
Reinbothe, Jörg / Lewinski, Silke von The WIPO Treaties 1996, London 2002 Zitiert: Reinbothe/v.Lewinski, WIPO Treaties

Rengeling, Hans-Werner / Szczekalla, Peter Grundrechte in der Europäischen Union. Charta der Grundrechte und allgemeine Rechtsgrundsätze, Köln u.a. 2004

Zitiert: Rengeling/Szczekalla, Charta der Grundrechte

Reschke, Johannes Die verfassungs- und dreistufentestkonforme Auslegung der Schranken des Urheberrechts - zugleich eine Überprüfung von $\S 52$ b UrhG, Göttingen 2010

Zitiert: Reschke, Verfassungs- und dreistufentestkonforme Auslegung

Reuß, Robert $M$. Naturrecht oder positivistisches Konzept - Die Entstehung des Urheberrechts im 18. Jahrhundert in England und den Vereinigten Staaten von Amerika, Baden-Baden 2010

Zitiert: Reuß, Naturrecht oder positivistisches Konzept

Richards, Neil M. Intellectual Privacy, in: Texas Law Review, Vol. 87 (2008), S. 387-445

Zitiert: Richards, 87 Texas L. Rev. 387 (2008)

Ricketson, Sam The Berne Convention for the Protection of Literary and Artistic Works 1886-1986, London 1987

Zitiert: Ricketson, Berne Convention

ders. The Copyright Term, in: IIC 1992, S. 753-785

Zitiert: Ricketson, IIC 1992, 753

ders. The Boundaries of Copyright: Its Proper Limitations and Exceptions: International Conventions and Treaties, in: IPQ 1999, No. 1, S. 56-94

Zitiert: Ricketson, IPQ 1999, 56

ders. The Three-Step Test, Deemed Quantities, Libraries and Closed Exceptions - A Study of the Three-Step Test in Article 9(2) of the Berne Convention, Article 13 of the TRIPS Agreement and Article 10 of the WIPO Copyright Treaty, with Particular Respect to its Application to the Quantitative Test in Subsection 40(3) of the Fair Dealing Provisions, Library and Educational Copying, the Library Provisions Generally and Proposals for an Open Fair Dealing Exception, Strawberry Hills 2002, abrufbar unter: http://www.copyright.com.au/assets/documents/CCS0202

Berne.pdf

Zitiert: Ricketson, Three-Step Test

ders. WIPO Study on Limitations and Exceptions of Copyright and Related Rights in the Digital Environment, Genf 2003, abrufbar unter: http://www.wipo.int/edocs/ mdocs/copyright/en/sccr_9/sccr_9_7.pdf

Zitiert: Ricketson, WIPO-Study

ders. Memorandum of Advice: The Compatibility of the Proposed Google Book Settlement with the Provisions of the Berne Convention, 9. September 2009, abrufbar unter: http://thepublicindex.org/docs/commentary/Ricketson.pdf

Zitiert: Ricketson, Google Book Settlement

Ricketson, Sam / Ginsburg, Jane C. International Copyright and Neighbouring Rights, The Berne Convention and Beyond, Volume I, Second Edition, New York 2006 Zitiert: Ricketson/Ginsburg, International Copyright I 


\section{Literatur}

Riedel, Eibe H. Entschädigung für Eigentumsentzug nach Art. 1 des Ersten Zusatzprotokolls zur Europäischen Menschenrechtskonvention. Zur Herausbildung eines gemeineuropäischen Standards, in: EuGRZ 1988, S. 333-339

Zitiert: Riedel, EuGRZ 1988, 333

Rieder, Christian Copyrightverletzungen in der Online-Kommunikation nach US-amerikanischem Recht, Köln 2000

Zitiert: Rieder, Copyrightverletzungen

Riesenhuber, Karl Der Einfluss der RBÜ auf die Auslegung des deutschen Urheberrechtsgesetzes, in: ZUM 2003, S. 333-342

Zitiert: Riesenhuber, ZUM 2003, 333

Rigamonti, Cyrill P. Geistiges Eigentum als Begriff und Theorie des Urheberrechts, Baden-Baden 2001

Zitiert: Rigamonti, Geistiges Eigentum

ders. Eigengebrauch oder Hehlerei? - Zum Herunterladen von Musik- und Filmdateien aus dem Internet, in: GRUR Int. 2004, S. 278-289

Zitiert: Rigamonti, GRUR Int. 2004, 278

Rogers, Douglas L. Increasing Access to Knowledge Through Fair Use - Analyzing the Google Litigation to Unleash Developing Countries, in: Tulane Journal of Technology and Intellectual Property, Vol. 10 (2007), S. 1-75

Zitiert: Rogers, 10 Tul. J. Tech. \& Intell. Prop. 1 (2007)

Rogge, Tonia Elektronische Pressespiegel in urheber- und wettbewerbsrechtlicher Beurteilung, Hamburg 2001

Zitiert: Rogge, Elektronische Pressespiegel

Roggenkamp, Jan Dirk Anmerkung zu LG Erfurt, Urt. v. 15.3.2007, 3 O 1108/05, in: K\&R 2007, S. 328-330

Zitiert: Roggenkamp, K\&R 2007, 328

ders. Anmerkung zu OLG Jena, Urt. v. 27.2.2008, 2 U 319/07, in: jurisPR-ITR 14/2008 Anm. 2

Zitiert: Roggenkamp, jurisPR-ITR 14/2008 Anm. 2

ders. Anmerkung zu BGH, Urt. v. 29.4.2010, I ZR 69/08, in: jurisPR-ITR 14/2010 Anm. 2

Zitiert: Roggenkamp, jurisPR-ITR 14/2010 Anm. 2

Romman, Kinan H. The Google Book Search Library Project: A Market Analysis Approach to Fair Use, in: Houston Law Review, Vol. 43 (2006), S. 807-845

Zitiert: Romman, 43 Hous. L. Rev. 807 (2006)

Rose, Mark The Statute of Anne's authors' rights: Pope v. Curll (1741), in: Bently, Lionel/Suthersanen, Uma/Torremans, Paul (Hrsg.), Global Copyright - Three Hundred Years Since the Statute of Anne, From 1709 to Cyberspace, Cheltenham (UK) u.a. 2010, S. 70-78

Zitiert: Rose, in: Bently/Suthersanen/Torremans, Global Copyright

Ross, Deborah The United States Joins the Berne Convention: New Obligations for Authors' Moral Rights?, in: North Carolina Law Review, Vol. 68 (1990), S. 363-387

Zitiert: Ross, 68 N.C. L. Rev. 363 (1990)

Rössel, Markus Anmerkung zu BGH, Urt. v. 29.4.2010, I ZR 69/08 - Vorschaubilder, in: MMR 2010, S. 480-482

Zitiert: Rössel, MMR 2010, 480 
Runge, Philipp Die Vereinbarkeit einer Content-Flatrate für Musik mit dem Drei-Stufen-Test, in: GRUR Int. 2007, S. 130-137

Zitiert: Runge, GRUR Int. 2007, 130

Sack, Rolf Das internationale Wettbewerbs- und Immaterialgüterrecht nach der EGBGB-Novelle, in: WRP 2000, S. 269-289

Zitiert: Sack, WRP 2000, 269

ders. Das IPR des geistigen Eigentums nach der Rom II-VO, in: WRP 2008, S. 1405-1419

Zitiert: Sack, WRP 2008, 1405

Sag, Matthew God in the Machine: A New Structural Analysis of Copyright's Fair Use Doctrine, in: Michigan Telecommunications and Technology Law Review, Vol. 11 (2005), S. 381-435

Zitiert: Sag, 11 Mich. Telecomm. \& Tech. L. Rev. 381 (2005)

ders. The Google Book Settlement and the Fair Use Counterfactual, in: New York Law School Law Review, Vol. 55 (2010), S. 19-75

Zitiert: Sag, 55 N.Y.L. Sch. L. Rev. 19 (2010)

ders. Predicting Fair Use, in: Ohio State Law Journal, Vol. 73 (2012), S. 47-91

Zitiert: Sag, 73 Ohio St. L.J. 47 (2012)

Samuelson, Pamela Unbundling Fair Uses, in: Fordham Law Review, Vol. 77 (2009), S. 2537-2621

Zitiert: Samuelson, 77 Fordham L. Rev. 2537 (2009)

dies. The Dead Souls of the Google Book Search Settlement, in: Communications of the ACM, Vol. 52, No. 7 (2009), S. 28-30

Zitiert: Samuelson, 52 No. 7 Comm. ACM 28 (2009)

dies. Is the Proposed Google Book Settlement "Fair"?, in: Tijdschrift voor Auteurs-, Media \& Informatierecht (AMI), 2010, Heft 2, S. 50-54

Zitiert: Samuelson, AMI 2010, 50

dies. Google Book Search and the Future of Books in Cyberspace, in: Minnesota Law Review, Vol. 94 (2010), S. 1308-1374

Zitiert: Samuelson, 94 Minn. L. Rev. 1308 (2010)

dies. Should the Google Book Settlement Be Approved?, in: Communications of the ACM, Vol. 53, No. 7 (2010), S. 32-34

Zitiert: Samuelson, 53 No. 7 Comm. ACM 32 (2010)

dies. The Google Book Settlement as Copyright Reform, in: Wisconsin Law Review 2011, S. 479-562

Zitiert: Samuelson, 2011 Wis. L. Rev. 479

Samuelson, Pamela / Wheatland, Tara Statutory Damages in Copyright Law: A Remedy in Need of Reform, in: William and Mary Law Review, Vol. 51 (2009), S. 439-511

Zitiert: Samuelson/Wheatland, 51 Wm. \& Mary L. Rev. 439 (2009)

Sattler, Susen Der Status quo der urheberrechtlichen Schranken für Bildung und Wissenschaft - Eine Untersuchung anhand der konventions- und europarechtlichen sowie der verfassungsrechtlichen Vorgaben, Baden-Baden 2009

Zitiert: Sattler, Status quo 


\section{Literatur}

Schack, Haimo Urheberrechtliche Schranken, übergesetzlicher Notstand und verfassungskonforme Auslegung, in: Ohly, Ansgar/Bodewig, Theo/Dreier, Thomas/ Götting, Horst-Peter/Haedicke, Maximilian/Lehmann, Michael (Hrsg.), Perspektiven des Geistigen Eigentums und Wettbewerbsrechts, Festschrift für Gerhard Schricker zum 70. Geburtstag, München 2005, S. 511-521

Zitiert: Schack, in: FS Schricker II

ders. Zur Rechtfertigung des Urheberrechts als Ausschließlichkeitsrecht, in: Depenheuer, Otto/Peifer, Karl-Nikolaus (Hrsg.), Geistiges Eigentum - Schutzrecht oder Ausbeutungstitel?, Berlin u.a. 2008, S. 123-140

Zitiert: Schack, in: Geistiges Eigentum - Schutzrecht oder Ausbeutungstitel?

ders. BGB - Allgemeiner Teil, 12. Auflage, Heidelberg 2008

Zitiert: Schack, BGB AT

ders. Kunst und Recht, 2. Auflage, Tübingen 2009

Zitiert: Schack, Kunst und Recht

ders. Urheber- und Urhebervertragsrecht, 5. Auflage, Tübingen 2010

Zitiert: Schack, Urheberrecht

ders. Internationales Zivilverfahrensrecht - ein Studienbuch, 5. Auflage, München 2010

Zitiert: Schack, Int. Zivilverfahrensrecht

ders. Anmerkung zu BGH, Urt. v. 20.11.1986, I ZR 188/84 - Die Zauberflöte, in: GRUR 1987, S. 817-818

Zitiert: Schack, GRUR 1987, 817

ders. Die grenzüberschreitende Verletzung allgemeiner Urheberpersönlichkeitsrechte, in: UFITA 108 (1988), S. 51-72 Zitiert: Schack, UFITA 108 (1988), 51

ders. Neue Techniken und Geistiges Eigentum, in: JZ 1998, S. 753-763 Zitiert: Schack, JZ 1998, 753

ders. Internationale Urheber-, Marken- und Wettbewerbsrechtsverletzungen im Internet - Internationales Privatrecht, in: MMR 2000, S. 59-65

Zitiert: Schack, MMR 2000, 59

ders. Internationale Urheber-, Marken- und Wettbewerbsrechtsverletzungen im Internet - Internationales Zivilprozessrecht, in: MMR 2000, S. 135-140

Zitiert: Schack, MMR 2000, 135-140

ders. Europäisches Urheberrecht im Werden, in: ZEuP 2000, S. 799-819

Zitiert: Schack, ZEuP 2000, 799

ders. Urheberrechtliche Gestaltung von Webseiten unter Einsatz von Links und Frames, in: MMR 2001, S. 9-17

Zitiert: Schack, MMR 2001, 9

ders. Zum auf grenzüberschreitende Sendevorgänge anwendbaren Urheberrecht, Anmerkung zu OLG Saarbrücken, Urt. v. 28.6.2000, 1 U 872/99, in: IPRax 2003, S. 141-142

Zitiert: Schack, IPRax 2003, 141

ders. Rechtsprobleme der Online-Übermittlung, in: GRUR 2007, S. 639-645

Zitiert: Schack, GRUR 2007, 639 
ders. Anmerkung zu OLG Jena, Urt. v. 27.2.2008, 2 U 319/07, in: MMR 2008, S. 414-416

Zitiert: Schack, MMR 2008, 414

ders. Europäische Urheberrechts-Verordnung: erwünscht oder unvermeidlich?, in: ZGE 2009, S. 275-291

Zitiert: Schack, ZGE 2009, 275

Schäfer, Hans-Bernd / Ott, Claus Lehrbuch der ökonomischen Analyse des Zivilrechts, 4. Auflage, Berlin u.a. 2005

Zitiert: Schäfer/Ott, Ökonomische Analyse

Schaefer, Matthias Urheberrechtliche Rahmenbedingungen für Bildersuchmaschinen de lege lata und de lege ferenda, Marburg 2009

Zitiert: Schaefer, Bildersuchmaschinen

Schechter, Roger E. / Thomas, John R. Intellectual Property - The Law of Copyrights, Patents and Trademarks, St. Paul 2003

Zitiert: Schechter/Thomas, Intellectual Property

Scherzer, Robert Haftung eines Bildersuchdienstes für die Darstellung urheberrechtlich geschützter Thumbnails bei der Suchergebnisanzeige, Anmerkung zu LG Hamburg, Urt. v. 26.9.2008 - 308 O 42/06, in: jurisPR-ITR 5/2009 Anm. 2

Zitiert: Scherzer, jurisPR-ITR 5/2009 Anm. 2

Schieble, Klaus Die Kompetenz der Europäischen Gemeinschaft für die Harmonisierung des Urheberrechts im Zeitalter der Informationsgesellschaft, Frankfurt a.M. 2003

Zitiert: Schieble, Kompetenz der EG

Schippan, Martin Die Harmonisierung des Urheberrechts in Europa im Zeitalter von Internet und digitaler Technologie - Eine Betrachtung aus deutscher Sicht, BadenBaden 1999

Zitiert: Schippan, Harmonisierung des Urheberrechts

ders. Harmonisierung oder Wahrung der nationalen Kulturhoheit? - Die wundersame Vermehrung der Schrankenbestimmungen in Art. 5 der „Multimedia-Richtlinie“, in: ZUM 2001, S. 116-128

Zitiert: Schippan, ZUM 2001, 116

Schmidt, Jeffrey The Noerr-Pennington Doctrine, American Bar Association, Section of Antitrust Law, Monopraph 25, Chicago 2009

Zitiert: Schmidt, Noerr-Pennington Doctrine

Schmieder, Hans-Heinrich Das Recht des Werkmittlers, Baden-Baden 1963 Schmieder, Das Recht des Werkmittlers

Schockenhoff, Martin Der sachlich gerechtfertigte Grund - Rechtsmethodische Anmerkungen zu $\S 20$ Abs. 1 GWB, in: Brinker, Ingo/Scheuing, Dieter H./Stockmann, Kurt (Hrsg.), Recht und Wettbewerb - Festschrift für Rainer Bechtold zum 65. Geburtstag, München 2006, S. 419-435

Zitiert: Schockenhoff, in: FS Bechtold

Schönke, Adolf / Schröder, Horst (Hrsg.) Strafgesetzbuch - Kommentar, 28. Auflage, München 2010

Zitiert: Schönke/Schröder/Bearbeiter, StGB

Schønning, Peter Anwendbares Recht bei grenzüberschreitenden Direktübertragungen, in: ZUM 1997, S. 34-39

Zitiert: Schønning, ZUM 1997, 34 


\section{Literatur}

Schrader, Paul T. / Rautenstrauch, Birthe Urheberrechtliche Verwertung von Bildern durch Anzeige von Vorschaugrafiken (sog. ,thumbnails") bei Internetsuchmaschinen, in: UFITA 2007, S. 761-781

Zitiert: Schrader/Rautenstrauch, UFITA 2007, 761

Schricker, Gerhard (Hrsg.) Urheberrecht, Kommentar, 1. Auflage, München 1987 Zitiert: Schricker/Bearbeiter, 1. Aufl.

ders. (Hrsg.) Urheberrecht, Kommentar, 2. Auflage, München 1999 Zitiert: Schricker/Bearbeiter, 2. Aufl.

ders. (Hrsg.) Urheberrecht, Kommentar, 3. Auflage, München 2006 Zitiert: Schricker/Bearbeiter, 3. Aufl.

Schricker, Gerhard / Loewenheim, Ulrich (Hrsg.) Urheberrecht, Kommentar, 4. Auflage, München 2010

Zitiert: Schricker/Loewenheim/Bearbeiter

Schricker, Gerhard Die Einwilligung des Urhebers in entstellende Änderungen des Werkes, in: Forkel, Hans/Kraft, Alfons, Beiträge zum Schutz der Persönlichkeit und ihrer schöpferischen Leistungen, Festschrift für Heinrich Hubmann zum 70. Geburtstag, Frankfurt a.M. 1985, S. 409-419

Zitiert: Schricker, in: FS Hubmann

ders. Urheberrecht zwischen Industrie- und Kulturpolitik, in: GRUR 1992, S. 242-247 Zitiert: Schricker, GRUR 1992, 242

ders. Anmerkung zu BGH, Urt. v. 2.10.1997, I ZR 88/95 - Spielbankaffaire, in: MMR 1998, S. 39

Zitiert: Schricker, MMR 1998, 39

ders. Zum Begriff der angemessenen Vergütung im Urheberrecht - 10\% vom Umsatz als Maßstab?, in: GRUR 2002, S. 737-743

Zitiert: Schricker, GRUR 2002, 737

ders. Zur Frage der Urheberrechtsverletzung durch karikaturistische Darstellung des Gies-Adlers, in: JZ 2004, S. 311-312

Zitiert: Schricker, JZ 2004, 311

Schulze, Gernot Rechtsfragen von Printmedien im Internet, in: ZUM 2000, S. 432-454 Zitiert: Schulze, ZUM 2000, 432

ders. Spielraum und Grenzen richterlicher Rechtsfortbildung im Urheberrecht, in: Ahrens, Hans-Jürgen/Bornkamm, Joachim/Gloy, Wolfgang/Starck, Joachim/v. Ungern-Sternberg, Joachim (Hrsg.), Festschrift für Willi Erdmann zum 65. Geburtstag, Köln u.a. 2002, S. 173-194

Zitiert: Schulze, in: FS Erdmann

ders. Schleichende Harmonisierung des urheberrechtlichen Werkbegriffs? - Anmerkung zu EuGH „Infopaq/DDF“, in: GRUR 2009, S. 1019-1022

Zitiert: Schulze, GRUR 2009, 1019

ders. Aspekte zu Inhalt und Reichweite von $§ 19$ a UrhG, in: ZUM 2011, S. 2-13

Zitiert: Schulze, ZUM 2011, 2

Schulze, Marcel Die Katalogbild-Freiheit, in: Tades, Helmuth/Danzl, Karl-Heinz/ Graninger, Gernot (Hrsg.), Ein Leben für Rechtskultur: Festschrift Robert Dittrich zum 75. Geburtstag, Wien 2000, S. 311-330

Zitiert: Schulze, in: FS Dittrich 
Schwarz, Mathias Erster Entwurf eines Leistungsschutzrechts für Presseverleger in der Diskussion, in: GRUR-Prax. 2010, S. 283-287

Zitiert: Schwarz, GRUR-Prax. 2010, 283

Schweikart, Philipp Die Interessenlage im Urheberrecht, Regensburg 2004 Zitiert: Schweikart, Interessenlage

Seidel, Christian Die zeitliche Begrenzung des Urheberrechts, Frankfurt a.M. 2002 Zitiert: Seidel, Die zeitliche Begrenzung des Urheberrechts

Seifert, Fedor Über Bücher, Verleger und Autoren - Episoden aus der Geschichte des Urheberrechts, in: NJW 1992, S. 1270-1276

Zitiert: Seifert, NJW 1992, 1270

ders. Das Zitatrecht nach „Germania 3“, in: Ahrens, Hans-Jürgen/Bornkamm, Joachim/Gloy, Wolfgang/Starck, Joachim/v. Ungern-Sternberg, Joachim (Hrsg.), Festschrift für Willi Erdmann zum 65. Geburtstag, Köln u.a. 2002, S. 195-210

Zitiert: Seifert, in: FS Erdmann

Seltzer, Leon E. Exemptions and Fair Use in Copyright - The Exclusive Rights Tensions in the 1976 Copyright Act, Cambridge, Mass. u.a. 1978

Zitiert: Seltzer, Exemptions and Fair Use

Senftleben, Martin Copyright, Limitations and the Three-Step Test, Den Haag u.a. 2004

Zitiert: Senftleben, Three-Step Test

ders. Die Bedeutung der Schranken des Urheberrechts in der Informationsgesellschaft und ihre Begrenzung durch den Dreistufentest, in: Hilty, Reto/Peukert, Alexander (Hrsg.), Interessenausgleich im Urheberrecht, Baden-Baden 2004, S. 159-186

Zitiert: Senftleben, in: Hilty/Peukert, Interessenausgleich

ders. Privates Digitales Kopieren im Lichte des Dreistufentests, in: CR 2003, S. 914-919

Zitiert: Senftleben, CR 2003, 914

ders. Grundprobleme des urheberrechtlichen Dreistufentests, in: GRUR Int. 2004, S. 200-211

Zitiert: Senftleben, GRUR Int. 2004, 200

ders. Towards a Horizontal Standard for Limiting Intellectual Property Rights? - WTO

Panel Reports Shed Light on the Three-Step Test in Copyright Law and Related Tests in Patent and Trademark Law, in: IIC 2006, S. 407-438

Zitiert: Senftleben, IIC 2006, 407

ders. Fair Use in The Netherlands - a Renaissance?, in: Tijdschrift voor Auteurs-, Media \& Informatierecht (AMI), 2009, Heft 1, S. 1-7

Zitiert: Senftleben, AMI 2009, 1

ders. Bridging the Differences between Copyright's Legal Traditions - The Emerging EC Fair Use Doctrine, in: Journal of the Copyright Society of the U.S.A., Vol. 57 (2010), S. 521-552

Zitiert: Senftleben, 57 J. Copyright Soc'y U.S.A. 521 (2010)

ders. The International Three-Step Test: A Model Provision for EC Fair Use Legislation, in: JIPITEC 2010, S. 67-82

Zitiert: Senftleben, JIPITEC 2010, 67

Seville, Catherine EU Intellectual Property Law and Policy, Cheltenham (UK) 2009 Zitiert: Seville, EU IP Law 


\section{Literatur}

Seydel, Thomas Die Zitierfreiheit als Urheberrechtsschranke - unter besonderer Berücksichtigung der digitalen Werkverwertung im Internet, Köln u.a. 2002 Zitiert: Seydel, Zitierfreiheit

Shah, Manali Fair Use and the Google Book Search Project: The Case for Creating Digital Libraries, in: CommLaw Conspectus - Journal of Communications, Law \& Policy, Vol. 15 (2007), S. 569-613

Zitiert: Shah, 15 CommLaw Conspectus 569 (2007)

Shipley, David E. Conflicts Between Copyright and the First Amendment After Harper \& Row, Publishers v. Nation Enterprises, in: Brigham Young University Law Review (1986), S. 983-1042

Zitiert: Shipley, 1986 B.Y.U. L. Rev. 983

Siems, Mathias Effektivität und Legitimität einer Richtlinienumsetzung durch Generalklauseln, in: ZEuP 2002, S. 747-753

Zitiert: Siems, ZEuP 2002, 747

Sinclair, Ian The Vienna Convention on the Law of Treaties, Second Edition, Manchester 1984

Zitiert: Sinclair, Vienna Convention

Singer, Otto / Conde, Susanna Bibliothek im Internet - Die Google Buchsuche, in: Deutscher Bundestag, Wissenschaftliche Dienste, Nr. 43/07 (31.8.2007), abrufbar unter: http://www.bundestag.de/dokumente/analysen/2007/Bibliothek_im_Inter net.pdf

Zitiert: Singer/Conde, Bibliothek im Internet

Spieker, Oliver Die fehlerhafte Urheberbenennung: Falschbenennung des Urhebers als besonders schwerwiegender Fall, in: GRUR 2006, S. 118-124

Zitiert: Spieker, GRUR 2006, 118

Spindler, Gerald Deliktsrechtliche Haftung im Internet - Nationale und internationale Rechtsprobleme, in: ZUM 1996, S. 533-563

Zitiert: Spindler, ZUM 1996, 533

ders. Europäisches Urheberrecht in der Informationsgesellschaft, in: GRUR 2002, S. $105-120$

Zitiert: Spindler, GRUR 2002, 105

ders. Verantwortlichkeit und Haftung für Hyperlinks im neuen Recht, in: MMR 2002, S. 495-503

Zitiert: Spindler, MMR 2002, 495

ders. Das Gesetz zum elektronischen Geschäftsverkehr - Verantwortlichkeit der Diensteanbieter und Herkunftslandprinzip, in: NJW 2002, S. 921-927

Zitiert: Spindler, NJW 2002, 921

ders. Die kollisionsrechtliche Behandlung von Urheberrechtsverletzungen im Internet, in: IPRax 2003, S. 412-421

Zitiert: Spindler, IPRax 2003, 412

ders. Die Verantwortlichkeit der Provider für „Sich-zu-Eigen-gemachte” Inhalte und für beaufsichtigte Nutzer, in: MMR 2004, S. 440-444

Zitiert: Spindler, MMR 2004, 440

ders. Bildersuchmaschinen, Schranken und konkludente Einwilligung im Urheberrecht

- Besprechung der BGH-Entscheidung „Vorschaubilder“, in: GRUR 2010, S. 785-792

Zitiert: Spindler, GRUR 2010, 785 
ders. Kollisionsrecht und internationale Zuständigkeit bei Persönlichkeitsrechtsverletzungen im Internet - die eDate-Entscheidung des EuGH, in: AfP 2012, S 114-121 Zitiert: Spindler, AfP 2012, 114

ders. Anmerkung zu BGH, Urt. v. 19.10.2011, I ZR 140/10 - Vorschaubilder II, in: MMR 2012, S. 386-387

Zitiert: Spindler, MMR 2012, 386

Spindler, Gerald / Heckmann, Jörn Der rückwirkende Entfall unbekannter Nutzungsrechte (\$ 1371 UrhG-E) - Schließt die Archive?, in: ZUM 2006, S. 620-630 Zitiert: Spindler/Heckmann, ZUM 2006, 620

Spindler, Gerald / Leistner, Matthias Die Verantwortlichkeit für Urheberrechtsverletzungen im Internet - Neue Entwicklungen in Deutschland und in den USA, in: GRUR Int. 2005, S. 773-796

Zitiert: Spindler/Leistner, GRUR Int. 2005, 773

Spindler, Gerald / Prill, Aileen Keyword Advertising - eine europäische Rechtsprechungslinie beginnt..., Der erste und der zweite Streich des EuGH aus markenrechtlicher Sicht, in: CR 2010, S. 303-311

Zitiert: Spindler/Prill, CR 2010, 303

Splittgerber, Andreas Google France und Google - Klärung bei Markenrechtsverletzungen, in: NJW 2010, S. 2014-2017

Zitiert: Splittgerber, NJW 2010, 2014

Stang, Felix L. Das urheberrechtliche Werk nach Ablauf der Schutzfrist - Negative Schutzsrechtsüberschneidung, Remonopolisierung und der Grundsatz der Gemeinfreiheit, Tübingen 2011

Zitiert: Stang, Das urheberrechtliche Werk

Stang, Felix L. / Hühner, Sebastian Anmerkung zu BGH, Urt. v. 12.5.2010, I ZR 121/08 - Sommer unseres Lebens, in: GRUR 2010, S. 636-637

Zitiert: Stang/Hühner, GRUR 2010, 636

Staples, Matthew C. Kelly v. Arriba Soft Corp., in: Berkeley Technology Law Journal, Vol. 18 (2003), S. 69-91

Zitiert: Staples, 18 Berkeley Tech. L.J. 69 (2003)

Staudinger, Julius von (Begr.) Kommentar zum Bürgerlichen Gesetzbuch, Berlin, alle Bände in jeweils neuester Auflage, soweit nicht ausdrücklich anderweitig vermerkt Zitiert: Staudinger/Bearbeiter

Stieper, Malte Rechtfertigung, Rechtsnatur und Disponibilität der Schranken des Urheberrechts, Tübingen 2009

Zitiert: Stieper, Schranken

ders. Anmerkung zu BGH, Urt. v. 20.11.2008, I ZR 112/06 - Metall auf Metall, in: ZUM 2009, S. 223-225

Zitiert: Stieper, ZUM 2009, 223

ders. Anmerkung zu EuGH, Urt. v. 4.10.2011, C-403/08 und C-429/08 - Football Association Premier League Ltd. u.a... QC Leisure u.a. und Murphy./. Media Protection Services Ltd., in: MMR 2011, S. 825-827

Zitiert: Stieper, MMR 2011, 825

Stokes, Simon Digital Copyright: Law and Practice, Third Edition, Oxford, Portland 2009

Zitiert: Stokes, Digital Copyright 


\section{Literatur}

ders. Leslie A. Kelly v. Arriba Soft Corp: A View From the United Kingdom, in: EIPR 2000, 22(12), S. 599-603

Zitiert: Stokes, EIPR 2000, 22(12), 599

Stoll, Peter-Tobias / Busche, Jan / Arend, Katrin WTO - Trade-Related Aspects of Intellectual Property Rights, Leiden 2009

Zitiert: Stoll/Busche/Arend/Bearbeiter, WTO

Stolleis, Michael Gemeinwohlformeln im nationalsozialistischen Recht, Berlin 1974

Zitiert: Stolleis, Gemeinwohlformeln im nationalsozialistischen Recht

Straus, Joseph Der Schutz der ausübenden Künstler und das Rom-Abkommen von 1961 - Eine retrospektive Betrachtung, in: GRUR Int. 1985, S. 19-29

Zitiert: Straus, GRUR Int. 1985, 19

Streinz, Rudolf (Hrsg.) EUV/EGV: Vertrag über die Europäische Union und Vertrag zur Gründung der Europäischen Gemeinschaft, München 2003

Zitiert: Streinz/Bearbeiter, EUV/EGV

ders. Anmerkung zu EuGH, Urt. v. 10.5.2001, C-144/99, in: Juristische Schulung (JuS) 2001, S. 1113-1114

Zitiert: Streinz, JuS 2001, 1113

ders. Primärrechtliche Grundlagen des Europäischen Urheberrechts, in: Riesenhuber, Karl (Hrsg.), Systembildung im Europäischen Urheberrecht, INTERGU-Tagung 2006, Berlin 2007, S. 11-37

Zitiert: Streinz, in: Systembildung im Europäischen Urheberrecht

Strömholm, Stig Copyright and the Conflict of Laws - A Comparative Survey, Köln u.a. 2010

Zitiert: Strömholm, Conflict of Laws

Suarez, Christopher A. Continued DOJ Oversight of the Google Book Search Settlement: Defending Our Public Values and Protecting Competition, in: New York Law School Law Review, Vol. 55 (2010), S. 175-219

Zitiert: Suarez, 55 N.Y.L. Sch. L. Rev. 175 (2010)

Suarez, Michael F. To what degree did the Statute of Anne (8 Anne, c.19, [1709]) affect commercial practices of the book trade in eighteenth-century England? Some provisional answers about copyright, chiefly from bibliography and book history, in: Bently, Lionel/Suthersanen, Uma/Torremans, Paul (Hrsg.), Global Copyright Three Hundred Years Since the Statute of Anne, From 1709 to Cyberspace, Cheltenham (UK) u.a. 2010, S. 54-69

Zitiert: Suarez, in: Bently/Suthersanen/Torremans, Global Copyright

Sujecki, Bartosz Anmerkung zu Rechtbank Den Haag, Urt. v. 2.3.2005, No. 192880, LJN AS8778 - Uitgevers/De Staat, in: MR-Int. 2005, S. 40-41

Zitiert: Sujecki, MR-Int. 2005, 40

Sun, Haochen Overcoming the Achilles Heel of Copyright Law, in: Northwestern Journal of Technology \& Intellectual Property, Vol. 5 (2007), S. 265-329

Zitiert: Sun, 5 Nw. J. Tech. \& Intell. Prop. 265 (2007)

Szilágyi, Emese Leistungsschutzrecht für Verleger? Eine rechtstatsächliche Untersuchung zur Wiederherstellung des Interessenausgleichs zwischen Verlegern, Urhebern und Allgemeinheit, München 2011

Zitiert: Szilágyi, Leistungsschutzrecht für Verleger 
Teichmann, Arndt Die protestatio facto contraria, in: Pawlowski, Hans-Martin/ Wieacker, Franz (Hrsg.), Festschrift für Karl Michaelis zum 70. Geburtstag am 21. Dezember 1970, Göttingen 1972, S. 294-315

Zitiert: Teichmann, in: FS Michaelis

Tettinger, Peter J. / Stern, Klaus (Hrsg.) Kölner Gemeinschaftskommentar zur Europäischen Grundrechte-Charta, München 2006

Zitiert: Tettinger/Stern/Bearbeiter, GK Grundrechte-Charta

Thomas, Heinz / Putzo, Hans (Begr.) Zivilprozessordnung, Kommentar, 30. Auflage, München 2009

Zitiert: Thomas/Putzo/Bearbeiter, ZPO

Thormann, Martin Abstufungen in der Sozialbindung des Eigentums: zur Bestimmung von Inhalt und Schranken des Eigentums nach Art. 14 Abs. 1 Satz 2 GG im Spannungsfeld von Eigentumsfreiheit und Gemeinwohl, Stuttgart 1996

Zitiert: Thormann, Sozialbindung des Eigentums

Thum, Dorothee Das Territorialitätsprinzip im Zeitalter des Internet - Zur Frage des auf Urheberrechtsverletzungen im Internet anwendbaren Rechts, in: Bartsch, Michael/Lutterbeck, Bernd (Hrsg.), Neues Recht für neue Medien, Köln 1998, S. 117-144

Zitiert: Thum, in: Neues Recht für neue Medien

dies. Internationalprivatrechtliche Aspekte der Verwertung urheberrechtlich geschützter Werke im Internet - Zugleich Bericht über eine WIPO-Expertensitzung in Genf, in: GRUR Int. 2001, S. 9-28

Zitiert: Thum, GRUR Int. 2001, 9

dies. BGH: Schlichte Einwilligung zu Google-Thumbnails wirkt abstrakt-generell „Vorschaubilder II“, in: GRUR-Prax 2012, S. 215

Zitiert: Thum, GRUR-Prax 2012, 215

Tilmann, Winfried Europäische Gerichtsstruktur auch für Urheberrechte?, in: GRUR 2011, S. 1096-1098

Zitiert: Tilmann, GRUR 2011, 1096

Timberg, Sigmund A Modernized Fair Use Code For The Electronic As Well As The Gutenberg Age, in. Northwestern University Law Review, Vol. 75 (1980), S. 193-244

Zitiert: Timberg, 75 Nw. U. L. Rev. 193 (1980)

Timkovich, Elizabeth The New Significance of the Four Fair Use Factors as Applied to Parody: Interpreting the Court's Analysis in Campbell v. Acuff-Rose Music, Inc., in: Tulane Journal of Technology and Intellectual Property, Vol. 5 (2003), S. 61-75 Zitiert: Timkovich, 5 Tul. J. Tech. \& Intell. Prop. 61 (2003)

Timmann, Tobias Das Patentrecht im Lichte von Art. 14 GG, Tübingen 2008 Zitiert: Timmann, Patentrecht im Lichte von Art. 14 GG

Travis, Hannibal Google Book Search and Fair Use: iTunes for Authors, or Napster for Books?, in: University of Miami Law Review, Vol. 61 (2006), S. 87-167

Zitiert: Travis, 61 U. Miami L. Rev. 87 (2006)

ders. Opting Out of the Internet in the United States and the European Union: Copyright, Safe Harbors, and International Law, in: Notre Dame Law Review, Vol. 84 (2008), S. 331-407

Zitiert: Travis, 84 Notre Dame L. Rev 331 (2008) 


\section{Literatur}

ders. The Future According to Google: Technology Policy from the Standpoint of America's Fastest-Growing Technology Company, in: Yale Journal of Law \& Technology, Vol. 11 (2009), S. 209-227

Zitiert: Travis, 11 Yale J.L. \& Tech. 209 (2009)

ders. Estimating the Economic Impact of Mass Digitization Projects on Copyright Holders: Evidence from the Google Book Search Litigation, Journal of the Copyright Society of the U.S.A., Vol. 57 (2010), S. 907-949

Zitiert: Travis, 57 J. Copyright Soc'y U.S.A. 907 (2010)

Trayer, Martin Technische Schutzmaßnahmen und elektronische Rechtewahrnehmungssysteme - Die Umsetzung von Art. 6 und 7 der EU-Urheberrechtsrichtlinie in deutsches Recht und der Schutz des Nutzers urheberrechtlicher Werke, Baden-Baden 2003

Zitiert: Trayer, Technische Schutzmaßnahmen

Turner, Mark / Callaghan, Dominic You can Look but don't Touch! The Impact of the Google v. Copiepresse Decision on the Future of the Internet, in: EIPR 2008, 30(1), S. 34-38

Zitiert: Turner/Callaghan, EIPR 2008, 30(1), 34

Tushnet, Rebecca Copyright as a Model for Free Speech Law: What Copyright has in Common with Anti-Pornography Laws, Campaign Finance Reform, and Telecommunications Regulation, in: Boston College Law Review, Vol. 42 (2000), S. 1-79

Zitiert: Tushnet, 42 B.C. L. Rev. 1 (2000)

dies. My Library: Copyright and the Role of Institutions in a Peer-to-Peer World, in: UCLA Law Review, Vol. 53 (2006), S. 977-1029

Zitiert: Tushnet, 53 UCLA L. Rev. 977 (2006)

dies. User-Generated Discontent: Transformation in Practice, in: Columbia Journal of Law \& the Arts, Vol. 31 (2008), S. 497-516

Zitiert: Tushnet, 31 Colum. J.L. \& Arts 497 (2008)

Ullrich, Hanns Technologieschutz nach TRIPS: Prinzipien und Probleme, in: GRUR Int. 623-641

Zitiert: Ullrich, GRUR Int. 1995, 623

Ullrich, Jan Nicolaus Clash of Copyrights - Optionale Schranke und zwingender finanzieller Ausgleich im Fall der Privatkopie nach Art. 5 Abs. 2 lit. b) Richtlinie 2001/29/EG und Dreistufentest, in: GRUR Int. 2009, S. 283-292

Zitiert: Ullrich, GRUR Int. 2009, 283

Ulmer, Eugen Urheber- und Verlagsrecht, 3. Auflage, Berlin u.a. 1980 Zitiert: Ulmer

ders. Das Rom-Abkommen über den Schutz der ausübenden Künstler, der Hersteller von Tonträgern und der Sendeunternehmungen, in: GRUR Int. 1961, S. 569-594 Zitiert: Ulmer, GRUR Int. 1961, 569

ders. Anmerkung zu Corte Costituzionale Urt. v. 15.3.1972 Nr. 48 "Urheberpersönlichkeitsrecht des Photographen", in: GRUR Int. 1972, S. 429-430

Zitiert: Ulmer, GRUR Int. 1972, 429

Ungern-Sternberg, Joachim von Anmerkung zu BGH, Urt. v. 6.12.2007, I ZR 94/05 Drucker und Plotter, in: GRUR 2008, S. 247-249

Zitiert: v.Ungern-Sternberg, GRUR 2008, 247 
ders. Schlichte einseitige Einwilligung und treuwidrig widersprüchliches Verhalten des Urheberberechtigten bei Internetnutzungen, in: GRUR 2009, S. 369-375

Zitiert: v.Ungern-Sternberg, GRUR 2009, 369

ders. Die Rechtsprechung des Bundesgerichtshofs zum Urheberrecht und zu den verwandten Schutzrechten in den Jahren 2008 und 2009 (Teil I), in: GRUR 2010, S. 273-282

Zitiert: v.Ungern-Sternberg, GRUR 2010, 273

Vaidhyanathan, Siva The Googlization of Everything and the Future of Copyright, in: U.C. Davis Law Review, Vol. 40 (2007), S. 1207-1231

Zitiert: Vaidhyanathan, 40 U.C. Davis L. Rev. 1207 (2007)

Varian, Hal R. The Google Library Project, abrufbar unter: http://people.ischool.berke ley.edu/ hal/Papers/2006/google-library.pdf

Zitiert: Varian, Google Library Project

Verweyen, Urs Geräteabgaben: Eins vor, Zwei zurück - Besprechung von BGH, Urt. v. 30.11.2011, I ZR 59/10 - PC als Bild- und Tonaufzeichnungsgerät, in: GRUR 2012, S, 875-882

Zitiert: Verweyen, GRUR 2012, 875

Vitzthum, Wolfgang Graf (Hrsg.) Völkerrecht, 4. Auflage, Berlin 2007

Zitiert: Vitzthum/Bearbeiter, Völkerrecht

Vogel, Martin Die Geschichte des Urheberrechts im Kaiserreich, in: GRUR 1987, S. 873-883

Zitiert: Vogel, GRUR 1987, 873

ders. Urheberpersönlichkeitsrecht und Verlagsrecht im letzten Drittel des 19. Jahrhunderts, in: GRUR 1994, S. 587-593

Zitiert: Vogel, GRUR 1994, 587

Wadle, Elmar Das preußische Urheberrechtsgesetz von 1837 im Spiegel seiner Vorgeschichte, in: Dittrich, Robert (Hrsg.), Woher kommt das Urheberrecht und wohin geht es?, Wien 1988, S. 55-98

Zitiert: Wadle, in: Woher kommt das Urheberrecht

ders. Privilegienschutz gegen den Nachdruck um 1800 - Der Fall Artaria contra Götz, in: Wadle, Elmar (Hrsg.), Historische Studien zum Urheberrecht in Europa - Entwicklungslinien und Grundfragen, Berlin 1993, S. 33-55

Zitiert: Wadle, in: Historische Studien

Wagner, R. Polk The Perfect Storm: Intellectual Property and Public Values, in: Fordham Law Review, Vol. 74 (2005), S. 423-434

Zitiert: Wagner, 74 Fordham L. Rev. 423 (2005)

Wagner-Silva Tarouca, Beatrice Der Urheberschutz der ausübenden Künstler und Tonträgerhersteller in den USA, München 1983

Zitiert: Wagner-Silva Tarouca, Urheberschutz der ausübenden Künstler und Tonträgerhersteller in den USA

Walter, Michel M. (Hrsg.) Europäisches Urheberrecht - Kommentar, Wien u.a. 2001

Zitiert: Bearbeiter, in: Walter, Europäisches Urheberrecht

Walter, Michel M. / Lewinski, Silke von European Copyright Law - A Commentary, Oxford 2010

Zitiert: Bearbeiter, in: Walter/v.Lewinski, European Copyright Law 


\section{Literatur}

Wandtke, Artur-Axel Die Kommerzialisierung der Kunst und die Entwicklung des Urheberrechts im Lichte der Immaterialgüterrechtslehre von Josef Kohler, in: GRUR 1995, S. 385-392

Zitiert: Wandtke, GRUR 1995, 385

ders. Copyright und virtueller Markt in der Informationsgesellschaft - oder das Verschwinden des Urhebers im Nebel der Postmoderne?, in: GRUR 2002, S. 1-11

Zitiert: Wandtke, GRUR 2002, 1

ders. Beaumarchais et la propriété intellectuelle - „Eine Nation ist nur dann wahrhaft frei, wenn sie sich dem Recht beugt", in: UFITA 2008, S. 389-439

Zitiert: Wandtke, UFITA 2008, 389

ders. (Hrsg.) Urheberrecht, 2. Auflage, Berlin u.a. 2010

Zitiert: Wandtke/Bearbeiter, Urheberrecht

Wandtke, Artur-Axel / Bullinger, Winfried (Hrsg.) Praxiskommentar zum Urheberrecht, 2. Auflage, München 2006

Zitiert: Wandtke/Bullinger/Bearbeiter, 2. Aufl.

dies. Praxiskommentar zum Urheberrecht, 3. Auflage, München 2009

Zitiert: Wandtke/Bullinger/Bearbeiter

Wandtke, Artur-Axel / Dietz, Claire Anmerkung zu BGH, Urt. v. 2.10.2008, I ZR 18/06 - PC, in: ZUM 2009, S. 155-159

Zitiert: Wandtke/Dietz, ZUM 2009, 155

Wang, Laura J.J. An Antitrust Analysis of the Google Book Search Settlement, 2010, abrufbar unter: http://works.bepress.com/jianji_wang/1/

Zitiert: Wang, Antitrust Analysis of the GBS

Wasoff, Lois F. If Mass Digitization is the Problem, is Legislation the Solution? Some Practical Considerations Related to Copyright, in: Columbia Journal of Law \& the Arts, Vol. 34 (2011), S. 731-746

Zitiert: Wasoff, 34 Colum. J.L. \& Arts 731 (2011)

Wäßle, Florian Rechtliche Zulässigkeit von Bilder-Suchmaschinen im Internet - Zugleich Anmerkung zu LG Hamburg, Urt. v. 26.9.2008, 308 O 42/06, in: K\&R 2008, S. 729-731

Zitiert: Wäßle, K\&R 2008, 729

Wegmann, Katrin Der Rechtsgedanke der freien Benutzung des $\S 24$ UrhG und die verwandten Schutzrechte, Baden-Baden 2012

Zitiert: Wegmann, Der Rechtsgedanke der freien Benutzung

Weinreb, Lloyd L. Fair's Fair: A Comment on the Fair Use Doctrine, in: Harvard Law Review, Vol. 103 (1990), S. 1137-1161

Zitiert: Weinreb, 103 Harv. L. Rev. 1137 (1990)

Weller, Michael Abschluss des GEMA-Berechtigungsvertrages als Aufgabe von Urheberpersönlichkeitsrechten? („Klingeltöne für Mobiltelefone“), Anmerkung zu BGH, Urt. v. 18.12.2008, I ZR 23/06, in: jurisPR-ITR 8/2009 Anm. 4

Zitiert: Weller, jurisPR-ITR 8/2009 Anm. 4

Wenzel, Karl Egbert / Burkhardt, Emanuel Urheberrecht für die Praxis, 5. Auflage, Köln 2009

Zitiert: Wenzel/Burkhardt, Urheberrecht 
Weßling, Bernhard Der zivilrechtliche Schutz gegen digitales Sound-Sampling - Zum Schutz gegen Übernahme kleinster musikalischer Einheiten nach Urheber-, Leistungsschutz-, Wettbewerbs- und allgemeinem Persönlichkeitsrecht, Baden-Baden 1995

Zitiert: Weßling, Digitales Sound-Sampling

Westin, Cameron W. Is Kelly Shifting Under Google's Feet? New Ninth Circuit Impact on the Google Library Project Litigation, in: Duke Law \& Technology Review 2007, No. 2

Zitiert: Westin, 2007 Duke L. \& Tech. Rev. 2

Westkamp, Guido The Implementation of Directive 2001/29/EC in the Member States, Part II, February 2007, abrufbar unter: http://www.ivir.nl/publications/guibault/ InfoSoc_Study_2007.pdf

Zitiert: Westkamp, Implementation of Directive 2001/29/EC

ders. The "Three-Step Test" and Copyright Limitations in Europe: European Copyright Law Between Approximation and National Decision Making, in: Journal of the Copyright Society of the U.S.A., Vol. 56 (2008), S. 1-65

Zitiert: Westkamp, 56 J. Copyright Soc'y U.S.A. 1 (2008)

Wiebe, Andreas Vertrauensschutz und geistiges Eigentum am Beispiel der Suchmaschinen, in: GRUR 2011, S. 888-895

Zitiert: Wiebe, GRUR 2011, 888

Wieduwilt, Hendrik Das neue Leistungsschutzrecht für Presseverlage - eine Einführung, in: K\&R 2010, S. 555-561

Zitiert: Wieduwilt, K\&R 2010, 555

Wilhelm, Thomas E. Google Book Search: Fair Use or Fairly Useful Infringement?, in: Rutgers Computer and Technology Law Journal, Vol. 33 (2006), S. 107-135

Zitiert: Wilhelm, 33 Rutgers Computer \& Tech. L.J. 107 (2006)

Williams, Judith Harper \& Row, Publishers, Inc. v. Nation Enterprises: A Distortion of the Fair Use Doctrine, in: Houston Law Review, Vol. 24 (1987), S. 363-381

Zitiert: Williams, 24 Hous. L. Rev. 363 (1987)

Williams, Matt Recent Second Circuit Opinions Indicate that Google's Library Project is not Transformative, in: Cardozo Arts and Entertainment Law Journal, Vol. 25 (2007), S. 303-332

Zitiert: Williams, 25 Cardozo Arts \& Ent. L.J. 303 (2007)

Wimmers, Jörg / Schulz, Carsten Wer nutzt? - Zur Abgrenzung zwischen Werknutzer und technischem Vermittler im Urheberrecht, in: CR 2008, S. 170-177

Zitiert: Wimmers/Schulz, CR 2008, 170

Winghardt, Stefan Kopiervergütung für den PC, in: ZUM 2002, S. 349-362 Zitiert: Winghardt, ZUM 2002, 349

WIPO Records of the Intellectual Property Conference at Stockholm June 11 to July 14, 1967, Genf 1967

Zitiert: WIPO, Records of the IP Conference at Stockholm

Wittmann, Reinhard Der gerechtfertigte Nachdrucker? Nachdruck und literarisches Leben im achtzehnten Jahrhundert, in: UFITA 106 (1987), S. 109-135

Zitiert: Wittmann, UFITA 106 (1987), 109 


\section{Literatur}

Wong, Mary W.S. Toward an Alternative Normative Framework for Copyright: From Private Property to Human Rights, in: Cardozo Arts and Entertainment Law Journal, Vol. 26 (2009), S. 775-843

Zitiert: Wong, 26 Cardozo Arts \& Ent. L.J. 775 (2009)

Woods, Tanya Copyright Enforcement at All Costs? Considerations for Striking Balance in the International Enforcement Agenda, in: AIPLA Quarterly Journal, Vol. 37 (2009), S. 347-393

Zitiert: Woods, 37 AIPLA Q.J. 347, 385 (2009)

$W u$, Tim Tolerated Use, in: Columbia Journal of Law \& the Arts, Vol. 31 (2008), S. 617-635

Zitiert: $W u, 31$ Colum. J.L. \& Arts 617 (2008)

Würdinger, Markus Die Analogiefähigkeit von Normen - Eine methodologische Untersuchung über Ausnahmevorschriften und deklaratorische Normen, in: Archiv für civilistische Praxis (AcP), S. 949-979

Zitiert: Würdinger, AcP 206(2006), 946

ders. Ausnahmevorschriften sind analogiefähig!, in: JuS 2008, S. 949-951

Zitiert: Würdinger, JuS 2008, 949

Yankwich, Leon R. What is Fair Use?, in: University of Chicago Law Review, Vol. 22 (1954), S. 203-215

Zitiert: Yankwich, 22 U. Chi. L. Rev. 203 (1954)

Youm, Kyu Ho Copyright Law in the Republic of Korea, in: UCLA Pacific Basin Law Journal, Vol. 17 (1999/2000), S. 276-300

Zitiert: Youm, 17 UCLA Pac. Basin L.J. 276 (1999/2000)

$Y u$, Peter $K$. Ten Common Questions About Intellectual Property and Human Rights, in: Georgia State University Law J, Vol. 23 (2007), S. 709-753

Zitiert: Yu, 23 Ga. St. U. L. Rev. 709 (2007)

ders. Reconceptualizing Intellectual Property Interests in a Human Rights Framework, in: U.C. Davis Law Review, Vol. 40 (2007), S. 1039-1149

Zitiert: Yu, 40 U.C. Davis L. Rev. 1039 (2007)

Zahrt, Michael Der urheberrechtliche Schutz elektronischer Printmedien - Unter besonderer Berücksichtigung der Privilegierungstatbestände $\S \S 49,53$ UrhG, Frankfurt a.M. u.a. 1999

Zitiert: Zahrt, Der urheberrechtliche Schutz elektronischer Printmedien

Zech, Herbert Vertragliche Disposition über Schranken des geistigen Eigentums, in: Leible, Stefan/Ohly, Ansgar/Zech, Herbert (Hrsg.), Wissen - Märkte - Geistiges Eigentum, Tübingen 2010, S. 187-202

Zitiert: Zech, in: Wissen - Märkte - Geistiges Eigentum

Ziem, Claudia Die Bedeutung der Pressefreiheit für die Ausgestaltung der wettbewerbsrechtlichen und urheberrechtlichen Haftung von Suchdiensten im Internet, Frankfurt a.M. 2003

Zitiert: Ziem, Suchdienste im Internet

Zimmerman, Diane L. The More Things Change the Less They Seem "Transformed": Some Reflections on Fair Use, in: Journal of the Copyright Society of the U.S.A., Vol. 46 (1998), S. 251-269

Zitiert: Zimmerman, 46 J. Copyright Soc'y U.S.A. 251 (1998) 


\section{Literatur}

Zimmermann, Olaf Neue Initiative zur Einführung des Goethegroschens gestartet!, in: ZUM 1996, S. 862-864

Zitiert: Zimmermann, ZUM 1996, 826 
